\title{
Site Characterization and Monitoring Data from the Area 5 Pilot Wells
}

\author{
Prepared by \\ Bechtel Nevada \\ Geotechnical Sciences \\ Las Vegas, Nevada \\ Prepared for \\ U.S. Department of Energy \\ National Nuclear Security Administration \\ Nevada Site Office \\ Las Vegas, Nevada
}

September 2005 


\title{
DISCLAIMER STATEMENT
}

Reference herein to any specific commercial product, process, or service by trade name, trademark, manufacturer, or otherwise, does not necessarily constitute or imply its endorsement, recommendation, or favoring by the U.S. Government or any agency thereof or its contractors or subcontractors.

\section{AVAILABILITY STATEMENT}

Available for sale to the public from-

\author{
U.S. Department of Commerce \\ National Technical Information Service \\ 5285 Port Royal Road \\ Springfield, VA, 22161-0002 \\ Telephone: 800.553.6847 \\ Fax: 703.605.6900 \\ E-mail: orders@ntis.gov \\ Online ordering: http://www.ntis.gov/ordering.htm
}

Available electronically at http://www.osti.gov/bridge.

Available for a processing fee to U.S. Department of Energy and its contractors, in paper, from-

U.S. Department of Energy

Office of Scientific and Technical Information

P.O. Box 62

Oak Ridge, TN 37831-0062

Telephone: 865.576.8401

Fax: 865.576.5728

E-mail: reports@adonis.osti.gov 


\title{
Site Characterization and Monitoring Data from the Area 5 Pilot Wells
}

\author{
Prepared for \\ U.S. Department of Energy \\ National Nuclear Security Administration \\ Nevada Site Office \\ Las Vegas, Nevada
}

Prepared by

Bechtel Nevada

Geotechnical Sciences

Las Vegas, Nevada

September 2005 
This page intentionally left blank. 


\section{Site Characterization and Monitoring Data from the Area 5 Pilot Wells DOE/NV/11718--1067}

\section{PREFACE}

The Special Projects Section of Reynolds Electrical \& Engineering Co., Inc. (REECo), a predecessor to Bechtel Nevada, was responsible for characterizing the subsurface hydrogeology of the Area 5 Radioactive Waste Management Site (RWMS) at the Nevada Test Site for the U.S. Department of Energy, Nevada Operations Office in the early 1990s. Some of this work was documented in a series of unpublished data reports. As part of Bechtel Nevada's current scope for closure planning for the Area 5 RWMS, two of these REECo data reports, Hydrologic Characterization Data from the Area 5 Shallow Soil Trenches (DOE/NV/11718--1060) and this report on the pilot wells, have been updated to current editorial standards for approval for public release so they will be accessible for public review and for citation in future documents.

This data report for the Area 5 pilot wells was originally prepared under the same title in February 1994, and assigned the document number, DOE/NV/11432--74. The report has been updated by revising it to conform to current editorial standards of Bechtel Nevada and of the U.S. Department of Energy, National Nuclear Security Administration Nevada Site Office. In addition, some errors in the original unreviewed and unpublished report have been corrected. 
This page intentionally left blank. 


\title{
Site Characterization and Monitoring Data from the Area 5 Pilot Wells DOE/NV/11718--1067
}

\begin{abstract}
Three exploratory boreholes were drilled and completed to the uppermost alluvial aquifer in Area 5 of the Nevada Test Site, Nye County, Nevada, in 1992. The boreholes and associated investigations were part of the Area 5 Site Characterization Program developed to meet data needs associated with regulatory requirements applicable to the disposal of low-level, mixed, and high-specific-activity waste at this site. This series of boreholes was specifically designed to characterize the hydrogeology of the thick vadose zone and to help define the water quality and hydraulic properties of the uppermost aquifer.
\end{abstract}

Wells UE5PW-1, UE5PW-2, and UE5PW-3 are located in a triangular array near the southeast, northeast, and northwest corners, respectively, of the approximately 2.6-square-kilometer Area 5 Radioactive Waste Management Site to give reasonable spatial coverage for sampling and characterization, and to help define the nearly horizontal water table. Two of the wells, UE5PW-1 and UE5PW-2, penetrated only unconsolidated alluvial materials. The third well, located closer to the margin of the basin, penetrated both alluvium and underlying ash-flow and bedded tuff units. The water table was encountered at the elevation of approximately 734 meters.

The results of laboratory testing of core and drill cuttings samples indicate that the mineralogical, material, and hydrologic properties of the alluvium are very similar within and between boreholes. Additional tests on the same core and drill cuttings samples indicate that hydrologic conditions within the alluvium are also similar between pilot wells. Both core and drill cuttings samples are dry (less than 10 percent water content by weight) throughout the entire unsaturated section of alluvium, and water content increases slightly with depth in each borehole. Water potential measurements on core samples show a large positive potential gradient (water tends to move upward, rather than downward) to a depth of approximately 30.5 meters in each borehole, and a nearly zero potential gradient throughout the remaining portion of the vadose zone.

These hydrologic condition data and hydrologic property data indicate that little net downward liquid flow is occurring (if any) through the thick vadose zone. Conversely, gas flow by diffusion, and possibly by advection, may be an important transport mechanism. Environmental tracer measurements made on water extracted from geologic samples suggest that water vapor in the upper portion of the vadose zone is moving upward in response to evaporative demand of the present arid climate.

Preliminary water quality data indicate that the key hazardous and radioactive constituents do not exceed appropriate standards.

Monitoring instruments and equipment were installed in each pilot well for making in-situ measurements of key hydrologic and pneumatic parameters and to monitor change in these parameters over time. 
This page intentionally left blank. 


\section{Table of Contents}

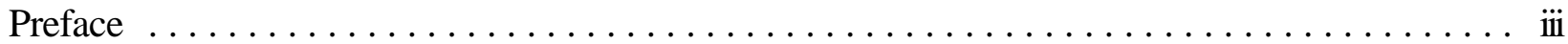

Abstract .............................................. v

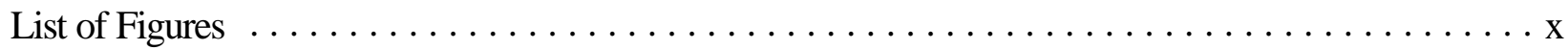

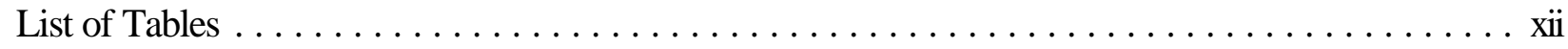

List of Appendices . . . . . . . . . . . . . . . . . . . . . . . . . . . . . . . . xiii

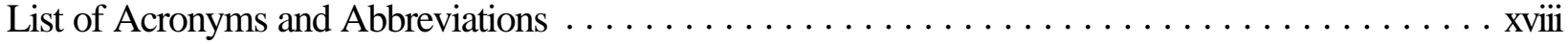

1.0 Introduction $\ldots \ldots \ldots \ldots \ldots \ldots \ldots \ldots \ldots \ldots \ldots \ldots \ldots \ldots \ldots \ldots \ldots \ldots \ldots \ldots \ldots \ldots \ldots, 1$

1.1 Background Information $\ldots \ldots \ldots \ldots \ldots \ldots \ldots \ldots \ldots \ldots \ldots \ldots \ldots \ldots \ldots \ldots \ldots \ldots, 1$

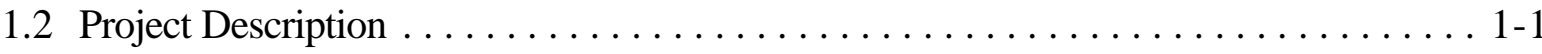

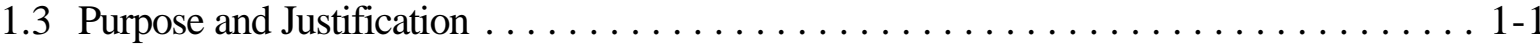

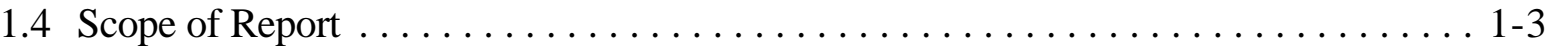

1.5 Overview of Activities . . . . . . . . . . . . . . . . . . . . . . . . . 1-4

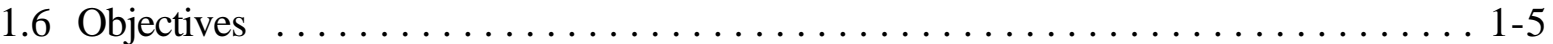

1.7 Site Description . . . . . . . . . . . . . . . . . . . . . . . . . . . . . 1-6

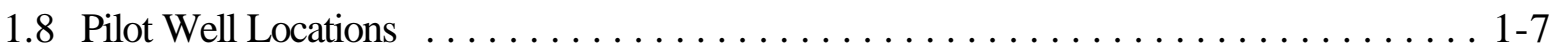

1.9 Site Climatology and Meteorology $\ldots \ldots \ldots \ldots \ldots \ldots \ldots \ldots \ldots \ldots \ldots \ldots \ldots \ldots \ldots$

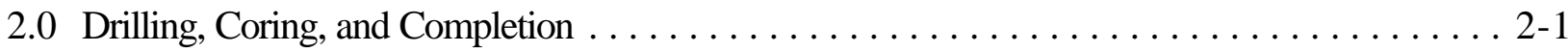

2.1 Drilling and Casing $\ldots \ldots \ldots \ldots \ldots \ldots \ldots \ldots \ldots \ldots \ldots \ldots \ldots \ldots \ldots \ldots \ldots \ldots \ldots \ldots \ldots, 1$

2.2 Collection of Geologic Samples ................................. 2-4

2.2.1 Collection of Core Samples $\ldots \ldots \ldots \ldots \ldots \ldots \ldots \ldots \ldots \ldots \ldots \ldots . \ldots \ldots \ldots$

2.2.2 Collection of Drill Cuttings Samples . . . . . . . . . . . . . . . . . . . . . . . 2-8

2.3 Geologic Description and Disposition of Samples .................... 2-8

2.3.1 Handling, Description, and Disposition of Core Samples .............. 2-8

2.3.2 Handling, Description, and Disposition of Drill Cuttings Samples . . . . . . . . 2-11

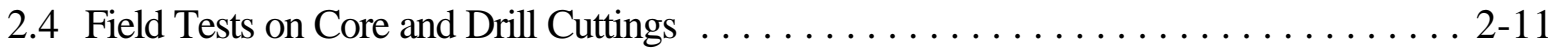

2.4.1 Tracer Tests for Estimating Disturbance from Air Drilling Fluid . . . . . . . . . 2-11

2.4.2 Radiological Surveys of Geologic Samples . . . . . . . . . . . . . . . . . . 2-12

2.5 Pilot Well Completion . . . . . . . . . . . . . . . . . . . . . . . . . . . . . . . 2 2-12

2.5.1 Subsurface Completion Design ............................. 2-13

2.5.2 Subsurface Completion Operations . ........................ 2-17

2.5.3 Surface Facilities and Wellhead Completion .................... 2-18 


\section{Table of Contents (Continued)}

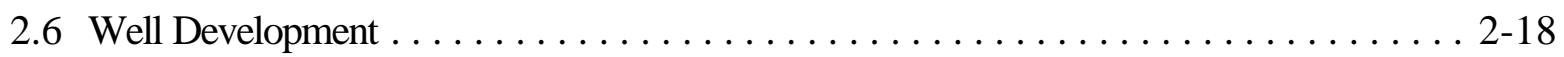

3.0 Laboratory Testing Methods and Results ............................ 3-1

3.1 General Geologic Description, Lithology, Stratigraphy, Mineralogy, and

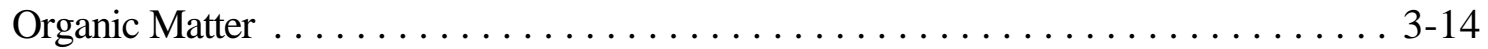

3.1.1 General Geologic, Lithologic, and Stratigraphic Data for Alluvium . . . . . . . . . 3-14

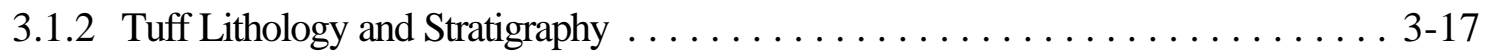

3.1.3 Elemental and Oxide Composition . . . . . . . . . . . . . . . 3-18

3.1 .4 Secondary Mineralogy and Organic Matter . . . . . . . . . . . . . 3-25

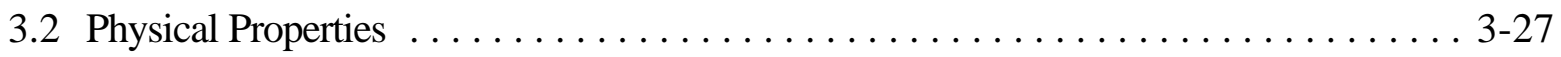

3.2.1 Particle Size Distribution . . . . . . . . . . . . . . . . . . . . . 3-27

3.2 .2 Bulk Density and Porosity $\ldots \ldots \ldots \ldots \ldots \ldots \ldots \ldots \ldots \ldots \ldots \ldots \ldots \ldots \ldots \ldots \ldots \ldots \ldots$

3.3 Hydrologic Properties .................................. 3-36

3.3.1 Saturated Hydraulic Conductivity $\ldots \ldots \ldots \ldots \ldots \ldots \ldots \ldots \ldots \ldots \ldots . . \ldots \ldots$

3.3.2 Moisture Retention Relations . . . . . . . . . . . . . . . . . . . . . . 3-38

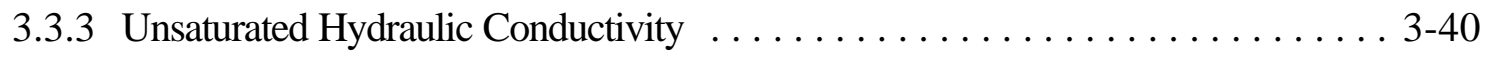

3.4 Hydrologic Conditions . . . . . . . . . . . . . . . . . . . . . . . . . . . 3-43

3.4.1 Water Content ...................................... 3-43

3.4 .2 Water Potential . . . . . . . . . . . . . . . . . . . . . . . . . . .

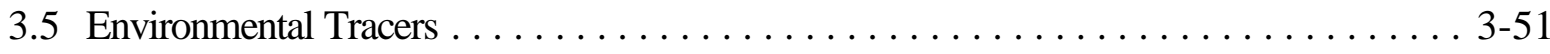

3.5.1 Chloride/Bromide Profiles . . . . . . . . . . . . . . . . . . . . . . 3-51

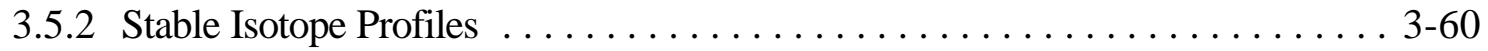

3.5.3 Cosmogenic Chlorine-36 Data . . . . . . . . . . . . . . . . . . . . . . . . . 3-60

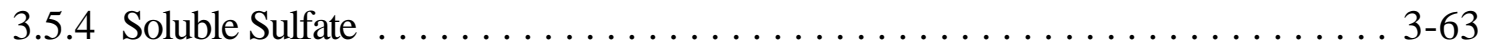

3.6 Sampling and Analysis of Core Samples for Hazardous and

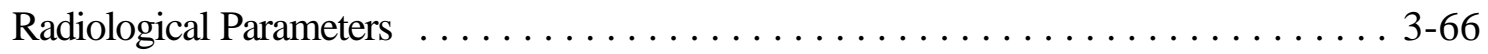

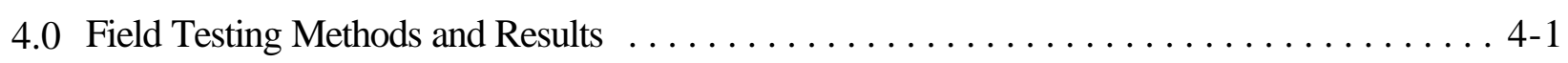

4.1 Preliminary Surface Surveys of Potential Contaminants at Drill Sites . . . . . . . . . . 4-1

4.1.1 Surface Soil Sampling, Analysis, and Results . . . . . . . . . . . . . . . . . 4-1

4.1.2 Near-Surface Radon and Tritium Gas Sampling, Analysis, and Results . . . . . . . 4-2

4.1.2.1 Radon Soil Gas Surveys . . . . . . . . . . . . . . . . . . . . 4-2

4.1.2.2 Tritium Soil Gas Surveys $\ldots \ldots \ldots \ldots \ldots \ldots \ldots \ldots \ldots \ldots \ldots . \ldots \ldots$ 


\section{Table of Contents (Continued)}

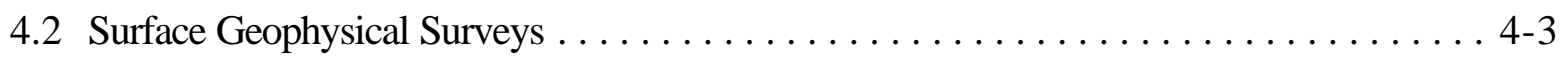

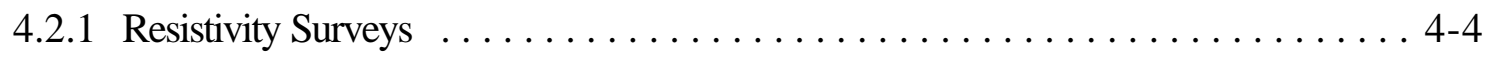

4.2.2 Magnetometer Surveys . . . . . . . . . . . . . . . . . . . . . . . . 4-6

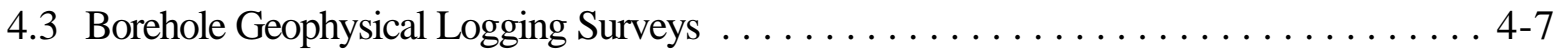

4.3.1 Description of Borehole Logging Activities $\ldots \ldots \ldots \ldots \ldots \ldots \ldots \ldots .4 .7$

4.3.2 Summary of Nuclear Logging Results $\ldots \ldots \ldots \ldots \ldots \ldots \ldots \ldots \ldots .4 .9$

4.3.3 Summary of Borehole Deviation Logs $\ldots \ldots \ldots \ldots \ldots \ldots \ldots \ldots \ldots \ldots .4-10$

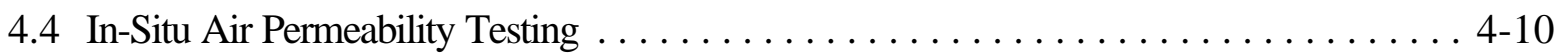

4.4.1 Air (Injection) Permeability Tests Below Drill Casing . . . . . . . . . . 4-11

4.4.2 Post-Drilling Air (Injection) Permeability Testing $\ldots \ldots \ldots \ldots \ldots \ldots \ldots \ldots .4-12$

4.5 Upper Aquifer Hydraulic Parameter Testing . . . . . . . . . . . . . . . . . . . . 4-13

4.5.1 Water Table Elevations and Gradient $\ldots \ldots \ldots \ldots \ldots \ldots \ldots \ldots \ldots . . \ldots \ldots$

4.5.2 Hydraulic Conductivity Recovery Tests . . . . . . . . . . . . . . . 4-15

4.6 Neutron Logging Calibration Boreholes . . . . . . . . . . . . . . . . . . . . . . . . 4-17

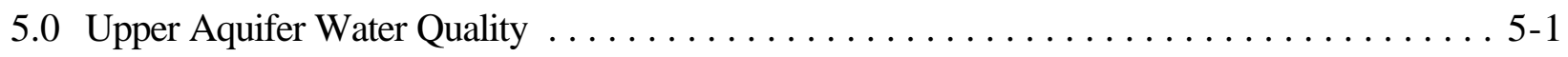

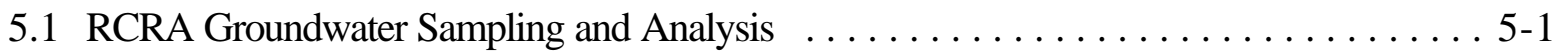

5.2 Preliminary Comparison of General Water Chemistry .................. 5-3

6.0 Preliminary Vadose Zone Monitoring Data $\ldots \ldots \ldots \ldots \ldots \ldots \ldots \ldots \ldots \ldots \ldots \ldots \ldots \ldots$

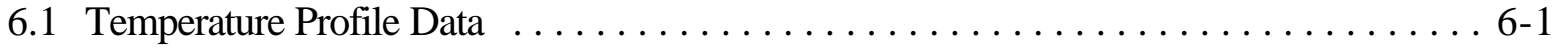

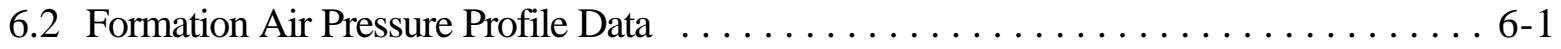

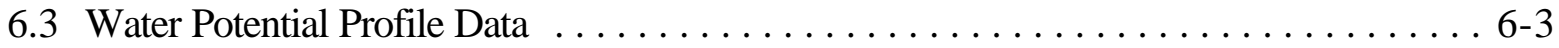

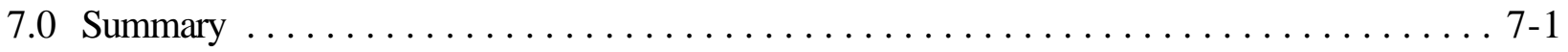

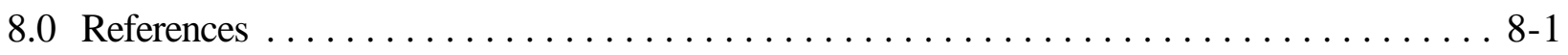

Distribution List 


\section{List of Figures}

Number

Title

Page

1-1 Location of the Area 5 Radioactive Waste Management Site . . . . . . . . . . . . . . 1-2

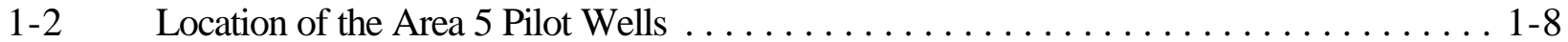

2-1 Completion Configuration for Well UE5PW-1 . . . . . . . . . . . . . . . . . . . 2-14

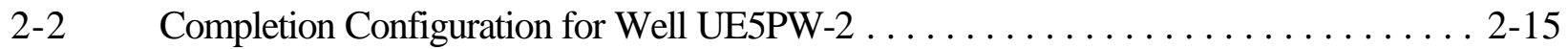

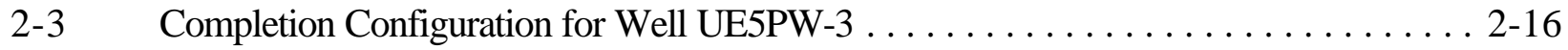

2-4 Area 5 Pilot Well Surface Facilities and Wellhead Completion Diagram . . . . . . . . . 2-19

3-1 Depth Profiles of Element and Oxide Composition Data by X-Ray Fluorescence (XRF) for Core Samples from Well UE5PW-1 . . . . . . . . . . . . . . . . . . . . . . . 3-19

3-2 Depth Profiles of Element and Oxide Composition Data by Instrumental Neutron Activation Analysis (INAA) for Core Samples from Well UE5PW-1 . . . . . . . . . . . . 3-22

3-3 Depth Profiles of Inorganic Carbon for Drill Cuttings Samples from the Pilot Wells . . . . . . . . . . . . . . . . . . . . . . . . . . . . . . 3-26

3-4 Depth Profiles of Dry Sieve Analyses for Core and Drill Cuttings Samples from Well UE5PW-1 . . . . . . . . . . . . . . . . . . . . . . . 3-28

3-5 Depth Profiles of Dry Sieve Analyses for Core and Drill Cuttings Samples from Well UE5PW-2 . . . . . . . . . . . . . . . . . . . . . . . . . . . . . . . . . . . . . 3-29

3-6 Depth Profiles of Dry Sieve Analyses for Core and Drill Cuttings Samples

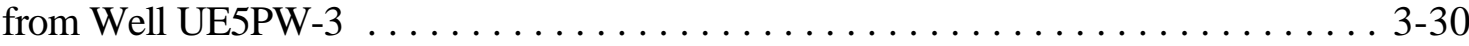

3-7 Depth Profiles of Dry Bulk Density for Core Samples from the Pilot Wells . . . . . . . 3-32

3-8 Depth Profiles of Calculated (calc) and Water-Saturated (sat) Porosity for Core Samples from Well UE5PW-1 . . . . . . . . . . . . . . . . . . 3-33

3-9 Depth Profiles of Calculated (calc) and Water-Saturated (sat) Porosity for Core Samples from Well UE5PW-2 . . . . . . . . . . . . . . . . . . . . 3-34

3-10 Depth Profiles of Calculated (calc) and Water-Saturated (sat) Porosity for Core Samples from Well UE5PW-3 . . . . . . . . . . . . . . . . . . 3-35

3-11 Depth Profiles of Saturated Hydraulic Conductivity for Core Samples from the Pilot Well3-37

3-12 Composite Moisture Retention Data for Core Samples from Well UE5PW-1 . . . . . 3-39

3-13 Composite Moisture Retention Data for Core Samples from Well UE5PW-2 . . . . . . 3-39

3-14 Composite Moisture Retention Data for Core Samples from Well UE5PW-3 . . . . . . 3-40

3-15 Fitted Unsaturated Hydraulic Conductivity Functions for Core Samples from Well UE5PBV4

3-16 Fitted Unsaturated Hydraulic Conductivity Functions for Core Samples from Well UE5P\$42 
3-17 Fitted Unsaturated Hydraulic Conductivity Functions for Core Samples from Well UE5P\$N43

3-18 Depth Profiles of Gravimetric Water Content for Core and Drill Cuttings Samples from Well

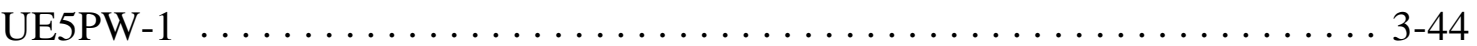

3-19 Depth Profiles of Gravimetric Water Content for Core and Drill Cuttings Samples from Well

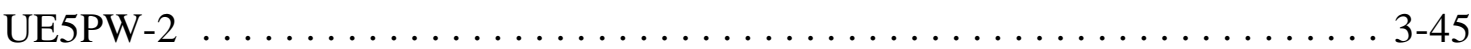

3-20 Depth Profiles of Gravimetric Water Content for Core and Drill Cuttings Samples from Well UE5PW-3 ..................................... 3-46

3-21 Depth Profiles of Volumetric Water Content for Core Samples from the Pilot Wells 3-48

3-22 Depth Profiles of Water Potential for Core Samples from the Pilot Wells . . . . . . . . 3-50

3-23 Depth Profiles of Dry Soil Chloride Concentrations for Drill Cuttings Samples from the Pilot

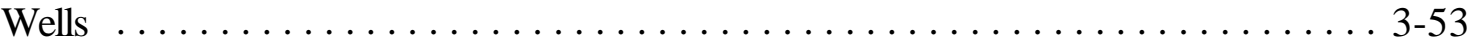

3-24 Depth Profiles of Dry Soil Chloride Concentrations for Core Samples from the Pilot Well3-54

3-25 Depth Profiles of Dry Soil Bromide Concentrations for Drill Cuttings Samples from the Pilot

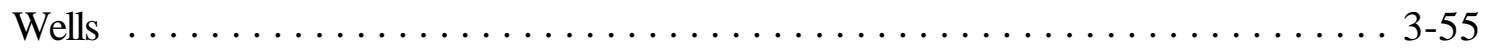

3-26 Depth Profiles of Dry Soil Bromide Concentrations for Core Samples from the Pilot Well3-56

3-27 Depth Profiles of Dry Soil Chloride/Bromide Ratios for Core and Drill Cuttings Samples from

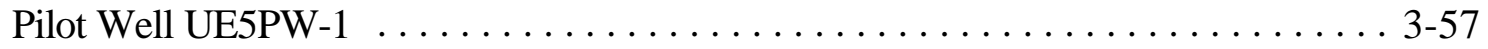

3-28 Depth Profiles of Dry Soil Chloride/Bromide Ratios for Core and Drill Cuttings Samples from

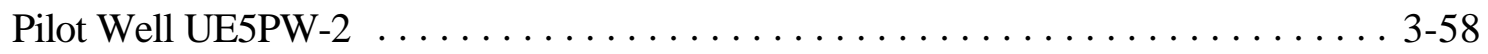

3-29 Depth Profiles of Dry Soil Chloride/Bromide Ratios for Core and Drill Cuttings Samples from

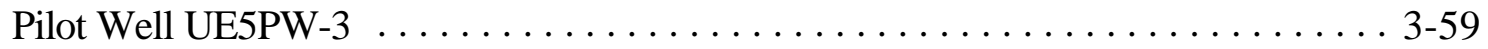

3-30 Depth Profiles of Stable Isotope Data for Core Samples from the Pilot Wells . . . . . . 3-61

3-31 Comparison of Measured Stable Isotopes for Core and Water Samples from the Pilot Wells with Stable Isotope Data for the Global Meteoric Water Line . . . . . . . . . . . . 3 3-62

3-32 Depth Profile of ${ }^{36} \mathrm{Cl} / \mathrm{Cl}$ Ratios for Core Samples from Well UE5PW-1 . . . . . . . . . 3 3-64

3-33 Depth Profiles of Soluble Sulfate for Drill Cuttings Samples from the Pilot Wells . . . . . 3-65

4-1 Resistivity Soundings at the Area 5 Pilot Well Locations .................... 4-5

6-1 Depth Profiles of In-Situ Temperatures from the Pilot Wells $\ldots \ldots \ldots \ldots \ldots \ldots$ 6-2

6-2 Depth Profiles of In-Situ Psychrometer Data from the Pilot Wells . . . . . . . . . . . 6-4 


\section{List of Tables}

Number

Title

Page

1-1 Regulatory Drivers for Site Characterization and Monitoring $\ldots \ldots \ldots \ldots \ldots \ldots \ldots$

1-2 Location Data for the Area 5 Pilot Wells $\ldots \ldots \ldots \ldots \ldots \ldots \ldots \ldots \ldots \ldots$

2-1 REECo Standard Operating Procedures and Test Plans Applicable to the Pilot Well Projeet 2

2-2 Summary of Pilot Well Drilling and Lithology Information . . . . . . . . . . . 2-3

2-3 Core Record for Well UE5PW-1 . . . . . . . . . . . . . . . . 2-6

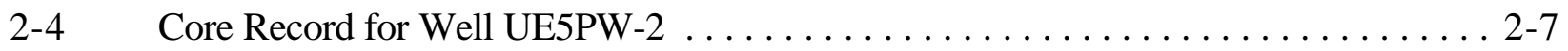

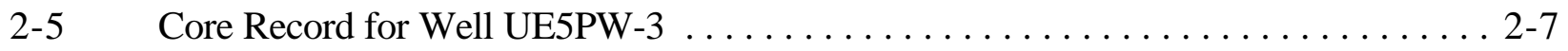

2-6 Definitions of Core and Drill Cuttings Sample Labels . . . . . . . . . . . . . 2-10

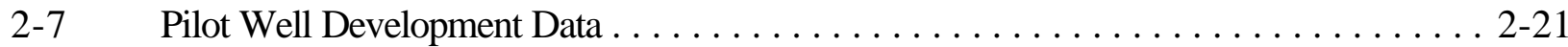

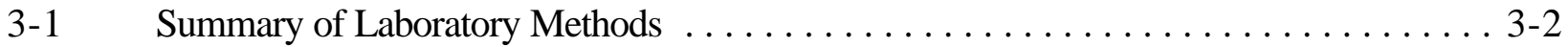

3-2 Summary of Tests Performed on Samples from the Pilot Wells . . . . . . . . . . . 3-5

3-3 Summary of Descriptive Statistics for Alluvium Samples from the Pilot Wells . . . . . . 3-6

3-4 Summary of Descriptive Statistics for Tuff Samples from Well UE5PW-3 . . . . . . . 3-13

3-5 Summary of USCS Assignments for Core and Drill Cuttings Samples from the Pilot Wells . . . . . . . . . . . . . . . . . . . . . . . .

3-6 Summary of Descriptive Statistics of Moisture Retention Curves for

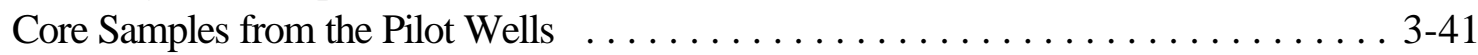

4-1 Borehole Geophysical Logging Episodes in the Area 5 Pilot Wells . . . . . . . . . . 4-8

4-2 Uncorrected Water Table Elevation Data . . . . . . . . . . . . . . . . . . . . . 4-14

5-1 Testing Laboratories, Chemical Parameters, and Analytical Methods . . . . . . . . . 5-2 


\section{List of Appendices}

A. Drilling Information

A.1 Chronological Drilling Summary for UE5PW-1

A.2 Chronological Drilling Summary for UE5PW-2

A.3 Chronological Drilling Summary for UE5PW-3

A.4 Drilling Penetration Rate Data for Pilot Wells

B. Core and Drill Cuttings Sample Description Data

B.1 Borehole Log Sheets for UE5PW-1

B.2 Borehole Log Sheets for UE5PW-2

B.3 Borehole Log Sheets for UE5PW-3

B.4 Drill Cuttings Log Data for UE5PW-1

B.5 Drill Cuttings Log Data for UE5PW-2

B.6 Drill Cuttings Log Data for UE5PW-3

C $\quad$ Tracer $\left(\mathrm{SF}_{6}\right)$ Test Data

C.1 UE5PW-1 $\mathrm{SF}_{6}$ Data from Core Samples and Compressor Air Lines

C. 2 Formation $\mathrm{SF}_{6}$ Tracer Gas Concentrations

D Completion Data

D.1 Pilot Well Completion

D.1.1 Annular Materials

D.1.2 Preparation for Completion

D.1.3 Casing and Instrumentation Installation Detail

D.1.4 Stemming Detail

D.1.5 Completion Operations Safety

D.2 Pilot Well Stemming Summaries

D.2.1 UE5PW-1 Stemming Summary

D.2.2 UE5PW-2 Stemming Summary

D.2.3 UE5PW-3 Stemming Summary

D.3 Pilot Well Casing Tallies

D.3.1 UE5PW-1 Casing Tally

D.3.2 UE5PW-2 Casing Tally

D.3.3 UE5PW-3 Casing Tally 


\section{List of Appendices (Continued)}

D.4 Pilot Well Daily Activities
D.4.1 UE5PW-1 Daily Activity
D.4.2 UE5PW-2 Daily Activity
D.4.3 UE5PW-3 Daily Activity

E Laboratory Testing Data of Geologic Samples

E.1 Stratigraphy and Mineralogy Data

E.1.1 Profiles of USCS Textural Classes

E.1.2 XRF and INAA Data

E.1.2.1 Oxide Composition Data Determined by Major Elements XRF and INAA Methods for Core Samples from UE5PW-1

E.1.2.2 Elemental Composition Data Determined by INAA and Trace Element XRF Methods for Core Samples from UE5PW-1

E.1.2.3 Oxide Composition Data Determined by Major Elements XRF and INAA Methods for Core Samples from UE5PW-2

E.1.2.4 Elemental Composition Data Determined by INAA and Trace Element XRF Methods for Core Samples from UE5PW-2

E.1.2.5 Oxide Composition Data Determined by Major Elements XRF and INAA Methods for Core Samples from UE5PW-3

E.1.2.6 Elemental Composition Data Determined by INAA and Trace Element XRF Methods for Core Samples from UE5PW-3

E.2 Material, Hydrologic, and Geochemical Parameter Data for Alluvial Samples

E.2.1 Results of Laboratory Tests for Core Samples from UE5PW-1

E.2.2 Results of Laboratory Tests for Core Samples from UE5PW-2

E.2.3 Results of Laboratory Tests for Core Samples from UE5PW-3

E.2.4 Results of Laboratory Tests for Drill Cuttings Samples from UE5PW-1

E.2.5 Results of Laboratory Tests for Drill Cuttings Samples from UE5PW-2

E.2.6 Results of Laboratory Tests for Drill Cuttings Samples from UE5PW-3

E.2.7 Moisture Retention Data for Core Samples from UE5PW-1

E.2.8 Moisture Retention Data for Core Samples from UE5PW-2

E.2.9 Moisture Retention Data for Core Samples from UE5PW-3 


\section{List of Appendices (Continued)}

E.2.10 Parameters Required to Calculate Unsaturated Hydraulic Conductivities for Core Samples

E.3 Material, Hydrologic, and Geochemical Parameter Data for Tuff Samples

E.3.1 Results of Laboratory Tests for Tuff Core Samples from UE5PW-3

E.3.2 Results of Laboratory Tests for Tuff Drill Cuttings Samples from UE5PW-3

E.4 Results of Sampling and Analysis for Hazardous and Radiological Parameters in Core Samples

F $\quad$ Field Test Data

F.1 Near-Surface Soil Gas Surveys

F.1.1 Surface Soil Sampling, Analysis, and Results

F.1.2 Near-Surface Radon and Tritium Gas Sampling, Analysis, and Results

F.2 Surface Geophysical Surveys

F.2.1 Resistivity Survey Data

F.2.2 Magnetic Survey Data

F.3 Borehole Geophysical Surveys

F.3.1 Description of Borehole Geophysical Logging Tools Used

F.3.2 Borehole Geophysical Logs Run in UE5PW-1 on 4/20/1992

F.3.3 Borehole Geophysical Logs Run in UE5PW-1 on 6/16/1992

F.3.4 Borehole Deviation Logs Run in UE5PW-1 on 2/24/1993

F.3.5 Borehole Geophysical Logs Run in UE5PW-2 on 7/20/1992

F.3.6 Borehole Geophysical Logs Run in UE5PW-2 on 9/28/1992 and 9/29/1992

F.3.7 Borehole Deviation Logs Run in UE5PW-2 on 2/25/1993

F.3.8 Borehole Geophysical Logs Run in UE5PW-3 on 9/28/1992

F.3.9 Borehole Geophysical Logs Run in UE5PW-3 on 11/18/1992

F.3.10 Borehole Deviation Logs Run in UE5PW-3 on 2/25/1993

F.4 In-Situ Air Permeability Testing Data

F.4.1 Dimensions of Air Permeability Testing Interval for the Pilot Wells

F.4.2 In-Situ Air Permeability Testing Data

F.4.3 Effective Air Permeabilities and Inertial Coefficients for Field Testing in the Pilot Wells

F.5 Upper Aquifer Hydraulic Parameter Testing

F.5.1 Estimating the Water Table Slope under the Area 5 RWMS

F.5.2 Results of Hydraulic Conductivity Recovery Tests 


\section{List of Appendices (Continued)}

G Data from Neutron Logging Calibration Boreholes

G.1 Drilling Information

G.1.1 Chronological Drilling Summary for UE5PW-2A, 2B, and 2C

G.1.2 Core Record for UE5PW-2A, 2B, and 2C

G.1.3 Nevada State Central Zone Coordinates for Neutron Logging Calibration

Boreholes

G.2 Core and Drill Cuttings Sample Description Data

G.2.1 Borehole Log Sheets for UE5PW-2A

G.2.2 Borehole Log Sheets for UE5PW-2B

G.2.3 Borehole Log Sheets for UE5PW-2C

G.2.4 Drill Cuttings Log Data for UE5PWW-2A

G.2.5 Drill Cuttings Log Data for UE5PWW-2B

G.2.6 Drill Cuttings Log Data for UE5PWW-2C

G.3 Laboratory Testing Data of Geologic Samples

G.3.1 Stratigraphy and Mineralogy Data

G.3.1.1 Summary of USCS Group Names for Core and Drill Cuttings Samples from Calibration Boreholes

G.3.1.2 Results from XRF and INAA for Core Samples from UE5PW-2A

G.3.1.3 Results from XRF and INAA for Core Samples from UE5PW-2B

G.3.1.4 Results from XRF and INAA for Core Samples from UE5PW-2C

G.3.2 Material, Hydrologic, and Geochemical Parameter Data

G.3.2.1 Results of Laboratory Tests for Core Samples from UE5PW-2A

G.3.2.2 Results of Laboratory Tests for Core Samples from UE5PW-2B

G.3.2.3 Results of Laboratory Tests for Core Samples from UE5PW-2C

G.3.2.4 Results of Laboratory Tests for Drill Cuttings Samples from UE5PW-2A

G.3.2.5 Results of Laboratory Tests for Drill Cuttings Samples from UE5PW-2B

G.3.2.6 Results of Laboratory Tests for Drill Cuttings Samples from UE5PW-2C

G.3.2.7 Summary of Descriptive Statistics of Alluvial Samples from UE5PW-2A, UE5PW-2B, and UE5PW-2C 


\section{List of Appendices (Continued)}

G.4 Field Test Data

G.4.1 Site Preparation Information

G.4.2 Neutron-Moisture Meter Data

G.4.2.1 Neutron-Moisture Meter Data for UE5PW-2A

G.4.2.2 Neutron-Moisture Meter Data for UE5PW-2B

G.4.2.3 Neutron-Moisture Meter Data for UE5PW-2C

G.4.3 Calibration of the Neutron-Moisture Meter in the Calibration Boreholes

H Upper Aquifer Water Quality Data

H.1 RCRA Groundwater Sampling and Analysis Methods and Results

H.2 Preliminary General Water Chemistry

I Vadose Zone Calibration and Monitoring Data

I.1 Thermistor Calibration Data

I.2 Preliminary Temperature Monitoring Data

I.3 Pressure Transducer Calibration Data

I.4 Preliminary Pressure Monitoring Data

I.5 In Situ Thermocouple Psychrometer Calibration Data

I.6 Thermocouple Psychrometer Monitoring Data 


\section{List of Acronyms and Abbreviations}

\begin{tabular}{|c|c|}
\hline "C & degrees Celsius \\
\hline "F & degrees Fahrenheit \\
\hline${ }^{36} \mathrm{Cl}$ & chlorine-36 \\
\hline${ }^{222} \mathrm{Rn}$ & radon-222 \\
\hline ASTM & American Society for Testing and Materials \\
\hline $\mathrm{BN}$ & Bechtel Nevada \\
\hline $\mathrm{Bq} / \mathrm{m}^{3}$ & Becquerels per cubic meter \\
\hline CAU & casing advance underreaming \\
\hline CFR & Code of Federal Regulations \\
\hline $\mathrm{cm}$ & centimeter(s) \\
\hline $\mathrm{cm} / \mathrm{s}$ & centimeters per second \\
\hline $\mathrm{D}$ & darcy \\
\hline $\mathrm{DOE} / \mathrm{NV}$ & U.S. Department of Energy, Nevada Operations Office \\
\hline DRI & Desert Research Institute \\
\hline Eh & reduction-oxidation potential \\
\hline EPA & Environmental Protection Agency \\
\hline $\mathrm{ft}$ & foot (feet) \\
\hline $\mathrm{g} / \mathrm{cm}^{3}$ & grams per cubic centimeter \\
\hline $\mathrm{gal} / \mathrm{min}$ & gallons per minute \\
\hline GCD & Great Confinement Disposal \\
\hline I.D. & inside diameter \\
\hline in. & inch(es) \\
\hline in./hr & inches per hour \\
\hline INAA & Instrumental Neutron Activation Analysis \\
\hline $\mathrm{K}(\mathrm{S})$ & unsaturated hydraulic conductivity \\
\hline $\mathrm{km}$ & kilometer(s) \\
\hline $\mathrm{km}^{2}$ & square kilometer(s) \\
\hline $\mathrm{kPa}$ & kiloPascal(s) \\
\hline KUT & potassium, uranium, thorium \\
\hline $\mathrm{L} / \mathrm{min}$ & liters per minute \\
\hline LANL & Los Alamos National Laboratory \\
\hline $\mathrm{lb} / \mathrm{ft}^{3}$ & pounds per cubic foot \\
\hline LDR & Land Disposal Restricted \\
\hline LLNL & Lawrence Livermore National Laboratory \\
\hline
\end{tabular}




\begin{tabular}{|c|c|}
\hline LLW & low-level waste \\
\hline $\mathrm{m}$ & meter(s) \\
\hline mi & mile(s) \\
\hline $\mathrm{mi}^{2}$ & square mile(s) \\
\hline $\mathrm{mm}$ & millimeter(s) \\
\hline MW & mixed waste \\
\hline MWL & Meteoric Water Line \\
\hline NEUT(F) & neutron tool (far spacing) \\
\hline NEUT(S) & neutron tool (short spacing) \\
\hline NNSA/NSO & $\begin{array}{l}\text { U.S. Department of Energy, National Nuclear Security Administration Nevada Site } \\
\text { Office }\end{array}$ \\
\hline No. & number \\
\hline NTS & Nevada Test Site \\
\hline O.D. & outside diameter \\
\hline $\mathrm{pCi} / \mathrm{m}^{3}$ & picoCuries per cubic meter \\
\hline psi & pounds per square inch \\
\hline QA & Quality Assurance \\
\hline RCRA & Resource Conservation and Recovery Act \\
\hline REECo & Reynolds Electrical \& Engineering Co., Inc. \\
\hline RWMS & Radioactive Waste Management Site \\
\hline $\mathrm{SF}_{6}$ & sulfur hexafluoride \\
\hline SI & le System International d'Unites \\
\hline SPS & Special Projects Section \\
\hline TKN & total Kjeldahl nitrogen \\
\hline TOC & total organic carbon \\
\hline TOX & total organic halogens \\
\hline TPH & total petroleum hydrocarbons \\
\hline TRU & transuranic waste \\
\hline USCS & Unified Soil Classification System \\
\hline USGS & U.S. Geological Survey \\
\hline XRF & $\mathrm{X}$-ray fluorescence \\
\hline
\end{tabular}


This page intentionally left blank. 


\subsection{Introduction}

\subsection{Background Information}

The Special Projects Section (SPS) of Reynolds Electrical and Engineering Co., Inc. (REECo) was responsible for characterizing the subsurface hydrogeology of the Area 5 Radioactive Waste Management Site (RWMS) (Figure 1-1) at the Nevada Test Site (NTS) for the U.S. Department of Energy, National Nuclear Security Administration Nevada Site Office (NNSA/NSO; formerly U.S. Department of Energy [DOE], Nevada Operations Office) Waste Management Division. REECo was a predecessor to Bechtel Nevada $(\mathrm{BN})$ at the NTS. This report was originally prepared under the same title in February 1994, and was assigned the document number, DOE/NV/11432--74. The original report has been updated to conform to current editorial standards of $\mathrm{BN}$ and of the NNSA/NSO, and to facilitate public distribution of the data contained herein. The original data appendices are included unchanged from the original report. No new data have been added to this report, though additional relevant studies of the area have been conducted in the intervening years.

\subsection{Project Description}

The pilot well project was one of a series of hydrogeologic site characterization projects conducted for the Area 5 RWMS, designed to determine its suitability for disposal of low-level waste (LLW), mixed waste (MW), and transuranic waste (TRU). The other projects in the series are the existing excavations project (REECo, 1993a), the science trench boreholes project (REECo, 1993b), and the shallow soil trenches project (also updated and reissued as BN, 2005). The pilot well project produced important geologic and hydrologic data for the upper 256 to 291 meters (m) (839 to 955 feet [ft]) of the alluvium in which the RWMS is constructed.

\subsection{Purpose and Justification}

The primary purpose of the pilot well project was two-fold: first, to characterize important water quality and hydrologic properties of the uppermost aquifer; and second, to characterize the lithologic, stratigraphic, and hydrologic conditions that influence infiltration, redistribution, percolation, and chemical transport through the thick vadose zone in the vicinity of the Area 5 RWMS. 


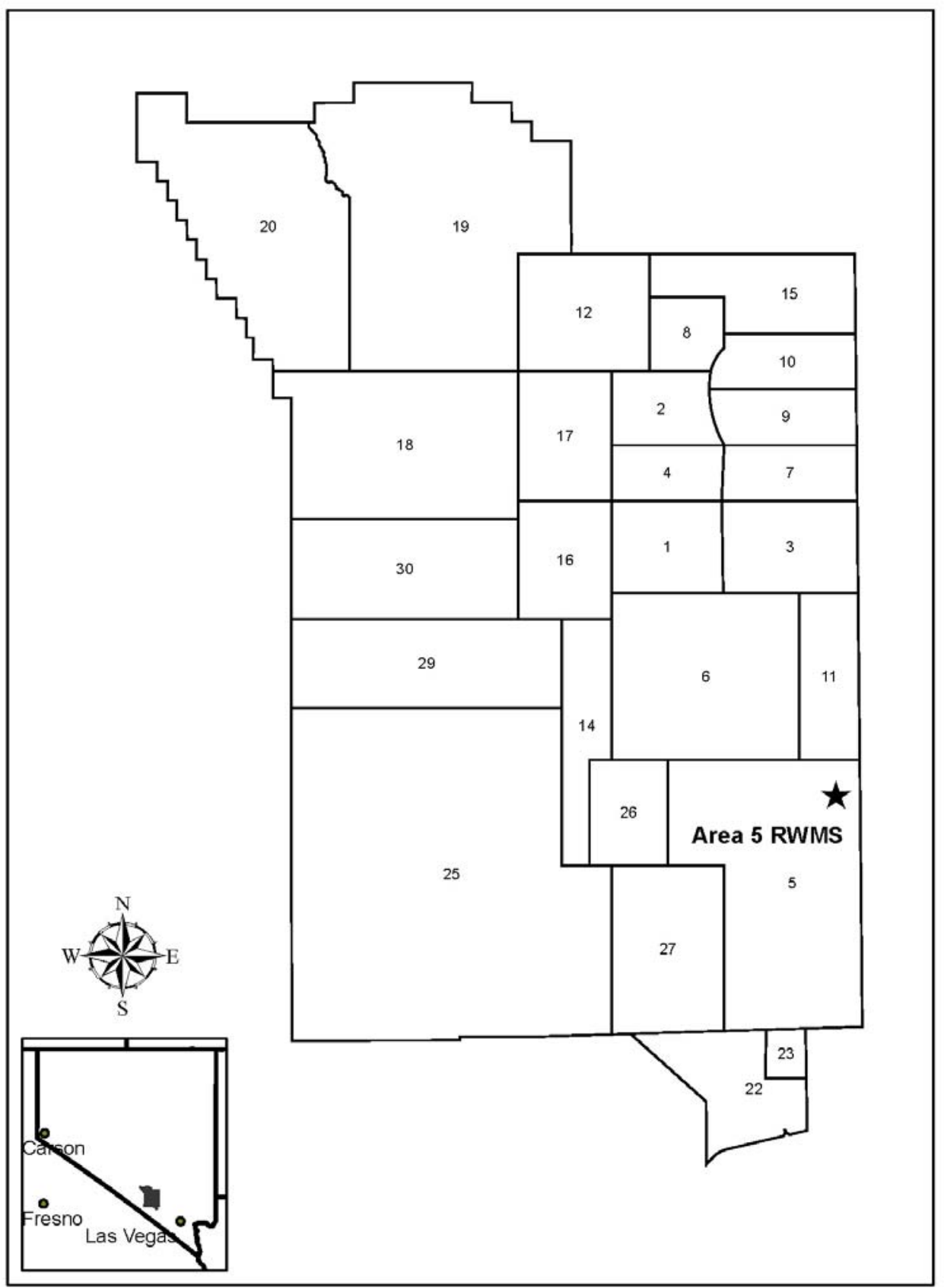

Figure 1-1

Location of the Area 5 Radioactive Waste Management Site 
The justification for this work came from the review by the State of Nevada of the original NNSA/NSO Resource Conservation and Recovery Act (RCRA) Part B Permit application submitted in 1988 for disposal of MW at the Area 5 RWMS. The State of Nevada determined that the permit was deficient in characterization data concerning the hydrogeology of the vadose zone and the water quality and hydraulic properties of the uppermost aquifer. The NNSA/NSO agreed with the state and proposed the pilot well project to satisfy these important site characterization data requirements. In addition, NNSA/NSO proposed to install and monitor vadose zone instruments to obtain baseline unsaturated hydraulic parameter data in the three pilot wells.

A number of federal regulations and DOE orders provided additional justification for the site characterization and baseline monitoring data collection activities incorporated in the pilot well project. These regulations include specific RCRA requirements for the land disposal of hazardous waste, requirements for obtaining waivers relating to the land disposal of hazardous waste, as well as DOE Order 5820.2A, "Radioactive Waste Management," (now DOE Order 435.1) and requirements in 40 Code of Federal Regulations (CFR) 191 for land disposal of radioactive waste. Regulatory requirements for characterization and baseline monitoring are summarized in Table 1-1 for different waste types that NNSA/NSO is currently disposing at the Area 5 RWMS.

\subsection{Scope of Report}

This report describes pilot well drilling and coring, geophysical logging, instrumentation and stemming, laboratory testing, and in-situ testing and monitoring activities. In addition, this report summarizes all data obtained from these activities up to April 23, 1993. Later sampling data from these wells are typically compiled in the NTS Annual Site Environmental Report (see for example, DOE, 2002).

Note that this report presents the data in le System International d'Unites (SI) system of units; however, the data in the appendices were not converted to SI units, but are presented in the units in which they were measured in the field or laboratory. 
Table 1-1

Regulatory Drivers for Site Characterization and Monitoring

\begin{tabular}{|c|c|c|c|}
\hline \multirow[b]{2}{*}{ Requirement } & \multicolumn{3}{|c|}{ Waste and Facility Category } \\
\hline & Low-Level Waste & $\begin{array}{l}\text { Mixed Waste } \\
\text { (existing cells) }\end{array}$ & $\begin{array}{c}\text { TRU \& Orphan } \\
\text { Mixed Waste } \\
\text { (existing GCD cells) }\end{array}$ \\
\hline \multicolumn{4}{|l|}{ DOE Order 435.1} \\
\hline Performance assessment & $\begin{array}{c}\text { Characterization and } \\
\text { Monitoring }\end{array}$ & $\begin{array}{c}\text { Characterization and } \\
\text { Monitoring }\end{array}$ & $\begin{array}{c}\text { Characterization and } \\
\text { Monitoring }\end{array}$ \\
\hline \multicolumn{4}{|l|}{ RCRA (Part B Permit) } \\
\hline $\begin{array}{l}\text { Groundwater monitoring waiver } \\
(40 \text { CFR } 264.90[\mathrm{~b}][2])^{\mathrm{a}}\end{array}$ & N/A & Characterization & Monitoring \\
\hline $\begin{array}{l}\text { No migration variance } \\
(40 \text { CFR 268.6[a]) }\end{array}$ & $\mathrm{N} / \mathrm{A}$ & $\mathrm{N} / \mathrm{A}$ & $\begin{array}{c}\text { Characterization and } \\
\text { Monitoring }\end{array}$ \\
\hline \multicolumn{4}{|l|}{40 CFR $193^{c}$} \\
\hline Groundwater protection & $\begin{array}{c}\text { Characterization and } \\
\text { Monitoring }\end{array}$ & $\mathrm{N} / \mathrm{A}$ & N/A \\
\hline \multicolumn{4}{|c|}{$40 \mathrm{CFR} 191^{\mathrm{d}}$ (vacated and remanded) } \\
\hline Performance assessment & $\mathrm{N} / \mathrm{A}$ & $\mathrm{N} / \mathrm{A}$ & $\begin{array}{c}\text { Characterization and } \\
\text { Monitoring }\end{array}$ \\
\hline
\end{tabular}

a 40 CFR 264 - Standards for Owners and Operators of Hazardous Waste Treatment, Storage, and Disposal Facilities

b 40 CFR 268 - Land Disposal Restrictions

c 40 CFR 193 - Environmental Standards for the Management, Storage, and Land Disposal of Low-Level Radioactive Waste and Naturally Occurring and Accelerator-produced Waste

d 40 CFR 191 - Environmental Radiation Protection Standards for Management and Disposal of Spent Nuclear Fuel, High-Level, and Transuranic Radioactive Wastes

\subsection{Overview of Activities}

Three wells were drilled and cored from the ground surface to approximately $21.3 \mathrm{~m}$ (70 ft) below the water table. Total depths of the wells ranged from approximately 256 to $292 \mathrm{~m}$ (840 to $955 \mathrm{ft}$ ). The drilling was accomplished using a casing-advance under-reaming (CAU) system to preserve in-situ hydraulic conditions (water content and water potential) of the formation and the drill cuttings. Core samples were collected in alluvium by driving a solid tube (containing segmented Lexan ${ }^{\circledR}$ liners) into the formation ahead of the casing with an air-percussion hammer. Standard air-rotary coring methods were used to core the underlying tuff formation in Well UE5PW-3. 
Cuttings were collected at 0.76-m (2.5-ft) intervals and cores were taken at selected intervals. The lithology of the drill cuttings and core was rapidly determined in the field before the samples were packaged to maintain their physical integrity and to minimize water loss by evaporation. Samples were then shipped to various testing laboratories or stored for future use. Laboratory tests were conducted on both drill cuttings and core samples to quantify the distribution with depth of hydrologic, geochemical, environmental tracer, and mineralogic parameters. These laboratory data will provide estimates of input parameters required to model liquid, vapor, and heat flow, and some of the parameters required to model solute transport both in the vadose zone and the upper regions of the deep alluvial aquifer. Finally, both environmental tracer and unsaturated hydrologic parameters will be used to calculate recharge and travel times to the water table.

Borehole geophysical logging was performed during selected stages of drilling to attempt to make insitu measurements of key physical and hydrologic parameters. These logs were intended to support and possibly augment the data obtained from geologic cuttings samples.

Upon completion of drilling, monitoring well casing and vadose zone instruments were installed and stemmed in place. In-situ hydrologic tests were conducted in the completed boreholes to characterize medium permeability to air and liquid. In addition, monitoring the vadose zone with instruments (including thermocouple psychrometers, thermistors, and air pressure transducers) was initiated. Finally, each pilot well was developed and purged, and water quality samples were collected to measure general water quality parameters and concentrations of hazardous chemical and radioactive constituents.

\subsection{Objectives}

The specific objective of the pilot well project was to collect sufficient samples required to meet geologic, hydrologic, geochemical, and hazardous constituent characterizations as specified below.

- Determine the stratigraphic, lithologic, mineralogic, physical, and magnetic characteristics of geologic samples to define vadose zone and groundwater flow paths.

- Determine the hydrologic characteristics (hydrologic properties and conditions) in geologic core samples and in-situ formation materials to help delineate both vadose zone and groundwater flow paths.

- Measure environmental tracer concentrations and hydraulic parameters in geologic samples necessary to estimate recharge. 
- Characterize the geochemical properties of geologic samples required to model the transport of contaminants.

- Measure concentrations of potential source term radionuclide and RCRA hazardous constituents in both geologic and groundwater samples to establish baseline conditions.

- Delineate the general background chemical composition of the uppermost aquifer to establish baseline conditions.

- Determine the extent to which drilling fluids invaded geologic core samples and in-situ formation materials.

\subsection{Site Description}

The NTS is a DOE facility occupying approximately 3,561 square kilometers $\left(\mathrm{km}^{2}\right)(1,375$ square miles $\left.\left[\mathrm{mi}^{2}\right]\right)$ in southern Nevada, approximately 104 kilometers $(\mathrm{km})$ (65 miles [mi]) northwest of Las Vegas (Figure 1-1). The site is bordered to the north, west, and east by the Nellis Air Force Test and Training Range, a government-owned, restricted-access area. Activities at the NTS include a variety of nuclear and non-nuclear projects and experiments.

The Area 5 RWMS encompasses 300 hectares (740 acres) north of Frenchman Lake playa, and is located near the junction of three alluvial fans within the Frenchman Lake drainage basin (RSN, 1991). The Low-Level Waste Management Unit is a 37-hectare (92-acre) facility located in the southeast section of the Area 5 RWMS. It was established in 1978 for the purpose of disposing of LLW generated at the NTS and other DOE facilities.

The Area 5 RWMS currently accepts low-level radioactive waste for shallow land burial. The Area 5 RWMS also currently accepts onsite-generated low-level waste containing hazardous constituents (mixed waste) that are not land-disposal restricted (LDR). Most wastes are disposed in steel drums, steel boxes, or wooden boxes. Plans are being made to accept mixed waste from both onsite and offsite generators in the near future. In the past, high-specific-activity wastes were disposed in 36.6-m (120-ft) deep boreholes called the Greater Confinement Disposal (GCD) boreholes. 


\subsection{Pilot Well Locations}

The locations of the three pilot wells are outside past, current, and future waste disposal areas, and are shown on Figure 1-2. In plan view, the wells are located approximately at the apexes of an equilateral triangle, with sides approximately $1.5 \mathrm{~km}(1 \mathrm{mi})$ in length. These locations were selected to facilitate measurement of the expected very small water table gradient. Wells UE5PW-2 and UE5PW-3 were positioned on the presumed up-gradient side of the Area 5 RWMS to attempt to resolve questions concerning the effect of Massachusetts Mountain on the uppermost aquifer groundwater gradient.

Wells UE5PW-1 and UE5PW-2 were both located on older pediment surfaces where early stages of desert pavement have developed. Well UE5PW-3 is located on a much younger alluvial fan. The Nevada State Central Zone coordinates of the boreholes and elevations above sea level are given in Table 1-2.

\subsection{Site Climatology and Meteorology}

The climate and meteorology of the region are typical of the upper Mojave Desert province. Two major air movement patterns affect this area: from fall through spring, the effects of the Pacific highpressure area moving over the Sierra Nevada are dominant; in summer, this high-pressure area dissipates, and the warm moist air mass in the Gulf of Mexico exerts its influence. Average daily temperatures range from 2 degrees Celsius (" C) (36 degrees Fahrenheit ["F]) in January to 24 " C $(75 \mathrm{~F})$ in August. Precipitation is highly variable in the desert. The summer months have intense, isolated thunderstorms, but the winter storms are of longer duration and lower intensity. The average precipitation is approximately 100 millimeters $(\mathrm{mm})$ (4 inches [in.]) per year, and the estimated evapotranspiration rate is $2,200 \mathrm{~mm}$ (87 in.) per year (EG\&G/SAIC, 1991). 


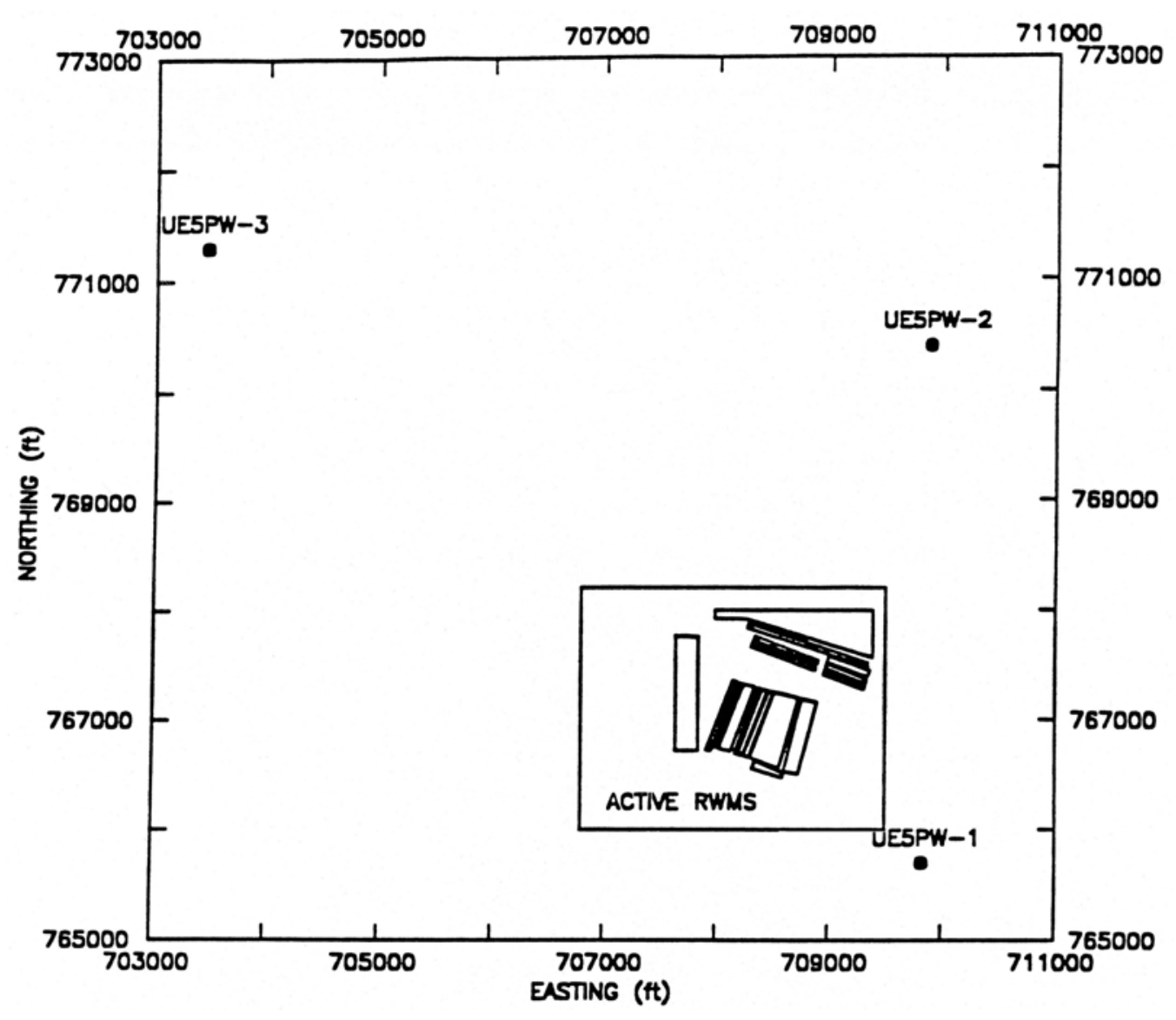

Figure 1-2

Location of the Area 5 Pilot Wells

Table 1-2

Location Data for the Area 5 Pilot Wells

\begin{tabular}{||c|c|c|c||}
\hline \multirow{2}{*}{ Borehole } & \multirow{2}{*}{$\begin{array}{c}\text { Elevation above Sea Level } \\
\text { meters (feet) }\end{array}$} & \multicolumn{2}{|c||}{ Nevada State Central Zone Coordinates ${ }^{\mathbf{b}}$} \\
\cline { 3 - 4 } & North (meters [feet]) & East (meters [feet]) \\
\hline \hline \multirow{2}{*}{ UE5PW-1 } & $\begin{array}{c}969.37 \\
(3,180.35)\end{array}$ & $\begin{array}{c}223,386.48 \\
(765,702.19)\end{array}$ & $\begin{array}{c}216,357.08 \\
(709,831.57)\end{array}$ \\
\hline \multirow{2}{*}{ UE5PW-2 } & 990.12 & $234,817.13$ & $216,376.00$ \\
& $(3,248.42)$ & $(770,395.90)$ & $(709,893.63)$ \\
\hline \multirow{2}{*}{ UE5PW-3 } & $1,005.22$ & $235,089.93$ & $214,415.04$ \\
& $(3,297.97)$ & $(771,290.92)$ & $(703,460.07)$ \\
\hline
\end{tabular}

a Measured from top of monitor well casing. 1929 National Geodetic Vertical Datum.

b 1927 North American Datum 


\subsection{Drilling, Coring, and Completion}

This section describes the drilling procedures used and data obtained; the collection of alluvial deposits, rock, and groundwater samples; and the installation and stemming of monitoring well casing/screen and vadose zone instruments. Detailed procedures used to accomplish these activities were given in REECo Quality Assurance (QA) standard operating procedures and test plans listed in Table 2-1. In addition to following these formal procedures and recording data in procedure-specific forms, information on drilling, sampling, and completion activities was recorded daily in a log book.

\subsection{Drilling and Casing}

All three pilot wells were drilled by Tonto Drilling Company with an Ingersol-Rand T-4W rig, using telescoping (successively smaller diameter) CAU drilling systems. Air was the only drilling fluid used. This drilling method has been described in detail by Hammermeister et al. (1986), so only a brief description is included here. In this method, a down-hole percussion hammer is used to drill and ream below the bottom joint of the casing. A pilot bit, in conjunction with an eccentric reamer, drills a hole slightly larger than the outside diameter (O.D.) of the casing. The percussion hammer forces the casing down the borehole by impacting on a shoe attached to the bottom joint of the casing. Thus the casing is advanced downward as the borehole is drilled deeper. Drill cuttings are brought to the land surface through the casing, thereby minimizing the disturbance to the formation. The casing is moved downward until the desired depth for coring is reached. The interval is cored and then enlarged (reamed), and the casing is advanced to the bottom of the cored interval. This sequence of drilling, coring, reaming, and casing is repeated until the total depth of the borehole is reached.

The CAU drilling system is ideally suited for vadose zone characterization studies because it minimizes the disturbance of properties related to in-situ water content in the drill cuttings, core, and formation. It works well with air as a drilling fluid. The CAU drilling system cases (seals off) the formation from the drying effects of air immediately above the drill bit, and minimizes the exposure of drill cuttings to the air by moving them rapidly to the land surface.

The drilling start and end dates, total depth, borehole diameters, and lithologies are summarized for all three pilot wells in Table 2-2. Related drilling information can also be found in the Nevada Test Site Drilling and Mining Summary compiled by Raytheon Services Nevada 
Table 2-1

REECo Standard Operating Procedures and Test Plans Applicable to the Pilot Well Project

\begin{tabular}{|c|c|c|c|}
\hline $\begin{array}{l}\text { Test Plans and } \\
\text { Procedures }\end{array}$ & Title & Date & Revision \\
\hline AADzD.T.01.00 & Surface Radiometric Survey Site Characterization Borehole & $08 / 21 / 1991$ & 0 \\
\hline AADzD.T.02.00 & Borehole Water Level Monitoring & $10 / 27 / 1991$ & 0 \\
\hline AADzD.T.03.00 & Drawdown and Recovery Aquifer Test Plan & $10 / 27 / 1991$ & 0 \\
\hline AADzD.T.04.00 & Surface Resistivity Survey Site Characterization Borehole & $10 / 17 / 1991$ & 0 \\
\hline AADzD.T.05.00 & Surface Magnetic Survey Site Characterization Borehole & $10 / 15 / 1991$ & 0 \\
\hline AADzD.T.06.00 & Geologic Logging of Core and Drill Cuttings & $02 / 21 / 1991$ & 0 \\
\hline AADzD.T.07.00 & Measurement of Tritium Oxide in Soil Pore Gas & $08 / 31 / 1991$ & 0 \\
\hline AADzD.T.10.00 & Drilling, Coring, and Well Installation Project Plan & $12 / 10 / 1991$ & 0 \\
\hline AADzD.T.13.00 & $\begin{array}{l}\text { Determination of Mineralogic and Geologic Characteristics } \\
\text { of Alluvial Samples }\end{array}$ & 01/13/1992 & 0 \\
\hline WMD-T16 & $\begin{array}{l}\text { Science Trench Sampling for Determining Characteristics of } \\
\text { Geologic Samples }\end{array}$ & 02/20/1992 & 0 \\
\hline WMD-T17 & Quality Assurance Project Plan for Pilot Well Project & $04 / 24 / 1992$ & 0 \\
\hline WMD-T18 & Pilot Well Geophysical Logging & 04/03/1992 & 0 \\
\hline WMD-T19 & $\begin{array}{l}\text { Pilot Well Core Sampling and Analysis for Hazardous and } \\
\text { Radiological Constituents }\end{array}$ & 05/01/1992 & 0 \\
\hline WMD-T20 & Pilot Well Groundwater Sampling and Analysis & $05 / 12 / 1992$ & 0 \\
\hline AADzD.D.04.00 & $\begin{array}{l}\text { Handling, Division, Preparation, Control, and Transport of } \\
\text { Characterization Samples }\end{array}$ & 02/13/1992 & 0 \\
\hline AADzD.D.08.00 & Calibration of the Organic Vapor Monitor & $01 / 31 / 1990$ & 0 \\
\hline WMD-D11 & $\begin{array}{l}\text { Handling In-Progress Data Records for Special Projects } \\
\text { Section Activities }\end{array}$ & 02/20/1992 & 0 \\
\hline WMD-D12 & Calculation Check Sheet & 05/07/1992 & 0 \\
\hline WMD-D13 & $\begin{array}{l}\text { Use of Tracers to Determine Core and Groundwater } \\
\text { Contamination from Drilling }\end{array}$ & 05/18/1992 & 0 \\
\hline WMD-D15 & Gross Gamma Analysis of Pilot Well Core Samples & 04/03/1992 & 0 \\
\hline WMD-D17 & Pilot Well Abandonment & 05/18/1992 & 0 \\
\hline
\end{tabular}


Table 2-2

Summary of Pilot Well Drilling and Lithology Information

\begin{tabular}{|c|c|c|c|c|c|c|c|c|c|c|c|c|}
\hline \multirow{4}{*}{ Borehole } & \multirow{4}{*}{ Start Date } & \multirow{4}{*}{ End Date } & \multicolumn{8}{|c|}{$\begin{array}{l}\text { Borehole Diameter } \\
\text { millimeters (inches) }\end{array}$} & \multirow{4}{*}{$\begin{array}{c}\text { Borehole } \\
\text { Total } \\
\text { Depth }^{\text {a }} \\
\text { meters } \\
\text { (feet) }\end{array}$} & \multirow{4}{*}{ Lithology a, b } \\
\hline & & & \multicolumn{2}{|c|}{$305.97(12.046)$} & \multicolumn{2}{|c|}{$237.31(9.343)$} & \multicolumn{2}{|c|}{$211.99(8.346)$} & \multicolumn{2}{|c|}{200.03 (7.875) } & & \\
\hline & & & from & to & from & to & from & to & from & to & & \\
\hline & & & \multicolumn{8}{|c|}{$\begin{array}{c}\text { Depth }^{\text {a }} \\
\text { meters (feet) } \\
\end{array}$} & & \\
\hline UE5PW-1 & 03/19/1992 & 06/16/1992 & 0 & $\begin{array}{l}116 \\
(380)\end{array}$ & $\begin{array}{c}116 \\
(380)\end{array}$ & $\begin{array}{l}256 \\
(839)\end{array}$ & -- & -- & -- & -- & $\begin{array}{c}256 \\
(839.0)\end{array}$ & $\begin{array}{l}\text { Alluvium } \\
0-256 \mathrm{~m} \\
(0-839 \mathrm{ft})\end{array}$ \\
\hline UE5PW-2 & 06/18/1992 & 09/04/1992 & 0 & $\begin{array}{c}122 \\
(400)\end{array}$ & $\begin{array}{c}122 \\
(400)\end{array}$ & $\begin{array}{c}280 \\
(919.5)\end{array}$ & -- & -- & -- & -- & $\begin{array}{c}280 \\
919.5)\end{array}$ & $\begin{array}{c}\text { Alluvium } \\
0-280 \mathrm{~m} \\
(0-919.5 \mathrm{ft})\end{array}$ \\
\hline UE5PW-3 & 09/16/1992 & 11/09/1992 & 0 & $\begin{array}{c}137 \\
(450)\end{array}$ & $\begin{array}{c}137 \\
(450)\end{array}$ & $\begin{array}{l}235 \\
(770)\end{array}$ & $\begin{array}{l}235 \\
(770)\end{array}$ & $\begin{array}{c}251 \\
(822.5)\end{array}$ & $\begin{array}{c}251 \\
(822.5)\end{array}$ & $\begin{array}{c}291 \\
(955)\end{array}$ & $\begin{array}{c}291 \\
(955.0)\end{array}$ & $\begin{array}{c}\text { Alluvium } \\
0-188 \mathrm{~m} \\
(0-617.5 \mathrm{ft}) \\
\text { Welded tuff } \\
188-280 \mathrm{~m} \\
(617.5-917.5 \mathrm{ft}) \\
\text { Bedded tuff } \\
280-291 \mathrm{~m} \\
(917.5-955 \mathrm{ft})\end{array}$ \\
\hline
\end{tabular}

a Measured from estimated ground surface.

b $m=$ meters; $\mathrm{ft}=$ feet 
(RSN, 1990). Detailed chronological drilling summaries of each well, including problems and their resolution, are presented in Appendices A.1, A.2, and A.3.

Drilling penetration rates are presented in graphical form in Appendix A.4. Penetration rates are related to rock formation properties, drilling equipment condition and performance, and the particular techniques used by the drillers. The penetration rate graphs, together with the drilling chronology summaries, show that numerous drilling problems were encountered and overcome during drilling of these holes. In almost all cases, these difficulties were related to the combined effects of formation materials and the use of air as the drilling fluid. The formation materials were primarily very dry, unconsolidated, coarse-grained alluvium. The use of air as the drilling fluid (required to prevent introduction of water or other fluids to the formation) further destabilized the already unstable borehole walls, resulting in "wash-out" zones in some regions of the borehole. However, the profiles of borehole diameter versus depth calculated from volumes of stemming materials required to fill the boreholes (Section 2.5) show that extensive hole erosion was confined to relatively small intervals of the boreholes. Borehole geophysical density logs confirm that hole erosion was restricted to specific depth intervals (Section 4.3). Hole caving occurred in other depth intervals, creating a great deal of friction between the casing and formation, and limiting the depth that a particular diameter CAU drilling system could be advanced. In summary, drilling activities never became routine, as different drilling problems were encountered in each borehole.

\section{$2.2 \quad$ Collection of Geologic Samples}

The CAU drilling system discussed above was selected in part because it produces drill cuttings samples that are representative of the formation. The system, when operated as designed, rapidly and nearly completely moves drill cuttings from the interval being drilled to the ground surface, ensuring that drill cuttings samples collected at the ground surface are in fact from the interval being drilled. Further, the rapid transport of drill cuttings to the surface minimizes the disturbance of the water content of the samples. Finally, the drilling action of the percussion hammer system minimizes the disturbance of the particle size distribution of unconsolidated alluvial materials penetrated. For these reasons, and because of the difficulty and high cost of coring unconsolidated alluvial materials, emphasis was placed on collection of drill cuttings samples during this project.

Certain important laboratory tests are not valid unless performed on samples with pore size distributions and water contents that are representative of the formation. Hence, coring unconsolidated alluvial materials, even though difficult and expensive, was necessary. The coring method described below is the only known method capable of producing this type of core sample from unconsolidated, relatively 
dry, coarse-grained alluvial deposits. Because this coring method is standard in the drilling industry, it is only briefly described in Section 2.2.1.

Air-rotary coring was employed for coring the tuff formation that underlies the alluvium in Well UE5PW-3. This coring method was also attempted unsuccessfully in several of the more consolidated alluvium intervals in Wells UE5PW-1 and UE5PW-2.

\subsubsection{Collection of Core Samples}

Core samples were collected from the alluvium at selected intervals (Tables 2-3, 2-4, and 2-5) using drive core methods. An air-percussion hammer was used to drive a 0.76-m (2.5-ft) long by 114.3-mm (3.5-in.) O.D. solid-tube core barrel containing clear Lexan ${ }^{\circledR}$ (polycarbonate) liner segments to hold the sample material. The Lexan ${ }^{\circledR}$ segments were $76.2 \mathrm{~mm}$ (3 in.) long by $88.9 \mathrm{~mm}$ (3.5 in.) O.D. In several cases a longer core barrel (1.5-m [5.0-ft] long by $114.3 \mathrm{~mm}$ [3.5-in.] O.D.) was substituted for the standard core barrel.

Past experience demonstrated that the drive core method can provide good core recovery and minimize the disturbance of hydrologic conditions and physical properties of relatively dry, coarsegrained, unconsolidated alluvial samples (Hammermeister et al., 1986). Actual core recovery using these methods was generally excellent. Core loss or less than maximum recovery was mainly due to blockage of the solid-tube sample barrel with large rocks, fall-back of the cuttings (usually no more than $150 \mathrm{~mm}$ [6 in.]), or loss of core from the core barrel while removing the core barrel from the borehole.

The process of drive coring unconsolidated alluvium could conceivably alter the pore size distribution of samples in several ways. Visual observation of core samples as they were removed from the core barrel indicated that the samples were generally very tightly packed into the liners. Visual inspection also showed fines accumulating along the outer edge of the core, suggesting some minor disturbance of the core along the outer circumference. This suggests that the drive coring process probably did not significantly decrease the compaction of the samples compared to in-situ conditions. At the same time, it is hard to imagine that the coring process could significantly increase the compaction of relatively dry, sandy alluvial materials which have in some cases been under as much as $275 \mathrm{~m}$ (900 ft) of overburden for many thousands of years. The possible effects of the coring process on the values of parameters that are sensitive to pore size distribution are discussed further in Section 3.0. 
Table 2-3

\section{Core Record For Well UE5PW-1}

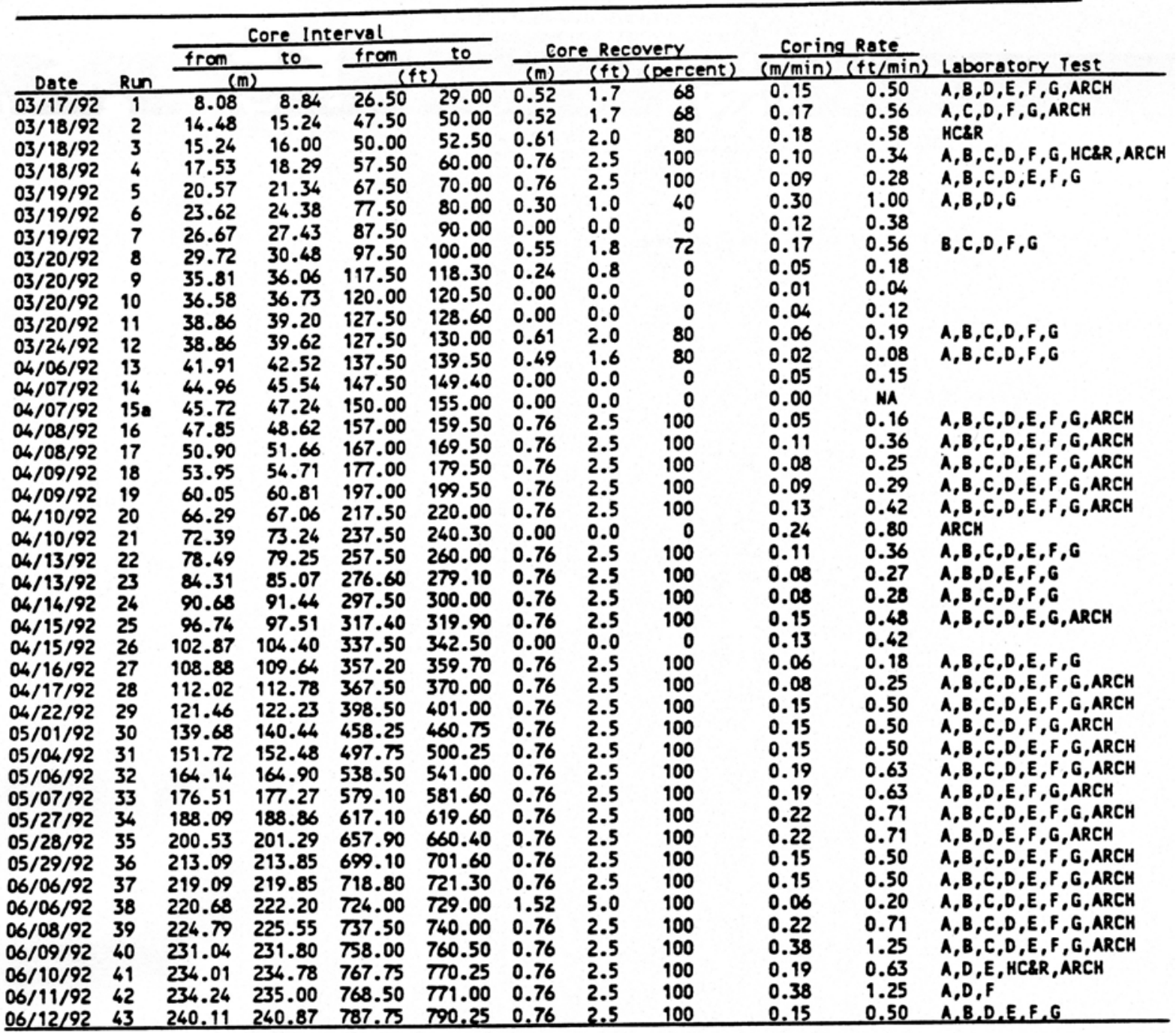

\footnotetext{
a: Rotary core

A: Physical and hydraulic properties

B: Particle size analysis, water content

C: Chlorine-36

D: Water potential, water content, bulk density

E: Clay mineralogy

F: Stable isotopes, tritium, bulk density, water content

G: Chloride, bromide, sulfate, carbon, elemental mineralogy

HC\&R: Hazardous constituents and radionuclides

ARCH: Archived sample
} 
Table 2-4

Core Record for Well UE5PW-2

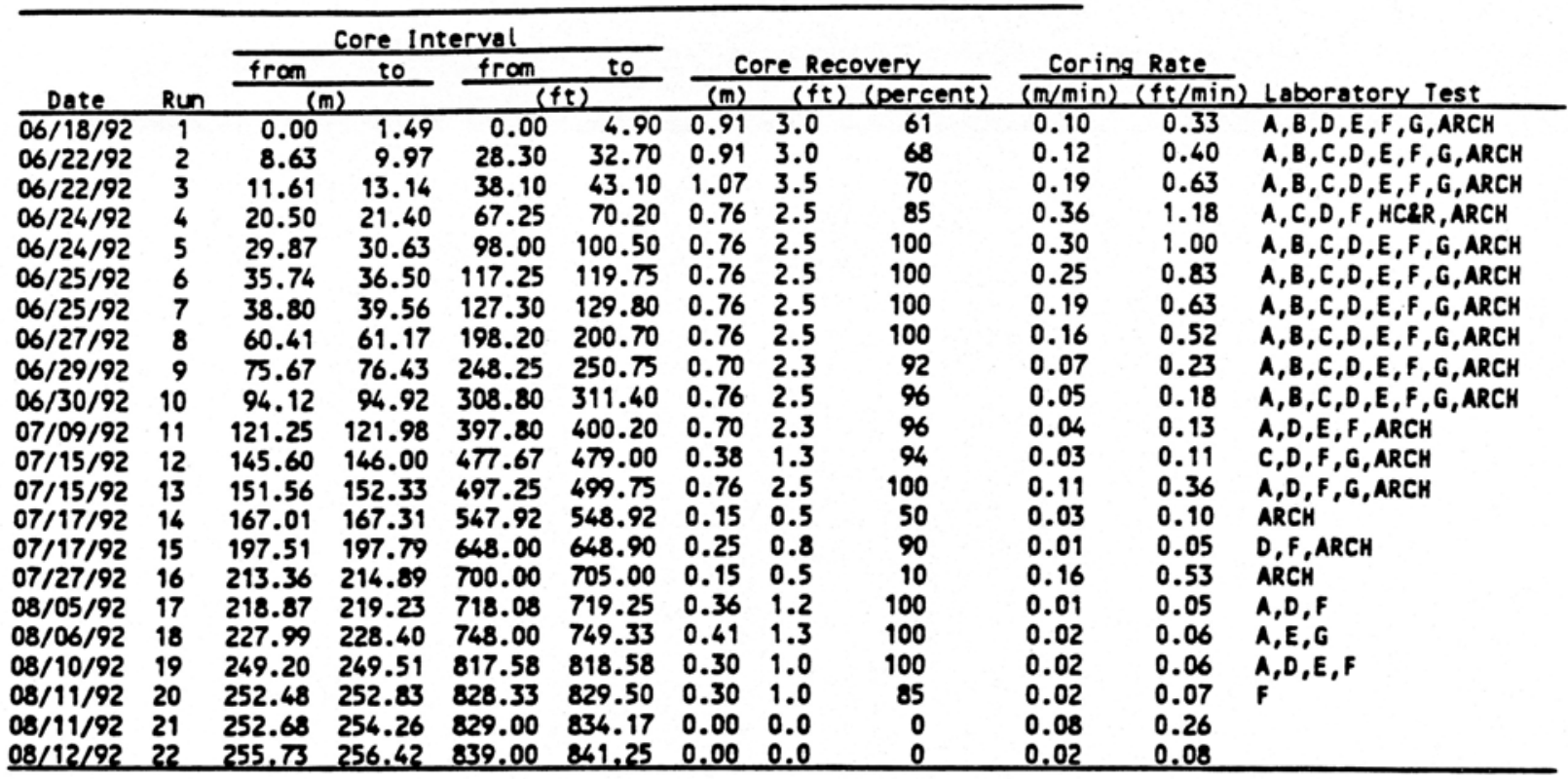

Table 2-5

Core Record for Well UE5PW-3

\begin{tabular}{|c|c|c|c|c|c|c|c|c|c|c|c|}
\hline \multirow[b]{3}{*}{ Date } & \multirow[b]{3}{*}{ Run } & \multicolumn{4}{|c|}{ Core interval } & \multirow{2}{*}{\multicolumn{3}{|c|}{ Core recovery }} & \multirow{2}{*}{\multicolumn{2}{|c|}{ Coring rate }} & \multirow[b]{3}{*}{ Laboratory test } \\
\hline & & from & to & from & to & & & & & & \\
\hline & & \multicolumn{2}{|c|}{ (m) } & \multicolumn{2}{|c|}{$(f t)$} & (m) & stt & percent) & $(\mathrm{m} / \mathrm{min}$ & $\mathrm{ft} / \mathrm{min}$ & \\
\hline $\begin{array}{l}09 / 16 / 92 \\
09 / 16 / 92 \\
09 / 17 / 92 \\
09 / 17 / 92 \\
09 / 17 / 92 \\
09 / 21 / 92 \\
09 / 22 / 92 \\
09 / 24 / 92 \\
09 / 25 / 92 \\
09 / 29 / 92 \\
09 / 30 / 92 \\
10 / 01 / 92 \\
10 / 02 / 92 \\
10 / 06 / 92 \\
10 / 21 / 92 \\
\end{array}$ & $\begin{array}{c}1 \\
2 \\
3 \\
4 \\
5 \\
6 \\
7 \\
8 \\
9 \\
10 \\
11 \\
12 \\
13 \\
14 a \\
158 \\
\end{array}$ & $\begin{array}{r}0.00 \\
0.48 \\
14.78 \\
29.87 \\
39.32 \\
60.35 \\
75.84 \\
106.30 \\
121.46 \\
137.47 \\
151.77 \\
167.34 \\
188.50 \\
194.54 \\
209.86 \\
\end{array}$ & $\begin{array}{r}0.76 \\
1.17 \\
16.21 \\
30.89 \\
40.44 \\
61.88 \\
76.91 \\
106.78 \\
121.90 \\
137.95 \\
152.53 \\
167.91 \\
188.70 \\
196.16 \\
210.87 \\
\end{array}$ & $\begin{array}{r}0.00 \\
1.58 \\
48.50 \\
98.00 \\
129.00 \\
198.00 \\
248.83 \\
348.75 \\
398.50 \\
451.00 \\
497.92 \\
549.00 \\
618.42 \\
638.25 \\
688.50 \\
\end{array}$ & $\begin{array}{r}2.50 \\
3.83 \\
53.17 \\
101.33 \\
132.67 \\
203.00 \\
252.33 \\
350.33 \\
399.92 \\
452.60 \\
500.42 \\
550.88 \\
619.08 \\
643.50 \\
691.83 \\
\end{array}$ & $\begin{array}{l}0.53 \\
0.53 \\
1.30 \\
0.69 \\
0.84 \\
1.22 \\
0.99 \\
0.61 \\
0.30 \\
0.49 \\
0.76 \\
0.53 \\
0.08 \\
0.30 \\
0.32 \\
\end{array}$ & $\begin{array}{l}1.8 \\
1.8 \\
4.3 \\
2.3 \\
2.8 \\
4.0 \\
3.3 \\
1.3 \\
1.0 \\
1.6 \\
2.5 \\
1.8 \\
0.3 \\
1.0\end{array}$ & $\begin{array}{c}70 \\
78 \\
91 \\
68 \\
75 \\
80 \\
93 \\
84 \\
70 \\
100 \\
100 \\
93 \\
38 \\
19 \\
31 \\
\end{array}$ & $\begin{array}{l}0.59 \\
0.53 \\
1.09 \\
0.78 \\
0.86 \\
1.17 \\
0.82 \\
0.37 \\
0.33 \\
0.04 \\
0.07 \\
0.04 \\
0.02 \\
0.03 \\
0.03 \\
\end{array}$ & $\begin{array}{l}1.92 \\
1.73 \\
3.59 \\
2.56 \\
2.82 \\
3.85 \\
2.69 \\
1.22 \\
1.09 \\
0.12 \\
0.22 \\
0.14 \\
0.08 \\
0.11 \\
0.09 \\
\end{array}$ & $\begin{array}{l}A, B, C, D, F, G, A R C H \\
A, B, D, F, G, A R C H \\
A, B, C, D, E, F, G, A R C H \\
A, B, C, D, E, F, G, A R C H \\
A, B, C, D, E, F, G, A R C H \\
A, B, C, D, E, F, G, A R C H \\
A, B, C, D, E, F, G \\
A, D, E, F, A R C H \\
A, D, E, F \\
A, D, E, F, G, A R C H \\
A, B, C, D, E, F, G, A R C H \\
A, B, C, D, F, G, A R C H \\
A R C H \\
A, B, D, F \\
A, B, D, G\end{array}$ \\
\hline
\end{tabular}

\footnotetext{
a: Rotary core

A: Physical and hydraulic properties

B: Particle size analysis, water content

C: Chlorine-36

D: Water potential, water content, bulk density

E: Clay mineralogy

F: Stable isotopes, tritium, bulk density, water content

G: Chloride, bromide, sulfate, carbon, elemental mineralogy

HC\&R: Hazardous constituents and radionuclides

ARCH: Archived sample
} 
Air-rotary core sampling methods were attempted in Wells UE5PW-1 and UE5PW-2 in the more consolidated (though still poorly consolidated) intervals of alluvium using "HX" core barrels (split inner tubes) with less success than drive core methods. In all cases, air-rotary core recovery was very poor in alluvial material. Air-rotary coring generally requires significant consolidation and/or cementation of the formation to yield reasonable recovery. Poor recovery in the two air-rotary core runs in welded tuff at Well UE5PW-3 was probably due to a combination of factors, including the fractured nature of the formation and problems with stabilizing the core barrel and core rod while drilling within the relatively large diameter borehole.

In all cases, the core barrels were transported to a temperature-controlled field laboratory for geologic description and disposition as soon as possible after removal from the borehole.

\subsubsection{Collection of Drill Cuttings Samples}

Drill cuttings samples were collected at 0.76-m (2.5-ft) depth intervals from a cyclone separator. Drill cuttings samples were not collected during hole cleaning activities. Sample collection procedures were designed to minimize the loss of water by evaporation. Immediately after drilling each 0.76-m (2.5-ft) interval, a valve on the bottom of the cyclone separator was opened and a representative sample was collected in a bucket as the cuttings fell into a large dumpster. A sample splitter was then used to obtain four sub-samples from the bucket. These sub-samples were placed in jars, which were capped, labeled with appropriate sample identification information, stored in plastic coolers, and taken to a temperature-controlled field laboratory as soon as logistically feasible.

\subsection{Geologic Description and Disposition of Samples}

Both drill cuttings and core samples were handled, in the field laboratory and during subsequent storage and transport, in a manner designed to minimize evaporative water loss, ensuring that the water content of samples was as close to in-situ formation conditions as possible. Procedures and plans were developed for the Pilot Well project (Table 2-1) to standardize sample collection and handling.

\subsubsection{Handling, Description, and Disposition of Core Samples}

Liner segments containing core samples were removed from the solid-tube drive core samplers by a pneumatic core extruder. A geologic description of the core was then made by examining the open ends of each 76.2-mm (3-in.) long liner segment. This geologic description was recorded on field data forms, which are presented in Appendices B.1, B.2, and B.3. The description of the alluvial samples 
was based on methods from the American Society for Testing and Materials (ASTM), and the description of the tuff samples was based on procedures developed specifically for the NTS (Section 3.0).

Apparent magnetic susceptibility measurements were made on both core and drill cuttings samples. Changes in magnetic susceptibility may be related to changes in lithology as well as other factors such as rate of drill bit wear and the mixing of fine metal particles into the drill cuttings. These measurements were made on the flat ends of core segments and on the base of drill cuttings samples bottles using a Model KT-5 Exploranium meter. Individual sample measurements should not be compared because they were made under different measurement conditions, including geometry, density, and type of container.

Following geologic description and measurement of magnetic susceptibility, each 76.2-mm (3-in.) long core segment was capped, taped, and labeled with appropriate sample-identification and intended-use information. Core segments were further sealed in Protec-Core ${ }^{\circledR}$ (a tubular aluminized mylar laminate which protects the core from tampering and damage when correctly sealed) and labeled again with the same information. Most of the core segments were specified for particular types of laboratory tests, and the remainder were stored for future use. Tables 2-3, 2-4, and 2-5 summarize the uses specified for each core run. The intended use of each 76.2-mm (3-in.) core segment was summarized on detailed borehole log sheets. Because core recovery was not always 100 percent, and further, because some core segments were more disturbed than others (e.g., disturbance of water content, porosity, and aggregation), the assignment of core segments for various tests was based on a priority system. This system took into account the relative importance of various laboratory tests, as well as the degree of sample disturbance acceptable for each test, and is described in detail in the applicable procedures and plans listed in Table 2-1. The core assignment procedure was altered when a core run contained a stratigraphic contact. In this case, cores on both sides of the stratigraphic contact were assigned to the same high priority hydrologic parameter tests.

The labeling system used in the field to assign core segments and drill cuttings samples for different laboratory tests is summarized in Table 2-6. A particular sample label defined the laboratory testing required, the priority of these tests, and the laboratory responsible for conducting the analyses. In this report these labels are used to distinguish samples and responsible testing laboratories in tables of summary descriptive statistics of testing results, in figures of selected testing results in Section 3.0, and in tables of individual test results in Appendix E. 
Table 2-6

Definitions of Core and Drill Cuttings Sample Labels

\begin{tabular}{|c|c|c|c|c|}
\hline $\begin{array}{l}\text { Sample } \\
\text { Type }\end{array}$ & $\begin{array}{c}\text { Sample } \\
\text { Label }\end{array}$ & $\begin{array}{l}\text { Sample } \\
\text { Priority }\end{array}$ & Laboratory Testing Specified & Testing Laboratory \\
\hline \multirow{10}{*}{ Core } & DB1 & 1 & $\begin{array}{l}\text { Saturated hydraulic conductivity, moisture } \\
\text { retention curves }{ }^{\text {a }} \text {, volumetric water content, } \\
\text { dry bulk density, particle size distribution }\end{array}$ & $\begin{array}{l}\text { Daniel B. Stephens \& } \\
\text { Associates, Albuquerque, NM }\end{array}$ \\
\hline & \multirow{3}{*}{ HYD1 } & \multirow{3}{*}{2} & Gravimetric water content & $\begin{array}{l}\text { Daniel B. Stephens \& } \\
\text { Associates, Albuquerque, NM }\end{array}$ \\
\hline & & & $\begin{array}{l}\text { Chloride, bromide, sulfate, inorganic carbon, } \\
\text { organic carbon }\end{array}$ & $\begin{array}{l}\text { New Mexico Institute of } \\
\text { Mining and Technology, } \\
\text { Dr. D. Branvold, Socorro, NM }\end{array}$ \\
\hline & & & Mineral element and oxide composition ${ }^{a}$ & $\begin{array}{l}\text { New Mexico Institute of } \\
\text { Mining and Technology, Dr. P. } \\
\text { Kyle, Socorro, NM }\end{array}$ \\
\hline & DRI1 & 3 & Stable isotopes of hydrogen and oxygen ${ }^{a}$ & $\begin{array}{l}\text { Desert Research Institute, } \\
\text { Dr. S. Tyler, Reno, NV }\end{array}$ \\
\hline & DRI2 & 4 & $\begin{array}{l}\text { Water potential, volumetric water content, dry } \\
\text { bulk density }\end{array}$ & $\begin{array}{l}\text { Desert Research Institute, } \\
\text { Dr. S. Tyler, Reno, NV }\end{array}$ \\
\hline & DB2 & 5 & $\begin{array}{l}\text { Particle size distribution, gravimetric water } \\
\text { content }\end{array}$ & $\begin{array}{l}\text { Daniel B. Stephens \& } \\
\text { Associates, Albuquerque, NM }\end{array}$ \\
\hline & HYD2 & 6 & Chlorine- $36^{a}$ & $\begin{array}{l}\text { Hydro GeoChem, Inc., } \\
\text { Tucson, AZ } \\
\text { and Lawrence Livermore } \\
\text { National Laboratory, } \\
\text { Dr. M. Caffee, Livermore, CA }\end{array}$ \\
\hline & SNL & 7 & Clay mineralogy ${ }^{a}$ & $\begin{array}{l}\text { Sandia National } \\
\text { Laboratories, Dr. } \\
\text { H. Stockman, } \\
\text { Albuquerque, NM }\end{array}$ \\
\hline & $\mathrm{ARCH}$ & 8 & None & None \\
\hline \multirow{5}{*}{$\begin{array}{l}\text { Drill } \\
\text { Cuttings }\end{array}$} & DB2 & 1 & $\begin{array}{l}\text { Particle size distribution, gravimetric water } \\
\text { content }\end{array}$ & $\begin{array}{l}\text { Daniel B. Stephens \& } \\
\text { Associates, Albuquerque, NM }\end{array}$ \\
\hline & \multirow{2}{*}{ HYD1 } & \multirow[b]{2}{*}{1} & Gravimetric water content & $\begin{array}{l}\text { Daniel B. Stephens \& } \\
\text { Associates, Albuquerque, NM }\end{array}$ \\
\hline & & & $\begin{array}{l}\text { Chloride, bromide, sulfate, inorganic carbon, } \\
\text { organic carbon }\end{array}$ & $\begin{array}{l}\text { New Mexico Institute of } \\
\text { Mining and Technology, } \\
\text { Dr. D. Branvold, Socorro, NM }\end{array}$ \\
\hline & HYD2 & 1 & Chlorine-36 ${ }^{\mathrm{b}}$ & $\begin{array}{l}\text { Hydro GeoChem, Inc., } \\
\text { Tucson, AZ } \\
\text { and Lawrence Livermore } \\
\text { National Laboratory, Dr. M. } \\
\text { Caffee, Livermore, CA } \\
\end{array}$ \\
\hline & $\mathrm{ARCH}$ & 1 & None & None \\
\hline
\end{tabular}

a Tests conducted on selected samples.

b Chlorine-36 samples stored for future testing. 


\subsubsection{Handling, Description, and Disposition of Drill Cuttings Samples}

Geologic descriptions of drill cuttings samples were made after the samples were transported to the temperature-controlled field laboratory (Appendices B.4, B.5, and B.6). Sample jars containing drill cuttings were briefly opened and the same geologic description and magnetic survey procedures described in Section 2.3.2 for core samples were followed. Sample jars were then taped shut, sealed in Protec-Core ${ }^{\circledR}$, and labeled once again with appropriate sample- identification and intended-use information. Because these samples were more disturbed than core samples, fewer laboratory tests were specified. Four replicate drill cuttings samples were collected for these tests and other uses from each 0.76-m (2.5-ft) depth interval. The labels assigned to drill cuttings samples, which specified the tests to be conducted as well as the testing laboratories, are summarized in Table 2-6.

\section{$2.4 \quad$ Field Tests on Core and Drill Cuttings}

\subsubsection{Tracer Tests for Estimating Disturbance from Air Drilling Fluid}

Every effort was made to insure that air-percussion hammer-drive core samples were representative of in-situ formation conditions. For example, drilling and air-percussion coring procedures in alluvium were designed and implemented so that drive core samples were collected from the bottom of the borehole in formation materials where density, porosity, and pore size distribution had not been previously disturbed. However, the degree of intrusion of the drilling fluid (air) into the formation ahead of the drill bit, and consequently into core samples collected from these formation materials, could not be accurately estimated prior to this drilling program. Even more difficult to estimate were the potentially disturbing effects of the drilling air on hydrologic conditions such as water content and water potential.

With this in mind, a program was implemented to estimate the extent to which the drilling fluid (air) penetrated into the formation (and core samples) directly ahead of the drill bit. A tracer gas (sulfur hexafluoride, $\mathrm{SF}_{6}$ ) was injected via a mass flow controller into the airstream originating from the air compressor during drilling and coring operations at Well UE5PW-1. Failure of the mass flow controller prevented similar injections during drilling and coring in Well UE5PW-2 and UE5PW-3. However, $\mathrm{SF}_{6}$ was injected into the uncased bottom portion of Well UE5PW-3 in the interval 235 to $291 \mathrm{~m}$ (770 to $955 \mathrm{ft}$ ) for 15 minutes during final reaming/cleaning of the borehole. This injection was accomplished by setting the $\mathrm{SF}_{6}$ tank pressure at 689 kiloPascals $(\mathrm{kPa})(100$ pounds per square inch [psi]) above the compressor airstream pressure. 
Concentrations of $\mathrm{SF}_{6}$ were measured in air sub-samples collected from the airstream, from the entire 0.76-m (2.5-ft) long core barrel, and from 76.2-mm (3-in.) long individual core segments. The results of these analyses are presented in Appendix C.1. The results show that $\mathrm{SF}_{6}$ invaded all core samples to some extent, even segments located in the bottom of the core barrel which originated $0.76 \mathrm{~m}(2.5 \mathrm{ft})$ from the bottom of the original borehole. Large fluctuations in airstream line pressure resulted in large fluctuations in $\mathrm{SF}_{6}$ concentrations in the airstream. This in turn prevented any quantitative analyses on the replacement of natural soil gases by air drilling fluid.

Analyses were conducted on extracted gases from 20.7-mm (0.814-in.) inside diameter (I.D.) nylon access tubes leading to five instrument stations in Well UE5PW-1 and one instrument station in Well UE5PW-3. These analyses indicated that significant quantities of $\mathrm{SF}_{6}$ were still in the formation adjacent to these stations several months after drilling and coring activities were completed (Appendix C.2).

\subsubsection{Radiological Surveys of Geologic Samples}

Gamma radiation levels from drill cuttings were monitored continuously with an energy-compensated Geiger-Mueller detector mounted directly on the cyclone separator. In addition, radiation protection personnel analyzed drill cuttings samples and drilling and logging equipment via gamma spectroscopy, and collected swipe samples to analyze for removable alpha and beta radiation contamination on a daily basis. Swipe samples were also collected from core barrels after each core run. All radiological monitoring results were consistent with natural levels of background radiation.

\subsection{Pilot Well Completion}

This section briefly describes the materials, methods, and design followed to complete the three pilot wells. The completion involved installation and stemming of monitoring well casing/screen and vadose zone instruments in each well. Further details of all components of the completion design and operations are given in Appendix D.

Completion objectives for the pilot well program were:

- Install monitoring well casing/screen to provide access for sampling and hydraulic testing of the uppermost aquifer.

- Install instrumentation for measuring pressure, temperature, and humidity at selected intervals. 
- Install delivery tubing for air permeability tests and tubing for remote pressure sensing and gas sampling at selected intervals.

- Emplace annular sand pack to enhance filter pack/well screen effectiveness.

- Emplace permeable sand at instrument stations to enhance air movement between instrument stations and the vadose zone formation.

- Emplace low-permeability annular seal materials between instrument stations to restrict preferential flow (short circuiting) of fluids between instrument stations in the borehole annulus.

\subsubsection{Subsurface Completion Design}

The 3 pilot wells were completed according to the same basic design (Figures 2-1, 2-2, and 2-3). Each design includes a centralized stainless-steel casing with an approximate I.D. of $63.5 \mathrm{~mm}$ (2.5-in.). An 18.3-m (60-ft) long dual-screen prefabricated filter pack (Pre-Pack ${ }^{\circledR}$ ) was attached to the bottom of the central casing. Attached to the outside of the casing were 34 instruments with associated cables and tubing running to 10 different depths in the borehole. Three major groups (stations) of instruments were located at selected depths. Instrument stations and the associated instruments were installed as follows:

- Water level monitoring stations consist of 1 submersible pressure transducer located approximately $12.2 \mathrm{~m}$ (40 ft) below the water table.

- Type A instrument stations consist of 2 thermistors for temperature measurements, 2 psychrometers for humidity measurements, and 1 air pressure transducer, located at depths of approximately 30.5, 61.0, 91.4, 152.4, and $213.4 \mathrm{~m}(100,200,300,500$, and $700 \mathrm{ft})$.

- Type B instrument stations consist of screened air piezometers attached to 20.7-mm (0.814-in.) I.D. nylon tubing and 4.6-mm (0.18 in.) I.D. stainless-steel tubing for air permeability testing and gas sampling, located at depths of approximately 45.7, 76.2, 106.7, and $182.9 \mathrm{~m} \mathrm{(150,}$ $250,350$, and $600 \mathrm{ft})$. 


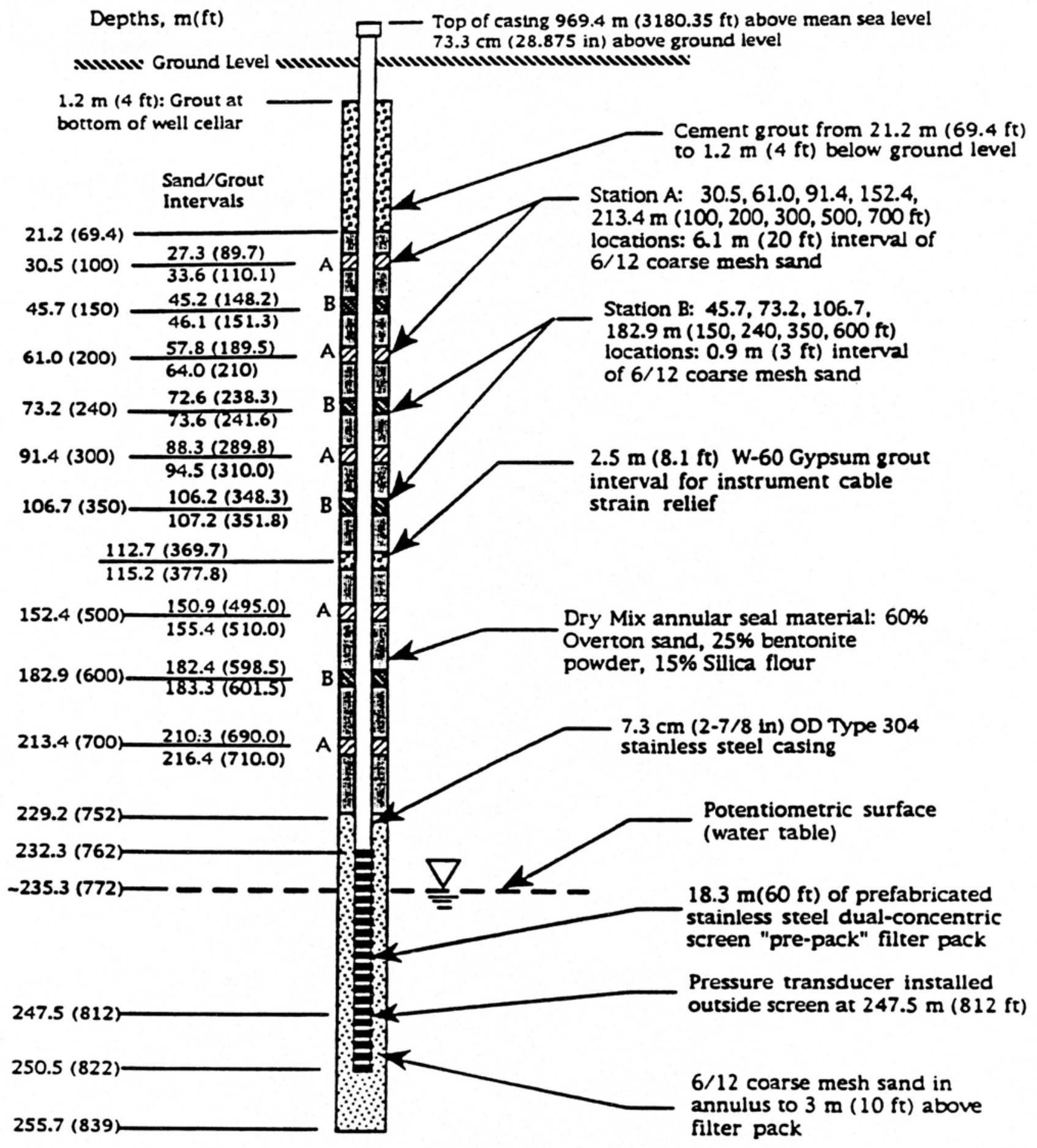

Figure 2-1

Completion Configuration for Well UE5PW-1 


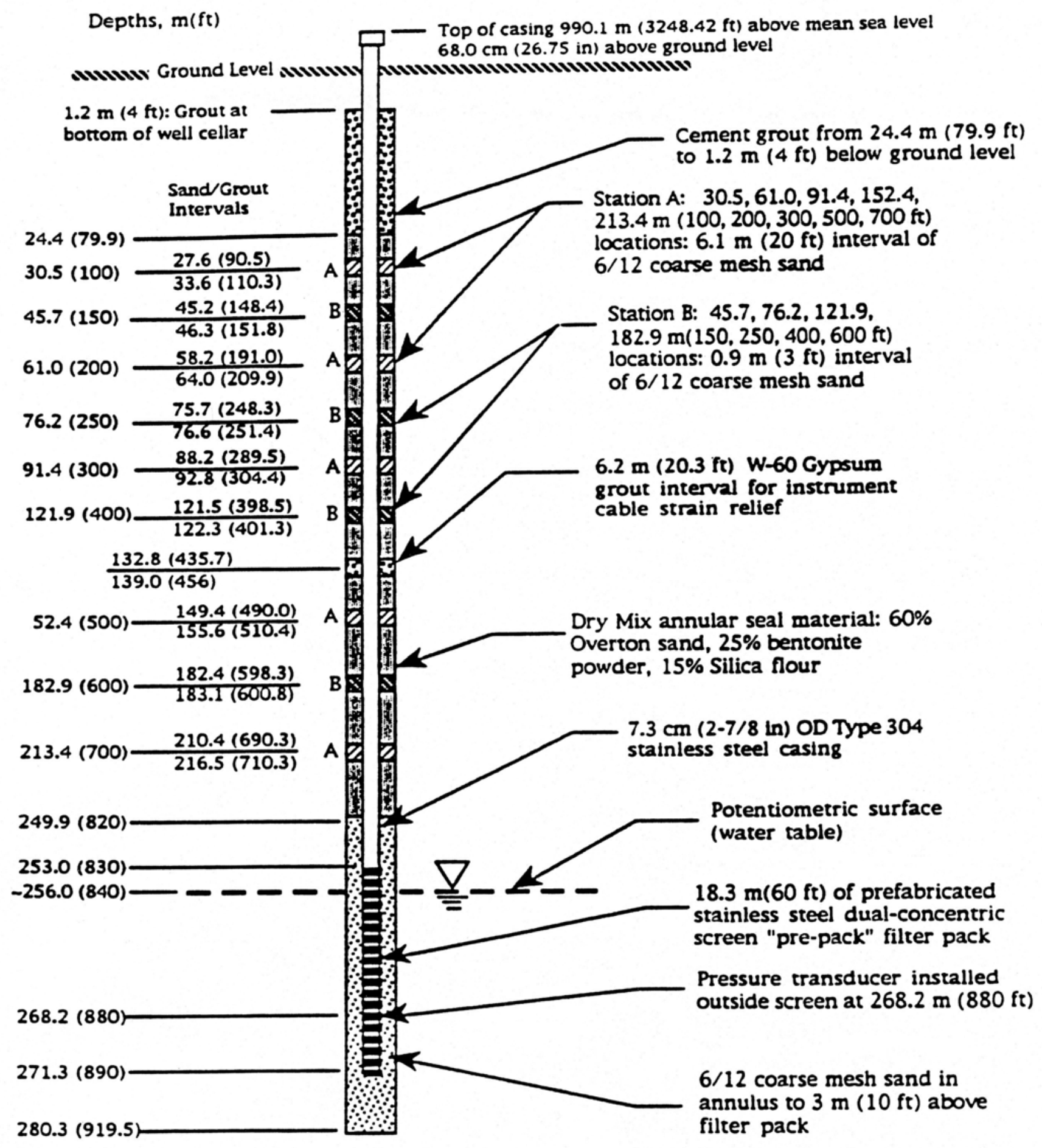

Figure 2-2

Completion Configuration for Well UE5PW-2 


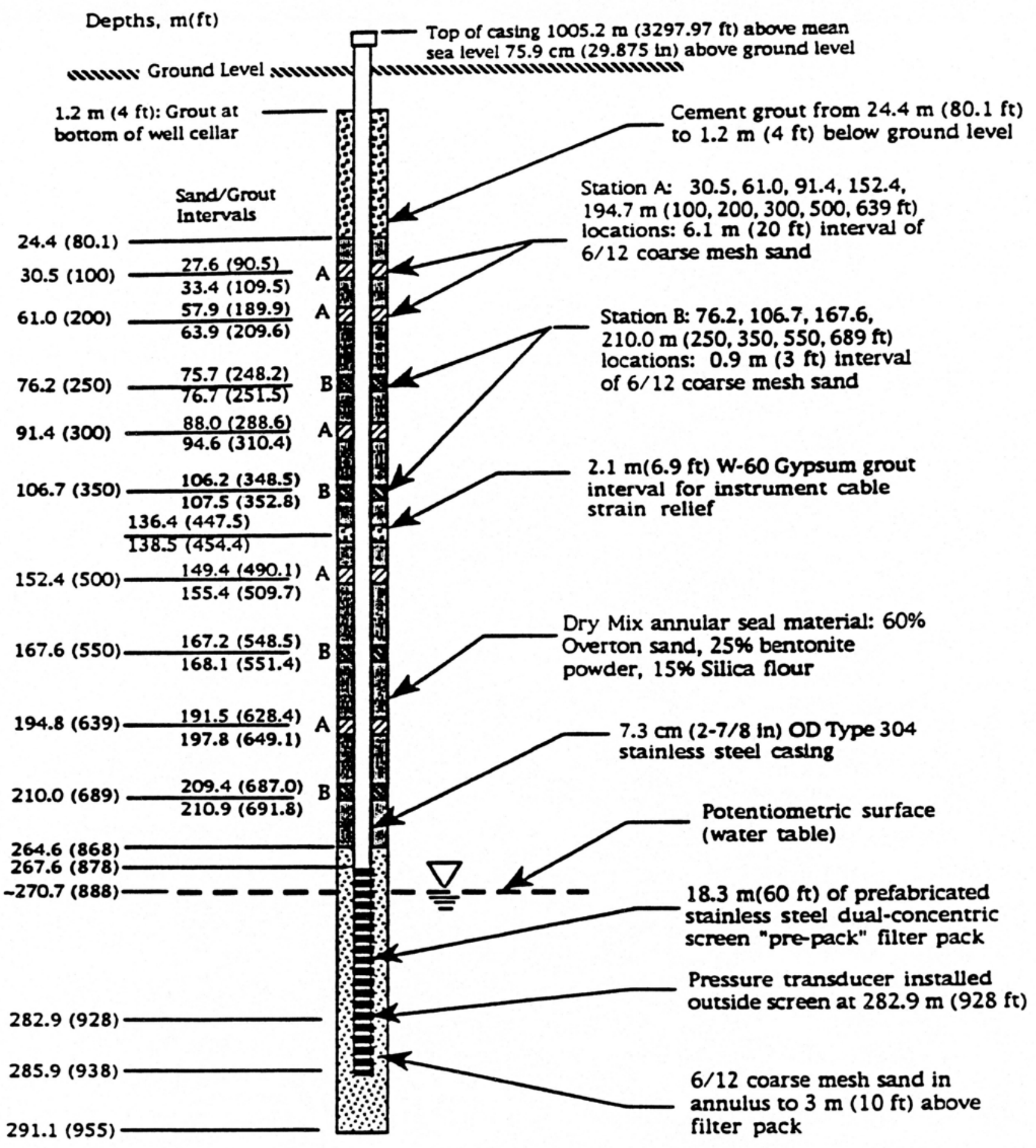

Figure 2-3

Completion Configuration for Well UE5PW-3 
Note that some changes to the depths of several instrument stations were made to avoid "washed out" areas of the borehole or to correspond with core sample intervals. The actual depth of each instrument station is shown on the completion diagram for each pilot well.

The annular space around each station was stemmed with coarse-grained sand to facilitate pneumatic communication with the surrounding formation. The intervals between each station were stemmed with a low permeability mixture of bentonite, silica flour, and sand to eliminate preferential flow paths between the central casing and the formation. The air permeability of the dry, low permeability mixture was found to be approximately $9.0 \times 10^{14}$ square meters $\left(\mathrm{m}^{2}\right)(90$ millidarcy $)$ in laboratory tests. This value is at least two orders of magnitude less than the air permeability of the alluvial formation (Section 4.4.2).

\subsubsection{Subsurface Completion Operations}

After drilling was completed at each pilot well site, the drill rig was moved off the location, leaving the borehole with two strings of steel casing in place: $219.1-\mathrm{mm}$ (8.625-in.) O.D. casing, telescoped inside of 273.0-mm (10.75-in.) O.D. casing. An Ingersoll-Rand TH-60 drill rig with a two-man crew was then moved in to complete each pilot well as described in the following paragraphs. Details concerning materials used, preparation of the central casing and attachment of instruments, casing and instrument installation into the borehole, and stemming and cementing of the borehole are given in Appendix D.

The completion drill rig was used to run the centralized monitoring well casing/screen with attached instruments and associated cables and tubes inside the inner 219.1-mm (8.625-in.) casing to the required depth. The completion rig was then used to pull (with hydraulic jacks) the inner drill casing from the borehole in 3.0- or 6.1-m (10- or 20-ft) stages. As this casing was pulled from the borehole, dry stemming materials were added to fill the annular space between the formation and the centralized casing and attached instruments. The low permeability mixture was pumped down a steel "tremmie" pipe (1-in. Schedule 80) to the depth interval of interest with a shotcrete injector. The coarse-grained sand was simply poured into the tremmie line and allowed to fall by gravity to the interval being stemmed. Frequent measurements of the level of stemming materials in the borehole demonstrated that these materials did not settle downward during the stemming operation. To minimize future settling and provide strain relief for instrument cables and tubes, a gypsum grout interval was placed midway in each borehole.

When the 219.1-mm (8.625-in.) inner casing was pulled up and the borehole stemmed to the depth of the 273.0-mm (10.75-in.) casing, the smaller casing was pulled completely from the hole. The larger 
casing was then pulled up in stages and stemming materials added as described above for the smaller casing. When the 273.0-mm (10.75-in.) casing was pulled up to approximately $24.4 \mathrm{~m}$ (80 ft) below ground surface, cement grout was poured into the casing. The casing was then pulled completely out of the hole while grout was added as required, leaving a cement surface seal from a depth of approximately $24.4 \mathrm{~m}(80 \mathrm{ft})$ to the ground surface.

\subsubsection{Surface Facilities and Wellhead Completion}

Figure 2-4 shows the surface facilities constructed at each pilot well site. Two buildings were originally positioned at each location: a wellhead building and an instrument building. The instrument buildings housed the data acquisition systems and related equipment, but have since been removed from the well sites.

The wellhead buildings, in conjunction with 3- by 3-m [10- by 10-ft] concrete pads at each site, provide weather protection, surface seal, and lockable access to the wells in accordance with RCRA requirements. Each wellhead building consists of a 2.4 - by $6.1-\mathrm{m}$ (8- by $10-\mathrm{ft})$ transportainer positioned over the casing. Each building houses the Bennett sample pump and other equipment and tools needed for groundwater sampling. A steel floor plate with a $0.6-$ by $0.6-\mathrm{m}$ (2- by 2 -ft) trapdoor provides access to the 1.8-m (6-ft) diameter by 1.2-m (4-ft) deep well cellar.

\subsection{Well Development}

The 3 pilot wells were developed to help insure that hydraulic and other testing conducted in these wells will yield results that are as representative as possible of the uppermost aquifer, and are not indicative of disturbed conditions caused by drilling and coring activities. The small diameter of the monitoring well tubing (63.5 $\mathrm{mm}$ [2.5 in.] I.D.) and screen (60.3 $\mathrm{mm}$ [2.375 in.] I.D.), combined with the great depth to the water table (greater than $235 \mathrm{~m}$ [770 ft]) restricted the choice of development methods to bailing and low-flow-rate pumping.

Initial development was conducted by bailing with a polyvinyl chloride bailer, approximately 38.1-mm

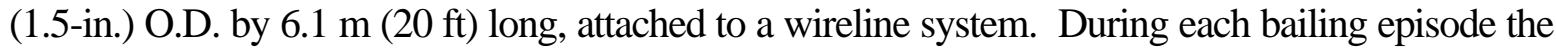
bailer was run up and down between the water table surface and the bottom of the well screen several times before removing the bailer from the well. The turbidity of the water removed from the borehole decreased significantly with bailing. However, in all 3 wells the water never cleared completely. Bailing was discontinued when it began to appear that this activity had little or no noticeable effect on turbidity. 


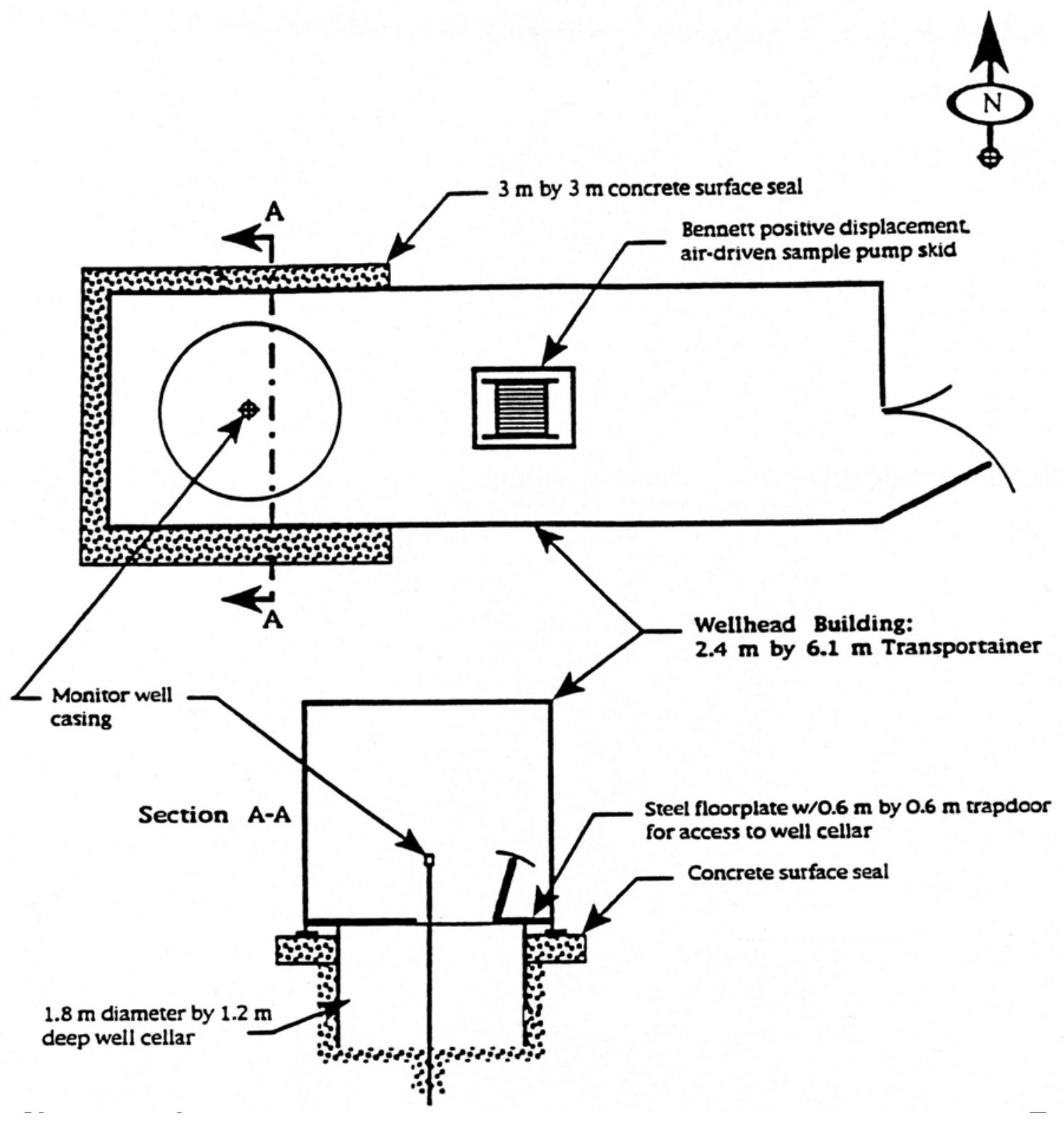

Figure 2-4

Area 5 Pilot Well Surface Facilities and Wellhead Completion Diagram (not to scale) 
Further development with a low-flow-rate sample pump (Bennett pump) was not started until at least several days after bailing was completed, to allow suspended sediment to settle to the bottom of the well screen. The sample pump was then lowered into the well screen to a pre-determined depth and the well was pumped at the maximum sample rate of approximately 2 liters per minute $(\mathrm{L} / \mathrm{min})$ (0.5 gallons per minute $[\mathrm{gal} / \mathrm{min}])$. In all cases the pump was positioned at least $6.1 \mathrm{~m}(20 \mathrm{ft})$ above the bottom of the screen. The outlet line of the pump was connected to a flow-through cell and the general water quality parameters of $\mathrm{pH}$, temperature, conductivity, and reduction-oxidation potential (Eh) of the pumped water were monitored, together with the flow rate. Pumping generally continued at a particular depth until at least three well-bore volumes of water were removed and the general water quality parameters stabilized. If the schedule for development and sampling permitted, the above described procedure was repeated at several $1.5-\mathrm{m}$ (5-ft) intervals. The volumes of water bailed and pumped, as well as final values of water quality parameters for each development episode, are summarized in Table 2-7. 
Table 2-7

Pilot Well Development Data

\begin{tabular}{|c|c|c|c|c|c|c|c|c|}
\hline Borehole & $\begin{array}{c}\text { Date(s) } \\
\text { Develope } \\
\text { d }\end{array}$ & $\begin{array}{c}\text { Type of } \\
\text { Developmen } \\
t\end{array}$ & $\begin{array}{l}\text { Volume Removed } \\
\text { L/well-bores } \\
\text { (gal/well-bores) }\end{array}$ & $\begin{array}{c}\text { Pump Depth } \\
\text { Below Static } \\
\text { Water Level } \\
\mathrm{m}(\mathrm{ft})\end{array}$ & $\begin{array}{c}\text { Averag } \\
\text { e pH }\end{array}$ & $\begin{array}{c}\text { Averag } \\
\text { e Eh } \\
(\mathrm{mv})\end{array}$ & $\begin{array}{c}\text { Average } \\
\text { Conductivit } \\
\mathbf{y} \\
(\mathrm{mmhos} / \mathrm{cm})\end{array}$ & $\begin{array}{c}\text { Aveage } \\
\text { Temperatu } \\
\text { re } \\
\text { (" C) }\end{array}$ \\
\hline \multirow[t]{3}{*}{ UE5PW-1 } & $\begin{array}{l}08 / 31 / 1992 \\
09 / 01 / 1992 \\
09 / 05 / 1992 \\
09 / 11 / 1992\end{array}$ & Bail & $454 / 10.3(120 / 10.3)$ & $\mathrm{N} / \mathrm{A}$ & N/M & $\mathrm{N} / \mathrm{M}$ & $\mathrm{N} / \mathrm{M}$ & $\mathrm{N} / \mathrm{M}$ \\
\hline & $09 / 16 / 1992$ & Pump & $23 / 0.5(6 / 0.5)$ & $6.1(20)$ & 8.59 & $\mathrm{~N} / \mathrm{M}$ & 0.330 & 22.5 \\
\hline & 09/11/1992 & Pump & $246 / 5.6(65 / 5.6)$ & $6.1(20)$ & 8.49 & $\mathrm{~N} / \mathrm{M}$ & 0.370 & 22.7 \\
\hline \multirow{8}{*}{ UE5PW-2 } & $\begin{array}{l}02 / 16 / 1993 \\
02 / 17 / 1993 \\
02 / 18 / 1993 \\
02 / 19 / 1993\end{array}$ & Bail & $\begin{array}{l}1,170 / 27.2 \\
(309 / 27.2)\end{array}$ & $\mathrm{N} / \mathrm{A}$ & $\mathrm{N} / \mathrm{M}$ & $\mathrm{N} / \mathrm{M}$ & $\mathrm{N} / \mathrm{M}$ & $\mathrm{N} / \mathrm{M}$ \\
\hline & $03 / 09 / 1993$ & Pump & $712 / 16.6(188 / 16.6)$ & $4.6(15)$ & 7.77 & 177 & 0.385 & 20.3 \\
\hline & $03 / 11 / 1993$ & Pump & $612 / 14.2(162 / 14.2)$ & $\mathrm{N} / \mathrm{A}$ & 7.77 & 177 & 0.385 & 20.3 \\
\hline & $03 / 15 / 1993$ & Pump & $746 / 17.4(197 / 17.4)$ & $4.6-6.1(15-20)$ & 7.95 & 192 & 0.315 & 20.1 \\
\hline & $03 / 16 / 1993$ & Pump & $780 / 18.2(206 / 18.2)$ & $6.1-7.6(20-25)$ & 7.96 & 176 & 0.375 & 19.8 \\
\hline & $03 / 17 / 1993$ & Pump & $791 / 18.4(209 / 18.4)$ & $7.6(25)$ & 7.99 & 171 & 0.368 & 20.5 \\
\hline & $03 / 18 / 1993$ & Pump & $678 / 15.7(179 / 15.7)$ & $7.6-9.1(25-30)$ & 8.02 & 180 & 0.368 & 20.1 \\
\hline & $03 / 30 / 1993$ & Pump & $757 / 17.2(200 / 17.2)$ & $1.5-9.1(5-30)$ & 8.10 & 157 & 0.404 & 20.0 \\
\hline \multirow{4}{*}{ UE5PW-3 } & $\begin{array}{l}01 / 04 / 1993 \\
01 / 06 / 1993 \\
01 / 07 / 1993 \\
01 / 08 / 1993\end{array}$ & Bail & $\begin{array}{l}1,071 / 23.5 \\
(283 / 23.5)\end{array}$ & $\mathrm{N} / \mathrm{A}$ & $\mathrm{N} / \mathrm{M}$ & $\mathrm{N} / \mathrm{M}$ & $\mathrm{N} / \mathrm{M}$ & $\mathrm{N} / \mathrm{M}$ \\
\hline & 04/7/1993 & Pump & $254 / 5.5(67 / 5.5)$ & $1.5-3.0(5-10)$ & 8.31 & 1.71 & 0.399 & 20.4 \\
\hline & $04 / 12 / 1993$ & Pump & $935 / 20.5(247 / 20.5)$ & $3.0-4.6(10-15)$ & 8.43 & 166 & 0.391 & 19.8 \\
\hline & $03 / 13 / 1993$ & Pump & $\begin{array}{l}1,128 / 24.8 \\
(298 / 24.8)\end{array}$ & $6.1(20)$ & 8.18 & 192 & 0.384 & 19.3 \\
\hline
\end{tabular}

\section{NOTES}

L/Well bores $=$ liters $/$ boreholes

gal/well bores = gallons $/$ borehole

$\mathrm{m}=$ meters

$\mathrm{ft}=$ feet

$\mathrm{mv}=$ millivolts

$\mathrm{mmhos} / \mathrm{cm}=$ millimhos $/$ centimeter

" $C=$ degrees Celsius

$\mathrm{N} / \mathrm{A}=$ not applicable

$\mathrm{N} / \mathrm{M}=$ parameter not measured 
This page intentionally left blank. 


\subsection{Laboratory Testing Methods and Results}

A summary of laboratory tests and testing methods is given in Table 3-1, and specific details are contained in the cited references. In addition, descriptions of all laboratory testing methods used in the pilot well project are given in the data report for the science trench borehole (REECo, 1993a).

As described in Section 2.3 and Table 2-6, drill cuttings and core samples were sent to selected testing laboratories for measurement of material, hydrologic, mineralogic, and geochemical properties. In most cases, a testing laboratory conducted a number of related tests on the same core segment. For example, initial water content, bulk density, porosity, hydraulic conductivity, moisture retention, and particle size distribution measurements were conducted on the same core segment. A number of samples were placed in storage (archived) but have now been disposed of.

REECo audited and approved the QA programs of the following laboratories involved in the pilot well project. Daniel B. Stephens \& Associates, Inc., Albuquerque, New Mexico, was responsible for review and approval of the QA programs for the laboratories of Dr. B. Branvold and Dr. P. Kyle, New Mexico Institute of Mining and Technology, Socorro, New Mexico. REECo reviewed and approved the QA program of Hydro GeoChem, Inc., Tucson, Arizona. Sandia National Laboratories, Albuquerque, New Mexico, was responsible for review and approval of the QA programs for the laboratories of Dr. S. Tyler, Desert Research Institute (DRI), Reno, Nevada, and Dr. M. Caffee, Lawrence Livermore National Laboratory (LLNL), Livermore, California.

The types and numbers of tests conducted on core and drill cuttings samples for each pilot well are summarized in Table 3-2. The tabular results from these laboratory tests for both core and drill cuttings samples are summarized in Appendix E. Summary statistics for laboratory measurements, where appropriate, are presented in Table 3-3 for samples from the alluvium, and in Table 3-4 for tuff samples. Plots of laboratory testing results for specific tests are presented in the appropriate sections that follow. 
Table 3-1

Summary of Laboratory Methods

\begin{tabular}{|c|c|}
\hline Method Description & Reference \\
\hline $\begin{array}{l}\text { Geologic Description } \\
\cdot \text { Unconsolidated Alluvium } \\
\qquad \text { Consolidated Rock }\end{array}$ & $\begin{array}{l}\text { ASTM D 2488-90, 1990. Standard Recommended Practice for } \\
\text { the Description of Soils - Visual Manual Procedure. In: } 1990 \\
\text { Annual Book of ASTM Standards, Vol. 04.08, American } \\
\text { Society for Testing and Material. Philadelphia, PA. } \\
\text { Fenix \& Scisson, Inc., 1987. Lithologic Descriptions of } \\
\text { Volcanic Rocks, Memorandum GEO-0237, dated } \\
\text { May 26, } 1987 . \\
\text { Fenix \& Scisson, Inc., 1990. The Description of Rock } \\
\text { Samples - Geology/Hydrology Division Procedure GP-003, } \\
\text { Revision } 1 .\end{array}$ \\
\hline Moisture Content & $\begin{array}{l}\text { ASTM D 2216-80, 1980. Method for laboratory determination } \\
\text { of water (moisture) content of soil, rock, and soil-aggregate } \\
\text { moisture. In: } 1987 \text { Annual Book of ASTM Standards, } \\
\text { Vol. 04.08, American Society for Testing and Material. } \\
\text { Philadelphia, PA. }\end{array}$ \\
\hline Bulk Density & $\begin{array}{l}\text { Blake, G. R., and K. H. Hartge, } 1986 \text {. Bulk Density. } \underline{\text { In: }} \\
\text { Klute, A. L. (ed.), Methods of Soil Analysis, Part I, Physical } \\
\text { and Mineralogical Methods, } 2^{\text {nd }} \text { Edition, American Society of } \\
\text { Agronomy, Madison, WI. Chapter 13, pages } 363-367 .\end{array}$ \\
\hline Porosity & $\begin{array}{l}\text { Danielson, R. E., and P. L. Sutherland, } 1986 \text {. Total Porosity. } \\
\text { In: Klute, A. L. (ed.), Methods of Soil Analysis, Part I, } \\
\text { Physical and Mineralogical Methods, } 2^{\text {nd }} \text { Edition, American } \\
\text { Society of Agronomy, Madison, WI. Chapter } 18 \text {, } \\
\text { pages 444-445. }\end{array}$ \\
\hline $\begin{array}{l}\text { Saturated Hydraulic Conductivity } \\
\text { • Constant Head }\end{array}$ & $\begin{array}{l}\text { ASTM D 2434-68, 1974. Test method for permeability of } \\
\text { granular soils (constant head). In: } 1987 \text { Annual Book of } \\
\text { ASTM Standards, Vol. 04.08, American Society for Testing } \\
\text { and Material. Philadelphia, PA. } \\
\text { Klute, A. L., and C. Dirksen, 1986. Hydraulic conductivity and } \\
\text { diffusivity: Laboratory methods - Falling head method. In: } \\
\text { Klute, A. L. (ed.), Methods of Soil Analysis, Part I, Physical } \\
\text { and Mineralogical Methods, } 2^{\text {nd }} \text { Edition, American Society of } \\
\text { Agronomy, Madison, WI. Chapter 28, pages } 700-703 .\end{array}$ \\
\hline
\end{tabular}


Table 3-1

Summary of Laboratory Methods (continued)

\begin{tabular}{|c|c|}
\hline Method Description & Reference \\
\hline $\begin{array}{l}\text { Moisture Retention Curves } \\
\text { • Pressure Plate Extractor } \\
\cdot \text { Hanging Column }\end{array}$ & $\begin{array}{l}\text { ASTM D 2325-68, 1981. Test Method for Capillary Moisture } \\
\text { Relationships for Coarse- and Medium-Textured Soils by } \\
\text { Pressure-Plate Apparatus. In: } 1987 \text { Annual Book of ASTM } \\
\text { Standards, Vol. 04.08, American Society for Testing and } \\
\text { Material. Philadelphia, PA. } \\
\text { Klute, A. L., 1986. Water Retention: Laboratory methods - } \\
\text { Falling head method. In: Klute, A. L. (ed.), Methods of Soil } \\
\text { Analysis, Part I, Physical and Mineralogical Methods, } 2^{\text {nd }} \\
\text { Edition, American Society of Agronomy, Madison, WI. } \\
\text { Chapter 26, pages } 635-641 .\end{array}$ \\
\hline Particle Size Characteristics, Dry Sieve & $\begin{array}{l}\text { ASTM D 422-63, } 1972 . \text { Method for particle size analysis of } \\
\text { soils. In: } 1987 \text { Annual Book of ASTM Standards, Vol. 04.08, } \\
\text { American Society for Testing and Material. Philadelphia, PA. }\end{array}$ \\
\hline Water Potential & $\begin{array}{l}\text { Gee, G. W., M. D. Campbell, G. S. Campbell, and J. H. } \\
\text { Campbell, 1992. Rapid Measurement of Low Soil Water } \\
\text { Potential Using a Water Activity Meter. Soil Science Society } \\
\text { of America Journal, Vol. 56, Pages 1,068-1,071. } \\
\text { Campbell, G. S., and G. W. Gee, 1986. Water Potential } \\
\text { Measurement Using the Filter Paper Technique. In: Klute, } \\
\text { A. L. (ed.), Methods of Soil Analysis, Part I, Physical and } \\
\text { Mineralogical Methods, } 2^{\text {nd }} \text { Edition, American Society of } \\
\text { Agronomy, Madison, WI. Chapter } 25 \text {, pages } 628-630 .\end{array}$ \\
\hline $\begin{array}{l}\text { Chloride and Bromide } \\
\qquad \begin{array}{l}\cdot \text { Extraction from Soil } \\
\cdot \text { Ion Chromatography }\end{array}\end{array}$ & $\begin{array}{l}\text { Los Alamos National Laboratory, 1992. Sample Leaching to } \\
\text { Extract Soluble Chloride and Bromide. LANL-INC-DP-92.R0. } \\
\text { Pages 3-15. } \\
\text { Los Alamos National Laboratory, 1991. Draft Procedure for } \\
\text { Using lon Chromatography to Determine Chloride and Bromide } \\
\text { Concentrations. LANL-INC-DP-94.R0. Pages 3-25. }\end{array}$ \\
\hline Total Organic Carbon & $\begin{array}{l}\text { USEPA Method 9060, September 1986. Total Organic } \\
\text { Carbon. Test Methods for Evaluating Solid Waste (SW-846), } \\
\text { Chapter 5, Miscellaneous Test Methods. } 5 \text { pages. } \\
\text { ASTM D 2579-85, 1990. Test Method for Determining Total } \\
\text { Organic Carbon. } \underline{\text { In: }} 1990 \text { Annual Book of ASTM Standards, } \\
\text { Vol. 11.02, American Society for Testing and Material. } \\
\text { Philadelphia, PA. }\end{array}$ \\
\hline Inorganic Carbon & $\begin{array}{l}\text { Nelson, R. E., 1982. Carbonate and gypsum: Pressure- } \\
\text { calcimeter method. In: Page, A., R. H. Miller, and D. R. } \\
\text { Keeney (eds.), Methods of Soil Analysis, Part 2, Chemical } \\
\text { and Microbiological Properties, } 2^{\text {nd }} \text { Edition, American Society } \\
\text { of Agronomy, Madison, WI, Chapter 11, pages 188-192. }\end{array}$ \\
\hline
\end{tabular}


Table 3-1

Summary of Laboratory Methods (continued)

\begin{tabular}{|c|c|}
\hline Method Description & Reference \\
\hline $\begin{array}{l}\text { Chlorine-36 Extraction from Soil } \\
\text { - Mass Spectrometry Analysis }\end{array}$ & $\begin{array}{l}\text { Los Alamos National Laboratory - Internal Document. Draft } \\
\text { Procedure, March 16, } 1993 \text {. Preparation of samples for } \\
\text { chlorine-36 analysis. LANL-INC-DP-95.R1, pages 3-14. } \\
\text { Davis, J. C., I. D. Proctor, J. R. Southon, M. W. Caffee, D. W. } \\
\text { Heikkinen, M. L. Roberts, K. W. Turtletaub, D. E. Nelson, D. } \\
\text { H. Lloyd, and J. S. Vogel, 1990. LLNL/UC AMS Facility and } \\
\text { Research Program. Nuclear Instruments and Methods in } \\
\text { Physics Research, Vol. B52, pages 269-272. }\end{array}$ \\
\hline $\begin{array}{l}\text { Stable Isotopes } \\
\qquad \text { Toluene Extraction } \\
\text { - Mass Spectroscopy Analysis }\end{array}$ & $\begin{array}{l}\text { Ingraham, N. L. and C. Shadel, 1992. A Comparison of the } \\
\text { Toluene Distillation and Vacuum/Heat Methods for Extracting } \\
\text { Soil Water for Stable Isotope Analysis. Journal of Hydrology, } \\
\text { Vol. 140, pages 371-387. } \\
\text { Davis, J. C., I. D. Proctor, J. R. Southon, M. W. Caffee, D. W. } \\
\text { Heikkinen, M. L. Roberts, K. W. Turtletaub, D. E. Nelson, D. } \\
\text { H. Lloyd, and J. S. Vogel, 1990. LLNL/UC AMS Facility and } \\
\text { Research Program. Nuclear Instruments and Methods in } \\
\text { Physics Research, Vol. B52, pages 269-272. }\end{array}$ \\
\hline Water Soluble and Adsorbed Sulfate & $\begin{array}{l}\text { Tabatabai, M. A., 1982. Sulfur: Inorganic Sulfate. In: Page, } \\
\text { A. L., R. H. Miller, and D. R Keeney (eds.), Methods of Soil } \\
\text { Analysis, Part 2, Chemical and Microbiological Properties, } 2^{\text {nd }} \\
\text { Edition, American Society of Agronomy, Madison, WI, } \\
\text { Chapter 28, pages 518-522. }\end{array}$ \\
\hline $\begin{array}{l}\text { Sample Preparation and Analysis by } \\
\text { X-Ray Fluorescence (XRF) }\end{array}$ & $\begin{array}{l}\text { Norrish, K, and B. W. Chappell, 1977. X-Ray Fluorescence } \\
\text { Spectrometry. In: Zussman, J. (ed.), Physical Methods in } \\
\text { Determinative Mineralogy, } 2^{\text {nd }} \text { Edition, Academic Press, New } \\
\text { York, Pages } 210-272 . \\
\text { Norrish, K. and J. T. Hutton, 1969. An Accurate X-Ray } \\
\text { Spectrographic Method for the Analysis of a Wide Range of } \\
\text { Geochemical Samples. Geochim. Cosmochim. Acta, v. 33, } \\
\text { Pages 431-453. }\end{array}$ \\
\hline $\begin{array}{l}\text { Sample Preparation and Instrumental } \\
\text { Neutron Activation Analysis (INAA) }\end{array}$ & $\begin{array}{l}\text { Jacobs, J. W., R. L. Korotev, D. P. Blanchard, and L. A. } \\
\text { Haskins, 1977. A Well-Tested Procedure for Instrumental } \\
\text { Neutron Activation Analysis of Silicate Rocks and Minerals. } \\
\text { Journal of Radioanalytical Chemistry, Vol. 40, pages 93-114. }\end{array}$ \\
\hline
\end{tabular}


Table 3-2

Summary of Tests Performed on Samples from the Pilot Wells

\begin{tabular}{|c|c|c|c|c|c|c|c|c|c|c|c|c|c|c|c|}
\hline \multicolumn{2}{|c|}{ Borehole } & \multicolumn{2}{|c|}{ UE5PW-1 } & \multicolumn{2}{|c|}{ UE5PW-2 } & \multicolumn{4}{|c|}{ UE5PW-3 } & \multicolumn{2}{|c|}{ UE5PW-2A } & \multicolumn{2}{|c|}{ UE5PW-2B } & \multicolumn{2}{|c|}{ UE5PW-2C } \\
\hline \multirow{4}{*}{$\begin{array}{l}\text { Sample } \\
\text { Type }\end{array}$} & Alluvium & $x$ & $x$ & $x$ & $x$ & $x$ & $x$ & & & $x$ & $x$ & $x$ & $x$ & $x$ & $x$ \\
\hline & Tuff & & & & & & & $x$ & $x$ & & & & & & \\
\hline & Core & $x$ & & $x$ & & $x$ & & $x$ & & $x$ & & $x$ & & $x$ & \\
\hline & Cuttings & & $x$ & & $\mathrm{X}$ & & $x$ & & $\mathrm{X}$ & & $\mathrm{X}$ & & $x$ & & $\mathrm{X}$ \\
\hline \multirow{6}{*}{$\begin{array}{l}\text { Hydrologic } \\
\text { Properties }\end{array}$} & $\begin{array}{l}\text { Hydraulic } \\
\text { Conductivity }\end{array}$ & 34 & -- & 16 & -- & 10 & -- & 3 & -- & -- & -- & -- & -- & -- & -- \\
\hline & $\begin{array}{l}\text { Air } \\
\text { Permeability }\end{array}$ & -- & -- & -- & -- & -- & -- & 3 & -- & -- & -- & -- & -- & -- & -- \\
\hline & \begin{tabular}{|l} 
Moisture \\
Retention
\end{tabular} & 24 & -- & 16 & -- & 9 & -- & -- & -- & -- & -- & -- & -- & -- & - \\
\hline & $\begin{array}{l}\text { Gravimetric } \\
\text { Water } \\
\text { Content }\end{array}$ & 146 & 595 & 58 & 706 & 50 & 488 & 5 & 79 & 15 & 26 & 5 & 15 & 12 & 30 \\
\hline & $\begin{array}{l}\text { Volumetric } \\
\text { Water } \\
\text { Content }\end{array}$ & 76 & -- & 34 & -- & 23 & -- & 3 & -- & 14 & -- & 5 & -- & 12 & -- \\
\hline & $\begin{array}{l}\text { Water } \\
\text { Potential }\end{array}$ & 59 & -- & 25 & -- & 18 & -- & 2 & 19 & 4 & -- & 1 & -- & 3 & -- \\
\hline \multirow{7}{*}{\begin{tabular}{|c} 
Material \\
Properties
\end{tabular}} & Hydrometer & 5 & 11 & 15 & 96 & 12 & -- & -- & -- & 3 & -- & 1 & -- & 1 & -- \\
\hline & Dry Sieve & 56 & 299 & 26 & 355 & 25 & 244 & -- & -- & 7 & 13 & 2 & 8 & 5 & 15 \\
\hline & Bulk Density & 76 & -- & 34 & -- & 23 & -- & 3 & -- & 14 & -- & 5 & -- & 12 & -- \\
\hline & Grain Density & -- & -- & -- & -- & -- & -- & 3 & -- & -- & -- & -- & -- & -- & -- \\
\hline & $\begin{array}{l}\text { Calculated } \\
\text { Porosity }\end{array}$ & 76 & -- & 34 & -- & 23 & -- & 3 & -- & 14 & -- & 5 & -- & 12 & -- \\
\hline & $\begin{array}{l}\text { Saturated } \\
\text { Porosity }\end{array}$ & 24 & -- & 16 & -- & 9 & -- & -- & -- & -- & -- & -- & -- & -- & -- \\
\hline & Mineralogy & 34 & -- & 13 & -- & 13 & -- & 3 & -- & 4 & -- & 2 & -- & 4 & -- \\
\hline \multirow{6}{*}{$\begin{array}{l}\text { Environ- } \\
\text { mental } \\
\text { Tracers }\end{array}$} & Carbon & 38 & 288 & 13 & 355 & 12 & 246 & 2 & 134 & -- & 13 & -- & 7 & -- & 15 \\
\hline & Chloride & 38 & 287 & 14 & 353 & 12 & 246 & -- & 134 & 4 & 13 & 2 & 7 & 4 & 15 \\
\hline & Bromide & 26 & 234 & 14 & 324 & 12 & 246 & -- & 129 & 4 & 13 & 2 & 7 & 4 & 15 \\
\hline & Sulfate & 1 & 15 & 14 & 353 & 12 & 246 & - & 134 & 4 & 13 & 2 & 7 & 4 & 15 \\
\hline & Chlorine-36 & 9 & -- & -- & -- & -- & -- & -- & -- & -- & -- & -- & -- & -- & -- \\
\hline & $\begin{array}{l}\text { Stable } \\
\text { Isotopes }\end{array}$ & 22 & -- & 16 & -- & 14 & -- & 1 & -- & -- & -- & -- & -- & -- & -- \\
\hline
\end{tabular}

\section{NOTE:}

Wells UE5PW-2A, 2B, and 2C are neutron-moisture meter calibration holes drilled near the pilot wells. See Section 4.6.

$34=$ number of tests conducted

$--\quad=$ test not conducted 


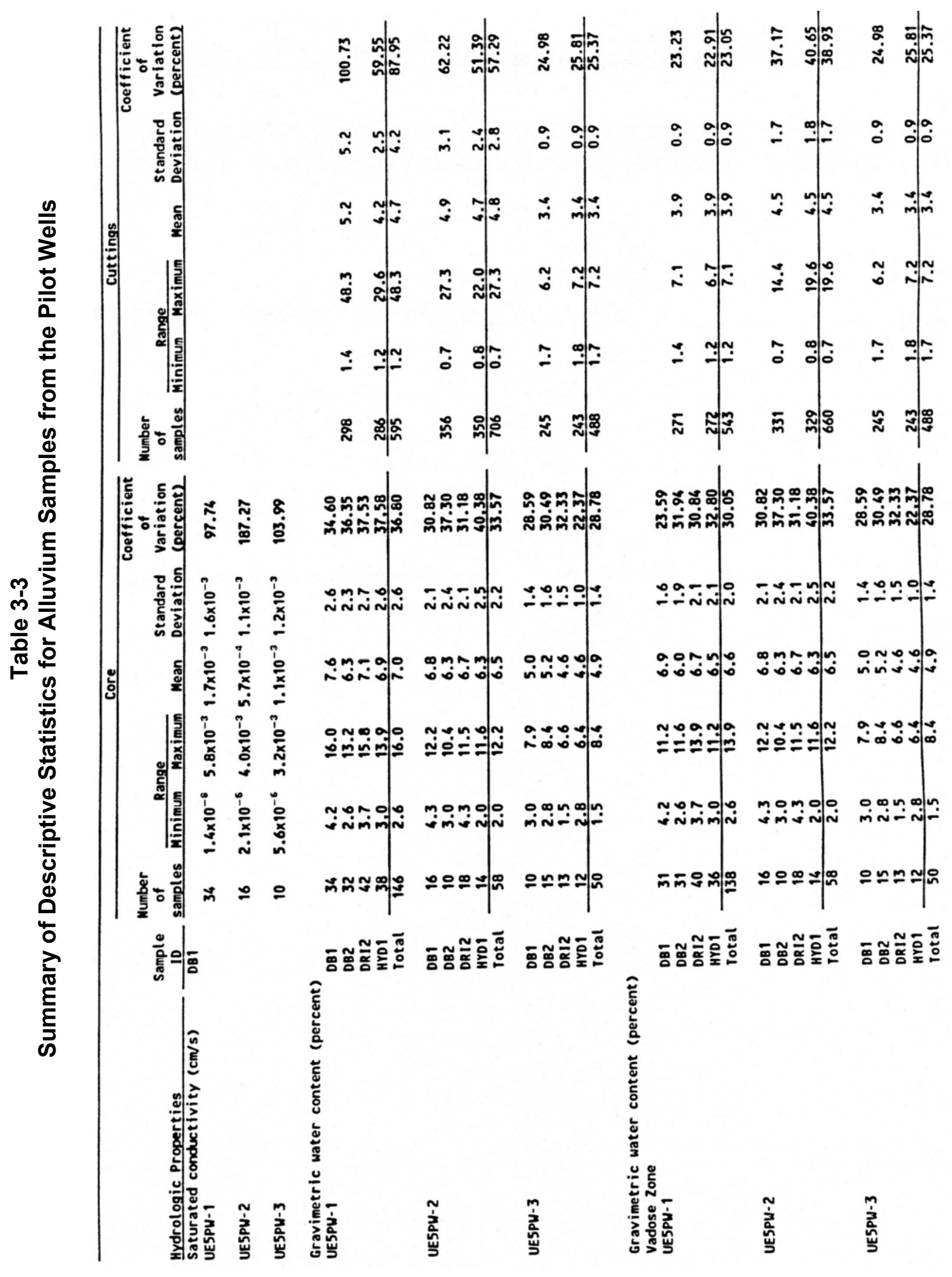




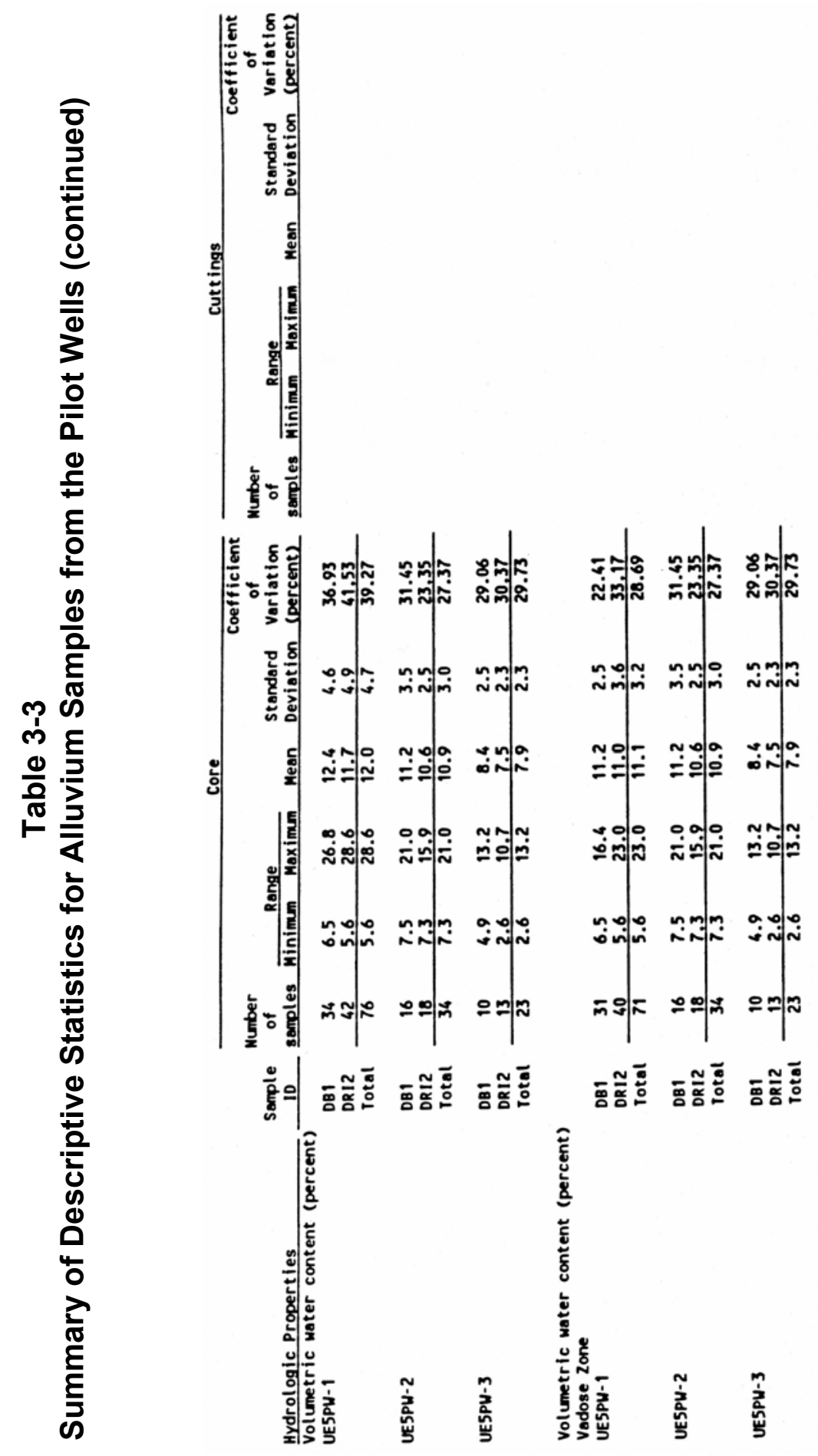




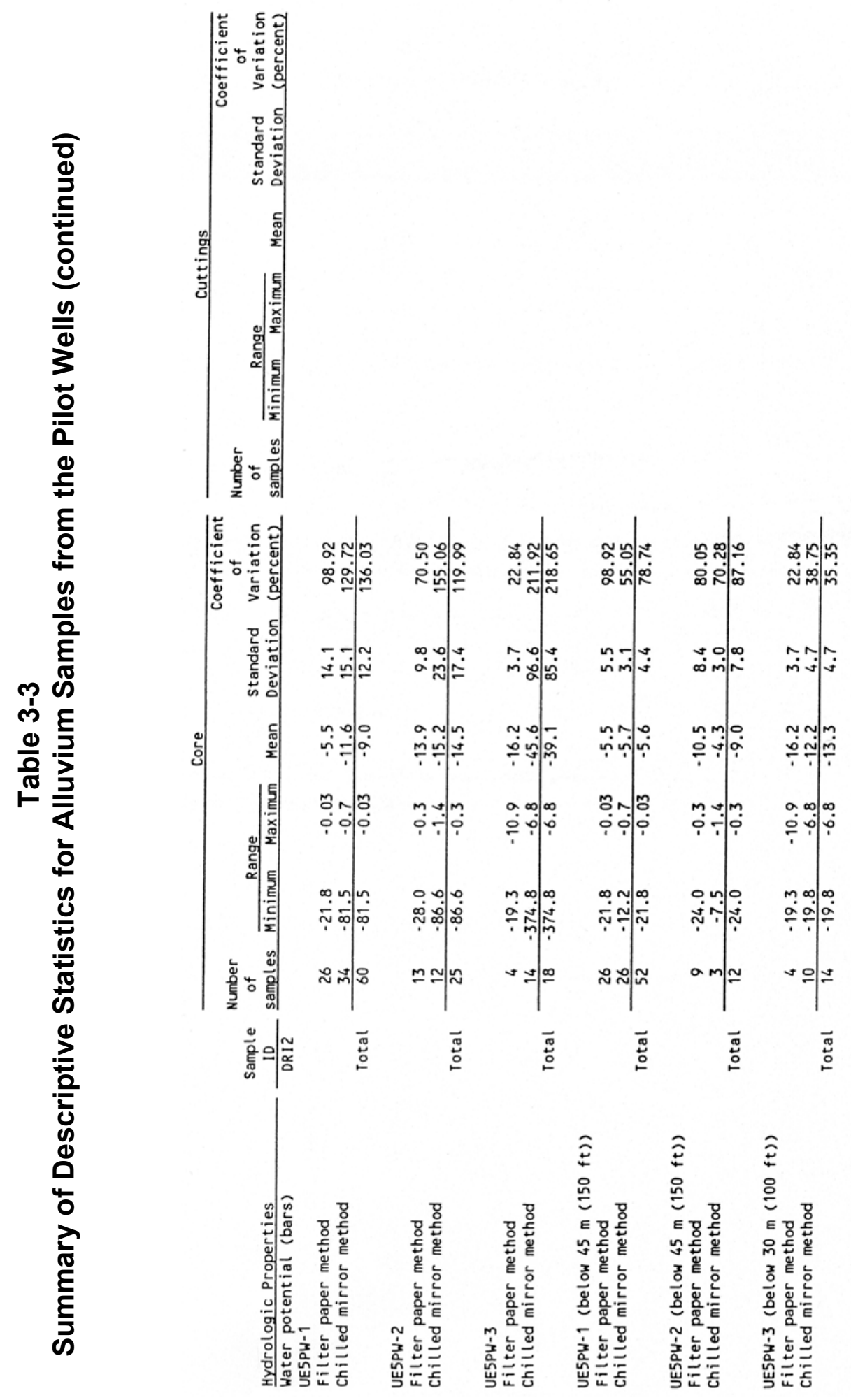




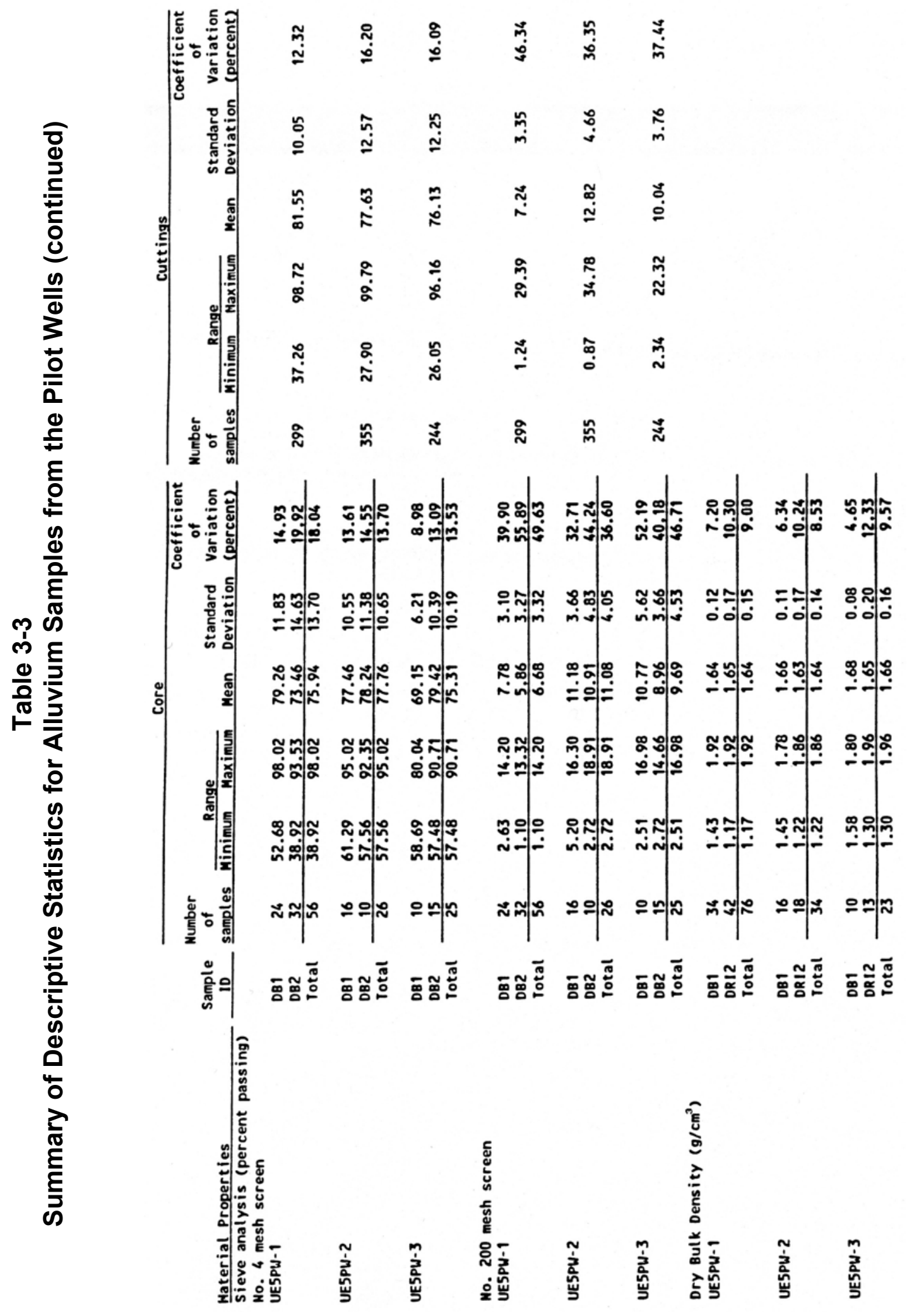




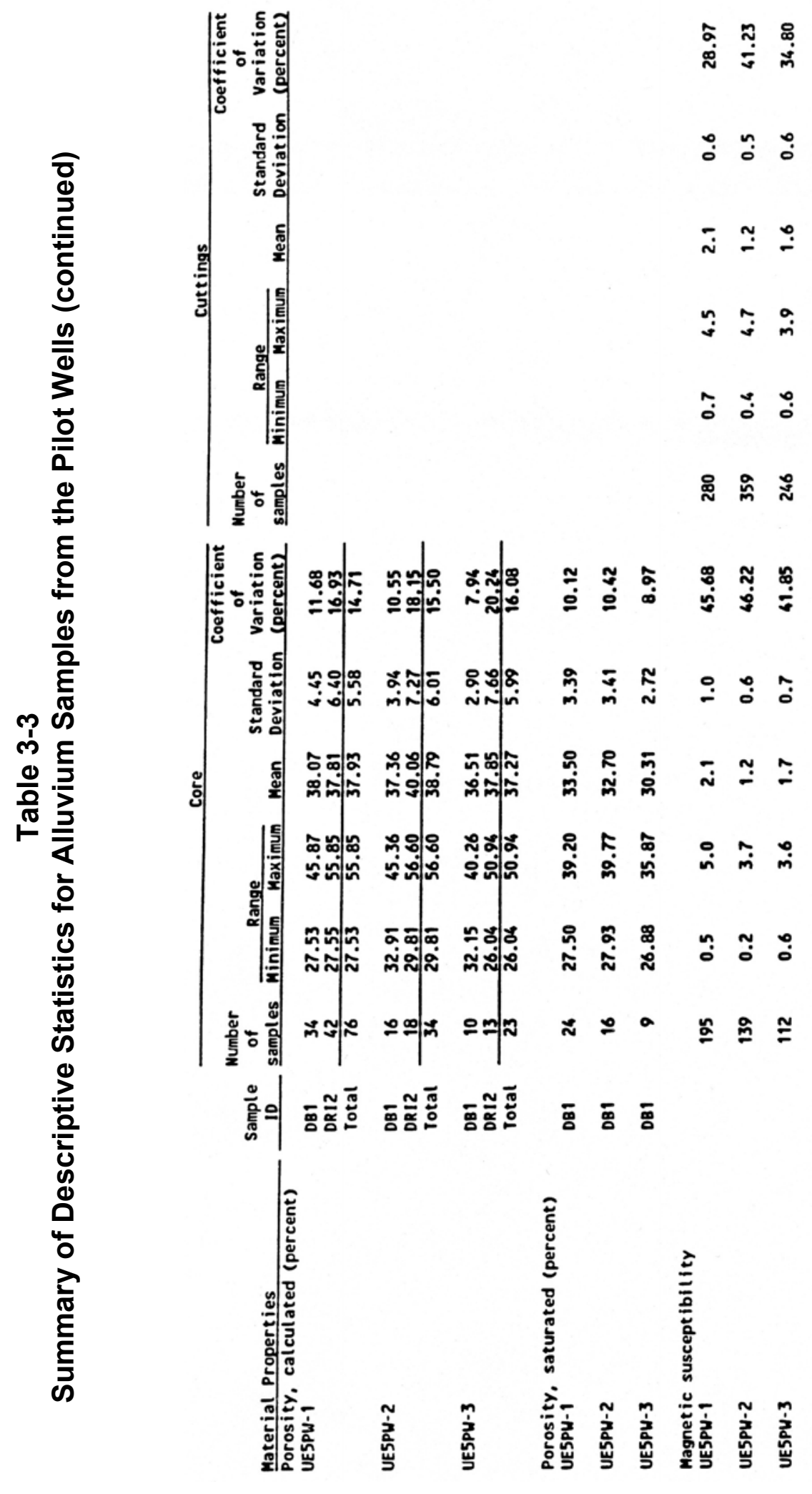




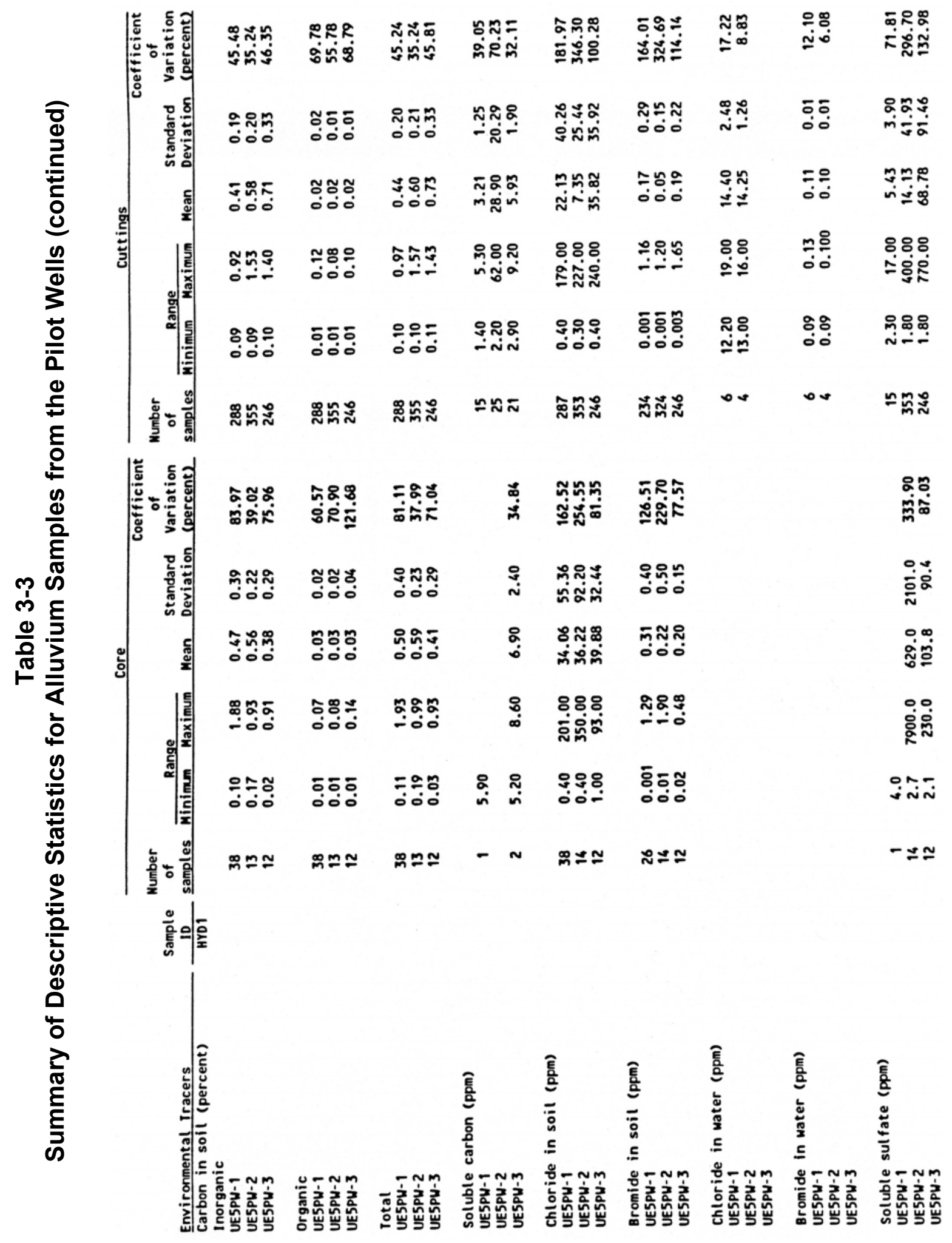




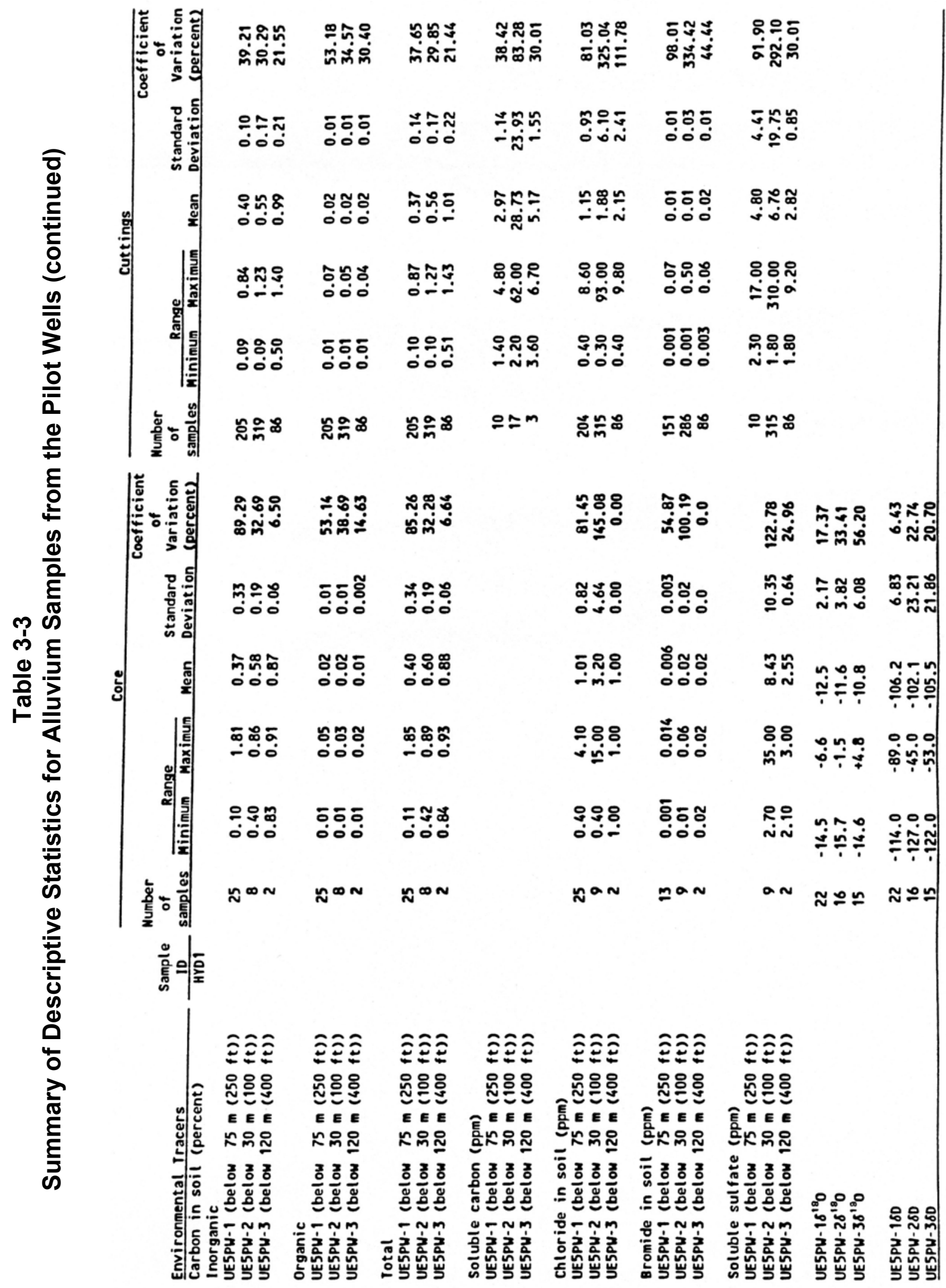


Table 3-4

Summary of Descriptive Statistics for Tuff Samples from Well UE5PW-3

\begin{tabular}{|c|c|c|c|c|c|c|c|}
\hline \multirow{2}{*}{ Properties } & \multirow{2}{*}{$\begin{array}{l}\text { Sampl } \\
\text { e ID }\end{array}$} & \multirow{2}{*}{$\begin{array}{c}\text { Number } \\
\text { of } \\
\text { Samples }\end{array}$} & \multicolumn{2}{|c|}{ Range } & \multirow{2}{*}{ Mean } & \multirow{2}{*}{$\begin{array}{l}\text { Standard } \\
\text { Deviation }\end{array}$} & \multirow{2}{*}{$\begin{array}{l}\text { Coefficient } \\
\text { of Variation } \\
\text { (percent) }\end{array}$} \\
\hline & & & Minimum & Maximum & & & \\
\hline \multicolumn{8}{|l|}{ Core } \\
\hline Saturated Conductivity $(\mathrm{cm} / \mathrm{s})$ & DB1 & 3 & $6.0 \times 10^{-7}$ & $2.7 \times 10^{-5}$ & $1.4 \times 10^{-6}$ & $1.3 \times 10^{-5}$ & 93.09 \\
\hline Air Permeability (cm/s) & DB1 & 3 & $2.0 \times 10^{-6}$ & $3.8 \times 10^{-5}$ & $2.8 \times 10^{-5}$ & $9.0 \times 10^{-6}$ & 32.44 \\
\hline \multirow{3}{*}{$\begin{array}{l}\text { Gravimetric Water Content } \\
\text { (percent) }\end{array}$} & DB1 & 3 & 7.5 & 7.6 & 7.6 & 0.01 & 0.13 \\
\hline & DRI2 & 2 & 0.8 & 1.6 & 1.2 & 0.57 & 47.14 \\
\hline & Total & 5 & 0.8 & 7.6 & 5.0 & 3.5 & 69.65 \\
\hline $\begin{array}{l}\text { Volumetric Water Content } \\
\text { (percent) }\end{array}$ & DB1 & 3 & 14.9 & 15.1 & 15.0 & 0.09 & 0.59 \\
\hline Water Potential (bars) & DRI2 & 2 & -23.2 & -16.3 & -19.8 & 4.90 & 24.56 \\
\hline Dry Bulk Density $\left(\mathrm{g} / \mathrm{cm}^{3}\right)$ & DB1 & 3 & 1.98 & 2.00 & 1.99 & 0.01 & 0.58 \\
\hline Grain Density $\left(\mathrm{g} / \mathrm{cm}^{3}\right)$ & DB1 & 3 & 2.57 & 2.58 & 2.57 & 0.01 & 0.22 \\
\hline Calculated Porosity (percent) & DB1 & 3 & 21.90 & 23.10 & 22.40 & 0.62 & 2.79 \\
\hline Pore Volume (percent) & DB1 & 3 & 70.00 & 74.90 & 72.80 & 2.52 & 3.47 \\
\hline Magnetic Susceptibility & & 5 & 0.04 & 2.83 & 0.75 & 1.17 & 156.57 \\
\hline \multicolumn{8}{|l|}{ Drill Cuttings } \\
\hline \multirow{3}{*}{$\begin{array}{l}\text { Gravimetric Water Content } \\
\text { (percent) }\end{array}$} & DRI2 & 19 & 0.6 & 18.1 & 3.4 & 4.53 & 131.84 \\
\hline & HYD1 & 60 & 0.3 & 3.6 & 1.3 & 0.81 & 60.45 \\
\hline & Total & 79 & 0.3 & 18.1 & 1.8 & 2.46 & 133.52 \\
\hline Water Potential (bars) & DRI2 & 19 & -381.9 & -2.7 & -102.7 & 98.61 & 96.01 \\
\hline Magnetic Susceptibility & & 135 & 0.5 & 4.4 & 1.9 & 0.9 & 46.05 \\
\hline Inorganic Carbon (percent) & HYD1 & 66 & 0.01 & 1.19 & 0.34 & 0.33 & 96.17 \\
\hline Organic Carbon ( percent) & HYD1 & 131 & 0.002 & 0.04 & .01 & 0.01 & 67.60 \\
\hline Total Carbon (percent) & HYD1 & 66 & 0.013 & 1.20 & 0.35 & 0.33 & 94.31 \\
\hline Soluble Organic Carbon (ppm) & HYD1 & 3 & 2.8 & 20.60 & 10.30 & 9.24 & 90.00 \\
\hline Chloride in Soil (ppm) & HYD1 & 134 & 0.30 & 6.30 & 2.00 & 1.37 & 68.06 \\
\hline Bromide in Soil (ppm) & HYD1 & 129 & 0.001 & 0.05 & 0.01 & 0.01 & 82.74 \\
\hline Soluble Sulfate (ppm) & HYD1 & 134 & 0.7 & 17.40 & 2.80 & 2.86 & 102.44 \\
\hline
\end{tabular}

NOTES

$\mathrm{cm} / \mathrm{s}=$ centimeters per second

$\mathrm{g} / \mathrm{cm}^{3}=$ grams per cubic centimeters

$\mathrm{ppm}=$ parts per million 


\subsection{General Geologic Description, Lithology, Stratigraphy, Mineralogy, and Organic Matter}

General geologic descriptive information, as well as specific lithologic and stratigraphic information, is useful in identifying layers with possibly distinctive physical and hydrogeologic properties and potentially important flow paths, and understanding the overall geometry of the hydrogeologic flow system. This information is necessary to understand and model important processes under the existing arid climate, as well as for possible future climatic scenarios.

\subsubsection{General Geologic, Lithologic, and Stratigraphic Data for Alluvium}

Visual geologic descriptions were made on both core and drill cuttings samples (Sections 2.3.1 and 2.3.2) and recorded on borehole log sheets (Appendices B.1, B.2, and B.3) and in field notebooks. The descriptions included a field description of lithology, texture, color, cementation, and reaction to hydrochloric acid. Field descriptions of texture (particle size distribution) were not as accurate as the textural classifications based on laboratory dry sieve analyses. Therefore, the laboratory textural classifications were added to the edited versions of the borehole log sheets. This geologic descriptive information is summarized below.

Clasts recovered in the alluvial core and drill cuttings were primarily tuff with occasional quartzite and limestone. Basalt clasts were even rarer and only identified in several samples. The degree of welding in the tuff clasts (observable only in large clasts) ranged from welded to nonwelded. The alluvium samples were generally weakly cemented to uncemented and exhibited a weak to strong reaction to dilute hydrochloric acid. The poorly graded gravel and coarse-sand fractions were more sub-angular than the well-graded fractions of similar particle size. Cobbles were generally sub-rounded. The general color of the alluvial samples was predominantly very pale brown to light yellowish brown. Gravels, when separated from the other size fractions, were pink and gray in color.

The Unified Soil Classification System (USCS) textural data are summarized in Table 3-5 for all alluvial core and drill cuttings samples. Note that Table 3-5 includes particle size distribution data from each drill cuttings interval, and from two core segments (DB1 and DB2 samples) in every core run. The justification for combining particle size distribution data for core and drill cuttings is given in Section 3.2. These textural classes are composed primarily of sand with silt, some gravel, and no clay. The predominant textural group found in all three pilot wells is well-graded sand with silt (SW-SM). The second most frequently occurring group in silty sand (SM) in Wells UE5PW-2 and UE5PW-3, and well-graded sand (SW). 
Table 3-5

Summary of USCS Assignments for Core and Drill Cuttings Samples from the Pilot Wells

\begin{tabular}{|c|c|c|c|c|c|c|c|c|c|c|c|}
\hline \multirow{2}{*}{ Borehole } & \multirow{2}{*}{$\begin{array}{c}\text { Sample } \\
\text { Type }\end{array}$} & \multicolumn{10}{|c|}{ Number and Percent ( ) of Samples with Given USCS Group Names ${ }^{a}$} \\
\hline & & SM & SP-SM & SW-SM & SP & sw & GM & GP & GW & GW-GM & Total \\
\hline UE5PW-1 & $\begin{array}{c}\text { Drill } \\
\text { Cuttings }\end{array}$ & $\begin{array}{l}24 \\
(8)\end{array}$ & $\begin{array}{c}10 \\
(3.3)\end{array}$ & $\begin{array}{c}193 \\
(64.5)\end{array}$ & $\begin{array}{c}2 \\
(0.7)\end{array}$ & $\begin{array}{c}66 \\
(22.1)\end{array}$ & -- & -- & $\begin{array}{c}2 \\
(0.7)\end{array}$ & $\begin{array}{c}2 \\
(0.7)\end{array}$ & 299 \\
\hline UE5PW-1 & Core & $\begin{array}{c}5 \\
(8.9)\end{array}$ & $\begin{array}{c}5 \\
(8.9)\end{array}$ & $\begin{array}{c}24 \\
(42.8)\end{array}$ & $\begin{array}{c}1 \\
(1.8)\end{array}$ & $\begin{array}{c}19 \\
(34.0)\end{array}$ & -- & -- & $\begin{array}{c}2 \\
(3.6)\end{array}$ & -- & 56 \\
\hline UE5PW-2 & $\begin{array}{c}\text { Drill } \\
\text { Cuttings }\end{array}$ & $\begin{array}{c}192 \\
(54.1)\end{array}$ & $\begin{array}{c}3 \\
(0.8)\end{array}$ & $\begin{array}{c}131 \\
(36.9)\end{array}$ & $\begin{array}{c}1 \\
(0.3)\end{array}$ & $\begin{array}{c}10 \\
(2.8)\end{array}$ & $\begin{array}{c}1 \\
(0.3)\end{array}$ & $\begin{array}{c}1 \\
(0.3)\end{array}$ & -- & $\begin{array}{c}16 \\
(4.5)\end{array}$ & 355 \\
\hline UE5PW-2 & Core & $\begin{array}{c}10 \\
(38.5)\end{array}$ & -- & $\begin{array}{c}15 \\
(57.5)\end{array}$ & $\begin{array}{c}1 \\
(3.8)\end{array}$ & -- & -- & -- & -- & -- & 26 \\
\hline UE5PW-3 & $\begin{array}{c}\text { Drill } \\
\text { Cuttings }\end{array}$ & $\begin{array}{c}71 \\
(29)\end{array}$ & -- & $\begin{array}{l}149 \\
(61)\end{array}$ & -- & $\begin{array}{l}11 \\
(4.5)\end{array}$ & -- & $\begin{array}{c}2 \\
(1)\end{array}$ & $\begin{array}{c}2 \\
(1)\end{array}$ & $\begin{array}{c}9 \\
(3.5)\end{array}$ & 244 \\
\hline UE5PW-3 & Core & $\begin{array}{c}9 \\
(36)\end{array}$ & -- & $\begin{array}{c}12 \\
(48)\end{array}$ & -- & $\begin{array}{c}4 \\
(16)\end{array}$ & -- & -- & -- & -- & 25 \\
\hline TOTAL & & $\begin{array}{c}311 \\
(31.0)\end{array}$ & $\begin{array}{c}18 \\
(1.8)\end{array}$ & $\begin{array}{l}524 \\
(52.1)\end{array}$ & $\begin{array}{c}5 \\
(0.5)\end{array}$ & $\begin{array}{c}110 \\
(10.9)\end{array}$ & $\begin{array}{c}1 \\
(0.2)\end{array}$ & $\begin{array}{c}3 \\
(0.3)\end{array}$ & $\begin{array}{c}6 \\
(0.6)\end{array}$ & $\begin{array}{c}27 \\
(2.7)\end{array}$ & 1,000 \\
\hline
\end{tabular}

a USCS = Unified Soil Classification System

SM: $\quad$ Silty sand (>12\%silt) SW: Well graded sand $(<5 \%$ silt $)$

SP-SM: $\quad$ Poorly graded sand with silt (5 to $12 \%$ silt) GM: $\quad$ Silty gravel (>12\% silt)

SW-SM: Well graded sand with silt (5 to $12 \%$ silt) $\quad$ GP: $\quad$ Poorly graded gravel ( $<5 \%$ silt)

SP: $\quad$ Poorly graded sand $(<5 \%$ silt $) \quad$ GW: Well graded gravel $(<5 \%$ silt $)$

GW-GM: $\quad$ Well graded gravel with silt (5 to $12 \%$ silt)

-- $\quad$ No samples in this USCS group

Preliminary stratigraphic columns (Appendix E.1.1) were prepared for each pilot well using particle size distribution data from each drill cuttings interval and one core segment (DB2) from each core run. In general these columns show, for all three wells, that the thickest layers consist of sand with silt (SW-SM) and silty sand (SM). These layers alternate with thinner layers of poorly graded sand (SP), poorly graded sand with silt (SP-SM), well graded sand (SW), and gravel zones. Some subtle differences in textural groups between each pilot well are briefly outlined below.

In Well UE5PW-1 textural units consist predominantly of well graded sand with silt (SW-SM) with a maximum thickness of $8.2 \mathrm{~m}$ (27 ft); numerous layers of well graded sand with gravel (SW) with a maximum thickness of $5.2 \mathrm{~m}(17 \mathrm{ft})$, but more commonly 0.76 to $1.5 \mathrm{~m}(2.5$ to $5 \mathrm{ft})$ thick; and less numerous and thinner layers of poorly graded sand (SP) and silty sand (SM). Textural units in Well UE5PW-2 are composed primarily of silty sand (SM) with a maximum thickness of $12.2 \mathrm{~m}$ (40 ft), with numerous inter-bedded gravel zones and layers of well graded sand with silt (SW-SM). In the depth 
intervals 42.7 to $122.0 \mathrm{~m}$ (140 to $400 \mathrm{ft})$ and 171 to $256 \mathrm{~m}$ (560 to $840 \mathrm{ft}$ ) the silty sand unit (SM) is fairly massive, less gravelly, and has fewer inter-bedded layers of well graded sand (SW). Finally, the alluvial section in Well UE5PW-3 is composed mainly of well graded sand with silt (SW-SM) with a maximum thickness of $27.4 \mathrm{~m}(90 \mathrm{ft})$. In the interval 38.1 to $115.8 \mathrm{~m}$ (125 to $380 \mathrm{ft})$ the $\mathrm{SW}-\mathrm{SM}$ unit is fairly massive, but in the interval 115.8 to $170.7 \mathrm{~m}$ (380 to $560 \mathrm{ft}$ ) there is an increase in the number of silty sand (SM) zones. Below $170.7 \mathrm{~m}(560 \mathrm{ft})$ the silty sand layer is quite massive with scattered zones of cobbles and boulders.

It is not surprising that these preliminary stratigraphic columns show no correlation between textural units in boreholes separated by approximately $1.5 \mathrm{~km}(1 \mathrm{mi})$. The various depositional processes that contribute to the formation of alluvial fans often interact to produce highly variable and discontinuous lithologic sequences both in the lateral and vertical directions. This makes it difficult to correlate deposits between even closely spaced boreholes. For example, attempts to correlate deposits in the

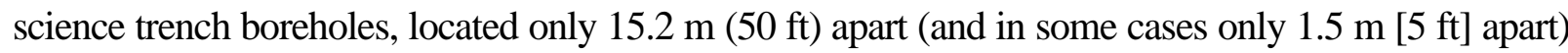
based solely on particle size distribution were unsuccessful (REECo, 1993a).

Through observations of existing excavations within the Area 5 RWMS, lithologic units (based on a visual description of texture and a field interpretation of the depositional process involved) have been identified to extend laterally up to several hundreds of meters (RSN, 1991). However, a detailed comparison of the physical and hydrologic properties of these units indicated that the differences between units were neither distinct nor statistically significant in most cases. Each unit is made up of textural groups that are nearly identical; the only difference is that one unit is slightly finer in texture than the other.

It should be emphasized that the inability to correlate textural units between the pilot wells and the science trench boreholes is not a significant problem in terms of understanding and simulating the movement of fluids in the regions between these boreholes. Sully et al. (1993), quantitatively demonstrate that the physical and hydrologic properties of these textural units (required to simulate fluid flow) are very similar. Therefore, the subsurface penetrated by both the science trench boreholes and the pilot wells can be approximated as a homogenous hydrogeologic system. Data and more qualitative arguments supporting this conclusion are presented in Sections 3.2 and 3.3. Similar data and qualitative arguments were presented for the science trench boreholes (REECo, 1993a). 


\subsubsection{Tuff Lithology and Stratigraphy}

Lithologic and stratigraphic descriptive data for the tuff units in Well UE5PW-3 were obtained by examining a complete record of drill cuttings samples collected over consecutive 0.76-m (2.5-ft) depth intervals from the alluvium-tuff contact at $188.2 \mathrm{~m}(617.5 \mathrm{ft})$ to the total borehole depth at $291.1 \mathrm{~m}$ $(955.0 \mathrm{ft})$. The detailed descriptive information presented below was obtained from an in-depth laboratory examination of the complete set of drill cuttings samples. Some general descriptive lithologic and stratigraphic information collected during drilling is presented in drill cuttings log sheets (Appendix B.6).

Two major lithologic and stratigraphic tuff units were penetrated in Well UE5PW-3. A rhyolitic ashflow tuff was encountered in the interval 188.2 to $279.7 \mathrm{~m}$ (617.6 to $917.5 \mathrm{ft}$ ). Underlying this unit is a bedded tuff that extends at least to the total borehole depth. The ash-flow tuff unit was identified as the Ammonia Tanks Tuff (Poole, 1965; Byers et al., 1976). This unit is of Tertiary age and grades from moderately welded at the alluvium-tuff contact to nonwelded at the bedded tuff contact. This gradation in welding character is also visible on the natural gamma logs presented in Section 4.3.2. The core samples from the tuff interval 194.54 to $196.14 \mathrm{~m}$ (638.25 to $643.50 \mathrm{ft})$ and from 209.86 to $210.87 \mathrm{~m}$ (688.50 to $691.83 \mathrm{ft}$ ) (Table 2-5) sampled the moderately welded and partially welded section of this unit, respectively.

The ash-flow unit is fairly uniformly gray in color, with a matrix that is glassy to devitrified. Abundant phenocrysts are present (20 to 25 percent by volume), consisting of bronze and black biotite, sanidine, sphene, and plagioclase feldspar minerals. Structural features were not observed in either the core or drill cuttings samples. Nearby outcrops of this unit at Massachusetts Mountain indicate that this unit dips approximately 15 to 25 degrees to the southeast. This significant dip may extend beneath Well UE5PW-3, which would cause the unit thickness in the borehole (91.4 m [300 ft]) to be greater than the true thickness. Where a nearby drill hole, UE11a, penetrated this unit, the bedding dip was reported to be 28 degrees to the southeast (Fernald et al., 1965).

The underlying bedded tuff unit was reworked by water (soon after deposition), is vitric and weakly calcareous, and contains abundant phenocrysts. The colors in the tuff include shades of red, orange, brown, and white. Overall, the bedded tuff is expected to exhibit a higher matrix porosity and hydraulic conductivity than the overlying moderately welded to nonwelded ash-flow tuff (Winograd and Thordarson, 1975). 


\subsubsection{Elemental and Oxide Composition}

Characterization of the gross elemental and oxide composition is helpful in identifying the source(s) of sediments and understanding the age and stability of pediments, and the potential for future erosion at the Area 5 RWMS. With this in mind, selected core samples were pulverized, sub-sampled, and analyzed by X-ray fluorescence (XRF) for major elements:

- $\quad$ silicon dioxide $\left(\mathrm{SiO}_{2}\right)$

- titanium dioxide $\left(\mathrm{TiO}_{2}\right)$

- aluminum oxide $\left(\mathrm{Al}_{2} \mathrm{O}_{3}\right)$

- $\quad$ iron oxide $\left(\mathrm{Fe}_{2} \mathrm{O}_{3}\right)$

- manganese oxide $(\mathrm{MnO})$
- $\quad$ magnesium oxide $(\mathrm{MgO})$

- $\quad$ calcium oxide $(\mathrm{CaO})$

- $\quad$ sodium oxide $\left(\mathrm{Na}_{2} \mathrm{O}\right)$

- potassium oxide $\left(\mathrm{K}_{2} \mathrm{O}\right)$

- phosphorous oxide $\left(\mathrm{P}_{2} \mathrm{O}_{5}\right)$

and for trace elements :

- rubidium $(\mathrm{Rb})$

- $\quad$ strontium $(\mathrm{Sr})$

- $\quad$ zirconium $(\mathrm{Zr})$

- $\quad y t t r i u m(Y)$
- $\quad \operatorname{niobium}(\mathrm{Nb})$

- $\quad$ lead $(\mathrm{Pb})$

- $\quad$ thorium (Th)

The weight loss on ignition was also determined for each sample as a check on the quality of the analyses. Selected core samples were also analyzed for the following elements by instrumental neutron activation analysis (INAA):

- $\quad$ iron oxide $(\mathrm{FeO})$

- $\quad$ sodium dioxide $\left(\mathrm{Na}_{2} \mathrm{O}\right)$

- $\quad$ scandium $(\mathrm{Sc})$

- $\operatorname{chromium}(\mathrm{Cr})$

- $\quad$ zinc ( $\mathrm{Zn})$

- $\operatorname{arsenic}(\mathrm{As})$

- bromine (Br)

- $\operatorname{tin}(\mathrm{Sb})$
- $\quad \operatorname{barium}(\mathrm{Ba})$
- $\quad \operatorname{cesium}(\mathrm{Cs})$
- lanthanum (La)
- $\quad \operatorname{cerium}(\mathrm{Ce})$
- $\operatorname{neodymium}(\mathrm{Nd})$
- $\quad$ samarium (Sm)
- $\quad$ europium $(\mathrm{Eu})$
- $\quad$ terbium $(\mathrm{Tb})$

- $\quad$ ytterbium (Yb)

- $\quad \operatorname{lutetium}(\mathrm{Lu})$

- $\quad$ hafnium (Hf)

- $\quad$ tantalum (Ta)

- thorium, (Th)

- $\operatorname{uranium}(\mathrm{U})$

The completed results of element and oxide composition analyses for core samples from the pilot wells are given in Appendix E.1.2. Figures 3-1 and 3-2 illustrate the variation of elemental and oxide composition with depth in Well UE5PW-1. Overall, the elemental and oxide composition of minerals remains fairly constant with depth. The results from the other two pilot wells also show that the mineralogy profiles are similar to Well UE5PW-1. The variation of the data with depth is not significantly different from the variability noted in several science trench boreholes located some 20 to $30 \mathrm{~m}$ (65 to $100 \mathrm{ft}$ ) to the southeast of Well UE5PW-1 (REECo, 1993a). 

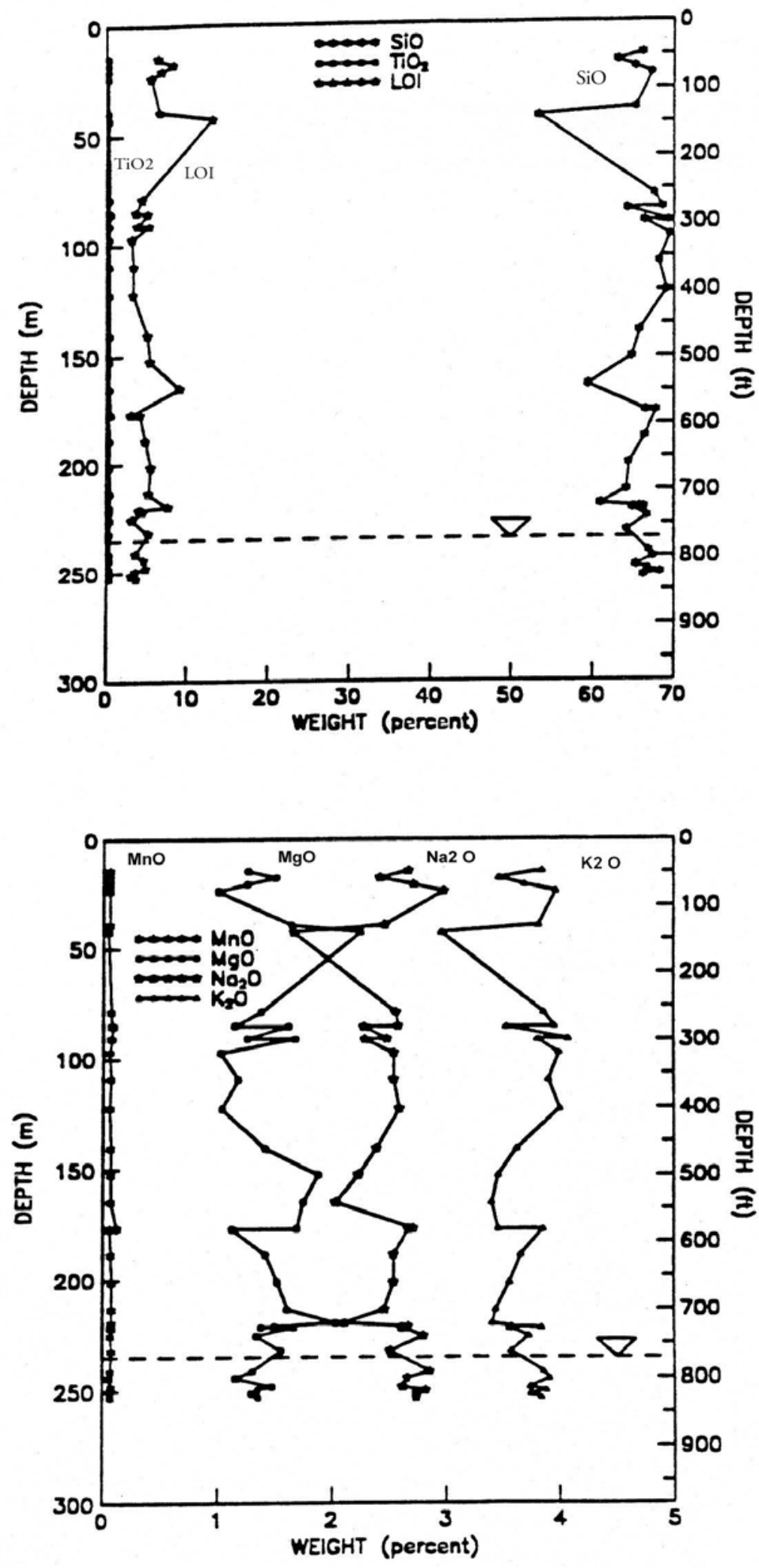

Figure 3-1

Depth Profiles of Element and Oxide Composition Data by X-Ray Fluorescence (XRF) for Core Samples from Well UE5PW-1 

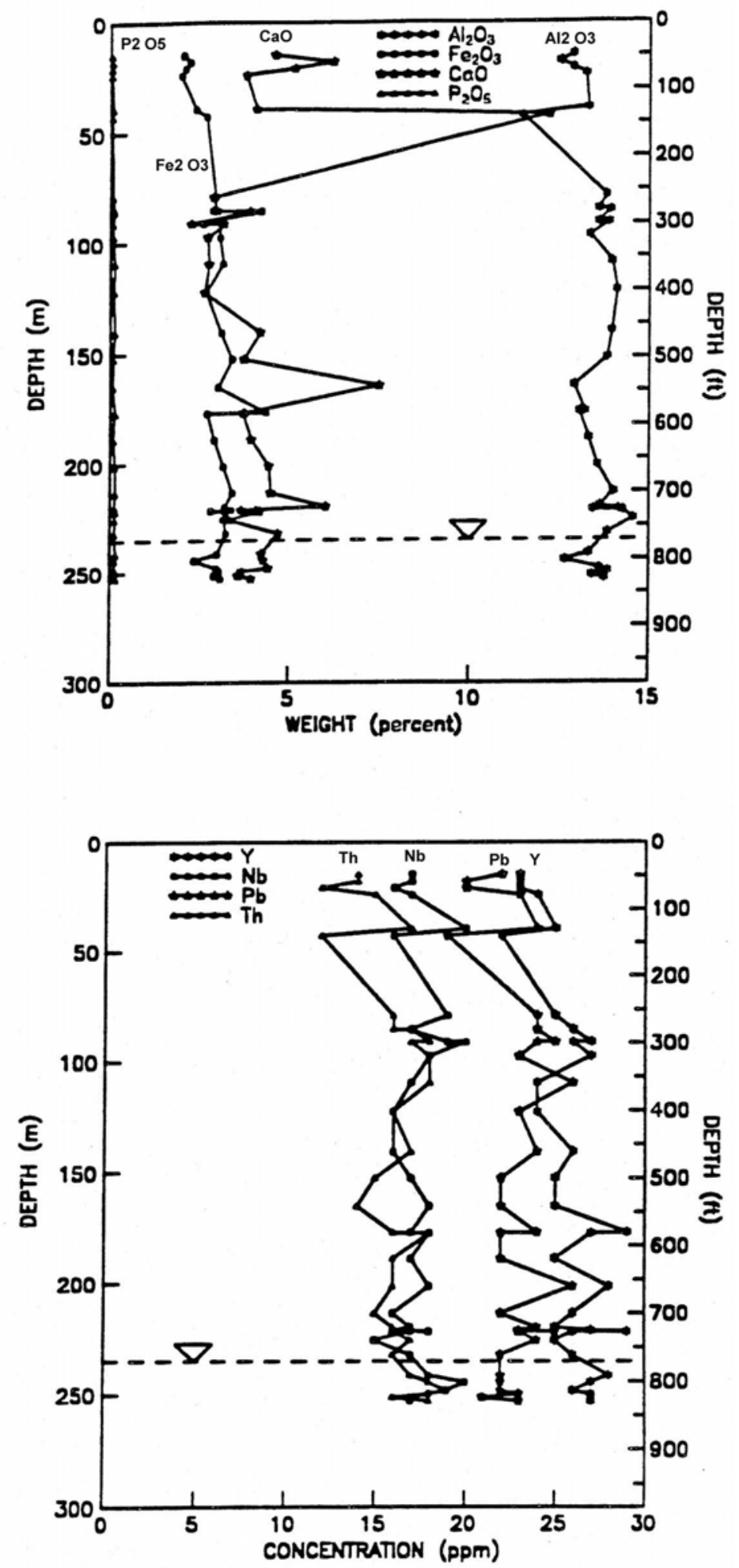

Figure 3-1

Depth Profiles of Element and Oxide Composition Data by XRF for Core Samples from Well UE5PW-1 (continued) 


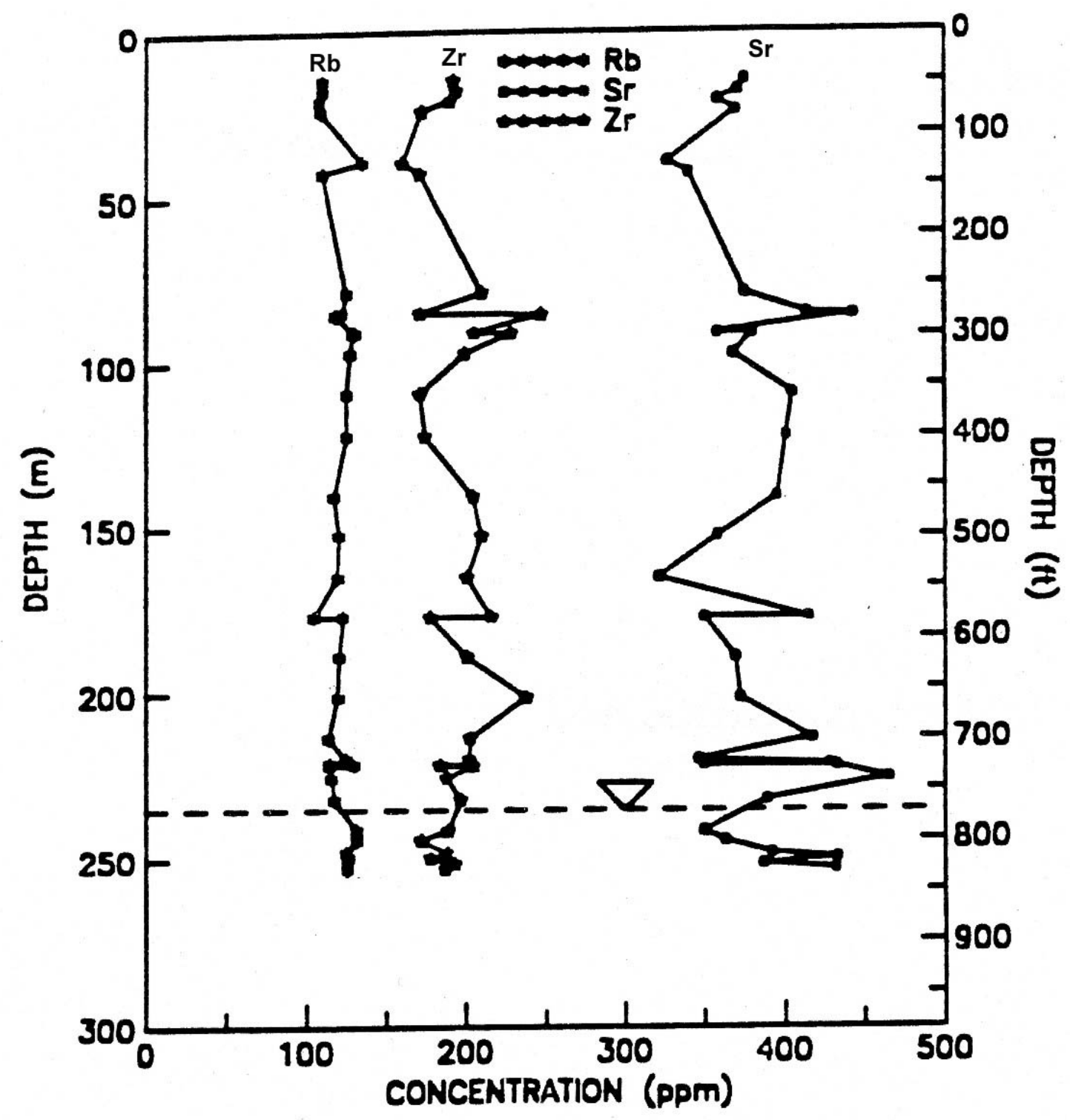

Figure 3-1

Depth Profiles of Element and Oxide Composition Data by XRF for Core Samples from Well UE5PW-1 (continued) 

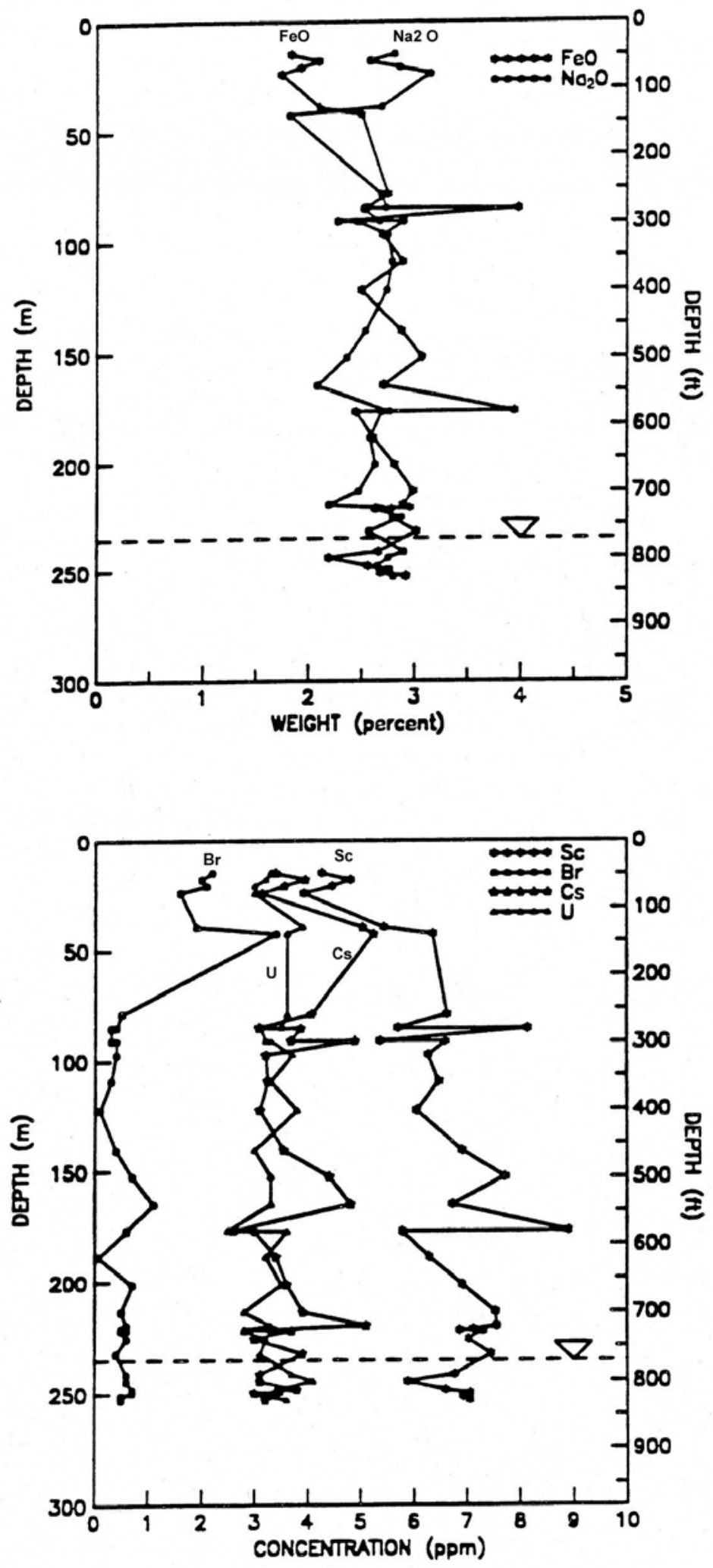

Figure 3-2

Depth Profiles of Element and Oxide Composition Data by Instrumental Neutron Activation Analysis (INAA) for Core Samples from Well UE5PW-1 

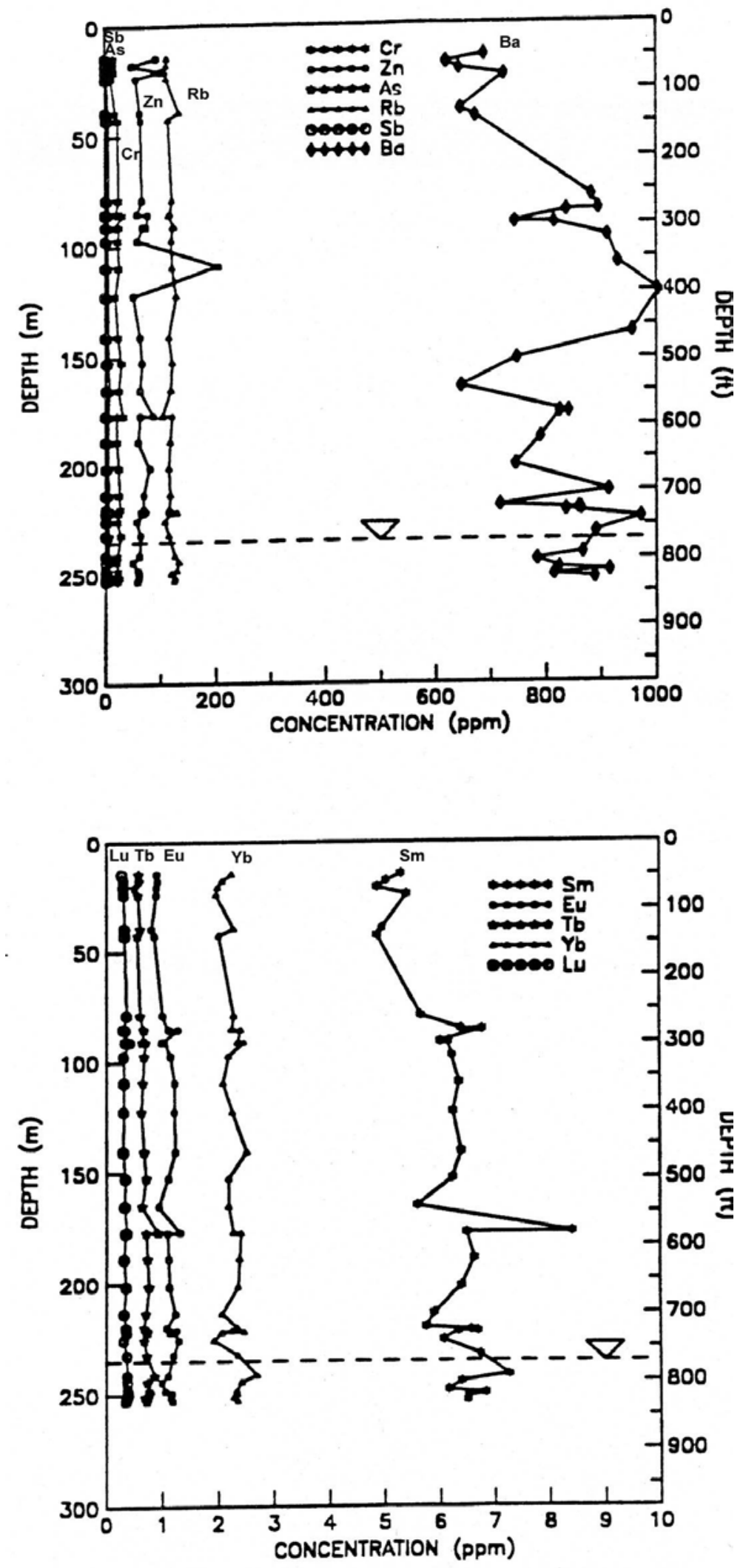

Figure 3-2

Depth Profiles of Element and Oxide Composition Data by INAA for Core Samples from Well UE5PW-1 (continued) 


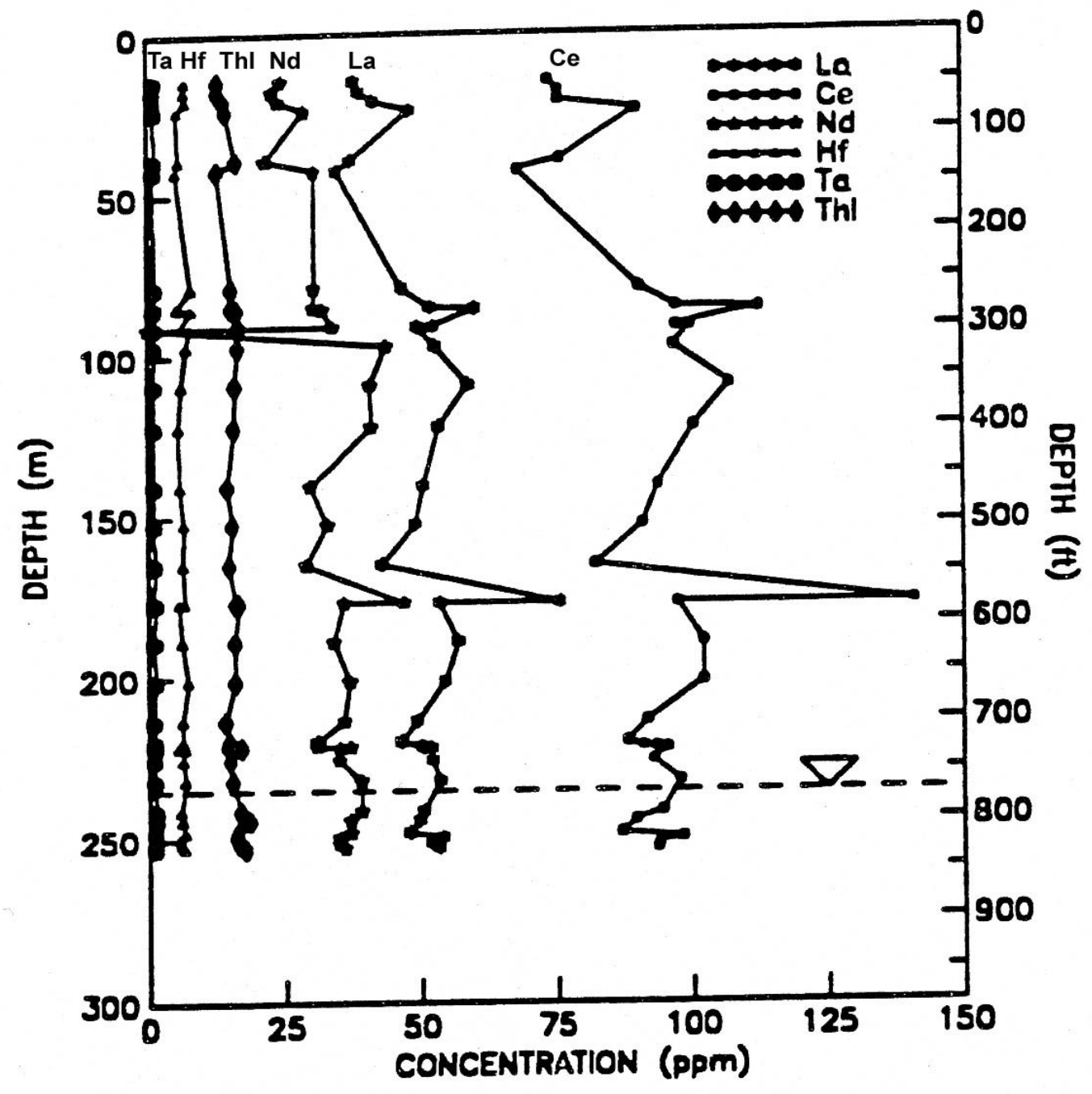

Figure 3-2

Depth Profiles of Element and Oxide Composition Data by INAA for Core Samples from Well UE5PW-1 (continued) 
These analyses further indicate that the samples from the pilot wells and the science trench boreholes have the same general composition as the source rock for the alluvium at the Area 5 RWMS, that is primarily Tertiary volcanic rocks (Ammonia Tanks Tuff) from the Massachusetts Mountain area. These results are consistent with visual lithologic descriptions presented in Section 3.1.2. The Tertiary volcanic rocks, and thus the alluvium, have a rhyolitic composition of approximately 65 percent $\mathrm{SiO}_{2}$ and 13 percent $\mathrm{Al}_{2} \mathrm{O}_{3}$; all other major elements total less than 5 percent.

\subsubsection{Secondary Mineralogy and Organic Matter}

Depth profiles of inorganic carbon in alluvial drill cuttings samples for all three pilot wells are illustrated in Figure 3-3. Tabular values of inorganic and organic carbon measurements, as well as calculated values of total carbon for core and drill cuttings samples, are presented in Appendix E.2 for samples from the alluvium, and Appendix E.3 for tuff; descriptive statistics for these data are summarized in Tables 3-3 and 3-4, respectively.

The data show that inorganic carbon concentrations are very low (mean values are less than 1 percent by weight) and nearly constant throughout the entire thickness of alluvium penetrated. The only noticeable interval of elevated inorganic carbon is in Well UE5PW-2, from approximately 168 to $171 \mathrm{~m}$ (550 to $560 \mathrm{ft}$ ). Elevated levels of chloride, bromide, and sulfate were also measured in this thin interval, further indicating that this a layer of secondary mineral accumulation that could possibly be called a caliche layer. However, there was no visible evidence in the core or drill cuttings samples of secondary mineral accumulation at this or any other depth interval in the pilot wells. Finally, the consistency in depth profiles of inorganic carbon concentrations also suggests that the source rock for the entire thickness of alluvium penetrated contained remarkably similar percentages of carbonates. This in turn suggests that the alluvial deposits originated from the same source rock.

Organic carbon values are generally an order of magnitude lower and equally as constant, demonstrating the absence of humus accumulation. The absence of caliche and humus layers helps support the argument (which is expanded in the following sections of this report) that the hydrogeologic system can be treated as a homogenous alluvial unit. 


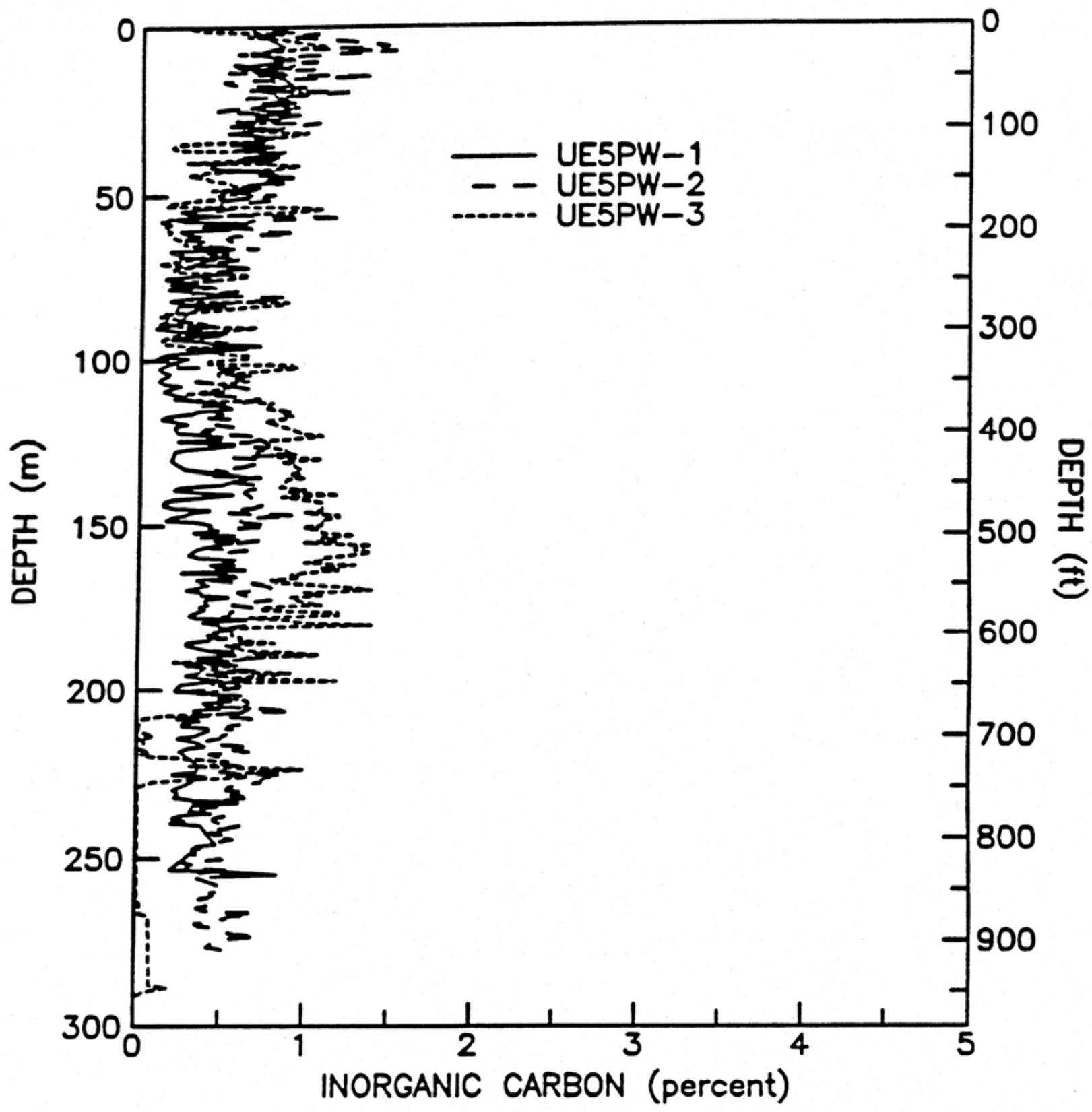

Figure 3-3

Depth Profiles of Inorganic Carbon for Drill Cuttings Samples from the Pilot Wells 


\subsection{Physical Properties}

Several physical properties are relatively easy and inexpensive to measure, and provide valuable insight into understanding the hydrogeologic system beneath the Area 5 RWMS. These physical properties include particle size distribution, bulk density, and porosity. Bulk density and porosity measurements are dependent on the arrangement and degree of packing of unconsolidated alluvial particles, and therefore were made only on intact core samples. Particle size distributions of alluvial samples are independent of arrangement or packing, and were determined on both intact core and drill cuttings samples. However, particle size distribution measurements are not appropriate for consolidated rock samples, and therefore were not conducted on tuff from Well UE5PW-3.

\subsubsection{Particle Size Distribution}

Particle size distribution analyses were conducted on all alluvial drill cuttings samples collected at 0.76-m (2.5-ft) intervals and on two 76.2-mm (3-in.) core segments from each core run (if available), using a dry sieve method. Previous analyses (REECo, 1993b) indicated only small differences between dry sieve and the much more expensive wet sieve methods on these relatively coarse-grained alluvial materials.

Because the sieve process destroys the physical integrity of the core samples, this test always followed a series of non-destructive physical and hydrologic tests on the same core sample. These precursor tests included saturated porosity, saturated hydraulic conductivity, and moisture retention measurements.

The results of particle size distribution analyses are presented in tabular form in Appendix E.2. Data from the Number (No.) 4 and No. 200 sieve screens (percent of material passing) for alluvial drill cuttings and core samples from Wells UE5PW-1, UE5PW-2, and UE5PW-3 are plotted verus depth in Figures 3-4, 3-5, and 3-6, respectively. These figures illustrate the relative percent of materials falling into the gravel, sand, and silt/clay fractions at each depth. They show that the particle size distribution of alluvial materials is remarkably similar with depth. These materials are composed predominantly of sand-size particles with considerable amounts 


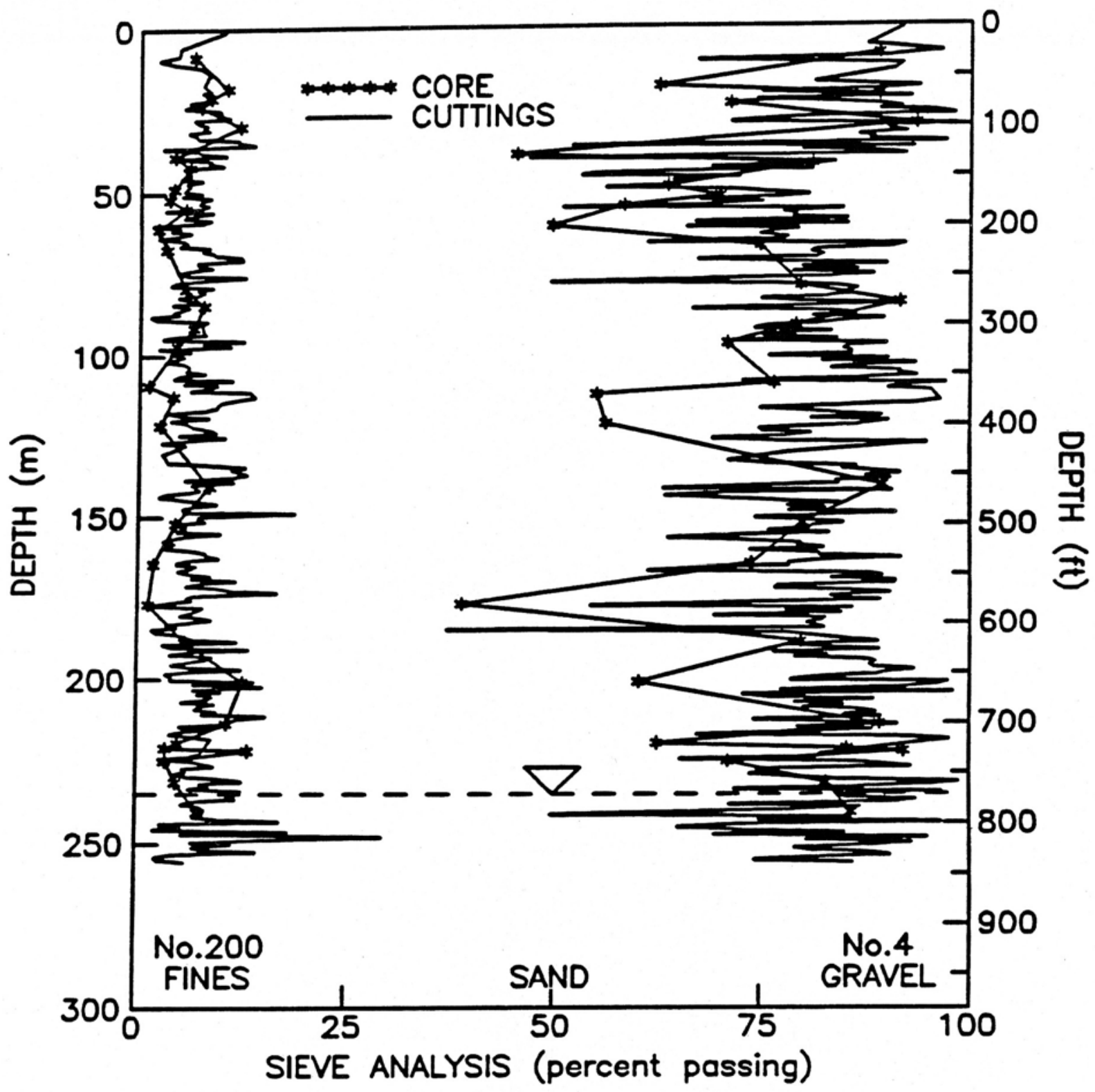

Figure 3-4

Depth Profiles of Dry Sieve Analyses for Core and Drill Cuttings Samples from Well UE5PW-1

(Percent Passing Number 4 and Number 200 Mesh Screens) 


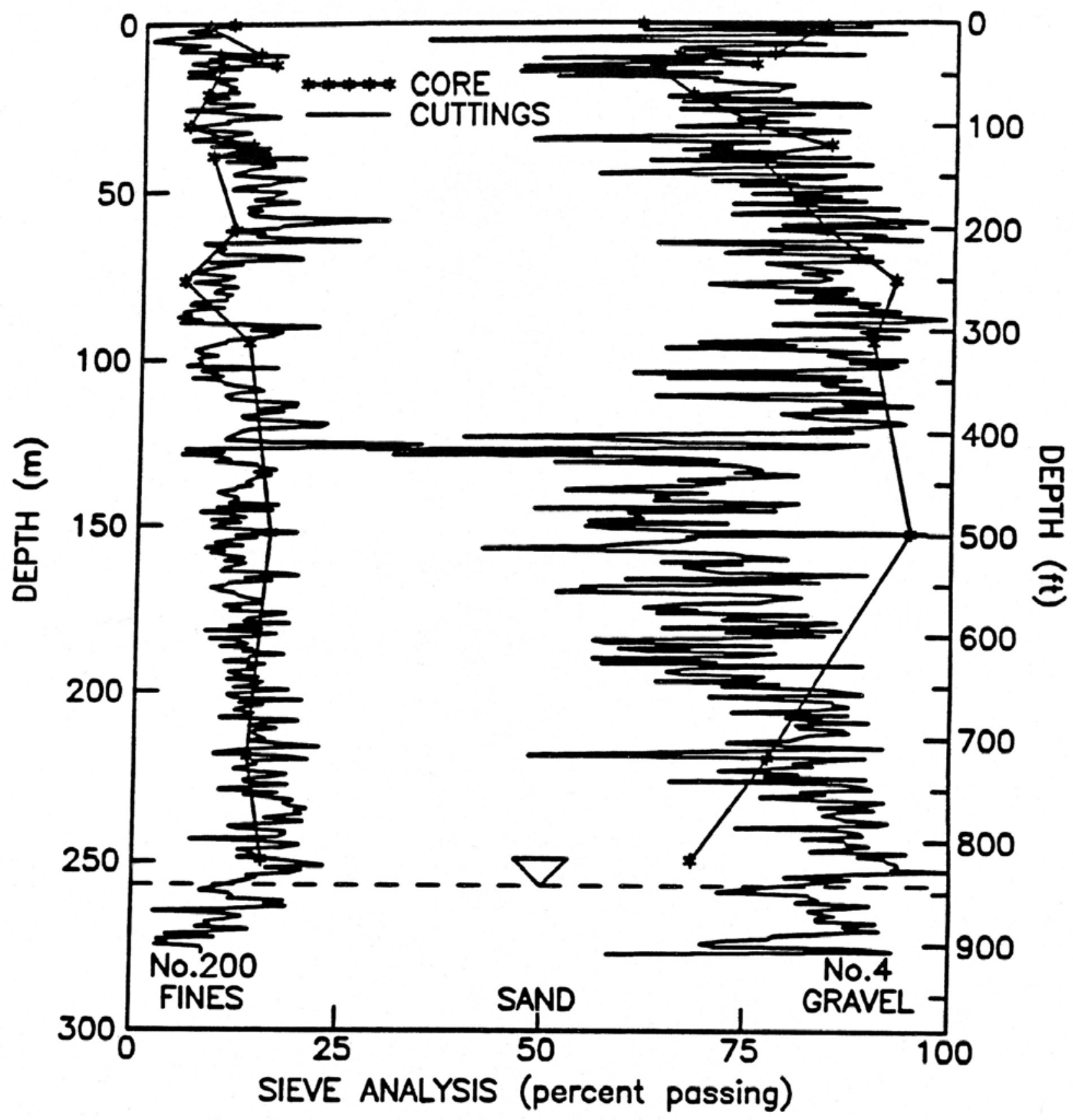

Figure 3-5

Depth Profiles of Dry Sieve Analyses for Core and Drill Cuttings Samples from Well UE5PW-2

(Percent Passing Number 4 and Number 200 Mesh Screens) 


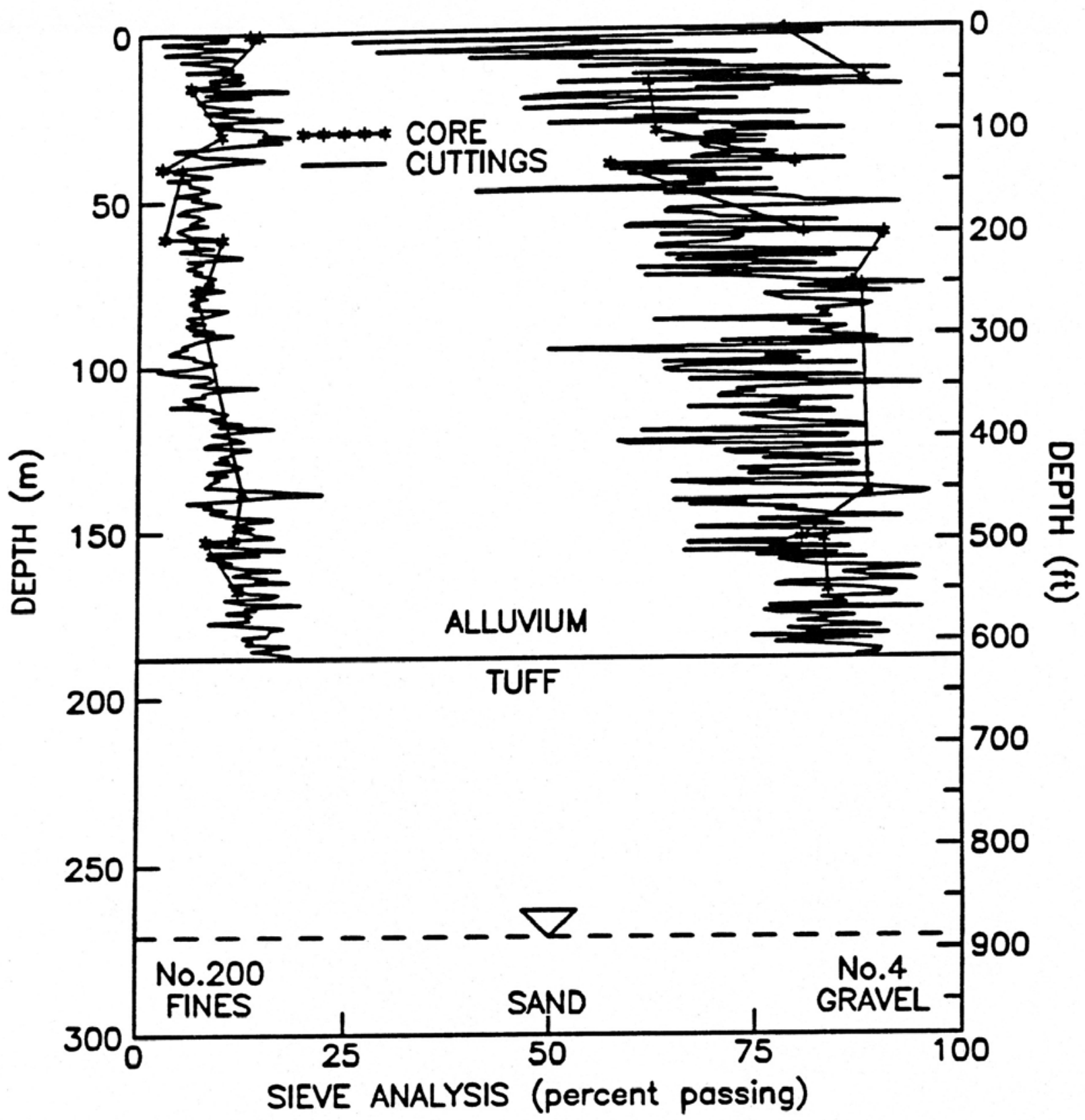

Figure 3-6

Depth Profiles of Dry Sieve Analyses for Core and Drill Cuttings Samples from Well UE5PW-3

(Percent Passing Number 4 and Number 200 Mesh Screens) 
of gravel, and typically contain less than 10 percent silt/clay. The small differences between profiles for core and drill cuttings may be due to a number of factors related to geology, drilling, or sampling. Apparently the different sample sizes (volumes) for core and drill cuttings is a factor.

Descriptive statistics for No. 4 and No. 200 sieve screen data for both core and drill cuttings from all three pilot wells are summarized in Table 3-3. These statistics were calculated separately for different sample types as well as for the combined pool of samples from each borehole (Table 2-6). Mean values of percent silt/clay material in Well UE5PW-2 appear to be significantly different from those for Wells UE5PW-1 and UE5PW-3. However, mean values of this size fraction are very similar within each borehole. Mean values of the gravel fraction (material held on the No. 4 screen) are very similar between holes for core samples but appear to significantly decrease from Well UE5PW-1 to Well UE5PW-3 for drill cuttings samples. This latter difference may be related to the ease and speed with which each borehole was drilled. The most drilling difficulty was encountered in Well UE5PW-1 and the least was encountered in Well UE5PW-3. This may suggest that air-percussion hammer drilling reduces the amount of gravel-size particle particles under different drilling conditions.

\subsubsection{Bulk Density and Porosity}

Dry bulk densities were determined on two 76.2-mm (3-in.) long core segments from each core run in alluvium and on 25.4- by 25.4-mm (1- by 1-in.) plug sub-samples from core in moderately welded tuff from Well UE5PW-3. These data are presented in tabular form in Appendix E.2. Plots of alluvial bulk densities versus depth are presented in Figure 3-7. There appear to be no consistent trends in bulk density with depth in the pilot wells. This may be due in part to the similarity of the particle size distribution (Section 3.2.1), consistency in lithology and mineralogy (Sections 3.1.2 and 3.1.3), and the near absence of secondary mineral cementing agents (Section 3.1.4).

Alluvial core porosities were calculated from dry bulk densities and using a particle density of approximately 2.65 grams per cubic centimeter $\left(\mathrm{g} / \mathrm{cm}^{3}\right)\left(165\right.$ pounds per cubic foot $\left.\left[\mathrm{lb} / \mathrm{ft}^{3}\right]\right)$. In addition, water-saturated porosities were measured on alluvial core segments from all pilot wells following measurement of saturated hydraulic conductivity on the same core segment (Section 3.3.1). Both calculated and water-saturated porosities of samples from Wells UE5PW-1, UE5PW-2, and UE5PW-3 are plotted versus depth on Figures 3-8, 3-9, and 3-10, respectively. Water-saturated porosities are considerably lower than calculated porosities. 


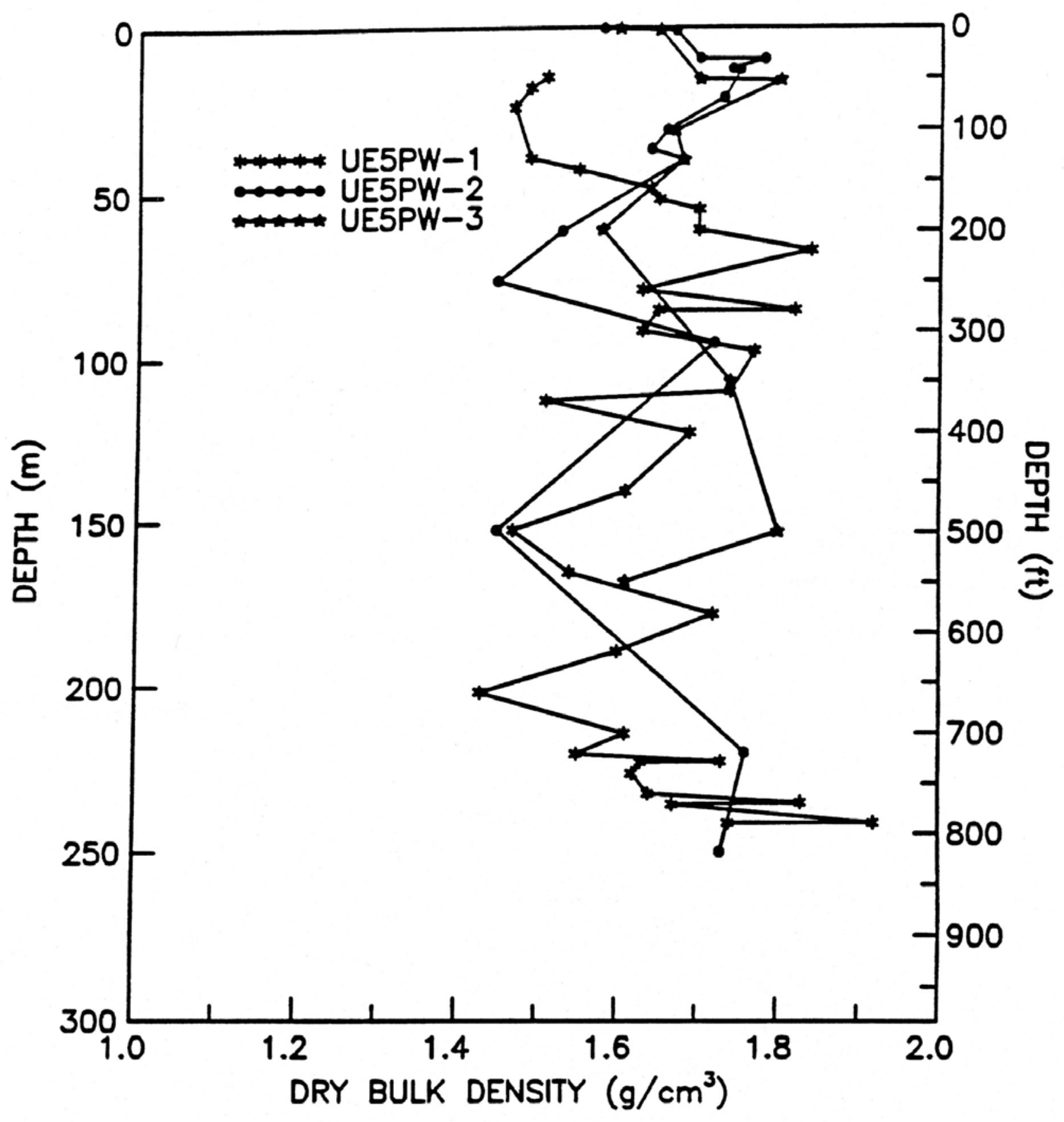

Figure 3-7

Depth Profiles of Dry Bulk Density for Core Samples from the Pilot Wells 


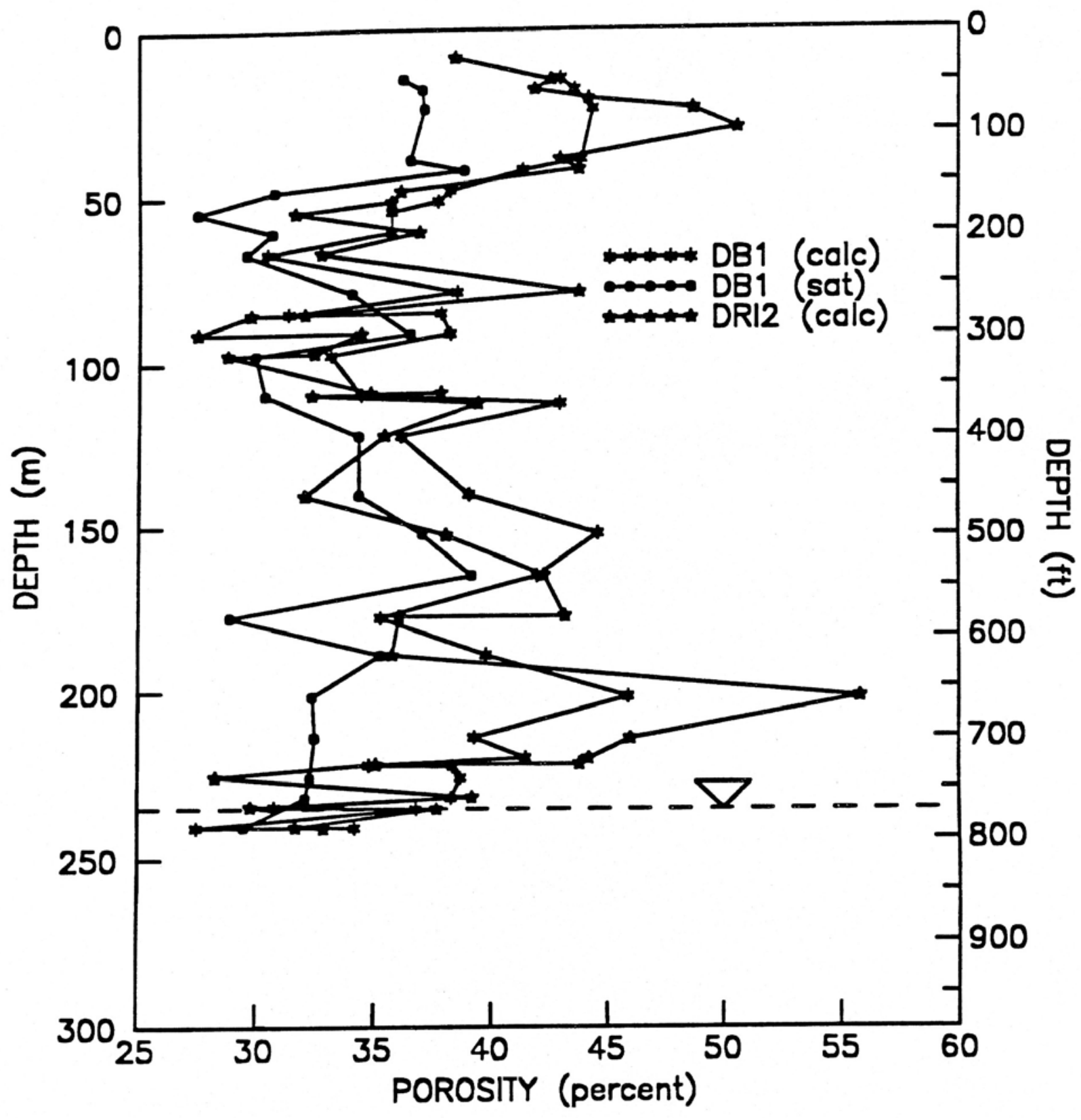

Figure 3-8

Depth Profiles of Calculated (calc) and Water Saturated (sat) Porosity for Core Samples from Well UE5PW-1 


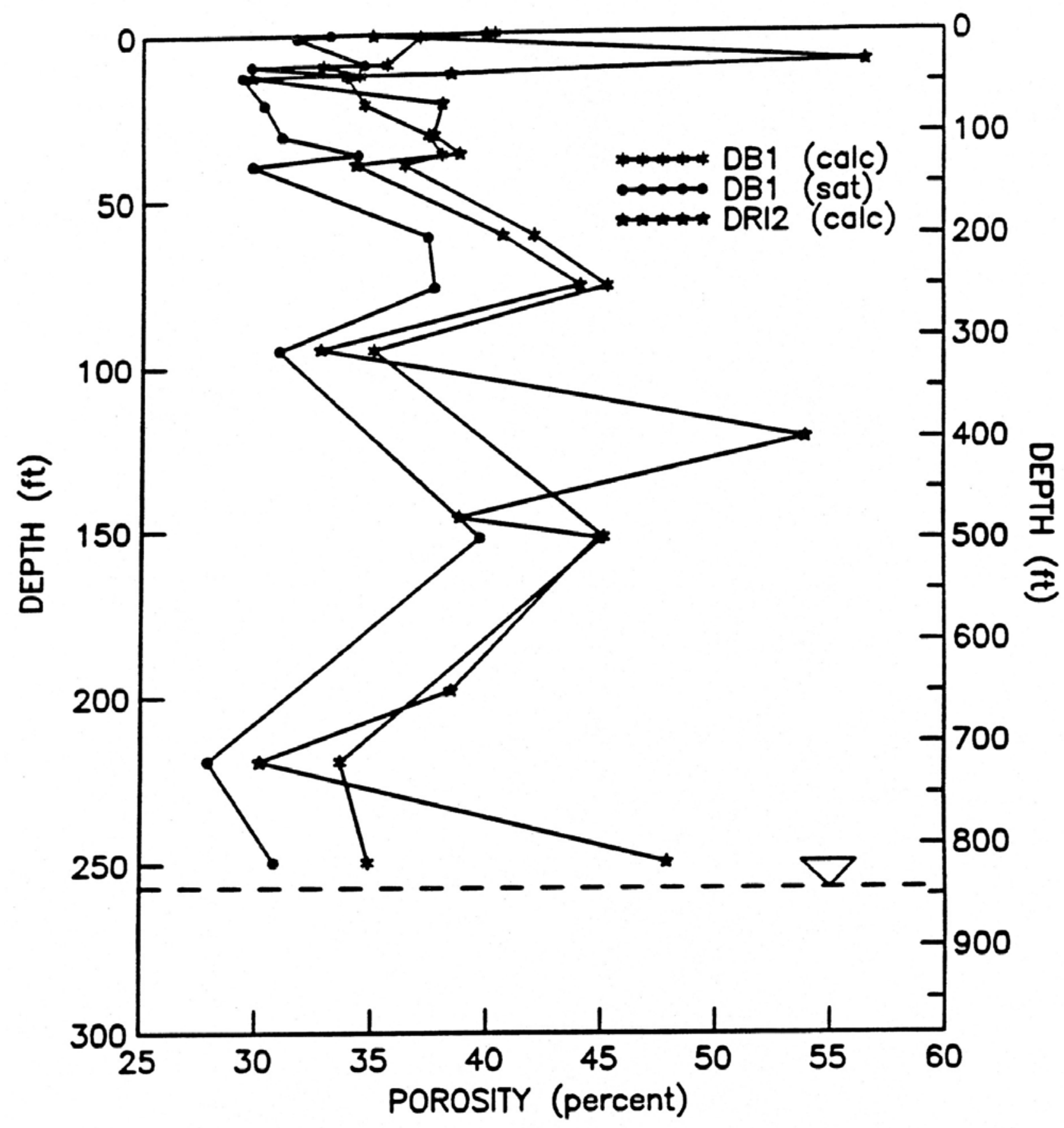

Figure 3-9

Depth Profiles of Calculated (calc) and Water Saturated (sat) Porosity for Core Samples from Well UE5PW-2 


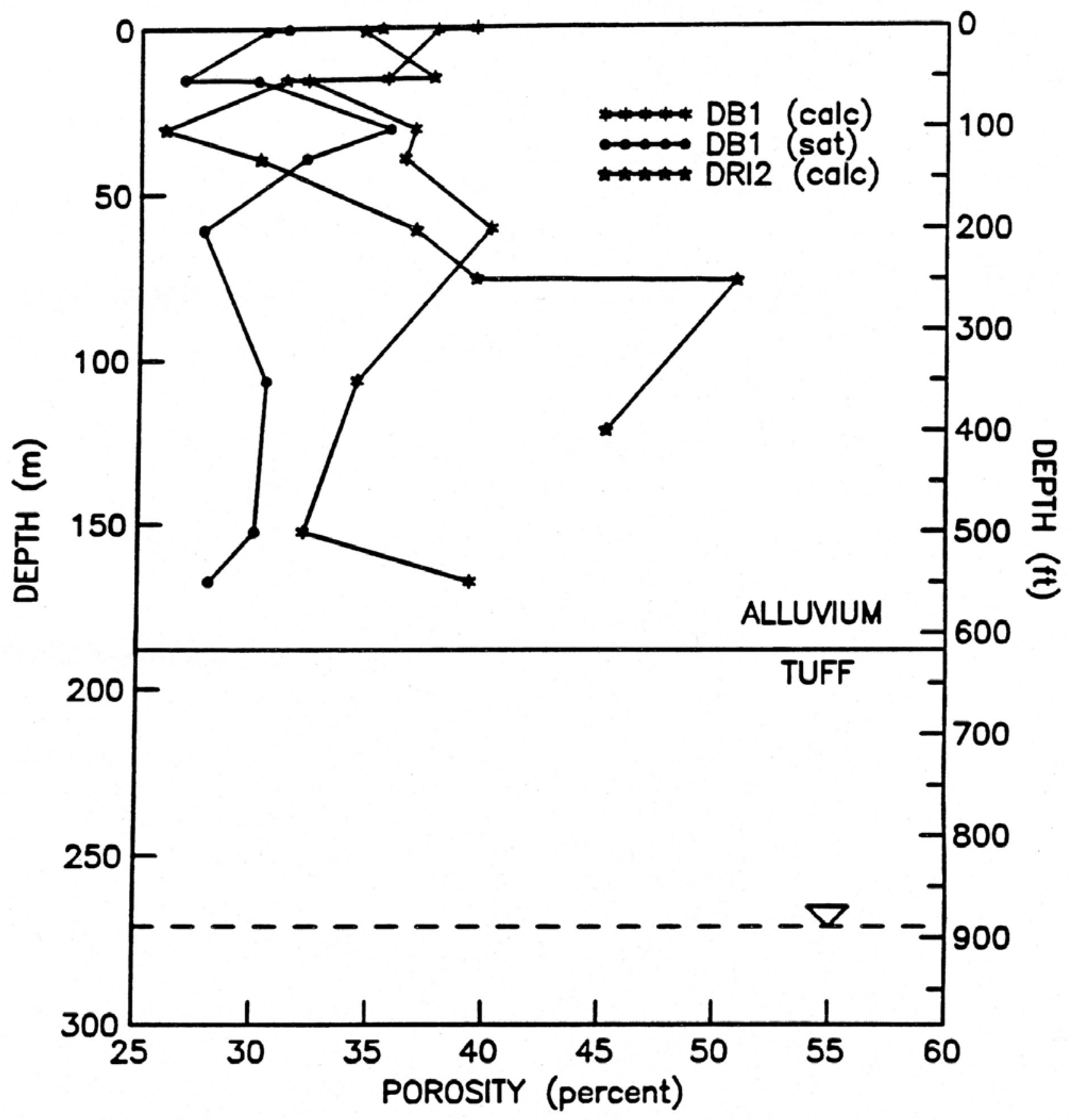

Figure 3-10

Depth Profiles of Calculated (calc) and Water Saturated (sat) Porosity for Core Samples from Well UE5PW-3 
Discussions with the testing laboratory indicated that the water-saturated porosity values are in error resulting from unavoidable water loss (drainage) that occurs from the coarse-grained samples just prior to the measurement.

Descriptive statistics for dry bulk densities and porosities of alluvium samples are summarized in Table 3-3. Mean values and coefficients of variation of dry bulk densities and calculated porosities (by definition) for each pilot well are nearly identical. Dry bulk densities range from 1.17 to $1.96 \mathrm{~g} / \mathrm{cm}^{3}$ ( 73 to $122 \mathrm{lb} / \mathrm{ft}^{3}$ ). Bulk densities near both the lower and higher ends of the range may reflect sampling disturbance rather than in-situ conditions.

The mean bulk density and calculated porosity of three partially welded tuff core samples are $1.99 \mathrm{~g} / \mathrm{cm}^{3}\left(124 \mathrm{lb} / \mathrm{ft}^{3}\right)$ and 22.40 percent, respectively (Table 3-4). These values fall into the range of values found for the same parameters on other partially welded tuff core samples from the NTS (Fernald et al., 1965).

\subsection{Hydrologic Properties}

Hydrologic properties are required, together with information about hydrologic conditions, to estimate rates of water movement and potential travel times. Hydrologic property measurements include saturated hydraulic conductivities and moisture retention curves. Unsaturated hydraulic conductivities were calculated from the above-mentioned parameters in this study, as they are very difficult, if not impossible, to measure in the laboratory at the very dry in-situ conditions (Section 3.4.1) found in the vadose zone beneath the Area 5 RWMS.

\subsubsection{Saturated Hydraulic Conductivity}

Saturated hydraulic conductivity measurements, like measurements of dry bulk density, were conducted on one 76.2-mm (3-in.) long core segment from each alluvial core run in each pilot well, and on 25.4- by 25.4-mm (1- by 1-in.) plug sub-samples from tuff from Well UE5PW-3. Saturated hydraulic conductivity profiles for the three pilot wells are presented in Figure 3-11 and tabular data are listed in Appendix E.2. Descriptive statistics are summarized in Table 3-3 (possible outliers were retained in computation of the descriptive statistics). These data show that hydraulic conductivities range from $1.4 \times 10^{-6}$ to $5.8 \times 10^{-3} \mathrm{~cm} / \mathrm{s}$ (centimeters per second) (0.002 to 8.2 inches per hour [in./hr]) for all the pilot wells. Mean values for each well range from $5.7 \times 10^{-4}$ to $1.1 \times 10^{-3} \mathrm{~cm} / \mathrm{s}(0.81$ to $1.6 \mathrm{in} . / \mathrm{hr})$. There are no obvious trends as a function of depth, and these values are typical of silty sand alluvial deposits (Freeze and Cherry, 1979.) 


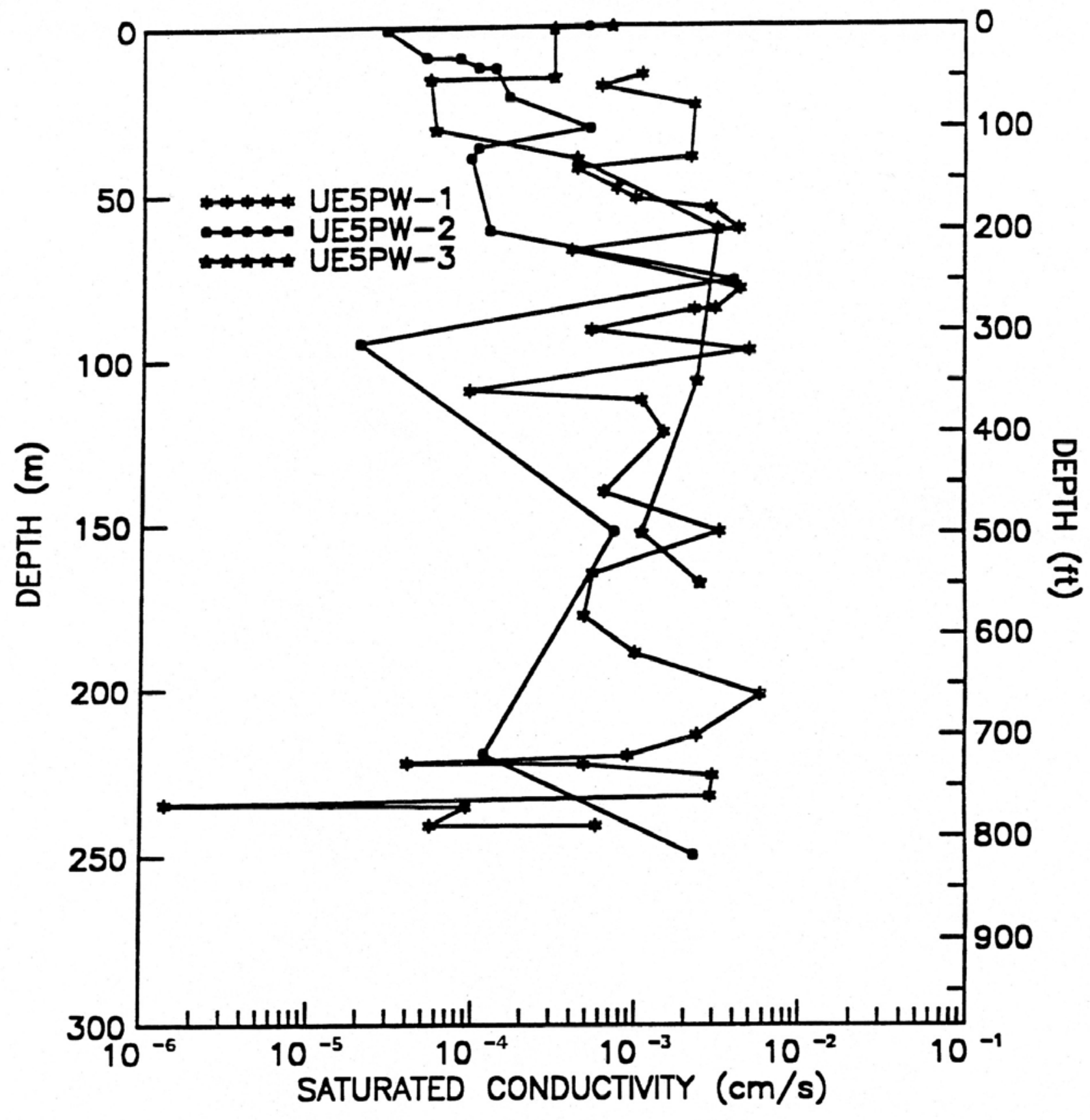

Figure 3-11

Depth Profiles of Saturated Hydraulic Conductivity for Core Samples from the Pilot Wells 
Statistical analyses have indicated that hydraulic conductivity might be lognormally distributed. A case could be made for presenting the geometric means and standard deviations, rather than arithmetic means and standard deviations. Means and standard deviations were used to facilitate comparison with other values reported in the literature.

\subsubsection{Moisture Retention Relations}

Following saturated hydraulic conductivity measurements, core samples were subjected to moisture retention measurements. These measurements (curves) for Wells UE5PW-1, UE5PW-2, and UE5PW-3 are presented in graphical form in Figures 3-12, 3-13, and 3-14, respectively; tabular data are listed in Appendices E.2.7, E.2.8, and E.2.9. Core interval depths for each curve are not identified in these plots. The general shape of these moisture retention curves is, without exception, typical of coarse-grained deposits (Hillel, 1980).

Moisture retention data were fit to the van Genuchten $(1978,1980)$ parameterization of the water retention curve described by:

$$
\theta=\theta_{\mathrm{r}}+\left(\theta_{\mathrm{s}}-\theta_{\mathrm{r}}\right)\left[1+(-\alpha \mathrm{h})^{\mathrm{n}}\right]^{-\mathrm{m}}
$$

where $\theta$ is volumetric water content $\left(\mathrm{cm}^{3} / \mathrm{cm}^{3}\right), \theta_{\mathrm{s}}$ is the saturated volumetric water content, $\theta_{\mathrm{r}}$ is the residual volumetric water content, $\mathrm{h}$ is matric potential $(\mathrm{cm}), \alpha\left(\mathrm{cm}^{-1}\right)$ and $\mathrm{n}$ (dimensionless) are curve fitting parameters, and $\mathrm{m}$ is $1-1 / \mathrm{n}$ ).

A nonlinear least squares computer code is used to calculate the curve-fitting parameters $\alpha$ and n, and residual saturation, $\theta_{\mathrm{r}}$. These parameters are tabulated in Appendix E.2.10 for all pilot well core samples, and summary descriptive statistics are given in Table 3-6. There is some evidence that $\alpha$ is lognormally distributed, indicating that the geometric mean and standard deviation would be more appropriate data summaries than the arithmetic mean and standard deviation. The latter are presented to facilitate comparison with other values reported in the literature. Observed values of $\alpha$ are consistent with values calculated for a number of coarse-grained materials (van Genuchten, 1978). 


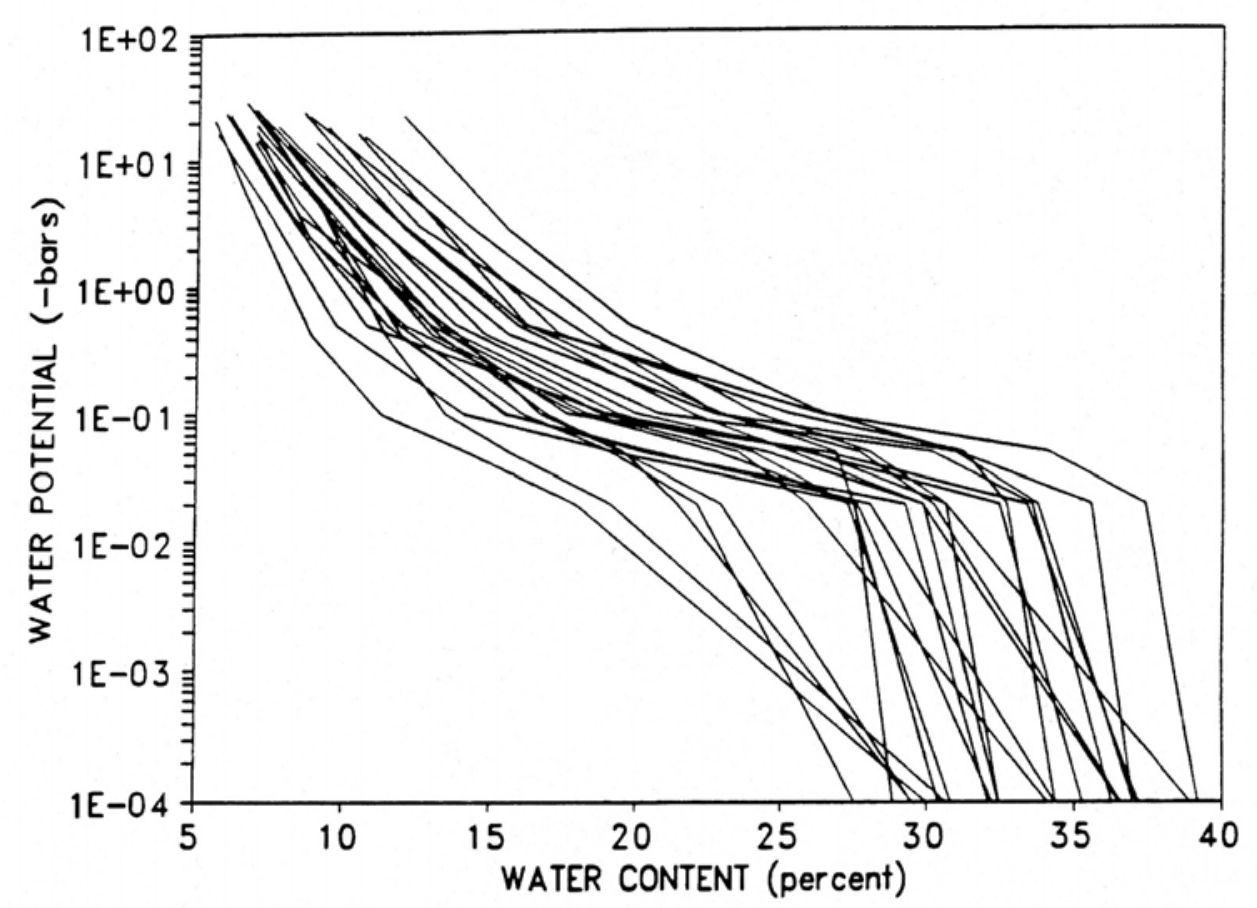

Figure 3-12

Composite Moisture Retention Data for Core Samples from Well UE5PW-1

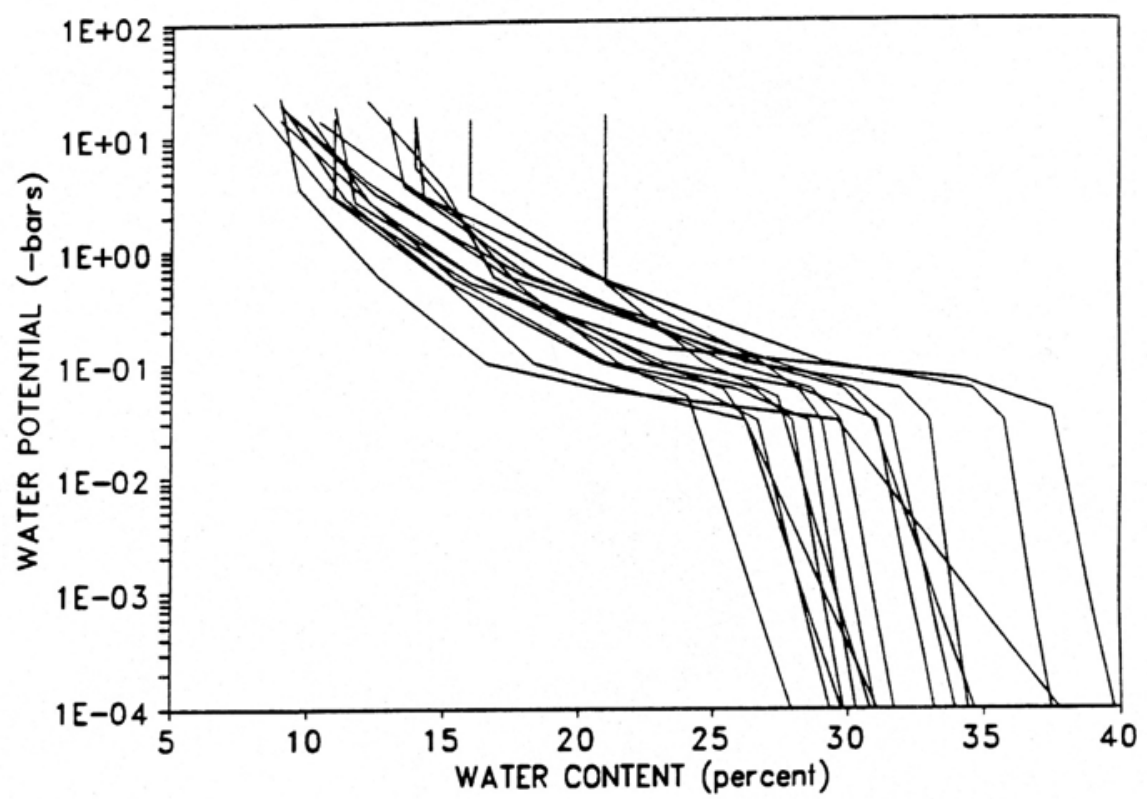

Figure 3-13

Composite Moisture Retention Data for Core Samples from Well UE5PW-2 


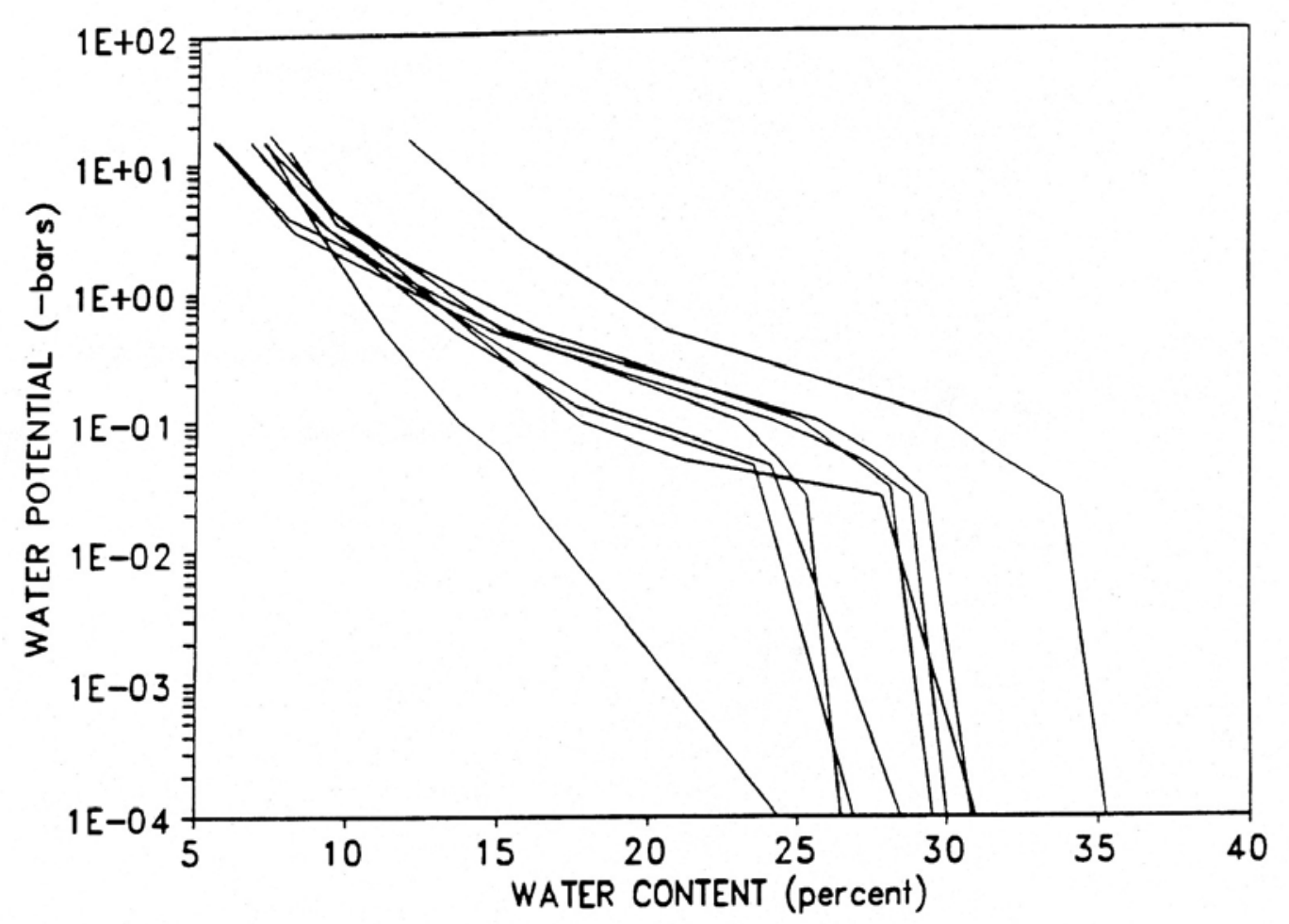

Figure 3-14

Composite Moisture Retention Data for Core Samples from Well UE5PW-3

\subsubsection{Unsaturated Hydraulic Conductivity}

Unsaturated hydraulic conductivity, $\mathrm{K}(\mathrm{S})$, of core samples is generally calculated from moisture retention data and saturated hydraulic conductivity, rather than being experimentally measured. This is primarily because experimental measurements, especially at low water content, are extremely difficult, if not impossible to obtain. The equation used to calculate $\mathrm{K}(\mathrm{S})$ in this program (van Genuchten, 1978, 1980) is derived by substituting the van Genuchten moisture retention curve-fitting parameters into the Mualem (1976) model of unsaturated hydraulic conductivity to obtain the following:

$$
K(S)-K_{s} S^{1 / 2}\left[1-\left(1-S^{1 / m}\right)^{m}\right]^{2}
$$

where $\mathrm{K}_{\mathrm{s}}$ is the saturated hydraulic conductivity, $\mathrm{m}$ is as in the van Genuchten water retention curve, and $\mathrm{S}$ is effective saturation as defined by:

$$
\mathrm{S}=\left(\theta-\theta_{\mathrm{r}}\right)\left(\theta_{\mathrm{s}}-\theta_{\mathrm{r}}\right)^{-1}
$$

The resulting $\mathrm{K}(\mathrm{S})$ data, which have been converted to $\mathrm{K}(\theta)$ through Equation 2, are illustrated for Wells UE5PW-1, UE5PW-2, and UE5PW-3 in Figures 3-15, 3-16, and 3-17, respectively. 
The resulting $\mathrm{K}(\mathrm{S})$ data, which have been converted to $\mathrm{K}(\theta)$ through Equation 2, are illustrated for Wells UE5PW-1, UE5PW-2, and UE5PW-3 in Figures 3-15, 3-16, and 3-17, respectively.

These plots illustrate that unsaturated hydraulic conductivity decreases rapidly with decreasing water content. At these low in-situ formation water contents (Section 3.4.1) the unsaturated hydraulic conductivities are many orders of magnitude less than saturated hydraulic conductivities.

Table 3-6

Summary of Descriptive Statistics of Moisture Retention Curves
for Core Samples from the Pilot Wells

\begin{tabular}{|c|c|c|c|c|c|}
\hline Borehole & Statistic & $\begin{array}{c}\theta_{\mathrm{r}} \\
\left(\mathrm{cm}^{3} / \mathrm{cm}^{3}\right) \\
\end{array}$ & $\begin{array}{c}\theta_{\mathrm{s}} \\
\left(\mathrm{cm}^{3} / \mathrm{cm}^{3}\right)\end{array}$ & $\begin{array}{c}\alpha \\
\mathrm{cm}^{-1}\end{array}$ & $n$ \\
\hline \multirow{5}{*}{$\begin{array}{l}\text { UE5PW-1 } \\
\qquad(\mathrm{s}=24)\end{array}$} & Minimum & 0.0 & 0.275 & 0.010 & 1.16 \\
\hline & Maximum & 0.108 & 0.392 & 0.037 & 1.82 \\
\hline & Mean & 0.061 & 0.335 & 0.090 & 1.49 \\
\hline & $\begin{array}{l}\text { Standard } \\
\text { Deviation }\end{array}$ & 0.030 & 0.034 & 0.100 & 0.22 \\
\hline & CV (percent) & 49.8 & 10.1 & 114.5 & 14.6 \\
\hline \multirow{5}{*}{$\begin{array}{l}\text { UE5PW-2 } \\
(\mathrm{s}=16)\end{array}$} & Minimum & 0.00 & 0.279 & 0.010 & 1.16 \\
\hline & Maximum & 0.105 & 0.398 & 0.060 & 1.97 \\
\hline & Mean & 0.052 & 0.327 & 0.020 & 1.39 \\
\hline & $\begin{array}{l}\text { Standard } \\
\text { Deviation }\end{array}$ & 0.031 & 0.034 & 0.010 & 0.20 \\
\hline & CV (percent) & 59.8 & 10.4 & 52.0 & 14.6 \\
\hline \multirow{5}{*}{$\begin{array}{l}\text { UE5PW-3 } \\
\qquad(\mathrm{s}=9)\end{array}$} & Minimum & 0.017 & 0.269 & 0.010 & 1.14 \\
\hline & Maximum & 0.086 & 0.359 & 2.31 & 1.48 \\
\hline & Mean & 0.045 & 0.303 & 0.028 & 1.38 \\
\hline & $\begin{array}{l}\text { Standard } \\
\text { Deviation }\end{array}$ & 0.022 & 0.027 & 0.76 & 0.11 \\
\hline & CV (percent) & 48.7 & 9.0 & 276.9 & 7.8 \\
\hline
\end{tabular}

\section{NOTES}

$\theta=$ volumetric water content

$\theta_{\mathrm{s}}=$ saturated water content

$\mathrm{n}$ = curve fitting parameter

$\theta_{r}=$ residual volumetric water content

$\mathrm{s}=$ the number of samples

$\mathrm{CV}=$ coefficient of variation 


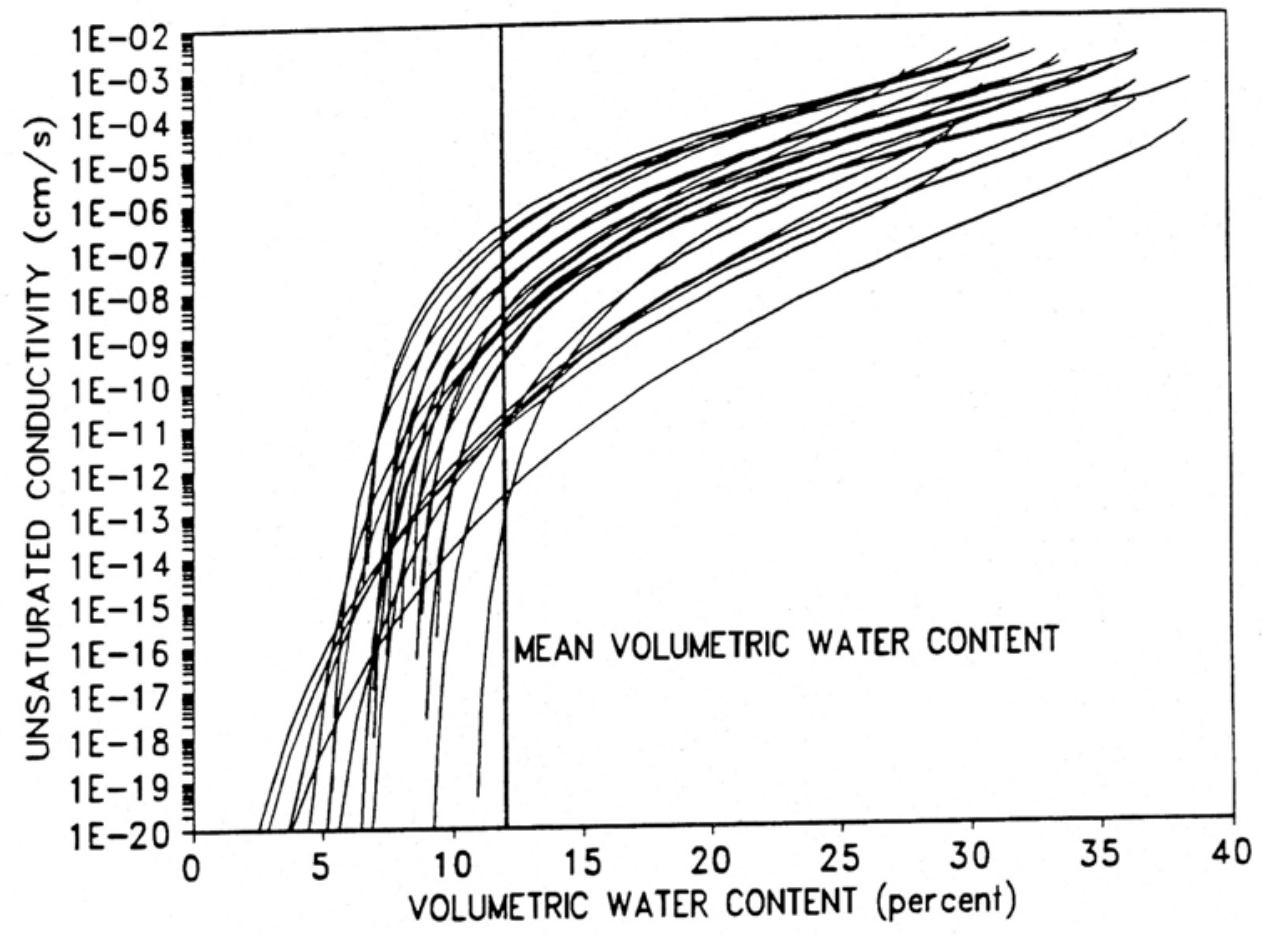

Figure 3-15

Fitted Unsaturated Hydraulic Conductivity Functions for Core Samples from Well UE5PW-1

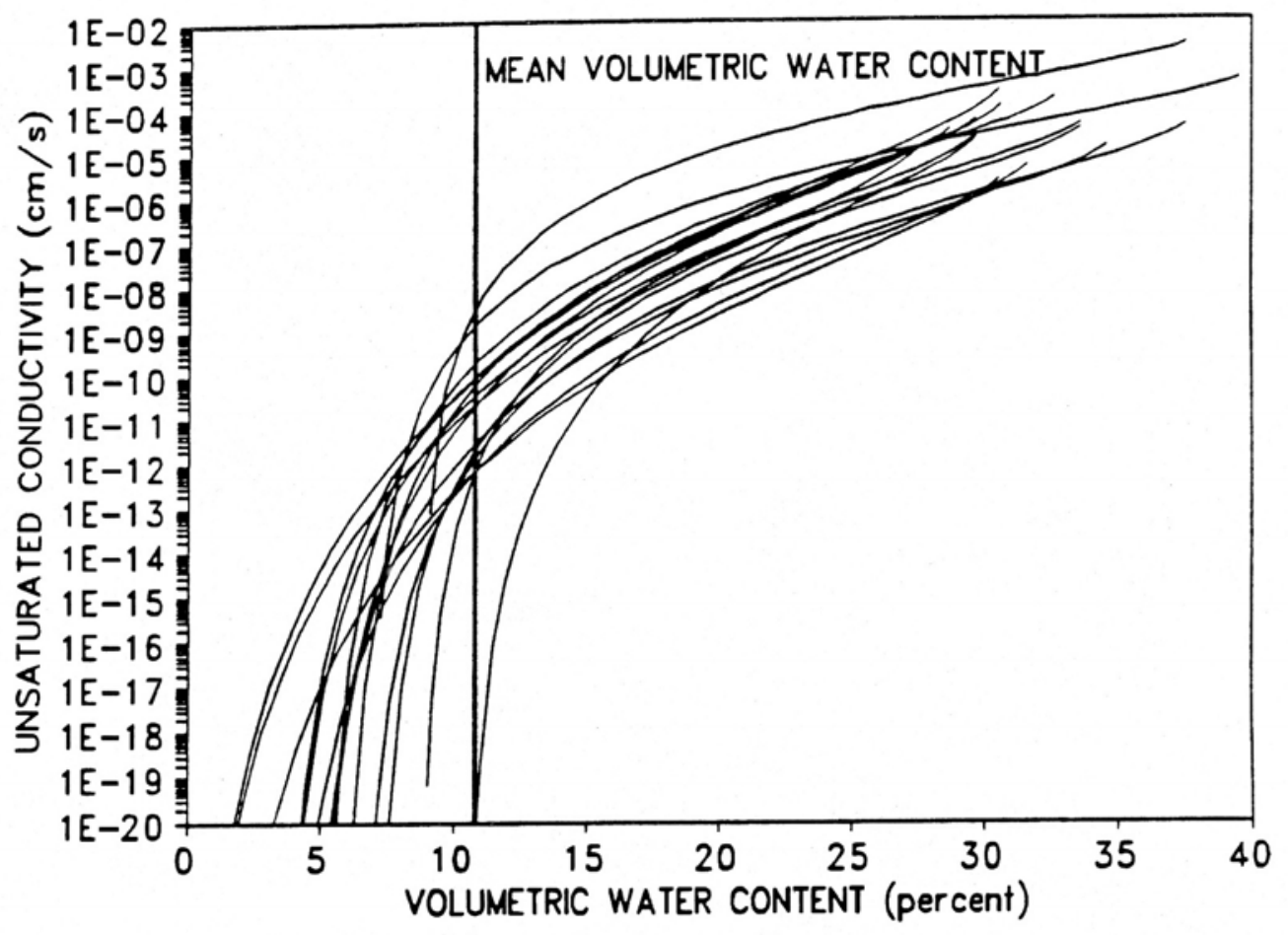

Figure 3-16

Fitted Unsaturated Hydraulic Conductivity Functions for Core Samples from Well UE5PW-2 


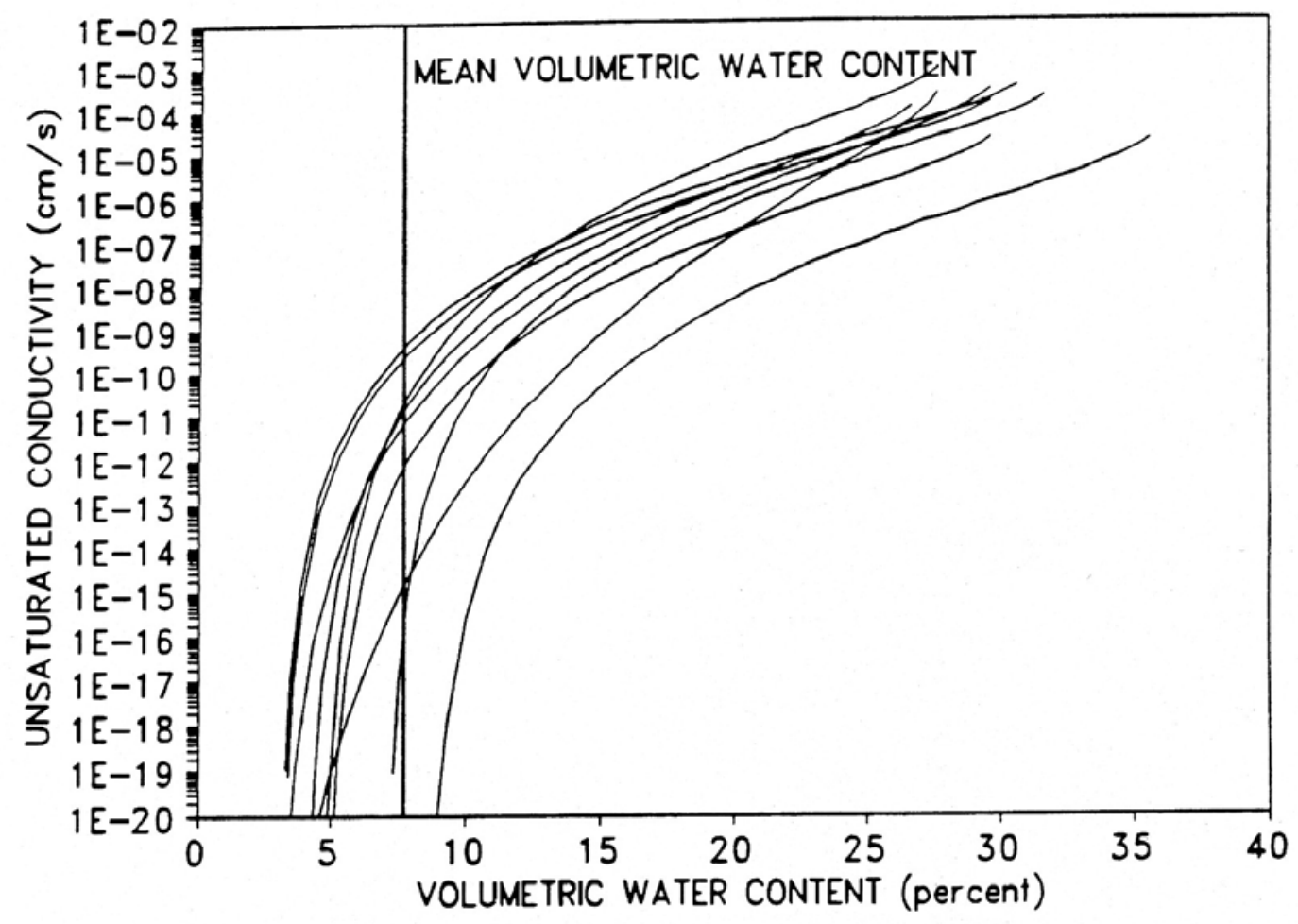

Figure 3-17

Fitted Unsaturated Hydraulic Conductivity Functions for Core Samples from Well UE5PW-3

\subsection{Hydrologic Conditions}

Hydrologic conditions are parameters that vary over time. These include water content and water potential, where the latter is dependent on the former. The gradient of water potential values (i.e, the difference in value between two points divided by the distance separating these points) is one of the primary forces that drive the movement of liquid water.

\subsubsection{Water Content}

Water content on a weight basis (gravimetric water content) was determined for both drill cuttings and core samples. Water content on a volume basis (volumetric water content) was determined only for core samples. These data are summarized in tabular form in Appendix E.2, and descriptive statistics are presented in Tables 3-3 and 3-4 for alluvium and tuff, respectively. Gravimetric water content for both core and drill cuttings samples from the alluvium are plotted versus depth for Wells UE5PW-1, UE5PW-2, and UE5PW-3 in Figures 3-18, 3-19, and 3-20, respectively. 


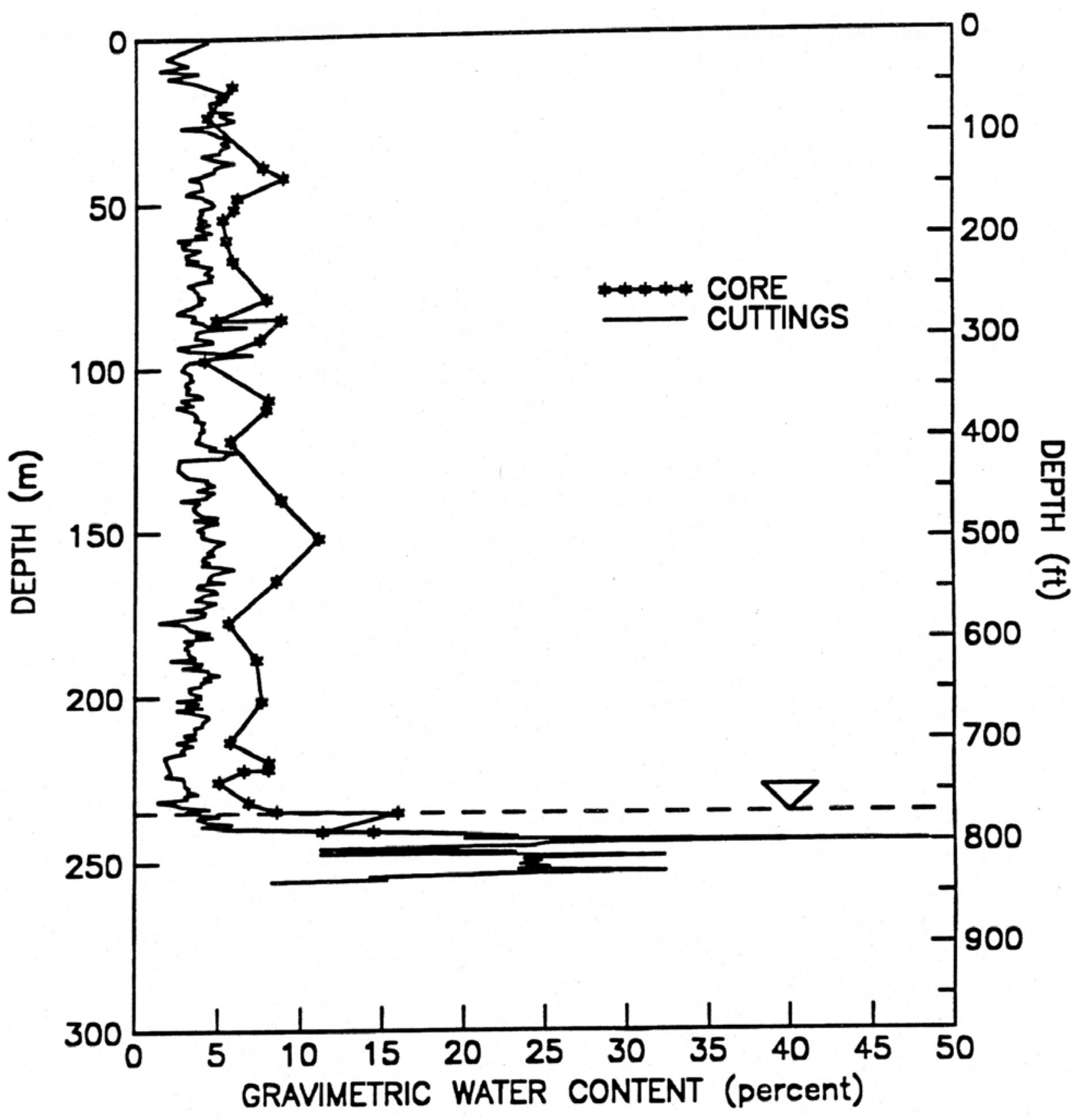

Figure 3-18

Depth Profiles of Gravimetric Water Content for Core and Drill Cuttings Samples From Well UE5PW-1 


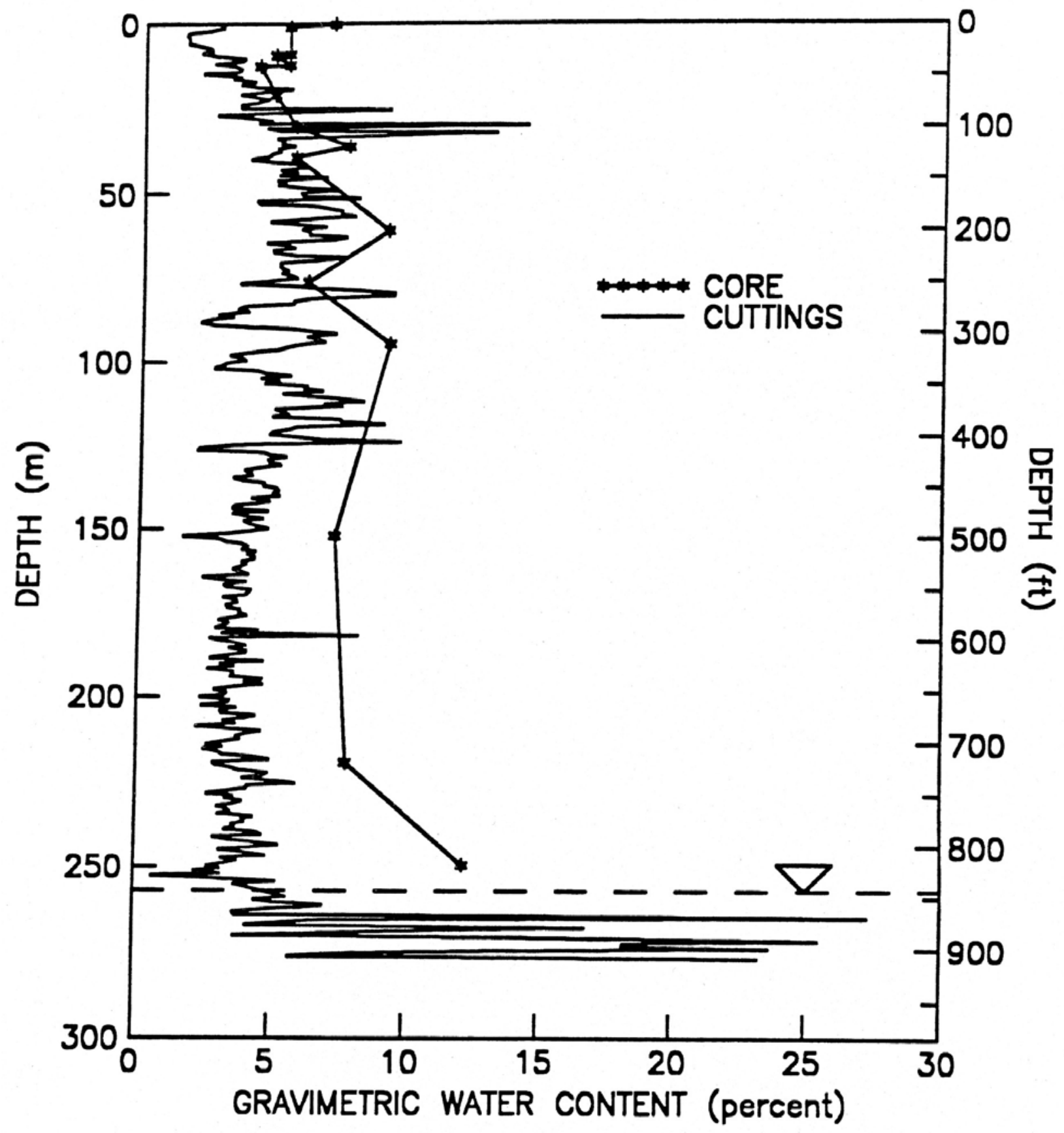

Figure 3-19

Depth Profiles of Gravimetric Water Content for Core and Drill Cuttings Samples From Well UE5PW-2 


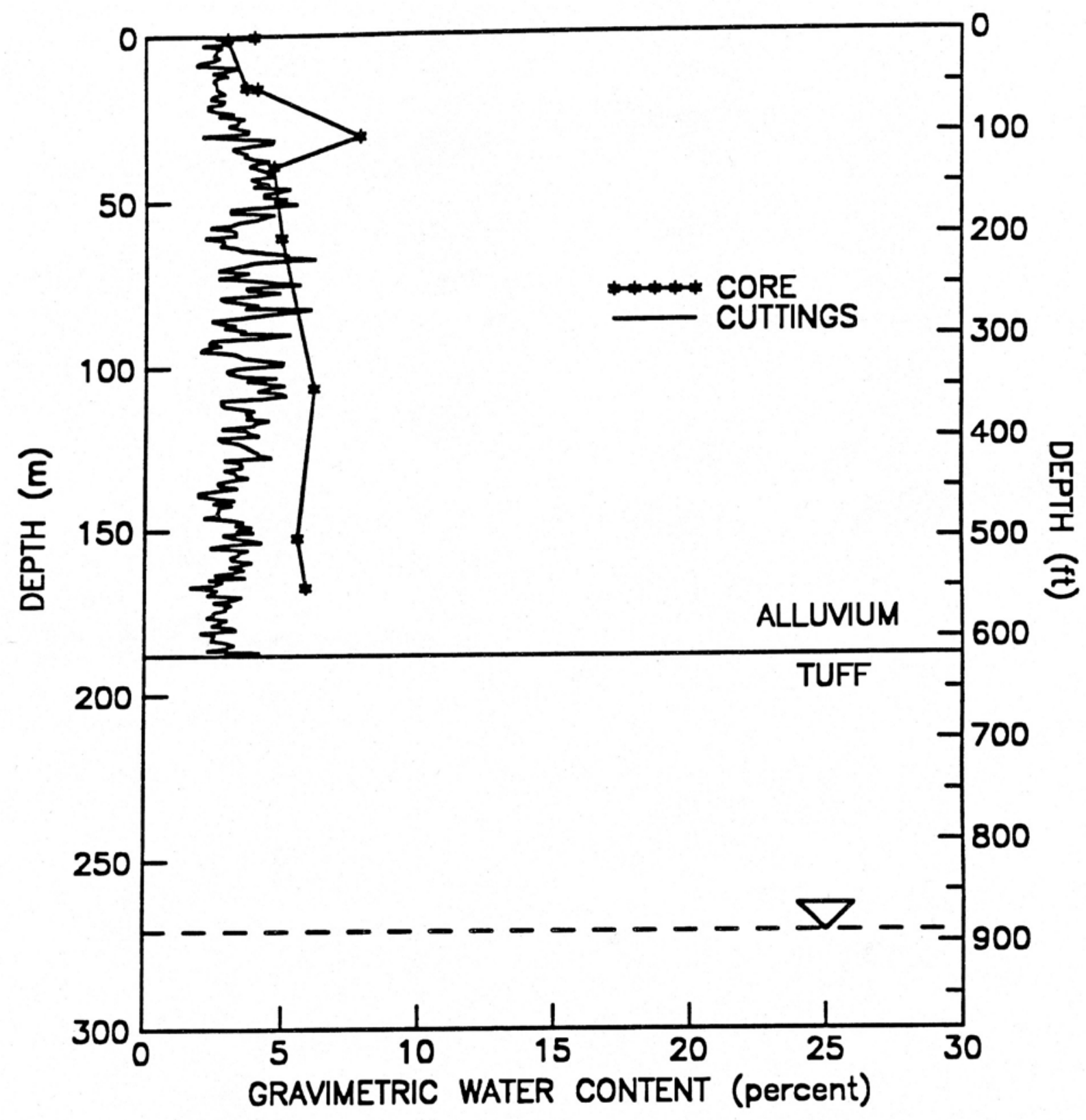

Figure 3-20

Depth Profiles of Gravimetric Water Content for Core and Drill Cuttings Samples From Well UE5PW-3 
The mean gravimetric water content of alluvial drill cuttings samples was generally several percent lower than the gravimetric water content of core samples. This is because the drill cuttings samples were subjected to drying by the air drilling fluid as they were lifted out of the borehole. The limited data available for comparing tuff core and drill cuttings samples suggest that this drying occurs even more when drilling the tuff formation. Less drying occurred with the coarse cuttings fragments than with the mixture of fine and coarse fragments that came directly out of the collection separator. The smaller surface area-to-volume ratio of coarse fragments is expected to be responsible for these effects. Moreover, based on only three core samples from one core run, the water content of the tuff is higher than that of the overlying alluvial core samples. However, these differences in water content are consistent with neutron geophysical logs described in Section 4.3.2.

A comparison of the alluvial volumetric water content profiles from all three pilot wells (Figure 3-21) illustrates that water content values are remarkably low and constant throughout the entire zone of the unsaturated alluvium. The only noticeable trend is a possible slight increase in water content from the ground surface to a depth of approximately $40 \mathrm{~m}(130 \mathrm{ft})$. The constancy in water content suggests that little, if any, water is presently draining from the system. Both the unsaturated hydraulic conductivity data discussed previously (Section 3.3.3) and the water potential data discussed in the next section support this picture of the system.

\subsubsection{Water Potential}

Depth profiles of water potential data from geologic samples are summarized in tabular form in Appendix E.2, and descriptive statistics are given in Tables 3-3 and 3-4. Water potential measurements were made on nearly every alluvial core sample, on two tuff core samples from Well UE5PW-3, and on coarse drill cuttings fragments of tuff to supplement data from tuff core samples. Coarse drill cuttings were separated from composite drill cuttings obtained from the cyclone separator by sieving on a No. 4 mesh screen. It was thought that the smaller surface area-to-volume ratio of these coarse drill cuttings, compared to a composite sample of drill cuttings, would make them less susceptible to disturbance (e.g., drying) by the air drilling fluid.

It was expected that in-situ water potentials would be nearly equal in the alluvial and underlying tuff formations penetrated in Well UE5PW-3, assuming quasi-steady-state conditions exist, as suggested in Section 3.4.1. This is true for alluvium and tuff core samples, however, the water potentials of coarse tuff fragments (sieved drill cuttings) were generally more than an order of magnitude less than alluvium core values. This suggests that measured water potentials for drill 


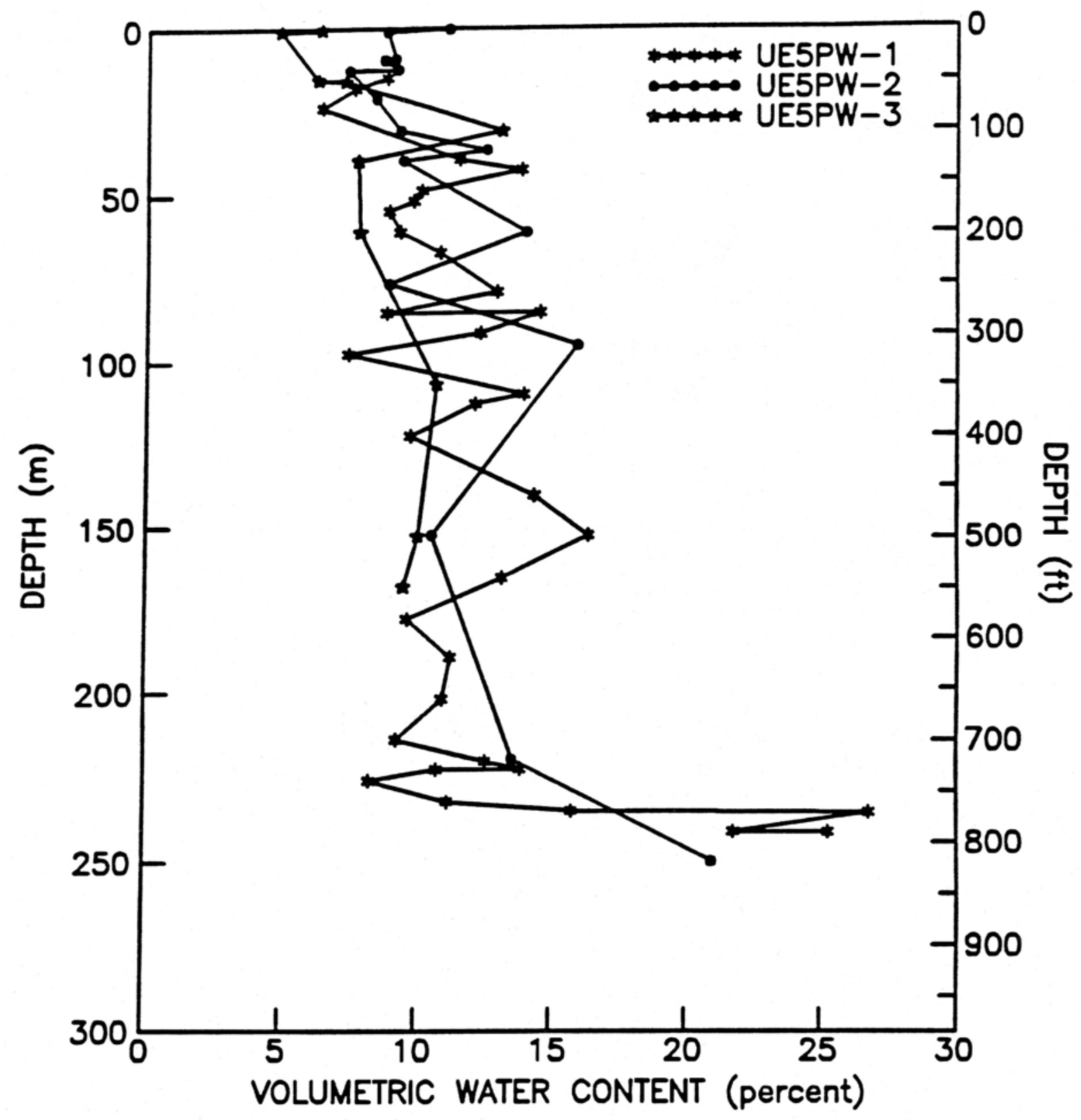

Figure 3-21

Depth Profiles of Volumetric Water Content for Core Samples from the Pilot Wells 
cuttings samples from the tuff were not representative of in-situ conditions. Because of the highly non-linear relationship between water potential and water content (Figures 3-12, 3-13, and 3-14), a small decrease in water content of coarse tuff drill cuttings resulting from the drying effects of the air drilling fluids could easily be responsible for the large order-of-magnitude decreases in water potential.

Water potential depth profile data (Figure 3-22; distance is positive downward), show a positive gradient (upward flow) to at least a depth of $30.5 \mathrm{~m}(100 \mathrm{ft})$ in each borehole. These data, coupled with unsaturated hydraulic conductivity data, indicate that liquid water is probably moving upward very slowly in this region. The water potential gradient is the principal driving force moving liquid water, because other potential gradients affecting water movement are small compared to the water potential gradient. For example, the water potential gradient near the ground surface is very large, the osmotic component of this potential has a value near zero (based on dissolved salt data), and the gravitational potential gradient is equal to unity (1.0) by definition. The hydraulic potential gradient, which is the total driving force, can be defined as the gravitational potential gradient plus the water potential gradient minus the osmotic potential gradient.

Environmental tracer data from the pilot wells suggest that the upward movement of liquid water, indicated by water potential measurements, results from evaporation, at least in the upper $30.5 \mathrm{~m}(100 \mathrm{ft})$. These data are presented in Section 3.5.

At greater depths the water potential gradient appears to be nearly zero. This is illustrated in

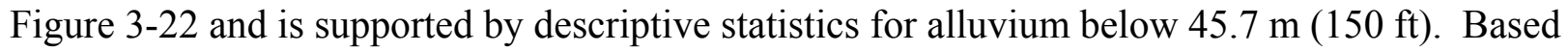
on these data and on unsaturated hydraulic conductivity data, it is possible to make an order-of-magnitude calculation of the rate of liquid water movement. The nearly zero water potential gradient at depth implies that the unit gravitational gradient is the main driver of liquid water movement and is equal to the hydraulic gradient. It follows then (from Darcy's law and assuming one-dimensional flow) that the flux of water is equal to the unsaturated hydraulic conductivity at the water content of interest. On Figure 3-15, for example, at the mean water content of 11.2 percent in Well UE5PW-1, the unsaturated hydraulic conductivity (also water flux) is in all cases less than $1 \times 10^{-7} \mathrm{~cm} / \mathrm{s}\left(1 \times 10^{-4} \mathrm{in} . / \mathrm{hr}\right)$. For the median unsaturated hydraulic conductivity curve it is approximately $1 \times 10^{-9} \mathrm{~cm} / \mathrm{s}\left(1 \times 10^{-6} \mathrm{in} . / \mathrm{hr}\right)$. Assuming a water-filled porosity of 10 percent, this average flux value is equivalent to a travel velocity of approximately 


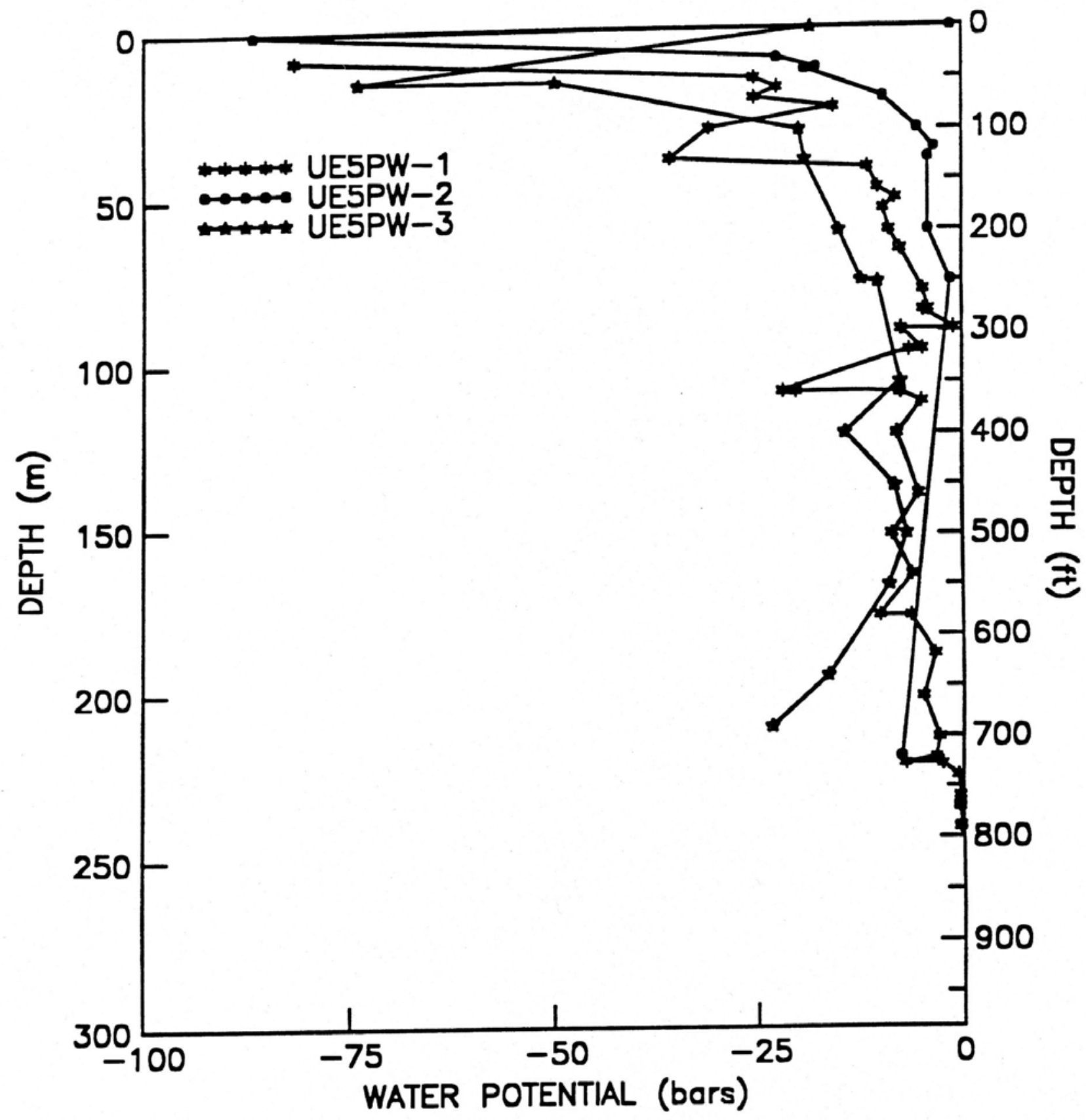

Figure 3-22

Depth Profiles of Water Potential for Core Samples from the Pilot Wells 
$3 \times 10^{-3}$ meters per year $\left(1 \times 10^{-2}\right.$ feet per year $)$. In other words, on the average it would take 1,000 years for water to travel $3 \mathrm{~m}(10 \mathrm{ft})$.

These calculations suggest that liquid water flow is not very important beneath the Area 5 RWMS, and that hazardous constituents (e.g., most metals) that move primarily with water will be essentially immobile if the disposal unit design does not significantly disturb the natural hydrologic setting. At the same time, the very low water content and liquid flux beneath the Area 5 RWMS imply that gas flow and transport are very important.

\subsection{Environmental Tracers}

Environmental tracers provide another method, independent of the hydraulic parameters mentioned above, for estimating water movement in the vadose zone, travel times, and recharge. The basic premise of this method is that infiltrating water (from precipitation and runoff) contains dissolved natural and man-made tracers that travel with the water as it moves into and through the vadose zone. Further, it is assumed that formation materials do not contribute to the concentrations of these tracers. The concentrations of these tracers were measured with depth in materials from the three pilot wells, and analysis of the profiles plotted from these data yields information concerning the history of water movement through the unsaturated zone. In the following sections only general observations are made concerning the tracer profile data.

\subsubsection{Chloride/Bromide Profiles}

Chloride and bromide ions can serve as tracers because their negative charge discourages sorption with negatively charged mineral surfaces at solution $\mathrm{pH}$ values commonly found in soils and alluvium. The chloride mass balance method for estimating recharge (Allison and Hughes, 1983 ) is based on the assumption that concentrations of chloride are relatively constant with precipitation, and as water evaporates from the soil, leaving this ion behind, the concentration of chloride increases in the soil water. A mass balance approach using bromide has not been used, primarily because of the low concentrations of bromide in precipitation and the related absence of bromide concentration data.

Chloride and bromide concentrations were measured on all drill cuttings and core samples. Tabular data are summarized in Appendix E.2. Descriptive statistics were calculated for chloride and bromide concentration data below the depths of 76.2, 30.5, and $121.9 \mathrm{~m}(250,100$, and $400 \mathrm{ft}$ ) in Wells UE5PW-1, UE5PW-2, and UE5PW-3, respectively (Table 3-3). Below these depths the concentrations of chloride and bromide are very low and approximately constant. 
Depth profiles of chloride concentrations (per unit dry weight of soil) for drill cuttings samples from all three boreholes are illustrated in Figure 3-23, and similar profiles from core samples are presented in Figure 3-24. These concentration data will be converted to a per-unit-volume basis when quantitative analysis of the data is conducted. Depth profiles of bromide concentrations for core and drill cuttings samples (Figures 3-25 and 3-26, respectively) are virtually identical in shape to the chloride profiles.

Depth profiles of chloride/bromide ratios in both drill cuttings and core samples for each well are presented in Figures 3-27, 3-28, and 3-29. The high variability in these ratios is most likely due to errors in bromide concentration measurements, which increase greatly near the detection level of the instrument/method.

The relatively high concentrations of chloride in the shallow subsurface suggest that evaporation rates are high compared to the downward movement of water under the present climate. The very low concentrations of chloride at depth suggest that this water entered the system under a much wetter climate, where recharge rates compared to evaporation rates were much higher than present rates (Conrad, 1993). These data support the general conclusions made previously from hydraulic data (Section 3.4.2): that is, the net downward movement of water under the present climate is very low, and in fact there may be a net upward movement of water.

The large differences in the shapes of the chloride (and bromide) profiles in the upper portions of each pilot well may be due to a number of factors. Differences in the amount of surface water runoff at each well site (which is in turn related to proximity to upland mountains and to the size of the drainage basin) will definitely affect the amount of infiltration, and ultimately, the accumulation of chloride and bromide. Variations in plant communities and their rooting habits affect relative amounts of evapotranspiration and infiltration, and therefore chloride and bromide concentrations. Finally, the relative rates of aggradation and erosion may play an important role in affecting the concentration profiles. 


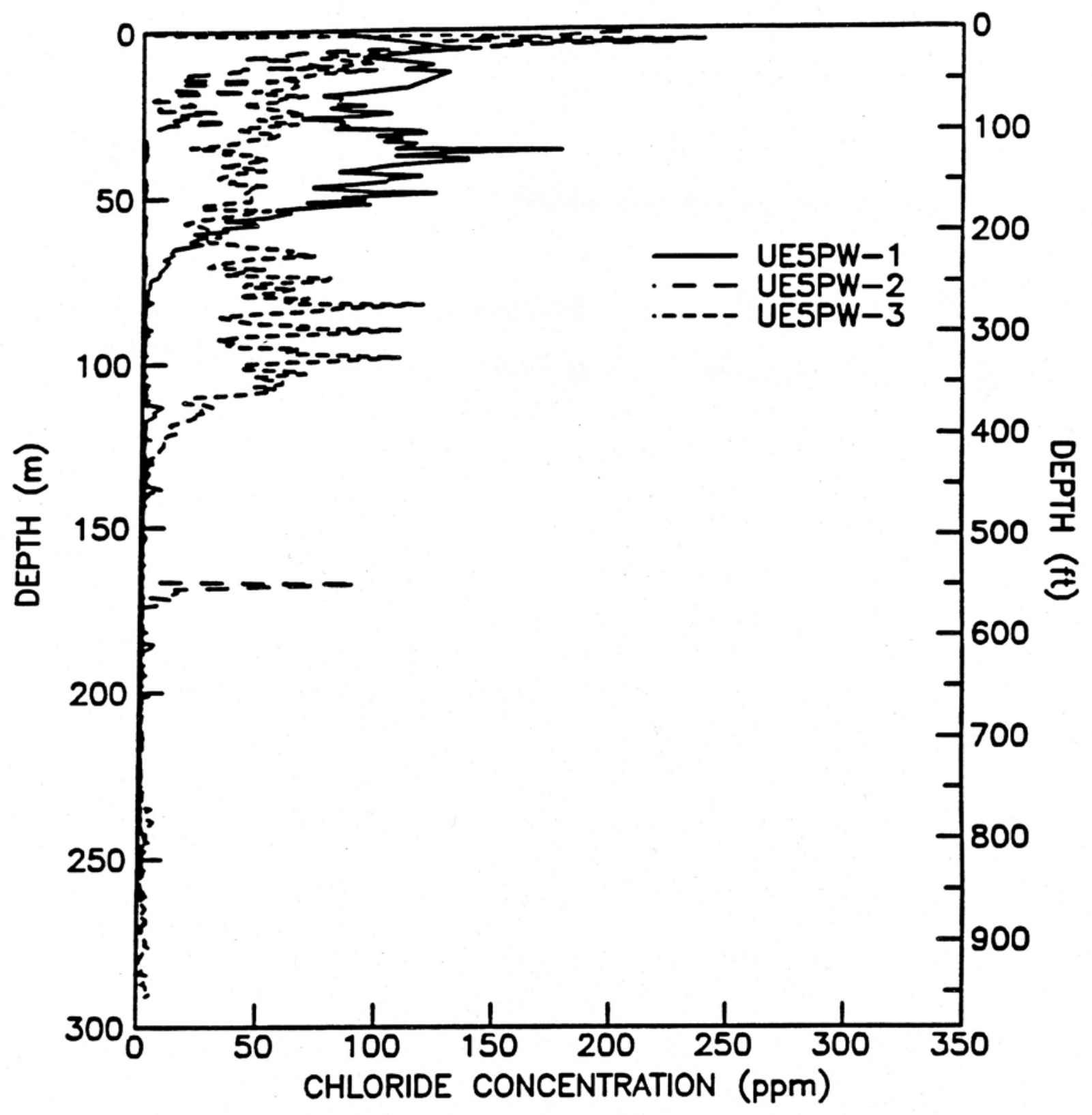

Figure 3-23

Depth Profiles of Dry Soil Chloride Concentrations for Drill Cuttings Samples from the Pilot Wells 


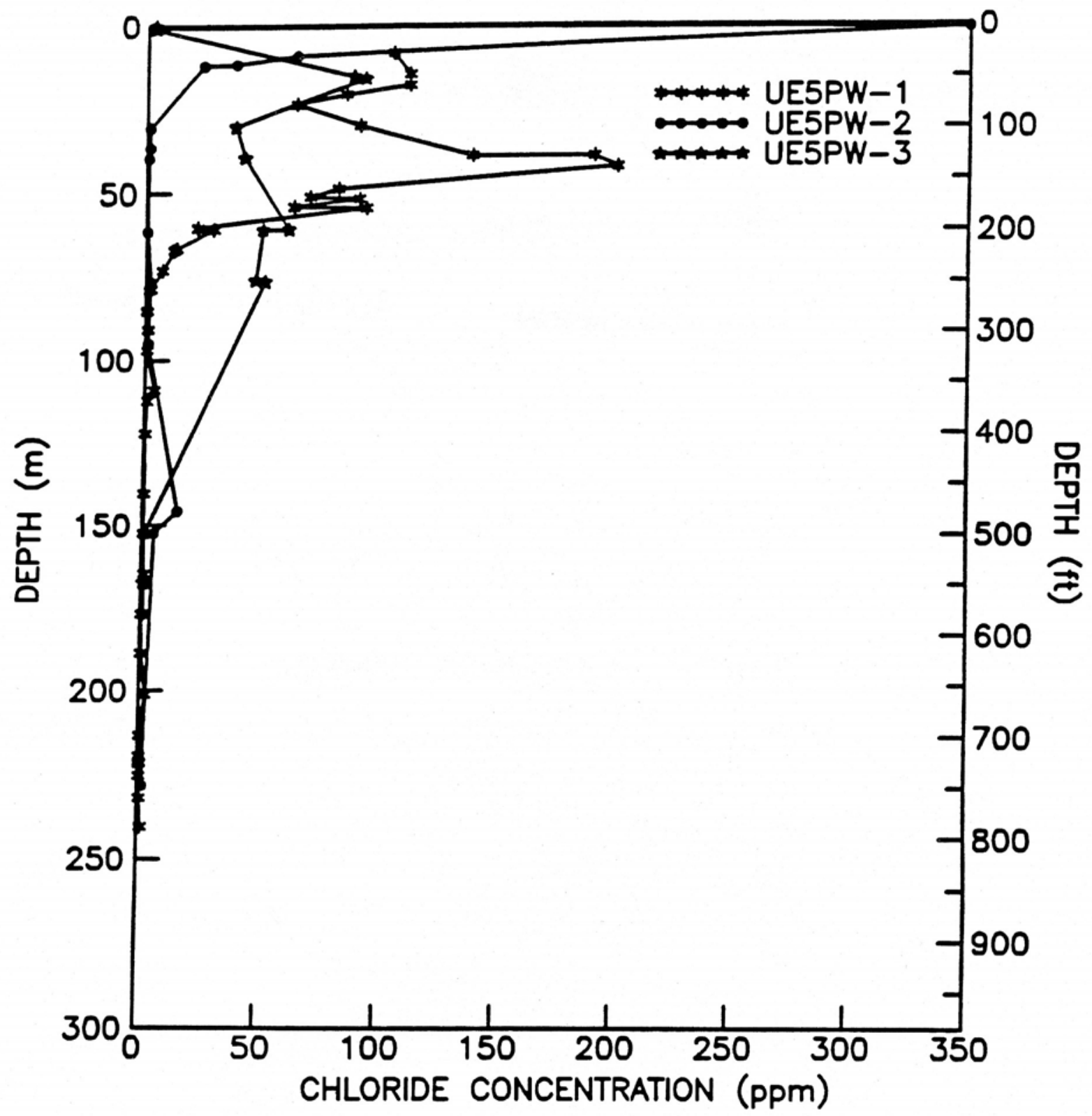

Figure 3-24

Depth Profiles of Dry Soil Chloride Concentrations for Core Samples from the Pilot Wells 


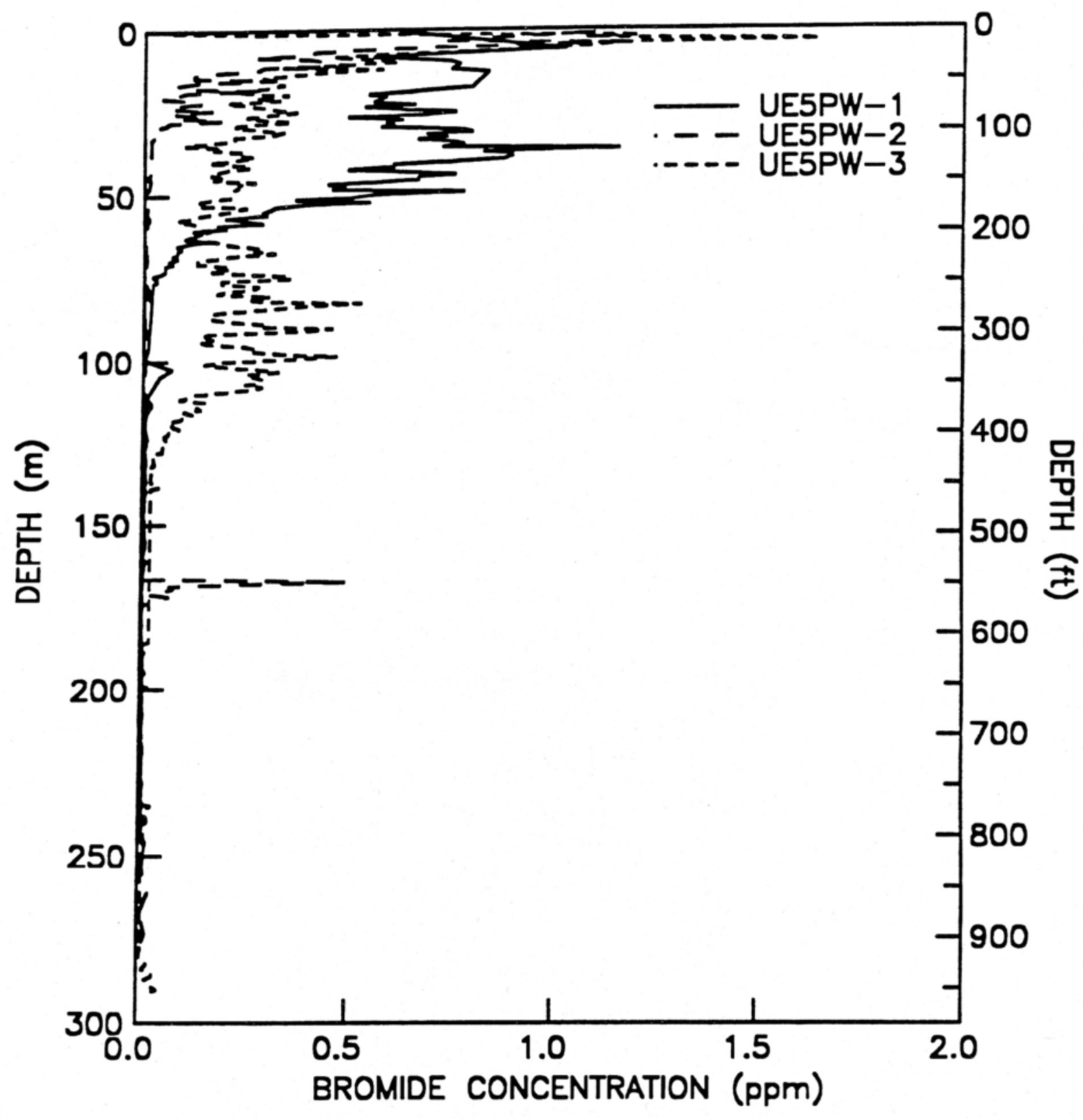

Figure 3-25

Depth Profiles of Dry Soil Bromide Concentrations for Drill Cuttings Samples from the Pilot Wells 


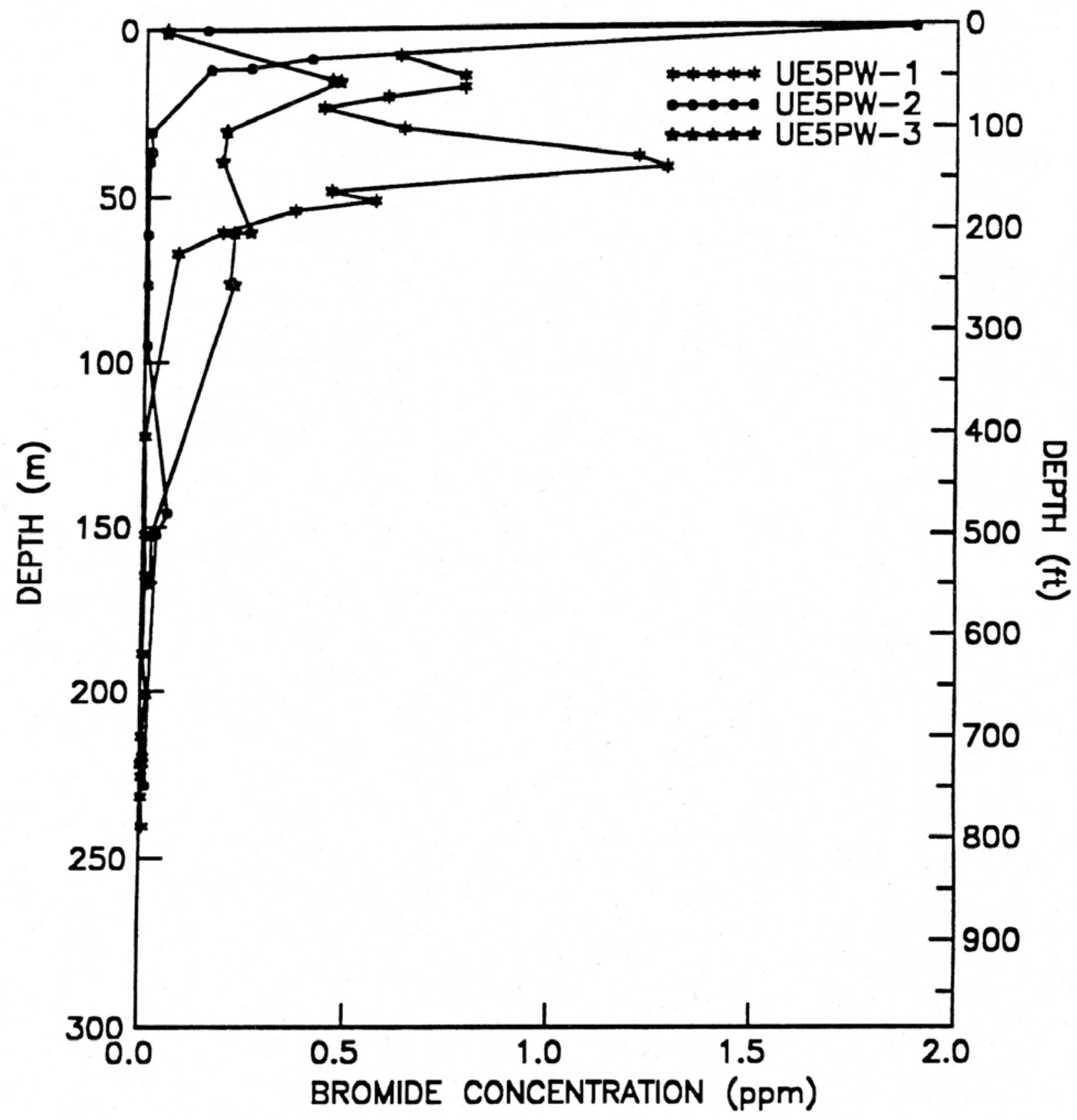

Figure 3-26

Depth Profiles of Dry Soil Bromide Concentrations for Core Samples from the Pilot Wells 


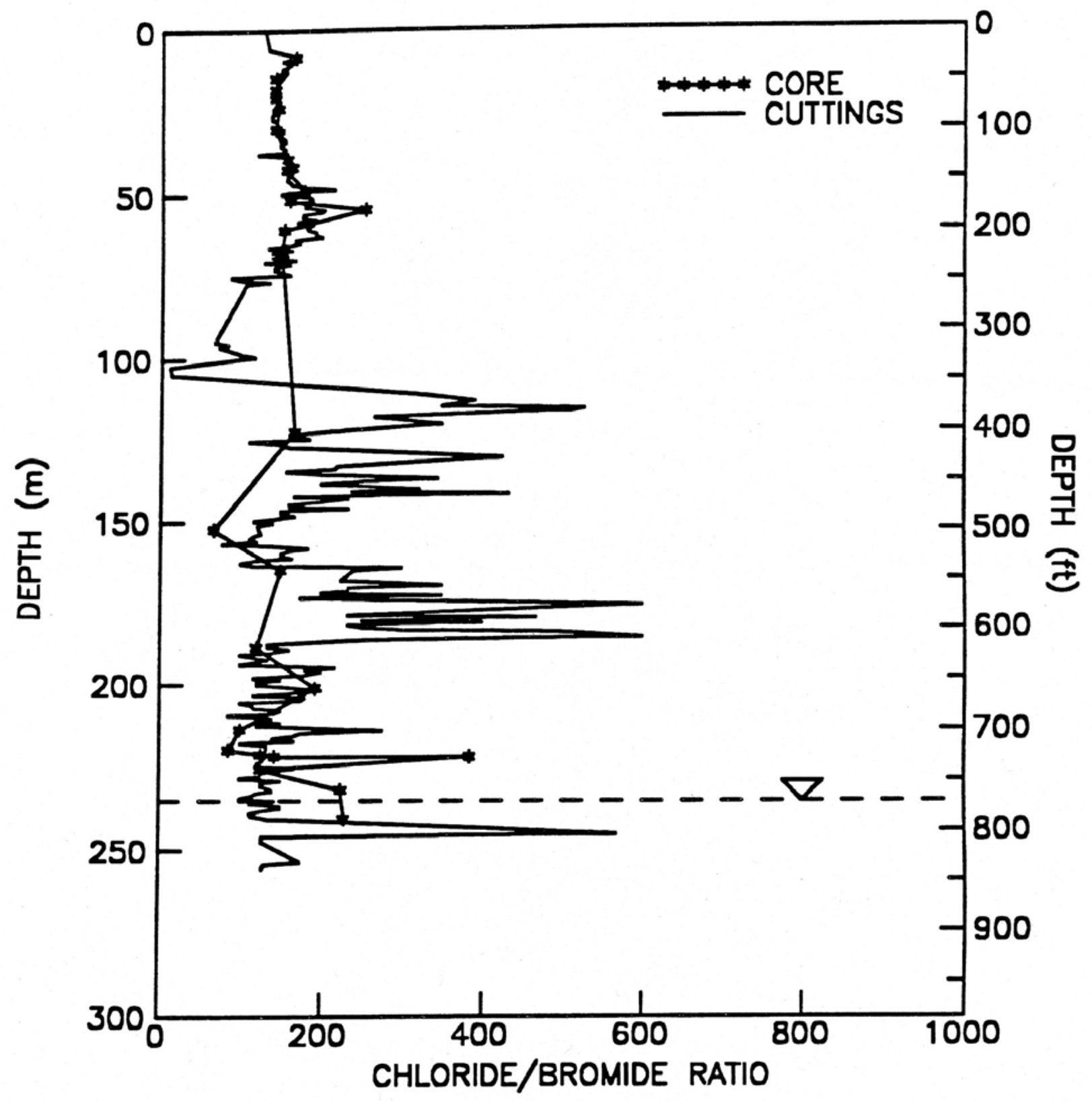

Figure 3-27

Depth Profiles of Dry Soil Chloride/Bromide Ratios for Core and Drill Cuttings Samples from Pilot Well UE5PW-1 


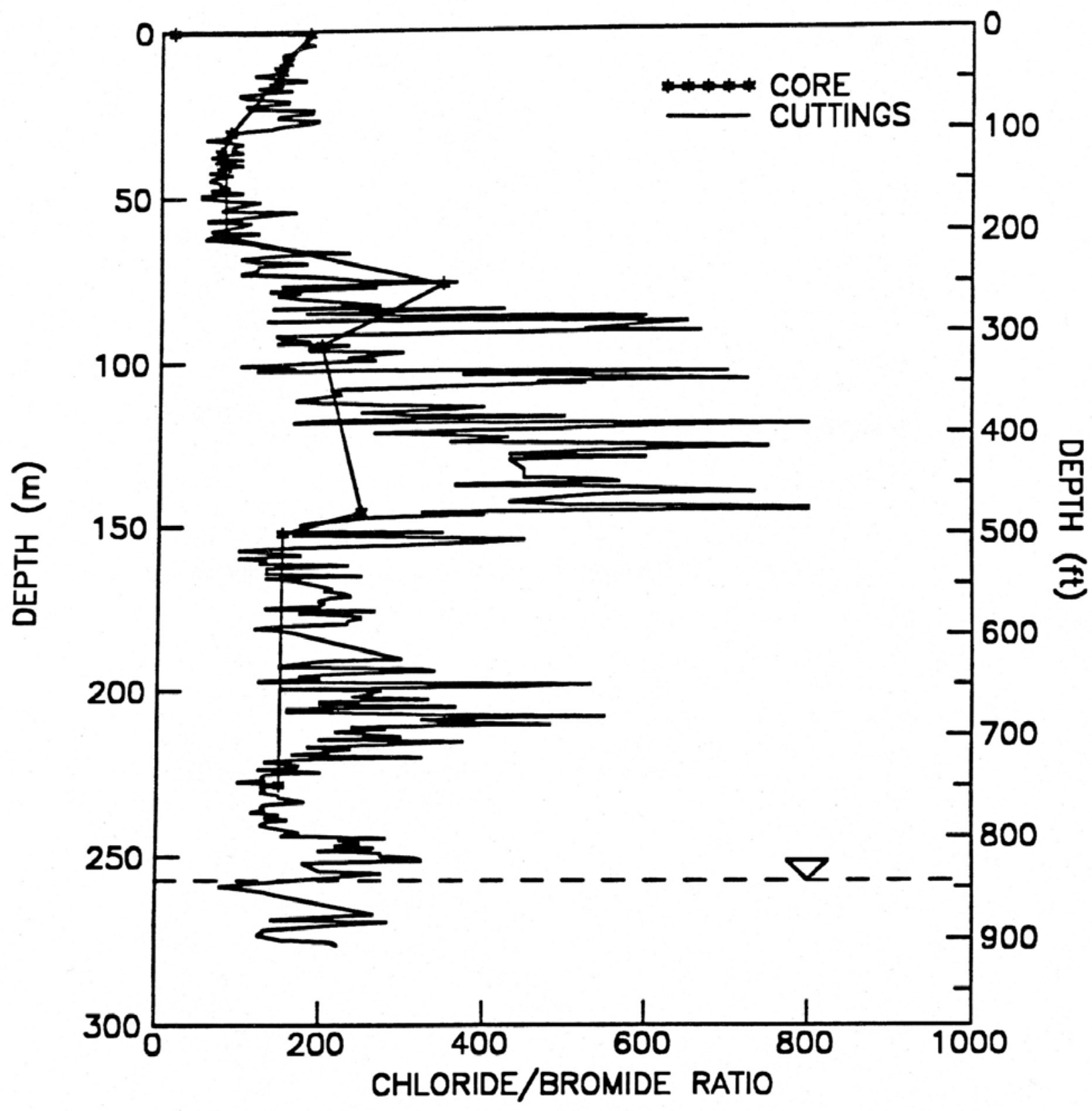

Figure 3-28

Depth Profiles of Dry Soil Chloride/Bromide Ratios for Core and Drill Cuttings Samples from Pilot Well UE5PW-2 


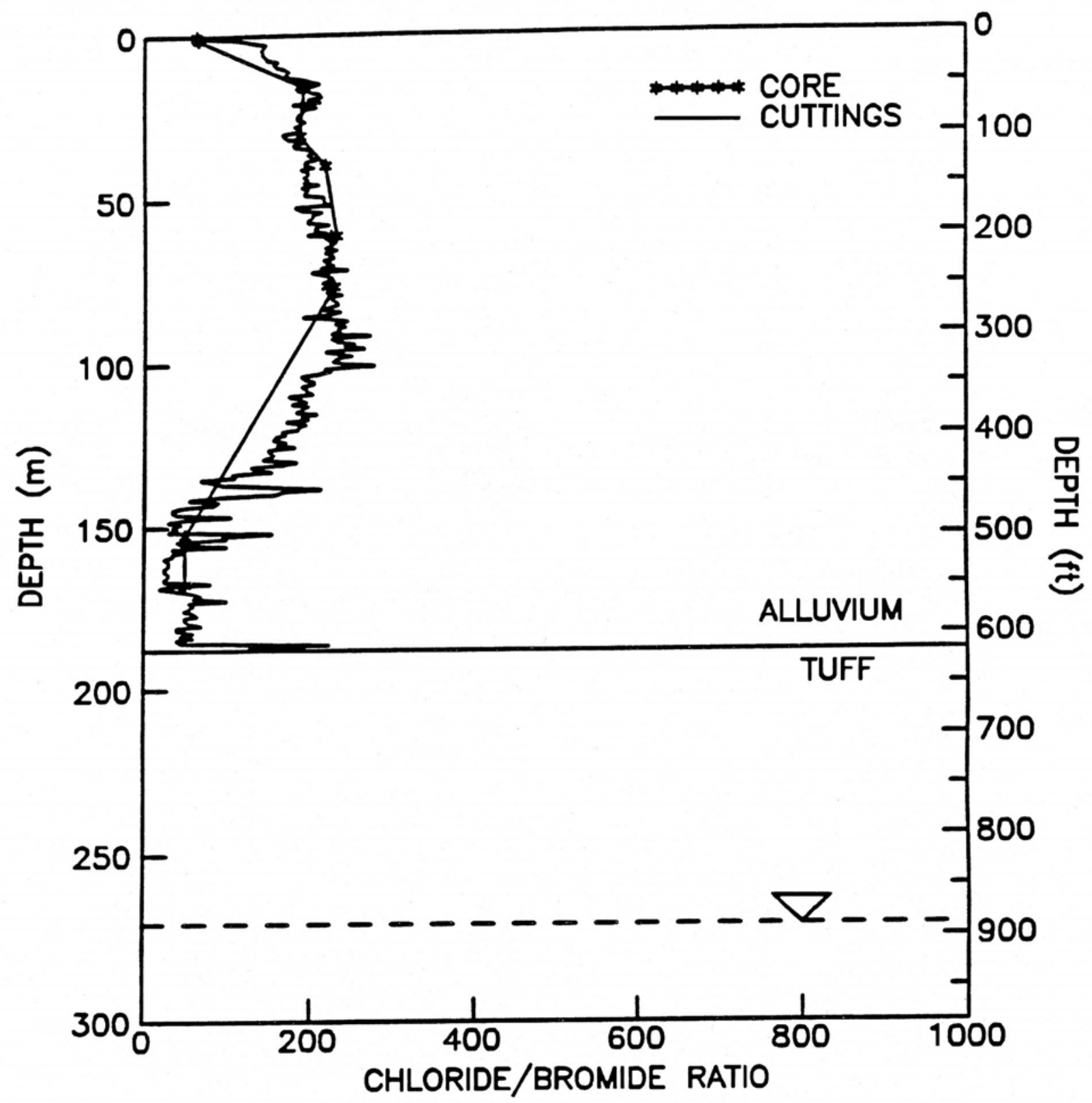

Figure 3-29

Depth Profiles of Dry Soil Chloride/Bromide Ratios for Core and Drill Cuttings Samples from Pilot Well UE5PW-3 


\subsubsection{Stable Isotope Profiles}

The stable isotopes of hydrogen (hydrogen and deuterium) and oxygen $\left({ }^{16} \mathrm{O}\right.$ and $\left.{ }^{18} \mathrm{O}\right)$ are excellent tracers of water movement because they are components of the water molecule itself. Stable isotopes are used in studies of the unsaturated zone to infer the source of soil water and determine if evaporation has occurred. Results are reported as a ratio of light to heavy isotopes (hydrogen/deuterium and ${ }^{16} \mathrm{O} /{ }^{18} \mathrm{O}$ ) in delta notation $(\delta$ ) relative to Standard Mean Ocean Water. Fractionation (a change in the ratio) occurs during phase change processes. Therefore, condensation and evaporation processes are both reflected in the isotopic ratios. The condensation of precipitation from the atmosphere occurs under very nearly thermodynamic equilibrium conditions, resulting in a linear relationship between hydrogen and oxygen isotopes in worldwide precipitation, known as the meteoric water line (MWL). Evaporation of water generally occurs under non-equilibrium conditions and fractionation of oxygen isotopes is greater than that of hydrogen isotopes. The water remaining behind in the evaporation process thus develops an isotopic composition that plots to the right of the MWL.

Stable isotope data from selected core samples from all the pilot wells are presented in Appendix E.2. Depth profiles for these wells are presented in Figure 3-30. In general, these profiles show more enrichment of heavy isotopes in the upper vadose zone, suggesting that shallow water has been subjected to more evaporation. A plot of oxygen isotopic ratios from selected core samples, with the MWL for reference, is shown in Figure 3-31. The shallow samples plot to the right of the MWL on a line with a slope between 3.5 and 4. This slope is consistent with the range found by Allison (1982) in experiments of water evaporating from sand columns, and strongly supports the hypothesis (Section 3.4.2) that evaporation rates are high relative to the downward rate of water movement in the upper vadose zone under the present climate (Chapman, 1993).

\subsubsection{Cosmogenic Chlorine-36 Data}

The radioisotope chlorine- $36\left({ }^{36} \mathrm{Cl}\right)$ is continually produced in the upper atmosphere. This isotope, together with the stable isotope, $\mathrm{Cl}$ (Section 3.5.1) is dissolved in ionic form in precipitation and enters the ground via infiltration. During periods of geomagnetic field fluctuations, increased production of ${ }^{36} \mathrm{Cl}$ is thought to occur (Blinov, 1988). Further, these field fluctuations and associated changes in ${ }^{36} \mathrm{Cl}$ production rates can possibly be dated. The relative magnitude of the ratios of these isotopes in the profiles provides information about the age of the soil water. 


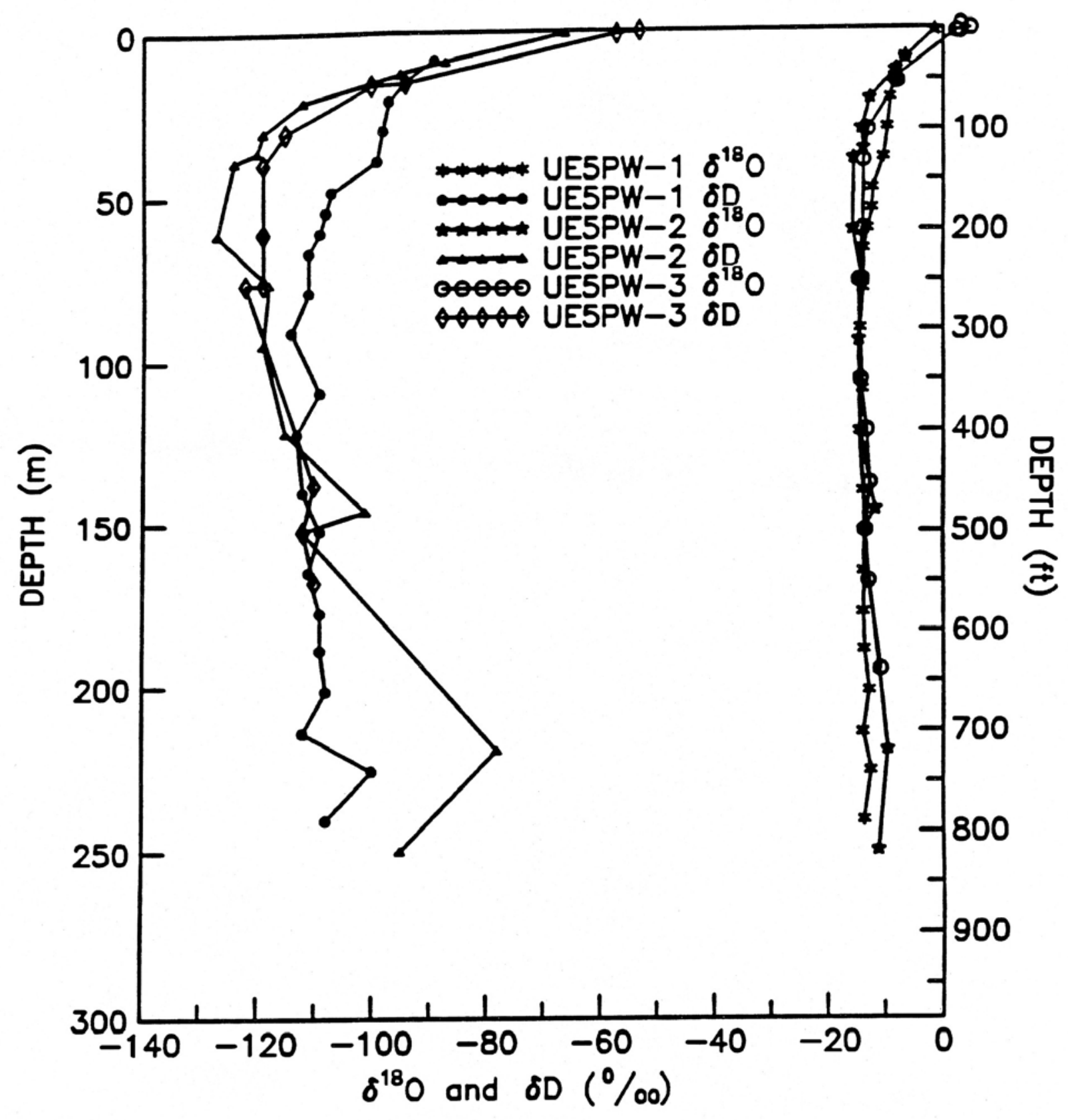

Figure 3-30

Depth Profiles of Stable Isotope Data for Core Samples from the Pilot Wells 


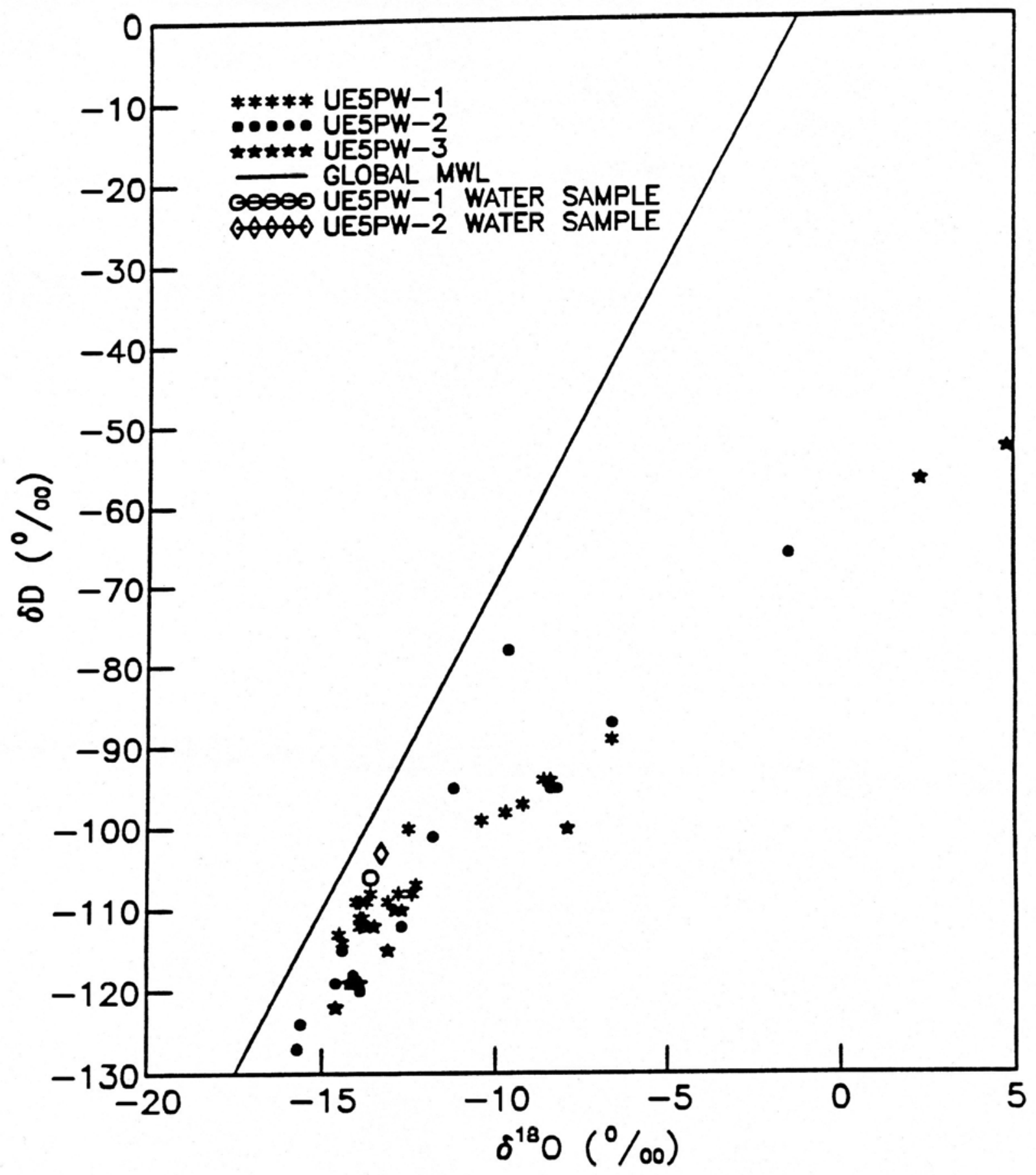

Figure 3-31

Comparison of Measured Stable Isotopes for Core and Water Samples from the Pilot Wells with Stable Isotope Data for the Global Meteoric Water Line (MWL) 
The depth profile of ${ }^{36} \mathrm{Cl} / \mathrm{Cl}$ ratios from selected core samples from Well UE5PW-1 is plotted in Figure 3-32. These data are presented in tabular form in Appendix E.2. Present-day precipitation yields ${ }^{36} \mathrm{Cl} / \mathrm{Cl}$ ratios in the range of 450 to $550 \times 10^{-15}$. The ratios found at depths

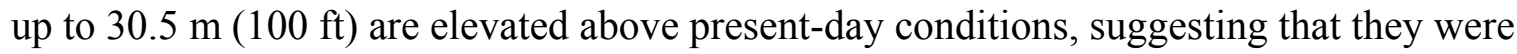
produced during the most recent period of geomagnetic field fluctuation (Conrad, 1993). Since this last period of fluctuations is thought to have occurred approximately 15,000 years ago, it has taken at least this amount of time for water to reach a depth of $30.5 \mathrm{~m}(100 \mathrm{ft})$. These elevated ratios have also been found in pack rat middens that have tentatively been dated to be approximately 21,000 years old by carbon-14 dating methods (Phillips et al., 1988). These data are consistent with both the hydraulic parameter data and the previously discussed environmental tracer data, which indicate that the downward rate of liquid water movement is extremely slow, if not zero.

\subsubsection{Soluble Sulfate}

Sulfate is not generally considered an environmental tracer because it is far less mobile than chloride and bromide for a number of reasons, including the lower solubility of sulfate salts. Moreover, there are many potentially important sources of sulfate, in addition to rainfall and runoff, which complicate the interpretation of depth concentration profile data. These sources include a number of common secondary minerals (e.g., gypsum) that occur in soils, alluvium and source rock. Even with these complicating factors, sulfate depth profile data provide useful additional information concerning the relative importance of evaporation and infiltration processes under the present arid climate, as well as under a previous, more humid climate. These data are discussed in the following paragraphs.

Measurements of soluble sulfate were made on all core and drill cuttings samples from Wells UE5PW-2 and UE5PW-3. Only a few samples from Well UE5PW-1 were analyzed for soluble sulfate because the decision to add this measurement to the suite of wet chemical analyses (which included inorganic and organic carbon, chloride, and bromide) was made near the completion of testing on Well UE5PW-1. Depth profiles of sulfate data from drill cuttings samples are presented for all three pilot wells in Figure 3-33, tabular data for both core and drill cuttings samples are presented in Appendix E.2, and descriptive statistics for the data in the lower vadose zone are presented in Table 3-3. 


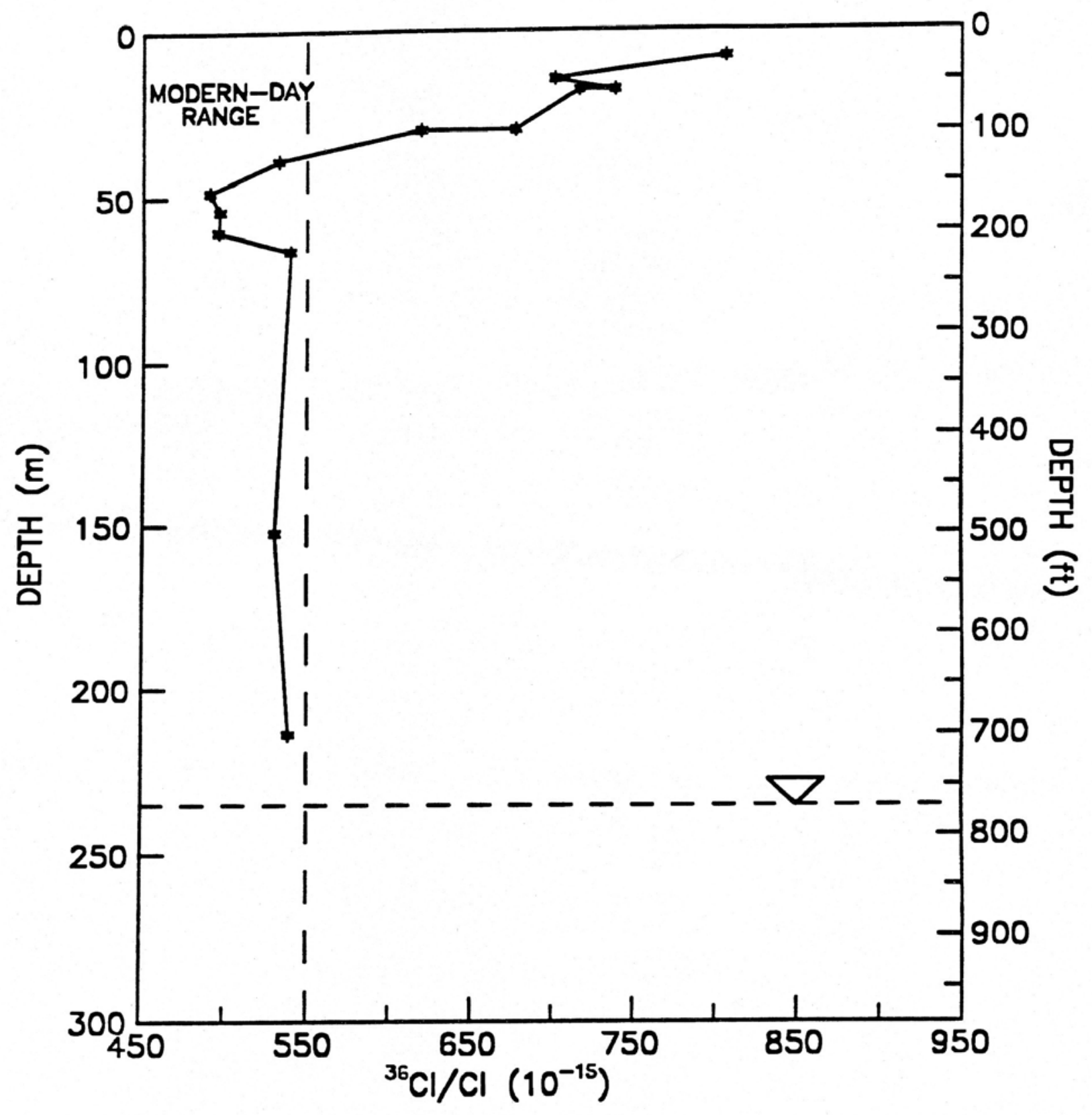

Figure 3-32

Depth Profile of ${ }^{36} \mathrm{Cl} / \mathrm{CI}$ Ratios for Core Samples from Well UE5PW-1 


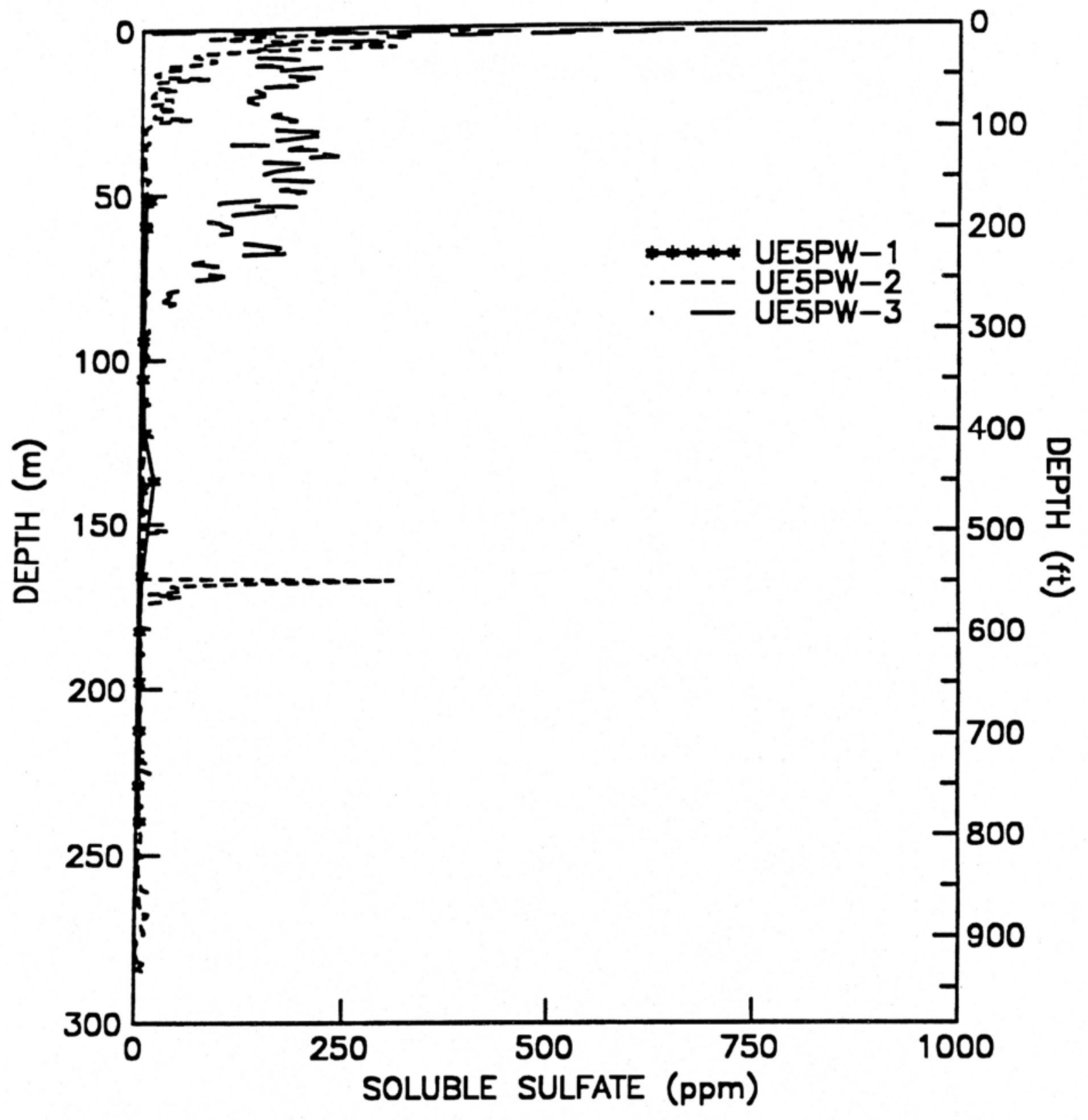

Figure 3-33

Depth Profiles of Soluble Sulfate for Drill Cuttings Samples from the Pilot Wells 
The data from drill cuttings samples for both Wells UE5PW-2 and UE5PW-3 show relatively high and variable concentrations of sulfate in the upper portion of the profile and much lower and less variable concentrations in the lower portion of the profile. These profiles are somewhat similar in shape to the chloride and bromide profiles (Section 3.5.1), however, the depth at which these concentrations decrease to lower values is much shallower for sulfate. These differences are probably due to the lower mobility of the sulfate anion, resulting (at least in part) from the generally lower solubility of sulfate salts compared to chloride and bromide salts.

In summary, these sulfate concentration profiles support the picture of water movement in the vadose zone suggested by the analyses of the other environmental tracers. In particular, these profiles imply that under the present arid climate, the liquid water that moves into the upper vadose zone, moves out of the vadose zone primarily by vapor flow in response to a high evaporative demand, and that the water that is presently in the lower vadose zone infiltrated under a more humid climate under which evaporation was not an important process.

\subsection{Sampling and Analysis of Core Samples for Hazardous and Radiological Parameters}

Alluvium samples were periodically collected during drilling and analyzed for selected hazardous and radiological parameters. The purpose of these analyses was to determine if core samples and the borehole were being contaminated by drilling and/or if the borehole had penetrated any contaminated regions.

Intact core samples were collected for analysis of volatile and semi-volatile organic compounds. Drill cuttings samples were collected for analysis of Total Kjeldahl Nitrogen (TKN), total metals, (As, $\mathrm{Ba}, \mathrm{Cd}, \mathrm{Cr}, \mathrm{Pb}, \mathrm{Se}, \mathrm{Ag}$, and $\mathrm{Hg}$ ), and photon-emitting radionuclides. Sample collection and field quality assurance procedures are described in a test procedure for sampling and analysis (Table 2-1). In addition, these procedures contain additional information concerning sampling and analytical methods. The results of these analyses are tabulated in Appendix E.4.

The analytical results indicate that the concentrations of these constituents measured in core and drill cuttings samples are consistent with expected background levels. That is, elevated levels were not encountered while penetrating the thick vadose zone sediments and the upper portion of the alluvial aquifer.

Low levels of several volatile organic compounds, known to be common laboratory contaminants, were sporadically detected in alluvium samples. The presence of these 
compounds is likely attributable to laboratory contamination. Semi-volatile organic compounds were not detected. Total metals analyses and TKN analyses were characteristic of uncontaminated soils. The only radionuclides detected were naturally occurring primordial radionuclides. 
This page intentionally left blank. 


\subsection{Field Testing Methods and Results}

\subsection{Preliminary Surface Surveys of Potential Contaminants at Drill Sites}

Frenchman Flat and the Area 5 RWMS have been the site of numerous activities that could potentially have contaminated surface soils with hazardous constituents and radionuclides. From 1951 to 1961 Frenchman Flat, and Yucca Flat to the north, were the site of numerous atmospheric nuclear weapons tests. After 1961, seven underground nuclear tests were conducted $4.4 \mathrm{~km}(2.4 \mathrm{mi})$ to the north and three were conducted at locations to the south of the Area 5 RWMS. Several safety tests were also conducted in the vicinity of the Area 5 RWMS. Safety tests involve chemical detonation of nuclear weapons components and could result in the dispersion of actinide contamination. Also, Area 5 is the site of a facility used for controlled chemical spill tests. Finally, all three pilot well sites had been disturbed to some extent by vehicle traffic.

Prior to initiating drilling operations, surface soil and near-surface gas samples were collected from the pilot well sites and analyzed to insure that the ground surfaces at these sites were free of elevated levels of contaminants that could be spread downward during drilling. The results of these sampling and analysis activities are described in the following paragraphs.

\subsubsection{Surface Soil Sampling, Analysis, and Results}

Surface soil samples were collected at each drill site prior to preparation and after grading and compaction. The purpose of these surveys was to determine if contamination existed at any of the drill sites at concentrations that could potentially result in contamination of the borehole through drilling activities. Samples from unprepared sites were analyzed for oil and grease, Total Petroleum Hydrocarbons (TPH), and photon-emitting radionuclides. Samples from prepared drill sites were analyzed for all the above parameters plus plutonium isotopes.

Samples were collected from 200 - by $200-\mathrm{mm}$ (7.9-in.) by $20-\mathrm{mm}(0.8$-in.) deep cells selected randomly from a 30 - by $30-\mathrm{m}$ (98-ft) grid centered at each borehole. Four random samples were collected from each of the unprepared and prepared sites, the only exception being the unprepared site at Well UE5PW-1. The Well UE5PW-1 site was disturbed by vehicle traffic prior to sampling for TPH and oil and grease. Due to the extent of the disturbance it was impossible to collect samples from this site using a randomized design. Therefore, $3 \mathrm{TPH}$ and oil and grease samples were collected $15.2 \mathrm{~m}$ (50 ft) east, west, and north of the borehole. Finally, an additional grab sample was collected from a dark stained area southeast of the borehole location at the unprepared site for Well UE5PW-2. 
Details of sample collection and analytical methods, together with the tabular testing results, are given in Appendix F.1.1. No analyte was detected at concentrations that would have presented potential contamination problems during drilling operations.

\subsubsection{Near-Surface Radon and Tritium Gas Sampling, Analysis, and Results} Soil gas surveys for tritium oxide and radon-222 $\left({ }^{222} \mathrm{Rn}\right)$ were conducted in the near-surface soils at each of the pilot well locations prior to drilling operations. Samples for tritium analysis were obtained as water vapor (tritium oxide) and analyzed to insure that the pilot well sites were free of elevated levels of tritium near the ground surface that could be harmful to human health, and/or could be carried downward by the drilling operations and contaminate the groundwater. Samples were collected and analyzed for ${ }^{222} \mathrm{Rn}$ to establish background concentrations, which are dependent on site-specific lithologies. In addition, ${ }^{222} \mathrm{Rn}$ samples were collected over time as part of a preliminary study of the effects of barometric pumping on the movement of gases in the near surface.

Soil gas samples for analysis for both tritium oxide and ${ }^{222} \mathrm{Rn}$ were collected from the same stainless-steel sampling lines driven to depths of approximately $0.9,2.7$, and $6.4 \mathrm{~m}(3,9$, and $21 \mathrm{ft}$ ) at each of the locations using a hydraulically driven probe. At the Well UE5PW-3 location the hydraulic probe used to install sample lines met refusal at $5.2 \mathrm{~m}(17 \mathrm{ft})$ rather than the target

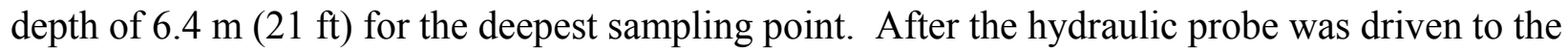
depth of interest, a sample line with a filter tip was run to the bottom of the probe hole, sand was then emplaced around the tip, and finally, the annulus between the sample line and the borehole wall was stemmed with bentonite to the ground surface to prevent preferential annular flow.

\subsubsection{Radon Soil Gas Surveys}

Details of ${ }^{222} \mathrm{Rn}$ sample collection and counting measurement methods, together with radon concentration data, are summarized in Appendix F.1.2. Soil gas concentrations of ${ }^{222} \mathrm{Rn}$ sampled at each pilot well location show increasing concentration and decreasing temporal variability with depth. The wider range of variability in the near-surface samples can probably be attributed to barometric pumping, while the trend of decreasing concentrations towards the surface is likely due to a combination of barometric pumping and the diffusion process across the zeroconcentration soil/atmosphere boundary.

At the Well UE5PW-3 site, located near Massachusetts Mountain, the ${ }^{222} \mathrm{Rn}$ concentrations were approximately three times those found at the Well UE5PW-1 and UE5PW-2 sites. The higher concentration of ${ }^{222} \mathrm{Rn}$ in the soils at the Well UE5PW-3 site is probably due to a change in lithology (e.g., tuff units closer to the ground surface) with a higher uranium content. 


\subsubsection{Tritium Soil Gas Surveys}

Descriptions of tritium oxide sample collection and analysis methods, as well as analytical results for all three pilot well sites, are given in Appendix F.1.2. With the exception of the 0.9-m (3-ft) depth at Well UE5PW-1, all sample activities were below detection limits. Detection limits ranged between 592 and 1,776 Becquerels per cubic meter $\left(\mathrm{Bq} / \mathrm{m}^{3}[0.127\right.$ picoCuries per milliliter ( $\mathrm{pCi} / \mathrm{ml}])$, depending on sample size and counting time.

Samples from the Well UE5PW-1 site were collected on October 24, 1991, and counted for 100 minutes. This count of the sample from the $0.9-\mathrm{m}(3-\mathrm{ft})$ depth gave a sample activity of $1,850 \mathrm{~Bq} / \mathrm{m}^{3}(0.500 \mathrm{pCi} / \mathrm{ml})$, with a sample error of $825 \mathrm{~Bq} / \mathrm{m}^{3}(0.223 \mathrm{pCi} / \mathrm{ml})$ and a minimum detectable amount of $1,306 \mathrm{~Bq} / \mathrm{m}^{3}(0.353 \mathrm{pCi} / \mathrm{ml})$. The other samples were below the minimum detectable amount. The samples were then recounted using a 300-minute count time, resulting in a sample activity of $1,550 \mathrm{~Bq} / \mathrm{m}^{3}(0.419 \mathrm{pCi} / \mathrm{ml})$ and a sample error of $470 \mathrm{~Bq} / \mathrm{m}^{3}(0.127 \mathrm{pCi} / \mathrm{ml})$ for the sample from the $0.9-\mathrm{m}(3-\mathrm{ft})$ depth. The other samples were again found to be below the minimum detectable amount of $725 \mathrm{~Bq} / \mathrm{m}^{3}(0.196 \mathrm{pCi} / \mathrm{ml})$ using a single background count.

In order to firmly establish whether these results were due to laboratory contamination or actual sample activity, a second sample was obtained from the Well UE5PW-1 site on October 30, 1991. The results confirmed the original sampling, indicating very low environmental levels of tritium oxide at the $0.9-\mathrm{m}$ (3-ft) depth, and less than detection limits at the 2.7- and 6.4-m (9- and 21-ft) depths.

It should be emphasized that tritium oxide levels were in all cases below or very near to both detection levels and environmental background levels (even the $0.9-\mathrm{m}$ [3- $\mathrm{ft}]$ depth sample in Well UE5PW-1). Based on these results, all sites were considered to be essentially free of elevated tritium oxide levels and were considered acceptable sites for drilling.

\subsection{Surface Geophysical Surveys}

A set of Schlumberger resistivity soundings, as well as total field and gradiometer magnetic field data were obtained at each of the pilot well locations. These data were collected prior to drilling activities in order to establish background control data before the sites were disturbed by the cultural effects of drilling operations. The primary purpose of these surveys was to attempt to obtain preliminary information about any subsurface lithologic/hydrologic feature that could be used to help design and focus future sampling and analysis activities. These surveys would also provide the opportunity to determine if in fact these geophysical tools could be used to help define lithologic/hydrologic features (as determined from analysis of core and drill cuttings samples) in thick unsaturated alluvium. If a positive correlation were found between 
geophysical tool response and lithology, these geophysical methods would be useful in delineating the lithology at other sites (where borehole data do not exist) with thick unsaturated alluvium. The resistivity and magnetic surveys were conducted under the applicable procedures and plans listed in Table 2-1.

\subsubsection{Resistivity Surveys}

The resistivity soundings were performed with a Schlumberger array and were taken using an ABEM SAS 300C Terrameter with an SAS 2000 booster capable of operating up to 500 milliamperes transmitted current. The soundings were centered over each borehole location and oriented in a manner that would minimize cultural effects from pipelines, power lines, fences, and other structures. Current electrode separations $(\mathrm{AB} / 2)$ were positioned logarithmically, ranging from 0.6 to $853.4 \mathrm{~m}$ ( 2 to $2,800 \mathrm{ft})$. The receiver dipole $(\mathrm{mn} / 2)$ length ranged from 0.3 to $45.7 \mathrm{~m}$ ( 1 to $150 \mathrm{ft}$ ) as required by signal strength. The resistivity sounding data and log plots of these data locations are found in Appendix F.2.1.

Apparent resistivity, $\rho$, in ohm-meters, was calculated by:

$$
\rho=\mathrm{V} / \mathrm{I}\left[(\mathrm{AB} / 2)^{2}-(\mathrm{mn} / 2)^{2}\right] \pi / \mathrm{mn}
$$

where $\mathrm{V}$ is the received voltage, $\mathrm{I}$ is the transmitted current, $\mathrm{AB}$ is the current electrode separation in meters, and $\mathrm{mn}$ is the receiver separation in meters.

The resistivity soundings (Figure 4-1) at Wells UE5PW-1 and UE5PW-2 are similar, showing high resistivity in the near-surface, and decreasing with depth. The water table is evident on each sounding, as the low resistivity bottom layer visible to the right of the $304.8-\mathrm{m}(1,000-\mathrm{ft})$ $\mathrm{AB} / 2$ separation. Overall resistivities are slightly higher at Well UE5PW-2 than at Well UE5PW-1, with the exception of the very near-surface reading. 


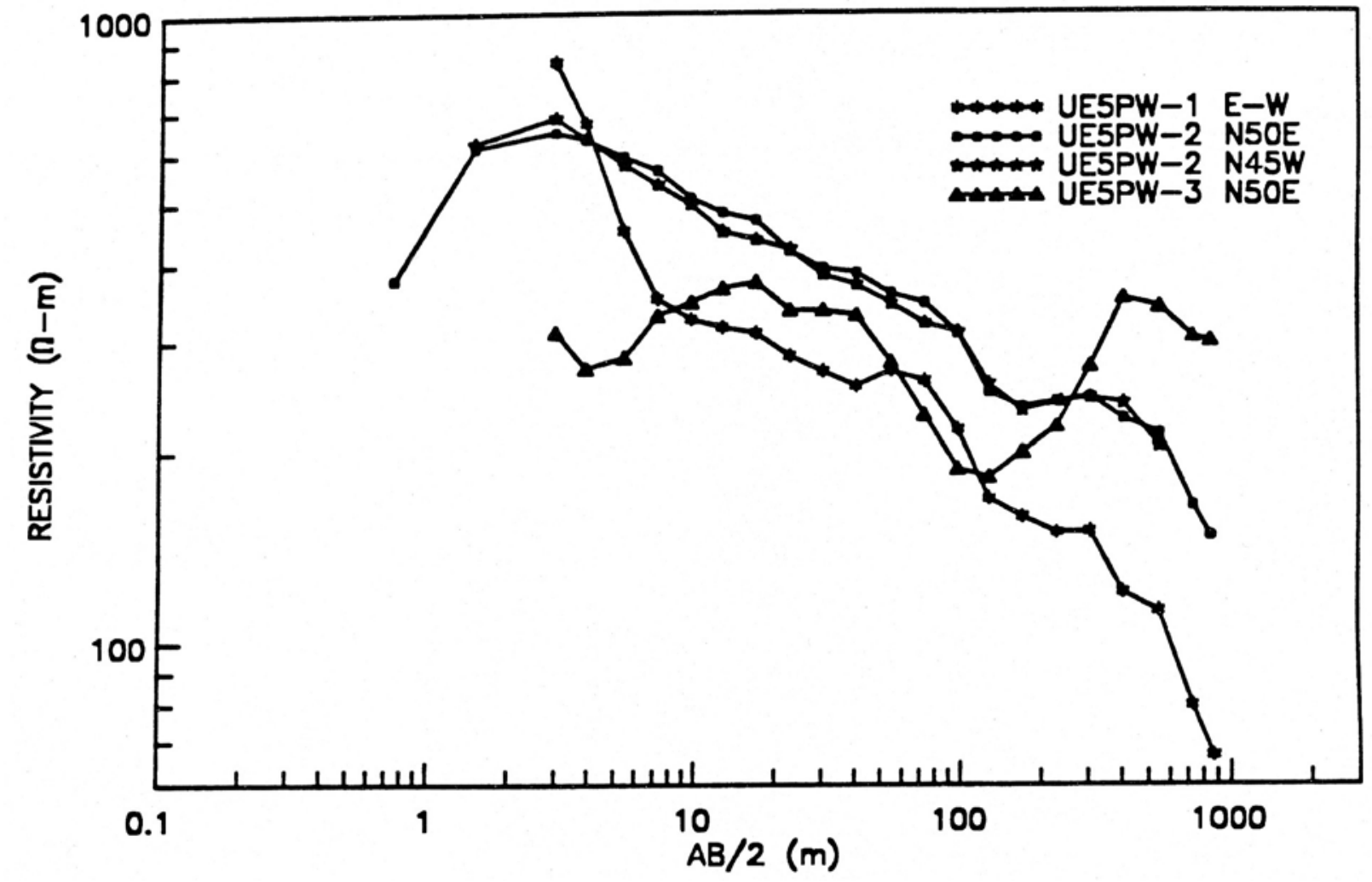

Figure 4-1

Resistivity Soundings at the Area 5 Pilot Well Locations 
Orthogonal Schlumberger arrays were used at Well UE5PW-2 to determine anisotropic and three-dimensional effects. Both soundings are remarkably similar, indicating that alluvium is both isotropic and lacking any three-dimensional effects in this area. Low resistivity was observed on both of these crossed arrays at an $\mathrm{AB} / 2$ of 170.7 and $405.4 \mathrm{~m}$ (560 and 1,330 ft). It is thought that these features are artifacts caused by interference arising from man-made structures.

The sounding data obtained at Well UE5PW-3 are clearly different from those seen at the other pilot well locations. It should be noted that the receiver-dipole porous-pot contact on this resistivity line became as high as $20,000 \mathrm{ohms}$, and the data may be somewhat noisy due to this. The layering seen on this line is a low-moderate-low-high-low sequence, whereas the other pilot wells show a high-low-low layering. Finally, the deep high resistivity response at Well UE5PW-3 is probably due to the presence of the volcanic tuff that was encountered during drilling at $188.2 \mathrm{~m}(617.5 \mathrm{ft})$ below the ground surface, and the low resistivity bottom layer is probably the water table, which was measured at approximately $271 \mathrm{~m}(888 \mathrm{ft})$.

\subsubsection{Magnetometer Surveys}

The magnetometer surveys were centered at the well locations, with 304.8-m (1,000-ft) profiles oriented north-south and east-west, and a station spacing of $15.2 \mathrm{~m}(50 \mathrm{ft})$. Total field magnetic data, as well as the vertical gradient, were obtained using a GEM Systems GSM-19 Overhauser magnetometer/gradiometer. Three-station in-phase and out-of-phase VLF data were also obtained while conducting the survey, but due to the lack of any significant response, the data are not reported here. A GEM systems recording base station was used to correct for diurnal variations and to monitor for magnetic storms during conduct of the survey. The base station and survey magnetometer clocks were synchronized, which allowed discrete time corrections to be made for the reduction of the diurnal data. Magnetic survey data are found in Appendix F.2.2

The total field and gradient data collected at each pilot well location are uniform and well behaved, which would be expected in homogeneous sedimentary alluvial basin fill. The total field intensities at Wells UE5PW-1, UE5PW-2, and UE5PW-3 are 50,975, 50,967, and 50,969 nanoteslas, respectively. Vertical gradients typically ranged between -2 and -6 nanoteslas per meter. It is thought that these local disturbances of the gradient and total field are artifacts caused by interference arising from the same man-made cultural effects mentioned above in relation to the resistivity surveys. Additional surveys in Frenchman Flat of the lithologic inhomogeneity are required to determine if magnetic surveys are useful tools to help delineate lithologies in alluvial basins with thick unsaturated zones. 


\subsection{Borehole Geophysical Logging Surveys}

Borehole geophysical logging was conducted in each pilot well during different stages of drilling to attempt to obtain additional stratigraphic, mineralogic, hydrologic, and borehole condition information. This logging was conducted by Century Geophysical Corporation, Chino Valley, Arizona, under the direction of REECo SPS personnel, according to the applicable QA procedures listed in Table 2-1.

\subsubsection{Description of Borehole Logging Activities}

Borehole logs were conducted in each pilot well upon completion of three different stages of drilling and stemming activities. Each logging episode was conducted, at least in part, inside cased portions of each well. The only uncased borehole segment logged was the lower part of the tuff interval in Well UE5PW-3. Table 4-1 summarizes logging episodes for each well, including casing diameters and depths, type of log conducted, and logging tool model number.

The first logging episode was conducted after driving the 273.0-mm (10.75-in.) O.D. casing to about half the total planned depth of each well. In Well UE5PW-2, a second 219.1-mm (8.625-in.) O.D. casing was advanced inside the $273.0-\mathrm{mm}$ (10.75-in.) O.D. casing from 121.9 to $167.9 \mathrm{~m}$ (400 to $551 \mathrm{ft}$ ) before the first episode of logging could be conducted. Therefore logs in this borehole from the ground surface to $121.9 \mathrm{~m}$ ( 0 to $400 \mathrm{ft}$ ) were conducted inside telescoped 273.0- and 219.1-mm (10.75- and 8.625-in.) casings, and logs were run from 121.9 to $167.9 \mathrm{~m}$ (400 to $551 \mathrm{ft}$ ) inside the 219.1 -mm (8.625-in.) casing only.

The second logging episode was conducted after drilling the remaining lower portion of each borehole with 219-mm (8.625-in.) casing. This casing was run inside (telescoped) the 273.0-mm (10.75-in.) casing, so the second-episode logs in the approximate upper half of each borehole were run inside two casings.

The final logging episode was conducted after the 273.0- and 219.1-mm (10.75- and 8.625-in.) casings were removed, and the wells were completed with stainless-steel monitoring well tubing of approximately 73.0-mm (2.875-in.) O.D. Vadose zone instruments were stemmed at different depths on the outside of this tubing.

The first two logging episodes included neutron, density, natural gamma, spectral gamma (potassium, uranium, and thorium [KUT]), and caliper logs. The caliper log data were obtained as part of the natural gamma and density tool output, and are of use only in the uncased portion of the tuff in Well UE5PW-3. 
Table 4-1

Borehole Geophysical Logging Episodes in the Area 5 Pilot Wells

\begin{tabular}{|c|c|c|c|c|c|c|c|c|c|c|}
\hline \multirow[b]{2}{*}{ Borehole } & \multirow{2}{*}{$\begin{array}{l}\text { Episode } \\
\text { Number }\end{array}$} & \multirow[b]{2}{*}{ Date } & \multirow{2}{*}{$\begin{array}{c}\text { Casing } \\
\text { Outside } \\
\text { Diameter } \\
\text { mm (in.) }\end{array}$} & \multirow{2}{*}{$\begin{array}{c}\text { Casing Depth } \\
\text { m (ft) }\end{array}$} & \multicolumn{6}{|c|}{ Log Type and Tool Model Number } \\
\hline & & & & & $\begin{array}{c}\text { Gamma Ray } \\
\text { (Natural } \\
\text { Gamma) } \\
\end{array}$ & $\begin{array}{l}\text { Gamma } \\
\text { Density }\end{array}$ & Caliper & $\begin{array}{c}\text { Spectral } \\
\text { Gamma } \\
\text { (KUT) } \\
\end{array}$ & Neutron & Deviation \\
\hline \multirow{3}{*}{ UE5PW-1 } & 1 & 04/20/1992 & $273.0(10.750)$ & $112.0(367.5)$ & 9030 & 9030 & 9030 & 9080 & 9055 & -- \\
\hline & 2 & 06/16/1992 & $\begin{array}{c}273.0(10.750) \\
219.1(8.625)\end{array}$ & $\begin{array}{l}112.0(367.5) \\
255.1(837.0)\end{array}$ & 9035 & 9035 & 9035 & 9080 & 9071 & -- \\
\hline & 3 & 02/24/1993 & $73.0(2.875)$ & $250.5(822.0)$ & -- & -- & -- & -- & -- & 9095 \\
\hline \multirow{3}{*}{ UE5PW-2 } & 1 & 07/20/1992 & $\begin{array}{c}273.0(10.750) \\
219.1(8.625)\end{array}$ & $\begin{array}{l}121.9(400.0) \\
167.9(551.0)\end{array}$ & $9035^{*}$ & 9035 & 9035 & 9080 & 9055 & -- \\
\hline & 2 & 09/29/1992 & $\begin{array}{c}273.0(10.750) \\
219.1(8.625)\end{array}$ & $\begin{array}{l}167.9(551.0) \\
259.1(850.0)\end{array}$ & 9035 & 9035 & 9035 & 9080 & 9071 & -- \\
\hline & 3 & 02/25/1993 & $73.0(2.875)$ & $271.3(890.0)$ & -- & -- & -- & -- & -- & 9095 \\
\hline \multirow{3}{*}{ UE5PW-3 } & 1 & 09/28/1992 & $273.0(10.750)$ & $137.2(450.0)$ & 9035 & 9035 & 9035 & 9010 & 9071 & -- \\
\hline & 2 & 11/12/1992 & $\begin{array}{c}273.0(10.750) \\
219.1(8.625)\end{array}$ & $\begin{array}{l}137.2(450.0) \\
213.4(700.0)\end{array}$ & 9035 & 9035 & 9035 & 9080 & 9071 & -- \\
\hline & 3 & $02 / 25 / 12993$ & $73.0(2.875)$ & $289.6(950.0)$ & -- & -- & -- & -- & -- & 9095 \\
\hline
\end{tabular}

NOTES

$\mathrm{mm}=$ millimeters
in. $=$ inches
$\mathrm{m}=$ meters
$\mathrm{ft}=$ feet

KUT = potassium, uranium, thorium

-- $\quad$ = Logs not run during this logging episode

* Problems were encountered with the density tool response during this episode. 
The final logging episode included borehole deviation logging (inclinometer-gyro tool) only. More detailed equipment information, as well as graphs of the results from each borehole logging episode, are presented for each pilot well in Appendix F.3.

\subsubsection{Summary of Nuclear Logging Results}

Borehole geophysical log results in alluvium (Appendix F.3) are not discussed in detail in this report because they provided little if any useful stratigraphic, mineralogic, and hydrologic information, other than to confirm the homogeneity of the geophysical response. This homogeneous response was not surprising, considering that the laboratory tests conducted on core and drill cuttings samples indicated that the alluvial deposits penetrated by the pilot wells were relatively homogeneous with respect to mineralogical, material, and hydrologic properties (Section 3.0). In addition, the fact that the logs in alluvium were conducted inside at least one steel casing further limited their potential usefulness. Steel casing dampens the response of most logs and greatly limits the usefulness of logging calibration curves, which are usually generated in uncased boreholes. It should be noted that unstable borehole wall conditions in the alluvium required that all $\log$ s be conducted inside the casing.

Several logs provided borehole condition information that was helpful in designing plans for instrumenting and stemming the vadose zone portion of each pilot well (Section 2.5). Both neutron and density logs identified regions in each borehole that were "washed out" (regions where borehole diameters were much larger than bit diameter). Density logs (including both short and long source/detector spacing) decreased significantly in these washed out regions, indicating the presence of void spaces behind the casing. Neutron logs, which are also dependent on formation (and casing) density, responded to these same washed out regions. As expected, the short neutron source/detector-spacing logs (NEUT [S]) responded similarly to density logs, and the long neutron source/detector-spacing logs (NEUT [F]) responded in the opposite direction. Specific intervals of boreholes where washed out regions were significant included:

Well UE5PW-1

112.8 to $173.7 \mathrm{~m}$ (370 to $570 \mathrm{ft})$

213.4 to $231.6 \mathrm{~m}(700$ to $760 \mathrm{ft})$
Well UE5PW-2

121.9 to $167.6 \mathrm{~m}$ (400 to $550 \mathrm{ft}$ ) 210.3 to $216.4 \mathrm{~m}(690$ to $710 \mathrm{ft})$
Well UE5PW-3

109.7 to $137.2 \mathrm{~m}$ (360 to $450 \mathrm{ft})$

Finally, it should be noted that problems were encountered with density log outputs (both short and long source/detector spacings) from Well UE5PW-2 on July 20, 1992. The resulting logs should not be considered representative of either formation or borehole conditions. 
The Ammonia Tanks ash-flow tuff was encountered at approximately $188.2 \mathrm{~m}(617.5 \mathrm{ft})$ in Well UE5PW-3. When logs were conducted in the lower portion of this borehole on November 18, 1992, the 219.1-mm (8.625-mm) casing extended to the depth of approximately $213.4 \mathrm{~m}(700 \mathrm{ft})$. The natural gamma log results show a gradual increase in counts with depth in both the cased (188.2 to $213.4 \mathrm{~m}$ [617.5 to $700 \mathrm{ft}]$ ) and uncased regions (213.4 to $291.0 \mathrm{~m}$ [700 to $955 \mathrm{ft}$ ]) of the borehole. This response may be due to changes in lithology and/or degree of welding (Section 3.1.2).

While the natural gamma log shows a significant response in the uncased tuff region of Well UE5PW-3, neutron and density logs show little variability in this region of the borehole down to a depth of approximately $3.0 \mathrm{~m}(10 \mathrm{ft})$ above the water table (approximately $270.7 \mathrm{~m}$ [888 ft]). This indicates that depth profiles of moisture content and density were relatively constant until approximately $3.0 \mathrm{~m}$ (10 ft) above the water table, where the logs exhibit a response indicative of increasing water content.

Similar responses to increasing water content beginning approximately $3.0 \mathrm{~m}(10 \mathrm{ft})$ above the water table were noted in neutron and density logs in alluvium for Well UE5PW-1 and UE5PW-2. These responses are consistent with water content data from analysis of drill cuttings samples and cores.

\subsubsection{Summary of Borehole Deviation Logs}

Borehole deviation logs were conducted after the 73.0-mm (2.875-in.) O.D. monitoring well tubing was installed in each well. The tool used collects both angle (inclinometer) and direction (gyro) data to correct actual logging cable length to true vertical depth. True vertical depth is required to obtain accurate water table elevation measurements.

The borehole deviation log data for Wells UE5PW-1, UE5PW-2, and UE5PW-3 are provided in Appendices F.3.4, F.3.7, and F.3.10, respectively, along with plan-view graphs of borehole deviation. An error analysis was conducted on individual depth correction measurements, and error bars were developed for the total depth correction. This information is discussed in detail in relation to water table elevation measurements in Section 4.5.1 and Appendix F.5.1.

\subsection{In-Situ Air Permeability Testing}

Air permeability tests were performed to address some of the data requirements for modeling the transport of water vapor, hazardous gases, and radioactive gases in the unsaturated alluvial materials found throughout Area 5. In-situ measurements provide estimates of both the magnitude and variability of the permeability of the gases of concern, as well as a means of 
determining whether laboratory-measured saturated hydraulic conductivities from 76.2-mm (3-in.) core samples are representative of permeabilities measured on a field scale.

In-situ air permeability measurements in Well UE5PW-1, using two different air-injection methods, are described in the following paragraphs.

\subsubsection{Air (Injection) Permeability Tests Below Drill Casing}

Single flow-rate air injection permeability measurements were made during the drilling of Well UE5PW-1 by using the steel drill casing as an air conduit. These injection tests were conducted at two depths, 8.4 and $45.7 \mathrm{~m}$ (27.5 and $150 \mathrm{ft})$, but experimental difficulties prevented collection of data suitable for analysis from the test at $45.7 \mathrm{~m}(150 \mathrm{ft})$.

Prior to beginning these tests, the drill rods, air-percussion hammer, and drill bits were removed from the borehole. Air was then injected into an uncased portion of the borehole approximately $304.8 \mathrm{~mm}$ (12 in.) in diameter and $152.4 \mathrm{~mm}$ (6 in.) long. This cylindrical cavity, created by the pilot and reamer bits during drilling, was located at the base of the outer 273.0-mm (10.75-in.) casing. It was assumed that the annular space between the drill casing and formation did not provide a preferential flow path. Air pressure was monitored in two 25.4-mm (1.0-in.) O.D. by 12.7-mm (0.5-in.) I.D. monitoring holes installed using the Geoprobe hydraulic punch at horizontal distances of 4.6 and $9.1 \mathrm{~m}$ (15 and $30 \mathrm{ft}$ ) from the Well UE5PW-1 collar. The Geoprobe holes were installed to a depth of $9.1 \mathrm{~m}(30 \mathrm{ft})$.

Data were analyzed using the extended Darcy equation. The air permeability for the injection test at $8.4 \mathrm{~m}(27.5 \mathrm{ft})$ was found to $7.8 \times 10^{-12} \mathrm{~m}^{2}$ (7.8 darcy [D]) using data from both the 4.6- and 9.1-m (15- and 30-ft) Geoprobe holes, which demonstrated good experimental reproducibility using this method. This value agrees well with field measurements of air permeability of NTS alluvium reported in the literature (Pasternak and McMullen, 1970; Morris et al., 1971; Snoeberger et al., 1974; Rozsa et al., 1975).

These tests were not repeated at additional depths in Well UE5PW-1 or the other pilot wells for several reasons. Among the key reasons for not repeating the tests were: the expense of the drill rig for standby time while conducting these tests; the additional disturbance of in-situ gas composition and possibly the hydrologic conditions of the formation by the injection of large volumes of air into the formation; and numerous experimental difficulties encountered during the in-situ testing. 


\subsubsection{Post-Drilling Air (Injection) Permeability Testing}

Injection tests were conducted in the type B instrument stations, which consisted of one $20.7-\mathrm{mm}$ (0.814-in.) I.D. nylon injection tube and one 4.6-mm (0.18-in.) I.D. stainless-steel piezometer

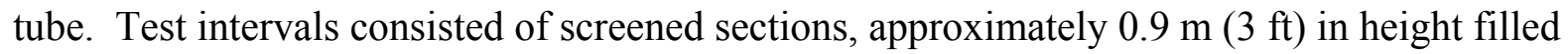
with coarse sand. The annular space above and below the screened section was sealed with a low permeability mixture of bentonite and sand. The depths and dimensions of the air permeability stations in the pilot wells are listed in Appendix F.4.1. Most of the test intervals were located in unsaturated alluvial deposits. Laboratory analysis of cores taken during drilling indicated that the hydraulic properties of these deposits were remarkably constant with depth. The only interval not located within alluvium was the 210-m (689-ft) testing interval in Well UE5PW-3, located in the rhyolitic ash-flow tuff unit (Section 3.1.2).

The tests consisted of injecting air into the screened interval (through the 20.7-mm [0.814-in.]) nylon tube) at a constant flow rate until the pressure in the interval (measured at the ground surface in the stainless-steel piezometer tube) reached a steady value (less than $0.7 \mathrm{kPa}[0.1 \mathrm{psi}]$ change in 10 minutes). In most cases this occurred within 15 minutes. The injection flow rate was then increased and a new steady-state pressure was obtained. A minium of 4 steady-state pressures corresponding to four constant flow rates were measured for each screen interval.

In Well UE5PW-1, tests were successfully conducted in the test intervals at the depths of 45.7, 73.2, and $107.0 \mathrm{~m}(150,240$, and $350 \mathrm{ft})$. Application of $552 \mathrm{kPa}$ (80 psi) air pressure to the interval at $183 \mathrm{~m}(600 \mathrm{ft})$ resulted in a flow rate of only 3.4 cubic meters per hour ( 2 cubic feet per minute) with no detectable pressure increase in the interval. The lack of flow and pressure response indicated that this injection line possibly became plugged during stemming, and no further testing was conducted in this interval. In Well UE5PW-2, tests were completed in the intervals at 45.7, 76.2, 122.0, and $183.0 \mathrm{~m}(150,250,400$, and $600 \mathrm{ft})$. In Well UE5PW-3, tests were successfully completed in the intervals at $76.2,107.0$, and $210.0 \mathrm{~m}(250,350$, and $689 \mathrm{ft})$. Flow and pressure testing from the 168-m (550-ft) testing interval in Well UE5PW-3 resulted in an atypically low permeability estimate that may have been due to contamination of the testing interval with stemming material. The test data are summarized in Appendix F.4.2. Test results were analyzed using a form of Darcy's law modified for compressible flow. If inertial effects were observed, an integrated form of the Forchheimer equation was used (Katz et al., 1959).

The estimates of apparent permeability and inertial coefficients obtained from the pilot wells are found in Appendix F.4.3. Permeabilities range from $0.9 \times 10^{-12}$ to $47 \times 10^{-12} \mathrm{~m}^{2}$ (0.9 to $47 \mathrm{D}$ ). 
These values are consistent with both the permeability values measured below the drill casing described in Section 4.4.1, and with the previous NTS studies cited above.

Permeabilities to water were determined on 60 core samples. The mean value of liquid permeability for these samples was $1.1 \times 10^{-12} \mathrm{~m}^{2}(1.1 \mathrm{D})$. The mean value for air permeability for the tested intervals, excluding the test in the tuff unit, was $12 \times 10^{-12} \mathrm{~m}^{2}$ (12 D). Permeability to air and water differed by approximately an order of magnitude. This was expected, as permeability to air of geologic materials generally exceeds permeability to water, due to interactions of water and matrix materials. Air permeability was determined in the laboratory on three unfractured core samples of the tuff. The mean permeability from these laboratory measurements was $4.3 \times 10^{-12} \mathrm{~m}^{2}$ (4.3 D). The air permeability obtained from injection tests in the tuff unit at $210 \mathrm{~m}(689 \mathrm{ft})$ in Well UE5PW-3 was $18 \times 10^{-12} \mathrm{~m}^{2}(18 \mathrm{D})$. This larger value from the in-situ tests suggests that the tuff unit is fractured at depth.

Because the stress induced in the formation by an air injection test is rapidly dissipated, the air permeability stations in th pilot wells can be tested repeatedly. Since the permeability is a strong, highly non-linear function of water content, these tests could potentially be used to monitor changes in water content. For example, an observed decrease in permeability would suggest an increase in water content.

\subsection{Upper Aquifer Hydraulic Parameter Testing}

\subsubsection{Water Table Elevations and Gradient}

The three pilot wells have defined an almost horizontal water table below the Area 5 RWMS. Water level measurements were made from the top of the monitoring well casing in each pilot well by REECo SPS personnel using an Solonist E-tape. The recorded depth and calculated water level elevations (not corrected for borehole deviation) are presented in Table 4-2. These measurements indicate little variation in the water table, and the changes that are seen are probably within the precision and accuracy of the instrument. U.S. Geological Survey (USGS) personnel also made water level measurements in each pilot well with a Solonist E-tape (an older instrument than the REECo E-tape), and these are also presented in Table 4-2. The USGS measurements indicated a slightly deeper water table than the REECo measurements taken on the same day. The USGS also used a calibrated steel tape (accurate to $\pm 0.003 \mathrm{~m}[ \pm 0.01 \mathrm{ft}]$ ) to measure the depth to water. 


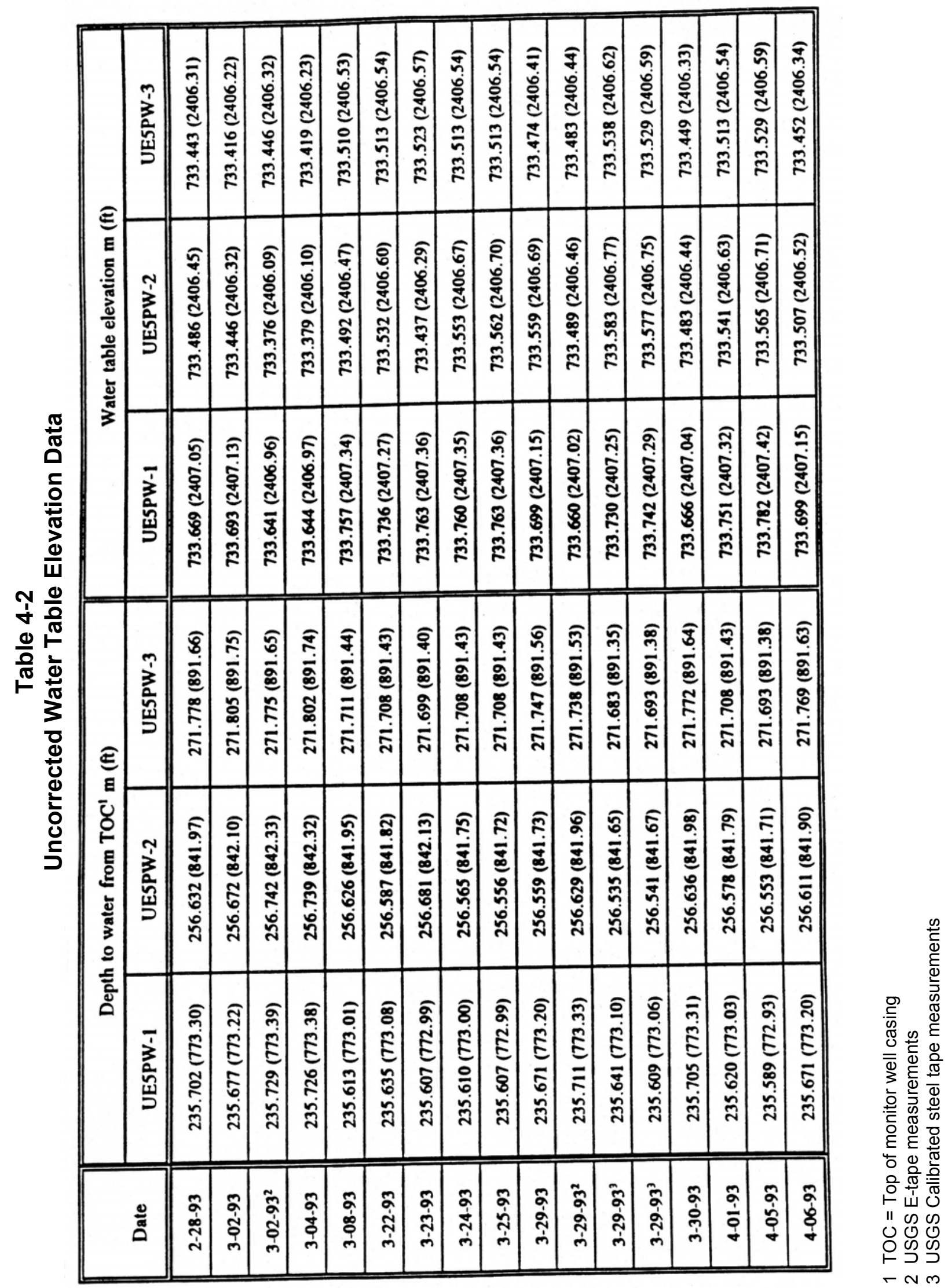


A borehole geophysical deviation survey log was run in each borehole (Section 4.3.3) to attempt to correct for borehole deviations from a vertical straight line. It should be emphasized that the error in the deviation logs may be equal to or greater than the differences in the uncorrected water table elevations. For example, data from the manufacturer and operator of the deviation tool (Century Geophysics Corporation) indicate that the error in the corrected depth provided by this tool is $\pm 0.15 \mathrm{~m}( \pm 0.5 \mathrm{ft})$. This error is as large as the difference observed between water table elevations. In addition, estimated errors arising from the use of a water level measurement tape are on the order of $\pm 0.03 \mathrm{~m}( \pm 0.1 \mathrm{ft})$, and the error associated with surveying of casing elevations is probably somewhat less. Because of these uncertainties, it only reasonable to conclude that differences in water table elevations are within the error of the measurement. The correction factors for Well UE5PW-1, UE5PW-2, and UE5PW-3 are $-0.08,-0.21$, and $-0.02 \mathrm{~m}$ $(-0.27,-0.68$, and $-0.06 \mathrm{ft})$, respectively. The elevations and coordinates of the top of each monitoring well casing were surveyed by REECo Engineering personnel and are listed in Table 2-2.

Various methods were employed to determine the shape of the water table below the Area 5 RWMS utilizing available water table elevations. The shape of the water table must be known to estimate the gradient and the direction of groundwater flow. These methods include a planar approximation and a statistical analysis that incorporates uncertainties in measurements (Appendix F.5.1). The conclusion reached from these analyses are similar: the water table below the Area 5 RWMS is approximately horizontal. Without elevation differences, the gradient is nearly zero and there will be essentially no horizontal movement in the uppermost aquifer.

\subsubsection{Hydraulic Conductivity Recovery Tests}

In-situ hydraulic conductivity tests were conducted in the pilot wells following standard slug test techniques (Table 2-1). Standard single-well pump test methods that would provide more reliable estimates of the uppermost aquifer hydraulic properties could not be conducted in the pilot wells primarily because of the small diameter of the monitoring well tubing and the great depth to water. The high volume, multi-stage pumps required to stress the permeable, relatively coarse-grained uppermost aquifer, approximately $243.8 \mathrm{~m} \mathrm{(800} \mathrm{ft)} \mathrm{below} \mathrm{the} \mathrm{ground} \mathrm{surface,} \mathrm{are}$ not available in small enough size to fit inside the $63.5-\mathrm{mm}$ (2.5-in.) I.D. monitoring well tubing. Pumps that do fit in this tubing and are capable of lifting at least $243.8 \mathrm{~m}$ (800 ft) (e.g., Bennett sample pumps) are, without exception, not capable of the high flow rates required to create drawdowns in the alluvial aquifer. 
Following well development (Section 2.6), in-situ hydraulic conductivity tests were conducted according to procedures in ASTM D 4044-91 (1992). A 38.1-mm (1.5-in.) O.D. by 6.1-m (20-ft) long mechanical slug was submerged in the screened interval of each pilot well. The water level was allowed to stabilize, then the slug was rapidly removed and the recovery of the aquifer versus time was monitored. Hydraulic conductivity values were calculated from a plot of the recovery data (log of water levels) versus time. Data were analyzed assuming the aquifer was partially penetrated, unconfined (or leaky confined), and incompressible. The average conductivities for Wells UE5PW1, UE5PW-2, and UE5PW-3 were $1.3 \times 10^{-3}, 3.4 \times 10^{-4}$, and $1.4 \times 10^{-3} \mathrm{~cm} / \mathrm{s}(1.8,0.5$, and $2.0 \mathrm{in} . / \mathrm{hr})$, respectively. The results of the individual slug tests are presented in Appendix F.5.2. The mean in-situ hydraulic conductivity values calculated for the upper portion of the alluvial aquifer in Wells UE5PW-1 and UE5PW-2 were nearly identical to the mean hydraulic conductivities calculated from core samples collected over the entire depth of each borehole. The mean in-situ hydraulic conductivity calculated for the upper portion of the tuff aquifer (Well UE5PW-3) is within the range of hydraulic conductivities previously measured on bedded tuff core samples collected at the NTS (Winograd and Thordarson, 1975).

In addition, a separate slug test was conducted during the final stages of drilling Well UE5PW-1 in an uncased portion of the borehole (occupied by the drill and reamer bits during drilling) located directly below the casing. Prior to the test, the drill string was removed from the borehole, leaving an uncased cylindrical cavity measuring approximately $304.8 \mathrm{~mm}$ (12 in.) in diameter by $152.4 \mathrm{~mm}$ (6 in.) long available for testing. The mechanical slug was rapidly lowered into the water, and the aquifer recovery rate was monitored. The same assumptions (described above) were made in analyzing the recovery data. The hydraulic conductivity value calculated from these data $\left(5 \times 10^{-8} \mathrm{~cm} / \mathrm{s}\left[7 \times 10^{-5} \mathrm{in} . / \mathrm{hr}\right]\right)$ is many order of magnitude less than the mean conductivities calculated by the recovery test method described above and mean values from laboratory tests on core samples. The reason for the differences in these values may be that the exposed walls of the formation in the small cylindrical cavity might have been smeared with fine materials during drilling, which in turn greatly reduced the hydraulic conductivity.

Alternatively, the slug tests in the 63.5-mm (2.5-in.) monitoring well tubing described previously, did not stress the aquifer enough to provide recovery data representative of the formation. However, comparisons of saturated hydraulic conductivity from core samples (Section 3.3.1) indicate that this slug test was anomalous. 


\subsection{Neutron Logging Calibration Boreholes}

Three shallow boreholes planned for calibration of the neutron-moisture meter were drilled and cased with the three different-size CAU drilling systems used in the pilot well project. These boreholes were installed when the drill casing became stuck during the drilling of Well UE5PW-2. The drilling operations at Well UE5PW-2 could not continue for about a week until equipment could be brought onsite to free the casing. Rather than put the drilling rig and crew on "standby time," it was decided to drill and sample three 12.2-m (40-ft) deep boreholes approximately $61 \mathrm{~m}$ (200 ft) from Well UE5PW-2 that could be used as calibration holes for a neutron-moisture meter and other borehole geophysical logging tools.

Neutron-moisture meter logging through large diameter steel casing has been proven to be a valuable method of monitoring changes in water content in alluvium at the NTS (Tyler, 1986). It was determined that this type of logging would prove useful during and after drilling of future vadose zone exploratory and monitoring wells with the CAU drilling system at the Area 5 RWMS. REECo SPS operated a CPN Model 503DR neutron-moisture meter for vadose zone monitoring of a mixed-waste storage facility, and the meter was readily available for logging in CAU drilling system boreholes.

The calibration boreholes, UE5PW-2A, UE5PW-2B, and UE5PW-2C, were drilled with 219.1-mm (8.625-in.) O.D., 193.7-mm (7.625-in.) O.D., and 273.0-mm (10.75-in.) O.D. CAU drilling system casing, respectively. The threaded connections on these casing sections had been damaged slightly during previous drilling activities and were not suited for deep drilling, which made these casings ideal for use in the shallow calibration holes.

A shallow trench was excavated and filled with water for several days to create a wetting front with depth. The boreholes were then drilled in the trench, and core and drill cuttings samples were collected. The geologic samples collected from these boreholes were subjected to the same laboratory tests as samples from the pilot wells (Table 3-2). Neutron-moisture logs were conducted immediately after completing each cased borehole, and were conducted periodically after completion. Depth profiles of neutron-moisture meter counts measured just after borehole completion are correlated with the volumetric water content from core samples to obtain calibration curves (relating counts to water content) for these different sized casings. Appendix $\mathrm{G}$ contains all data pertinent to drilling, sampling, laboratory results, neutron-moisture meter logs, and calibrations for these shallow test holes. 
This page intentionally left blank. 


\subsection{Upper Aquifer Water Quality}

\subsection{RCRA Groundwater Sampling and Analysis}

A primary objective of the pilot well project was to characterize the water quality of the uppermost aquifer under the Area 5 RWMS. With this in mind, a test plan was developed that was consistent with the detection and monitoring requirements of 40 CFR 264 (Table 2-1), and initial samples were collected from Well UE5PW-1 and analyzed. Based on this initial sampling and analysis activity, a standard operating procedure was developed to implement a groundwater characterization program at all three pilot wells. Field and laboratory testing results from the initial samples collected at Well UE5PW-1 are presented and discussed in the following paragraphs.

Groundwater samples were collected with a submersible stainless-steel, double-action piston pump operating at a flow rate of approximately $2 \mathrm{~L} / \mathrm{min}(0.5 \mathrm{gal} / \mathrm{min})$. Three wellbore volumes were purged prior to sample collection. Water temperature, $\mathrm{pH}$, specific conductance, and eH were monitored during purging and sample collection. Standard QA procedures (Table 2-1) were followed for sample collection and analysis (e.g., procedures identifying standard containers, preservatives, filtration, holding times, blanks, replicates, chain of custody, accuracy, and precision). See Appendix H.1 for descriptions of sample collection methods and a brief discussion of these results.

The chemical parameters analyzed and methods used are summarized in Table 5-1. All analyses were performed by the REECo Analytical Services Department, with the exception of total organic carbon (TOC), total organic halogens (TOX), and herbicides, for which samples were sent to subcontracted testing laboratories.

In summary, the concentrations of all parameters, including those required to assess the suitability of groundwater as drinking water, and parameters to establish groundwater quality, are below applicable standards. The only exceptions were manganese and possibly chromium. Manganese exceeds the state of Nevada secondary standards for drinking water. Chromium was not detected, but the detection limit was slightly higher than the state of Nevada primary standards for drinking water. The mean value of the $\mathrm{pH}(8.13)$ and specific conductance (0.0389 Siemens per meter [0.389 mmhos per centimeter]) were indicative of good quality drinking water. 
Table 5-1

Testing Laboratories, Chemical Parameters, and Analytical Methods

\begin{tabular}{|c|c|c|}
\hline Laboratory & Sample Parameters & Method \\
\hline REECo ASD ${ }^{a}$ & Volatile Organics & $8240^{b}$ \\
\hline DataChem Laboratories & Total Organic Halogen & $9020^{b}$ \\
\hline DataChem Laboratories & Total Organic Carbon & $9060^{b}$ \\
\hline REECo ASD & Oil and Grease & $413.2^{\mathrm{C}}$ \\
\hline REECo ASD & $\begin{array}{l}\text { Pesticides/PCBs: } \\
\text { Toxaphene, Lindane, Methoxychlor, Endrine }\end{array}$ & $8080^{b}$ \\
\hline DataChem Laboratories & Herbicides & $8150^{b}$ \\
\hline REECo ASD & Semi-volatile Organics & $8270^{b}$ \\
\hline REECo ASD & $\begin{array}{l}\text { Total Metals: } \\
\text { As, Ba, } \mathrm{Cd}, \mathrm{Cr}, \mathrm{Fe}, \mathrm{Hg}, \mathrm{Mn}, \mathrm{Na}, \mathrm{Pb}, \mathrm{Se}\end{array}$ & $6010^{b}$ \\
\hline REECo ASD & Total Silver & $6010^{b}$ \\
\hline REECo ASD & Cyanide & $335.2^{c}$ \\
\hline REECo ASD & Chloride, Sulfate, Fluoride, Nitrate & $300^{c}$ \\
\hline REECo ASD & Total Gross Alpha/Beta Gamma Spectroscopy & AABAB.D.04.30 \\
\hline REECo ASD & ${ }^{90}$ Strontium & AABAB.D.04.40 \\
\hline REECo ASD & ${ }^{99}$ Technetium & AAHCD.D.04.40 \\
\hline REECo ASD & Total Uranium & AABAB.D.04.20 ${ }^{\mathrm{d}}$ \\
\hline REECo ASD & ${ }^{131}$ Iodine & AABAB.D.04.55 \\
\hline REECo ASD & $238,239,240$ Plutonium & AABAB.D.04.10 \\
\hline REECo ASD & ${ }^{226,228}$ Radium & AAHCD.D.04.07 \\
\hline REECo ASD & $\begin{array}{l}\text { Dissolved Metals: } \\
\text { As, } \mathrm{Ba}, \mathrm{Cd}, \mathrm{Cr}, \mathrm{Fe}, \mathrm{Hg}, \mathrm{Mn}, \mathrm{Na}, \mathrm{Pb}, \mathrm{Se}\end{array}$ & $6010^{b}$ \\
\hline REECo ASD & Dissolved Silver & $6010^{b}$ \\
\hline REECo ASD & $\begin{array}{l}\text { Dissolved Gross Alpha/Beta Gamma } \\
\text { Spectroscopy }\end{array}$ & AABAB.D.04.30 ${ }^{d}$ \\
\hline REECo ASD & Total Dissolved Solids & $160.1^{c}$ \\
\hline REECo ASD & Tritium & $\begin{array}{l}\text { AABAB.D.04.70 } \\
\text { (Electrolyte Enrichment) }\end{array}$ \\
\hline
\end{tabular}

a Reynolds Electrical and Engineering Company, Analytical Services Department

b Test Methods for Evaluating Solid Waste, Physical/Chemical Methods, U.S. Environmental Protection Agency (USEPA), SW-846

c Methods for Chemical Analysis of Water and Wastes, USEPA, EPA-600/4-82-055, 1982

d REECo ASD Standard Operating Procedure 
Finally, organic contamination indicator parameters (TOC and TOX) were below or near detection levels. In conclusion, the initial sampling and analyses of groundwater from Well UE5PW-1 indicate that it is of high quality and meets all standards concerning hazardous and radioactive constituents.

\subsection{Preliminary Comparison of General Water Chemistry}

A preliminary general chemical analysis of groundwater samples collected from the pilot wells and several existing wells in the northern part of Frenchman Flat was conducted by DRI. The general chemical parameters analyzed included $\mathrm{pH}$, conductivity, major cations, anions, and several other indicator parameters. The purpose of this activity was to compare the general chemistries of the pilot wells and surrounding wells, to begin to characterize the variability in the water chemistry of the uppermost alluvial aquifer, and to obtain geochemical information relating to the possible sources(s) of these waters and therefore possible directions of flow. Details of the methods used, together with the results from this preliminary general water chemistry survey, are presented in Appendix H.2. A summary is presented in the following paragraphs.

Results discussed here are preliminary. For example, groundwater samples were collected from undeveloped pilot wells and the results may not be representative of in-situ water. Samples from a number of the surrounding wells were collected from screened intervals that are significantly below the uppermost zone sampled in the pilot wells.

Water quality data from Wells UE5PW-1 and UE5PW-3, UE5n, and six nearby wells, all located in the Frenchman Flat area, were collected and analyzed by DRI. Water samples from the two pilot wells and Well UE5n were collected in January and February of 1993, and submitted for gross chemical analysis, stable isotope analysis, and enriched tritium counting. Water chemistry data for the six nearby wells were obtained from data sets archived by DRI from past analyses. The conclusions are:

- The gross chemical analyses for Wells UE5PW-1 and UE5PW-3 are very similar.

- These pilot well waters can be characterized as sodium bicarbonate waters with a total dissolved solid content of approximately 360 milligrams per liter.

- All of the samples from the pilot wells were saturated with respect to calcite, dolomite, and several forms of silica and calcium-magnesium sulfates.

- Pilot well water chemistry was most similar to that of Water Well 4, located to the northwest, but presumably hydraulically separated from the pilot wells by the Cane Spring fault. 
- Analysis of the data with Stiff diagrams and tri-linear plots reveals that the pilot wells are higher in calcium and magnesium, relative to sodium, than most other wells.

DRI concluded that the groundwater from the pilot well area has had more contact with the carbonate material than water sampled elsewhere in Frenchman Flat. The report states that this is most likely to have occurred by percolation through alluvium derived from carbonate rocks from the CP Hills area north of Water Well 4 and from Nye Canyon, located east of the Area 5 RWMS. Further, DRI reported that water samples from Well UE5n, located in the west-central part of Frenchman Flat, were relatively calcium-poor, while still saturated with calcite. These findings were interpreted to mean that water from this well originated in volcanic terrain found to the west, or alternatively, that the water originated from downward percolation through carbonate-poor alluvial material in this area. 


\subsection{Preliminary Vadose Zone Monitoring Data}

The installation and stemming of thermistors, air pressure transmitters, and thermocouple psychrometers at type A instrument stations were described in Section 2.5.1. Calibration procedures, together with preliminary data collected to date, are briefly described in the following paragraphs. Delays in electric power distribution to each pilot well site has limited the data collection activities, but portable data loggers/controllers demonstrated that the instruments are in working order.

\subsection{Temperature Profile Data}

The thermistors were calibrated for each mode of operation (resistance and voltage drop) following the methods developed by the USGS (J. Rousseau, 1993) for the Yucca Mountain Project (USGS, 1990). These methods were made available through a Department of Energy technology transfer program. Summary calibration data are presented in Appendix I.1.

To date, thermistor temperatures (voltage drop method) have been measured at type A instrument stations in all three pilot wells. Temperature data were collected for Wells UE5PW-1 and UE5PW-3 in mid-April 1993. Due to instrumentation problems, data were not collected from Well UE5PW-2 until mid-July 1993. Preliminary temperature profile data are plotted in Figure 6-1 and tabular temperature data are presented in Appendix I.2. A high temperature measured at the 30.5-m (100-ft) level in Well UE5PW-3 is not plotted because it is probably an anomaly resulting from heat being generated from the nearby cement plug (Section 2.5.2) which had recently been poured. A similar anomaly was detected at the $30.5-\mathrm{m}(100-\mathrm{ft})$ level in Well UE5PW-2, and likewise was not plotted. Thermal gradients, per $304.8 \mathrm{~m}$ (1,000 ft), of

2.06, 4.30, and $3.83{ }^{\circ} \mathrm{C}\left(35.7,39.7\right.$, and $\left.38.9^{\circ} \mathrm{F}\right)$ in Wells UE5PW-1, UE5PW-2, and UE5PW-3, respectively, were calculated from these temperature profiles. Additional monitoring data are needed to determine if instrument stations are in thermal equilibrium with the formation and whether the observed differences in thermal gradients between boreholes are significant.

\subsection{Formation Air Pressure Profile Data}

Factory calibrations supplied with Druck PTX pressure transmitters are summarized in Appendix I.3 for the instruments installed in the three pilot wells. These pressure transmitters 


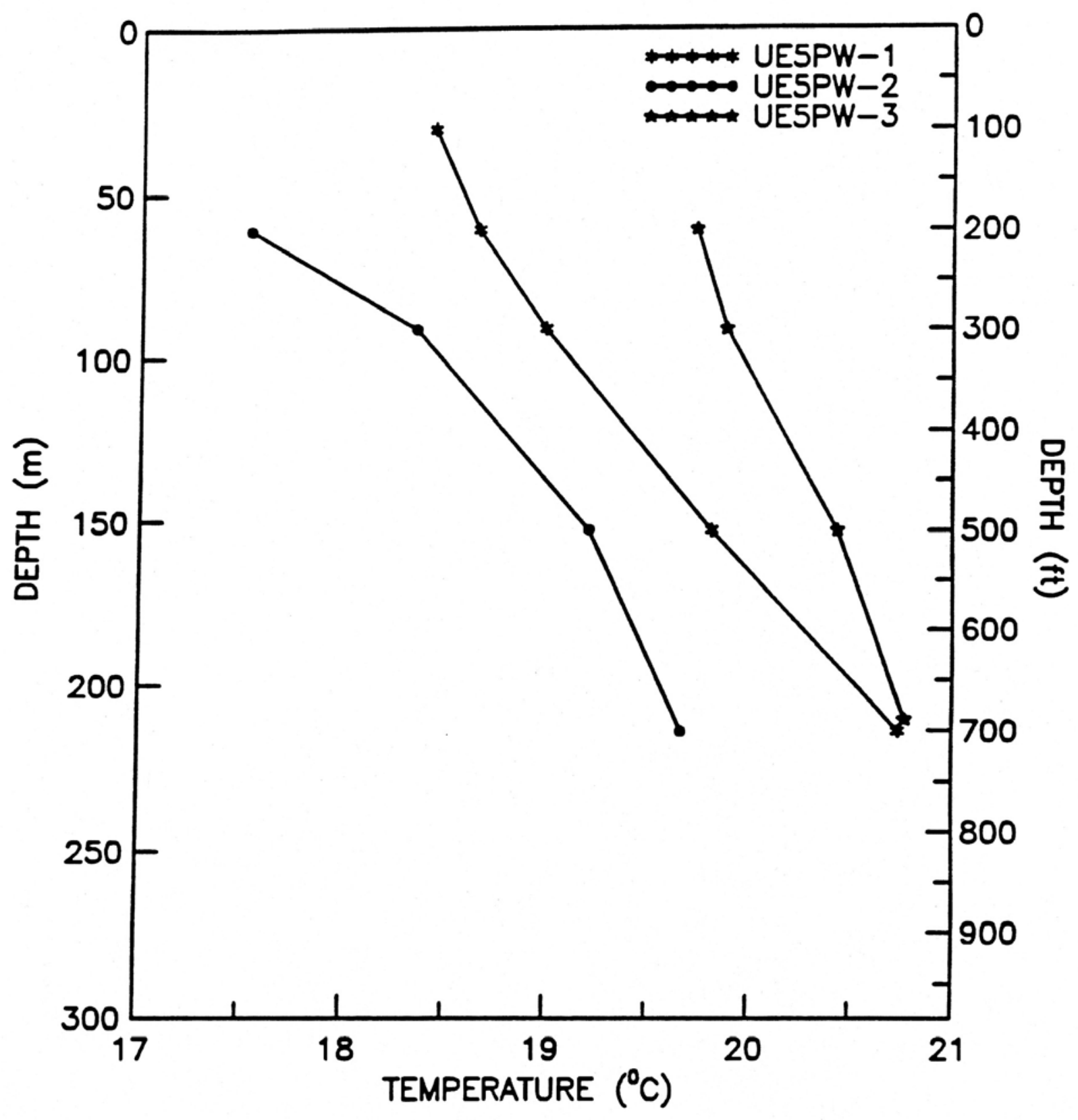

Figure 6-1

Depth Profiles of In-Situ Temperatures from the Pilot Wells 
were also independently calibrated by the Physical Standards and Calibration Laboratory operated by REECo. However, problems identified with the calibration methods used by REECo have prevented the use of these calibration data.

Preliminary formation air pressure measurements made at type B instrument stations in Wells UE5PW-1 and UE5PW-3 are summarized in Appendix I.4. It is difficult to determine if these measurements accurately reflect formation air pressures without monitoring these instruments as well as atmospheric air pressure over a period of time to observe at least several high and low pressure waves. However, these preliminary data indicate that nearly all transmitters are operational and produce readings that appear to be within a reasonable range.

\subsection{Water Potential Profile Data}

Thermocouple psychrometer design, calibration equipment and methods, and field data acquisition systems developed by the USGS for the Yucca Mountain Project (USGS, 1993) were adopted for the pilot well project. The USGS (Rousseau, 1993) shared both calibration equipment and expertise. Tables of the calibration coefficients are in Appendix I.5.

A portable rack-mounted data acquisition system was built to perform baseline monitoring of the in-situ thermocouple psychrometers. Preliminary in-situ psychrometer data obtained are presented in Appendix I.6 and in Figure 6-2. Water potential profile data (distance is positive downwards) show a positive gradient (upward flow) in the upper $61 \mathrm{~m}$ (200 ft). At greater depths the potential gradient becomes nearly zero and constant. These preliminary in-situ psychrometer data compare favorably with the water potentials measured in the laboratory for core samples (Section 3.4.2). 


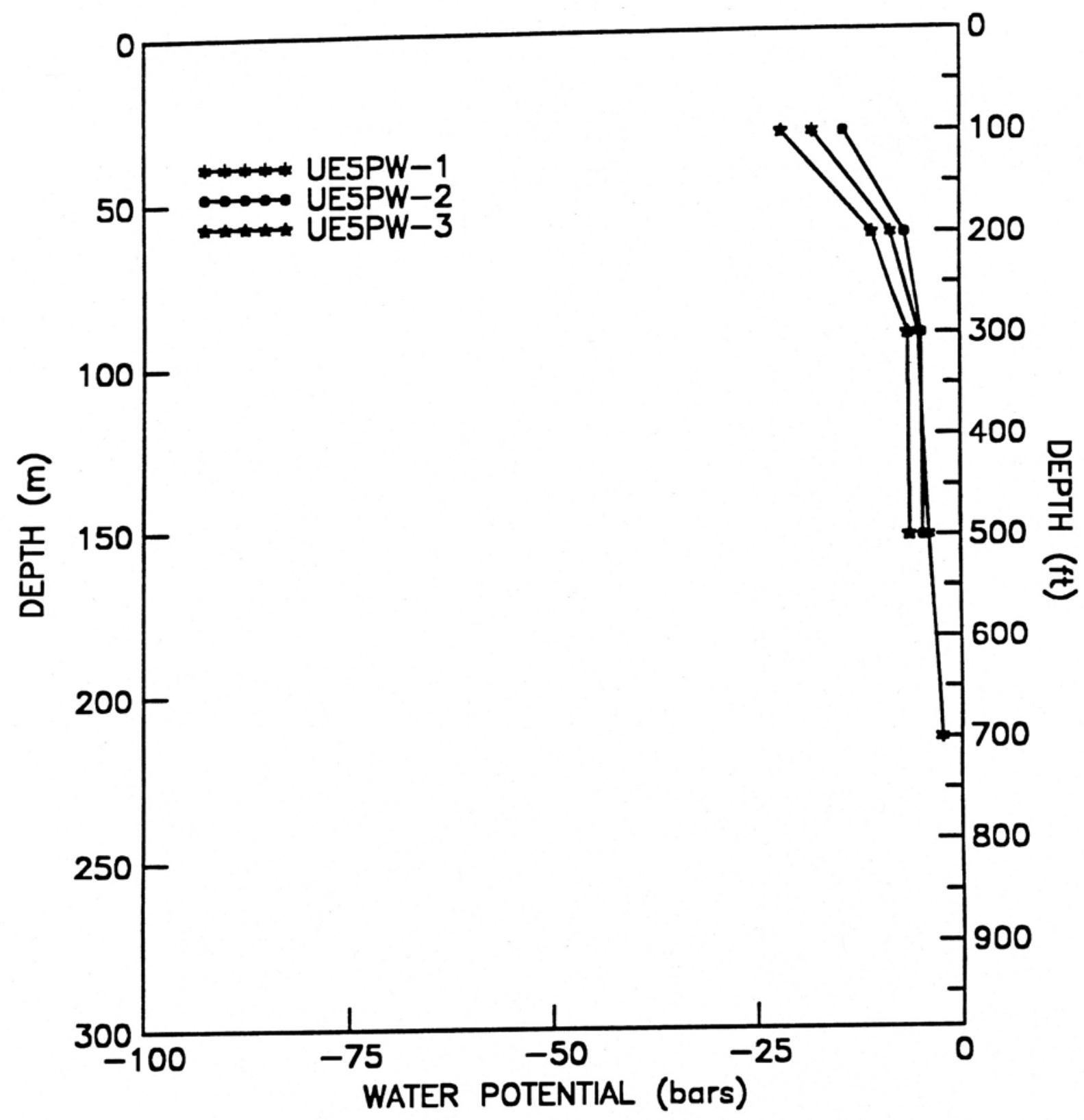

Figure 6-2

Depth Profiles of In-Situ Psychrometer Data from the Pilot Wells 


\subsection{Summary}

Three pilot wells were drilled and completed to the uppermost aquifer in the vicinity of the Area 5 RWMS in Frenchman Flat to meet data needs mandated by regulatory requirements applicable to the disposal of low-level, mixed, and high-specific-activity waste at this site. This series of boreholes was specifically designed to characterize the hydrogeology of the thick vadose zone and to help define the water quality and hydraulic characteristics of the uppermost aquifer.

This report describes the methods and results of the following activities:

- Pilot well borehole drilling

- Geologic sample collection

- Field geologic descriptions

- Laboratory testing of geologic samples

- Well and vadose zone monitoring system completion

- Geophysical logging and other in-situ testing

- Well development and in-situ aquifer testing

- Preliminary groundwater sampling and analyses

- Preliminary vadose zone monitoring

These results (data) are required to understand and model flow and transport processes both in the vadose zone and uppermost aquifer. This report provides only qualitative analyses and preliminary interpretations.

Some of the important findings are:

- The thick alluvial deposits penetrated by each pilot well are lithologically homogeneous and do not contain layers of secondary carbonate.

- The alluvial deposits are virtually homogeneous with respect to particle size distributions and are primarily composed of sands with some gravel and small amounts of fines.

- Hydrologic properties, including porosity, saturated hydraulic conductivity, moisture retention relations, and unsaturated hydraulic conductivity are typical of coarse-grained materials.

- Alluvial deposits are very dry near the surface and moisture increases only slightly with depth until a capillary fringe is reached approximately $3 \mathrm{~m}(10 \mathrm{ft})$ above the water table.

- Water potential measurements on core samples show a large positive potential gradient (water tends to move upward, rather than downward) in the upper $30.5 \mathrm{~m}(100 \mathrm{ft})$ in each borehole, and a nearly zero potential gradient throughout the remaining portion of the vadose zone. 
- Unsaturated hydraulic conductivity data, together with water potential data, indicate that very little liquid flow is occurring (if any) throughout the thick alluvial deposits, and the direction of liquid flow is upward in the upper portion of the vadose zone.

- Because liquid water movement is virtually negligible in the upper vadose zone, vapor movement is probably the dominant mechanism of water movement in this region.

- Environmental tracer measurements of chloride, bromide, sulfate, hydrogen and oxygen stable isotopes, and cosmogenic chlorine-36 concentrations in soil water versus depth provide strong evidence that the direction of movement for both liquid water and vapor in the upper vadose zone is upward in response to the evaporative demand of the present arid climate.

- Further, environmental tracer data suggest that water which is presently in the lower vadose zone infiltrated under a more humid climate, when evaporation was not an important process.

- The limited data collected from the tuff units underlying the alluvium below $188.2 \mathrm{~m}$ $(617.5 \mathrm{ft})$ in Well UE5PW-3 indicate that they have properties similar to those previously reported for these units.

- A variety of geophysical and in-situ hydrologic and pneumatic tests support results from core and drill cuttings data which suggest that vadose zone and uppermost aquifer alluvial deposits can be considered a homogeneous hydrogeologic system.

- Preliminary water quality data from each pilot well indicate that hazardous and radioactive constituents do not exceed appropriate standards in the uppermost aquifer.

- The uppermost water table gradient is nearly horizontal, with essentially a zero slope and no horizontal movement.

- Vadose zone monitoring instruments and equipment, which were stemmed in place around the central monitoring well casing in each pilot well, are being used to make insitu measurements of important hydrologic and pneumatic parameters and to monitor changes in these parameters over time. 


\subsection{References}

Allison, G. B., 1982. The Relationship Between ${ }^{18} \mathrm{O}$ and Deuterium in Water in Sand Columns Undergoing Evaporation. Journal of Hydrology, v. 55, pp. 163-169.

Allison, G. B., and M. W. Hughes, 1983. The Use of Natural Tracers as Indicators of SoilWater Movement in a Temperate Semi-Arid Region. Journal of Hydrology, v. 60, pp. 157-173.

ASTM D 2216-80, 1980. "Method for Laboratory Determination of Water (Moisture) Content of Soil, Rock, and Soil-Aggregate Moisture.” In: 1987 Annual Book of ASTM Standards, Vol. 04.08, American Society for Testing and Material. Philadelphia, PA.

ASTM D 2434-68, 1974. "Test Method for Permeability of Granular Soils (Constant Head)." In: 1987 Annual Book of ASTM Standards, Vol. 04.08, American Society for Testing and Material. Philadelphia, PA.

ASTM D 2325-68, 1981. "Test Method for Capillary Moisture Relationships for Coarse- and Medium-Textured Soils by Pressure-Plate Apparatus." In: 1987 Annual Book of ASTM Standards, Vol. 04.08, American Society for Testing and Material. Philadelphia, PA.

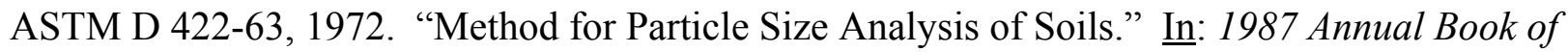
ASTM Standards, Vol. 04.08, American Society for Testing and Material. Philadelphia, PA.

ASTM D 2579-85, 1990. “Test Method for Determining Total Organic Carbon.” In: 1990 Annual Book of ASTM Standards, Vol. 11.02, American Society for Testing and Material. Philadelphia, PA.

ASTM D 2488-90, 1990. "Standard Recommended Practice for the Description of Soils - Visual Manual Procedure." In: 1990 Annual Book of ASTM Standards, Vol. 04.08, American Society for Testing and Material. Philadelphia, PA.

ASTM D 4044-91, 1992. "Standard Test Method (Field Procedure) for Instantaneous Change in Head (Slug Test) for Determining Hydraulic Properties of Aquifers." 프: ASTM Standards on Groundwater and Vadose Zone Investigations (PCN: 03-418192-38), American Society for Testing and Material. Philadelphia, PA.

Bechtel Nevada, 2005. Hydrogeologic Characterization Data from the Area 5 Shallow Soil Trenches, Revision 1. DOE/NV/11718--1060.

Blake, G. R., and K. H. Hartge, 1986. "Bulk Density.” In: Klute, A. L. (ed.), Methods of Soil Analysis, Part I, Physical and Mineralogical Methods, $2^{\text {nd }}$ Edition, American Society of Agronomy, Madison, WI. Chapter 13, pp. 363-367. 
Blinov, A., 1988. The Dependence of Cosmogenic Isotopic Production Rate on Solar Activity and Geomagnetic Field Variations. In: Stephenson, F. R., and A. .W. Wolfendale, eds.,

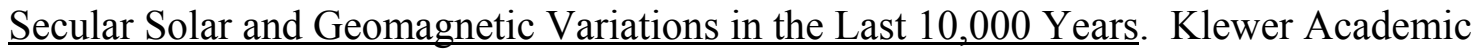
Publishing Co., Nordrecht, Netherlands, pp. 329-340.

BN, see Bechtel Nevada.

Byers, F. M., Jr., P. P. Orkild, W. D. Quinlivan, and K. A. Sargent, 1976. Volcanic Suites and Related Cauldrons of the Timber Mountain-Oasis Valley Caldera Complex, Southern Nevada. U.S. Geological Survey Professional Paper 919.

Campbell, G. S., and G. W. Gee, 1986. "Water Potential Measurement Using the Filter Paper Technique." In: Klute, A. L. (ed.), Methods of Soil Analysis, Part I, Physical and Mineralogical Methods, $2^{\text {nd }}$ Edition, American Society of Agronomy, Madison, WI. Chapter 25, pp. 628-630.

Chapman, J., Desert Research Institute, 1993. Personal communication regarding evaporation rates in the upper vadose zone.

Conrad, S. H., 1993. Using Environmental Tracers to Estimate Recharge Through an Arid Basin. 1993 International High-Level Radioactive Waste Management Conference, Las Vegas, NV. April 26-30, 1993.

Davis, J. C., I. D. Proctor, J. R. Southon, M. W. Caffee, D. W. Heikkinen, M. L. Roberts, K. W. Turtletaub, D. E. Nelson, D. H. Lloyd, and J. S. Vogel, 1990. LLNL/UC AMS Facility and Research Program. Nuclear Instruments and Methods in Physics Research, v. B52, pp. 269-272.

DOE, see U.S. Department of Energy.

Donaldson, R. E., and P. L. Sutherland, 1986. "Total Porosity.” In: Klute, A. L. (ed.), Methods of Soil Analysis, Part I, Physical and Mineralogical Methods, $2^{\text {nd }}$ Edition, American Society of Agronomy, Madison, WI. Chapter 18, pp. 444-445.

EG\&G/SAIC, 1991. Radiological Performance Assessment for the Area 5 Radioactive Waste Management Site at the Nevada Test Site, EG\&G Idaho, Inc., and Science Applications International Corporation (SAIC), Idaho Falls, ID.

Fenix \& Scisson, Inc., 1987. Lithologic Descriptions of Volcanic Rocks, Memorandum GEO-0237, dated May 26, 1987.

Fenix \& Scisson, Inc., 1990. The Description of Rock Samples - Geology/Hydrology Division Procedure GP-003, Revision 1.

Fernald, A. T., G. L. Dixon, W. J. Carr, and F. M. Byers, Jr., 1965. Geologic Report on Drill Hole UE11a, Nevada Test Site. U.S. Geological Survey Technical Letter NTS-160.

Freeze, R. A., and J. A. Cherry, 1979. Groundwater. Prentice-Hall, Inc., Englewood Cliffs, NJ. 
Gee, G. W., M. D. Campbell, G. S. Campbell, and J. H. Campbell, 1992. Rapid Measurement of Low Soil Water Potential Using a Water Activity Meter. Soil Science Society of America Journal, v. 56, pp. 1,068-1,071.

Hammermeister, D. P., D. O. Blout, and J. C. McDaniel, 1986. "Drilling and Coring Methods that Minimize the Disturbance of Cuttings, Core, and Rock Formations in the Unsaturated Zone, Yucca Mountain, Nevada." In: Proceedings of the NWWA Conference on Characterization and Monitoring of the Vadose (Unsaturated) Zone, Denver, CO, 1985, pp. 506-541. National Water Well Association, Worthington, OH.

Hillel, D., 1980. Fundamentals of Soil Physics. Academic Press, New York, NY.

Ingraham, N. L. and C. Shadel, 1992. A Comparison of the Toluene Distillation and Vacuum/Heat Methods for Extracting Soil Water for Stable Isotope Analysis. Journal of Hydrology, v. 140, pp. 371-387.

Jacobs, J. W., R. L. Korotev, D. P. Blanchard, and L. A. Haskins, 1977. A Well-Tested Procedure for Instrumental Neutron Activation Analysis of Silicate Rocks and Minerals. Journal of Radioanalytical Chemistry, v. 40, pp. 93-114.

Katz, D. L., D. Cornell, R. Kobayashi, F. H. Poettmann, J. A. Vary, J. R. Elenbaas, and C. F. Weinug, 1959. Handbook of Natural Gas Engineering. McGraw-Hill, New York, NY.

Klute, A. L., 1986. "Water Retention: Laboratory Methods - Falling Head Method.” In: Klute, A. L. (ed.), Methods of Soil Analysis, Part I, Physical and Mineralogical Methods, $2^{\text {nd }}$ Edition, American Society of Agronomy, Madison, WI. Chapter 26, pp. 635-641.

Klute, A. L., and C. Dirksen, 1986. "Hydraulic Conductivity and Diffusivity: Laboratory Methods - Falling Head Method." In: Klute, A. L. (ed.), Methods of Soil Analysis, Part I, Physical and Mineralogical Methods, $2^{\text {nd }}$ Edition, American Society of Agronomy, Madison, WI. Chapter 28, pp. 700-703.

Los Alamos National Laboratory, 1991. Draft Procedure for Using Ion Chromatography to Determine Chloride and Bromide Concentrations. Los Alamos National Laboratory Internal Report, LANL-INC-DP-94.R0, pp. 3-25.

Los Alamos National Laboratory, 1992. Sample Leaching to Extract Soluble Chloride and Bromide. Los Alamos National Laboratory Internal Report, LANL-INC-DP-92.R0, pp. 3-15.

Los Alamos National Laboratory, 1993. Draft Procedure for Preparation of Samples for Chlorine-36 Analysis. Los Alamos National Laboratory Internal Report, March 16, 1993. LANL-INC-DP-95.R1, pp. 3-14.

Morris, G. A., D. Snoeberger, C. Morris, and V. Du Val, 1971. Field Measurements of Permeability of NTS Alluvium in Area 10. Lawrence Radiation Laboratory Report UCID-15919. 
Mualem, Y., 1976. A New Model for Predicting the Hydraulic Conductivity of Unsaturated Porous Media. Water Resources Research, v. 12, pp. 513-522.

Nelson, R. E., 1982. “Carbonate and Gypsum: Pressure-Calcimeter Method.” In: Page, A., R. H. Miller, and D. R. Keeney (eds.), Methods of Soil Analysis, Part 2, Chemical and Microbiological Properties, $2^{\text {nd }}$ Edition, American Society of Agronomy, Madison, WI. Chapter 11, pp. 188-192.

Norrish, K, and B. W. Chappell, 1977. "X-Ray Fluorescence Spectrometry.” In: Zussman, J. (ed.), Physical Methods in Determinative Mineralogy, $2^{\text {nd }}$ Edition, Academic Press, New York, pp. 210-272.

Norrish, K. and J. T. Hutton, 1969. An Accurate X-Ray Spectrographic Method for the Analysis of a Wide Range of Geochemical Samples. Geochimica et Cosmochimica Acta Journal, v. 33, pp. 431-453.

Pasternak, A., and E. T. McMullen, 1970. Field Measurement of the Permeability of NTS Alluvium. Lawrence Radiation Laboratory Report UCID-15727.

Phillips, F. M., J. L. Mattick, T. A. Duval, D. Elmore, and P. W. Kubick, 1988. Chlorine-36 and Tritium from Nuclear Weapons Fallout as Tracers for Long-Term Liquid and Vapor Movement in Desert Soils. Water Resources Research, v. 24, pp. 877-891.

Poole, F. G., 1965. Geologic Map of the Frenchman Flat Quadrangle, Nye, Lincoln, and Clark Counties, Nevada. U.S. Geological Survey Map GQ-456.

Raytheon Services Nevada, 1990. Nevada Test Site Drilling and Mining Summary. Available from Bechtel Nevada, Mercury, NV.

Raytheon Services Nevada, 1991. Written communication. Subject: Surficial Geology of the Area 5 Radioactive Waste Management Site, Interim Report. Prepared for U.S. Department of Energy Nevada Operations Office. Las Vegas, NV.

REECo, see Reynolds Electrical and Engineering Co.

Reynolds Electrical and Engineering Co., Inc., 1993a. Hydrogeologic Data for Science Trench Boreholes at the Area 5 Radioactive Waste Management Site, Nevada Test Site, Nye County, Nevada. Special Projects Section, Environmental Management Division. Las Vegas, NV.

Reynolds Electrical and Engineering Co., Inc., 1993b Hydrogeologic Data for Existing Excavations at the Area 5 Radioactive Waste Management Site, Nevada Test Site. Special Projects Section, Environmental Management Division. Las Vegas

Rousseau, J., U.S. Geological Survey, 1993. Personnel communication regarding calibration and operation of thermistors at Yucca Mountain. 
Rozsa, R. B., D. F. Snoeberger, and J. Baker, 1975. Permeability of a Nuclear Chimney and Surface Alluvium, Area 2, ERDA, NTS. Lawrence Livermore Laboratory Report UCID-16722.

RSN, see Raytheon Services Nevada.

Snoeberger, D. F., J. Baker, C. J. Morris, and R. B. Rozsa, 1974. Permeability of a Nuclear Chimney and Surface Alluvium at the AEC Nevada Test Site. Lawrence Livermore Laboratory Report UCID-16479.

Sully, M. J., D. E. Cawlfield, D. O. Blout, L. E. Barker, B. L. Dozier, and D. P. Hammermeister, 1993. Characterization of the Spatial Variability of Hydraulic Properties of an Arid Region Vadose Zone, EOS Trans., American Geophysical Union, 74 (43), Fall Meeting, Supplement 286.

Tabatabai, M. A., 1982. "Sulfur: Inorganic Sulfate.” In: Page, A. L., R. H. Miller, and D. R Keeney (eds.), Methods of Soil Analysis, Part 2, Chemical and Microbiological Properties, $2^{\text {nd }}$ Edition, American Society of Agronomy, Madison, WI. Chapter 28, pp. 518-522.

Tyler, S., 1986. "Moisture Monitoring in Large Diameter Boreholes." In: Proceedings of the NWWA Conference on Characterization and Monitoring of the Vadose (Unsaturated) Zone, Denver, CO, 1985, pp. 97-106. National Water Well Association, Worthington, OH.

USEPA, see U.S. Environmental Protection Agency.

USGS, see U.S. Geological Survey.

U.S. Department of Energy, National Nuclear Security Administration Nevada Operations Office, 2002. Nevada Test Site Annual Site Environmental Report for Calendar Year 2001. Prepared by Bechtel Nevada. Report DOE/NV/11718--747. Las Vegas, NV.

U.S. Environmental Protection Agency, 1982. Methods for Chemical Analysis of Water and Wastes. EPA-600/4-82-055.

U.S. Environmental Protection Agency, 1986. USEPA Method 9060, Total Organic Carbon. Test Methods for Evaluating Solid Waste (SW-846), Chapter 5, Miscellaneous Test Methods. 5 pp.

U.S. Geological Survey, 1990. Method for Thermistor Calibration and Testing in a USGS Controlled Temperature Environment Laboratory. USGS Technical Procedure NWM-USGS-HP-162, R0, Draft, 9/10/90.

U.S. Geological Survey, 1993. Method for Calibrating Peltier-Type Thermocouple Psychrometers for Measuring Water Potentials of Partially Saturated Media. USGS Technical Procedure NWM-USGS-HP-14, R2.

van Genuchten, M. Th., 1978. Calculating the Unsaturated Hydraulic Conductivity with a New Closed-Form Analytical Model. Water Resources Program, Dept. of Civil Engineering, Princeton Univ., Princeton, NJ Res. Rpt. 78-WR-8, 63p. 
van Genuchten, M. Th., 1980. A Closed-Form Equation for Predicting the Hydraulic Conductivity of Unsaturated Soils. Soil Science Society of America Journal, v. 45, pp. 892-898.

Winograd, I. J., and W. Thordarson, 1975. Hydrogeologic and Hydrochemical Framework, South-Central Great Basin, Nevada-California, with Special Reference to the Nevada Test Site. U.S. Geological Survey Professional Paper 712-C. 


\section{Distribution List}

\section{U. S. Department of Energy}

\section{Copies}

Jhon Carilli

Waste Management Division

U.S. Department of Energy

National Nuclear Security Administration

Nevada Site Office

P.O. Box 98518, M/S 505

Las Vegas, NV 89193-8518

B. M. Crowe

Apogen Technologies

U.S. Department of Energy

National Nuclear Security Administration

Nevada Site Office

P.O. Box 98518, M/S 505

Las Vegas, NV 89193-8518

U.S. Department of Energy

National Nuclear Security Administration

Nevada Site Office

Technical Library

P.O. Box 98518, M/S 505

Las Vegas, NV 89193-8518

U.S. Department of Energy

2 (electronic)

National Nuclear Security Administration

Nevada Site Office

Nuclear Testing Archive

Public Reading Facility

P.O. Box 98518, M/S 400

Las Vegas, NV 89193-8518

U.S. Department of Energy

Office of Scientific and Technical Information

1 (electronic)

P.O. Box 62

Oak Ridge, Tennessee 37831-0062 
Distribution List (continued)

\section{Copies}

\section{Bechtel Nevada}

Max Dolenc

Bechtel Nevada

P.O. Box 98521, M/S NSF080

Las Vegas, NV 89193-8521

Environmental Management Library

Bechtel Nevada

P.O. Box 98521, M/S NLV094

Las Vegas, NV 89193-8521

Stuart Rawlinson

Bechtel Nevada

P.O. Box 98521, M/S NTS416

Las Vegas, NV 89193-8521

Dan Tobiason

Bechtel Nevada

P.O. Box 98521, M/S NTS416

Las Vegas, NV 89193-8521 
Site Characterization and Monitoring Data from Area 5 Pilot Wells

\section{Appendices A Through I}




\section{Errata to the Pilot Well Report Appendix}
APPENDIX
All
Table
Table
Table
D.1.3
E. 1.2 .2
E. 2.4
G.3.1.1
H.1
H.1
H.1
H.1
H.1
H. 1
H.1
I. 3
Correct borehole designations: UE5PW-1, UE5PW-2, and UE5PW-3.
F.2.1 Magnetic Survey Data should be F.2.2.
Add: F.5.2 Results of Hydraulic Conductivity Recovery Tests.
Appendix I title is "Vadose Zone Calibration and Monitoring Data".
Para. 5, line 4, should be "...a centralizer...".
Heading should be "Elemental...".
Heading should be "E.2.4".
Should contain the USCS profiles for the Calibration Boreholes found in Appendix E.1.1.
Section "Samples Collection and Preservation Methods", new first paragraph: Groundwater samples were collected with a submersible stainless-steel gas- operated double-action pump operated at a flow rate of approximately $21 / \mathrm{min}$. Static water level was measured prior to well evacuation. The well was prepared for sampling by purging three wellbore volumes from the well casing. Water temperature, $\mathrm{pH}$, specific conductance, and redox potential were monitored during purging and sample collection.
Section "Sample Collection and Preservation Methods", Para. 2, line 4, should be "...filtered...".
Section "Groundwater Analytical Results", para. 2, delete sentences 6 and 7, replace with "The $0.009 \mathrm{mg} / \mathrm{l} \mathrm{Pb}$ value is less than the primary standard of $0.05 \mathrm{mg} / \mathrm{l}$. Dissolved $\mathrm{Pb}$ was detected in a single sample at a concentration of $0.009 \mathrm{mg} / \mathrm{l}$ and found to be less than the detection limit in the duplicate." Section "Groundwater Analytical Results", para. 2, line 10, delete "...also...". Section "Groundwater Analytical Results", para. 3, Add last sentence: High levels of manganese can affect drinking water taste and stain laundry. Section "Groundwater Analytical Results", para. 10, line 2, delete "...uncertainties..." and replace with "...a measurement uncertainty...".
"Table 1 Groundwater Sample Containers and Preservation", Dissolved Silver Volume should be "500 ml".
Para. 6, line 2 should be "...a straight line....". 


\section{List of Appendices}

A. Drilling Information
A.1 Chronological Drilling Summary for UE5PW-1
A.2 Chronological Drilling Summary for UE5PW-2
A.3 Chronological Drilling Summary for UE5PW-3
A.4 Drilling Penetration Rate Data for Pilot Wells

B. Core and Drill Cuttings Sample Description Data

B.1 Borehole Log Sheets for UE5PW-1

B.2 Borehole Log Sheets for UE5PW-2

B.3 Borehole Log Sheets for UE5PW-3

B.4 Drill Cuttings Log Data for UE5PW-1

B.5 Drill Cuttings Log Data for UE5PW-2

B.6 Drill Cuttings Log Data for UE5PW-3

C Tracer $\left(\mathrm{SF}_{6}\right)$ Test Data

C.1 UE5PW-1 SF 6 Data from Core Samples and Compressor Air Lines

C.2 Formation $\mathrm{SF}_{6}$ Tracer Gas Concentrations

D Completion Data

D.1 Pilot Well Completion

D.1.1 Annular Materials

D.1.2 Preparation for Completion

D.1.3 Casing and Instrumentation Installation Detail

D.1.4 Stemming Detail

D.1.5 Completion Operations Safety

D.2 Pilot Well Stemming Summaries

D.2.1 UE5PW-1 Stemming Summary

D.2.2 UE5PW-2 Stemming Summary

D.2.3 UE5PW-3 Stemming Summary

D.3 Pilot Well Casing Tallies

D.3.1 UE5PW-1 Casing Tally

D.3.2 UE5PW-2 Casing Tally

D.3.3 UE5PW-3 Casing Tally 


\section{List of Appendices (Continued)}

D.4 Pilot Well Daily Activities

D.4.1 UE5PW-1 Daily Activity

D.4.2 UE5PW-2 Daily Activity

D.4.3 UE5PW-3 Daily Activity

E Laboratory Testing Data of Geologic Samples

E.1 Stratigraphy and Mineralogy Data

E.1.1 Profiles of USCS Textural Classes

E.1.2 XRF and INAA Data

E.1.2.1 Oxide Composition Data Determined by Major Elements XRF and INAA Methods for Core Samples from UE5PW-1

E.1.2.2 Elemental Composition Data Determined by INAA and Trace Element XRF Methods for Core Samples from UE5PW-1

E.1.2.3 Oxide Composition Data Determined by Major Elements XRF and INAA Methods for Core Samples from UE5PW-2

E.1.2.4 Elemental Composition Data Determined by INAA and Trace Element XRF Methods for Core Samples from UE5PW-2

E.1.2.5 Oxide Composition Data Determined by Major Elements XRF and INAA Methods for Core Samples from UE5PW-3

E.1.2.6 Elemental Composition Data Determined by INAA and Trace Element XRF Methods for Core Samples from UE5PW-3

E.2 Material, Hydrologic, and Geochemical Parameter Data for Alluvial Samples

E.2.1 Results of Laboratory Tests for Core Samples from UE5PW-1

E.2.2 Results of Laboratory Tests for Core Samples from UE5PW-2

E.2.3 Results of Laboratory Tests for Core Samples from UE5PW-3

E.2.4 Results of Laboratory Tests for Drill Cuttings Samples from UE5PW-1

E.2.5 Results of Laboratory Tests for Drill Cuttings Samples from UE5PW-2

E.2.6 Results of Laboratory Tests for Drill Cuttings Samples from UE5PW-3

E.2.7 Moisture Retention Data for Core Samples from UE5PW-1

E.2.8 Moisture Retention Data for Core Samples from UE5PW-2

E.2.9 Moisture Retention Data for Core Samples from UE5PW-3

E.2.10 Parameters Required to Calculate Unsaturated Hydraulic Conductivities for Core Samples 
E.3 Material, Hydrologic, and Geochemical Parameter Data for Tuff Samples

E.3.1 Results of Laboratory Tests for Tuff Core Samples from UE5PW-3

E.3.2 Results of Laboratory Tests for Tuff Drill Cuttings Samples from UE5PW-3

E.4 Results of Sampling and Analysis for Hazardous and Radiological Parameters in Core Samples

F Field Test Data

F.1 Near-Surface Soil Gas Surveys

F.1.1 Surface Soil Sampling, Analysis, and Results

F.1.2 Near-Surface Radon and Tritium Gas Sampling, Analysis, and Results

F.2 Surface Geophysical Surveys

F.2.1 Resistivity Survey Data

F.2.2 Magnetic Survey Data

F.3 Borehole Geophysical Surveys

F.3.1 Description of Borehole Geophysical Logging Tools Used

F.3.2 Borehole Geophysical Logs Run in UE5PW-1 on 4/20/1992

F.3.3 Borehole Geophysical Logs Run in UE5PW-1 on 6/16/1992

F.3.4 Borehole Deviation Logs Run in UE5PW-1 on 2/24/1993

F.3.5 Borehole Geophysical Logs Run in UE5PW-2 on 7/20/1992

F.3.6 Borehole Geophysical Logs Run in UE5PW-2 on 9/28/1992 and 9/29/1992

F.3.7 Borehole Deviation Logs Run in UE5PW-2 on 2/25/1993

F.3.8 Borehole Geophysical Logs Run in UE5PW-3 on 9/28/1992

F.3.9 Borehole Geophysical Logs Run in UE5PW-3 on 11/18/1992

F.3.10 Borehole Deviation Logs Run in UE5PW-3 on 2/25/1993

F.4 In-Situ Air Permeability Testing Data

F.4.1 Dimensions of Air Permeability Testing Interval for the Pilot Wells

F.4.2 In-Situ Air Permeability Testing Data

F.4.3 Effective Air Permeabilities and Inertial Coefficients for Field Testing in the Pilot Wells

F.5 Upper Aquifer Hydraulic Parameter Testing

F.5.1 Estimating the Water Table Slope under the Area 5 RWMS

F.5.2 Results of Hydraulic Conductivity Recovery Tests 


\section{List of Appendices (Continued)}

G Data from Neutron Logging Calibration Boreholes

G.1 Drilling Information

G.1.1 Chronological Drilling Summary for UE5PW-2A, 2B, and 2C

G.1.2 Core Record for UE5PW-2A, 2B, and 2C

G.1.3 Nevada State Central Zone Coordinates for Neutron Logging Calibration Boreholes

G.2 Core and Drill Cuttings Sample Description Data

G.2.1 Borehole Log Sheets for UE5PW-2A

G.2.2 Borehole Log Sheets for UE5PW-2B

G.2.3 Borehole Log Sheets for UE5PW-2C

G.2.4 Drill Cuttings Log Data for UE5PWW-2A

G.2.5 Drill Cuttings Log Data for UE5PWW-2B

G.2.6 Drill Cuttings Log Data for UE5PWW-2C

G.3 Laboratory Testing Data of Geologic Samples

G.3.1 Stratigraphy and Mineralogy Data

G.3.1.1 Summary of USCS Group Names for Core and Drill Cuttings Samples from Calibration Boreholes

G.3.1.2 Results from XRF and INAA for Core Samples from UE5PW-2A

G.3.1.3 Results from XRF and INAA for Core Samples from UE5PW-2B

G.3.1.4 Results from XRF and INAA for Core Samples from UE5PW-2C

G.3.2 Material, Hydrologic, and Geochemical Parameter Data

G.3.2.1 Results of Laboratory Tests for Core Samples from UE5PW-2A

G.3.2.2 Results of Laboratory Tests for Core Samples from UE5PW-2B

G.3.2.3 Results of Laboratory Tests for Core Samples from UE5PW-2C

G.3.2.4 Results of Laboratory Tests for Drill Cuttings Samples from UE5PW-2A

G.3.2.5 Results of Laboratory Tests for Drill Cuttings Samples from UE5PW-2B

G.3.2.6 Results of Laboratory Tests for Drill Cuttings Samples from UE5PW-2C

G.3.2.7 Summary of Descriptive Statistics of Alluvial Samples from UE5PW-2A, UE5PW-2B, and UE5PW-2C

\section{G.4 Field Test Data}

G.4.1 Site Preparation Information 


\section{List of Appendices (Continued)}

G.4.2 Neutron-Moisture Meter Data

G.4.2.1 Neutron-Moisture Meter Data for UE5PW-2A

G.4.2.2 Neutron-Moisture Meter Data for UE5PW-2B

G.4.2.3 Neutron-Moisture Meter Data for UE5PW-2C

G.4.3 Calibration of the Neutron-Moisture Meter in the Calibration Boreholes

H Upper Aquifer Water Quality Data

H.1 RCRA Groundwater Sampling and Analysis Methods and Results

H.2 Preliminary General Water Chemistry

I Vadose Zone Calibration and Monitoring Data

I.1 Thermistor Calibration Data

I. 2 Preliminary Temperature Monitoring Data

I.3 Pressure Transducer Calibration Data

I.4 Preliminary Pressure Monitoring Data

I.5 Thermocouple Psychrometer Calibration Data

I.6 In Situ Thermocouple Psychrometer Monitoring Data 


\title{
Area 5 Pilot Wells
}

\author{
APPENDIX A \\ Drilling Information
}

A.1 Chronological Drilling Summary for UE5PW-1

A.2 Chronological Drilling Summary for UE5PW-2

A.3 Chronological Drilling Summary for UE5PW-3

A.4 Drilling Penetration Rate Data for Pilot Wells 
Appendix A.1 Chronological Drilling Summary for Ue5PW-1

\begin{tabular}{|c|c|c|c|c|}
\hline $\begin{array}{l}\text { DATE } \\
1992 \\
\end{array}$ & $\begin{array}{c}\text { CASING } \\
\text { DEPTH (FT.) }\end{array}$ & $\begin{array}{l}\text { CASING } \\
\text { SIZE (IN.) }\end{array}$ & $\begin{array}{l}\text { CORE RUN } \\
\text { NO. }\end{array}$ & ACTIVITIES \& PROBLEMS \\
\hline $3-2$ & & & & $\begin{array}{l}\text { Mobilized from Mesquite, NV to } \\
\text { Mercury and processed in. }\end{array}$ \\
\hline $3-3$ & & & & $\begin{array}{l}\text { Set up accounts in Las Vegas. } \\
\text { Checked site and set trailer. }\end{array}$ \\
\hline $3-4$ & & & & $\begin{array}{l}\text { Met with REECo for Turtle Training } \\
\text { \& Safety Meetings. Went to Las } \\
\text { Vegas for under-reamer and steam } \\
\text { cleaner. }\end{array}$ \\
\hline 3-5 & & & & $\begin{array}{l}\text { Set up steam cleaner and cleaned } \\
\text { rods and subs. }\end{array}$ \\
\hline 3-6 & & & & $\begin{array}{l}\text { Steam cleaned equipment and rigged } \\
\text { up. Under reamer defective. }\end{array}$ \\
\hline $3-9$ & & & & $\begin{array}{l}\text { John Eddy interviewed drill helpers. } \\
\text { Helpers not qualified. Built dump for } \\
\text { cyclone. Put Odex together. }\end{array}$ \\
\hline $3-10$ & & & & John Eddy interviewed drill helpers. \\
\hline $3-11$ & & & & $\begin{array}{l}\text { Picked up parts and helper in Las } \\
\text { Vegas. }\end{array}$ \\
\hline 3-12 & & & & $\begin{array}{l}\text { Machined } 103 / 4 " \text { casing shoe } \& \text { anvil. } \\
\text { Inventoried casing. }\end{array}$ \\
\hline $3-13$ & 27.5 & 10.75 & & $\begin{array}{l}\text { Odex bit wouldn't unlock. Hammer } \\
\text { was not firing. Plugged "blooie" } \\
\text { line. Made T-line to cyclone. Wrong } \\
\text { core barrel threads. Very loose } \\
\text { ground. No core recovery in three } \\
\text { attempts. }\end{array}$ \\
\hline $3-14$ & & & & $\begin{array}{l}\text { Worked on rig. Built second sling } \\
\text { and worked on leaks. }\end{array}$ \\
\hline 3-15 & & & & $\begin{array}{l}\text { Cut down sub for sampler, but it still } \\
\text { wouldn't work. Picked up parts in } \\
\text { Las Vegas. }\end{array}$ \\
\hline $3-16$ & & & & Waited on sub for drive sampler. \\
\hline $3-17$ & 37.5 & 10.75 & 1 & $\begin{array}{l}\text { Had to drive sampler w/rig } \\
\text { hydraulics. Ran air perm tests. } \\
\text { Need 2nd air compressor. }\end{array}$ \\
\hline $3-18$ & 57.5 & 10.75 & $2,3,4$ & $\begin{array}{l}\text { Hooked up second air compressor } \\
\text { and changed return system. Casing } \\
\text { sinking into hole @ 42.5'. }\end{array}$ \\
\hline
\end{tabular}


Appendix A.1 Chronological Drilling Summary for Ue5PW-1 (Continued)

\begin{tabular}{|c|c|c|c|c|}
\hline $\begin{array}{l}\text { DATE } \\
1992\end{array}$ & $\begin{array}{l}\text { CASING } \\
\text { DEPTH (FT.) }\end{array}$ & $\begin{array}{l}\text { CASING } \\
\text { SIZE (IN.) }\end{array}$ & $\begin{array}{c}\text { CORE RUN } \\
\text { NO. }\end{array}$ & ACTIVITIES \& PROBLEMS \\
\hline $3-19$ & 97.5 & 10.75 & $5,6,7$ & $\begin{array}{l}\text { Rigged casing to cyclone return. No } \\
\text { recovery } 87.5-90^{\prime} \text {. Broke threads on } \\
\text { core barrel \& shoe. Switched to } \\
\text { rope threads. Pressed sampler } \\
\text { w/hydraulics. }\end{array}$ \\
\hline $3-20$ & 117.5 & 10.75 & 8 & $\begin{array}{l}\text { Casing turning in hole. Hammer was } \\
\text { difficult to remove. Ran air perm } \\
\text { tests at bottom of core run. }\end{array}$ \\
\hline $3-23$ & & & & $\begin{array}{l}\text { Re-routed air to hammer. Cleaned } \\
\text { out hole. Tripped in with sampler. }\end{array}$ \\
\hline $3-24$ & 137.5 & 10.75 & $9,10,11,12$ & $\begin{array}{l}\text { No recovery } 127.5-130^{\prime} \text {. Welded } \\
\text { seat valve in core sub. Upper part of } \\
\text { core barrel (fill material) had some oil } \\
\text { contamination. }\end{array}$ \\
\hline $3-25$ & & & & Had Tonto/REECo meeting. \\
\hline $3-26$ & & & & $\begin{array}{l}\text { Proposed changeover to } 7 " \text { dual wall } \\
\text { R. C. Rods. }\end{array}$ \\
\hline $3-27$ & & & & $\begin{array}{l}\text { Unloaded 7" dual wall R. C. rods. } \\
\text { Started changeover to } 7 \text { rods." }\end{array}$ \\
\hline $3-28$ & & & & Went to Las Vegas for parts. \\
\hline $3-29$ & & & & $\begin{array}{l}\text { Installed 4" king swivel, broke down } \\
\text { Odex hammer and rigged boom } \\
\text { truck. }\end{array}$ \\
\hline $3-30$ & & & & Steam cleaned rods and equipment. \\
\hline $3-31$ & & & & $\begin{array}{l}\text { Changed over to } 7^{\prime \prime} \text { dual wall R. C. } \\
\text { rods. }\end{array}$ \\
\hline 4-1 & & & & $\begin{array}{l}\text { Changed over to 7" dual wall R. C. } \\
\text { rods. }\end{array}$ \\
\hline 4-2 & & & & $\begin{array}{l}\text { Changed over to 7" dual wall R. C. } \\
\text { rods. Drove to Las Vegas for } \\
\text { supplies. }\end{array}$ \\
\hline $4-3$ & & & & $\begin{array}{l}\text { Completed changeover. Tested } \\
\text { equipment. Surveyed hole with } \\
\text { camera. }\end{array}$ \\
\hline 4-4 & & & & $\begin{array}{l}\text { Cleaned up site. Steam cleaned and } \\
\text { tested equipment. }\end{array}$ \\
\hline 4-6 & 147.5 & 10.75 & 13,14 & $\begin{array}{l}\text { No recovery } 147.5-149.9^{\prime} \text { w/mobile } \\
\text { sampler. }\end{array}$ \\
\hline
\end{tabular}


Appendix A.1 Chronological Drilling Summary for Ue5PW-1 (Continued)

\begin{tabular}{|c|c|c|c|c|}
\hline $\begin{array}{l}\text { DATE } \\
1992 \\
\end{array}$ & $\begin{array}{c}\text { CASING } \\
\text { DEPTH (FT.) }\end{array}$ & $\begin{array}{l}\text { CASING } \\
\text { SIZE (IN.) }\end{array}$ & $\begin{array}{l}\text { CORE RUN } \\
\text { NO. }\end{array}$ & ACTIVITIES \& PROBLEMS \\
\hline 4-7 & 157.5 & 10.75 & 15,16 & $\begin{array}{l}\text { Ran air perm tests before core runs. } \\
\text { High compressor flow rate }(>1000 \\
\text { C.F.M.) melted wire for air perm test. } \\
\text { Rotary core } 150-155^{\prime} \text {. Oil } \\
\text { contamination in upper core barrel in } \\
\text { Run } 15 .\end{array}$ \\
\hline 4-8 & 177.5 & 10.75 & 17,18 & \\
\hline $4-9$ & 217.5 & 10.75 & 19 & Replaced dust hose. \\
\hline 4-10 & 257.5 & 10.75 & 20,21 & \\
\hline 4-11 & & & & Drove to Las Vegas for parts. \\
\hline 4-12 & & & & Built line guide for wireline. \\
\hline 4-13 & 277.5 & 10.75 & 22,23 & Surveyed hole with camera. \\
\hline 4-14 & 317.5 & 10.75 & 24 & $\begin{array}{l}40,000 \text { Lbs. required to pull out } \\
\text { sampler. Sampler became oblonged. }\end{array}$ \\
\hline 4-15 & 337.5 & 10.75 & 25,26 & $\begin{array}{l}\text { Rotary core } 337.5-342.5^{\prime} \text {. No } \\
\text { recovery. }\end{array}$ \\
\hline 4-16 & 357.5 & 10.75 & 27 & Fished hammer out of hole. \\
\hline 4-17 & 370 & 10.75 & 28 & $\begin{array}{l}\text { Hammered through casing shoe } \\
\text { (casing shoe wore out.) Started } \\
\text { changeover to } 8^{\prime \prime} \text {. }\end{array}$ \\
\hline 4-18 & & & & Ran for parts. Cleaned $4 \times 4$ truck. \\
\hline $4-20$ & & & & $\begin{array}{l}\text { Century Geophysical ran deviation, } \\
\text { density, K.U.T. neutron and } \\
\text { induction logs. Changed over to } 8 \% \mathrm{~s}^{\prime \prime} \\
\text { casing. }\end{array}$ \\
\hline $4-21$ & & & & $\begin{array}{l}\text { Century Geophysical ran K.U.T. and } \\
\text { neutron logs. Ran } 8 \% \mathrm{~s}^{\prime \prime} \text { casing in } \\
\text { hole. Shut down due to lightning. }\end{array}$ \\
\hline 4-22 & 417.5 & 8.625 & 29 & \\
\hline $4-27$ & 420 & 8.625 & & $\begin{array}{l}\text { Odex modifications. Prepared and } \\
\text { ran } 4^{\prime \prime} \text { casing with centralizers to } \\
320^{\prime} \text {. }\end{array}$ \\
\hline $4-28$ & & & & $\begin{array}{l}\text { Ran HMO rods to } 424.5^{\prime} \text {. Odex } \\
\text { modifications \& securing casing. }\end{array}$ \\
\hline
\end{tabular}


Appendix A.1 Chronological Drilling Summary for Ue5PW-1 (Continued)

\begin{tabular}{|c|c|c|c|c|}
\hline $\begin{array}{l}\text { DATE } \\
1992 \\
\end{array}$ & $\begin{array}{c}\text { CASING } \\
\text { DEPTH (FT.) }\end{array}$ & $\begin{array}{l}\text { CASING } \\
\text { SIZE (IN.) }\end{array}$ & $\begin{array}{c}\text { CORE RUN } \\
\text { NO. } \\
\end{array}$ & ACTIVITIES \& PROBLEMS \\
\hline $4-29$ & 427.5 & 8.625 & $\begin{array}{c}2 \\
\text { Unnumbered }\end{array}$ & $\begin{array}{l}\text { Rigged dust head and hose to } \\
\text { cyclone. Rotary core w/no recovery. } \\
\text { Core runs were not numbered due to } \\
\text { no recovery. Air was leaking } \\
\text { through split barrel. Casing } \\
\text { unscrewed. Casing locked in core } \\
\text { rods. }\end{array}$ \\
\hline 4-30 & & & & $\begin{array}{l}\text { Pulled out casing and rods. Had to } \\
\text { cut casing with torch. }\end{array}$ \\
\hline $5-1$ & 457.5 & 8.625 & 30 & Had trouble getting Odex loose. \\
\hline $5-2$ & & & & $\begin{array}{l}\text { Performed service and maintenance } \\
\text { on rig. }\end{array}$ \\
\hline $5-4$ & 497.5 & 8.625 & 31 & Hydraulic pump needed repairs. \\
\hline $5-5$ & & & & Hydraulics repaired and lines bled. \\
\hline $5-6$ & 537.5 & 8.625 & 32 & Shutdown due to lightning. \\
\hline $5-7$ & 612.5 & 8.625 & 33 & $\begin{array}{l}\text { Some oil in cuttings. Drilled through } \\
\text { casing shoe. }\end{array}$ \\
\hline $5-8$ & & & & $\begin{array}{l}\text { Repaired leaking hydraulic hoses. } \\
\text { Casing stuck. }\end{array}$ \\
\hline $5-9$ & & & & $\begin{array}{l}\text { Move filter for air system. Repair } \\
4 \times 4 \text { truck. Drove to Reno for } \\
\text { casing pulling hammer. }\end{array}$ \\
\hline $5-10$ & & & & $\begin{array}{l}\text { Returned from Reno with casing } \\
\text { puller. }\end{array}$ \\
\hline $5-11$ & & & & $\begin{array}{l}\text { Casing stuck. Shoe wore out in last } \\
70^{\prime} \text {. Pulled on casing. } 4 \text { " stretch on } \\
\text { casing. }\end{array}$ \\
\hline $5-12$ & & & & Waiting for casing jacks. \\
\hline $5-13$ & & & & $\begin{array}{l}\text { Waiting and rigging up for casing } \\
\text { spear, grapple and jacks. Pulled top } \\
10^{\prime} \text { of casing. }\end{array}$ \\
\hline $5-14$ & & & & $\begin{array}{l}\text { Ran camera survey at } 580^{\prime} \text {. Pulled } \\
\text { rods. Built dust head and hoist plug. }\end{array}$ \\
\hline $5-15$ & & & & $\begin{array}{l}\text { Steam cleaned 7" casing. Set and } \\
\text { hooked up jacks. }\end{array}$ \\
\hline
\end{tabular}


Appendix A.1 Chronological Drilling Summary for Ue5PW-1 (Continued)

\begin{tabular}{|c|c|c|c|c|}
\hline $\begin{array}{l}\text { DATE } \\
1992 \\
\end{array}$ & $\begin{array}{c}\text { CASING } \\
\text { DEPTH (FT.) }\end{array}$ & $\begin{array}{l}\text { CASING } \\
\text { SIZE (IN.) }\end{array}$ & $\begin{array}{l}\text { CORE RUN } \\
\text { NO. }\end{array}$ & ACTIVITIES \& PROBLEMS \\
\hline $5-16$ & & & & $\begin{array}{l}\text { Assembled Bowens spear. Began } \\
\text { pulling casing w/114K lbs. on jacks } \\
\text { and } 60 \mathrm{~K} \text { Ibs. on rods. Cracked } \\
\text { HUSCO hydraulic valve. Casing } \\
\text { wedged. Pulled } 20^{\prime} \text { of casing. }\end{array}$ \\
\hline $5-17$ & & & & Serviced and washed $4 \times 4$ truck. \\
\hline 5-18 & & & & Pulled out $460^{\prime}$ of casing. \\
\hline $5-19$ & & & & $\begin{array}{l}\text { Finished pulling out casing. Shoe } \\
\text { broken. Casing grade too soft for } \\
\text { formation and joints didn't butt. } \\
\text { Bottom tagged at } 500^{\prime} \text {. Repaired } \\
\text { hydraulic high speed gear box. }\end{array}$ \\
\hline $5-20$ & & & & Repaired rig. \\
\hline $5-21$ & & & & $\begin{array}{l}\text { Met } w / \text { Tonto, REECo SPS \& REECo } \\
\text { Contracts Administration to discuss } \\
\text { repairs and changes. }\end{array}$ \\
\hline $5-22$ & & & & $\begin{array}{l}\text { Replaced hoses and fittings. Ran } \\
\text { casing to } 490^{\prime} \text {. }\end{array}$ \\
\hline $5-26$ & & & & $\begin{array}{l}\text { Rigged and changed side air routing. } \\
\text { Geolograph to be installed. Welded } \\
\text { casing head. Run } 8 \% \%^{\prime \prime} \text { casing in to } \\
600^{\prime} \text {. Reamed casing from } 490 \text { - } \\
600^{\circ} \text {. }\end{array}$ \\
\hline $5-27$ & 627.5 & 8.625 & 34 & $\begin{array}{l}\text { Reamed fan casing to } 617.5^{\prime} . \\
\text { Cleaned hole. Some oil } \\
\text { contamination was in core. }\end{array}$ \\
\hline $5-28$ & 657.5 & 8.625 & 35 & Serviced rig. \\
\hline $5-29$ & 697.5 & 8.625 & 36 & $\begin{array}{l}\text { Steam cleaned system. Some oil } \\
\text { contamination was in core. }\end{array}$ \\
\hline $5-30$ & & & & $\begin{array}{l}\text { Steam cleaned rods. Mounted } \\
\text { geolograph. Cleaned air system. }\end{array}$ \\
\hline $5-31$ & & & & Mounted 8 " dumpgate on cyclone. \\
\hline $6-1$ & 717.5 & 8.625 & 37 & $\begin{array}{l}\text { Steam cleaned rods for } 8 \text { " Odex. } \\
\text { Drilling was shut down until oil can } \\
\text { be removed from "fill" in core runs. }\end{array}$ \\
\hline
\end{tabular}


Appendix A.1 Chronological Drilling Summary for Ue5PW-1 (Continued)

\begin{tabular}{|c|c|c|c|c|}
\hline $\begin{array}{l}\text { DATE } \\
1992 \\
\end{array}$ & $\begin{array}{c}\text { CASING } \\
\text { DEPTH (FT.) }\end{array}$ & $\begin{array}{l}\text { CASING } \\
\text { SIZE (IN.) }\end{array}$ & $\begin{array}{l}\text { CORE RUN } \\
\text { NO. } \\
\end{array}$ & ACTIVITIES \& PROBLEMS \\
\hline $6-2$ & & & & $\begin{array}{l}\text { Made conference call: Tonto and } \\
\text { REECo, re: compressor and line } \\
\text { filters and misters on radiators. } \\
\text { Drove to Las Vegas for parts. }\end{array}$ \\
\hline $6-3$ & & & & $\begin{array}{l}\text { Ran Tricone bit to } 724.5^{\prime} \text {. Waiting } \\
\text { on solid tube samplers. Changed } \\
\text { separator filters and compressor oil } \\
\text { filters. Rigged cat pump. }\end{array}$ \\
\hline $6-4$ & & & 38 & $\begin{array}{l}\text { Rigged 5' core sampler. Core barrel } \\
\text { broke off at back head in hole. }\end{array}$ \\
\hline $6-5$ & 727.5 & 8.625 & & $\begin{array}{l}\text { Drilled over core barrel } w / 47 \%^{\prime \prime} \times 5^{\prime} \\
\text { barrel to retrieve. Retrieved sampler. }\end{array}$ \\
\hline $6-8$ & 757.5 & 8.625 & 39 & Replaced casing hoist cable. \\
\hline $6-9$ & 767.5 & 8.625 & 40 & Changed filters. \\
\hline $6-10$ & & & 41 & $\begin{array}{l}\text { Re-designed cross bar for side air. } \\
\text { Was shut down due to drill helper } \\
\text { injury. }\end{array}$ \\
\hline 6-11 & 778.5 & 8.625 & 42 & $\begin{array}{l}\text { Had safety meeting. Very moist } \\
\text { cuttings. }\end{array}$ \\
\hline $6-12$ & 830 & 8.625 & 43 & $\begin{array}{l}\text { Water level at } 778.25^{\prime} \text {. Bailed water } \\
\text { for sample. Cleaned hole. }\end{array}$ \\
\hline $6-13$ & & & & $\begin{array}{l}\text { Serviced drill rig and } 4 \times 4 \text { truck. } \\
\text { Repaired hydraulic leaks. }\end{array}$ \\
\hline $6-14$ & & & & Drove to Las Vegas for parts. \\
\hline $6-15$ & & & & $\begin{array}{l}\text { Water level at } 771.7^{\prime} \text {. Bailed water } \\
\text { for sample. Sand heaved in hole to } \\
823^{\prime}\left(7^{\prime} \text { of sand) }\right.\end{array}$ \\
\hline $6-16$ & 839 & 8.625 & & $\begin{array}{l}\text { T.D. hole. Bailed hole for water } \\
\text { sample. Ran recovery test. Moved } \\
\text { rig off hole. Hole caved to } 825^{\prime} \\
\text { according to Century Geophysical. } \\
\text { Ran gamma, neutron and density } \\
\text { logs. Moved drill rig off hole. }\end{array}$ \\
\hline 6-17 & & & & $\begin{array}{l}\text { Century Geophysical ran deviation, } \\
\text { gamma, neutron density and K.U.T. } \\
\text { logs. }\end{array}$ \\
\hline $7-13$ & & & & Stemming rig set up on hole. \\
\hline $11-19$ & & & & Century Geophysical ran neutron log. \\
\hline
\end{tabular}


Appendix A.2 Chronological Drilling Summary for Ue5PW-2

\begin{tabular}{|c|c|c|c|c|}
\hline $\begin{array}{l}\text { DATE } \\
1992 \\
\end{array}$ & $\begin{array}{c}\text { CASING } \\
\text { DEPTH (FT.) }\end{array}$ & $\begin{array}{l}\text { CASING SIZE } \\
\text { (IN.) }\end{array}$ & $\begin{array}{c}\text { CORE } \\
\text { RUN NO. }\end{array}$ & ACTIVITIES \& PROBLEMS \\
\hline $6-17$ & & & & Moved rig, trailer and casing to site. \\
\hline $6-18$ & 17.5 & 10.75 & 1 & Spuded hole. \\
\hline $6-19$ & & & & Eight hours standby without crew. \\
\hline $6-22$ & 47.5 & 10.75 & 2,3 & $\begin{array}{l}\text { Casing parted in hole. Stripped threads } \\
\text { in core barrel. Pulled casing. }\end{array}$ \\
\hline $6-23$ & & & & $\begin{array}{l}\text { Reamed casing back in hole. Surveyed } \\
\text { hole with camera. }\end{array}$ \\
\hline $6-24$ & 97.5 & 10.75 & 4,5 & \\
\hline $6-25$ & 157.5 & 10.75 & 6,7 & \\
\hline $6-26$ & 197.5 & 10.75 & 8 & $\begin{array}{l}\text { Sampler broke off in hole. Retrieved } \\
\text { sampler. Generator leaking oil. }\end{array}$ \\
\hline $6-27$ & & & & $\begin{array}{l}\text { Changed filter location and dust bag. } \\
\text { Rig maintenance. }\end{array}$ \\
\hline $6-29$ & 247.5 & 10.75 & 9 & $\begin{array}{l}\text { Unable to unscrew sampler off sub. Had } \\
\text { to cut off sampler sub with torch. }\end{array}$ \\
\hline $6-30$ & 307.5 & 10.75 & 10 & \\
\hline $7-1$ & 357.5 & 10.75 & & $\begin{array}{l}\text { Cleaned hole. Steam cleaned rods for } \\
8^{\prime \prime} \text { Odex system. Waited for casings to } \\
\text { arrive. }\end{array}$ \\
\hline $7-2$ & & & & $\begin{array}{l}\text { Rig on standby due to running out of } \\
10^{\prime \prime} \text { casing. }\end{array}$ \\
\hline $7-7$ & & & & $\begin{array}{l}\text { Steam cleaned rods and replaced discs } \\
\text { on interchange of } 8 \text { " Odex system. 15- } \\
103_{4}^{\prime \prime} \times 10^{\prime} \text { sections of casing arrived. } \\
\text { Seven were damaged. }\end{array}$ \\
\hline $7-8$ & & & & $\begin{array}{l}\text { Steam cleaned } 4 \frac{1}{2} \text { " rods and casing. } \\
\text { Tonto/REECo; met in Las Vegas. }\end{array}$ \\
\hline $7-9$ & 397.5 & 10.75 & 11 & $\begin{array}{l}\text { Casing shoe wearing out. Shoe 1.5- } \\
1.75^{*} \text {. Had to cut off sampler shoe. } \\
\text { Broke hydraulic line. }\end{array}$ \\
\hline $7-10$ & 400 & 10.75 & & $\begin{array}{l}\text { Drove through shoe. Standby waiting } \\
\text { for shoe joint. Will telescope to } 8 \%{ }^{\prime \prime} \\
\text { casing. }\end{array}$ \\
\hline $7-13$ & & & & $\begin{array}{l}\text { Tripped in hole w/8\%" casing. } \\
\text { Inventoried equipment. }\end{array}$ \\
\hline $7-14$ & 477.5 & 8.625 & & $\begin{array}{l}\text { Generator problems. Was producing } 300 \\
\text { volts. }\end{array}$ \\
\hline
\end{tabular}


Appendix A.2 Chronological Drilling Summary for Ue5PW-2 (Continued)

\begin{tabular}{|c|c|c|c|c|}
\hline $\begin{array}{l}\text { DATE } \\
1992\end{array}$ & $\begin{array}{l}\text { CASING } \\
\text { DEPTH (FT.) }\end{array}$ & $\begin{array}{l}\text { CASING SIZE } \\
\text { (IN.) }\end{array}$ & $\begin{array}{c}\text { CORE } \\
\text { RUN NO. }\end{array}$ & ACTIVITIES \& PROBLEMS \\
\hline $7-15$ & 497.5 & 8.625 & 12,13 & $\begin{array}{l}\text { Core barrel unthreaded in hole. Tripped } \\
\text { in rotary core barrel to retrieve. }\end{array}$ \\
\hline $7-16$ & 547.5 & 8.625 & & $\begin{array}{l}\text { Pulled } 8 \% " \text { casing to loosen. Ran in } \\
\text { fishing tool. }\end{array}$ \\
\hline $7-17$ & & & 14 & Moved off hole. \\
\hline $7-20$ & & & & Century Geophysical ran K.U.T. log. \\
\hline $7-21$ & & & & $\begin{array}{l}\text { Moved back on hole. Steam cleaned } \\
\text { pipe. }\end{array}$ \\
\hline $7-22$ & 617.5 & 8.625 & & $\begin{array}{l}\text { Continued drilling PW-2. Had to pull up } \\
\text { casing at } 587.5,597.5 \& 607.5^{\prime} \text { to } \\
\text { loosen. Many boulders and cobbles. }\end{array}$ \\
\hline $7-23$ & 647.5 & 8.625 & 15 & Pulled up casing to loosen at $647.5^{\prime}$. \\
\hline $7-24$ & 700.0 & 8.625 & & $\begin{array}{l}\text { Pulled up casing to loosen at } 657.5 \text {, } \\
667.5,687.5 \text { and } 697.5 \text {. }\end{array}$ \\
\hline 7.25 & & & & Repaired sprockets on chain pull down. \\
\hline $7-27$ & 707.5 & 8.625 & 16 & $\begin{array}{l}\text { Rotary core } 700-705^{\prime} \text {. Pulled up casing } \\
\text { to loosen. }\end{array}$ \\
\hline $7-28$ & 717.5 & 8.625 & & Casing shoe parted in hole. \\
\hline $7-29$ & & & & $\begin{array}{l}\text { Broke hydraulic line while pulling out } \\
\text { casing. }\end{array}$ \\
\hline $7-30$ & & & & $\begin{array}{l}\text { Replaced hydraulic hose. Dug cellar for } \\
\text { jacks. }\end{array}$ \\
\hline $7-31$ & & & & $\begin{array}{l}\text { Set jacks over } 10^{\prime \prime} \text { casing. Pulled casing } \\
\text { back } 10^{\prime} \text {. Blew another hoist hose. } \\
\text { Pulled } 70,000 \mathrm{lbs} \text {. on top and on bottom } \\
\text { to move casing. Replaced all hoses with } \\
6000 \text { psi rating. }\end{array}$ \\
\hline 8-1 & & & & $\begin{array}{l}\text { Pulled and replaced sprockets and } \\
\text { adjusted chains. Replaced hydraulic } \\
\text { fittings and gauges. Repaired hydraulic } \\
\text { cooler. Changed hydraulic and } \\
\text { compressor filters. }\end{array}$ \\
\hline $8-3$ & & & & $\begin{array}{l}\text { Tripped out } w / 8 \% " \text { casing. Tripped in } \\
w / 120^{\circ} \text { of casing. }\end{array}$ \\
\hline $8-4$ & & & & $\begin{array}{l}\text { Casing down to } 660^{\prime} \text {. } 60^{\prime} \text { of "cave" in } \\
\text { hole. Replaced casing hoist system } w / R \text {. } \\
\text { C. side air. Reamed casing to } 680^{\prime} \text {. }\end{array}$ \\
\hline
\end{tabular}


Appendix A.2 Chronological Drilling Summary for Ue5PW-2 (Continued)

\begin{tabular}{|c|c|c|c|c|}
\hline $\begin{array}{l}\text { DATE } \\
1992\end{array}$ & $\begin{array}{c}\text { CASING } \\
\text { DEPTH (FT.) }\end{array}$ & $\begin{array}{l}\text { CASING SIZE } \\
\text { (IN.) }\end{array}$ & $\begin{array}{c}\text { CORE } \\
\text { RUN NO. }\end{array}$ & ACTIVITIES \& PROBLEMS \\
\hline $8-5$ & 717.5 & 8.625 & 17 & Cleaned out hole. \\
\hline $8-6$ & 747.5 & 8.625 & 18 & Changed compressor filters. \\
\hline 8-7 & 817.5 & 8.625 & & $\begin{array}{l}\text { Moist below 797.5'. Pulled casing up to } \\
\text { loosen. }\end{array}$ \\
\hline $8-8$ & & & & $\begin{array}{l}\text { Pulled and replaced sprockets and } \\
\text { adjusted chains. Replaced hydraulic } \\
\text { fittings and gauges. Repaired hydraulic } \\
\text { cooler. Changed hydraulic and } \\
\text { compressor filters. }\end{array}$ \\
\hline $8-10$ & 828.5 & 8.625 & 19 & \\
\hline $8-11$ & 839.0 & 8.625 & 20,21 & $\begin{array}{l}\text { Had to cut off sampler shoe to remove a } \\
\text { core run } \# 20 \text {. }\end{array}$ \\
\hline $8-12$ & & & 22 & $\begin{array}{l}160^{\prime} \text { of drill rod and sampler unscrewed } \\
\text { and fell down hole. Was unsuccessful at } \\
\text { spearing attempts. }\end{array}$ \\
\hline $8-13$ & & & & $\begin{array}{l}\text { Drill string fell } 120^{\prime} \text {. Tripped in } w / \text { Sandia } \\
\text { video camera. Drill R.C. rod pushed into } \\
\text { drill pipe. Tripped in w/wall hook and } \\
\text { overshot. Unable to pull. }\end{array}$ \\
\hline $8-14$ & & & & Pulled on fishing tool. \\
\hline $8-15$ & & & & $\begin{array}{l}\text { Rigged and ran "jars." Ran at } 50 \mathrm{~K}-70 \mathrm{~K} \\
\text { lbs., but nothing moved. }\end{array}$ \\
\hline $8-17$ & & & & $\begin{array}{l}\text { John Eddy went to Fontana, CA for } \\
\text { casing puller. }\end{array}$ \\
\hline $8-18$ & & & & $\begin{array}{l}\text { Rigged jacks. Jacked casing and jarring } \\
\text { rods. Casing jacked } 3.5^{\circ} \text {, but rods still } \\
\text { stuck. }\end{array}$ \\
\hline $8-19$ & & & & $\begin{array}{l}\text { Jarring rods at } 70 \mathrm{~K}-80 \mathrm{~K} \text { lbs. Broke pull- } \\
\text { down chains. Repaired chains. Rigged } \\
\text { to jack casing and rods at same time. } \\
\text { Jacked at } 90 \mathrm{~K}-190 \mathrm{~K} \text { lbs. With grapple in } \\
\text { overshot. Broke loose. Pulled overshot. }\end{array}$ \\
\hline $8-20$ & & & & $\begin{array}{l}\text { Ran rods open ended and screwed into } \\
\text { fish. Worked rods and jacked rods and } \\
\text { casing. Rods moved } 8^{\prime \prime} \text { then became } \\
\text { stuck. Top head froze up. }\end{array}$ \\
\hline
\end{tabular}


Appendix A.2 Chronological Drilling Summary for Ue5PW-2 (Continued)

\begin{tabular}{|c|c|c|c|c|}
\hline $\begin{array}{l}\text { DATE } \\
1992 \\
\end{array}$ & $\begin{array}{c}\text { CASING } \\
\text { DEPTH (FT.) }\end{array}$ & $\begin{array}{c}\text { CASING SIZE } \\
\text { (IN.) }\end{array}$ & $\begin{array}{c}\text { CORE } \\
\text { RUN NO. }\end{array}$ & ACTIVITIES \& PROBLEMS \\
\hline $8-21$ & & & & $\begin{array}{l}\text { Pulled off top head motor and took to } \\
\text { Las Vegas for repairs. Motor beyond } \\
\text { repair. Driller reports that failure caused } \\
\text { by jarring. }\end{array}$ \\
\hline $8-24$ & & & & $\begin{array}{l}\text { Installed new rotation motor. Cleaned } \\
\text { out metal from hydraulic system. }\end{array}$ \\
\hline $8-25$ & & & & $\begin{array}{l}\text { Flushed and drained system. Jacked } \\
\text { casing and pulled rods at } 210 \mathrm{~K} \text { PSI. No } \\
\text { success. Broke inserts in dog collars. }\end{array}$ \\
\hline $8-26$ & & & & $\begin{array}{l}\text { Jacked casing to } 210,000 \mathrm{lbs} \text {. Casing } \\
\text { moved } 1.5^{\prime \prime} \text {. Added } 50 \text { gal., of } \mathrm{KBr} \text {, } \\
60 \text { ppm, tracer solution to hole. }\end{array}$ \\
\hline $8-27$ & & & & $\begin{array}{l}\text { Was unsuccessful at retrieving } w / s p e a r, \\
\text { overshot and sinker bar. Everything } \\
\text { behind hammer, backhead was retrieved. }\end{array}$ \\
\hline $8-28$ & & & & $\begin{array}{l}\text { Photo taken of hole bottom. Drilled over } \\
\text { top of sampler, but couldn't retrieve. } \\
\text { Ordered larger drillover. }\end{array}$ \\
\hline $8-31$ & & & & $\begin{array}{l}\text { Was unsuccessful at retrieving } w / 5 " \\
\text { diameter core (PWC) barrel. Retrieved } \\
\text { hammer and sampler w/SWC casing } \\
\text { overshot by coring to } 848.2^{\prime} \text { and pouring } \\
\text { sand down rods to "sand lock" sampler } \\
\text { and hammer. }\end{array}$ \\
\hline $9-1$ & & & & $\begin{array}{l}\text { Removed hammer from SWC drillover. } \\
\text { Tripped in w/Odex. Couldn't pull up } \\
\text { casing. Top threads dented. }\end{array}$ \\
\hline $9-2$ & 867.5 & 8.625 & & $\begin{array}{l}\text { Made up casing spear for top. Pulled } \\
\text { back casing. }\end{array}$ \\
\hline $9-3$ & $888.5 \pm$ & 8.625 & & $\begin{array}{l}\text { Hole yielded water overnight at } 848^{\prime} \pm . \\
\text { Took water sample. }\end{array}$ \\
\hline $9-4$ & 911 T.D. & 8.625 & & $\begin{array}{l}\text { Drilled to T.D. Blew out hole and ran } \\
\text { recovery test. Pulled out jacks. }\end{array}$ \\
\hline $9-8$ & & & & Water level at $840.4^{\prime}$. \\
\hline $9-9$ & & & & Tore down and rebuilt XL-4 hammer. \\
\hline $9-10$ & & & & $\begin{array}{l}\text { Tripped out w/Odex. Water level at } \\
840.7 \text { ". Bottom of hole "tagged" at } \\
910.2 \text { '. Bailed hole w/bailer. }\end{array}$ \\
\hline
\end{tabular}


Appendix A.2 Chronological Drilling Summary for Ue5PW-2 (Continued)

\begin{tabular}{|c|c|c|c|c|}
\hline $\begin{array}{l}\text { DATE } \\
1992 \\
\end{array}$ & $\begin{array}{c}\text { CASING } \\
\text { DEPTH (FT.) }\end{array}$ & $\begin{array}{l}\text { CASING SIZE } \\
\text { (IN.) }\end{array}$ & $\begin{array}{c}\text { CORE } \\
\text { RUN NO. }\end{array}$ & ACTIVITIES \& PROBLEMS \\
\hline $9-11$ & & & & $\begin{array}{l}\text { Steam cleaned rods and rig. Rigged } \\
\text { down. Loaded rods and equipment with } \\
\text { crane. }\end{array}$ \\
\hline $9-12$ & & & & $\begin{array}{l}\text { John Eddy went over inventory and } \\
\text { equipment list for REECo. }\end{array}$ \\
\hline $9-14$ & & & & Moved rig off hole. \\
\hline $9-29$ & & & & $\begin{array}{l}\text { Century Geophysical ran neutron and } \\
\text { gamma logs. }\end{array}$ \\
\hline $10-5$ & & & & Stemming rig set up on hole. \\
\hline $11-13$ & & & & $\begin{array}{l}\text { John Eddy moves T4W rig back on hole } \\
\text { to free casing. }\end{array}$ \\
\hline $11-14$ & & & & $\begin{array}{l}\text { Ran Odex in hole and freed casing. } \\
\text { Casing broke. }\end{array}$ \\
\hline $11-15$ & & & & Replaced hydraulic cooler fan motor. \\
\hline $11-16$ & & & & $\begin{array}{l}\text { Waiting on logging truck to log casing } \\
\text { break. }\end{array}$ \\
\hline $11-17$ & & & & $\begin{array}{l}\text { Worked Odex loose and pulled rods. } \\
\text { Century Geophysical ran caliper log. }\end{array}$ \\
\hline $11-18$ & & & & $\begin{array}{l}\text { Ran in hole with spear. Century } \\
\text { Geophysical ran compensated density } \\
\text { and neutron, K.U.T., E-log, induction, } \\
\text { resistivity short guard and deviation logs. }\end{array}$ \\
\hline $11-19$ & & & & $\begin{array}{l}\text { Worked bottom casing joint free. Pulled } \\
\text { up and attempted to hook top piece, but } \\
\text { spear wouldn't grab. Need new grapple. }\end{array}$ \\
\hline $11-20$ & & & & Ran spear to $400^{\prime}$. Lost hydraulic pump. \\
\hline $11-21$ & & & & $\begin{array}{l}\text { Replaced pump. Ran spear and speared } \\
\text { casing } \# 1 \text { and pulled back } 20^{\prime} \text {. Speared } \\
\text { casing } \# 2 \text { and pulled back } 20^{\circ} \text { but casing } \\
\text { stopped. Unhooked and pulled back into } \\
\text { casing } \# 1 \text {. Grapple wouldn't grab. } \\
\text { Pulled out spear. }\end{array}$ \\
\hline $11-22$ & & & & $\begin{array}{l}\text { Returned w/new grapple. Pulled casing } \\
\text { back } 5^{\circ} \text {, but casing stuck again. }\end{array}$ \\
\hline $11-23$ & & & & $\begin{array}{l}\text { Spear wouldn't work. Ordered new } \\
\text { spear. }\end{array}$ \\
\hline
\end{tabular}


Appendix A.2 Chronological Drilling Summary for Ue5PW-2 (Continued)

\begin{tabular}{|c|c|l|l|l|}
\hline $\begin{array}{c}\text { DATE } \\
1992\end{array}$ & $\begin{array}{c}\text { CASING } \\
\text { DEPTH (FT.) }\end{array}$ & $\begin{array}{c}\text { CASING SIZE } \\
\text { (IN.) }\end{array}$ & $\begin{array}{c}\text { CORE } \\
\text { RUN NO. }\end{array}$ & ACTIVITIES \& PROBLEMS \\
\hline $12-1$ & & & & $\begin{array}{l}\text { Rigged up spear. Both casing strings } \\
\text { backed up 52'. }\end{array}$ \\
\hline $12-2$ & & & & Pulled casing. \\
\hline & & & & \\
\hline & & & & \\
\hline & & & & \\
\hline & & & & \\
\hline & & & & \\
\hline & & & & \\
\hline
\end{tabular}


Appendix A.3 Chronological Drilling Summary for Ue5PW-3

\begin{tabular}{|c|c|c|c|c|}
\hline $\begin{array}{l}\text { DATE } \\
1992\end{array}$ & $\begin{array}{l}\text { CASING } \\
\text { DEPTH (FT.) }\end{array}$ & $\begin{array}{l}\text { CASING } \\
\text { SIZE (IN.) }\end{array}$ & $\begin{array}{l}\text { CORE } \\
\text { RUN } \\
\text { NO. }\end{array}$ & ACTIVITIES \& PROBLEMS \\
\hline $9-14$ & & & & Mobilized and setup rig. \\
\hline $9-15$ & & & & $\begin{array}{l}\text { Most equipment on site. Fork lift } \\
\text { dropped pipe and casing. }\end{array}$ \\
\hline $9-16$ & 47.5 & 10.75 & $1,2,3$ & $\begin{array}{l}\text { Rigged Odex hammer and casing with } \\
\text { floor plate. Revised pipe damage list. }\end{array}$ \\
\hline $9-17$ & 127.5 & 10.75 & 4,5 & \\
\hline $9-18$ & 197.5 & 10.75 & & $\begin{array}{l}\text { Extensive coarse-grained alluvium with } \\
<5 \% \text { silt. }\end{array}$ \\
\hline $9-21$ & 247.5 & 10.75 & 6,7 & Surveyed hole with camera. \\
\hline $9-22$ & 327.5 & 10.75 & & $\begin{array}{l}\text { Hooked up } \mathrm{SF}_{\mathrm{o}} \text { gas to air system. Meter } \\
\text { doesn't work. }\end{array}$ \\
\hline $9-24$ & 377.5 & 10.75 & 8 & \\
\hline $9-25$ & 450.0 & 10.75 & 9 & $\begin{array}{l}\text { Surveyed hole with camera. Extensive } \\
\text { fine SM debris flows } 387.5-417.5^{\prime} \text {. } \\
\text { Shoe worn. }\end{array}$ \\
\hline $9-26$ & & & & Serviced rig and $4 \times 4$ truck. \\
\hline $9-28$ & & & & $\begin{array}{l}\text { Century geophysical ran neutron density } \\
\text { and K.U.T. logs. Steam cleaned } 8^{\prime \prime} \\
\text { casing. }\end{array}$ \\
\hline $9-29$ & 455 & 8.625 & 10 & Tripped in with $8 \% "$ casing and Odex. \\
\hline $9-30$ & 497.5 & 8.625 & 11 & \\
\hline $10-1$ & 557.5 & 8.625 & 12 & \\
\hline $10-2$ & 617.5 & 8.625 & 13 & $\begin{array}{l}\text { Slow drilling due to scattered boulders } \\
<2.5^{\prime} \text { diam. }\end{array}$ \\
\hline $10-5$ & 637.5 & 8.625 & & $\begin{array}{l}\text { Surveyed hole with camera. Ammonia } \\
\text { Tanks welded tuff at } 617.5^{\circ} \pm\end{array}$ \\
\hline $10-6$ & & & 14 & $\begin{array}{l}\text { HQ rotary core } 638.25-643.5^{\prime} \text {. Set } \\
\text { jacks. }\end{array}$ \\
\hline $10-7$ & & & & $\begin{array}{l}\text { Broke pull-down chain. Down until next } \\
\text { week while custom chain being made. }\end{array}$ \\
\hline $10-13$ & & & & $\begin{array}{l}\text { Replaced chain and sprockets. Pulled } \\
\text { casing up } 25^{\circ} \text { to loosen. }\end{array}$ \\
\hline $10-14$ & 663.0 & 8.625 & & $\begin{array}{l}\text { Pulled casing back to } 577^{\prime} \text {. Reamed } \\
\text { back to bottom. Drove through casing. }\end{array}$ \\
\hline
\end{tabular}


Appendix A.3 Chronological Drilling Summary for Ue5PW-3 (Continued)

\begin{tabular}{|c|c|c|c|c|}
\hline $\begin{array}{l}\text { DATE } \\
1992\end{array}$ & $\begin{array}{l}\text { CASING } \\
\text { DEPTH (FT.) }\end{array}$ & $\begin{array}{l}\text { CASING } \\
\text { SIZE (IN.) }\end{array}$ & $\begin{array}{l}\text { CORE } \\
\text { RUN } \\
\text { NO. }\end{array}$ & ACTIVITIES \& PROBLEMS \\
\hline 10-15 & & & & $\begin{array}{l}\text { Tripped in casing spear and pulled out } \\
\text { casing. }\end{array}$ \\
\hline $10-16$ & & & & $\begin{array}{l}\text { Extracted spear from casing and loaded } \\
\text { for shipping. }\end{array}$ \\
\hline 10-19 & & & & $\begin{array}{l}\text { No drilling - waiting on new casing } \\
\text { shoe. }\end{array}$ \\
\hline $10-20$ & & & & $\begin{array}{l}\text { Tripped in w/8\%" casing to } 625^{\prime} \text { (top of } \\
\text { cave). }\end{array}$ \\
\hline $10-21$ & 687.5 & 8.625 & 15 & Built up Odex. \\
\hline $10-22$ & & & & $\begin{array}{l}\text { No drilling. Tonto/REECo meeting, re: } \\
\text { payment. }\end{array}$ \\
\hline $10-23$ & 727.5 & 8.625 & & $\begin{array}{l}\text { Scattered thin fractured, Mafic and Ash } \\
\text { zones in cuttings. Repaired antifreeze } \\
\text { and hydraulic leaks. Changed under } \\
\text { reamer bit. Pulled back every } 10^{\prime} \text { to keep } \\
\text { casing free. }\end{array}$ \\
\hline $10-26$ & 767.5 & 8.625 & & Hard drilling. Casing tight. \\
\hline $10-27$ & 770.0 & 8.625 & & $\begin{array}{l}\text { Milled out casing shoe w/casing reamer. } \\
400 \text { gallons of water were injected and } \\
200 \text { gallons were recovered. }\end{array}$ \\
\hline $10-28$ & & & & $\begin{array}{l}\text { Tripped out w/reamer. Built casing brake } \\
\text { and seal for } 7 \% \%^{*} \text { casing. }\end{array}$ \\
\hline $10-29$ & & & & Tripped in $w / 7 \% "$ casing and Odex. \\
\hline $10-30$ & 795.0 & 7.625 & & $\begin{array}{l}\text { Difficult to get } 7 \% \%^{\prime \prime} \text { casing started in } \\
\text { hole. Had to rotate casing while drilling. }\end{array}$ \\
\hline $11-2$ & 822.5 & 7.625 & & $\begin{array}{l}\text { Odex reamer was worn out. Pulled back } \\
8 \%{ }^{*} \text { casing. Stuck casing. Rigged for } \\
\text { jacks. }\end{array}$ \\
\hline $11-3$ & & & & $\begin{array}{l}\text { Obtained jacks, slips and under reamer } \\
\text { bit. No drilling activities. Set jacks. }\end{array}$ \\
\hline $11-4$ & & & & $\begin{array}{l}\text { Worked casing }(7 \% ") \text { free } w / \text { jacks and } \\
\text { Odex. Started tripping out } w / 7 \% \%^{\prime \prime} \\
\text { casing. }\end{array}$ \\
\hline $11-5$ & & & & Tripped out w/7\%" casing and Odex. \\
\hline $11-6$ & & & & $\begin{array}{l}\text { Drilled to } 905^{\prime} \text { w/R-380 and } 77 / \mathrm{s}^{\prime \prime} \text { button } \\
\text { bit open hole. }\end{array}$ \\
\hline
\end{tabular}


Appendix A.3 Chronological Drilling Summary for Ue5PW-3 (Continued)

\begin{tabular}{|c|l|l|l|l||}
\hline $\begin{array}{c}\text { DATE } \\
1992\end{array}$ & $\begin{array}{c}\text { CASING } \\
\text { DEPTH (FT.) }\end{array}$ & $\begin{array}{c}\text { CASING } \\
\text { SIZE (IN.) }\end{array}$ & $\begin{array}{l}\text { CORE } \\
\text { RUN } \\
\text { NO. }\end{array}$ & ACTIVITIES \& PROBLEMS \\
\hline $11-9$ & & & $\begin{array}{l}\text { Drilled to 955' T.D. w/77\%" button bit } \\
\text { open hole. Bedded tuff from 917.5' } \pm \text { to } \\
955^{\prime} \text { T.D. Surveyed hole w/camera. }\end{array}$ \\
\hline $11-10$ & & & $\begin{array}{l}\text { Water level 887.83'. } \\
\text { Ran recovery test. Injected SF, gas. } \\
\text { Pulled rods. Jack 8\%" casing loose. }\end{array}$ \\
\hline $11-12$ & & & $\begin{array}{l}\text { Tripped in casing spear. Started pulling } \\
\text { up 8\%" casing. Pulled and jacked casing } \\
\text { up 17'. }\end{array}$ \\
\hline $11-16$ & & & $\begin{array}{l}\text { Pulled casing back to 700'. Moved off } \\
\text { hole. }\end{array}$ \\
\hline $11-18$ & & & & $\begin{array}{l}\text { Stemming rig moved on hole. } \\
\text { Century Geophysical ran caliper, } \\
\text { compensated neutron, K.U.T., induction, } \\
\text { resistivity short guard, E-Log, } \\
\text { compensated density, deviation and } \\
\text { temperature logs. }\end{array}$ \\
\hline
\end{tabular}


Appendix A.4 Drilling penetration rate data for Ue5PW-1

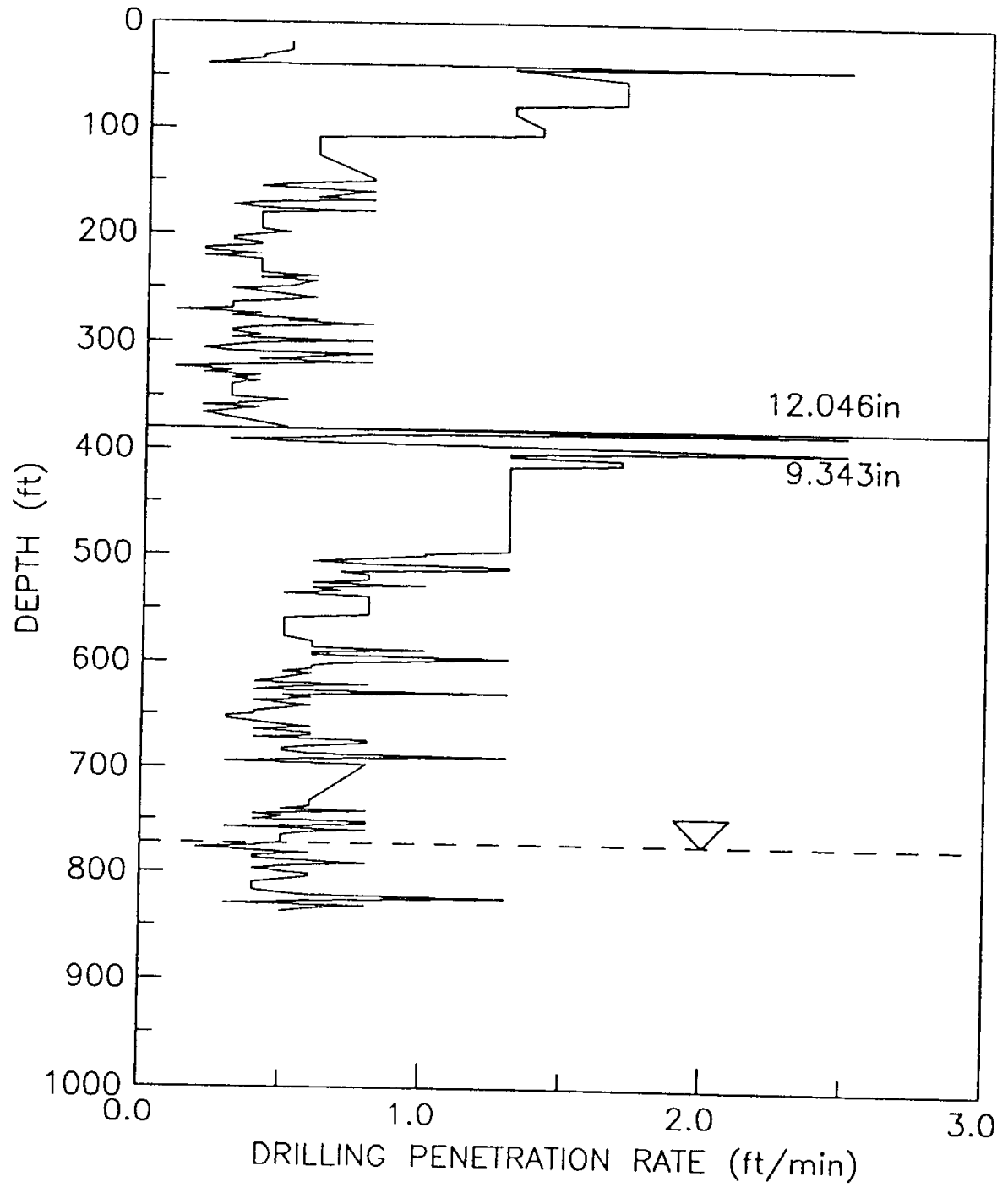


Appendix A.4 Drilling penetration rate data for Ue5PW-2 (Continued)

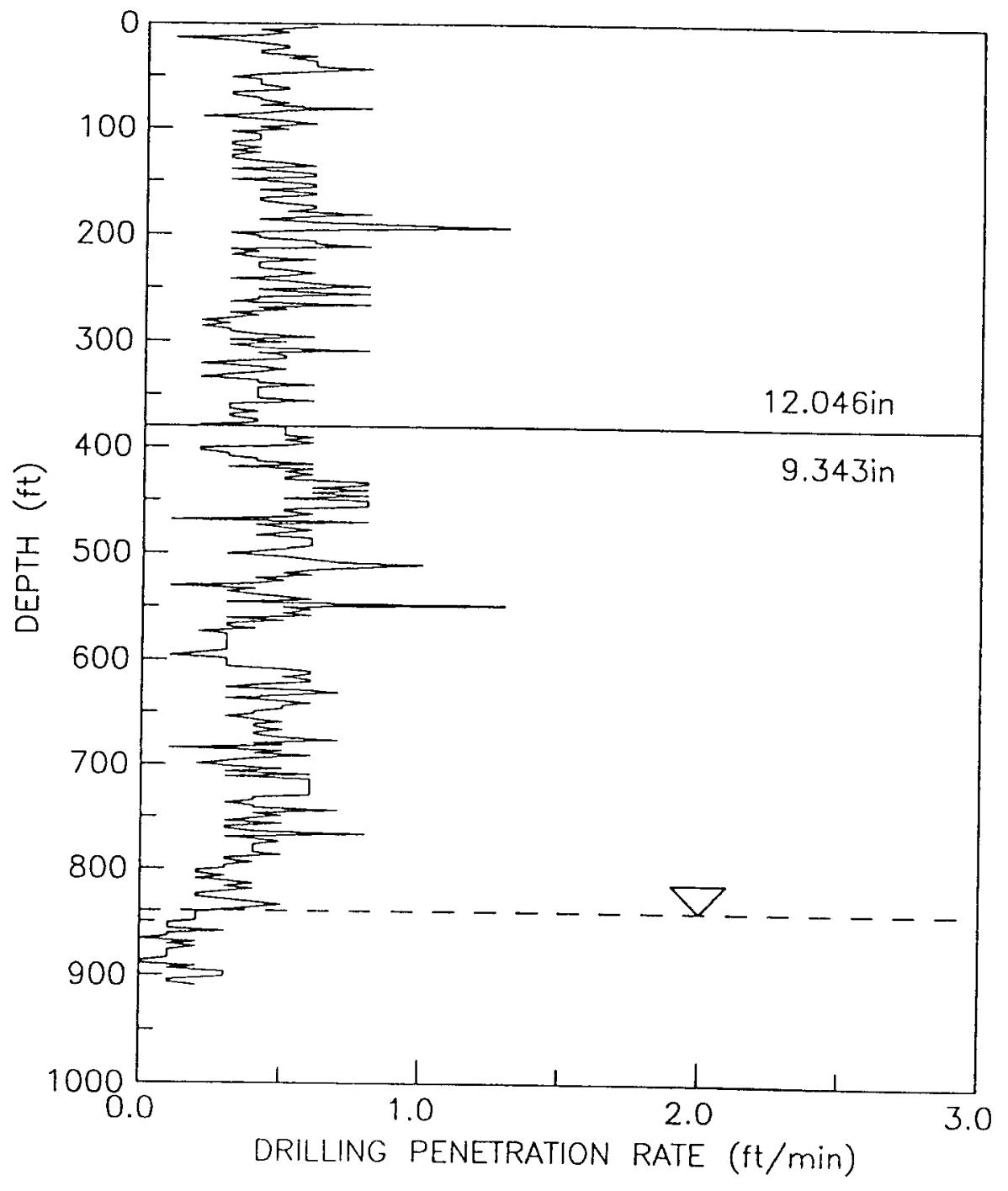


Appendix A.4 Drilling penetration rate data for Ue5PW-3 (Continued)

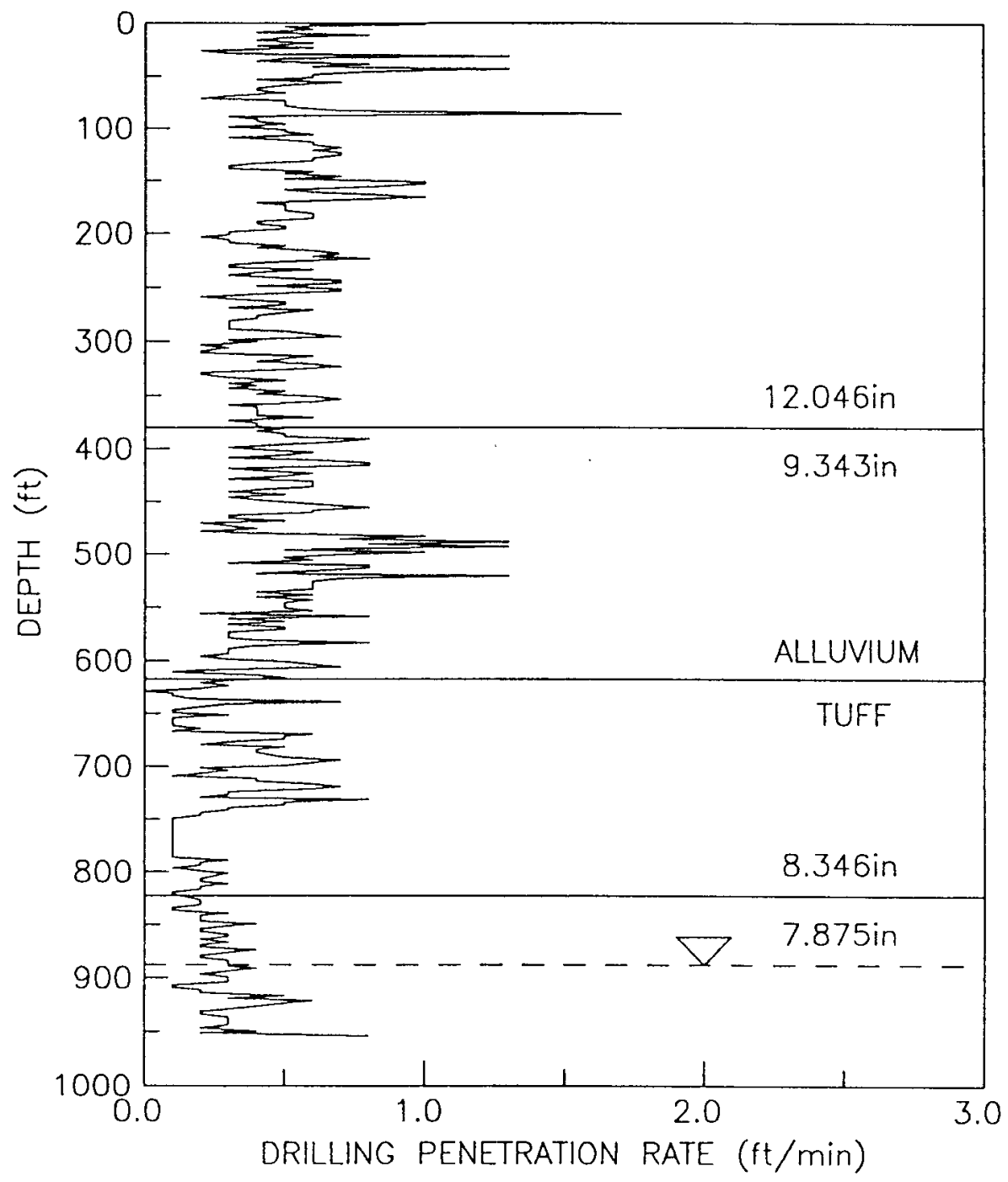




\section{Area 5 Pilot Wells}

\section{APPENDIX B \\ Core and Drill Cuttings Sample Description Data}

B.1 Borehole Log Sheets for UE5PW-1

B.2 Borehole Log Sheets for UE5PW-2

B.3 Borehole Log Sheets for UE5PW-3

B.4 Drill Cuttings Log Data for UE5PW-1

B.5 Drill Cuttings Log Data for UE5PW-2

B.6 Drill Cuttings Log Data for UE5PW-3 


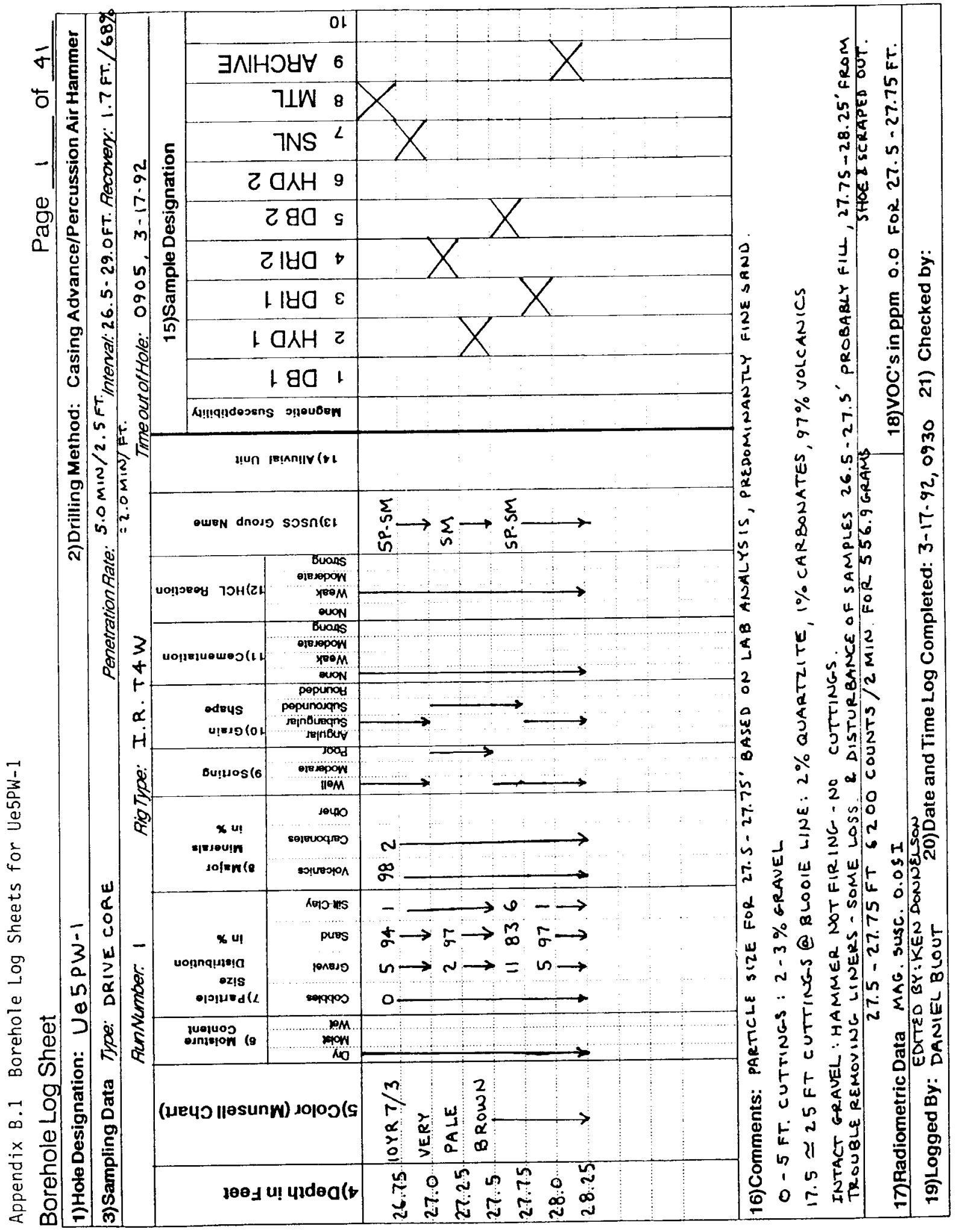




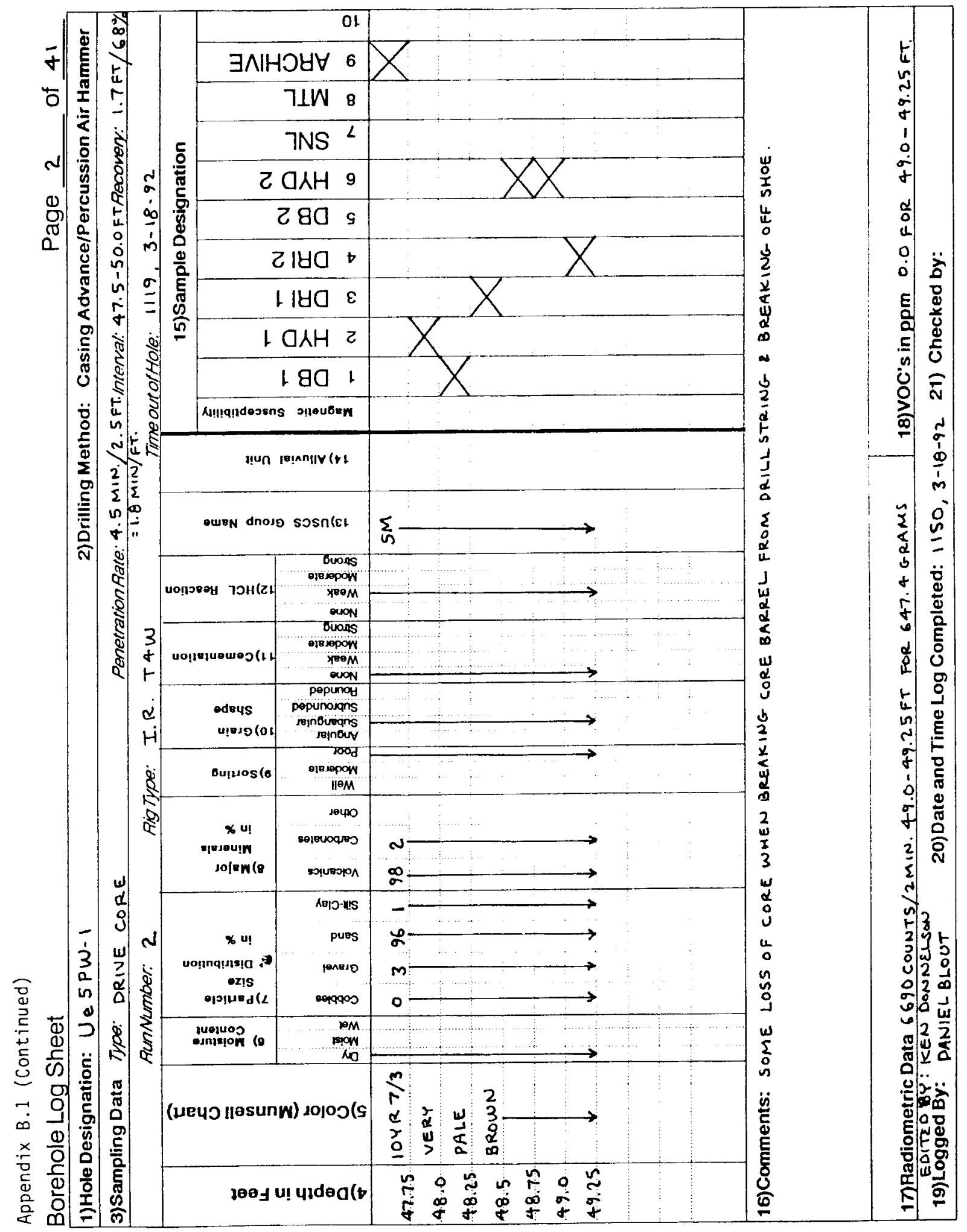




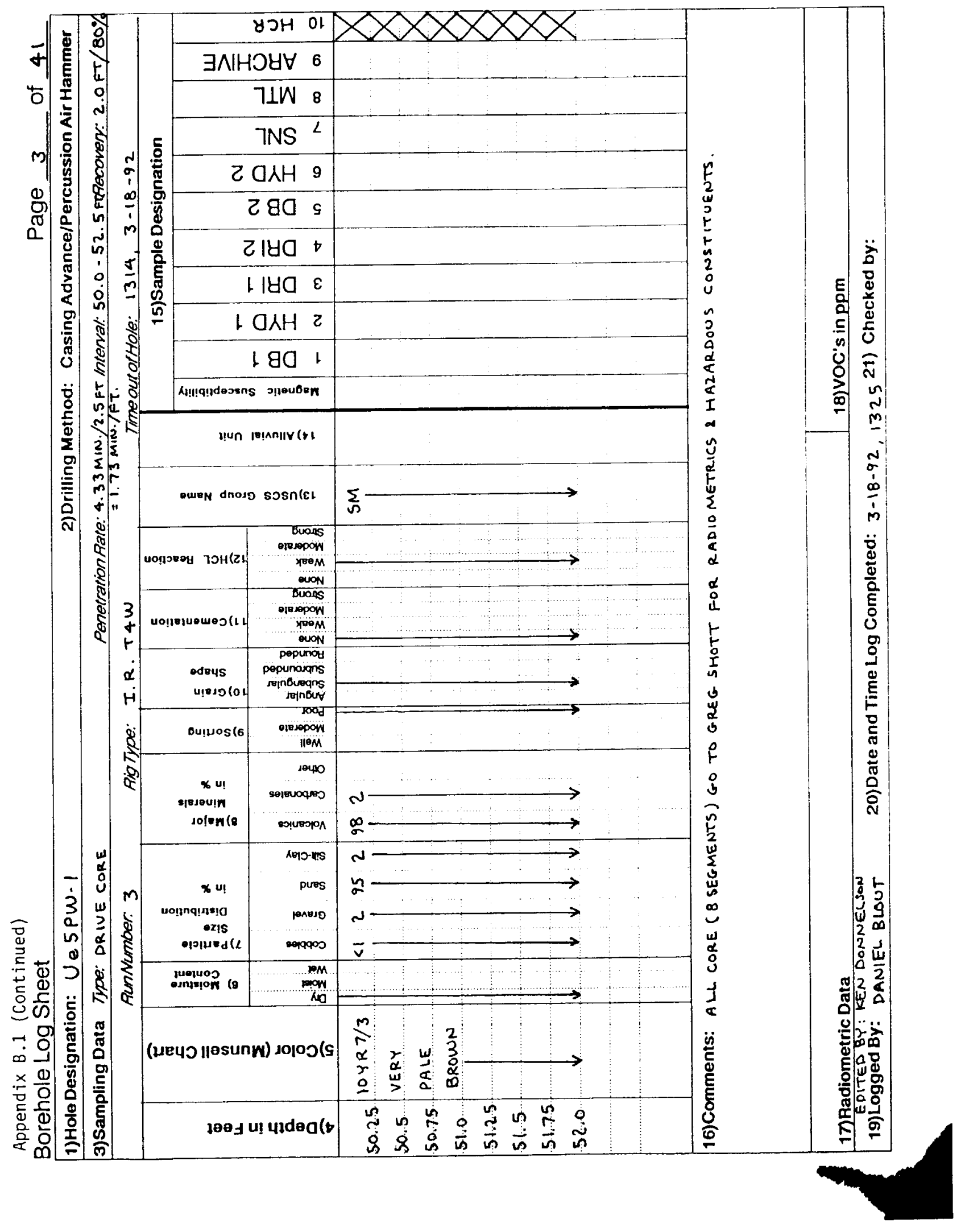




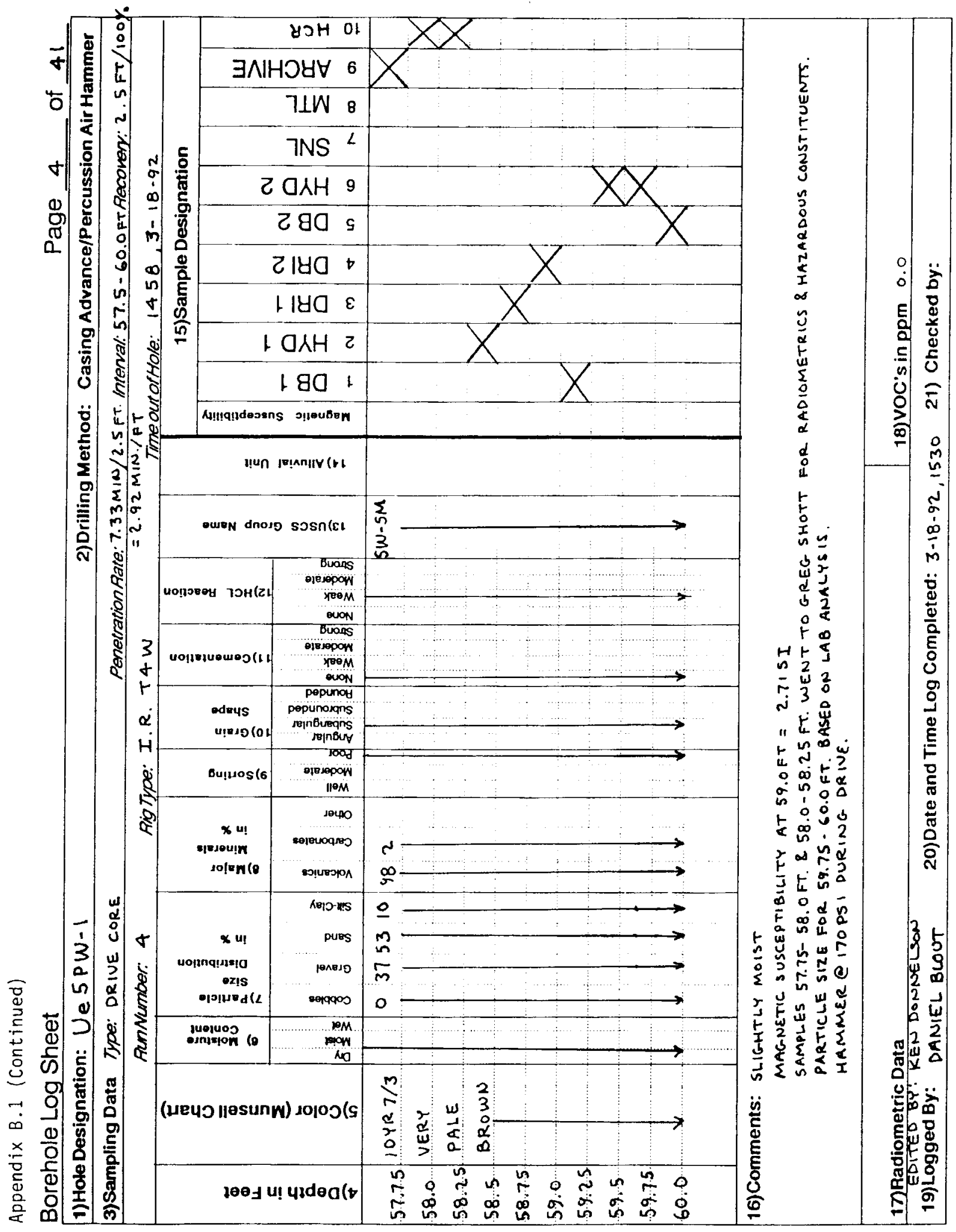




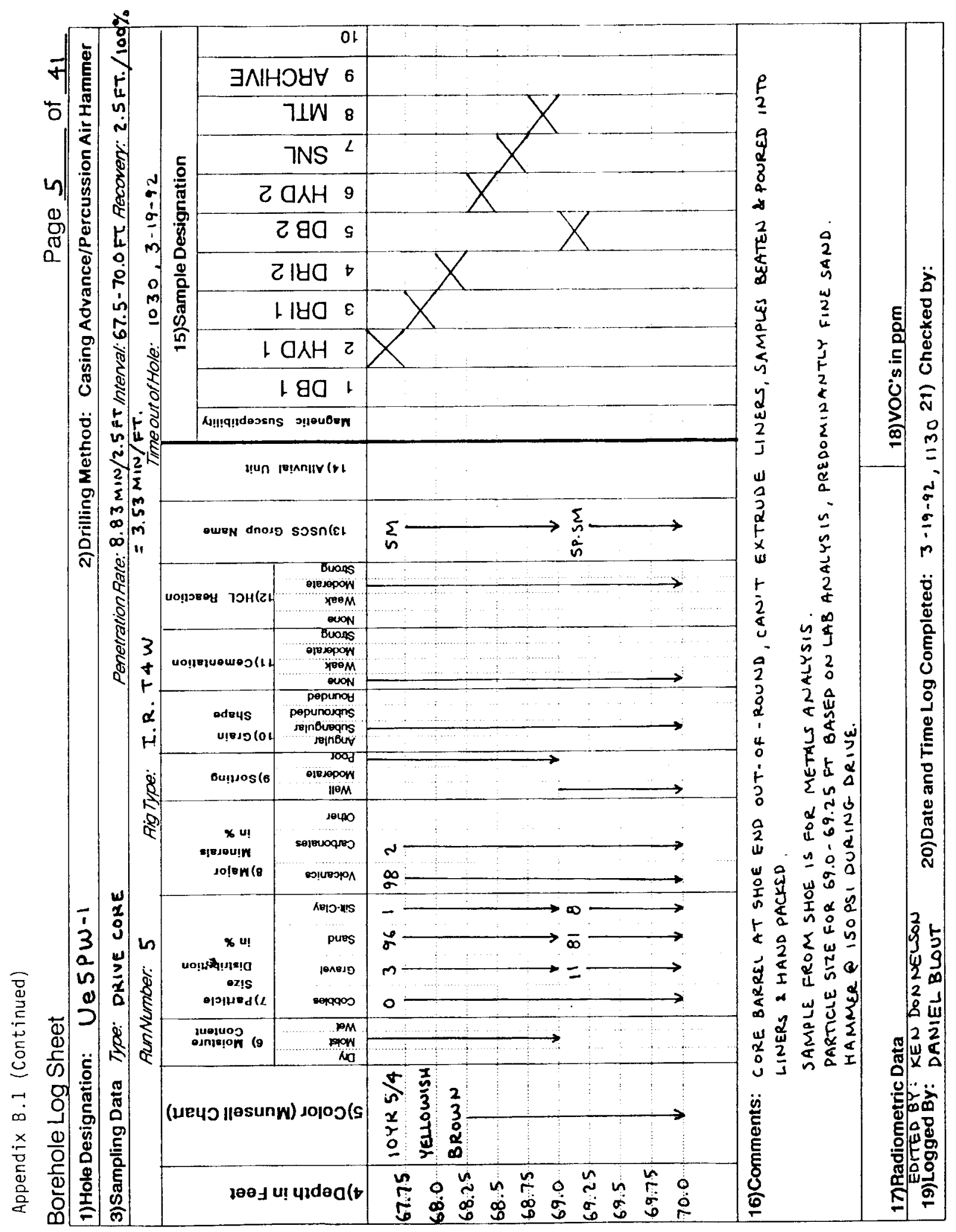




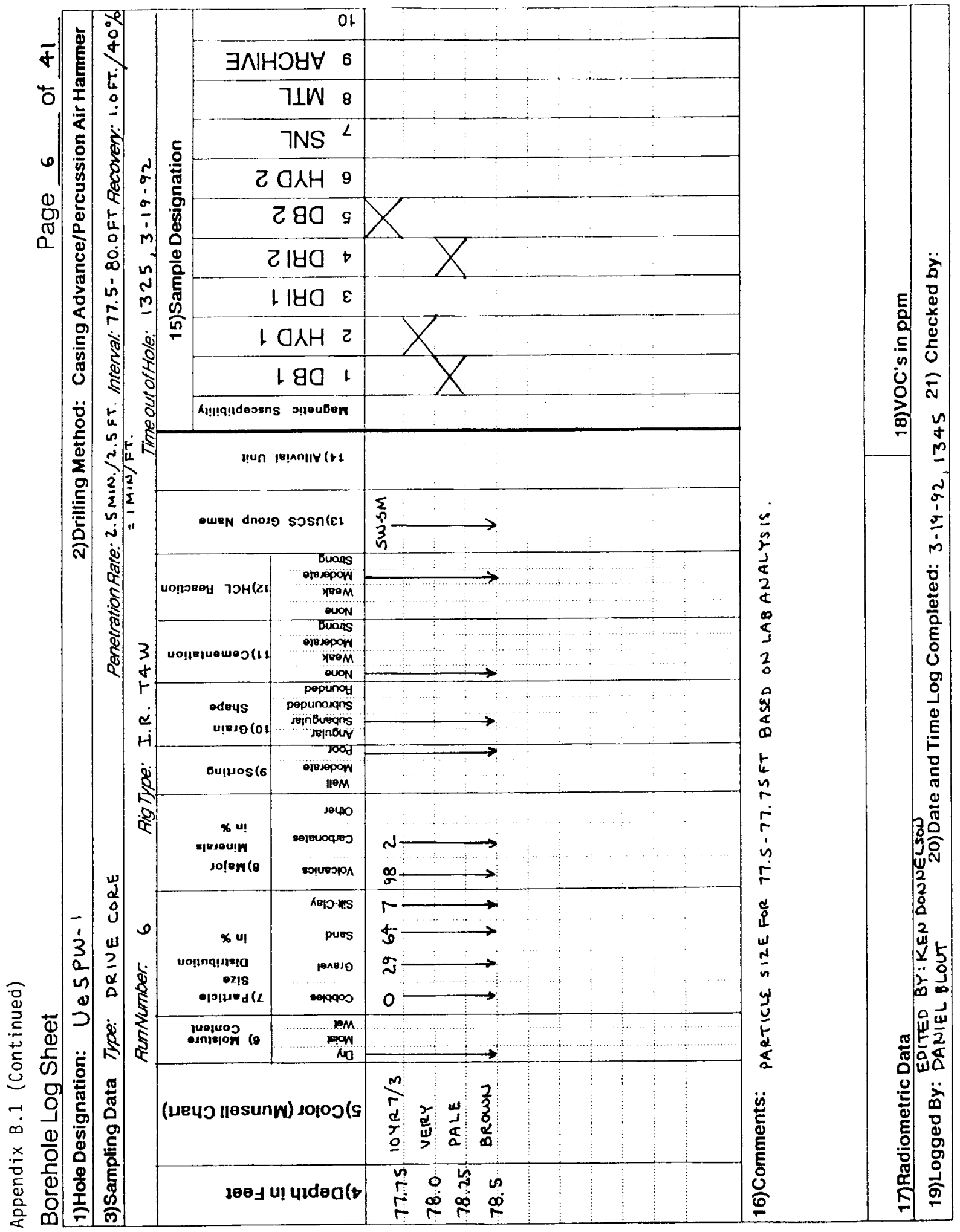




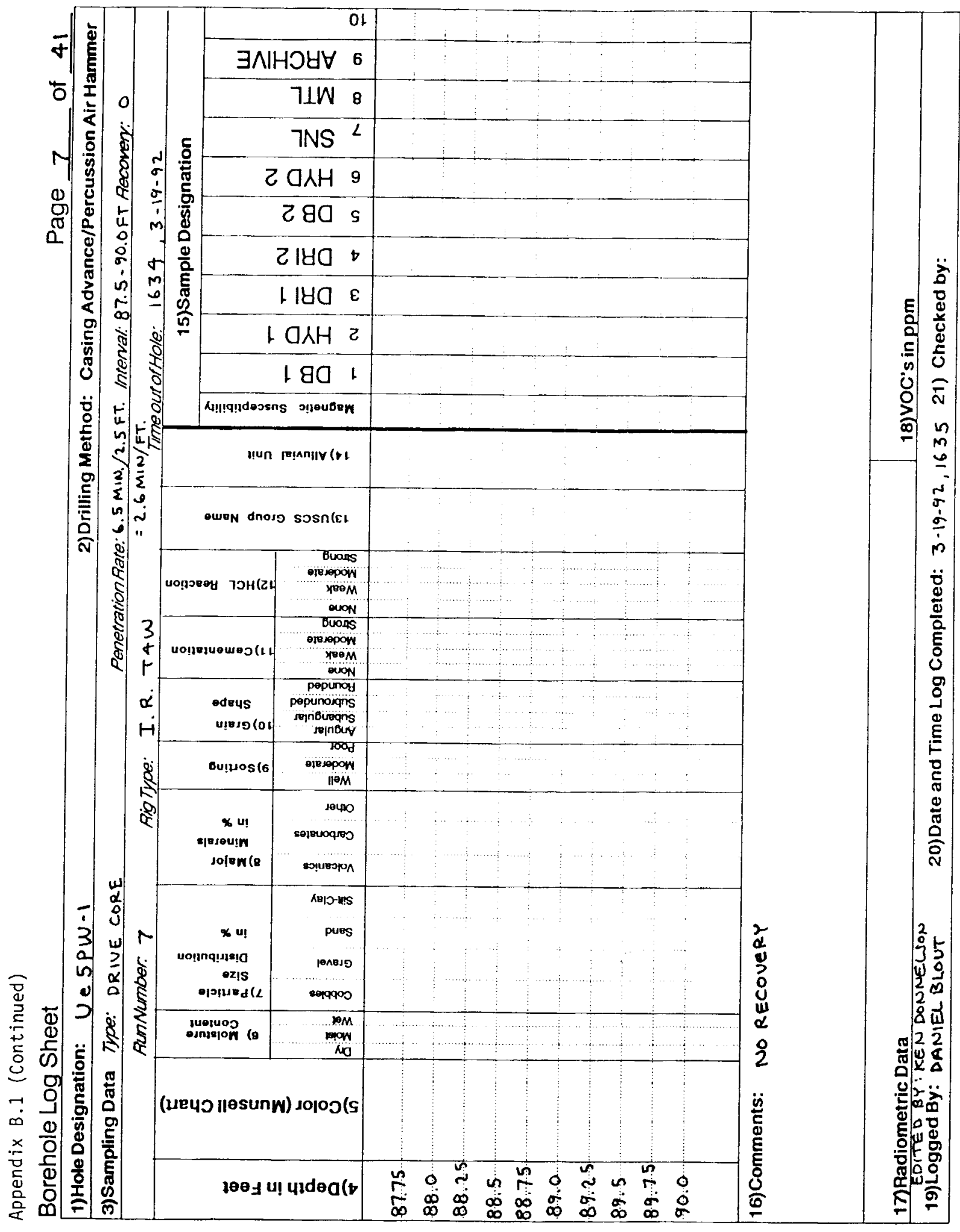




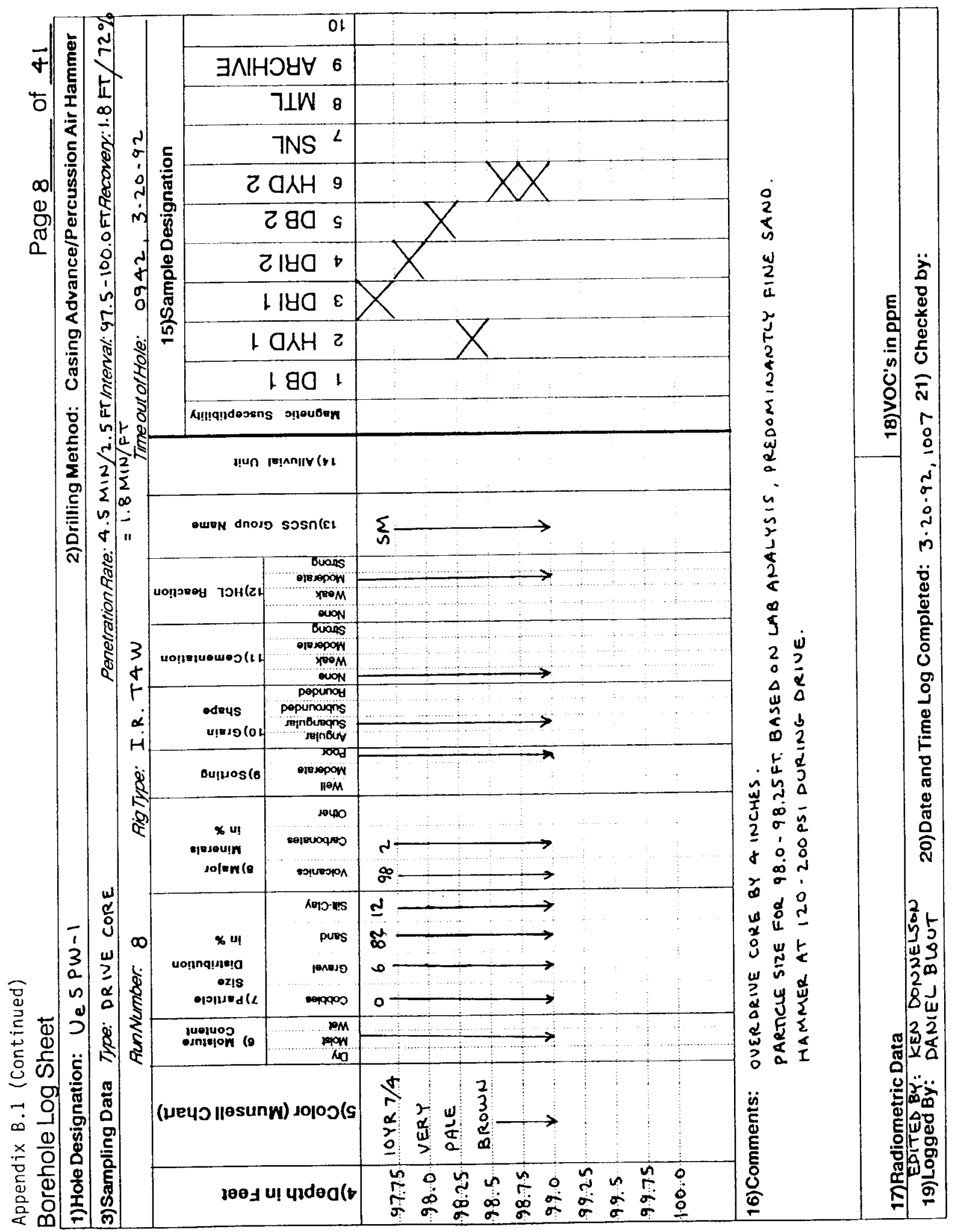




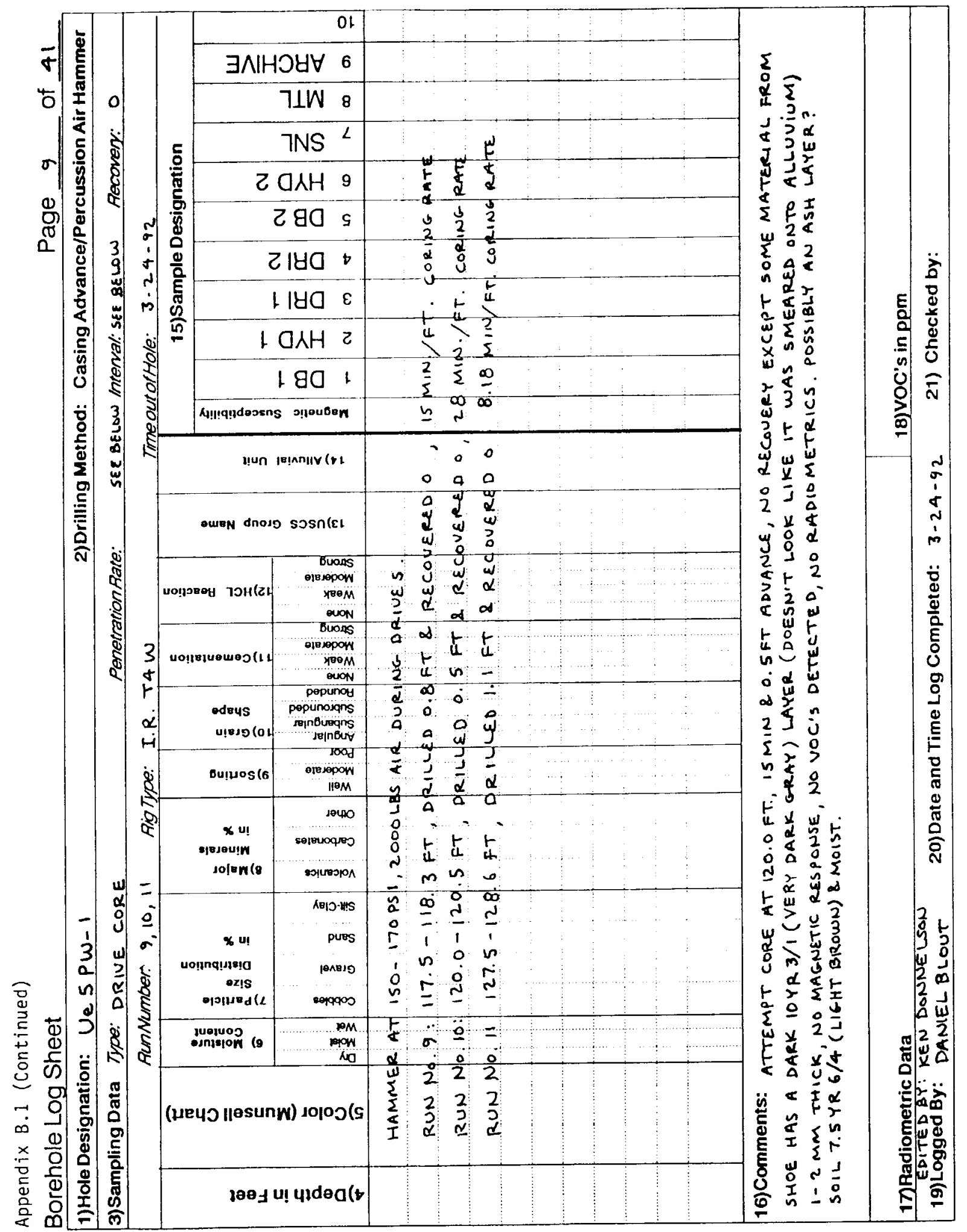




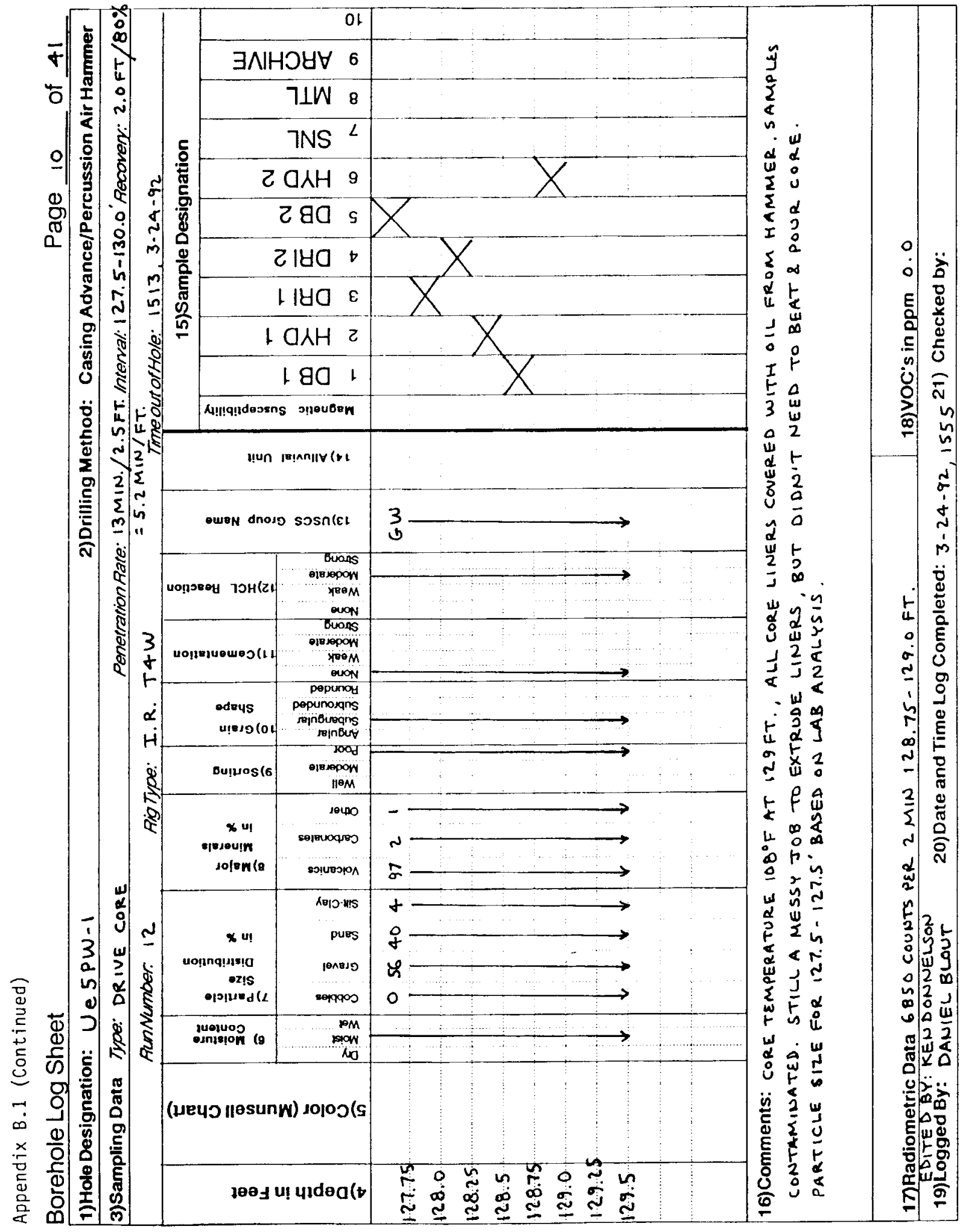




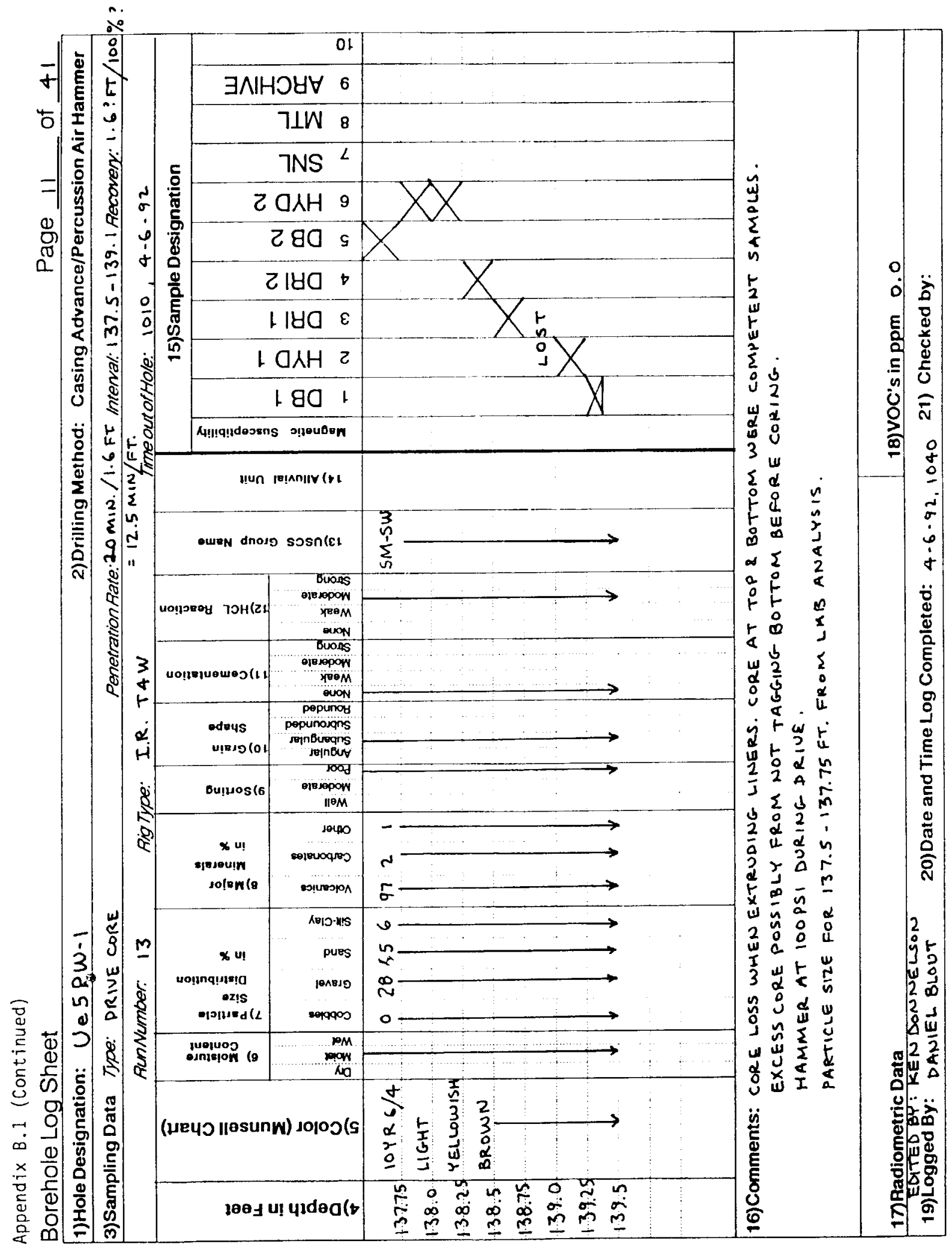




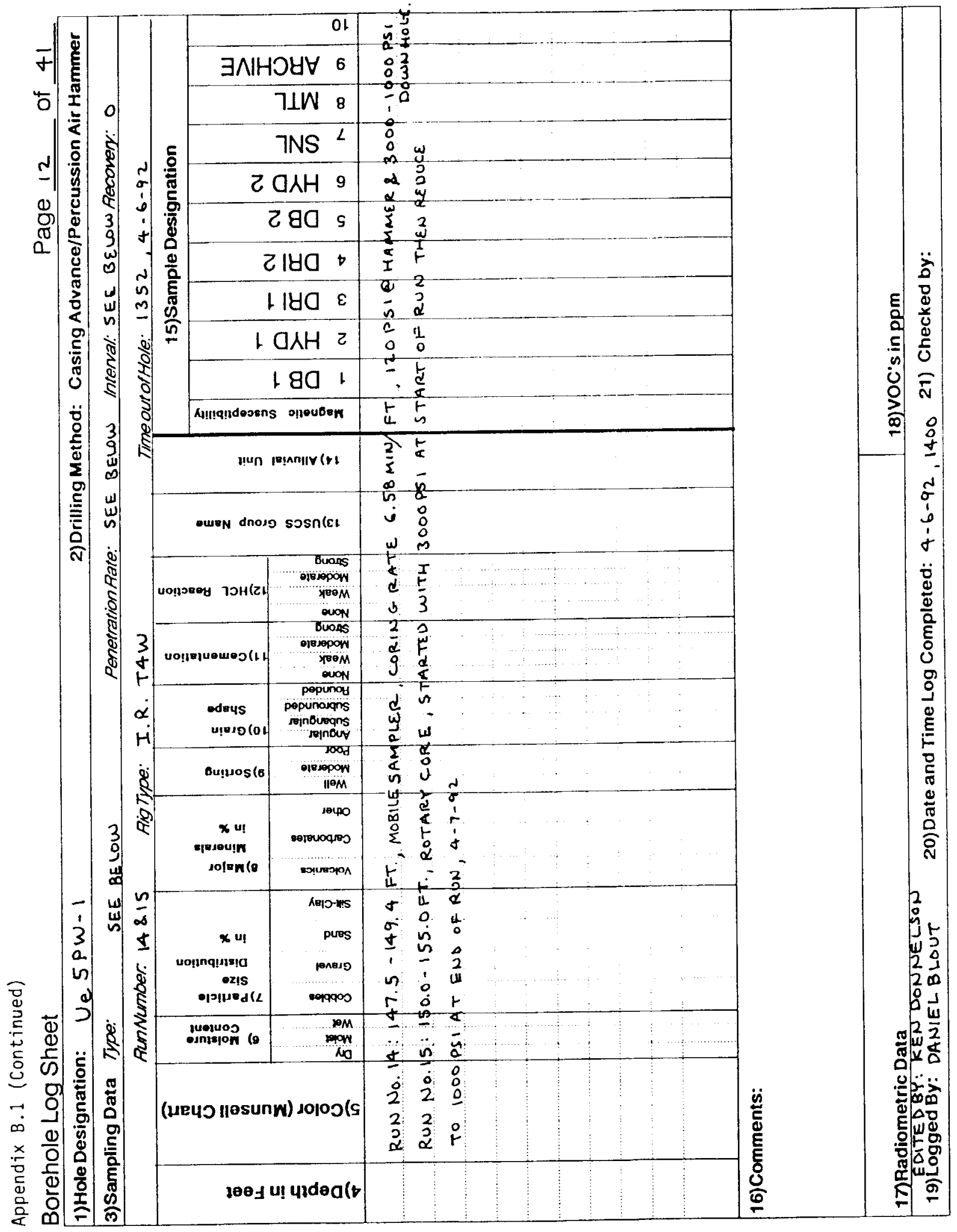




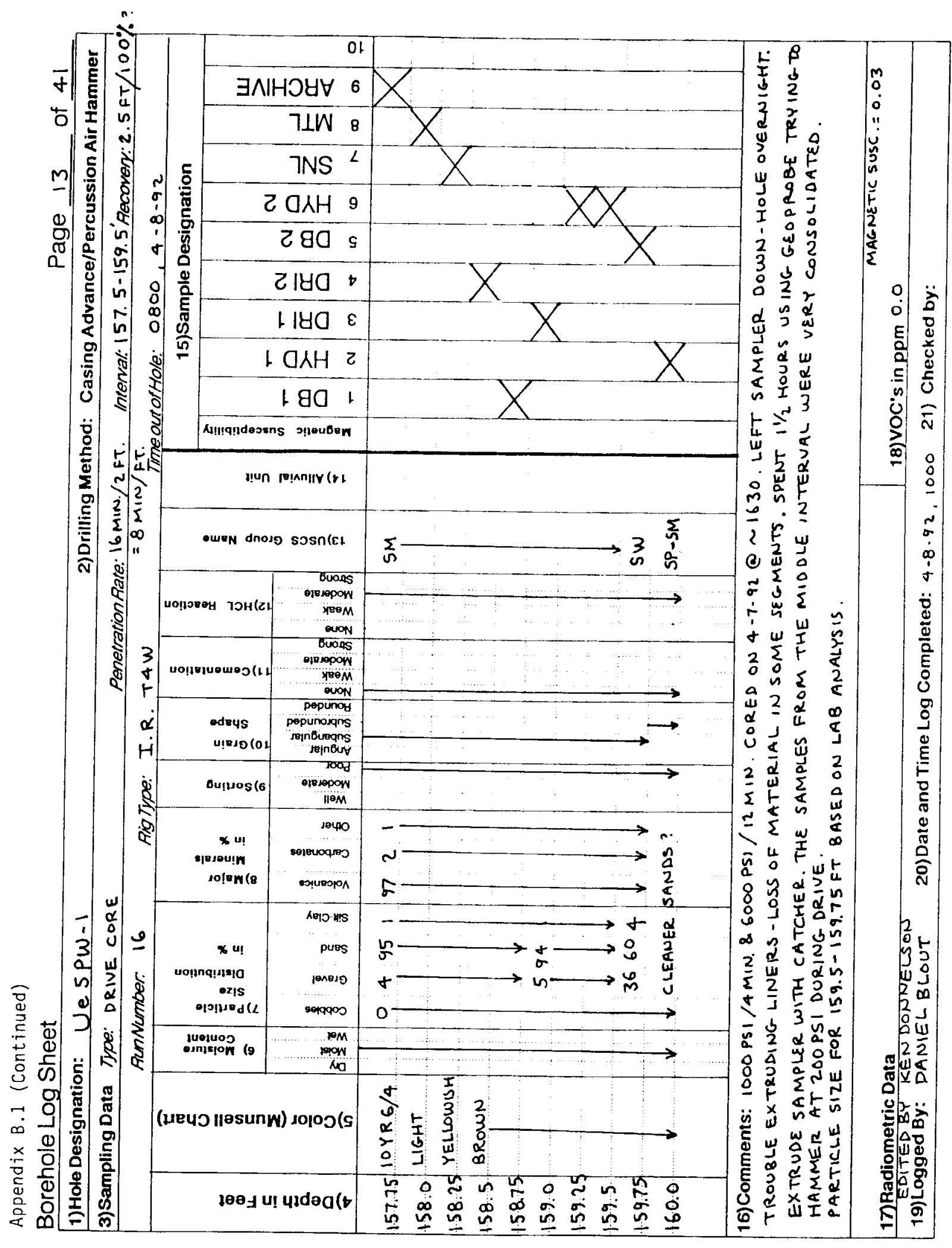




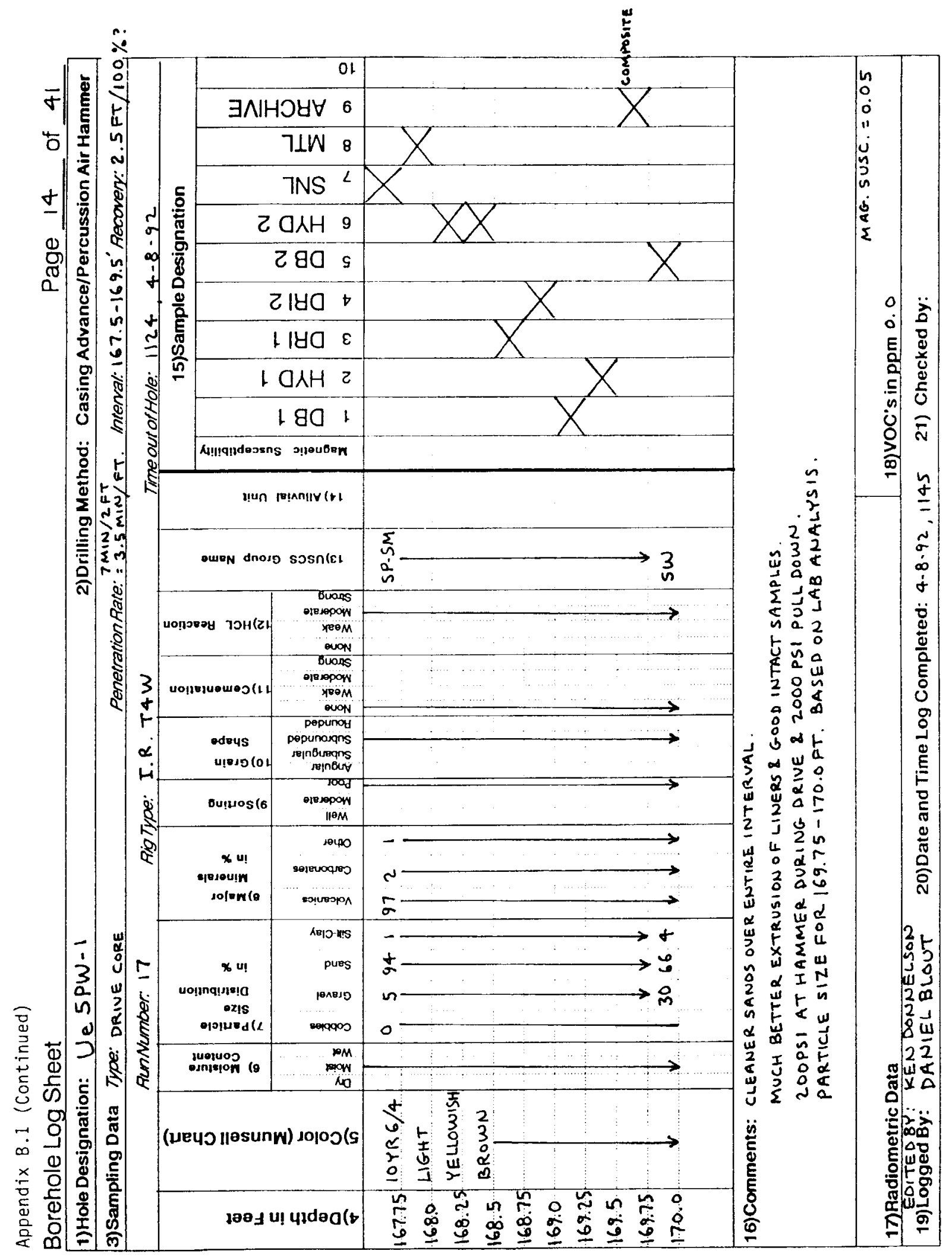




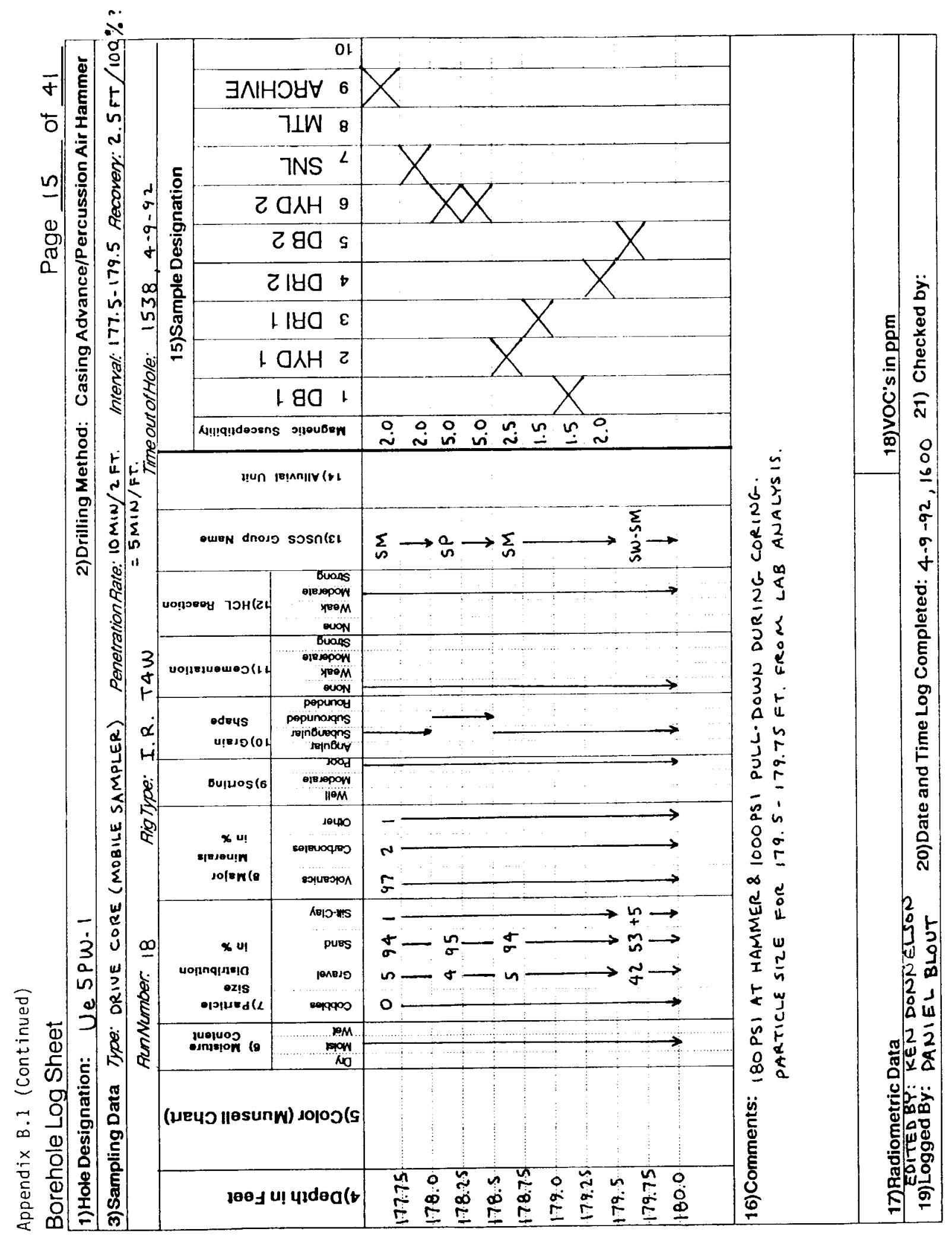




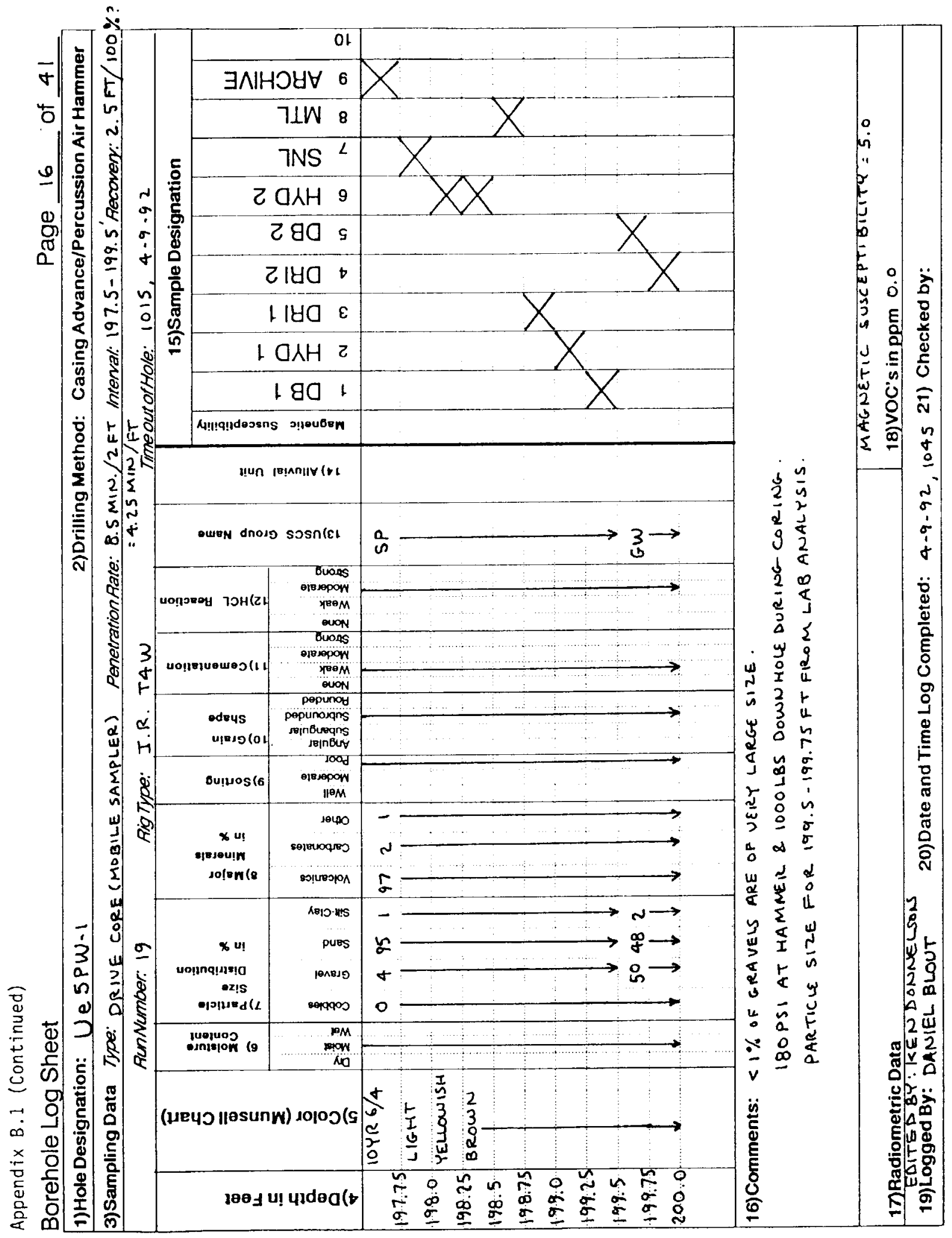




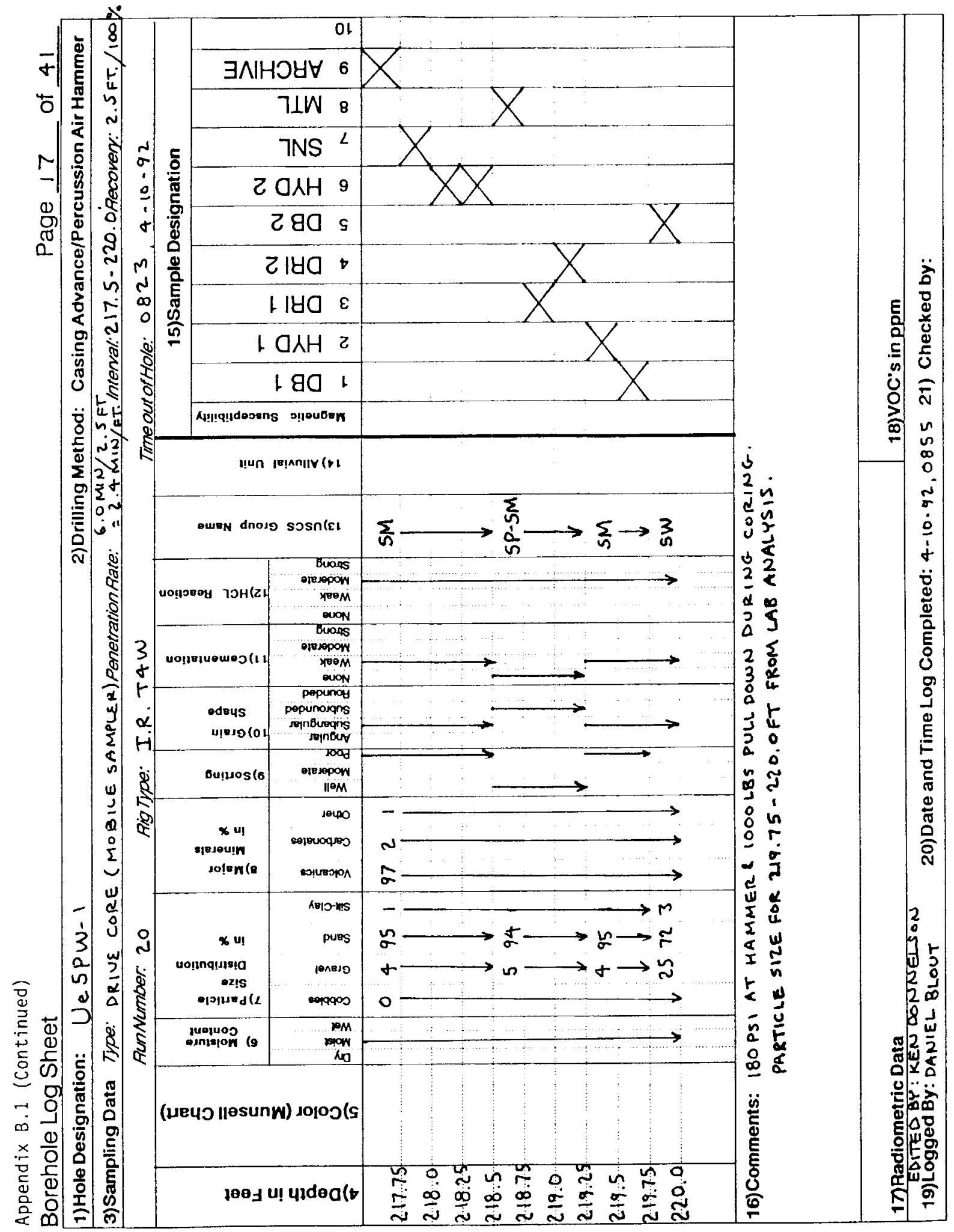




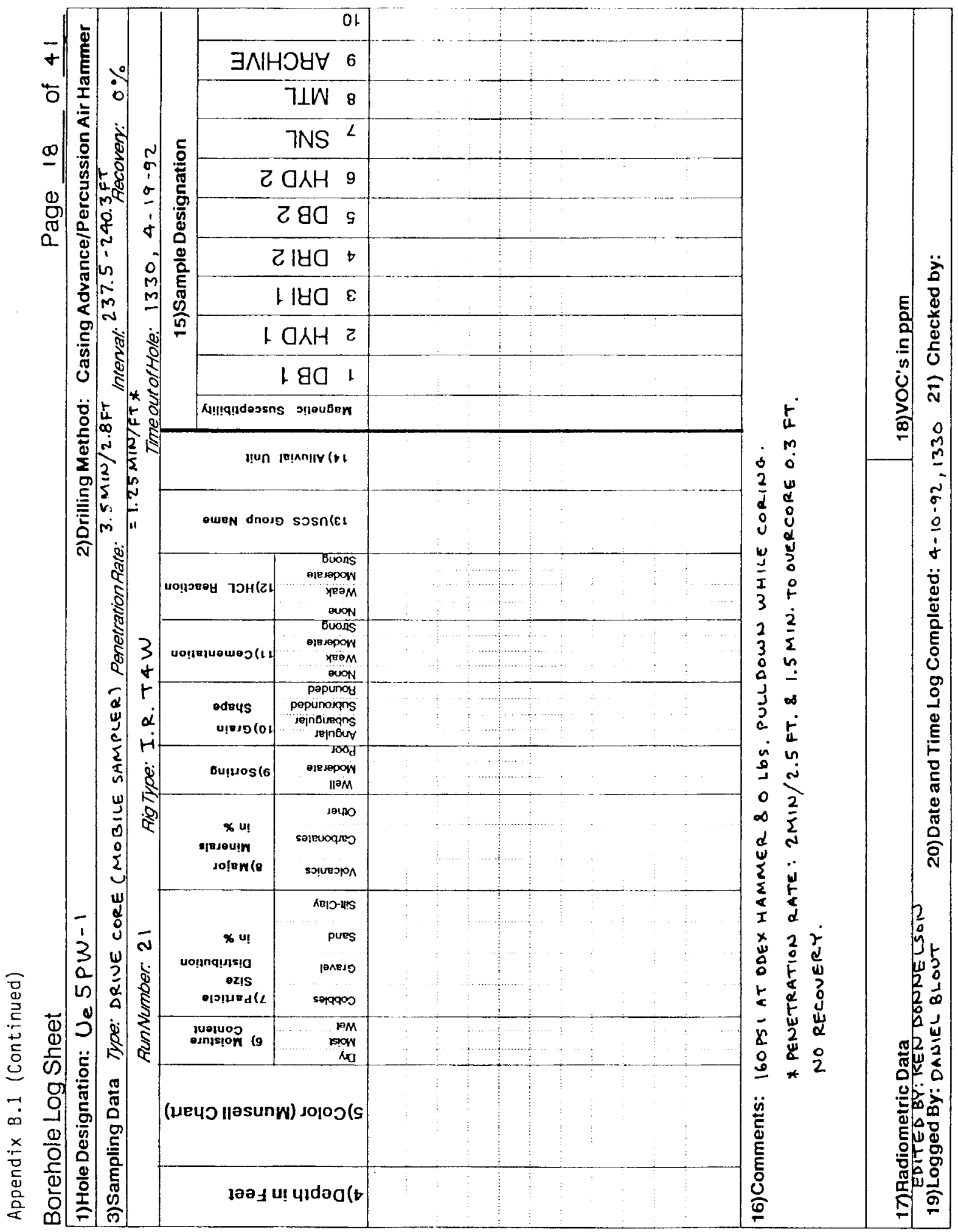




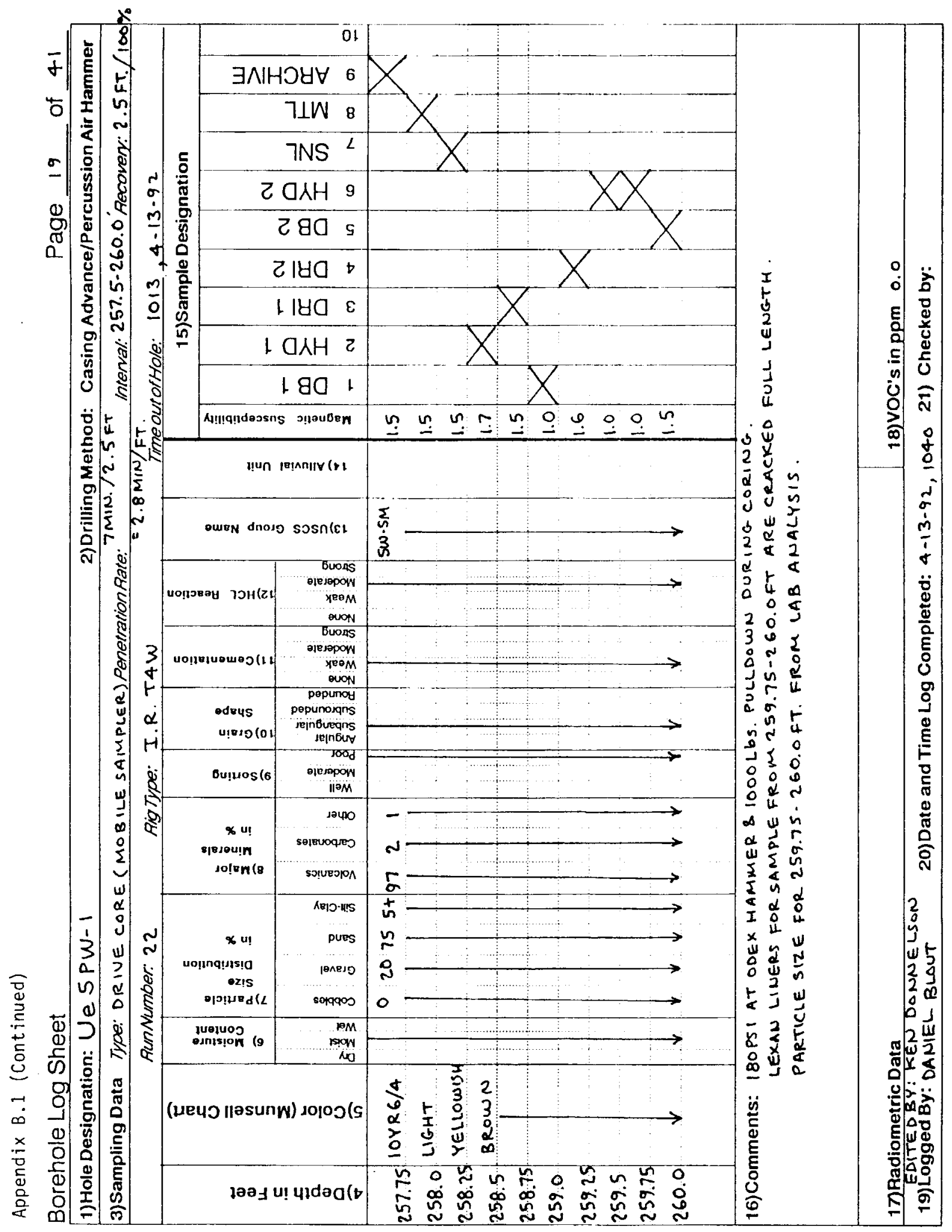




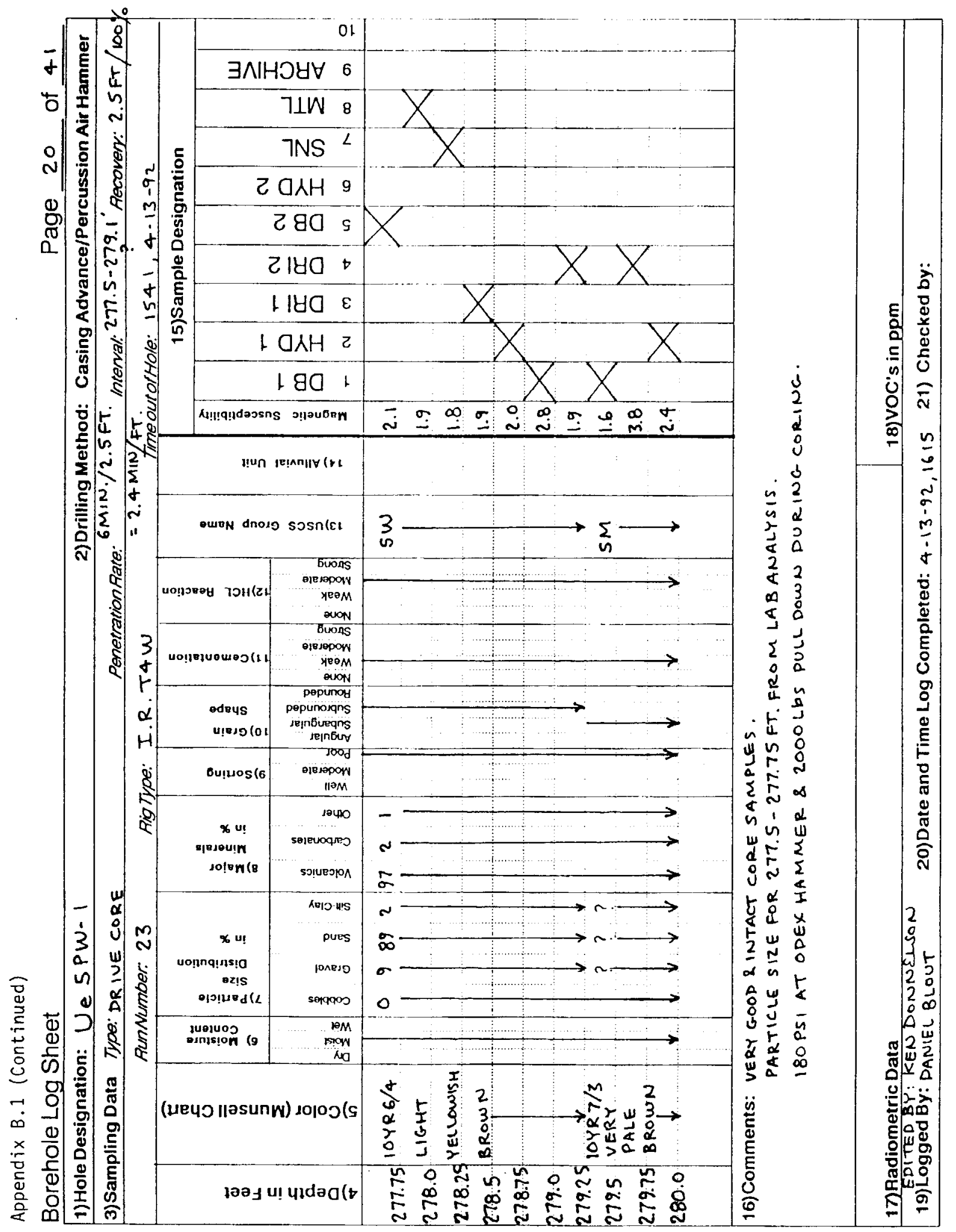




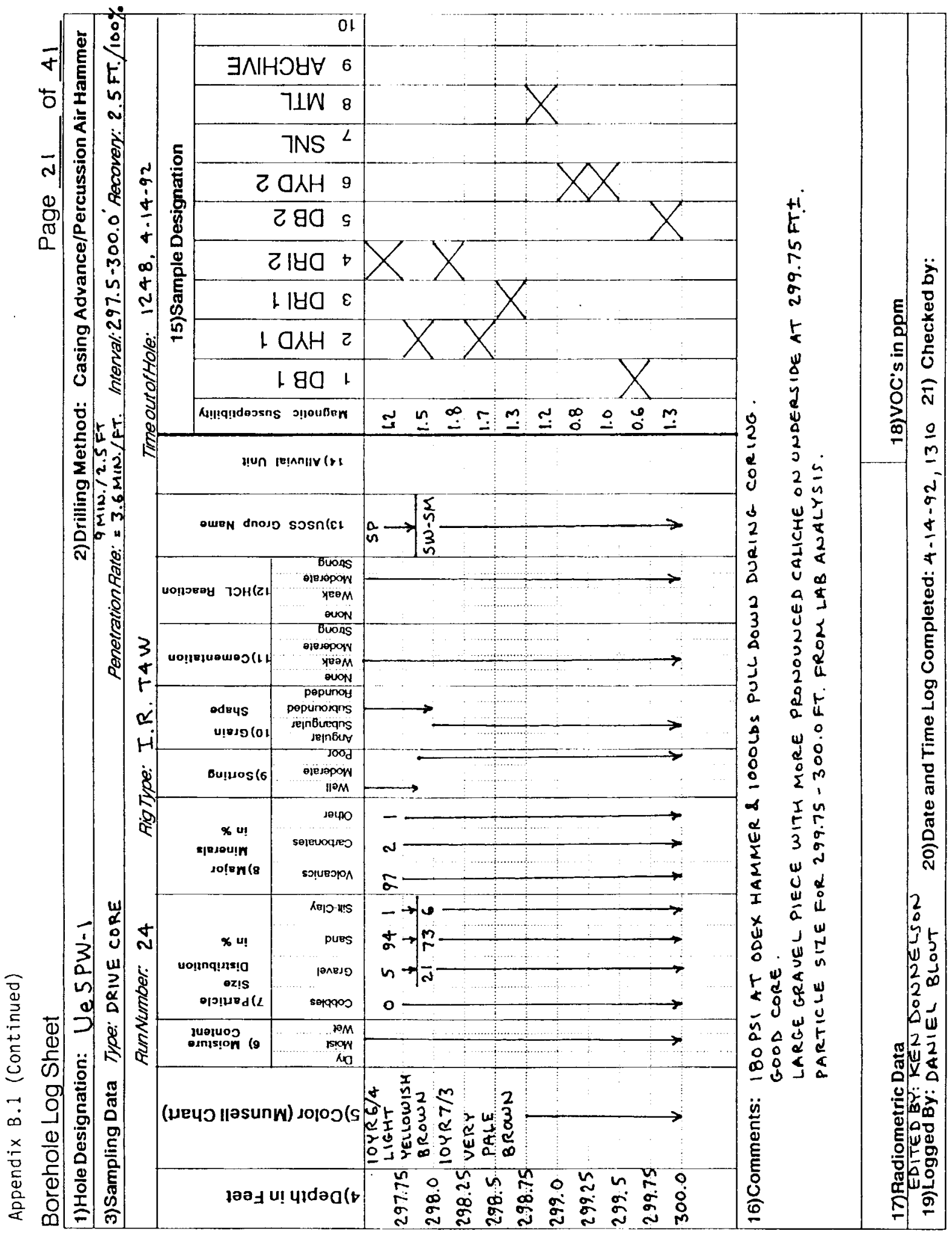




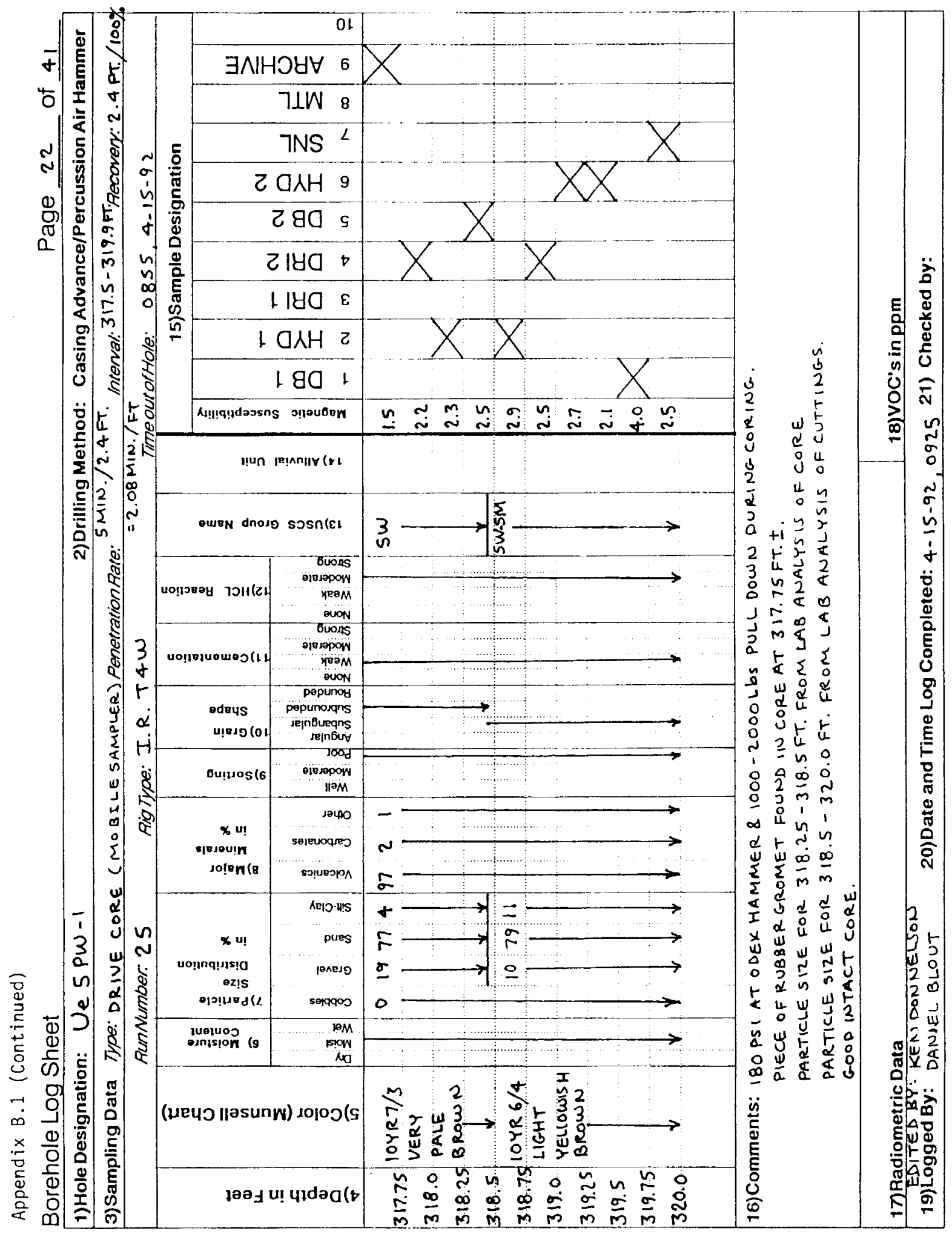




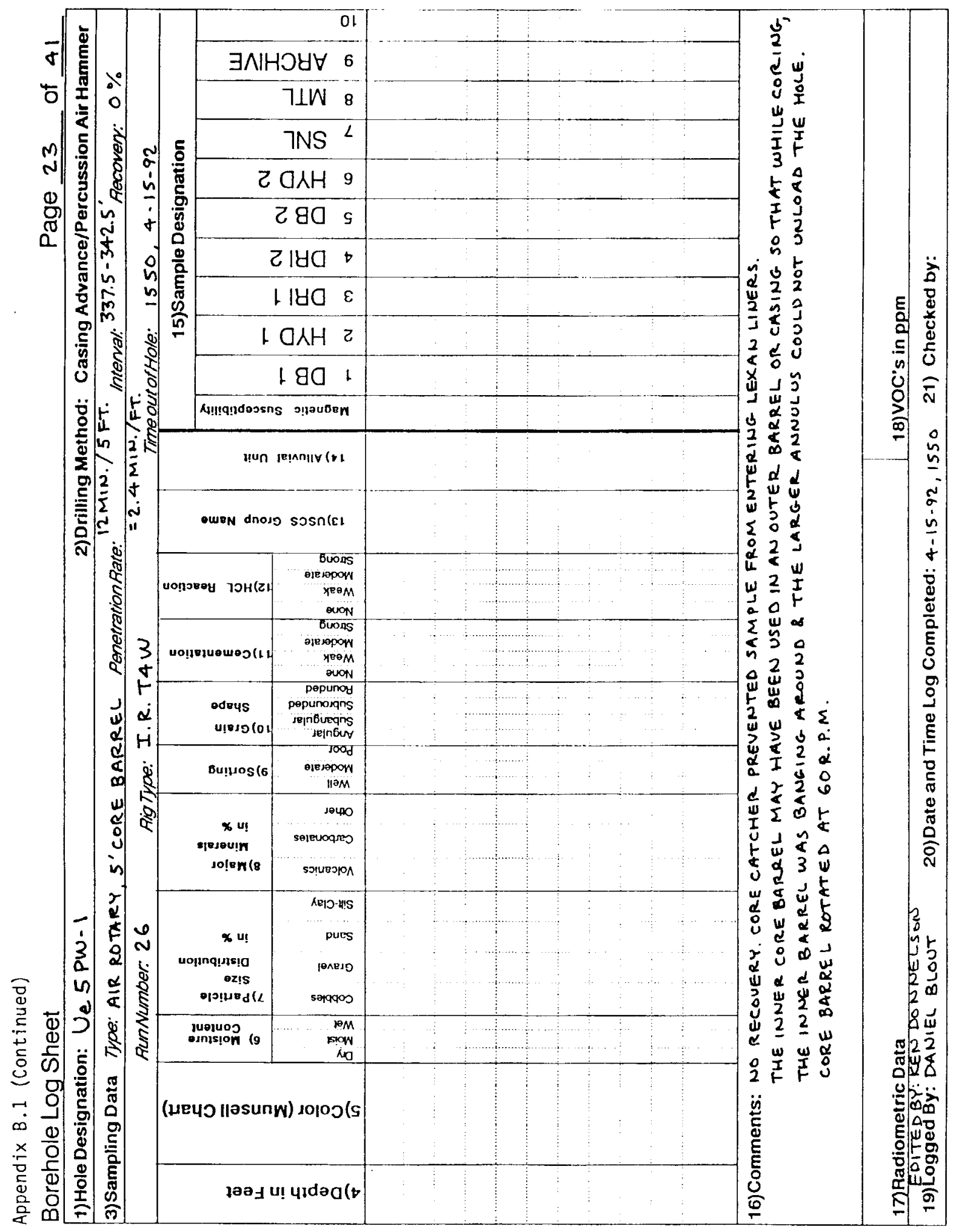









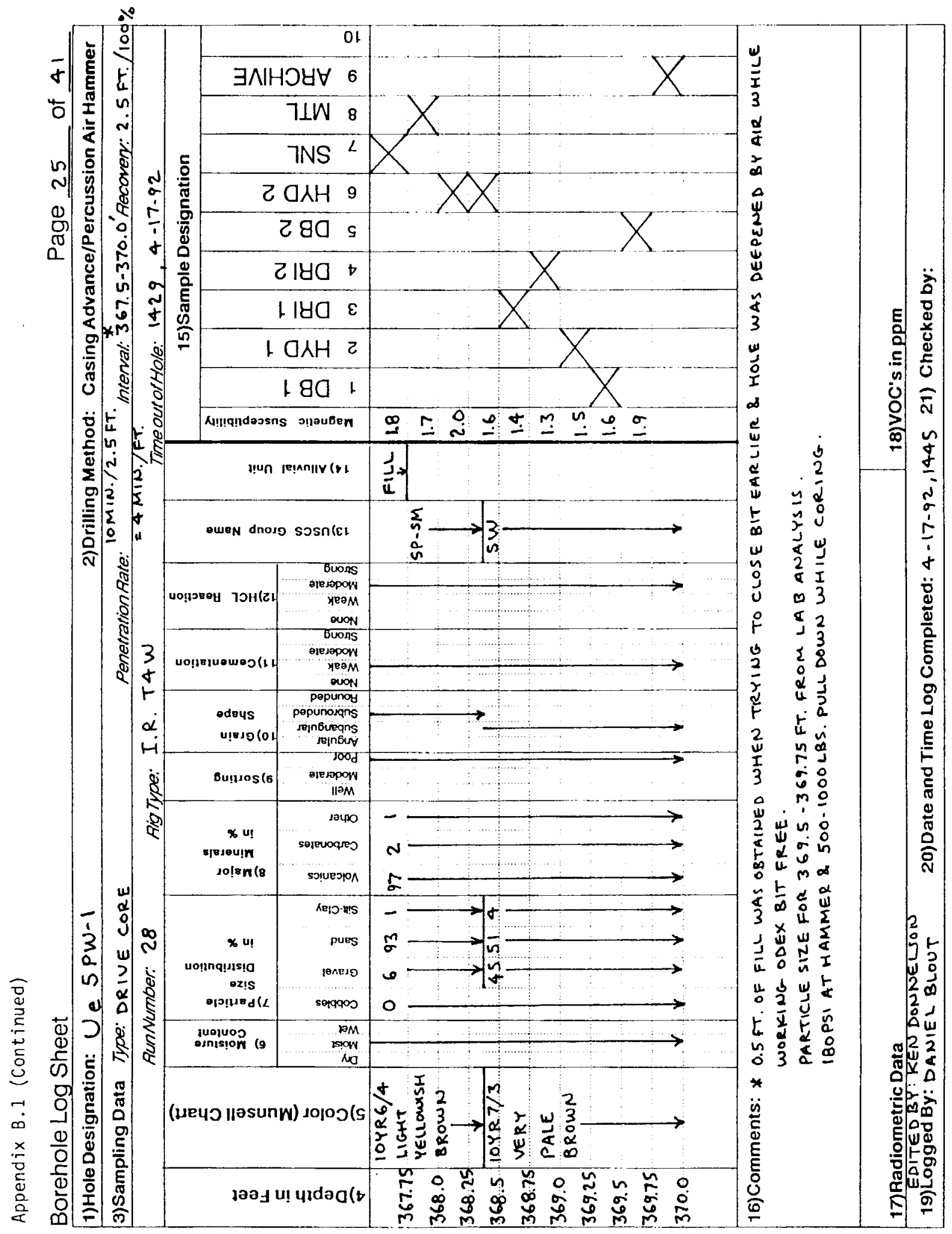




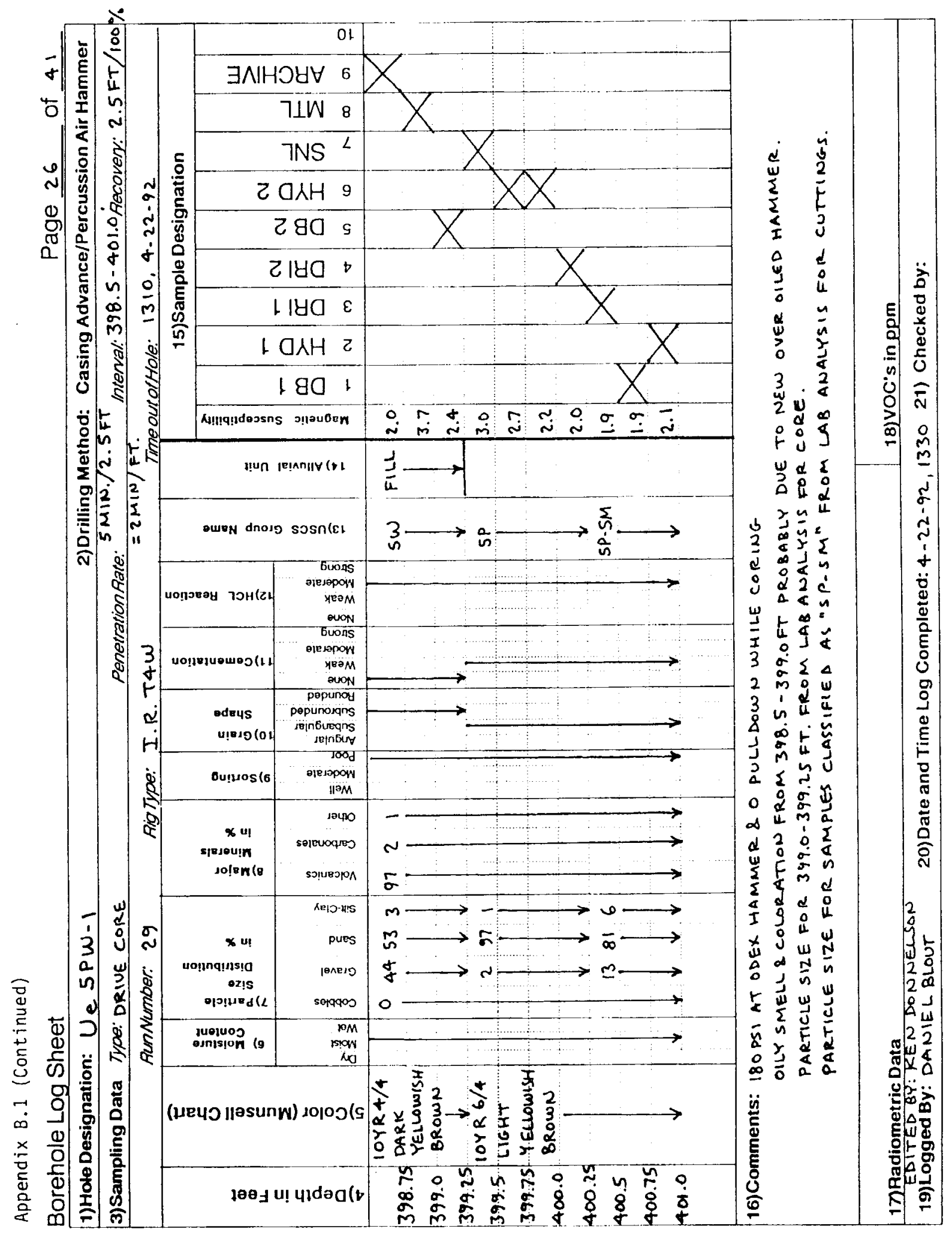









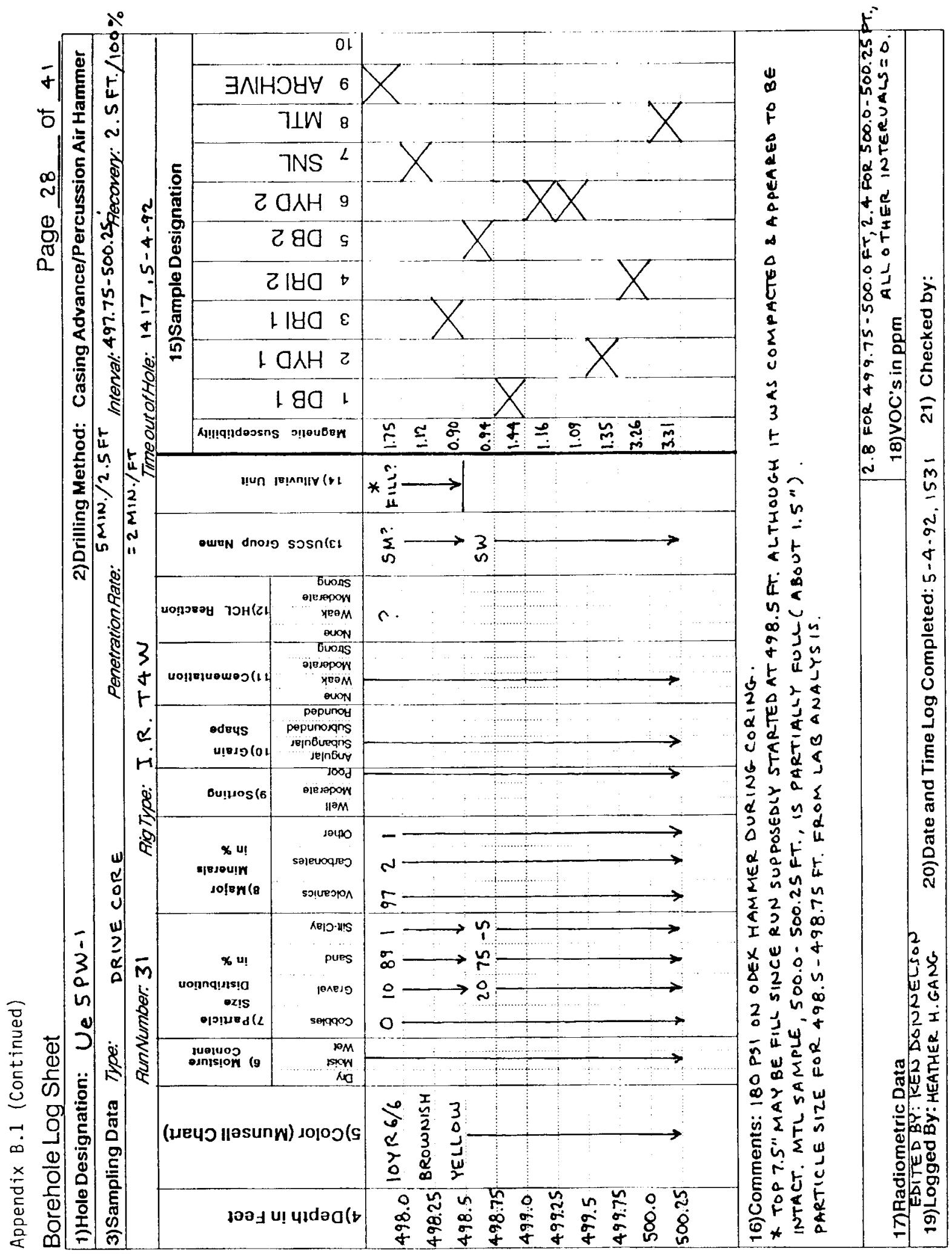




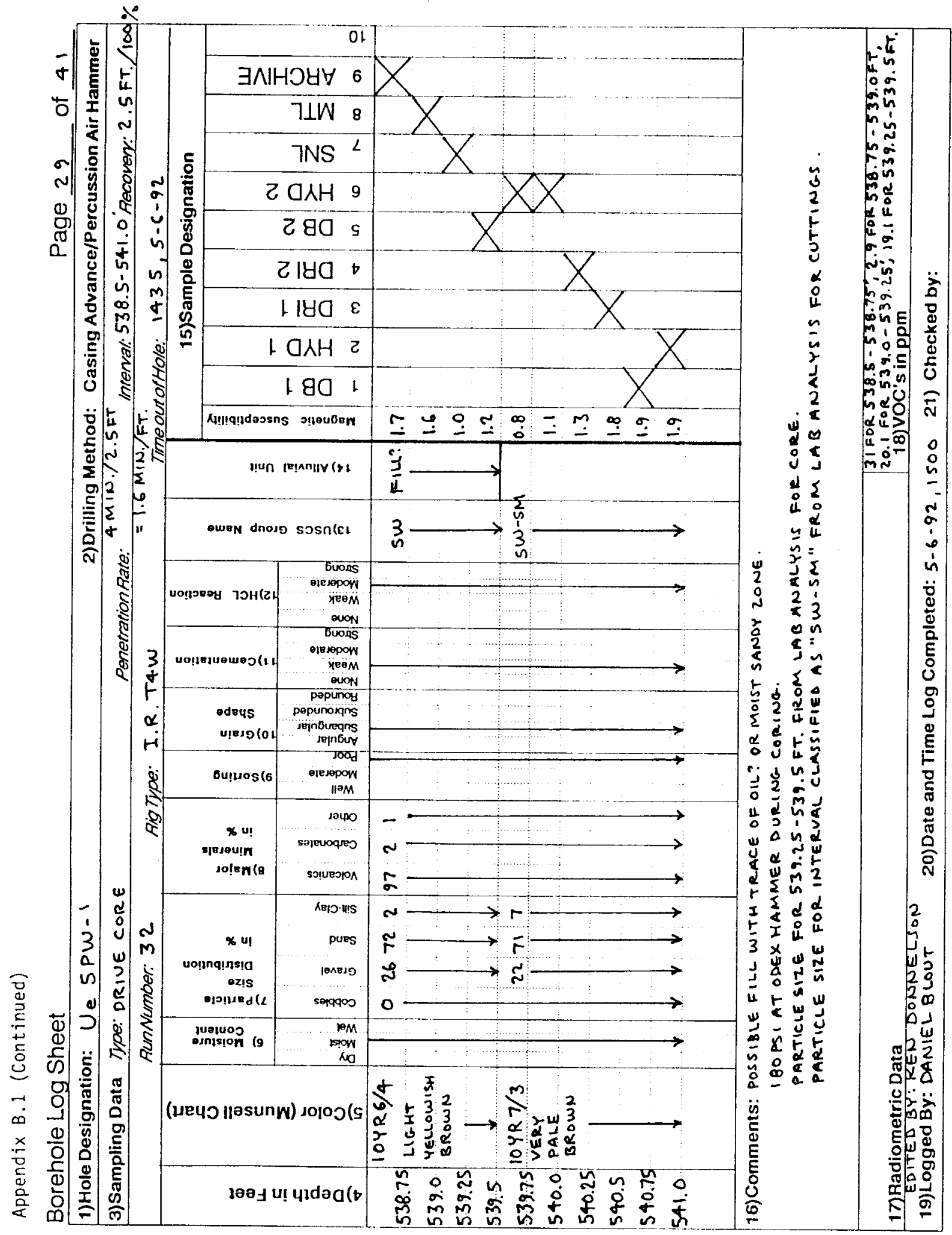




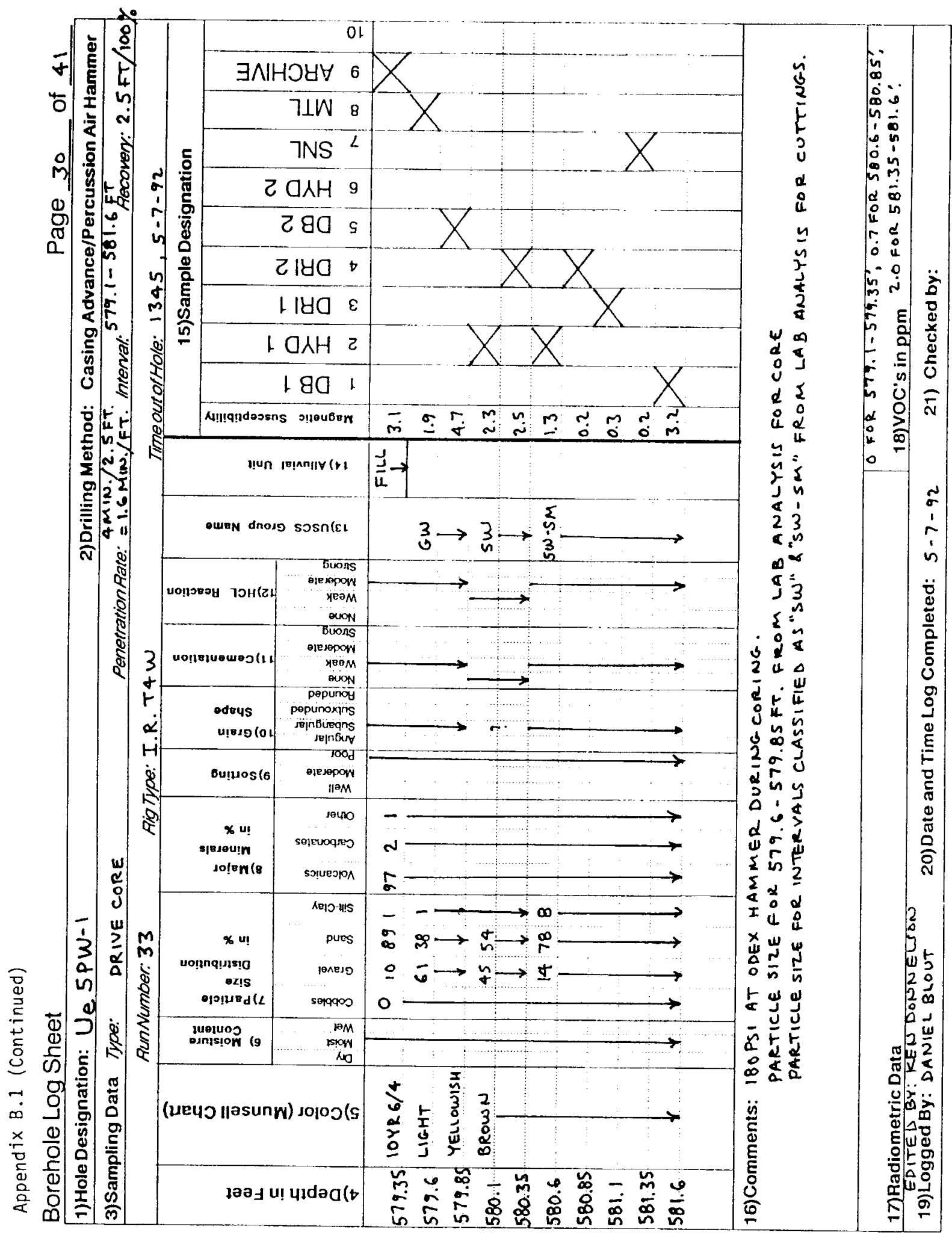




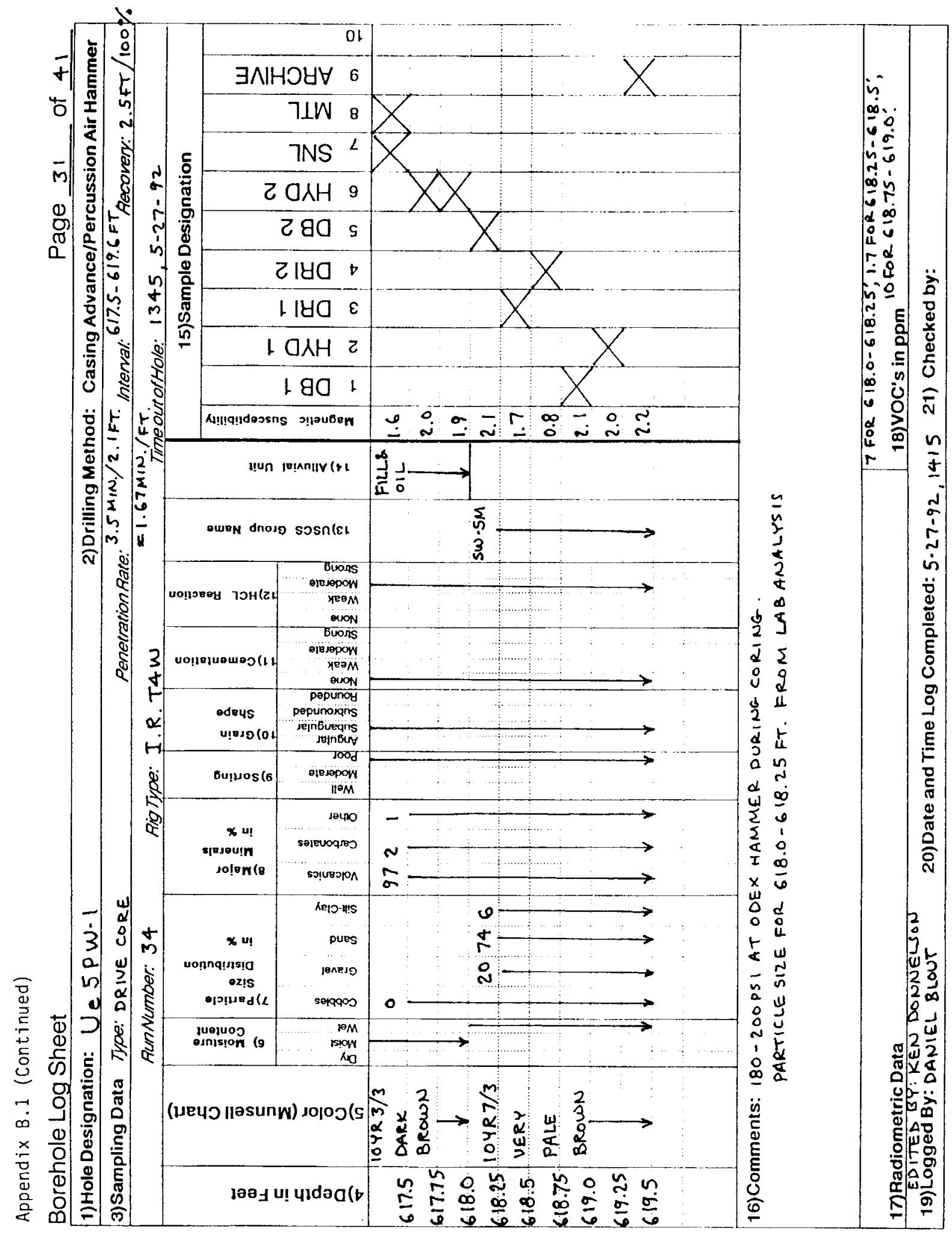




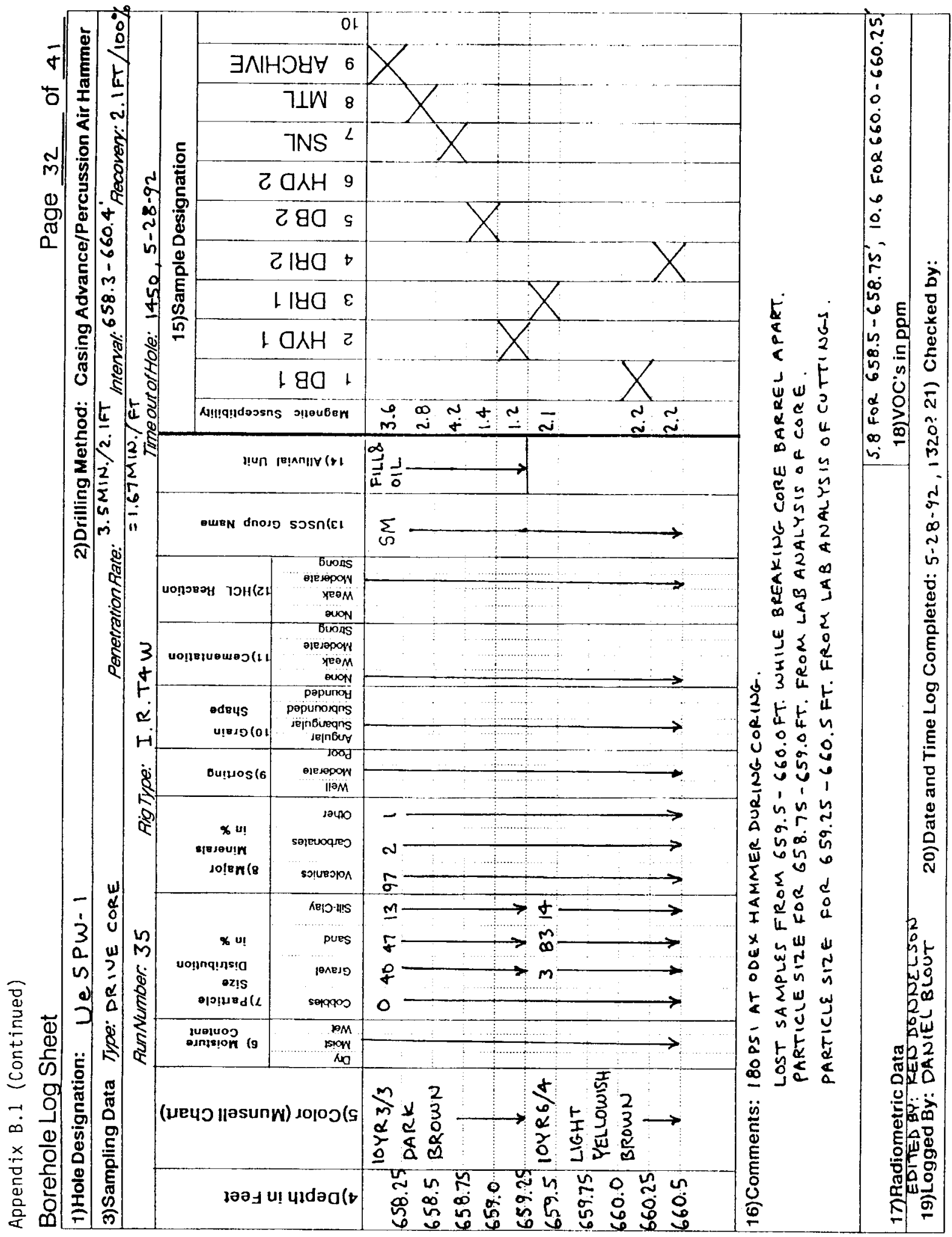




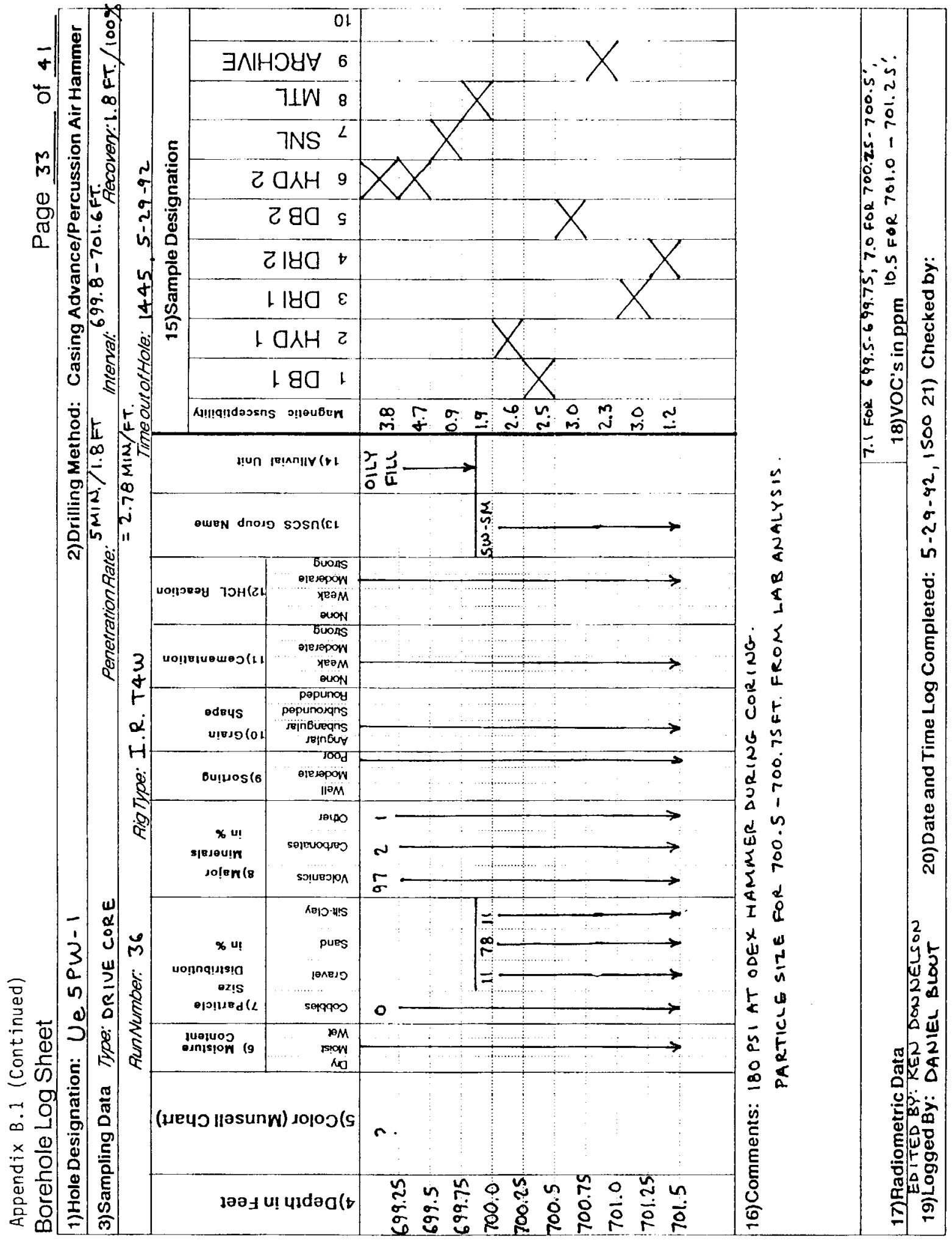




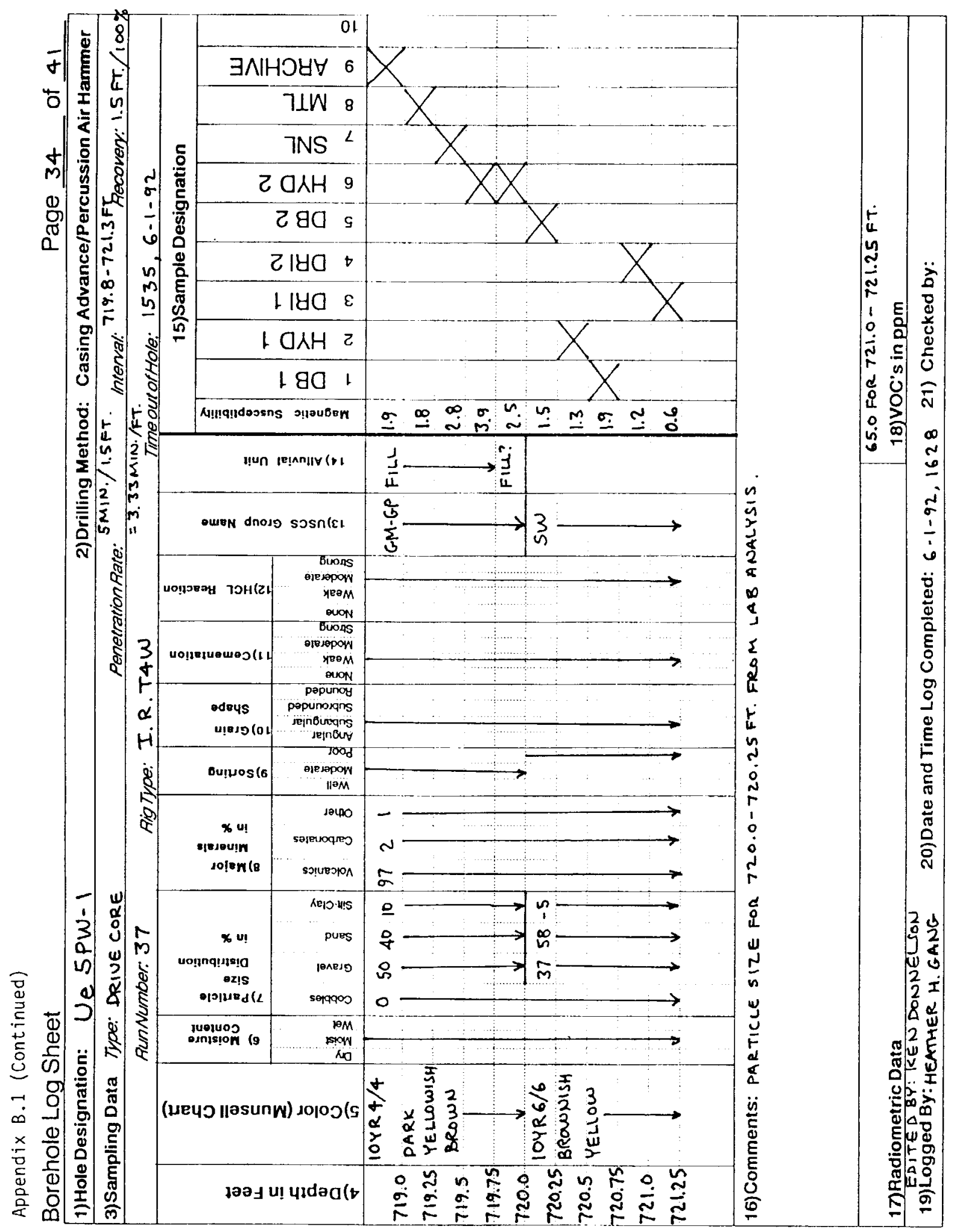




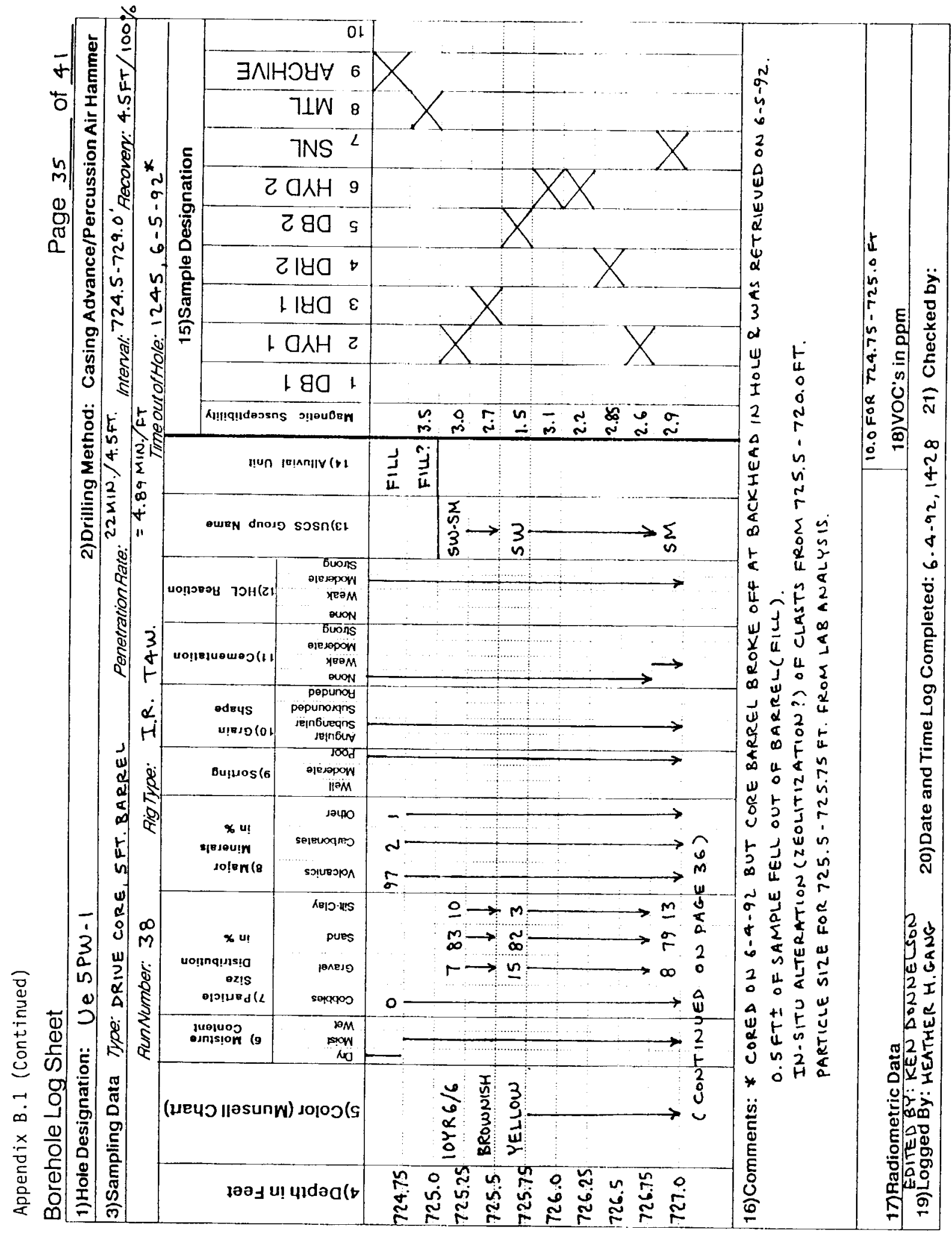




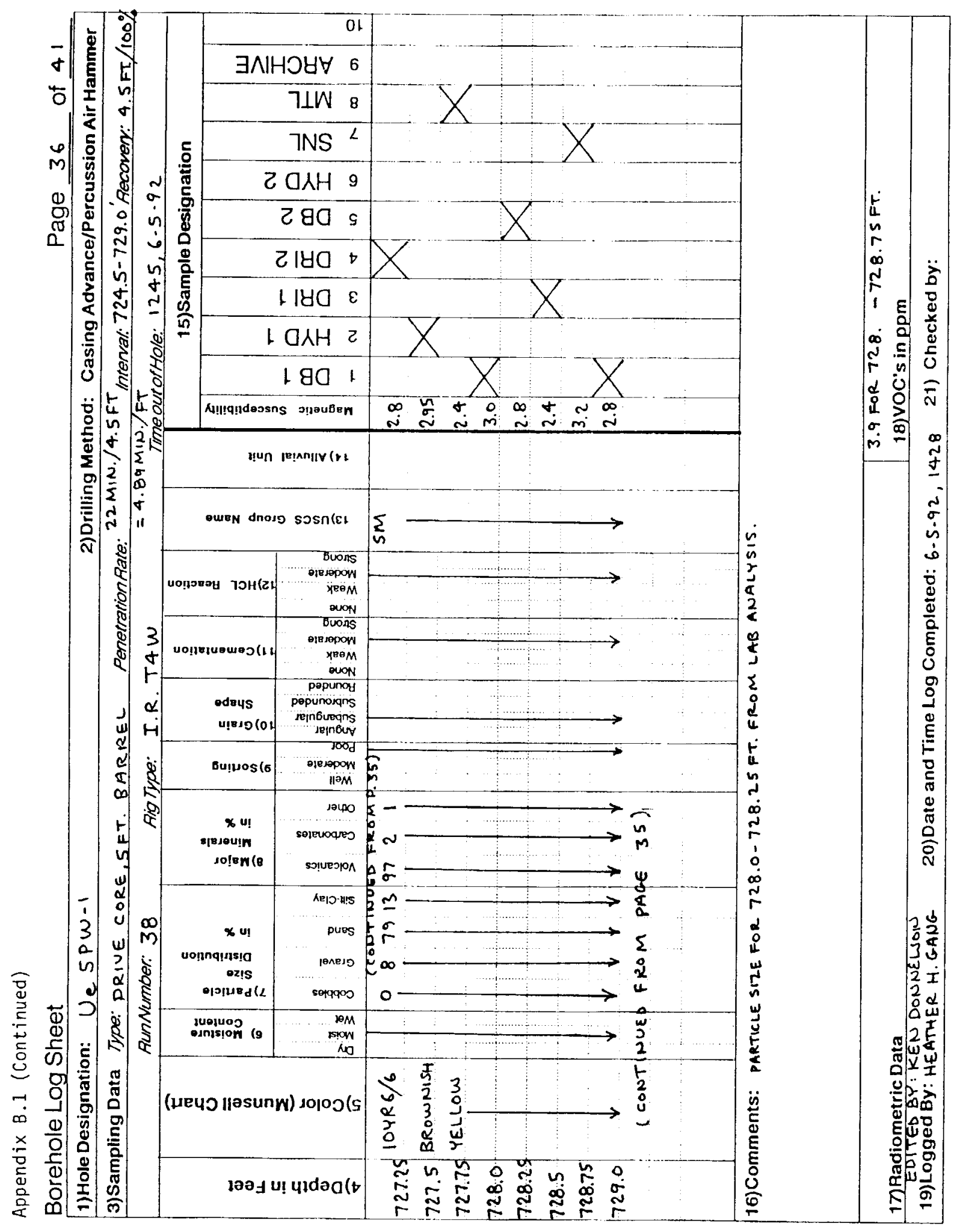




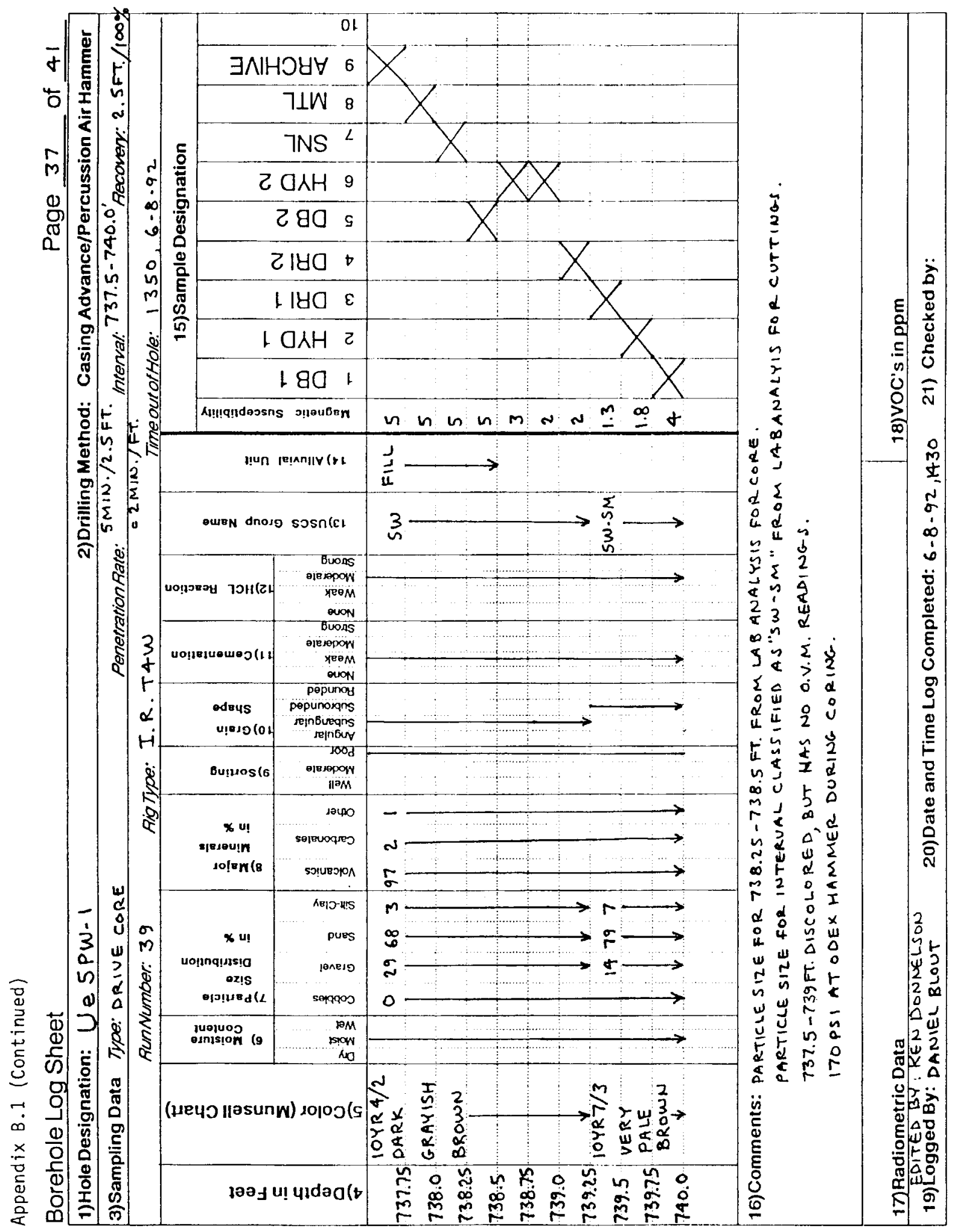




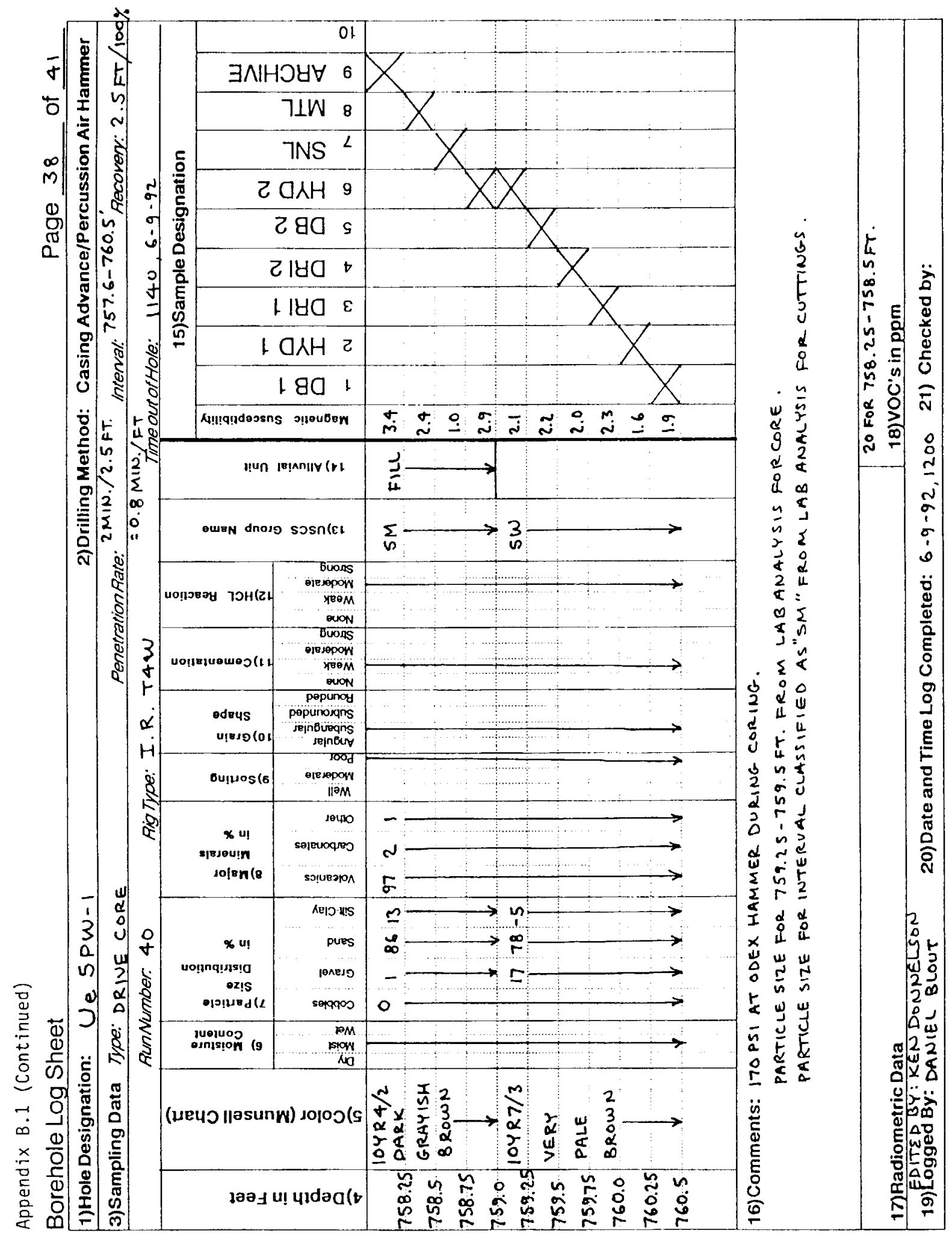




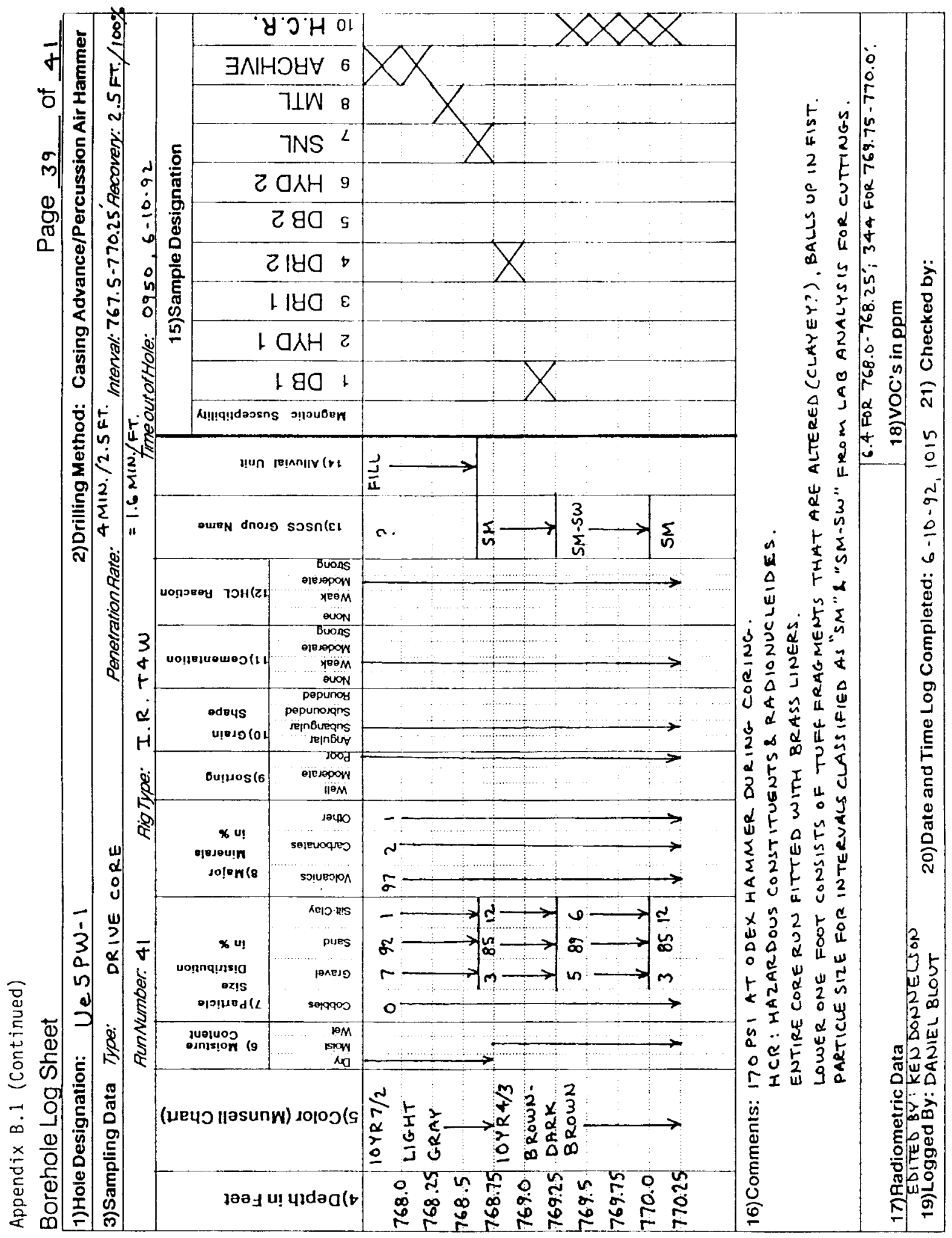




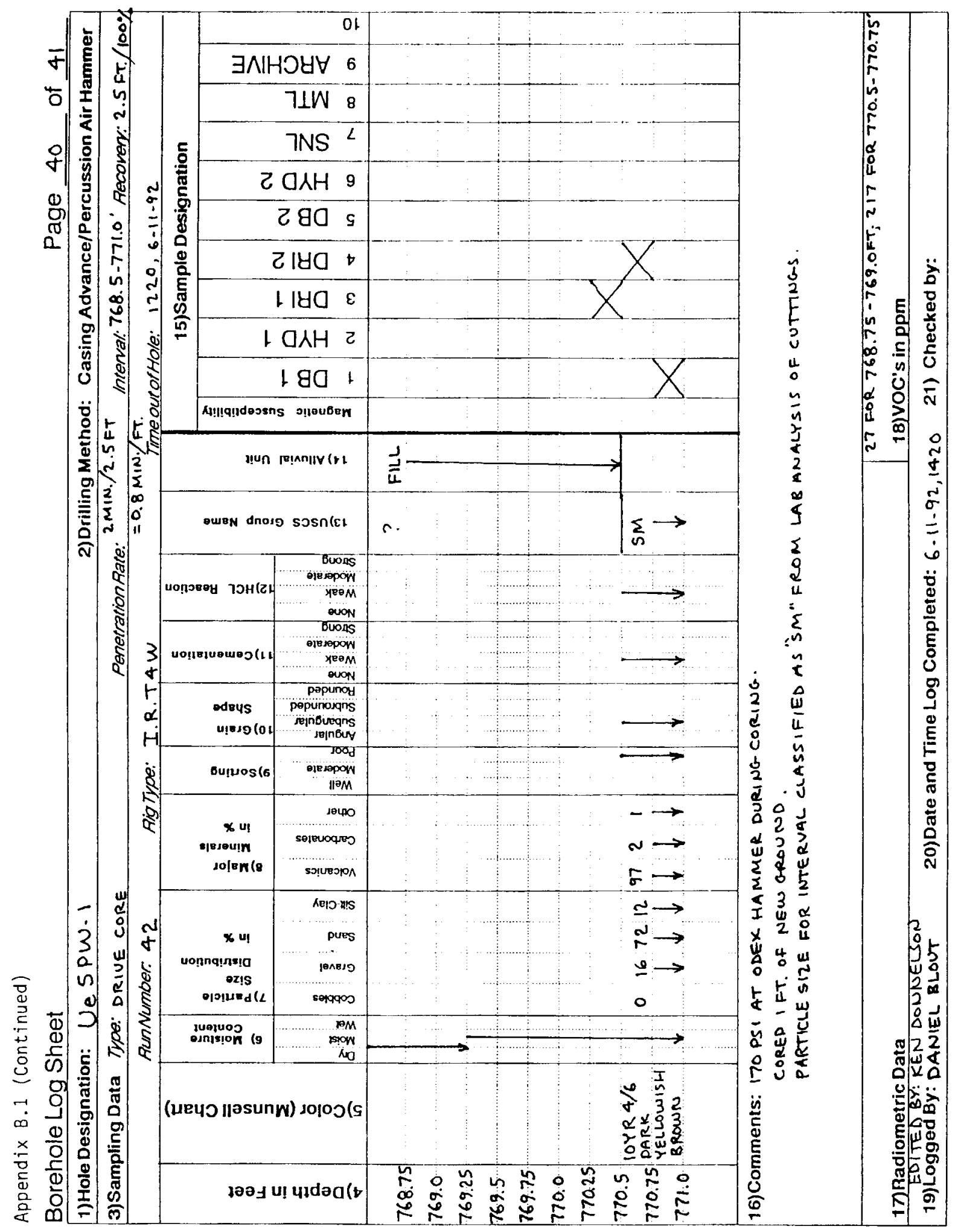




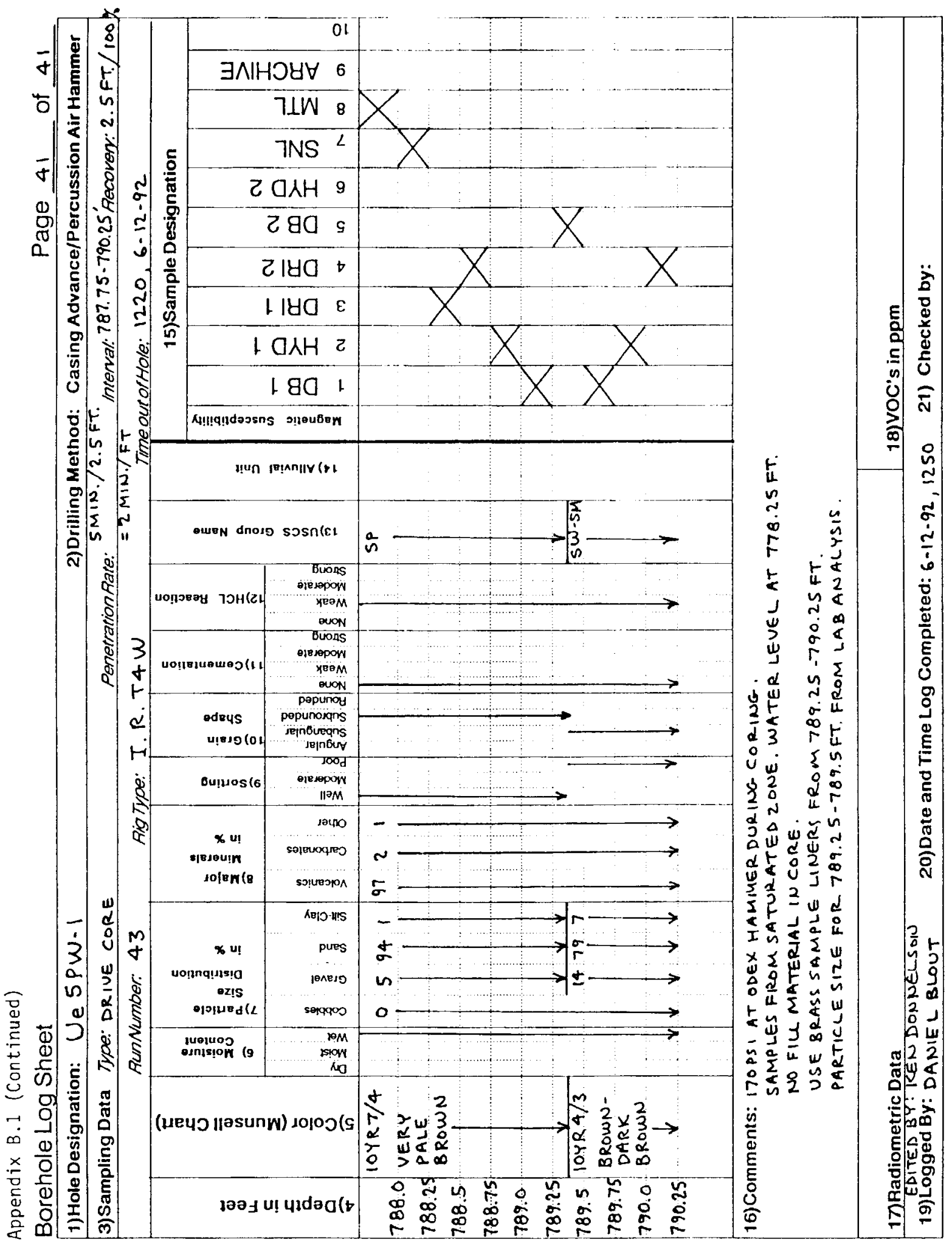




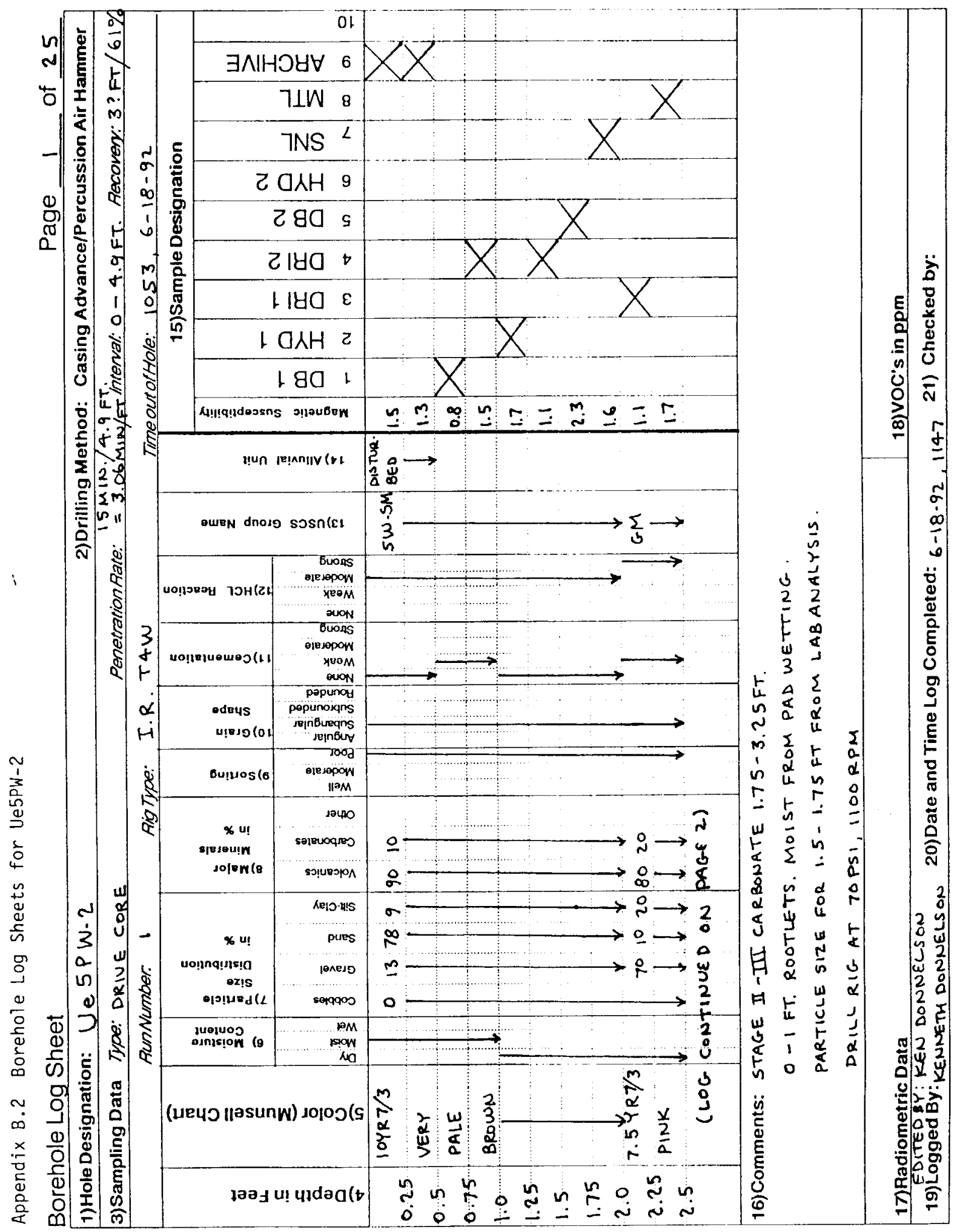




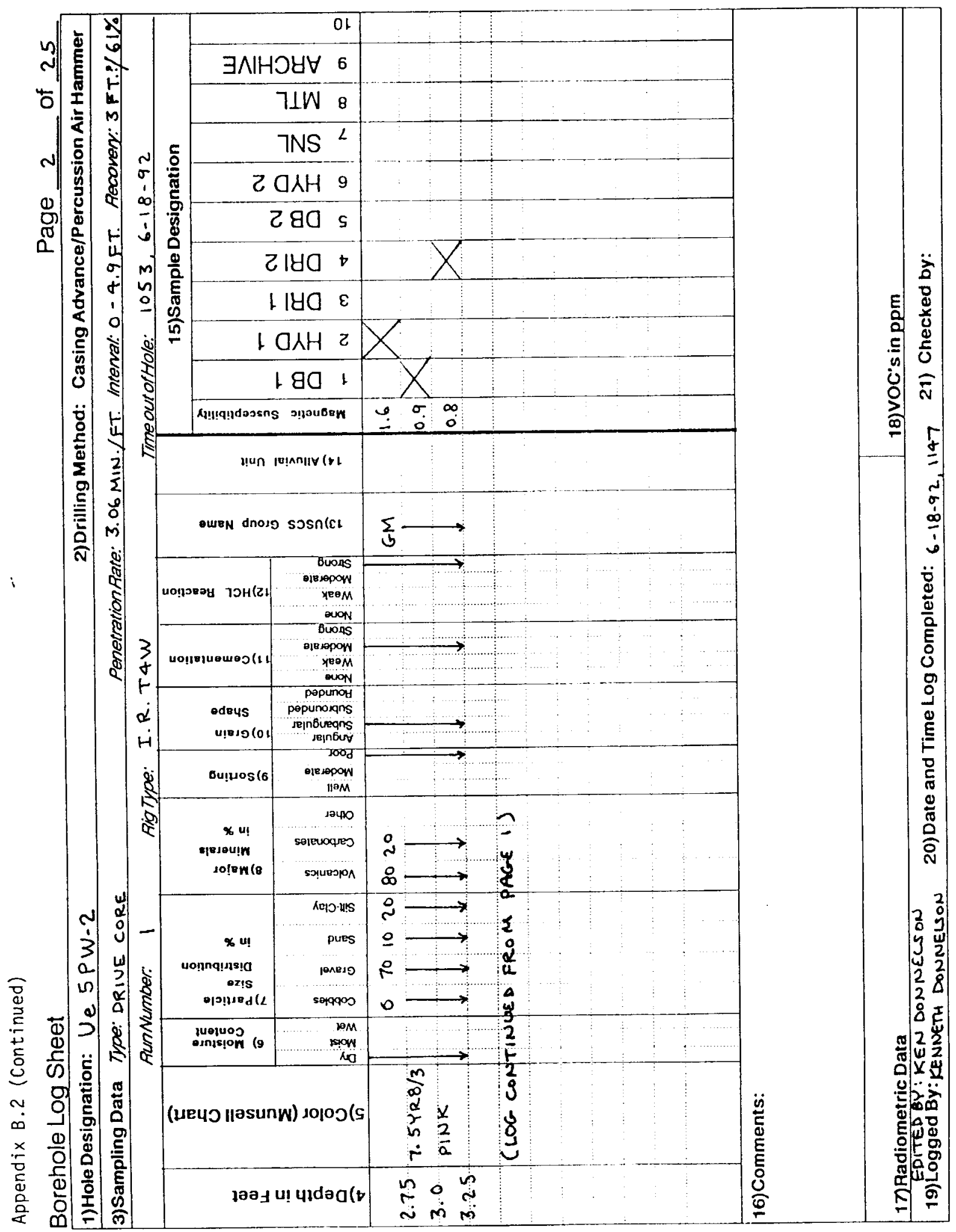




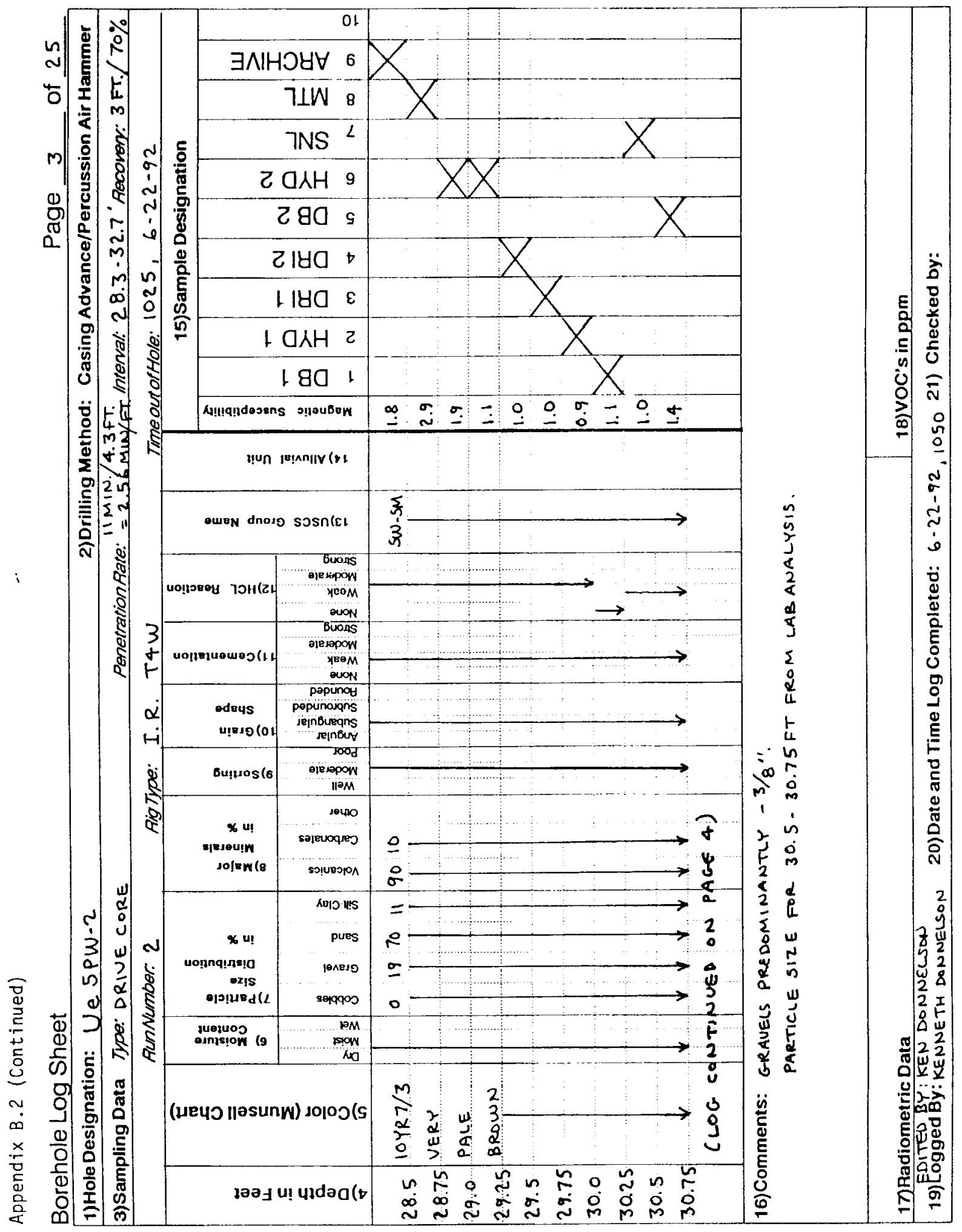




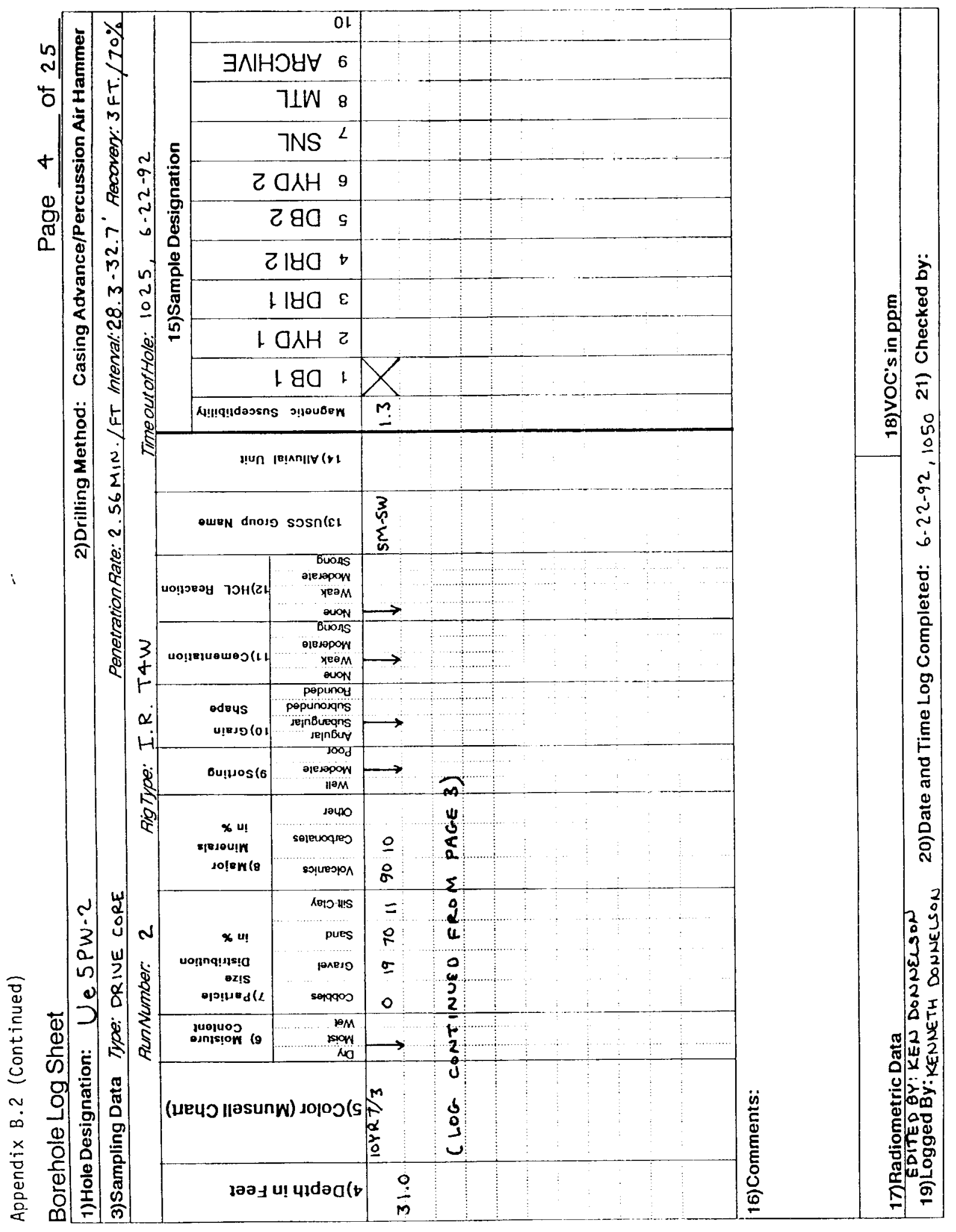




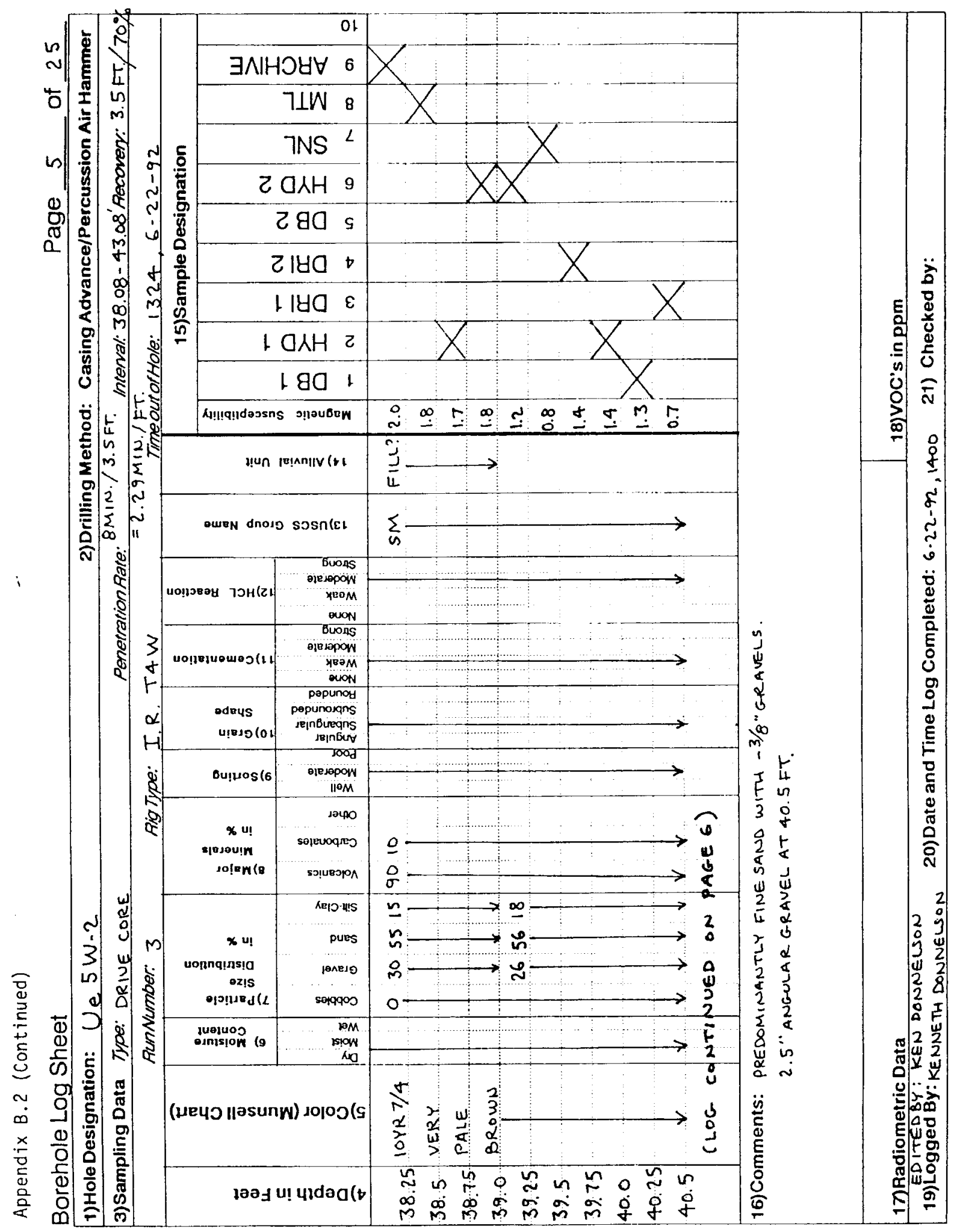




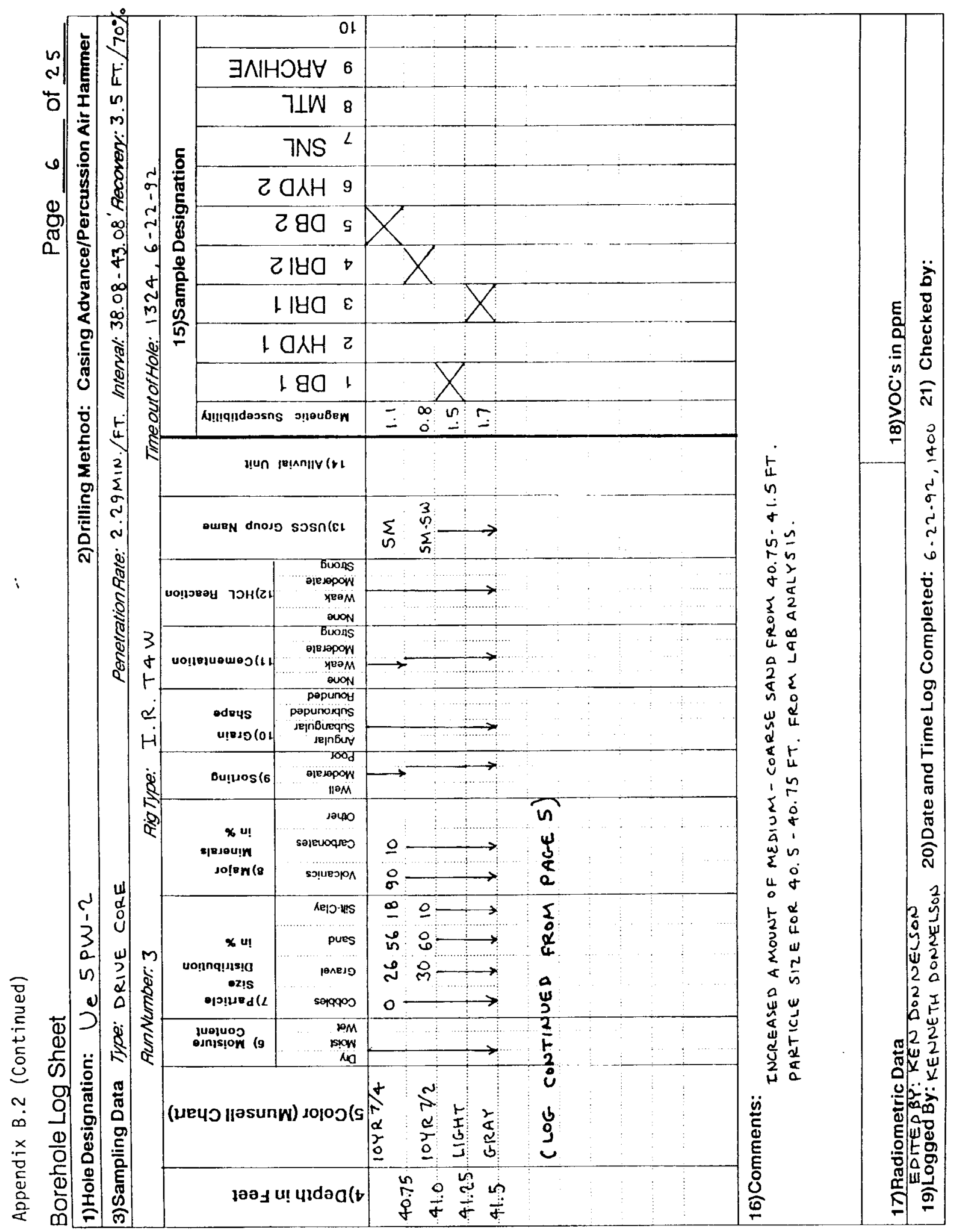




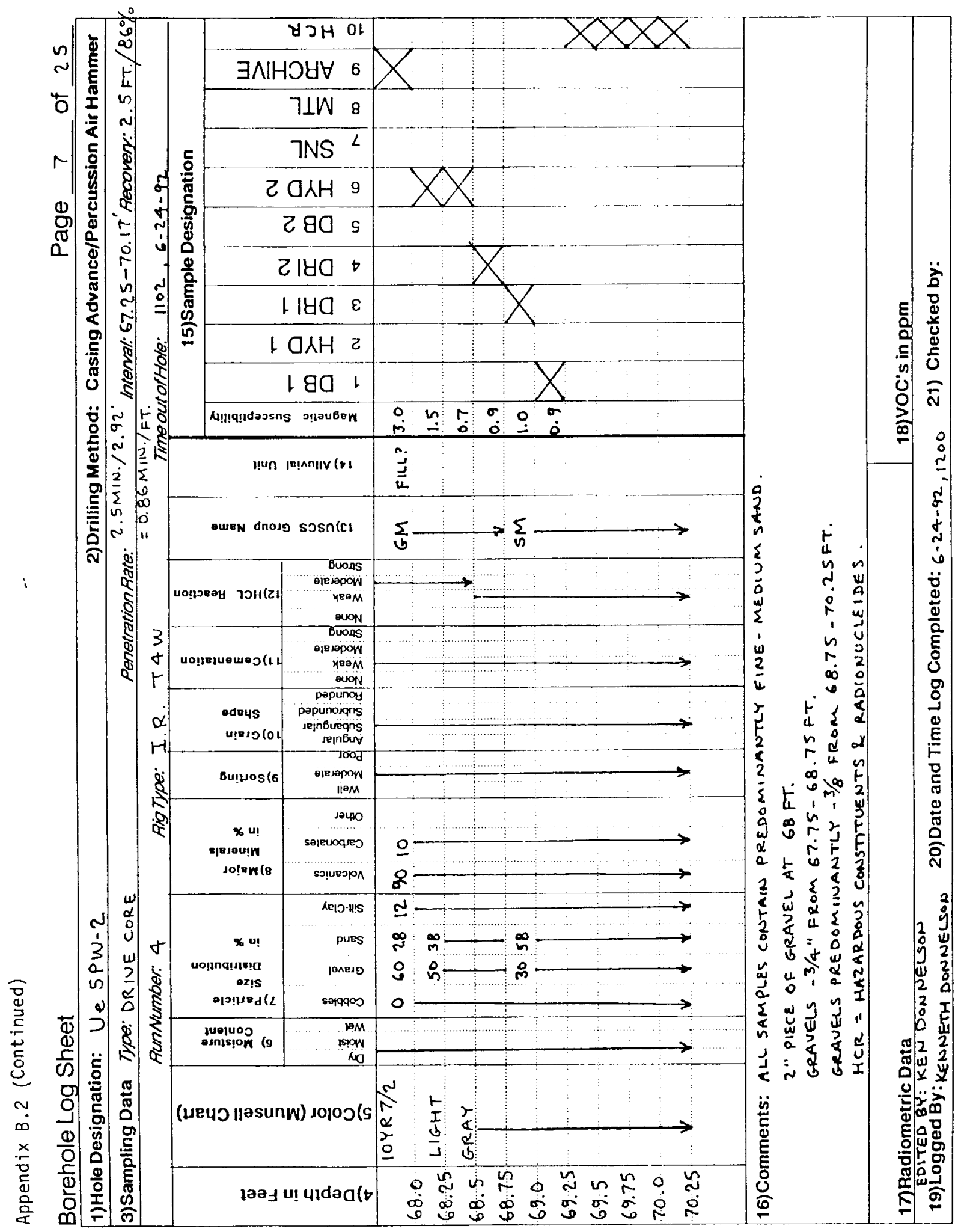




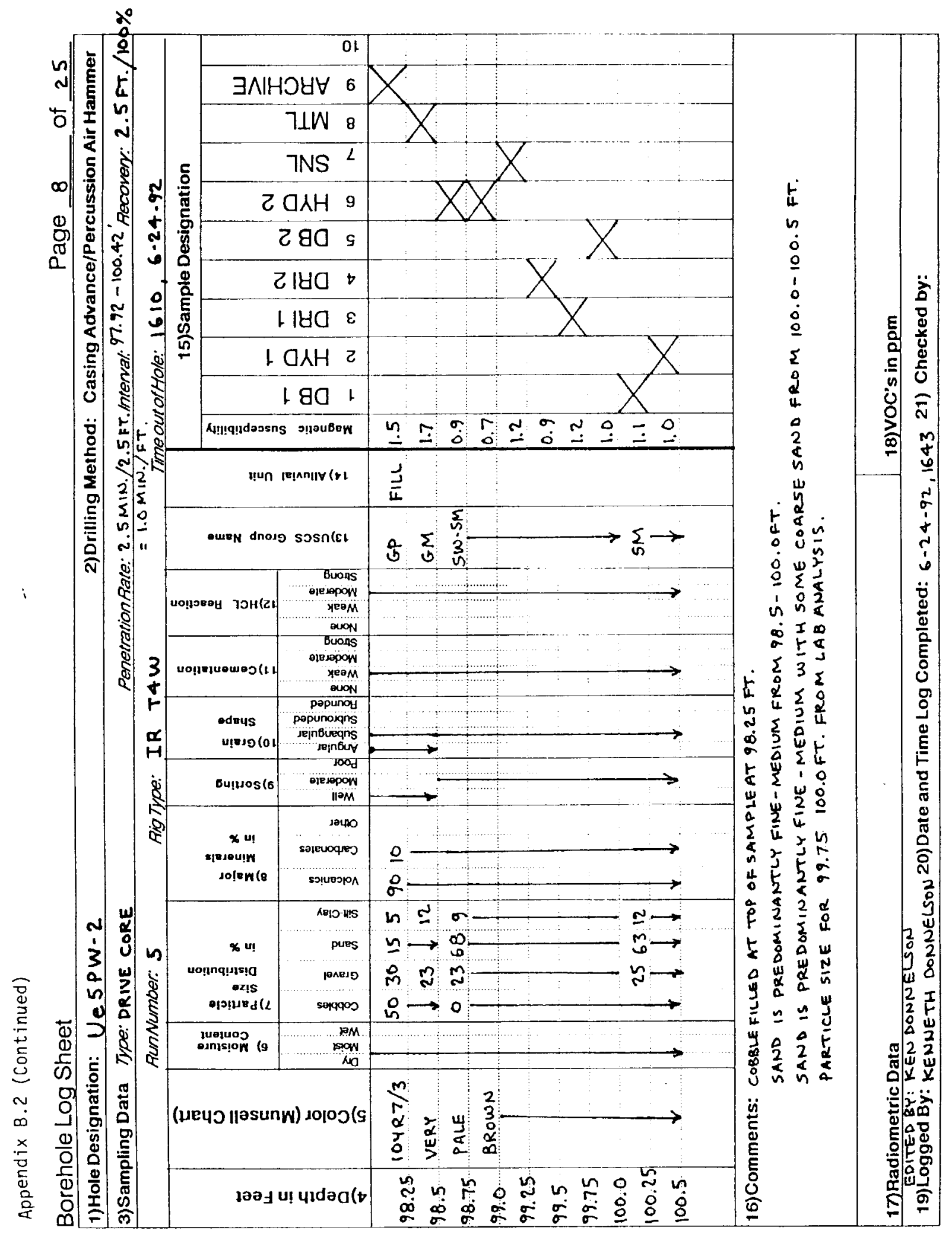




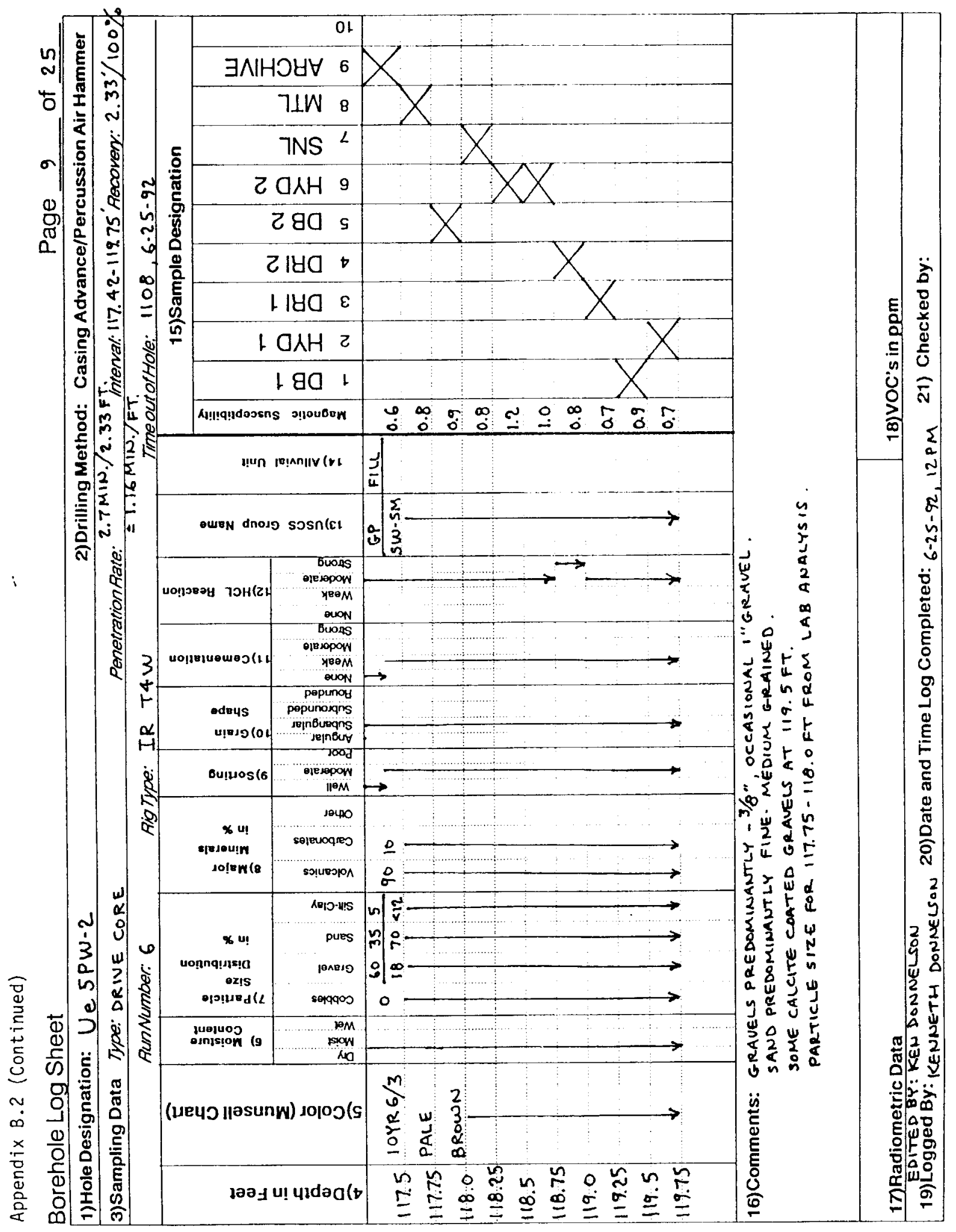




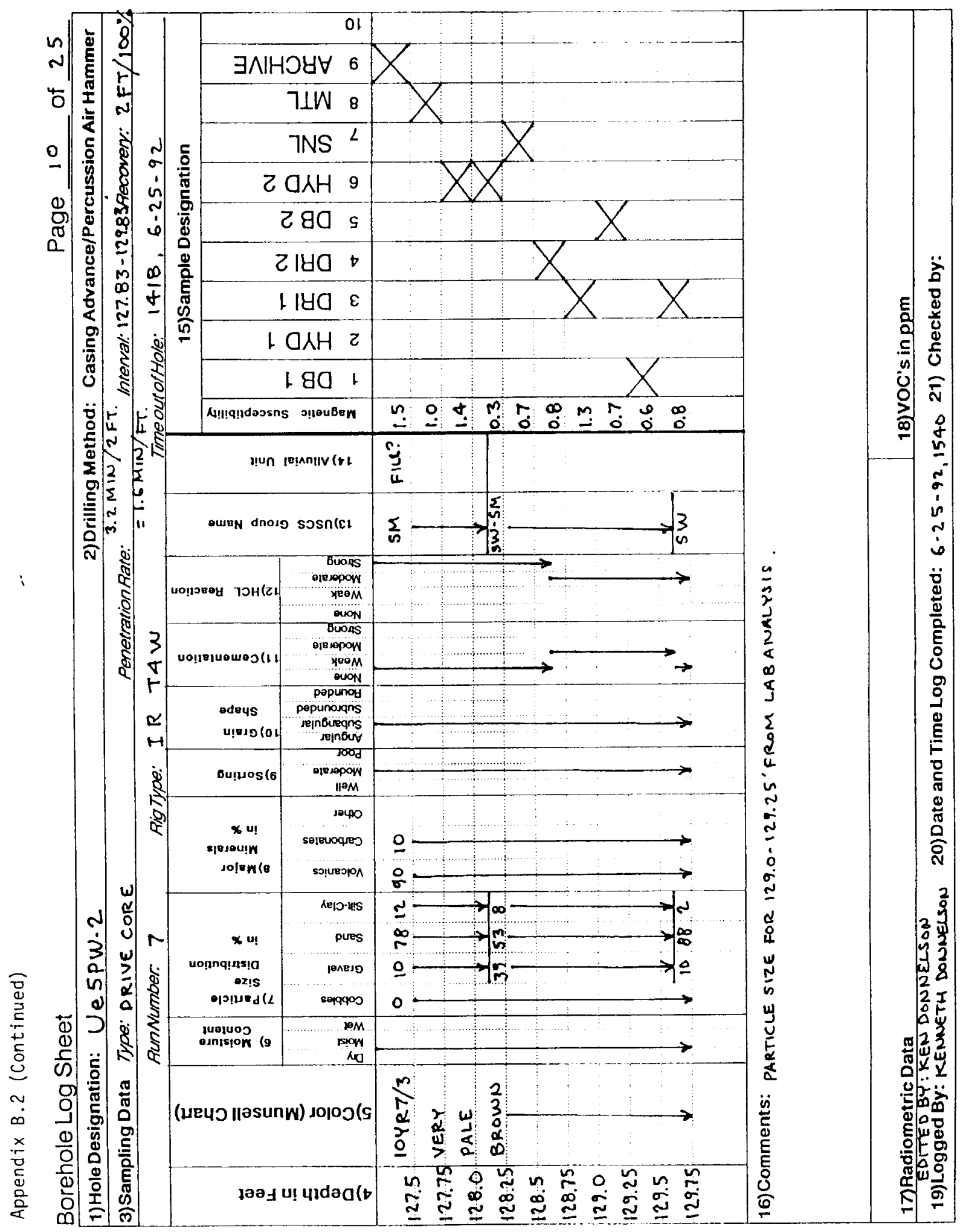




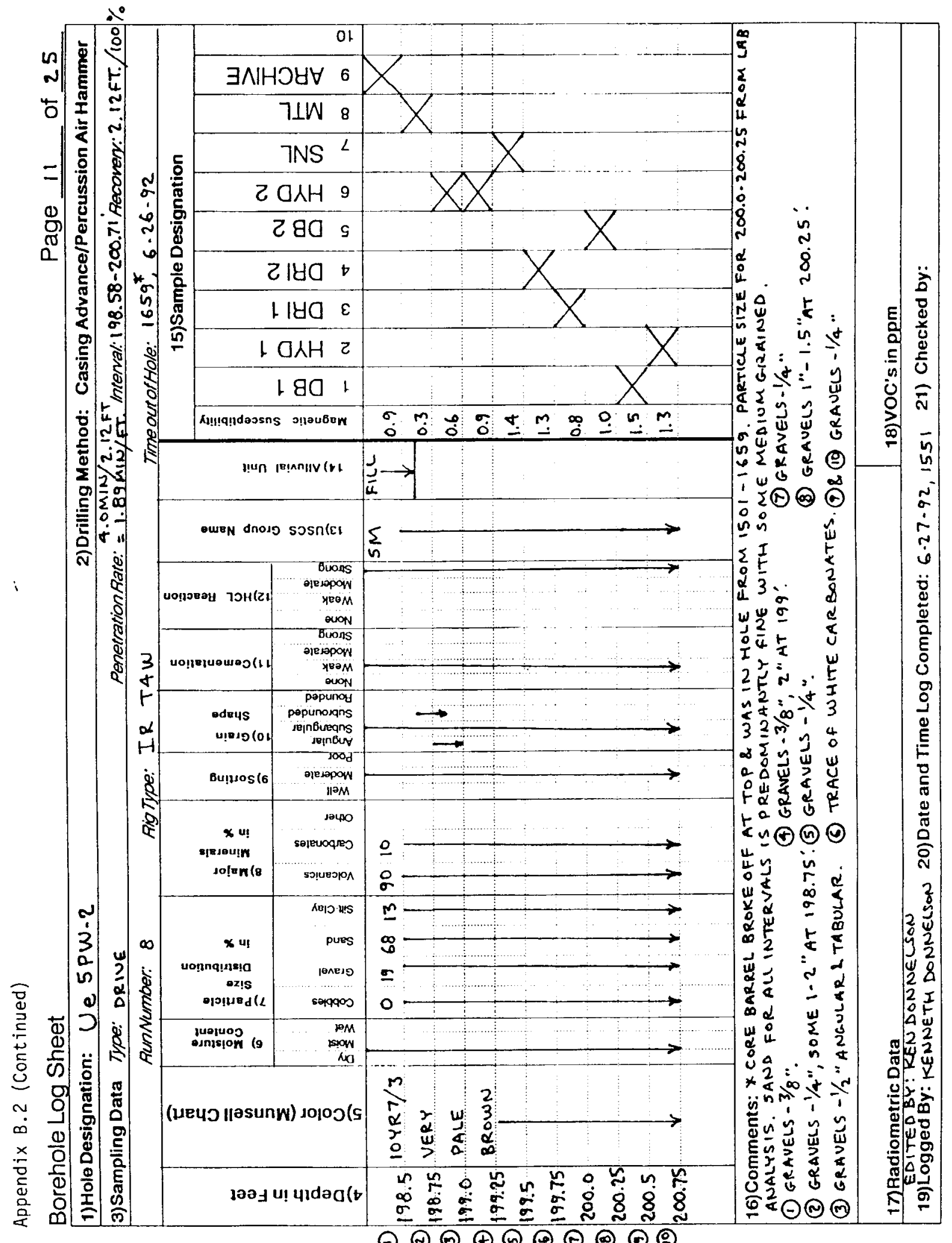




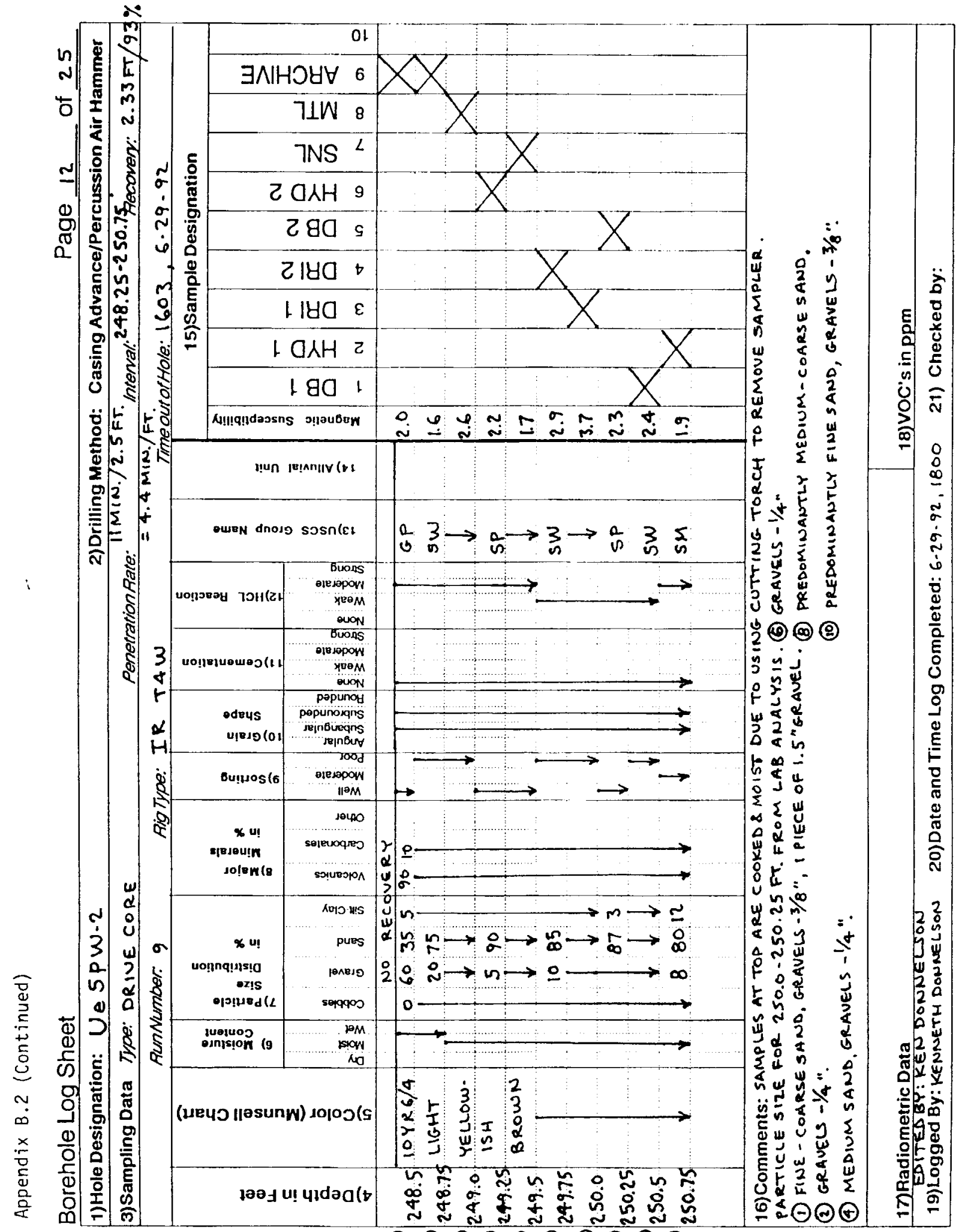

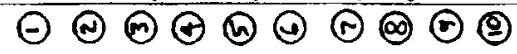




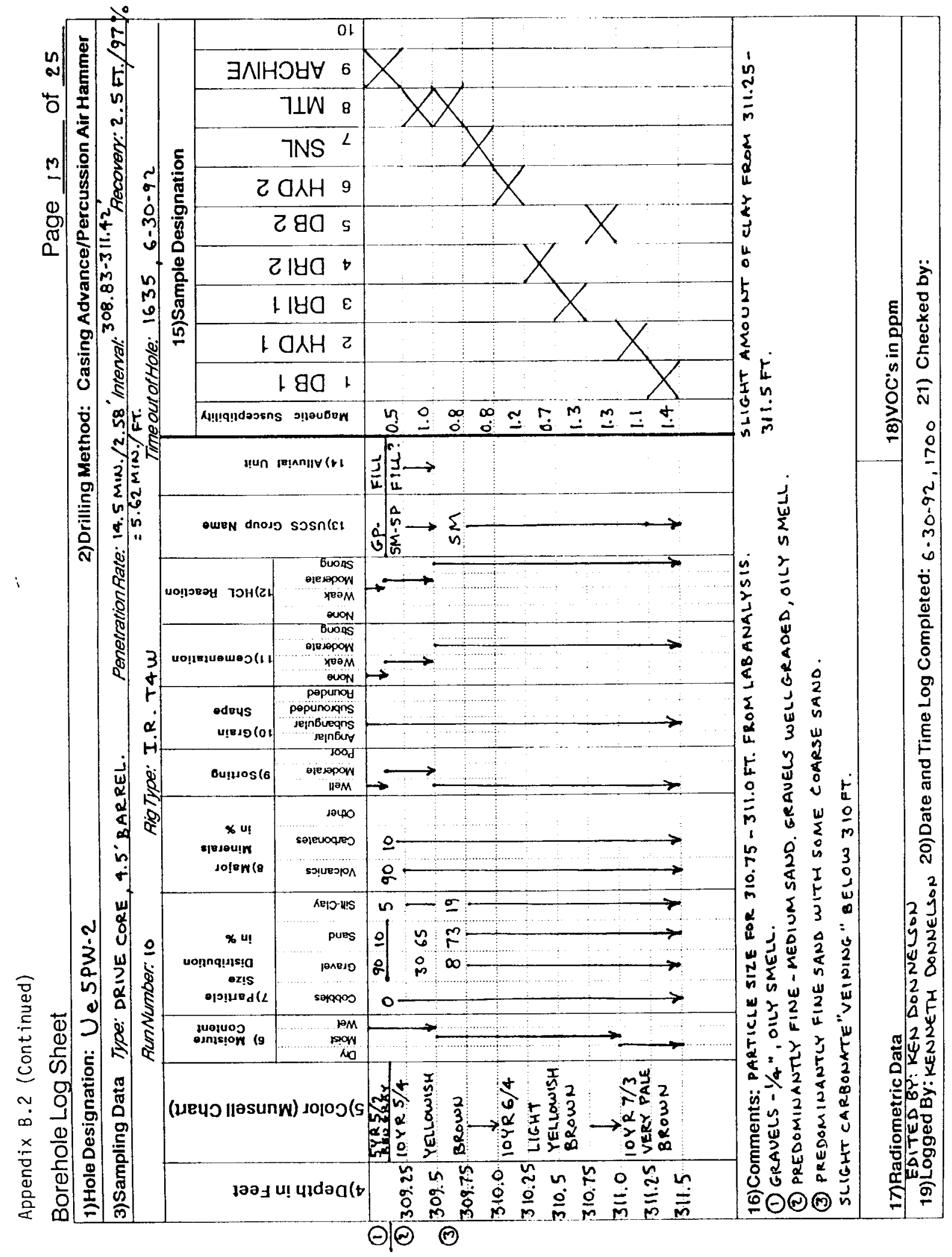




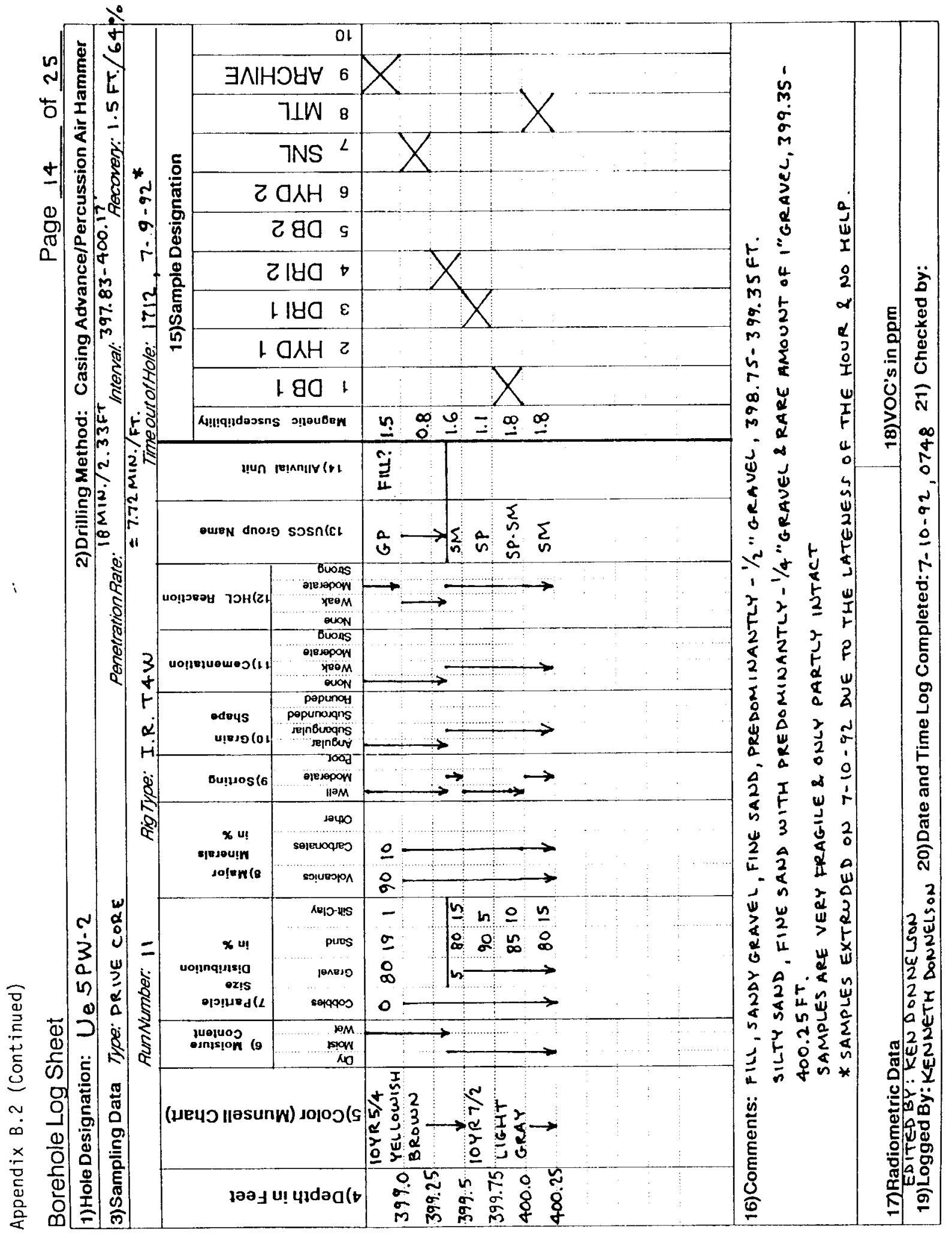




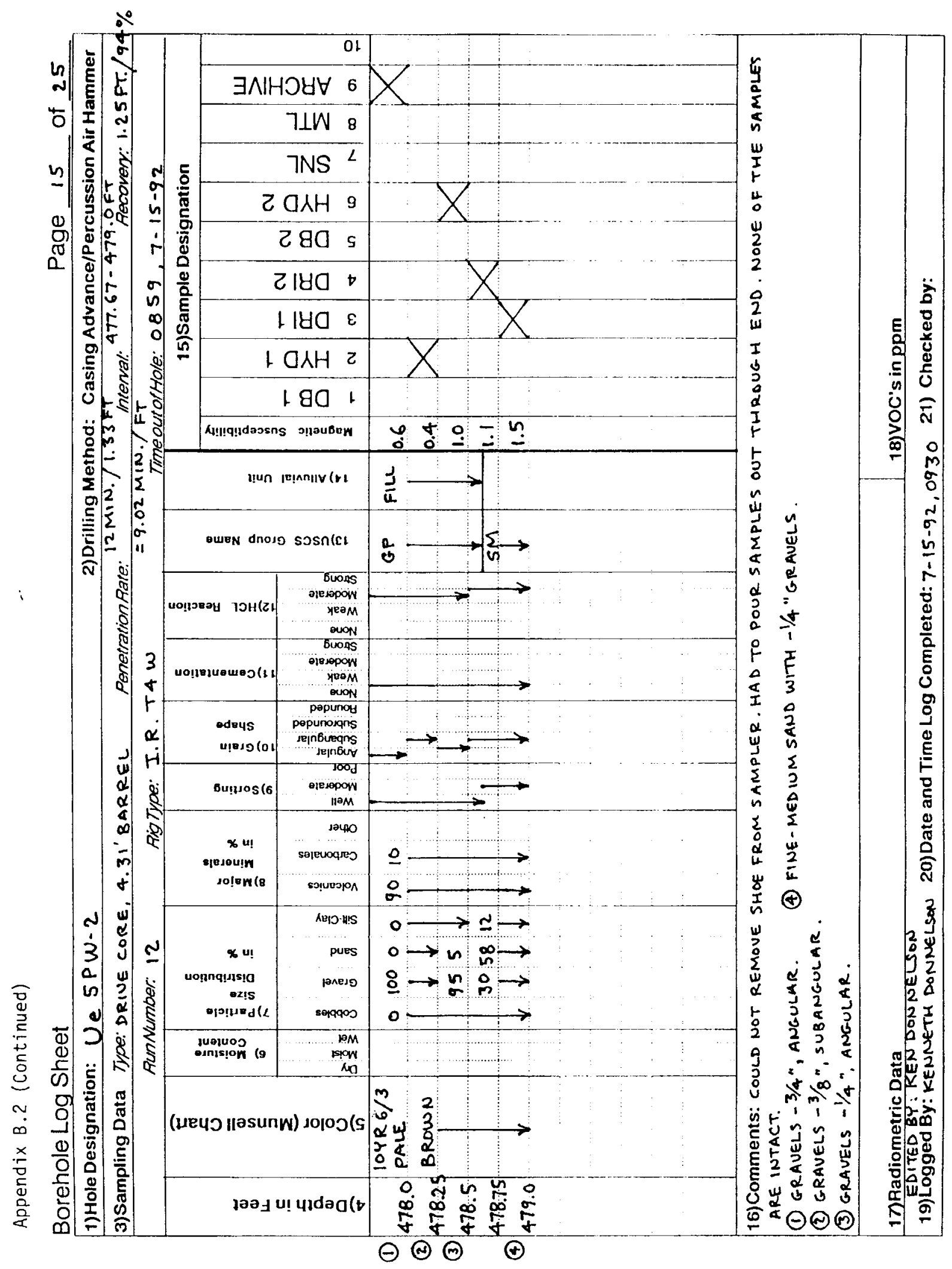




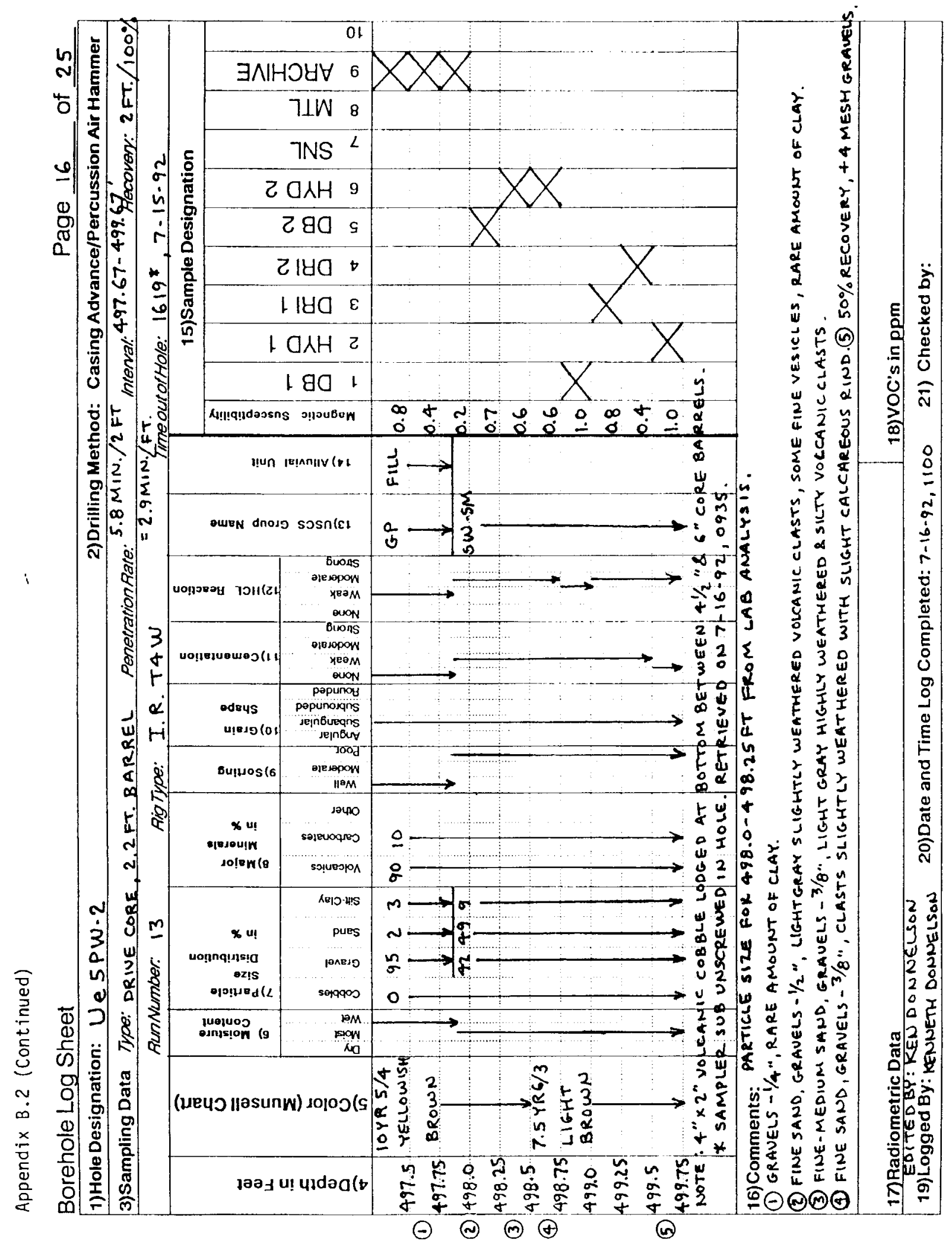




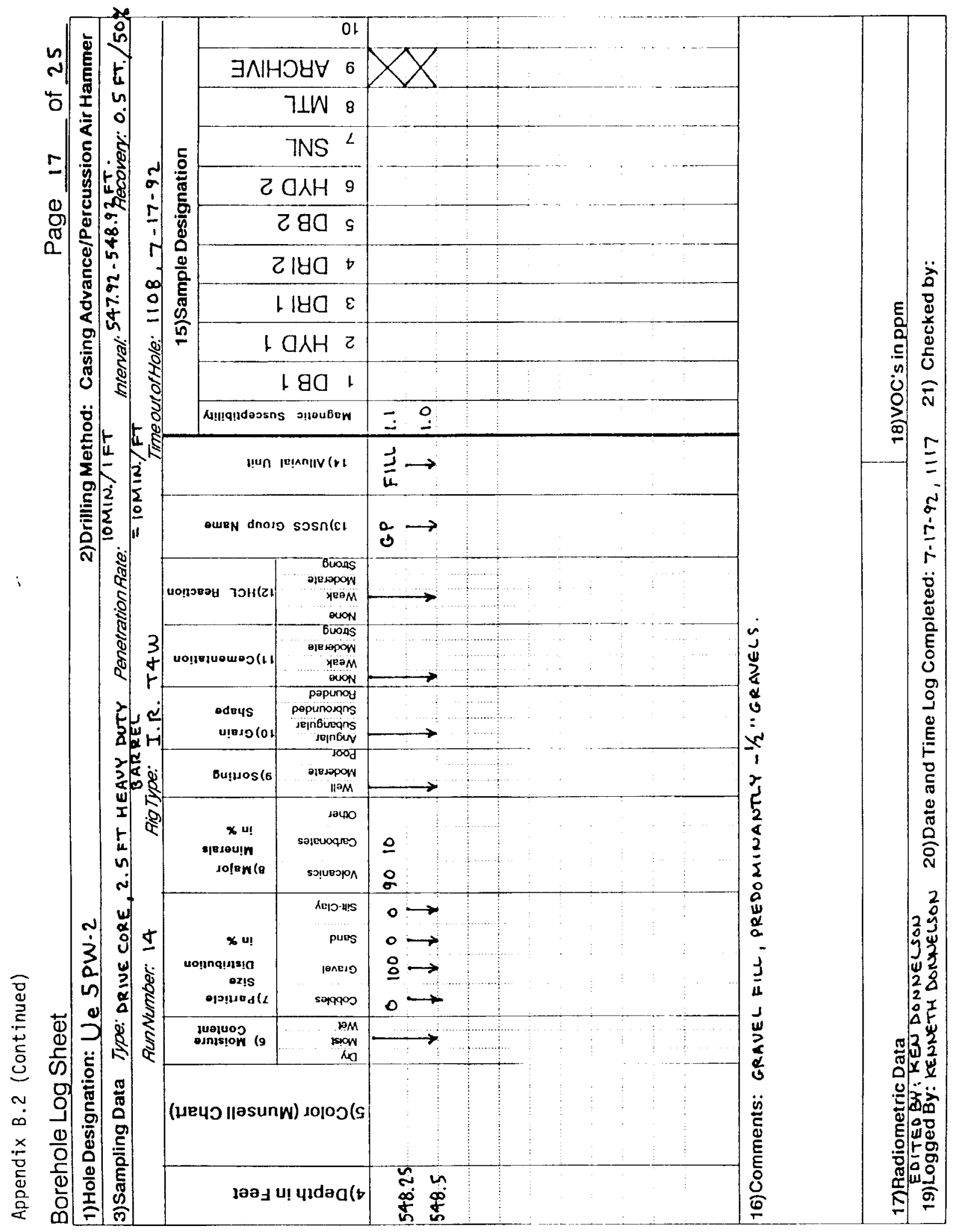




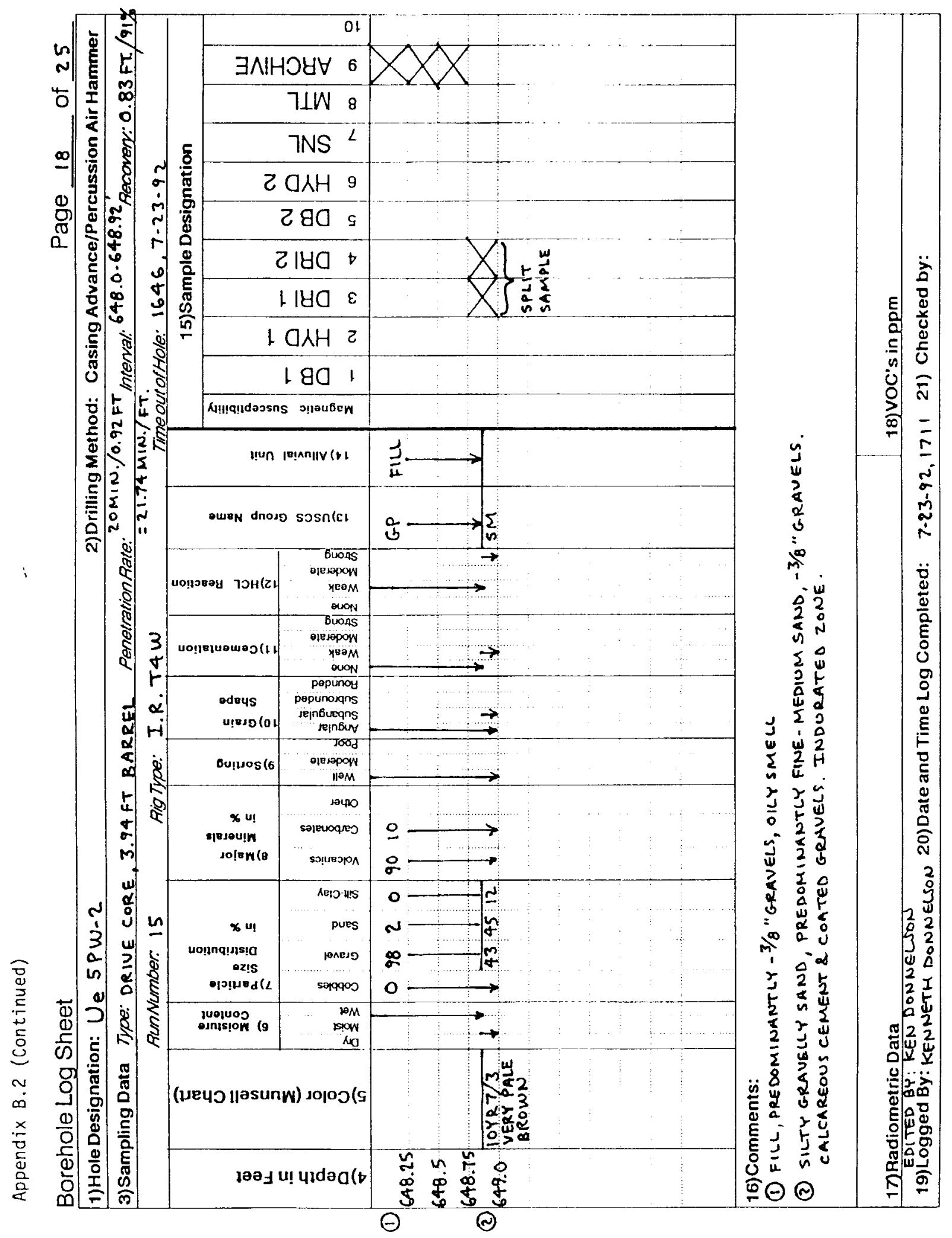




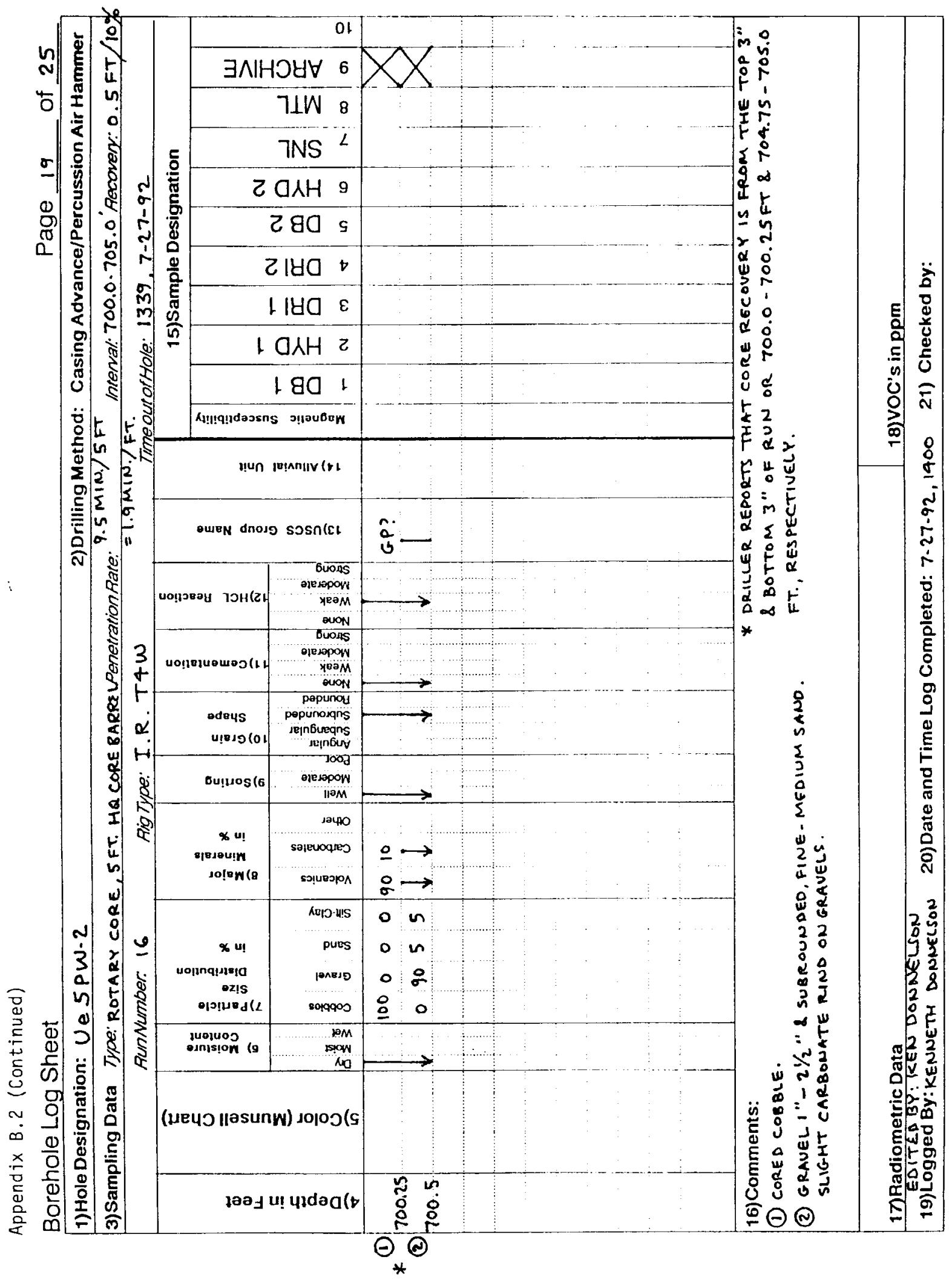




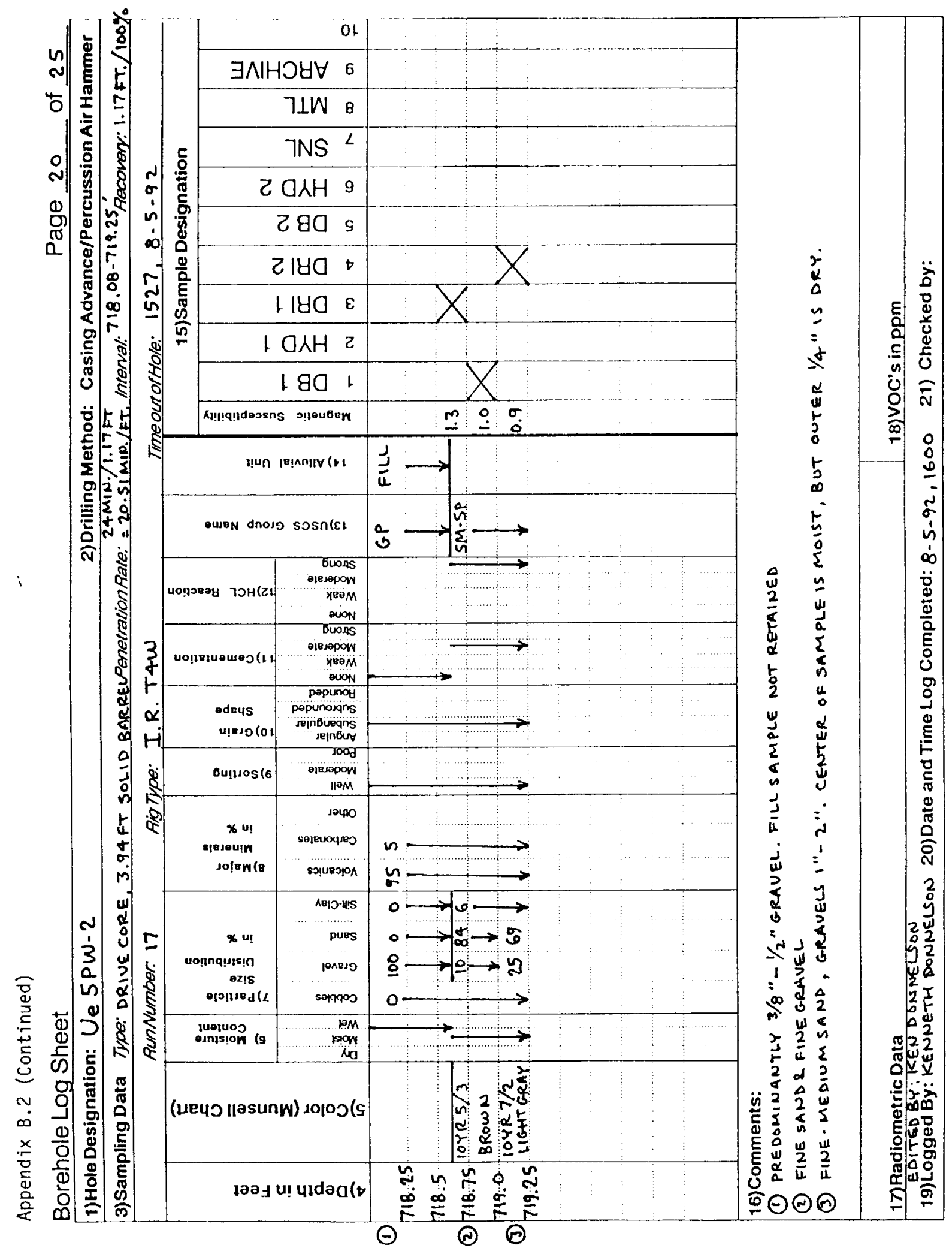




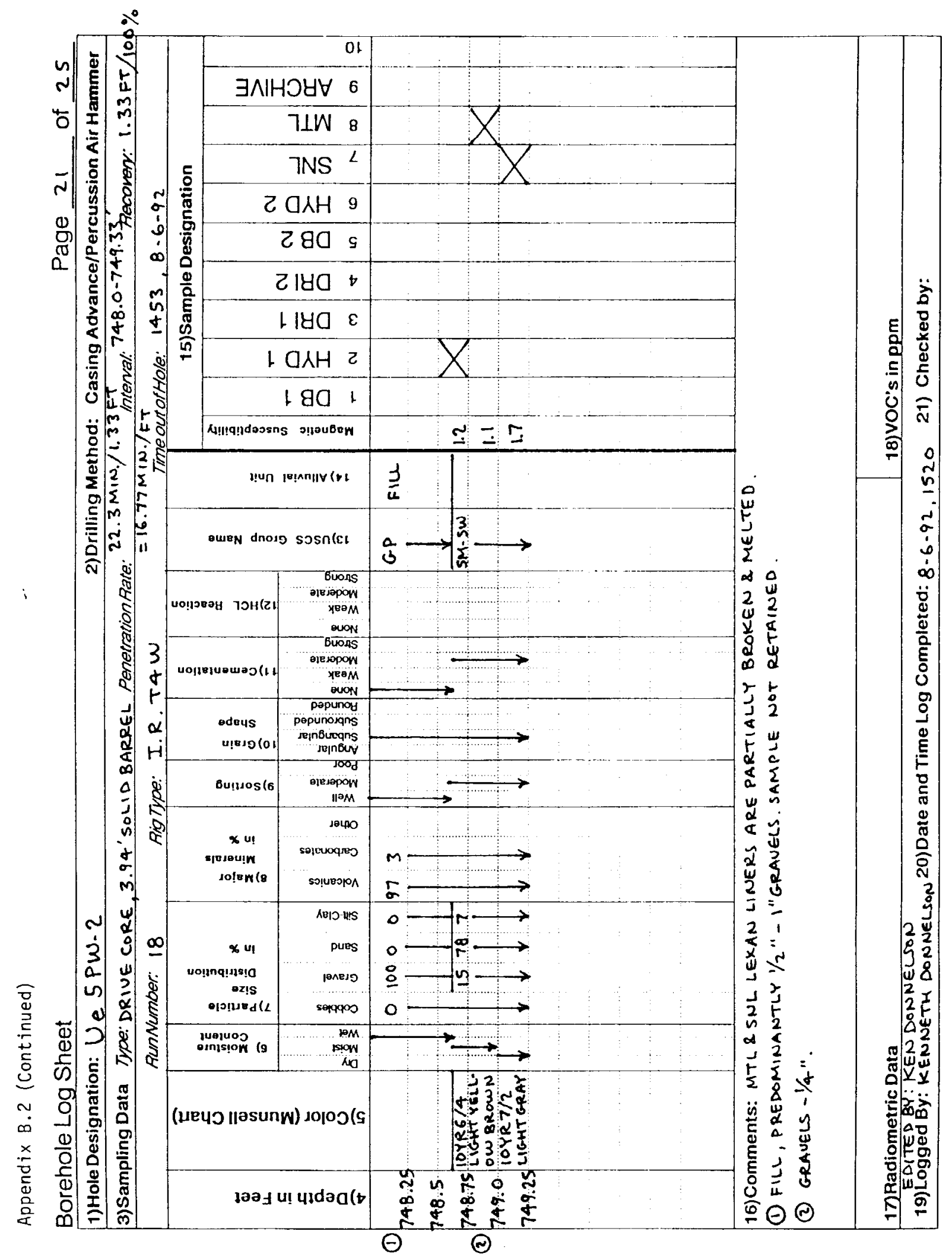




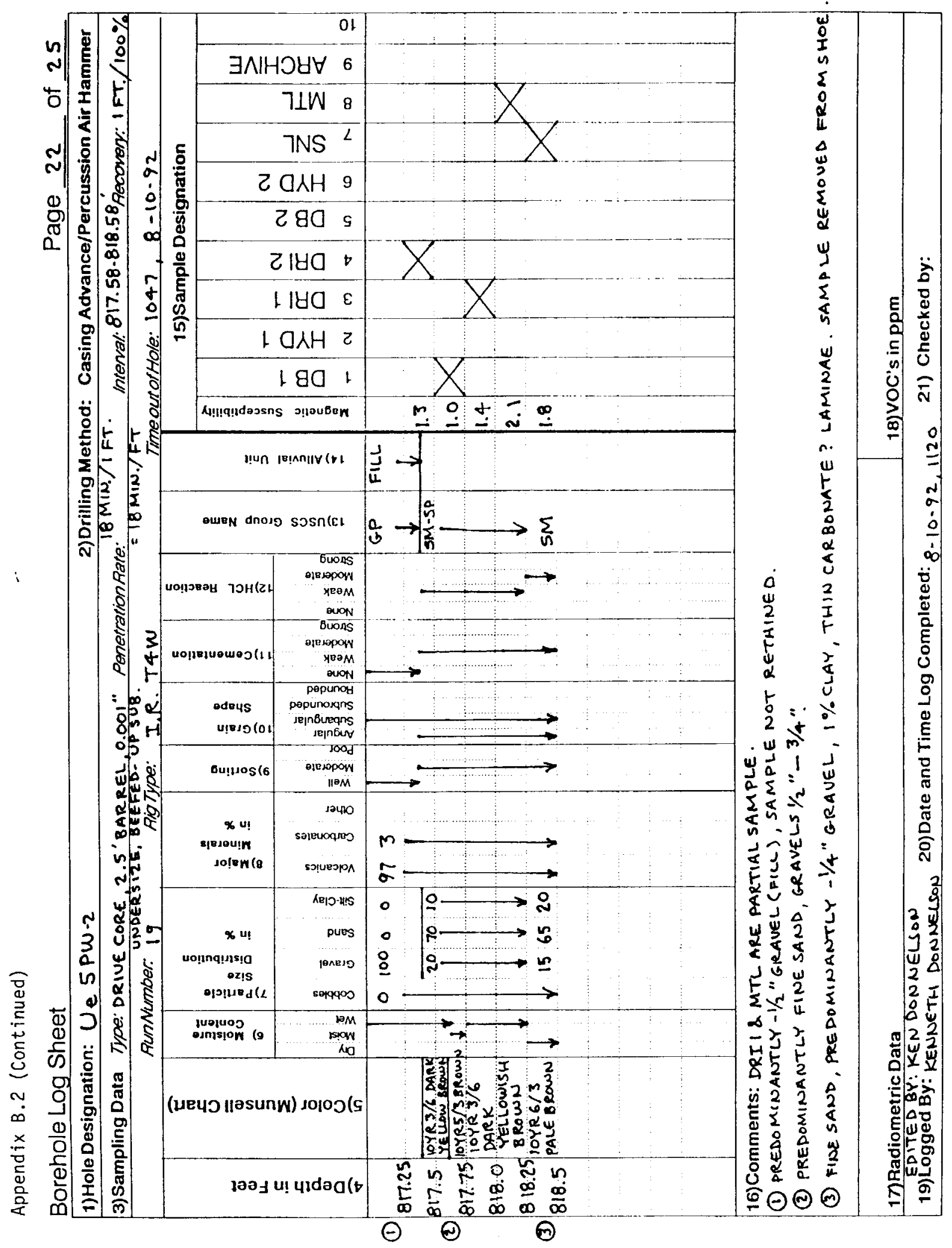




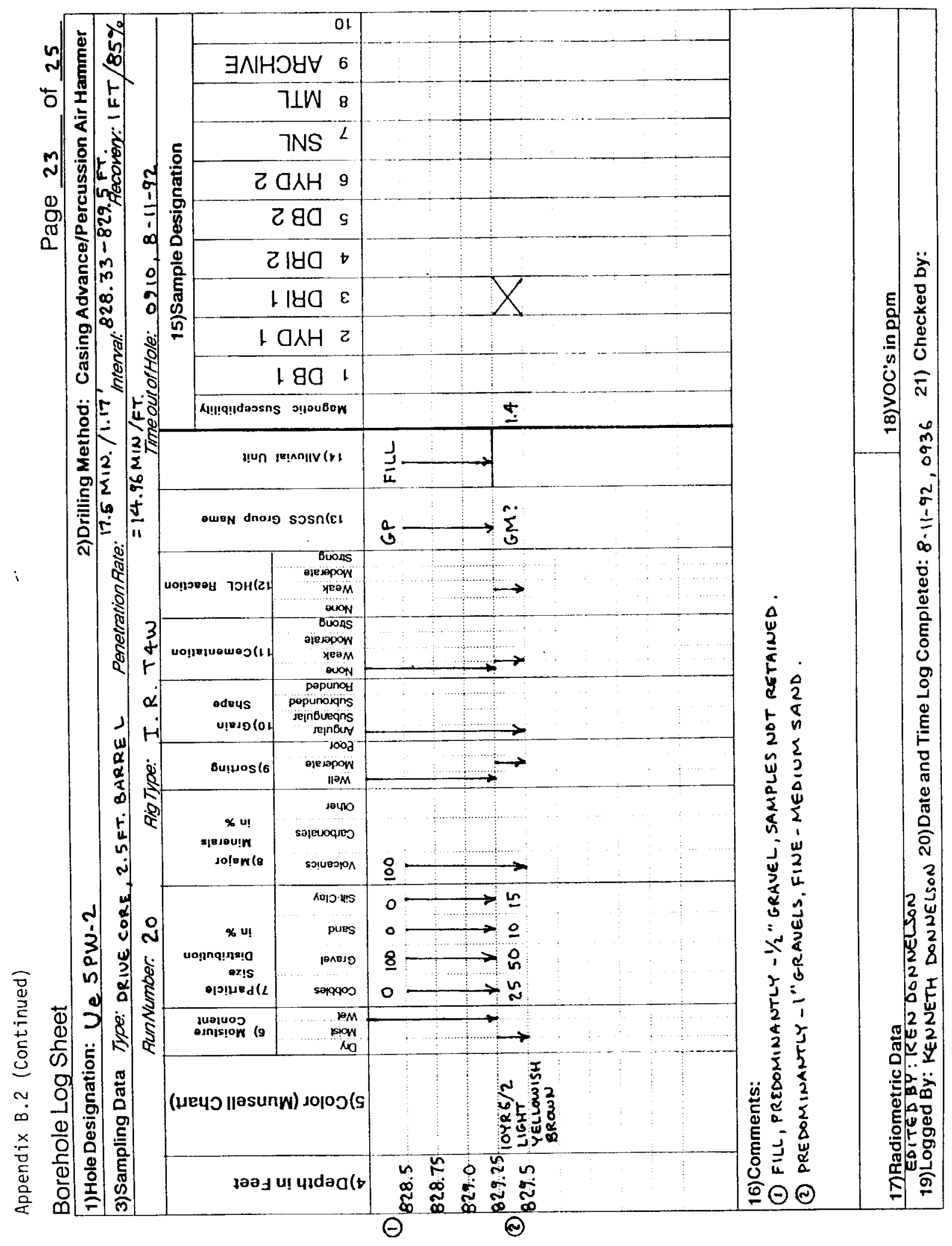




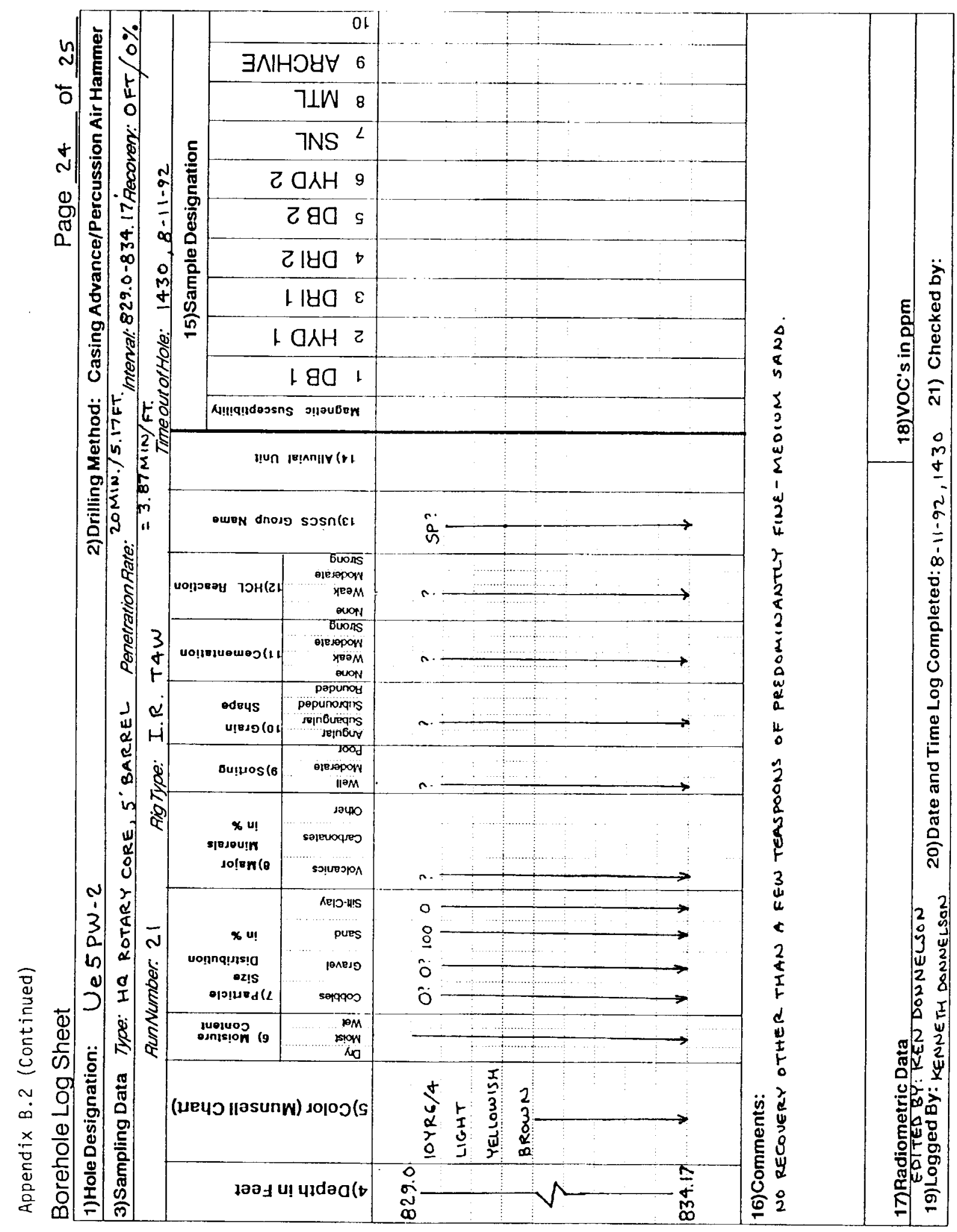




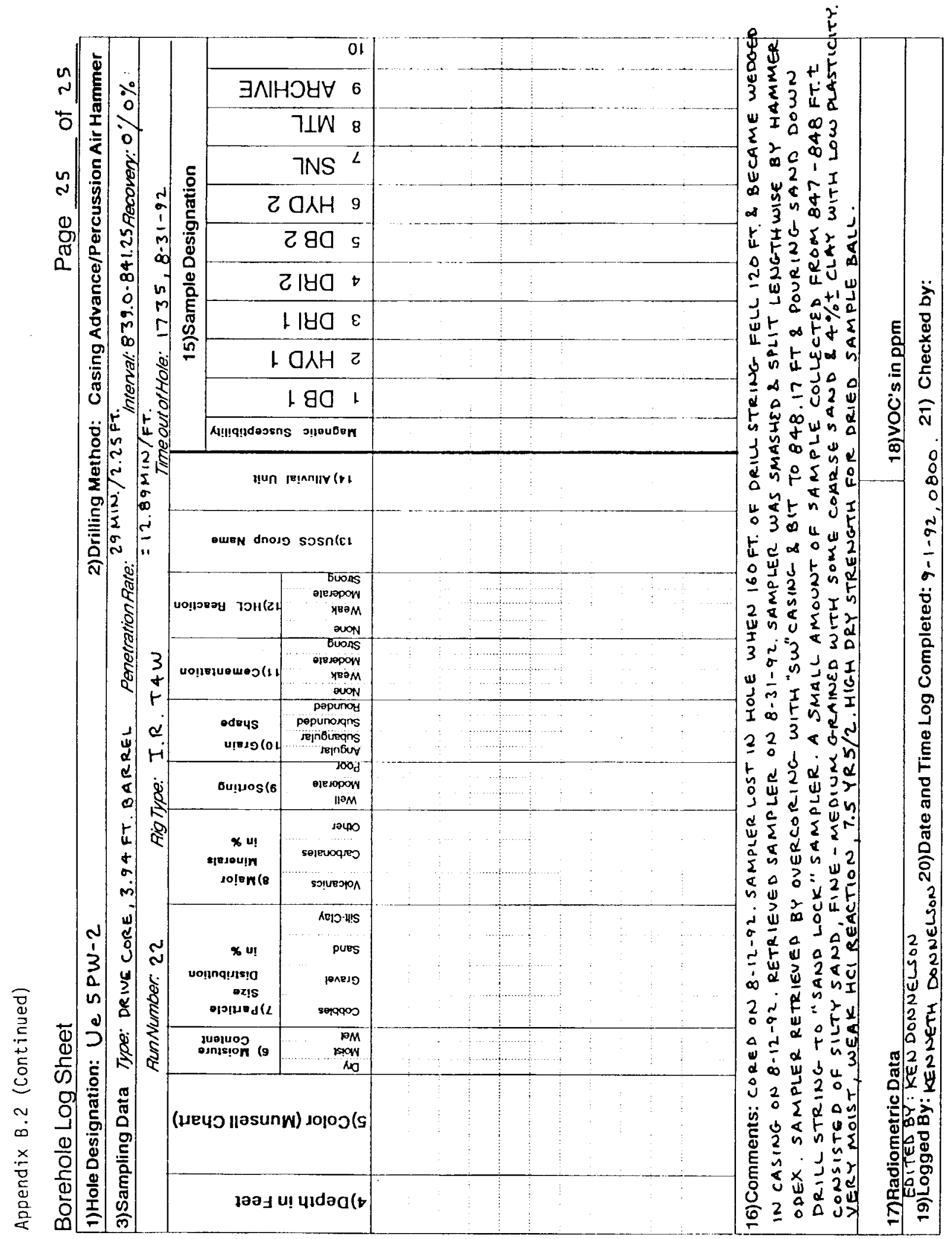




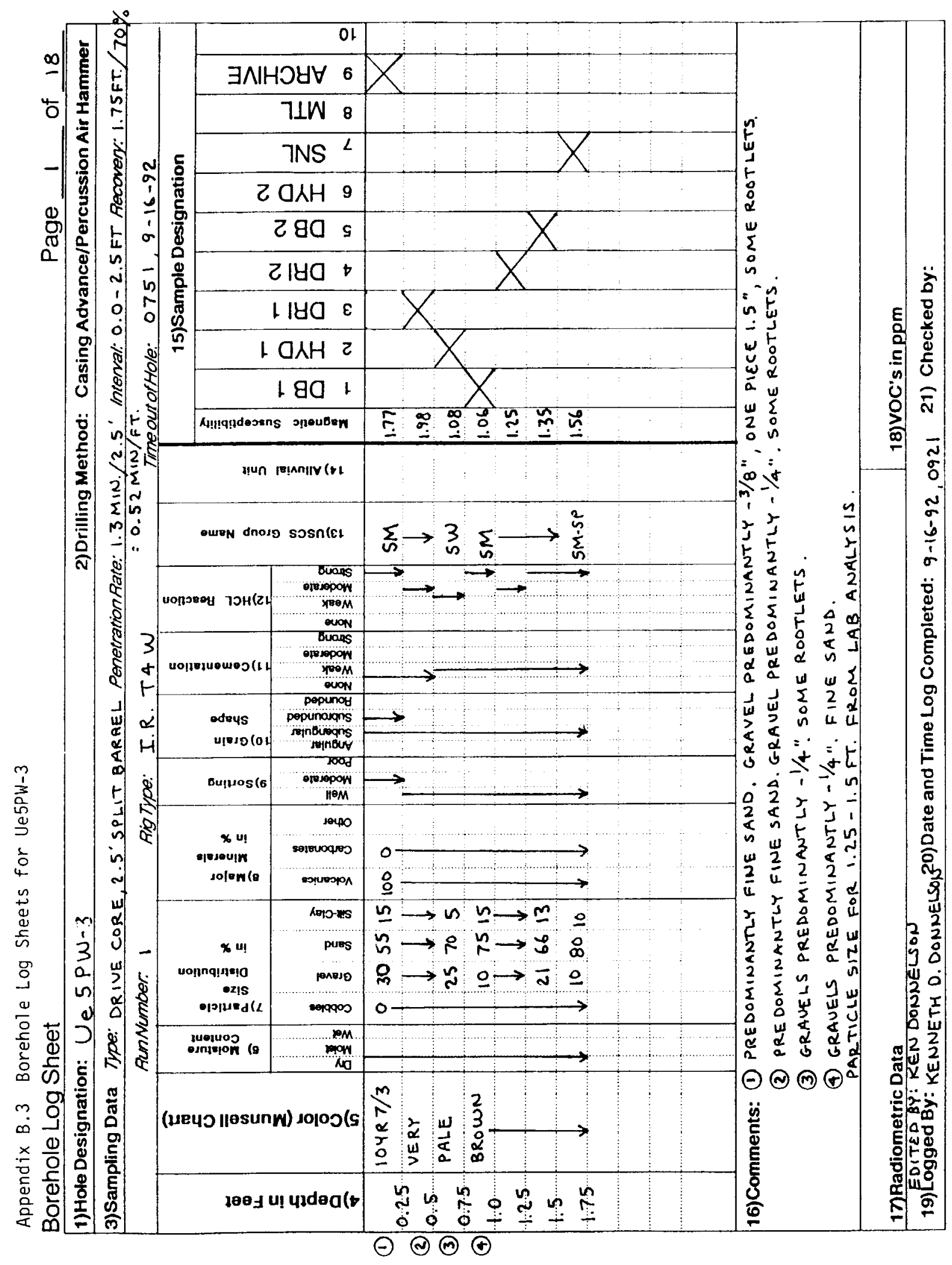




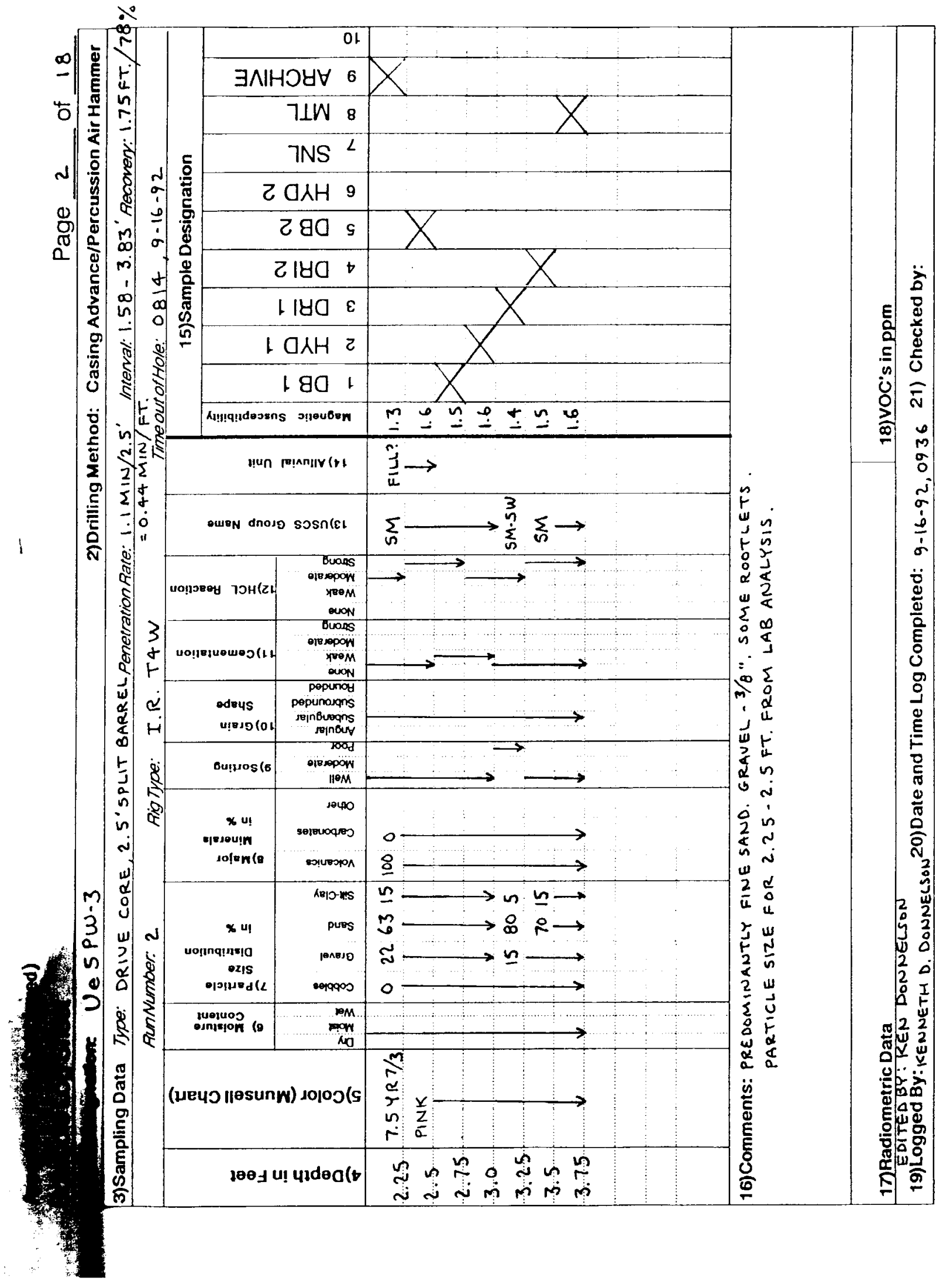




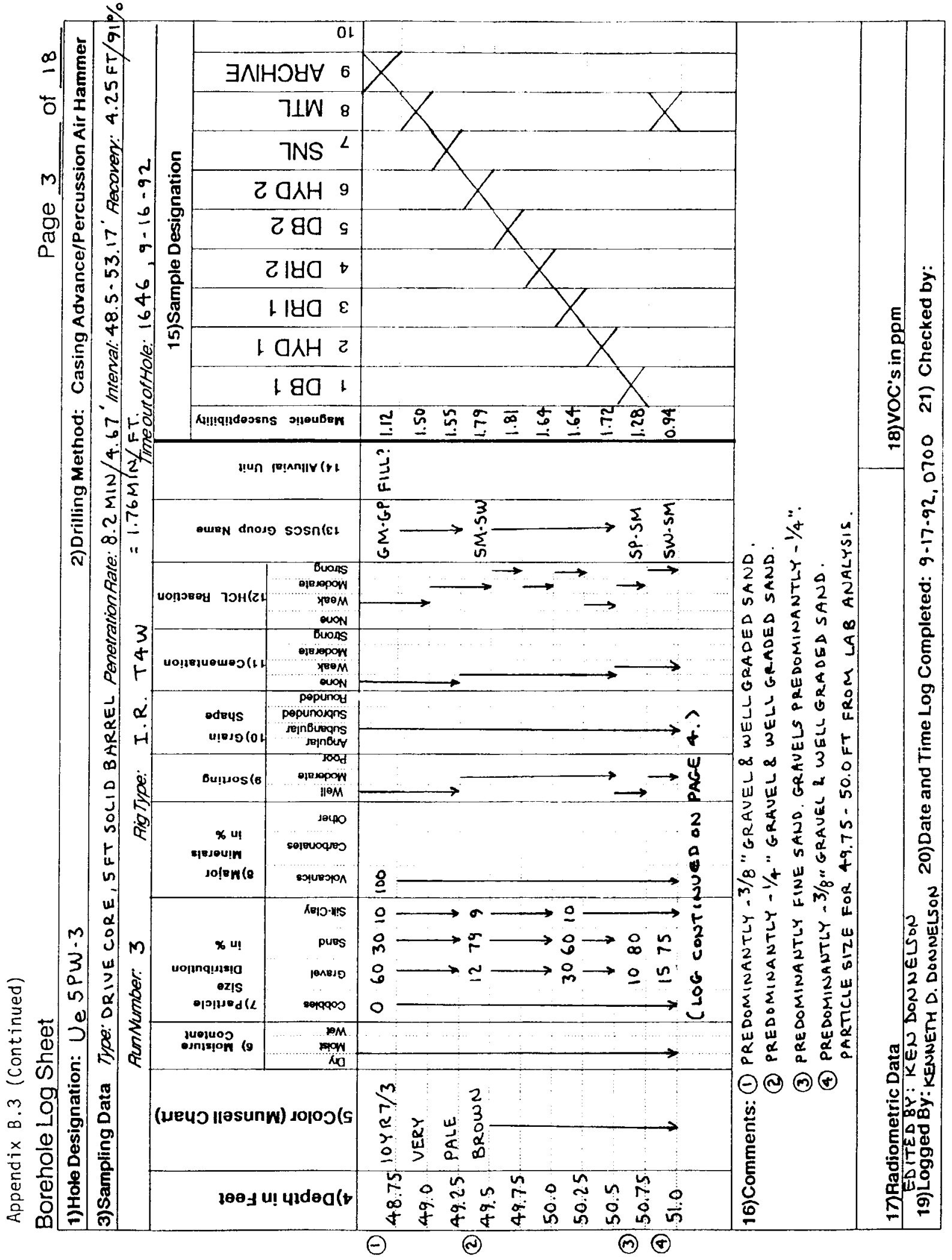




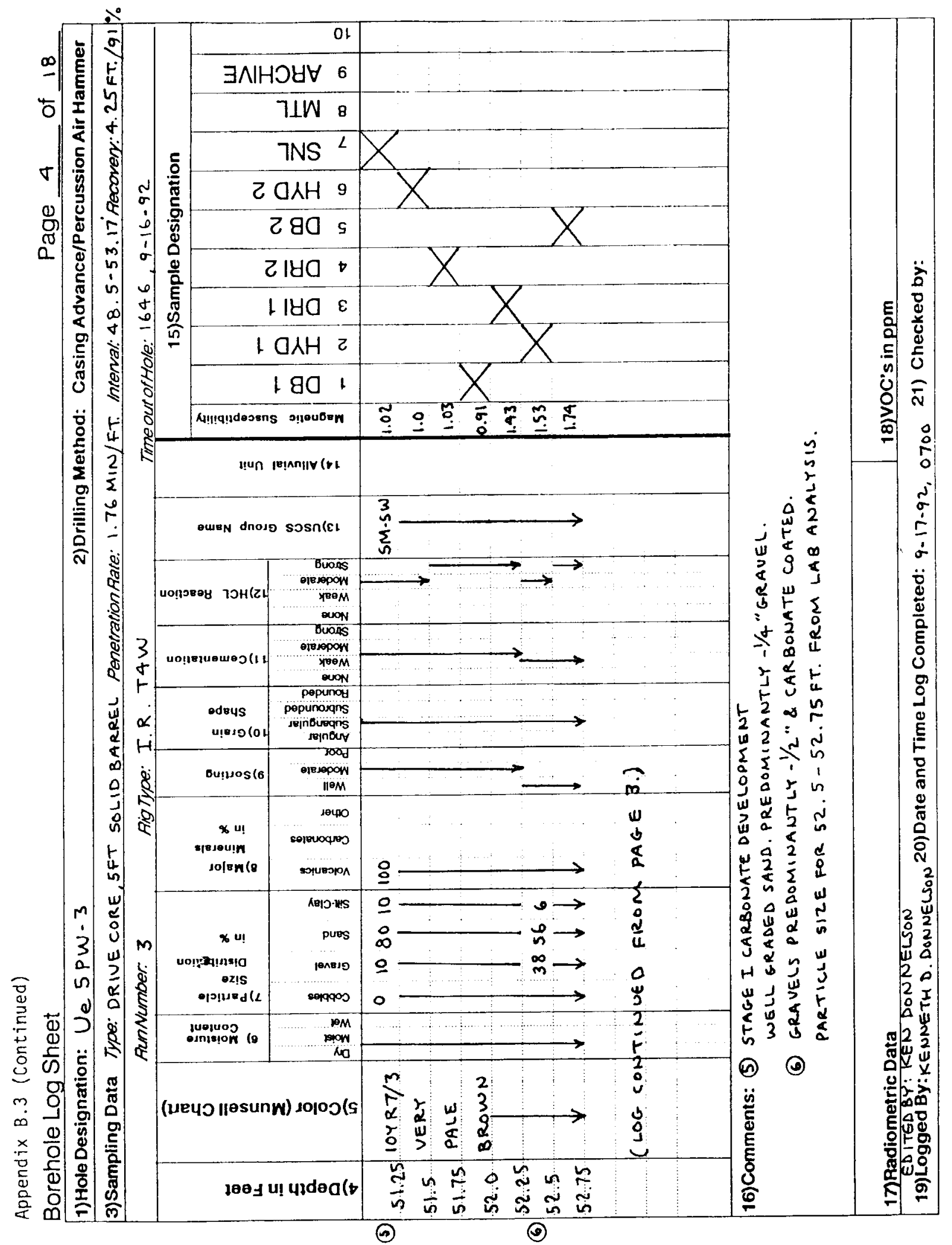




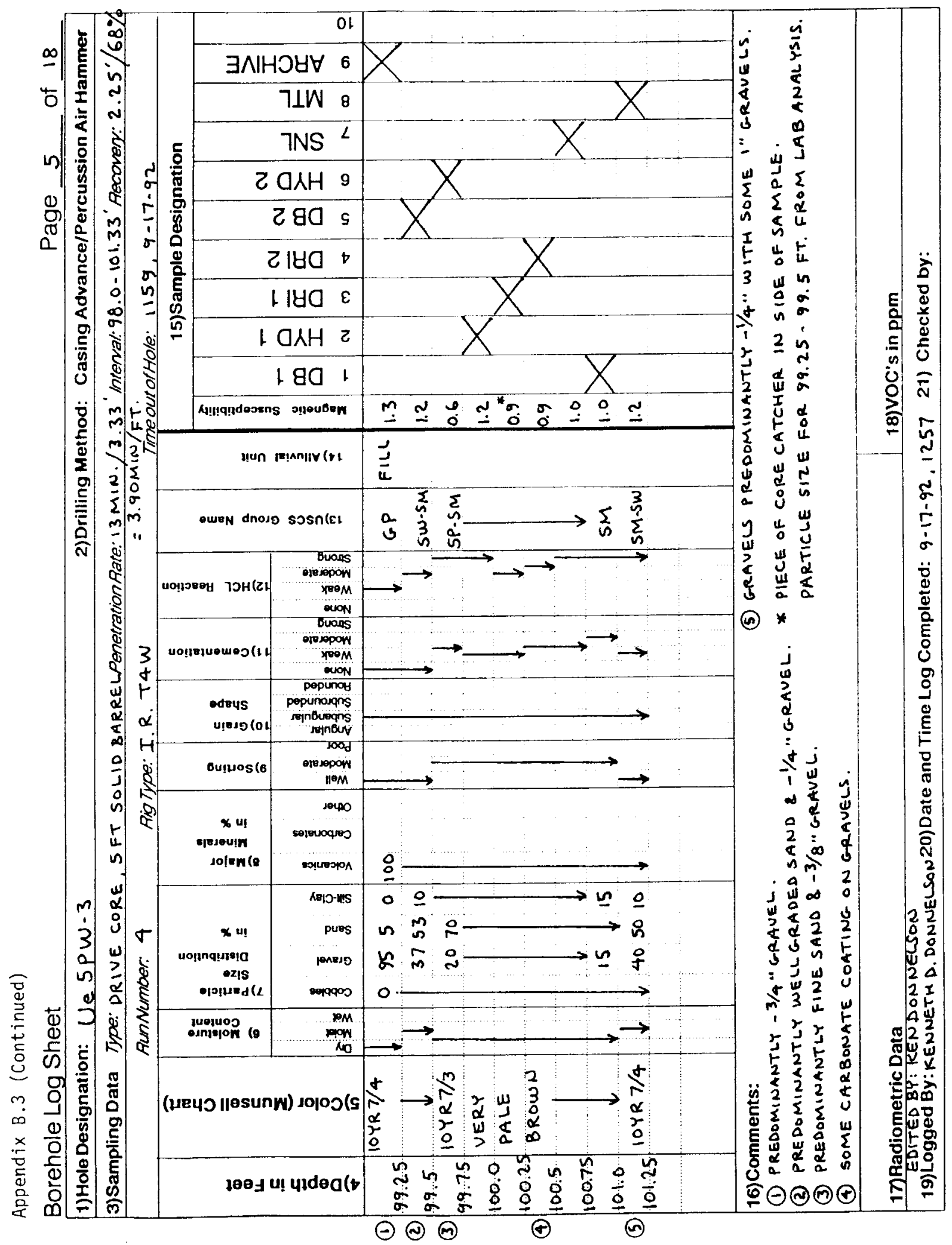




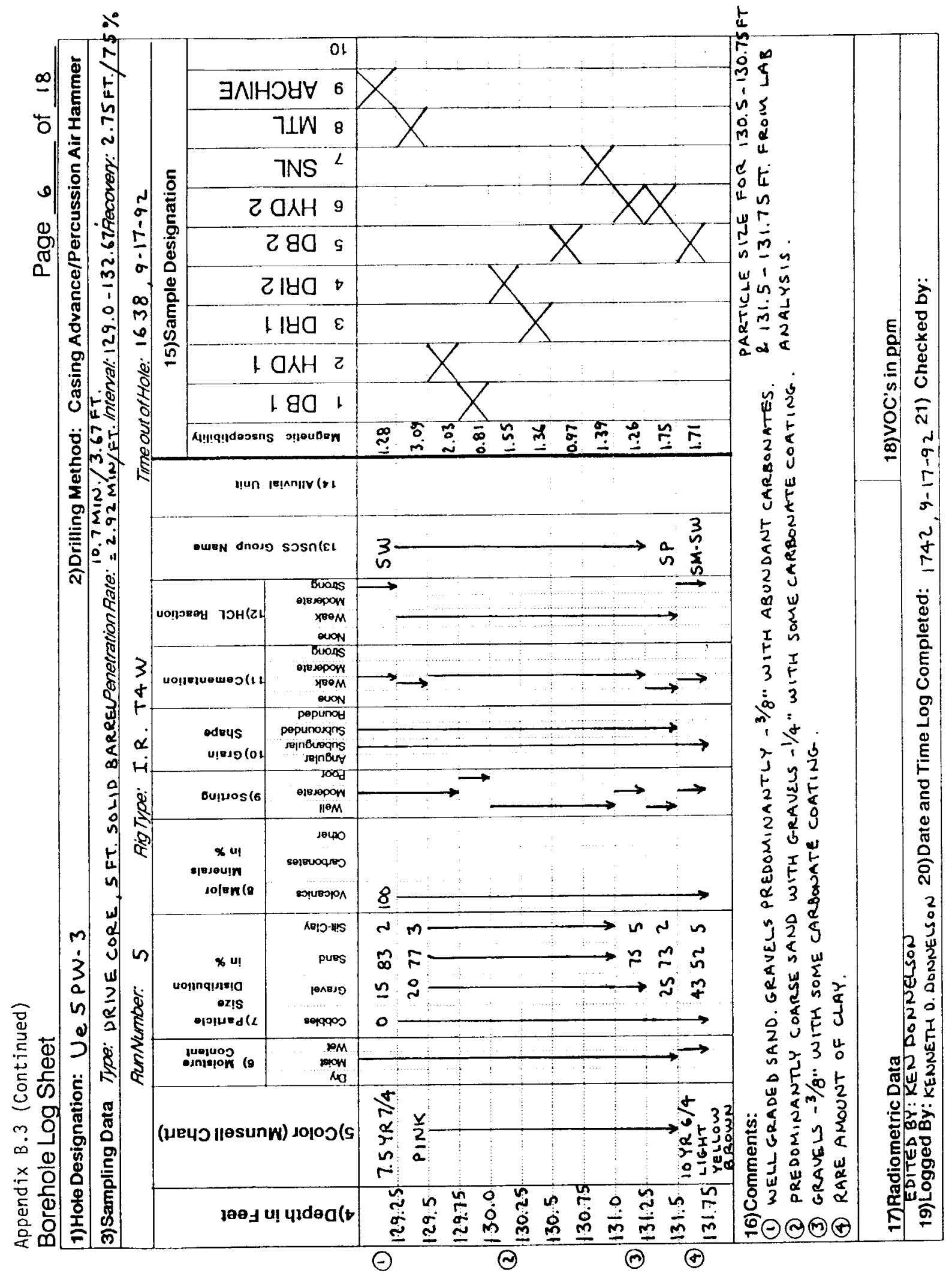




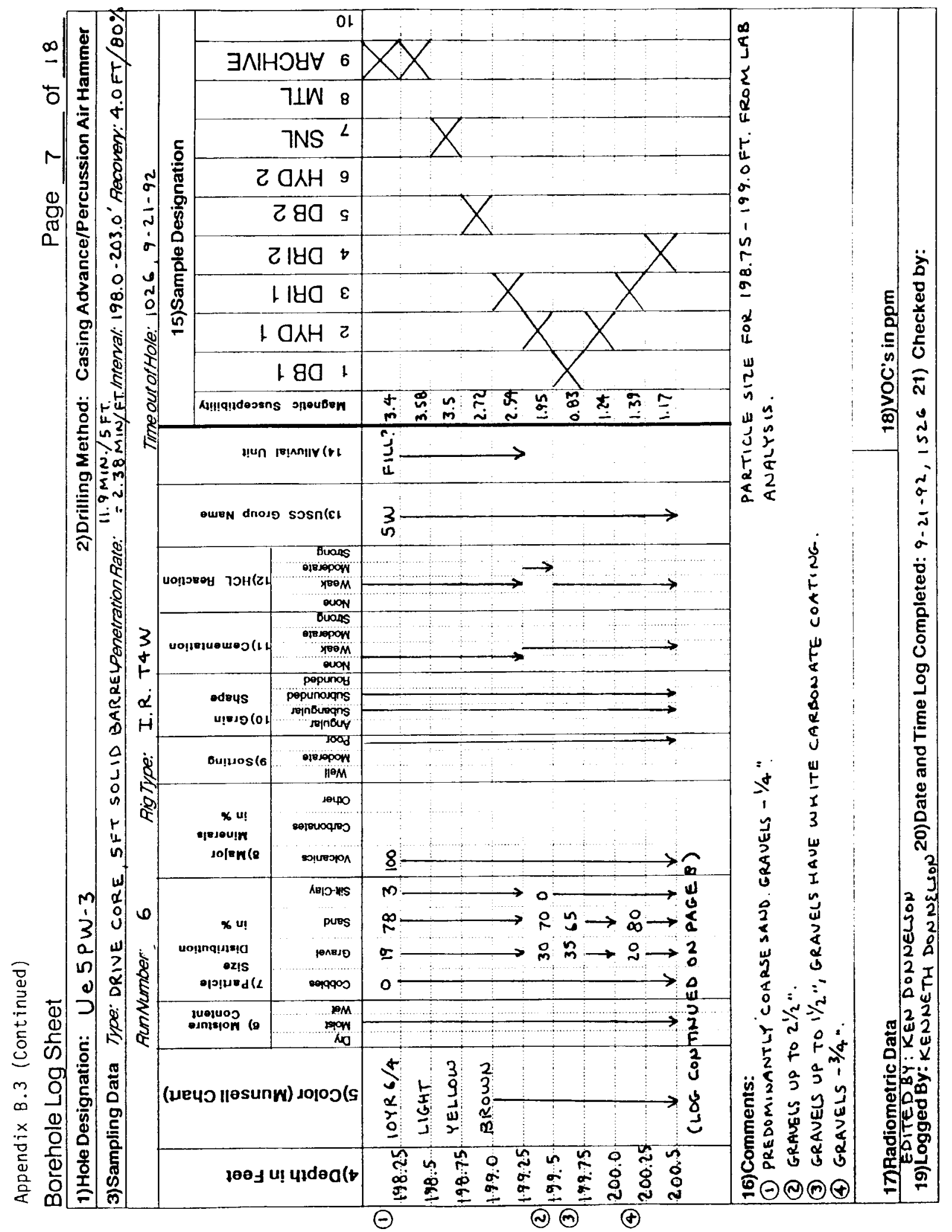




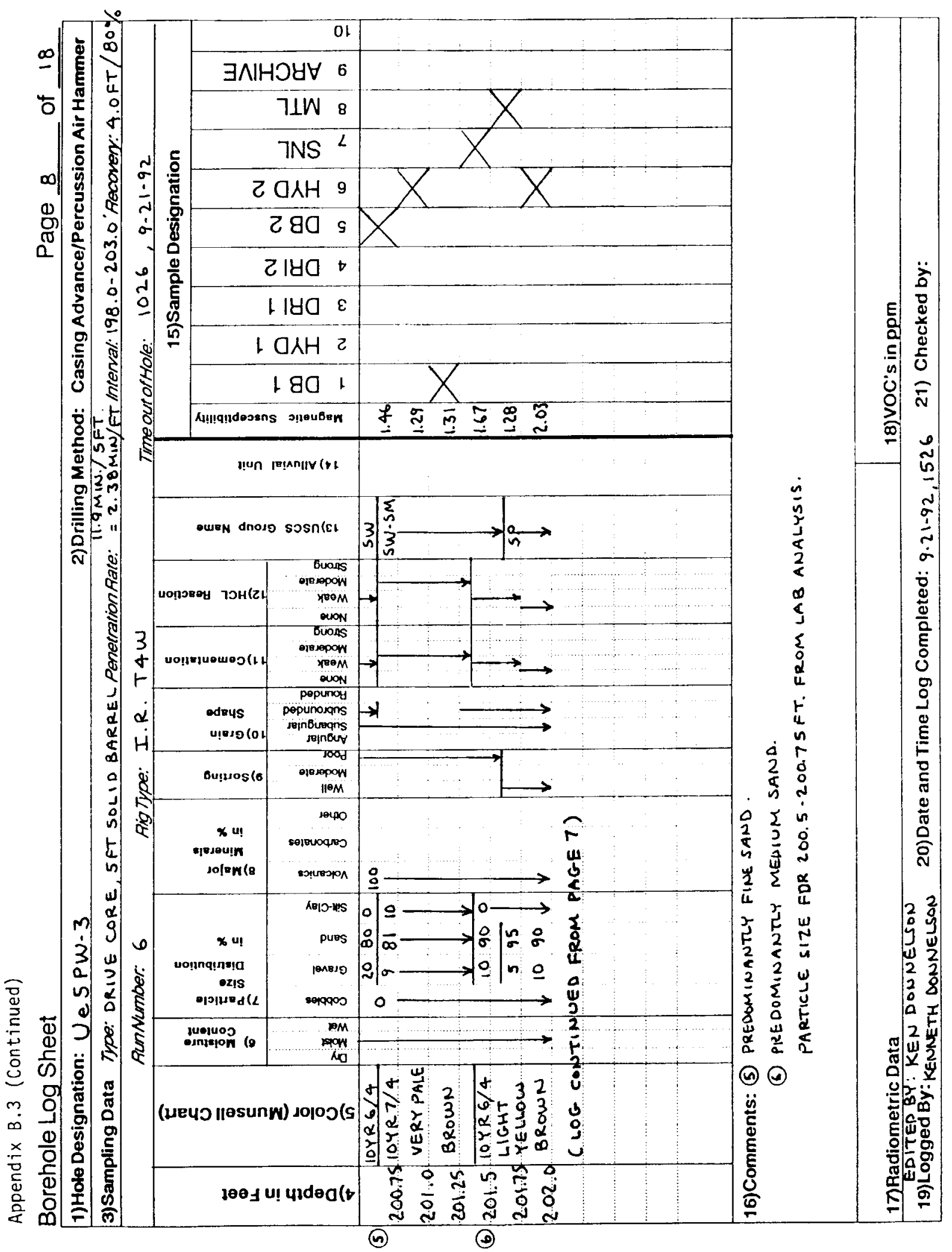




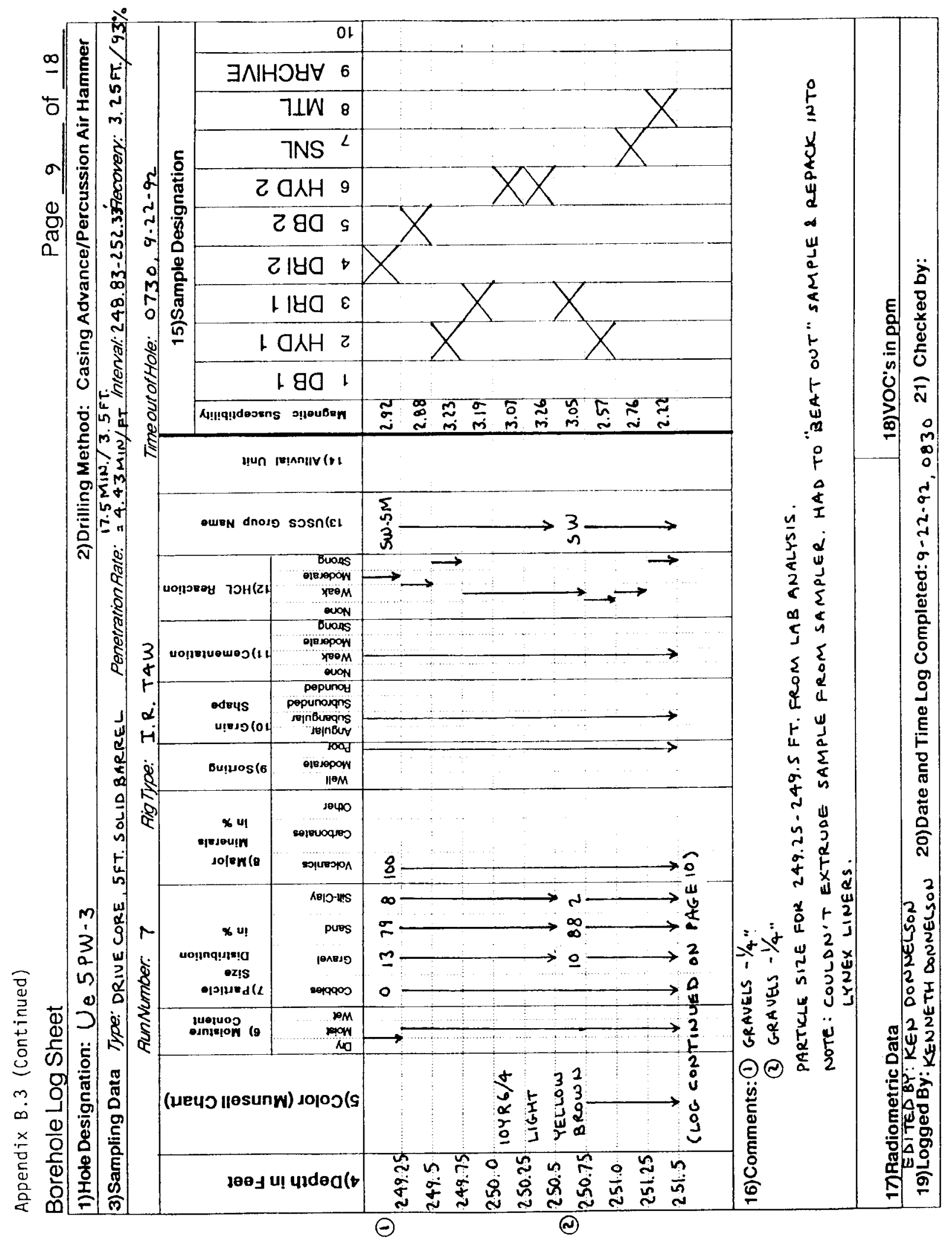




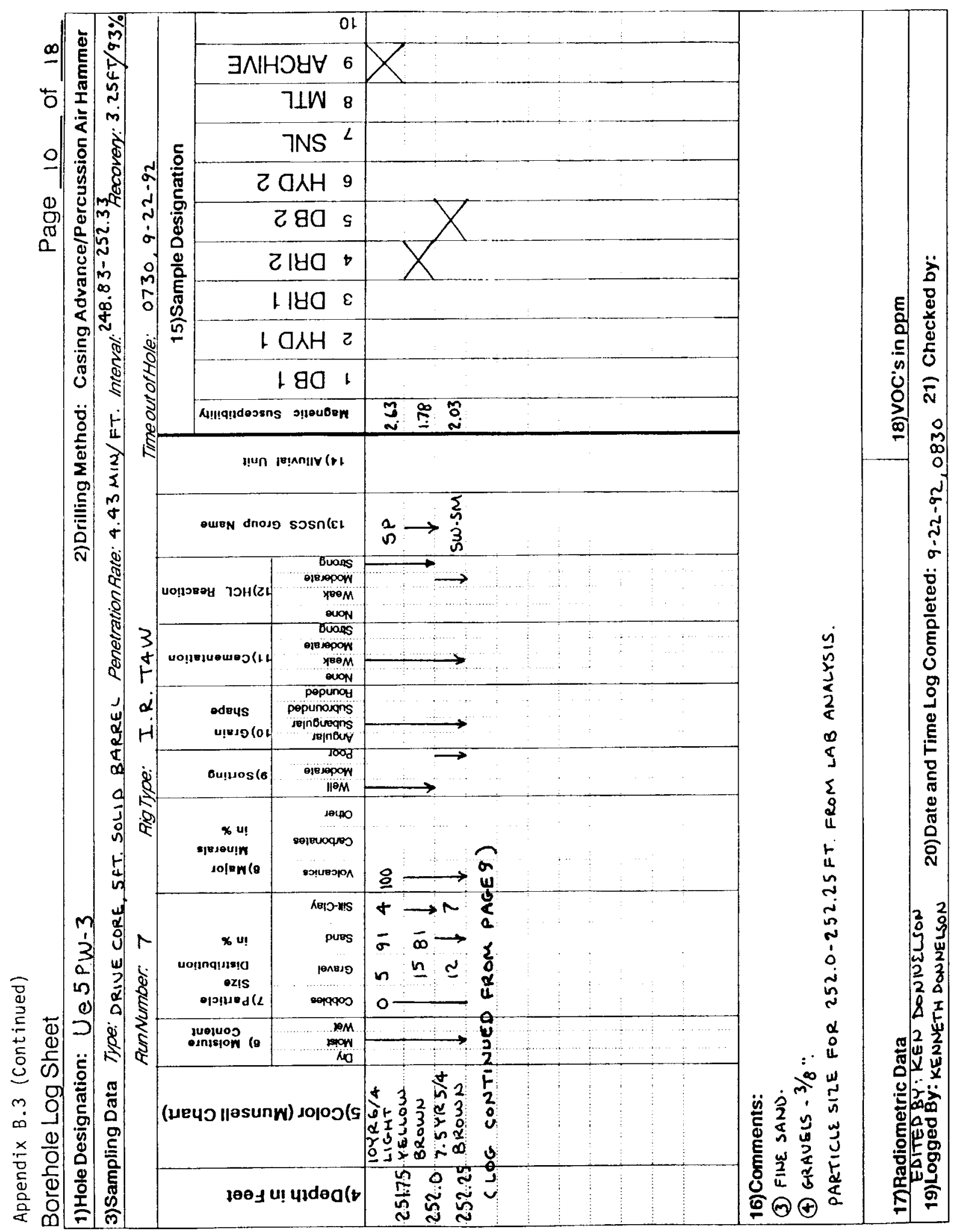




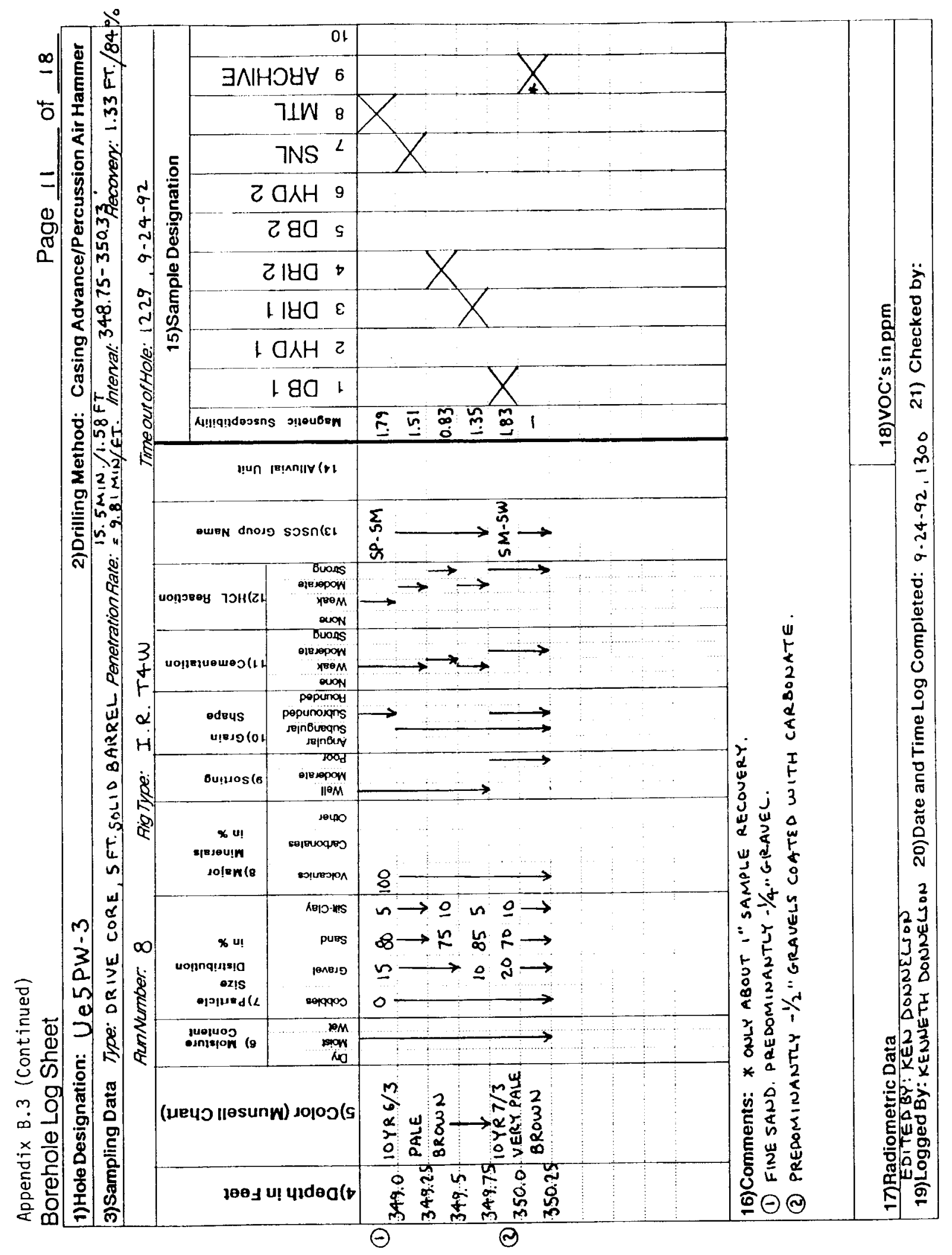




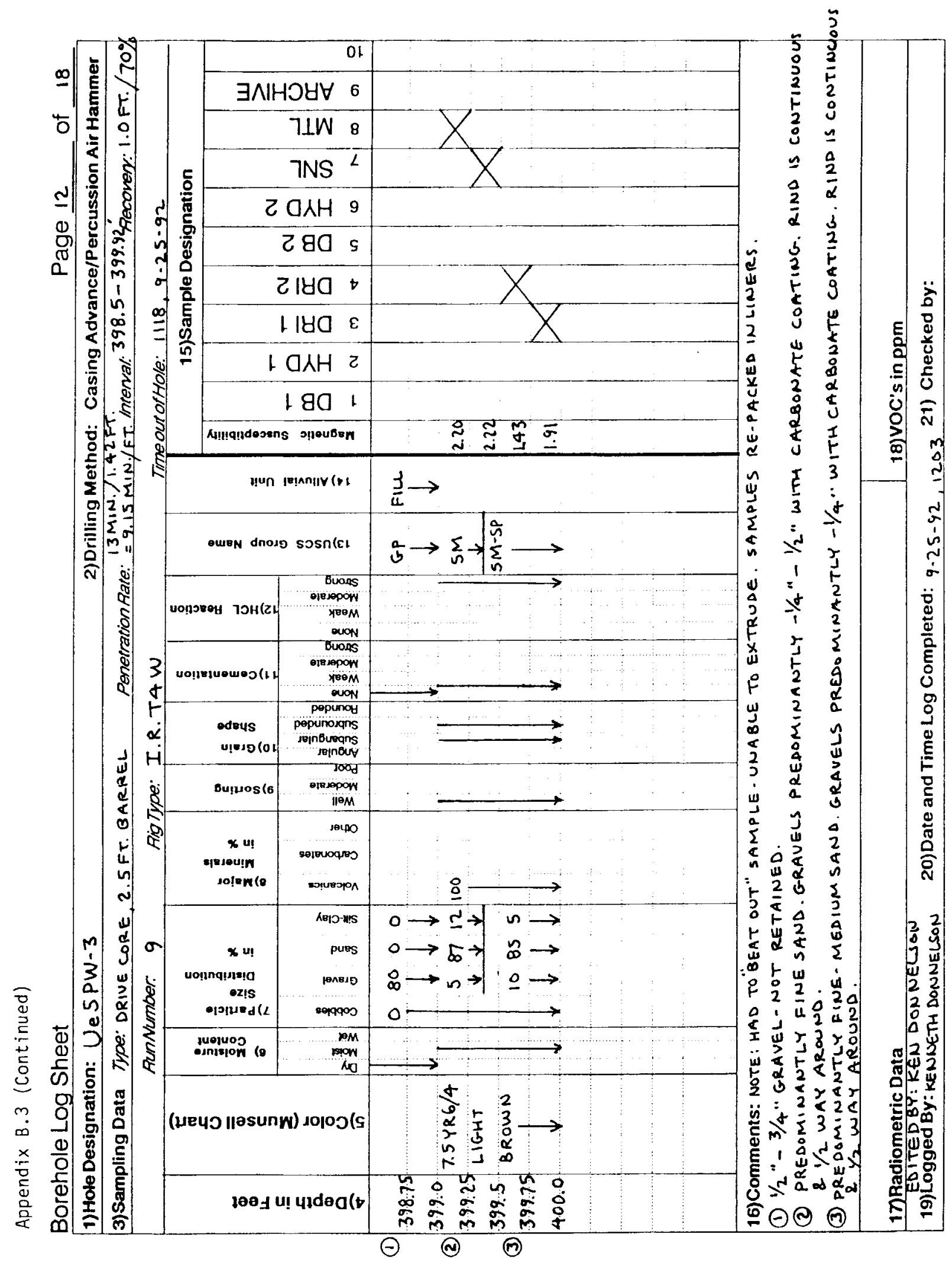




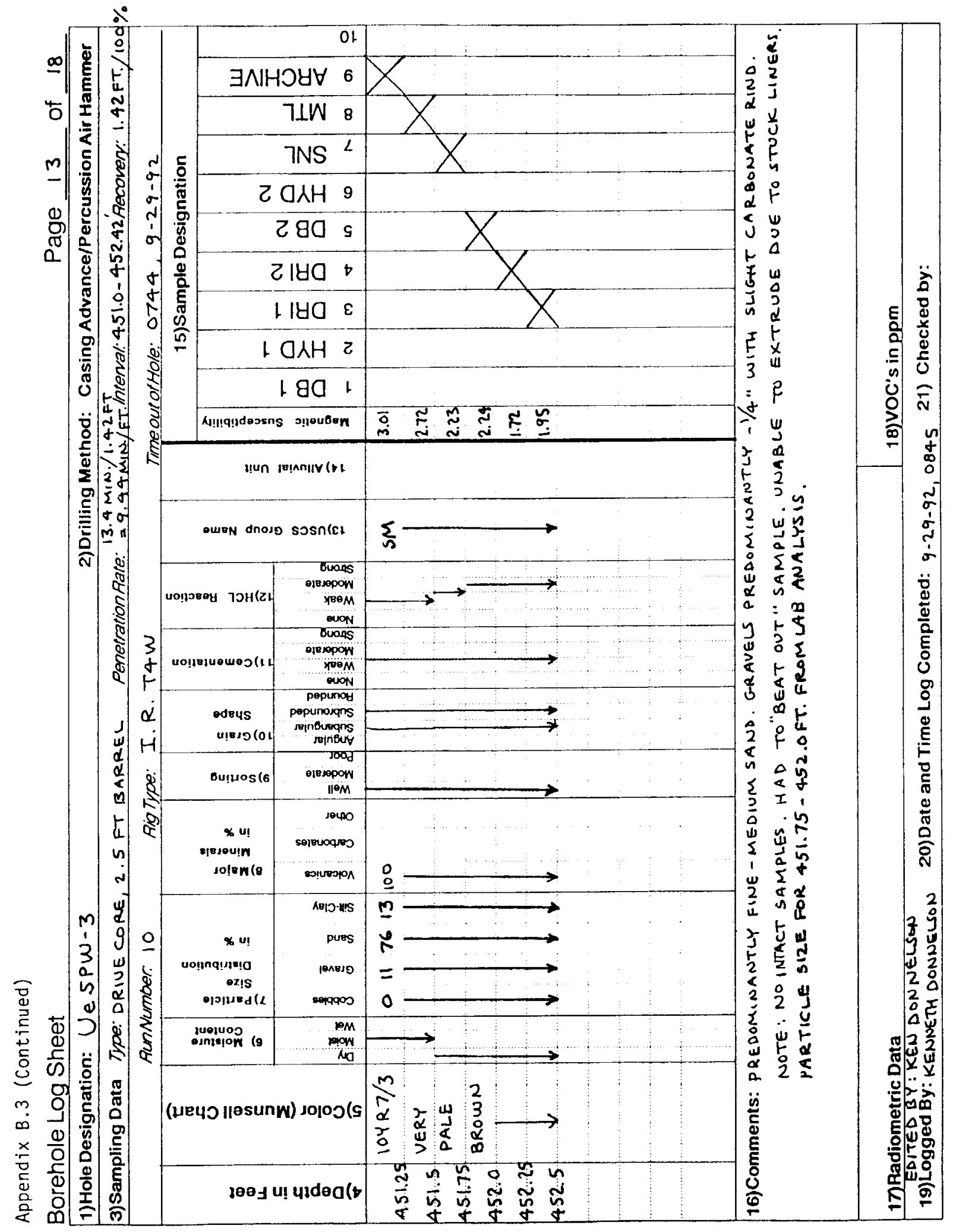




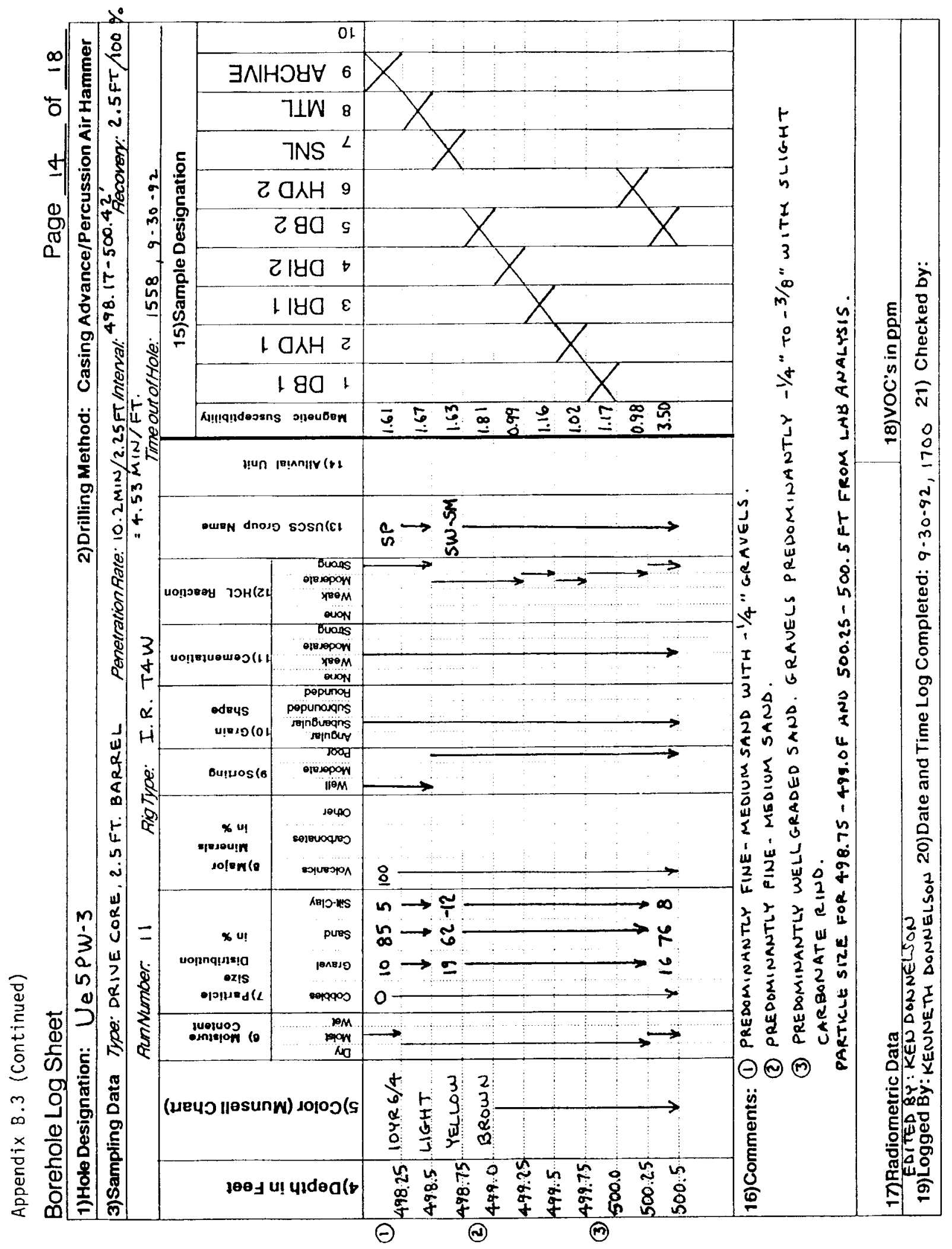




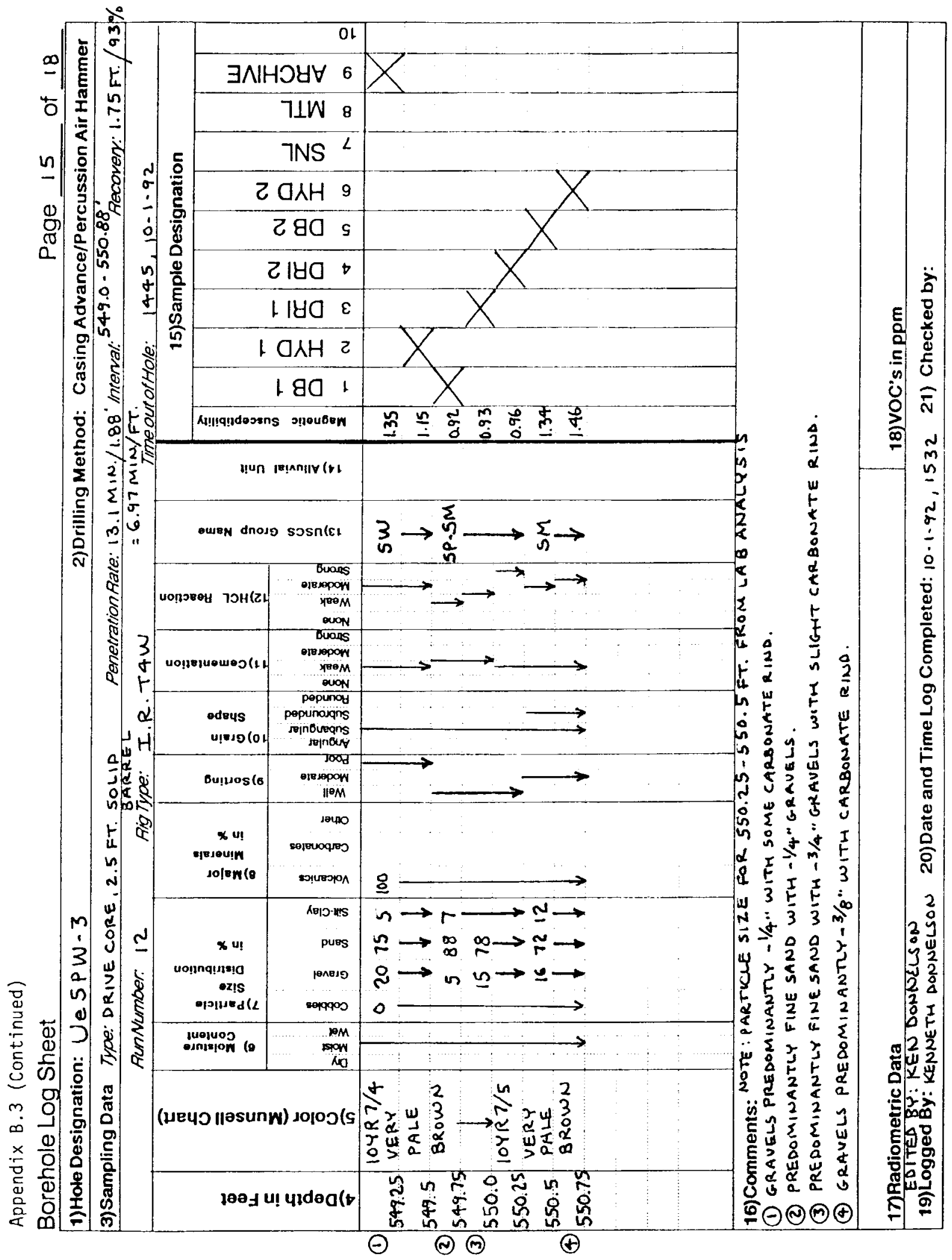




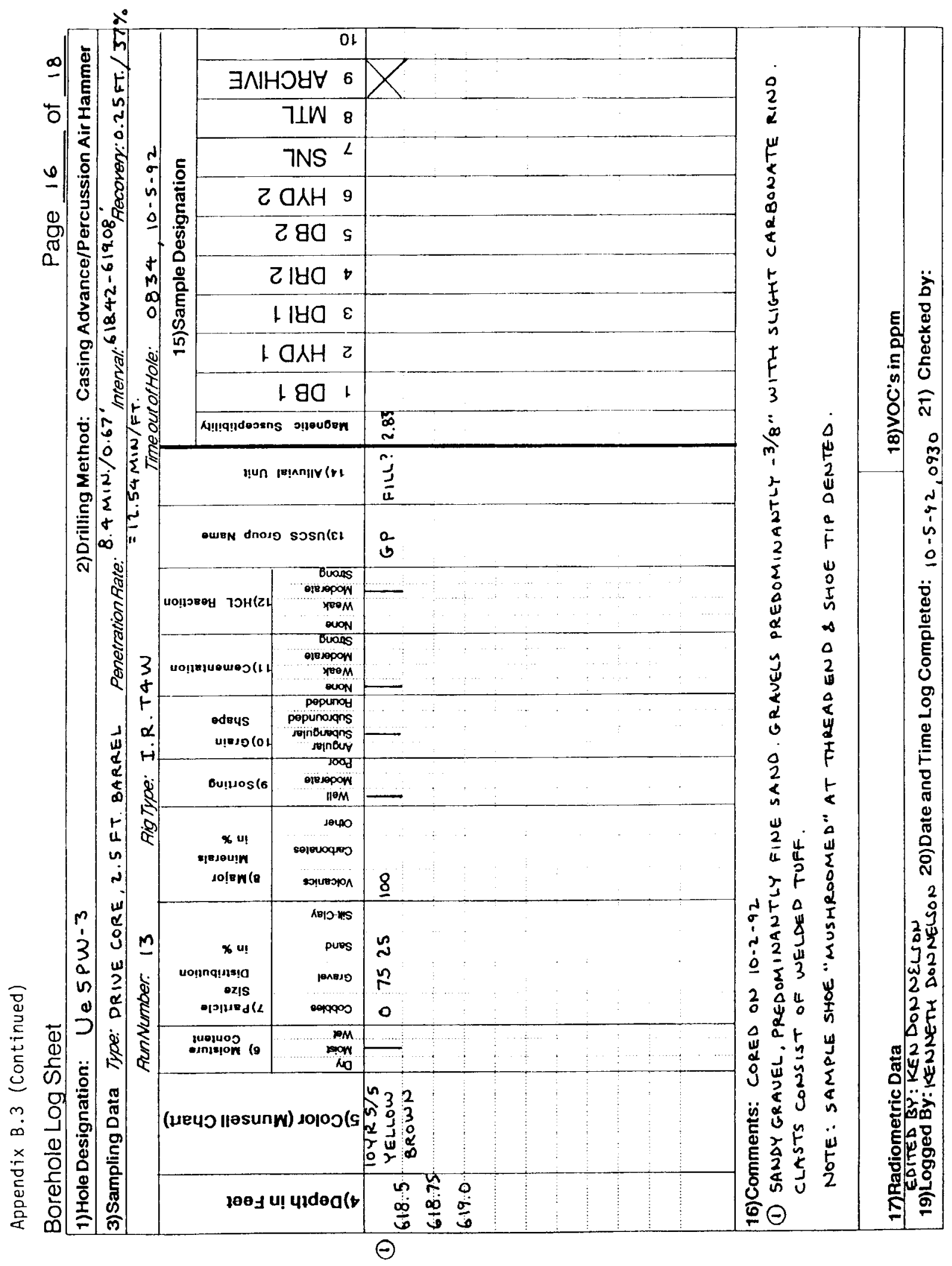




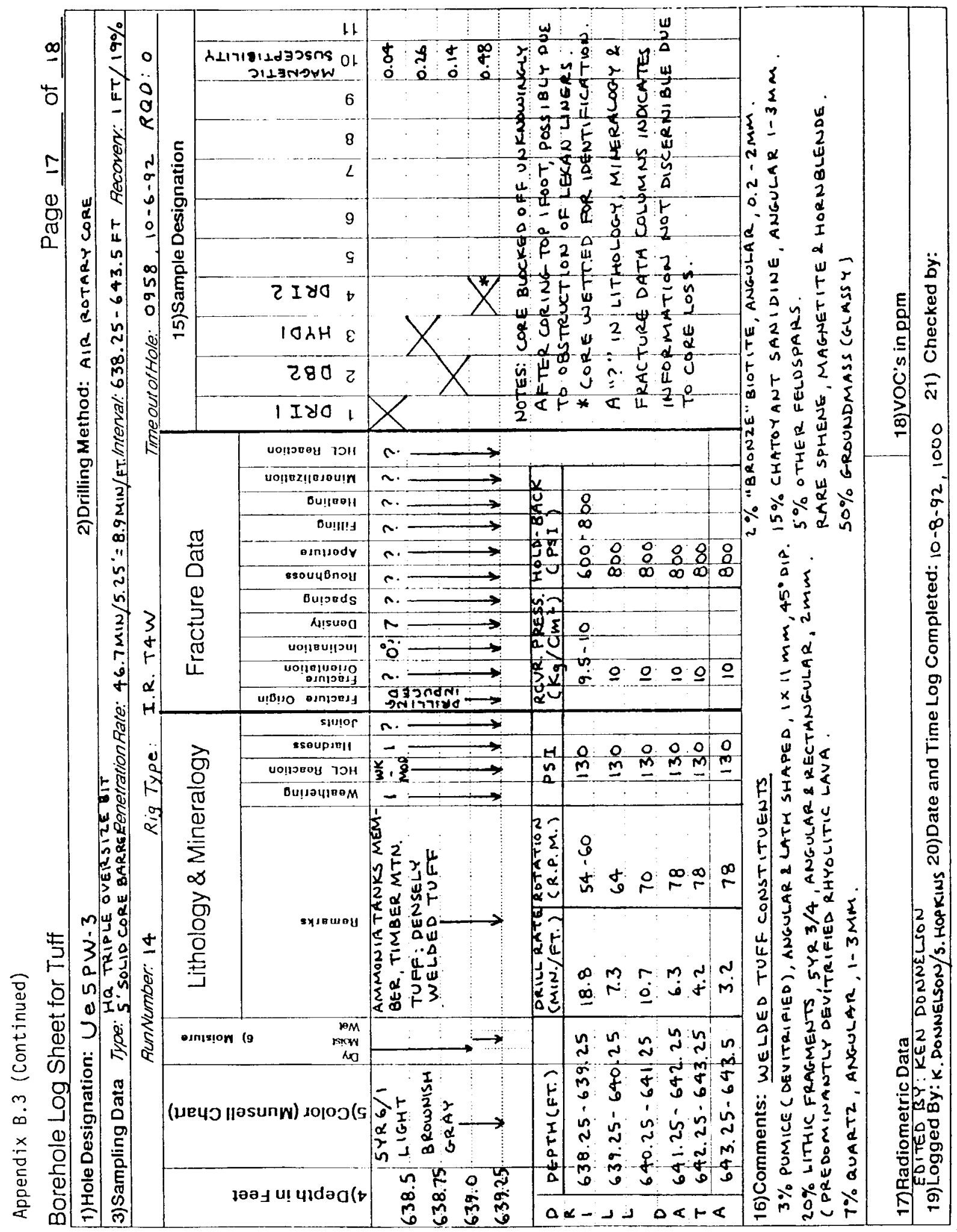




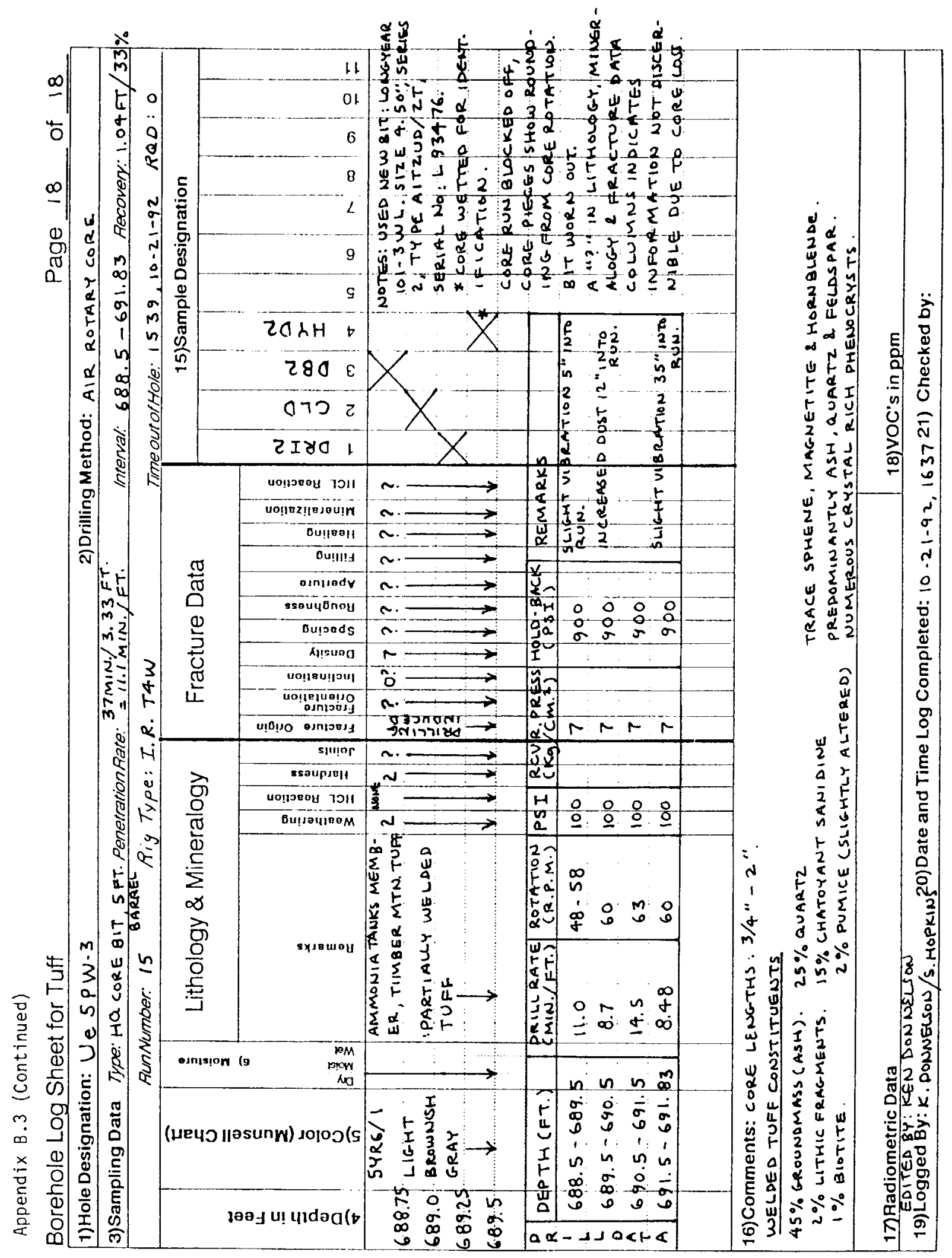




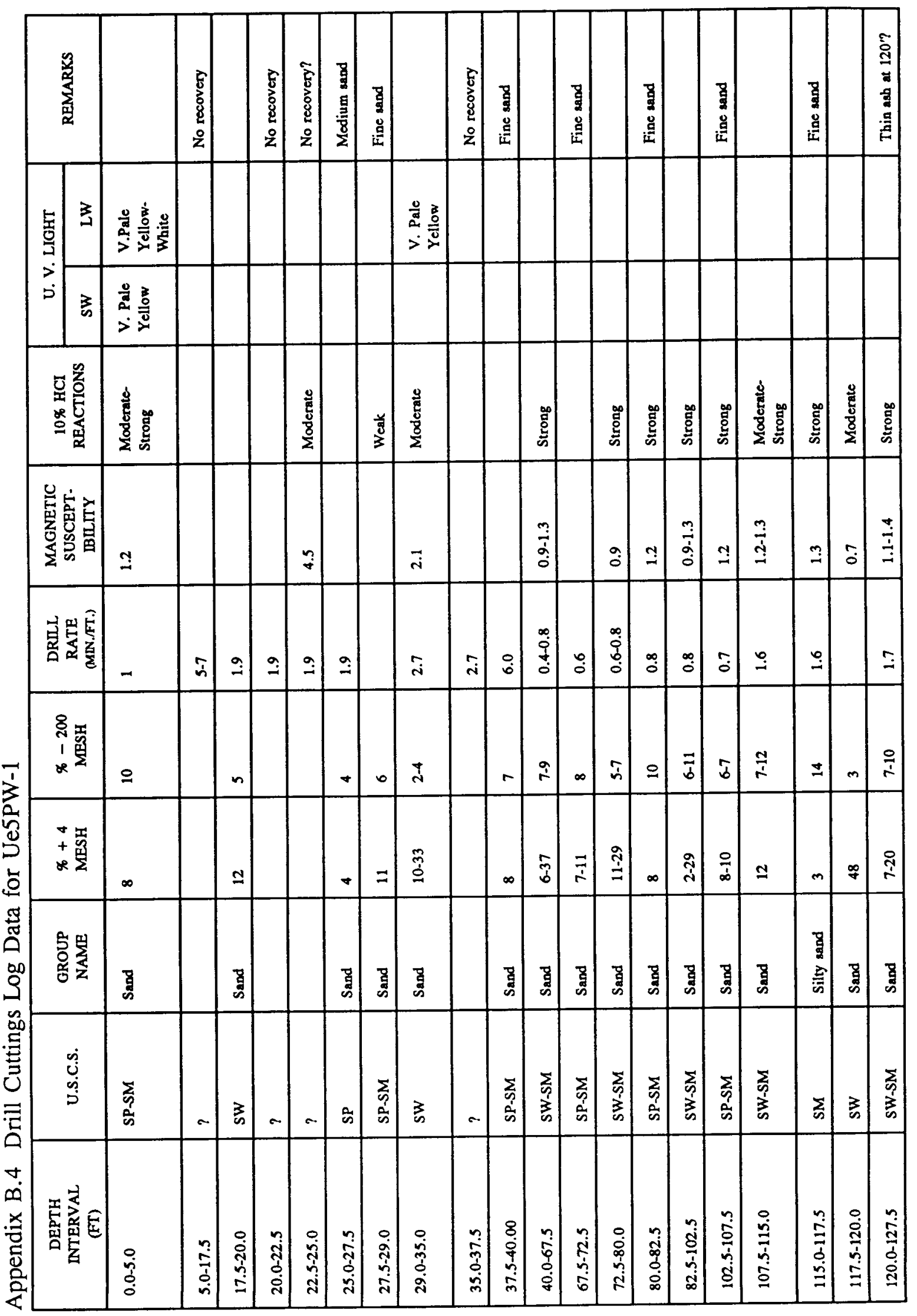




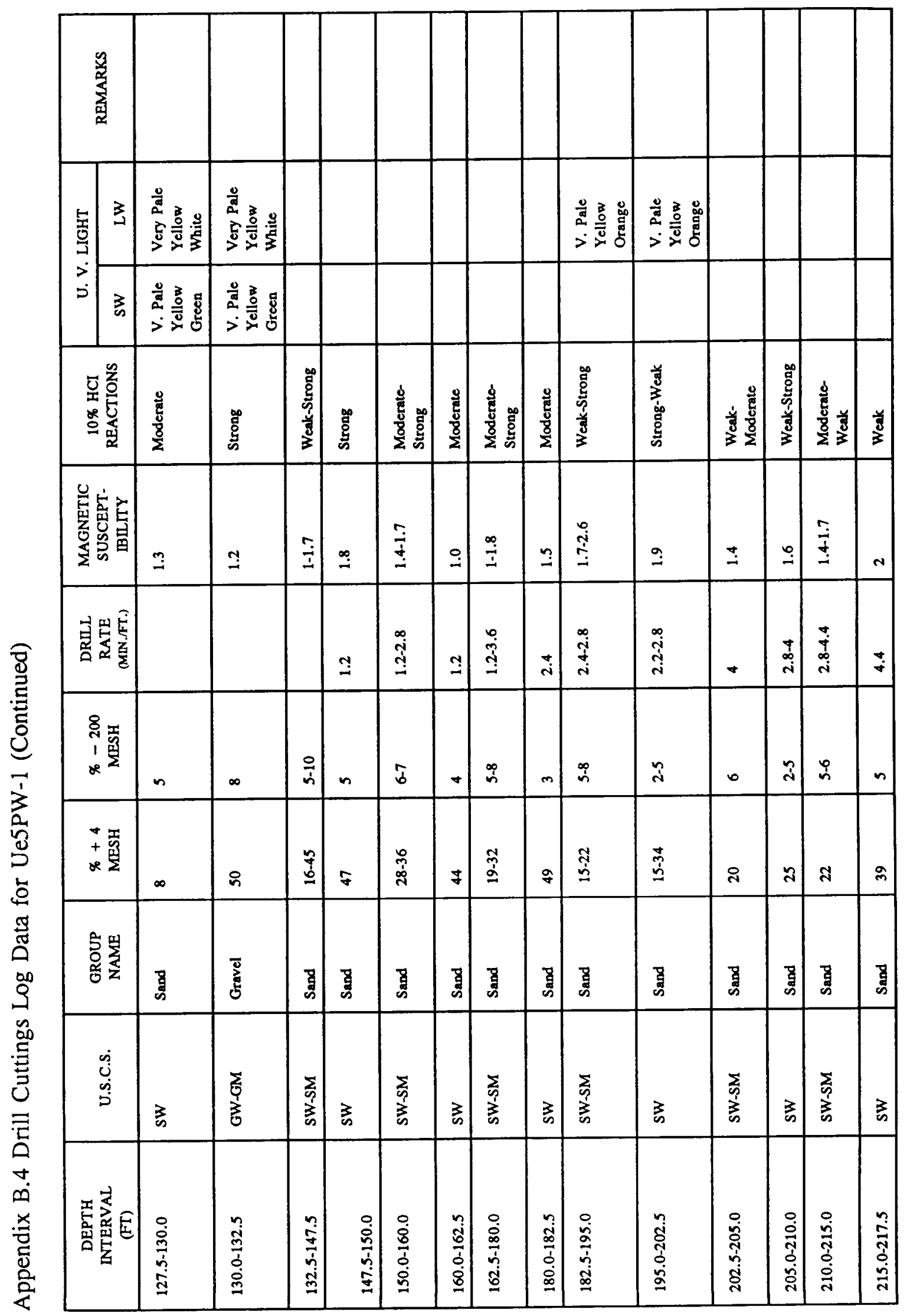




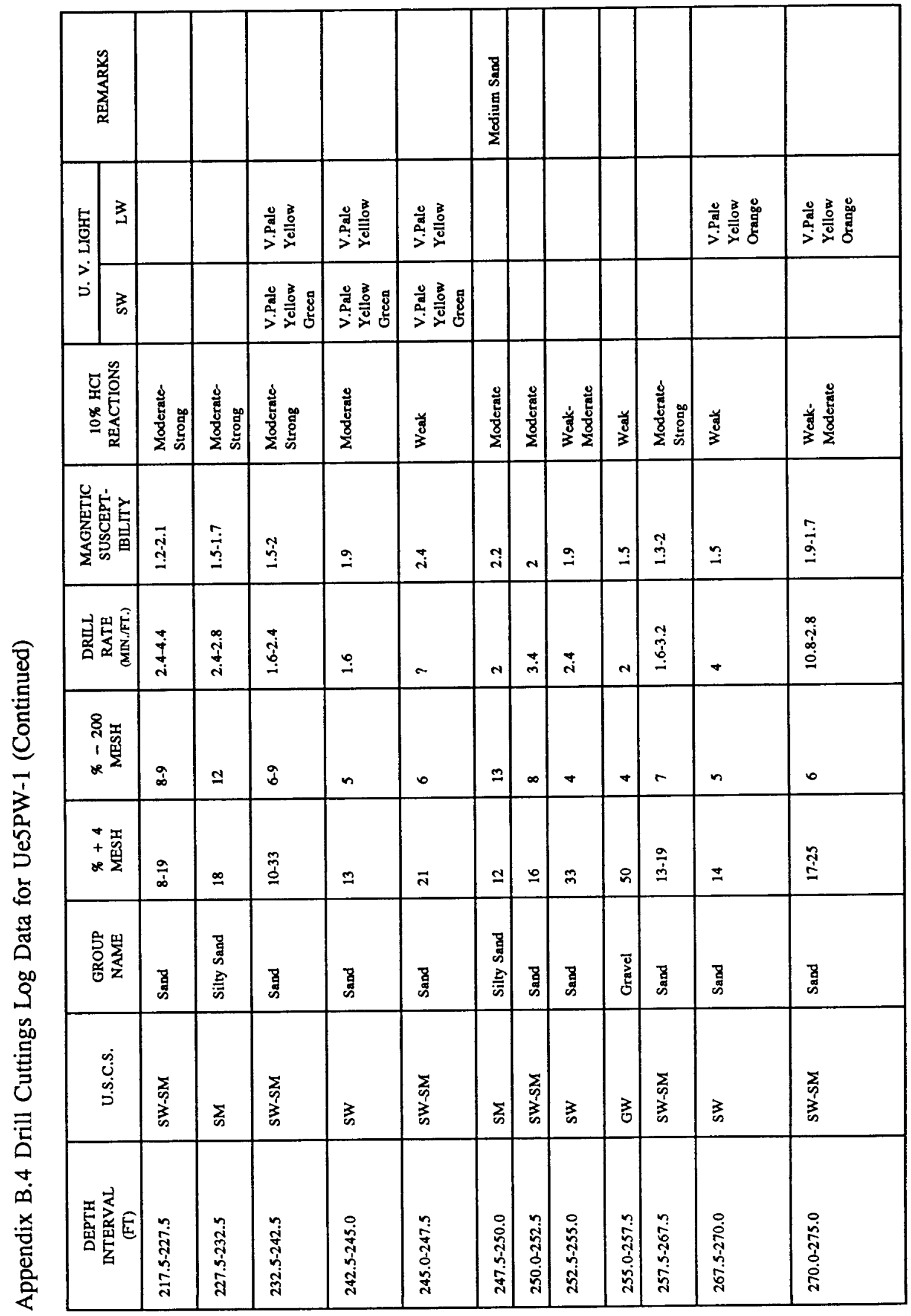




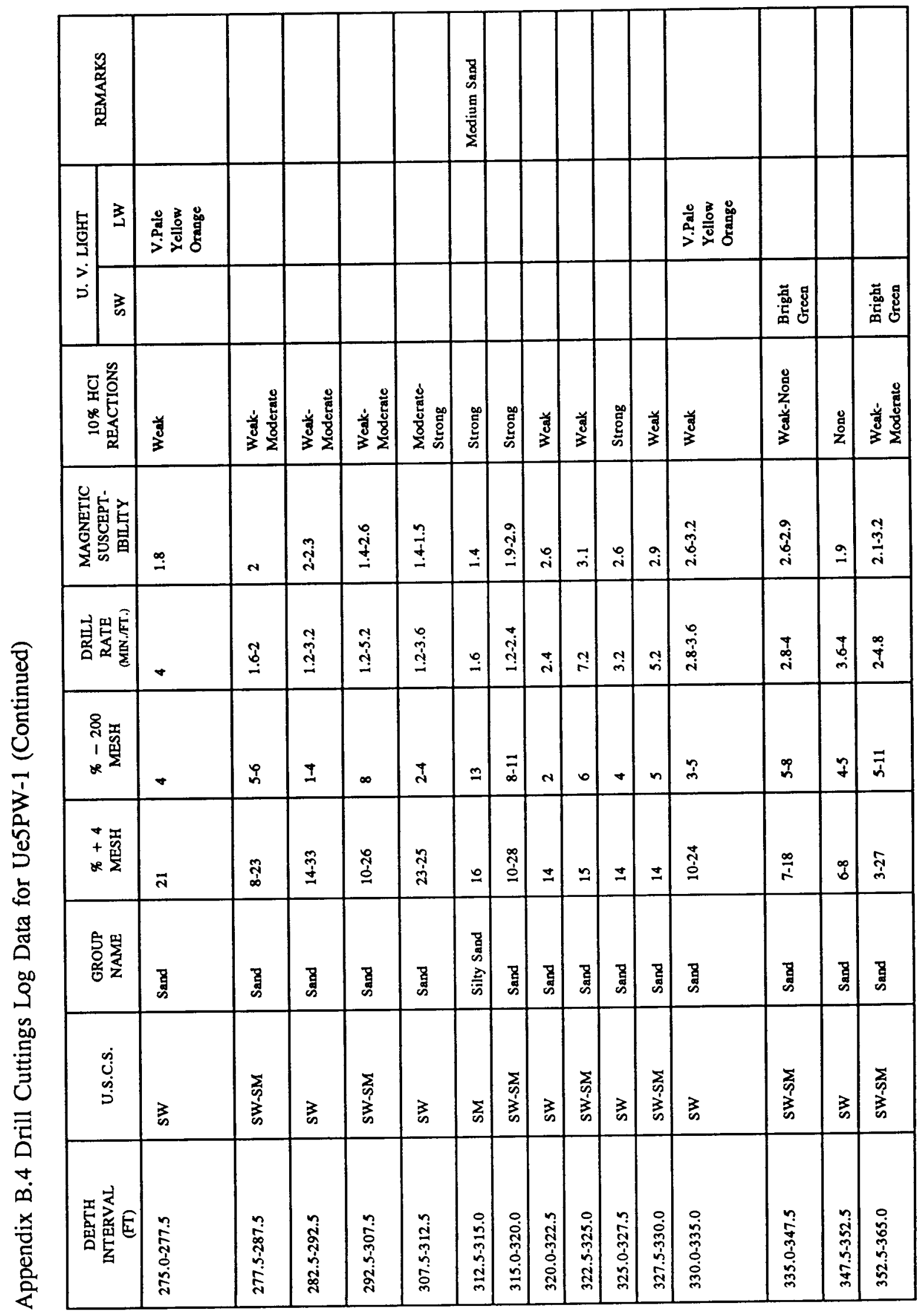




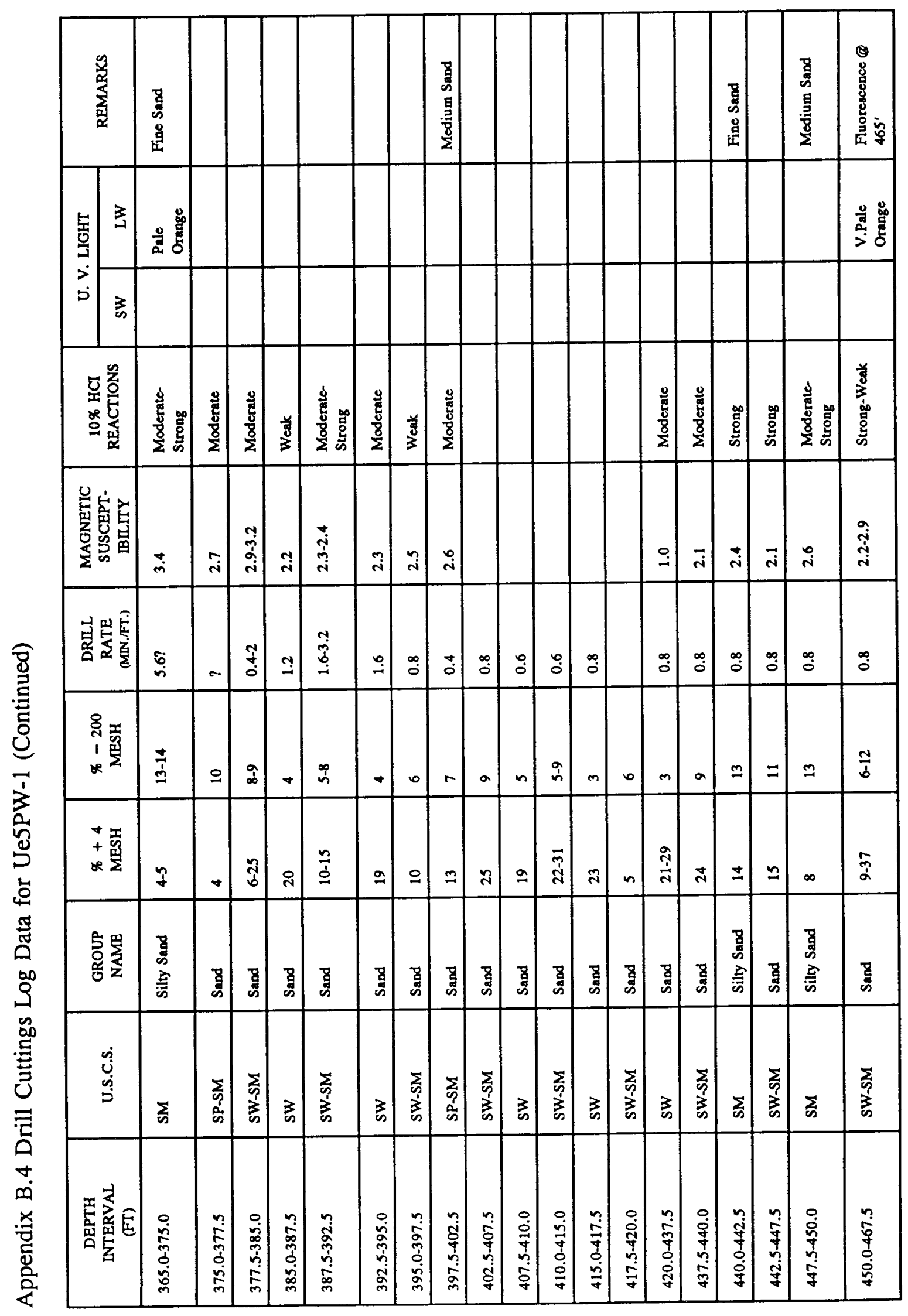




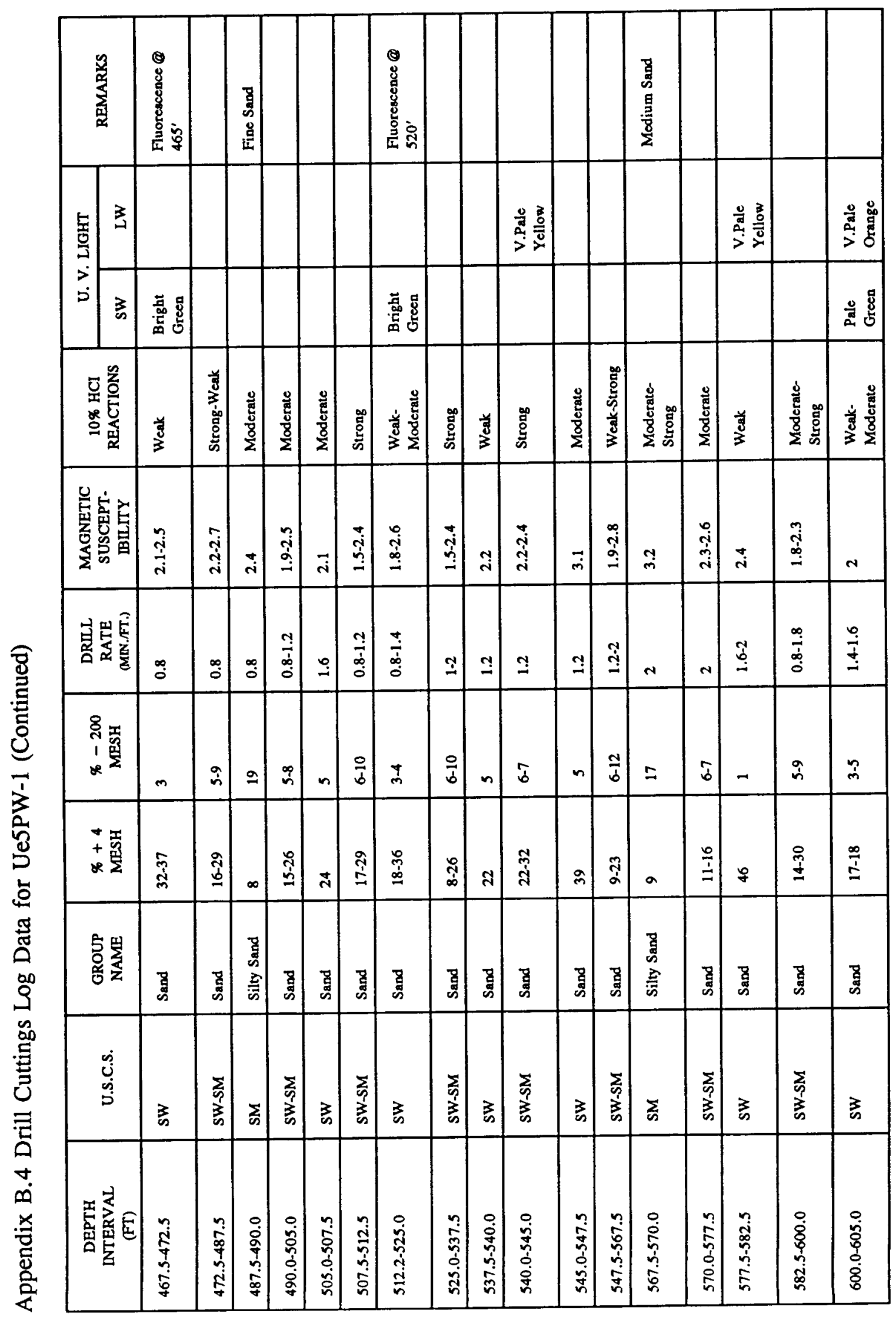




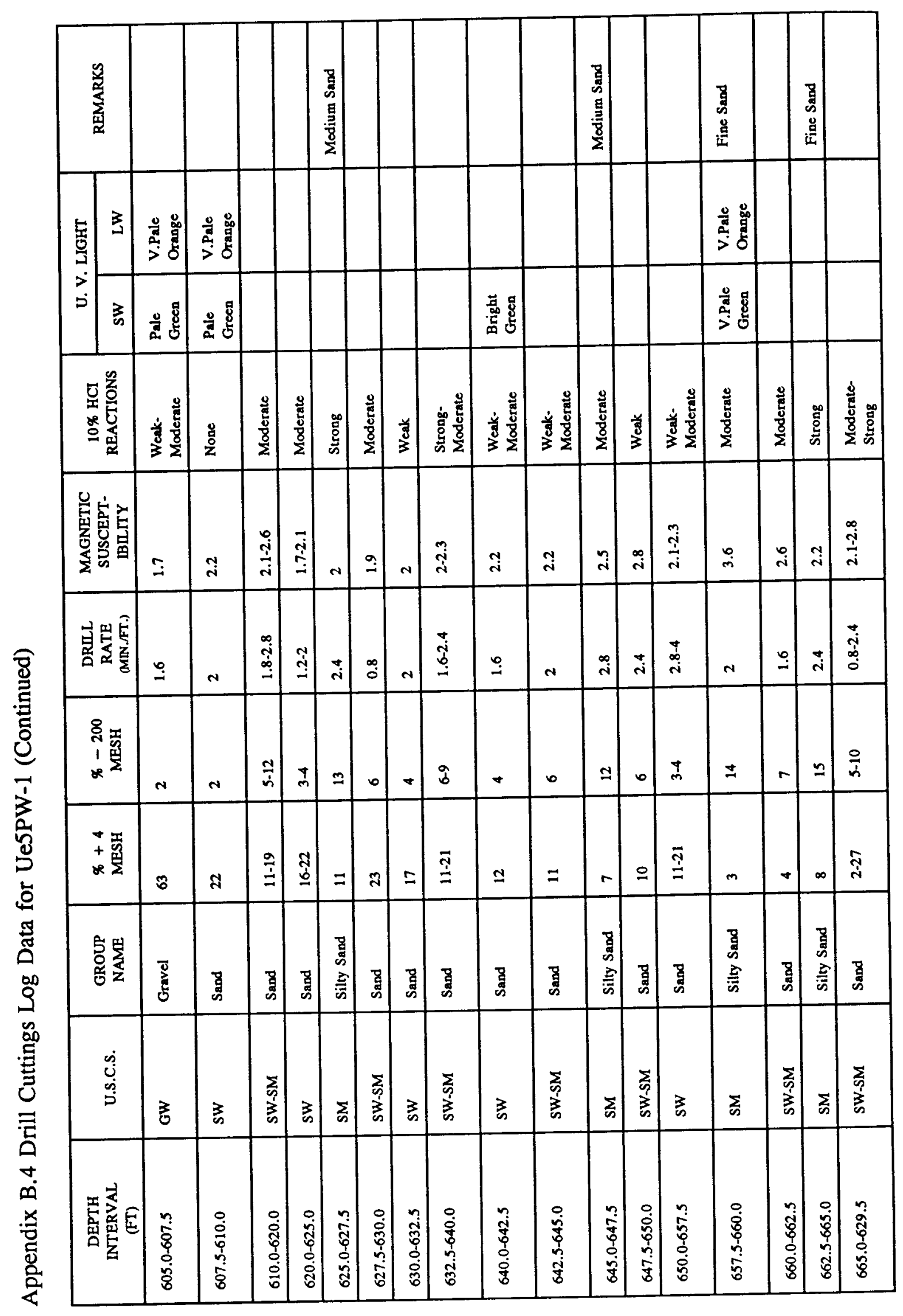




\begin{tabular}{|c|c|c|c|c|c|c|c|c|c|c|c|c|c|c|}
\hline 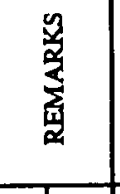 & 晋 & & & & & & 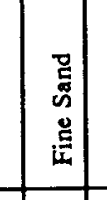 & & & & & & & 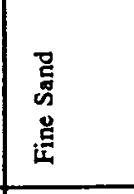 \\
\hline 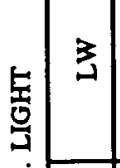 & 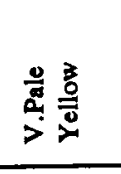 & 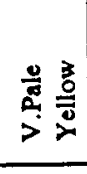 & 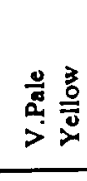 & & & 童 & & & & & & & 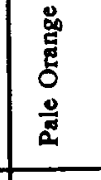 & 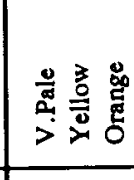 \\
\hline 3 & 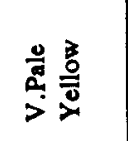 & 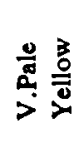 & 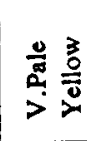 & & & 产| & & & & & & & & \\
\hline 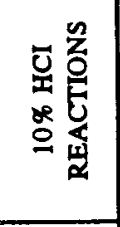 & 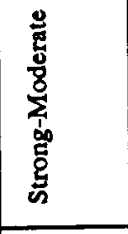 & 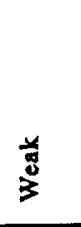 & \begin{tabular}{|l} 
\\
\end{tabular} & 皁 & & & 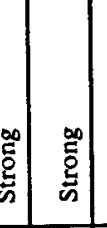 & 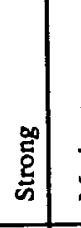 & $\frac{8}{2}$ & & 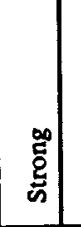 & 圞 & 鋀 & \begin{tabular}{|l}
$\frac{0}{\frac{0}{5}}$ \\
$\frac{8}{2}$
\end{tabular} \\
\hline 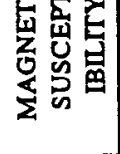 & 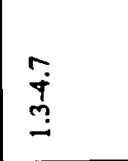 & : & $\because$ & \pm & 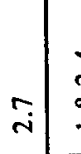 & & $\pi \approx$ & 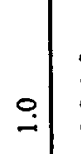 & $\stackrel{\overbrace{}}{\circ}$ & $\Xi$ & $=$ & $\overrightarrow{\mathrm{a}}$ & $\frac{\dot{b}}{\delta}$ & $\cong$ \\
\hline 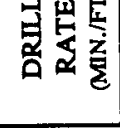 & \begin{tabular}{|l} 
\\
\multirow{i}{0}{} \\
\end{tabular} & $\underset{\infty}{\infty}$ & $\Rightarrow$ & ت्ञ & 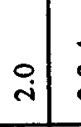 & & \begin{tabular}{c|c} 
\\
$ن$
\end{tabular} & إنه & $=$ & $\Xi$ & 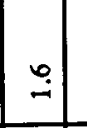 & $:$ & $\stackrel{n}{3}$ & $\stackrel{d}{\dot{j}}$ \\
\hline 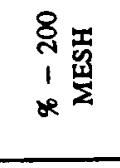 & $\dot{i}$ & 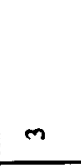 & - & + & $\infty$ & - & $=0$ & $\infty$ & i. & $\approx$ & 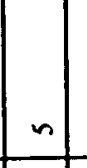 & . & $\frac{2}{2}$ & $\cong$ \\
\hline 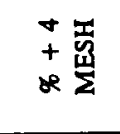 & 范 & 8 & $\because$ & $\therefore$ & $=1$ & 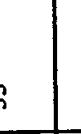 & $=$ & & 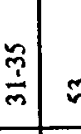 & 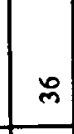 & $=$ & 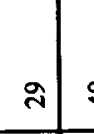 & $f$ & $\simeq$ \\
\hline 彭竞 & 离 & 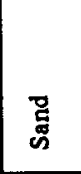 & 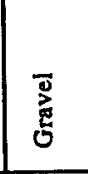 & 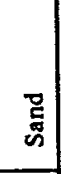 & 煦 & 咅 & 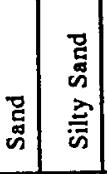 & & 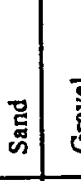 & 颜 & & 离 & $\begin{array}{l}\mathfrak{b}^{5} \\
\end{array}$ & 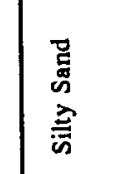 \\
\hline 岁 & \begin{tabular}{|l}
. \\
咅
\end{tabular} & $\frac{3}{2}$ & 苂 & $\frac{3}{n}$ & & 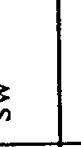 & 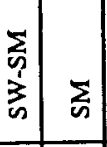 & $\begin{array}{l}5 \\
\vdots \\
\vdots \\
\vdots\end{array}$ & 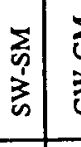 & & \begin{tabular}{|l|} 
\\
$\vdots$ \\
$\vdots$ \\
$\vdots$
\end{tabular} & 育 & $\begin{array}{l}\vdots \\
\vdots \\
\vdots\end{array}$ & $\bar{n}$ \\
\hline 麇兽 & 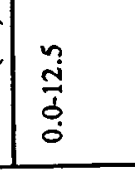 & 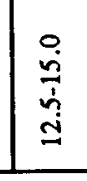 & 恣 & & & 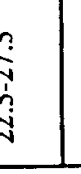 & 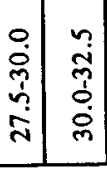 & & 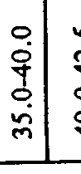 & 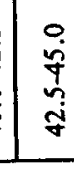 & $\mid$ & 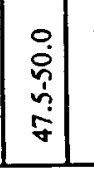 & 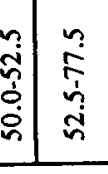 & 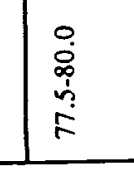 \\
\hline
\end{tabular}




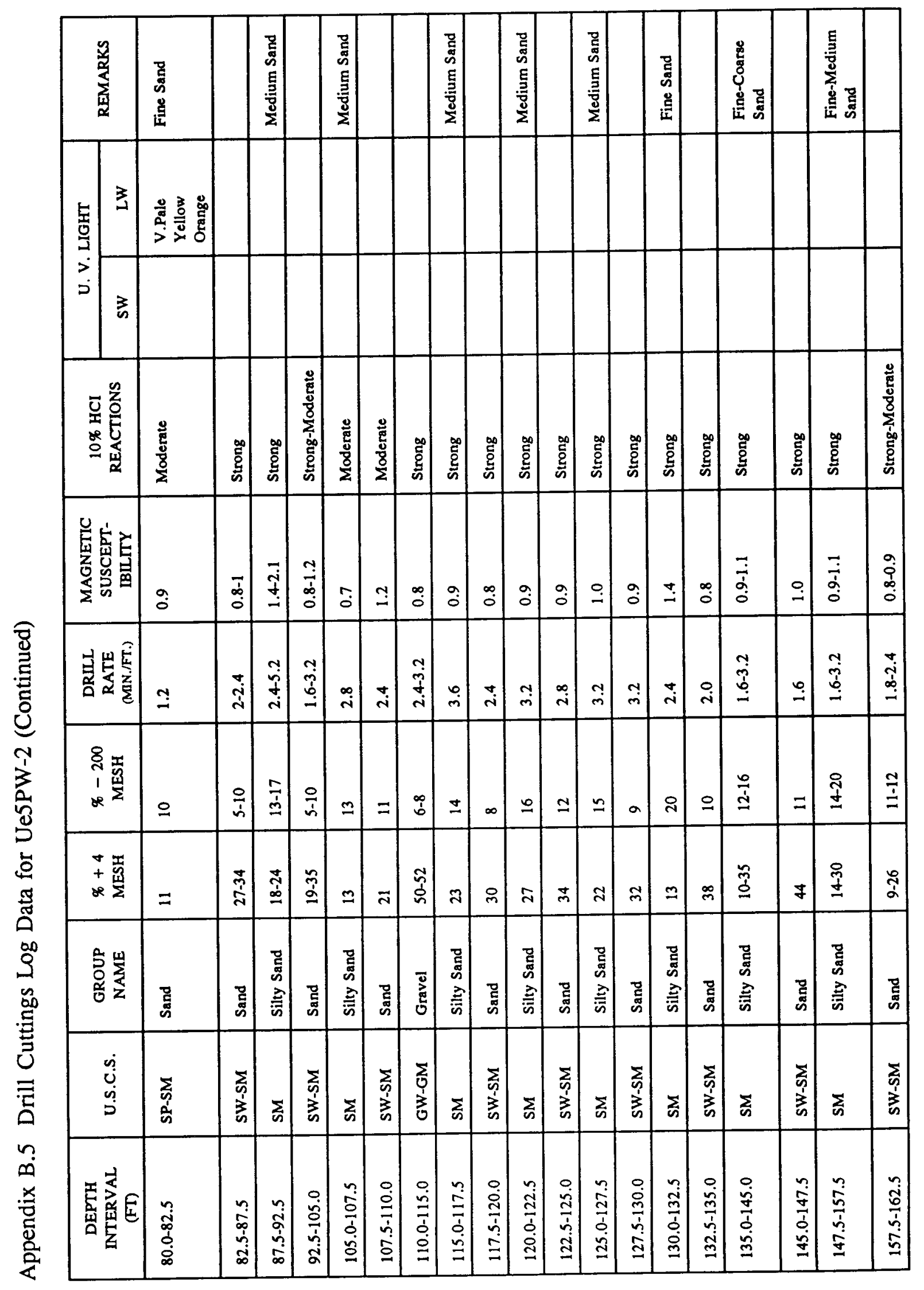




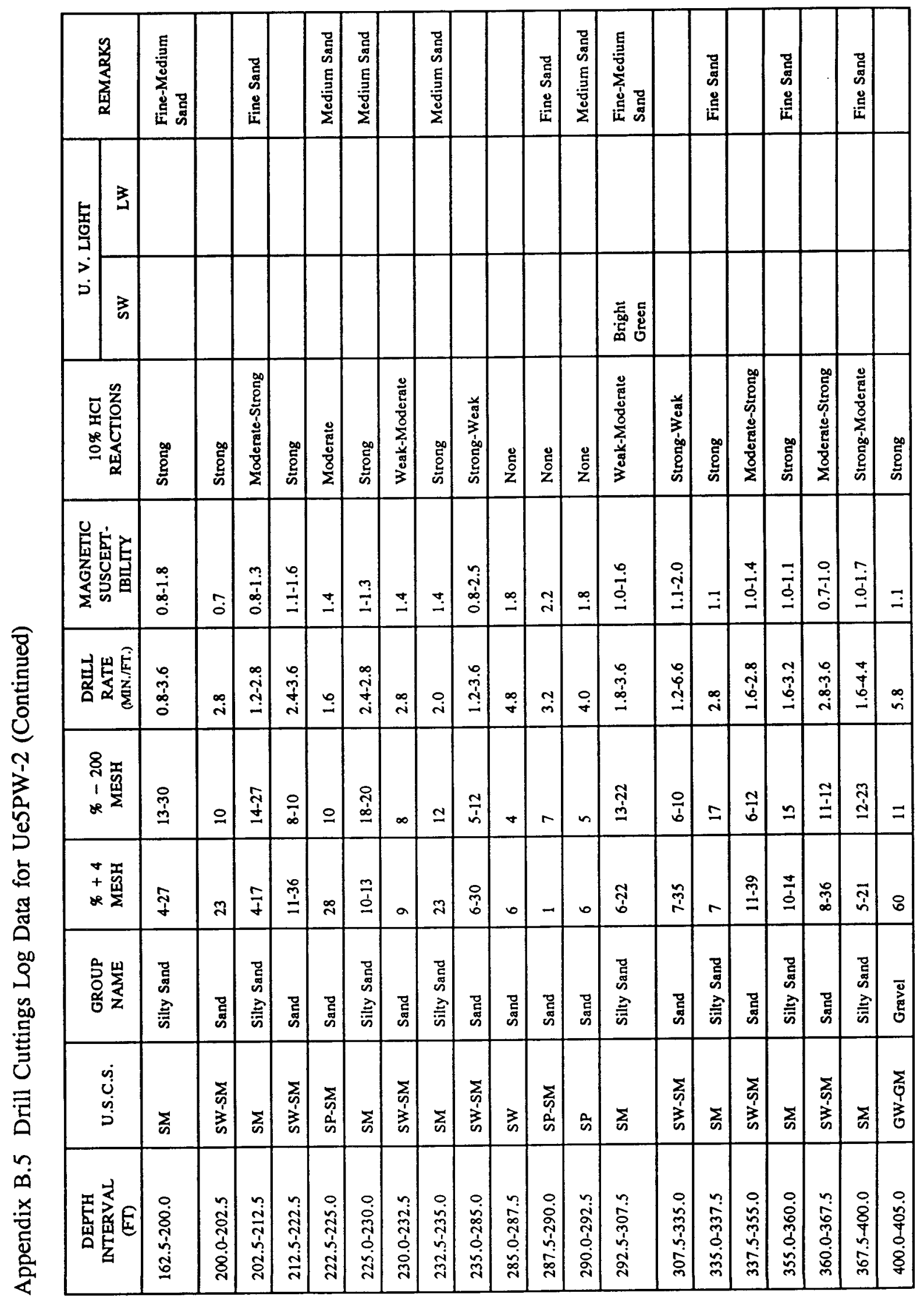




\begin{tabular}{|c|c|c|c|c|c|c|c|c|c|c|c|c|c|c|}
\hline$\frac{2}{2}$ & 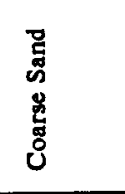 & & | & & 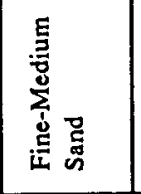 & & 煦 & 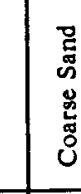 & & & 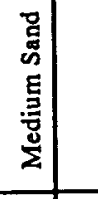 & 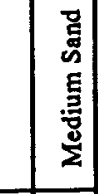 & & 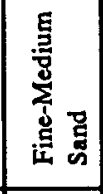 \\
\hline 题 & 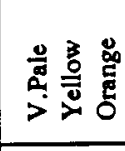 & & & 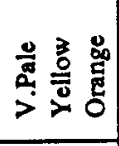 & 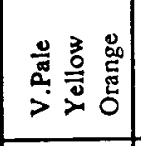 & & & & & & & & 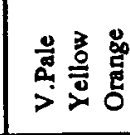 & 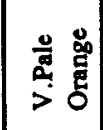 \\
\hline $\begin{array}{ll}2 \\
5\end{array}$ & 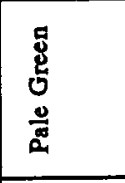 & & & 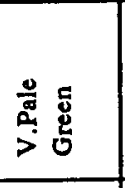 & 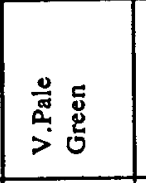 & & & & & & & & 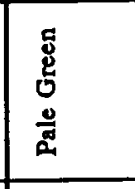 & 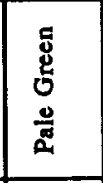 \\
\hline 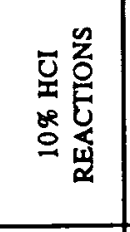 & 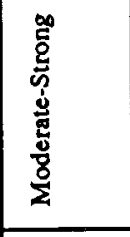 & & & $\begin{array}{c}\frac{0}{5} \\
\frac{2}{5} \\
\end{array}$ & 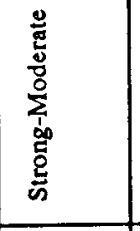 & 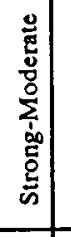 & 紊| & & \begin{tabular}{|l|} 
\\
$\vdots$ \\
$\vdots$ \\
$\vdots$ \\
\end{tabular} & & 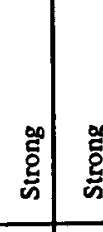 & 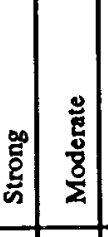 & \begin{tabular}{|l}
0 \\
息 \\
\end{tabular} & \begin{tabular}{|l} 
\\
$\frac{8}{2}$ \\
$\frac{5}{8}$ \\
$\frac{1}{2}$ \\
\end{tabular} \\
\hline 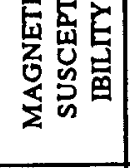 & \begin{tabular}{|l|l} 
\\
\\
\\
\end{tabular} & $\exists$ & 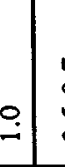 & 厗 & $a$ & 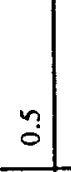 & : & : & $:$ & $\begin{array}{l}3 \\
\vdots \\
\vdots \\
\end{array}$ & $\exists:$ & $\begin{array}{ccc} & \overrightarrow{1} \\
\dot{0} & 0 \\
\end{array}$ & $\vec{i}$ & \begin{tabular}{|l} 
\\
$\dot{0}$ \\
0
\end{tabular} \\
\hline 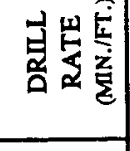 & 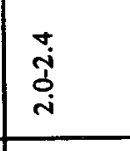 & . & : & $\stackrel{0}{-}$ & 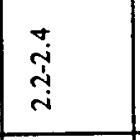 & $\stackrel{m}{m}$ & $\begin{array}{c} \\
\end{array}$ & 立. & $\cong$ & & i & ت & 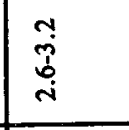 & 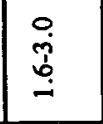 \\
\hline 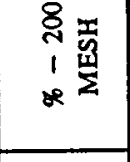 & $\stackrel{m}{\dot{\Xi}}$ & a & $=$ & $\frac{0}{1}$ & 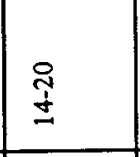 & $\approx$ & $\simeq$ & 히 $=$ & $\infty$ & $\overline{2}$ & $\approx=$ & $=9$ & $\overline{\bar{g}}$ & $\stackrel{\Xi}{ \pm}$ \\
\hline 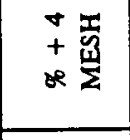 & $\infty$ & 7 & $\therefore$ & 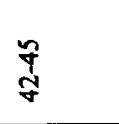 & \begin{tabular}{|l}
$\tilde{y}$ \\
$\bar{n}$
\end{tabular} & $\approx$ & $\vec{m}$ & 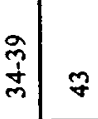 & $\infty$ & : & $\therefore$ & 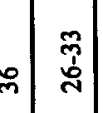 & 总 & 象 \\
\hline 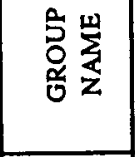 & 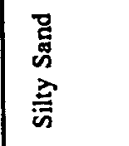 & 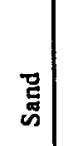 & 离 & 胥 & 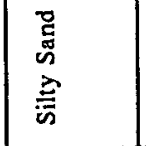 & 离 & 离 & & 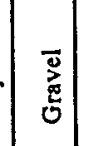 & & 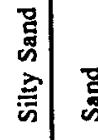 & 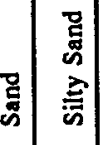 & 总 & 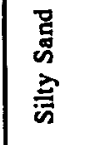 \\
\hline 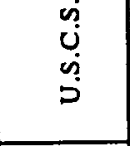 & $\Sigma$ & $\begin{array}{c}\frac{2}{0} \\
\vdots \\
\vdots\end{array}$ & $\Sigma$ & 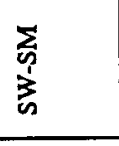 & $\Sigma_{0}$ & \begin{tabular}{|l}
$n$ \\
0 \\
$\vdots$ \\
$n$
\end{tabular} & $\Sigma$ & $\begin{array}{l}\Sigma \\
\vdots \\
\vdots \\
\vdots\end{array}$ & \begin{tabular}{|l|} 
\\
0 \\
0 \\
0 \\
\end{tabular} & $\begin{array}{l}\bar{y} \\
\vdots \\
\vdots \\
0\end{array}$ & 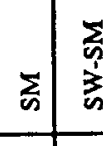 & 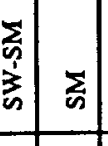 & \begin{tabular}{|l} 
\\
$\vdots$ \\
$\vdots$ \\
$\vdots$ \\
\end{tabular} & 望 \\
\hline 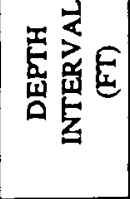 & 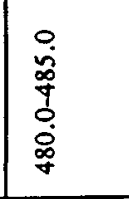 & 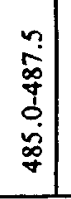 & $\begin{array}{l}0 \\
\vdots \\
\vdots \\
\vdots \\
\vdots \\
\vdots \\
\vdots \\
\vdots\end{array}$ & $\begin{array}{l}\dot{\dot{\alpha}} \\
\hat{q} \\
\dot{0} \\
\dot{\alpha} \\
\dot{\alpha}\end{array}$ & 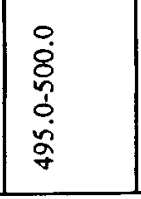 & $\begin{array}{l}0 \\
\vdots \\
0 \\
0 \\
0 \\
\vdots \\
\vdots\end{array}$ & 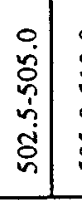 & 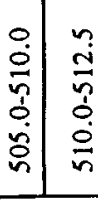 & 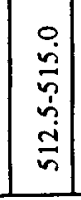 & 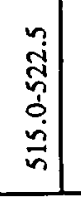 & 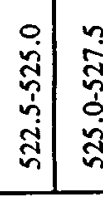 & 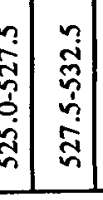 & 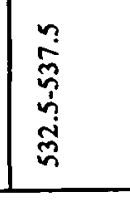 & 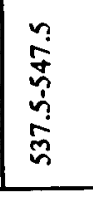 \\
\hline
\end{tabular}




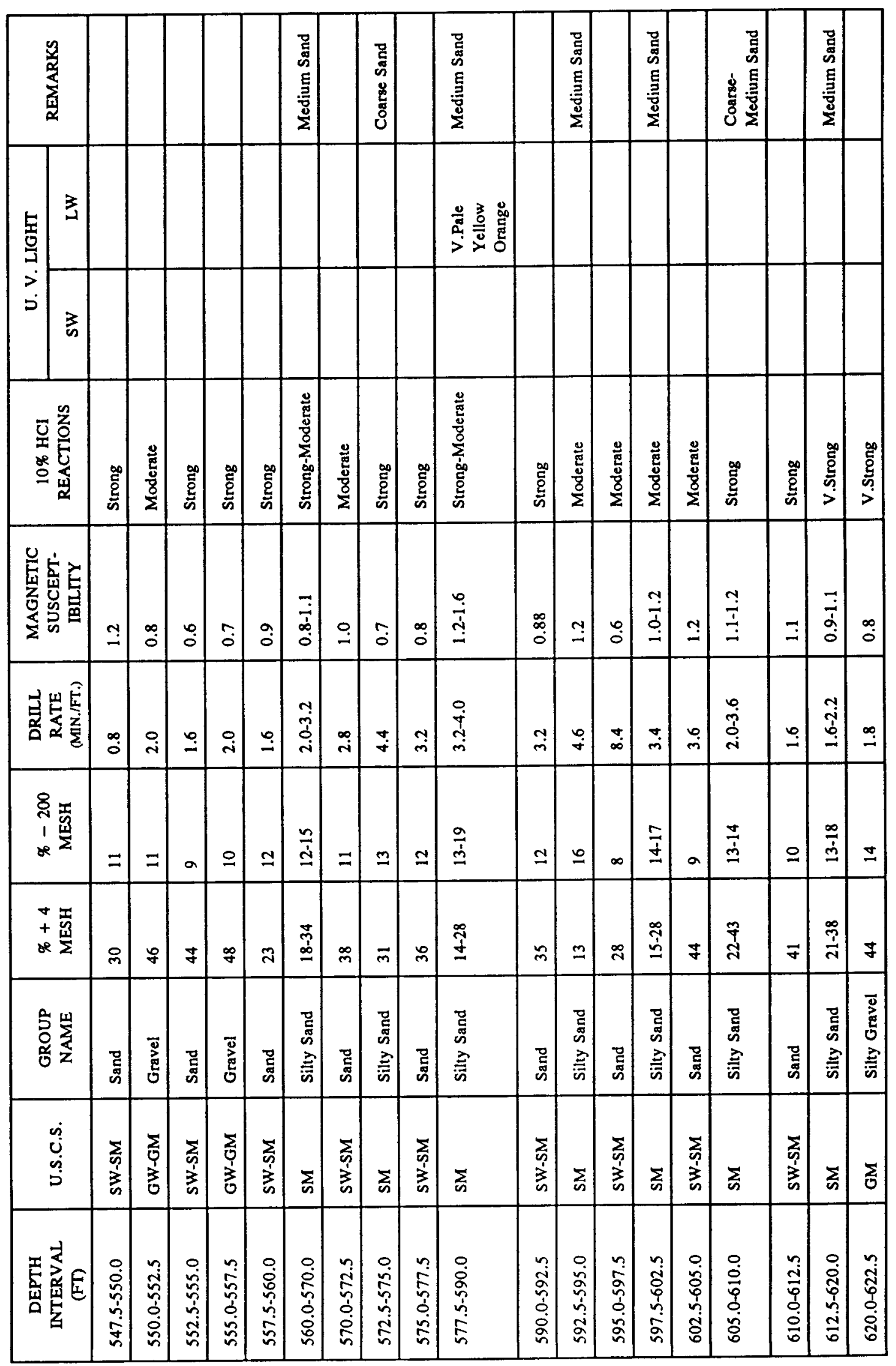




\begin{tabular}{|c|c|c|c|c|c|c|c|c|c|c|c|c|c|c|c|c|}
\hline 商 & & 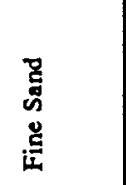 & & & & & & 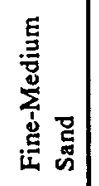 & & & 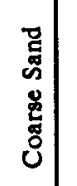 & & 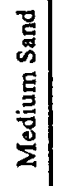 & & 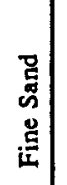 & \\
\hline \begin{tabular}{l|l} 
& 3 \\
5 & \\
\end{tabular} & & $\begin{array}{l}\frac{0}{a} \\
>\end{array}$ & & 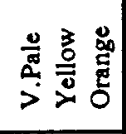 & & & & & & & & & & & & 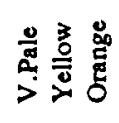 \\
\hline $\begin{array}{ll}3 \\
\dot{3}\end{array}$ & & & & 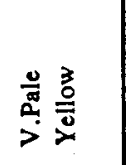 & & & & & & & & & & & & 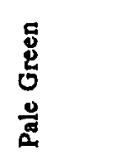 \\
\hline 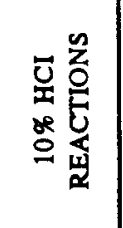 & 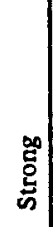 & 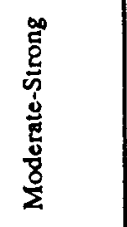 & 品 & 总 & 品 & $\begin{array}{l}0 \\
\vdots \\
\vdots \\
\vdots \\
5\end{array}$ & 总 & 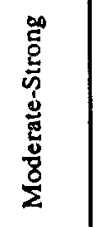 & $\begin{array}{l}\text { 品 } \\
\text { : } \\
\text { के }\end{array}$ & 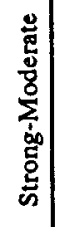 & 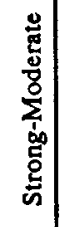 & $\begin{array}{l}\infty \\
\stackrel{\infty}{5} \\
\stackrel{5}{5}\end{array}$ & 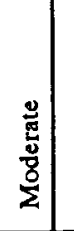 & 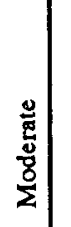 & 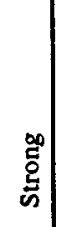 & 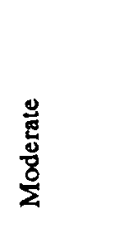 \\
\hline 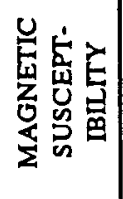 & $\ddot{o}$ & $\stackrel{+}{\dot{d}}$ & $\stackrel{+}{0}$ & $\stackrel{\infty}{0}$ & $\because$ & $\begin{array}{l}\infty \\
0 \\
\vdots \\
0\end{array}$ & $\stackrel{-}{-}$ & 柋 & $\stackrel{0}{-1}$ & $=1$ & $\begin{array}{l}0 \\
\dot{a} \\
\dot{0} \\
0\end{array}$ & $\stackrel{\Upsilon}{-}$ & $\dot{o}$ & $\ddot{o}$ & $a$ & $\stackrel{ \pm}{\leftrightarrows}$ \\
\hline 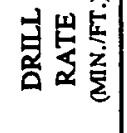 & $\stackrel{0}{\dot{m}}$ & $\begin{array}{l}0 \\
\dot{y} \\
\dot{i}\end{array}$ & $\stackrel{0}{-1}$ & $\stackrel{\circ}{\dot{m}}$ & $\stackrel{\infty}{-}$ & 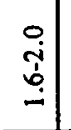 & $\stackrel{0}{i}$ & $\stackrel{\stackrel{0}{i}}{\stackrel{I}{I}}$ & $\cong$ & $\stackrel{\circ}{i}$ & $\begin{array}{l}\stackrel{0}{i} \\
\stackrel{i}{i}\end{array}$ & $\begin{array}{l}\infty \\
\vdots \\
\vdots\end{array}$ & $\stackrel{\simeq}{=}$ & $\stackrel{+}{i}$ & $\stackrel{\circ}{i}$ & $\stackrel{\circ}{-}$ \\
\hline 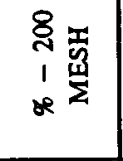 & $=$ & $\stackrel{\check{2}}{=}$ & 0 & 으 & $n$ & $\overline{\overline{0}}$ & $a$ & $\bar{I}$ & $\simeq$ & $\bar{\Xi}$ & $\simeq$ & $=$ & $=$ & 오 & $\stackrel{0}{-}$ & $\infty$ \\
\hline $\begin{array}{l}+\frac{T}{3} \\
+\frac{3}{2} \\
0\end{array}$ & $\mathcal{F}$ & ปั & $\approx$ & Z & 8 & $\begin{array}{l}\approx \\
\grave{2} \\
\tilde{n}\end{array}$ & $g$ & \& & 7 & $\begin{array}{l}0 \\
\grave{1} \\
\dot{p}\end{array}$ & $\begin{array}{c}\hat{0} \\
\hat{n} \\
\tilde{m}\end{array}$ & 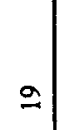 & $\vec{\lambda}$ & $\vec{n}$ & $\approx$ & 욤 \\
\hline 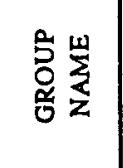 & 营 & 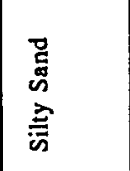 & 离 & 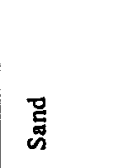 & $\begin{array}{l}\bar{D} \\
\stackrel{5}{5}\end{array}$ & 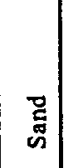 & $\begin{array}{l}\text { Dे } \\
\text { 胥 } \\
0\end{array}$ & 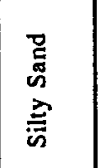 & $\begin{array}{l}\overrightarrow{0} \\
\vec{D} \\
\end{array}$ & 总 & 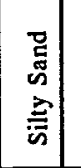 & 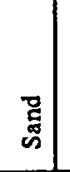 & 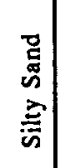 & $\begin{array}{l}\overline{\mathbf{D}} \\
\overrightarrow{\mathrm{D}} \\
\mathrm{E}\end{array}$ & 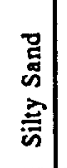 & 熙 \\
\hline 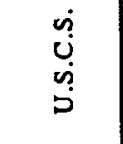 & $\begin{array}{l}\sum_{n} \\
\vdots \\
\vdots \\
\vdots\end{array}$ & $\sum_{n}$ & $\begin{array}{l}\sum \\
0 \\
\vdots \\
\vdots \\
0\end{array}$ & $\begin{array}{l}\sum_{0}^{5} \\
\vdots \\
\sum_{n}\end{array}$ & $\begin{array}{l}\Sigma \\
0 \\
⿱ 亠 䒑 \\
0\end{array}$ & $\begin{array}{l}\Sigma \\
\vdots \\
\vdots \\
\vdots \\
n\end{array}$ & $\begin{array}{l}\Sigma \\
\vdots \\
\vdots \\
\vdots \\
0\end{array}$ & $\sum_{n}$ & $\begin{array}{l}\Sigma \\
0 \\
\vdots \\
0 \\
0\end{array}$ & $\begin{array}{l}\sum_{0} \\
\vdots \\
\vdots \\
\vdots \\
n\end{array}$ & $\sum$ & $\begin{array}{l}\sum_{\infty} \\
⿱ 亠 䒑 \\
\vdots \\
\vdots\end{array}$ & $\sum_{\infty}$ & $\begin{array}{l}\Sigma \\
\vdots \\
\vdots \\
0 \\
0\end{array}$ & $\Sigma$ & $\sum_{0}^{n}$ \\
\hline 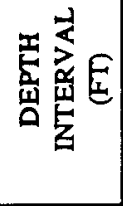 & $\begin{array}{l}n \\
\vdots \\
\vdots \\
\vdots \\
\vdots \\
\dot{\zeta}\end{array}$ & 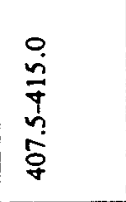 & 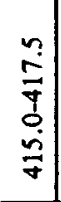 & 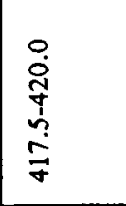 & 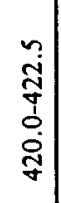 & 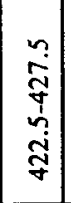 & \begin{tabular}{c}
0 \\
$\dot{0}$ \\
$\tilde{y}$ \\
$\sim$ \\
\cline { 1 - 1 } \\
$y$
\end{tabular} & 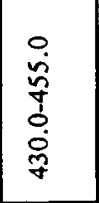 & $\begin{array}{l}n \\
\vdots \\
y \\
0 \\
\dot{y} \\
y\end{array}$ & $\begin{array}{c}n \\
i \\
0 \\
\vdots \\
\vdots \\
\vdots \\
5 \\
y\end{array}$ & $\begin{array}{c}n \\
5 \\
0 \\
\vdots \\
\vdots \\
0 \\
0\end{array}$ & $\begin{array}{c}0 \\
0 \\
5 \\
5 \\
\vdots \\
\vdots \\
0 \\
0\end{array}$ & 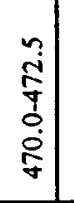 & $\begin{array}{c}0 \\
\dot{L} \\
\dot{q} \\
\tilde{n} \\
\tilde{\sigma} \\
\dot{\sigma}\end{array}$ & $\begin{array}{c}n \\
r \\
\dot{y} \\
0 \\
\dot{q} \\
\dot{q}\end{array}$ & 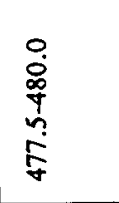 \\
\hline
\end{tabular}




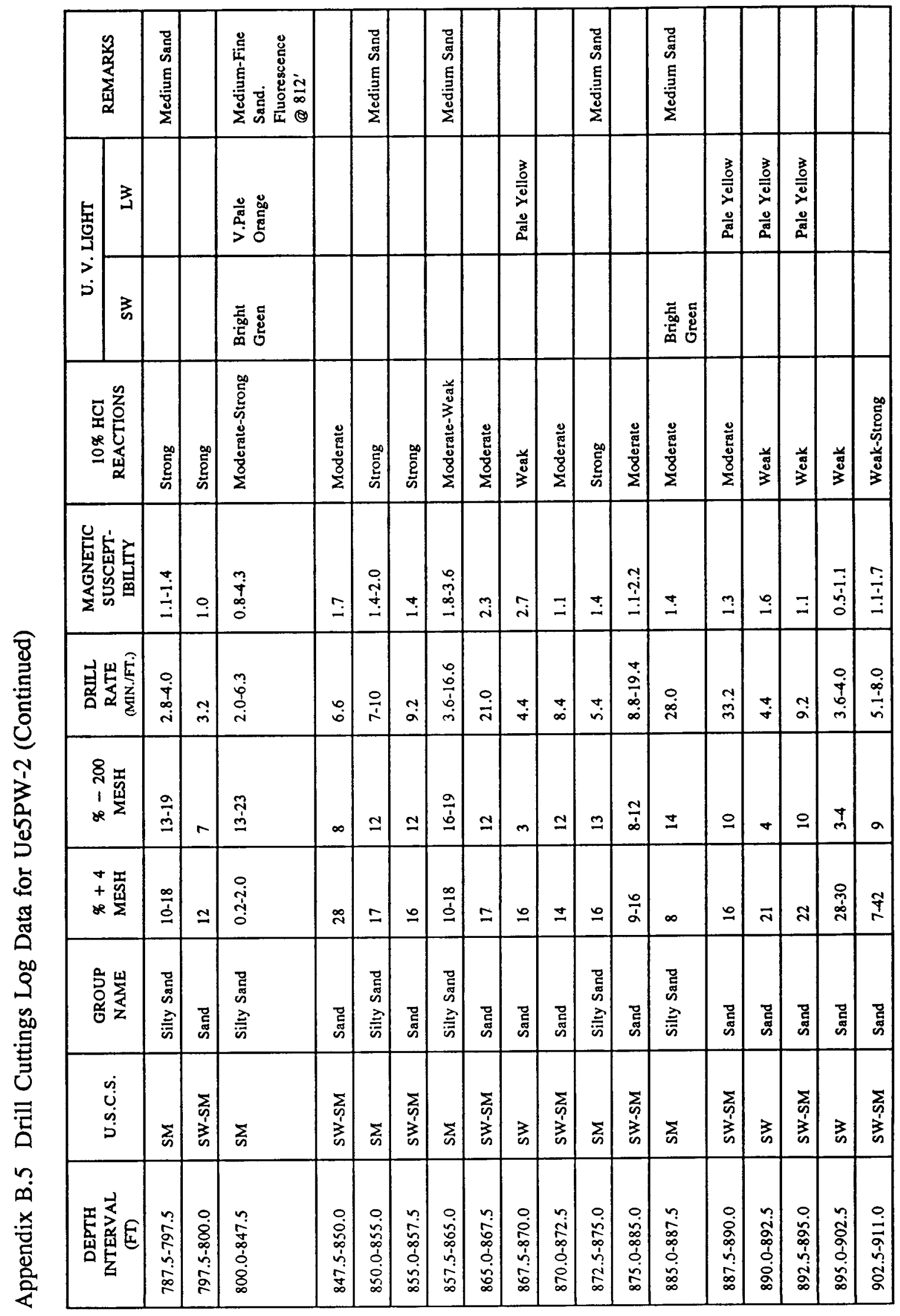




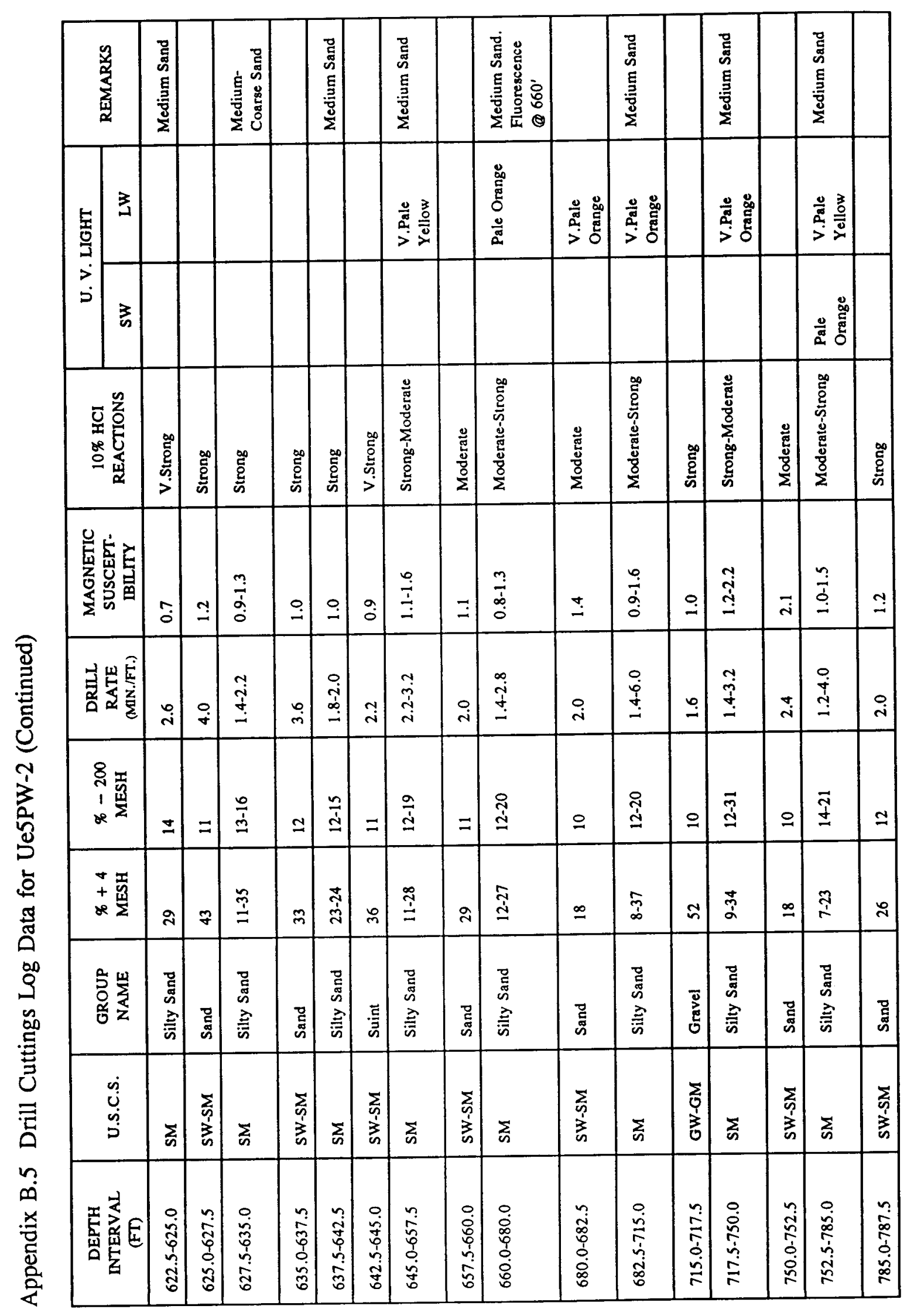




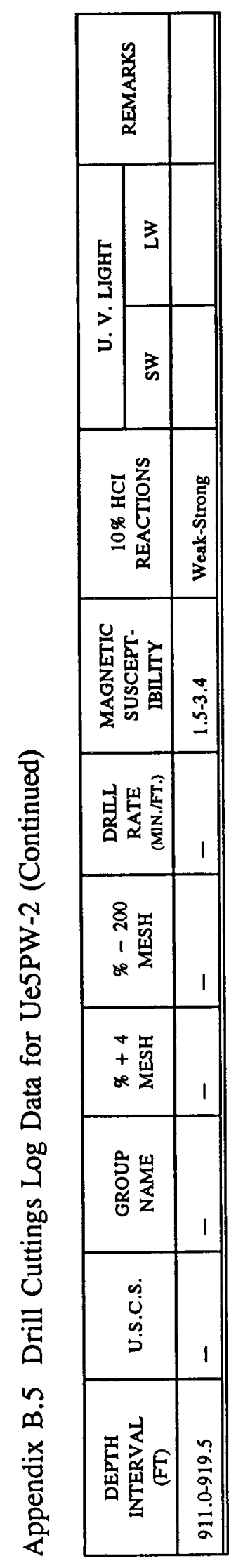




\begin{tabular}{|c|c|c|c|c|c|c|c|c|c|c|c|c|c|c|c|}
\hline 䈉 & & & & 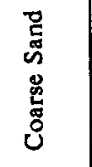 & & & & & & & 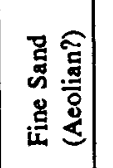 & & 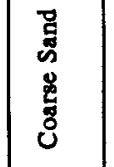 & & \\
\hline & 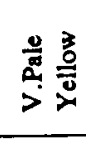 & 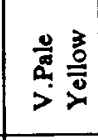 & 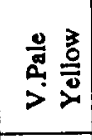 & 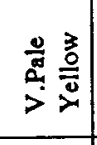 & 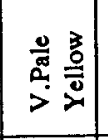 & 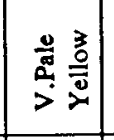 & 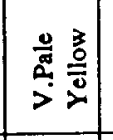 & 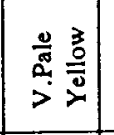 & 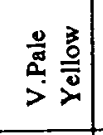 & 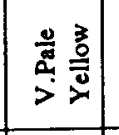 & 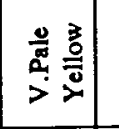 & 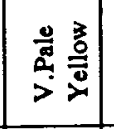 & 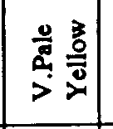 & & \\
\hline$\dot{3} \mid \frac{3}{n}$ & 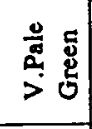 & 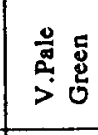 & 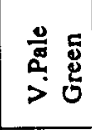 & 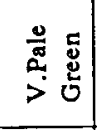 & 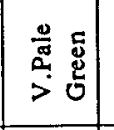 & 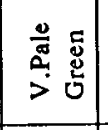 & 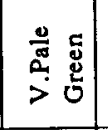 & 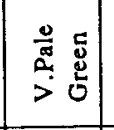 & 1 & 1 & 1 & 1 & 1 & & \\
\hline 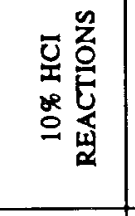 & 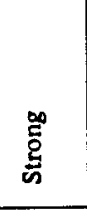 & \begin{tabular}{|l}
$\frac{0}{2}$ \\
$\frac{8}{8}$ \\
$\frac{8}{2}$ \\
\end{tabular} & 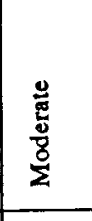 & 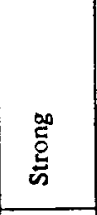 & \begin{tabular}{|l}
0 \\
$\frac{0}{5}$ \\
0
\end{tabular} & 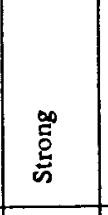 & 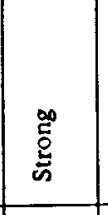 & 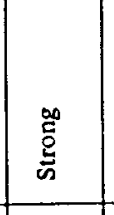 & 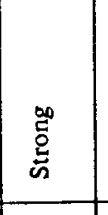 & \begin{tabular}{|l} 
\\
\\
\end{tabular} & 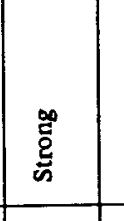 & \begin{tabular}{|l} 
\\
$\vdots$ \\
$\vdots$ \\
0
\end{tabular} & \begin{tabular}{|l|} 
\\
\\
$\frac{5}{5}$ \\
\end{tabular} & & $\begin{array}{l}\frac{2}{2} \\
\frac{2}{2} \\
\end{array}$ \\
\hline 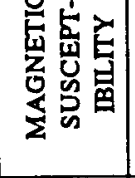 & $\stackrel{3}{\vec{I}}$ & $I$ & $\equiv$ & $\stackrel{9}{-}$ & $\stackrel{9}{-1}$ & $\stackrel{-}{i}$ & $\Xi$ & $\stackrel{\infty}{0}$ & \pm & $\begin{array}{ll}7 \\
0 \\
0 \\
0 \\
0\end{array}$ & \begin{tabular}{|l}
3 \\
$\dot{a}$ \\
0 \\
0 \\
\end{tabular} & 9 & $\exists$ & & $\stackrel{-}{-}$ \\
\hline 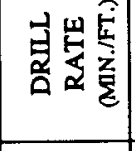 & $I$ & $\underset{\text { i }}{\infty}$ & $\cong$ & I & $\underset{i}{i}$ & $\stackrel{\circ}{-}$ & $\stackrel{i}{i}$ & $\stackrel{\circ}{-}$ & z & \begin{tabular}{|l} 
\\
a \\
0 \\
\end{tabular} & 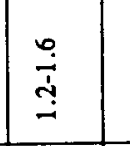 & $\infty$ & 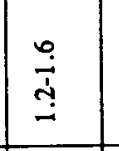 & & i. \\
\hline 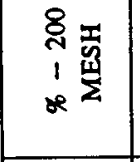 & $\overline{\vec{n}}$ & $m$ & - & 9 & I- & m & $\Omega$ & $\simeq$ & $n$ & $\overline{\vec{b}}$ & 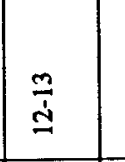 & $a$ & $\stackrel{\stackrel{m}{\Xi}}{\dot{I}}$ & & $\infty$ \\
\hline 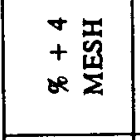 & ב. & \pm & $F$ & $\approx$ & 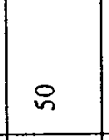 & $\approx$ & $\tilde{n}$ & 2 & 8 & \begin{tabular}{|l}
0 \\
0 \\
0 \\
0
\end{tabular} & \begin{tabular}{|l|l|}
\multirow{2}{*}{} \\
\end{tabular} & 9 & 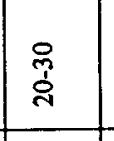 & & 2 \\
\hline 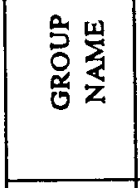 & 总 & 竎 & 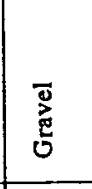 & 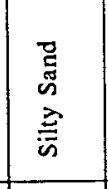 & 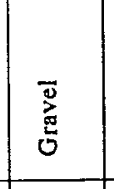 & 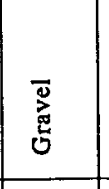 & 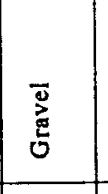 & \begin{tabular}{|l} 
\\
离 \\
\end{tabular} & 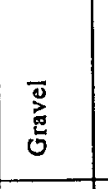 & 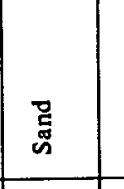 & 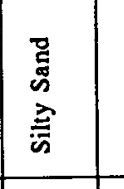 & \begin{tabular}{|l} 
\\
\\
\end{tabular} & 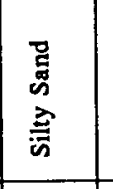 & 离 & 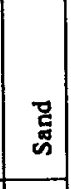 \\
\hline $\begin{array}{l}\dot{g} \\
\dot{u} \\
\dot{j} \\
\dot{j}\end{array}$ & 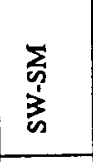 & 3 & \begin{tabular}{|l} 
\\
0 \\
0 \\
$\vdots$ \\
\end{tabular} & $\Sigma_{\Sigma}$ & \begin{tabular}{|l}
5 \\
0 \\
0 \\
0 \\
\end{tabular} & i & \begin{tabular}{|l} 
\\
0 \\
$\vdots$ \\
\\
\end{tabular} & 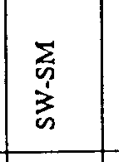 & \begin{tabular}{|l}
5 \\
0 \\
0 \\
0 \\
\end{tabular} & $\begin{array}{l}\text { 离 } \\
\text { 音 } \\
\end{array}$ & \begin{tabular}{|l|} 
\\
\end{tabular} & 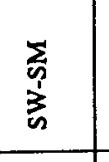 & $\Sigma_{n}$ & & \begin{tabular}{|c|}
5 \\
0 \\
$\vdots$ \\
$\vdots$ \\
\end{tabular} \\
\hline 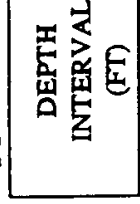 & \begin{tabular}{|l} 
\\
$\vdots$ \\
0 \\
0 \\
0 \\
\end{tabular} & 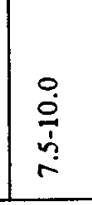 & 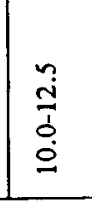 & 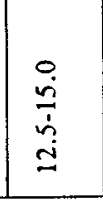 & 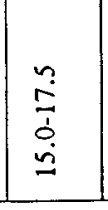 & 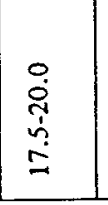 & 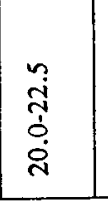 & 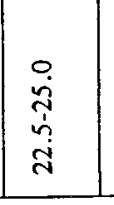 & 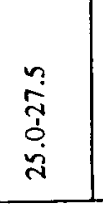 & 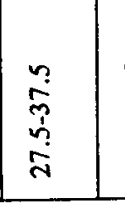 & 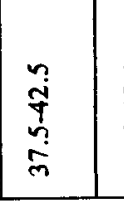 & 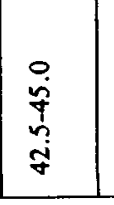 & 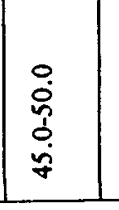 & & \\
\hline
\end{tabular}




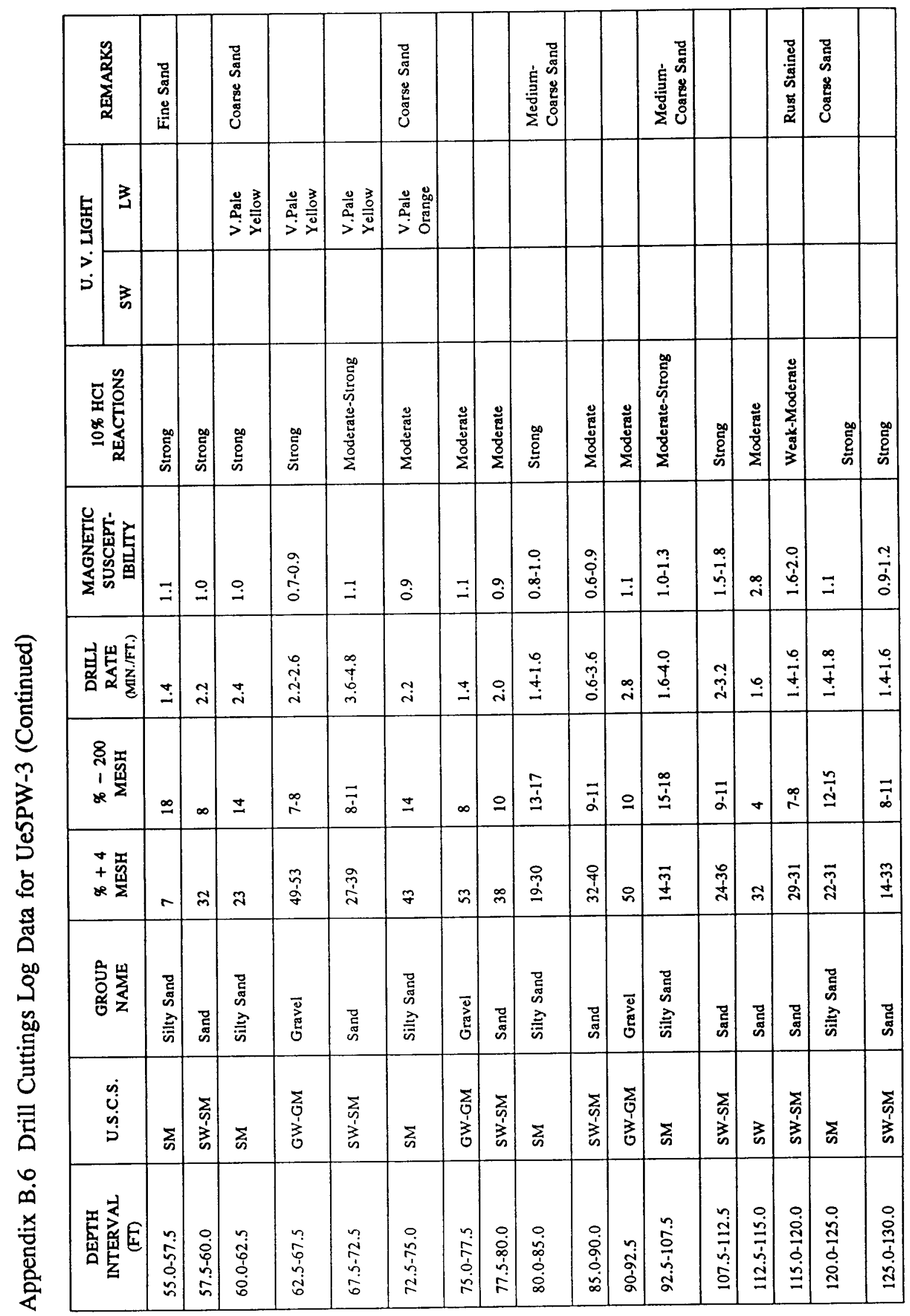




\begin{tabular}{|c|c|c|c|c|c|c|c|c|c|c|c|c|c|c|c|c|c|}
\hline$\frac{2}{2}$ & & & & & & & & 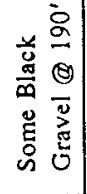 & & 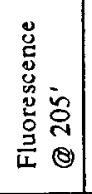 & & & 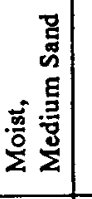 & 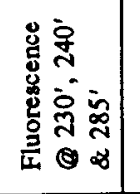 & & & \\
\hline & & & & & & & & & & 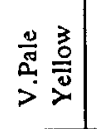 & & & & 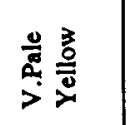 & & & 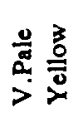 \\
\hline 3 & & & & & & & & & & & & & & 善㺃 & & & \\
\hline 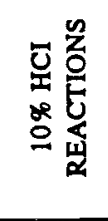 & $\begin{array}{l}\frac{\pi}{\mathrm{s}} \\
\frac{\mathrm{s}}{2} \\
\end{array}$ & 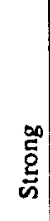 & & $\begin{array}{l}\frac{0}{0} \\
\frac{0}{2}\end{array}$ & $\frac{2}{\bar{n}}$ & 竞 & 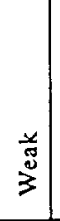 & $\begin{array}{l}\text { 总 } \\
\frac{3}{3}\end{array}$ & & 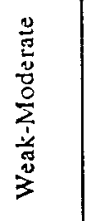 & & 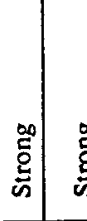 & 惫 & 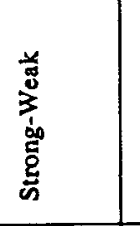 & 兽 & & 噌 \\
\hline 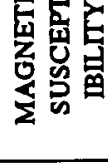 & ث̊. & பே. & $\stackrel{-}{-}$ & $\begin{array}{l}\vec{y} \\
\dot{y}\end{array}$ & $\because$ & | & $\vec{i}$ & 孚 & $\stackrel{\infty}{-}$ & $\underset{\substack{\hat{j} \\
\dot{\alpha}}}{-}$ & $\pi$ & 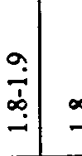 & $\stackrel{\infty}{-}$ & 官 & $\stackrel{\circ}{\circ}$ & & 㐫 \\
\hline 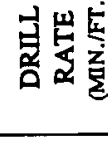 & 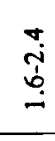 & ㅇ. & 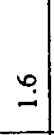 & $\begin{array}{c}7 \\
\text { î } \\
\text { - }\end{array}$ & $\cong$ & - & i) & 节 & i & 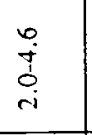 & $\stackrel{i}{i}$ & 叫 & 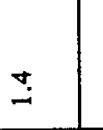 & 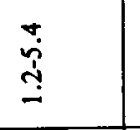 & 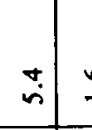 & & $\underset{j}{ \pm}$ \\
\hline 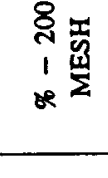 & + & $i$ & $m$ & $\begin{array}{l}0 \\
\vdots \\
\vdots\end{array}$ & $n$ & $\vec{b}$ & $n$ & $\begin{array}{l}\infty \\
\vdots \\
0\end{array}$ & $n$ & $\frac{0}{n}$ & $n$ & $\therefore=$ & 9 & $\overline{\bar{n}}$ & 0 & & $\hat{b}$ \\
\hline 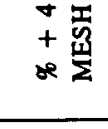 & ב. & $\frac{d}{\mathcal{Z}}$ & 8 & \begin{tabular}{|c|c} 
\\
\hdashline \\
\end{tabular} & $a$ & $\begin{array}{ll}0 \\
:\end{array}$ & $\simeq$ & 号 & 8 & F & $\approx$ & $\stackrel{9}{\stackrel{9}{4}}=$ & 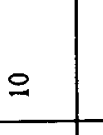 & $\hat{i}$ & $=$ & & $\underset{2}{\infty}$ \\
\hline 蓉宸 & 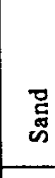 & 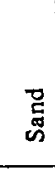 & 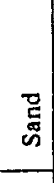 & \begin{tabular}{|l|} 
\\
$\vdots$ \\
\\
\end{tabular} & & 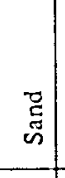 & 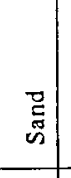 & $\begin{array}{l}\text { 总 } \\
\text { D. } \\
\end{array}$ & 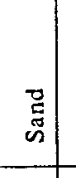 & 总 & \begin{tabular}{c|c}
0 \\
$\vdots$ \\
$\vdots$
\end{tabular} & 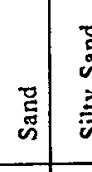 & 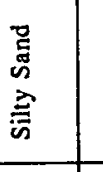 & 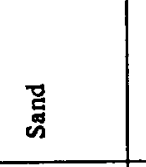 & 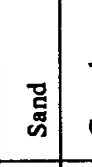 & & 莴 \\
\hline 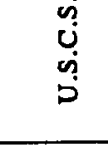 & 3 & $\begin{array}{l}\Sigma \\
\vdots \\
\vdots \\
\vdots \\
\vdots\end{array}$ & 莕 & \begin{tabular}{|l|} 
\\
$\vdots$ \\
$\vdots$ \\
$\vdots$
\end{tabular} & 3 & $\begin{array}{l}0 \\
\vdots \\
\vdots \\
\vdots \\
\end{array}$ & $\geqslant$ & $\begin{array}{l}\bar{n} \\
\bar{y} \\
\bar{y}\end{array}$ & 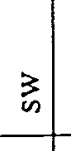 & 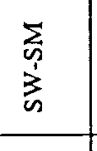 & 童 & \begin{tabular}{c|c}
$\bar{n}$ \\
$\vdots$ \\
$\vdots$ \\
$\vdots$
\end{tabular} & $\sum_{n}^{\Sigma}$ & 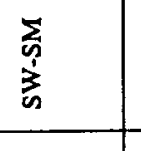 & 咅 & 히 & $\begin{array}{l}\Sigma \\
\bar{n} \\
\vdots \\
\vdots \\
\end{array}$ \\
\hline 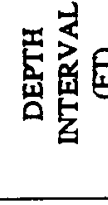 & 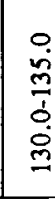 & 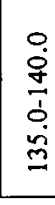 & 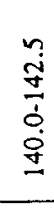 & 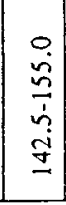 & $\begin{array}{l}n \\
\vdots \\
\vdots \\
\dot{0} \\
\vdots \\
2\end{array}$ & $\mid$ & | & 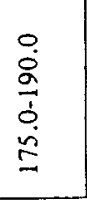 & $\begin{array}{ll} & 0 \\
\vdots \\
\vdots \\
0 \\
0\end{array}$ & 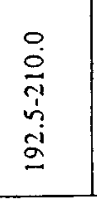 & 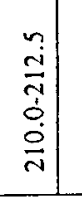 & 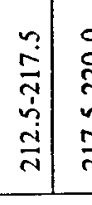 & 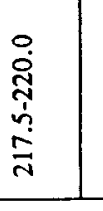 & $\begin{array}{l}\stackrel{0}{0} \\
\overline{0} \\
\dot{8} \\
\text { ते }\end{array}$ & 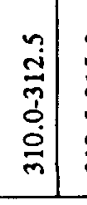 & & 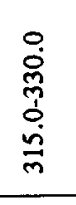 \\
\hline
\end{tabular}




\begin{tabular}{|c|c|c|c|c|c|c|c|c|c|c|c|c|c|c|c|c|c|c|}
\hline 竞 & & & & 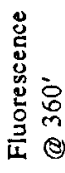 & & & | & & 苟 & & 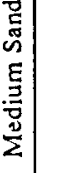 & & & 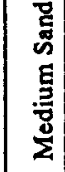 & & 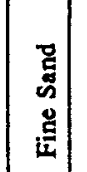 & & \\
\hline & & 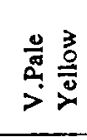 & & 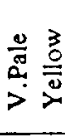 & & & & & & & & & & & 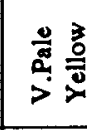 & & 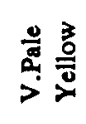 & \\
\hline 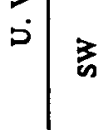 & 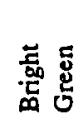 & & & & & & & & & & & & & & 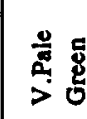 & & & \\
\hline 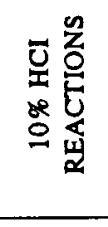 & 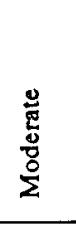 & $\begin{array}{l}\text { 竞 } \\
\frac{0}{5} \\
\end{array}$ & 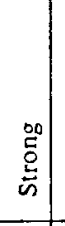 & 总 & $\begin{array}{l}\frac{.}{5} \\
3\end{array}$ & 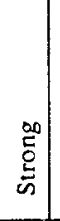 & 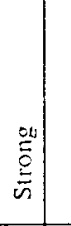 & $\begin{array}{ll}\frac{2}{4} \\
\frac{3}{2} \\
\frac{0}{2}\end{array}$ & 織 & & |ct & 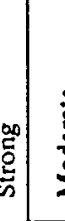 & & 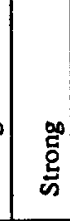 & 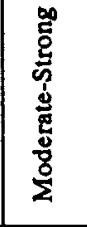 & & 密 & $\mid \begin{array}{l}0 \\
\frac{0}{0} \\
\vdots\end{array}$ \\
\hline 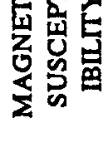 & 9 & $\stackrel{n}{0}$ & \pm & 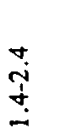 & $=$ & 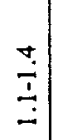 & $\Xi$ & $=$ & 字 & | & & : & \pm & $\stackrel{-}{\prime}$ & $\stackrel{9}{\leftrightarrows}$ & $\mid \begin{array}{l}\stackrel{\sharp}{i} \\
\end{array}$ & 葱 & $\mid \begin{array}{l}0 \\
\vec{b} \\
-1\end{array}$ \\
\hline 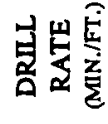 & 立 & 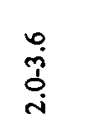 & 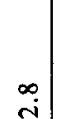 & 芦 & 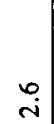 & 它 & | & i & בี & | & & : & ב & ป & 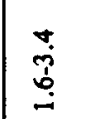 & $\left|\begin{array}{l}\infty \\
\\
\end{array}\right|$ & 京 & 主 \\
\hline 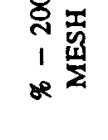 & $\stackrel{\dot{i}}{ }$ & $\hat{\dot{b}}$ & $\simeq$ & ì & 寸 & $\overline{\dot{\alpha}}$ & $\approx$ & $\therefore$ & $\dot{g}$ & $\frac{\stackrel{9}{\alpha}}{\dot{\alpha}}$ & $=:$ & $\dot{\infty}=$ & $\pm \frac{5}{0}$ & $\cong$ & $\overline{\overline{\dot{\omega}}}$ & 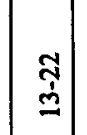 & $\tilde{\tilde{b}}$ & 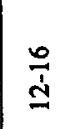 \\
\hline $\begin{array}{l}+\frac{1}{2} \\
+\frac{3}{2} \\
x\end{array}$ & 品 & 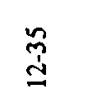 & $n$ & ‡ે & $\pi$ & $\begin{array}{l}\stackrel{\tilde{p}}{\mathfrak{m}} \\
-\end{array}$ & $\approx$ & $\simeq$ & $\approx$ & ڤे. & \pm & $\begin{array}{l}q \\
a \\
a\end{array}$ & $=\stackrel{9}{=}$ & $\simeq$ & $\stackrel{\cong}{\Xi}$ & $\begin{array}{l}5 \\
7\end{array}$ & $\tilde{m}$ & $\begin{array}{c}2 \\
2 \\
\end{array}$ \\
\hline 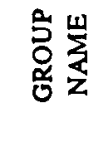 & 总 & $\begin{array}{l}\text { 总 } \\
\text { n. }\end{array}$ & 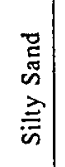 & 总 & 总 & 㤩 & 离 & 㤩 & 总 & 莺 & 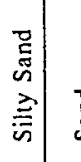 & & 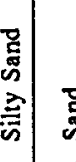 & 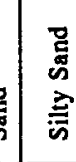 & 袁 & 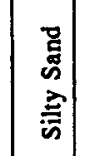 & : & 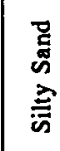 \\
\hline 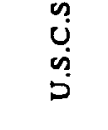 & 吾 & 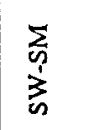 & $\sum_{n}$ & $\begin{array}{l}\bar{y} \\
\overline{1} \\
\bar{y}\end{array}$ & 3 & $\begin{array}{l}\bar{\Sigma} \\
\bar{n} \\
\bar{n} \\
\bar{n}\end{array}$ & $\Sigma_{D}$ & $\begin{array}{l}\bar{n} \\
\vdots \\
\vdots \\
\vdots \\
\vdots\end{array}$ & $\Sigma_{0}^{\Sigma}$ & 竞 & $\sum_{i}^{\Sigma}$ & & $\frac{y}{y}$ & $\Sigma$ & 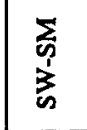 & \begin{tabular}{|l|}
5 \\
0
\end{tabular} & 亦 & $\sum$ \\
\hline 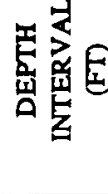 & $\begin{array}{l}\text { 品 } \\
\text { 宽 } \\
\end{array}$ & 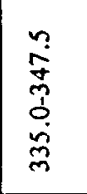 & 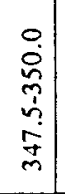 & 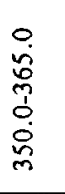 & 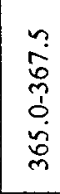 & $\begin{array}{l}0 \\
\infty \\
0 \\
0 \\
0 \\
0\end{array}$ & 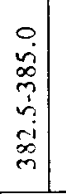 & 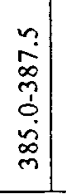 & 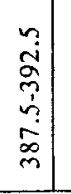 & 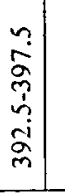 & \begin{tabular}{c|c}
4 \\
$\vdots$ \\
$\vdots$ \\
0
\end{tabular} & 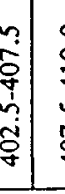 & 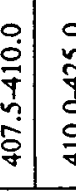 & 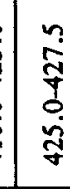 & 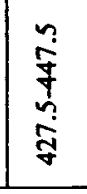 & 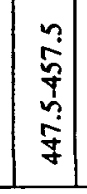 & $\begin{array}{l}0 \\
0 \\
0 \\
4 \\
\vdots \\
5 \\
5 \\
\end{array}$ & $\mid \begin{array}{l}0 \\
0 \\
0 \\
0 \\
0 \\
0\end{array}$ \\
\hline
\end{tabular}




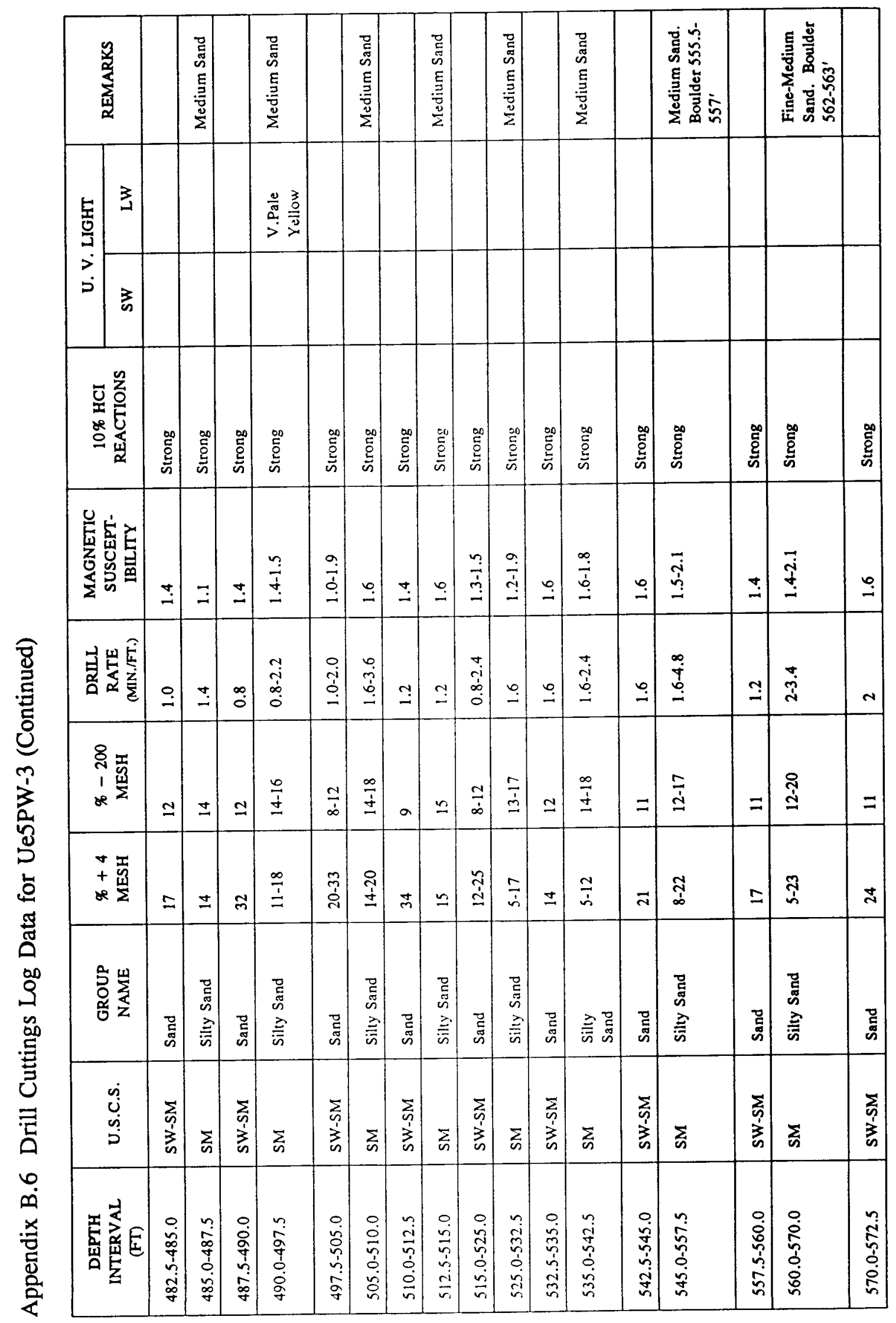




\begin{tabular}{|c|c|c|c|c|c|c|c|c|c|c|c|c|c|c|}
\hline 管 & 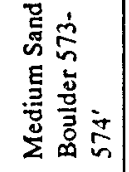 & & 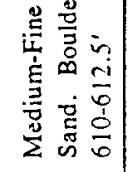 & 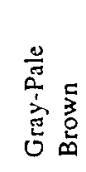 & 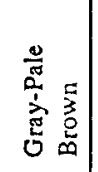 & 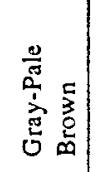 & 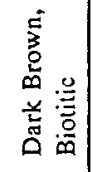 & 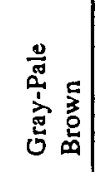 & 变 & 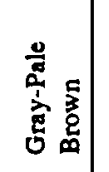 & 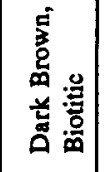 & 胥 & & 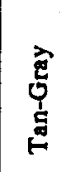 \\
\hline & 产 & 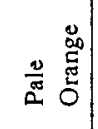 & & 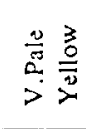 & 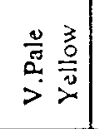 & & & & 品 & $\frac{\mathrm{o}}{\mathrm{a}}$ & & & & \\
\hline 3 & & & & 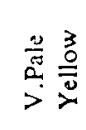 & 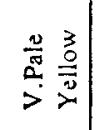 & & & & 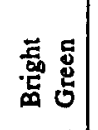 & & & & & \\
\hline 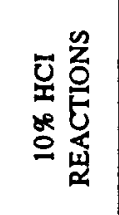 & 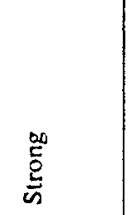 & 噩 & 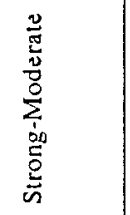 & 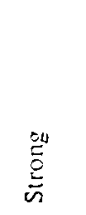 & $\begin{array}{l}\frac{\frac{0}{5}}{\frac{3}{8}} \\
\frac{8}{2}\end{array}$ & 受 & $\frac{\stackrel{2}{5}}{2}$ & 产 & 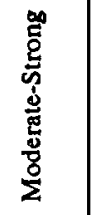 & 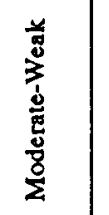 & 总 & $\begin{array}{c}\stackrel{0}{0} \\
\stackrel{0}{2}\end{array}$ & & $\mid \begin{array}{l}\frac{2}{0} \\
\stackrel{2}{2}\end{array}$ \\
\hline 列 & 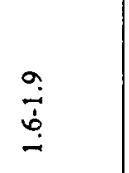 & 寄 & $\stackrel{9}{9}$ & : & $\begin{array}{c}\vec{j} \\
\dot{\alpha} \\
0 \\
0\end{array}$ & 离 & 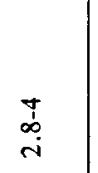 & $\stackrel{\infty}{\vec{I}}$ & ì & $\stackrel{n}{\Xi}$ & 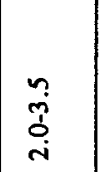 & 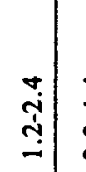 & & 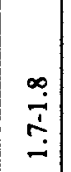 \\
\hline 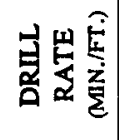 & 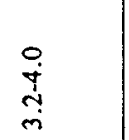 & 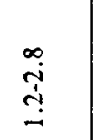 & 亦 & \begin{tabular}{l} 
通 \\
\multirow{I}{*}{}
\end{tabular} & 递 & 审 & 它 & 导 & 苞 & 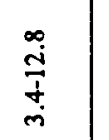 & \begin{tabular}{|l}
$\stackrel{0}{0}$ \\
$\stackrel{0}{0}$ \\
$\stackrel{0}{0}$
\end{tabular} & 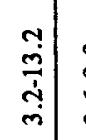 & & $\mid$ \\
\hline 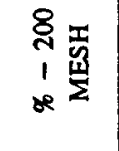 & $\stackrel{\vec{J}}{\dot{\rho}}$ & $a$ & $\stackrel{\circ}{\dot{j}}$ & & & & & & & & & & & \\
\hline $\begin{array}{l}+\frac{x}{2} \\
+\frac{5}{2} \\
x\end{array}$ & $\tilde{I}$ & i & సू & & & & & & & & & & & \\
\hline 岂崖 & 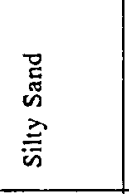 & 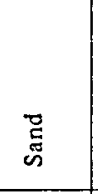 & 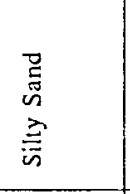 & 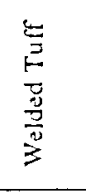 & $\begin{array}{l}\text { 言 } \\
\frac{8}{8} \\
\frac{8}{3} \\
\frac{3}{3}\end{array}$ & 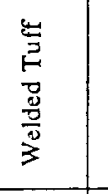 & 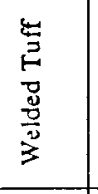 & 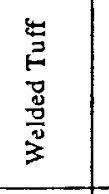 & 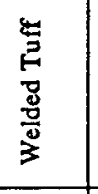 & 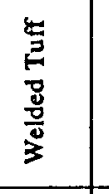 & 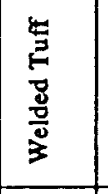 & 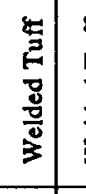 & & \begin{tabular}{|l|} 
\\
$\frac{n}{2}$ \\
$\frac{2}{3}$ \\
$\frac{3}{3}$ \\
\end{tabular} \\
\hline 岁 & $\Sigma$ & 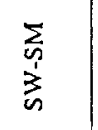 & $\bar{\Sigma}$ & 1 & 1 & 1 & 1 & 1 & 1 & 1 & 1 & & & 1 \\
\hline 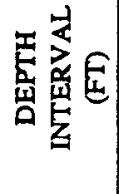 & 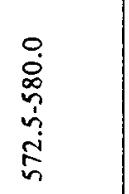 & 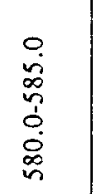 & 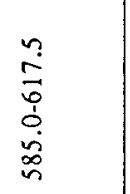 & 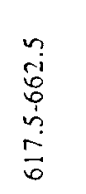 & $\begin{array}{c}n \\
0 \\
0 \\
\vdots \\
0 \\
0 \\
0\end{array}$ & $\begin{array}{l}\text { : } \\
\dot{0} \\
\dot{0} \\
0 \\
0\end{array}$ & $\begin{array}{l}\stackrel{0}{0} \\
\dot{0} \\
0 \\
0 \\
0\end{array}$ & $\begin{array}{l}\text { तें } \\
\text { d. } \\
\stackrel{0}{\circ}\end{array}$ & 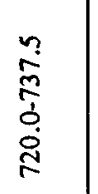 & 总 & 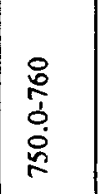 & & & 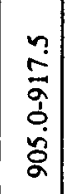 \\
\hline
\end{tabular}




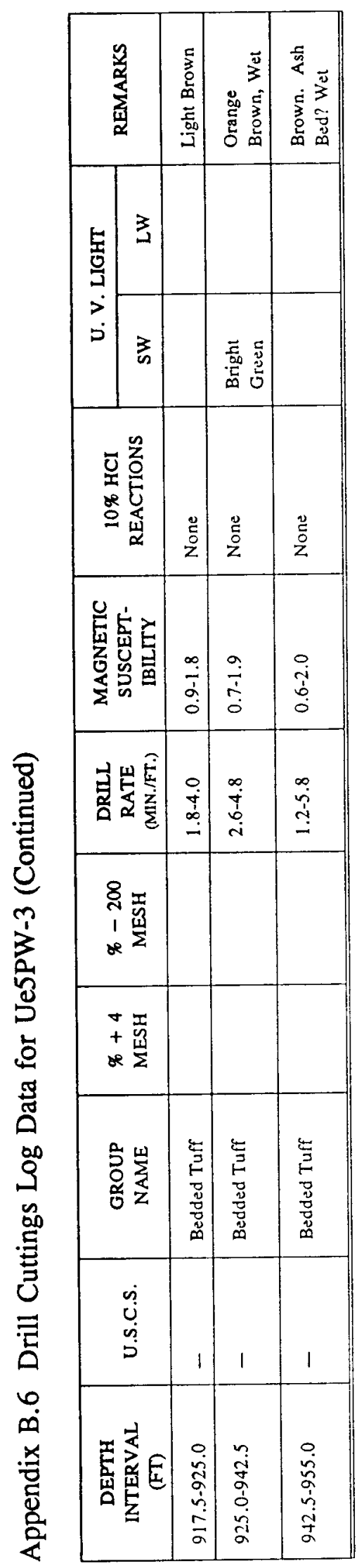




\title{
Area 5 Pilot Wells
}

\author{
APPENDIX C \\ Tracer $\left(\mathrm{SF}_{6}\right)$ Test Data
}

C.1 UE5PW-1 SF 6 Data from Core Samples and Compressor Air Lines C.2 Formation $\mathrm{SF}_{6}$ Tracer Gas Concentrations 


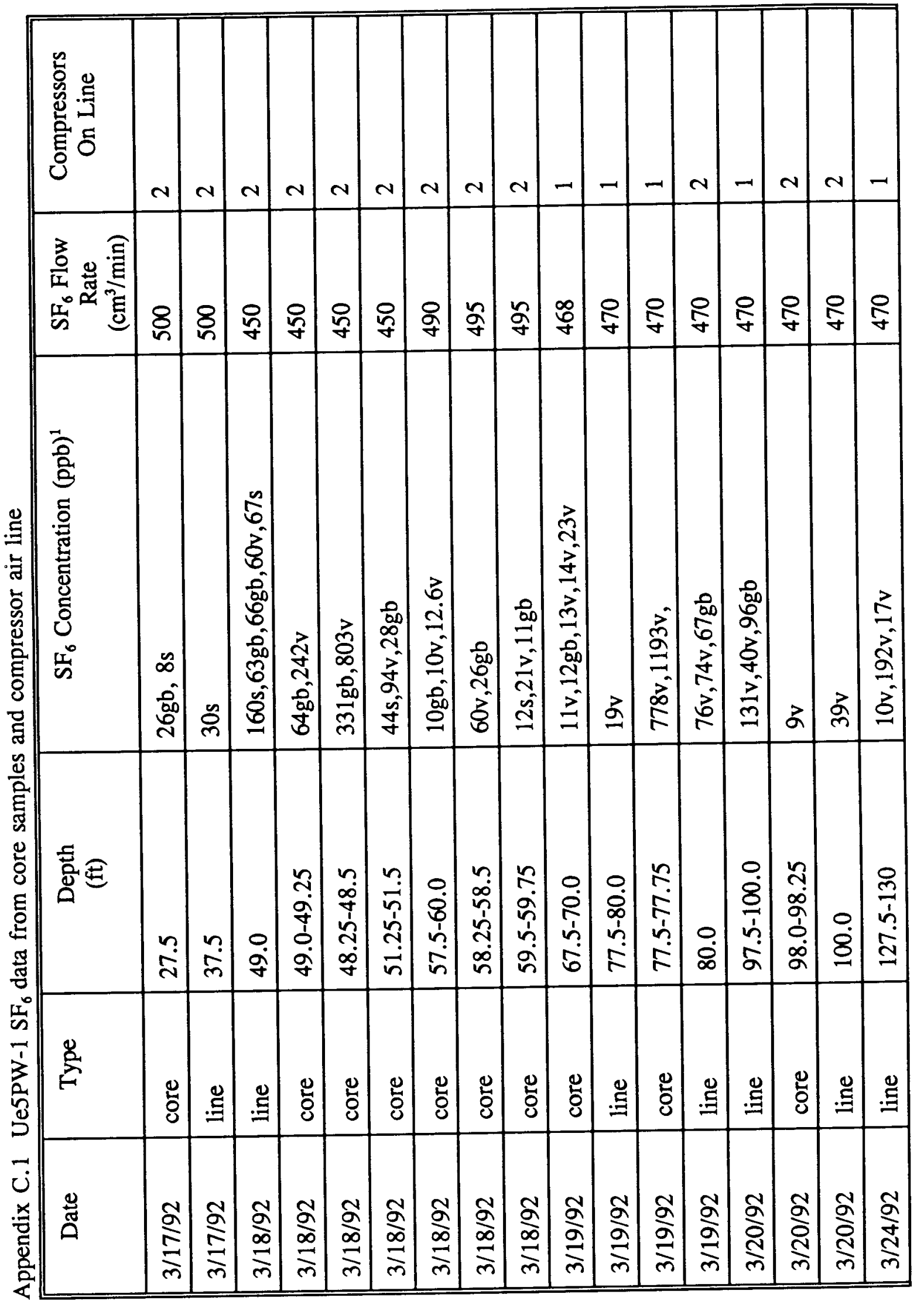




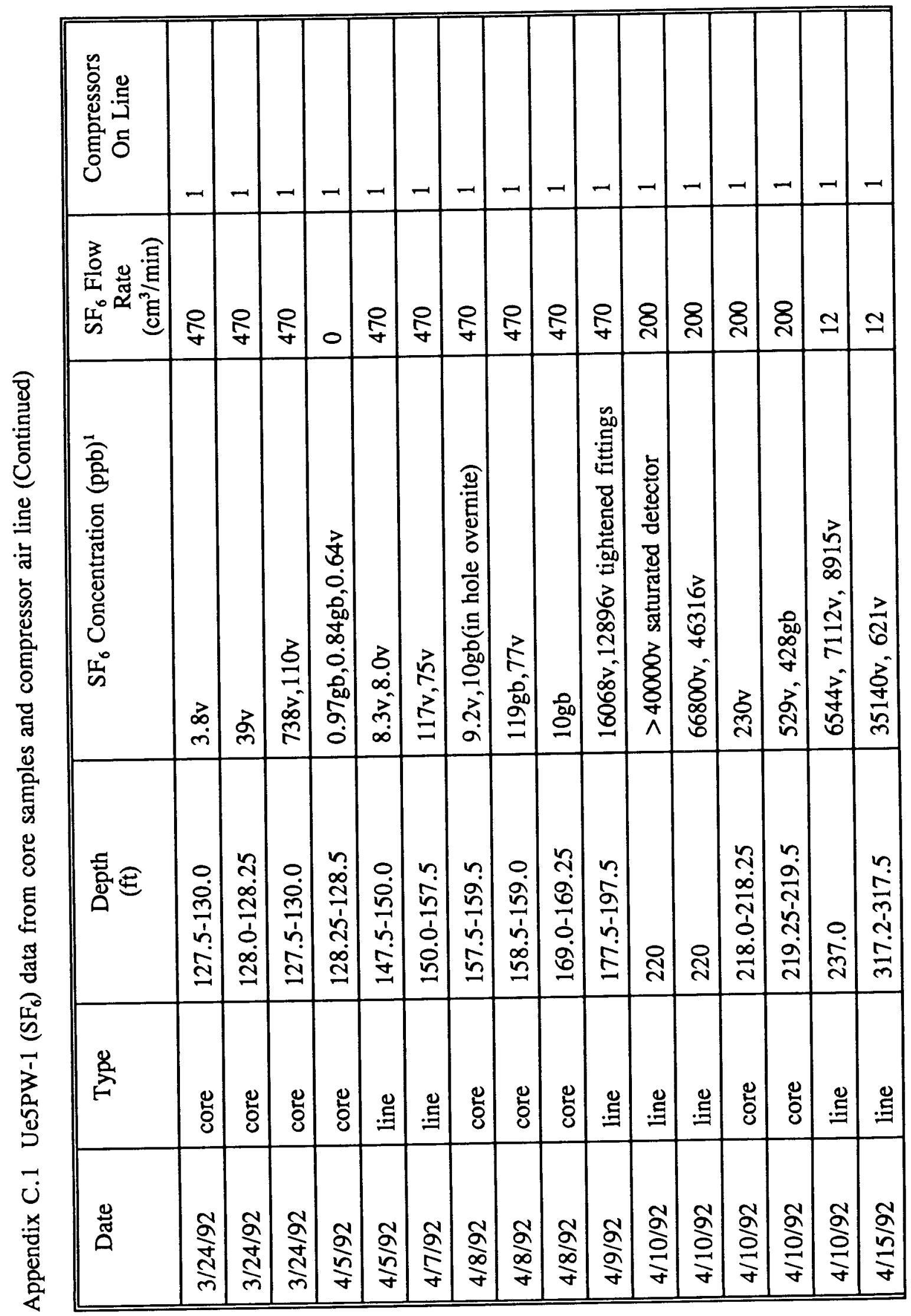




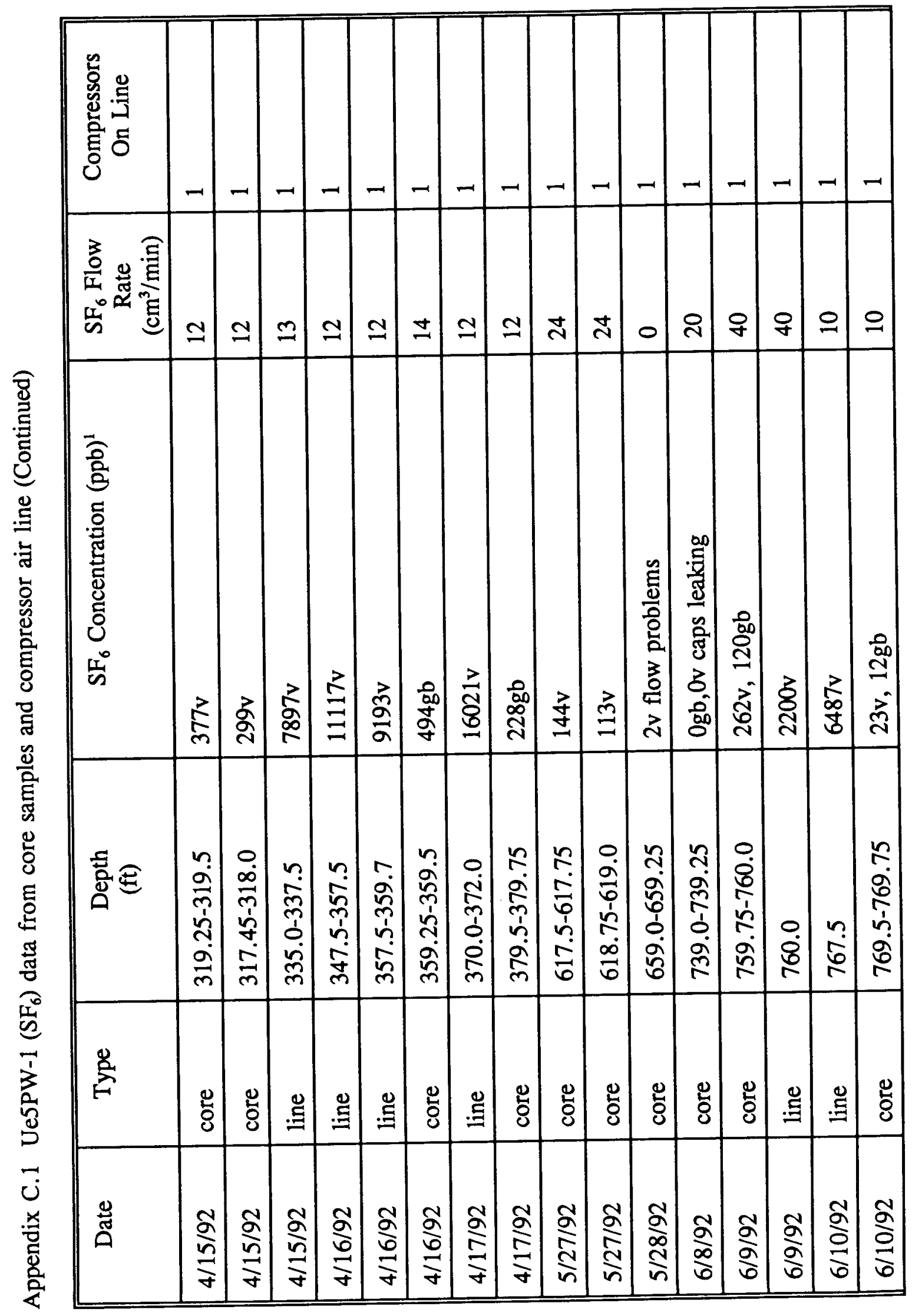




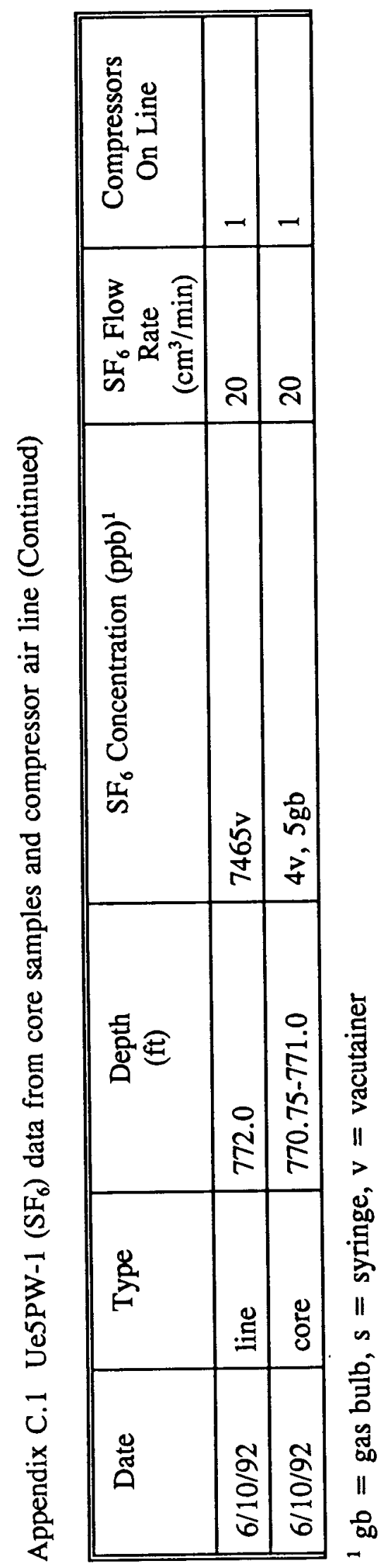




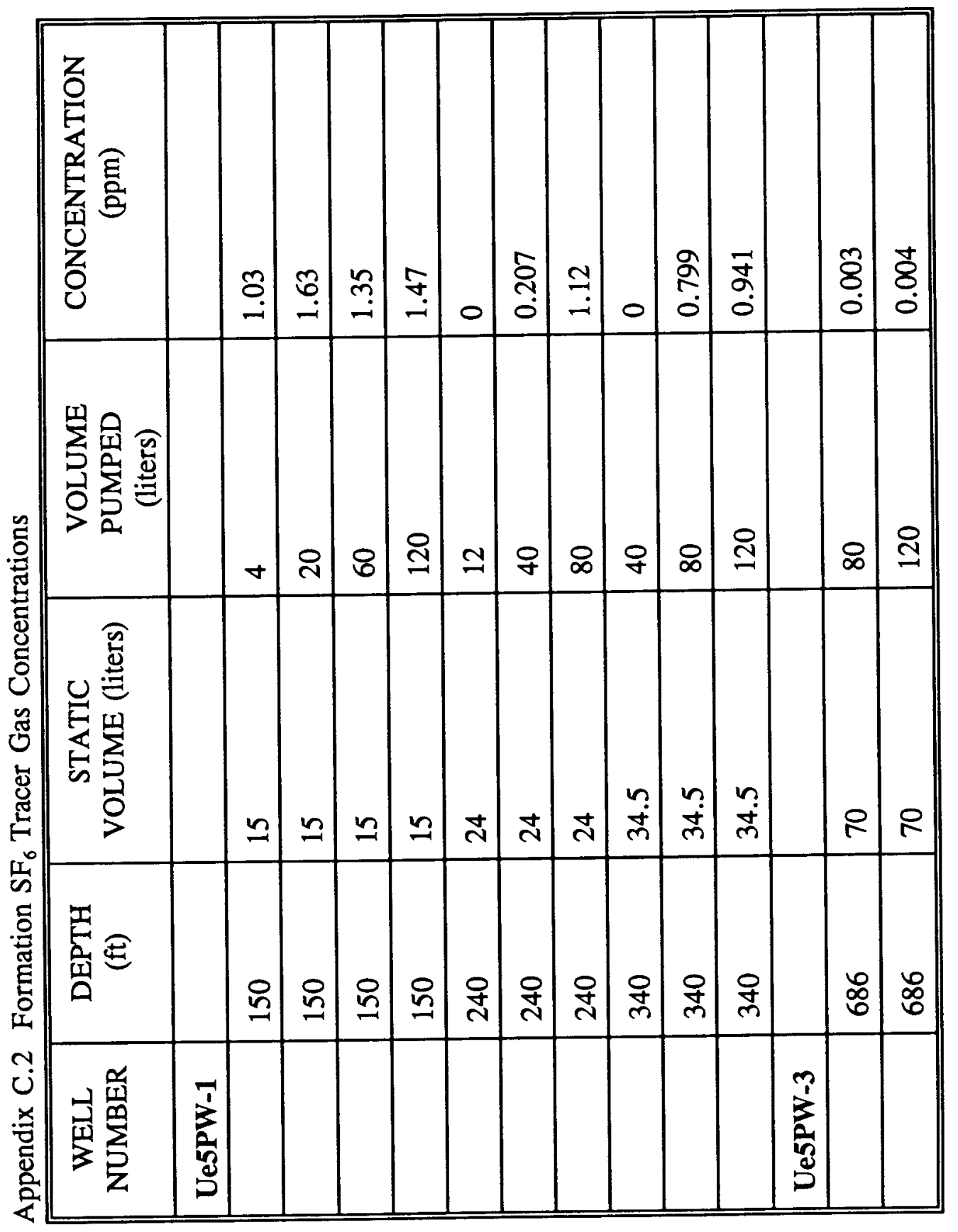




\title{
Area 5 Pilot Wells
}

\author{
APPENDIX D \\ Completion Data
}

D.1 Pilot Well Completion

D.1.1 Annular Materials

D.1.2 Preparation for Completion

D.1.3 Casing and Instrumentation Installation Detail

D.1.4 Stemming Detail

D.1.5 Completion Operations Safety

D.2 Pilot Well Stemming Summaries

D.2.1 UE5PW-1 Stemming Summary

D.2.2 UE5PW-2 Stemming Summary

D.2.3 UE5PW-3 Stemming Summary

D.3 Pilot Well Casing Tallies

D.3.1 UE5PW-1 Casing Tally

D.3.2 UE5PW-2 Casing Tally

D.3.3 UE5PW-3 Casing Tally

D.4 Pilot Well Daily Activities

D.4.1 UE5PW-1 Daily Activity

D.4.2 UE5PW-2 Daily Activity

D.4.3 UE5PW-3 Daily Activity 


\section{D.1.1 Annular Materials:}

Annular sand pack and seal materials were emplaced as follows:

6/12 coarse-mesh "Colorado Silica Sand" (grain size 0.132 to $0.0661 \mathrm{in}$ ) from the bottom of the hole to $10 \mathrm{ft}$ above the screen (approximently $20 \mathrm{ft}$ above water the table). This was installed to improve the performance of the pre-pack screen.

6/12 sand at the instrument stations: 20-ft interval at Station A installations and 3-ft intervals at Station B installations. The stations are located at the midpoint of the sand interval. In Ue5PW-2 and Ue5PW-3 Stations A, the sand was pre-wetted to approximately 0.1 percent by weight in order to bring the water potential of the sand closer to that of the formation. This was done in order to reduce the time for the psychrometers to equilibrate.

A low-permeability dry mixture was placed between instrument stations. This material consisted of 60 percent Overton sand (approximately 80 mesh sand), 25 percent Bentonite powder (200 mesh), and 15 percent silica flour ( 325 mesh). The dry mixture was blended (by weight) at REECo Cement Services, by blowing the material back and forth between two silos until uniform consistency was obtained.

A cement-based grout ("DR-1") was placed as a surface seal interval from approximately 80 $\mathrm{ft}$ to the ground surface. This grout was selected for its non-shrinking and low settemperature characteristics to avoid overheating and possibly damaging the cables and tubing. The grout was blended as follows:

\begin{tabular}{ll} 
Material & Slurry $\left(\mathrm{lb} / \mathrm{ft}^{3}\right)$ \\
\cline { 1 - 2 } Type II cement & 30 \\
W-60 Gypsum & 2.3 \\
Barite & 54 \\
Gel (bentonite) & 3.8 \\
D-19 (friction reducer) & 0.256 \\
Water & 37.72
\end{tabular}

The slurry density was calculated to be $17.12 \mathrm{lb} / \mathrm{gal}\left(128.076 \mathrm{lb} / \mathrm{ft}^{3}\right)$.

A gypsum grout interval, approximately 8 to $10-\mathrm{ft}$ long, was placed to relieve cable strain which was usually between a depth of 350 to $460 \mathrm{ft}$. The W-60 gypsum cement was blended with approximately 5.5 gal of water per $100-1 b$ sack. This low viscosity mixture was able to be pumped through a small diameter line.

\section{D.1.2 Preparation for Completion}

Once the rig was mobilized onto the location, the equipment for running casing, screen, and the instruments was organized. A heavy plastic sheet with a "pig blanket" absorptive pad was placed under the rig and generator to contain any diesel, oil, or other spills. It was desirable, although not necessary, to install the casing jacks at this time. The casing jacks 
used had 4-ea hydraulic cylinders with a total cross-sectional area of $78.5 \mathrm{in}^{2}$. Separate sets of casing slips were used for 10.75-in and 8.625-in casing. It was necessary to dig a well cellar approximately $4 \mathrm{ft}$ deep to set the jacks properly.

Before running the casing and tremie pipes into the hole, these items were thoroughly steam cleaned, washed with Alconox (highly soluble laboratory detergent), and rinsed with distilled water. The couplings were removed from the casing to ensure a complete cleaning of threads. Once cleaned, the couplings were attached to the casing while on the pipe racks. Based on results from leak tests performed on the stainless steel casing during June 1992, it was determined that five wraps with 0.75 -in width PTFE tape plus a thin coating of Jet-Lube "TFW" (Teflon-based environmental pipe joint sealant) would be used on casing joints to ensure airtight connections.

\section{D.1.3 Casing and Instrumentation Installation Detail}

The first item run in the hole was the dual string of tremie pipes. One tremie pipe was intended to deliver the materials downhole. The other tremie pipe was used as an access tube for a depth tagging device which would prevent entanglement with the instrumentation. The $20-\mathrm{ft}$ long tremie joints were constructed of 1 -in schedule 80 , carbon steel pipe with 4thread/inch flush-joint connections. The tremies were run close to the screened interval on bottom, typically from 750 to $850 \mathrm{ft}$ to approximately 20 to $30 \mathrm{ft}$ above the water level. Once at the intended depth, the tremies were attached to a simple slotted device allowing them to be hung on the side of the 8.625-in casing.

Next, six 10-ft long 'pre-pack' well screen joints were run into the hole. The first joint had a 304 sst plate welded on the bottom, effectively sealing the bottom of the screen. A simple "bullet nose" assembly (304 sst) extends approximately 1.75 in below the bottom plate to reduce the chance of hanging on any obstructions. Screen joints No. 1, No. 3, and No. 5 (numbered from the bottom up) have centralizer fins welded to the upper box (female) end of the joint (four 1/4-in thick sst fins welded at $90^{\circ}$ spacing around the screen). All screen and casing joints were measured for effective length after being made up. The joint lengths were recorded on a casing tally sheet, and the cumulative length of the string was used to determine instrument locations. A "dog collar" clamp was used to hold the screen from the rig table while picking up the next screen joint.

The first instrument (pressure transducer) was attached to the top of screen joint No. 1 with a "Band-It" stainless steel band. This instrument was protected by the centralizer fins at that location. The cable for this instrument came off of a spool located on the series of spooling racks. The instrument cable was secured to the screen and casing using a series of heavyduty (125-lb strength) nylon cable ties located every 3 to $5 \mathrm{ft}$.

Once the 60 -ft screen was in the hole, the 2.875-in casing was then lowered down into the borehole. Because the casing has conventional (external-upset) couplings, a simple floorplate was used to support the casing in the hole while picking up the next piece of casing. Typically at 20 to $40 \mathrm{ft}$ intervals, centralizers were placed on the casing. These centralizers (type 304 sst) were constructed from 3.375 -in long by 3 -in inside diameter tubing with four 
0.25 -in fins welded on. The centralizer was secured to the casing by 4-ea $1 / 4-20$ sst socketdrive setscrews. In most cases, the centralizer was located immediately under the casing coupling. However, additional resistance from sliding was obtained in some cases by driving a stainless wedge between the centralizer and the casing.

The casing was run into the hole to the next lowest instrument station location. Preparations were made to attach the specific instruments to the casing from the spooling racks. Multiple checks were made to confirm and document instrument serial numbers and calibration coefficients. Before making up the threads on a casing joint, it was necessary to put on an centralizer. These centralizers were designed to provide protection for the instruments and tubing terminations. Station B centralizers were identical to the centralizers described above. Station A centralizers were fabricated with a cutout on two opposite sides to accommodate a 0.5 -in thick Teflon insert. This insert was used to keep the thermistors thermally isolated from the casing, so that actual formation temperature is preferentially observed.

As the quantity of cables and tubing accumulated, extreme care was taken to ensure an organized arrangement. A major cable tie attached the cables to the casing approximently every $5 \mathrm{ft}$, with a minor cable tie every $2.5 \mathrm{ft}$. Extra-large, 0.5 -in, wide $300 \mathrm{lb}$ capacity cable ties were used to secure the 1-in nylon tubing without pinching. Approximately 1500 cable ties were used to complete a single well.

After all instruments and casing were in the hole, the top of the casing was hung at the appropriate height above ground level (as calculated from the casing tally) in order to place all instruments at the correct depth.

\section{D.1.4 Stemming Detail}

When the entire screen/casing/instrument assembly was in the hole, arrangements were made to convert the operation to stemming the borehole. All spooling racks were removed, and the stemming equipment was moved into place and connected to air and power supplies. The primary equipment used for delivery of material was a Shotcrete injector. This unit is designed to deliver dry materials continuously under pressure. The air supply for the Shotcrete unit was run through an air-dryer and supplied to the unit at approximately 3 to 5 psig. The dry mix was delivered to the location in a dry bulk tanker and blown with air into the material hopper.

The first interval to stem was the filter pack sand interval. The $6 / 12$ coarse silica sand was fed into one of the two tremies using a funnel. The 8.625-in casing was typically retracted to immediately above the bottom of the tremies, just above the water level. Sand was poured until the material tagging device in the other tremie indicated that the desired level had been reached. Instrument station sand (also 6/12 silica sand) was dropped the same way, that is, gravity fed through one tremie while tagging the depth through the other tremie.

The material tagging device used was simply an electric tape with depth markings commonly used to measure depth-to-water. The bottom of the tape was modified by adding a pushbutton switch protected by a heavy rubber sheath. When the switch on the bottom of the tool came in contact with the material, it would close the circuit and sound an audible alarm. The depth was then read directly from the tape. At shallower depths, typically above $400 \mathrm{ft}$, 
it became possible to "feel" the material depth without relying solely on the electric circuit.

While delivering the dry mixture, the level of material was tagged frequently and documented along with the amount of material delivered. Using these tools and techniques, developed specifically for the Pilot Well completions, material intervals were typically placed to within 1 to 2 inches of the desired depth, depending on the particular material's characteristic angle of repose.

After several hundred feet of the borehole had been stemmed, there would have been a risk of collapsing the screen from the weight of the entire screen/casing/instrument assembly. Using a lifting tool and techniques developed for this project, full tension was maintained on the casing from the surface while jacking and removing the 8.625-in casing. Once there was sufficient material emplaced above the screen, the tension could be released. At that point, the casing string would "relax" approximately 2 in.

Typically, the tremie pipes extended immediately below the temporary casing shoe, and material was placed up to the tremies. At that point, another section of tremie pipes and casing could be removed. Certain intervals of the Pilot Well Boreholes had a tendency to cave easily. To minimize such caving, the tremies were retracted within the casing, and the dry mixture was placed inside the temporary casing, sometimes up to $6 \mathrm{ft}$ or more. The casing was then pulled up while the material spilled out the bottom, thus filling the borehole. A review of the density logs prior to stemming often identified the areas prone to caving. Starting at a depth of $80 \mathrm{ft}$, the surface seal was placed. The "DR-1" Bentonite-cement was mixed by REECo Cement Services using cold water and ice to keep the set-temperature at a minimum. The cement slurry was poured down the remaining temporary casing until full. The final joints of casing were then removed from the borehole. After each $20-\mathrm{ft}$ joint was removed, the depth to the cement slurry was measured. If the level fell more than $20 \mathrm{ft}$ below the ground surface, more slurry was added to bring the level back to near-surface. When the last joint of pipe was out of the hole, the casing jacks and support timbers were removed from the well cellar, and slurry was added until several inches of cement had accumulated in the floor of the well cellar.

\section{D.1.5 Completion Operations Safety}

After moving the completion rig onto the hole, but prior to conducting any operations, a safety inspection by a REECo safety representative was conducted to determine compliance with all applicable REECo, NTS, OSHA, and other safety regulations. At no time during completion operations were any incidents of rig noncompliance noted or reported by the REECo safety representative. Regular, unscheduled safety inspections were also conducted during the completion work. Also, frequent jobsite "tailgate" safety meetings were held to address general safety considerations and specifics of the job. 


\section{Appendix D.2.1 Stemming summary for UE5PW-1}

\begin{tabular}{|c|c|c|c|c|c|}
\hline \multicolumn{2}{|c|}{ PW-1 Stemming Summary } & & & & \\
\hline \multicolumn{2}{|c|}{ All depths in $\mathrm{ft}$., ref: Ground Level } & \multicolumn{2}{|c|}{ Interval Depths } & & \multirow{2}{*}{$\begin{array}{c}\text { Mean Hole } \\
\text { Size, Inches }\end{array}$} \\
\hline Interval & Type of Matl. & Top & Bottom & L.bs Mat'l & \\
\hline Surface seal & Bentonite-Cement & 4.0 & 69.4 & 13716 & 17.6 \\
\hline Annular Seal & $60 / 25 / 15$ Dry Mix & 69.4 & 89.7 & 440 & 6.9 \\
\hline Station A-100 & Silica Sand & 89.7 & 110.1 & 1151 & 10.8 \\
\hline Annular Seal & 60/25/15 Dry Mix & 110.1 & 148.2 & 1986 & 10.2 \\
\hline Station B-150 & Silica Sand & 148.2 & 151.3 & 159 & 10.3 \\
\hline Annular Seal & $60 / 25 / 15$ Dry Mix & 151.3 & 189.5 & 1340 & 8.5 \\
\hline Station A-200 & Silica Sand & 189.5 & 210.0 & 1800 & 13.3 \\
\hline Annular Seal & $60 / 25 / 15$ Dry Mix & 210.0 & 238.3 & 1092 & 8.9 \\
\hline Station B-240 & Silica Sand & 238.3 & 241.6 & 188 & 10.8 \\
\hline Annular Seal & $60 / 25 / 15$ Dry Mix & 241.6 & 289.8 & 2720 & 10.6 \\
\hline Station A-300 & Silica Sand & 289.8 & 310.0 & 1100 & 10.6 \\
\hline Annular Seal & $60 / 25 / 15$ Dry Mix & 310.0 & 348.3 & 2440 & 11.2 \\
\hline Station B-350 & Silica Sand & 348.3 & 351.8 & 213 & 11.2 \\
\hline Annular Seal & 60/25/15 Dry Mix & 351.8 & 369.7 & 1600 & 13.1 \\
\hline Strain Relief & Gypsum grout & 369.7 & 377.8 & 874 & 13.4 \\
\hline Annular Seal & 60/25/15 Dry Mix & 377.8 & 495.0 & 9360 & 12.4 \\
\hline Station A-500 & Silica Sand & 495.0 & 510.0 & 700 & 9.9 \\
\hline Annular Seal & $60 / 25 / 15$ Dry Mix & 510.0 & 598.5 & 3160 & 8.6 \\
\hline Station B-600 & Silica Sand & 598.5 & 601.5 & 150 & 10.2 \\
\hline Annular Seal & 60/25/15 Dry Mix & 601.5 & 690.0 & $3+13$ & 8.9 \\
\hline Station A-700 & Silica Sand & 690.0 & 710.0 & 900 & 9.7 \\
\hline Annular Seal & $60 / 25 / 15$ Dry Mix & 710.0 & 752.0 & 3264 & 12.3 \\
\hline Filter Pack & Coarse Silica Sand & 752.0 & 839.0 & 3500 & 9.7 \\
\hline & \multicolumn{3}{|c|}{ Total Lbs of Bentonite-Cement: } & 13,716 & \\
\hline & \multicolumn{3}{|c|}{ Total Lbs of Dry Mix: } & 30,815 & \\
\hline \multicolumn{4}{|c|}{ Total Lbs of Instrument Station Silica Sand } & 6,362 & \\
\hline & \multicolumn{3}{|c|}{ Total Lbs of Gypsum grout: } & 874 & \\
\hline & \multicolumn{3}{|c|}{ Total L.bs of Filter Pack Silica Sand: } & 3,500 & \\
\hline & \multicolumn{3}{|c|}{ Total Lbs of Material Placed in Hole: } & 55,267 & \\
\hline Material Notes: & & & & & \\
\hline \multicolumn{6}{|c|}{ Surface Seal: Portland Type II-based cement $w / 4.6 \%$ bentonite; total of 13,716 Lbs placed } \\
\hline \multicolumn{6}{|c|}{ Dry Mix: $60 \%$ Overton (fine) sand, $25 \%$ Bentonite powder, $15 \%$ Silica Flour; } \\
\hline \multicolumn{6}{|c|}{ Mix permeability: 90 millidarcies; total of 30,815 Lbs placed } \\
\hline \multicolumn{6}{|c|}{ Instrument Stations: $6 / 12$ mesh washed Silica Sand w/layer of $16 / 40$ mesh sand top/bottom; } \\
\hline \multicolumn{6}{|c|}{\begin{tabular}{|l|l|} 
Total of 6362 Lbs sand placed at stations & \\
\end{tabular}} \\
\hline \multicolumn{6}{|c|}{ Strain Relief Interval: $15.5 \mathrm{Lb} / \mathrm{gal}$ neat gypsum grout; total of $874 \mathrm{Lbs}$ placed } \\
\hline \multicolumn{6}{|c|}{ Filter Pack: 6/12 mesh washed Silica Sand; total of 3500 Lbs placed } \\
\hline & & & & & $\mathrm{JCH} 10 / 6 / 92$ \\
\hline
\end{tabular}


Appendix D.2.2 Stemming summary for UE5PW-2

\begin{tabular}{|c|c|c|c|c|c|}
\hline \multicolumn{2}{|c|}{ PW-2 Stemming Summary } & \multirow{2}{*}{\multicolumn{2}{|c|}{ Interval Depths }} & \multirow[b]{3}{*}{ L.bs Mat'1 } & \multirow{3}{*}{$\begin{array}{l}\text { Mean Hole } \\
\text { Size, Inches }\end{array}$} \\
\hline \multicolumn{2}{|c|}{ All depths in $\mathrm{ft}$., ref: Ground Level } & & & & \\
\hline Interval & Type of Matl. & Top & Bottom & & \\
\hline Surface seal & Bentonite-Cement & 4.0 & 79.9 & 17280 & 18.3 \\
\hline Annular Seal & 60/25/15 Dry Mix & 79.9 & 90.5 & 400 & 8.8 \\
\hline Station A-100 & Silica Sand & 90.5 & 110.3 & 1150 & 10.7 \\
\hline Annular Seal & 60/25/15 Dry Mix & 110.3 & 148.4 & 1840 & 9.8 \\
\hline Station B-150 & Silica Sand & 148.4 & 151.8 & 164 & 9.8 \\
\hline Annular Seal & 60/25/15 Dry Mix & 151.8 & 191.0 & 1120 & 7.8 \\
\hline Station A-200 & Silica Sand & 191.0 & 209.9 & 900 & 9.8 \\
\hline Annular Seal & $60 / 25 / 15$ Dry Mix & 209.9 & 248.3 & 1840 & 9.8 \\
\hline Station B-250 & Silica Sand & 248.3 & 251.4 & 114 & 8.7 \\
\hline Annular Seal & $60 / 25 / 15$ Dry Mix & 251.4 & 289.5 & 2280 & 10.9 \\
\hline Station A-300 & Silica Sand & 289.5 & 304.4 & 800 & 10.3 \\
\hline Annular Seal & $60 / 25 / 15$ Dry Mix & 304.4 & 398.5 & 4280 & 9.6 \\
\hline Station B-400 & Silica Sand & 398.5 & 401.3 & 134 & 9.8 \\
\hline Annular Seal & $60 / 25 / 15$ Dry Mix & 401.3 & 435.7 & 1580 & 9.6 \\
\hline Strain Relief & Gypsum Grout & 435.7 & 456.0 & 1457 & 11.8 \\
\hline Annular Seal & $60 / 25 / 15$ Dry Mix & 456.0 & 490.0 & 1520 & 9.5 \\
\hline Station A-500 & Silica Sand & 490.0 & 510.4 & 1131 & 10.5 \\
\hline Annular Seal & $60 / 25 / 15$ Dry Mix & 510.4 & 598.3 & 3120 & 8.6 \\
\hline Station B-600 & Silica Sand & 598.3 & 600.8 & 117 & 9.7 \\
\hline Annular Seal & $60 / 25 / 15$ Dry Mix & 600.8 & 690.3 & 3460 & 8.9 \\
\hline Station A-700 & Silica Sand & 690.3 & 710.3 & 1083 & 10.4 \\
\hline Annular Seal & $60 / 25 / 15$ Dry Mix & 710.3 & 820.1 & 4120 & 8.8 \\
\hline \multirow[t]{3}{*}{ Filter Pack } & Coarse Silica Sand & 820.1 & $906.0^{\star}$ & 4133 & 10.0 \\
\hline & \multicolumn{3}{|c|}{ Total Lbs of Bentonite-Cement: } & 17,280 & \\
\hline & & \multicolumn{2}{|c|}{ Total Lbs of Dry Mix: } & 25,560 & \\
\hline \multicolumn{4}{|c|}{ Total Lbs of Instrument Station Silica Sand } & 5,594 & \\
\hline & \multicolumn{3}{|c|}{ Total Lbs of Gypsum grout: } & 1,457 & \\
\hline & \multicolumn{3}{|c|}{ Total Lbs of Filter Pack Silica Sand: } & 4,133 & \\
\hline & \multicolumn{3}{|c|}{ Total Lbs of Material Placed in Hole: } & 54,024 & \\
\hline & & & & & \\
\hline Material Notes: & & & & & \\
\hline \multicolumn{6}{|c|}{ Surface Seal: Portland Type Il-based cement w/4.6\% bentonite; total of 17,280 Lbs placed } \\
\hline \multicolumn{6}{|c|}{ Dry Mix: $60 \%$ Overton (fine) sand, $25 \%$ Bentonite powder, $15 \%$ Silica Flour; } \\
\hline \multicolumn{6}{|c|}{ Mix permeability: 90 millidarcies; total of 25,560 Lbs placed } \\
\hline \multicolumn{6}{|c|}{ Instrument Stations: $6 / 12$ mesh washed Silica Sand w/layer of $16 / 40$ mesh sand top/bottom; } \\
\hline \multicolumn{6}{|c|}{ Total of 5,594 Lbs sand placed at stations } \\
\hline \multicolumn{6}{|c|}{ Strain Relief Interval: $15.5 \mathrm{Lb} /$ gal neat gypsum grout; total of $1,457 \mathrm{Lbs}$ placed } \\
\hline \multicolumn{6}{|c|}{ Filter Pack: 6/12 mesh washed Silica Sand; total of 4,133 Lbs placed } \\
\hline & & & & & \\
\hline \multicolumn{5}{|c|}{ *Hole caved from TD of 919.9 It to 906 prior to stemming filter pack } & $\mathrm{JCH} 3 / 19 / 93$ \\
\hline
\end{tabular}


Appendix D.2.3 Stemming summary for UE5PW-3

\begin{tabular}{|c|c|c|c|c|c|}
\hline \multicolumn{2}{|c|}{ PW-3 Stemming Summary } & & & & \\
\hline \multicolumn{2}{|c|}{ All depths in ft., ref: Ground Level } & \multicolumn{2}{|c|}{ Interval Depths } & \multirow[b]{2}{*}{ L.bs Mat'l } & \multirow{2}{*}{$\begin{array}{l}\text { Mean Hole } \\
\text { Size, Inches }\end{array}$} \\
\hline Interval & Type of Matl. & Top & Bottom & & \\
\hline Surface seal & Bentonite-Cement & 4.0 & 80.1 & 12103 & 15.4 \\
\hline Annular Seal & $60 / 25 / 15$ Dry Mix & 80.1 & 90.5 & 640 & 11.0 \\
\hline Station A-100 & Silica Sand & 90.5 & 109.9 & 1063 & 10.6 \\
\hline Annular Seal & $60 / 25 / 15$ Dry Mix & 109.9 & 189.9 & 4480 & 10.7 \\
\hline Station A-200 & Silica Sand & 189.9 & 209.6 & 950 & 10.0 \\
\hline Annular Seal & 60/25/15 Dry Mix & 209.6 & 248.2 & 2440 & 11.4 \\
\hline Station B-250 & Silica Sand & 248.2 & 251.5 & 163 & 10.1 \\
\hline Annular Seal & 60/25/15 Dry Mix & 251.5 & 288.6 & 2640 & 12.0 \\
\hline Station A-300 & Silica Sand & 288.6 & 310.4 & 900 & 9.3 \\
\hline Annular Seal & 60/25/15 Dry Mix & 310.4 & 348.5 & 2400 & 11.3 \\
\hline Station B-350 & Silica Sand & 348.5 & 352.8 & 273 & 11.4 \\
\hline Annular Seal & $60 / 25 / 15$ Dry Mix & 352.8 & 447.5 & 8800 & 13.6 \\
\hline Strain Relief & Gypsum Grout & 447.5 & 454.4 & 1165 & 18.2 \\
\hline Annular Seal & 60/25/15 Dry Mix & 454.4 & 490.1 & 1680 & 9.9 \\
\hline Station A-500 & Silica Sand & 490.1 & 509.7 & 1263 & 11.5 \\
\hline Annular Seal & 60/25/15 Dry Mix & 509.7 & 548.5 & 1840 & 9.9 \\
\hline Station B-550 & Silica Sand & 548.5 & 551.4 & 113 & 9.1 \\
\hline Annular Seal & $60 / 25 / 15$ Dry Mix & 551.4 & 628.4 & 3480 & 9.7 \\
\hline Station A-639 & Silica Sand & 628.4 & 649.1 & 713 & 8.6 \\
\hline Annular Seal & $60 / 25 / 15$ Dry Mix & 649.1 & 687.0 & 1440 & 9.0 \\
\hline Station B-689 & Silica Sand & 687.0 & 691.8 & 126 & 7.6 \\
\hline Annular Seal & 60/25/15 Dry Mix & 691.8 & 868.0 & 6560 & 8.9 \\
\hline \multirow[t]{3}{*}{ Filter Pack } & Coarse Silica Sand & 868.0 & 955.0 & 2500 & 7.9 \\
\hline & \multicolumn{3}{|c|}{ Total Lbs of Bentonite-Cement: } & 12,103 & \\
\hline & & \multicolumn{2}{|c|}{ Total Lbs of Dry Mix: } & 36,400 & \\
\hline \multicolumn{4}{|c|}{ Total Lbs of Instrument Station Silica Sand } & 5,563 & \\
\hline & \multicolumn{3}{|c|}{ Total Lbs of Gypsum grout: } & 1,165 & \\
\hline & \multicolumn{3}{|c|}{ Total Lbs of Filter Pack Silica Sand: } & 2,500 & \\
\hline & \multicolumn{3}{|c|}{ Total Lbs of Material Placed in Hole: } & 57,731 & \\
\hline & & & & & \\
\hline Material Notes: & & & & & \\
\hline \multicolumn{6}{|c|}{ Surface Seal: Portland Type II-based cement $w / 4.6 \%$ bentonite; total of 12,103 Lbs placed } \\
\hline \multicolumn{6}{|c|}{ Dry Mix: $60 \%$ Overton (fine) sand, $25 \%$ Bentonite powder, $15 \%$ Silica Flour; } \\
\hline \multicolumn{6}{|c|}{ Mix permeability: 90 millidarcies; total of 36,400 Lbs placed } \\
\hline \multicolumn{6}{|c|}{ Instrument Stations: $6 / 12$ mesh washed Silica Sand w/layer of $16 / 40$ mesh sand top/bottom; } \\
\hline \multicolumn{6}{|c|}{ Total of 5563 Lbs sand placed at stations } \\
\hline \multicolumn{6}{|c|}{ Strain Relief Interval: $15.5 \mathrm{Lb} /$ gal neat gypsum grout; total of 1,165 Lbs placed } \\
\hline \multirow{2}{*}{\multicolumn{6}{|c|}{ Filter Pack: 6/12 mesh washed Silica Sand; total of 2500 Lbs placed }} \\
\hline & & & & & JCH $3 / 19 / 93$ \\
\hline
\end{tabular}




\section{Appendix D.3.1 Casing tally for UE5PW-1}

\begin{tabular}{|c|c|c|c|}
\hline \multicolumn{4}{|c|}{\begin{tabular}{|l|} 
Pilot Well PW-1 Casing Tally \\
All lengths measured "as made un"
\end{tabular}} \\
\hline \multirow{2}{*}{\multicolumn{4}{|c|}{\begin{tabular}{|c|c|c|l|}
\multicolumn{2}{|l|}{ All lengths measured "as made up" } & \\
Joint \# & Length, in. $\quad$ Cum. length, in. & Comments
\end{tabular}}} \\
\hline & & & \\
\hline \multicolumn{4}{|c|}{ Screen jts 1-6 } \\
\hline 1 & 125.5 & 125.5 & Screen jt.1 has $1.75^{\prime \prime}$ nose below 0 ref. \\
\hline 2 & 124.875 & 250.375 & Druck-812 located between screen jts.\#1-2 \\
\hline 3 & 125 & 375.375 & \\
\hline 4 & 124.75 & 500.125 & \\
\hline 5 & 124.75 & 624.875 & \\
\hline 6 & 124.875 & 749.75 & \\
\hline \multicolumn{4}{|c|}{ Casing jts $1-38$} \\
\hline 1 & 241.75 & 991.5 & \\
\hline 2 & 241.625 & 1233.125 & \\
\hline 3 & 240.25 & 1473.375 & Station A-700 9.375" below top of jt. $\# 3$ \\
\hline 4 & 239.25 & 1712.625 & \\
\hline 5 & 239.5 & 1952.125 & \\
\hline 6 & 239.875 & 2192 & \\
\hline 7 & 239.75 & 2431.75 & \\
\hline 8 & 239.5 & 2671.25 & Station B-600 7.25" below top of jt.\#8 \\
\hline 9 & 239.75 & 2911 & \\
\hline 10 & 239.25 & 3150.25 & \\
\hline 11 & 239.5 & 3389.75 & \\
\hline 12 & 239.75 & 3629.5 & \\
\hline 13 & 240.25 & 3869.75 & Station A-500 5.75" below top of jt.\#13 \\
\hline 14 & 239.5 & 4109.25 & \\
\hline 15 & 239.5 & 4348.75 & \\
\hline 16 & 240.25 & 4589 & \\
\hline 17 & 241.5 & 4830.5 & \\
\hline 18 & 240.25 & 5070.75 & \\
\hline 19 & 242 & 5312.75 & \\
\hline 20 & 242.25 & 5555 & \\
\hline 21 & 241.75 & 5796.75 & Station B-350 132.75" below top of jt. $\# 21$ \\
\hline 22 & 241.75 & 6038.5 & \\
\hline 23 & 241.5 & 6280 & Station A-300 16" from top of jt. $\$ 23$ \\
\hline 24 & 241.5 & 6521.5 & \\
\hline 25 & 241.25 & 6762.75 & \\
\hline 26 & 242.125 & 7004.875 & Station B-240 20.875" below top of jt.\#26 \\
\hline 27 & 238.875 & 7243.75 & \\
\hline 28 & 240.5 & 7484.25 & Station A-200 20.5 " below top of jt. $\# 28$ \\
\hline$\because 29$ & 239.5 & 7723.75 & \\
\hline 30 & 240 & 7963.75 & \\
\hline 31 & 240.25 & 8204 & Station B-150 140.25" below top of jt. $\# 31$ \\
\hline 32 & 241.5 & 8445.5 & \\
\hline 33 & 241.5 & 8687 & Station $\mathrm{A}-10023^{\prime \prime}$ below top of jt. $\# 33$ \\
\hline 34 & 240.5 & 8927.5 & \\
\hline 35 & 240.625 & 9168.125 & \\
\hline 36 & 241.5 & 9409.625 & \\
\hline 37 & 241.75 & 9651.375 & \\
\hline 38 & 241.5 & 9892.875 & $\mathrm{GL}=28.875^{\prime \prime}$ below top of jt. $\# 38$ \\
\hline
\end{tabular}


Appendix D.3.2 Casing tally for UE5PW-2

\begin{tabular}{|c|c|c|c|}
\hline \multicolumn{3}{|c|}{ Pilot Well PW-2 Casing Tally } & \multirow[t]{2}{*}{$\mathrm{PW}-2.2$ Final JCH $1 / 27 / 93$} \\
\hline \multicolumn{3}{|c|}{ All lengths measured "as made up" } & \\
\hline Joint \# & Length, in. & Cum. length, in. & Comments \\
\hline \multicolumn{2}{|c|}{ Screen jts $1-6$} & & \\
\hline 1 & 125.25 & 125.25 & Centralizer on cplg; Bullet nose $+1.625^{\prime \prime}$ below \\
\hline 2 & 124.75 & 250 & Druck 880 on top of screen jt. $\# 1$ \\
\hline 3 & 124.5 & 374.5 & Centralizer on coupling \\
\hline 4 & 124.75 & 499.25 & \\
\hline 5 & 124.25 & 623.5 & Centralizer on coupling \\
\hline 6 & 124.75 & 748.25 & \\
\hline \multicolumn{2}{|c|}{ Casing jts 1-41 } & & \\
\hline 1 & 240.5 & 988.75 & Centralizer on coupling \\
\hline 2 & 242 & 1230.75 & \\
\hline 3 & 242 & 1472.75 & Centralizer on coupling \\
\hline 4 & 242 & 1714.75 & \\
\hline 5 & 240 & 1954.75 & Centralizer on coupling \\
\hline 6 & 241.875 & 2196.625 & \\
\hline 7 & 240.5 & 2437.125 & Station A-700 $156.875^{\prime \prime}$ below top of joint \\
\hline 8 & 241 & 2678.125 & \\
\hline 9 & 240 & 2918.125 & Centralizer on coupling \\
\hline 10 & 242.5 & 3160.625 & \\
\hline 11 & 240.5 & 3401.125 & Centralizer on coupling \\
\hline 12 & 242 & 3643.125 & Station B-600 163.125" below top of joint \\
\hline 13 & 242 & 3885.125 & Centralizer on coupling \\
\hline 14 & 242 & 4127.125 & \\
\hline 15 & 240.5 & 4367.625 & Centralizer on coupling \\
\hline 16 & 241.75 & 4609.375 & \\
\hline 17 & 242 & 4851.375 & Station A-500 171.375" below top of joint \\
\hline 18 & 242.5 & 5093.875 & Centralizer on coupling \\
\hline 19 & 242 & 5335.875 & \\
\hline 20 & 241.75 & 5577.625 & Centralizer on coupling \\
\hline 21 & 242.5 & 5820.125 & \\
\hline 22 & 242.5 & 6062.625 & Station B-400 $182.625^{\prime \prime}$ below TO jt. 22 \\
\hline 23 & 242.25 & 6304.875 & Centralizer on coupling \\
\hline 24 & 239.875 & 6544.75 & \\
\hline 25 & 240 & 6784.75 & Centralizer on coupling \\
\hline 26 & 242.5 & 7027.25 & \\
\hline 27 & 242 & 7269.25 & Station A-300 189.25 below TO jt. 27 \\
\hline 28 & 242 & 7511.25 & Centralizer on coupling \\
\hline 29 & 242.25 & 7753.5 & Station B-250 73.5" below TO jt. 29 \\
\hline 30 & 254.5 & 8008 & Centralizer on coupling \\
\hline 31 & 254.25 & 8262.25 & \\
\hline 32 & 254.25 & 8516.5 & Station A-200 236.5" below TO jt. 32 \\
\hline 33 & 254.5 & 8771 & Centralizer on coupling \\
\hline 34 & 254.25 & 9025.25 & Station B-150 145.25" below TO jt. 34 \\
\hline 35 & 255.25 & 9280.5 & Centralizer on coupling \\
\hline 36 & 254.5 & 9535 & Station A-100 55" below TO jt. 36 \\
\hline 37 & 254 & 9789 & Centralizer on coupling \\
\hline 38 & 254.5 & 10043.5 & \\
\hline 39 & 254 & 10297.5 & Centralizer on coupling \\
\hline 40 & 254 & 10551.5 & Centralizer on coupling \\
\hline 41 & 155.25 & 10706.75 & Jt. $\# 41$ located $26.75^{\prime \prime}$ above ground level \\
\hline
\end{tabular}




\section{Appendix D.3.3 Casing tally for UESPW-3}

\begin{tabular}{|c|c|c|c|}
\hline \multirow{2}{*}{\multicolumn{3}{|c|}{$\begin{array}{l}\text { Pilot Well PW-3 Casing Tally } \\
\text { All lengths measured "as made up" }\end{array}$}} & \multirow[t]{2}{*}{$\mathrm{JCH}$ rev. $3 / 15 / 93$} \\
\hline & & & \\
\hline Joint \# & Length, in. & Cum. length, in. & Comments \\
\hline \multicolumn{4}{|c|}{ Screen jts $1-6$} \\
\hline 1 & 125.5625 & 125.5625 & Centralizer on cplg; Bullet nose $+1.75^{\prime \prime}$ below \\
\hline 2 & 124.75 & 250.3125 & \\
\hline 3 & 124.625 & 374.9375 & Centralizer on cplg. \\
\hline 4 & 124.625 & 499.5625 & \\
\hline 5 & 124.75 & 624.3125 & Centralizer on cplg. \\
\hline 6 & 124.875 & 749.1875 & \\
\hline \multicolumn{4}{|c|}{ Casing jts 1-44 } \\
\hline 1 & 242 & 991.1875 & Centralizer on top of joint \\
\hline 2 & 241.625 & 1232.8125 & \\
\hline 3 & 241.5 & 1474.3125 & Centralizer on top of joint \\
\hline 4 & 241.25 & 1715.5625 & \\
\hline 5 & 241.625 & 1957.1875 & Centralizer on top of joint \\
\hline 6 & 241.25 & 2198.4375 & \\
\hline 7 & 239.625 & 2438.0625 & Centralizer on top of joint \\
\hline 8 & 239.5 & 2677.5625 & \\
\hline 9 & 235.25 & 2912.8125 & Centralizer on top of joint \\
\hline 10 & 241.4375 & 3154.25 & Station B-689 168.25" below top of joint \\
\hline 11 & 239.16 & 3393.41 & Centralizer on top of joint \\
\hline 12 & 243.3 & 3636.71 & Station A-639 $48.75^{\prime \prime}$ below top of joint \\
\hline 13 & 241.5 & 3878.21 & \\
\hline 14 & 240.5 & 4118.71 & Centralizer on top of joint \\
\hline 15 & 233.25 & 4351.96 & \\
\hline 16 & 235.25 & 4587.21 & Centralizer on top of joint \\
\hline 17 & 239.25 & 4826.46 & Station B-550 170.5" below top of joint \\
\hline 18 & 241.54 & 5068 & \\
\hline 19 & 240 & 5308 & Station A-500 52" below top of joint \\
\hline 20 & 241.5 & 5549.5 & Centralizer on top of joint \\
\hline 21 & 241.75 & 5791.25 & \\
\hline 22 & 241.25 & 6032.5 & Centralizer on top of joint \\
\hline 23 & 239.75 & 6272.25 & \\
\hline 24 & 235.25 & 6507.5 & Centralizer on top of joint \\
\hline 25 & 240.125 & 6747.625 & \\
\hline 26 & 241.5 & 6989.125 & Centralizer on top of joint \\
\hline 27 & 241.5 & 7230.625 & Station B-350 174.625" below top of joint \\
\hline 28 & 241.75 & 7472.375 & Centralizer on top of joint \\
\hline 29 & 241.5 & 7713.875 & Station A-300 57.875" below top of joint \\
\hline 30 & 241.5 & 7955.375 & Centralizer on top of joint \\
\hline 31 & 241 & 8196.375 & \\
\hline 32 & 241.625 & 8438 & Station B-250 182" below top of joint \\
\hline 33 & 241.875 & 8679.875 & Centralizer on top of joint \\
\hline 734 & 241.5 & 8921.375 & Station A-200 65.375" below top of joint \\
\hline 35 & 241.25 & 9162.625 & Centralizer on top of joint \\
\hline 36 & 241.5 & 9404.125 & \\
\hline 37 & 241.625 & 9645.75 & Centralizer on top of joint \\
\hline 38 & 241.625 & 9887.375 & \\
\hline 39 & 235.25 & 10122.625 & Station A-100 66.625" below top of joint \\
\hline 40 & 241.625 & 10364.25 & Centralizer on top of joint \\
\hline 41 & 241.5 & 10605.75 & \\
\hline 42 & 237.5 & 10843.25 & \\
\hline 43 & 235.5 & 11078.75 & Centralizer on top of joint \\
\hline 44 & 207.125 & 11285.875 & Top of joint $\# 44$ is $29.875 "$ above $G L$ \\
\hline
\end{tabular}




\section{Appendix D.4.1 Daily activities for UE5PW-1}

\begin{tabular}{|c|c|c|c|c|}
\hline \multicolumn{4}{|c|}{ PW-1 Daily Activity } & \\
\hline Day & Hours & Date & Depth & Activity \\
\hline 1 & 7 & $7 / 13 / 92$ & 0 & Rig up, badging \\
\hline 2 & 8 & $7 / 14 / 92$ & 0 & Slug testing, steam cleaning SST casing \\
\hline 3 & 8 & $7 / 15 / 92$ & 60 & Ran $60^{\prime}$ screen, steam clean $720^{\prime}$ tremies \\
\hline 4 & 8 & $7 / 16 / 92$ & 60 & Complete steam clean tremies, total $88 \mathrm{jts}$; spool $375^{\prime}$ and $647^{\prime}$ of $1^{\prime \prime}$ tubing \\
\hline 5 & 8 & $7 / 17 / 92$ & 143 & Ran csg jts \#1-4, Station A-700 \\
\hline 6 & 8 & $7 / 20 / 92$ & 282 & Ran csg jts \#5-11, Station B-600 \\
\hline 7 & 8 & $7 / 21 / 92$ & 362 & Ran csg jts \#12-15, Station A-500 \\
\hline 8 & 8 & $7 / 22 / 92$ & 483 & Ran csg jts \#16-21, Station B-350 \\
\hline 9 & 8 & $7 / 23 / 92$ & 543 & Ran csg jts \#22-24, Station A-300 \\
\hline 10 & 8 & $7 / 24 / 92$ & 624 & Ran csg jts \#25-28, Station B-240 \\
\hline 11 & 8 & $7 / 27 / 92$ & 684 & Ran csg jts \#29-31, Station A-200 \\
\hline 12 & 8 & $7 / 28 / 92$ & 724 & Ran csg jts \#32-33, Station B-150 \\
\hline 13 & 8 & $7 / 29 / 92$ & 784 & Ran csg jts \#24-36, Station A-100 \\
\hline 14 & 8 & $7 / 30 / 92$ & 804 & Ran csg jt \#37 \\
\hline 15 & 8 & $7 / 31 / 92$ & 822 & Ran csg jt \#38 (final), cutoff $10 "$ csg, terminated cables, hoses, move spooling racks \\
\hline 16 & 8 & $8 / 3 / 92$ & 822 & Set hydraulic jacks in cellar \\
\hline 17 & 8 & $8 / 4 / 92$ & 822 & Fabricate lift sub, RU to pull $8-5 / 8 "$ \\
\hline 18 & 8 & $8 / 5 / 92$ & 822 & RU casing/tremie lift mechanism, work stuck csg, free w/102KIb, pull $20^{\prime}$ \\
\hline 19 & 8 & $8 / 6 / 92$ & 822 & Pull 60 ft 8-5/8" csg@600 psi hyd \\
\hline 20 & 8 & $8 / 7 / 92$ & 752 & Placed 35 sx $6 / 12$ sand, pull 20 ft. $8-5 / 8$ \\
\hline 21 & 8 & $8 / 10 / 92$ & 740 & RU shotcrete inj., stem \\
\hline 22 & 8 & $8 / 11 / 92$ & 730 & Stem to 710, pull $10^{\prime} 8^{\prime \prime}$ \\
\hline 23 & 8 & $8 / 12 / 92$ & 700 & Start Stem A-700, $4 \mathrm{sx} 6 / 12$ \\
\hline 24 & 8 & $8 / 13 / 92$ & 630 & Complete stem $A-700,5 s \times 6 / 12$, pulled $60^{\prime} 8^{\prime \prime}$ to 640 \\
\hline 25 & 8 & $8 / 14 / 92$ & 595 & Pull $40^{\prime} 8^{\prime \prime}$, stem \\
\hline 26 & 8 & $8 / 17 / 92$ & 595 & De-stem 595-602, work on tagging tool \\
\hline 27 & 8 & $8 / 18 / 92$ & 562 & Pull $408^{\prime \prime}, 1.5 \mathrm{~s} \times 6 / 12598.5-601.5$, stem up to 562 \\
\hline 28 & 8 & $8 / 19 / 92$ & 510 & Pull $50^{\prime} 8^{\prime \prime}$, stem to 510 , re-design tagging tool, RU vibrator \\
\hline 29 & 8 & $8 / 20 / 92$ & 495 & Vibrator trip 500-600, pull $30^{\prime} 8^{\prime \prime}, 7 \mathrm{~s} \times 6 / 12$ station $A-500,(495-510)$ hole caved $483-495$ \\
\hline 30 & 8 & $8 / 21 / 92$ & 469 & Stem $479-469$, hole caving \\
\hline 31 & 8 & $8 / 24 / 92$ & 450 & Pull 50' 8", stem to 455 \\
\hline
\end{tabular}


Appendix D.4.1 Daily activities for UE5PW-1 (Continued)

\begin{tabular}{|c|c|c|c|c|}
\hline 32 & 8 & $8 / 25 / 92$ & 434 & Vibrator trip to 500 , stem $450-434$ \\
\hline 33 & 8 & $8 / 26 / 92$ & 421 & Pull 20' 8", stemming large hole to 414 \\
\hline 34 & 8 & $8 / 27 / 92$ & 379 & Pull 40' 8", stem to 373 \\
\hline 35 & 8 & $8 / 28 / 92$ & 373 & Vibrator trip $450-370$, pull $370^{\prime} 8^{\prime \prime}$ \\
\hline 36 & 8 & $8 / 31 / 92$ & 373 & Move jacks, clean cellar, welded 10" pup, RU bailer, bail \\
\hline 37 & 8 & $9 / 1 / 92$ & 373 & Config jacks for $10^{\prime \prime}$, pull $1000 \mathrm{psi} / 2 \mathrm{hrs}, 1300 / 3 \mathrm{hrs}$, pull 4 '-10", bail \\
\hline 38 & 8 & $9 / 2 / 92$ & 366 & Pumped $\sim 15.1$ ppg gypsum $W-60$ slurry, 6 sx, bail \\
\hline 39 & 8 & $9 / 3 / 92$ & 348 & Stem to $351.5,6 / 12$ sand $351.5-348.52$ sx, pull $10^{\prime} 10^{\prime \prime}$ \\
\hline 40 & 8 & $9 / 10 / 92$ & 315 & Pulled $20^{\prime} 10^{\prime \prime}$, stem to 315 \\
\hline 41 & 9 & $9 / 11 / 92$ & 290 & Bail, stem to $310,11 \mathrm{sx} 6 / 12,1$ sk $16 / 40$ station $A-300$ \\
\hline 42 & 10 & $9 / 14 / 92$ & 238 & Pull $10^{\prime} 10^{\prime \prime}$, stem $290-241.5,2$ gal $16 / 40+1.5 \mathrm{sx} 6 / 12+3$ gal $16 / 40$, to 238.5 \\
\hline 43 & 10 & $9 / 15 / 92$ & 238 & Bail, neutron logging, RU Bennett pump \# 1 \\
\hline 44 & 10 & $9 / 16 / 92$ & 238 & Run Bennett pump \#1 in hole, pump, bail \\
\hline 45 & 10 & $9 / 17 / 92$ & 238 & Run Bennett pump \#2 in hole, sampling all day \\
\hline 46 & 9 & $9 / 18 / 92$ & 211 & Stem $238-211$, pull $20^{\prime} 10^{\prime \prime}$ \\
\hline 47 & 10 & $9 / 21 / 92$ & 169 & Stem $211-169,17 \mathrm{~s} \times 6 / 12$ sand $+6 " 16 / 40$ Sta. A-200 \\
\hline 48 & 10 & $9 / 22 / 92$ & 144 & Stem $169-144,1.33 \mathrm{sx} 6 / 12,6 \# 16 / 40$ St. B-150 \\
\hline 49 & $\{8\}$ & $9 / 23 / 92$ & 144 & Standby w/o crew (event) \\
\hline 50 & 10 & $9 / 24 / 92$ & 106 & Stem 144-110,3 $5 \times 6 / 12110-106$ \\
\hline 51 & 9 & $9 / 25 / 92$ & 80 & Complete St. A-100 $8 \mathrm{~s} \times 6 / 12+12 \# 16 / 40$, stem $90-80 \mathrm{ft}$ \\
\hline 52 & 8 & $9 / 28 / 92$ & 69 & Pull 20' 10"; lost 60' tremie; hole sluffed 80-69 ft \\
\hline 53 & 10 & $9 / 29 / 92$ & 0 & RU for cementing; place 4 yds low-set-temperature cement; $L D$ all remaining pipe \\
\hline 54 & 10 & $9 / 30 / 92$ & 0 & Neutron logging; Rigdown/move to PW-2 Activity \\
\hline 55 & 8 & $10 / 1 / 92$ & 0 & Continue logging \\
\hline 56 & 8 & $10 / 2 / 92$ & 0 & Complete logging; Rig off hole 1200 hrs \\
\hline
\end{tabular}


Appendix D.4.2 Daily activities for UE5PW-2

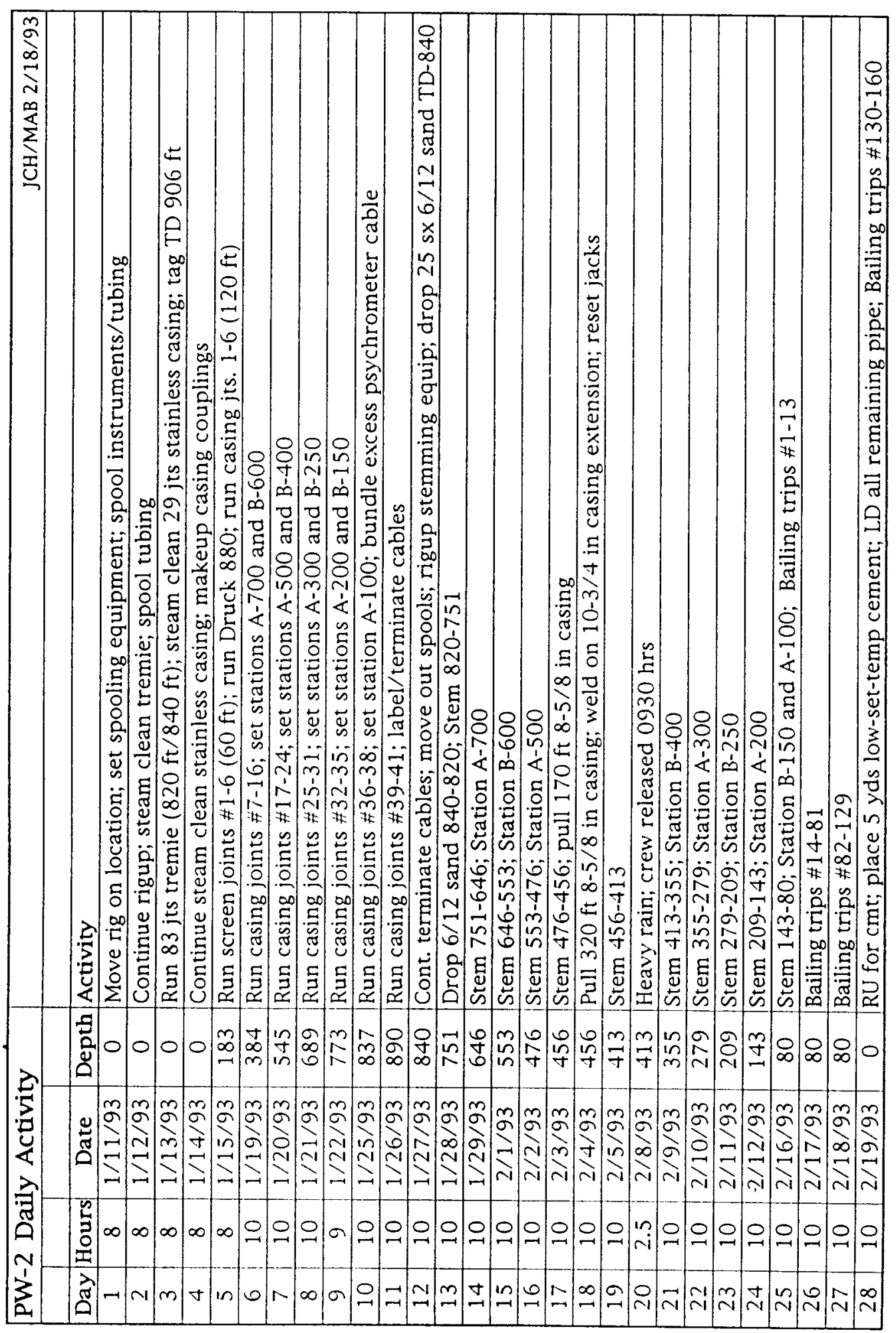


Appendix D.4.3 Daily activities for UE5PW-3

\begin{tabular}{|c|c|c|c|c|}
\hline \multicolumn{5}{|c|}{ PW-3 Daily Activity } \\
\hline Day & Hours & Date & Depth & Activity \\
\hline 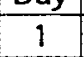 & 8 & $11 / 16 / 92$ & 0 & Move rig onto PW-3 location, setup cable spools, cut tubing/hoses \\
\hline 2 & 8 & $11 / 17 / 92$ & 0 & Log 690-440 w/SPS neutron logger \\
\hline 3 & 8 & $11 / 18 / 92$ & 0 & Log w/Century Geophysical Logging (Ray Federwisch) \\
\hline 4 & 8 & $11 / 19 / 92$ & 200 & Run 83 jts. tremie; run screen jts $1-6$; run csg jts 1-7; set Druck 940 \\
\hline 5 & 8 & $11 / 20 / 92$ & 300 & Ran csg jts $8-12$; set stations B-689, and A-639 \\
\hline 6 & 8 & $11 / 23 / 92$ & 560 & Ran csg jts $13-25$; set stations A-639, B-550, A-500 \\
\hline 7 & 9 & $11 / 24 / 92$ & 740 & Ran csg jts $26-34$; set stations B-350, A-300 \\
\hline 8 & 10 & $11 / 25 / 92$ & 860 & Ran csg jts 35-40; set stations B-250, A-200 \\
\hline 9 & 10 & $11 / 30 / 92$ & 920 & Ran csg jts 41-43; set station A-100; splice cable on Druck 639 \\
\hline 10 & 10 & $12 / 1 / 92$ & 940 & Ran csg jt 44 ; terminate cables at WH \\
\hline 11 & 10 & $12 / 2 / 92$ & 837 & Rig down cable spooling equip; rig up shotcrete unit, hopper, etc. Stem 955-837 \\
\hline 12 & 9 & $12 / 3 / 92$ & 778 & Stem $837-778$ \\
\hline 13 & 9 & $12 / 4 / 92$ & 687 & Stem 778-687, Station B-689 \\
\hline 14 & 10 & $12 / 5 / 92$ & 548 & Stem $687-548$, Station A-639, B-550 \\
\hline 5 & 2 & $12 / 7 / 92$ & 548 & Heavy rain; crew released $0900 \mathrm{hrs}$ \\
\hline$\sqrt{6}$ & 10 & $12 / 8 / 92$ & 455 & Stem 548-455; Station A-500 \\
\hline 17 & 10 & $12 / 9 / 92$ & 455 & Pull $450 \mathrm{ft} .8-5 / 8^{\prime \prime}$ casing; Pull jacks, weld on 10-3/4", reset jacks \\
\hline 18 & 10 & $12 / 10 / 92$ & 455 & Continue changeover to $10-3 / 4$ " casing; Pull on $10-3 / 4$ casing \\
\hline 19 & 10 & $12 / 11 / 92$ & 403 & Mix/pump 8 sx W-60 gypsum grout; mixed $5.5 \mathrm{gal} / 100 \mathrm{lb}$ sk; Gypsum interval $6^{\prime}-11$ " stem to 403 \\
\hline 20 & 2 & $12 / 12 / 92$ & 403 & Generator down; crew released 0900 hrs \\
\hline 21 & 10 & $12 / 14 / 92$ & 348 & Stem 403-348; Station B-350 \\
\hline 22 & 10 & $12 / 15 / 92$ & 268 & Stem 348-268; Station A-300 \\
\hline 23 & 10 & $12 / 16 / 92$ & 198 & Stem 268-198; Stations B-250, A-200 \\
\hline 24 & 10 & $12 / 17 / 92$ & 110 & Stem $198-110$ \\
\hline 25 & 10 & $12 / 18 / 92$ & 80 & Stem 110-80, Station A-100 \\
\hline 26 & 10 & $1 / 4 / 93$ & 80 & Pull remaining tremie; Bailing trips \#1-23 \\
\hline 27 & 10.5 & $1 / 5 / 93$ & 0 & RU for cementing; place 3.5 yds low-set-temperature cement; $L D$ all remaining pipe \\
\hline 28 & 10 & $1 / 6 / 93$ & 0 & Bailing trips \#24-55 \\
\hline 29 & 8 & $1 / 7 / 93$ & 0 & Bailing trips \#56-85; move jacks to PW-2 \\
\hline 30 & 8 & $1 / 8 / 93$ & 0 & Bailing trips \#86-125 \\
\hline
\end{tabular}




\section{Area 5 Pilot Wells \\ APPENDIX E \\ Laboratory Testing Data of Geologic Samples}

E.1 Stratigraphy and Mineralogy Data

E.1.1 Profiles of USCS Textural Classes

E.1.2 XRF and INAA Data

E.1.2.1 Oxide Composition Data Determined by Major Elements XRF and INAA Methods for Core Samples from UE5PW-1

E.1.2.2 Elemental Composition Data Determined by INAA and Trace Element XRF Methods for Core Samples from UE5PW-1

E.1.2.3 Oxide Composition Data Determined by Major Elements XRF and INAA Methods for Core Samples from UE5PW-2

E.1.2.4 Elemental Composition Data Determined by INAA and Trace Element XRF Methods for Core Samples from UE5PW-2

E.1.2.5 Oxide Composition Data Determined by Major Elements XRF and INAA Methods for Core Samples from UE5PW-3

E.1.2.6 Elemental Composition Data Determined by INAA and Trace Element XRF Methods for Core Samples from UE5PW-3

E.2 Material, Hydrologic, and Geochemical Parameter Data for Alluvial Samples

E.2.1 Results of Laboratory Tests for Core Samples from UE5PW-1

E.2.2 Results of Laboratory Tests for Core Samples from UE5PW-2

E.2.3 Results of Laboratory Tests for Core Samples from UE5PW-3

E.2.4 Results of Laboratory Tests for Drill Cuttings Samples from UE5PW-1

E.2.5 Results of Laboratory Tests for Drill Cuttings Samples from UE5PW-2

E.2.6 Results of Laboratory Tests for Drill Cuttings Samples from UE5PW-3

E.2.7 Moisture Retention Data for Core Samples from UE5PW-1

E.2.8 Moisture Retention Data for Core Samples from UE5PW-2

E.2.9 Moisture Retention Data for Core Samples from UE5PW-3

E.2.10 Parameters Required to Calculate Unsaturated Hydraulic Conductivities for Core Samples

E.3 Material, Hydrologic, and Geochemical Parameter Data for Tuff Samples

E.3.1 Results of Laboratory Tests for Tuff Core Samples from UE5PW-3

E.3.2 Results of Laboratory Tests for Tuff Drill Cuttings Samples from UE5PW-3

E.4 Results of Sampling and Analysis for Hazardous and Radiological Parameters in Core Samples 


\section{Appendix E.1.1 Profile of USCS Textural Classes}

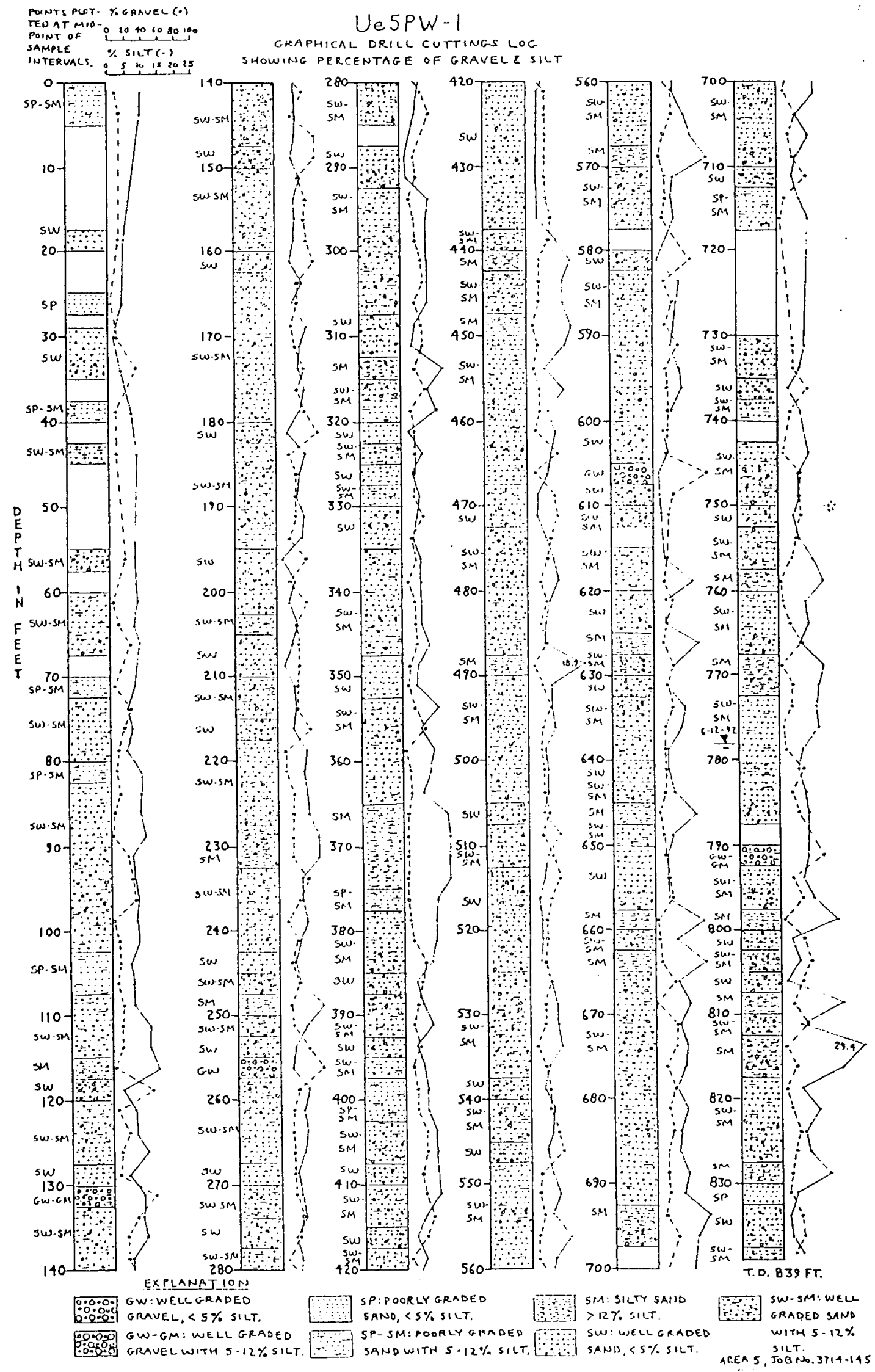




\section{Appendix E.1.1 Profile of USCS Textural Classes (Continued)}

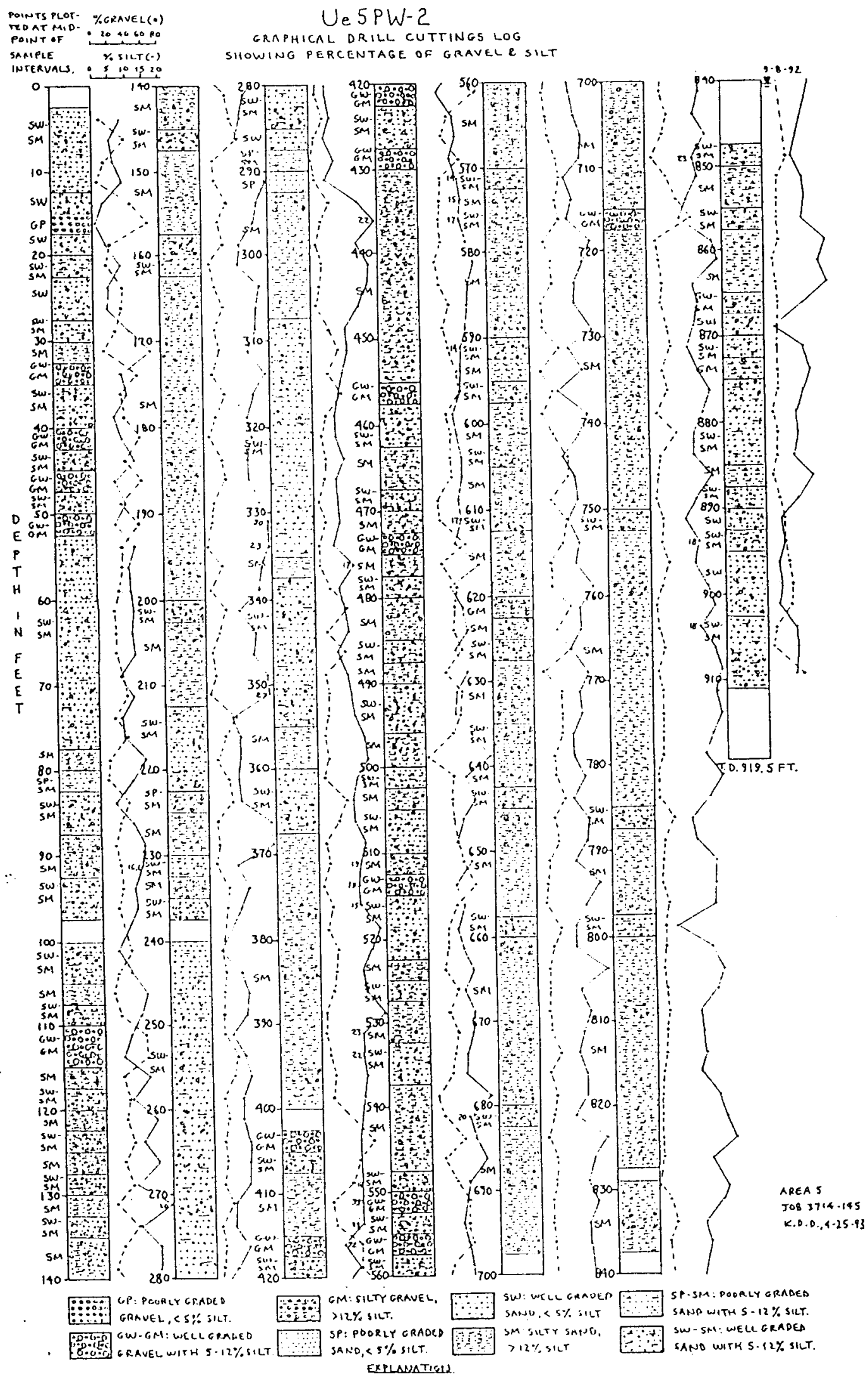


Appendix E.1.1 Profile of USCS Textural Classes (Continued)

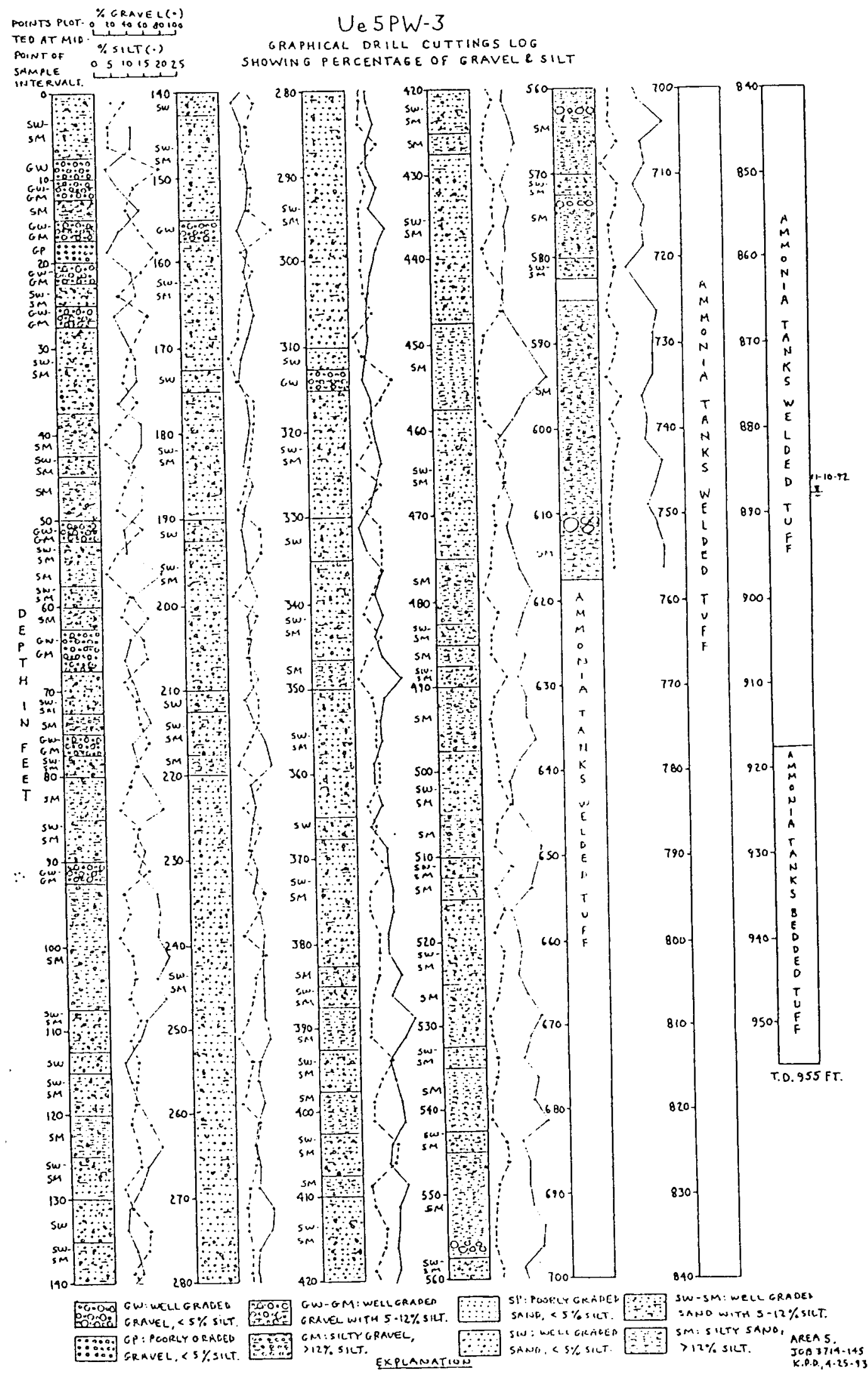




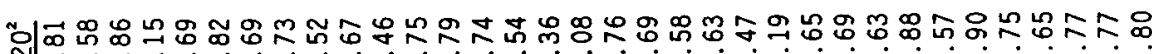

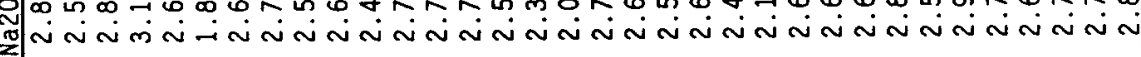

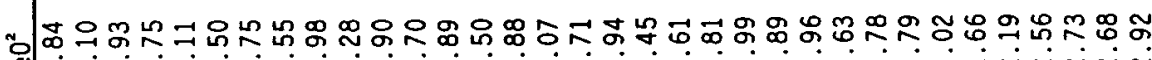

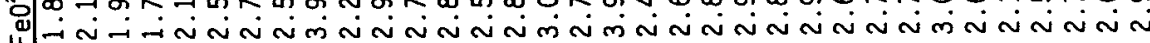

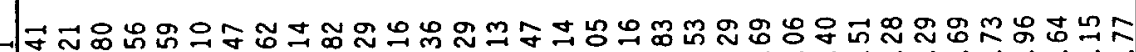
ف

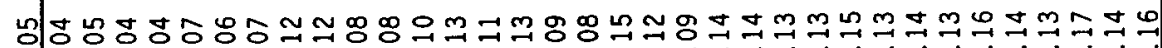

ล

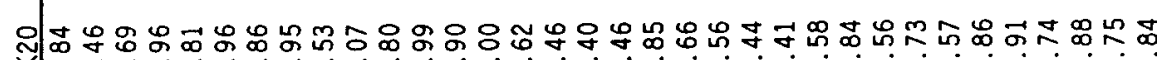

芒

में लंखिं

$\stackrel{\Phi}{\underline{y}}$

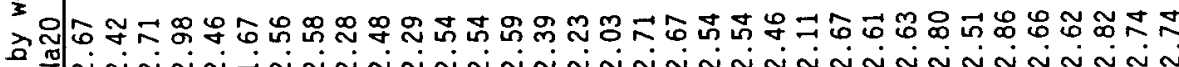

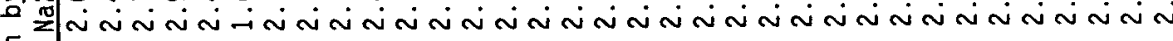

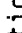

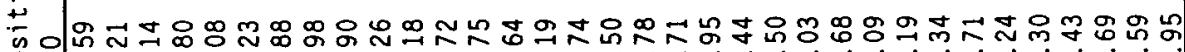
응

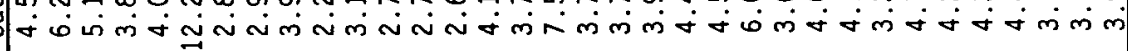

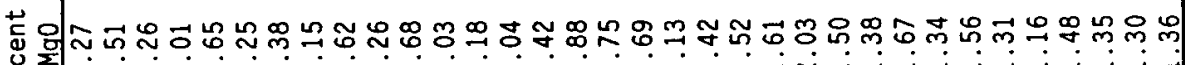

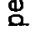
-

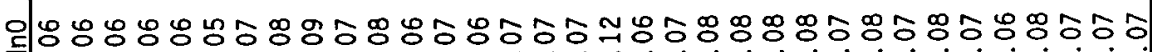

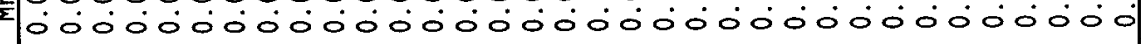

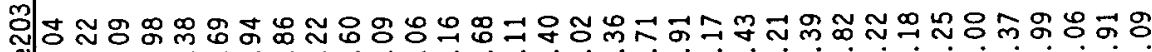

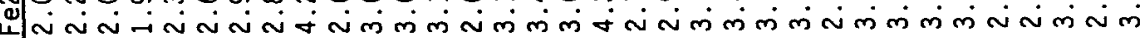

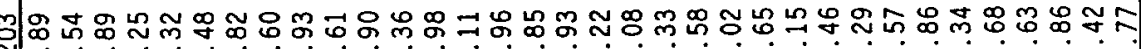

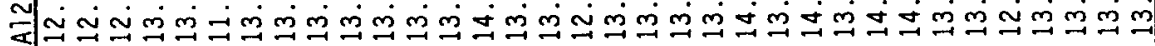

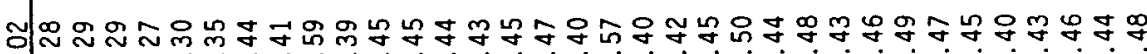
Fó000000000000000000000000000000

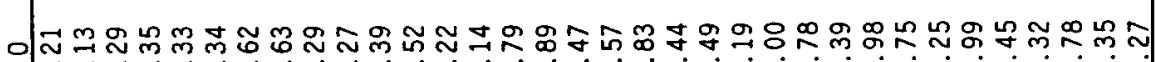
क ஜ

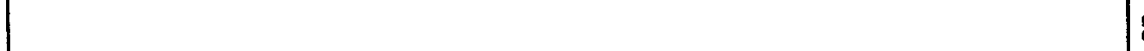

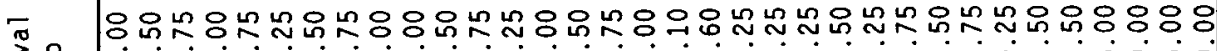

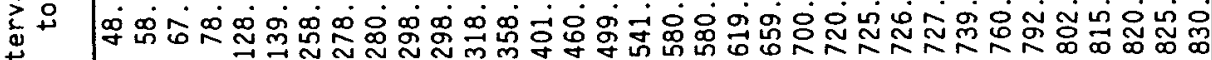

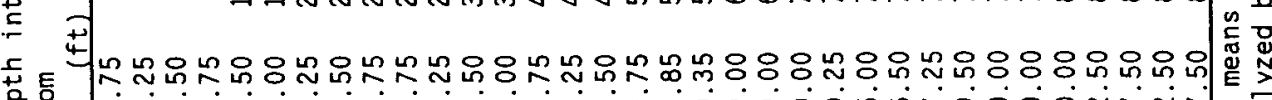




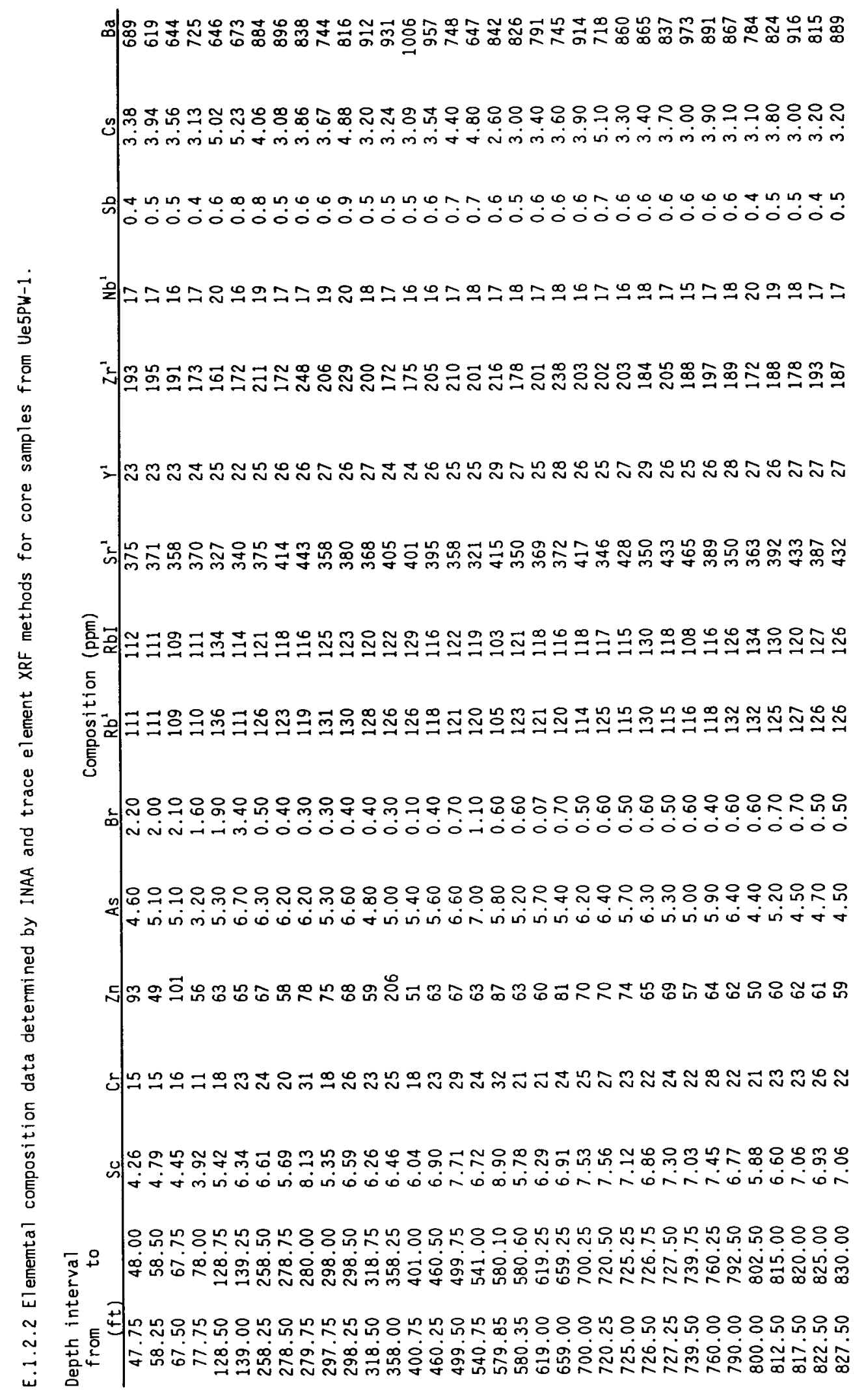




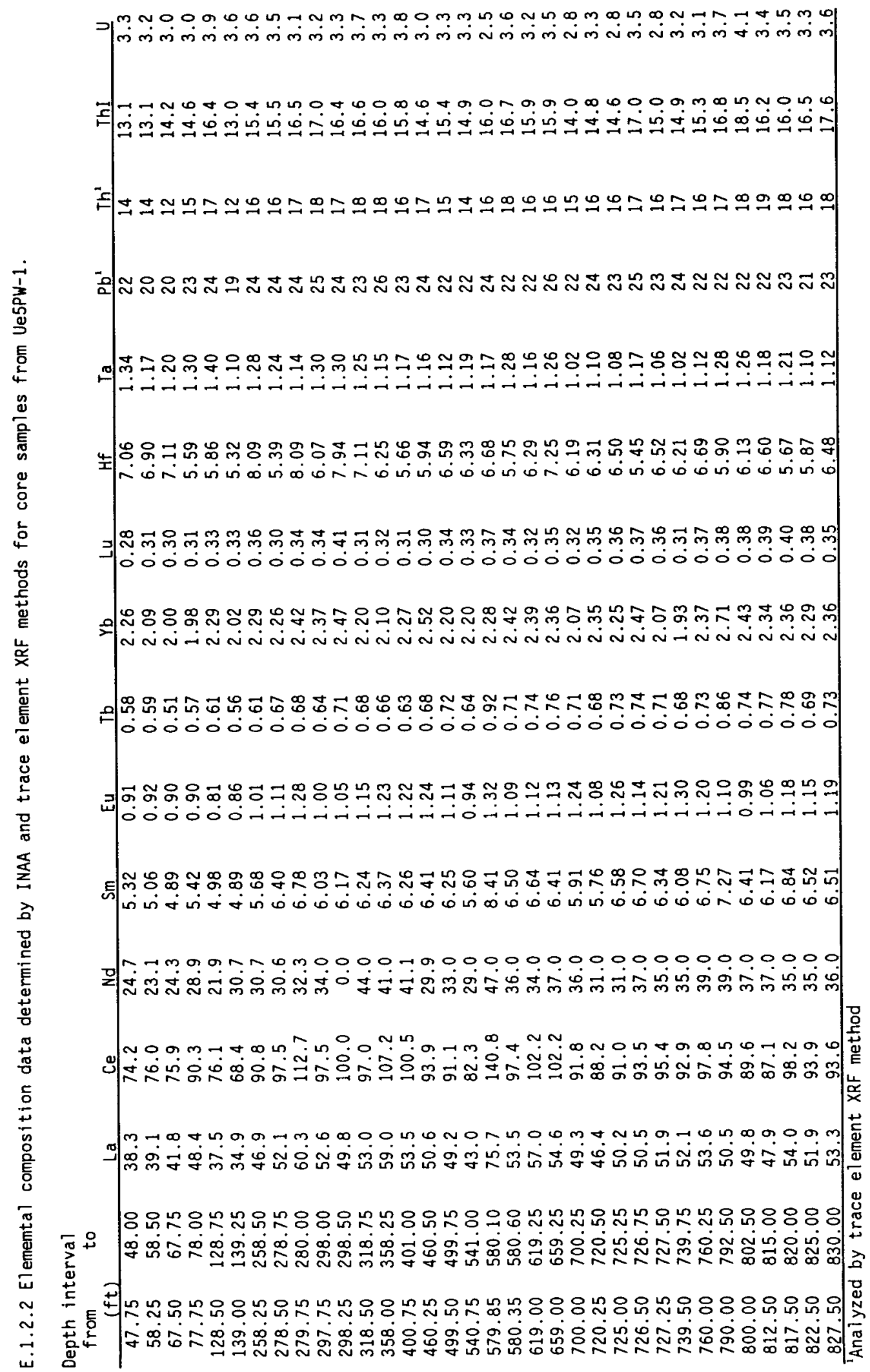




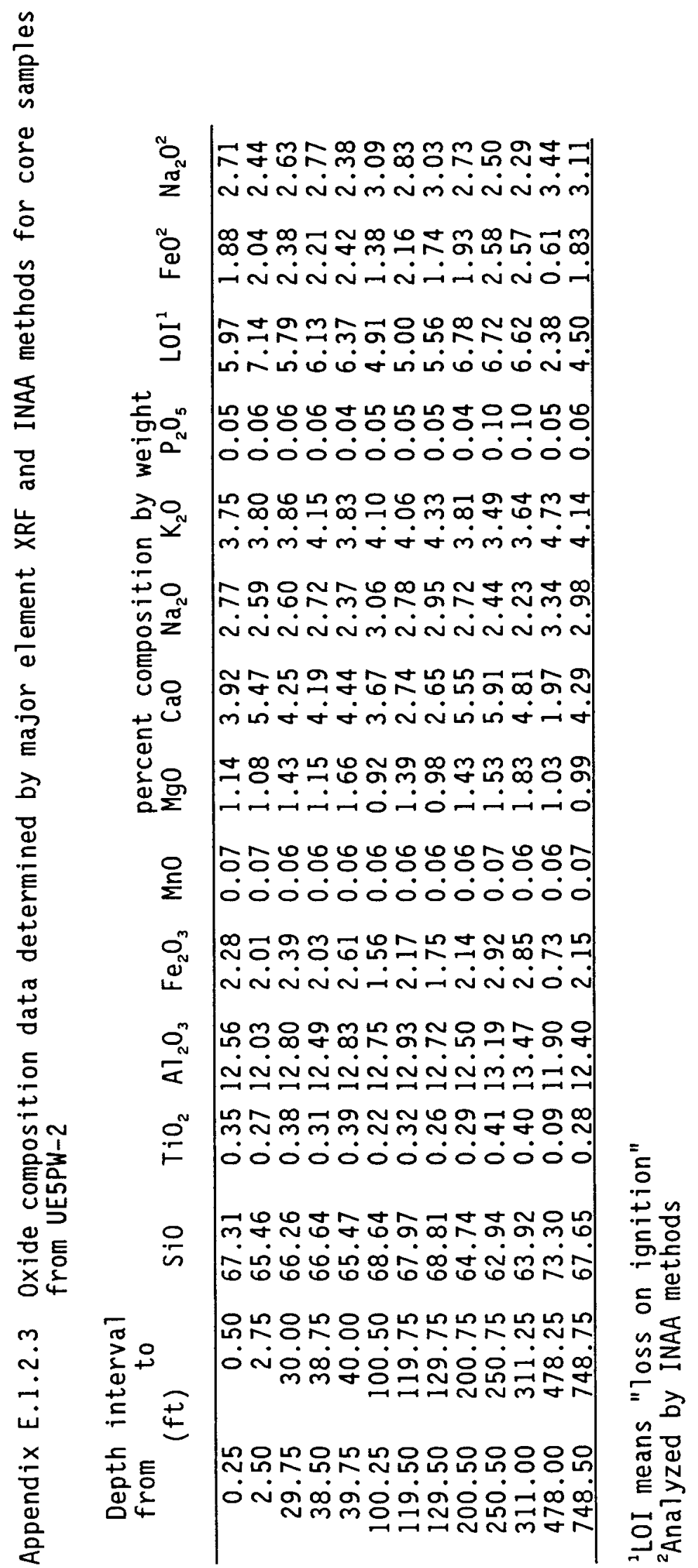




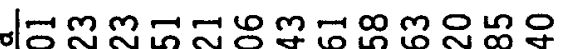

$\mid$ mommn $\infty$ on

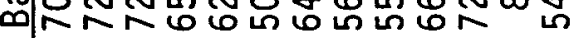

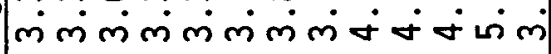

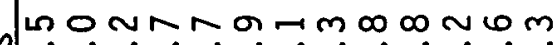

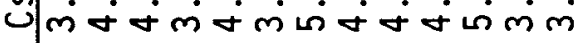

L R R जी०ं $\dot{0} \dot{0} \dot{0} \dot{0} \dot{0} \dot{0} \dot{0} \dot{0}$ 임 $\infty$ a $\sigma \infty$ a

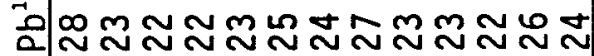

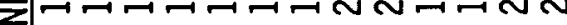
- 웜ำ

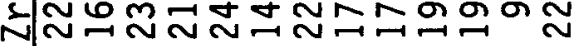

ᄀहิ드.

- $+\infty \infty \pi \omega \infty m$ m

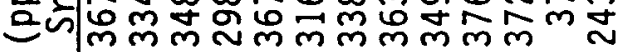

동

$\because$ 으요

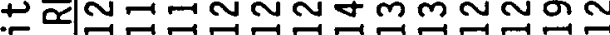

$\stackrel{0}{0}$

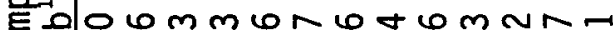

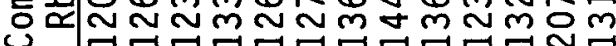

ป

s

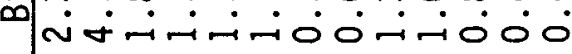

nั0น

كن

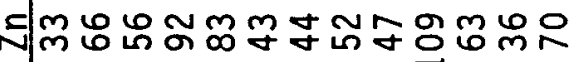

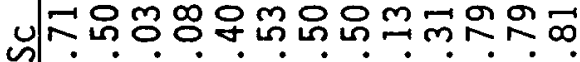

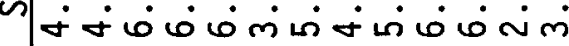

Nㅐmono

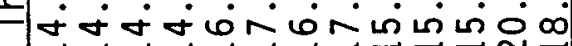

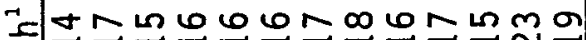

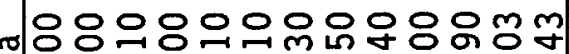

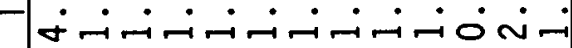

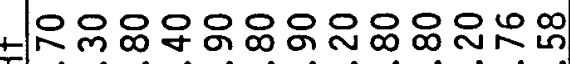
ம

NNL $\exists m m m m m m m m m m m$ q

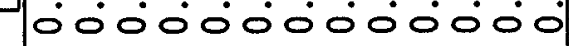

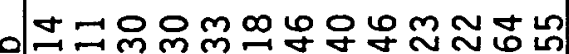
- vنं $\dot{\sim} \dot{\sim} \dot{\sim} \sim \vec{\sim}$

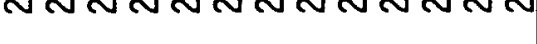

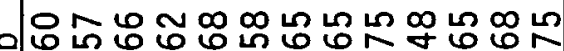

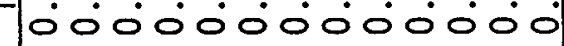

-

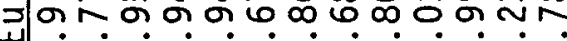
ن 00000000 - 000 nan a n

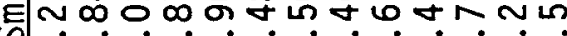

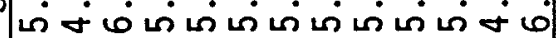

mNG

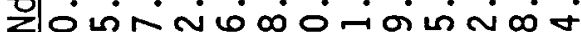
$m \backsim N m \sim m m \backsim m m$ Namanamantamo ه) $\dot{0} \dot{0} \dot{\dot{\theta}} \dot{0} \dot{0} \dot{0} \dot{0} \dot{0} \dot{0}$ जర

- $m$ m

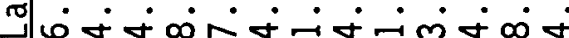
m

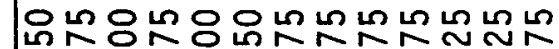
mRó i $\dot{0} \dot{0} \dot{0} \dot{0} \dot{0} \dot{0} \dot{0} \dot{\infty}$

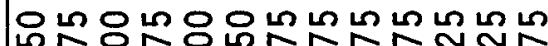
LOROOLRNRNNNN - $\dot{0} \dot{0} \dot{0} \dot{0} \dot{0} \dot{0} \dot{0} \dot{0} \dot{0}$

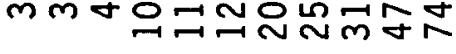

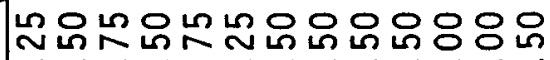
○ i Nmm

느은 NUR - Nंक Nm 


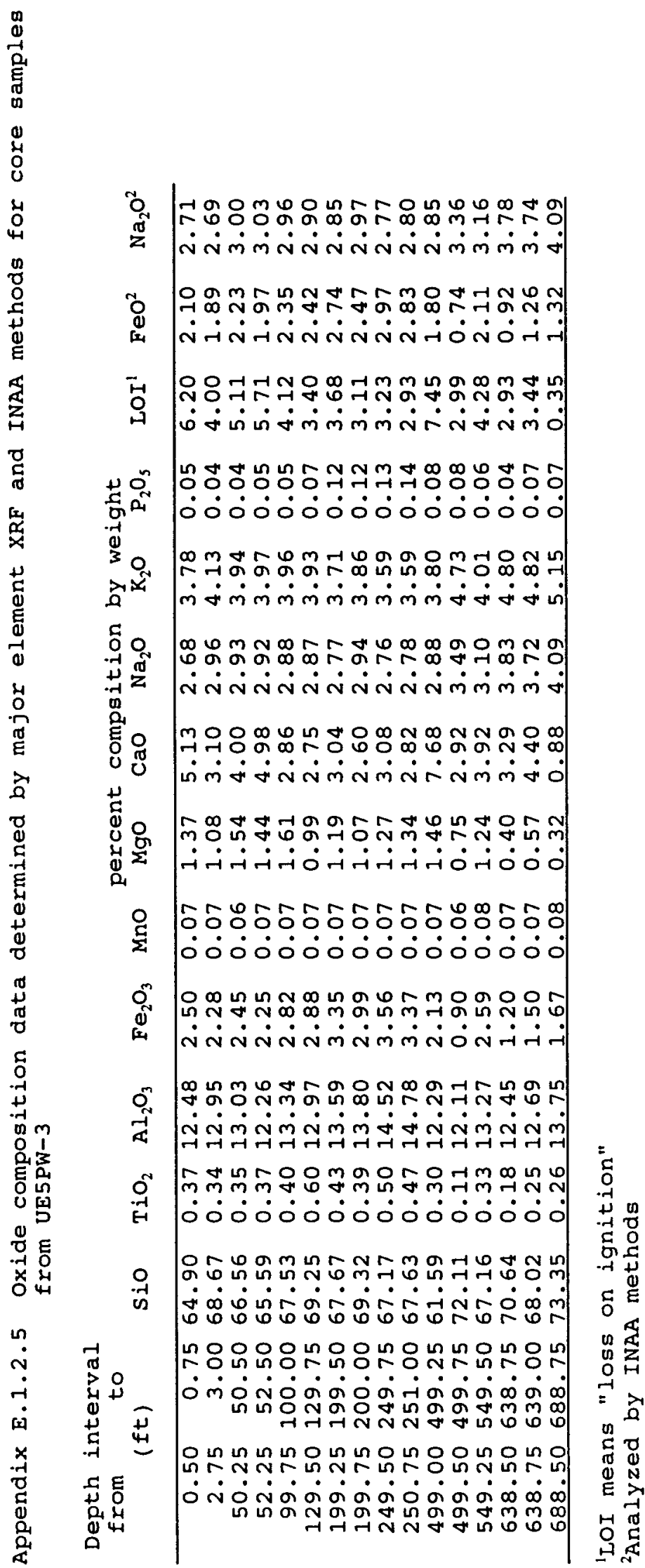


ศ ตी

"NopuOm\&

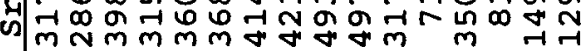

แn $\infty$ ㅇmm

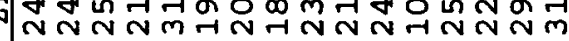

แn un 0 in $06 \omega$ o HNNNNNNNNNNNMNMmM

ด

:

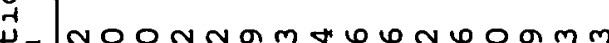

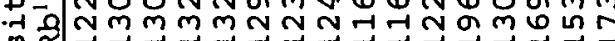
of م. 员.

\section{ติ}

onanamonhm Mm nn

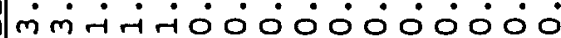

m

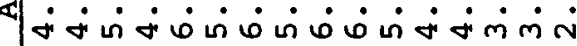

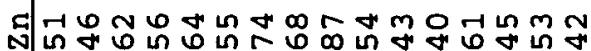

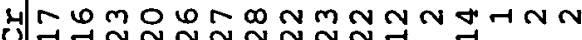

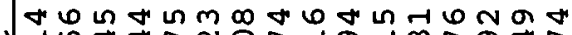

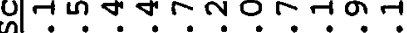
实的

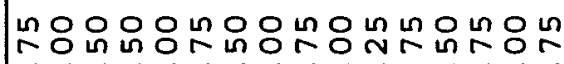

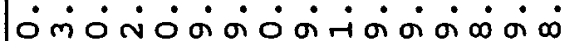
แ

to 4⿻ำ 는

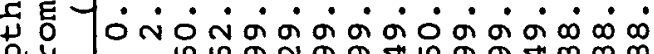

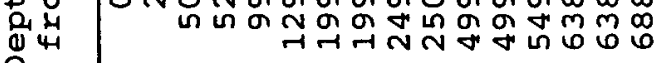

mnoanatatmonnmmn $D \dot{m} \dot{m} \dot{\sigma} \dot{m} \dot{m} \dot{m} \dot{m} \dot{m} \dot{\sigma} \dot{\sigma} \dot{\sigma} \dot{\sigma} \dot{\sigma}$

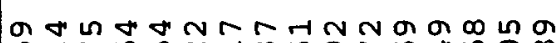
द

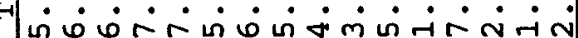

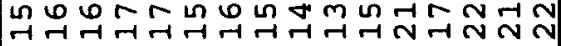

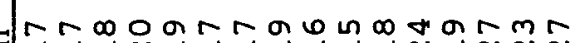

- mmonむl

แ $\infty \omega \sigma \infty+N R m a n \infty$ n

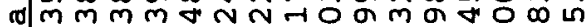

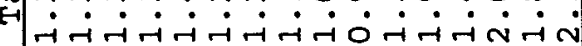

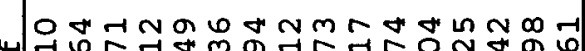

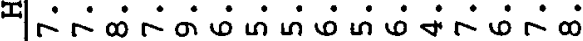
n. J $\mathrm{mmmmmm} \mathrm{mm} \mathrm{m} \mathrm{m} \mathrm{m}$ ن 0 o 0 o 0 o 0 o 0 o 0 o 00

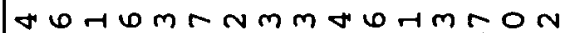

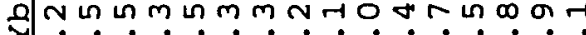
Nं $\dot{N} \dot{N} \dot{N} \dot{N} \dot{N} \dot{N} \dot{N} \dot{N}$

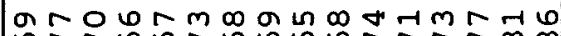

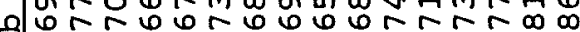
i $\dot{0} \dot{0} \dot{0} \dot{0} \dot{0} \dot{0} \dot{0} \dot{0} \dot{0} \dot{0} 0$

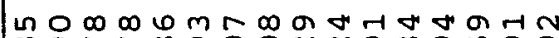

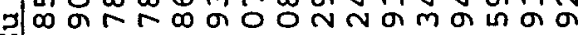

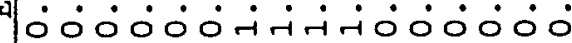
E

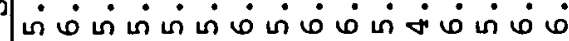
an $N \infty$ - $m \infty \infty \infty$ in a $\infty$ in in $\mathrm{n}$

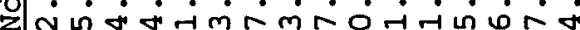
लूल od $\| \dot{0} \dot{0} \dot{0} \dot{0} \dot{0} \dot{0} \dot{0} \dot{0} \dot{0} \dot{0} \dot{0}$

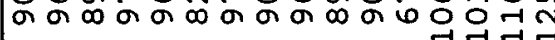

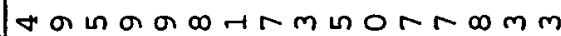

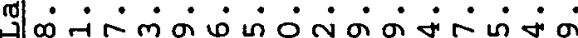

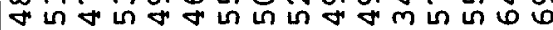
no o o o no o mo m no mo m

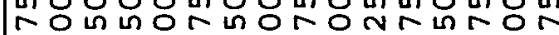
- $\dot{0} \dot{0} \dot{0} \dot{\sigma} \dot{0} \dot{0} \dot{\theta} \dot{\sigma} \dot{\sigma} \dot{\sigma} \dot{\sigma} \dot{0}$

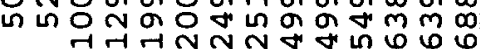
o un un un un o in in o un o o in o un Unt

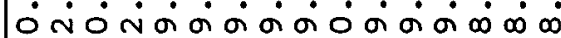
แ 


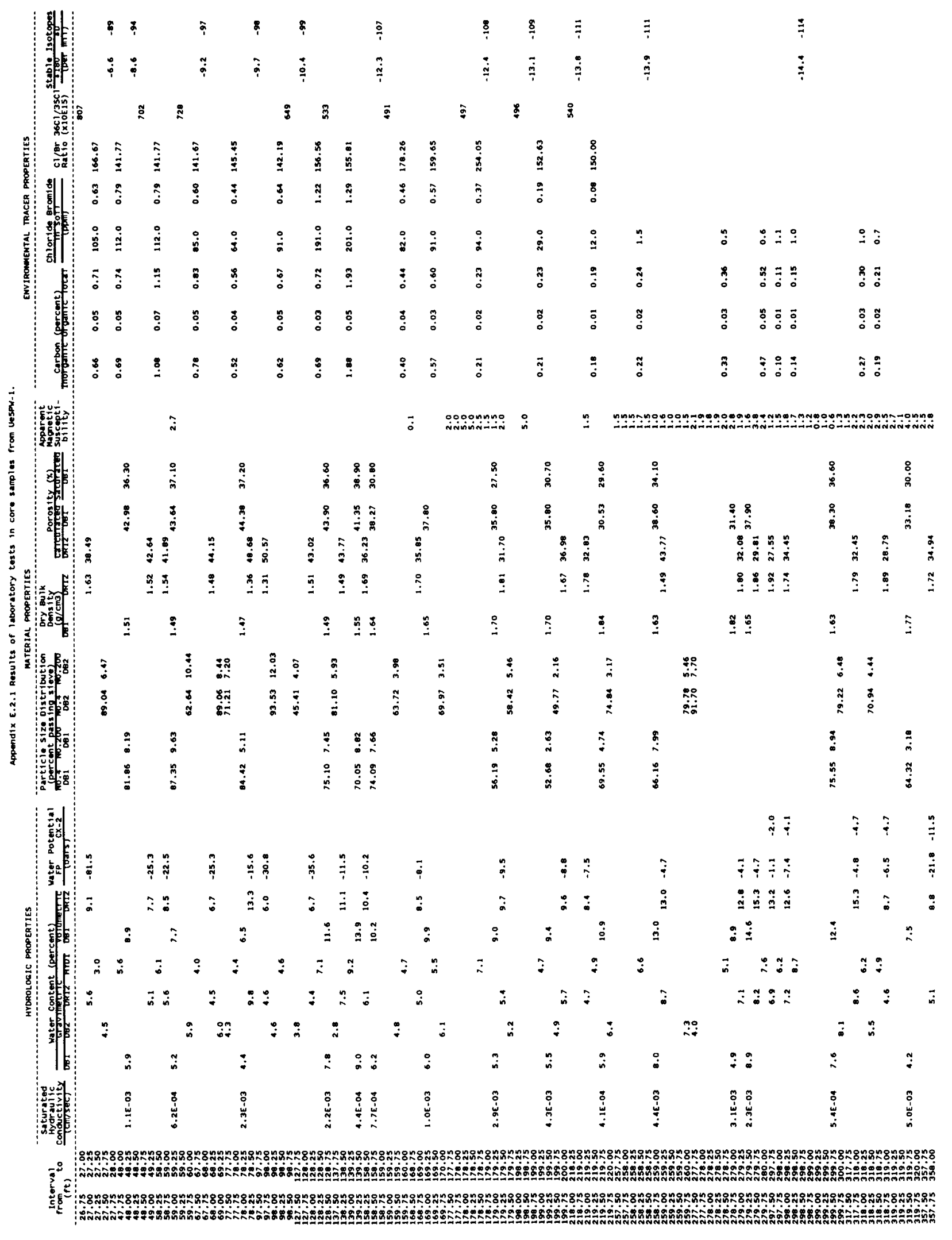




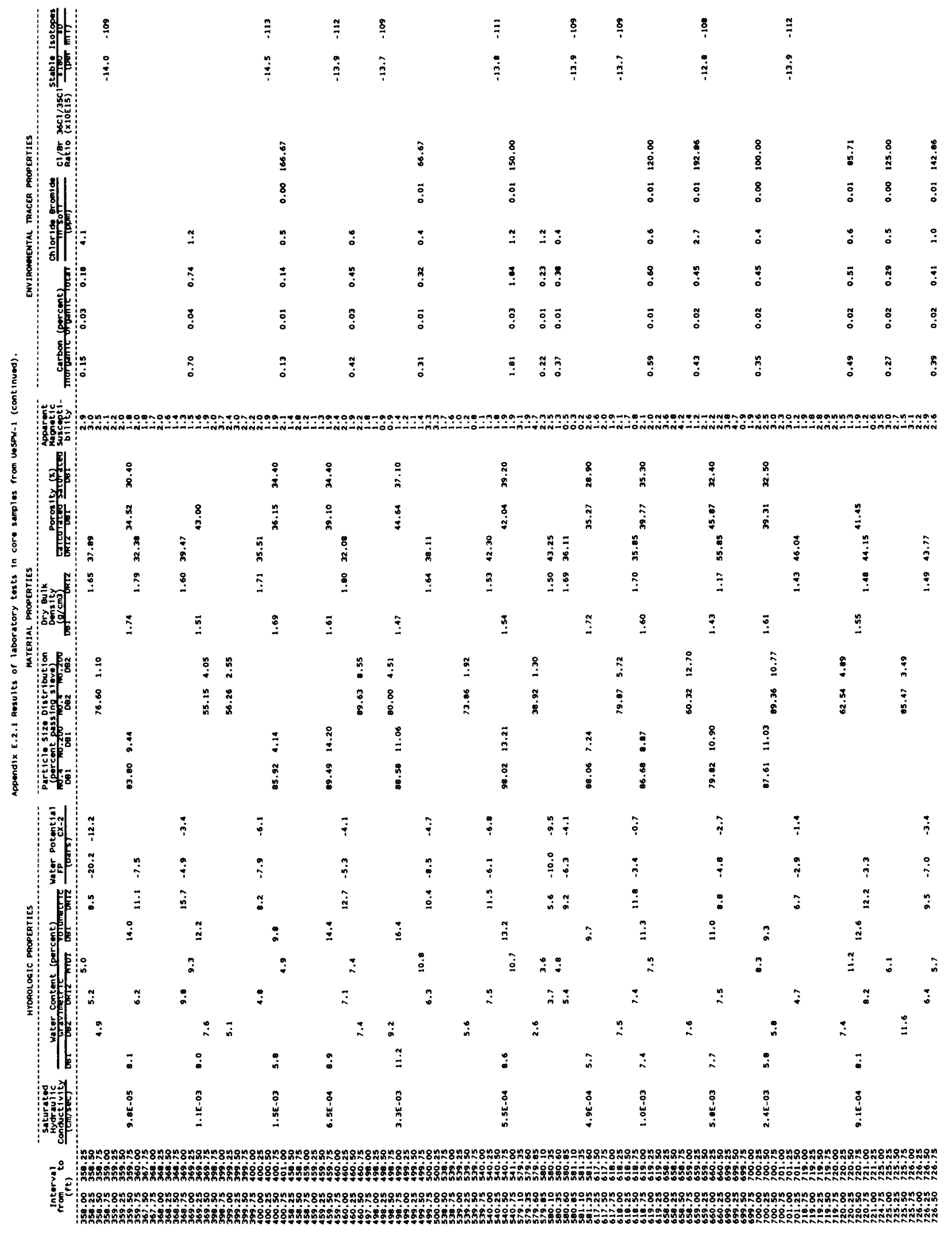




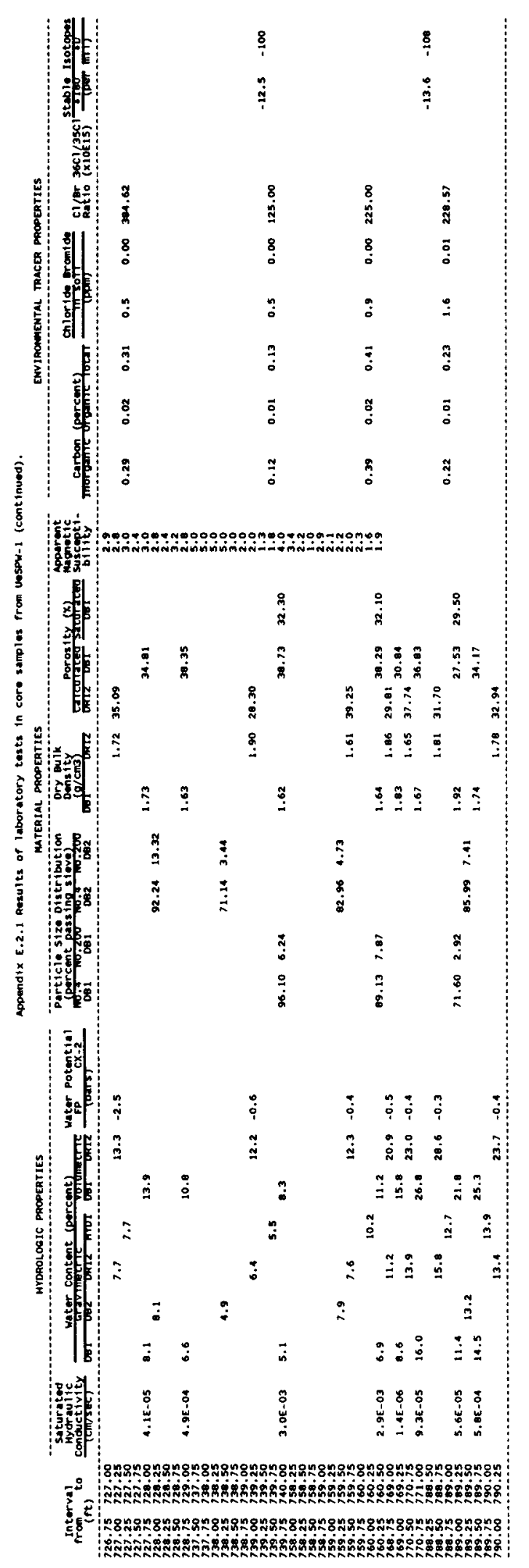




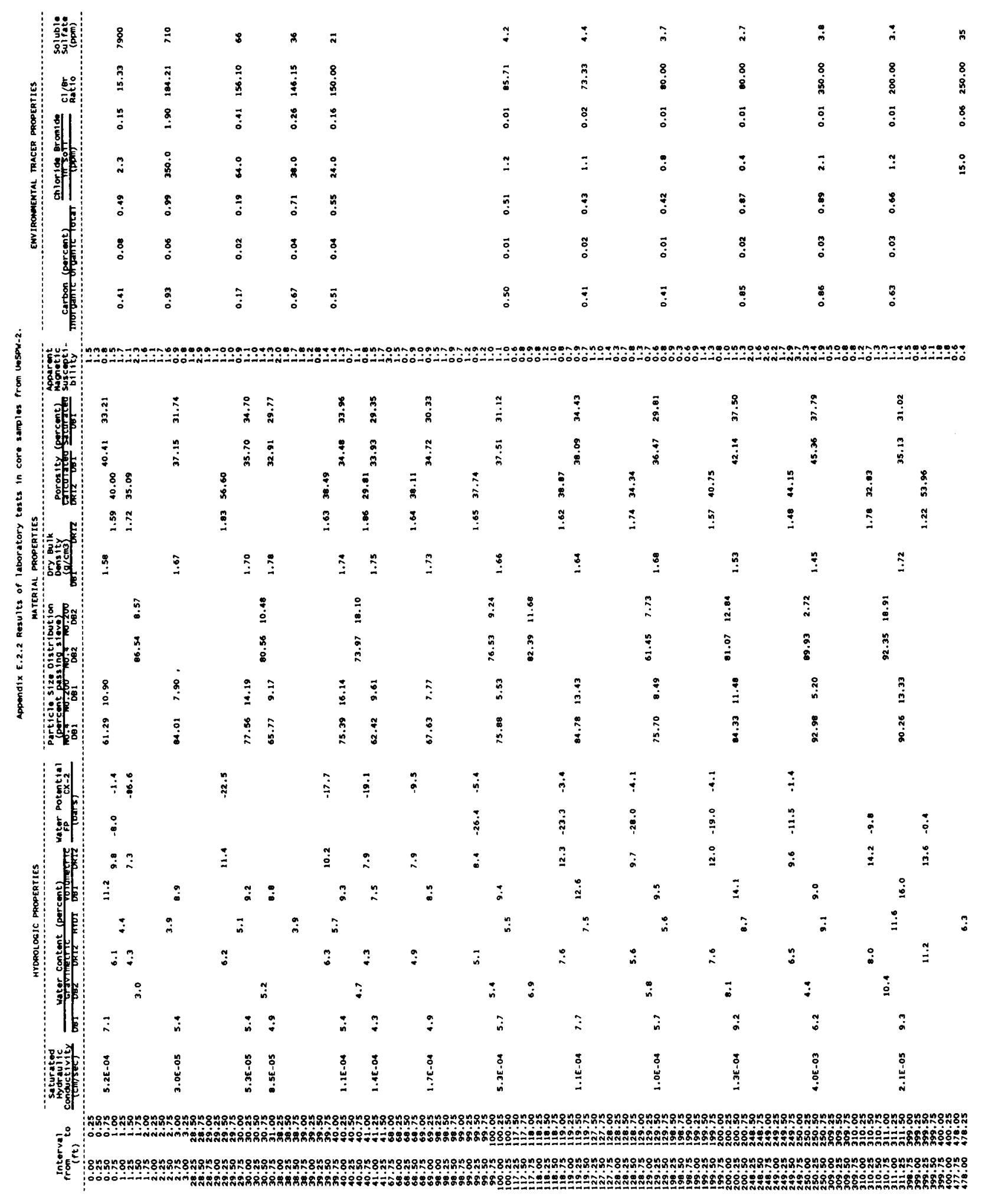




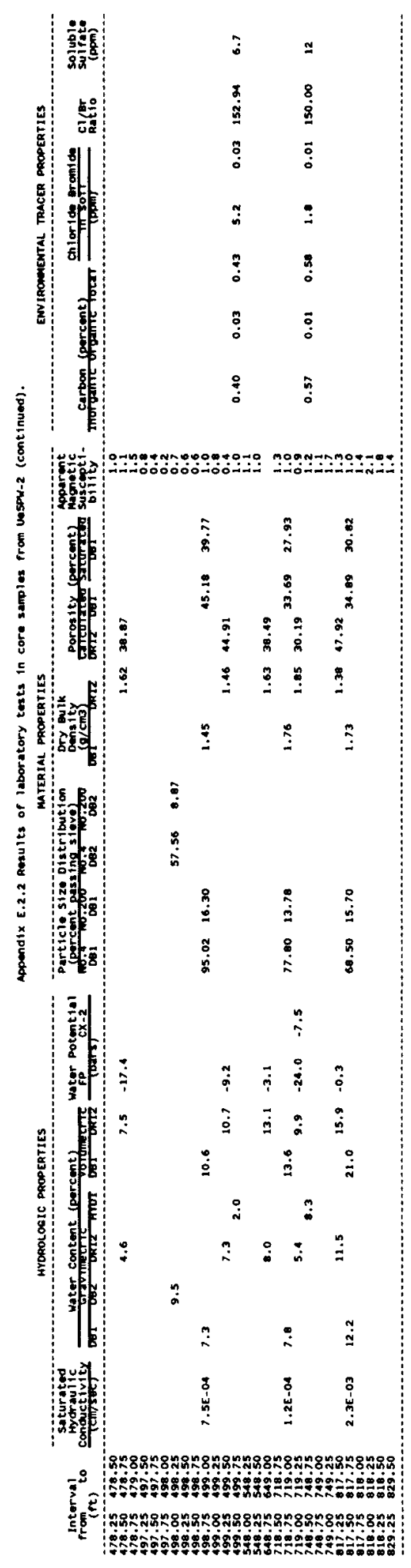




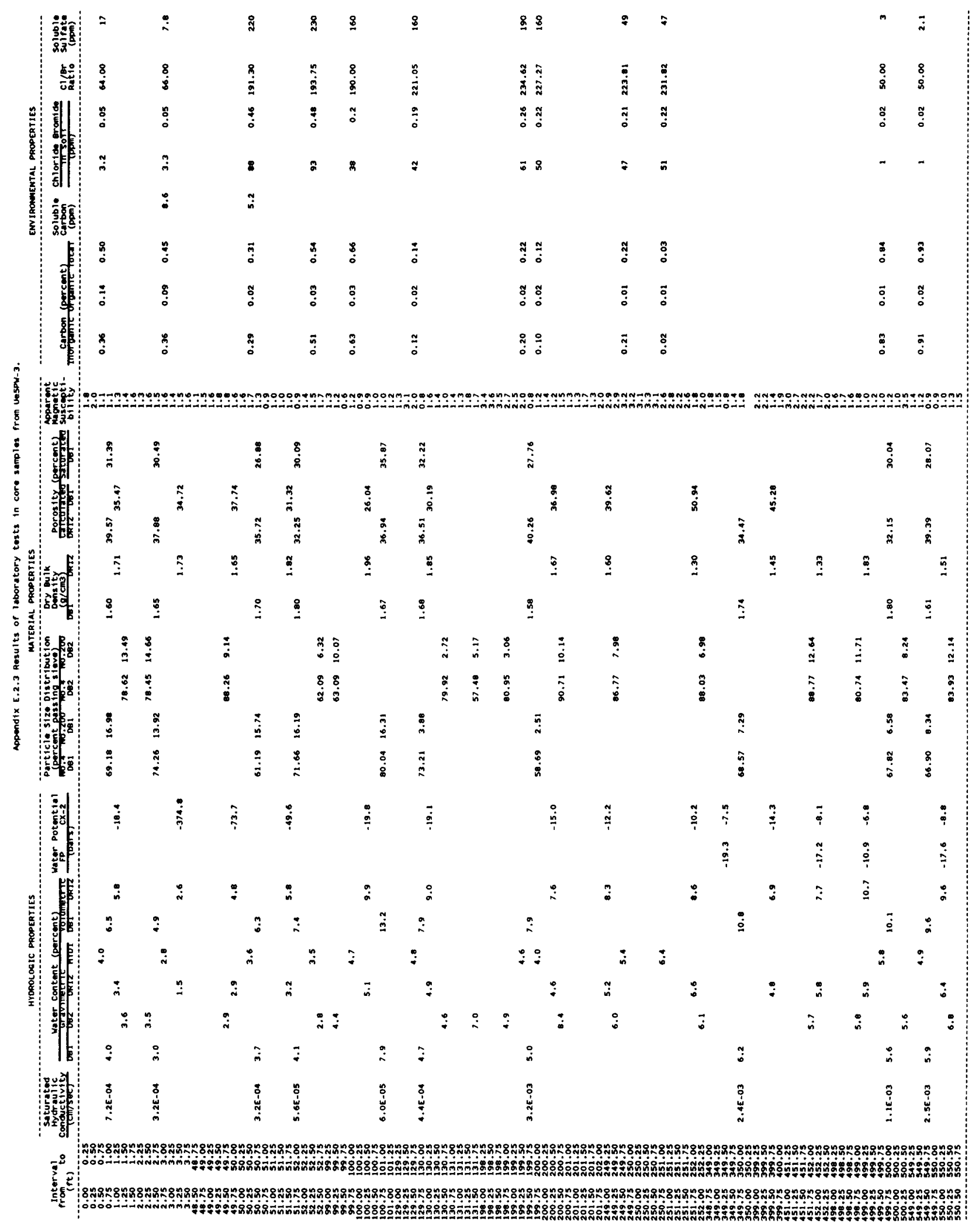




\section{Addenda}

Appendix E.2.1 Results of laboratory tests for core samples from UE5PW-1.

\begin{tabular}{|c|c|}
\hline \multicolumn{2}{|l|}{ Interval } \\
\hline $\begin{array}{c}\text { from to } \\
\text { (ft) }\end{array}$ & $\begin{array}{l}{ }^{36} \mathrm{Cl} / \mathrm{Cl} \\
\left(\times 10^{-15}\right) \\
\end{array}$ \\
\hline 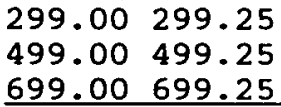 & $\begin{array}{l}184 \\
531 \\
539\end{array}$ \\
\hline
\end{tabular}

Appendix E.2.2 Results of laboratory tests for core samples from UE5PW-2.

\begin{tabular}{|c|c|c|c|c|}
\hline $\begin{array}{r}\text { Int } \\
\text { from } \\
(\end{array}$ & $\begin{array}{r}\text { erval } \\
\text { to } \\
\text { tel }\end{array}$ & $\begin{array}{c}\text { Stable } \\
\delta^{18} \mathrm{O}\end{array}$ & $\begin{array}{c}\text { Isotpoes } \\
\delta \mathrm{D} \\
\text { per mill }\end{array}$ & $\begin{array}{l}{ }^{36} \mathrm{Cl} / \mathrm{Cl} \\
\left(\times 10^{-15}\right)\end{array}$ \\
\hline $\begin{array}{r}2.00 \\
28.75 \\
29.50 \\
38.75 \\
40.25 \\
41.25 \\
68.00 \\
68.75 \\
99.50 \\
119.00 \\
128.75 \\
199.75 \\
249.75 \\
310.50 \\
399.50 \\
478.75 \\
499.00 \\
718.50 \\
817.75\end{array}$ & $\begin{array}{r}2.25 \\
29.00 \\
29.75 \\
39.00 \\
40.50 \\
41.50 \\
68.25 \\
69.00 \\
99.75 \\
119.25 \\
129.00 \\
200.00 \\
250.00 \\
310.75 \\
399.75 \\
479.00 \\
499.25 \\
718.75 \\
818.00\end{array}$ & $\begin{array}{r}-1.5 \\
-6.6 \\
-8.2 \\
-8.4 \\
-12.7 \\
-14.2 \\
-13.9 \\
-15.6 \\
-15.7 \\
-14.1 \\
-14.6 \\
-14.4 \\
-11.8 \\
-13.8 \\
-9.6 \\
-11.2\end{array}$ & $\begin{array}{l}-66 \\
-87 \\
-45 \\
-95 \\
-112 \\
-119 \\
-120 \\
-124 \\
-127 \\
-118 \\
-119 \\
-115 \\
-101 \\
-112 \\
-78 \\
-95\end{array}$ & $\begin{array}{r}882 \\
906 \\
716\end{array}$ \\
\hline
\end{tabular}

Appendix E.2.3 Results of laboratory tests for core samples from UE5PW-3.

\begin{tabular}{|c|c|c|c|c|}
\hline $\begin{array}{r}\text { Int } \\
\text { from }\end{array}$ & $\begin{array}{l}\text { erval } \\
\text { to } \\
\text { et) }\end{array}$ & $\begin{array}{c}\text { Stable } \\
\delta^{18} \mathrm{O} \\
\text { (pe }\end{array}$ & $\begin{array}{c}\text { Isotopes } \\
\delta D \\
\text { mill }\end{array}$ & $\begin{array}{l}{ }^{36} \mathrm{Cl} / \mathrm{Cl} \\
\left(\times 10^{-15}\right)\end{array}$ \\
\hline $\begin{array}{r}0.25 \\
3.00 \\
49.25 \\
50.00 \\
52.00 \\
99.50 \\
100.00 \\
130.75 \\
131.00 \\
199.00 \\
200.00 \\
200.75 \\
249.75 \\
250.00 \\
250.50 \\
349.50 \\
399.75 \\
452.25 \\
499.25 \\
549.75 \\
638.25\end{array}$ & $\begin{array}{r}0.50 \\
3.25 \\
49.50 \\
50.25 \\
52.25 \\
99.75 \\
100.25 \\
131.00 \\
131.25 \\
199.25 \\
200.25 \\
201.00 \\
250.00 \\
250.25 \\
250.75 \\
349.75 \\
400.00 \\
452.50 \\
499.50 \\
550.00 \\
638.50\end{array}$ & $\begin{array}{r}+4.8 \\
+2.3 \\
-8.4 \\
-7.9 \\
-13.1 \\
-13.9 \\
-14.0 \\
-14.2 \\
-14.1 \\
-14.6 \\
-14.3 \\
-13.3 \\
-12.7 \\
-13.5 \\
-12.9 \\
-10.8\end{array}$ & $\begin{array}{r}-53 \\
-57 \\
-94 \\
-100 \\
-115 \\
-119 \\
-119 \\
-119 \\
-119 \\
-122 \\
\\
-110 \\
-112 \\
-110\end{array}$ & $\begin{array}{l}657 \\
642\end{array}$ \\
\hline
\end{tabular}


Appendix 2.4 Results of laboratory tests in cuttings samples from Ue5PW-1.

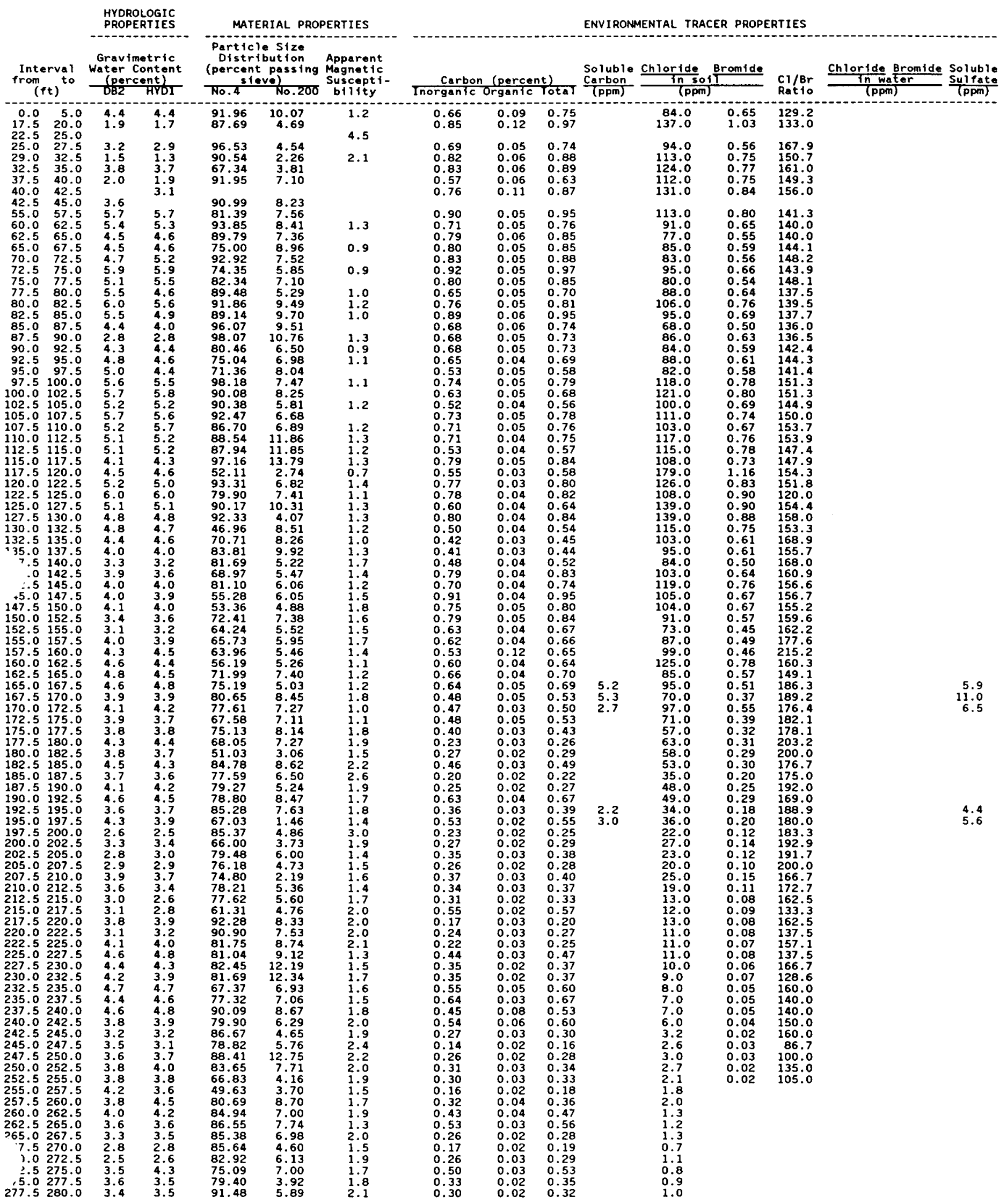




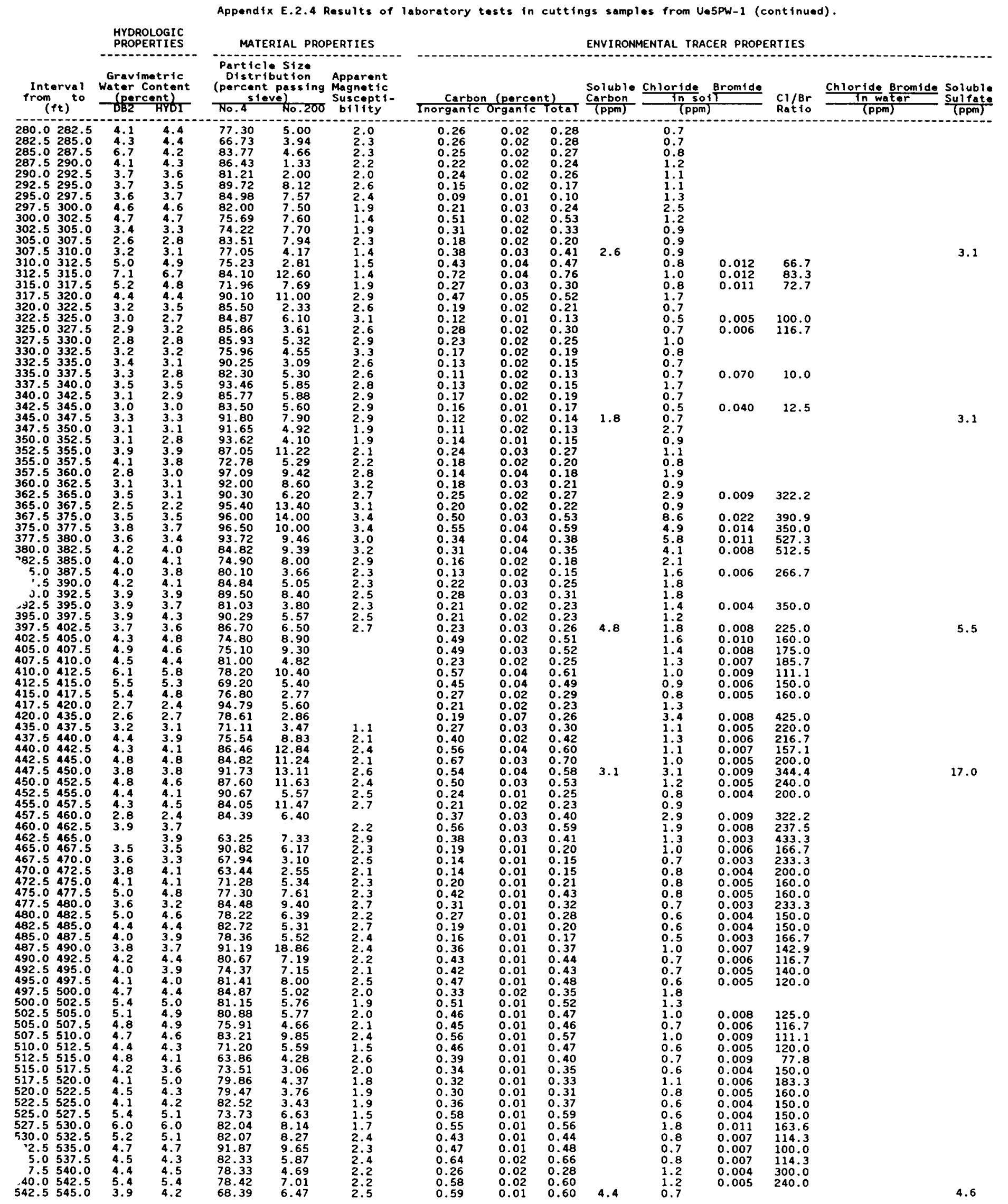


Appendix E.2.4 Results of laboratory tests in cuttings samples from Ue5P-1 (continued).

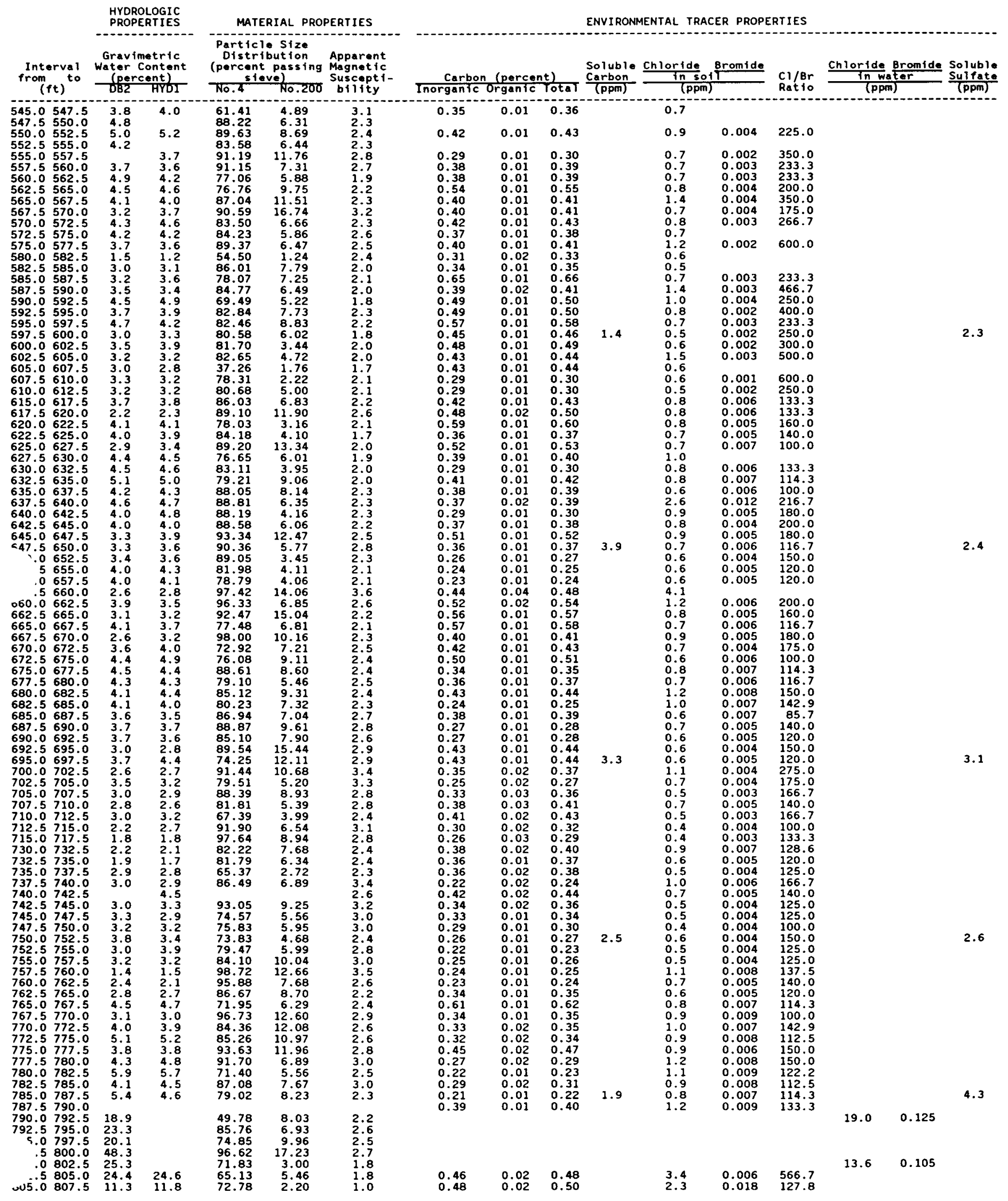




\begin{tabular}{|c|c|c|c|c|c|c|c|c|c|c|c|c|c|c|c|}
\hline \multirow[b]{2}{*}{$\begin{array}{l}\text { Interval } \\
\text { from to } \\
(f t)\end{array}$} & \multicolumn{2}{|c|}{$\begin{array}{l}\text { HYOROLOGIC } \\
\text { PROPERTIES }\end{array}$} & \multicolumn{3}{|c|}{ MATERIAL PROPERTIES } & \multicolumn{10}{|c|}{ ENVIROMMENTAL TRACER PROPERTIES } \\
\hline & $\begin{array}{r}\text { Gravt } \\
\text { water } \\
\text { (per } \\
0 B 2\end{array}$ & $\begin{array}{l}\text { etric } \\
\text { ontent } \\
\text { ent } \\
\text { HYb }\end{array}$ & $\begin{array}{r}\text { Particl } \\
\text { Distiri } \\
\text { (percent } \\
\text { ste } \\
\text { No.4 }\end{array}$ & $\begin{array}{l}\text { Size } \\
\text { bution } \\
\text { passing } \\
\text { ve) } \\
\text { Ho.200 }\end{array}$ & $\begin{array}{l}\text { Apparent } \\
\text { Magnetic } \\
\text { Suscepti- } \\
\text { bility }\end{array}$ & $\frac{\text { Carbo }}{\text { Inorgantc }}$ & $\frac{\text { (perce }}{\text { Organic }}$ & nt) & $\begin{array}{l}\text { Solubie } \\
\text { Carbon } \\
\text { (ppm) }\end{array}$ & $\frac{\frac{\text { Chloride }}{\text { in sort }}}{\text { (ppm) }}$ & Bromide & $\begin{array}{l}\mathrm{Cl} / \mathrm{Br} \\
\text { Ratto }\end{array}$ & $\frac{\frac{\text { Chloride }}{\text { in wat }}}{(\mathrm{ppm})}$ & $\frac{\text { Bromide }}{\text { ter }}$ & $\begin{array}{l}\text { Soluble } \\
\text { Sulfate } \\
\text { (ppm) }\end{array}$ \\
\hline 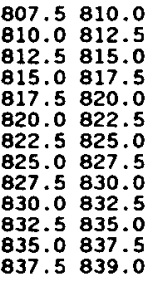 & $\begin{array}{r}23.2 \\
11.3 \\
32.3 \\
23.7 \\
24.8 \\
23.5 \\
25.3 \\
23.4 \\
32.4 \\
20.9 \\
14.3 \\
15.3 \\
8.3\end{array}$ & $\begin{array}{r}19.9 \\
14.7 \\
29.6 \\
8.1\end{array}$ & $\begin{array}{l}85.24 \\
69.56 \\
95.07 \\
80.63 \\
93.22 \\
89.25 \\
79.25 \\
80.99 \\
88.63 \\
90.70 \\
79.13 \\
74.44 \\
86.20\end{array}$ & $\begin{array}{r}18.26 \\
5.50 \\
29.39 \\
17.78 \\
6.66 \\
11.56 \\
6.79 \\
7.83 \\
14.43 \\
4.05 \\
2.40 \\
2.67 \\
5.80\end{array}$ & $\begin{array}{l}1.7 \\
1.0 \\
1.8 \\
2.2 \\
2.6 \\
2.8 \\
2.8 \\
3.4 \\
2.7 \\
2.5 \\
1.2 \\
0.9 \\
1.5\end{array}$ & $\begin{array}{l}0.21 \\
0.64 \\
0.84 \\
0.45\end{array}$ & $\begin{array}{l}0.01 \\
0.02 \\
0.03 \\
0.02\end{array}$ & $\begin{array}{l}0.22 \\
0.66 \\
0.87 \\
0.47\end{array}$ & & $\begin{array}{l}2.1 \\
1.7 \\
1.8 \\
1.4\end{array}$ & $\begin{array}{l}0.012 \\
0.013 \\
0.014 \\
0.011\end{array}$ & $\begin{array}{l}175.0 \\
130.8 \\
128.6 \\
127.3\end{array}$ & $\begin{array}{l}14.5 \\
12.2 \\
12.4 \\
14.7\end{array}$ & $\begin{array}{l}0.11 \\
0.09 \\
0.095 \\
0.115\end{array}$ & \\
\hline
\end{tabular}




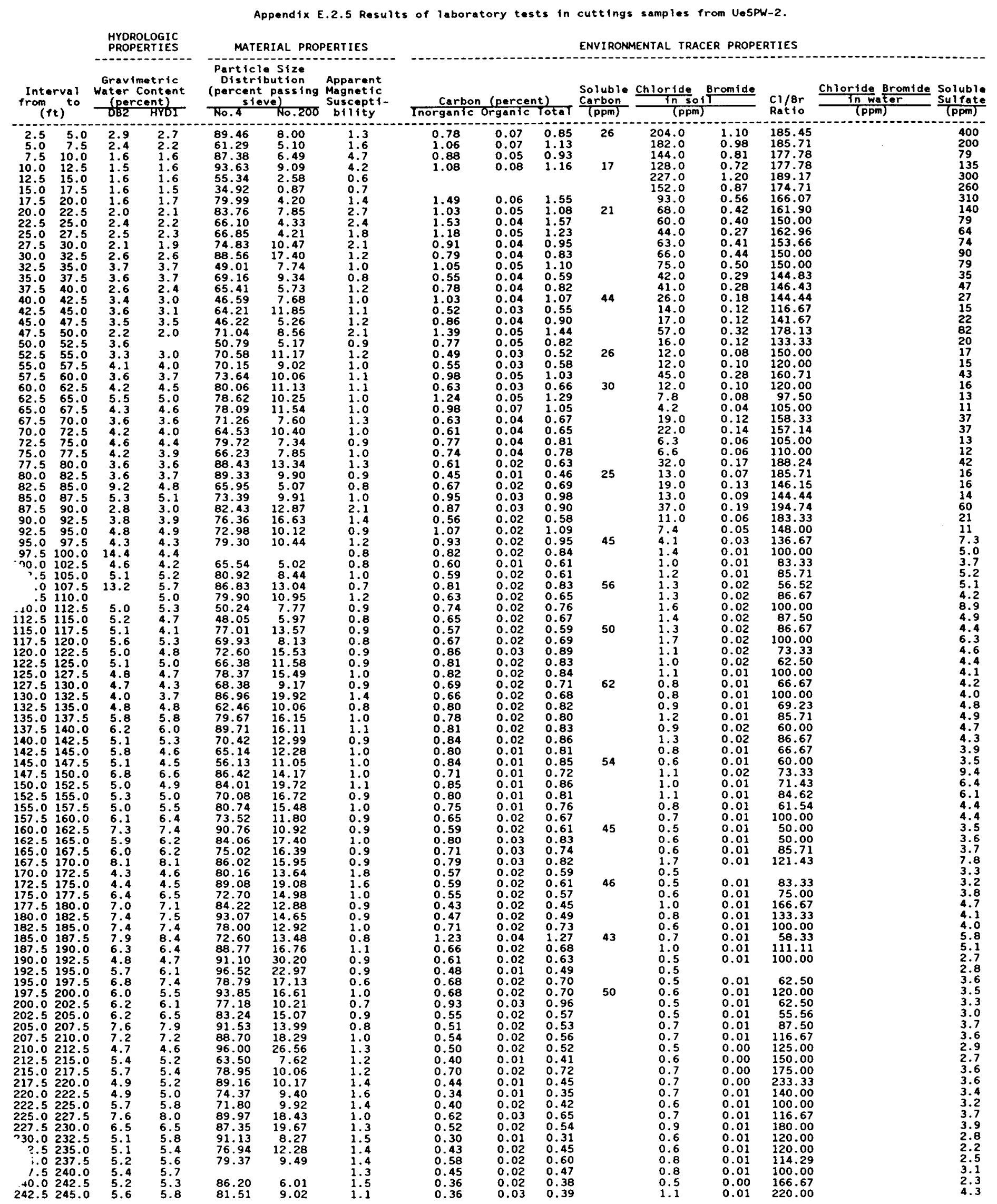




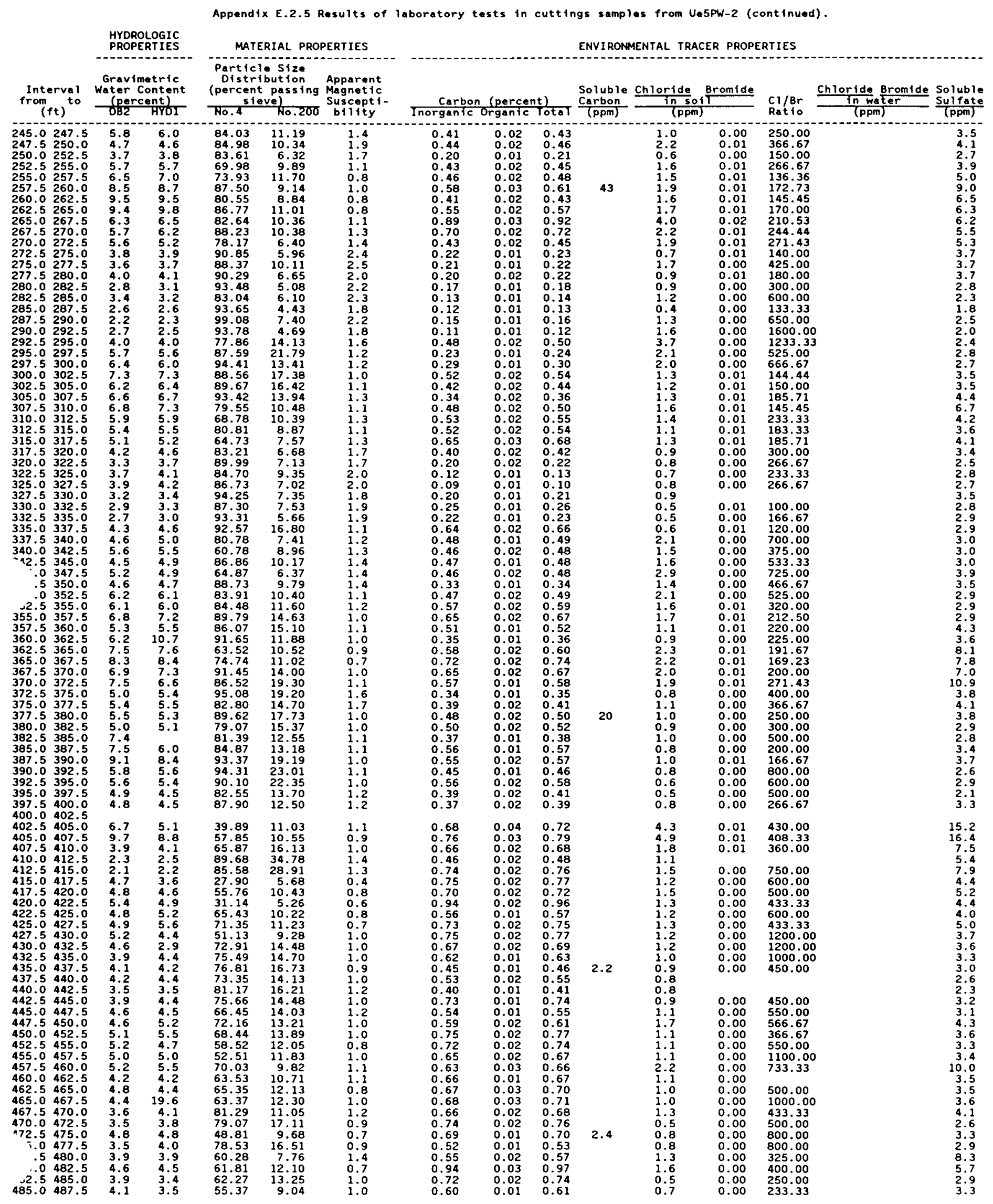




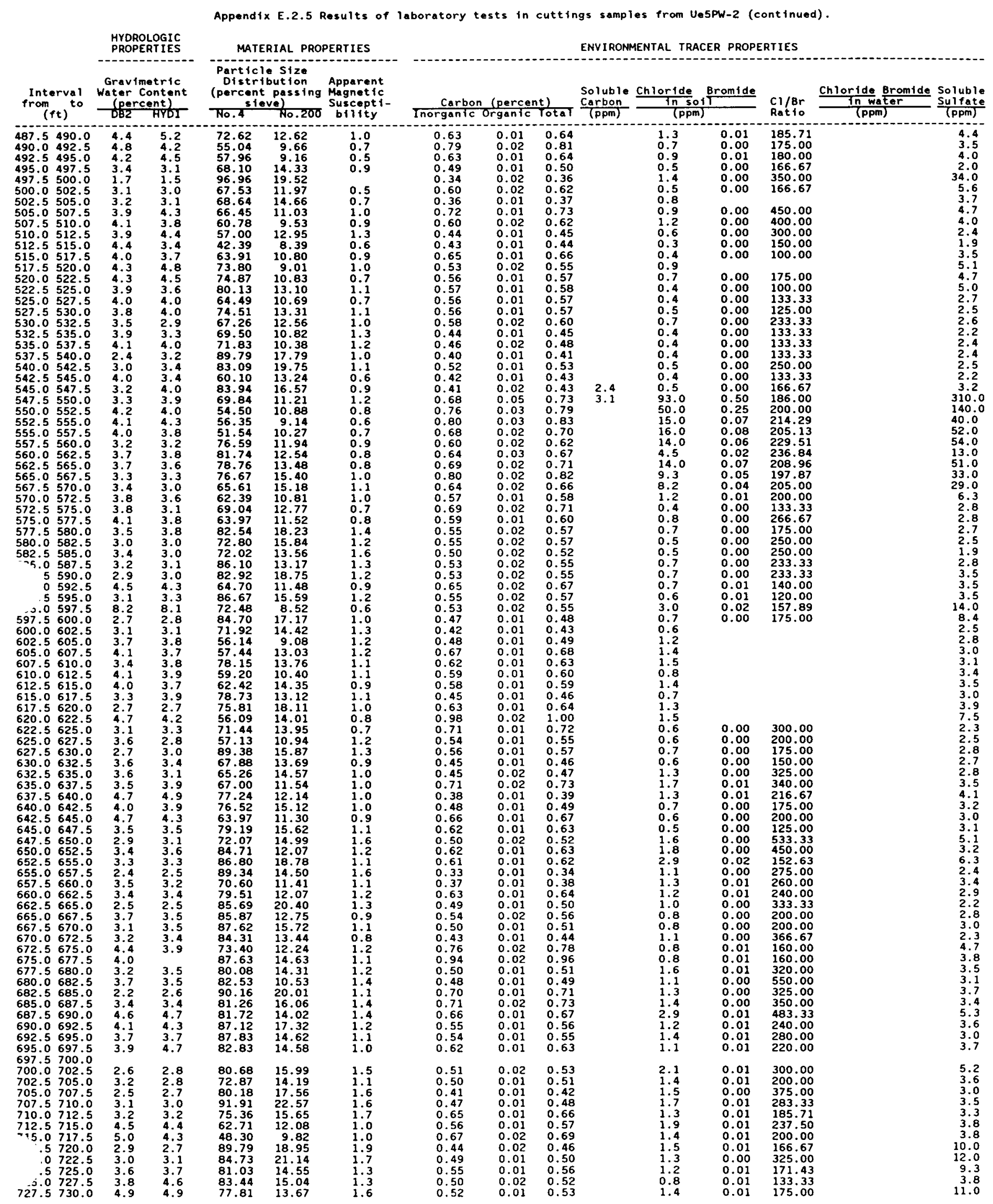




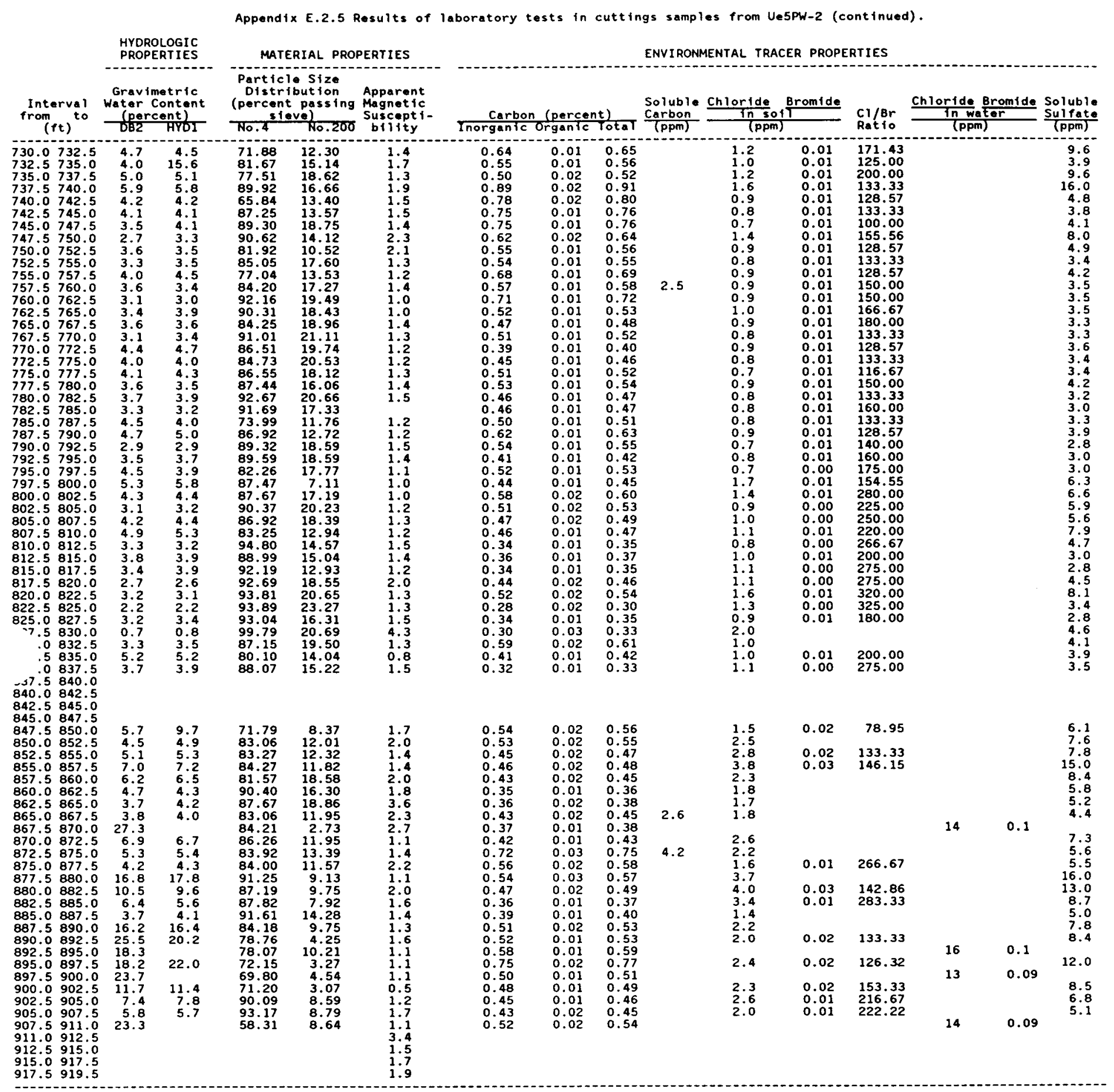


Appendix E.2.6 Results of laboratory tests in cuttings samples from Ue5PW-3.

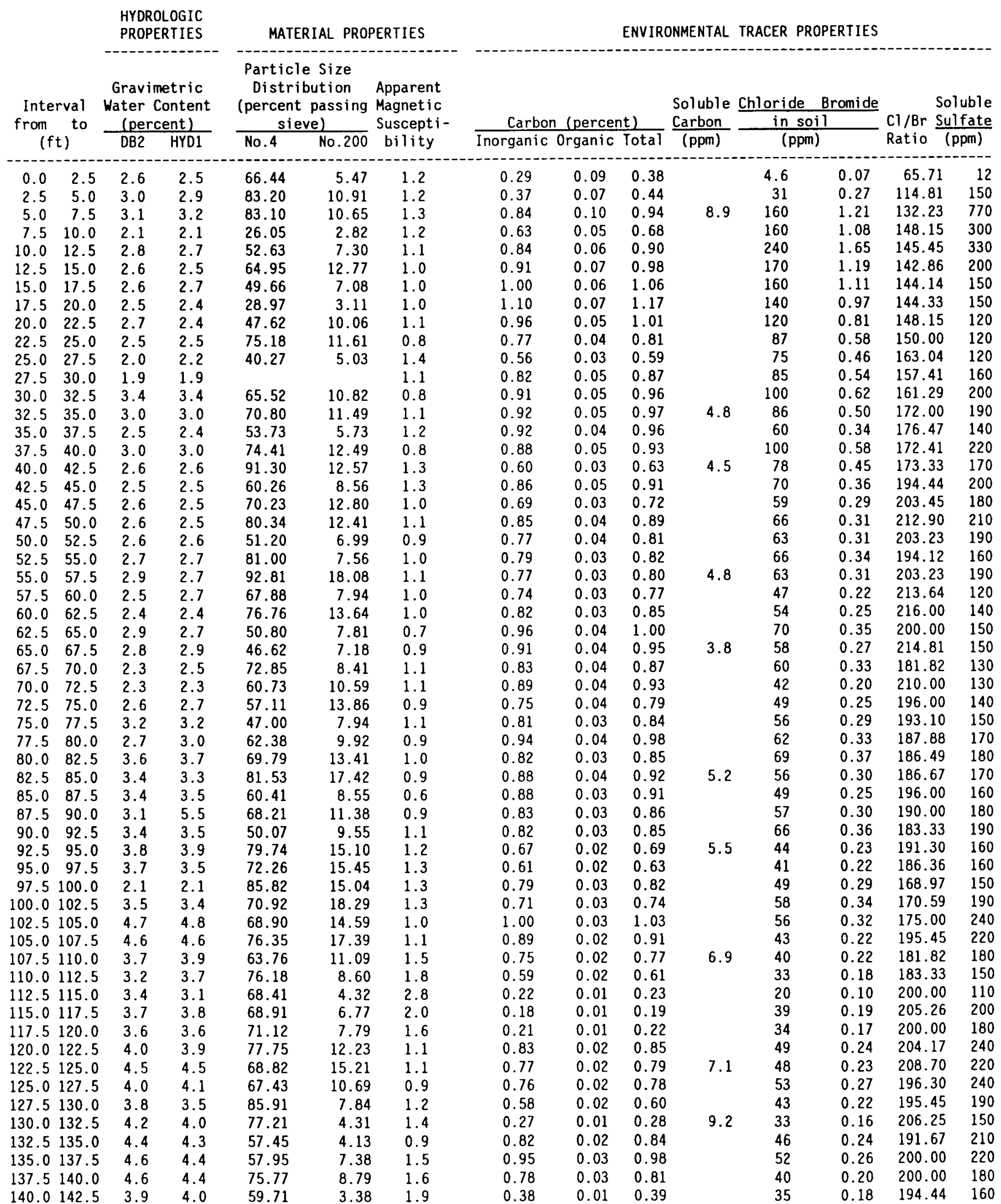


Appendix E.2.6 Results of laboratory tests in cuttings samples from Ue5PW-3 (continued).

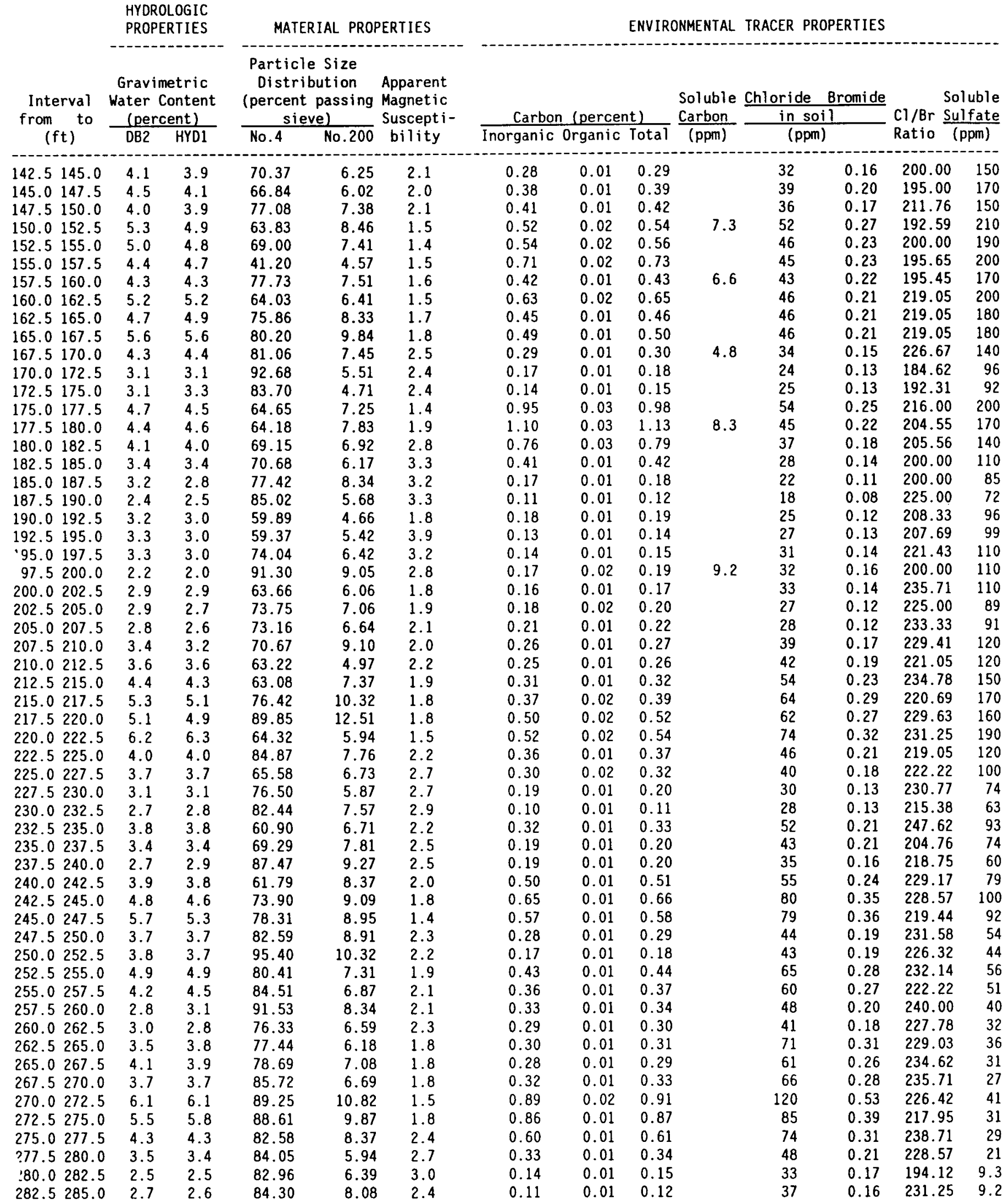


Appendix E.2.6 Results of laboratory tests in cuttings samples from Ve5PW-3 (continued).

\begin{tabular}{|c|c|c|c|c|c|c|c|c|c|c|c|c|c|}
\hline \multirow{3}{*}{$\begin{array}{l}\text { Interval } \\
\text { from to } \\
\text { (ft })\end{array}$} & \multicolumn{2}{|c|}{$\begin{array}{l}\text { HYOROLOGIC } \\
\text { PROPERTIES }\end{array}$} & \multicolumn{3}{|c|}{ MATERIAL PROPERTIES } & \multicolumn{6}{|c|}{ ENVIRONMENTAL TRACER PROPERTIES } & & \\
\hline & \multicolumn{2}{|c|}{$\begin{array}{l}\text { Gravimetric } \\
\text { Water Content } \\
\text { (percent) }\end{array}$} & \multicolumn{2}{|c|}{$\begin{array}{c}\text { Particle Size } \\
\text { Distribution } \\
\text { (percent passing } \\
\text { sieve) } \\
\end{array}$} & $\begin{array}{l}\text { Apparent } \\
\text { Magnet ic } \\
\text { Suscepti- }\end{array}$ & \multicolumn{3}{|c|}{ Carbon (percent) } & Soluble & $\begin{array}{c}\text { Chloride } \\
\text { in soi }\end{array}$ & Bromide & $\begin{array}{r}\text { So } \\
\mathrm{Cl} / \mathrm{Br} \text { Su }\end{array}$ & $\begin{array}{l}\text { uble } \\
\text { fate }\end{array}$ \\
\hline & DB2 & HYD1 & No. 4 & No. 200 & bility & Inorganic & Organic & Total & (ppm) & (ppm) & & Ratio (1 & $\mathrm{pm})$ \\
\hline 285.0287 .5 & 3.3 & 3.0 & 62.96 & 5.83 & 2.3 & 0.20 & 0.01 & 0.21 & & 42 & 0.17 & 247.06 & 8.7 \\
\hline 287.5290 .0 & 2.9 & 3.1 & 82.99 & 6.26 & 2.5 & 0.26 & 0.01 & 0.27 & & 49 & 0.21 & 233.33 & 9.0 \\
\hline 290.0292 .5 & 3.7 & 3.6 & 79.18 & 9.14 & 2.1 & 0.40 & 0.01 & 0.41 & & 71 & 0.29 & 244.83 & 8.1 \\
\hline 292.5295 .0 & 3.5 & 3.6 & 86.10 & 6.61 & 2.3 & 0.22 & 0.01 & 0.23 & & 66 & 0.28 & 235.71 & 5.9 \\
\hline 295.0297 .5 & 5.3 & 5.3 & 85.03 & 11.46 & 1.7 & 0.70 & 0.01 & 0.71 & 2.9 & 110 & 0.46 & 239.13 & 8.2 \\
\hline 297.5300 .0 & 4.4 & 4.4 & 81.83 & 8.81 & 2.2 & 0.50 & 0.01 & 0.51 & & 87 & 0.38 & 228.95 & 9.7 \\
\hline 300.0302 .5 & 2.5 & 3.2 & 85.04 & 7.27 & 3.4 & 0.27 & 0.01 & 0.28 & & 44 & 0.16 & 275.00 & 6.6 \\
\hline 302.5305 .0 & 2.4 & 2.5 & 89.91 & 6.40 & 2.9 & 0.19 & 0.01 & 0.20 & & 32 & 0.14 & 228.57 & 5.6 \\
\hline 305.0307 .5 & 2.8 & 3.0 & 71.10 & 5.28 & 2.6 & 0.13 & 0.01 & 0.14 & & 40 & 0.17 & 235.29 & 7.0 \\
\hline 307.5310 .0 & 2.2 & 2.1 & 94.07 & 5.88 & 2.2 & 0.12 & 0.01 & 0.13 & 3.7 & 36 & 0.14 & 257.14 & 6.1 \\
\hline 310.0312 .5 & 2.1 & 2.0 & 83.28 & 4.52 & 3.0 & 0.14 & 0.01 & 0.15 & & 39 & 0.16 & 243.75 & 7.2 \\
\hline 312.5315 .0 & 3.2 & 3.3 & 50.03 & 3.80 & 1.3 & 0.33 & 0.01 & 0.34 & & 67 & 0.25 & 268.00 & 6.8 \\
\hline 315.0317 .5 & 3.5 & 3.5 & 61.99 & 6.86 & 1.2 & 0.56 & 0.02 & 0.58 & & 62 & 0.28 & 221.43 & 6.6 \\
\hline 317.5320 .0 & 3.6 & 3.7 & 81.71 & 6.67 & 1.5 & 0.46 & 0.01 & 0.47 & & 64 & 0.27 & 237.04 & 6.6 \\
\hline 320.0322 .5 & 4.4 & 4.4 & 76.35 & 7.72 & 1.2 & 0.47 & 0.01 & 0.48 & & 86 & 0.34 & 252.94 & 7.0 \\
\hline 322.5325 .0 & 5.1 & 5.1 & 80.69 & 9.44 & 1.1 & 0.66 & 0.02 & 0.68 & & 110 & 0.47 & 234.04 & 9.8 \\
\hline $325.0 \quad 327.5$ & 5.0 & 7.2 & 64.00 & 7.63 & 1.4 & 0.65 & 0.01 & 0.66 & & 83 & 0.36 & 230.56 & 8.4 \\
\hline 327.5330 .0 & 3.4 & 3.2 & 87.29 & 5.95 & 1.8 & 0.41 & 0.01 & 0.42 & & 44 & 0.18 & 244.44 & 5.9 \\
\hline 330.0332 .5 & 3.0 & 2.9 & 66.89 & 2.34 & 1.3 & 0.41 & 0.01 & 0.42 & & 42 & 0.15 & 280.00 & 6.0 \\
\hline 332.5335 .0 & 3.1 & 3.1 & 64.10 & 4.45 & 1.3 & 0.92 & 0.02 & 0.94 & & 44 & 0.20 & 220.00 & 5.2 \\
\hline $335.0 \quad 337.5$ & 3.5 & 3.5 & 64.84 & 8.43 & 1.0 & 0.95 & 0.02 & 0.97 & & 66 & 0.29 & 227.59 & 6.3 \\
\hline $37.5 \quad 340.0$ & 4.8 & 5.1 & 76.07 & 8.97 & 1.3 & 0.75 & 0.02 & 0.77 & & 70 & 0.33 & 212.12 & 8.6 \\
\hline 40.0342 .5 & 3.8 & 3.7 & 87.88 & 8.83 & 1.5 & 0.51 & 0.01 & 0.52 & & 48 & 0.25 & 192.00 & 4.8 \\
\hline 342.5345 .0 & 4.5 & 4.0 & 67.14 & 6.38 & 1.3 & 0.66 & 0.01 & 0.67 & & 53 & 0.27 & 196.30 & 5.7 \\
\hline 345.0347 .5 & 5.1 & 5.0 & 83.41 & 8.41 & 1.4 & 0.56 & 0.01 & 0.57 & & 60 & 0.29 & 206.90 & 6.1 \\
\hline 347.5350 .0 & 4.5 & 4.3 & 95.06 & 14.51 & 1.4 & 0.65 & 0.02 & 0.67 & & 60 & 0.29 & 206.90 & 7.5 \\
\hline 350.0352 .5 & 4.2 & 4.1 & 78.56 & 8.96 & 1.4 & 0.46 & 0.01 & 0.47 & & 48 & 0.25 & 192.00 & 4.7 \\
\hline 352.5355 .0 & 5.0 & 4.8 & 72.87 & 7.73 & 1.4 & 0.55 & 0.01 & 0.56 & & 57 & 0.29 & 196.55 & 4.4 \\
\hline 355.0357 .5 & 5.2 & 5.0 & 75.13 & 8.12 & 1.5 & 0.47 & 0.01 & 0.48 & & 54 & 0.27 & 200.00 & 4.1 \\
\hline 357.5360 .0 & 4.4 & 4.0 & 70.95 & 5.45 & 1.9 & 0.40 & 0.01 & 0.41 & & 43 & 0.21 & 204.76 & 3.8 \\
\hline 360.0362 .5 & 2.8 & 2.7 & 70.64 & 5.98 & 2.4 & 0.26 & 0.01 & 0.27 & & 23 & 0.13 & 176.92 & 3.1 \\
\hline 362.5365 .0 & 2.8 & 2.6 & 86.79 & 8.01 & 2.2 & 0.27 & 0.01 & 0.28 & & 21 & 0.11 & 190.91 & 2.7 \\
\hline 365.0367 .5 & 2.9 & 2.8 & 77.03 & 3.90 & 1.7 & 0.23 & 0.01 & 0.24 & & 18 & 0.091 & 197.80 & 2.7 \\
\hline 367.5370 .0 & 3.4 & 3.1 & 80.55 & 9.25 & 1.4 & 0.68 & 0.01 & 0.69 & & 27 & 0.15 & 180.00 & 3.4 \\
\hline 370.0372 .5 & 4.0 & 4.1 & 67.05 & 9.02 & 1.1 & 0.80 & 0.02 & 0.82 & & 30 & 0.15 & 200.00 & 3.6 \\
\hline 372.5375 .0 & 3.7 & 3.6 & 84.27 & 10.86 & 1.1 & 0.76 & 0.01 & 0.77 & & 25 & 0.13 & 192.31 & 3.3 \\
\hline 375.0377 .5 & 3.9 & 3.8 & 84.75 & 10.29 & 1.2 & 0.77 & 0.01 & 0.78 & & 26 & 0.14 & 185.71 & 3.4 \\
\hline 377.5380 .0 & 3.7 & 3.7 & 73.35 & 8.77 & 1.2 & 0.91 & 0.02 & 0.93 & & 21 & 0.10 & 210.00 & 3.4 \\
\hline $380.0 \quad 382.5$ & 4.5 & 4.5 & 75.05 & 9.45 & 1.1 & 0.86 & 0.01 & 0.87 & & 23 & 0.12 & 191.67 & 2.9 \\
\hline 382.5385 .0 & 4.0 & 3.9 & 77.82 & 12.57 & 1.4 & 0.92 & 0.01 & 0.93 & & 20 & 0.10 & 200.00 & 2.8 \\
\hline 385.0387 .5 & 4.0 & 4.0 & 81.79 & 9.82 & 1.5 & 0.87 & 0.01 & 0.88 & & 16 & 0.092 & 173.91 & 2.5 \\
\hline 387.5390 .0 & 2.9 & 2.8 & 87.75 & 16.50 & 1.8 & 0.76 & 0.01 & 0.77 & 5.5 & 12 & 0.061 & 196.72 & 2.5 \\
\hline 390.0392 .5 & 3.7 & 3.8 & 88.41 & 12.87 & 1.5 & 0.81 & 0.01 & 0.82 & & 13 & 0.069 & 188.41 & 2.3 \\
\hline 392.5395 .0 & 3.8 & 3.6 & 61.36 & 9.03 & 0.8 & 0.86 & 0.01 & 0.87 & & 14 & 0.075 & 186.67 & 2.6 \\
\hline 395.0397 .5 & 4.2 & 4.1 & 75.45 & 10.32 & 1.2 & 0.91 & 0.01 & 0.92 & & 15 & 0.089 & 168.54 & 2.9 \\
\hline 397.5400 .0 & 2.7 & 2.6 & 86.37 & 12.36 & 1.6 & 0.95 & 0.02 & 0.97 & & 11 & 0.064 & 171.88 & 3.2 \\
\hline $400.0 \quad 402.5$ & 2.9 & 2.9 & 86.09 & 12.84 & 1.5 & 0.98 & 0.01 & 0.99 & & 9.8 & 0.061 & 160.66 & 2.8 \\
\hline 402.5405 .0 & 3.4 & 3.0 & 58.49 & 8.68 & 1.5 & 1.10 & 0.02 & 1.12 & & 8.2 & 0.052 & 157.69 & 2.8 \\
\hline 405.0407 .5 & 3.6 & 3.4 & 59.59 & 8.09 & 1.3 & 0.94 & 0.02 & 0.96 & & 9.5 & 0.055 & 172.73 & 2.8 \\
\hline 407.5410 .0 & 3.8 & 3.5 & 90.44 & 13.65 & 1.4 & 0.74 & 0.01 & 0.75 & 3.6 & 9.4 & 0.058 & 162.07 & 2.6 \\
\hline $410.0 \quad 412.5$ & 4.0 & 3.7 & 86.96 & 11.33 & 1.3 & 0.79 & 0.01 & 0.80 & & 8.4 & 0.046 & 182.61 & 2.5 \\
\hline 412.5415 .0 & 4.1 & 3.4 & 71.43 & 11.04 & 1.5 & 0.76 & 0.01 & 0.77 & & 7.4 & 0.049 & 151.02 & 2.3 \\
\hline 415.0417 .5 & 4.2 & 4.1 & 72.66 & 9.98 & 1.7 & 0.88 & 0.01 & 0.89 & & 7.3 & 0.048 & 152.08 & 2.8 \\
\hline 417.5420 .0 & 4.6 & 4.6 & 86.96 & 11.02 & 1.1 & 0.89 & 0.01 & 0.90 & & 7.4 & 0.047 & 157.45 & 2.7 \\
\hline $420.0 \quad 422.5$ & 2.9 & 2.8 & 76.09 & 9.36 & 1.4 & 0.93 & 0.02 & 0.95 & & 3.7 & 0.024 & 154.17 & 2.4 \\
\hline 422.5425 .0 & 3.5 & 3.4 & 83.35 & 11.70 & 1.3 & 0.83 & 0.01 & 0.84 & & 4.2 & 0.029 & 144.83 & 2.4 \\
\hline $425.0 \quad 427.5$ & 3.6 & 3.5 & 87.63 & 12.56 & 1.6 & 1.10 & 0.02 & 1.12 & & 4.8 & 0.026 & 184.62 & 2.7 \\
\hline
\end{tabular}


Appendix E.2.6 Results of laboratory tests in cuttings samples from Ue5PW-3 (continued).

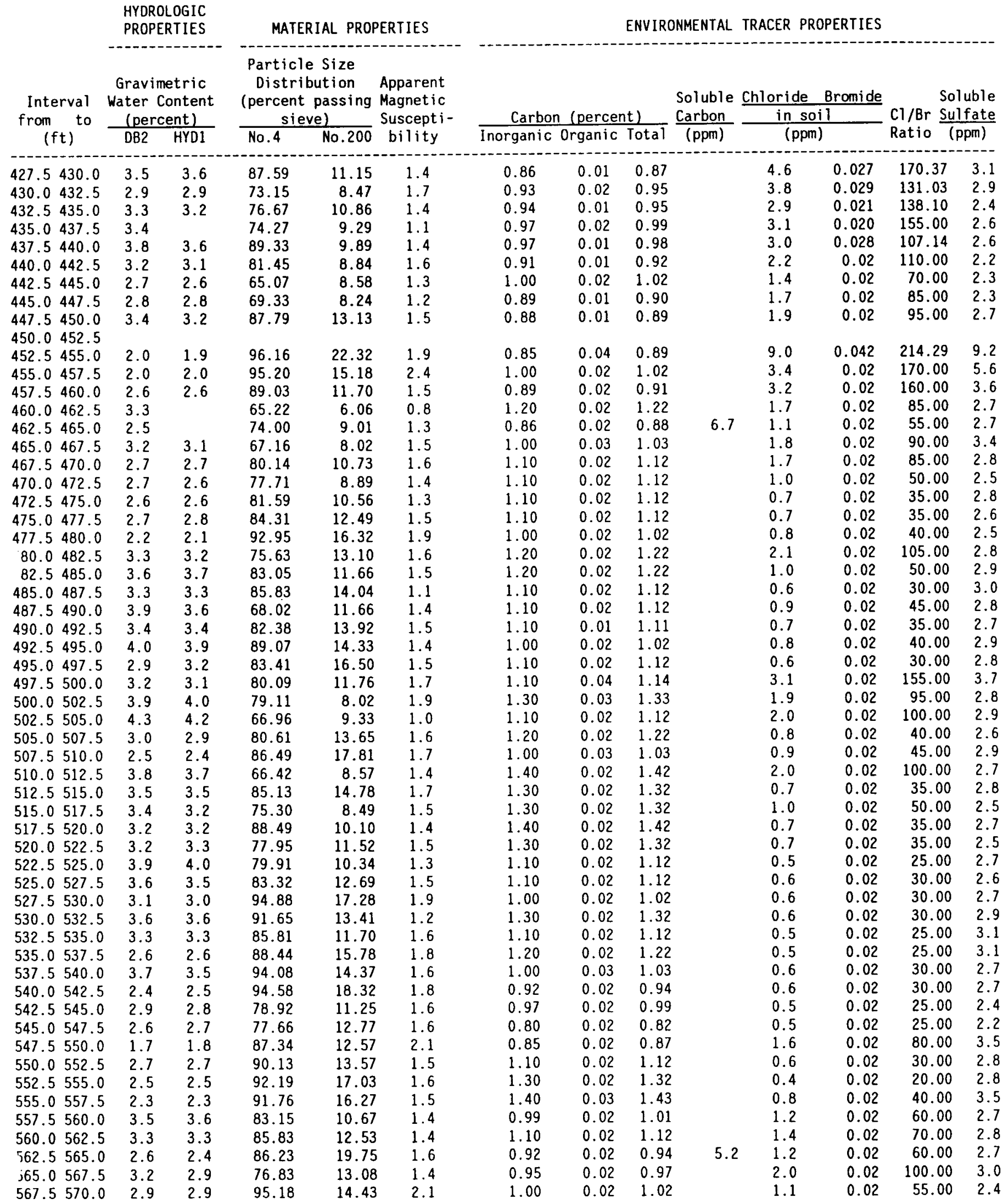


Appendix E.2.6 Results of laboratory tests in cuttings samples from Ue5PW-3 (continued).

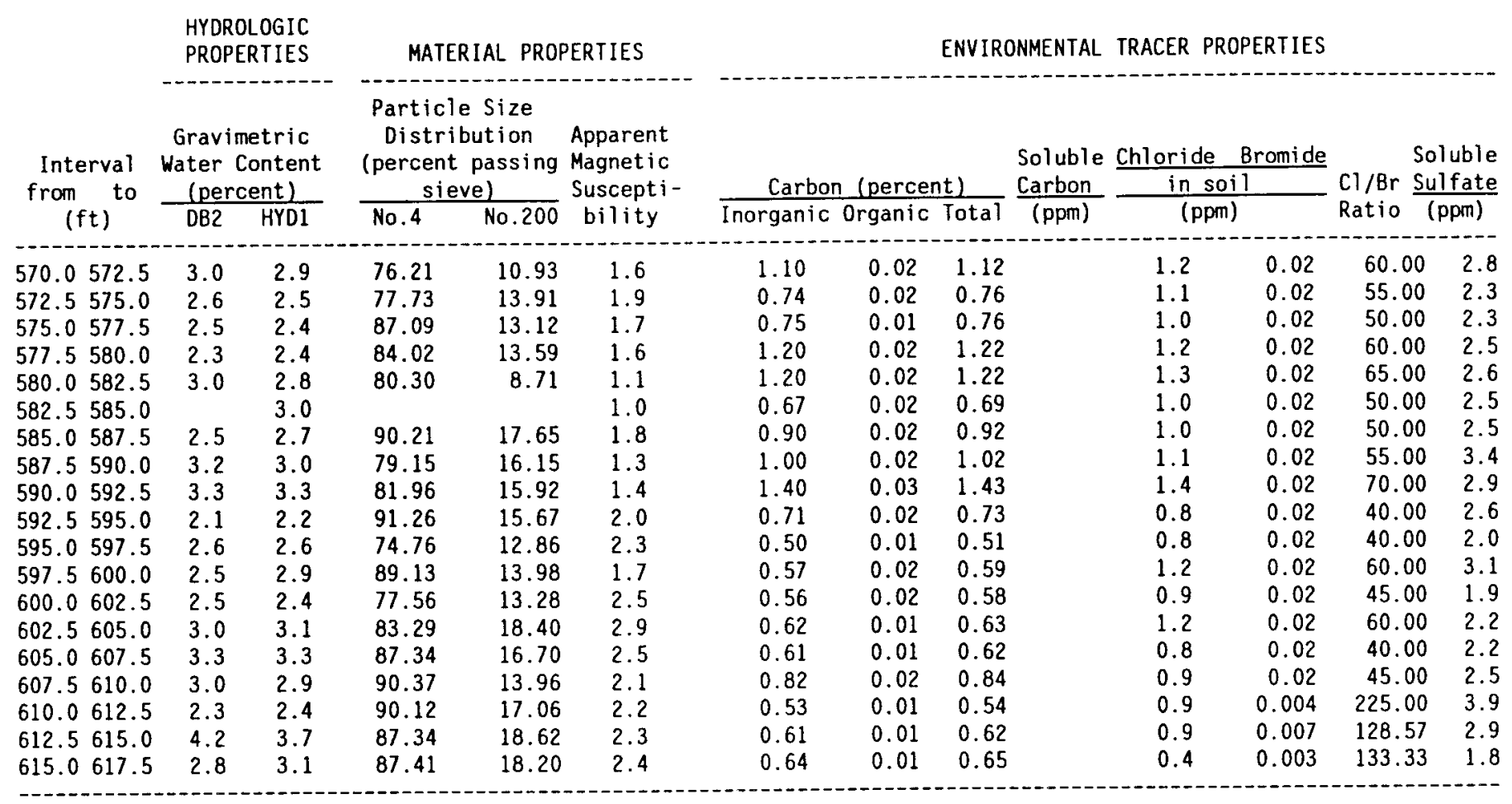


Appendix E.2.7 Moisture retention data in core samples from Ue5PW-1.

\begin{tabular}{|c|c|c|c|c|c|}
\hline $\begin{array}{c}\text { Sample } \\
\text { Depth } \\
(f t)\end{array}$ & $\begin{array}{l}\text { Volumetric } \\
\text { Water } \\
\text { Content } \\
\text { (percent) }\end{array}$ & $\begin{array}{c}\text { Water } \\
\text { Potential } \\
\text { (bars) }\end{array}$ & $\begin{array}{l}\text { Sample } \\
\text { Depth } \\
(\mathrm{ft})\end{array}$ & $\begin{array}{l}\text { Volumetric } \\
\text { Water } \\
\text { Content } \\
\text { (percent) }\end{array}$ & $\begin{array}{c}\text { Water } \\
\text { Potential } \\
\text { (bars) }\end{array}$ \\
\hline 48 & $\begin{array}{r}7.7 \\
11.0 \\
14.8 \\
20.8 \\
30.2 \\
33.6 \\
36.3\end{array}$ & $\begin{array}{r}18.448 \\
3.182 \\
0.433 \\
0.102 \\
0.051 \\
0.020 \\
0.000\end{array}$ & 179 & $\begin{array}{r}7.1 \\
8.5 \\
11.9 \\
16.1 \\
19.2 \\
22.1 \\
27.5\end{array}$ & $\begin{array}{r}14.389 \\
4.344 \\
0.515 \\
0.102 \\
0.051 \\
0.020 \\
0.000\end{array}$ \\
\hline 59 & $\begin{array}{r}7.0 \\
10.7 \\
15.6 \\
22.7 \\
31.0 \\
33.8 \\
37.1\end{array}$ & $\begin{array}{r}25.505 \\
3.600 \\
0.433 \\
0.102 \\
0.051 \\
0.020 \\
0.000\end{array}$ & 199 & $\begin{array}{r}7.5 \\
9.2 \\
11.5 \\
13.5 \\
15.7 \\
19.2 \\
30.7\end{array}$ & $\begin{array}{r}16.521 \\
4.212 \\
0.433 \\
0.102 \\
0.051 \\
0.020 \\
0.000\end{array}$ \\
\hline 78 & $\begin{array}{r}7.0 \\
10.3 \\
13.6 \\
17.7 \\
26.5 \\
33.4 \\
37.2\end{array}$ & $\begin{array}{r}19.080 \\
2.488 \\
0.433 \\
0.102 \\
0.051 \\
0.020 \\
0.000\end{array}$ & 219 & $\begin{array}{r}6.7 \\
10.0 \\
13.2 \\
16.9 \\
19.6 \\
21.4 \\
29.6\end{array}$ & $\begin{array}{r}28.361 \\
2.651 \\
0.433 \\
0.102 \\
0.051 \\
0.020 \\
0.000\end{array}$ \\
\hline 129 & $\begin{array}{r}9.5 \\
12.6 \\
18.3 \\
22.9 \\
27.7 \\
30.2 \\
36.6\end{array}$ & $\begin{array}{r}17.857 \\
2.998 \\
0.433 \\
0.102 \\
0.051 \\
0.020 \\
0.000\end{array}$ & 259 & $\begin{array}{r}7.6 \\
9.6 \\
13.0 \\
18.3 \\
23.5 \\
25.9 \\
34.1\end{array}$ & $\begin{array}{r}15.654 \\
3.325 \\
0.433 \\
0.102 \\
0.051 \\
0.020 \\
0.000\end{array}$ \\
\hline 139 & $\begin{array}{l}10.8 \\
14.3 \\
19.1 \\
24.2 \\
28.0 \\
30.6 \\
38.9\end{array}$ & $\begin{array}{r}15.266 \\
3.049 \\
0.433 \\
0.102 \\
0.051 \\
0.020 \\
0.000\end{array}$ & 300 & $\begin{array}{r}8.6 \\
12.1 \\
15.9 \\
21.9 \\
25.4 \\
29.8 \\
36.6\end{array}$ & $\begin{array}{r}24.322 \\
2.825 \\
0.515 \\
0.102 \\
0.051 \\
0.020 \\
0.000\end{array}$ \\
\hline 159 & $\begin{array}{r}7.5 \\
10.0 \\
13.3 \\
19.3 \\
24.0 \\
27.3 \\
30.8\end{array}$ & $\begin{array}{r}18.683 \\
4.120 \\
0.515 \\
0.102 \\
0.051 \\
0.020 \\
0.000\end{array}$ & 320 & $\begin{array}{r}5.6 \\
6.6 \\
9.0 \\
11.3 \\
14.2 \\
18.0 \\
30.0\end{array}$ & $\begin{array}{r}21.069 \\
5.905 \\
0.433 \\
0.102 \\
0.051 \\
0.020 \\
0.000\end{array}$ \\
\hline
\end{tabular}


Appendix E.2.7 Moisture retention data in core samples from Ue5PW-1 (Continued)

\begin{tabular}{|c|c|c|c|c|c|}
\hline $\begin{array}{l}\text { Sample } \\
\text { Depth } \\
(\mathrm{ft})\end{array}$ & $\begin{array}{l}\text { Volumetric } \\
\text { Water } \\
\text { Content } \\
\text { (percent) }\end{array}$ & $\begin{array}{c}\text { Water } \\
\text { Potential } \\
\text { (bars) }\end{array}$ & $\begin{array}{c}\text { Sample } \\
\text { Depth } \\
\text { (ft) }\end{array}$ & $\begin{array}{l}\text { Volumetric } \\
\text { Water } \\
\text { Content } \\
\text { (percent) }\end{array}$ & $\begin{array}{c}\text { Water } \\
\text { Potential } \\
\text { (bars) }\end{array}$ \\
\hline 360 & $\begin{array}{l}10.5 \\
12.2 \\
16.3 \\
22.9 \\
26.9 \\
27.5 \\
30.4\end{array}$ & $\begin{array}{r}16.041 \\
5.690 \\
0.515 \\
0.102 \\
0.051 \\
0.020 \\
0.000\end{array}$ & 619 & $\begin{array}{r}8.1 \\
10.7 \\
13.8 \\
20.0 \\
25.8 \\
32.4 \\
35.3\end{array}$ & $\begin{array}{r}13.441 \\
2.804 \\
0.515 \\
0.102 \\
0.051 \\
0.020 \\
0.000\end{array}$ \\
\hline 400 & $\begin{array}{r}7.1 \\
9.1 \\
12.0 \\
15.5 \\
20.6 \\
28.1 \\
34.4\end{array}$ & $\begin{array}{r}24.496 \\
4.926 \\
0.433 \\
0.102 \\
0.051 \\
0.020 \\
0.000\end{array}$ & 660 & $\begin{array}{r}7.1 \\
10.0 \\
13.0 \\
18.8 \\
24.5 \\
29.9 \\
32.4\end{array}$ & $\begin{array}{r}15.736 \\
2.784 \\
0.515 \\
0.102 \\
0.051 \\
0.020 \\
0.000\end{array}$ \\
\hline 460 & $\begin{array}{r}8.9 \\
13.2 \\
17.4 \\
25.3 \\
31.3 \\
32.8 \\
34.4\end{array}$ & $\begin{array}{r}21.783 \\
3.427 \\
0.433 \\
0.102 \\
0.051 \\
0.020 \\
0.000\end{array}$ & 700 & $\begin{array}{r}6.0 \\
7.7 \\
10.8 \\
19.0 \\
26.0 \\
30.6 \\
32.5\end{array}$ & $\begin{array}{r}23.425 \\
5.069 \\
0.515 \\
0.102 \\
0.051 \\
0.020 \\
0.000\end{array}$ \\
\hline 499 & $\begin{array}{l}12.1 \\
15.6 \\
19.7 \\
26.5 \\
31.0 \\
35.6 \\
37.1\end{array}$ & $\begin{array}{r}21.783 \\
2.794 \\
0.515 \\
0.102 \\
0.051 \\
0.020 \\
0.000\end{array}$ & 740 & $\begin{array}{r}5.7 \\
7.3 \\
9.8 \\
14.1 \\
19.3 \\
27.7 \\
32.3\end{array}$ & $\begin{array}{r}16.194 \\
4.457 \\
0.515 \\
0.102 \\
0.051 \\
0.020 \\
0.000\end{array}$ \\
\hline 541 & $\begin{array}{r}9.1 \\
11.4 \\
16.2 \\
26.3 \\
34.1 \\
37.4 \\
39.2\end{array}$ & $\begin{array}{r}13.778 \\
3.977 \\
0.515 \\
0.102 \\
0.051 \\
0.020 \\
0.000\end{array}$ & 760 & $\begin{array}{r}6.1 \\
8.3 \\
11.5 \\
15.5 \\
20.3 \\
29.3 \\
32.1\end{array}$ & $\begin{array}{r}22.701 \\
3.610 \\
0.515 \\
0.102 \\
0.051 \\
0.020 \\
0.000\end{array}$ \\
\hline 581 & $\begin{array}{r}7.0 \\
8.8 \\
12.1 \\
18.0 \\
22.8 \\
27.6 \\
28.9\end{array}$ & $\begin{array}{r}16.867 \\
2.519 \\
0.515 \\
0.102 \\
0.051 \\
0.020 \\
0.000\end{array}$ & 798 & $\begin{array}{r}7.0 \\
8.5 \\
14.0 \\
16.7 \\
19.5 \\
23.0 \\
29.5\end{array}$ & $\begin{array}{r}13.767 \\
3.681 \\
0.433 \\
0.102 \\
0.051 \\
0.020 \\
0.000\end{array}$ \\
\hline
\end{tabular}


Appendix E.2.8 Moisture retention data in core samples from Ue5PW-2.

\begin{tabular}{|c|c|c|c|c|c|}
\hline $\begin{array}{l}\text { Sample } \\
\text { Depth } \\
(\mathrm{ft})\end{array}$ & $\begin{array}{l}\text { Volumetric } \\
\text { Water } \\
\text { Content } \\
\text { (percent) }\end{array}$ & $\begin{array}{l}\text { Water } \\
\text { Potential } \\
\text { (bars) }\end{array}$ & $\begin{array}{c}\text { Sample } \\
\text { Depth } \\
(\mathrm{ft})\end{array}$ & $\begin{array}{l}\text { Volumetric } \\
\text { Water } \\
\text { Content } \\
\text { (percent) }\end{array}$ & $\begin{array}{c}\text { Water } \\
\text { Potential } \\
\text { (bars) }\end{array}$ \\
\hline 0.5 & $\begin{array}{l}11.0 \\
11.8 \\
16.2 \\
23.2 \\
28.3 \\
31.1 \\
33.2\end{array}$ & $\begin{array}{r}18.866 \\
2.713 \\
0.583 \\
0.102 \\
0.061 \\
0.032 \\
0.000\end{array}$ & 69 & $\begin{array}{r}9.0 \\
11.5 \\
15.4 \\
21.1 \\
25.8 \\
28.6 \\
30.3\end{array}$ & $\begin{array}{r}14.553 \\
4.038 \\
0.583 \\
0.102 \\
0.061 \\
0.032 \\
0.000\end{array}$ \\
\hline 3 & $\begin{array}{l}10.5 \\
14.3 \\
19.0 \\
25.5 \\
28.7 \\
29.8 \\
31.7\end{array}$ & $\begin{array}{r}13.961 \\
2.978 \\
0.583 \\
0.102 \\
0.061 \\
0.032 \\
0.000\end{array}$ & 100 & $\begin{array}{r}9.0 \\
11.5 \\
15.0 \\
18.4 \\
21.6 \\
26.3 \\
31.1\end{array}$ & $\begin{array}{r}20.896 \\
2.845 \\
0.583 \\
0.102 \\
0.061 \\
0.032 \\
0.000\end{array}$ \\
\hline 30 & $\begin{array}{r}9.0 \\
12.2 \\
17.5 \\
26.6 \\
29.9 \\
31.0 \\
34.7\end{array}$ & $\begin{array}{r}19.478 \\
4.049 \\
0.583 \\
0.102 \\
0.061 \\
0.032 \\
0.000\end{array}$ & 119 & $\begin{array}{l}13.0 \\
13.6 \\
18.3 \\
26.2 \\
32.0 \\
33.0 \\
34.4\end{array}$ & $\begin{array}{r}15.511 \\
3.681 \\
0.583 \\
0.102 \\
0.061 \\
0.032 \\
0.000\end{array}$ \\
\hline 31 & $\begin{array}{l}12.2 \\
15.1 \\
17.0 \\
22.8 \\
25.4 \\
26.3 \\
29.8\end{array}$ & $\begin{array}{r}21.538 \\
3.569 \\
0.583 \\
0.102 \\
0.061 \\
0.032 \\
0.000\end{array}$ & 129 & $\begin{array}{l}10.0 \\
12.4 \\
16.2 \\
22.3 \\
26.6 \\
28.0 \\
29.8\end{array}$ & $\begin{array}{r}16.103 \\
2.631 \\
0.583 \\
0.102 \\
0.061 \\
0.032 \\
0.000\end{array}$ \\
\hline 40 & $\begin{array}{r}9.5 \\
12.6 \\
18.1 \\
27.4 \\
30.3 \\
31.6 \\
34.0\end{array}$ & $\begin{array}{r}14.838 \\
3.121 \\
0.583 \\
0.102 \\
0.061 \\
0.032 \\
0.000\end{array}$ & 200 & $\begin{array}{l}14.0 \\
14.3 \\
20.7 \\
29.2 \\
34.6 \\
35.8 \\
37.5\end{array}$ & $\begin{array}{r}15.338 \\
3.008 \\
0.583 \\
0.102 \\
0.061 \\
0.032 \\
0.000\end{array}$ \\
\hline 41 & $\begin{array}{r}8.0 \\
10.9 \\
14.9 \\
20.9 \\
24.4 \\
26.7 \\
29.4\end{array}$ & $\begin{array}{r}20.886 \\
3.059 \\
0.583 \\
0.102 \\
0.061 \\
0.032 \\
0.000\end{array}$ & 250 & $\begin{array}{r}9.0 \\
9.8 \\
12.7 \\
16.7 \\
20.7 \\
29.7 \\
37.8\end{array}$ & $\begin{array}{r}22.711 \\
3.579 \\
0.583 \\
0.102 \\
0.061 \\
0.032 \\
0.000\end{array}$ \\
\hline
\end{tabular}


Appendix E.2.8 Moisture retention data in core samples from Ue5PW-2 (Cont inued)

\begin{tabular}{|c|c|c|}
\hline $\begin{array}{c}\text { Sample } \\
\text { Depth } \\
\text { (ft) }\end{array}$ & $\begin{array}{l}\text { Volumetric } \\
\text { Water } \\
\text { Content } \\
\text { (percent) }\end{array}$ & $\begin{array}{c}\text { Water } \\
\text { Potential } \\
\text { (bars) }\end{array}$ \\
\hline 311 & $\begin{array}{l}16.0 \\
16.0 \\
21.3 \\
26.8 \\
28.3 \\
29.1 \\
31.0\end{array}$ & $\begin{array}{r}14.063 \\
3.008 \\
0.500 \\
0.102 \\
0.056 \\
0.031 \\
0.000\end{array}$ \\
\hline 499 & $\begin{array}{l}11.0 \\
11.0 \\
16.1 \\
23.2 \\
34.3 \\
37.6 \\
39.8\end{array}$ & $\begin{array}{r}14.940 \\
2.947 \\
0.510 \\
0.135 \\
0.071 \\
0.038 \\
0.000\end{array}$ \\
\hline 719 & $\begin{array}{l}14.0 \\
14.0 \\
17.8 \\
21.5 \\
24.1 \\
27.9\end{array}$ & $\begin{array}{r}14.430 \\
5.293 \\
0.505 \\
0.102 \\
0.051 \\
0.000\end{array}$ \\
\hline 817 & $\begin{array}{l}21.0 \\
21.0 \\
21.1 \\
24.6 \\
27.4 \\
30.8\end{array}$ & $\begin{array}{r}15.287 \\
4.395 \\
0.505 \\
0.102 \\
0.051 \\
0.000\end{array}$ \\
\hline
\end{tabular}


Appendix E.2.9 Moisture retention data in core samples from Ue5PW-3.

\begin{tabular}{|c|c|c|c|c|c|}
\hline $\begin{array}{l}\text { Sample } \\
\text { Depth } \\
\text { (ft) }\end{array}$ & $\begin{array}{c}\text { Volumetric } \\
\text { Water } \\
\text { Content } \\
\text { (percent) }\end{array}$ & $\begin{array}{c}\text { Water } \\
\text { Potential } \\
\text { (bars) }\end{array}$ & $\begin{array}{l}\text { Sample } \\
\text { Depth } \\
\text { (ft) }\end{array}$ & $\begin{array}{c}\text { Volumetric } \\
\text { Water } \\
\text { Content } \\
\text { (percent) }\end{array}$ & $\begin{array}{c}\text { Water } \\
\text { Potential } \\
\text { (bars) }\end{array}$ \\
\hline 1 & $\begin{array}{r}5.7 \\
8.0 \\
15.3 \\
25.7 \\
27.9 \\
29.3 \\
31.4\end{array}$ & $\begin{array}{r}14.777 \\
3.916 \\
0.505 \\
0.102 \\
0.051 \\
0.027 \\
0.000\end{array}$ & 130 & $\begin{array}{r}7.4 \\
9.6 \\
14.1 \\
17.7 \\
21.2 \\
27.8 \\
32.2\end{array}$ & $\begin{array}{r}16.786 \\
4.161 \\
0.505 \\
0.102 \\
0.051 \\
0.027 \\
0.000\end{array}$ \\
\hline 3 & $\begin{array}{r}5.5 \\
8.3 \\
14.8 \\
24.2 \\
27.1 \\
28.8 \\
30.5\end{array}$ & $\begin{array}{r}15.246 \\
2.988 \\
0.505 \\
0.102 \\
0.051 \\
0.027 \\
0.000\end{array}$ & 200 & $\begin{array}{r}7.3 \\
9.1 \\
11.3 \\
13.8 \\
15.1 \\
16.4 \\
27.8\end{array}$ & $\begin{array}{r}14.410 \\
2.906 \\
0.510 \\
0.099 \\
0.057 \\
0.020 \\
0.000\end{array}$ \\
\hline 51 & $\begin{array}{r}7.2 \\
9.3 \\
15.2 \\
23.0 \\
24.4 \\
25.4 \\
26.3 \\
26.9\end{array}$ & $\begin{array}{r}15.042 \\
4.691 \\
0.505 \\
0.102 \\
0.051 \\
0.027 \\
0.000\end{array}$ & 500 & $\begin{array}{r}7.1 \\
9.4 \\
14.3 \\
18.5 \\
24.1 \\
30.0\end{array}$ & $\begin{array}{r}11.942 \\
3.110 \\
0.505 \\
0.133 \\
0.046 \\
0.000\end{array}$ \\
\hline 52 & $\begin{array}{r}0.9 \\
8.1 \\
9.7 \\
16.4 \\
25.1 \\
26.9 \\
28.1 \\
30.1\end{array}$ & $\begin{array}{r}12.462 \\
3.427 \\
0.515 \\
0.102 \\
0.051 \\
0.031 \\
0.000\end{array}$ & 550 & \begin{tabular}{r|}
6.8 \\
8.9 \\
13.5 \\
17.6 \\
23.5 \\
28.1
\end{tabular} & $\begin{array}{r}14.899 \\
3.896 \\
0.505 \\
0.133 \\
0.046 \\
0.000\end{array}$ \\
\hline 101 & $\begin{array}{l}12.1 \\
15.8 \\
20.6 \\
30.0 \\
31.9 \\
33.8 \\
35.9\end{array}$ & $\begin{array}{l}15.093 \\
2.651 \\
0.505 \\
0.102 \\
0.051 \\
0.027 \\
0.000\end{array}$ & & & \\
\hline
\end{tabular}


Appendix E.2.10 Parameters required to calculate unsaturated hydraulic conductivity.

\begin{tabular}{|c|c|c|c|c|c|}
\hline Borehole & $\begin{array}{l}\text { Sample } \\
\text { Depth } \\
(\mathrm{ft})\end{array}$ & $\begin{array}{c}\text { Saturated } \\
\text { Hydraulic } \\
\text { Conductivity } \\
\text { (cm/sec) }\end{array}$ & $\begin{array}{c}\text { Residual } \\
\text { Volumetric } \\
\text { Water } \\
\text { Content } \\
\text { (percent) }\end{array}$ & $a$ & $n$ \\
\hline Ue5PW-1 & $\begin{array}{r}48 \\
59 \\
78 \\
129 \\
139 \\
159 \\
179 \\
199 \\
219 \\
259 \\
300 \\
320 \\
360 \\
400 \\
460 \\
499 \\
541 \\
581 \\
619 \\
660 \\
700 \\
740 \\
760 \\
789\end{array}$ & $\begin{array}{l}1.1 \mathrm{E}-03 \\
6.2 \mathrm{E}-04 \\
2.3 \mathrm{E}-03 \\
2.2 \mathrm{E}-03 \\
4.4 \mathrm{E}-04 \\
7.7 \mathrm{E}-04 \\
2.9 \mathrm{E}-03 \\
4.3 \mathrm{E}-03 \\
4.1 \mathrm{E}-04 \\
4.4 \mathrm{E}-03 \\
5.4 \mathrm{E}-04 \\
5.0 \mathrm{E}-03 \\
9.8 \mathrm{E}-05 \\
1.5 \mathrm{E}-03 \\
6.5 \mathrm{E}-04 \\
3.3 \mathrm{E}-03 \\
5.5 \mathrm{E}-04 \\
4.9 \mathrm{E}-04 \\
1.0 \mathrm{E}-03 \\
5.8 \mathrm{E}-03 \\
2.4 \mathrm{E}-03 \\
3.0 \mathrm{E}-03 \\
2.9 \mathrm{E}-03 \\
5.6 \mathrm{E}-05\end{array}$ & $\begin{array}{r}8.6 \\
6.7 \\
8.3 \\
2.0 \\
0.0 \\
6.3 \\
3.9 \\
6.6 \\
0.0 \\
4.8 \\
4.7 \\
5.2 \\
9.1 \\
7.8 \\
8.8 \\
10.8 \\
9.2 \\
6.8 \\
8.4 \\
7.3 \\
6.4 \\
6.5 \\
7.3 \\
0.0\end{array}$ & $\begin{array}{l}0.0211 \\
0.0237 \\
0.0305 \\
0.0939 \\
0.1657 \\
0.0376 \\
0.1038 \\
0.3740 \\
0.3093 \\
0.0899 \\
0.0957 \\
0.2168 \\
0.0197 \\
0.0494 \\
0.0146 \\
0.0246 \\
0.0160 \\
0.0241 \\
0.0295 \\
0.0280 \\
0.0213 \\
0.0382 \\
0.0344 \\
0.1834\end{array}$ & $\begin{array}{l}1.73 \\
1.53 \\
1.77 \\
1.21 \\
1.16 \\
1.42 \\
1.28 \\
1.33 \\
1.16 \\
1.33 \\
1.27 \\
1.43 \\
1.44 \\
1.68 \\
1.55 \\
1.43 \\
1.71 \\
1.61 \\
1.63 \\
1.58 \\
1.77 \\
1.82 \\
1.78 \\
1.19\end{array}$ \\
\hline Ue5PW-2 & $\begin{array}{r}1 \\
3 \\
30 \\
31 \\
40 \\
41 \\
69 \\
100 \\
119 \\
129 \\
200 \\
250 \\
311 \\
499 \\
719 \\
817\end{array}$ & $\begin{array}{l}5.2 \mathrm{E}-04 \\
3.0 \mathrm{E}-05 \\
5.3 \mathrm{E}-05 \\
8.5 \mathrm{E}-05 \\
1.1 \mathrm{E}-04 \\
1.4 \mathrm{E}-04 \\
1.7 \mathrm{E}-04 \\
5.3 \mathrm{E}-04 \\
1.1 \mathrm{E}-04 \\
1.0 \mathrm{E}-04 \\
1.3 \mathrm{E}-04 \\
4.0 \mathrm{E}-03 \\
2.1 \mathrm{E}-05 \\
7.5 \mathrm{E}-04 \\
1.2 \mathrm{E}-04 \\
2.3 \mathrm{E}-03\end{array}$ & $\begin{array}{r}5.4 \\
3.6 \\
4.8 \\
10.5 \\
7.4 \\
3.8 \\
6.1 \\
4.9 \\
8.8 \\
3.8 \\
6.8 \\
9.0 \\
1.1 \\
7.1 \\
0.0 \\
0.0\end{array}$ & $\begin{array}{l}0.0185 \\
0.0180 \\
0.0209 \\
0.0320 \\
0.0204 \\
0.0226 \\
0.0191 \\
0.0603 \\
0.0116 \\
0.0187 \\
0.0140 \\
0.0344 \\
0.0134 \\
0.0141 \\
0.0249 \\
0.0199\end{array}$ & $\begin{array}{l}1.40 \\
1.25 \\
1.33 \\
1.34 \\
1.40 \\
1.32 \\
1.39 \\
1.29 \\
1.50 \\
1.31 \\
1.39 \\
1.97 \\
1.21 \\
1.73 \\
1.20 \\
1.20\end{array}$ \\
\hline Ue $5 \mathrm{PW}-3$ & $\begin{array}{r}1 \\
3 \\
51 \\
52 \\
101 \\
130 \\
200 \\
500 \\
550\end{array}$ & $\begin{array}{l}7.2 \mathrm{E}-04 \\
3.2 \mathrm{E}-04 \\
3.2 \mathrm{E}-04 \\
5.6 \mathrm{E}-05 \\
6.0 \mathrm{E}-05 \\
4.4 \mathrm{E}-04 \\
3.2 \mathrm{E}-03 \\
2.4 \mathrm{E}-03 \\
1.1 \mathrm{E}-03\end{array}$ & $\begin{array}{l}3.1 \\
3.2 \\
4.1 \\
4.9 \\
8.6 \\
7.2 \\
1.6 \\
3.0 \\
4.7\end{array}$ & $\begin{array}{r}0.0103 \\
0.0107 \\
0.0115 \\
0.0114 \\
0.0153 \\
0.0450 \\
2.3097 \\
0.0383 \\
0.0274\end{array}$ & $\begin{array}{l}1.47 \\
1.48 \\
1.38 \\
1.43 \\
1.37 \\
1.48 \\
1.14 \\
1.30 \\
1.38\end{array}$ \\
\hline
\end{tabular}




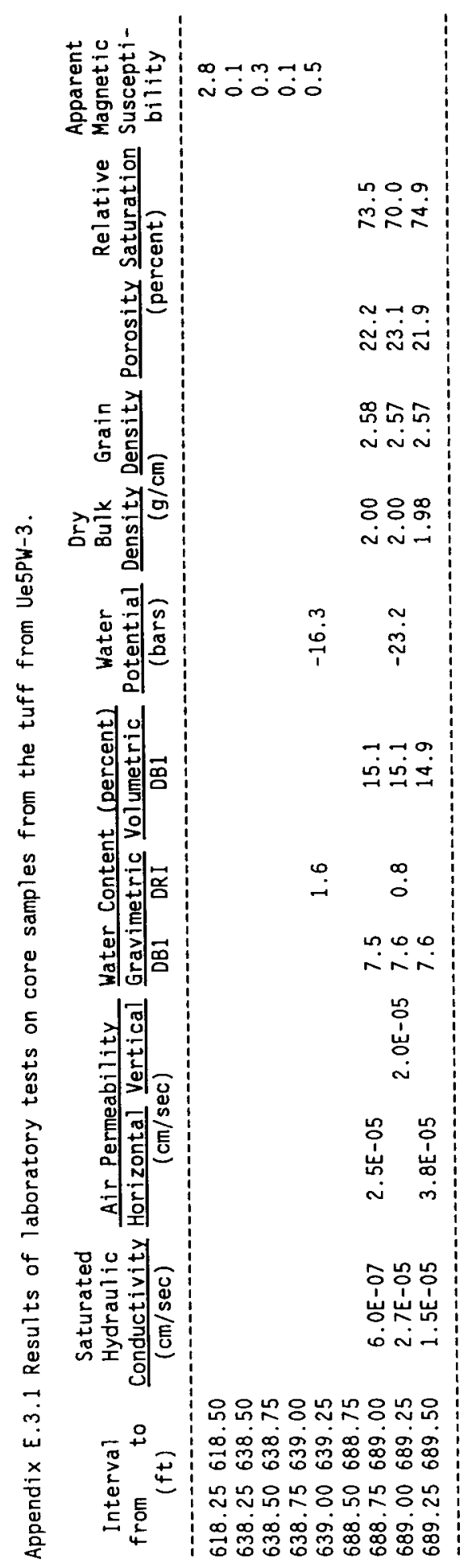


Appendix E.3.2 Results of laboratory test on cuttings samples from the tuff from Ue5PW-3.

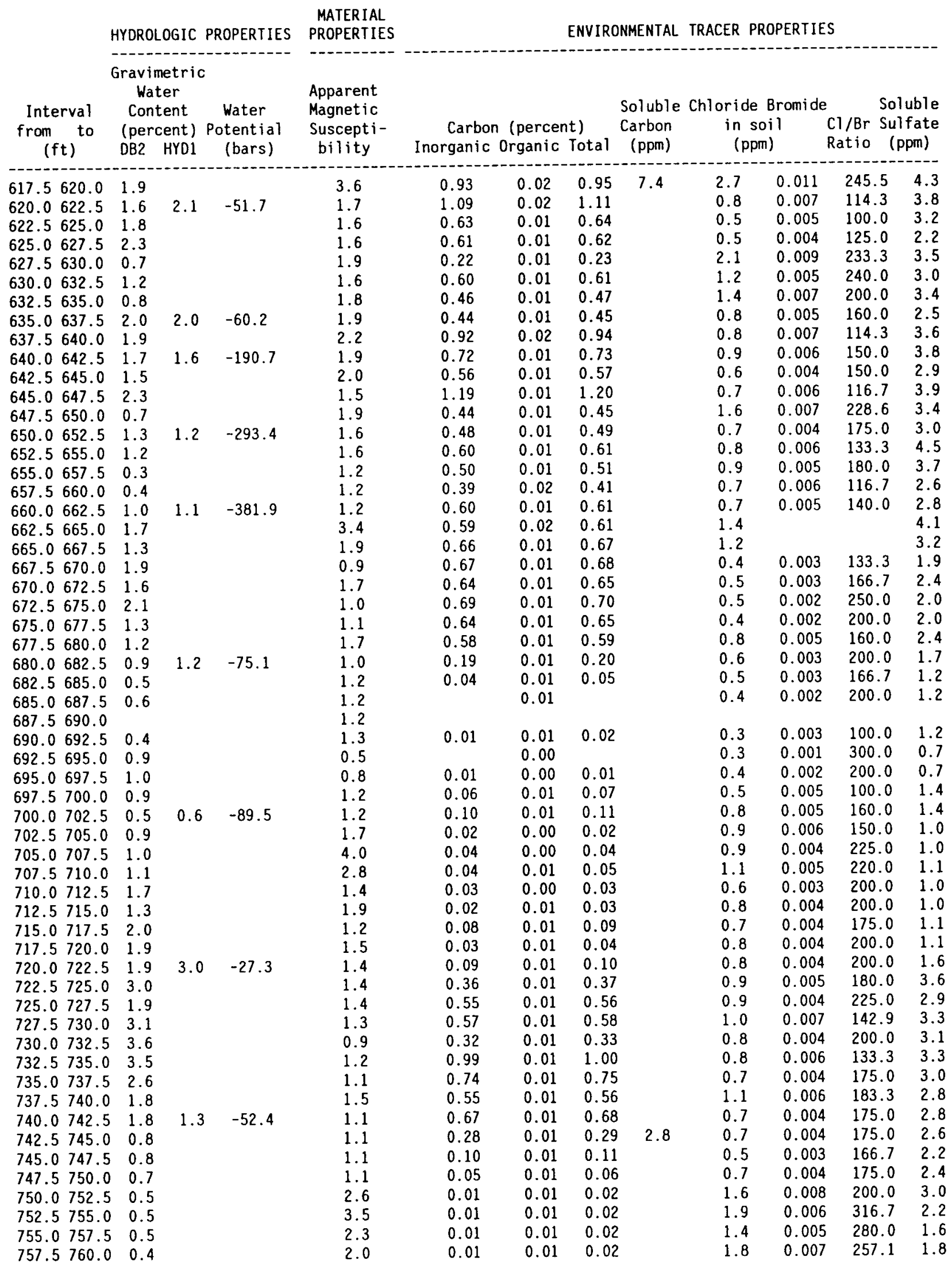


Appendix E.3.2 Results of laboratory test on cuttings samples from the tuff from Ue5PW-3 (continued).

\begin{tabular}{|c|c|c|c|c|c|c|c|c|c|c|c|c|}
\hline \multirow[b]{2}{*}{$\begin{array}{l}\text { Interval } \\
\text { from to } \\
(\mathrm{ft})\end{array}$} & \multicolumn{4}{|c|}{ HYDROLOGIC PROPERTIES PROPERTIES } & \multicolumn{8}{|c|}{ ENVIRONMENTAL TRACER PROPERTIES } \\
\hline & $\begin{array}{c}\text { Gravin } \\
\text { Wat } \\
\text { Cont } \\
\text { (pero } \\
\text { DB2 }\end{array}$ & $\begin{array}{l}\text { netric } \\
\text { ter } \\
\text { tent } \\
\text { cent) } \\
\text { HYD1 }\end{array}$ & $\begin{array}{l}\text { Water } \\
\text { Potential } \\
\text { (bars) }\end{array}$ & $\begin{array}{l}\text { Apparent } \\
\text { Magnetic } \\
\text { Suscepti- } \\
\text { bility }\end{array}$ & $\begin{array}{l}\text { Carbo } \\
\text { Inorganic }\end{array}$ & $\begin{array}{l}\text { n (percen } \\
\text { Organic }\end{array}$ & $\begin{array}{l}\text { t) } \\
\text { Total }\end{array}$ & $\begin{array}{c}\text { Soluble } \\
\text { Carbon } \\
\text { (ppm) }\end{array}$ & $\begin{array}{r}\text { Chloride } \\
\text { in so } \\
\text { (ppm }\end{array}$ & $\begin{array}{l}\text { Bromide } \\
\text { n) } \\
\text { n) }\end{array}$ & $\begin{array}{l}\text { So } \\
\mathrm{Cl} / \mathrm{Br} \mathrm{Su} \\
\text { Ratio }\end{array}$ & $\begin{array}{l}\text { Soluble } \\
\text { Sulfate } \\
\text { (ppm) }\end{array}$ \\
\hline $\begin{array}{l}760.0762 .5 \\
762.5765 .0\end{array}$ & 0.3 & & & 1.4 & 0.01 & 0.01 & 0.02 & & 1.7 & 0.007 & 242.9 & 1.4 \\
\hline $\begin{array}{l}762.5765 .0 \\
765.0767 .5\end{array}$ & 0.3 & & & 1.3 & & & & & 1.7 & 0.006 & 283.3 & 1.1 \\
\hline $\begin{array}{l}765.0767 .5 \\
767.5770 .0\end{array}$ & 0.3 & & & 1.2 & & & & & 1.9 & 0.007 & 271.4 & 1.4 \\
\hline $\begin{array}{l}767.5770 .0 \\
770.0772 .5\end{array}$ & 0.6 & & & 1.3 & 0.01 & 0.01 & 0.02 & & 1.5 & 0.007 & 214.3 & 1.0 \\
\hline $\begin{array}{l}770.0772 .5 \\
772.5775 .0\end{array}$ & & & & 1.2 & & 0.04 & & & 5.5 & 0.028 & 196.4 & 7.5 \\
\hline $\begin{array}{l}772.5775 .0 \\
775.0777 .5\end{array}$ & & & & 1.2 & & 0.01 & & & 3.5 & 0.015 & 233.3 & 2.9 \\
\hline $\begin{array}{l}775.0777 .5 \\
777.5780 .0\end{array}$ & & & & 1.5 & & 0.01 & & & 3.8 & & & 2.8 \\
\hline $\begin{array}{l}777.5780 .0 \\
780.0782 .5\end{array}$ & & & & 1.4 & & 0.01 & & & 3.1 & 0.013 & 238.5 & 3.3 \\
\hline $\begin{array}{l}780.0782 .5 \\
782.5785 .0\end{array}$ & & & & 1.4 & & 0.01 & & & 4.1 & 0.017 & 241.2 & 3.3 \\
\hline $\begin{array}{l}782.5785 .0 \\
785.0787 .5\end{array}$ & & & & 1.5 & & 0.02 & & & 6.3 & 0.021 & 300.0 & 3.2 \\
\hline $\begin{array}{l}785.0787 .5 \\
787.5790 .0\end{array}$ & & & & 1.4 & & 0.01 & & & 5.1 & 0.020 & 255.0 & 2.7 \\
\hline $\begin{array}{l}787.5790 .0 \\
790.0792 .5\end{array}$ & & & & 1.3 & & 0.01 & & & 3.8 & 0.015 & 253.3 & 2.4 \\
\hline $\begin{array}{l}790.0792 .5 \\
792.5795 .0\end{array}$ & & & & 1.4 & & 0.01 & & & 3.3 & 0.016 & 206.2 & 2.6 \\
\hline $\begin{array}{l}792.5795 .0 \\
795.0797 .5\end{array}$ & & & & 1.5 & & 0.01 & & & 3.3 & 0.017 & 194.1 & 2.6 \\
\hline $\begin{array}{l}795.0797 .5 \\
797.5800 .0\end{array}$ & & & & 1.6 & & 0.01 & & & 3.5 & 0.016 & 218.8 & 2.5 \\
\hline $\begin{array}{l}797.5 \quad 800.0 \\
800.0802 .5\end{array}$ & & & & 1.4 & & 0.01 & & & 3.5 & 0.013 & 269.2 & 1.4 \\
\hline $\begin{array}{l}800.0802 .5 \\
802.5805 .0\end{array}$ & & & & 1.5 & & 0.01 & & & 3.2 & 0.013 & 246.2 & 1.2 \\
\hline $\begin{array}{l}802.5805 .0 \\
805.0807 .5\end{array}$ & & & & 2.4 & & 0.02 & & & 4.6 & 0.015 & 306.7 & 2.9 \\
\hline $\begin{array}{l}805.0807 .5 \\
807.5810 .0\end{array}$ & & & & 1.5 & & 0.01 & & & 3.6 & 0.011 & 327.3 & 1.3 \\
\hline $\begin{array}{l}807.5810 .0 \\
810.0812 .5\end{array}$ & & & & 1.4 & & 0.01 & & & 3.1 & 0.011 & 281.8 & 1.1 \\
\hline $\begin{array}{l}810.0812 .5 \\
812.5815 .0\end{array}$ & & & & 1.5 & & 0.01 & & & 3.3 & 0.013 & 253.8 & 1.2 \\
\hline $\begin{array}{l}812.5 \quad 815.0 \\
815.0 \quad 817.5\end{array}$ & & & & 2.1 & & 0.01 & & & 2.6 & 0.010 & 260.0 & 1.7 \\
\hline 815.0817 .5 & & & & 1.4 & 0.01 & 0.00 & 0.01 & & 1.6 & 0.011 & 145.5 & 1.0 \\
\hline 817.5820 .0 & & & & 1.8 & & 0.00 & & & 2.3 & 0.010 & 230.0 & 1.0 \\
\hline 820.0822 .5 & & & & 1.8 & & 0.01 & & & 2.1 & 0.009 & 233.3 & 0.9 \\
\hline 822.5825 .0 & & & & 2.2 & & 0.03 & & 20.6 & 2.0 & & & 3.1 \\
\hline $825.0 \quad 827.5$ & & & & 2.2 & & 0.02 & & & 2.1 & & & 2.3 \\
\hline 827.5830 .0 & & & & 2.4 & 0.01 & 0.01 & 0.02 & & 2.7 & 0.012 & 225.0 & 1.3 \\
\hline 830.0832 .5 & & & & 2.4 & & 0.01 & & & 2.8 & 0.013 & 215.4 & 1.1 \\
\hline 832.5835 .0 & & & & 2.7 & & 0.01 & & & 2.2 & 0.009 & 244.4 & 0.9 \\
\hline 835.0837 .5 & & & & 2.7 & & 0.01 & & & 2.2 & 0.008 & 275.0 & 1.0 \\
\hline 837.5840 .0 & & & & 2.6 & & 0.01 & & & 0.9 & 0.007 & 128.6 & 0.7 \\
\hline 840.0842 .5 & & 1.0 & -132.0 & 3.5 & & 0.01 & & & 1.0 & 0.008 & 125.0 & 0.8 \\
\hline 842.5845 .0 & & & & 3.3 & & 0.01 & & & 1.7 & 0.007 & 242.9 & 0.8 \\
\hline $845.0 \quad 847.5$ & & & & 3.3 & & 0.01 & & & 1.7 & 0.009 & 188.9 & 1.0 \\
\hline 847.5850 .0 & & & & 3.2 & & 0.01 & & & 1.0 & 0.007 & 142.9 & 0.7 \\
\hline $850.0 \quad 852.5$ & & & & 2.6 & & 0.01 & & & 1.2 & 0.007 & 171.4 & 0.7 \\
\hline 852.5855 .0 & & & & 2.9 & & 0.01 & & & 2.3 & 0.009 & 255.6 & 0.9 \\
\hline 855.0857 .5 & & & & 2.3 & & 0.01 & & & 2.0 & 0.008 & 250.0 & 0.8 \\
\hline 857.5860 .0 & & & & 2.5 & & 0.01 & & & 1.1 & 0.007 & 157.1 & 0.8 \\
\hline 860.0862 .5 & & 8.1 & -8.1 & 2.7 & 0.01 & 0.00 & 0.01 & & 1.6 & 0.008 & 200.0 & 0.8 \\
\hline 862.5865 .0 & & & & 3.2 & 0.03 & 0.01 & 0.04 & & 2.0 & 0.006 & 333.3 & 1.1 \\
\hline $865.0 \quad 867.5$ & & & & 2.5 & & 0.02 & & & 3.0 & 0.008 & 375.0 & 1.6 \\
\hline $867.5 \quad 870.0$ & & & & 2.7 & & 0.01 & & & 3.5 & 0.009 & 388.9 & 1.1 \\
\hline 870.0872 .5 & & & & 2.8 & & 0.01 & & & 2.7 & 0.008 & 337.5 & 1.1 \\
\hline $872.5 \quad 875.0$ & & 5.1 & -10.9 & 2.9 & 0.03 & 0.01 & 0.04 & & 2.3 & 0.007 & 328.6 & 1.1 \\
\hline 875.0877 .5 & & & & 3.2 & 0.08 & 0.01 & 0.09 & & 2.5 & 0.006 & 416.7 & 1.2 \\
\hline 877.5880 .0 & & 1.0 & -144.0 & 4.4 & & 0.01 & & & 2.5 & 0.008 & 312.5 & 1.1 \\
\hline 880.0882 .5 & & & & 4.1 & & 0.01 & & & 3.2 & 0.008 & 400.0 & 1.1 \\
\hline 882.5885 .0 & & 1.3 & -121.6 & 4.1 & & 0.01 & & & 2.7 & 0.007 & 385.7 & 1.1 \\
\hline 885.0887 .5 & & & & 3.9 & & 0.01 & & & 2.3 & 0.007 & 328.6 & 1.1 \\
\hline 887.5890 .0 & & 1.8 & -75.1 & 3.0 & & 0.01 & & & 1.8 & 0.005 & 360.0 & 1.1 \\
\hline 890.0892 .5 & & & & 4.1 & & 0.01 & & & 1.6 & 0.006 & 266.7 & 1.1 \\
\hline 892.5895 .0 & & 1.6 & -89.5 & 3.6 & & 0.01 & & & 2.1 & 0.005 & 420.0 & 1.1 \\
\hline 895.0897 .5 & & & & 3.5 & & 0.01 & & & 3.7 & 0.010 & 370.0 & 1.5 \\
\hline 897.5900 .0 & & 1.5 & -129.1 & 3.3 & & 0.01 & & & 3.3 & 0.009 & 366.7 & 1.1 \\
\hline 900.0902 .5 & & & & 3.6 & & 0.01 & & & 3.9 & 0.011 & 354.5 & 1.4 \\
\hline
\end{tabular}


Appendix E.3.2 Results of laboratory test on cuttings samples from the tuff from Ue5PW-3 (continued).

\begin{tabular}{|c|c|c|c|c|c|c|c|c|c|c|c|}
\hline \multirow[b]{2}{*}{$\begin{array}{l}\text { Interval } \\
\text { from to } \\
(\mathrm{ft})\end{array}$} & \multicolumn{3}{|c|}{ HYDROLOGIC PROPERTIES PROPERTIES } & \multicolumn{8}{|c|}{ ENVIRONMENTAL TRACER PROPERTIES } \\
\hline & $\begin{array}{c}\text { Gravimetric } \\
\text { Water } \\
\text { Content } \\
\text { (percent) } \\
\text { DB2 HYD1 }\end{array}$ & $\begin{array}{c}\text { Water } \\
\text { Potential } \\
\text { (bars) }\end{array}$ & $\begin{array}{l}\text { Apparent } \\
\text { Magnetic } \\
\text { Suscepti- } \\
\text { bility }\end{array}$ & $\begin{array}{r}\text { Carb } \\
\text { Inorgani }\end{array}$ & $\begin{array}{l}\text { (percen } \\
\text { Organic }\end{array}$ & $\begin{array}{l}\text { t) } \\
\text { Total }\end{array}$ & $\begin{array}{l}\text { Soluble } \\
\text { Carbon } \\
\text { (ppm) }\end{array}$ & $\begin{array}{r}\text { Chlorid } \\
\text { in } \\
\text { (p }\end{array}$ & $\begin{array}{l}\text { Bromide } \\
\text { iil } \\
\text { त) }\end{array}$ & $\begin{array}{l}\mathrm{So} \\
\mathrm{Cl} / \mathrm{Br} \mathrm{Su} \\
\mathrm{Ratio}\end{array}$ & $\begin{array}{c}\text { Soluble } \\
\text { Sulfate } \\
\text { (ppm) }\end{array}$ \\
\hline 902.5905 .0 & & & 2.7 & & 0.01 & & & 3.4 & 0.009 & 377.8 & 1.3 \\
\hline 5.0907 .5 & & & 1.8 & & 0.01 & & & 5.2 & 0.017 & 305.9 & 3.2 \\
\hline 907.5910 .0 & & & 1.7 & & 0.01 & & & 2.9 & 0.010 & 290.0 & 1.4 \\
\hline 910.0912 .5 & & & 1.8 & & 0.01 & & & 2.7 & 0.009 & 300.0 & 1.2 \\
\hline 12.5915 .0 & & & 1.8 & & 0.01 & & & 2.3 & 0.007 & 328.6 & 1.2 \\
\hline 15.0917 .5 & & & 1.8 & & 0.01 & & & 1.8 & 0.007 & 257.1 & 1.4 \\
\hline 917.5920 .0 & & & 1.2 & & 0.01 & & & 0.9 & 0.005 & 180.0 & 1.8 \\
\hline 920.0922 .5 & 11.7 & -16.3 & 0.9 & & 0.01 & & & 1.1 & 0.010 & 110.0 & 3.6 \\
\hline 922.5925 .0 & & & 1.0 & & 0.01 & & & 1.7 & 0.010 & 170.0 & 4.2 \\
\hline 925.0927 .5 & 18.1 & -2.7 & 0.7 & & 0.01 & & & 3.0 & 0.024 & 125.0 & $\begin{array}{ll}0 & 10.7\end{array}$ \\
\hline 927.5930 .0 & & & 1.3 & & 0.01 & & & 2.2 & 0.018 & 122.2 & 7.5 \\
\hline 930.0932 .5 & & & 1.9 & & 0.01 & & & 1.5 & 0.012 & 125.0 & 4.5 \\
\hline 932.5935 .0 & & & 1.5 & & 0.00 & & & 5.0 & 0.033 & 151.5 & 9.6 \\
\hline 935.0937 .5 & & & 1.3 & & 0.00 & & & 4.5 & 0.036 & 125.0 & $0 \quad 12.4$ \\
\hline 937.5940 .0 & & & 1.2 & & 0.01 & & & 4.3 & 0.035 & 122.9 & $9 \quad 12.5$ \\
\hline 940.0942 .5 & & & 1.0 & & 0.00 & & & 2.2 & 0.019 & 115.8 & 6.7 \\
\hline 942.5945 .0 & & & 1.4 & 0.09 & 0.04 & 0.13 & & 4.0 & 0.020 & 200.0 & $0 \quad 11.1$ \\
\hline 945.0947 .5 & & & 1.0 & 0.20 & 0.00 & 0.20 & & 3.9 & 0.027 & 144.4 & 9.3 \\
\hline 947.5950 .0 & & & 0.6 & & 0.01 & & & 4.1 & 0.038 & 107.9 & $9 \quad 13.6$ \\
\hline 950.0952 .5 & & & 1.0 & 0.05 & 0.01 & 0.06 & & 6 . & 0.048 & 125.0 & $\begin{array}{ll}0 & 17.4\end{array}$ \\
\hline 952.5955 .0 & & & 2.0 & 0.02 & 0.00 & 0.02 & & 4.0 & 0.034 & 117.6 & $\begin{array}{ll}6 & 11.9\end{array}$ \\
\hline
\end{tabular}


Intact core samples and rotary air cuttings samples were collected periodically during pilot well drilling to determine if radiological or chemical contamination was present. Core and cuttings samples were not found to be contaminated with hazardous constituents or radioactivity.

Sampling locations were selected in advance and modified to accommodate drilling conditions and schedules. Samples from Ue5PW-1 were collected at higher frequencies near the surface and water table because of the expected greater potential for contamination at these locations. Sample frequencies were reduced for Ue5PW-2 and Ue5PW-3 because of the accelerated drilling schedule and the lack of detection of contamination in Ue5PW-1.

Sampling procedures and field quality assurance were conducted as described in WMD-T19 (Table 2.1). Alluvium samples analyzed for volatile organics, EPA method 8240 (EPA 1982), and semi-volatile organics, EPA method 8270 (EPA 1982), were collected as intact cores with a split spoon coring tool. Samples from Ue5PW-1 at a depth of $70 \mathrm{ft}(21 \mathrm{~m})$ were collected in polycarbonate liners with plastic end caps. All subsequent samples were collected in brass liners with plastic end caps. In each case, the end caps were taped and the cores were placed in a cooler at $4^{\circ} \mathrm{C}$ and transported to the laboratory.

Alluvium samples analyzed for photon emitting radionuclides, total kehldahl nitrogen and total metals ( $\mathrm{As}, \mathrm{Ba}, \mathrm{Cd}, \mathrm{Cr}, \mathrm{Pb}, \mathrm{Hg}, \mathrm{Se}$ and $\mathrm{Ag}$ ) were collected as rotary air cuttings at the cyclone separator. Samples for analysis of photon emitting radionuclides and total metals were collected in precleaned $500 \mathrm{ml}$ high density polyethylene bottles. Total kehldahl nitrogen samples were collected in $500 \mathrm{ml}$ glass jars.

Photon emitting samples were measured by gamma spectrometry of wet non-homogenized samples. The total kehldahl nitrogen analysis was performed using EPA method 351.5 (EPA 1982). Samples for total metals were prepared by EPA method 3050 (EPA 1982) and analyzed by inductively coupled plasma using EPA method 6010 (EPA 1982). In some instances total metals samples were prepared using the TCLP method.

Co-located samples (i.e. adjacent core samples) were periodically collected as duplicates for analysis of volatile organics and semi-volatile organics. Field blanks were prepared by filling sample containers with laboratory pure water at the drill site. Equipment or rinsate blanks were prepared by rinsing the coring tool with laboratory pure water. Trip blanks for analysis of volatile organics were prepared at the laboratory and transported into the field and returned for analysis.

Field quality assurance samples were prepared for photon emitting radionuclides, total metals and total kehldahl nitrogen. Duplicates were prepared by passing alluvium samples through a sample splitter. Field blanks were prepared from laboratory pure water in the field. Equipment or rinsate blanks were prepared by rinsing the coring tool with laboratory pure water. 
Appendix E.4 Results of sampling and analysis for hazardous and radiological parameters in core samples (Continued)

References

EPA, 1982. Methods for Chemical Analysis of Water and Waste, EPA-600/4-82-005

EPA, 1986. Test Methods for Evaluating Solid Waste, Physical /Chemical Methods, SW846. 


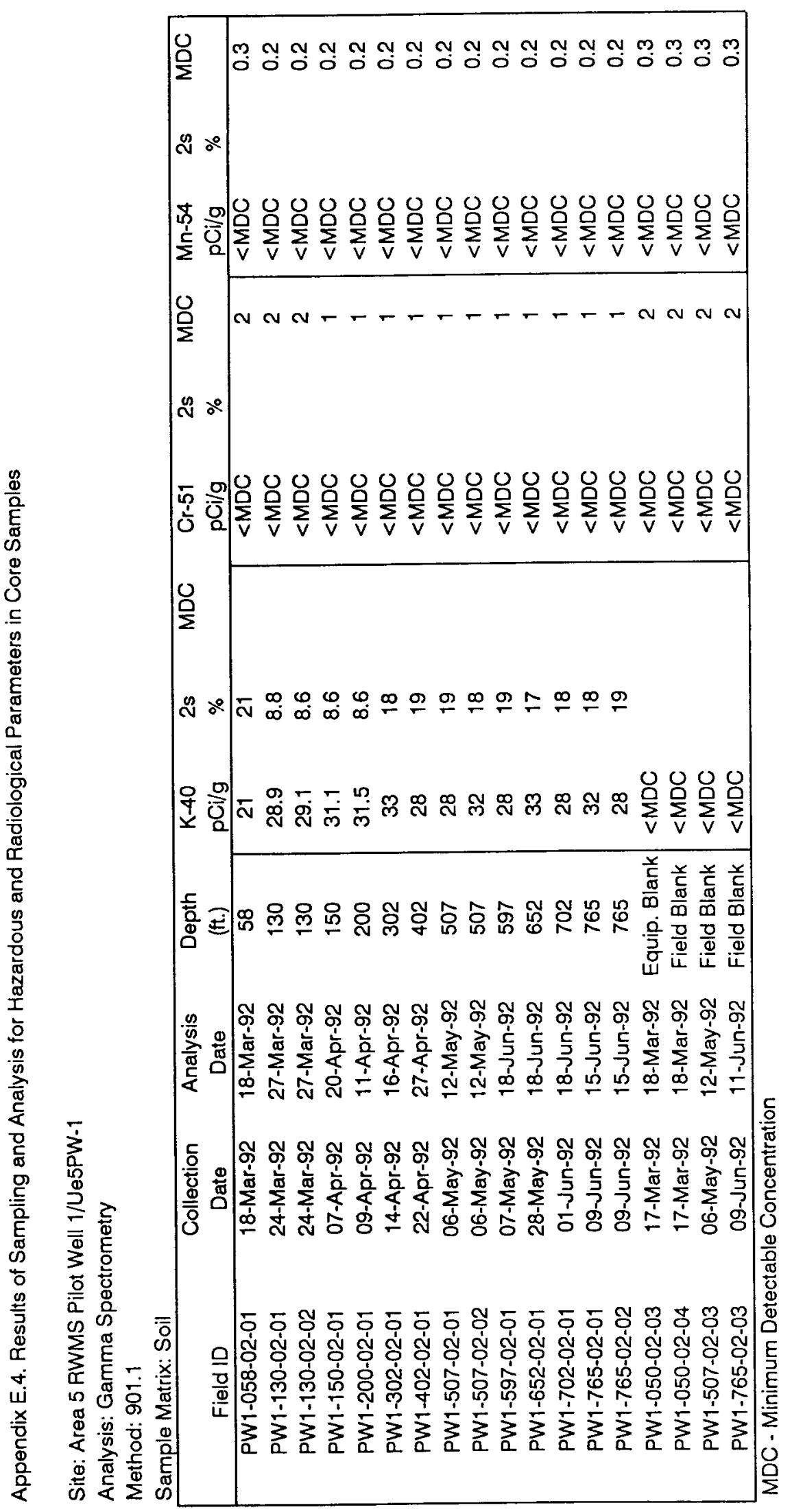




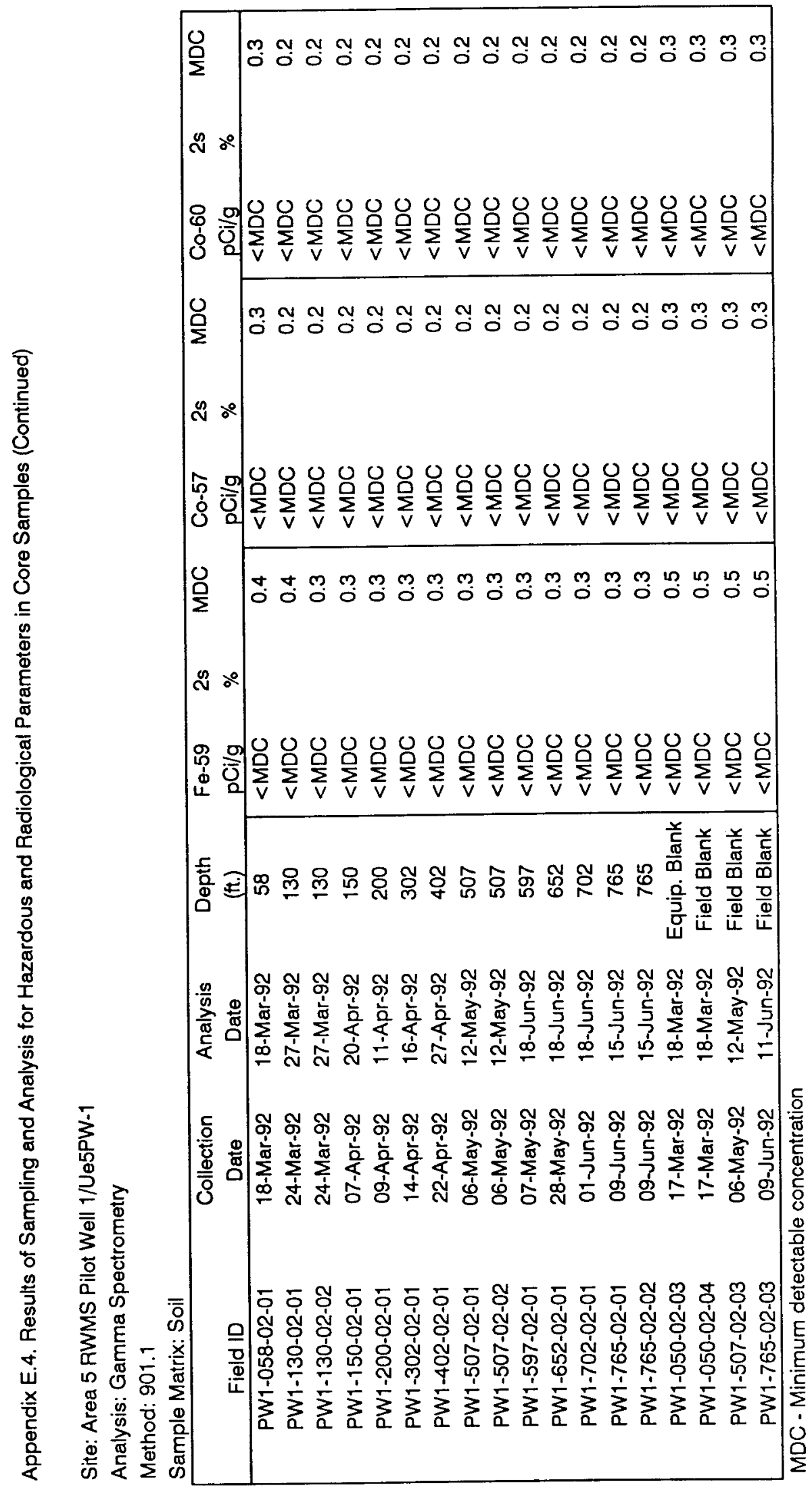




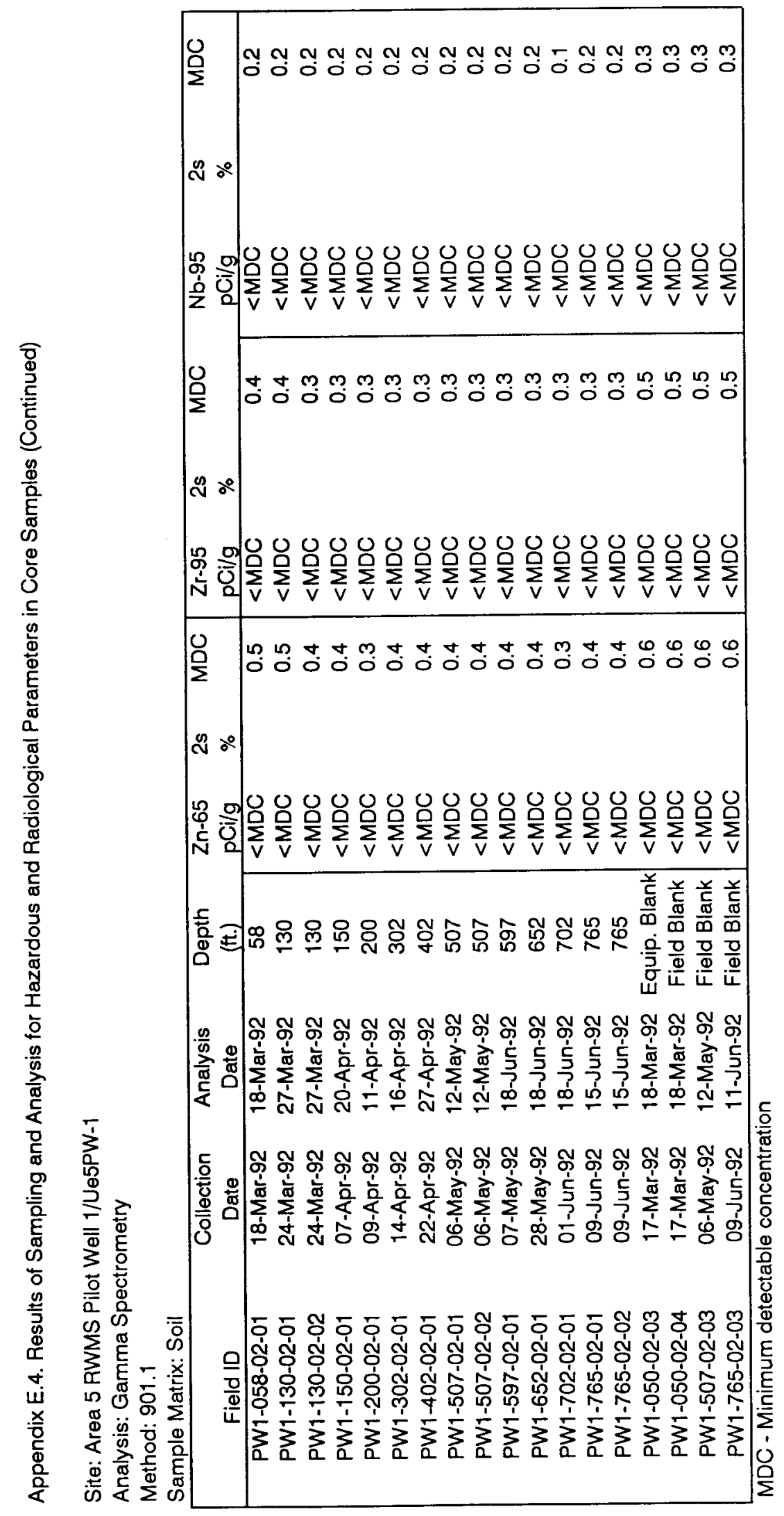




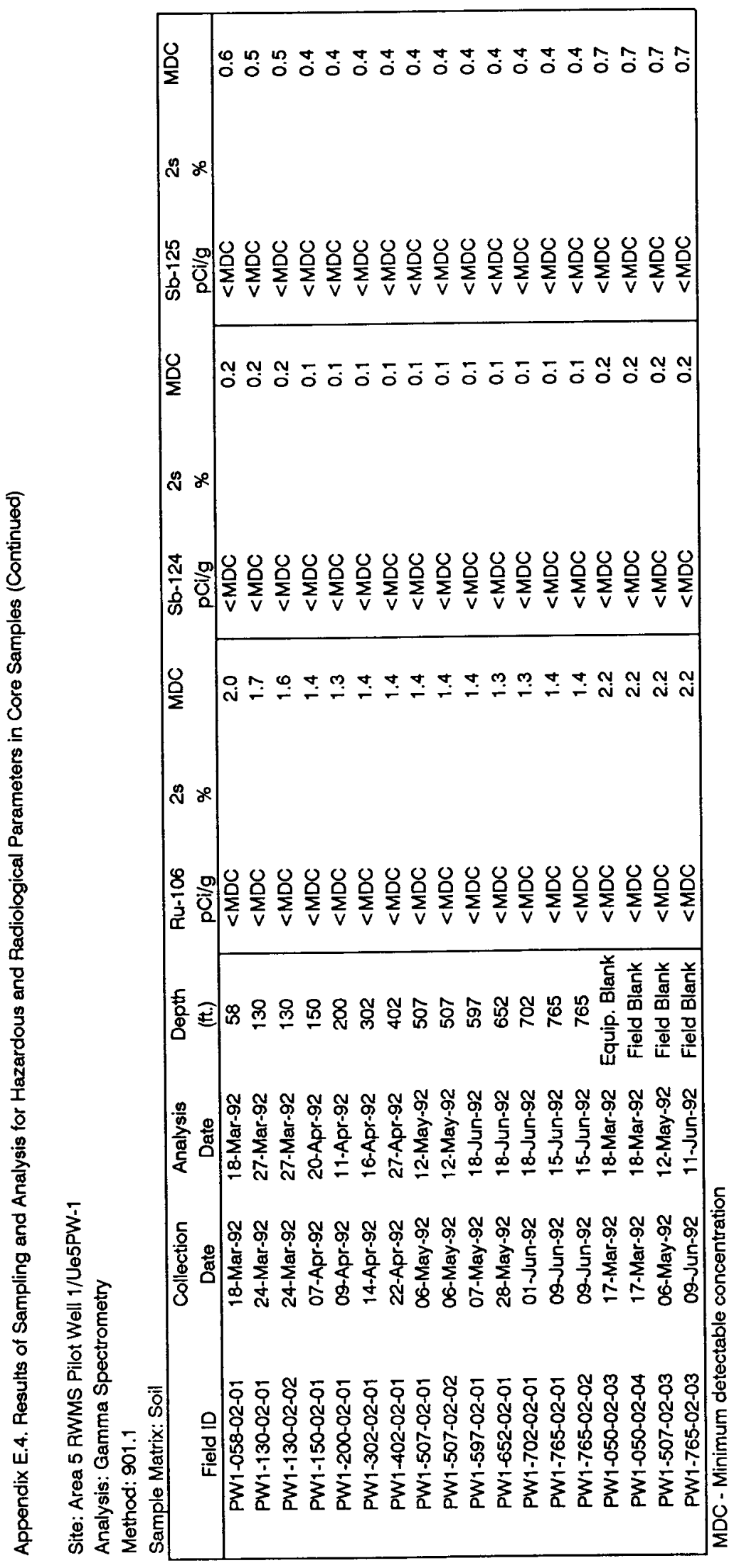




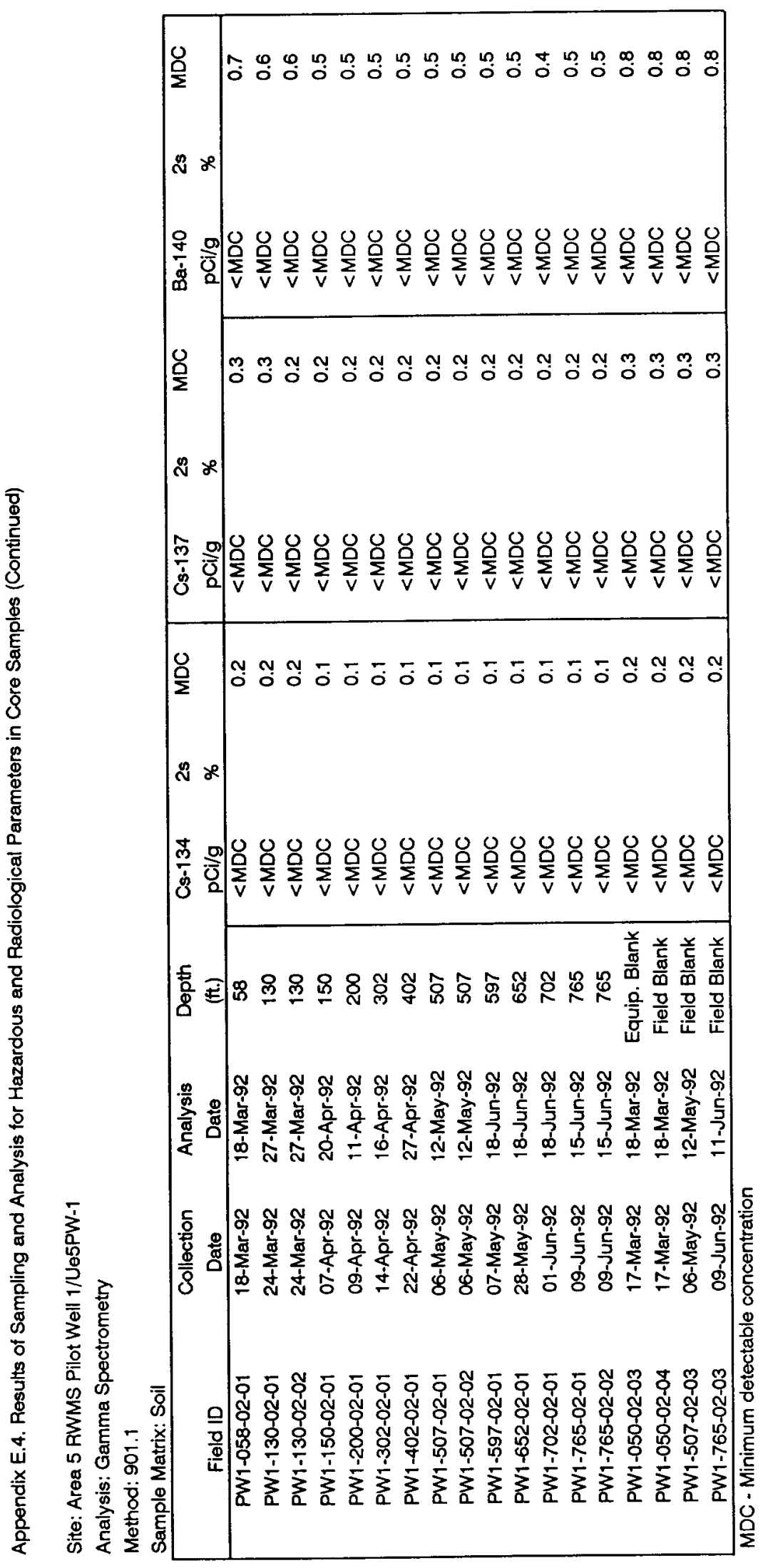




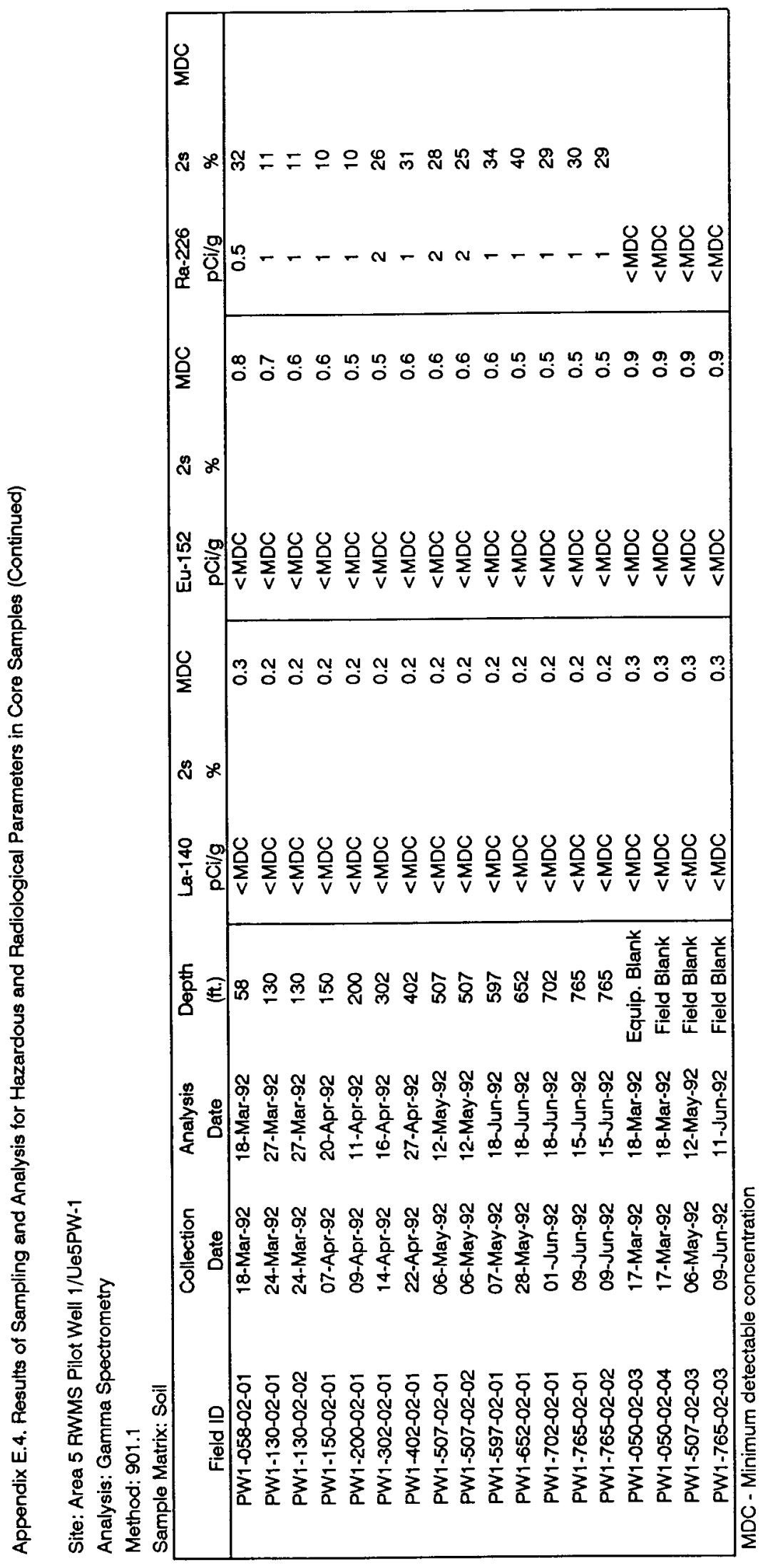




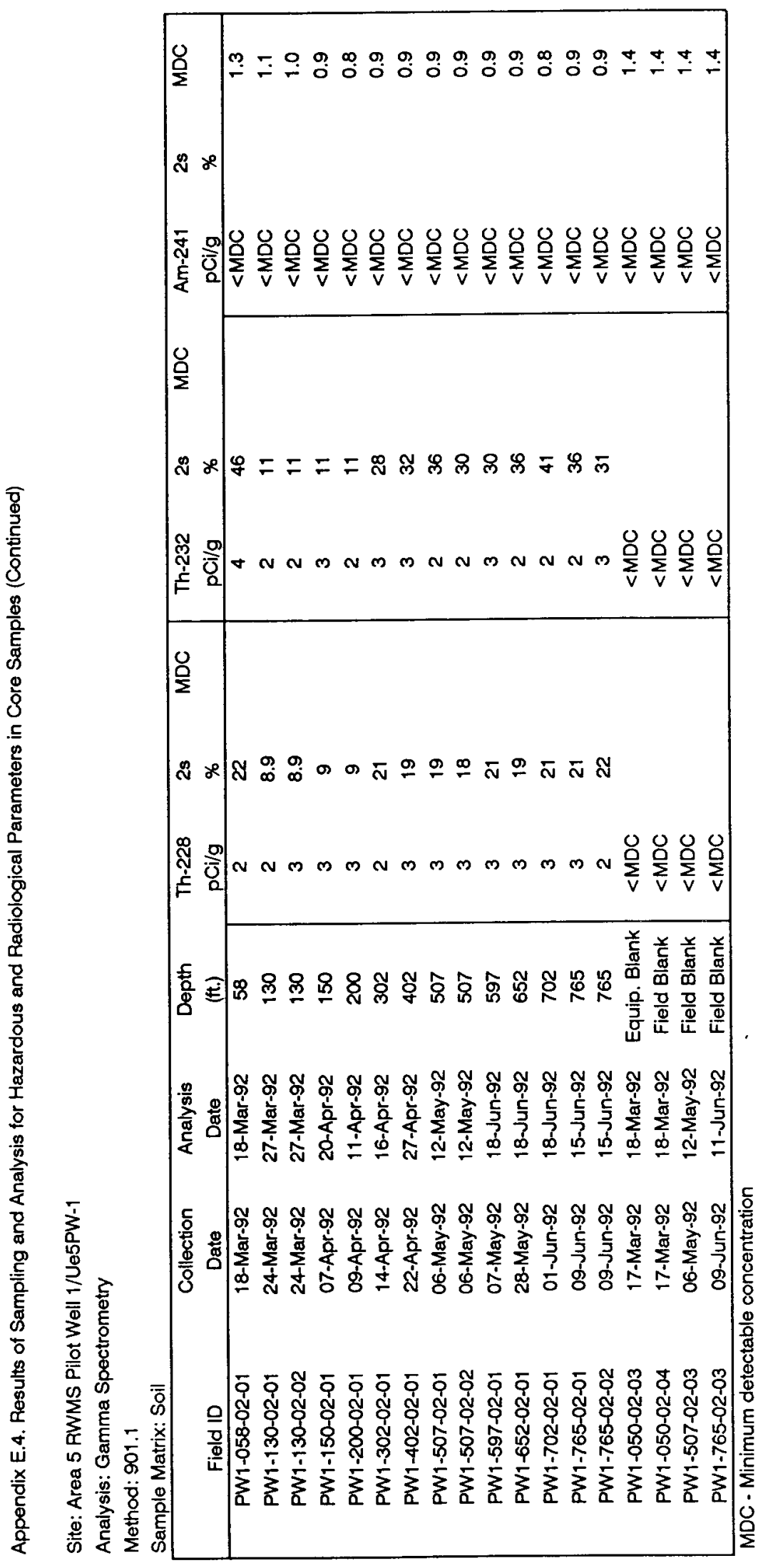




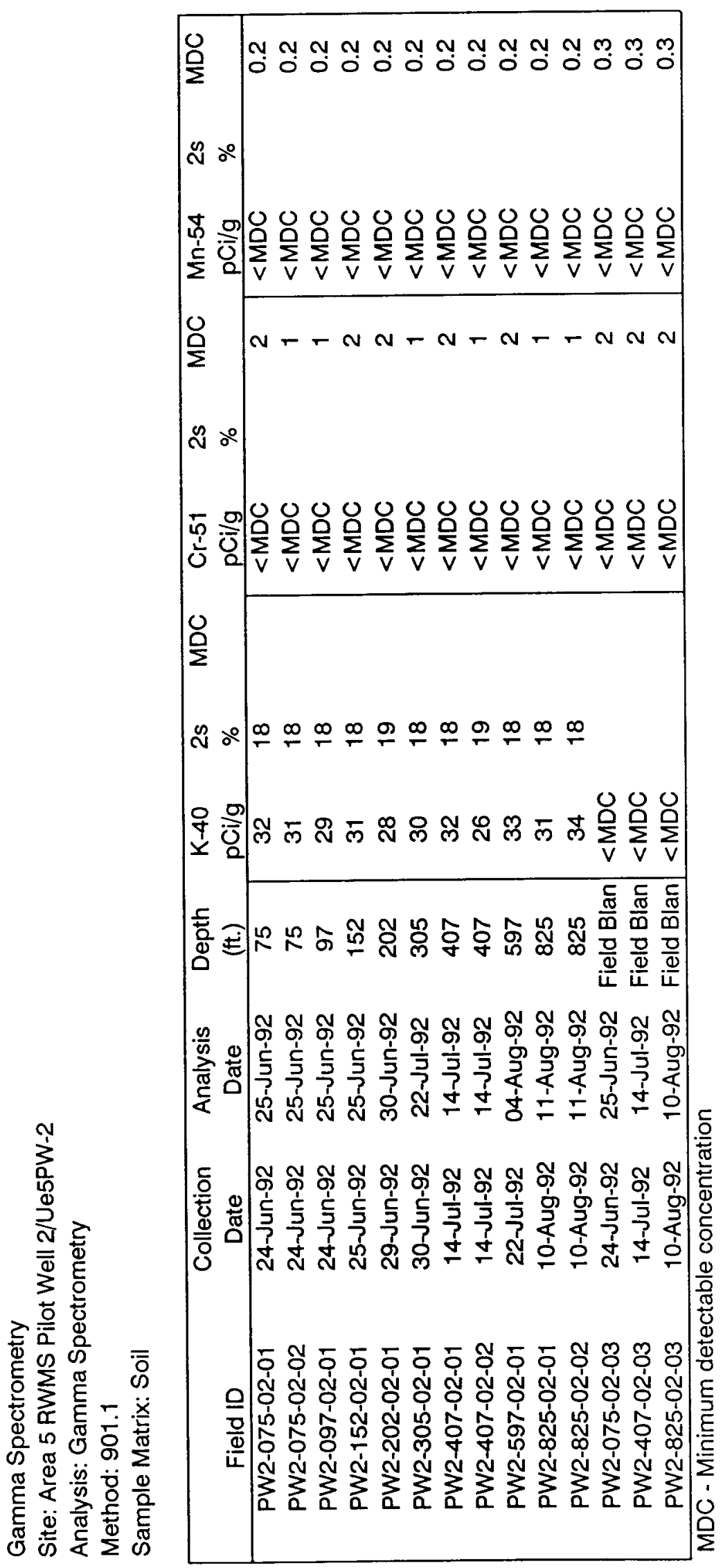




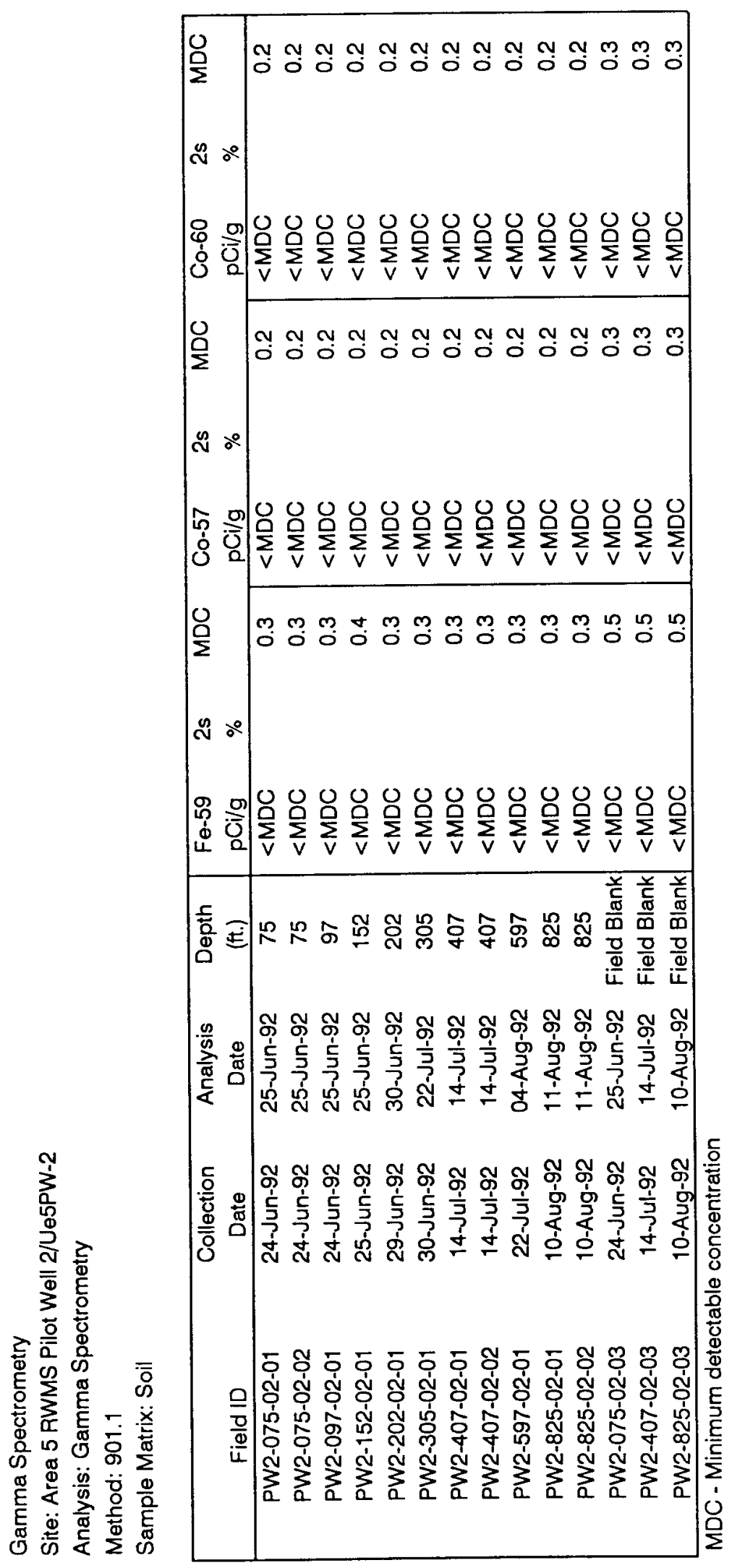




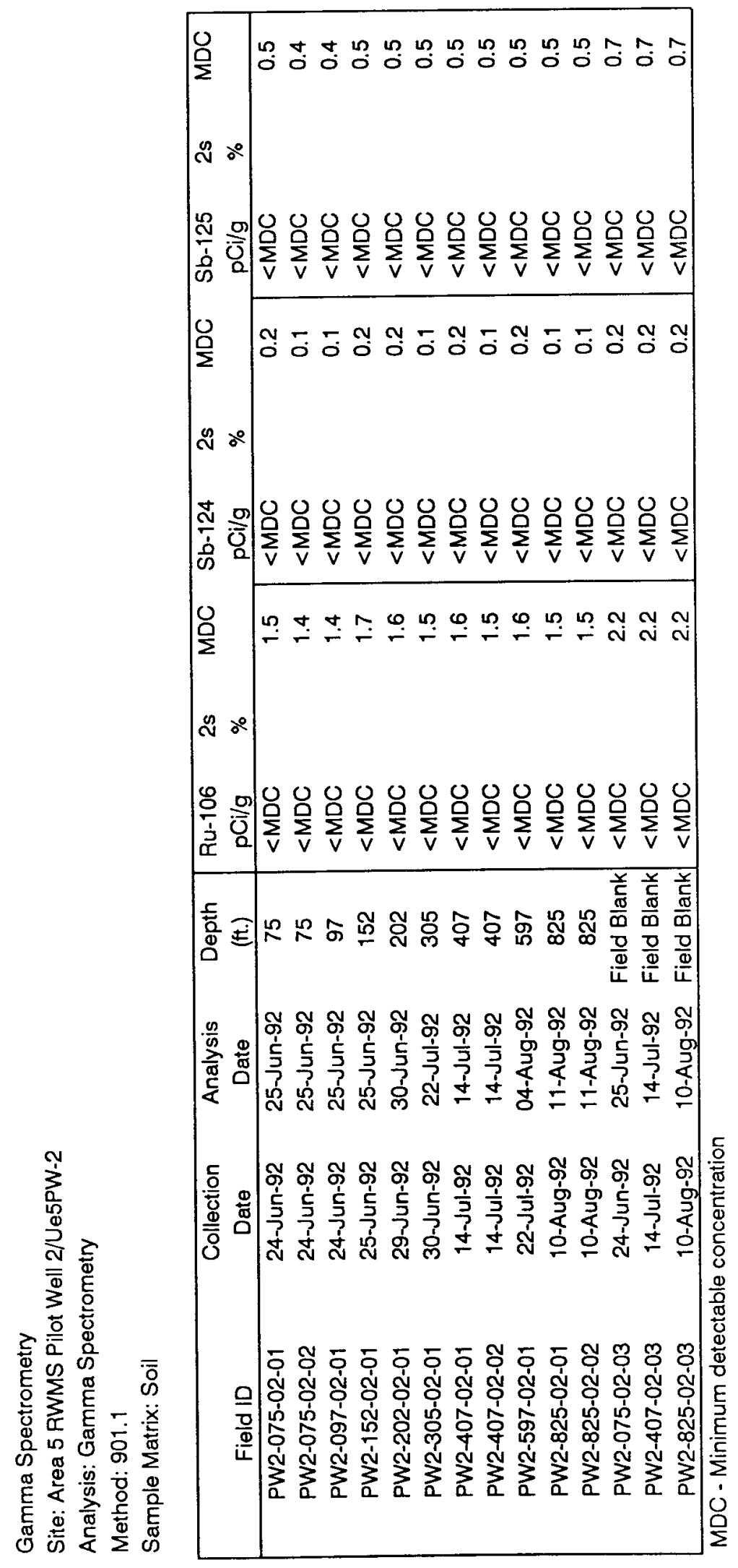




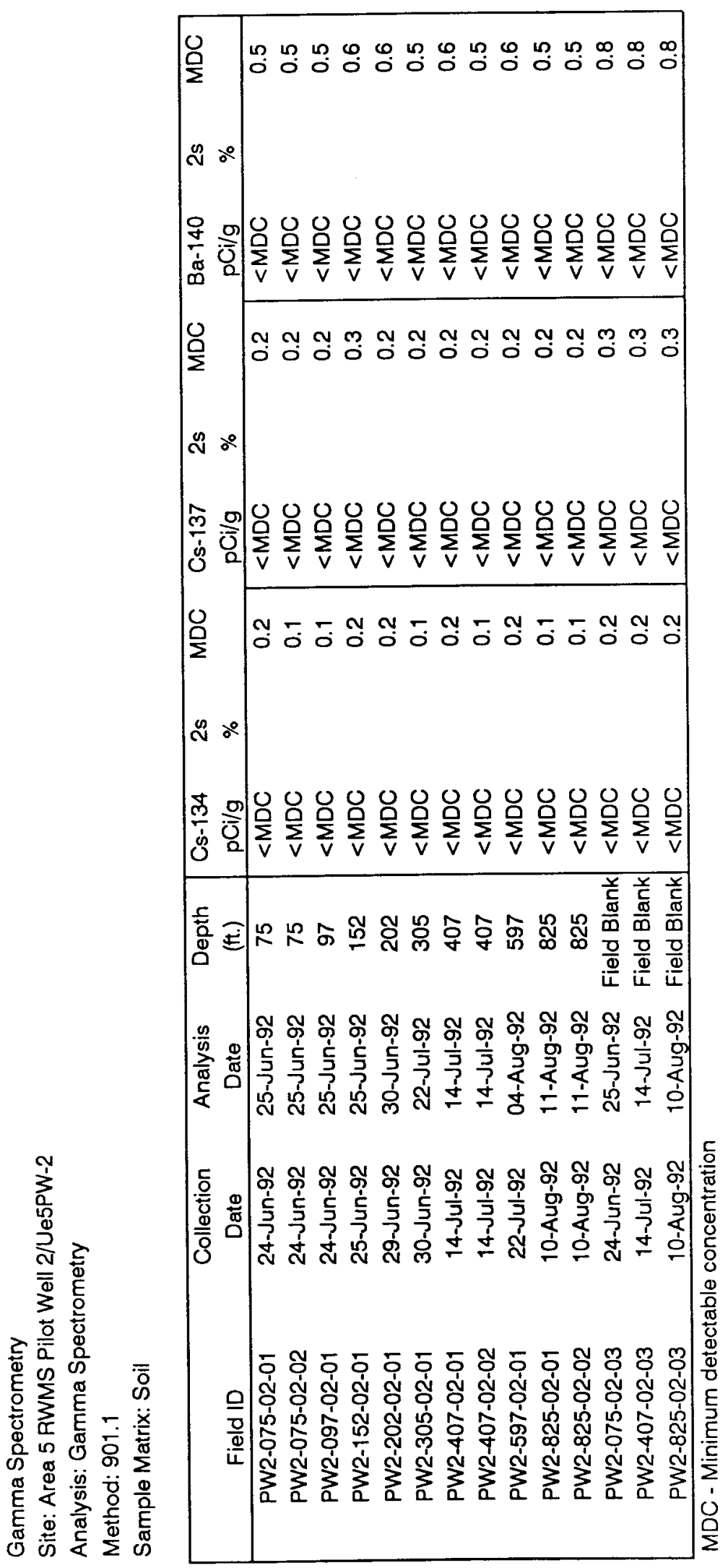




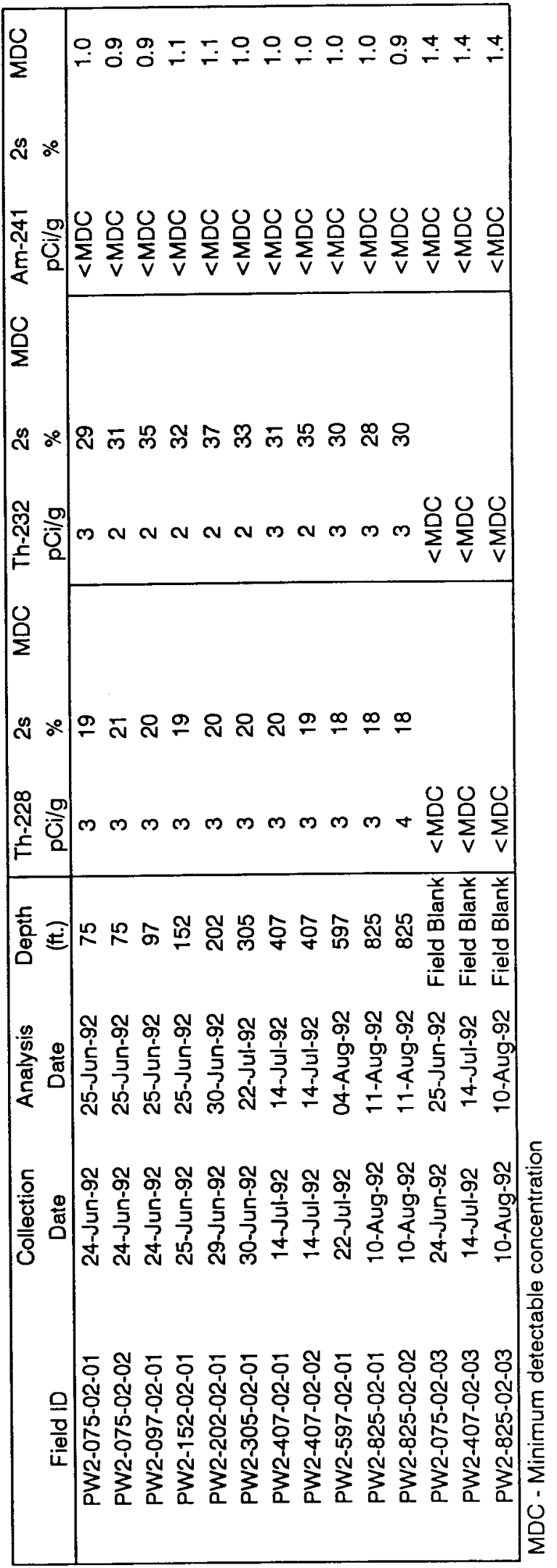



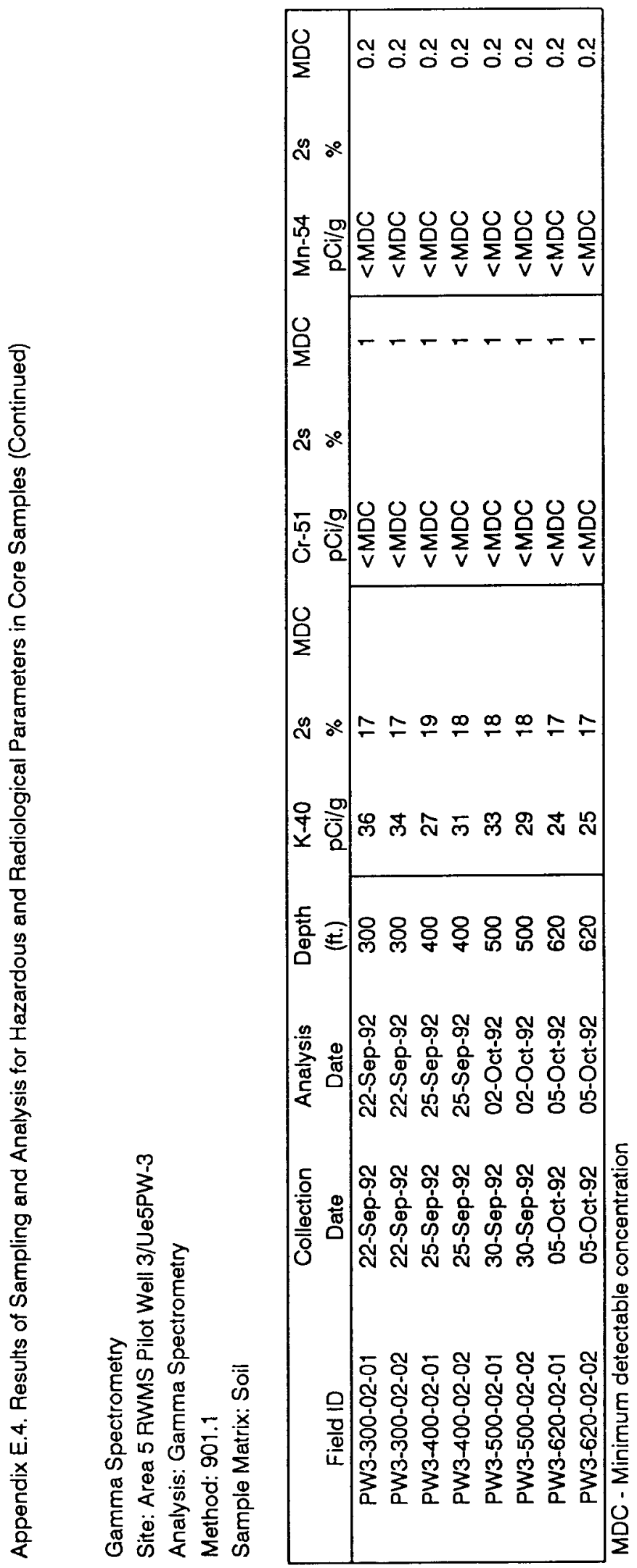


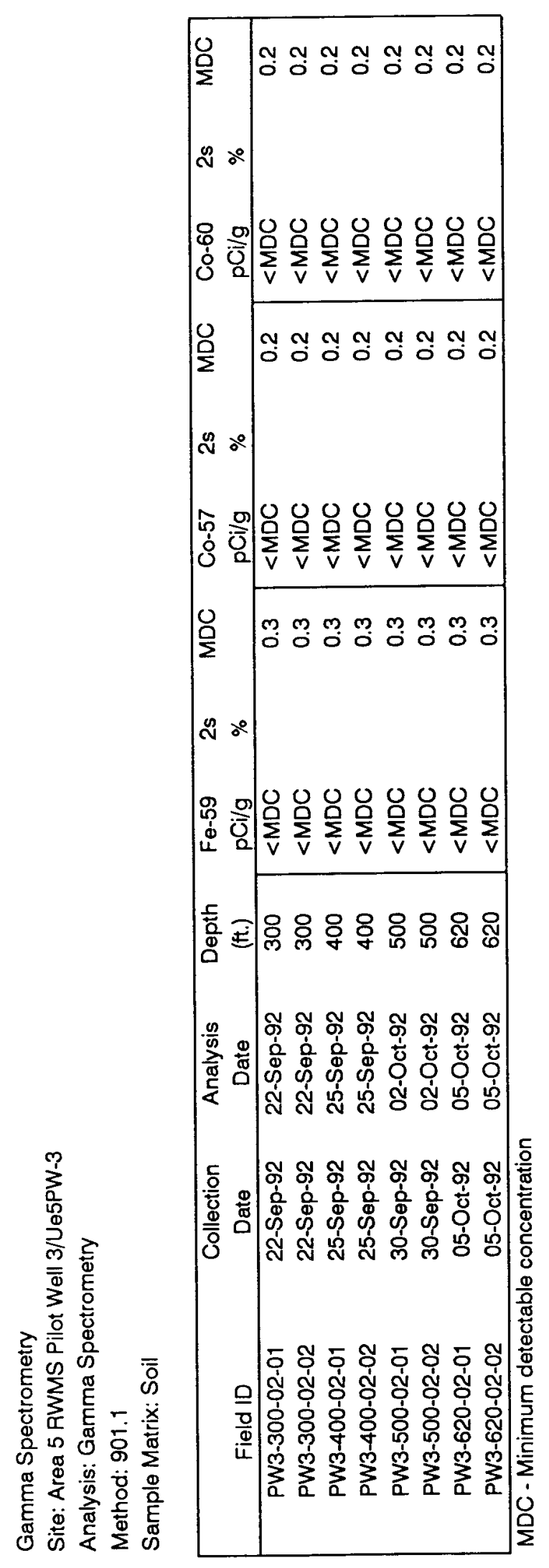




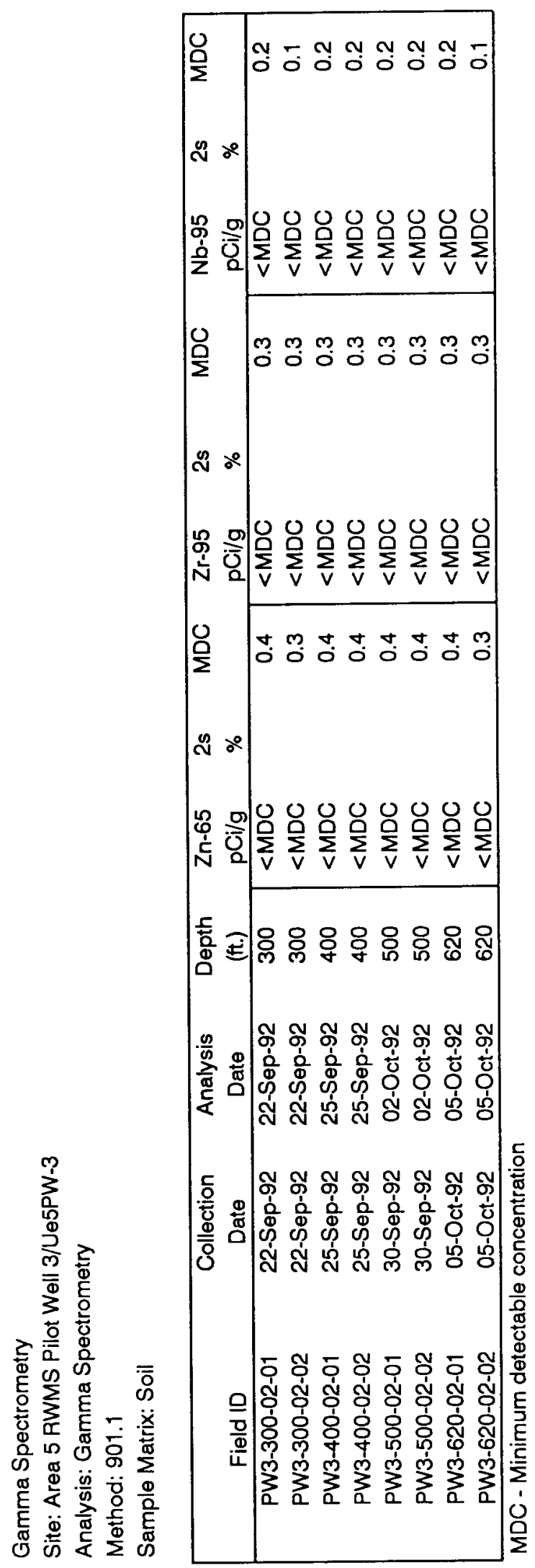




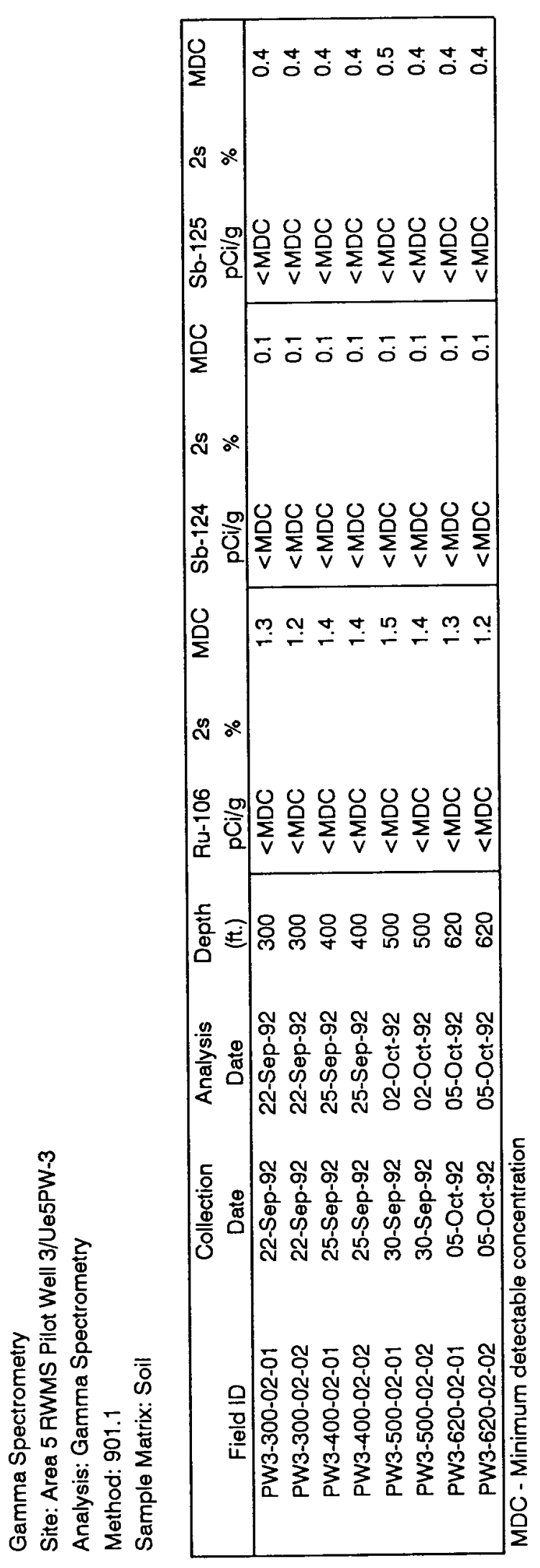




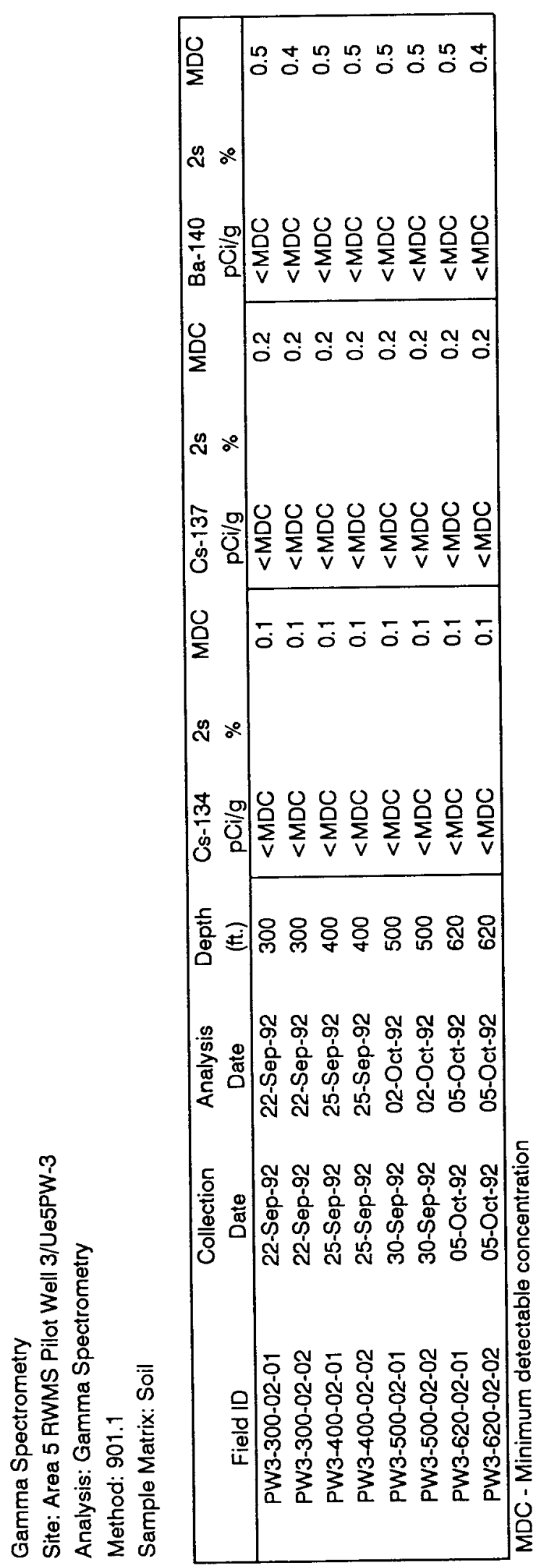




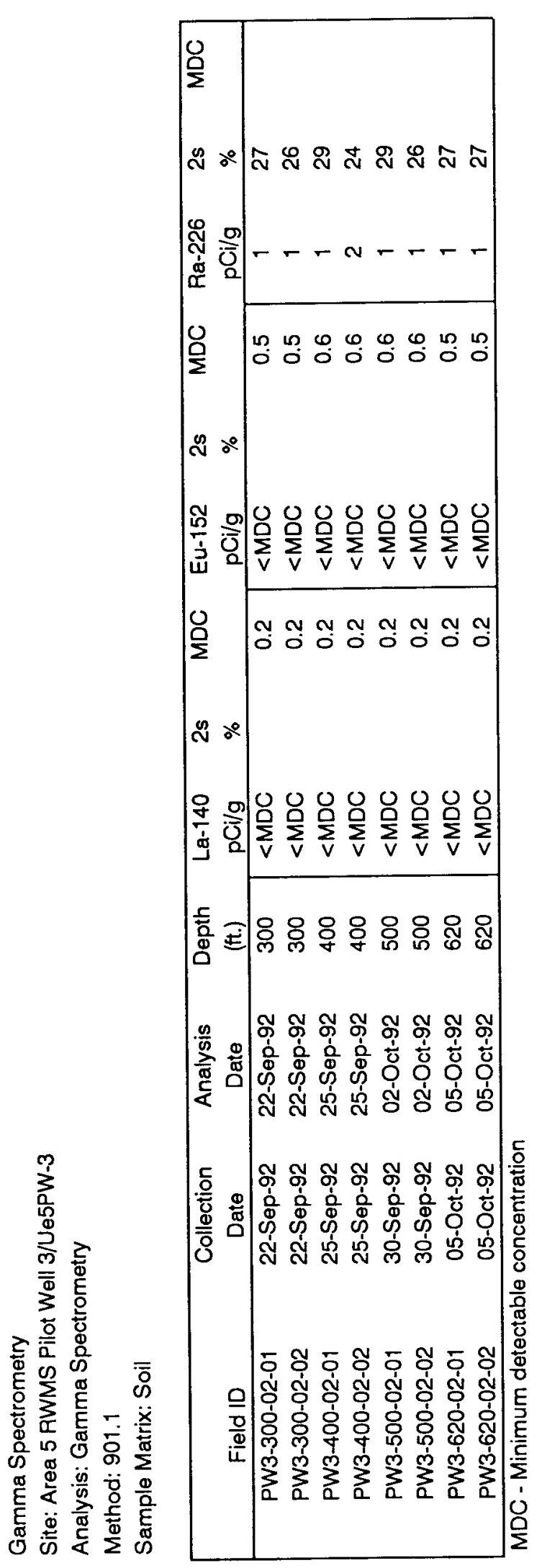




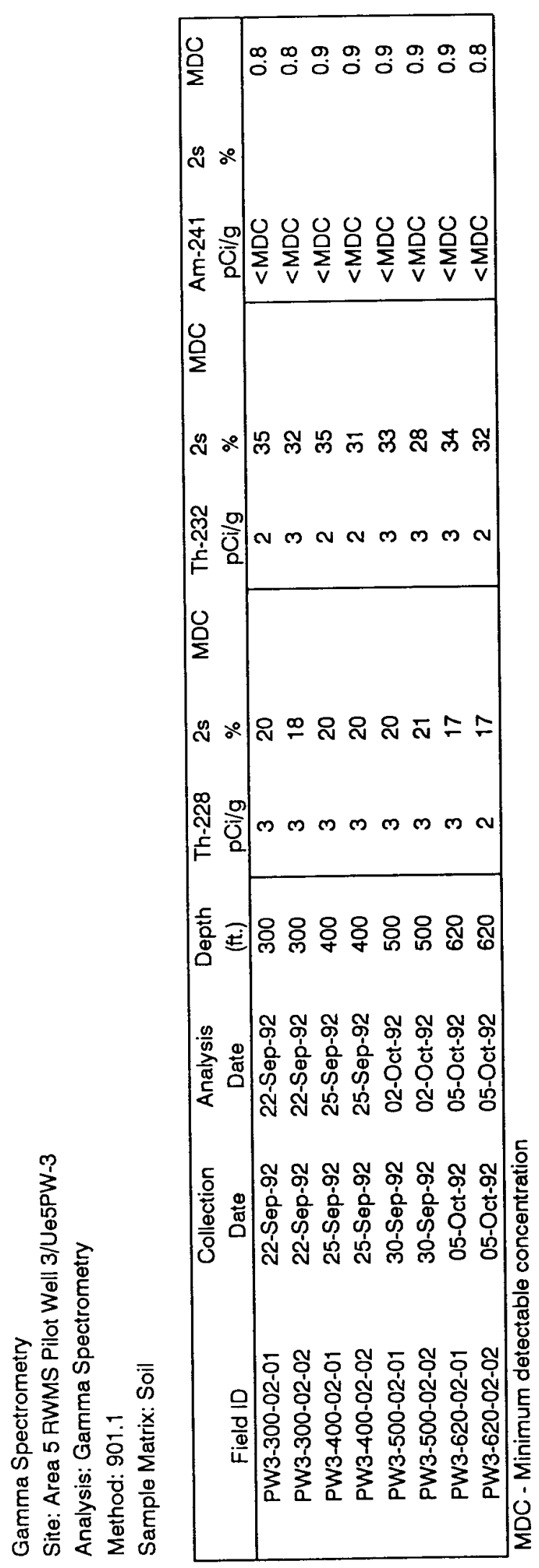


Appendix E.4. Results of Sampling and Analysis for Hazardous and Radiological Parameters in Core Samples (Continued)

Site: Area 5 RWMS Pilot Well 1/Ue5PW1 Analysis: Total Kehldahl Nitrogen

Method: 351.5

Sample Matrix: Soil

\begin{tabular}{|cccccc|}
\hline Field ID & $\begin{array}{c}\text { Collection } \\
\text { Date }\end{array}$ & $\begin{array}{c}\text { Depth } \\
(\mathrm{ft})\end{array}$ & $\begin{array}{c}\text { Concentration } \\
(\mathrm{mg} / \mathrm{kg})\end{array}$ & $\begin{array}{c}\text { Detection } \\
\text { Limit }\end{array}$ & $\begin{array}{c}\text { Holding Time } \\
\text { (days) }\end{array}$ \\
\hline PW1-058-02-01 & 18-Mar-92 & 58 & 20 & 20 & 28 \\
PW1-130-02-01 & 24-Mar-92 & 130 & 40 & 20 & 22 \\
PW1-130-02-02 & 24-Mar-92 & 130 & 20 & 20 & 22 \\
PW1-200-02-01 & 09-Apr-92 & 200 & 30 & 20 & 21 \\
PW1-402-02-01 & 22-Apr-92 & 402 & 40 & 10 & 20 \\
PW1-507-02-01 & 06-May-92 & 507 & 22 & 2 & 21 \\
PW1-507-02-01 & 06-May-92 & 507 & 51 & 2 & 21 \\
PW1-765-02-01 & 09-Jun-92 & 765 & 20 & 10 & 30 \\
PW1-765-02-02 & 09-Jun-92 & 765 & 10 & 10 & 30 \\
PW1-050-02-03 & 17-Mar-92 & Field Blank & 0.11 & 0.05 & 13 \\
PW1-050-02-04 & 17-Mar-92 & Equip. Blank & 0.06 & 0.05 & 13 \\
PW1-507-02-03 & 06-May-92 & Field Blank & 0.03 & 0.01 & 19 \\
PW1-765-02-03 & 09-Jun-92 & Field Blank & 0.22 & 0.05 & 30 \\
\hline
\end{tabular}


Appendix E.4. Results of Sampling and Analysis for Hazardous and Radiological Parameters in Core Samples (Continued)

Site: Area 5 RWMS Pilot Well 2/Ue5PW-2

Analysis: Total Kehldahl Nitrogen

Method: 351.5

Sample Matrix: Soil

\begin{tabular}{|cccccc|}
\hline Field ID & $\begin{array}{c}\text { Collection } \\
\text { Date }\end{array}$ & $\begin{array}{c}\text { Depth } \\
(\mathrm{ft})\end{array}$ & $\begin{array}{c}\text { Concentration } \\
(\mathrm{mg} / \mathrm{kg})\end{array}$ & $\begin{array}{c}\text { Detection } \\
\text { Limit }\end{array}$ & $\begin{array}{c}\text { Holding Time } \\
\text { (days) }\end{array}$ \\
\hline PW2-075-02-01 & 24-Jun-92 & 75 & 50 & 10 & 14 \\
PW2-075-02-02 & 24-Jun-92 & 75 & 20 & 10 & 14 \\
PW2-097-02-01 & 24-Jun-92 & 97 & 20 & 10 & 14 \\
PW2-202-02-01 & 29-Jun-92 & 202 & 20 & 10 & 22 \\
PW2-407-02-01 & 14-Jul-92 & 407 & 20 & 10 & 7 \\
PW2-407-02-02 & 14-Jul-92 & 407 & 10 & 10 & 7 \\
PW2-825-02-01 & 10-Aug-92 & 825 & 8 & 4 & 21 \\
PW2-825-02-02 & 10-Aug-92 & 825 & 8 & 4 & 21 \\
PW2-075-02-03 & 24-Jun-92 & Field Blank & <DL & 0.05 & 14 \\
PW2-407-02-03 & 14-Jul-92 & Field Blank & <DL & 0.05 & 7 \\
PW2-825-02-03 & 10-Aug-92 & Field Blank & <DL & 0.1 & 21 \\
\hline
\end{tabular}

$<D L$ - Les than detection limit 
Appendix E.4. Results of Sampling and Analysis for Hazardous and Radiological Parameters in Core Samples (Continued)

Site: Area 5 RWMS Pilot Well 3/Ue5PW-3

Analysis: Total Kehldahl Nitrogen

Method: 351.5

Sample Matrix: Soil

\begin{tabular}{|cccccc|}
\hline Field ID & $\begin{array}{c}\text { Collection } \\
\text { Date }\end{array}$ & $\begin{array}{c}\text { Depth } \\
(\mathrm{ft})\end{array}$ & $\begin{array}{c}\text { Concentration } \\
(\mathrm{mg} / \mathrm{kg})\end{array}$ & $\begin{array}{c}\text { Detection } \\
\text { Limit }\end{array}$ & $\begin{array}{c}\text { Holding Time } \\
\text { (days) }\end{array}$ \\
\hline PW3-300-02-01 & $22-$ Sep-92 & 300 & 90 & 10 & 16 \\
PW3-300-02-02 & $22-$ Sep-92 & 300 & 50 & 10 & 16 \\
PW3-400-02-01 & $25-S e p-92$ & 400 & 30 & 10 & 18 \\
PW3-400-02-02 & $25-S e p-92$ & 400 & 20 & 10 & 18 \\
PW3-500-02-01 & $30-S e p-92$ & 500 & 20 & 10 & 12 \\
PW3-500-02-02 & $30-S e p-92$ & 500 & $<\mathrm{DL}$ & 10 & 12 \\
PW3-620-02-01 & 05-Oct-92 & 620 & 70 & 10 & 8 \\
PW3-620-02-02 & 05-Oct-92 & 620 & $<\mathrm{DL}$ & 10 & 8 \\
\hline
\end{tabular}

$<\mathrm{DL}$ - Less than detection limit 
Appendix E.4. Results of Sampling and Analysis for Hazardous and Radiological Parameters in Core Samples (Continued)

Site: Area 5 RWMS Pilot Well 1/Ue5PW1

Analysis: Total Metals

Method: Arsenic 3050, 6010

Sample Matrix: Soil

\begin{tabular}{|cccccc|}
\hline Field ID & $\begin{array}{c}\text { Collection } \\
\text { Date }\end{array}$ & $\begin{array}{c}\text { Depth } \\
\text { (ft.) }\end{array}$ & $\begin{array}{c}\text { Concentration } \\
\text { (mg/kg) }\end{array}$ & $\begin{array}{c}\text { Detection } \\
\text { Limit }\end{array}$ & $\begin{array}{c}\text { Holding Time } \\
\text { (days) }\end{array}$ \\
\hline PW1-058-02-01 & 18-Mar-92 & 58 & ND & 6 & 14 \\
PW1-130-02-01 & 24-Mar-92 & 130 & ND & 5 & 8 \\
PW1-130-02-02 & 24-Mar-92 & 130 & $<15$ & 4 & 8 \\
PW1-200-02-01 & 09-Apr-92 & 200 & ND & 6 & 12 \\
PW1-402-02-01 & 22-Apr-92 & 402 & ND & 6 & 19 \\
PW1-507-02-01 & 06-May-92 & 507 & $<18$ & 5 & 14 \\
PW1-507-02-02 & 06-May-92 & 507 & ND & 5 & 14 \\
PW1-765-02-01 & 09-Jun-92 & 765 & ND & 4 & 13 \\
PW1-765-02-02 & 09-Jun-92 & 765 & ND & 4 & 13 \\
& & & & & \\
PW1-050-02-03 & 17-Mar-92 & Field Blank & ND & 0.06 & 14 \\
PW1-050-02-04 & 17-Mar-92 & Equip. Blank & ND & 0.06 & 14 \\
PW1-507-02-03 & 06-May-92 & Field Blank & ND & 0.06 & 14 \\
PW1-765-02-03 & 09-Jun-92 & Field Blank & ND & 0.06 & 13 \\
\hline
\end{tabular}

ND - Not detected 
Appendix E.4. Results of Sampling and Analysis for Hazardous and Radiological Parameters in Core Samples (Continued)

Site: Area 5 RWMS Pilot Well 1/Ue5PW1

Analysis: Total Metals

Method: Barium 3050, 6010

Sample Matrix: Soil

\begin{tabular}{|cccccc|}
\hline Field ID & $\begin{array}{c}\text { Collection } \\
\text { Date }\end{array}$ & $\begin{array}{c}\text { Depth } \\
(\mathrm{ft})\end{array}$ & $\begin{array}{c}\text { Concentration } \\
\text { (mg/kg) }\end{array}$ & $\begin{array}{c}\text { Detection } \\
\text { Limit }\end{array}$ & $\begin{array}{c}\text { Holding Time } \\
\text { (days) }\end{array}$ \\
\hline PW1-058-02-01 & 18-Mar-92 & 58 & 140 & 0.09 & 14 \\
PW1-130-02-01 & 24-Mar-92 & 130 & 120 & 0.08 & 8 \\
PW1-130-02-02 & 24-Mar-92 & 130 & 140 & 0.07 & 8 \\
PW1-200-02-01 & 09-Apr-92 & 200 & 130 & 0.09 & 12 \\
PW1-402-02-01 & 22-Apr-92 & 402 & 130 & 0.1 & 19 \\
PW1-507-02-01 & 06-May-92 & 507 & 110 & 0.09 & 14 \\
PW1-507-02-02 & 06-May-92 & 507 & 140 & 0.09 & 14 \\
PW1-765-02-01 & 09-Jun-92 & 765 & 150 & 0.07 & 13 \\
PW1-765-02-02 & 09-Jun-92 & 765 & 150 & 0.07 & 13 \\
& & & & & 14 \\
PW1-050-02-03 & 17-Mar-92 & Field Blank & 0.02 & 0.001 & 14 \\
PW1-050-02-04 & 17-Mar-92 & Equip. Blank & 0.004 & 0.001 & 14 \\
PW1-507-02-03 & 06-May-92 & Field Blank & ND & 0.001 & 13 \\
PW1-765-02-03 & 09-Jun-92 & Field Blank & $<0.003$ & 0.001 & 14 \\
\hline
\end{tabular}

ND - Not detected 
Appendix E.4. Results of Sampling and Analysis for Hazardous and Radiological Parameters in Core Samples (Continued)

Site: Area 5 RWMS Pilot Well 1/Ue5PW1

Analysis: Total Metals

Method: Cadmium 3050, 6010

Sample Matrix: Soil

\begin{tabular}{|cccccc|}
\hline Field ID & $\begin{array}{c}\text { Collection } \\
\text { Date }\end{array}$ & $\begin{array}{c}\text { Depth } \\
\text { (ft.) }\end{array}$ & $\begin{array}{c}\text { Concentration } \\
\text { (mg/kg) }\end{array}$ & $\begin{array}{c}\text { Detection } \\
\text { Limit }\end{array}$ & $\begin{array}{c}\text { Holding Time } \\
\text { (days) }\end{array}$ \\
\hline PW1-058-02-01 & 18-Mar-92 & 58 & ND & 0.3 & 14 \\
PW1-130-02-01 & 24-Mar-92 & 130 & ND & 0.2 & 8 \\
PW1-130-02-02 & 24-Mar-92 & 130 & ND & 0.2 & 8 \\
PW1-200-02-01 & 09-Apr-92 & 200 & ND & 0.3 & 12 \\
PW1-402-02-01 & 22-Apr-92 & 402 & ND & 0.3 & 19 \\
PW1-507-02-01 & 06-May-92 & 507 & ND & 0.3 & 14 \\
PW1-507-02-02 & 06-May-92 & 507 & ND & 0.3 & 14 \\
PW1-765-02-01 & 09-Jun-92 & 765 & $<0.07$ & 0.2 & 13 \\
PW1-765-02-02 & 09-Jun-92 & 765 & ND & 0.2 & 13 \\
PW1-050-02-03 & 17-Mar-92 & Field Blank & ND & 0.003 & 14 \\
PW1-050-02-04 & 17-Mar-92 & Equip. Blank & ND & 0.003 & 14 \\
PW1-507-02-03 & 06-May-92 & Field Blank & ND & 0.003 & 14 \\
PW1-765-02-03 & 09-Jun-92 & Field Blank & ND & 0.003 & 13 \\
\hline
\end{tabular}

ND - Not detected 
Appendix E.4. Results of Sampling and Analysis for Hazardous and Radiological Parameters in Core Samples (Continued)

Site: Area 5 RWMS Pilot Well 1/Ue5PW1

Analysis: Total Metals

Method: Chromium 3050, 6010

Sample Matrix: Soil

\begin{tabular}{|cccccc|}
\hline Field ID & $\begin{array}{c}\text { Collection } \\
\text { Date }\end{array}$ & $\begin{array}{c}\text { Depth } \\
(\mathrm{ft})\end{array}$ & $\begin{array}{c}\text { Concentration } \\
(\mathrm{mg} / \mathrm{kg})\end{array}$ & $\begin{array}{c}\text { Detection } \\
\text { Limit }\end{array}$ & $\begin{array}{c}\text { Holding Time } \\
\text { (days) }\end{array}$ \\
\hline PW1-058-02-01 & 18-Mar-92 & 58 & 4.2 & 0.4 & 14 \\
PW1-130-02-01 & 24-Mar-92 & 130 & 4.4 & 0.3 & 8 \\
PW1-130-02-02 & 24-Mar-92 & 130 & 5.0 & 0.3 & 8 \\
PW1-200-02-01 & 09-Apr-92 & 200 & 5.1 & 0.4 & 12 \\
PW1-402-02-01 & 22-Apr-92 & 402 & 5.7 & 0.4 & 19 \\
PW1-507-02-01 & 06-May-92 & 507 & 4.3 & 0.4 & 14 \\
PW1-507-02-02 & 06-May-92 & 507 & 4.3 & 0.4 & 14 \\
PW1-765-02-01 & 09-Jun-92 & 765 & 5.0 & 0.3 & 13 \\
PW1-765-02-02 & 09-Jun-92 & 765 & 5.0 & 0.3 & 13 \\
& & & & & 14 \\
PW1-050-02-03 & 17-Mar-92 & Field Blank & ND & 0.003 & 14 \\
PW1-050-02-04 & 17-Mar-92 & Equip. Blank & ND & 0.004 & 14 \\
PW1-507-02-03 & 06-May-92 & Field Blank & ND & 0.004 & 13 \\
PW1-765-02-03 & 09-Jun-92 & Field Blank & ND & 0.004 & \\
\hline
\end{tabular}

ND - Not detected 
Appendix E.4. Results of Sampling and Analysis for Hazardous and Radiological Parameters in Core Samples (Continued)

Site: Area 5 RWMS Pilot Well 1/Ue5PW1

Analysis: Total Metals

Method: Lead 3050, 6010

Sample Matrix: Soil

\begin{tabular}{|cccccc|}
\hline Field ID & $\begin{array}{c}\text { Collection } \\
\text { Date }\end{array}$ & $\begin{array}{c}\text { Depth } \\
\text { (ft.) }\end{array}$ & $\begin{array}{c}\text { Concentration } \\
\text { (mg/kg) }\end{array}$ & $\begin{array}{c}\text { Detection } \\
\text { Limit }\end{array}$ & $\begin{array}{c}\text { Holding Time } \\
\text { (days) }\end{array}$ \\
\hline PW1-058-02-01 & 18-Mar-92 & 58 & 10 & 3 & 14 \\
PW1-130-02-01 & 24-Mar-92 & 130 & 8 & 2 & 8 \\
PW1-130-02-02 & 24-Mar-92 & 130 & 11 & 2 & 8 \\
PW1-200-02-01 & 09-Apr-92 & 200 & 6 & 3 & 12 \\
PW1-402-02-01 & 22-Apr-92 & 402 & $<9$ & 3 & 19 \\
PW1-507-02-01 & 06-May-92 & 507 & $<8$ & 2 & 14 \\
PW1-507-02-02 & 06-May-92 & 507 & 9 & 2 & 14 \\
PW1-765-02-01 & 09-Jun-92 & 765 & 7 & 2 & 13 \\
PW1-765-02-02 & 09-Jun-92 & 765 & $<6$ & 2 & 13 \\
& & & & & 14 \\
PW1-050-02-03 & 17-Mar-92 & Field Blank & ND & 0.03 & 14 \\
PW1-050-02-04 & 17-Mar-92 & Equip. Blank & ND & 0.03 & 14 \\
PW1-507-02-03 & 06-May-92 & Field Blank & ND & 0.03 & 13 \\
PW1-765-02-03 & 09-Jun-92 & Field Blank & ND & 0.03 & \\
\hline
\end{tabular}

ND - Not detected 
Appendix E.4. Results of Sampling and Analysis for Hazardous and Radiological Parameters in Core Samples (Continued)

Site: Area 5 RWMS Pilot Well 1/Ue5PW1

Analysis: Total Metals

Method: Mercury 3050, 7470

Sample Matrix: Soil

\begin{tabular}{|cccccc|}
\hline Field ID & $\begin{array}{c}\text { Collection } \\
\text { Date }\end{array}$ & $\begin{array}{c}\text { Depth } \\
\text { (ft.) }\end{array}$ & $\begin{array}{c}\text { Concentration } \\
(\mathrm{mg} / \mathrm{kg})\end{array}$ & $\begin{array}{c}\text { Detection } \\
\text { Limit }\end{array}$ & $\begin{array}{c}\text { Holding Time } \\
\text { (days) }\end{array}$ \\
\hline PW1-058-02-01 & 18-Mar-92 & 58 & ND & 0.05 & 14 \\
PW1-130-02-01 & 24-Mar-92 & 130 & ND & 0.05 & 8 \\
PW1-130-02-02 & 24-Mar-92 & 130 & ND & 0.05 & 8 \\
PW1-200-02-01 & 09-Apr-92 & 200 & ND & 0.01 & 12 \\
PW1-402-02-01 & 22-Apr-92 & 402 & ND & 0.02 & 14 \\
PW1-507-02-01 & 06-May-92 & 507 & ND & 0.03 & 15 \\
PW1-507-02-02 & 06-May-92 & 507 & ND & 0.03 & 15 \\
PW1-765-02-01 & 09-Jun-92 & 765 & ND & 0.03 & 13 \\
PW1-765-02-02 & 09-Jun-92 & 765 & ND & 0.03 & 13 \\
& & & & & \\
PW1-050-02-03 & 17-Mar-92 & Field Blank & ND & 0.0001 & 14 \\
PW1-050-02-04 & 17-Mar-92 & Equip. Blank & ND & 0.0001 & 14 \\
PW1-507-02-03 & 06-May-92 & Field Blank & ND & $6 E-05$ & 15 \\
PW1-765-02-03 & 09-Jun-92 & Field Blank & ND & $6 E-05$ & 13 \\
\hline
\end{tabular}

ND - Not detected 
Appendix E.4. Results of Sampling and Analysis for Hazardous and Radiological Parameters in Core Samples (Continued)

Site: Area 5 RWMS Pilot Well 1/Ue5PW1

Analsysis: Total Metals

Method: Selenium 3050, 6010

Sample Matrix: Soil

\begin{tabular}{|cccccc|}
\hline Field ID & $\begin{array}{c}\text { Collection } \\
\text { Date }\end{array}$ & $\begin{array}{c}\text { Depth } \\
\text { (ft.) }\end{array}$ & $\begin{array}{c}\text { Concentration } \\
\text { (mg/kg) }\end{array}$ & $\begin{array}{c}\text { Detection } \\
\text { Limit }\end{array}$ & $\begin{array}{c}\text { Holding Time } \\
\text { (days) }\end{array}$ \\
\hline PW1-058-02-01 & 18-Mar-92 & 58 & ND & 8 & 14 \\
PW1-130-02-01 & 24-Mar-92 & 130 & ND & 7 & 8 \\
PW1-130-02-02 & 24-Mar-92 & 130 & ND & 6 & 8 \\
PW1-200-02-01 & 09-Apr-92 & 200 & ND & 8 & 12 \\
PW1-402-02-01 & 22-Apr-92 & 402 & ND & 9 & 19 \\
PW1-507-02-01 & 06-May-92 & 507 & 11 & 8 & 14 \\
PW1-507-02-02 & 06-May-92 & 507 & 11 & 8 & 14 \\
PW1-765-02-01 & 09-Jun-92 & 765 & $<22$ & 6 & 13 \\
PW1-765-02-02 & 09-Jun-92 & 765 & $<22$ & 6 & 13 \\
& & & & & 14 \\
PW1-050-02-03 & 17-Mar-92 & Field Blank & ND & 0.09 & 14 \\
PW1-050-02-04 & 17-Mar-92 & Equip. Blank & ND & 0.09 & 14 \\
PW1-507-02-03 & 06-May-92 & Field Blank & ND & 0.09 & 13 \\
PW1-765-02-03 & 09-Jun-92 & Field Blank & ND & 0.09 & \\
\hline
\end{tabular}

ND - Not detected 
Appendix E.4. Results of Sampling and Analysis for Hazardous and Radiological Parameters in Core Samples (Continued)

Site: Area 5 RWMS Pilot Well 1/Ue5PW1

Analysis: Total Methods

Method: Silver 3050, 6010

Sample Matrix: Soil

\begin{tabular}{|cccccc|}
\hline Field ID & $\begin{array}{c}\text { Collection } \\
\text { Date }\end{array}$ & $\begin{array}{c}\text { Depth } \\
(\mathrm{ft} .)\end{array}$ & $\begin{array}{c}\text { Concentration } \\
\text { (mg/kg) }\end{array}$ & $\begin{array}{c}\text { Detection } \\
\text { Limit }\end{array}$ & $\begin{array}{c}\text { Holding Time } \\
\text { (days) }\end{array}$ \\
\hline PW1-058-02-01 & 18-Mar-92 & 58 & ND & 0.2 & 14 \\
PW1-130-02-01 & 24-Mar-92 & 130 & ND & 0.2 & 8 \\
PW1-130-02-02 & 24-Mar-92 & 130 & ND & 0.2 & 8 \\
PW1-200-02-01 & 09-Apr-92 & 200 & ND & 0.2 & 12 \\
PW1-402-02-01 & 22-Apr-92 & 402 & ND & 0.3 & 19 \\
PW1-507-02-01 & 06-May-92 & 507 & ND & 0.2 & 14 \\
PW1-507-02-02 & 06-May-92 & 507 & ND & 0.2 & 14 \\
PW1-765-02-01 & 09-Jun-92 & 765 & ND & 0.2 & 13 \\
PW1-765-02-02 & 09-Jun-92 & 765 & ND & 0.2 & 13 \\
& & & & & 14 \\
PW1-050-02-03 & 17-Mar-92 & Field Blank & 0.009 & 0.003 & 14 \\
PW1-050-02-04 & 17-Mar-92 & Equip. Blank & ND & 0.003 & 14 \\
PW1-507-02-03 & 06-May-92 & Field Blank & ND & 0.003 & 13 \\
PW1-765-02-03 & 09-Jun-92 & Field Blank & ND & 0.003 & \\
\hline
\end{tabular}

ND - Not detected 
Appendix E.4. Results of Sampling and Analysis for Hazardous and Radiological Parameters in Core Samples (Continued)

Site: Area 5 RWMS Pilot Well 2/Ue5PW2

Analysis: Total Metals

Method: Arsenic 3050, 6010

Sample Matrix: Soil

\begin{tabular}{|cccccc|}
\hline Field ID & $\begin{array}{c}\text { Collection } \\
\text { Date }\end{array}$ & $\begin{array}{c}\text { Depth } \\
(\text { ft. })\end{array}$ & $\begin{array}{c}\text { Concentration } \\
\text { (mg/kg) }\end{array}$ & $\begin{array}{c}\text { Detection } \\
\text { Limit }\end{array}$ & $\begin{array}{c}\text { Holding Time } \\
\text { (days) }\end{array}$ \\
\hline PW2-075-02-01* & 24-Jun-92 & 75 & n.d. & 0.06 & 8 \\
PW2-075-02-02* & 24-Jun-92 & 75 & n.d & 0.06 & 8 \\
PW2-097-02-01* & 24-Jun-92 & 97 & n.d. & 0.06 & 8 \\
PW2-202-02-01 & 29-Jun-92 & 202 & n.d & 3 & 25 \\
PW2-407-02-01 & 14-Jul-92 & 407 & $<9.9$ & 3 & 14 \\
PW2-407-02-02 & 14-Jul-92 & 407 & $<9.9$ & 3 & 14 \\
PW2-825-02-01 & 10-Aug-92 & 825 & n.d. & 3 & 3 \\
PW2-825-02-02 & 10-Aug-92 & 825 & n.d. & 3 & 3 \\
& & & & & 8 \\
PW2-075-02-03* & 24-Jun-92 & Field Blank & n.d. & 0.06 & 14 \\
PW2-407-02-03 & 14-Jul-92 & Field Blank & n.d. & 0.03 & 3 \\
PW2-825-02-03 & 10-Aug-92 & Field Blank & n.d. & 0.03 & \\
\hline
\end{tabular}

n.d. - Not detected

* - TCLP analysis 
Appendix E.4. Results of Sampling and Analysis for Hazardous and Radiological Parameters in Core Samples (Continued)

Site: Area 5 RWMS Pilot Well 2/Ue5PW2

Analysis: Total Metals

Method: Barium 3050, 6010

Sample Matrix: Soil

\begin{tabular}{|cccccc|}
\hline Field ID & $\begin{array}{c}\text { Collection } \\
\text { Date }\end{array}$ & $\begin{array}{c}\text { Depth } \\
\text { (ft.) }\end{array}$ & $\begin{array}{c}\text { Concentration } \\
\text { (mg/kg) }\end{array}$ & $\begin{array}{c}\text { Detection } \\
\text { Limit }\end{array}$ & $\begin{array}{c}\text { Holding Time } \\
\text { (days) }\end{array}$ \\
\hline PW2-075-02-01* $^{*}$ & 24-Jun-92 & 75 & 0.17 & 0.001 & 8 \\
PW2-075-02-02* & 24-Jun-92 & 75 & 0.15 & 0.001 & 8 \\
PW2-097-02-01* & 24-Jun-92 & 97 & 0.11 & 0.001 & 8 \\
PW2-202-02-01 & 29-Jun-92 & 202 & 120 & 0.04 & 25 \\
PW2-407-02-01 & 14-Jul-92 & 407 & 120 & 0.04 & 14 \\
PW2-407-02-02 & 14-Jul-92 & 407 & 99 & 0.04 & 14 \\
PW2-825-02-01 & 10-Aug-92 & 825 & 71 & 0.08 & 3 \\
PW2-825-02-02 & 10-Aug-92 & 825 & 71 & 0.09 & 3 \\
PW2-075-02-03 & 24-Jun-92 & Field Blank & n.d. & 0.001 & 8 \\
PW2-407-02-03 & 14-Jul-92 & Field Blank & n.d. & 0.0004 & 14 \\
PW2-825-02-03 & 10-Aug-92 & Field Blank & n.d. & 0.0009 & 3 \\
\hline
\end{tabular}

n.d. - Not detected

* - TCLP analysis 
Appendix E.4. Results of Sampling and Analysis for Hazardous and Radiological Parameters in Core Samples (Continued)

Site: Area 5 RWMS Pilot Well 2/Ue5PW2

Analysis: Total Metals

Method: Cadmium 3050, 6010

Sample Matrix: Soil

\begin{tabular}{|cccccc|}
\hline Field ID & $\begin{array}{c}\text { Collection } \\
\text { Date }\end{array}$ & $\begin{array}{c}\text { Depth } \\
\text { (ft.) }\end{array}$ & $\begin{array}{c}\text { Concentration } \\
\text { (mg/kg) }\end{array}$ & $\begin{array}{c}\text { Detection } \\
\text { Limit }\end{array}$ & $\begin{array}{c}\text { Holding Time } \\
\text { (days) }\end{array}$ \\
\hline PW2-075-02-01* & 24-Jun-92 & 75 & n.d. & 0.003 & 8 \\
PW2-075-02-02* & 24-Jun-92 & 75 & n.d. & 0.003 & 8 \\
PW2-097-02-01* & 24-Jun-92 & 97 & $<0.01$ & 0.003 & 8 \\
PW2-202-02-01 & 29-Jun-92 & 202 & n.d. & 0.3 & 25 \\
PW2-407-02-01 & 14-Jul-92 & 407 & n.d. & 0.3 & 14 \\
PW2-407-02-02 & 14-Jul-92 & 407 & n.d. & 0.3 & 14 \\
PW2-825-02-01 & 10-Aug-92 & 825 & n.d. & 0.4 & 3 \\
PW2-825-02-02 & 10-Aug-92 & 825 & n.d. & 0.4 & 3 \\
PW2-075-02-03* & 24-Jun-92 & Field Blank & n.d. & 0.003 & 8 \\
PW2-407-02-03 & 14-Jul-92 & Field Blank & n.d. & 0.003 & 14 \\
PW2-825-02-03 & 10-Aug-92 & Field Blank & n.d. & 0.004 & 3 \\
\hline
\end{tabular}

n.d. - Not detected

* - TCLP analysis 
Appendix E.4. Results of Sampling and Analysis for Hazardous and Radiological Parameters in Core Samples (Continued)

Site: Area 5 RWMS Pilot Well 2/Ue5PW2

Analysis: Total Metals

Method: Chromium 3050, 6010

Sample Matrix: Soil

\begin{tabular}{|cccccc|}
\hline Field ID & $\begin{array}{c}\text { Collection } \\
\text { Date }\end{array}$ & $\begin{array}{c}\text { Depth } \\
\text { (ft.) }\end{array}$ & $\begin{array}{c}\text { Concentration } \\
\text { (mg/kg) }\end{array}$ & $\begin{array}{c}\text { Detection } \\
\text { Limit }\end{array}$ & $\begin{array}{c}\text { Holding Time } \\
\text { (days) }\end{array}$ \\
\hline PW2-075-02-01* $^{*}$ 24-Jun-92 & 75 & n.d. & 0.004 & 8 \\
PW2-075-02-02* & 24-Jun-92 & 75 & n.d & 0.004 & 8 \\
PW2-097-02-01* & 24-Jun-92 & 97 & n.d. & 0.004 & 8 \\
PW2-202-02-01 & 29-Jun-92 & 202 & 3.0 & 0.2 & 25 \\
PW2-407-02-01 & 14-Jul-92 & 407 & 5.0 & 0.2 & 14 \\
PW2-407-02-02 & 14-Jul-92 & 407 & 5.7 & 0.2 & 14 \\
PW2-825-02-01 & 10-Aug-92 & 825 & 2.2 & 0.6 & 3 \\
PW2-825-02-02 & 10-Aug-92 & 825 & 2.4 & 0.6 & 3 \\
& & & & & \\
PW2-075-02-03* & 24-Jun-92 & Field Blank & n.d. & 0.004 & 8 \\
PW2-407-02-03 & 14-Jul-92 & Field Blank & n.d. & 0.002 & 14 \\
PW2-825-02-03 & 10-Aug-92 & Field Blank & n.d. & 0.006 & 3 \\
\hline
\end{tabular}

n.d. - Not detected

* TCLP analysis 
Appendix E.4. Results of Sampling and Analysis for Hazardous and Radiological Parameters in Core Samples (Continued)

Site: Area 5 RWMS Pilot Well 2/Ue5PW2

Analysis: Total Metals

Method: Lead 3050, 6010

Sample Matrix: Soil

\begin{tabular}{|cccccc|}
\hline Field ID & $\begin{array}{c}\text { Collection } \\
\text { Date }\end{array}$ & $\begin{array}{c}\text { Depth } \\
(\mathrm{ft.})\end{array}$ & $\begin{array}{c}\text { Concentration } \\
(\mathrm{mg} / \mathrm{kg})\end{array}$ & $\begin{array}{c}\text { Detection } \\
\text { Limit }\end{array}$ & $\begin{array}{c}\text { Holding Time } \\
\text { (days) }\end{array}$ \\
\hline PW2-075-02-01* & 24-Jun-92 & 75 & n.d. & 0.03 & 8 \\
PW2-075-02-02* & 24-Jun-92 & 75 & n.d. & 0.03 & 8 \\
PW2-097-02-01* & 24-Jun-92 & 97 & n.d. & 0.03 & 8 \\
PW2-202-02-01 & 29-Jun-92 & 202 & 7.7 & 1.5 & 25 \\
PW2-407-02-01 & 14-Jul-92 & 407 & 5.7 & 1.5 & 14 \\
PW2-407-02-02 & 14-Jul-92 & 407 & 6.7 & 1.5 & 14 \\
PW2-825-02-01 & 10-Aug-92 & 825 & $<9.4$ & 2.9 & 3 \\
PW2-825-02-02 & 10-Aug-92 & 825 & $<9.7$ & 3 & 3 \\
& & & & & \\
PW2-075-02-03* & 24-Jun-92 & Field Blank & n.d. & 0.03 & 8 \\
PW2-407-02-03 & 14-Jul-92 & Field Blank & n.d. & 0.01 & 14 \\
PW2-825-02-03 & 10-Aug-92 & Field Blank & n.d. & 0.03 & 3 \\
\hline
\end{tabular}

n.d. - Not detected

* - TCLP analysis 
Appendix E.4. Results of Sampling and Analysis for Hazardous and Radiological Parameters in Core Samples (Continued)

Site: Area 5 RWMS Pilot Well 2/Ue5PW2

Analysis: Total Metals

Method: Mercury 3050, 7470

Sample Matrix: Soil

\begin{tabular}{|cccccc|}
\hline Field ID & $\begin{array}{c}\text { Collection } \\
\text { Date }\end{array}$ & $\begin{array}{c}\text { Depth } \\
\text { (ft.) }\end{array}$ & $\begin{array}{c}\text { Concentration } \\
\text { (mg/kg) }\end{array}$ & $\begin{array}{c}\text { Detection } \\
\text { Limit }\end{array}$ & $\begin{array}{c}\text { Holding Time } \\
\text { (days) }\end{array}$ \\
\hline PW2-075-02-01* & 24-Jun-92 & 75 & n.d. & $6 E-05$ & 8 \\
PW2-075-02-02* & 24-Jun-92 & 75 & n.d. & $6 E-05$ & 8 \\
PW2-097-02-01* & 24-Jun-92 & 97 & n.d. & $6 E-05$ & 8 \\
PW2-202-02-01 & 29-Jun-92 & 202 & n.d & 0.06 & 22 \\
PW2-407-02-01 & 14-Jul-92 & 407 & n.d. & 0.06 & 14 \\
PW2-407-02-02 & 14-Jul-92 & 407 & n.d. & 0.06 & 14 \\
PW2-825-02-01 & 10-Aug-92 & 825 & n.d & 0.06 & 10 \\
PW2-825-02-02 & 10-Aug-92 & 825 & n.d. & 0.06 & 10 \\
& & & & & \\
PW2-075-02-03* & 24-Jun-92 & Field Blank & n.d. & $6 E-05$ & 8 \\
PW2-407-02-03 & 14-Jul-92 & Field Blank & n.d. & 0.0001 & 14 \\
PW2-825-02-03 & 10-Aug-92 & Field Blank & n.d. & 0.0001 & 10 \\
\hline
\end{tabular}

n.d. - Not detected

* - TCLP analysis 
Appendix E.4. Results of Sampling and Analysis for Hazardous and Radiological Parameters in Core Samples (Continued)

Site: Area 5 RWMS Pilot Well 2/Ue5PW2

Analsysis: Total Metals

Method: Selenium 3050, 6010

Sample Matrix: Soil

\begin{tabular}{|cccccc|}
\hline Field ID & $\begin{array}{c}\text { Collection } \\
\text { Date }\end{array}$ & $\begin{array}{c}\text { Depth } \\
\text { (ft.) }\end{array}$ & $\begin{array}{c}\text { Concentration } \\
\text { (mg/kg) }\end{array}$ & $\begin{array}{c}\text { Detection } \\
\text { Limit }\end{array}$ & $\begin{array}{c}\text { Holding Time } \\
\text { (days) }\end{array}$ \\
\hline PW2-075-02-01* & 24-Jun-92 & 75 & n.d. & 0.09 & 8 \\
PW2-075-02-02* & 24-Jun-92 & 75 & n.d. & 0.09 & 8 \\
PW2-097-02-01* & 24-Jun-92 & 97 & n.d. & 0.09 & 8 \\
PW2-202-02-01 & 29-Jun-92 & 202 & n.d. & 5 & 25 \\
PW2-407-02-01 & 14-Jul-92 & 407 & n.d. & 5 & 14 \\
PW2-407-02-02 & 14-Jul-92 & 407 & n.d. & 5 & 14 \\
PW2-825-02-01 & 10-Aug-92 & 825 & n.d. & 6 & 3 \\
PW2-825-02-02 & 10-Aug-92 & 825 & n.d. & 6 & 3 \\
& & & & & \\
PW2-075-02-03* & 24-Jun-92 & Field Blank & n.d. & 0.09 & 8 \\
PW2-407-02-03 & 14-Jul-92 & Field Blank & n.d. & 0.05 & 14 \\
PW2-825-02-03 & 10-Aug-92 & Field Blank & n.d. & 0.07 & 3 \\
\hline
\end{tabular}

n.d. - Not detected

* - TCLP analysis 
Appendix E.4. Results of Sampling and Analysis for Hazardous and Radiological Parameters in Core Samples (Continued)

Site: Area 5 RWMS Pilot Well 2/Ue5PW2

Analysis: Total Methods

Method: Silver 3050, 6010

Sample Matrix: Soil

\begin{tabular}{|cccccc|}
\hline Field ID & $\begin{array}{c}\text { Collection } \\
\text { Date }\end{array}$ & $\begin{array}{c}\text { Depth } \\
\text { (ft.) }\end{array}$ & $\begin{array}{c}\text { Concentration } \\
\text { (mg/kg) }\end{array}$ & $\begin{array}{c}\text { Detection } \\
\text { Limit }\end{array}$ & $\begin{array}{c}\text { Holding Time } \\
\text { (days) }\end{array}$ \\
\hline PW2-075-02-01* & 24-Jun-92 & 75 & n.d & 0.003 & 8 \\
PW2-075-02-02* & 24-Jun-92 & 75 & n.d. & 0.003 & 8 \\
PW2-097-02-01* & 24-Jun-92 & 97 & n.d. & 0.003 & 8 \\
PW2-202-02-01 & 29-Jun-92 & 202 & n.d. & 0.3 & 25 \\
PW2-407-02-01 & 14-Jul-92 & 407 & n.d. & 0.3 & 14 \\
PW2-407-02-02 & 14-Jul-92 & 407 & n.d. & 0.3 & 14 \\
PW2-825-02-01 & 10-Aug-92 & 825 & $<1.5$ & 0.4 & 3 \\
PW2-825-02-02 & 10-Aug-92 & 825 & n.d. & 0.5 & 3 \\
PW2-075-02-03* & 24-Jun-92 & Field Blank & n.d. & 0.003 & 8 \\
PW2-407-02-03 & 14-Jul-92 & Field Blank & n.d. & 0.003 & 14 \\
PW2-825-02-03 & 10-Aug-92 & Field Blank & n.d. & 0.005 & 3 \\
\hline
\end{tabular}

n.d. - Not detected

* - TCLP analysis 
Appendix E.4. Results of Sampling and Analysis for Hazardous and Radiological Parameters in Core Samples (Continued)

Site: Area 5 RWMS Pilot Well 3/Ue5PW-3

Analsysis: Total Metals

Method: Selenium 3050, 6010

Sample Matrix: Soil

\begin{tabular}{|cccccc|}
\hline Field ID & $\begin{array}{c}\text { Collection } \\
\text { Date }\end{array}$ & $\begin{array}{c}\text { Depth } \\
\text { (ft.) }\end{array}$ & $\begin{array}{c}\text { Concentration } \\
\text { (mg/kg) }\end{array}$ & $\begin{array}{c}\text { Detection } \\
\text { Limit }\end{array}$ & $\begin{array}{c}\text { Holding Time } \\
\text { (days) }\end{array}$ \\
\hline PW3-300-02-01 & 22-Sep-92 & 300 & n.d. & 6 & 7 \\
PW3-300-02-02 & 22-Sep-92 & 300 & n.d. & 6 & 7 \\
PW3-400-02-01 & 25-Sep-92 & 400 & n.d. & 6 & 12 \\
PW3-400-02-02 & $25-S e p-92$ & 400 & n.d. & 6 & 12 \\
PW3-500-02-01 & $30-S e p-92$ & 500 & n.d. & 6 & 5 \\
PW3-500-02-02 & 30-Sep-92 & 500 & n.d. & 6 & 5 \\
PW3-620-02-01 & 05-Oct-92 & 620 & n.d. & 6 & 2 \\
PW3-620-02-02 & 05-Oct-92 & 620 & n.d. & 6 & 2 \\
\hline
\end{tabular}

n.d. - Not detected 
Appendix E.4. Results of Sampling and Analysis for Hazardous and Radiological Parameters in Core Samples (Continued)

Site: Area 5 RWMS Pilot Well 3/Ue5PW-3

Analysis: Total Metals

Method: Arsenic 3050, 6010

Sample Matrix: Soil

\begin{tabular}{|cccccc|}
\hline Field ID & $\begin{array}{c}\text { Collection } \\
\text { Date }\end{array}$ & $\begin{array}{c}\text { Depth } \\
(\mathrm{ft} .)\end{array}$ & $\begin{array}{c}\text { Concentration } \\
\text { (mg/kg) }\end{array}$ & $\begin{array}{c}\text { Detection } \\
\text { Limit }\end{array}$ & $\begin{array}{c}\text { Holding Time } \\
\text { (days) }\end{array}$ \\
\hline PW3-300-02-01 & $22-$ Sep-92 & 300 & 19 & 3 & 7 \\
PW3-300-02-02 & $22-S e p-92$ & 300 & 20 & 3 & 7 \\
PW3-400-02-01 & $25-S e p-92$ & 400 & n.d. & 3 & 12 \\
PW3-400-02-02 & 25-Sep-92 & 400 & n.d. & 3 & 12 \\
PW3-500-02-01 & 30-Sep-92 & 500 & $<9$ & 3 & 5 \\
PW3-500-02-02 & 30-Sep-92 & 500 & $<9$ & 3 & 5 \\
PW3-620-02-01 & 05-Oct-92 & 620 & n.d. & 3 & 2 \\
PW3-620-02-02 & 05-Oct-92 & 620 & $<9$ & 3 & 2 \\
\hline
\end{tabular}

n.d. - Not detected 
Appendix E.4. Results of Sampling and Analysis for Hazardous and Radiological Parameters in Core Samples (Continued)

Site: Area 5 RWMS Pilot Well 3/Ue5PW-3

Analysis: Total Metals

Method: Barium 3050, 6010

Sample Matrix: Soil

\begin{tabular}{|cccccc|}
\hline Field ID & $\begin{array}{c}\text { Collection } \\
\text { Date }\end{array}$ & $\begin{array}{c}\text { Depth } \\
\text { (ft.) }\end{array}$ & $\begin{array}{c}\text { Concentration } \\
\text { (mg/kg) }\end{array}$ & $\begin{array}{c}\text { Detection } \\
\text { Limit }\end{array}$ & $\begin{array}{c}\text { Holding Time } \\
\text { (days) }\end{array}$ \\
\hline PW3-300-02-01 & $22-S e p-92$ & 300 & 140 & 0.08 & 7 \\
PW3-300-02-02 & $22-S e p-92$ & 300 & 139 & 0.08 & 7 \\
PW3-400-02-01 & $25-S e p-92$ & 400 & 140 & 0.09 & 12 \\
PW3-400-02-02 & $25-S e p-92$ & 400 & 140 & 0.09 & 12 \\
PW3-500-02-01 & $30-S e p-92$ & 500 & 140 & 0.09 & 5 \\
PW3-500-02-02 & 30-Sep-92 & 500 & 130 & 0.09 & 5 \\
PW3-620-02-01 & 05-Oct-92 & 620 & 83 & 0.09 & 2 \\
PW3-620-02-02 & 05-Oct-92 & 620 & 75 & 0.09 & 2 \\
\hline
\end{tabular}

n.d. - Not detected 
Appendix E.4. Results of Sampling and Analysis for Hazardous and Radiological Parameters in Core Samples (Continued)

Site: Area 5 RWMS Pilot Well 3/Ue5PW-3

Analysis: Total Metals

Method: Cadmium 3050, 6010

Sample Matrix: Soil

\begin{tabular}{|cccccc|}
\hline Field ID & $\begin{array}{c}\text { Collection } \\
\text { Date }\end{array}$ & $\begin{array}{c}\text { Depth } \\
\text { (ft.) }\end{array}$ & $\begin{array}{c}\text { Concentration } \\
\text { (mg/kg) }\end{array}$ & $\begin{array}{c}\text { Detection } \\
\text { Limit }\end{array}$ & $\begin{array}{c}\text { Holding Time } \\
\text { (days) }\end{array}$ \\
\hline PW3-300-02-01 & 22-Sep-92 & 300 & n.d. & 0.4 & 7 \\
PW3-300-02-02 & 22-Sep-92 & 300 & n.d. & 0.4 & 7 \\
PW3-400-02-01 & 25-Sep-92 & 400 & n.d. & 0.4 & 12 \\
PW3-400-02-02 & 25-Sep-92 & 400 & n.d. & 0.4 & 12 \\
PW3-500-02-01 & 30-Sep-92 & 500 & n.d. & 0.4 & 5 \\
PW3-500-02-02 & 30-Sep-92 & 500 & n.d. & 0.4 & 5 \\
PW3-620-02-01 & 05-Oct-92 & 620 & n.d. & 0.4 & 2 \\
PW3-620-02-02 & 05-Oct-92 & 620 & n.d. & 0.4 & 2 \\
\hline
\end{tabular}

n.d. - Not detected 
Appendix E.4. Results of Sampling and Analysis for Hazardous and Radiological Parameters in Core Samples (Continued)

Site: Area 5 RWMS Pilot Well 3/Ue5PW-3

Analysis: Total Metals

Method: Chromium 3050, 6010

Sample Matrix: Soil

\begin{tabular}{|cccccc|}
\hline Field ID & $\begin{array}{c}\text { Collection } \\
\text { Date }\end{array}$ & $\begin{array}{c}\text { Depth } \\
\text { (ft.) }\end{array}$ & $\begin{array}{c}\text { Concentration } \\
\text { (mg/kg) }\end{array}$ & $\begin{array}{c}\text { Detection } \\
\text { Limit }\end{array}$ & $\begin{array}{c}\text { Holding Time } \\
\text { (days) }\end{array}$ \\
\hline PW3-300-02-01 & 22-Sep-92 & 300 & 5.9 & 0.6 & 7 \\
PW3-300-02-02 & 22-Sep-92 & 300 & 5.6 & 0.6 & 7 \\
PW3-400-02-01 & 25-Sep-92 & 400 & 5.4 & 0.6 & 12 \\
PW3-400-02-02 & 25-Sep-92 & 400 & 6.0 & 0.6 & 12 \\
PW3-500-02-01 & 30-Sep-92 & 500 & 6.8 & 0.6 & 5 \\
PW3-500-02-02 & 30-Sep-92 & 500 & 6.9 & 0.6 & 5 \\
PW3-620-02-01 & 05-Oct-92 & 620 & 6.8 & 0.6 & 2 \\
PW3-620-02-02 & 05-Oct-92 & 620 & 7.1 & 0.6 & 2 \\
\hline
\end{tabular}

n.d. - Not detected 
Appendix E.4. Results of Sampling and Analysis for Hazardous and Radiological Parameters in Core Samples (Continued)

Site: Area 5 RWMS Pilot Well 3/Ue5PW-3

Analysis: Total Metals

Method: Lead 3050, 6010

Sample Matrix: Soil

\begin{tabular}{|cccccc|}
\hline Field ID & $\begin{array}{c}\text { Collection } \\
\text { Date }\end{array}$ & $\begin{array}{c}\text { Depth } \\
(\mathrm{ft} .)\end{array}$ & $\begin{array}{c}\text { Concentration } \\
(\mathrm{mg} / \mathrm{kg})\end{array}$ & $\begin{array}{c}\text { Detection } \\
\text { Limit }\end{array}$ & $\begin{array}{c}\text { Holding Time } \\
\text { (days) }\end{array}$ \\
\hline PW3-300-02-01 & $22-$ Sep-92 & 300 & $<9.5$ & 2.9 & 7 \\
PW3-300-02-02 & $22-$ Sep-92 & 300 & $<9.3$ & 2.9 & 7 \\
PW3-400-02-01 & $25-$ Sep-92 & 400 & $<9.8$ & 3 & 12 \\
PW3-400-02-02 & $25-$ Sep-92 & 400 & $<9.8$ & 3 & 12 \\
PW3-500-02-01 & $30-$ Sep-92 & 500 & $<9.7$ & 3 & 5 \\
PW3-500-02-02 & $30-$ Sep-92 & 500 & $<9.7$ & 3 & 5 \\
PW3-620-02-01 & 05-Oct-92 & 620 & $<9.7$ & 3 & 2 \\
PW3-620-02-02 & 05-Oct-92 & 620 & $<9.7$ & 3 & 2 \\
\hline
\end{tabular}

n.d. - Not detected 
Appendix E.4. Results of Sampling and Analysis for Hazardous and Radiological Parameters in Core Samples (Continued)

Site: Area 5 RWMS Pilot Well 3/Ue5PW-3

Analysis: Total Metals

Method: Mercury 3050, 7470

Sample Matrix: Soil

\begin{tabular}{|cccccc|}
\hline Field ID & $\begin{array}{c}\text { Collection } \\
\text { Date }\end{array}$ & $\begin{array}{c}\text { Depth } \\
(\mathrm{ft} .)\end{array}$ & $\begin{array}{c}\text { Concentration } \\
(\mathrm{mg} / \mathrm{kg})\end{array}$ & $\begin{array}{c}\text { Detection } \\
\text { Limit }\end{array}$ & $\begin{array}{c}\text { Holding Time } \\
\text { (days) }\end{array}$ \\
\hline PW3-300-02-01 & 22-Sep-92 & 300 & n.d. & 0.06 & 7 \\
PW3-300-02-02 & $22-$ Sep-92 & 300 & n.d. & 0.06 & 7 \\
PW3-400-02-01 & $25-S e p-92$ & 400 & n.d. & 0.06 & 12 \\
PW3-400-02-02 & $25-S e p-92$ & 400 & n.d. & 0.06 & 12 \\
PW3-500-02-01 & $30-S e p-92$ & 500 & n.d. & 0.06 & 5 \\
PW3-500-02-02 & 30-Sep-92 & 500 & n.d. & 0.06 & 5 \\
PW3-620-02-01 & 05-Oct-92 & 620 & n.d. & 0.06 & 2 \\
PW3-620-02-02 & 05-Oct-92 & 620 & n.d. & 0.06 & 2 \\
\hline
\end{tabular}

n.d. - Not detected 
Appendix E.4. Results of Sampling and Analysis for Hazardous and Radiological Parameters in Core Samples (Continued)

Site: Area 5 RWMS Pilot Well 3/Ue5PW-3

Analysis: Total Methods

Method: Silver 3050, 6010

Sample Matrix: Soil

\begin{tabular}{|cccccc|}
\hline Field ID & $\begin{array}{c}\text { Collection } \\
\text { Date }\end{array}$ & $\begin{array}{c}\text { Depth } \\
(\mathrm{ft})\end{array}$ & $\begin{array}{c}\text { Concentration } \\
(\mathrm{mg} / \mathrm{kg})\end{array}$ & $\begin{array}{c}\text { Detection } \\
\text { Limit }\end{array}$ & $\begin{array}{c}\text { Holding Time } \\
\text { (days) }\end{array}$ \\
\hline PW3-300-02-01 & 22-Sep-92 & 300 & n.d. & 0.5 & 7 \\
PW3-300-02-02 & 22-Sep-92 & 300 & n.d. & 0.5 & 7 \\
PW3-400-02-01 & 25-Sep-92 & 400 & n.d. & 0.5 & 12 \\
PW3-400-02-02 & 25-Sep-92 & 400 & n.d. & 0.5 & 12 \\
PW3-500-02-01 & 30-Sep-92 & 500 & n.d. & 0.5 & 5 \\
PW3-500-02-02 & 30-Sep-92 & 500 & n.d. & 0.5 & 5 \\
PW3-620-02-01 & 05-Oct-92 & 620 & n.d. & 0.5 & 2 \\
PW3-620-02-02 & 05-Oct-92 & 620 & n.d. & 0.5 & 2 \\
\hline
\end{tabular}

n.d. - Not detected 
Appendix E.4. Results of Sampling and Analysis for Hazardous and Radiological Parameters

in Core Samples (Continued)

Site: Pilot Well 1/Ue5PW-1

Analysis: Volatile Organics

Method: 8240

Collection Date: 18-Mar-92

Analysis Date: 26-Mar-92, 1-Apr-92

Matrix: Soil

Depth: $51 \mathrm{ft}$.

\begin{tabular}{|c|c|c|c|c|c|c|c|c|}
\hline Compound & CAS Number & Sample & Duplicate & $\begin{array}{c}\text { Trip } \\
\text { Blank }\end{array}$ & $\begin{array}{l}\text { Field } \\
\text { Blank }\end{array}$ & $\begin{array}{c}\text { Equipment } \\
\text { Blank }\end{array}$ & $\begin{array}{c}\text { Detection } \\
\text { Limit }\end{array}$ & Units \\
\hline Chloromethane & $74-87-3$ & n.d. & n.d. & n.d. & n.d. & n.d. & 10 & $\mathrm{ug} / \mathrm{kg}$ \\
\hline Vinyl Chloride & $75-01-4$ & n.d. & n.d. & n.d. & n.d. & n.d. & 10 & $\mathrm{ug} / \mathrm{kg}$ \\
\hline Chloroethane & $75-00-3$ & n.d. & n.d. & n.d. & n.d. & n.d. & 10 & $\mathrm{ug} / \mathrm{kg}$ \\
\hline Methylene Chloride & $75-09-2$ & 5.B & 4.JB & 5 & 9 & 15 & 5 & $\mathrm{ug} / \mathrm{kg}$ \\
\hline Carbon Disulfide & $75-15-0$ & n.d. & n.d. & n.d. & n.d. & n.d. & 5 & $\mathrm{ug} / \mathrm{kg}$ \\
\hline 1.1-Dichloroethene & $75-35-4$ & n.d. & n.d. & n.d. & n.d. & n.d. & 5 & $u g / \mathrm{kg}$ \\
\hline 1,2-Dichloroethane & $75-34-3$ & n.d. & n.d. & n.d. & n.d. & n.d. & 5 & $\mathrm{ug} / \mathrm{kg}$ \\
\hline 1,2-Dichloroethene(Total) & $540-59-0$ & n.d. & n.d. & n.d. & n.d. & n.d. & 5 & $\mathrm{ug} / \mathrm{kg}$ \\
\hline trans-1,2-Dichloroethene & $540-59-0$ & n.d. & n.d. & n.d. & n.d. & n.d. & 5 & $\mathrm{ug} / \mathrm{kg}$ \\
\hline Carbon Tetrachloride & $56-23-5$ & n.d. & n.d. & n.d. & n.d. & n.d. & 5 & $\mathrm{ug} / \mathrm{kg}$ \\
\hline Vinyl Acetate & $108-05-4$ & n.d. & n.d. & n.d. & n.d. & n.d. & 10 & $\mathrm{ug} / \mathrm{kg}$ \\
\hline Bromodichloromethane & $75-27-4$ & n.d. & n.d. & n.d. & n.d. & n.d. & 5 & $\mathrm{ug} / \mathrm{kg}$ \\
\hline 1.2-Dichloropropane & $78-87-5$ & n.d. & n.d. & 3.J & 3.J & $3 . J$ & 5 & $\mathrm{ug} / \mathrm{kg}$ \\
\hline cis-1,3-Dichloropropene & $10061-01-5$ & n.d. & n.d. & n.d. & n.d. & n.d. & 5 & $\mathrm{ug} / \mathrm{kg}$ \\
\hline Trichloroethene & $79-01-6$ & n.d. & n.d. & n.d. & n.d. & n.d. & 5 & $\mathrm{ug} / \mathrm{kg}$ \\
\hline Dibromochloromethane & $124-48-1$ & n.d. & n.d. & n.d. & n.d. & n.d. & 5 & $\mathrm{ug} / \mathrm{kg}$ \\
\hline 1,1,2-Trichloroethane & $79-00-5$ & n.d. & n.d. & n.d. & n.d. & n.d. & 5 & $\mathrm{ug} / \mathrm{kg}$ \\
\hline Benzene & $71-43-2$ & n.d. & n.d. & n.d. & n.d. & n.d. & 5 & $\mathrm{ug} / \mathrm{kg}$ \\
\hline Chlorobenzene & $108-90-7$ & n.d. & n.d. & n.d. & n.d. & n.d. & 5 & $\mathrm{ug} / \mathrm{kg}$ \\
\hline Ethylbenzene & $100-41-4$ & n.d. & n.d. & n.d. & n.d. & n.d. & 5 & $\mathrm{ug} / \mathrm{kg}$ \\
\hline Styrene & $100-42-5$ & n.d. & n.d. & n.d. & n.d. & n.d. & 5 & $u g / k g$ \\
\hline$m, p-X y l e n e$ & $133-02-7$ & n.d. & n.d. & n.d. & n.d. & n.d. & 5 & $\mathrm{ug} / \mathrm{kg}$ \\
\hline Xylene(Total) & 133-02-7 & n.d. & n.d. & n.d. & n.d. & n.d. & 5 & $\mathrm{ug} / \mathrm{kg}$ \\
\hline
\end{tabular}

n.d. - Not detected

$J$ - Estimated value, less than sample quantitation limit

B - Analyte detected in blank 
Appendix E.4. Results of Sampling and Analysis for Hazardous and Radiological Parameters in Core Samples (Continued)

Site: Pilot Well 1/Ue5PW-1 Analysis: Volatile Organics Method: 8240

Collection Date: 10-Jun-92

Analysis Date: 23-Jun-92

Matrix: Soil, Alluvium

Depth: $770 \mathrm{ft}$.

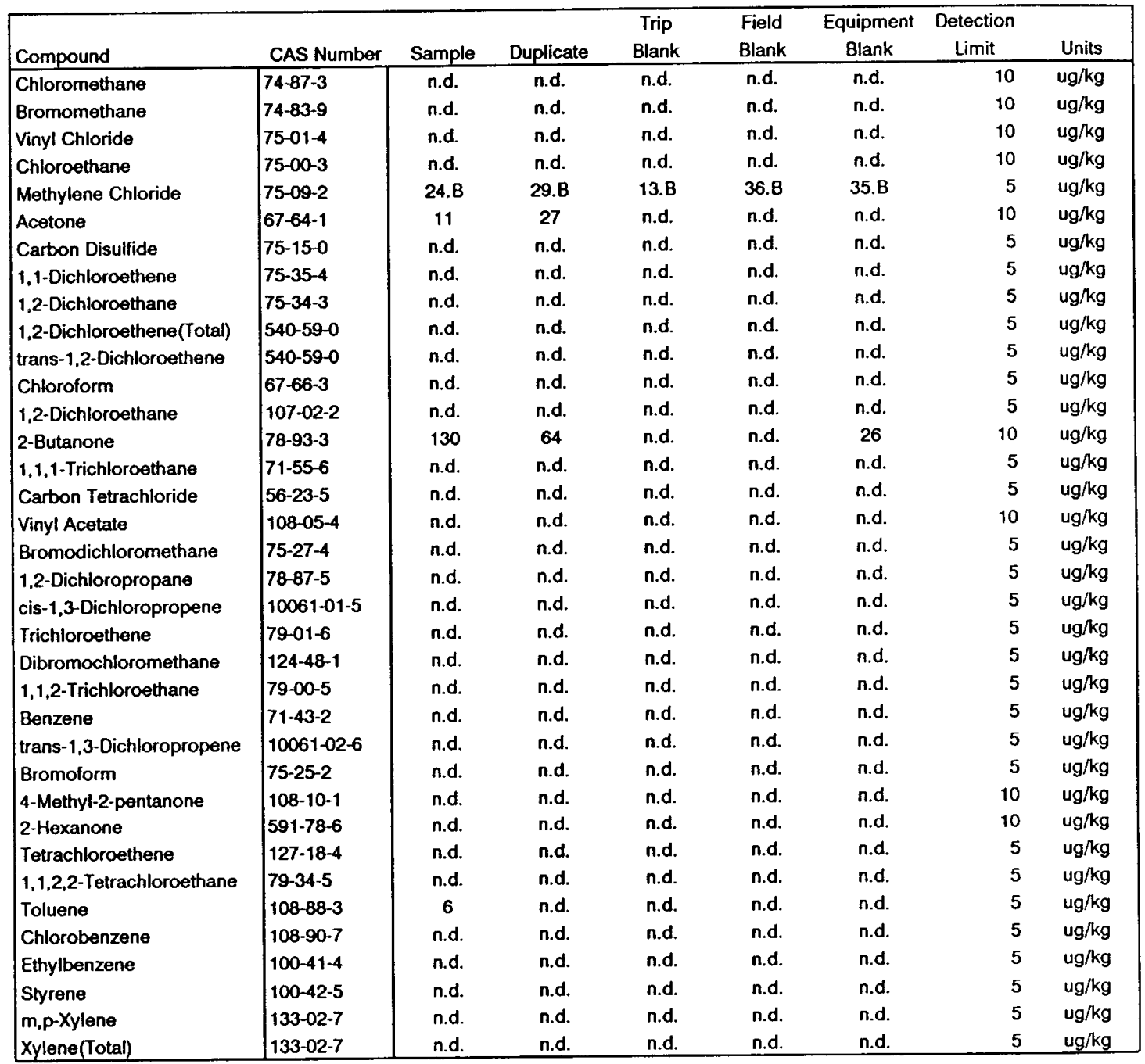

n.d. - Not detected

$J$ - Estimated value, less than sample quantitation limit

B - Analyte detected in blank 
Appendix E.4. Results of Sampling and Analysis for Hazardous and Radiological Parameters in Core Samples (Continued)

Site: Pilot Well 2/Ue5PW-2

Analysis: Volatile Organics

Method: 8240

Collection Date: 24-Jun-92

Analysis Date: 7-July-92

Matrix: Soil

Depth: $70 \mathrm{ft}$.

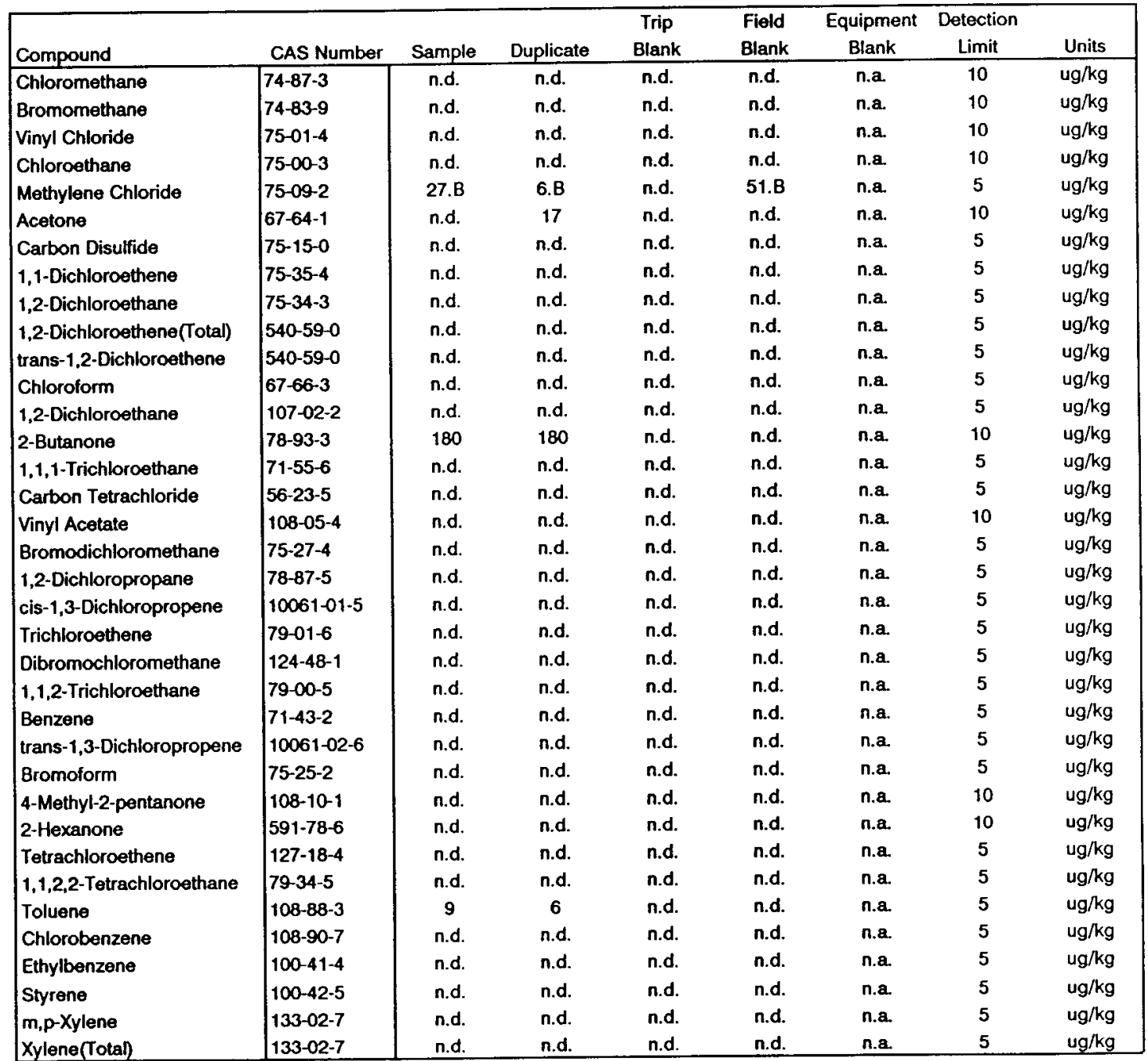

n.d. - Not detected

$J$ - Estimated value, less than sample quantitation limit

B - Analyte detected in blank

n.a. - Not analyzed 
Appendix E.4. Results of Sampling and Analysis for Hazardous and Radiological Parameters in Core Samples (Continued)

Site: Area 5 Pilot Well 1/Ue5PW-1

Analysis: Semi-Volatile Organics

Method: 8270

Collection Date: 18-Mar-92

Extraction Date: 19-Mar-92, 23-Mar-92

Analysis Date: 13-Apr-92

Matrix: Soil

Depth: $51 \mathrm{ft}$.

\begin{tabular}{|c|c|c|c|c|c|c|c|}
\hline Compound & CAS Number & Sample & Duplicate & $\begin{array}{l}\text { Field } \\
\text { Blank }\end{array}$ & $\begin{array}{l}\text { Equipment } \\
\text { Blank }\end{array}$ & $\begin{array}{c}\text { Detection } \\
\text { Limit }\end{array}$ & Units \\
\hline Phenol & $108-95-2$ & n.d. & n.d. & n.d. & n.d. & 670 & $\mathrm{ug} / \mathrm{kg}$ \\
\hline bis(2-Chloroethyl)ether & $111-44-4$ & n.d. & n.d. & n.d. & n.d. & 670 & $u g / k g$ \\
\hline 2-Chlorophenol & $95-57-8$ & n.d. & n.d. & n.d. & n.d. & 670 & $u g / k g$ \\
\hline 1,3-Dichlorobenzene & $541-73-1$ & n.d. & n.d. & n.d. & n.d. & 670 & $\mathrm{ug} / \mathrm{kg}$ \\
\hline 1,4-Dichlorobenzene & $106-46-7$ & n.d. & n.d. & n.d. & n.d. & 670 & $u g / k g$ \\
\hline Benzyl alcohol & $100-51-6$ & n.d. & n.d. & n.d. & n.d. & 670 & $u g / k g$ \\
\hline 1,2-Dichlorobenzene & $95-50-1$ & n.d. & n.d. & n.d. & n.d. & 670 & $u g / k g$ \\
\hline 2-Methylphenol & $95-48-7$ & n.d. & n.d. & n.d. & n.d. & 670 & $\mathrm{ug} / \mathrm{kg}$ \\
\hline 2,2'-oxybis(1-Chloropropane) & $108-60-1$ & n.d. & n.d. & n.d. & n.d. & 670 & $\mathrm{ug} / \mathrm{kg}$ \\
\hline bis(2-Chloroisopropyl)ether & $39638-32-9$ & n.d. & n.d. & n.d. & n.d. & 670 & $u g / k g$ \\
\hline 4-Methylphenol & $106-44-5$ & n.d. & n.d. & n.d. & n.d. & 670 & $u g / k g$ \\
\hline N-Nitroso-di-n-propylamine & $621-64-7$ & n.d. & n.d. & n.d. & n.d. & 670 & $\mathrm{ug} / \mathrm{kg}$ \\
\hline Hexachloroethane & $67-72-1$ & n.d. & n.d. & n.d. & n.d. & 670 & $\mathrm{ug} / \mathrm{kg}$ \\
\hline Nitrobenzene & $98-95-3$ & n.d. & n.d. & n.d. & n.d. & 670 & $\mathrm{ug} / \mathrm{kg}$ \\
\hline Isophorone & $78-59-1$ & n.d. & n.d. & n.d. & n.d. & 670 & $\mathrm{ug} / \mathrm{kg}$ \\
\hline 2-Nitrophenol & $88-75-5$ & n.d. & n.d. & n.d. & n.d. & 670 & $\mathrm{ug} / \mathrm{kg}$ \\
\hline 2,4-Dimethylphenol & $105-67-9$ & n.d. & n.d. & n.d. & n.d. & 670 & $\mathrm{ug} / \mathrm{kg}$ \\
\hline Benzoic acid & $65-85-0$ & n.d. & n.d. & n.d. & n.d. & 3400 & $\mathrm{ug} / \mathrm{kg}$ \\
\hline bis (2-Chloroethoxy) methane & $111-91-1$ & n.d. & n.d. & n.d. & n.d. & 670 & $u g / \mathrm{kg}$ \\
\hline 2,4-Dichlorophenol & $120-83-2$ & n.d. & n.d. & n.d. & n.d. & 670 & $\mathrm{ug} / \mathrm{kg}$ \\
\hline 1,2,4-Trichlorobenzene & $120-82-1$ & n.d. & n.d. & n.d. & n.d. & 670 & $\mathrm{ug} / \mathrm{kg}$ \\
\hline Naphthalene & $91-20-3$ & n.d. & n.d. & n.d. & n.d. & 670 & $\mathrm{ug} / \mathrm{kg}$ \\
\hline 4-Chloroaniline & $106-47-8$ & n.d. & n.d. & n.d. & n.d. & 670 & $\mathrm{ug} / \mathrm{kg}$ \\
\hline Hexachlorobutadiene & $87-68-3$ & n.d. & n.d. & n.d. & n.d. & 670 & $\mathrm{ug} / \mathrm{kg}$ \\
\hline 4-Chloro-3-methylphenol & $59-50-7$ & n.d. & n.d. & n.d. & n.d. & 670 & $u g / \mathrm{kg}$ \\
\hline 2-Methylnaphthalene & $91-57-6$ & n.d. & n.d. & n.d. & n.d. & 670 & $u g / k g$ \\
\hline Hexachlorocyclopentadiene & $77-47-4$ & n.d. & n.d. & n.d. & n.d. & 670 & $u g / k g$ \\
\hline 2,4,6-Trichlorophenol & $88-06-2$ & n.d. & n.d. & n.d. & n.d. & 670 & $\mathrm{ug} / \mathrm{kg}$ \\
\hline $2,4,5$-Trichlorophenol & $95-95-4$ & n.d. & n.d. & n.d. & n.d. & 3400 & $u g / k g$ \\
\hline 2-Chloronaphthalene & $91-58-7$ & n.d. & n.d. & n.d. & n.d. & 670 & $\mathrm{ug} / \mathrm{kg}$ \\
\hline 2-Nitroaniline & $88-74-4$ & n.d. & n.d. & n.d. & n.d. & 3400 & $\mathrm{ug} / \mathrm{kg}$ \\
\hline Dimethylphthalate & $131-11-3$ & n.d. & n.d. & n.d. & n.d. & 670 & $\mathrm{ug} / \mathrm{kg}$ \\
\hline
\end{tabular}

n.d. - Not detected

$\mathrm{J}$ - Estimated value, less than sample quantitation limit

B - Analyte detected in blank 
Appendix E.4. Results of Sampling and Analysis for Hazardous and Radiological Parameters

in Core Samples (Continued)

Site: Area 5 Pilot Well 1/Ue5PW-1

Analysis: Semi-Volatile Organics

Method: 8270

Collection Date: 18-Mar-92

Extraction Date: 19-Mar-92, 23-Mar-92

Analysis Date: 13-Apr-92

Matrix: Soil

Depth: $51 \mathrm{ft}$

\begin{tabular}{|c|c|c|c|c|c|c|c|}
\hline Compound & CAS Number & Sample & Duplicate & $\begin{array}{l}\text { Field } \\
\text { Blank }\end{array}$ & $\begin{array}{l}\text { Equipment } \\
\text { Blank }\end{array}$ & $\begin{array}{c}\text { Detection } \\
\text { Limit } \\
\end{array}$ & Units \\
\hline Acenaphthylene & $208-96-8$ & n.d. & n.d. & n.d. & n.d. & 670 & $\mathrm{ug} / \mathrm{kg}$ \\
\hline 2,6-Dinitrotoluene & $606-20-2$ & n.d. & n.d. & n.d. & n.d. & 670 & $\mathrm{ug} / \mathrm{kg}$ \\
\hline 3-Nitroaniline & $99-09-2$ & n.d. & n.d. & n.d. & n.d. & 3400 & $\mathrm{ug} / \mathrm{kg}$ \\
\hline Acenaphthene & $83-32-9$ & n.d. & n.d. & n.d. & n.d. & 670 & $\mathrm{ug} / \mathrm{kg}$ \\
\hline 2,4-Dinitrophenol & $51-28-5$ & n.d. & n.d. & n.d. & n.d. & 3400 & $\mathrm{ug} / \mathrm{kg}$ \\
\hline 4-Nitrophenol & $100-02-7$ & n.d. & n.d. & n.d. & n.d. & 3400 & $\mathrm{ug} / \mathrm{kg}$ \\
\hline Dibenzofuran & $132-64-9$ & n.d. & n.d. & n.d. & n.d. & 670 & $\mathrm{ug} / \mathrm{kg}$ \\
\hline 2,4-Dinitrotoluene & $121-14-2$ & n.d. & n.d. & n.d. & n.d. & 670 & $u g / k g$ \\
\hline Diethylphthalate & $84-66-2$ & n.d. & n.d. & n.d. & n.d. & 670 & $\mathrm{ug} / \mathrm{kg}$ \\
\hline 4-Chlorophenyl-phenylether & $7005-72-3$ & n.d. & n.d. & n.d. & n.d. & 670 & $\mathrm{ug} / \mathrm{kg}$ \\
\hline Fluorene & $86-73-7$ & n.d. & n.d. & n.d. & n.d. & 670 & $\mathrm{ug} / \mathrm{kg}$ \\
\hline 4-Nitroaniline & $100-01-6$ & n.d. & n.d. & n.d. & n.d. & 3400 & $\mathrm{ug} / \mathrm{kg}$ \\
\hline 4,6-Dinitro-2-methylphenol & $534-52-1$ & n.d. & n.d. & n.d. & n.d. & 3400 & $\mathrm{ug} / \mathrm{kg}$ \\
\hline N-Nitrosodiphenylamine & $86-30-6$ & n.d. & n.d. & n.d. & n.d. & 670 & $\mathrm{ug} / \mathrm{kg}$ \\
\hline 4-Bromophenyl-phenylether & $101-55-3$ & n.d. & n.d. & n.d. & n.d. & 670 & $\mathrm{ug} / \mathrm{kg}$ \\
\hline Hexachlorobenzene & $118-74-1$ & n.d. & n.d. & n.d. & n.d. & 670 & $\mathrm{ug} / \mathrm{kg}$ \\
\hline Pentachlorophenol & $87-86-5$ & n.d. & n.d. & n.d. & n.d. & 3400 & $\mathrm{ug} / \mathrm{kg}$ \\
\hline Phenanthrene & $85-01-8$ & n.d. & n.d. & n.d. & n.d. & 670 & $u g / \mathrm{kg}$ \\
\hline Anthracene & $120-12-7$ & n.d. & n.d. & n.d. & n.d. & 670 & $u g / k g$ \\
\hline Carbazole & $86-74-8$ & n.d. & n.d. & n.d. & n.d. & 670 & $u g / k g$ \\
\hline Di-n-butylphthalate & $84-74-2$ & n.d. & n.d. & n.d. & n.d. & 670 & $\mathrm{ug} / \mathrm{kg}$ \\
\hline Fluoranthene & $206-44-0$ & n.d. & n.d. & n.d. & n.d. & 670 & ug/kg \\
\hline Pyrene & $129-00-0$ & n.d. & n.d. & n.d. & n.d. & 670 & $\mathrm{ug} / \mathrm{kg}$ \\
\hline Butylbenzylphthalate & $85-68-7$ & n.d. & n.d. & n.d. & n.d. & 670 & $\mathrm{ug} / \mathrm{kg}$ \\
\hline 3,3'-Dichlorobenzidine & $91-94-1$ & n.d. & n.d. & n.d. & n.d. & 1300 & $\mathrm{ug} / \mathrm{kg}$ \\
\hline Benzo(a)anthracene & $56-55-3$ & n.d. & n.d. & n.d. & n.d. & 670 & $\mathrm{ug} / \mathrm{kg}$ \\
\hline Chrysene & $218-01-9$ & n.d. & n.d. & n.d. & n.d. & 670 & $\mathrm{ug} / \mathrm{kg}$ \\
\hline bis(2-Ethylhexyl)phthalate & $117-81-7$ & n.d. & n.d. & n.d. & n.d. & 670 & $\mathrm{ug} / \mathrm{kg}$ \\
\hline Di-n-octylphthalate & $117-84-0$ & n.d. & n.d. & n.d. & n.d. & 670 & $\mathrm{ug} / \mathrm{kg}$ \\
\hline Benzo(b) fluoranthene & 205-99-2 & n.d. & n.d. & n.d. & n.d. & 670 & $\mathrm{ug} / \mathrm{kg}$ \\
\hline Benzo(k) fluoranthene & $207-08-9$ & n.d. & n.d. & n.d. & n.d. & 670 & $\mathrm{ug} / \mathrm{kg}$ \\
\hline Benzo(a)pyrene & $50-32-8$ & n.d. & n.d. & n.d. & n.d. & 670 & $\mathrm{ug} / \mathrm{kg}$ \\
\hline Indeno $(1,2,3-c d)$ pyrene & $193-39-5$ & n.d. & n.d. & n.d. & n.d. & 670 & $\mathrm{ug} / \mathrm{kg}$ \\
\hline Dibenzo(a,h)anthracene & $53-70-3$ & n.d. & n.d. & n.d. & n.d. & 670 & $u g / k g$ \\
\hline Benzo $(g, h, i)$ perylene & $191-24-2$ & n.d. & n.d. & n.d. & n.d. & 670 & $u g / k g$ \\
\hline
\end{tabular}

n.d. - Not detected

$J$ - Estimated value, less than sample quantitation limit

B - Analyte detected in blank 
Appendix E.4. Results of Sampling and Analysis for Hazardous and Radiological Parameters in Core Samples (Continued)

Site: Area 5 Pilot Well 1/Ue5PW-1

Analysis: Semi-Volatile Organics

Method: 8270

Collection Date: 10-Jun-92

Extraction Date: 10-Jun-92, 11-Jun-92

Analysis Date: 29-Jun-92

Matrix: Soil

Depth: $770 \mathrm{ft}$

\begin{tabular}{|c|c|c|c|c|c|c|c|}
\hline Compound & CAS Number & Sample & Duplicate & $\begin{array}{l}\text { Field } \\
\text { Blank } \\
\end{array}$ & $\begin{array}{l}\text { Equipment } \\
\text { Blank }\end{array}$ & $\begin{array}{c}\text { Detection } \\
\text { Limit }\end{array}$ & Units \\
\hline Phenol & $108-95-2$ & n.d. & n.d. & n.d. & n.d. & 330 & ug/kg \\
\hline bis(2-Chloroethyl)ether & $111-44-4$ & n.d. & n.d. & n.d. & n.d. & 330 & ug/kg \\
\hline 2-Chlorophenol & $95-57-8$ & n.d. & n.d. & n.d. & n.d. & 330 & $\mathrm{ug} / \mathrm{kg}$ \\
\hline 1,3-Dichlorobenzene & $541-73-1$ & n.d. & n.d. & n.d. & n.d. & 330 & $\mathrm{ug} / \mathrm{kg}$ \\
\hline 1,4-Dichlorobenzene & $106-46-7$ & n.d. & n.d. & n.d. & n.d. & 330 & $\mathrm{ug} / \mathrm{kg}$ \\
\hline Benzyl alcohol & $100-51-6$ & n.d. & n.d. & n.d. & n.d. & 330 & ug/kg \\
\hline 1,2-Dichlorobenzene & $95-50-1$ & n.d. & n.d. & n.d. & n.d. & 330 & $\mathrm{ug} / \mathrm{kg}$ \\
\hline 2-Methylphenol & $95-48-7$ & n.d. & n.d. & n.d. & n.d. & 330 & $u g / k g$ \\
\hline 2,2'-oxybis (1-Chloropropane) & $108-60-1$ & n.d. & n.d. & n.d. & n.d. & 330 & $\mathrm{ug} / \mathrm{kg}$ \\
\hline bis(2-Chloroisopropyl)ether & $39638-32-9$ & n.d. & n.d. & n.d. & n.d. & 330 & $u g / k g$ \\
\hline 4-Methylphenol & $106-44-5$ & n.d. & n.d. & n.d. & n.d. & 330 & $u g / k g$ \\
\hline N-Nitroso-di-n-propylamine & $621-64-7$ & n.d. & n.d. & n.d. & n.d. & 330 & $u g / k g$ \\
\hline Hexachloroethane & $67-72-1$ & n.d. & n.d. & n.d. & n.d. & 330 & $\mathrm{ug} / \mathrm{kg}$ \\
\hline Nitrobenzene & $98-95-3$ & n.d. & n.d. & n.d. & n.d. & 330 & $u g / k g$ \\
\hline Isophorone & $78-59-1$ & n.d. & n.d. & n.d. & n.d. & 330 & $\mathrm{ug} / \mathrm{kg}$ \\
\hline 2-Nitrophenol & $88-75-5$ & n.d. & n.d. & n.d. & n.d. & 330 & $u g / k g$ \\
\hline 2,4-Dimethylphenol & $105-67-9$ & n.d. & n.d. & n.d. & n.d. & 330 & $u g / k g$ \\
\hline Benzoic acid & $65-85-0$ & n.d. & n.d. & n.d. & n.d. & 1700 & $u g / k g$ \\
\hline bis (2-Chloroethoxy) methane & $111-91-1$ & n.d. & n.d. & n.d. & n.d. & 330 & $u g / k g$ \\
\hline 2,4-Dichlorophenol & $120-83-2$ & n.d. & n.d. & n.d. & n.d. & 330 & $u g / k g$ \\
\hline 1,2,4-Trichlorobenzene & $120-82-1$ & n.d. & n.d. & n.d. & n.d. & 330 & $\mathrm{ug} / \mathrm{kg}$ \\
\hline Naphthalene & $91-20-3$ & n.d. & n.d. & n.d. & n.d. & 330 & $u g / k g$ \\
\hline 4-Chloroaniline & $106-47-8$ & n.d. & n.d. & n.d. & n.d. & 330 & $u g / k g$ \\
\hline Hexachlorobutadiene & $87-68-3$ & n.d. & n.d. & n.d. & n.d. & 330 & $\mathrm{ug} / \mathrm{kg}$ \\
\hline 4-Chloro-3-methylphenol & $59-50-7$ & n.d. & n.d. & n.d. & n.d. & 330 & $u g / k g$ \\
\hline 2-Methylnaphthalene & $91-57-6$ & n.d. & n.d. & n.d. & n.d. & 330 & $\mathrm{ug} / \mathrm{kg}$ \\
\hline Hexachlorocyclopentadiene & $77-47-4$ & n.d. & n.d. & n.d. & n.d. & 330 & $\mathrm{ug} / \mathrm{kg}$ \\
\hline 2,4,6-Trichiorophenol & $88-06-2$ & n.d. & n.d. & n.d. & n.d. & 330 & $\mathrm{ug} / \mathrm{kg}$ \\
\hline 2,4,5-Trichiorophenol & $95-95-4$ & n.d. & n.d. & n.d. & n.d. & 1700 & $\mathrm{ug} / \mathrm{kg}$ \\
\hline 2-Chloronaphthalene & $91-58-7$ & n.d. & n.d. & n.d. & n.d. & 330 & $\mathrm{ug} / \mathrm{kg}$ \\
\hline 2-Nitroaniline & $88-74-4$ & n.d. & n.d. & n.d. & n.d. & 1700 & $u g / k g$ \\
\hline Dimethylphthalate & $131-11-3$ & n.d. & n.d. & n.d. & n.d. & 330 & $\mathrm{ug} / \mathrm{kg}$ \\
\hline
\end{tabular}

n.d - Not detected

$\mathrm{J}$ - Estimated value, less than sample quantitation limit

$B$ - Analyte detected in blank 
Appendix E.4. Results of Sampling and Analysis for Hazardous and Radiological Parameters in Core Samples (Continued)

Site: Area 5 Pilot Well 1/Ue5PW-1

Analysis: Semi-Volatile Organics

Method: 8270

Collection Date: 10-Jun-92

Extraction Date: 10-Jun-92, 11-Jun-92

Analysis Date: 29-Jun-92

Matrix: Soil

Depth: $770 \mathrm{ft}$.

\begin{tabular}{|c|c|c|c|c|c|c|c|}
\hline Compound & CAS Number & Sample & Duplicate & $\begin{array}{l}\text { Field } \\
\text { Blank }\end{array}$ & $\begin{array}{l}\text { Equipment } \\
\text { Blank }\end{array}$ & $\begin{array}{c}\text { Detection } \\
\text { Limit }\end{array}$ & Units \\
\hline Acenaphthylene & $208-96-8$ & n.d. & n.d. & n.d. & n.d. & 330 & $u g / k g$ \\
\hline 2,6-Dinitrotoluene & $606-20-2$ & n.d. & n.d. & n.d. & n.d. & 330 & $\mathrm{ug} / \mathrm{kg}$ \\
\hline 3-Nitroaniline & $99-09-2$ & n.d. & n.d. & n.d. & n.d. & 1700 & $u g / k g$ \\
\hline Acenaphthene & $83-32-9$ & n.d. & n.d. & n.d. & n.d. & 330 & $\mathrm{ug} / \mathrm{kg}$ \\
\hline 2,4-Dinitrophenol & $51-28-5$ & n.d. & n.d. & n.d. & n.d. & 1700 & $u g / k g$ \\
\hline 4-Nitrophenol & $100-02-7$ & n.d. & n.d. & n.d. & n.d. & 1700 & $\mathrm{ug} / \mathrm{kg}$ \\
\hline Dibenzofuran & $132-64-9$ & n.d. & n.d. & n.d. & n.d. & 330 & $u g / k g$ \\
\hline 2,4-Dinitrotoluene & $121-14-2$ & n.d. & n.d. & n.d. & n.d. & 330 & $u g / k g$ \\
\hline Diethylphthalate & $84-66-2$ & n.d. & n.d. & n.d. & n.d. & 330 & $\mathrm{ug} / \mathrm{kg}$ \\
\hline 4-Chlorophenyl-phenylether & $7005-72-3$ & n.d. & n.d. & n.d. & n.d. & 330 & $\mathrm{ug} / \mathrm{kg}$ \\
\hline Fluorene & $86-73-7$ & n.d. & n.d. & n.d. & n.d. & 330 & $\mathrm{ug} / \mathrm{kg}$ \\
\hline 4-Nitroaniline & $100-01-6$ & n.d. & n.d. & n.d. & n.d. & 1700 & $\mathrm{ug} / \mathrm{kg}$ \\
\hline 4,6-Dinitro-2-methylphenol & $534-52-1$ & n.d. & n.d. & n.d. & n.d. & 1700 & $\mathrm{ug} / \mathrm{kg}$ \\
\hline N-Nitrosodiphenylamine & $86-30-6$ & n.d. & n.d. & n.d. & n.d. & 330 & $\mathrm{ug} / \mathrm{kg}$ \\
\hline 4-Bromophenyl-phenylether & $101-55-3$ & n.d. & n.d. & n.d. & n.d. & 330 & $\mathrm{ug} / \mathrm{kg}$ \\
\hline Hexachiorobenzene & $118-74-1$ & n.d. & n.d. & n.d. & n.d. & 330 & $\mathrm{ug} / \mathrm{kg}$ \\
\hline Pentachlorophenol & $87-86-5$ & n.d. & n.d. & n.d. & n.d. & 1700 & $\mathrm{ug} / \mathrm{kg}$ \\
\hline Phenanthrene & $85-01-8$ & n.d. & n.d. & n.d. & n.d. & 330 & $\mathrm{ug} / \mathrm{kg}$ \\
\hline Anthracene & $120-12-7$ & n.d. & n.d. & n.d. & n.d. & 330 & $\mathrm{ug} / \mathrm{kg}$ \\
\hline Carbazole & $86-74-8$ & n.d. & n.d. & n.d. & n.d. & 330 & $\mathrm{ug} / \mathrm{kg}$ \\
\hline Di-n-butylphthalate & $84-74-2$ & n.d. & n.d. & n.d. & n.d. & 330 & $\mathrm{ug} / \mathrm{kg}$ \\
\hline Fluoranthene & $206-44-0$ & n.d. & n.d. & n.d. & n.d. & 330 & $\mathrm{ug} / \mathrm{kg}$ \\
\hline Pyrene & $129-00-0$ & n.d. & n.d. & n.d. & n.d. & 330 & $\mathrm{ug} / \mathrm{kg}$ \\
\hline Butylbenzylphthalate & $85-68-7$ & n.d. & n.d. & n.d. & n.d. & 330 & $\mathrm{ug} / \mathrm{kg}$ \\
\hline 3,3'-Dichlorobenzidine & $91-94-1$ & n.d. & n.d. & n.d. & n.d. & 660 & $u g / k g$ \\
\hline Benzo(a)anthracene & $56-55-3$ & n.d. & n.d. & n.d. & n.d. & 330 & ug/kg \\
\hline Chrysene & $218-01-9$ & n.d. & n.d. & n.d. & n.d. & 330 & $u g / k g$ \\
\hline bis (2-Ethylhexyl)phthalate & $117-81-7$ & n.d. & n.d. & n.d. & n.d. & 330 & $\mathrm{ug} / \mathrm{kg}$ \\
\hline Di-n-octylphthalate & $117-84-0$ & n.d. & n.d. & n.d. & n.d. & 330 & $\mathrm{ug} / \mathrm{kg}$ \\
\hline Benzo(b)fluoranthene & 205-99-2 & n.d. & n.d. & n.d. & n.d. & 330 & $\mathrm{ug} / \mathrm{kg}$ \\
\hline Benzo(k)fluoranthene & $207-08-9$ & n.d. & n.d. & n.d. & n.d. & 330 & $u g / k g$ \\
\hline Benzo(a)pyrene & $50-32-8$ & n.d. & n.d. & n.d. & n.d. & 330 & $\mathrm{ug} / \mathrm{kg}$ \\
\hline Indeno $(1,2,3-c d)$ pyrene & $193-39-5$ & n.d. & n.d. & n.d. & n.d. & 330 & $\mathrm{ug} / \mathrm{kg}$ \\
\hline Dibenzo $(a, h)$ anthracene & $53-70-3$ & n.d. & n.d. & n.d. & n.d. & 330 & $u g / k g$ \\
\hline Benzo $(g, h, i)$ perylene & 191-24-2 & n.d. & n.d. & n.d. & n.d. & 330 & $u g / k g$ \\
\hline
\end{tabular}

n.d. - Not detected

$J$ - Estimated value, less than sample quantitation limit

B - Analyte detected in blank 
Appendix E.4. Results of Sampling and Analysis for Hazardous and Radiological Parameters in Core Samples (Continued)

Site: Area 5 Pilot Well 2/Ue5PW-2

Analysis: Somi-Volatile Organics

Method: 8270

Collection Date: 24-Jun-92

Extraction Date: 29-Jun-92

Analysis Date: 28-Jul-92

Matrix: Soil

Depth: $70 \mathrm{ft}$.

\begin{tabular}{|c|c|c|c|c|c|c|c|}
\hline Compound & CAS Number & Sample & Duplicate & $\begin{array}{l}\text { Field } \\
\text { Blank }\end{array}$ & $\begin{array}{l}\text { Equipment } \\
\text { Blank }\end{array}$ & $\begin{array}{c}\text { Detection } \\
\text { Limit }\end{array}$ & Units \\
\hline Phenol & $108-95-2$ & n.d. & n.d. & n.d. & n.d. & 330 & $\mathrm{ug} / \mathrm{kg}$ \\
\hline bis(2-Chloroethyl)ether & $111-44-4$ & n.d. & n.d. & n.d. & n.d. & 330 & $u g / k g$ \\
\hline 2-Chlorophenol & $95-57-8$ & n.d. & n.d. & n.d. & n.d. & 330 & $u g / k g$ \\
\hline 1,3-Dichlorobenzene & $541-73-1$ & n.d. & n.d. & n.d. & n.d. & 330 & $u g / k g$ \\
\hline 1,4-Dichlorobenzene & $106-46-7$ & n.d. & n.d. & n.d. & n.d. & 330 & $u g / k g$ \\
\hline Benzyl aicohol & $100-51-6$ & n.d. & n.d. & n.d. & n.d. & 330 & $u g / k g$ \\
\hline 1,2-Dichlorobenzene & $95-50-1$ & n.d. & n.d. & n.d. & n.d. & 330 & $u g / k g$ \\
\hline 2-Methylphenol & $95-48-7$ & n.d. & n.d. & n.d. & n.d. & 330 & $u g / k g$ \\
\hline 2,2'-oxybis(1-Chloropropane) & $108-60-1$ & n.d. & n.d. & n.d. & n.d. & 330 & $u g / k g$ \\
\hline bis (2-Chloroisopropyl)ether & $39638-32-9$ & n.d. & n.d. & n.d. & n.d. & 330 & $u g / k g$ \\
\hline 4-Methylphenol & $106-44-5$ & n.d. & n.d. & n.d. & n.d. & 330 & $u g / k g$ \\
\hline N-Nitroso-di-n-propylamine & $621-64.7$ & n.d. & n.d. & n.d. & n.d. & 330 & $\mathrm{ug} / \mathrm{kg}$ \\
\hline Hexachloroethane & $67-72-1$ & n.d. & n.d. & n.d. & n.d. & 330 & $u g / k g$ \\
\hline Nitrobenzene & $98-95-3$ & n.d. & n.d. & n.d. & n.d. & 330 & $u g / k g$ \\
\hline Isophorone & $78-59-1$ & n.d. & n.d. & n.d. & n.d. & 330 & $\mathrm{ug} / \mathrm{kg}$ \\
\hline 2-Nitrophenol & $88-75-5$ & n.d. & n.d. & n.d. & n.d. & 330 & $u g / k g$ \\
\hline 2,4-Dimethylphenol & $105-67-9$ & n.d. & n.d. & n.d. & n.d. & 330 & $\mathrm{ug} / \mathrm{kg}$ \\
\hline Benzoic acid & $65-85-0$ & n.d. & n.d. & n.d. & n.d. & 1700 & $u g / k g$ \\
\hline bis(2-Chloroethoxy)methane & $111-91-1$ & n.d. & n.d. & n.d. & n.d. & 330 & $u g / k g$ \\
\hline 2,4-Dichlorophenol & $120-83-2$ & n.d. & n.d. & n.d. & n.d. & 330 & $\mathrm{ug} / \mathrm{kg}$ \\
\hline 1,2,4-Trichlorobenzene & $120-82-1$ & n.d. & n.d. & n.d. & n.d. & 330 & $u g / k g$ \\
\hline Naphthalene & $91-20-3$ & n.d. & n.d. & n.d. & n.d. & 330 & $u g / k g$ \\
\hline 4-Chloroaniline & $106-47-8$ & n.d. & n.d. & n.d. & n.d. & 330 & $u g / k g$ \\
\hline Hexachlorobutadiene & $87-68-3$ & n.d. & n.d. & n.d. & n.d. & 330 & $\mathrm{ug} / \mathrm{kg}$ \\
\hline 4-Chloro-3-methylphenol & $59-50-7$ & n.d. & n.d. & n.d. & n.d. & 330 & $u g / k g$ \\
\hline 2-Methylnaphthalene & $91-57-6$ & n.d. & n.d. & n.d. & n.d. & 330 & $u g / k g$ \\
\hline Hexachlorocyclopentadiene & $77-47-4$ & n.d. & n.d. & n.d. & n.d. & 330 & $u g / k g$ \\
\hline 2,4,6-Trichlorophenol & $88-06-2$ & n.d. & n.d. & n.d. & n.d. & 330 & $\mathrm{ug} / \mathrm{kg}$ \\
\hline 2,4,5-Trichlorophenol & $95-95-4$ & n.d. & n.d. & n.d. & n.d. & 1700 & $u g / k g$ \\
\hline 2-Chloronaphthalene & $91-58-7$ & n.d. & n.d. & n.d. & n.d. & 330 & ug $/ \mathrm{kg}$ \\
\hline 2-Nitroaniline & $88-74-4$ & n.d. & n.d. & n.d. & n.d. & 1700 & $\mathrm{ug} / \mathrm{kg}$ \\
\hline Dimethylphthalate & $131-11-3$ & n.d. & n.d. & n.d. & n.d. & 330 & $\mathrm{ug} / \mathrm{kg}$ \\
\hline
\end{tabular}

n.d. - Not detected

$J$ - Estimated value, less than sample quantitation limit

B - Analyte detected in blank 
Appendix E.4. Results of Sampling and Analysis for Hazardous and Radiological Parameters in Core Samples (Continued)

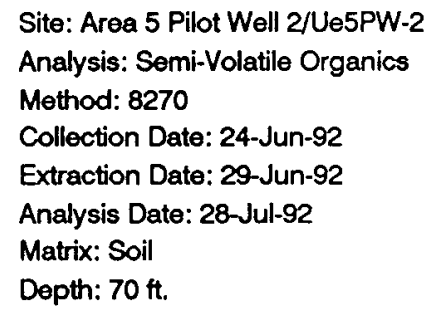

\begin{tabular}{|c|c|c|c|c|c|c|c|}
\hline Compound & CAS Number & Sample & Duplicate & $\begin{array}{l}\text { Field } \\
\text { Blank }\end{array}$ & $\begin{array}{c}\text { Equipment } \\
\text { Blank }\end{array}$ & $\begin{array}{c}\text { Detection } \\
\text { Limit }\end{array}$ & Units \\
\hline Acenaphthylene & $208-96-8$ & n.d. & n.d. & n.d. & n.d. & 330 & $\mathrm{ug} / \mathrm{kg}$ \\
\hline 2,6-Dinitrotoluene & $606-20-2$ & n.d. & n.d. & n.d. & n.d. & 330 & $\mathrm{ug} / \mathrm{kg}$ \\
\hline 3-Nitroaniline & $99-09-2$ & n.d. & n.d. & n.d. & n.d. & 1700 & $\mathrm{ug} / \mathrm{kg}$ \\
\hline Acenaphthene & $83-32-9$ & n.d. & n.d. & n.d. & n.d. & 330 & $\mathrm{ug} / \mathrm{kg}$ \\
\hline 2,4-Dinitrophenol & $51-28-5$ & n.d. & n.d. & n.d. & n.d. & 1700 & $u g / k g$ \\
\hline 4-Nitrophenol & $100-02-7$ & n.d. & n.d. & n.d. & n.d. & 1700 & $\mathrm{ug} / \mathrm{kg}$ \\
\hline Dibenzofuran & $132-64-9$ & n.d. & n.d. & n.d. & n.d. & 330 & $u g / k g$ \\
\hline 2,4-Dinitrotoluene & $121-14-2$ & n.d. & n.d. & n.d. & n.d. & 330 & $\mathrm{ug} / \mathrm{kg}$ \\
\hline Diethylphthalate & $84-66-2$ & n.d. & n.d. & n.d. & n.d. & 330 & $\mathrm{ug} / \mathrm{kg}$ \\
\hline 4-Chlorophenyl-phenylether & $7005-72-3$ & n.d. & n.d. & n.d. & n.d. & 330 & $\mathrm{ug} / \mathrm{kg}$ \\
\hline Fluorene & $86-73-7$ & n.d. & n.d. & n.d. & n.d. & 330 & $\mathrm{ug} / \mathrm{kg}$ \\
\hline 4-Nitroaniline & $100-01-6$ & n.d. & n.d. & n.d. & n.d. & 1700 & $\mathrm{ug} / \mathrm{kg}$ \\
\hline 4,6-Dinitro-2-methylphenol & $534-52-1$ & n.d. & n.d. & n.d. & n.d. & 1700 & $u g / k g$ \\
\hline N-Nitrosodiphenylamine & $86-30-6$ & n.d. & n.d. & n.d. & n.d. & 330 & $\mathrm{ug} / \mathrm{kg}$ \\
\hline 4-Bromophenyl-phenylether & $101-55-3$ & n.d. & n.d. & n.d. & n.d. & 330 & $\mathrm{ug} / \mathrm{kg}$ \\
\hline Hexachlorobenzene & $118-74-1$ & n.d. & n.d. & n.d. & n.d. & 330 & $\mathrm{ug} / \mathrm{kg}$ \\
\hline Pentachlorophenol & $87-86-5$ & n.d. & n.d. & n.d. & n.d. & 1700 & $\mathrm{ug} / \mathrm{kg}$ \\
\hline Phenanthrene & $85-01-8$ & n.d. & n.d. & n.d. & n.d. & 330 & $\mathrm{ug} / \mathrm{kg}$ \\
\hline Anthracene & $120-12-7$ & n.d. & n.d. & n.d. & n.d. & 330 & $u g / k g$ \\
\hline Carbazole & $86-74-8$ & n.d. & n.d. & n.d. & n.d. & 330 & $u g / k g$ \\
\hline Di-n-butylphthalate & $84-74-2$ & n.d. & n.d. & n.d. & n.d. & 330 & $\mathrm{ug} / \mathrm{kg}$ \\
\hline Fluoranthene & $206-44-0$ & n.d. & n.d. & n.d. & n.d. & 330 & $u g / k g$ \\
\hline Pyrene & $129-00-0$ & n.d. & n.d. & n.d. & n.d. & 330 & $u g / k g$ \\
\hline Butylbenzylphthalate & $85-68-7$ & n.d. & n.d. & n.d. & n.d. & 330 & $\mathrm{ug} / \mathrm{kg}$ \\
\hline 3,3'-Dichlorobenzidine & $91-94-1$ & n.d. & n.d. & n.d. & n.d. & 660 & $u g / \mathrm{kg}$ \\
\hline Benzo(a)anthracene & $56-55-3$ & n.d. & n.d. & n.d. & n.d. & 330 & $\mathrm{ug} / \mathrm{kg}$ \\
\hline Chrysene & $218-01-9$ & n.d. & n.d. & n.d. & n.d. & 330 & $\mathrm{ug} / \mathrm{kg}$ \\
\hline bis (2-Ethylhexyl)phthalate & $117-81-7$ & n.d. & n.d. & n.d. & n.d. & 330 & $u g / k g$ \\
\hline Di-n-octylphthalate & $117-84-0$ & n.d. & n.d. & n.d. & n.d. & 330 & $\mathrm{ug} / \mathrm{kg}$ \\
\hline Benzo(b) fluoranthene & $205-99-2$ & n.d. & n.d. & n.d. & n.d. & 330 & $\mathrm{ug} / \mathrm{kg}$ \\
\hline Benzo(k)fluoranthene & $207-08-9$ & n.d. & n.d. & n.d. & n.d. & 330 & $\mathrm{ug} / \mathrm{kg}$ \\
\hline Benzo(a)pyrene & $50-32-8$ & n.d. & n.d. & n.d. & n.d. & 330 & $\mathrm{ug} / \mathrm{kg}$ \\
\hline Indeno $(1,2,3-c d)$ pyrene & $193-39-5$ & n.d. & n.d. & n.d. & n.d. & 330 & $u g / k g$ \\
\hline Dibenzo $(a, h)$ anthracene & $53-70-3$ & n.d. & n.d. & n.d. & n.d. & 330 & $\mathrm{ug} / \mathrm{kg}$ \\
\hline Benzo(g,h,i)perylene & $191-24-2$ & n.d. & n.d. & n.d. & n.d. & 330 & $\mathrm{ug} / \mathrm{kg}$ \\
\hline
\end{tabular}

n.d. - Not detected

$\mathrm{J}$ - Estimated value, less than sample quantitation limit B - Analyte detocted in blank 


\title{
Area 5 Pilot Wells
}

\author{
APPENDIX F \\ Field Test Data
}

F.1 Near-Surface Soil Gas Surveys

F.1.1 Surface Soil Sampling, Analysis, and Results

F.1.2 Near-Surface Radon and Tritium Gas Sampling, Analysis, and Results

F.2 Surface Geophysical Surveys

F.2.1 Resistivity Survey Data

F.2.2 Magnetic Survey Data

F.3 Borehole Geophysical Surveys

F.3.1 Description of Borehole Geophysical Logging Tools Used

F.3.2 Borehole Geophysical Logs Run in UE5PW-1 on 4/20/1992

F.3.3 Borehole Geophysical Logs Run in UE5PW-1 on 6/16/1992

F.3.4 Borehole Deviation Logs Run in UE5PW-1 on 2/24/1993

F.3.5 Borehole Geophysical Logs Run in UE5PW-2 on 7/20/1992

F.3.6 Borehole Geophysical Logs Run in UE5PW-2 on 9/28/1992 and 9/29/1992

F.3.7 Borehole Deviation Logs Run in UE5PW-2 on 2/25/1993

F.3.8 Borehole Geophysical Logs Run in UE5PW-3 on 9/28/1992

F.3.9 Borehole Geophysical Logs Run in UE5PW-3 on 11/18/1992

F.3.10 Borehole Deviation Logs Run in UE5PW-3 on 2/25/1993

F.4 In-Situ Air Permeability Testing Data

F.4.1 Dimensions of Air Permeability Testing Interval for the Pilot Wells

F.4.2 In-Situ Air Permeability Testing Data

F.4.3 Effective Air Permeabilities and Inertial Coefficients for Field Testing in the Pilot Wells

F.5 Upper Aquifer Hydraulic Parameter Testing

F.5.1 Estimating the Water Table Slope under the Area 5 RWMS

F.5.2 Results of Hydraulic Conductivity Recovery Tests 
Appendix F.1.1 Surface Soil Sampling, Analysis, and Results

\section{Soil Sampling and Analysis Methods}

Samples were collected from $20 \mathrm{~cm}$ by $20 \mathrm{~cm}$ by $2 \mathrm{~cm}$ deep cells selected randomly from a $30 \mathrm{~m}$ by $30 \mathrm{~m}$ grid centered at the borehole. Four random samples were collected from each of the unprepared and prepared sites, the only exception being the unprepared site at Ue5PW-1. The Ue5PW-1 site was disturbed by vehicle traffic prior to sampling for TPH and oil and grease. Due to the extent of the disturbance it was impossible to collect samples from this site using a randomized design. Therefore, three TPH and oil and grease samples were collected at $50 \mathrm{ft}$ east, west and north of the borehole. Finally an additional grab sample was collected from a dark stained area southeast of the borehole location at the unprepared Ue5PW-2 site.

Oil and grease and TPH samples were collected in precleaned $500 \mathrm{ml}$ glass jars. Samples for analysis of photon emitting radionuclides and plutonium were collected in $500 \mathrm{ml}$ polyethylene bottles. Aliquots which were taken for analysis were not dried to constant mass or homogenized. Concentrations are expressed on a wet mass basis.

TPH samples were analyzed using EPA method 8015 (EPA 1986). Oil and grease samples were analyzed using a modification of EPA method 413.2 (EPA 1982). Photon emitting radionuclides and plutonium isotopes were analyzed using REECo Analytical Services Department (ASD) procedures. Analyses for photon emitting radionuclides were conducted with a high purity germanium detector. Soil samples for plutonium analysis were prepared by $\mathrm{NaCO}_{3}$ fusion. Plutonium was separated from the dissolved sample by ion exchange and prepared for counting by electro-deposition. Plutonium isotopes were identified and quantified by alpha spectrometry.

\section{Results for Ue5PW-1}

The concentrations of chemical and radiological parameters found in soils from the unprepared and prepared Ue5PW-1 drill site do not indicate that this site was significantly contaminated. TPH was not detected in undisturbed soils. Oil was detected by TPH analysis in a single soil sample from the prepared drill site. The oil in this sample is most likely due to contamination from equipment used to grade and compact the site. The oil concentration, $44 \mathrm{mg} / \mathrm{kg}$, was unlikely to have presented significant contamination concerns to drilling operations. Concentrations of oil and grease were low and unchanged by site preparation. These low concentrations may be due to naturally occurring organic matter in the soil.

The concentration of naturally occurring primordial radionuclides were unchanged by site preparation. The activity concentrations of ${ }^{137} \mathrm{Cs}$ in soil were low and reduced by site preparation to levels that posed little contamination concerns. The mean activity concentration of ${ }^{137} \mathrm{Cs}$ for the undisturbed site was $0.5 \mathrm{pCi} / \mathrm{g}$. McArthur and Miller (1989) have reported that the activity concentration of ${ }^{137} \mathrm{Cs}$ in off-site surface soils in southern Nevada ranges from $0.3 \mathrm{pCi} / \mathrm{g}$ to $1.2 \mathrm{pCi} / \mathrm{g}$. After preparation of the site, the mean ${ }^{137} \mathrm{Cs}$ activity concentration decreased to $0.1 \mathrm{pCi} / \mathrm{g}$. ${ }^{238} \mathrm{Plutonium}$ activity concentrations were 
Appendix F.1.1 Surface Soil Sampling, Analysis, and Results (Continued)

less than the detection limit in all samples. Low concentrations of ${ }^{239,240} \mathrm{Pu}$ were detected in two out of four samples.

\section{Results for Ue5PW-2}

The concentrations of chemical and radiological parameters in soils from undisturbed soils and the prepared drill site do not indicate that the Ue5PW-2 drill site was contaminated. Low concentrations of TPH as oil were detected in all samples from the undisturbed site. At a single site where used oil filters were present, a TPH(oil) concentration of $4200 \mathrm{mg} / \mathrm{kg}$ was found in a grab sample. The total area stained with oil was small, less than $1 \mathrm{~m}^{2}$, and was removed during site preparation. After preparation of the site, TPH concentrations were less than the detection limit for all samples. Low concentrations of oil and grease were detected in a single random sample from the undisturbed site and from two samples in the prepared site. The mean oil and grease concentration was not changed by site preparation.

The activity concentrations of radionuclides at Ue5PW-2 were not different from that found in off-site soils for southern Nevada (McArthur and Miller 1989). The activity concentration of primordial radionuclides was unaffected by site preparation. Site preparation decreased the mean activity concentration of ${ }^{137} \mathrm{Cs}$ from $0.7 \mathrm{pCi} / \mathrm{g}$ to less than $0.06 \mathrm{pCi} / \mathrm{g}$. ${ }^{238} \mathrm{Plutonium}$ and ${ }^{239,240} \mathrm{Pu}$ were detected in a single soil sample. The highest concentration of ${ }^{239,240} \mathrm{Pu}$ detected, $0.004 \mathrm{pCi} / \mathrm{g}$, is within the range of concentrations expected for fallout in southern Nevada.

\section{Results for Ue5PW-3}

The concentrations of chemical and radiological parameters in soils from undisturbed soils and the prepared drill site do not indicate that the Ue5PW-3 drill site was contaminated. Low concentrations of TPH as oil were detected in undisturbed soils at Ue5PW-3. All TPH samples from the prepared site were less than the detection limit. Oil and grease concentration were low and unchanged by site preparation.

The activity concentrations of radionuclides at Ue5PW-3 were similar to those found in offsite soils for southern Nevada (McArthur and Miller 1989). The activity concentration of primordial radionuclides was unaffected by site preparation. The mean activity concentration of ${ }^{137} \mathrm{Cs}$ in undisturbed soil was $0.5 \mathrm{pCi} / \mathrm{g}$ and was not detected in any samples from the prepared site. The mean activity concentration of ${ }^{239,240} \mathrm{Pu}, 0.032 \mathrm{pCi} / \mathrm{g}$, was within the range of off-site soils. ${ }^{238}$ Plutonium was not detected in any sample.

\section{References}

EPA, 1982. Methods for Chemical Analysis of Water and Waste, EPA-600/4-82-005.

EPA, 1986. Test Methods for Evaluating Solid Waste, Physical /Chemical Methods, SW846. 
Appendix F.1.1 Surface Soil Sampling, Analysis, and Results (Continued)

McArther, R.D., F.L. Miller, 1989. Off-Site Radiation Review Project Phase II, Soils Program, Desert Research Institute, Univ. of Nevada.

Appendix F.1.2 Near Surface Radon and Tritium Gas Sampling, Analysis, and Results 
Appendix F.1.1 Surface Soil Sampling, Analysis, and Results (Continued)

Appendix F.1.1. Surface Soil Sampling. Analysis and Results

Area 5 Pilot Well 1/Ne5PW1

Undisturbed Drill Site/Simple Random Surface Samples

\begin{tabular}{|c|c|c|c|c|c|c|c|c|}
\hline Sample tdentification & Parameter & Method & Collection Date & Analysis Date & Concentration & $\begin{array}{c}\text { \% Uncertainty } \\
(2.0 \mathrm{~s})\end{array}$ & $\begin{array}{l}\text { Detection } \\
\text { Limit } \\
\end{array}$ & Units \\
\hline N785.702.33 & TPH(Total) & 8015 & 28-Jan-92 & $30-\operatorname{Jan}-92$ & $<\mathrm{DL}$ & & 20 & $\mathrm{mg} / \mathrm{kg}$ \\
\hline E709.681.50 & TPH(Diesel) & 8015 & 28-Jan-92 & $30-\operatorname{Jan}-92$ & $<D L$ & & 10 & $\mathrm{mg} / \mathrm{kg}$ \\
\hline \multirow{2}{*}{ (SE-5OW) } & TPH(Oil) & 8015 & 28-Jan-92 & 30-Jan-92 & $<D L$ & & 10 & $\mathrm{mg} / \mathrm{kg}$ \\
\hline & Oil and Grease & 413.2 & 28-Jan-82 & 19-Mar-92 & $\angle \mathrm{DL}$ & & 0.7 & $\mathrm{mg} / \mathrm{kg}$ \\
\hline$N 765,723.26$ & $K \cdot 40$ & 901.1 & $\infty$-Jan- 82 & o6-Feb-92 & 24 & 21 & 2 & $\mathrm{pCi} / \mathrm{g}$ \\
\hline E $709,856.17$ & Cs- 137 & 901.1 & $09-J a n-82$ & $06-F e b-92$ & 0.4 & 42 & 0.1 & $p C i / 9$ \\
\hline \multirow[t]{3}{*}{ (SE-578-10-60) } & $\operatorname{Ra}-226$ & 901.1 & $09-\operatorname{Jan}-92$ & 06-Feb-92 & 1 & 31 & 0.2 & $\rho C i / g$ \\
\hline & Th-232 & 901.1 & 09-Jan-92 & 06-Feb-92 & 2 & 39 & 0.4 & $\mathrm{pCi} / \mathrm{g}$ \\
\hline & Th-228 & 901.1 & $09 \cdot \operatorname{Jan}-92$ & 06-Feb-82 & 2 & 25 & 0.2 & $\mathrm{pCi} / \mathrm{g}$ \\
\hline N765,702.33 & TPH(Total) & 8015 & $28-\operatorname{Jan} \cdot 92$ & 30-Jan-92 & $<D L$ & & 20 & $\mathrm{mg} / \mathrm{kg}$ \\
\hline$E 709,831.50$ & TPH(Diesel) & 8015 & 28.Jan-92 & 30-Jan-92 & $<\mathrm{DL}$ & & 10 & $\mathrm{mg} / \mathrm{kg}$ \\
\hline \multirow[t]{2}{*}{ (SE-5ON) } & TPH(Oil) & 8015 & 28-Jan-92 & 30-Jan-92 & $<D L$ & & 10 & $\mathrm{mg} / \mathrm{kg}$ \\
\hline & Oil and Grease & 413.2 & 28-Jan-92 & 19-Mar-92 & 5.6 & & 0.7 & $\mathrm{mg} / \mathrm{kg}$ \\
\hline N765,720.05 & $K-40$ & 901.1 & $09-\operatorname{Jan}-92$ & 06-Feb-92 & 22 & 22 & 2 & $\mathrm{DCi} / \mathrm{g}$ \\
\hline$E 709,811.81$ & Cs. 137 & 901.1 & 09-Jan-92 & $06-F$ eb-92 & 0.4 & 38 & 0.1 & $\mathrm{pCi} / \mathrm{g}$ \\
\hline \multirow[t]{3}{*}{ (SE-592-50-40) } & Ra-226 & 901.1 & $09-\operatorname{Jan}-92$ & O6-Feb-92 & 1 & 30 & 0.1 & $\mathrm{pCi} / \mathrm{g}$ \\
\hline & Th.232 & 901.1 & $09-\operatorname{Jan}-92$ & 06-Feb-92 & 2 & 36 & 0.4 & $\rho C i / g$ \\
\hline & Th-228 & 901.1 & 09.Jan-92 & $06-\mathrm{Feb}-92$ & 2 & 25 & 0.2 & $\rho \mathrm{Ci} / \mathrm{g}$ \\
\hline N765,702.33 & TPH(Total) & 8015 & $28-\operatorname{Jan}-92$ & $30-\operatorname{Jan}-92$ & $\angle D L$ & & 20 & $\mathrm{mg} / \mathrm{kg}$ \\
\hline$E 709.781 .50$ & TPH(Diesel) & 8015 & 28-Jan-92 & 30-Jan-92 & $<O L$ & & 10 & $\mathrm{mg} / \mathrm{kg}$ \\
\hline \multirow[t]{2}{*}{ (SE-5OE) } & TPH(Oil) & 8015 & 28-Jan-92 & 30-Jan-92 & $<D$ & & 10 & $\mathrm{mg} / \mathrm{kg}$ \\
\hline & Oil and Grease & 413.2 & 28.Jan. 92 & 19-Mar-92 & $<\mathrm{DL}$ & & 0.7 & $\mathrm{mg} / \mathrm{kg}$ \\
\hline$N 765,665.91$ & $k \cdot 40$ & 901.1 & $09-\operatorname{Jan}-92$ & 06-Feb-92 & 25 & 20 & 1 & $\mathrm{pCi} / \mathrm{g}$ \\
\hline$E 709,788.85$ & Cs-137 & 901.1 & $09-\operatorname{Jan}-92$ & 06-Feb-82 & 0.6 & 32 & 0.1 & $\mathrm{pCi} / \mathrm{g}$ \\
\hline \multirow[t]{3}{*}{ (SE-89-40-90) } & Ra-226 & 901.1 & 09-Jan-92 & $\infty 6-F e b-92$ & 1 & 29 & 0.2 & $\mathrm{pCi} / \mathrm{g}$ \\
\hline & Th.232 & 901.1 & $09-\operatorname{Jan} \cdot 82$ & $06 \cdot F e b \cdot 92$ & 2 & 37 & 0.4 & $\mathrm{pCi} / \mathrm{g}$ \\
\hline & Th-228 & 901.1 & 09-Jan-82 & $06-F e b-92$ & 2 & 22 & 0.2 & $\mathrm{pCi} / \mathrm{g}$ \\
\hline N765,665.54 & $K-40$ & 901.1 & $09 \cdot \operatorname{Jan}-92$ & O6-Feb-92 & 22 & 22 & 1 & $\mathrm{pCi} / 9$ \\
\hline$E 709,788.19$ & Cs-137 & 901.1 & 09-Jan-92 & $06-F e b-92$ & 0.4 & 39 & 0.1 & $p C i / g$ \\
\hline \multirow[t]{3}{*}{ (SE-119-19-70) } & Ra.226 & 901.1 & $09 . J a n \cdot 92$ & 06-Feb-92 & 0.9 & 34 & 0.2 & $\mathrm{pCi} / \mathrm{g}$ \\
\hline & Th-232 & 901.1 & 09-Jan-92 & $06-$ Feb-92 & 2 & 38 & 0.4 & $\mathrm{pCi} / \mathrm{g}$ \\
\hline & Th-228 & 901.1 & 09.Jan-92 & Q6-Feb-92 & 2 & 24 & 0.2 & $p$ Ci/g \\
\hline Mean Pilot Well 1 & TPH(Total) & & & & $\angle \mathrm{OL}$ & & & $\mathrm{mg} / \mathrm{kg}$ \\
\hline \multirow{8}{*}{ Concentrations } & TPH(Diesel) & & & & $<D L$ & & & $\mathrm{mg} / \mathrm{kg}$ \\
\hline & TPH(Oil) & & & & $<\mathrm{OL}$ & & & $\mathrm{mg} / \mathrm{kg}$ \\
\hline & Oil and Grease & & & & $1.9-2.3$ & & & $\mathrm{mg} / \mathrm{kg}$ \\
\hline & $K-40$ & & & & 23 & 11 & & $\mathrm{pCi} / \mathrm{g}$ \\
\hline & Cs.137 & & & & 0.5 & 38 & & $\mathrm{pCi} / \mathrm{g}$ \\
\hline & Ra.226 & & & & 1 & 8.9 & & $\mathrm{pCi} / \mathrm{g}$ \\
\hline & Th.232 & & & & 2 & 0.0 & & $\mathrm{pCi} / \mathrm{g}$ \\
\hline & Th-228 & & & & 2 & 0.0 & & $\mathrm{pCi} / \mathrm{g}$ \\
\hline
\end{tabular}


Appendix F.1.1 Surface Soil Sampling, Analysis, and Results (Continued)

Area 5 Pilot Well 1/Ne5PW-

Prepared Drill Sites/Simple Random Surface Samples

\begin{tabular}{|c|c|c|c|c|c|c|c|c|}
\hline Sample Identification & Parameter & Method & Collection Date & Analysis Date & Concentration & $\begin{array}{c}\text { \% Uncertainty } \\
\text { (2s) }\end{array}$ & $\begin{array}{l}\text { Detection } \\
\text { Limit }\end{array}$ & Units \\
\hline$N 765,680.02$ & TPH(Total) & 8015 & $27-F e b-82$ & 16-Mar-92 & $<D L$ & & 20 & $\mathrm{mg} / \mathrm{kg}$ \\
\hline \multirow{2}{*}{ E709.836.09 } & TPH(Diesel) & 8015 & $27-F e b-92$ & 16-Mar-82 & $<D L$ & & 10 & $\mathrm{mg} / \mathrm{kg}$ \\
\hline & TPH(Oil) & 8015 & $27 \cdot$ Feb-92 & 16-Mar-92 & $<O L$ & & 10 & $\mathrm{mg} / \mathrm{kg}$ \\
\hline \multirow[t]{8}{*}{ (SE-6.8-1.4) } & Oil and Grease & 413.2 & 27-Feb-92 & $28+M a r-82$ & 3.9 & & 0.7 & $\mathrm{mg} / \mathrm{kg}$ \\
\hline & $K \cdot 40$ & 901.1 & $27-F e b-92$ & 13-Mar-92 & 24 & 8.9 & & $D C i / g$ \\
\hline & Cs.137 & 901.1 & 27-Feb-82 & 13-Mar-92 & 0.1 & 23 & & $\infty \mathrm{Ci} / \mathrm{g}$ \\
\hline & Ra.226 & 901.1 & 27-Feb-92 & 13-Mar-92 & 0.8 & 12 & & $p C i / g$ \\
\hline & $T h-232$ & 901.1 & 27-Feb-92 & 13-Mar-92 & 1.4 & 13 & & pCi/g \\
\hline & Th-228 & 901.1 & $27 \cdot F e b-92$ & 13-Mar-92 & 1.6 & 9.5 & & $p C i / g$ \\
\hline & Pu-238 & AABAB 0.04 .1 & $27 \cdot$ Feb-92 & 08-Jun-92 & 0.002 & 445 & & $\rho \mathrm{Ci} / \mathrm{g}$ \\
\hline & Pu.239,240 & AABAB.D.04.1 & $27 \cdot F e b-92$ & 08-Jun-92 & 0.003 & 105 & & $p \mathrm{Ci} / \mathrm{g}$ \\
\hline N765,666.90 & TPH(Total) & 8015 & $27 \cdot F e b-92$ & $16-\mathrm{Mar}-82$ & $<\mathrm{DL}$ & & 20 & $\mathrm{mg} / \mathrm{kg}$ \\
\hline \multirow[t]{2}{*}{$E 709,821.66$} & TPH(Diesel) & 6015 & 27-Feb-92 & 16-Mar-92 & $<D L$ & & 10 & $\mathrm{mg} / \mathrm{kg}$ \\
\hline & $\mathrm{TPH}(\mathrm{Oil})$ & 8015 & $27-F e b-92$ & 16-Mar-92 & $<D L$ & & 10 & $\mathrm{mg} / \mathrm{kg}$ \\
\hline \multirow[t]{8}{*}{ (SE-10.8-3) } & Oil and Grease & 413.2 & $27 \cdot$ Feb-92 & 28-Mar-92 & 1.4 & & 0.7 & $\mathrm{mg} / \mathrm{kg}$ \\
\hline & $K \cdot 40$ & 901.1 & $27-F e b-92$ & 14-Mar-92 & 24.1 & 8.9 & & $D \mathrm{Ci} / 9$ \\
\hline & Cs.137 & 901.1 & $27 \cdot$ Feb-92 & 14-Mar-92 & 0.05 & 40 & & $D C i / g$ \\
\hline & Ra-226 & 901.1 & $27 \cdot$ Feb-92 & 14-Mar-92 & 0.8 & 12 & & $p C i / g$ \\
\hline & Th-232 & 901.1 & $27 \cdot F e b-92$ & 14-Mar-92 & 1.4 & 13 & & $\infty \mathrm{Ci} / \mathrm{g}$ \\
\hline & $T h-228$ & 901.1 & 27-Feb-92 & 14-Mar-92 & 1.5 & 9.6 & & $D C i / 9$ \\
\hline & Pu-238 & AABAB.D.04.1 & $27 \cdot F e b-92$ & 08-Jun-92 & 0.004 & 283 & & $p C i / 9$ \\
\hline & Pu-239,240 & AABAB.0.04.1 & $27 \cdot F e b-92$ & 08-Jun-92 & 0.06 & 44 & & $\mathrm{pCi} / \mathrm{g}$ \\
\hline N765.707.58 & TPH(Total) & 8015 & 27-Feb-92 & 16-Mar-82 & $\angle D L$ & & 20 & $\mathrm{mg} / \mathrm{kg}$ \\
\hline \multirow[t]{2}{*}{$E 709,856.11$} & TPH(Diesel) & 8015 & $27 \cdot$ Feb-92 & 16-Mar.92 & $<D L$ & & 10 & $\mathrm{mg} / \mathrm{kg}$ \\
\hline & TPH(OI) & 8015 & $27 \cdot F e b-92$ & 16-Mar-92 & $<\mathrm{OL}$ & & 10 & $\mathrm{mg} / \mathrm{kg}$ \\
\hline \multirow[t]{8}{*}{ (SE-1.6-7) } & Oil and Grease & 413.2 & $27-F e b-92$ & 28-Mar-82 & $<D L$ & & 0.7 & $\mathrm{mg} / \mathrm{kg}$ \\
\hline & $K-40$ & 901.1 & $27-F e b-92$ & $20-$ Mar-92 & 23.6 & 8.9 & & $p C i / g$ \\
\hline & Cs-137 & $\infty 01.1$ & 27-Feb- 02 & 20-Mar-92 & 0.04 & 48 & & $\infty \mathrm{Ci} / 9$ \\
\hline & Ra-226 & 901.1 & 27-Feb- 92 & $20-$ Mar-92 & 0.8 & 13 & & $\mathrm{pCi} / \mathrm{g}$ \\
\hline & Th.232 & 901.1 & $27-F e b-92$ & 20-Mar-92 & 1.4 & 13 & & $p C i / g$ \\
\hline & Th-228 & 901.1 & $27-F e b-92$ & $20-$ Mar-92 & 1.6 & 9.5 & & $D C i / g$ \\
\hline & Pu.238 & АABAB.D.04.1 & 27-Feb-92 & 08-Jun-92 & 0.006 & 202 & & $p \mathrm{Ci} / \mathrm{g}$ \\
\hline & Pu-239,240 & AABAB.D.04.1 & 27-Feb-92 & 08-Jun-92 & 0.006 & 92 & & $\mathrm{pCi} / \mathrm{g}$ \\
\hline$N 765,721.36$ & TPH(Total) & 8015 & 27-Feb-92 & 16-Mar-92 & 44.2 & & 20 & $\mathrm{mg} / \mathrm{kg}$ \\
\hline \multirow[t]{2}{*}{$E 709.828 .22$} & TPH(Diesel) & 8015 & 27-Feb-82 & 16-Mar-92 & $<O L$ & & 10 & $\mathrm{mg} / \mathrm{kg}$ \\
\hline & TPH(Oil) & 8015 & 27-Feb-92 & 16-Mar-92 & 44.2 & & 10 & $\mathrm{mg} / \mathrm{kg}$ \\
\hline \multirow[t]{8}{*}{ (SE-5.8-1) } & Oil and Grease & 413.2 & 27-Feb-92 & 28-Mar-92 & $<\mathrm{DL}$ & & 0.7 & $\mathrm{mg} / \mathrm{kg}$ \\
\hline & K. 40 & 901.1 & 27-Feb-92 & 21-Mar-92 & 25.0 & 8.8 & & $D C i / g$ \\
\hline & Cs-137 & 901.1 & 27-Feb-92 & 21-Mar-92 & 0.1 & 20 & & $\mathrm{pCi} / \mathrm{g}$ \\
\hline & $\mathrm{Rla}-226$ & 901.1 & 27-Feb-92 & 21-Mar-82 & 0.9 & 12 & & $\mathrm{pCi} / \mathrm{g}$ \\
\hline & Th.232 & 901.1 & $27-$ Feb-92 & 21-Mar-92 & 1.6 & 12 & & $\mathrm{pCi} / \mathrm{g}$ \\
\hline & Th-228 & 901.1 & 27-Feb-92 & 21-Mar-92 & 1.7 & 9.4 & & $\mathrm{pCi} / \mathrm{g}$ \\
\hline & Pu.238 & AABAB D. 04 & $27-\mathrm{Feb}-92$ & 08-Jun-92 & -0.007 & 96 & & $\rho C i / g$ \\
\hline & Pu-239.240 & AABAB D.04 1 & 27-Fet-92 & 08-Jun-92 & 0.020 & 59 & & $\mathrm{pCi} / \mathrm{g}$ \\
\hline Mean Pilot Well 1 & TPH(Total) & & & & 11.26 & & & $\mathrm{mg} / \mathrm{kg}$ \\
\hline \multirow[t]{10}{*}{ Concentrations } & TPH(Diesel) & & & & $\angle D$ & & & $m g / k g$ \\
\hline & $\operatorname{TPH}(\mathrm{Oil})$ & & & & $11 \cdot 21$ & & & $\mathrm{mg} / \mathrm{kg}$ \\
\hline & Oil and Grease & & & & 2.6 & & & $\mathrm{mg} / \mathrm{kg}$ \\
\hline & $K+40$ & & & & 24.2 & 4.2 & & $\mathrm{pCi} / \mathrm{g}$ \\
\hline & Cs-137 & & & & 0.1 & 76.5 & & $\mathrm{pCi} / \mathrm{g}$ \\
\hline & Pat226 & & & & 0.8 & 10.5 & & $\mathrm{DC} / \mathrm{g}$ \\
\hline & Th.232 & & & & 1 & 11.9 & & $\mathrm{pCi} / \mathrm{g}$ \\
\hline & Th-228 & & & & 2 & 8.6 & & $D C i / 9$ \\
\hline & Pu-238 & & & & 0.001 & 795.0 & & $\mathrm{DCi} / \mathrm{g}$ \\
\hline & Pu.239,240 & & & & 0.022 & 204.2 & & $\mathrm{pC}: / \mathrm{g}$ \\
\hline
\end{tabular}


Appendix F.1.1 Surface Soil Sampling, Analysis, and Results (Continued)

Area 5 Pilot Well 2Ne5PW2

Undisturbed Sites/Random Surface Soil Samples

\begin{tabular}{|c|c|c|c|c|c|c|c|c|}
\hline Sample Identification & Parameter & Method & Collection Date & Analysis Date & Concentration & $\begin{array}{c}\text { \% Uncertainty } \\
(2.0 \mathrm{~s})\end{array}$ & $\begin{array}{c}\text { Detection } \\
\text { Limit }\end{array}$ & Units \\
\hline$N 770,395.89$ & TPH(Total) & 8015 & 28-Jan-92 & 30-Jan-92 & 21.2 & & 10 & $\mathrm{mg} / \mathrm{kg}$ \\
\hline \multirow{2}{*}{$E 709.831 .47$} & TPH(Diesel) & 8015 & 28-Jan-92 & 30- $\tan -92$ & $\angle D L$ & & 10 & $\mathrm{mg} / \mathrm{kg}$ \\
\hline & TPH(Oil) & 8015 & 28-Jan-92 & 30-Jan-92 & 21.2 & & 10 & $\mathrm{mg} / \mathrm{kg}$ \\
\hline \multirow{6}{*}{ (NE-409-20-90) } & Oil and Grease & 413.2 & 28.Jan-92 & $19 \cdot$ Mar-92 & $<D L$ & & 0.7 & $\mathrm{mg} / \mathrm{kg}$ \\
\hline & $K-40$ & 901.1 & 09.Jan-92 & $06-F e b-92$ & 25 & 20 & 1 & $D C i / 9$ \\
\hline & Cs-137 & 901.1 & $09-\operatorname{Jan}+92$ & 06-Feb-92 & 0.5 & 38 & 0.1 & $\mathrm{pCi} / \mathrm{g}$ \\
\hline & Ra.226 & 901.1 & $09-\operatorname{Jan} \cdot 92$ & 06-Feb-92 & 1 & 32 & 0.2 & $p c i / g$ \\
\hline & Th-232 & 901.1 & 09-Jan-92 & 06-Feb-92 & 2 & 34 & 0.4 & $p C i / g$ \\
\hline & Th-228 & 901.1 & $09-\operatorname{Jan}-92$ & 06-Feb-92 & 2 & 21 & 0.2 & $\mathrm{pCl} / \mathrm{g}$ \\
\hline$N 770,367.35$ & TPH(Total) & 8015 & 28-Jan-92 & $30-\mathrm{Jan} \cdot 92$ & 20 & & 10 & $\mathrm{mg} / \mathrm{kg}$ \\
\hline \multirow[t]{2}{*}{ E $709,887.90$} & TPH(Oiesel) & 8015 & 28-Jan-92 & $30-\operatorname{Jan}-92$ & $\angle D L$ & & 10 & $\mathrm{mg} / \mathrm{kg}$ \\
\hline & TPH(Oil) & 8015 & 28-Jan.92 & 30-Jan-92 & 20 & & 10 & $\mathrm{mg} / \mathrm{kg}$ \\
\hline \multirow[t]{6}{*}{ (NE. 167-70-20) } & Oil and Grease & 413.2 & 28-Jan-92 & 19-Mar-92 & $<D L$ & & 0.7 & $\mathrm{mg} / \mathrm{kg}$ \\
\hline & $K-40$ & 901.1 & $09-J a n-92$ & $06-$ Feb-92 & 25 & 20 & 1 & pCi/g \\
\hline & Cs. 137 & 901.1 & $09 \cdot \mathrm{Jan}-92$ & $06-F e b-92$ & 0.6 & 32 & 0.1 & $\rho C \mathrm{i} / 9$ \\
\hline & Ra-226 & 901.1 & $09-J a n-92$ & $06 \cdot F e b-92$ & 1 & 33 & 0.2 & $D C i / 9$ \\
\hline & Th.232 & 901.1 & $09 \cdot \operatorname{Jan} \cdot 92$ & $06 \cdot F e b-92$ & 2 & 36 & 0.4 & $\rho C i / g$ \\
\hline & Th-228 & 901.1 & $09 \cdot \operatorname{Jan}-92$ & 06-Feb-92 & 2 & 22 & 0.2 & $\mathrm{pCi} / \mathrm{g}$ \\
\hline$N 770,350.61$ & TPH(Total) & 8015 & 28-Jan-92 & $30-\operatorname{Jan}-92$ & 21.8 & & 10 & $\mathrm{mg} / \mathrm{kg}$ \\
\hline \multirow{2}{*}{ E $709,889.21$} & TPH(Diesel) & 8015 & 28-Jan-92 & $30-\operatorname{Jan}-92$ & $<D L$ & & 10 & $\mathrm{mg} / \mathrm{kg}$ \\
\hline & $\mathrm{TPH}$ (Oil) & 8015 & 28-Jan-92 & 30-Jan-92 & 21.8 & & 10 & $\mathrm{mg} / \mathrm{kg}$ \\
\hline \multirow{6}{*}{ (NE-16-30-10) } & Oil and Grease & 413.2 & 28-Jan-92 & $19-\operatorname{Mar}-82$ & 5.6 & & 0.7 & $\mathrm{mg} / \mathrm{kg}$ \\
\hline & K. 40 & $\infty 01.1$ & $09-J a n-92$ & $06-$ Feb-92 & 29 & 19 & 1 & $\mathrm{pCi} / \mathrm{g}$ \\
\hline & Cs-137 & 901.1 & $09-\operatorname{Jan}-92$ & $06 \cdot$ Feb 92 & 0.6 & 31 & 0.1 & $o \mathrm{Ci} / \mathrm{g}$ \\
\hline & Pla.226 & 901.1 & $09-\mathrm{Jan}-92$ & O6.Feb-92 & 1 & 30 & 0.2 & $p C i / g$ \\
\hline & Th-232 & 901.1 & $08-\operatorname{Jan}-92$ & $06-F e b-92$ & 2 & 37 & 0.4 & $\mathrm{pCi} / \mathrm{g}$ \\
\hline & Th-228 & 901.1 & $09-J a n-92$ & 06.Feb-92 & 2 & 21 & 0.2 & $\mathrm{pCi} / \mathrm{g}$ \\
\hline$N 770,413.93$ & TPH(Total) & 8015 & $28 \cdot \operatorname{Jan}-92$ & $30-\operatorname{Jan} \cdot 92$ & 22.2 & & 10 & $\mathrm{mg} / \mathrm{kg}$ \\
\hline \multirow{2}{*}{$E 709,857.39$} & TPH(Diesel) & 8015 & $28 \cdot \operatorname{Jan}-82$ & $30-\mathrm{Jan}-92$ & $<D$ & & 10 & $\mathrm{mg} / \mathrm{kg}$ \\
\hline & $\mathrm{TPH}(\mathrm{O}$ il) & 8015 & 28-Jan-92 & $30-J a n-92$ & 22.2 & & 10 & $\mathrm{mg} / \mathrm{kg}$ \\
\hline \multirow{6}{*}{ (NE.597-40-0) } & Oil and Grease & 413.2 & $28 \cdot \tan -92$ & 19-Mar-92 & $\angle D L$ & & 0.7 & $\mathrm{mg} / \mathrm{kg}$ \\
\hline & $K-40$ & 901.1 & $09 \cdot \operatorname{Jan}-92$ & $06-F e b-92$ & 25 & 20 & 1 & $\rho \mathrm{Ci} / \mathrm{g}$ \\
\hline & Cs.137 & 901.1 & $09 \cdot \operatorname{Jan}-92$ & $05 \cdot F e b-92$ & 0.9 & 27 & 0.1 & $p \mathrm{Ci} / \mathrm{g}$ \\
\hline & Ra-226 & 901.1 & $09-J a n-92$ & $06-$ Feb-92 & 0.9 & 37 & 0.2 & $\mathrm{pCi} / \mathrm{g}$ \\
\hline & Th-232 & 901.1 & $09-\operatorname{Jan}-82$ & $06-F e b-92$ & 2 & 39 & 0.4 & pCi/g \\
\hline & Th-228 & 801.1 & 09-Jan-92 & 06-Feb-92 & 2 & 23 & 0.2 & $\mathrm{pCi} / \mathrm{g}$ \\
\hline Pilot Well 2 Site & TPH(Total) & 8015 & $27 \cdot \mathrm{Jan}-02$ & $04-F e b-92$ & 4200 & & 10 & $\mathrm{mg} / \mathrm{kg}$ \\
\hline Soil Grab Sample & TPH(Diesel) & 8015 & 27-Jan-02 & $04-F e b-92$ & $<D L$ & & 10 & $\mathrm{mg} / \mathrm{kg}$ \\
\hline from & TPH(Oil) & 6015 & 27-Jan-02 & $04-F e b-92$ & 4200 & & 10 & $\mathrm{mg} / \mathrm{kg}$ \\
\hline Discarded Oil Fllters & Oil and Grease & 413.2 & 27-Jan-02 & 11-Feb-92 & 1435 & & 0.7 & $\mathrm{mg} / \mathrm{kg}$ \\
\hline \multirow{9}{*}{ Concentration } & TPH(Total) & & & & 21.3 & 7.8 & & $\mathrm{mg} / \mathrm{kg}$ \\
\hline & TPH(Diesel) & & & & $<D$ & & & $\mathrm{mg} / \mathrm{kg}$ \\
\hline & TPH(Oil) & & & & 21.3 & 7.8 & & $\mathrm{mg} / \mathrm{kg}$ \\
\hline & Oil and Grease & & & & $1.4 \cdot 1.9$ & & & $\mathrm{mg} / \mathrm{kg}$ \\
\hline & $K-40$ & & & & 26 & 13.3 & & $\mathrm{pCi} / \mathrm{g}$ \\
\hline & Cs-137 & & & & 0.7 & 46.2 & & $\mathrm{pCi} / \mathrm{g}$ \\
\hline & $\mathrm{Ra} \cdot 226$ & & & & 1.0 & 8.9 & & $\mathrm{pCl} / \mathrm{g}$ \\
\hline & Th.232 & & & & 2 & 0.0 & & $p C i / g$ \\
\hline & Th-228 & & & & 2 & 0.0 & & $\mathrm{pCi} / \mathrm{g}$ \\
\hline
\end{tabular}


Appendix F.1.1 Surface Soil Sampling, Analysis, and Results (Continued)

Area 5 Pilot Well 2JUe5PW2

Prepared Drill Site/Simple Random Surface Sample

\begin{tabular}{|c|c|c|c|c|c|c|c|c|}
\hline Sample Identification & Parameter & Method & Collection Date & Analysis Date & Concentration & $\begin{array}{c}\text { \% Uncertainty } \\
\text { (2s) }\end{array}$ & $\begin{array}{l}\text { Detection } \\
\text { Limit }\end{array}$ & Units \\
\hline$N 770,369.70$ & TPH(Total) & 8015 & 07-May-92 & 16-May-92 & $\angle D L$ & & 10 & $\mathrm{mg} / \mathrm{kg}$ \\
\hline \multirow[t]{2}{*}{ E $709,913.82$} & TPH(Diesel) & 8015 & 07-May-92 & 16-May-92 & $<\mathrm{DL}$ & & 10 & $\mathrm{mg} / \mathrm{kg}$ \\
\hline & TPH(Oil) & 8015 & 07-May-92 & 16-May-92 & $<\mathrm{OL}$ & & 10 & $\mathrm{mg} / \mathrm{kg}$ \\
\hline \multirow[t]{8}{*}{ (PW2-620-1080) } & Oll and Grease & 4132 & 07-May-92 & 27-May-92 & $<\mathrm{DL}$ & & 14 & $\mathrm{mg} / \mathrm{kg}$ \\
\hline & $K-40$ & 901.1 & $07 \cdot$ May-92 & 18-Jun-92 & 30.8 & 11.9 & 0.4 & $p C i / g$ \\
\hline & Cs-137 & 901,1 & 07-May-92 & 18-Jun-92 & $\angle O L$ & & & $p C_{1 / 9}$ \\
\hline & Ra.226 & 901.1 & 07-May-92 & 18-Jun-92 & 1 & 17 & 0.08 & $\mathrm{DCi} / 9$ \\
\hline & Th.232 & 901.1 & 07-May-92 & 18.Jun-92 & 2 & 20 & 0.1 & $\mathrm{pCi} / \mathrm{g}$ \\
\hline & Th-228 & 901.1 & 07-May-92 & 18-Jun-92 & 2 & 14 & 0.1 & $p C i / 9$ \\
\hline & $\mathrm{Pu}-238$ & AABAB.D.04 & 07-May-92 & 07-Jul-92 & 0.01 & 86 & 0.008 & $\mathrm{pCi} / \mathrm{g}$ \\
\hline & $\mathrm{Pu}-239.240$ & AABAB.0.04 & 07-May-92 & $07 \cdot J u 1-92$ & 0.002 & 106 & 0.003 & $p C i / g$ \\
\hline$N 770.354 .22$ & TPH(Total) & 8015 & 07-May-92 & 16-May- 82 & $\angle D L$ & & 10 & $\mathrm{mg} / \mathrm{kg}$ \\
\hline \multirow[t]{2}{*}{ E 709.94138} & TPH(Diesel) & 8015 & 07-May-92 & 16-May-92 & $<D$ & & 10 & $\mathrm{mg} / \mathrm{kg}$ \\
\hline & TPH(Oil) & 8015 & 07-May-92 & 16-May-92 & $<\mathrm{OL}$ & & 10 & $\mathrm{mg} / \mathrm{kg}$ \\
\hline \multirow[t]{8}{*}{$(P W 2-1460 \cdot 1280)$} & Oil and Grease & 413.2 & 07-May-92 & 27-May-92 & $<\mathrm{DL}$ & & 14 & $\mathrm{mg} / \mathrm{kg}$ \\
\hline & $K \cdot 40$ & 901.1 & $07-M a y \cdot 82$ & 18-Jun-92 & 28.7 & 12 & 03 & $\mathrm{pCl} / \mathrm{g}$ \\
\hline & Cs 137 & 901.1 & $07 \cdot M a y \cdot 92$ & 18-Jun-92 & 006 & 81 & 0.04 & $\mathrm{DCl} / \mathrm{g}$ \\
\hline & Ra-226 & 901.1 & 07-May-92 & 18-Jun-92 & 1 & 17 & 01 & $\mathrm{pCl} / \mathrm{g}$ \\
\hline & Th.232 & 901.1 & 07-May-92 & 18-Jun-92 & 2 & 21 & 0.2 & DCi/g \\
\hline & Th. 228 & 901.1 & 07-May-92 & 18-Jun-92 & 2 & 14 & 0.1 & $\mathrm{pCi} / 9$ \\
\hline & Pu.238 & AABAB 0.04 & $07 \cdot$ May-92 & 07-Jul-92 & -0.005 & 135 & 0.01 & $\rho \mathrm{Ci} / \mathrm{g}$ \\
\hline & Pu.239.240 & AABAB.D.04 & $07 \cdot$ May-92 & 07-Jul-92 & 0.002 & $\$ 52$ & 0.003 & $D C \mathrm{i} / \mathrm{g}$ \\
\hline$N 770,364.72$ & TPH(Total) & 8015 & $07-$ May-92 & 16-May-92 & $\angle \mathrm{DL}$ & & 10 & $\mathrm{mg} / \mathrm{kg}$ \\
\hline \multirow[t]{2}{*}{ E 709850.82} & TPH(Diesel) & 8015 & $07-$ May-92 & 16. May-92 & $<D L$ & & 10 & $\mathrm{mg} / \mathrm{kg}$ \\
\hline & TPH(OIl) & 8015 & $07-$ May-92 & 16-May-92 & $\angle O L$ & & 10 & $\mathrm{mg} / \mathrm{kg}$ \\
\hline \multirow[t]{8}{*}{$(P W 2 \cdot 1300-960)$} & OIl and Grease & 413.2 & 07-May-92 & $27 \cdot$ May-92 & 2 & & 07 & $\mathrm{mg} / \mathrm{kg}$ \\
\hline & $K \cdot 40$ & 901.1 & $07 \cdot$ May-92 & 18-Jun-92 & 26.6 & 12 & 0.4 & $\rho \mathrm{Ci} / \mathrm{g}$ \\
\hline & Cs.137 & 901.1 & 07-May-92 & 18-Jun-92 & $<\mathrm{OL}$ & & & $\mathrm{DCi} / \mathrm{g}$ \\
\hline & Ra-226 & 901.1 & 07-May-92 & 18-Jun-92 & $<D L$ & & & $\mathrm{pCi} / \mathrm{g}$ \\
\hline & Th.232 & 901.1 & 07-May-92 & 18-Jun-92 & 2 & 20 & 0.2 & $p C i / g$ \\
\hline & Th-228 & 901.1 & 07-May-92 & 18-Jun-92 & 2 & 15 & 0.1 & $\rho \mathrm{Ci} / \mathrm{g}$ \\
\hline & Pu-238 & AABAB 0.04 & 07.May-92 & $07-J u l-92$ & -0.004 & $14 !$ & 0.007 & $\mathrm{DCi} / \mathrm{g}$ \\
\hline & Pu.239,240 & AABAB. D. 04 & 07-May-92 & 07-Jul-92 & 0.004 & 81 & 0.003 & $\mathrm{pCi} / \mathrm{g}$ \\
\hline$N 770,432.31$ & TPH(Total) & 8015 & 07-May-92 & 16-May-92 & $\angle O L$ & & 10 & $\mathrm{mg} / \mathrm{kg}$ \\
\hline \multirow{2}{*}{ E 709.926.94 } & TPH(Diesel) & 8015 & 07-May-82 & 16-May-92 & $\angle D$ & & 10 & $\mathrm{mg} / \mathrm{kg}$ \\
\hline & TPH(Oil) & 8015 & 07-May-92 & 16-May-92 & $<\mathrm{DL}$ & & 10 & $\mathrm{mg} / \mathrm{kg}$ \\
\hline \multirow[t]{8}{*}{ (PW2-1020-1100) } & Oil and Grease & 413.2 & 07-May-92 & 27-May-92 & 2 & & 07 & $\mathrm{mg} / \mathrm{kg}$ \\
\hline & K. 40 & 801.1 & $07 \cdot M a y-82$ & 16-Jun-92 & 27.6 & 12 & 0.3 & $\rho \mathrm{Ci} / \mathrm{g}$ \\
\hline & Cs-137 & 801.1 & 07-May-82 & 18-Jun-92 & $<D$ & & & $\mathrm{pCi} / \mathrm{g}$ \\
\hline & $\mathrm{Ra} \cdot 226$ & 901.1 & 07-May-92 & 18-Jun-92 & 1 & 19 & 0.1 & $\rho C i / g$ \\
\hline & Th. 232 & 901.1 & $07 \cdot$ May -92 & 18-Jun-92 & 2 & 21 & 0.2 & $\mathrm{pCi} / g$ \\
\hline & Th. 228 & 901.1 & $07-$ May -92 & 18-Jun-92 & 2 & 15 & 0.1 & $\mathrm{DCl} / \mathrm{g}$ \\
\hline & Pu-238 & AABAB 0.04 & 07-May-92 & $07-J u l-92$ & 000 & 397 & 0.006 & $\mathrm{pCi} / \mathrm{g}$ \\
\hline & Pu-239,240 & AABAB.D 04 & 07-May.92 & 07-Jul-92 & 0.002 & 117 & 0.002 & $p \mathrm{Ci} / \mathrm{g}$ \\
\hline Mean Pilot Well 2 & TPH(Total) & & & & $\angle O L$ & & & $\mathrm{mg} / \mathrm{kg}$ \\
\hline \multirow[t]{10}{*}{ Concentrations } & TPH(Diesel) & & & & $\angle D L$ & & & $\mathrm{mg} / \mathrm{kg}$ \\
\hline & TPH(Oil) & & & & $\angle D L$ & & & $\mathrm{mg} / \mathrm{kg}$ \\
\hline & Orl and Grease & & & & 15 & & & $\mathrm{mg} / \mathrm{kg}$ \\
\hline & $K-40$ & & & & 28 & 42 & & $\mathrm{DCi} / 9$ \\
\hline & Cs-137 & & & & $0.01 \cdot 0.06$ & & & $\rho \mathrm{Ci} / \mathrm{g}$ \\
\hline & Ra-226 & & & & 0.3 & & & $p C i / 9$ \\
\hline & $T h-232$ & & & & 2.0 & 22 & & $\mathrm{pCi} / \mathrm{g}$ \\
\hline & $T h \cdot 228$ & & & & 2.0 & 0 & & $p \mathrm{Ci} / \mathrm{g}$ \\
\hline & Pu.238 & & & & 0.001 & 1187 & & $\mathrm{pCi} / \mathrm{g}$ \\
\hline & Pu-239.240 & & & & 0.003 & 137 & & $\mathrm{pCi} / \mathrm{g}$ \\
\hline
\end{tabular}


Appendix F.1.1 Surface Soil Sampling, Analysis, and Results (Continued)

Area 5 Pilot Well 3/Ue5PW3

Undisturbed Sites/Random Surtace Soll Samples

\begin{tabular}{|c|c|c|c|c|c|c|c|c|}
\hline Sample Identification & Parameter & Methoo & Collection Date & Analysis Date & Concentration & $\begin{array}{c}\text { \% Uncertainty } \\
(2.05)\end{array}$ & $\begin{array}{c}\text { Detection } \\
\text { Limit }\end{array}$ & Units \\
\hline N767194.61 & TPH(Total) & 8015 & $28 \cdot \operatorname{Jan}-92$ & $30-\operatorname{Jan}-92$ & 15.7 & & 10 & $\mathrm{mg} / \mathrm{kg}$ \\
\hline \multirow[t]{2}{*}{ E707032.88 } & ТРн(Diesel) & 8015 & $28 \cdot \operatorname{Jan} \cdot 92$ & 30-Jan-92 & $\angle D L$ & & 10 & $\mathrm{mg} / \mathrm{kg}$ \\
\hline & IPH(Oil) & 8015 & 28- $\tan -82$ & 30-Jan-92 & 15.7 & & 10 & $\mathrm{mg} / \mathrm{kg}$ \\
\hline \multirow[t]{6}{*}{ (NW-10-20-30) } & Oil and Grease & 413.2 & 28-Jan-92 & 19-Mar-92 & 3.4 & & 0.7 & $\mathrm{mg} / \mathrm{kg}$ \\
\hline & $K \cdot 40$ & 901.1 & $09 \cdot \operatorname{Jan}-92$ & $06 \cdot F e b-92$ & 25 & 21 & 2 & $\mathrm{pCt} / \mathrm{g}$ \\
\hline & Cs. 137 & 901.1 & $09 \cdot \operatorname{Jan} \cdot 92$ & $06-F e b-92$ & 0.6 & 33 & 0.1 & $p \mathrm{Ci} / \mathrm{g}$ \\
\hline & $\mathrm{Ra}-226$ & 901.1 & 09-Jan-92 & O6-Feb-92 & 0.8 & 39 & 0.2 & $\mathrm{pCi} / \mathrm{g}$ \\
\hline & Th.232 & 901.1 & 09.Jan-92 & $06-F e b-92$ & 2 & 34 & 0.4 & $\rho \mathrm{ci} / \mathrm{g}$ \\
\hline & Th. 228 & 901.1 & 09-Jan-92 & $06-F e b-92$ & 2 & 22 & 0.2 & $p C_{i} / g$ \\
\hline N767247.10 & TPH(Total) & 8015 & 28-Jan-92 & $30-$ Jan-92 & 21.5 & & 10 & $\mathrm{mg} / \mathrm{kg}$ \\
\hline \multirow[t]{2}{*}{ E707051.89 } & TPH(Diesel) & 8015 & $28 \cdot \operatorname{Jan} \cdot 92$ & $30 \cdot \operatorname{Jan} \cdot 92$ & $<D L$ & & 10 & $\mathrm{mg} / \mathrm{kg}$ \\
\hline & TPH(Oil) & 8015 & 28-Jan-92 & 30-Jan-92 & 21.5 & & 10 & $\mathrm{mg} / \mathrm{kg}$ \\
\hline \multirow[t]{6}{*}{$(N W \cdot 125-60-90)$} & Oil and Grease & 413.2 & 28-Jan-92 & 19-Mar-92 & $<\mathrm{DL}$ & & 07 & $\mathrm{mg} / \mathrm{kg}$ \\
\hline & $K \cdot 40$ & 801.1 & $09-\mathrm{Jan}-92$ & O6-Feb-92 & 30 & 19 & 1 & $p C i / g$ \\
\hline & Cs-137 & 901.1 & $09 \cdot$ Jan-92 & $06-F e b-92$ & 0.3 & 45 & 01 & $p C i / g$ \\
\hline & Ra-226 & 901.1 & $09 \cdot \operatorname{Jan} \cdot 92$ & $06 \cdot$ Feb-92 & 1 & 31 & 02 & $D C i / g$ \\
\hline & Th. 232 & 901.1 & $09 \cdot \operatorname{Jan}-92$ & $06 \cdot F e b-92$ & 2 & 35 & 0.5 & $D C / / g$ \\
\hline & Th.228 & 901.1 & 09-Jan-92 & 06-Feb-92 & 3 & 20 & 0.2 & pCirg \\
\hline N767155.89 & TPH(Total) & 8015 & $28-\operatorname{Jan}-92$ & 30-Jan-92 & 20.6 & & 10 & $\mathrm{mg} / \mathrm{kg}$ \\
\hline \multirow[t]{2}{*}{$E 706970.85$} & TPH(Diesel) & 8015 & 28-Jan-92 & $30-\operatorname{Jan}-92$ & $<\mathrm{DL}$ & & 10 & $\mathrm{mg} / \mathrm{kg}$ \\
\hline & TPH(Oil) & 8015 & 28-Jan-92 & 30-Jan-92 & 20.6 & & 10 & $\mathrm{mg} / \mathrm{kg}$ \\
\hline \multirow[t]{6}{*}{$(N W-300-20-20)$} & Oil and Grease & 413.2 & $26-J \operatorname{an}-92$ & 19-Mar-92 & $<\mathrm{DL}$ & & 0.7 & $\mathrm{mg} / \mathrm{kg}$ \\
\hline & $k \cdot 40$ & 901.1 & 09-Jan-92 & $06-F e b-92$ & 31 & 18 & 1 & $\mathrm{pCl} / \mathrm{g}$ \\
\hline & Cs.137 & 901.1 & $09 \cdot$ Jan-92 & $06 \cdot \mathrm{Feb}-92$ & 0.5 & 41 & 0.1 & pCirg \\
\hline & Ra.226 & 901.1 & $09 \cdot \mathrm{Jan}-92$ & $06-$ Feb-92 & 1 & 31 & 0.2 & $\mathrm{oCi} / \mathrm{g}$ \\
\hline & Th.232 & 901.1 & 09-Jan-92 & $06 \cdot F$ eb. 92 & 2 & 32 & 0.4 & $\mathrm{pCi} / \mathrm{g}$ \\
\hline & Th. 228 & 901.1 & 09-Jan-92 & $06 \cdot \mathrm{Feb} \cdot 92$ & 3 & 19 & 0.2 & $\mathrm{pCl} / \mathrm{g}$ \\
\hline N767173.61 & TPH(Total) & 8015 & $28-J a n-92$ & $30-\mathrm{Jan} \cdot 92$ & $\angle O L$ & & 20 & $\mathrm{mg} / \mathrm{kg}$ \\
\hline \multirow[t]{2}{*}{ E707052.21 } & TPH(Diesel) & 8015 & $28 \cdot J a n \cdot 92$ & 30-Jan-92 & $<\mathrm{DL}$ & & 10 & $\mathrm{mg} / \mathrm{kg}$ \\
\hline & $\mathrm{TPH}(\mathrm{O} i)$ & 8015 & $28-J a n-92$ & 30-Jan-92 & $<D L$ & & 10 & $\mathrm{mg} / \mathrm{kg}$ \\
\hline \multirow[t]{6}{*}{$(N W-545-40-30)$} & Oil and Grease & 413.2 & 28-Jan-92 & 19-Mar-92 & $<O$ & & 0.7 & $\mathrm{mg} / \mathrm{kg}$ \\
\hline & $K \cdot 40$ & 901.1 & $09-\operatorname{Jan}-92$ & $06 \cdot$ Feb-92 & 32 & 18 & 1 & $\mathrm{pCi} / \mathrm{g}$ \\
\hline & Cs.137 & 901.1 & $09 \cdot \operatorname{Jan}-92$ & 06-Feb-92 & 0.5 & 38 & 0.5 & $\infty \mathrm{Citg}$ \\
\hline & Ra.226 & 901.1 & $09-J a n-92$ & 06-Feb-92 & 1 & 31 & 0.2 & $\mathrm{pCi} / \mathrm{g}$ \\
\hline & Th.232 & 901.1 & $09 \cdot \operatorname{Jan}-92$ & $a 6 \cdot F e b-92$ & 3 & 26 & 0.04 & $\mathrm{pCi} / \mathrm{g}$ \\
\hline & Th-228 & 901.1 & 09-Jan-92 & 06-Feb-92 & 3 & 19 & 0.2 & $\mathrm{DCi} / \mathrm{g}$ \\
\hline Mean Pilot Well 3 & TPH(Total) & & & & 16.7 & & & $\mathrm{mg} / \mathrm{kg}$ \\
\hline \multirow[t]{8}{*}{ Concentrations } & TPH(Diesel) & & & & $\angle D$ & & & $\mathrm{mg} / \mathrm{kg}$ \\
\hline & TPH(OIl) & & & & 13.6 & & & $\mathrm{mg} / \mathrm{kg}$ \\
\hline & Oil and Grease & & & & $0.8-1.4$ & & & $\mathrm{mg} / \mathrm{kg}$ \\
\hline & $K \cdot 40$ & & & & 30 & 18 & & $\mathrm{pCi} / 9$ \\
\hline & Cs. 137 & & & & 0.5 & 46 & & $\mathrm{DCi} / \mathrm{g}$ \\
\hline & Ra.226 & & & & 1.0 & 18 & & $\mathrm{pCi} / \mathrm{g}$ \\
\hline & Th-232 & & & & 2 & 38 & & $\mathrm{pCi} / \mathrm{g}$ \\
\hline & $T h .228$ & & & & 3 & 31 & & $\mathrm{pCi} / 9$ \\
\hline
\end{tabular}


Appendix F.1.1 Surface Soil Sampling, Analysis, and Results (Continued)

Area 5 Pilot Well 3/Ue5PW3

Prepared Drill Site/Simple Random Surface Sample

\begin{tabular}{|c|c|c|c|c|c|c|c|c|}
\hline Sample identification & Parameter & Method & Collection Date & Analysis Date & Concentration & $\begin{array}{l}\text { \% Uncertainty } \\
\text { (2s) }\end{array}$ & $\begin{array}{l}\text { Detection } \\
\text { Limit } \\
\end{array}$ & Units \\
\hline N767195.14 & TPH(Total) & 8015 & Q8.Sep-92 & 17-Sep-92 & $<\mathrm{OL}$ & & 10 & $\mathrm{mg} / \mathrm{kg}$ \\
\hline \multirow[t]{2}{*}{ E707011.82 } & TPH(Diesel) & 8015 & 08-Sep-92 & $17 \cdot$ Sep-92 & $<D L$ & & 10 & $\mathrm{mg} / \mathrm{kg}$ \\
\hline & TPH(Oil) & 8015 & 08-Sep-92 & $17 \cdot \operatorname{Sep}-92$ & $<D L$ & & 10 & $\mathrm{mg} / \mathrm{kg}$ \\
\hline \multirow[t]{8}{*}{ (PW3-168-22) } & Oil and Grease & 413.2 & $08-\operatorname{Sep}-92$ & $01.0 x t-92$ & 2.7 & & 1.4 & $\mathrm{mg} / \mathrm{kg}$ \\
\hline & $k \cdot 40$ & 901,1 & $08-\operatorname{Sep}-92$ & $09-S e p-92$ & 15 & 24 & & $\rho C i / g$ \\
\hline & Cs.137 & 901.1 & $08-$ Sep-92 & $09-S e p-92$ & $<D L$ & & & DCi/g \\
\hline & $\operatorname{Ra}-226$ & $\infty 01.1$ & $08-\operatorname{Sep}-92$ & $09-\operatorname{Sep}-92$ & 0.9 & 32 & & $\mathrm{pCi} / \mathrm{g}$ \\
\hline & Th.232 & 901.1 & $08-\operatorname{Sep}-92$ & $09-\operatorname{Sep}-92$ & 1 & 41 & & $\mathrm{pCi} / \mathrm{g}$ \\
\hline & Th.228 & 901.1 & $08-\operatorname{Sep}-92$ & $09-\operatorname{Sep}-92$ & 1 & 27 & & $\mathrm{DCi} / \mathrm{g}$ \\
\hline & Pu-238 & AABAB.D.04 & $08 . \operatorname{Sep}-92$ & $29-\operatorname{Sep}-82$ & 0.0005 & 116 & & pCi/g \\
\hline & $\mathrm{Pu} \cdot 239,240$ & AABAB.D.04 & 08-Sep-82 & 29-Sep-92 & 0.009 & 29 & & $\mathrm{pCi} / \mathrm{g}$ \\
\hline$N 767247.64$ & TPH(Total) & 8015 & C8-Sep-82 & $17-\operatorname{sep}-92$ & $<\mathrm{Dl}$ & & 10 & $\mathrm{mg} / \mathrm{kg}$ \\
\hline \multirow[t]{2}{*}{$E 707006.31$} & TPH(Diesel) & 8015 & $08 \cdot \operatorname{Sep}-92$ & $17 \cdot \operatorname{Sep}-92$ & $<D L$ & & 10 & $\mathrm{mg} / \mathrm{kg}$ \\
\hline & TPH(OII) & 6015 & $08-\operatorname{sep}-92$ & $17 . \operatorname{Sep} \cdot 92$ & $<D L$ & & 10 & $\mathrm{mg} / \mathrm{kg}$ \\
\hline \multirow[t]{8}{*}{$(P W 3.0 .138)$} & Oil and Grease & 413.2 & $08-\operatorname{Sep}-92$ & $01-0 \times 1-92$ & $<D$ & & 14 & $\mathrm{mg} / \mathrm{kg}$ \\
\hline & $K \cdot 40$ & 9011 & Do-Sep.92 & $09-\operatorname{Sep}-92$ & 32 & 18 & & $\mathrm{DCi} / 9$ \\
\hline & Cs-137 & 901.1 & $08 \cdot \operatorname{Sep} \cdot 92$ & $09 \cdot \operatorname{Sep} \cdot 92$ & $<\mathrm{OL}$ & & & $\mathrm{pCi} / \mathrm{g}$ \\
\hline & Pa-226 & 901.1 & $08 \cdot \operatorname{Sep}-92$ & 09-Sep-92 & 2 & 29 & & $\mathrm{pCl} / \mathrm{g}$ \\
\hline & Th-232 & 901.1 & 0.Sep-92 & $09-\operatorname{Sep}-92$ & 3 & 27 & & $\mathrm{pCi} / \mathrm{g}$ \\
\hline & Th-228 & 901.1 & 08-Sep-92 & $09-\operatorname{Sep}-92$ & 3 & 19 & & $\mathrm{pCi} / \mathrm{g}$ \\
\hline & Pu-238 & AABAB.D.04 & $08-\operatorname{Sep}-92$ & 29-Sep.92 & 0.0007 & 201 & & $D C i / 9$ \\
\hline & $P_{u-239,240}$ & AABAB.0.04 & 08-Sep-92 & 29-Sep-92 & 0.08 & 26 & & $p C i / 9$ \\
\hline N767156.43 & TPH(Total) & 8015 & $08-\operatorname{Sep}-92$ & $17 \cdot \operatorname{Sep}-92$ & $\angle O L$ & & 10 & $\mathrm{mg} / \mathrm{kg}$ \\
\hline \multirow[t]{2}{*}{$E 707048.96$} & TPH(Diesel) & 8015 & os.Sep.92 & $17-\operatorname{Sep}-92$ & $\angle D L$ & & 10 & $\mathrm{mg} / \mathrm{kg}$ \\
\hline & TPH(OIl) & 8015 & $08-\operatorname{Sep}-92$ & 17. Sep-92 & $<D L$ & & 10 & $\mathrm{mg} / \mathrm{kg}$ \\
\hline \multirow[t]{8}{*}{ (PW3-13-14) } & Oil and Grease & 413.2 & 08-Sep-92 & 01. Oct -92 & $<\mathrm{OL}$ & & 1.4 & $\mathrm{mg} / \mathrm{kg}$ \\
\hline & $k \cdot 40$ & 901.1 & 08-Sep-92 & $09-$ Sep-92 & 18 & 22 & & DCi/g \\
\hline & Cs- 137 & 901.1 & $08-S e p-92$ & $09 \cdot$ Sep-92 & $<D L$ & & & $\mathrm{pCi} / \mathrm{g}$ \\
\hline & $\mathrm{Ra} \cdot 226$ & 901,1 & $08-$ Sep-92 & $09-\operatorname{Sep}-92$ & 1 & 28 & & $p C i / g$ \\
\hline & Th.232 & 901.1 & 08-Sep-92 & 09-Sep.92 & 1 & 34 & & $\mathrm{pCi} / \mathrm{g}$ \\
\hline & Th-228 & 901.1 & 08-Sep-92 & $09-$ Sep-92 & 1 & 20 & & $p C i / g$ \\
\hline & Pu.238 & AABAB.D.04 & $08-\operatorname{Sep}-92$ & 29-Sep-92 & 0.0004 & 142 & & $\mathrm{DCi} / \mathrm{g}$ \\
\hline & Pu.239.240 & AABAB 0.04 & $08.5 e p .92$ & 29-Sep-92 & 0.02 & 24. & & $D C i / g$ \\
\hline N767174.14 & TPH(Total) & 8015 & $08 \cdot \operatorname{Sep}-92$ & $17-\operatorname{sep}-92$ & $\angle D L$ & & 10 & $\mathrm{mg} / \mathrm{kg}$ \\
\hline \multirow[t]{2}{*}{$E 706980.39$} & TPH(Diesel) & 8015 & $08 \cdot \operatorname{Sep} \cdot 92$ & 17-Sep-92 & $<\mathrm{QL}$ & & 10 & $\mathrm{mg} / \mathrm{kg}$ \\
\hline & TPH(Oil) & 8015 & $08-\operatorname{Sep}-92$ & $17-\operatorname{Sep}-92$ & $<D L$ & & 10 & $\mathrm{mg} / \mathrm{kg}$ \\
\hline \multirow[t]{8}{*}{ (PW3-79-86) } & Oil and Grease & 4132 & 08-Sep-82 & $01-0 \mathrm{ct}-92$ & $<\mathrm{DL}$ & & 1.4 & $\mathrm{mg} / \mathrm{kg}$ \\
\hline & $K-40$ & 901.1 & 08-Sep-92 & $09 \cdot \operatorname{Sep}-92$ & 30 & 18 & & $\mathrm{pCi} / 9$ \\
\hline & $C_{5-137}$ & 901.1 & $08-\operatorname{Sep}-92$ & $09-\operatorname{Sep} \cdot 92$ & $<\mathrm{DL}$ & & & $\rho C i / g$ \\
\hline & Ra-226 & 901.1 & $08-\operatorname{Sep}-92$ & 09-Sep-92 & 1 & 28 & & $\mathrm{pCi} / \mathrm{g}$ \\
\hline & Th.232 & 901.1 & Os.Sep.92 & 09-Sep-92 & 2 & 34 & & $\mathrm{DCi} / \mathrm{g}$ \\
\hline & Th.228 & 901.1 & 08-Sep-92 & $09-\operatorname{Sep}-92$ & 3 & 20 & & $\mathrm{pCi} / \mathrm{g}$ \\
\hline & Pu-238 & AABAB. 0.04 & 08-Sep-82 & $29-\operatorname{Sep} \cdot 92$ & 0.0004 & 142 & & $p \mathrm{Ci} / \mathrm{g}$ \\
\hline & Pu-239,240 & AABAB.D.04 & O8-Sep-92 & 29-Sep-92 & 0.02 & 24 & & $\mathrm{pCi} / \mathrm{g}$ \\
\hline Mean Pilol Well 3 & TPH(Total) & & & & $\angle D$ & & & $\mathrm{mg} / \mathrm{kg}$ \\
\hline \multirow{10}{*}{ Concentrations } & TPH(Diesel) & & & & $<\mathrm{OL}$ & & & $\mathrm{mg} / \mathrm{kg}$ \\
\hline & TPH(Oil) & & & & $<D L$ & & & $\mathrm{mg} / \mathrm{kg}$ \\
\hline & Oil and Grease & & & & $0.7 \cdot 1.7$ & & & $\mathrm{mg} / \mathrm{kg}$ \\
\hline & $K-40$ & & & & 24 & 54 & & $p \mathrm{Ci} / \mathrm{g}$ \\
\hline & Cs- 137 & & & & $<D L$ & & & $\mathrm{pCi} / \mathrm{g}$ \\
\hline & Ra.226 & & & & 1 & 58 & & pCilg \\
\hline & $T h-232$ & & & & 2 & 40 & & $\mathrm{pCi} / \mathrm{g}$ \\
\hline & Th-228 & & & & 2 & 43 & & $\mathrm{pCi} / \mathrm{g}$ \\
\hline & Pu-238 & & & & 0.001 & 24 & & $\mathrm{DCi} / \mathrm{g}$ \\
\hline & Pu-239.240 & & & & 0.032 & 92 & & $\mathrm{pCi} / \mathrm{g}$ \\
\hline
\end{tabular}


Appendix F.1.2 Near Surface Radon and Tritium Gas Sampling, Analysis, and Results

\section{Radon Soil Gas Surveys}

Gas samples were obtained by connecting the appropriate sample line through a 0.8 micron filter to a $175 \mathrm{~cm}^{3}$ Lucas cell. The Lucas cell and sample lines were purged by pumping at least 10 exchange volumes at a 3 liter per minute rate. The Lucas cell was then sealed. The samples were then allowed to decay for approximately 4 hours and counted by a photomultiplier for 10 to 30 minutes in order to obtain a minimum of 1000 counts. Specific Lucas cells were assigned to each sample depth so that the same cell would be used for each specific depth at any particular location, as well as for repeat measurements.

The radon counting system used was an RDA-200 manufactured by EDA Instruments in Toronto, Canada. Calibration of the Lucas cells was performed at the Environmental Protection Agency's Radon Calibration Facility in Las Vegas, Nevada on April 22, 1992. Cell calibration factors and assignments are detailed in Table 1. Sampling, operation, calibration, and calculation procedures followed are found in the EDA-200 Operators Manual and REECO Standard Operating Procedures Manual - Radon Sampling Procedures, 3/11/91, AADzA.D.06.00. Radon-222 activity levels in the soils at the three Pilot Well sites is summarized in Tables 2, Table 3, and Table 4 in the following.

Table 1. Lucas Cell Assignments

\begin{tabular}{|c|c|c|c||}
\hline Cell number & $\begin{array}{c}\text { Cell Volume } \\
(\mathrm{L})\end{array}$ & $\begin{array}{c}\text { Depth } \\
\text { (ft) }\end{array}$ & $\begin{array}{c}\text { Calibration } \\
\text { CPM/pCi }\end{array}$ \\
\hline 2 & 0.170 & 3 & 3.00 \\
\hline 5 & 0.170 & 9 & 3.30 \\
\hline 3 & 0.170 & 21 & 3.53 \\
\hline
\end{tabular}


Appendix F.1.2 Near Surface Radon and Tritium Gas Sampling, Analysis, and Results (Continued)

Table 2. Pilot Well Ue5PW-1 Radon-222 Soil Gas Survey Data

\begin{tabular}{|c|c|c|c|c|c|c|c||}
\hline \hline Date & Counts & \multirow{2}{*}{$\begin{array}{c}\text { Count } \\
\text { time } \\
\end{array}$} & & \multirow{2}{*}{$\begin{array}{c}\text { Count } \\
\text { time } \\
\text { delay } \\
\end{array}$} & & \multirow{2}{*}{$\begin{array}{c}\text { Decay } \\
\text { correction }\end{array}$} & \multicolumn{3}{|c||}{$\begin{array}{c}\text { Concentration } \\
\text { pCi/L }\end{array}$} \\
\cline { 7 - 9 } & & & & $3 \mathrm{ft}$ & $9 \mathrm{ft}$ & $21 \mathrm{ft}$ \\
\hline $10 / 17 / 91$ & 1162 & 10 & 4.00 & .9702 & 232 & & \\
\hline & 4377 & 30 & 6.05 & .9554 & & 270 & \\
\hline & 4463 & 30 & 5.10 & .9622 & & & 255 \\
\hline $10 / 23 / 91$ & 1867 & 30 & 3.33 & .9752 & 122 & & \\
\hline & 4019 & 30 & 3.78 & .9719 & & 243 & \\
\hline & 4573 & 30 & 5.63 & .9584 & & & 263 \\
\hline $10 / 30 / 91$ & 211 & 10 & 6.73 & .9504 & 44 & & \\
\hline & 940 & 10 & 6.93 & .9490 & & 177 & \\
\hline & 1262 & 10 & 7.06 & .9481 & & & 222 \\
\hline
\end{tabular}


Appendix F.1.2 Near Surface Radon and Tritium Gas Sampling, Analysis, and Results (Continued)

Table 3 Pilot Well Ue5PW-2 Radon-222 Soil Gas Survey Data

\begin{tabular}{|c|c|c|c|c|c|c|c|}
\hline \multirow[t]{2}{*}{ Date } & \multirow[t]{2}{*}{ Counts } & \multirow{2}{*}{$\begin{array}{c}\text { Count } \\
\text { time } \\
\text { (min) }\end{array}$} & \multirow{2}{*}{$\begin{array}{c}\text { Count } \\
\text { time } \\
\text { delay } \\
\text { (hr) }\end{array}$} & \multirow[t]{2}{*}{$\begin{array}{l}\text { Decay } \\
\text { correction }\end{array}$} & \multicolumn{3}{|c|}{$\begin{array}{c}\text { Concentration } \\
\mathrm{pCi} / \mathrm{L} \\
\end{array}$} \\
\hline & & & & & $3 \mathrm{ft}$ & $9 \mathrm{ft}$ & $17 \mathrm{ft}$ \\
\hline \multirow[t]{3}{*}{$1 / 23 / 92$} & 967 & 10 & 3.58 & 0.9733 & 192 & & \\
\hline & 2260 & 10 & 2.47 & 0.9815 & & 385 & \\
\hline & 2172 & 10 & 2.02 & 0.9849 & & & 366 \\
\hline \multirow[t]{3}{*}{$1 / 28 / 92$} & 1217 & 10 & 4.70 & 0.9651 & 245 & & \\
\hline & 2068 & 10 & 5.05 & 0.9626 & & 380 & \\
\hline & 2132 & 10 & 5.53 & 0.9591 & & & 369 \\
\hline \multirow[t]{3}{*}{$2 / 4 / 92$} & 750 & 10 & 4.37 & 0.9675 & 147 & & \\
\hline & 985 & 10 & 4.67 & 0.9654 & & 179 & \\
\hline & 1266 & 10 & 4.95 & 0.9633 & & & 217 \\
\hline \multirow[t]{3}{*}{$2 / 5 / 92$} & 656 & 10 & 5.57 & 0.9588 & 132 & & \\
\hline & 1127 & 10 & 5.28 & 0.9609 & & 207 & \\
\hline & 1164 & 10 & 5.68 & 0.9580 & & & 201 \\
\hline \multirow[t]{3}{*}{$2 / 19 / 92$} & 675 & 10 & 4.48 & 0.9667 & 135 & & \\
\hline & 1041 & 10 & 4.93 & 0.9635 & & 190 & \\
\hline & 1261 & 10 & 5.27 & 0.9610 & & & 217 \\
\hline
\end{tabular}


Appendix F.1.2 Near Surface Radon and Tritium Gas Sampling, Analysis, and Results (Continued)

Table 4 Pilot Well Ue5PW-3 Radon-222 Soil Gas Survey Data

\begin{tabular}{|c|c|c|c|c|c|c|c|}
\hline \multirow[t]{2}{*}{ Date } & \multirow[t]{2}{*}{ Counts } & \multirow{2}{*}{$\begin{array}{l}\text { Count } \\
\text { time } \\
(\min )\end{array}$} & \multirow{2}{*}{$\begin{array}{c}\text { Count } \\
\text { time } \\
\text { delay } \\
\text { (hr) }\end{array}$} & \multirow[t]{2}{*}{$\begin{array}{l}\text { Decay } \\
\text { correction }\end{array}$} & \multicolumn{3}{|c|}{$\begin{array}{c}\text { Concentration } \\
\mathrm{pCi} / \mathrm{L}\end{array}$} \\
\hline & & & & & $3 \mathrm{ft}$ & $9 \mathrm{ft}$ & $21 \mathrm{ft}$ \\
\hline \multirow[t]{3}{*}{$7 / 28 / 92$} & 1966 & 10 & 7.68 & 0.9501 & 403 & & \\
\hline & 4520 & 10 & 6.17 & 0.9545 & & 842 & \\
\hline & 6044 & 10 & 5.41 & 0.9600 & & & 1047 \\
\hline \multirow[t]{3}{*}{$7 / 29 / 92$} & 2316 & 10 & 8.65 & 0.9368 & 482 & & \\
\hline & 4261 & 10 & 8.43 & 0.9383 & & 807 & \\
\hline & 5112 & 10 & 7.40 & 0.9457 & & & 899 \\
\hline \multirow[t]{3}{*}{$7 / 30 / 92$} & 7048 & 30 & 6.56 & 0.9517 & 482 & & \\
\hline & 14431 & 30 & 6.15 & 0.9546 & & 897 & \\
\hline & 15913 & 30 & 6.97 & 0.9488 & & & 930 \\
\hline \multirow[t]{3}{*}{$8 / 3 / 92$} & 2259 & 10 & 4.28 & 0.9682 & 455 & & \\
\hline & 4837 & 10 & 4.50 & 0.9666 & & 889 & \\
\hline & 4927 & 10 & 5.16 & 0.9618 & & & 852 \\
\hline \multirow[t]{3}{*}{$8 / 4 / 92$} & 2558 & 10 & 6.18 & 0.9544 & 523 & & \\
\hline & 5067 & 10 & 6.42 & 0.9527 & & 946 & \\
\hline & 4950 & 10 & 6.80 & 0.9500 & & & 867 \\
\hline \multirow[t]{3}{*}{$8 / 11 / 92$} & 6328 & 30 & 6.35 & 0.9532 & 431 & & \\
\hline & 13309 & 30 & 6.83 & 0.9497 & & 830 & \\
\hline & 14016 & 30 & 7.76 & 0.9431 & & & 824 \\
\hline
\end{tabular}


Appendix F.1.2 Near Surface Radon and Tritium Gas Sampling, Analysis, and Results (Continued)

\section{Tritium Soil Gas Surveys}

Soil gas samples of water vapor were obtained from each of the pilot well locations for screening purposes to insure that drill sites were free of elevated levels of tritium that could cause health and saftey and/or environmental problems. Possible sources of tritium could be expected to occur from world-wide fallout and local fallout of pre-1963 above ground nuclear weapons testing as well as from waste disposal operations.

The soil gas samples were obtained by driving a soil gas probe to selected depths and extracting a sufficient volume of pore gas (water vapor) through two series connected cold traps to condense and extract approximately $5 \mathrm{ml}$ of liquid sample. The cold traps were inserted into a dewar flask containing dry ice and alcohol which condensed and extracted the water vapor. Flow rates were set at approximately 3 liters per minute so that all of the moisture was condensed within the first trap. The second trap was used to provide an indication of break-through from the first trap if flow rates were set too high. In all cases the first cold trap was sufficient to extract all the water vapor.

Tritium was analyzed as tritium oxide using REECO Analytical Service's low background liquid scintillation counter. This system is capable of detection limits near environmental levels without using enrichment techniques. Count times of 300 minutes were used with the minimum detectable amount ranging between 0.16 to $0.48 \mathrm{pCi} / \mathrm{ml}$. Sampling methodologies and counting procedures are found in REECO Special Projects Section Standard Operating Procedures Manual - Measurement of Tritium Oxide in Soil Pore Gas, 8/13/91, AADzD.T.07.00. Tables 5,6, and 7 detail the results of the tritium soil gas survey for Pilot Wells sites Ue5PW-1, Ue5PW-2 and Ue5Pw-3, respectively. 
Appendix F.1.2 Near Surface Radon and Tritium Gas Sampling, Analysis, and Results (Continued)

Table 5 Pilot Well Ue5PW-1 Tritium Oxide Soil Gas Survey Data

\begin{tabular}{|c|c|c|c|c|c|}
\hline \multirow[t]{2}{*}{ Sample ID / Lab ID } & \multirow[t]{2}{*}{$\begin{array}{c}\text { Sample } \\
\text { Date }\end{array}$} & \multirow{2}{*}{$\begin{array}{c}\text { Minimum } \\
\text { Detectable } \\
\text { Amount } \\
\text { pCi } / \mathrm{ml}\end{array}$} & \multicolumn{3}{|c|}{$\begin{array}{l}\text { Sample Activity } \\
\text { pCi } / \mathrm{ml}\end{array}$} \\
\hline & & & $3 \mathrm{ft}$ & $9 \mathrm{ft}$ & $21 \mathrm{ft}$ \\
\hline T7SE 3FT / 77502 & $10 / 24 / 91$ & 0.353 & 0.500 & & \\
\hline T6SE 9FT / 77501 & $10 / 24 / 91$ & 0.353 & & $(0.042)$ & \\
\hline T3SE 21FT / 77500 & $10 / 24 / 91$ & 0.353 & & & $(0.152)$ \\
\hline T7SE 3FT / 77513 & $10 / 24 / 91$ & 0.196 & 0.419 & & \\
\hline T6SE 9FT / 77512 & $10 / 24 / 91$ & 0.196 & & $(-0.090)$ & \\
\hline T3SE 21FT / 77511 & $10 / 24 / 91$ & 0.196 & & & $(-0.090)$ \\
\hline 3BT5 3FT / 77507 & $10 / 30 / 91$ & 0.248 & 0.536 & & \\
\hline 2BT5 9FT / 77506 & $10 / 30 / 91$ & 0.248 & & $(0.082)$ & \\
\hline 4BT6 21FT /77508 & $10 / 30 / 91$ & 0.248 & & & $(0.053)$ \\
\hline
\end{tabular}


Appendix F.1.2 Near Surface Radon and Tritium Gas Sampling, Analysis, and Results (Continued)

Table 6 Pilot Well Ue5PW-2 Tritium Oxide Soil Gas Survey Data

\begin{tabular}{|c|c|c|c|c|c|}
\hline \multirow[t]{2}{*}{ Sample ID / Lab ID } & \multirow[t]{2}{*}{$\begin{array}{c}\text { Sample } \\
\text { Date }\end{array}$} & \multirow{2}{*}{$\begin{array}{c}\text { Minimum } \\
\text { Detectable } \\
\text { Amount } \\
\mathrm{pCi} / \mathrm{ml}\end{array}$} & \multicolumn{3}{|c|}{$\begin{array}{l}\text { Sample Activity } \\
\text { pCi } / \mathrm{ml}\end{array}$} \\
\hline & & & $3 \mathrm{ft}$ & $9 \mathrm{ft}$ & $17 \mathrm{ft}$ \\
\hline T6 3' PWNE / 77533 & $1 / 28 / 92$ & 0.283 & $(0.129)$ & & \\
\hline T8 9' PWNE / 77530 & $1 / 28 / 92$ & 0.480 & & $(-0.379)$ & \\
\hline T5 17' PWNE / 77534 & $1 / 28 / 92$ & 0.283 & & & $(-0.250)$ \\
\hline T6 3' PWNEB / 77535 & $2 / 04 / 92$ & 0.283 & $(0.151)$ & & \\
\hline T8 9' PWNEB / 77538 & $2 / 04 / 92$ & 0.197 & & $(0.017)$ & \\
\hline T5 17' PWNE / 77539 & $2 / 04 / 92$ & 0.197 & & & $(-0.088)$ \\
\hline
\end{tabular}


Appendix F.1.2 Near Surface Radon and Tritium Gas Sampling, Analysis, and Results (Continued)

Table 7 Pilot Well Ue5PW-3 Tritium Oxide Soil Gas Survey Data

\begin{tabular}{||c|c|c|c|c|c||}
\hline Sample ID / Lab ID & \multirow{2}{*}{$\begin{array}{c}\text { Sample } \\
\text { Date }\end{array}$} & \multirow{2}{*}{\begin{tabular}{c} 
Minimum \\
Detectable \\
Amount \\
\cline { 5 - 7 }
\end{tabular}} & & \multicolumn{3}{|c||}{$\begin{array}{c}\text { Sample Activity } \\
\text { pCi/ml }\end{array}$} \\
\cline { 5 - 7 } & & & $3 \mathrm{ft}$ & $9 \mathrm{ft}$ & $21 \mathrm{ft}$ \\
\hline PW3 T5 3' / 77614 & $7 / 30 / 92$ & 0.161 & $(0.093)$ & & \\
\hline PW3 T7 9' / 77615 & $7 / 30 / 92$ & 0.161 & & $(0.023)$ & \\
\hline PW3 T6 21' / 77616 & $7 / 30 / 92$ & 0.161 & & & $(-0.031)$ \\
\hline
\end{tabular}

${ }^{1}$ ( ) Denotes less than Minimum Detectable Amount 
Appendix F.2.1 Resistivity survey data

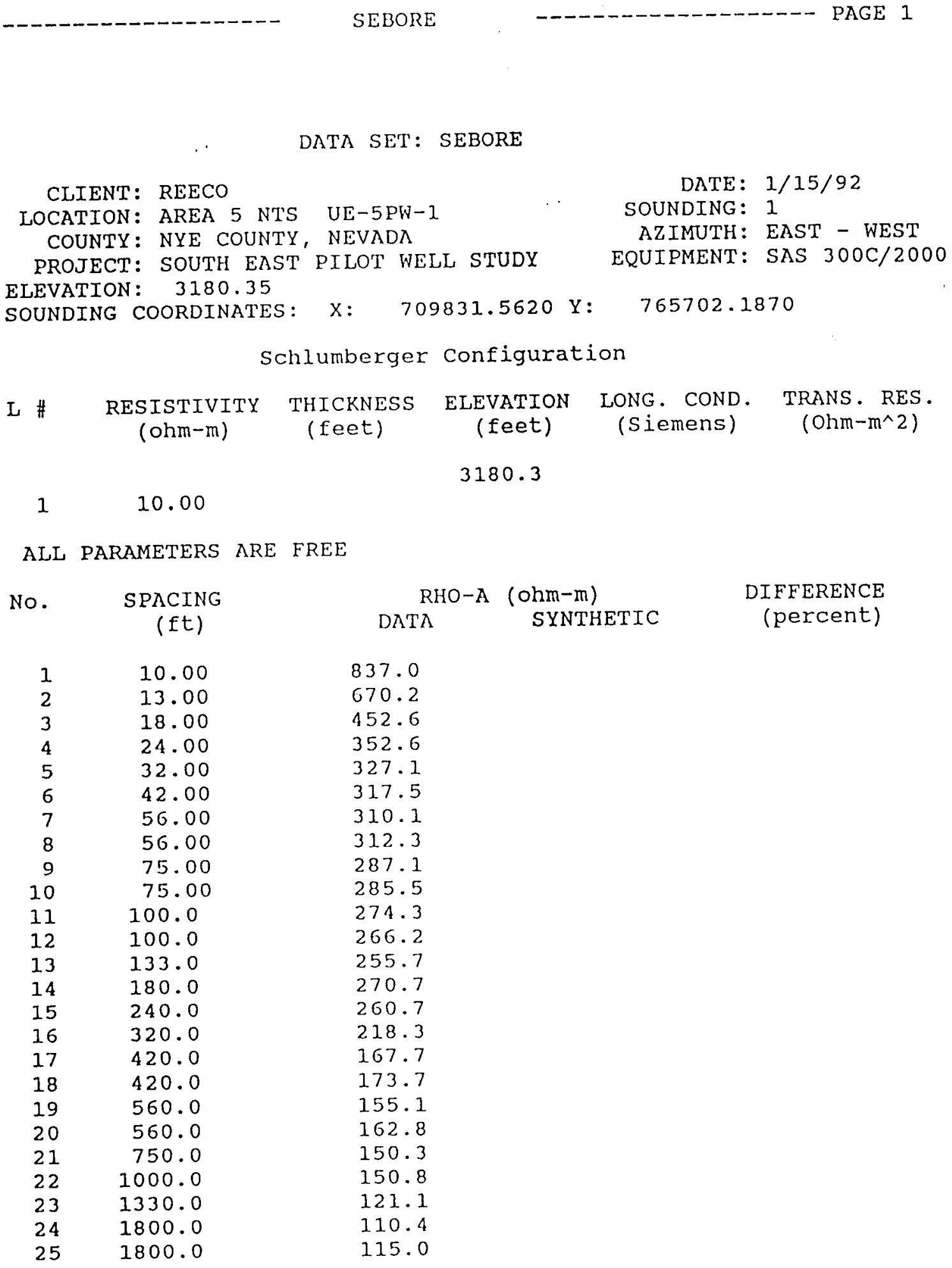


Appendix F.2.1 Resistivity survey data (Continued)

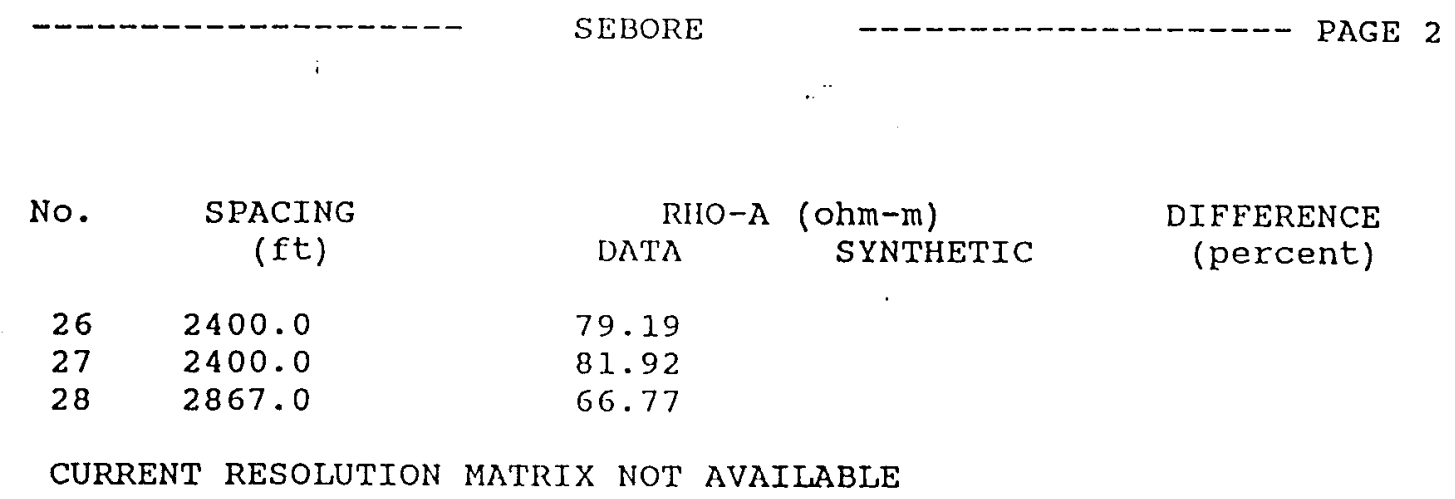

* Reynolds Electrical \& Engineering Co * 
Appendix F.2.1 Resistivity survey data (Continued)

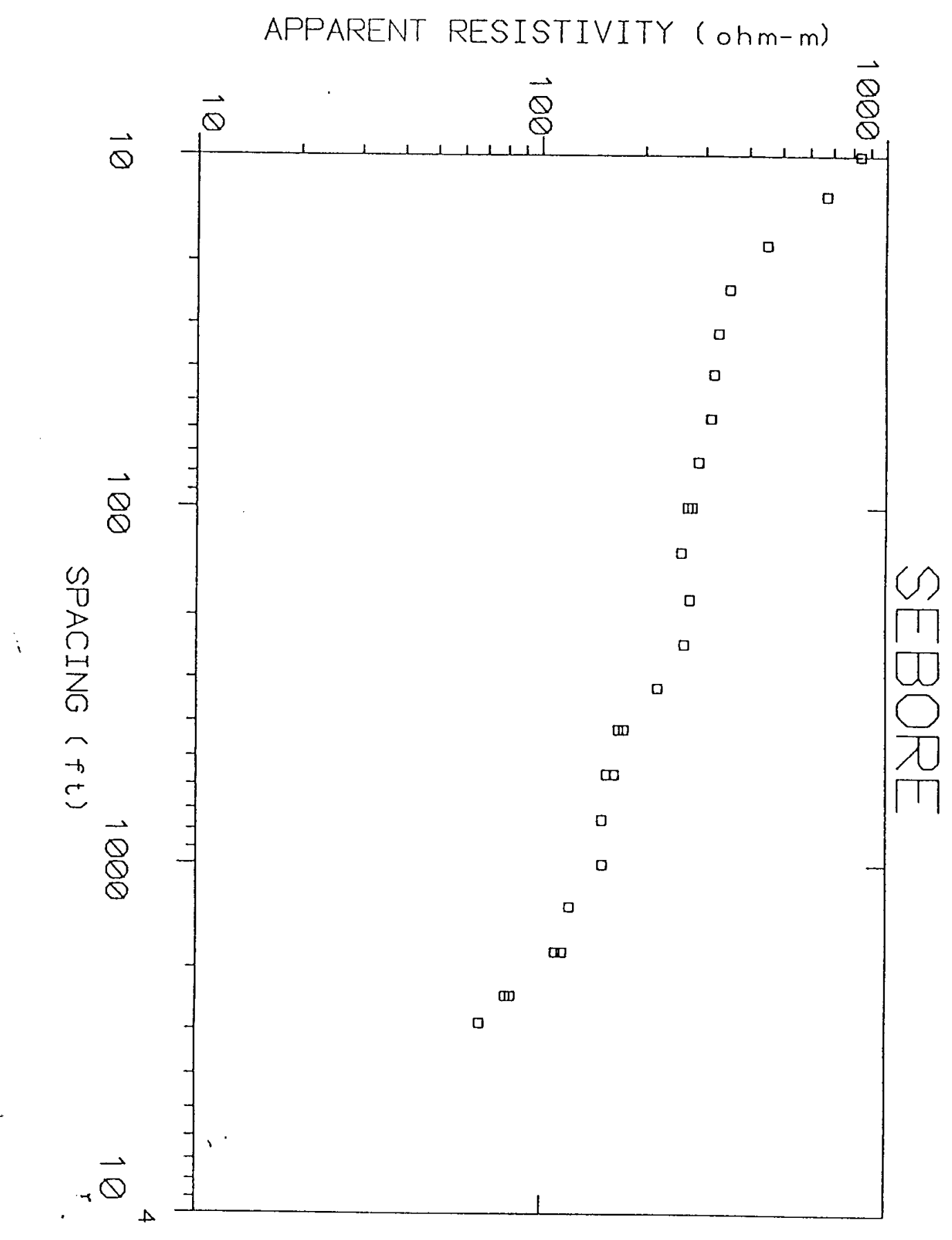


Appendix F.2.1 Resistivity survey data (Continued)

PWNE

PAGE 1

DATA SET: PWNE

CLIENT: REECO

LOCATION: AREA 5 NTS UE-5PW-2

COUNTY: NYE COUNTY, NEVADA

PROJECT: North East pilot Well

ELEVATION: $\quad 3248.42$

SOUNDING COORDINATES: $\mathrm{X}: \quad 709893.6250 \mathrm{Y}: \quad 770395.8750$

Schlumberger configuration

L\# RESISTIVITY THICKNESS ELEVATION LONG. COND. TRANS. RES.

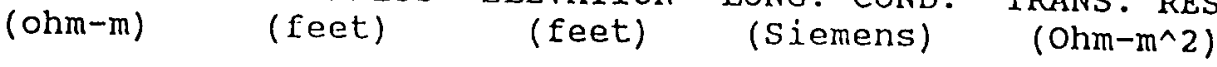

$1 \quad 10.00$

3248.4

ALL PARAMETERS ARE FREE

$\begin{array}{rrrr}\text { No. } & \begin{array}{c}\text { SPACING } \\ (\mathrm{ft})\end{array} & \begin{array}{c}\text { RHO-A } \\ \text { DATh }\end{array} & \begin{array}{c}\text { (ohm-m) } \\ \text { SYNTHETIC }\end{array} \\ 1 & 2.50 & 377.3 & \\ 2 & 5.00 & 611.5 & \\ 3 & 10.00 & 649.0 & \\ 4 & 13.00 & 631.5 & \\ 5 & 18.00 & 594.0 & \\ 6 & 24.00 & 564.5 & \\ 7 & 32.00 & 483.7 & \\ 8 & 42.00 & 454.8 & \\ 9 & 56.00 & 491.6 & \\ 10 & 56.00 & 406.7 & \\ 11 & 75.00 & 434.5 & \\ 12 & 75.00 & 383.7 & \\ 13 & 100.0 & 408.7 & \\ 14 & 100.0 & 387.5 & \\ 15 & 133.0 & 359.5 & \\ 16 & 180.0 & 347.2 & \\ 17 & 240.0 & 311.1 & \\ 18 & 320.0 & 260.7 & \\ 19 & 420.0 & 239.8 & \\ 20 & 420.0 & 247.1 & \\ 21 & 560.0 & 227.1 & \\ 22 & 560.0 & 241.8 & \\ 23 & 750.0 & 230.8 & \\ 24 & 1000.0 & & \\ 25 & 1330.0 & & \\ & & & \end{array}$

* Reynolds Electrical \& Engineering Co * 
Appendix F.2.1 Resistivity survey data (Continued)

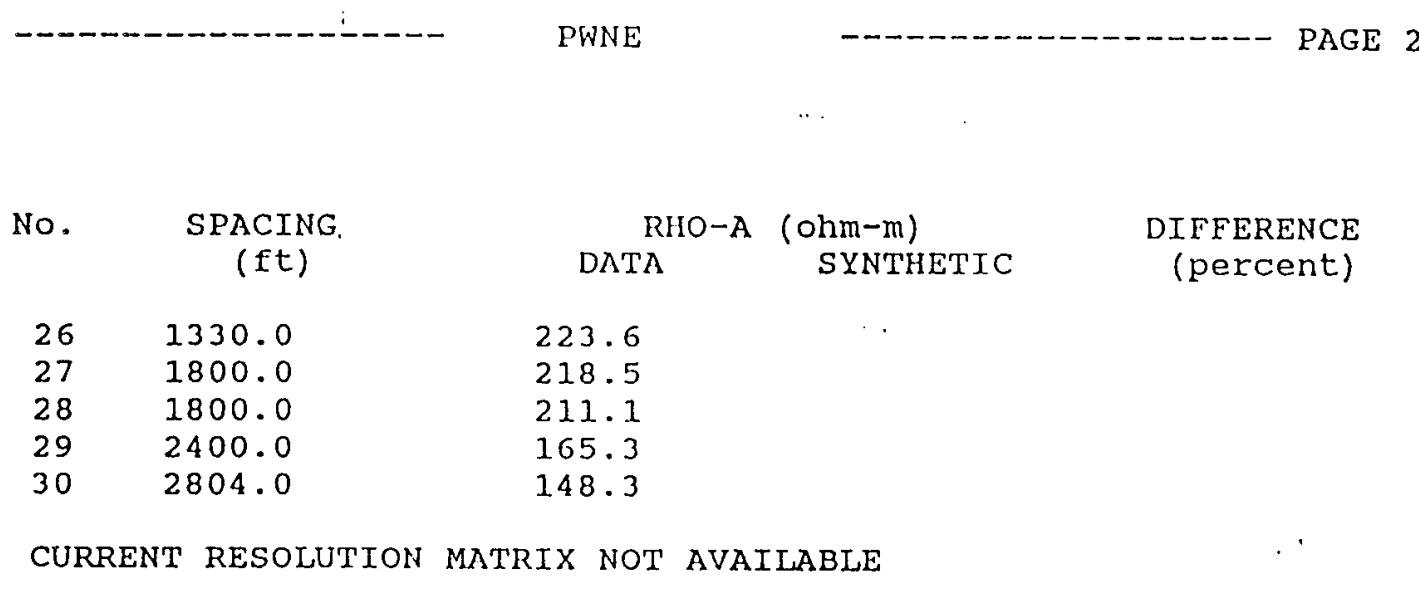


Appendix F.2.1 Resistivity survey data (Continued)

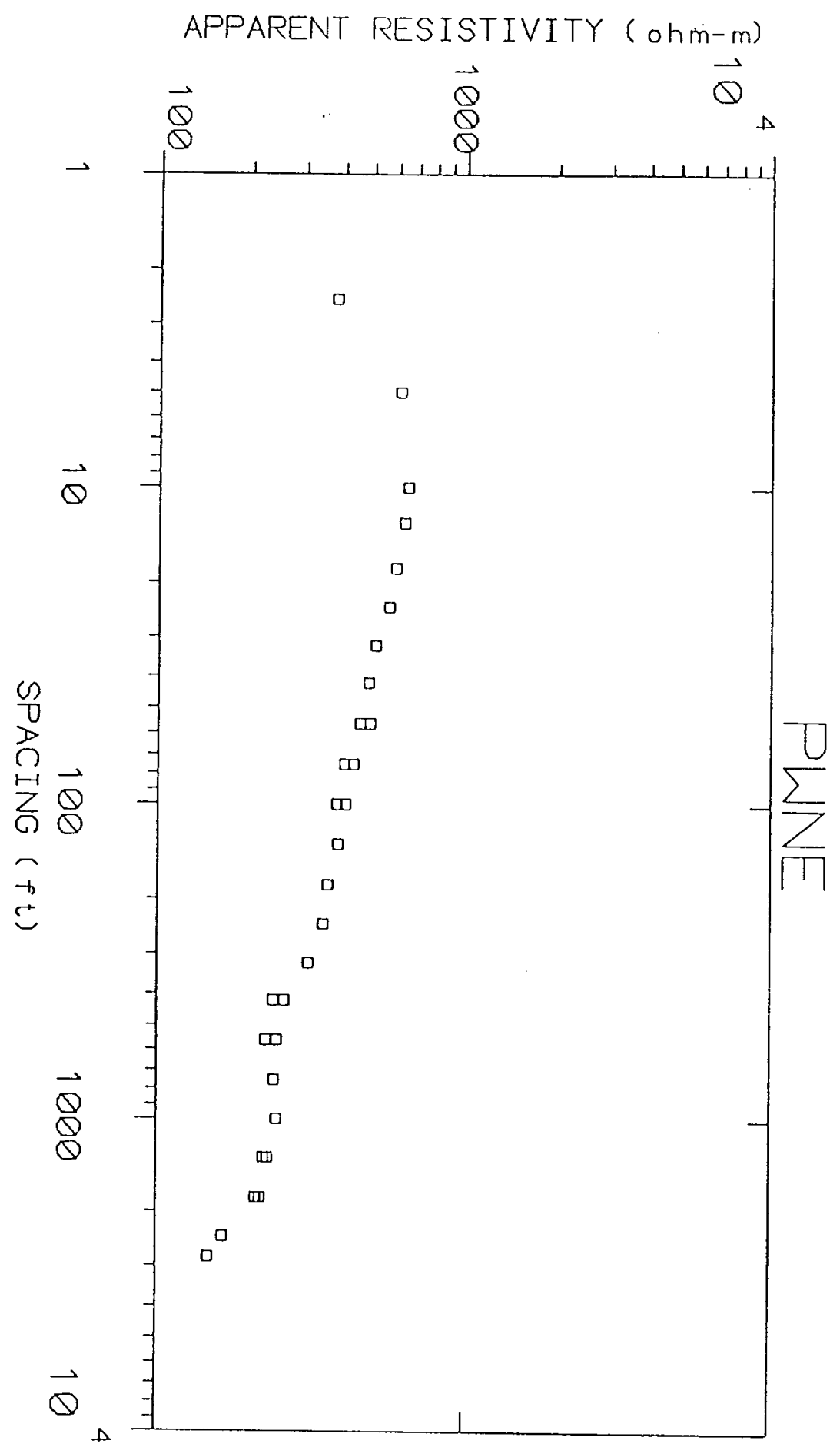


Appendix F.2.1 Resistivity survey data (Continued)

PTXNE

PAGE 1

DATA SET: PWXNE

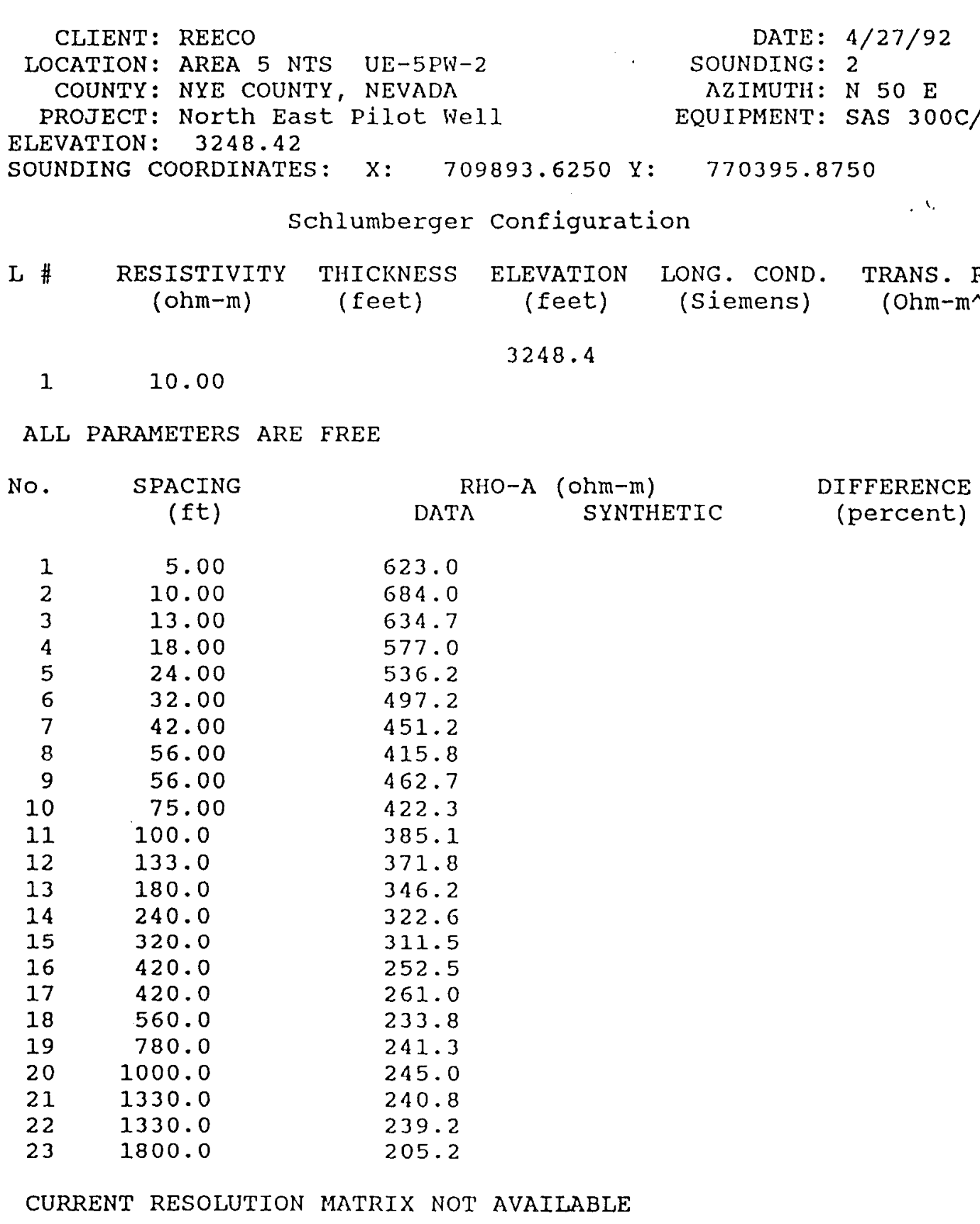

* Reynolds Electrical \& Engineering co * 
Appendix F.2.1 Resistivity survey data (Continued)

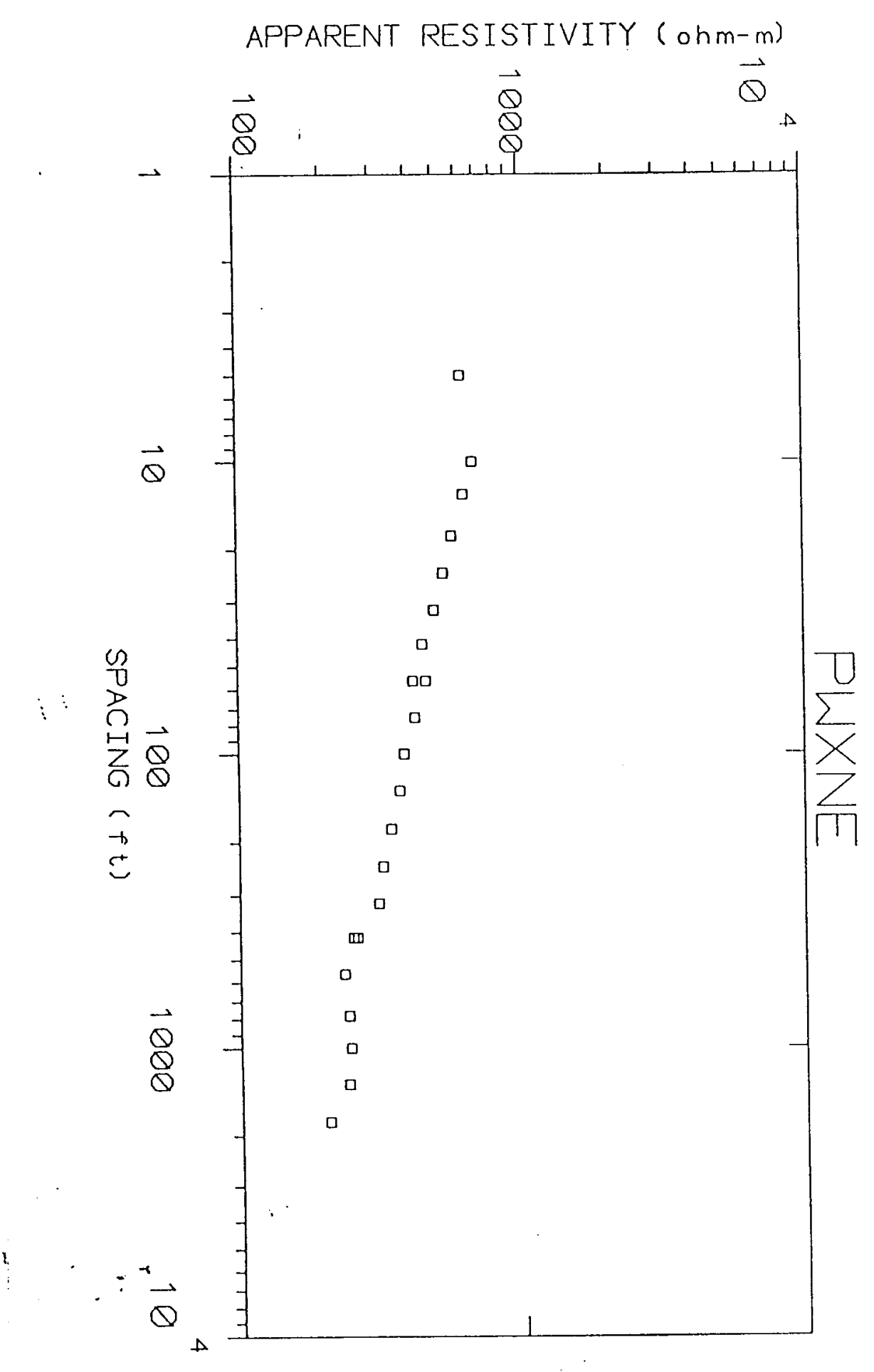


Appendix F.2.1 Resistivity survey data (Continued)

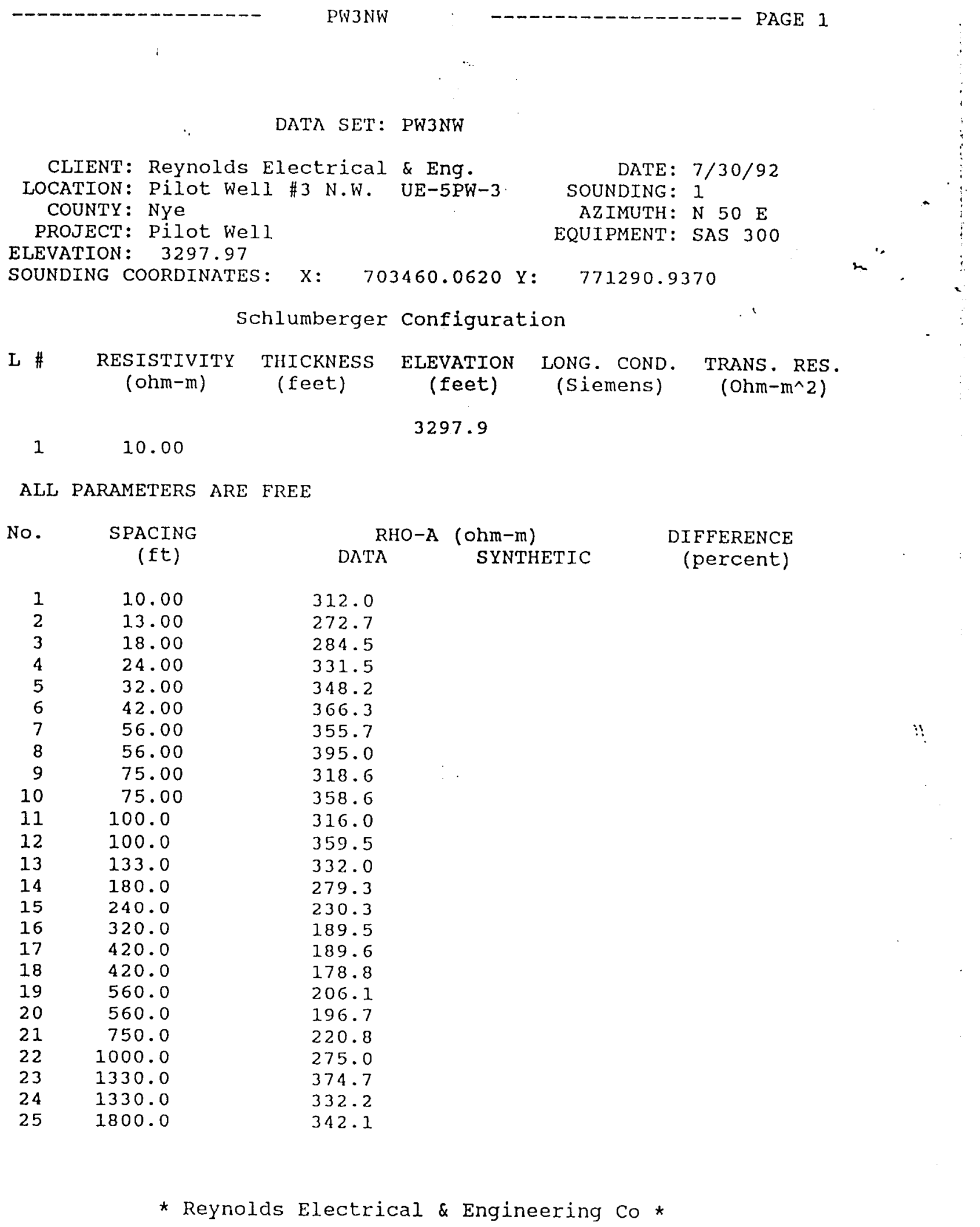


Appendix F.2.1 Resistivity survey data (Continued)

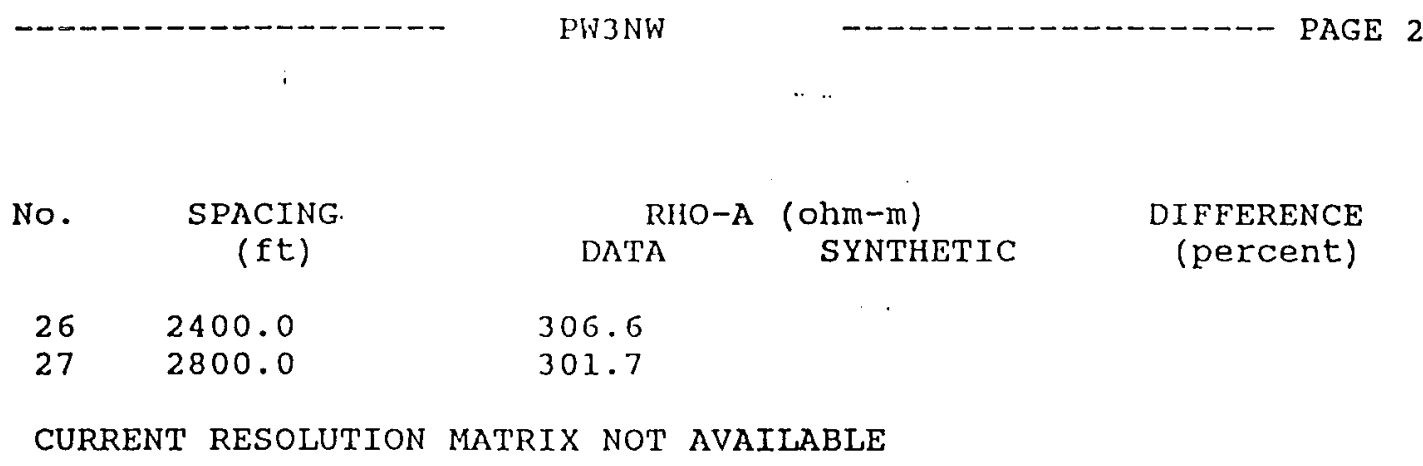

* Reynolds Electrical \& Engineering Co * 
Appendix F.2.1 Resistivity survey data (Continued)

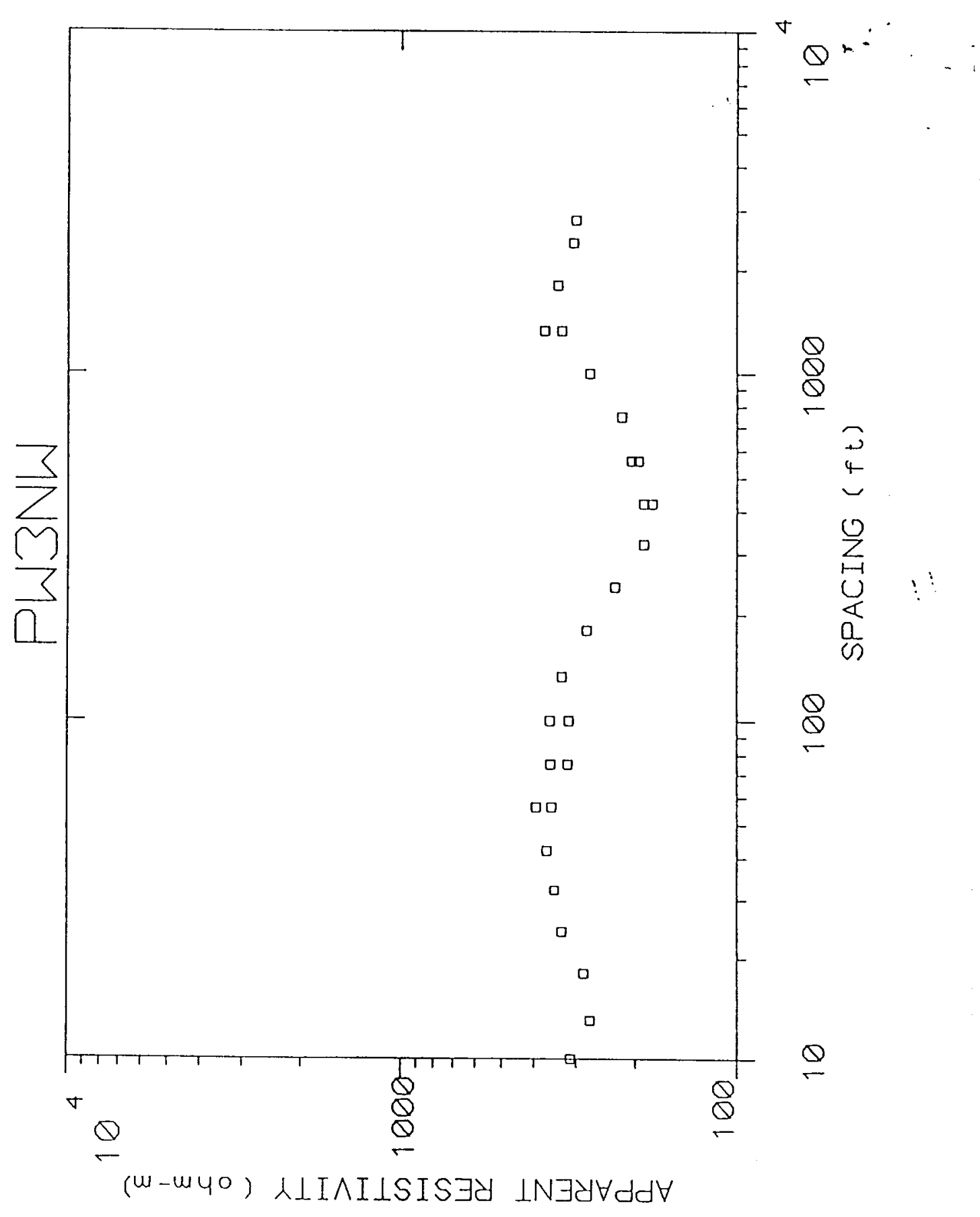


Appendix F.2.2 Magnetic survey data

Ue-5PW-1

Gem Systems GSM-19 13 IX 90 ID 000000001

05 XII91

141426 se borehole bkg survey

\begin{tabular}{|c|c|c|c|c|c|}
\hline Time & Line & $\begin{array}{c}\text { Station } \\
\text { (ft) }\end{array}$ & $\begin{array}{l}\text { Total Fld } \\
\text { (nT) }\end{array}$ & $\begin{array}{c}\text { Gradient } \\
\text { (nT/m) }\end{array}$ & $\begin{array}{c}\text { Corrected } \\
\text { Total Fld } \\
\text { (nT) }\end{array}$ \\
\hline 142236 & O001E & $000550 \mathrm{~W}$ & 050927.02 & -007.69 & 050922.85 \\
\hline 142309 & 0001E & $000500 \mathrm{~W}$ & 050926.64 & -008.13 & 050922.45 \\
\hline 142336 & 0001E & $000500 W$ & 050926.73 & -008.37 & 050922.59 \\
\hline 142415 & 0001E & 000450W & 050896.89 & -031.00 & 050892.51 \\
\hline 142445 & 0001E & 000450W & 050897.04 & -030.83 & 050892.63 \\
\hline 142524 & 0001E & $000400 \mathrm{~W}$ & 050963.86 & -001.47 & 050959.37 \\
\hline 142548 & O001E & $000400 \mathrm{~W}$ & 050964.58 & -001.03 & 050959.85 \\
\hline 142621 & 0001E & 000350W & 050968.87 & -002.53 & 050964.39 \\
\hline 142642 & 0001E & 000350W & 050969.40 & -001.82 & 050964.82 \\
\hline 142715 & $0001 \mathrm{E}$ & 000300W & 050965.64 & -004.16 & 050961.14 \\
\hline 142739 & 0001E & 000300W & 050965.90 & -003.85 & 050961.37 \\
\hline 142815 & 0001E & $000250 \mathrm{~W}$ & 050968.96 & -004.42 & 050964.30 \\
\hline 142836 & $0001 \mathrm{E}$ & 000250W & 050968.69 & -004.61 & 050964.03 \\
\hline 142912 & 0001E & $000200 W$ & 050978.92 & -003.34 & 050973.98 \\
\hline 142936 & 0001E & $000200 W$ & 050978.97 & -003.46 & 050974.01 \\
\hline 143009 & $0001 E$ & $000150 \mathrm{~W}$ & 050977.82 & -005.07 & 050973.05 \\
\hline 143030 & 0001E & 000150W & 050978.22 & -004.45 & 050973.39 \\
\hline 143103 & 0001E & $000100 \mathrm{~W}$ & 050979.81 & -002.81 & 050975.05 \\
\hline 143121 & 0001E & 000100W & 050979.88 & -002.81 & 050974.98 \\
\hline 143151 & 0001E & $000050 \mathrm{~W}$ & 050980.16 & -004.07 & 050975.28 \\
\hline 143212 & 0001E & 000050W & 050979.05 & -004.10 & 050974.35 \\
\hline 143418 & 0001E & $000050 \mathrm{~W}$ & 050979.00 & -005.39 & 050973.89 \\
\hline 143442 & 0001E & 000050W & 050980.64 & -003.89 & 050975.36 \\
\hline 143503 & 0001E & $000050 \mathrm{~W}$ & 050978.70 & -005.99 & 050973.45 \\
\hline 143521 & 0001E & 000050W & 050979.11 & -005.54 & 050973.93 \\
\hline 143545 & $0001 \mathrm{E}$ & $000050 \mathrm{~W}$ & 050980.03 & -004.69 & 050974.64 \\
\hline 143603 & 0001E & $000050 \mathrm{~W}$ & 050979.89 & -004.91 & 050974.46 \\
\hline 143739 & $0001 \mathrm{E}$ & $000000 \mathrm{~W}$ & 050980.92 & -005.36 & 050975.02 \\
\hline 143803 & 0001E & $000000 \mathrm{E}$ & 050981.27 & -005.10 & 050975.18 \\
\hline 143824 & 0001E & $000000 \mathrm{E}$ & 050981.41 & -004.94 & 050975.41 \\
\hline 143845 & 0001E & $000000 \mathrm{E}$ & 050981.55 & -004.81 & 050975.38 \\
\hline 143903 & 0001E & $000000 \mathrm{E}$ & 050981.76 & -004.71 & 050975.58 \\
\hline 143924 & 0001E & $000000 \mathrm{E}$ & 050981.62 & -004.82 & 050975.38 \\
\hline 143945 & 0001E & O00000E & 050982.02 & -004.63 & 050975.59 \\
\hline 144021 & 0001E & $000050 \mathrm{E}$ & 050978.32 & -007.00 & 050971.89 \\
\hline 144042 & 0001E & $000050 \mathrm{E}$ & 050978.64 & -006.87 & 050972.09 \\
\hline
\end{tabular}


Appendix F.2.2 Magnetic survey data (Continued)

\begin{tabular}{|c|c|c|c|c|c|}
\hline Time & Line & $\begin{array}{l}\text { Station } \\
\text { (ft) }\end{array}$ & $\begin{array}{l}\text { Total Fld } \\
\text { (nT) }\end{array}$ & $\begin{array}{c}\text { Gradient } \\
\text { (nT/m) }\end{array}$ & $\begin{array}{c}\text { Corrected } \\
\text { Total Fld } \\
\text { (nT) }\end{array}$ \\
\hline 144103 & 0001E & 000050E & 050978.75 & -006.59 & 050972.37 \\
\hline 144133 & 0001E & 000100E & 050986.82 & -004.29 & 050980.29 \\
\hline 144151 & 0001E & 000100E & 050987.46 & -003.76 & 050980.77 \\
\hline 144209 & 0001E & 000100E & 050987.72 & -003.65 & 050980.86 \\
\hline 144242 & 0001E & 000150E & 050987.82 & -002.96 & 050980.89 \\
\hline 144300 & 0001E & 000150E & 050987.90 & -002.71 & 050980.96 \\
\hline 144321 & 0001E & 000150E & 050987.80 & -003.00 & 050980.72 \\
\hline 144354 & OOO1E & 000200E & 050981.32 & -006.51 & 050974.12 \\
\hline 144412 & $0001 \mathrm{E}$ & $000200 \mathrm{E}$ & 050983.60 & -004.06 & 050976.45 \\
\hline 144433 & 0001E & 000200E & 050984.53 & -003.25 & 050977.18 \\
\hline 144457 & $0001 \mathrm{E}$ & $000200 \mathrm{E}$ & 050984.75 & -002.90 & 050977.51 \\
\hline 144518 & 0001E & 000200E & 050984.63 & -002.94 & 050977.32 \\
\hline 144551 & $0001 \mathrm{E}$ & $000250 \mathrm{E}$ & 050987.04 & -003.51 & 0.00 \\
\hline 144612 & $0001 \mathrm{E}$ & $000250 \mathrm{E}$ & 050987.01 & -003.52 & 050979.99 \\
\hline 144645 & $0001 E$ & 000300E & 050992.87 & -000.63 & .90 \\
\hline 144709 & 0001E & 000300E & 050993.09 & -000.47 & 050986.08 \\
\hline 144757 & $0001 \mathrm{E}$ & $000350 \mathrm{E}$ & 050988.70 & $-0 x$ & 63 \\
\hline 144821 & 0001E & $000350 \mathrm{E}$ & 050991.89 & -000.25 & 050984.86 \\
\hline 144842 & $0001 \mathrm{E}$ & 000350E & 050988.72 & -004.22 & 0509 \\
\hline 144906 & 0001E & $000350 \mathrm{E}$ & 050988.91 & -003.96 & 050981.78 \\
\hline 144927 & $0001 \mathrm{E}$ & $000350 \mathrm{E}$ & 050991.98 & -000.61 & 0509 \\
\hline 145015 & $0001 \mathrm{E}$ & 000350E & 050993.58 & 001.82 & 050986.24 \\
\hline 145242 & $0001 \mathrm{E}$ & 000350E & 050995.09 & -003.57 & 050987.44 \\
\hline 145303 & 0001E & 000400E & 050994.95 & -003.46 & 050987.15 \\
\hline 145333 & 0001E & 000400E & 050995.68 & -002.99 & 7.88 \\
\hline 145357 & 0001E & $000400 \mathrm{E}$ & 050995.55 & -003.07 & 050987.84 \\
\hline 145445 & 0001E & $000450 \mathrm{E}$ & 050831.29 & -218.67 & 050823.54 \\
\hline 145509 & 0001E & 000450E & 050836.59 & -214.13 & 050828.74 \\
\hline 145545 & 0001E & 000500E & 050986.27 & -004.32 & 050978.12 \\
\hline 145606 & 0001E & 000500E & 050986.37 & -004.17 & 050978.32 \\
\hline 145627 & 0001E & 000500E & 050986.52 & -004.08 & 050978.28 \\
\hline 150412 & $0002 \mathrm{~N}$ & & & 4 & 92 \\
\hline 150451 & $0002 \mathrm{~N}$ & $000500 S$ & 050986.05 & -008.02 & 050977.67 \\
\hline 150509 & $0002 \mathrm{~N}$ & $000500 S$ & 050986.57 & -008.26 & 050978.02 \\
\hline 150818 & $0002 \mathrm{~N}$ & O00450S & 050983.77 & -008.52 & 050974.84 \\
\hline 150839 & $0002 \mathrm{~N}$ & $000450 S$ & 050983.99 & -008.66 & 050975.23 \\
\hline 150912 & $0002 \mathrm{~N}$ & 000400S & 050995.28 & -004.40 & 050986.30 \\
\hline 150933 & $0002 \mathrm{~N}$ & 000400S & 050994.82 & -004.96 & 050985.88 \\
\hline 151006 & $0002 \mathrm{~N}$ & 000350S & 050990.77 & -005.53 & 050981.74 \\
\hline 151036 & $0002 \mathrm{~N}$ & OOD350S & 050990.59 & -006.21 & 050981.28 \\
\hline
\end{tabular}


Appendix F.2.2 Magnetic survey data (Continued)

\begin{tabular}{|c|c|c|c|c|c|}
\hline Time & Line & $\begin{array}{l}\text { Station } \\
\text { (ft) }\end{array}$ & $\begin{array}{l}\text { Total Fld } \\
\text { (nT) }\end{array}$ & $\begin{array}{c}\text { Gradient } \\
\text { (nT/m) }\end{array}$ & $\begin{array}{c}\text { Corrected } \\
\text { Total Fld } \\
\text { (nT) }\end{array}$ \\
\hline 151115 & $0002 \mathrm{~N}$ & $000300 \mathrm{~S}$ & 050985.42 & -007.97 & 050975.93 \\
\hline 151136 & $0002 \mathrm{~N}$ & $000300 \mathrm{~S}$ & 050986.98 & -006.41 & 050977.37 \\
\hline 151154 & $0002 \mathrm{~N}$ & $000300 \mathrm{~S}$ & 050987.56 & -006.49 & 050977.48 \\
\hline 151227 & $0002 \mathrm{~N}$ & $000250 \mathrm{~S}$ & 050986.23 & -007.03 & 050975.92 \\
\hline 151245 & $0002 \mathrm{~N}$ & $000250 \mathrm{~S}$ & 050986.37 & -006.96 & 050976.06 \\
\hline 151306 & $0002 \mathrm{~N}$ & $000250 \mathrm{~S}$ & 050986.03 & -006.99 & 050975.99 \\
\hline 151336 & $0002 \mathrm{~N}$ & $000200 \mathrm{~S}$ & 050986.78 & -006.52 & 050976.33 \\
\hline 151357 & $0002 \mathrm{~N}$ & $000200 \mathrm{~S}$ & 050987.3 .1 & -006.28 & 050976.67 \\
\hline 151436 & $0002 \mathrm{~N}$ & 000150S & 050986.45 & -006.18 & 050976.50 \\
\hline 151457 & $0002 \mathrm{~N}$ & $000150 \mathrm{~S}$ & 050985.58 & -007.58 & 050975.47 \\
\hline 151518 & $0002 \mathrm{~N}$ & $000150 \mathrm{~S}$ & 050985.47 & -007.60 & 050975.37 \\
\hline 151551 & $0002 \mathrm{~N}$ & $000100 \mathrm{~s}$ & 050980.78 & -008.43 & 050970.56 \\
\hline 151609 & $0002 \mathrm{~N}$ & $000100 \mathrm{~S}$ & 050980.00 & -009.06 & 050969.97 \\
\hline 151633 & $0002 \mathrm{~N}$ & $000100 \mathrm{~S}$ & 050980.26 & -008.83 & 050970.29 \\
\hline 151706 & $0002 \mathrm{~N}$ & $000050 \mathrm{~S}$ & 050982.78 & -008.39 & 050972.41 \\
\hline 151727 & $0002 \mathrm{~N}$ & $000050 \mathrm{~S}$ & 050981.80 & -009.18 & 050971.81 \\
\hline 151748 & $0002 \mathrm{~N}$ & $000050 \mathrm{~S}$ & 050981.79 & -009.04 & 050971.99 \\
\hline 151824 & $0002 \mathrm{~N}$ & $000000 \mathrm{~S}$ & 050984.27 & -006.46 & 050974.22 \\
\hline 151845 & $0002 \mathrm{~N}$ & $000000 \mathrm{~N}$ & 050984.65 & -006.39 & 050974.39 \\
\hline 151909 & $0002 \mathrm{~N}$ & $000000 \mathrm{~N}$ & 050985.13 & -006.20 & 050974.69 \\
\hline 151936 & $0002 \mathrm{~N}$ & $000000 \mathrm{~N}$ & 050986.89 & -003.68 & 050976.48 \\
\hline 152000 & $0002 \mathrm{~N}$ & $000000 \mathrm{~N}$ & 050987.25 & -003.62 & 050976.74 \\
\hline 152024 & $0002 \mathrm{~N}$ & $000000 \mathrm{~N}$ & 050984.35 & -007.18 & 050973.70 \\
\hline 152106 & $0002 \mathrm{~N}$ & $000050 \mathrm{~N}$ & 050984.18 & -007.05 & 050973.84 \\
\hline 152130 & $0002 \mathrm{~N}$ & $000050 \mathrm{~N}$ & 050984.21 & -007.26 & 050973.68 \\
\hline 152154 & $0002 \mathrm{~N}$ & $000050 \mathrm{~N}$ & 050984.08 & -007.59 & 050973.42 \\
\hline 152230 & $0002 \mathrm{~N}$ & $000100 \mathrm{~N}$ & 050983.63 & -007.29 & 050972.75 \\
\hline 152251 & $0002 \mathrm{~N}$ & $000100 \mathrm{~N}$ & 050983.73 & -007.67 & 050972.72 \\
\hline 152327 & $0002 \mathrm{~N}$ & $000150 \mathrm{~N}$ & 050982.40 & -007.32 & 050971.09 \\
\hline 152348 & $0002 \mathrm{~N}$ & $000150 \mathrm{~N}$ & 050982.58 & -007.40 & 050970.94 \\
\hline 152427 & $0002 \mathrm{~N}$ & $000200 \mathrm{~N}$ & 050982.81 & -006.20 & 050970.84 \\
\hline 152451 & $0002 \mathrm{~N}$ & $000200 \mathrm{~N}$ & 050982.79 & -006.56 & 050970.71 \\
\hline 152527 & $0002 \mathrm{~N}$ & $000250 \mathrm{~N}$ & 050980.10 & -008.77 & 050968.07 \\
\hline 152548 & $0002 \mathrm{~N}$ & $000250 \mathrm{~N}$ & 050980.01 & -009.10 & 050967.97 \\
\hline 152624 & $0002 \mathrm{~N}$ & $000300 \mathrm{~N}$ & 050984.50 & -006.10 & 050972.29 \\
\hline 152648 & $0002 \mathrm{~N}$ & $000300 \mathrm{~N}$ & 050983.77 & -006.63 & 050971.65 \\
\hline 152736 & $0002 \mathrm{~N}$ & $000350 \mathrm{~N}$ & 050947.36 & -061.59 & 050935.39 \\
\hline 152803 & $0002 \mathrm{~N}$ & $000350 \mathrm{~N}$ & 050947.35 & -061.51 & 050935.39 \\
\hline 152842 & $0002 \mathrm{~N}$ & $000400 \mathrm{~N}$ & 050977.53 & -009.03 & 050965.73 \\
\hline 152903 & $0002 \mathrm{~N}$ & $000400 \mathrm{~N}$ & 050979.02 & -007.39 & 050967.08 \\
\hline 152927 & $0002 \mathrm{~N}$ & $000400 \mathrm{~N}$ & 050977.18 & -009.50 & 050965.15 \\
\hline
\end{tabular}


Appendix F.2.2 Magnetic survey data (Continued)

$\begin{array}{llcccc}\text { Time } & \text { Line } & \begin{array}{c}\text { Station } \\ (\mathrm{ft})\end{array} & \begin{array}{c}\text { Total Fld } \\ (\mathrm{nT})\end{array} & \begin{array}{c}\text { Gradient } \\ (\mathrm{nT} / \mathrm{m})\end{array} & \begin{array}{c}\text { Corrected } \\ \text { Total Fld } \\ (\mathrm{nT})\end{array} \\ 153012 & 0002 \mathrm{~N} & 000450 \mathrm{~N} & 050981.04 & -006.18 & 050968.65 \\ 153039 & 0002 \mathrm{~N} & 000450 \mathrm{~N} & 050981.26 & -006.02 & 050968.94 \\ 153112 & 0002 \mathrm{~N} & 000500 \mathrm{~N} & 050973.12 & -005.94 & 050960.73 \\ 153142 & 0002 \mathrm{~N} & 000500 \mathrm{~N} & 050972.87 & -006.56 & 050960.32 \\ 153221 & 0002 \mathrm{~N} & 000500 \mathrm{~N} & 050946.59 & -008.74 & 050933.97 \\ 153254 & 0002 \mathrm{~N} & 000550 \mathrm{~N} & 050890.12 & -009.25 & 050877.53 \\ 153324 & 0002 \mathrm{~N} & 000600 \mathrm{~N} & 050889.94 & -009.72 & 050877.19 \\ 153354 & 0002 \mathrm{~N} & 000650 \mathrm{~N} & 051490.51 & 920.71 & 051477.78 \\ 153415 & 0002 \mathrm{~N} & 000650 \mathrm{~N} & 051409.38 & 708.45 & 051396.58\end{array}$


Appendix F.2.2 Magnetic survey data (Continued)

\section{Ue-5PW-2}

Gem Systems GSM-19 13 IX 90 ID 000000001

03 II 92

\begin{tabular}{|c|c|c|c|c|c|}
\hline Time & Line & $\begin{array}{l}\text { Station } \\
\text { (ft) }\end{array}$ & $\begin{array}{l}\text { Total Fld } \\
\text { (nT) }\end{array}$ & $\begin{array}{c}\text { Gradient } \\
(\mathrm{nT} / \mathrm{m})\end{array}$ & $\begin{array}{l}\text { Corrected } \\
\text { Total Fld } \\
\text { (nT) }\end{array}$ \\
\hline 144733 & $0000 \mathrm{~N}$ & $000750 \mathrm{E}$ & 050954.34 & -007.86 & 050954.34 \\
\hline 145042 & $0000 \mathrm{~N}$ & $000750 \mathrm{E}$ & 050954.83 & -007.44 & 050954.59 \\
\hline 145127 & $0000 \mathrm{~N}$ & $000700 \mathrm{E}$ & 050955.13 & -006.85 & 050955.48 \\
\hline 145245 & $0000 \mathrm{~N}$ & $000700 \mathrm{E}$ & 050947.36 & -008.74 & 050948.51 \\
\hline 145327 & $0000 \mathrm{~N}$ & $000650 \mathrm{E}$ & 050947.25 & -009.36 & 050948.26 \\
\hline 145406 & $0000 \mathrm{~N}$ & $000650 \mathrm{E}$ & 050947.73 & -008.82 & 050948.83 \\
\hline 145509 & $0000 \mathrm{~N}$ & $000600 \mathrm{E}$ & 050964.09 & -004.86 & 050965.43 \\
\hline 145536 & $0000 \mathrm{~N}$ & $000600 \mathrm{E}$ & 050963.88 & -004.88 & 050965.17 \\
\hline 145618 & $0000 \mathrm{~N}$ & $000550 \mathrm{E}$ & 050970.59 & -002.73 & 050972.04 \\
\hline 145642 & $0000 \mathrm{~N}$ & $000550 \mathrm{E}$ & 050970.49 & -002.90 & 050972.19 \\
\hline 145721 & $0000 \mathrm{~N}$ & $000500 \mathrm{E}$ & 050953.04 & -010.87 & 050954.24 \\
\hline 145803 & $0000 \mathrm{~N}$ & $000500 \mathrm{E}$ & 050952.91 & -010.74 & 050954.42 \\
\hline 145845 & $0000 \mathrm{~N}$ & $000450 \mathrm{E}$ & 050959.85 & -007.09 & 050961.16 \\
\hline 145915 & $0000 \mathrm{~N}$ & $000450 \mathrm{E}$ & 050959.68 & -007.97 & 050960.63 \\
\hline 150003 & $0000 \mathrm{~N}$ & $000400 \mathrm{E}$ & 050975.76 & -002.10 & 050976.02 \\
\hline 150045 & $0000 \mathrm{~N}$ & $000400 \mathrm{E}$ & 050975.34 & -001.81 & 050976.13 \\
\hline 150124 & $0000 \mathrm{~N}$ & $000350 \mathrm{E}$ & 050957.98 & -006.67 & 050958.60 \\
\hline 150151 & $0000 \mathrm{~N}$ & $000350 \mathrm{E}$ & 050958.38 & -006.90 & 050958.88 \\
\hline 150236 & $0000 \mathrm{~N}$ & $000300 \mathrm{E}$ & 050959.72 & -006.33 & 050959.54 \\
\hline 150306 & $0000 \mathrm{~N}$ & $000300 \mathrm{E}$ & 050960.42 & -006.33 & 050959.81 \\
\hline 150439 & $0000 \mathrm{~N}$ & $000250 \mathrm{E}$ & 050963.10 & -004.23 & 050961.85 \\
\hline 150506 & $0000 \mathrm{~N}$ & $000250 \mathrm{E}$ & 050963.13 & -004.39 & 050961.62 \\
\hline 150539 & $0000 \mathrm{~N}$ & $000200 \mathrm{E}$ & 050966.43 & -004.75 & 050964.71 \\
\hline 150621 & $0000 \mathrm{~N}$ & 000150E & 050971.69 & 004.84 & 050971.12 \\
\hline 150645 & $0000 \mathrm{~N}$ & $000150 \mathrm{E}$ & 050971.22 & 004.07 & 050970.59 \\
\hline 150727 & $0000 \mathrm{~N}$ & $000100 \mathrm{E}$ & 050969.03 & -002.12 & 050968.46 \\
\hline 150821 & $0000 \mathrm{~N}$ & $000050 \mathrm{E}$ & 050975.35 & -001.09 & 050974.81 \\
\hline 150848 & $0000 \mathrm{~N}$ & $000050 \mathrm{E}$ & 050975.47 & -001.21 & 050974.97 \\
\hline 151021 & $0000 \mathrm{~N}$ & $000000 \mathrm{E}$ & 050966.80 & -004.86 & 050967.18 \\
\hline 151057 & $0000 \mathrm{~N}$ & $000000 \mathrm{~W}$ & 050966.85 & -004.64 & 050967.36 \\
\hline 151139 & $0000 \mathrm{~N}$ & $000050 \mathrm{~W}$ & 050959.16 & -005.15 & 050959.41 \\
\hline 151206 & $0000 \mathrm{~N}$ & $000050 \mathrm{~W}$ & 050959.32 & -005.10 & 050959.57 \\
\hline 151242 & $0000 \mathrm{~N}$ & $000100 \mathrm{~W}$ & 050966.60 & -002.96 & 050966.52 \\
\hline 151324 & $0000 \mathrm{~N}$ & $000150 \mathrm{~W}$ & 050958.84 & -006.24 & 050957.98 \\
\hline 151651 & $0000 \mathrm{~N}$ & $000150 \mathrm{~W}$ & 050962.29 & -006.76 & 050957.53 \\
\hline 151812 & $0000 \mathrm{~N}$ & $000150 \mathrm{~W}$ & 050962.47 & -007.20 & 050956.96 \\
\hline 151836 & $0000 \mathrm{~N}$ & $000150 \mathrm{~W}$ & 050962.30 & -007.44 & 050956.79 \\
\hline
\end{tabular}


Appendix F.2.2 Magnetic survey data (Continued)

\begin{tabular}{|c|c|c|c|c|c|}
\hline Time & Line & $\begin{array}{c}\text { Station } \\
(\mathrm{ft})\end{array}$ & $\begin{array}{l}\text { Total Fld } \\
\text { (nT) }\end{array}$ & $\begin{array}{c}\text { Gradient } \\
\text { (nT/m) }\end{array}$ & $\begin{array}{c}\text { Corrected } \\
\text { Total Fld } \\
\text { (nT) }\end{array}$ \\
\hline 151912 & $0000 \mathrm{~N}$ & $000200 \mathrm{~W}$ & 050964.54 & -004.19 & 050959.05 \\
\hline 151954 & $0000 \mathrm{~N}$ & $000250 \mathrm{~W}$ & 050963.71 & -004.52 & 050958.17 \\
\hline 152036 & $0000 \mathrm{~N}$ & $000300 \mathrm{~W}$ & 050960.92 & -006.36 & 050955.22 \\
\hline 152124 & $0000 \mathrm{~N}$ & $000350 \mathrm{~W}$ & 050998.61 & 013.91 & 050992.87 \\
\hline 152157 & $0000 N$ & $000350 \mathrm{~W}$ & 050998.91 & 013.97 & 050993.21 \\
\hline 152300 & $0000 \mathrm{~N}$ & $000350 \mathrm{~W}$ & 050999.38 & 013.60 & 050993.01 \\
\hline 152348 & $0000 \mathrm{~N}$ & $000400 \mathrm{~W}$ & 050970.65 & -001.34 & 050964.07 \\
\hline 152433 & $0000 \mathrm{~N}$ & $000400 W$ & 050971.04 & -001.12 & 050964.52 \\
\hline 152518 & $0000 \mathrm{~N}$ & $000450 \mathrm{~W}$ & 050967.45 & -005.26 & 050960.74 \\
\hline 152609 & $0000 \mathrm{~N}$ & $000500 \mathrm{~W}$ & 050970.99 & -001.34 & 050964.52 \\
\hline 152648 & $0000 \mathrm{~N}$ & $000500 \mathrm{~W}$ & 050971.16 & -001.56 & 050964.94 \\
\hline 153345 & $0000 \mathrm{E}$ & $000500 S$ & 050965.46 & -004.37 & 050956.54 \\
\hline 153415 & $0000 \mathrm{E}$ & $000500 S$ & 050965.41 & -004.60 & 050956.59 \\
\hline 153500 & $0000 \mathrm{E}$ & $000450 S$ & 050967.41 & -004.02 & 050958.39 \\
\hline 153542 & $0000 \mathrm{E}$ & $000400 S$ & 050962.19 & -004.95 & 050953.96 \\
\hline 153624 & $0000 \mathrm{E}$ & OOO350S & 050965.67 & -003.16 & 050957.73 \\
\hline 153712 & $0000 \mathrm{E}$ & $000300 \mathrm{~S}$ & 050971.70 & -002.36 & 050964.31 \\
\hline 153757 & $0000 \mathrm{E}$ & $000250 \mathrm{~S}$ & 050970.41 & -002.54 & 050963.18 \\
\hline 153839 & $0000 \mathrm{E}$ & $000200 \mathrm{~S}$ & 050968.58 & -004.76 & 050961.39 \\
\hline 153915 & $0000 \mathrm{E}$ & $000150 \mathrm{~S}$ & 050968.22 & -002.05 & 050961.39 \\
\hline 154003 & $0000 \mathrm{E}$ & $000100 \mathrm{~S}$ & 050975.68 & -000.15 & 050968.81 \\
\hline 154051 & $0000 \mathrm{E}$ & $000100 \mathrm{~S}$ & 050974.45 & -000.66 & 050968.36 \\
\hline 154127 & $0000 \mathrm{E}$ & 000050S & 050970.50 & -003.15 & 050964.45 \\
\hline 154200 & $0000 \mathrm{E}$ & $000050 \mathrm{~S}$ & 050970.18 & -003.16 & 050964.44 \\
\hline 154257 & $0000 \mathrm{E}$ & 000050S & 050966.76 & -002.21 & 050961.61 \\
\hline 154551 & $0000 \mathrm{E}$ & $000000 \mathrm{~S}$ & 050972.24 & -001.44 & 050970.08 \\
\hline 154618 & $0000 \mathrm{E}$ & $000000 \mathrm{~N}$ & 050971.72 & -001.65 & 050969.90 \\
\hline 154651 & $0000 \mathrm{E}$ & $000000 \mathrm{~N}$ & 050971.11 & -002.55 & 050969.34 \\
\hline 154754 & $0000 \mathrm{E}$ & $000050 \mathrm{~N}$ & 050961.25 & -004.36 & 050959.81 \\
\hline 154924 & 0000E & $000050 \mathrm{~N}$ & 050960.18 & -004.69 & 050958.75 \\
\hline 154957 & $0000 \mathrm{E}$ & $000100 \mathrm{~N}$ & 050963.12 & -004.80 & 050962.09 \\
\hline 155033 & $0000 \mathrm{E}$ & $000100 \mathrm{~N}$ & 050962.76 & -005.20 & 050961.56 \\
\hline 155106 & OOOOE & $000150 \mathrm{~N}$ & 050968.85 & -004.05 & 050967.70 \\
\hline 155142 & $0000 \mathrm{E}$ & $000200 \mathrm{~N}$ & 050962.32 & -003.36 & 050961.18 \\
\hline 155215 & $0000 \mathrm{E}$ & $000200 \mathrm{~N}$ & 050961.76 & -003.84 & 050960.74 \\
\hline 155251 & $0000 \mathrm{E}$ & $000250 \mathrm{~N}$ & 050951.59 & -005.99 & 050950.38 \\
\hline 155342 & $0000 \mathrm{E}$ & $000300 \mathrm{~N}$ & 050991.04 & 008.53 & 050989.70 \\
\hline 155418 & $0000 \mathrm{E}$ & $000300 \mathrm{~N}$ & 050990.76 & 008.38 & 050989.63 \\
\hline 155509 & $0000 \mathrm{E}$ & $000350 \mathrm{~N}$ & 050964.74 & -003.86 & 050963.85 \\
\hline 155557 & 0000E & $000400 \mathrm{~N}$ & 050966.64 & -002.16 & 050965.79 \\
\hline
\end{tabular}


Appendix F.2.2 Magnetic survey data (Continued)

\begin{tabular}{|c|c|c|c|c|c|}
\hline Time & Line & $\begin{array}{c}\text { Station } \\
\text { (ft) }\end{array}$ & $\begin{array}{l}\text { Total Fld } \\
\text { (nT) }\end{array}$ & $\begin{array}{c}\text { Gradient } \\
\text { (nT/m) }\end{array}$ & $\begin{array}{c}\text { Corrected } \\
\text { Total Fld } \\
\text { (nT) }\end{array}$ \\
\hline
\end{tabular}

$\begin{array}{llllll}155709 & 0000 \mathrm{E} & 000450 \mathrm{~N} & 050953.42 & -007.71 & 050952.82\end{array}$

$\begin{array}{llllll}155742 & 0000 \mathrm{E} & 000450 \mathrm{~N} & 050953.07 & -007.46 & 050952.59\end{array}$

$\begin{array}{llllll}155821 & 0000 \mathrm{E} & 000500 \mathrm{~N} & 050957.02 & -004.23 & 050956.86\end{array}$ 
Appendix F.2.2 Magnetic survey data (Continued)

Ue-5PW-3

Gem Systems GSM-19 13 IX 90 ID 000000001

20 VII92

\begin{tabular}{|c|c|c|c|c|c|}
\hline Time & Line & $\begin{array}{l}\text { Station } \\
\text { (ft) }\end{array}$ & $\begin{array}{l}\text { Total Fld } \\
\quad(\mathrm{nT})\end{array}$ & $\begin{array}{c}\text { Gradient } \\
\text { (nT/m) }\end{array}$ & $\begin{array}{c}\text { Corrected } \\
\text { Total Fld } \\
\text { (nT) }\end{array}$ \\
\hline 105245 & $0001 \mathrm{E}$ & $000500 \mathrm{~N}$ & 050838.90 & -001.23 & 050964.03 \\
\hline 105445 & $0001 \mathrm{E}$ & $000450 \mathrm{~N}$ & 050837.55 & -002.57 & 050963.07 \\
\hline 105533 & $0001 \mathrm{E}$ & $000400 \mathrm{~N}$ & 050835.79 & -005.91 & 050961.44 \\
\hline 105600 & $0001 \mathrm{E}$ & $000400 \mathrm{~N}$ & 050834.87 & -006.60 & 050960.61 \\
\hline 105651 & 0001E & $000350 \mathrm{~N}$ & 050837.66 & -004.09 & 050963.37 \\
\hline 105742 & 0001E & $000300 \mathrm{~N}$ & 050836.95 & -004.38 & 050962.51 \\
\hline 105827 & 0001E & $000250 \mathrm{~N}$ & 050839.52 & -003.62 & 050965.47 \\
\hline 105909 & $0001 E$ & $000200 \mathrm{~N}$ & 050839.97 & -002.95 & 050966.35 \\
\hline 110015 & $0001 \mathrm{E}$ & $000150 \mathrm{~N}$ & 050840.75 & -002.99 & 050967.62 \\
\hline 110042 & $0001 E$ & $000150 \mathrm{~N}$ & 050839.90 & -003.41 & 050967.22 \\
\hline 110121 & $0001 \mathrm{E}$ & $000100 \mathrm{~N}$ & 050840.03 & -002.34 & 050967.56 \\
\hline 110206 & 0001E & $000050 \mathrm{~N}$ & 050840.63 & -002.04 & 050968.61 \\
\hline 110233 & $0001 \mathrm{E}$ & $000050 \mathrm{~N}$ & 050840.34 & -002.23 & 050968.35 \\
\hline 110303 & $0001 \mathrm{E}$ & $000050 \mathrm{~N}$ & 050840.04 & -002.38 & 050968.21 \\
\hline 110345 & 0001E & $000000 \mathrm{~N}$ & 050841.31 & -001.86 & 050969.64 \\
\hline 110412 & $0001 E$ & 000000S & 050840.69 & -002.39 & 050968.95 \\
\hline 110439 & 0001E & $000000 S$ & 050839.80 & -002.97 & 050968.43 \\
\hline 110545 & 0001E & OOOO50S & 050834.42 & -005.31 & 050963.34 \\
\hline 110621 & 0001E & OOOO50S & 050833.25 & -006.56 & 050962.35 \\
\hline 110712 & 0001E & $000100 S$ & 050836.36 & -004.95 & 050965.31 \\
\hline 110739 & 0001E & O00100S & 050835.95 & -005.78 & 050964.56 \\
\hline 110821 & 0001E & $000150 S$ & 050835.51 & -004.74 & 050963.78 \\
\hline 110851 & 0001E & O00150S & 050834.75 & -005.40 & 050962.97 \\
\hline 110927 & 0001E & $000200 S$ & 050836.60 & -004.07 & 050964.75 \\
\hline 111015 & 0001E & OOO250S & 050837.74 & -003.23 & 050966.17 \\
\hline 111057 & 0001E & 000300S & 050839.44 & -000.90 & 050968.13 \\
\hline 111124 & 0001E & 000300S & 050839.22 & -001.06 & 050967.92 \\
\hline 111212 & 0001E & OO0350S & 050842.06 & -000.90 & 050970.71 \\
\hline 111257 & $0001 \mathrm{E}$ & $000400 S$ & 050833.57 & -005.46 & 050962.13 \\
\hline Time & Line & $\begin{array}{l}\text { Station } \\
\text { (ft) }\end{array}$ & $\begin{array}{l}\text { Total Fld } \\
\text { (nT) }\end{array}$ & $\begin{array}{c}\text { Gradient } \\
(\mathrm{nT} / \mathrm{m})\end{array}$ & $\begin{array}{c}\text { Corrected } \\
\text { Total Fld } \\
\text { (nT) }\end{array}$ \\
\hline 111324 & O001E & 000400S & 050833.14 & -006.19 & 050961.36 \\
\hline 111403 & 0001E & $000450 S$ & 050839.32 & -003.15 & 050967.41 \\
\hline 111442 & 0001E & 000500S & 050837.62 & -004.33 & 050965.58 \\
\hline 111506 & 0001E & 000500S & 050837.17 & -005.12 & 050965.00 \\
\hline
\end{tabular}


Appendix F.2.2 Magnetic survey data (Continued)

\begin{tabular}{|c|c|c|c|c|c|}
\hline Time & Line & $\begin{array}{c}\text { Station } \\
(\mathrm{ft})\end{array}$ & $\begin{array}{l}\text { Total Fld } \\
\text { (nT) }\end{array}$ & $\begin{array}{c}\text { Gradient } \\
\text { (nT/m) }\end{array}$ & $\begin{array}{l}\text { Corrected } \\
\text { Total Fld } \\
\text { (nT) }\end{array}$ \\
\hline 112315 & $0001 N$ & $000500 \mathrm{~W}$ & 050830.31 & 001.98 & 050956.69 \\
\hline 112348 & $0001 N$ & $000500 \mathrm{~W}$ & 050830.43 & 001.95 & 050956.65 \\
\hline 112424 & $0001 N$ & $000500 \mathrm{~W}$ & 050825.95 & -003.21 & 050951.96 \\
\hline 112454 & $0001 N$ & $000500 \mathrm{~W}$ & 050825.91 & -003.54 & 050951.90 \\
\hline 112600 & $0001 N$ & $000500 \mathrm{~W}$ & 050832.65 & 003.33 & 050958.02 \\
\hline 112642 & $0001 N$ & $000500 \mathrm{~W}$ & 050827.19 & -002.36 & 050952.59 \\
\hline 112739 & $0001 N$ & $000500 \mathrm{~W}$ & 050832.14 & 003.02 & 050957.80 \\
\hline 112930 & $0001 N$ & $000500 \mathrm{~W}$ & 050828.81 & -001.25 & 050953.92 \\
\hline 112957 & $0001 N$ & $000500 \mathrm{~W}$ & 050828.69 & -001.30 & 050953.93 \\
\hline 113027 & $0001 N$ & $000500 \mathrm{~W}$ & 050828.77 & -000.78 & 050954.36 \\
\hline 113103 & $0001 N$ & $000500 \mathrm{~W}$ & 050829.53 & -000.02 & 050955.09 \\
\hline 113148 & $0001 N$ & $000500 \mathrm{~W}$ & 050829.30 & -000.51 & 050954.75 \\
\hline 113554 & $0001 N$ & $000450 \mathrm{~W}$ & 050827.70 & -004.01 & 050952.72 \\
\hline 113642 & $0001 N$ & $000400 \mathrm{~W}$ & 050828.80 & -002.40 & 050953.71 \\
\hline 113730 & $0001 N$ & $000350 \mathrm{~W}$ & 050830.62 & -006.25 & 050954.95 \\
\hline 113757 & $0001 N$ & $000350 \mathrm{~W}$ & 050829.49 & -007.44 & 050953.95 \\
\hline 113824 & $0001 N$ & $000350 \mathrm{~W}$ & 050829.77 & -007.30 & 050954.06 \\
\hline 113906 & $0001 N$ & $000300 \mathrm{~W}$ & 050832.07 & -005.23 & 050956.46 \\
\hline 113954 & $0001 N$ & $000250 \mathrm{~W}$ & 050833.75 & -003.42 & 050958.00 \\
\hline 114033 & $0001 N$ & $000200 \mathrm{~W}$ & 050838.65 & -002.29 & 050962.71 \\
\hline 114121 & $0001 N$ & $000150 W$ & 050843.03 & -003.71 & 050967.13 \\
\hline 114145 & $0001 N$ & 000150W & 050842.05 & -004.55 & 050966.37 \\
\hline 114227 & $0001 N$ & $000100 \mathrm{~W}$ & 050839.30 & -004.41 & 050963.31 \\
\hline 114254 & $0001 N$ & $000100 \mathrm{~W}$ & 050838.85 & -004.74 & 050963.06 \\
\hline 114348 & $0001 N$ & 000050W & 050839.91 & -002.31 & 050964.03 \\
\hline 114415 & $0001 N$ & $000050 \mathrm{~W}$ & 050839.83 & -002.53 & 050963.94 \\
\hline 114506 & $0001 N$ & $000000 \mathrm{~W}$ & 050846.03 & -000.95 & 050970.34 \\
\hline 114533 & $0001 N$ & $000000 \mathrm{E}$ & 050846.15 & -001.07 & 050970.48 \\
\hline 114733 & $0001 N$ & $000050 \mathrm{E}$ & 050843.00 & -002.96 & 050966.54 \\
\hline 114800 & $0001 N$ & $000050 \mathrm{E}$ & 050843.39 & -002.47 & 050966.70 \\
\hline 114951 & $0001 N$ & $000100 \mathrm{E}$ & 050847.68 & -002.99 & 050970.92 \\
\hline 115015 & $0001 N$ & $000100 \mathrm{E}$ & 050847.61 & -003.02 & 050970.63 \\
\hline 115054 & $0001 N$ & $000150 \mathrm{E}$ & 050847.40 & -001.89 & 050970.43 \\
\hline 115139 & $0001 N$ & $000200 \mathrm{E}$ & 050847.15 & -004.29 & 050970.20 \\
\hline 115227 & $0001 N$ & $000250 \mathrm{E}$ & 050849.94 & -000.65 & 050973.10 \\
\hline 115315 & $0001 N$ & $000300 \mathrm{E}$ & 050853.70 & -003.03 & 050976.78 \\
\hline Time & Line & $\begin{array}{c}\text { Station } \\
\text { (ft) }\end{array}$ & $\begin{array}{l}\text { Total Fld } \\
\text { (nT) }\end{array}$ & $\begin{array}{c}\text { Gradient } \\
\text { (nT/m) }\end{array}$ & $\begin{array}{l}\text { Corrected } \\
\text { Total Fld } \\
\text { (nT) }\end{array}$ \\
\hline 115415 & $0001 \mathrm{~N}$ & O00350E & 050855.26 & -003.31 & 050978.01 \\
\hline 115500 & $0001 N$ & 000400E & 050851.24 & -004.12 & 050973.95 \\
\hline
\end{tabular}


Appendix F.2.2 Magnetic survey data (Continued)

$\begin{array}{ccccc}\text { Time Line } & \begin{array}{c}\text { Station } \\ (\mathrm{ft})\end{array} & \begin{array}{c}\text { Total Fld } \\ (\mathrm{nT})\end{array} & \begin{array}{c}\text { Gradient } \\ (\mathrm{nT} / \mathrm{m})\end{array} & \begin{array}{c}\text { Corrected } \\ \text { Total Fld } \\ (\mathrm{nT})\end{array}\end{array}$

$\begin{array}{llllll}115527 & 0001 \mathrm{~N} & 000400 \mathrm{E} & 050850.59 & -004.78 & 050973.39\end{array}$

$\begin{array}{llllll}115612 & 0001 \mathrm{~N} & 000450 \mathrm{E} & 050857.85 & -002.80 & 050980.06\end{array}$

$\begin{array}{llllll}115700 & 0001 \mathrm{~N} & 000500 \mathrm{E} & 050855.53 & -002.73 & 050977.74\end{array}$

$\begin{array}{llllll}115745 & 0001 \mathrm{~N} & 000500 \mathrm{E} & 050855.56 & -002.75 & 050977.64\end{array}$

$\begin{array}{llllll}115812 & 0001 \mathrm{~N} & 000500 \mathrm{E} & 050855.49 & -002.72 & 050977.77\end{array}$ 
Appendix F.3.1 Description of borehole geophysical logging tools used

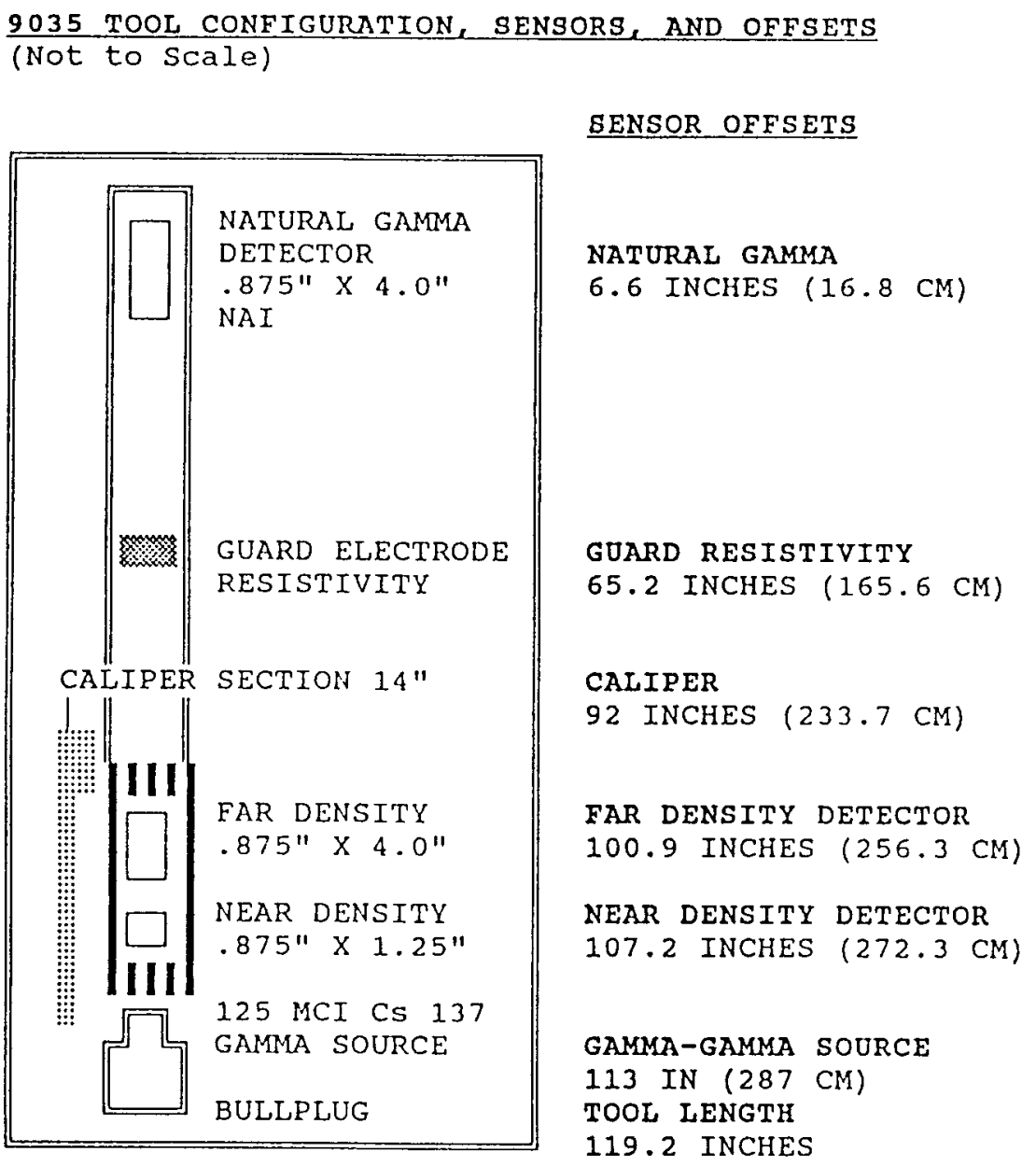

TOOL SPECIFICATIONS:

Length: 119.2 Inches $(299.7 \mathrm{~cm})$ Temperature: $185 \mathrm{~F}$ (85 C) Diameter: 2.8 Inches $(7.1 \mathrm{~cm}) \quad$ Pressure: 2500 PSI $(175 \mathrm{~kg} / \mathrm{cc})$

Weight: 78 Pounds $(35.3 \mathrm{~kg})$ Logging speed: 30 FPM (9 M/M)

\section{SENSOR RESPONSE RANGES}

$\begin{array}{lll}\text { Sensor } & \text { Response Limits } & \text { Accuracy } \\ \text { Natural Gamma } & 0 \text { to } 10,000 \text { api units } & +/-5 \% \\ \text { Long Arm Caliper } & 0 \text { to } 14 \text { inches } & +/-.25 \text { inches } \\ \text { Near Density } & .5 \text { to } 3.5 \mathrm{~g} / \mathrm{Cc} & +/-.05 \mathrm{~g} / \mathrm{cc} \\ \text { Far Density } & .5 \text { to } 3.5 \mathrm{~g} / \mathrm{cc} & +/-.05 \mathrm{~g} / \mathrm{Cc} \\ \text { Resistivity } & 0 \text { to } 60,000 \mathrm{ohm} \text { meters } & +/-5 \%\end{array}$


Appendix F.3.1 Description of borehole geophysical logging tools used (Continued)

9030 TOOL CONFIGURATION, SENSORS, AND OFFSETS

BENSOR OFFSETS

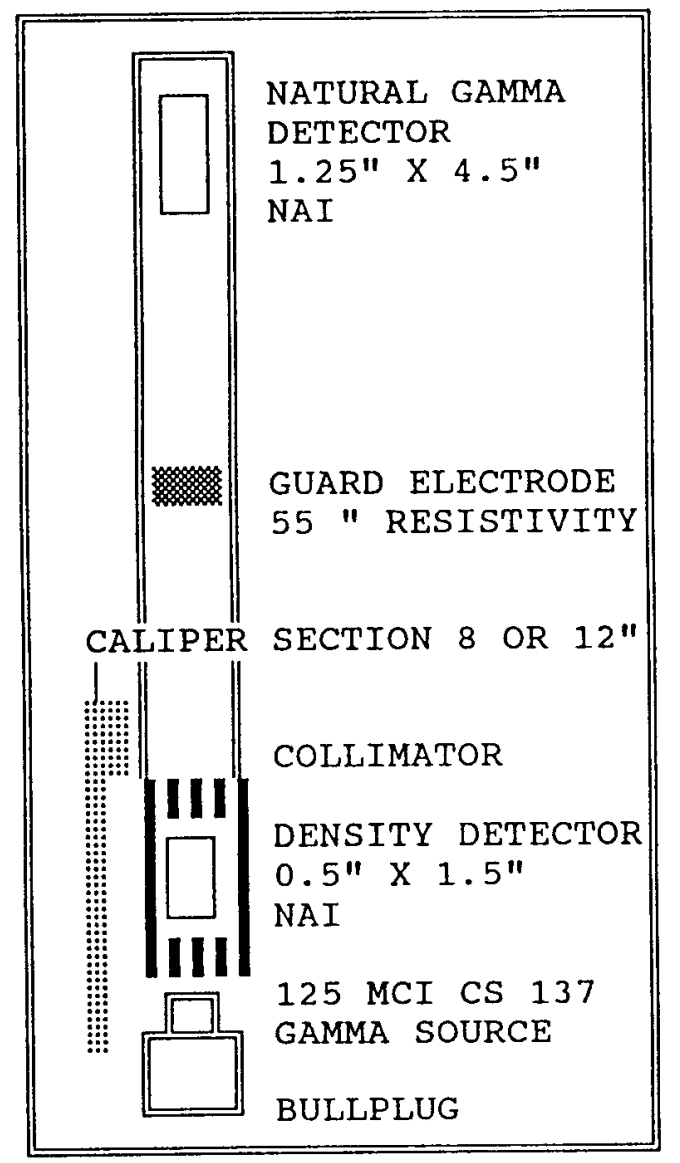

NATURAL GAMMA

18 INCHES $(45.7 \mathrm{CM})$

GUARD RESISTIVITY

28 INCHES $(71.1 \mathrm{CM})$

CALIPER

102 INCHES (259 CM)

DENSITY DETECTOR

111.6 INCHES $(283.5 \mathrm{CM})$

SOURCE TO DETECTOR SPACING

8.0 INCHES $(20.3 \mathrm{CM})$

TOOL LENGTH

121 INCHES $(307.3 \mathrm{CM})$

TOOL SPECIFICATIONS:

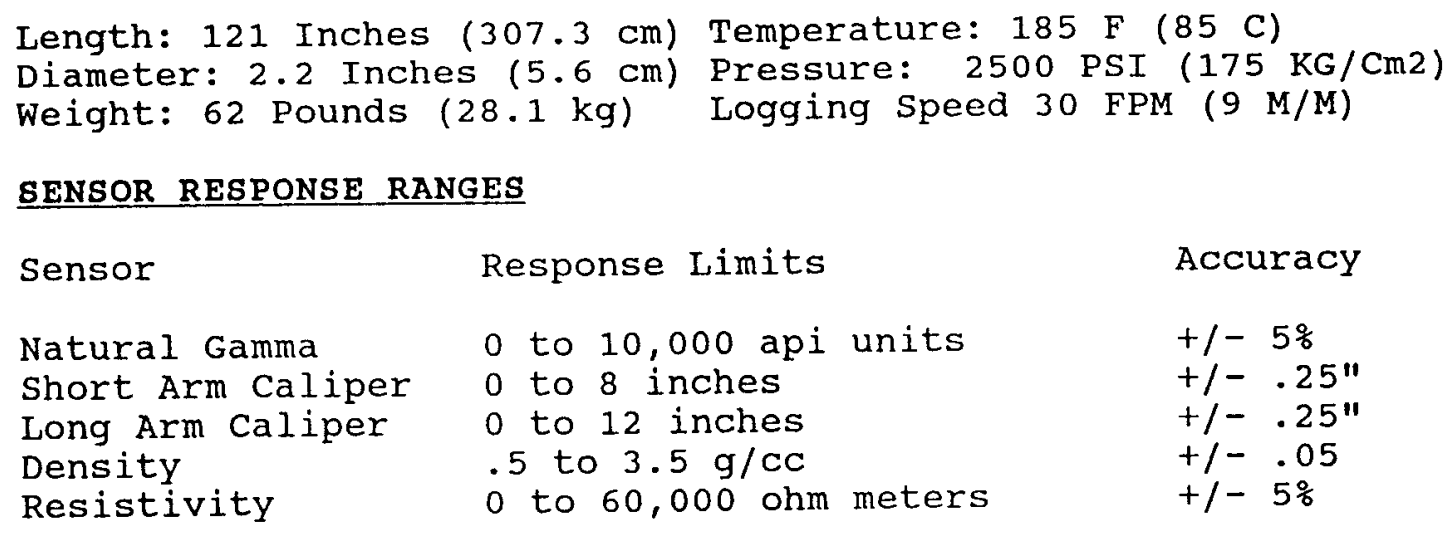


Appendix F.3.1 Description of borehole geophysical logging tools used (Continued)

9071 TOOL CONFIGURATION, SENSORS, AND OFFSETS

(Not to Scale)

\section{GENSOR OFFSETS}

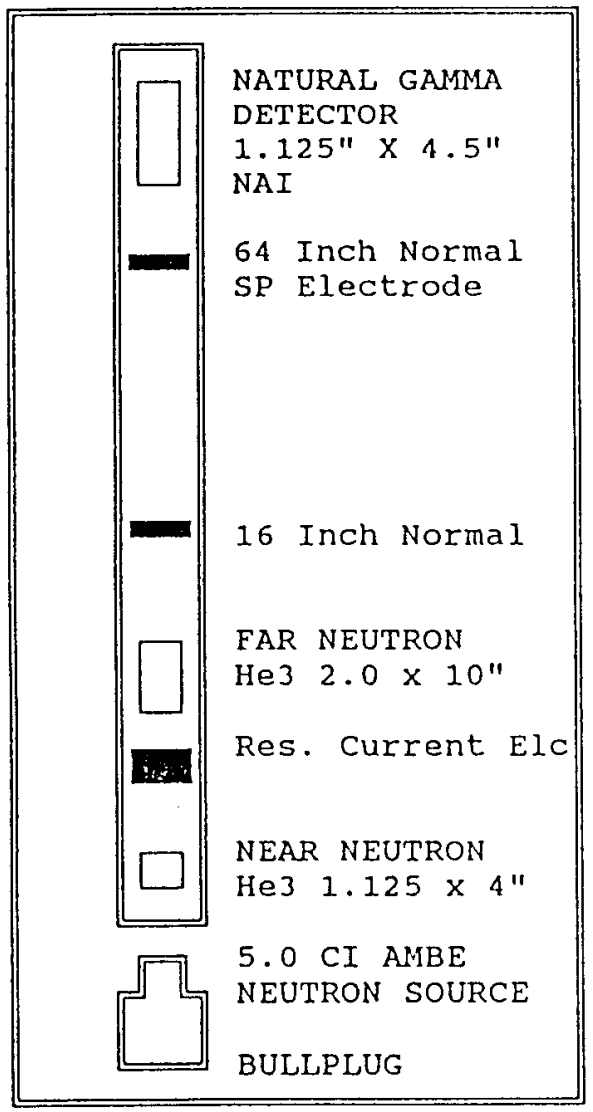

NATURAL GAMMA

14 INCHES $(35.6 \mathrm{CM})$

64 INCH NORMAL 8 P

20 INCHES $(50.8 \mathrm{CM})$

16 INCH NORMAL ELECTRODE

68 INCHES $(172.7 \mathrm{CM})$

FAR NEUTRON DETECTOR

75 INCHES (190.5 CM)

RESISTIVITY CURRENT ELECTRODE 84 INCHES $(213.4 \mathrm{CM})$

NEAR NEOTRON DETECTOR

88.25 INCHES (224.2 CM)

AMBE 241 SOURCE

99 INCHES (251.5 CM)

TOOL LENGTH

105 INCHES $(266.7 \mathrm{CM})$

TOOL SPECIFICATIONS:

Length: 105 Inches $(266.7 \mathrm{~cm})$

Temperature: $221 \mathrm{~F}(105 \mathrm{C})$

Diameter: 2.9 Inches $(7.4 \mathrm{~cm})$

Pressure: 3300 PSI $(232 \mathrm{~kg} / \mathrm{CC})$

Weight: 57 Pounds $(26 \mathrm{~kg}$ )

Logging speed: 30 FPM $(9 \mathrm{M} / \mathrm{M})$

\section{SENSOR RESPONSE RANGES}

$\begin{array}{lll}\text { Sensor } & \text { Response Limits } & \text { Accuracy } \\ \text { Natural Gamma } & 0 \text { to } 10,000 \text { api units } & +1-5 \% \\ \text { Near Neutron CPS } & 0 \text { to } 20,000 & +1-5 \% \text { cps } \\ \text { Far Neutron CPS } & 0 \text { to } 5,000 & +1-5 \% \text { cps } \\ \text { Neutron Porosity } & -10 \text { to } 100 \text { \% Porosity } & +1-2 \% \text { to } 60 \% \\ \text { Resistivity } & 0 \text { to } 2,000 \text { ohm meters } & +1-5 \% \\ \text { SP } & -400 \text { to } 400 \mathrm{mV} & +1-10 \mathrm{mv}\end{array}$


Appendix F.3.1 Description of borehole geophysical logging tools used (Continued)

9080 TOOL CONFIGURATION, SENSORS, AND OFFSETS

(Not to Scale)

BENSOR OFESETS
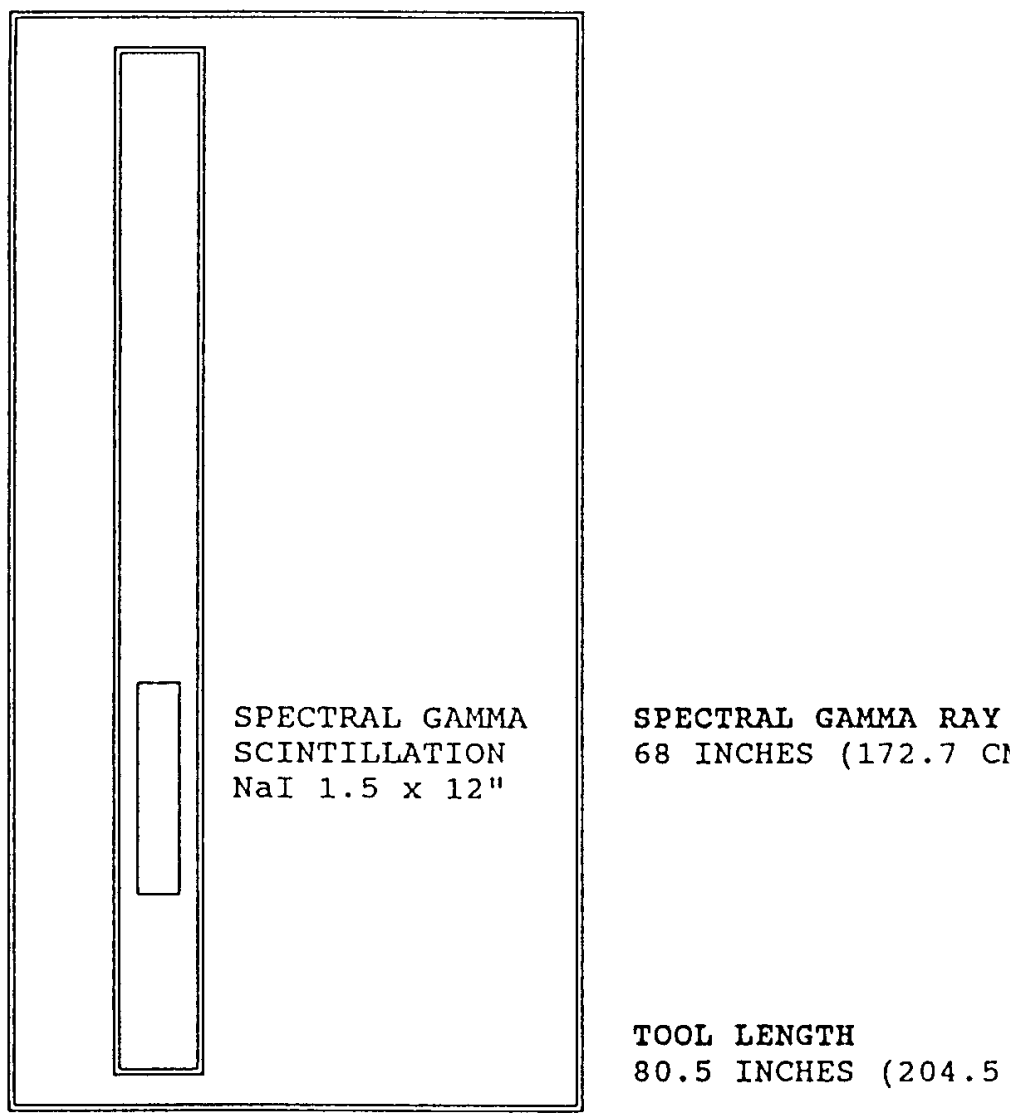

TOOL LENGTH

80.5 INCHES $(204.5 \mathrm{CM})$

TOOL SPECIFICATIONS:

Length: 80.5 Inches $(204.5 \mathrm{~cm})$
Diameter: 2.5 Inches $(6.35 \mathrm{~cm})$
Weight: 47 Pounds $(21.3 \mathrm{~kg})$

\section{SENSOR RESPONSE RANGES}

Sensor

Response Limits

Total Gamma

Potassium

Uranium

Thorium

0 to $100,000 \mathrm{cps}$

0 to 40 percent

0 to $1000 \mathrm{ppm}$

0 to $1000 \mathrm{ppm}$
Temperature: $221 \mathrm{~F}(105 \mathrm{C})$

Pressure: 3300 PSI $(232 \mathrm{~kg} / \mathrm{cm} 2)$

Logging speed: 10 FPM ( $3 \mathrm{M} / \mathrm{M})$

* Accuracy from Technical Report Number 174 . 
Appendix F.3.1 Description of borehole geophysical logging tools used (Continued)

9095 TOOL CONFIGURATION, SENSORS, AND OFFSETS

(Not to Scale)

\section{SENSOR OFFSETS}

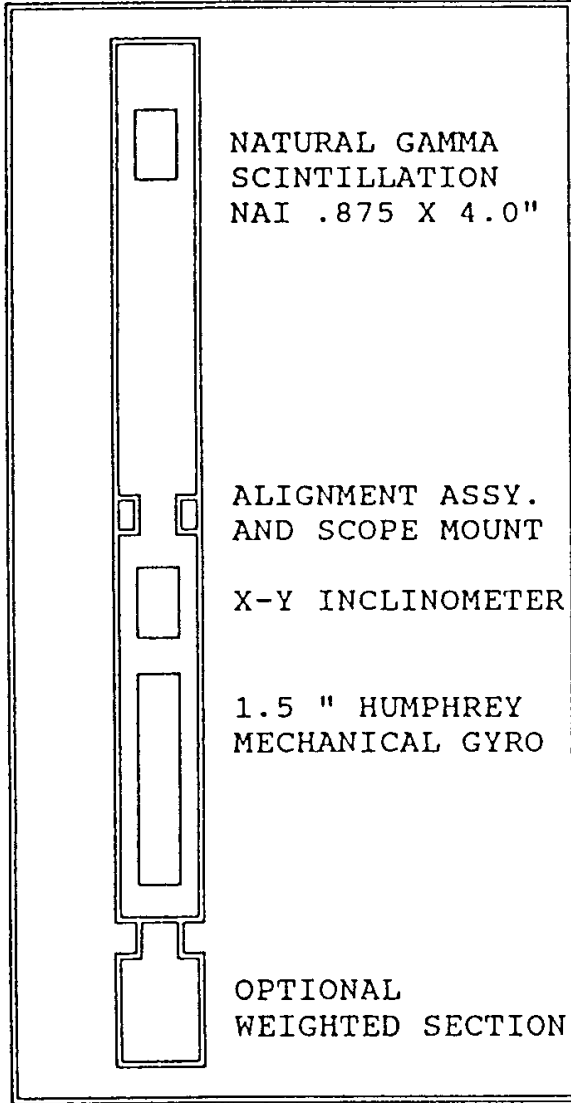

NATURAL GAMMA

6.3 INCHES (16 CM)

$X-Y$ INCLINOMETER

70.9 INCHES $(180 \mathrm{CM})$

GYRO

80.6 INCHES $(204.7 \mathrm{CM})$

TOOL LENGTH (WITHOUT WEIGHT)

95.5 INCHES ( $242.6 \mathrm{CM})$

TOOL SPECIFICATIONS:

Length: 95.5 Inches $(246.6 \mathrm{~cm})$

Temperature: $185 \mathrm{~F}(85 \mathrm{C})$

Diameter: 1.75 Inches $(4.4 \mathrm{~cm})$

Pressure: 3300 PSI $(232 \mathrm{~kg} / \mathrm{cm} 2)$

Weight: 29.5 Pounds $(13.4 \mathrm{~kg})$

Logging speed: 50 FPM $(15 \mathrm{M} / \mathrm{M})$

\section{SENSOR RESPONSE RANGES}

$\begin{array}{llc}\text { Sensor } & \text { Response Limits } & \text { Accuracy } \\ \text { Natural Gamma } & 0 \text { to } 10,000 \text { api units } & +/-5 \% \\ \text { Inclination } & 0 \text { to } 45 \text { degrees } & +/-.5 \text { degrees } \\ \text { Direction } & 0 \text { to } 360 \text { degrees }+/-2.0 \text { degrees }\end{array}$


Appendix F.3.1 Description of borehole geophysical logging tools used (Continued)
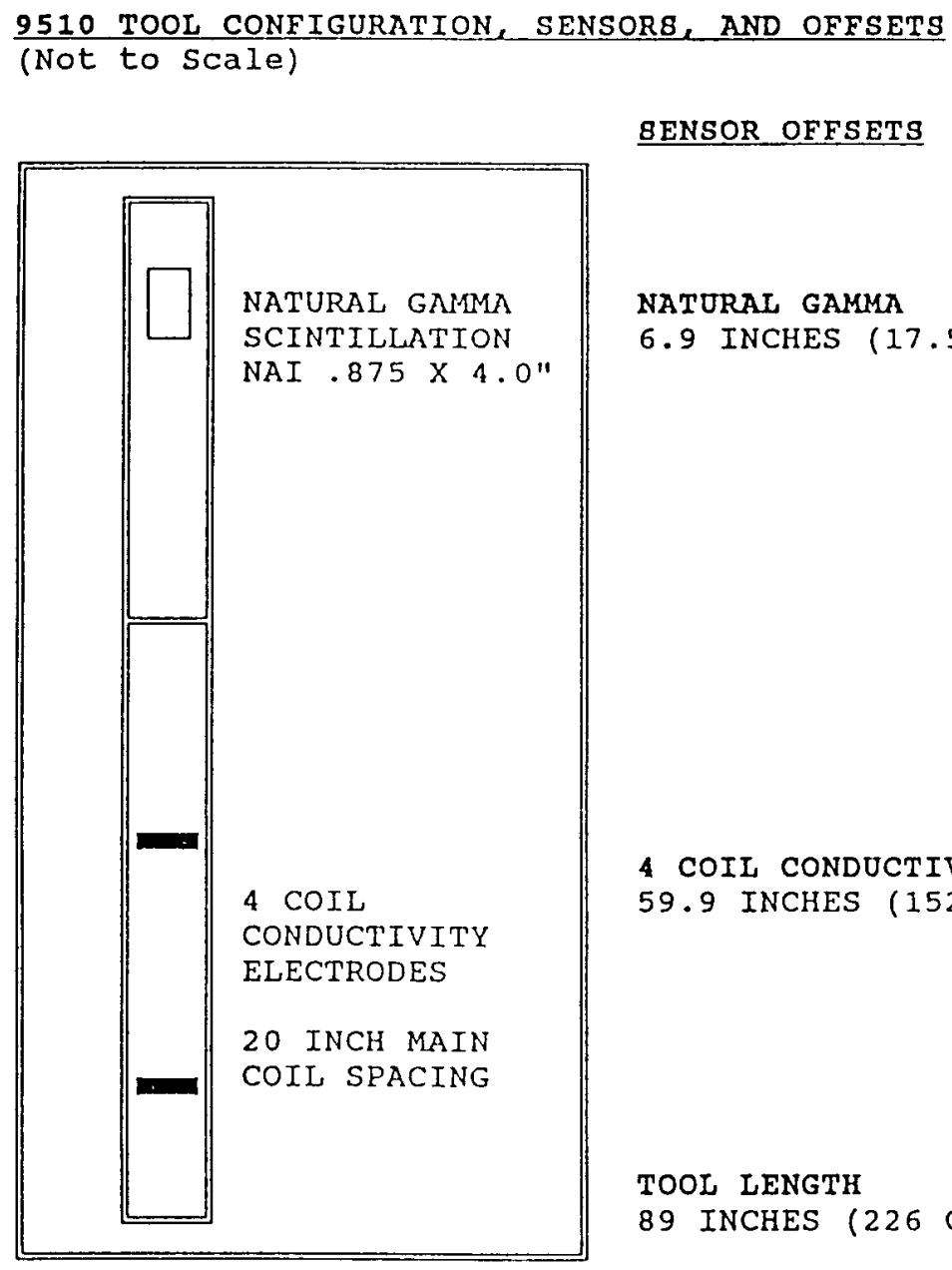

BENSOR OFFSETS

NATURAL GAMMA

6.9 INCHES $(17.5 \mathrm{CM})$

4 COIL CONDUCTIVITY ELECTRODE

59.9 INCHES (152.2CM)

TOOL LENGTH

89 INCHES (226 CM)

TOOL SPECIFICATIONS:

Length: 89.0 Inches $(226 . \mathrm{cm})$

Diameter: 1.625 Inches $(4.1 \mathrm{~cm})$

Weight: 16 Pounds $(7.2 \mathrm{~kg})$

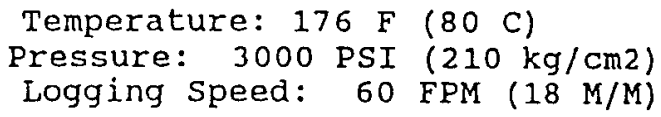

\section{SENSOR RESPONSE RANGES}

Sensor

Natural Gamma Conductivity

\section{Response Limits}

0 to 10,000 api units

0 to 1000 mmho/meter
Accuracy

$+1-5 \%$

$+/-5$ a $50 \mathrm{mmho} / \mathrm{m}$ 
Appendix F.3.2 Borehole geophysical logs run in Ue5PW-1 on 4/20/92

\begin{tabular}{|c|c|c|c|}
\hline \multicolumn{4}{|c|}{ EQUIPMENT DATA SHEET } \\
\hline $\begin{array}{l}\text { HELL \# UESPW-1 } \\
\text { DATE: }\end{array}$ & GAMMA RAY & \multicolumn{2}{|c|}{ DENSITY/NEUTRON } \\
\hline $\begin{array}{l}\text { TOOL INFORMATION } \\
\text { RUN NO. } \\
\text { MODEL NO. } \\
\text { TOOL DIAMETER } \\
\text { DISTANCE TO SOURCE } \\
\text { DETECTOR TYPE } \\
\text { DETECTOR OFFSET (FROM O) } \\
\text { LENGTH \& DIAMETER (NEA) } \\
\text { LENGTH \& DIAMETER (FAY) } \\
\text { LOGGING SPEED } \\
\text { CENTRALIZER } \\
\text { GAMMA RAY API CONVERSION } \\
\text { MANUFACTURER }\end{array}$ & $\begin{array}{l}\text { Three } \\
9030 \\
2.2 " \\
\text { na } \\
\text { Scintln. } \\
18.0 " \\
4.5 \times 1.25 " \\
30 \text { fpm } \\
\text { sidewall } \\
.618 \\
\text { Century }\end{array}$ & $\begin{array}{c}\text { Three } \\
9030 \\
2.2^{\prime \prime} \\
119.6 " \\
1-\text { Sctln } \\
111.6^{\prime \prime} \\
1.5 \times 0.5^{\prime \prime} \\
30 \text { fpm } \\
\text { sidewall } \\
\text { century }\end{array}$ & $\begin{array}{l}\text { Two } \\
9055 \\
1.8^{\prime \prime} \\
111.8^{\prime \prime} \\
1-\mathrm{He} 3 \\
97.8^{\prime \prime} \\
6.0 \times 1.0^{\prime \prime} \\
30 \text { fpm } \\
\text { free hang } \\
1.0176 \\
\text { Century }\end{array}$ \\
\hline $\begin{array}{l}\text { RADIOACTIVE SOURCES } \\
\text { SOURCE TYPE } \\
\text { SOURCE SPACING } \\
\text { SOURCE STRENGTH } \\
\text { SOURCE SERIAL NO. }\end{array}$ & & $\begin{array}{cc}\text { Cs } & 137 \\
8 " & \\
125 & \mathrm{mCi} \\
V L & -1-278\end{array}$ & $\begin{array}{l}\text { AmBe } \\
14^{\prime \prime} \\
1.0 \mathrm{Ci} \\
71-1-404\end{array}$ \\
\hline $\begin{array}{l}\text { TOOL INFORMATION } \\
\text { RUN NO. } \\
\text { MODEL NO. } \\
\text { TOOL DIAMETER } \\
\text { DETECTOR OFFSET (FROM } \\
\text { LOGGING SPEED } \\
\text { TYPE }\end{array}$ & $\begin{array}{l}\text { RESISTIVITY } \\
\text { Four } \\
9510 \\
1.625 \\
59.9 " \\
60 \text { FPM } \\
\text { Single Indct. }\end{array}$ & $\begin{array}{l}\text { CALI } \\
\text { Three } \\
9030 \\
2.2^{\prime \prime} \\
102^{\prime \prime} \\
30 \text { Fi } \\
\text { Sing. }\end{array}$ & $\begin{array}{l}\text { PER } \\
\text { PM Arm } \\
\text { le Arm }\end{array}$ \\
\hline $\begin{array}{l}\text { OTHER TOOL INFORMATION } \\
\text { Detector TYpe and Sjze } \\
\text { Tool TYpe } \\
\text { Offset } \\
\text { Run Number }\end{array}$ & $\begin{array}{l}\text { SPECTRAL GAMHA } \\
\text { NaI } 1.5 \times 12^{\prime \prime} \\
9080 \\
68^{\prime \prime} \\
\text { One }\end{array}$ & & \\
\hline \multicolumn{4}{|c|}{ 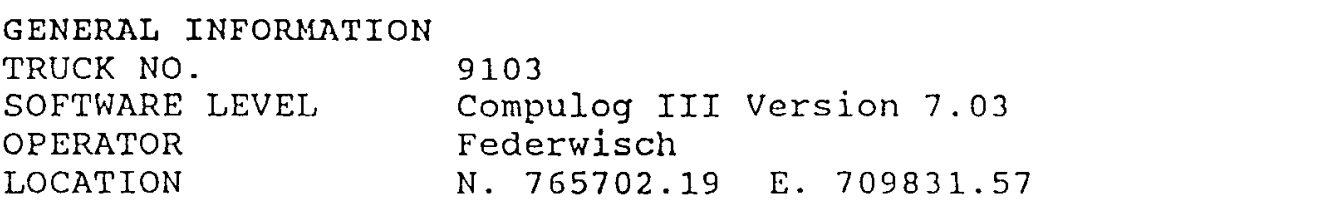 } \\
\hline 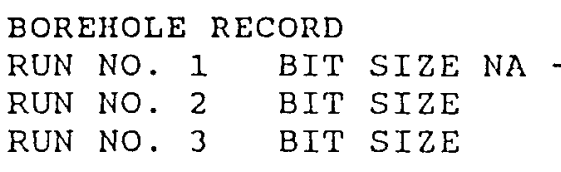 & - CASING IS DRIVE & & \\
\hline $\begin{array}{lll}\text { CASING } & \text { RECORD } \\
\text { RUN NO. } 1 & \text { SIZE } & 10 " \\
\text { RUN NO. } 2 & \text { SIZE } & \\
\text { RUN NO. } 3 & \text { SIZE }\end{array}$ & $\begin{array}{lr}\text { FROM } & 0 \quad \text { TO } \\
\text { FROM } & \text { TO } \\
\text { FROM } & \text { TO }\end{array}$ & $\begin{array}{l}367.5 \\
\end{array}$ & \\
\hline $\begin{array}{ll}\text { REMARKS: } & \text { Run } 1 \text { of this } \\
& \text { Induction Resis } \\
& \text { Casing. }\end{array}$ & $\begin{array}{l}\text { welli } \\
\text { stivity in not va }\end{array}$ & id in & $e l$ \\
\hline
\end{tabular}


Appendix F.3.2 Borehole geophysical logs run in Ue5PW-1 on 4/20/92 (Continued)

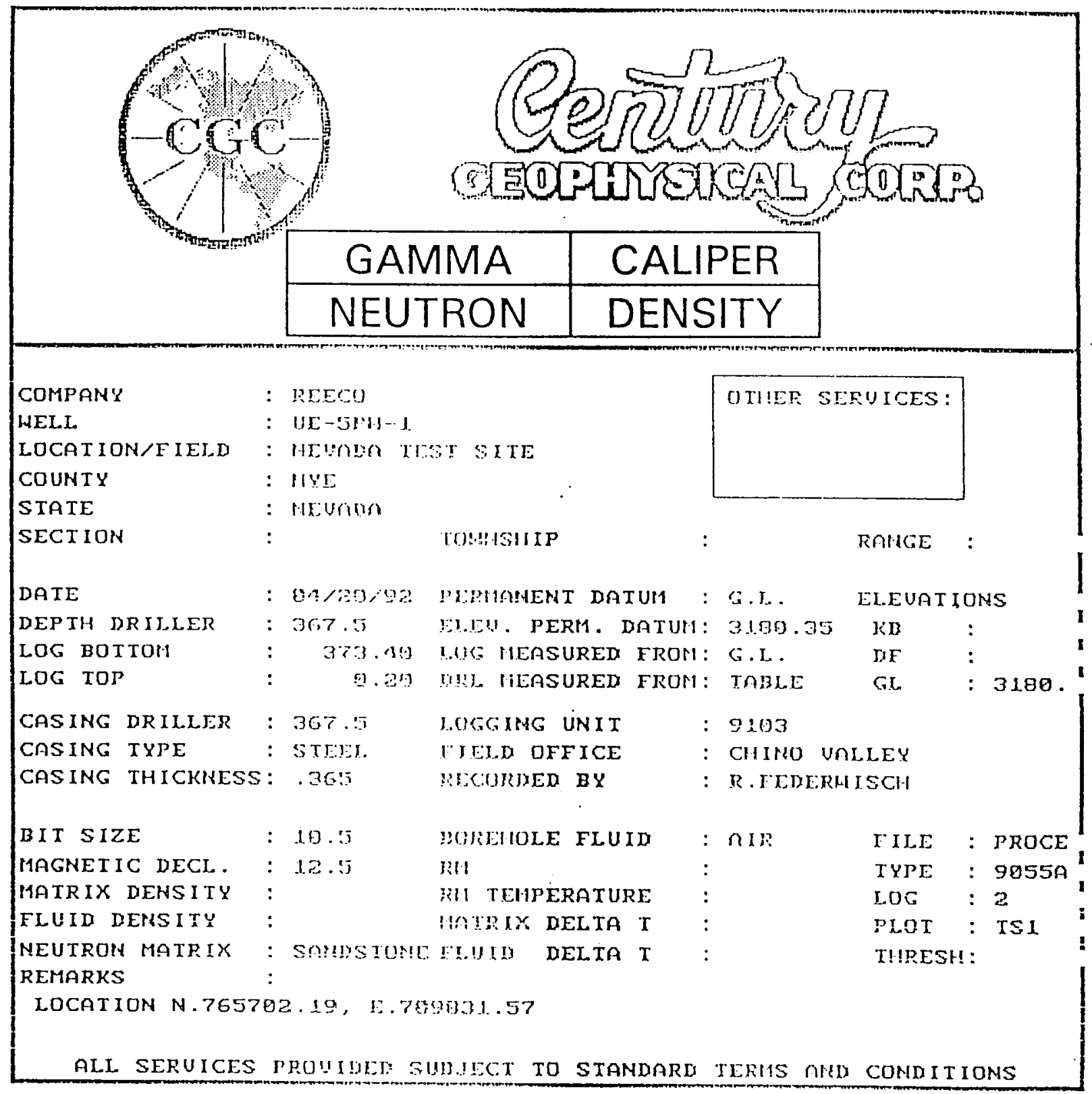


Appendix F.3.2 Borehole geophysical logs run in Ue5PW-1 on 4/20/92 (Continued)
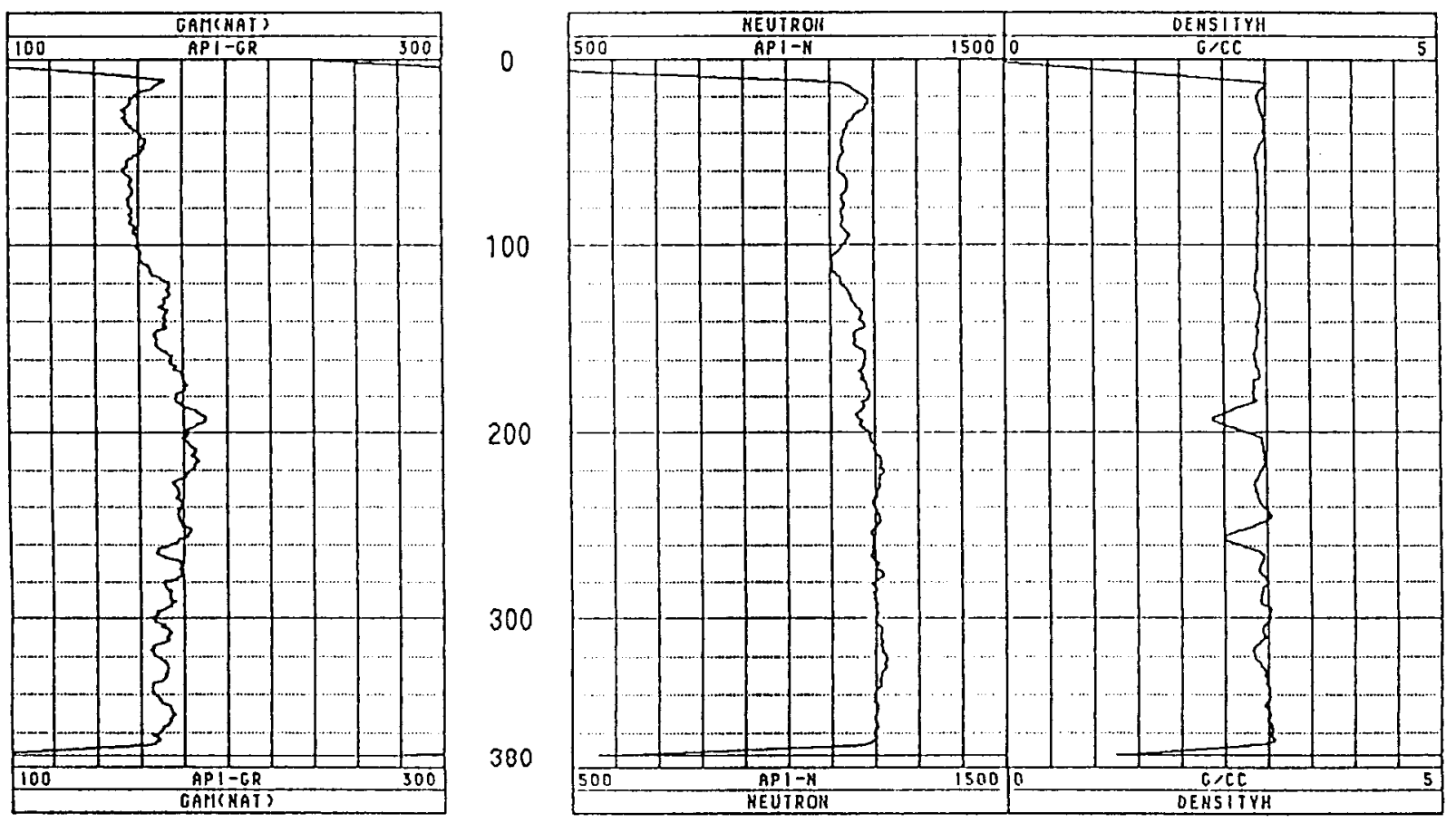

UE-5PW-1 $04 / 20 / 92 \quad 80$ 
Appendix F.3.2 Borehole geophysical logs run in Ue5PW-1 on 4/20/92 (Continued)

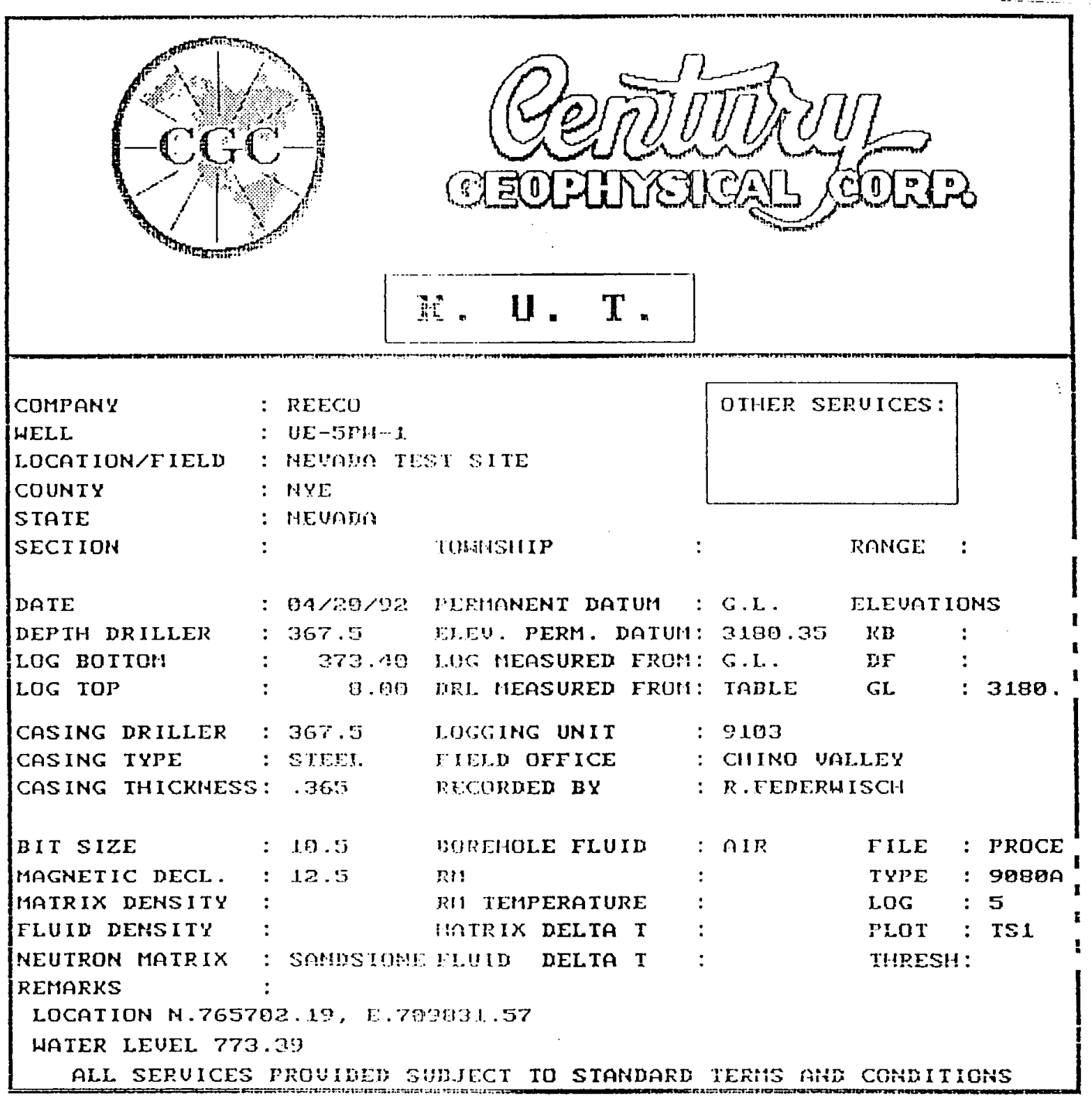


Appendix F.3.2 Borehole geophysical logs run in Ue5PW-1 on 4/20/92 (Continued)
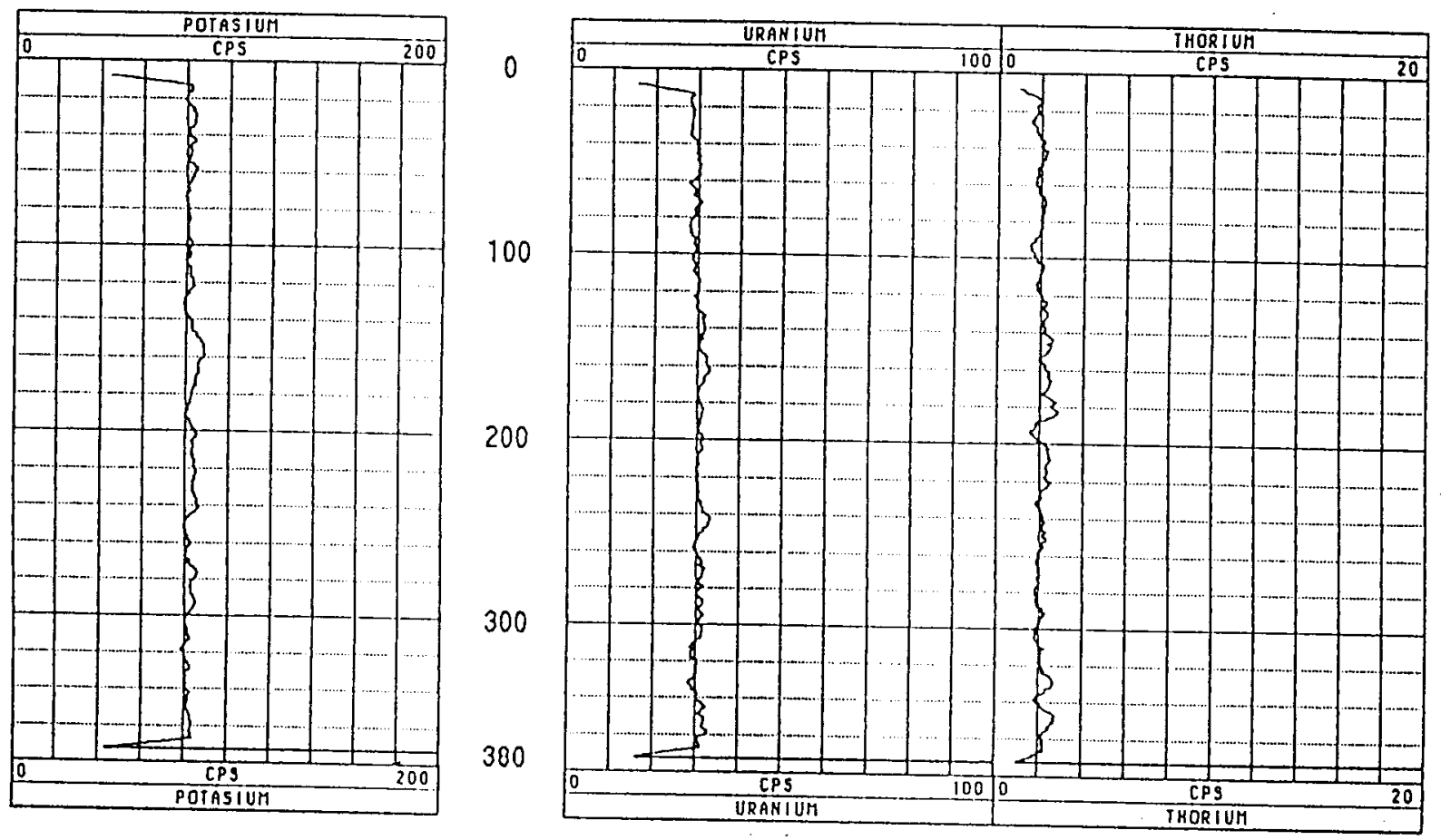

UE-5PW-1 $\quad 04 / 20 / 92 \quad 270$ 
Appendix F.3.3 Borehole geophysical logs run in Ue5PW-1 on $6 / 16 / 92$

\begin{tabular}{|c|c|c|c|}
\hline \multicolumn{4}{|c|}{ EQUIPMENT DATA SHEET } \\
\hline $\begin{array}{ll}\text { WELL \# UE5PH-1 } & \text { UETE: } \\
\text { DATE-16-92 }\end{array}$ & GAMMA RAY & \multicolumn{2}{|c|}{ DENSITY/NEOTRON } \\
\hline $\begin{array}{l}\text { TOOL INFORYATION } \\
\text { RUN NO. } \\
\text { MODEL NO. } \\
\text { TOOL DIAMETER } \\
\text { DISTANCE TO SOURCE } \\
\text { DETECTOR TYPE } \\
\text { DETECTOR OFFSET (FROM O) } \\
\text { LENGTH \& DIAMETER (NEAT) } \\
\text { LENGTH \& DIAMETER (FAT) } \\
\text { LOGGING SPEED } \\
\text { CENTRALIZER } \\
\text { GAMMA RAY API CONVERSION } \\
\text { MANUFACTURER }\end{array}$ & $\begin{array}{l}\text { Three } \\
9035 \\
2.8^{\prime \prime} \\
\text { na } \\
\text { Scintln. } \\
6.6^{\prime \prime} \\
4.0 \times .875^{\prime \prime} \\
30 \text { fpm } \\
\text { sidewall } \\
\text {.658 } \\
\text { Century }\end{array}$ & \begin{tabular}{|c||} 
Three \\
9035 \\
$2.8 "$ \\
$114.7 "$ \\
$2-$ Sctin \\
$101 / 107^{\prime \prime}$ \\
$4.0 \times .875$ \\
$1.2 \times .875$ \\
30 fpm \\
sidewall \\
century
\end{tabular} & $\begin{array}{c}\text { Two } \\
9071 \\
2.9 " 1 \\
9.9 .0 " \\
2-\text { He3 } \\
75 / 88.2 " \\
4.0 \times 1.125 \\
10.0 \times 2.0 \\
30 \text { fpm } \\
\text { free hang } \\
\text { Century }\end{array}$ \\
\hline $\begin{array}{l}\text { RADIOACTIVE SOURCES } \\
\text { SOURCE TYPE } \\
\text { SOURCE SPACING } \\
\text { SOURCE STRENGTH } \\
\text { SOURCE SERIAL NO. }\end{array}$ & & $\left|\begin{array}{ccc}C 5 & 137 \\
6 & 12^{\prime \prime} \\
125 & \mathrm{mCi} \\
\mathrm{VL}-1 & -278\end{array}\right|$ & $\begin{array}{c}\mathrm{AmBe} \\
10.8 \& 24^{\prime \prime} \\
5.0 \mathrm{Ci} \\
71-1-399 \mathrm{~B}\end{array}$ \\
\hline $\begin{array}{l}\text { TOOL INFORMATION } \\
\text { RUN NO. } \\
\text { MODEL NO. } \\
\text { TOOL DIAMETER } \\
\text { DETECTOR OFFSET (FROM } \\
\text { LOGGING SPEED } \\
\text { TYPE }\end{array}$ & RESISTIVITY & $\begin{array}{l}\text { CALIP } \\
\text { Three } \\
9035 \\
2.8 " \\
92^{\prime \prime} \\
30 \text { FP } \\
\text { Singl }\end{array}$ & $\begin{array}{l}\text { PER } \\
\text { PM Arm }\end{array}$ \\
\hline $\begin{array}{l}\text { OTHER TOOL INFORMAION } \\
\text { Detector TYpe and Size } \\
\text { Tool Type } \\
\text { Offset } \\
\text { Run Number }\end{array}$ & $\begin{array}{l}\text { Spectral Gamma } \\
\text { NaI } 1.5 \times 12^{\prime \prime} \\
9080 \\
68^{\prime \prime} \\
\text { One }\end{array}$ & & \\
\hline $\begin{array}{ll}\text { GENERAL INFORHATION } \\
\text { TRUCK NO. } & 9010 \\
\text { SOFTWARE LEVEL } & \text { COMp } \\
\text { OPERATOR } & \text { Fedex } \\
\text { LOCATION } & \mathrm{N} .7\end{array}$ & 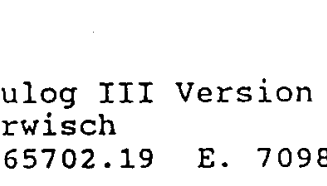 & $\begin{array}{c}7.03 \\
831.57\end{array}$ & \\
\hline 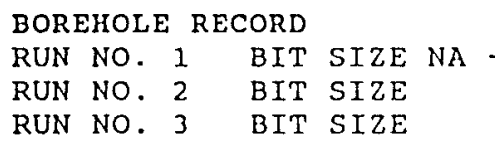 & - CASING IS DRIVE & & \\
\hline 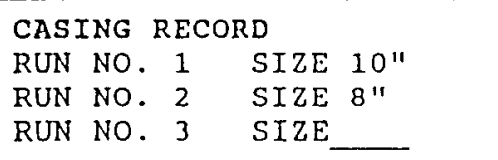 & $\begin{array}{lll}\text { FROM } & 0 & \text { TO } \\
\text { FROM } & 0 & \text { TO } \\
\text { FROM } & & \text { TO } \\
\end{array}$ & $\begin{array}{l}367.5 \\
837.0 \\
\end{array}$ & \\
\hline REMARRS: Run 2 of this & well. & & \\
\hline
\end{tabular}


Appendix F.3.3 Borehole geophysical logs run in Ue5PW-1 on 6/16/92 (Continued)

\begin{tabular}{ll}
\hline & \\
&
\end{tabular}


Appendix F.3.3 Borehole geophysical logs run in Ue5PW-1 on 6/16/92 (Continued)
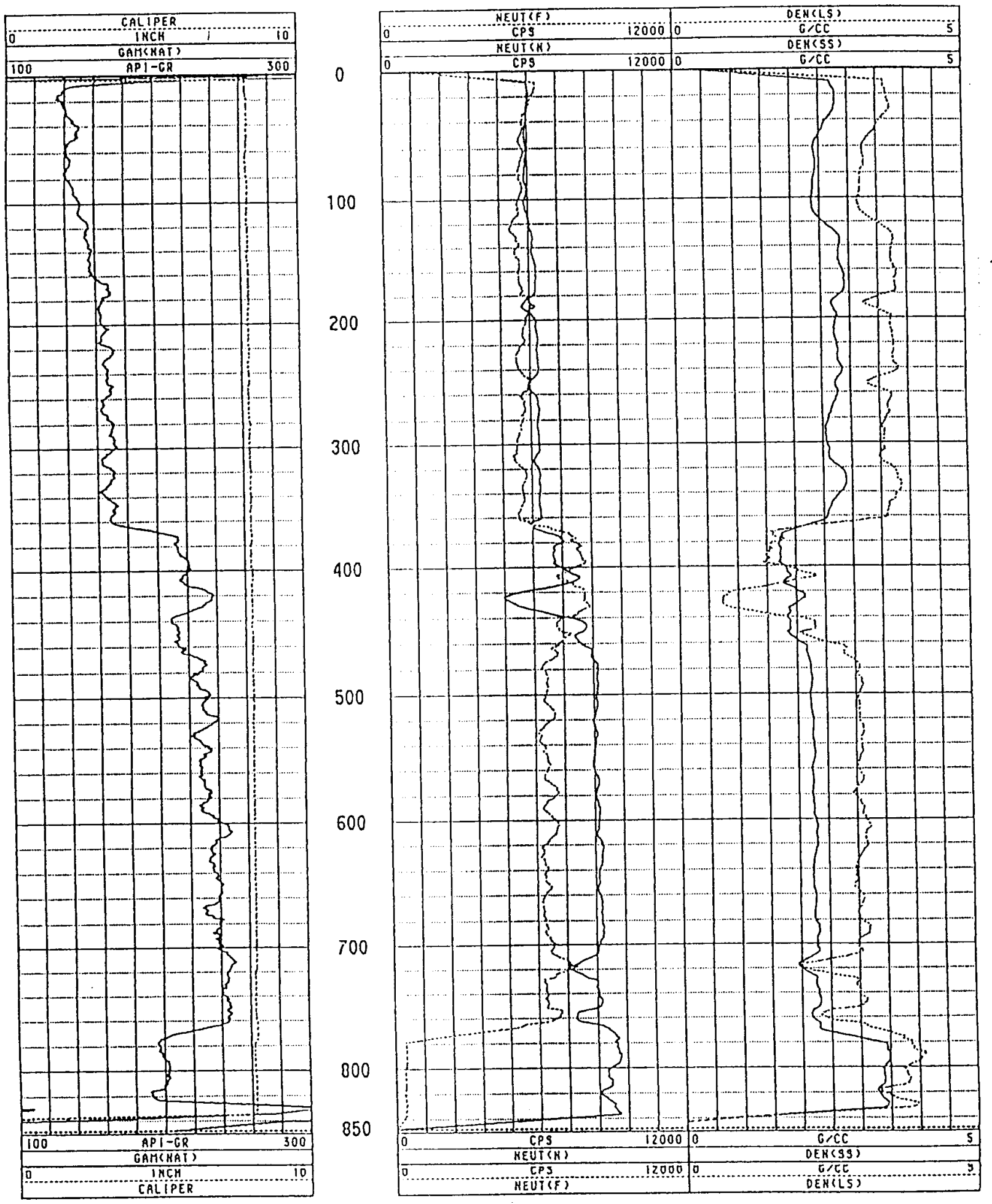

UE-5PW-1 $06 / 16 / 92 \quad 820$ 
Appendix F.3.3 Borehole geophysical logs run in Ue5PW-1 on 6/16/92 (Continued)

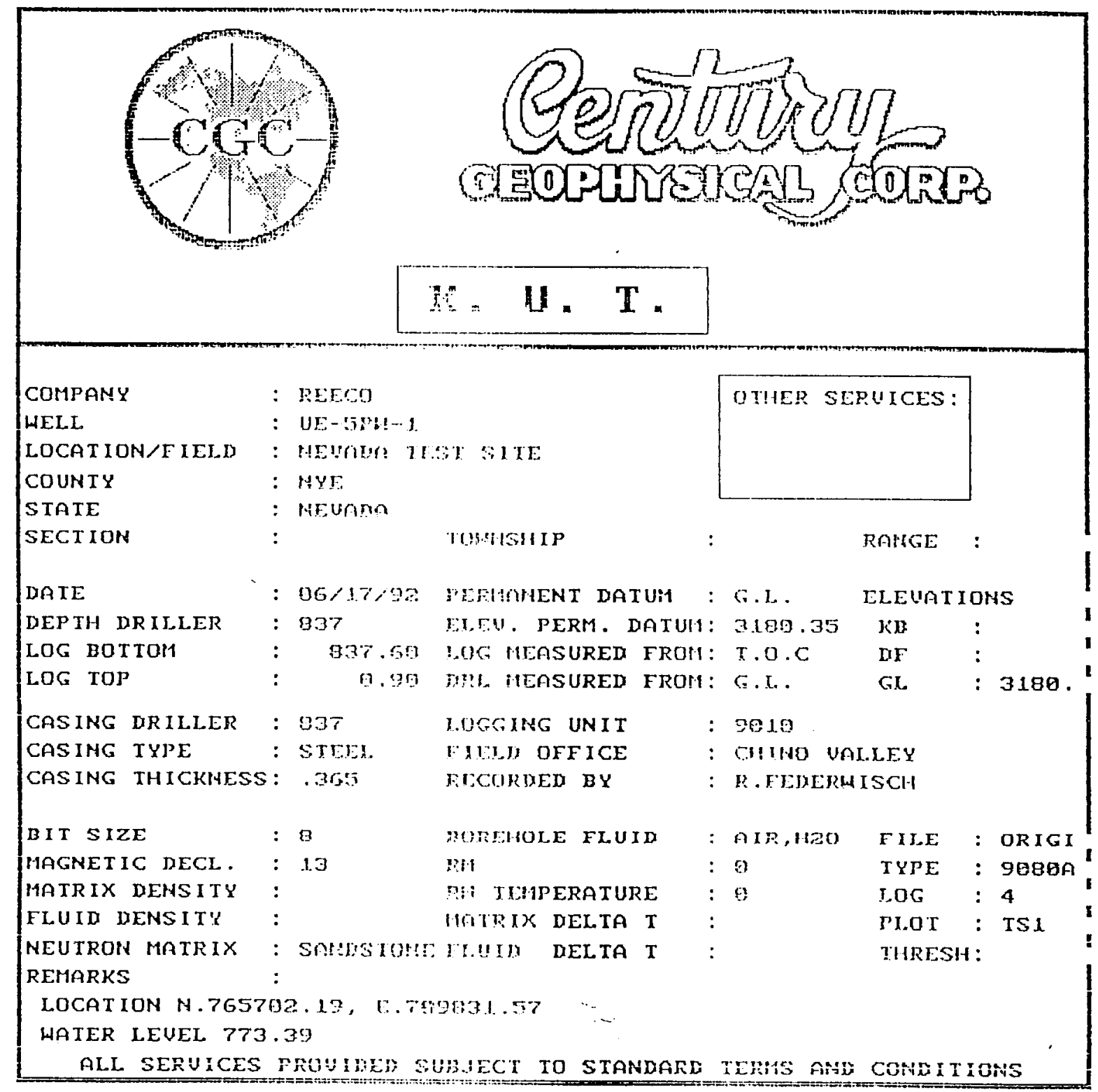


Appendix F.3.3 Borehole geophysical logs run in Ue5PW-1 on 6/16/92 (Continued)
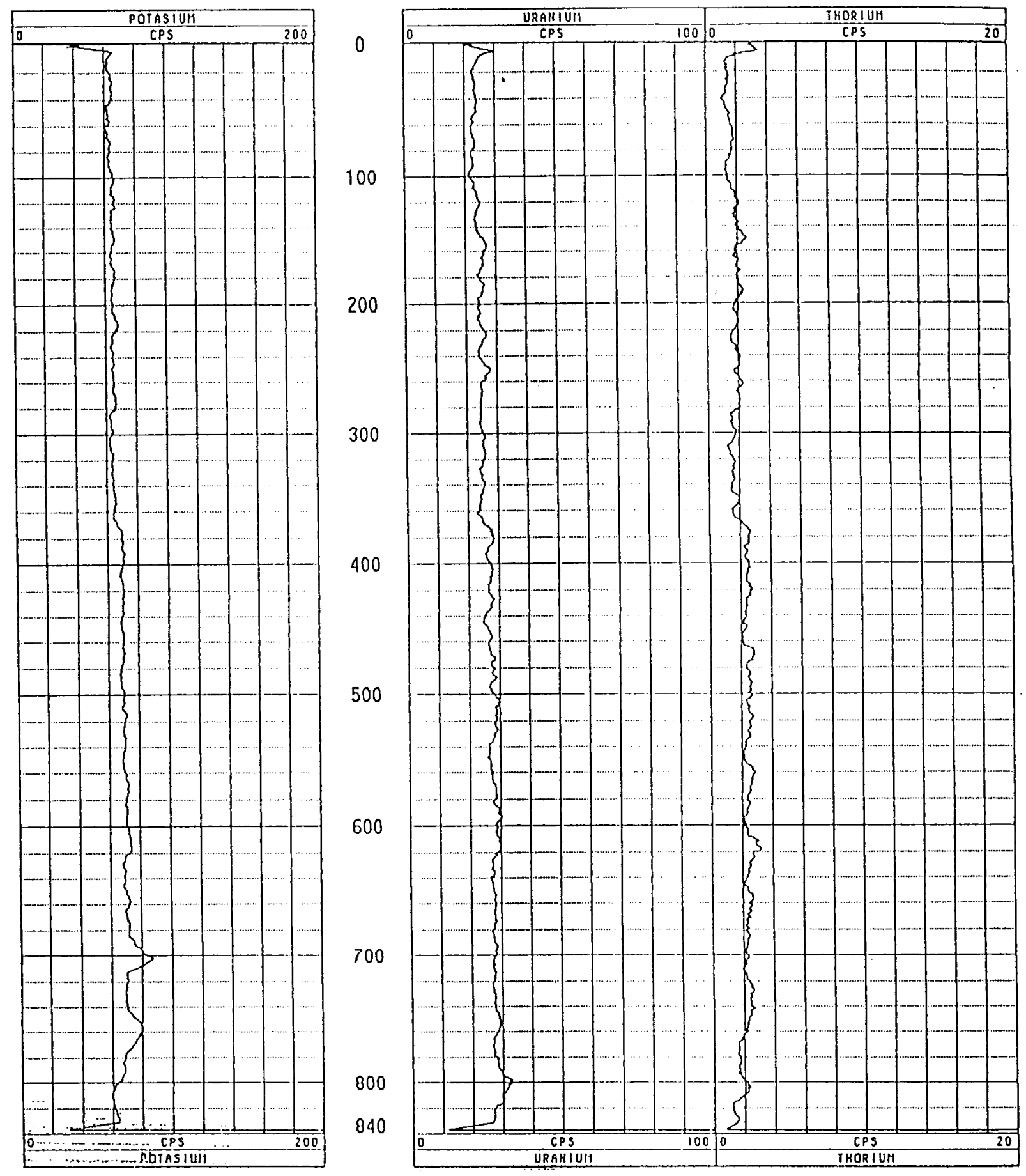

UE-5PW-1 $\quad 06 / 17 / 92 \quad 270$ 
F.3.4 Borehole deviation logs run in UE5PW-1 on 2/24/93 (replaces previous Equipment Data Sheet)

\begin{tabular}{|c|c|c|}
\hline \multicolumn{3}{|c|}{ EQUIPMENT DATA SHEET } \\
\hline $\begin{array}{l}\text { WELL \# UE5PW-1 } \\
\text { DATE: } \quad 2-24-93\end{array}$ & GAMMA RAY & DENB ITY / NEUTRON \\
\hline $\begin{array}{l}\text { TOOL INFORMATION } \\
\text { RUN NO. } \\
\text { MODEL NO. } \\
\text { TOOL DIAMETER } \\
\text { DISTANCE TO SOURCE } \\
\text { DETECTOR TYPE } \\
\text { DETECTOR OFFSET (FROM 0) } \\
\text { LENGTH \& DIAMETER (Near) } \\
\text { LENGTH \& DIAMETER (FAY) } \\
\text { LOGGING SPEED } \\
\text { CENTRALIZER } \\
\text { GAMMA RAY API CONVERSION } \\
\text { MANUFACTURER }\end{array}$ & & \\
\hline 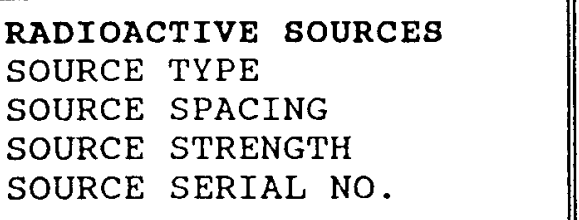 & & \\
\hline $\begin{array}{l}\text { TOOL INFORMATION } \\
\text { RUN NO. } \\
\text { MODEL NO. } \\
\text { TOOL DIAMETER } \\
\text { DETECTOR OFFSET }\left(\begin{array}{lll}\text { FROM } & 0\end{array}\right) \\
\text { LOGGING SPEED } \\
\text { TYPE }\end{array}$ & RESISTIVITY & CALIPER \\
\hline $\begin{array}{l}\text { OTHER TOOL INFORMATION } \\
\text { Detector Type and Size } \\
\text { Tool Type } \\
\text { Offset } \\
\text { Run Number }\end{array}$ & $\begin{array}{l}\text { DEVIATION } \\
\text { Incl/Gyro } \\
9095 \\
70.9 / 80.6 \\
\text { One }\end{array}$ & $\begin{array}{l}\text { Manufacturer } \\
\text { CGC/Humphrey }\end{array}$ \\
\hline $\begin{array}{ll}\text { GENERAL INFORMATION } \\
\text { TRUCK NO. } & 9101 \\
\text { SOFTWARE LEVEL } & \text { COMPu } \\
\text { OPERATOR } & \text { T. Kn } \\
\text { LOCATION } & \text { N. } 76\end{array}$ & 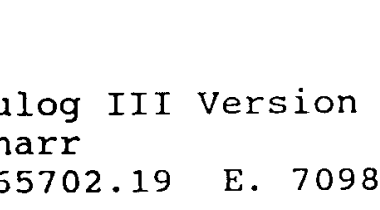 & $\begin{array}{l}7.03 \\
31.57\end{array}$ \\
\hline 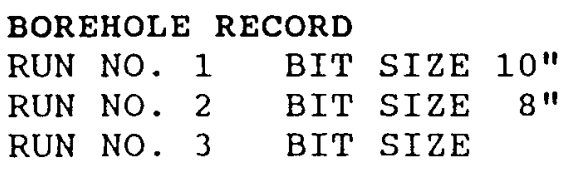 & $\begin{array}{l}0-367.5 \\
367.5-839\end{array}$ & \\
\hline 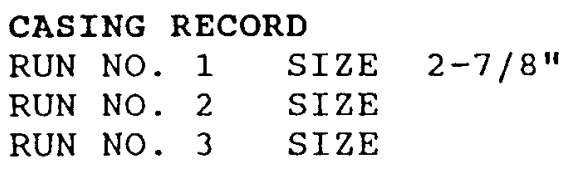 & $\begin{array}{lll}\text { FROM } & 0 & \text { TO } \\
\text { FROM } & & \\
\text { FROM } & & \end{array}$ & 839 \\
\hline $\begin{array}{l}\text { REMARKS: Client supplied } \\
\text { Bottom log dept }\end{array}$ & $\begin{array}{l}\text { d sighting stake } \\
\text { th } 823 \text {. }\end{array}$ & direction. \\
\hline
\end{tabular}


Appendix F.3.4 Borehole deviation logs run in Ue5PW-1 on 2/24/93 (Continued)

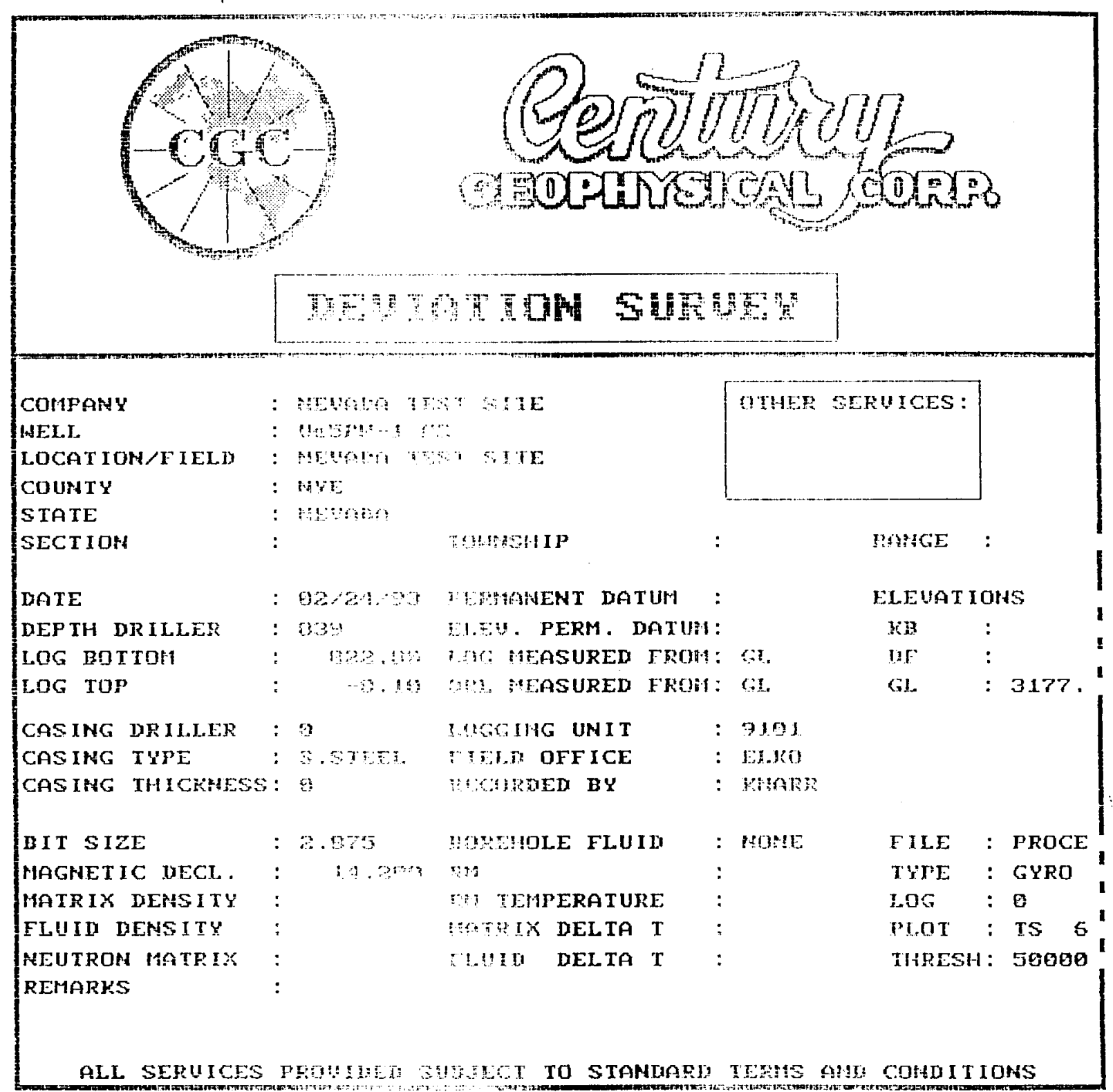


Appendix F.3.4 Borehole deviation logs run in Ue5PW-1 on 2/24/93 (Continued)

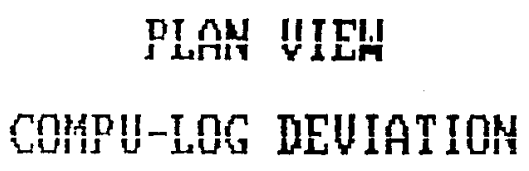

CLIENT: NEVADA IEST SITE LOCATION: NEUADA IEST SITE HOLE ID: VESPH-1 DAIE OF LOG: $82 / 24 / 93$ PROBE: GYRO 1201

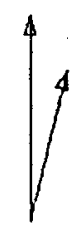

IAPG DECL: 14.2
SCALE: $10 \mathrm{FT} / \mathrm{IH}$

TRUE DEPTH: $822.47 \mathrm{FT}$

AZIMUTH: 158.1

DISTANCE: $18.8 \mathrm{FT}$

$t=100 \mathrm{FI}$ IHCR

$O=$ BOITOM OF HOLE

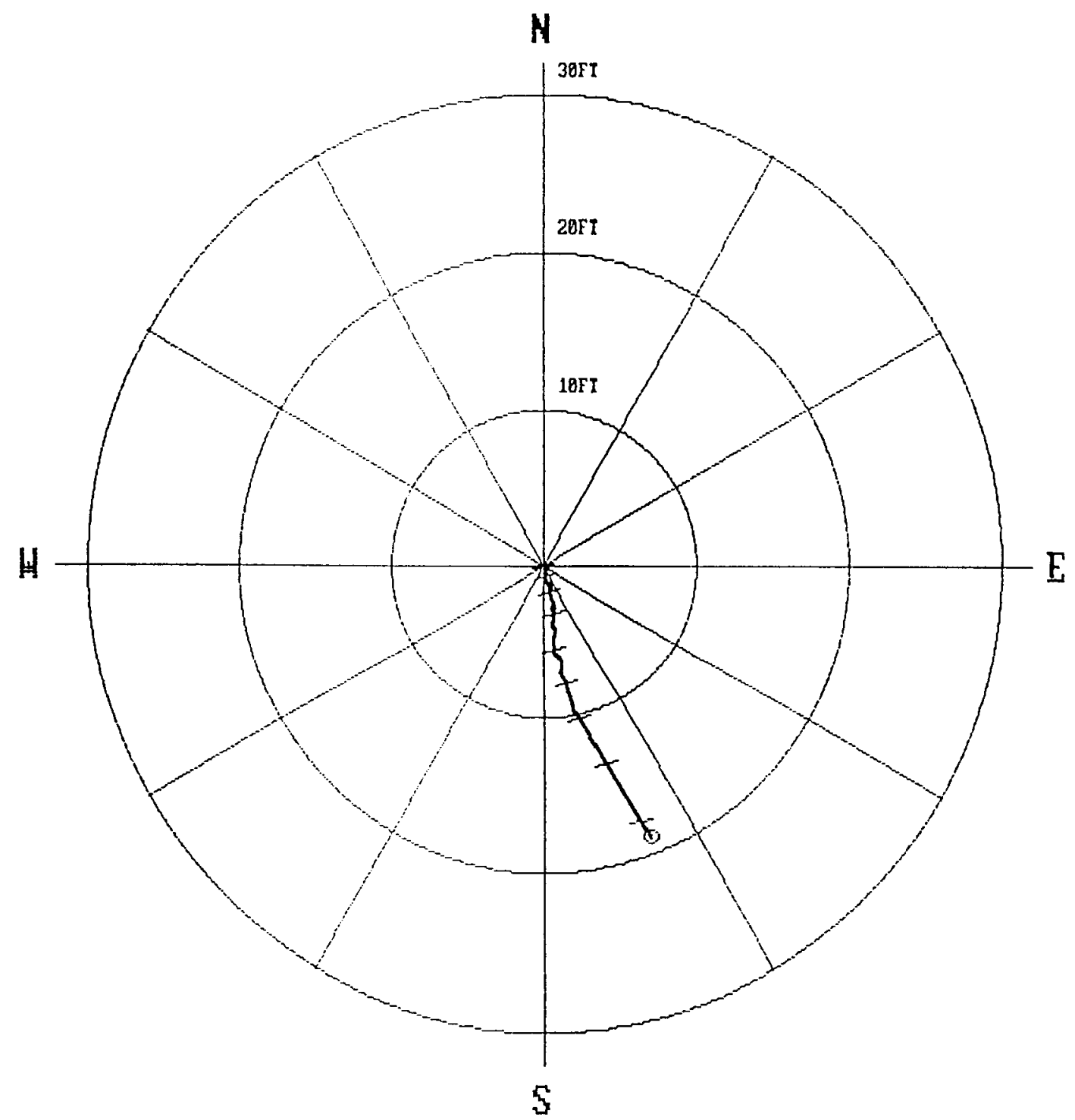


Appendix F.3.4 Borehole deviation logs run in Ue5PW-1 on 2/24/93 (Continued)

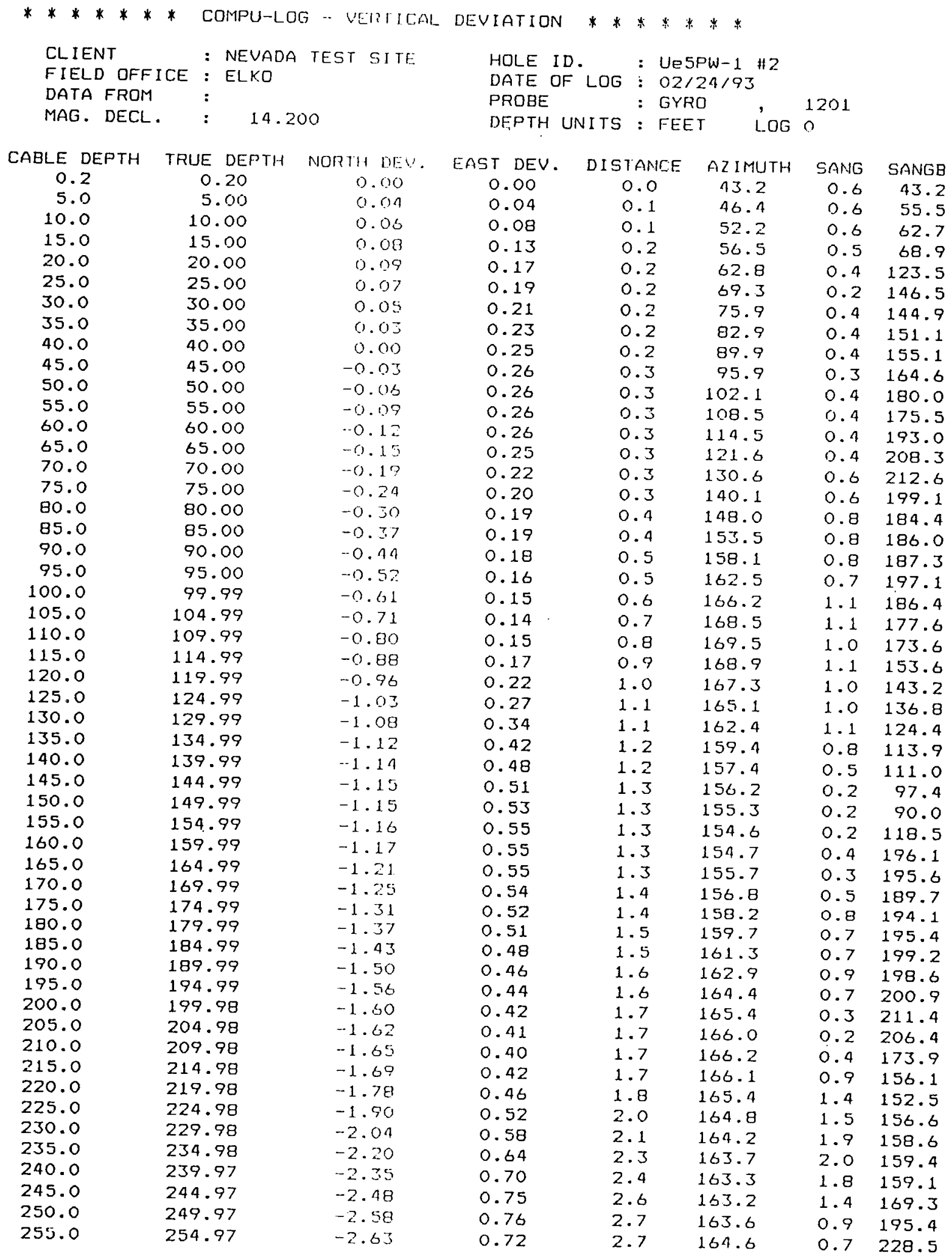


Appendix F.3.4 Borehole deviation logs run in Ue5PW-1 on 2/24/93 (Continued)

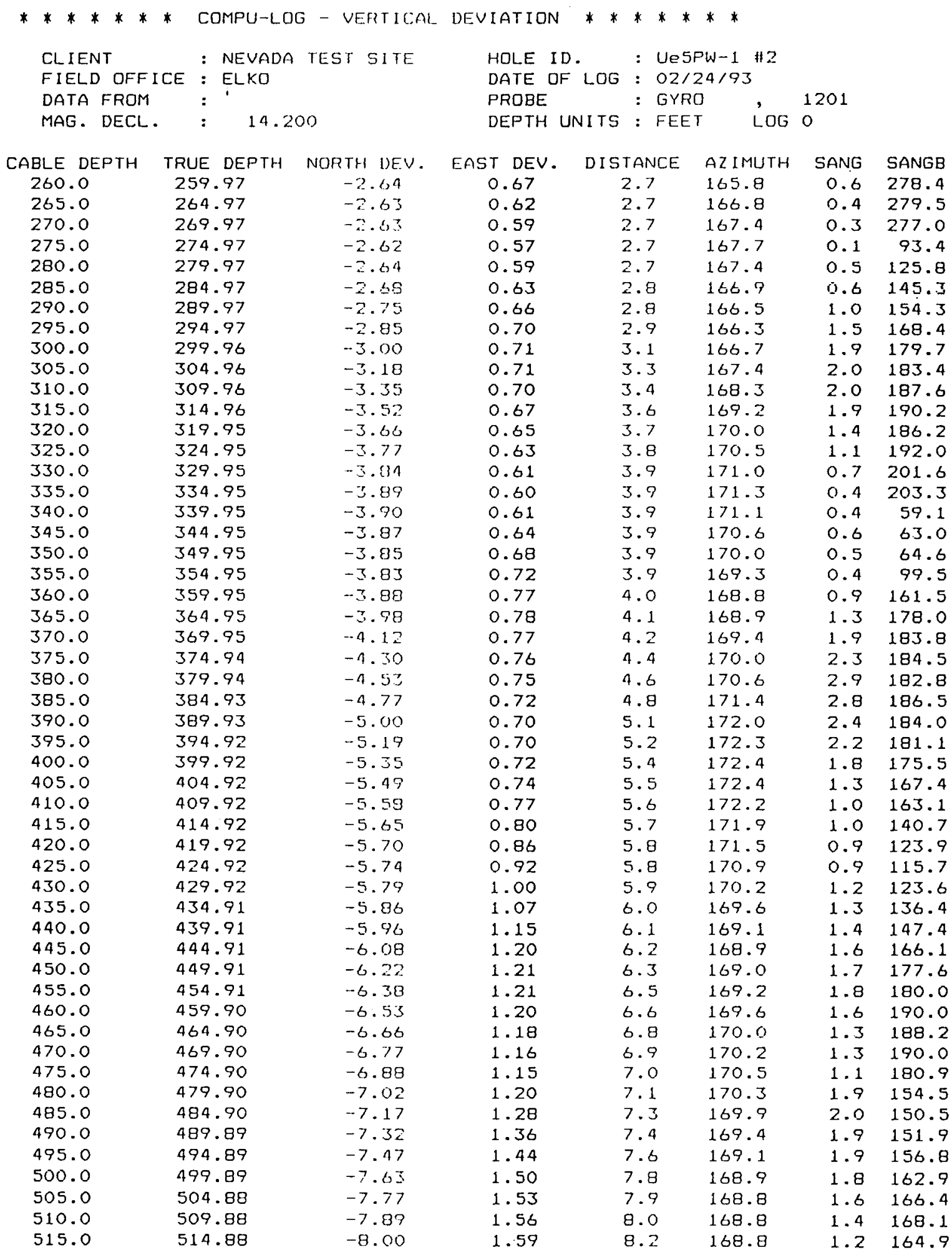


Appendix F.3.4 Borehole deviation logs run in Ue5PW-1 on 2/24/93 (Continued)

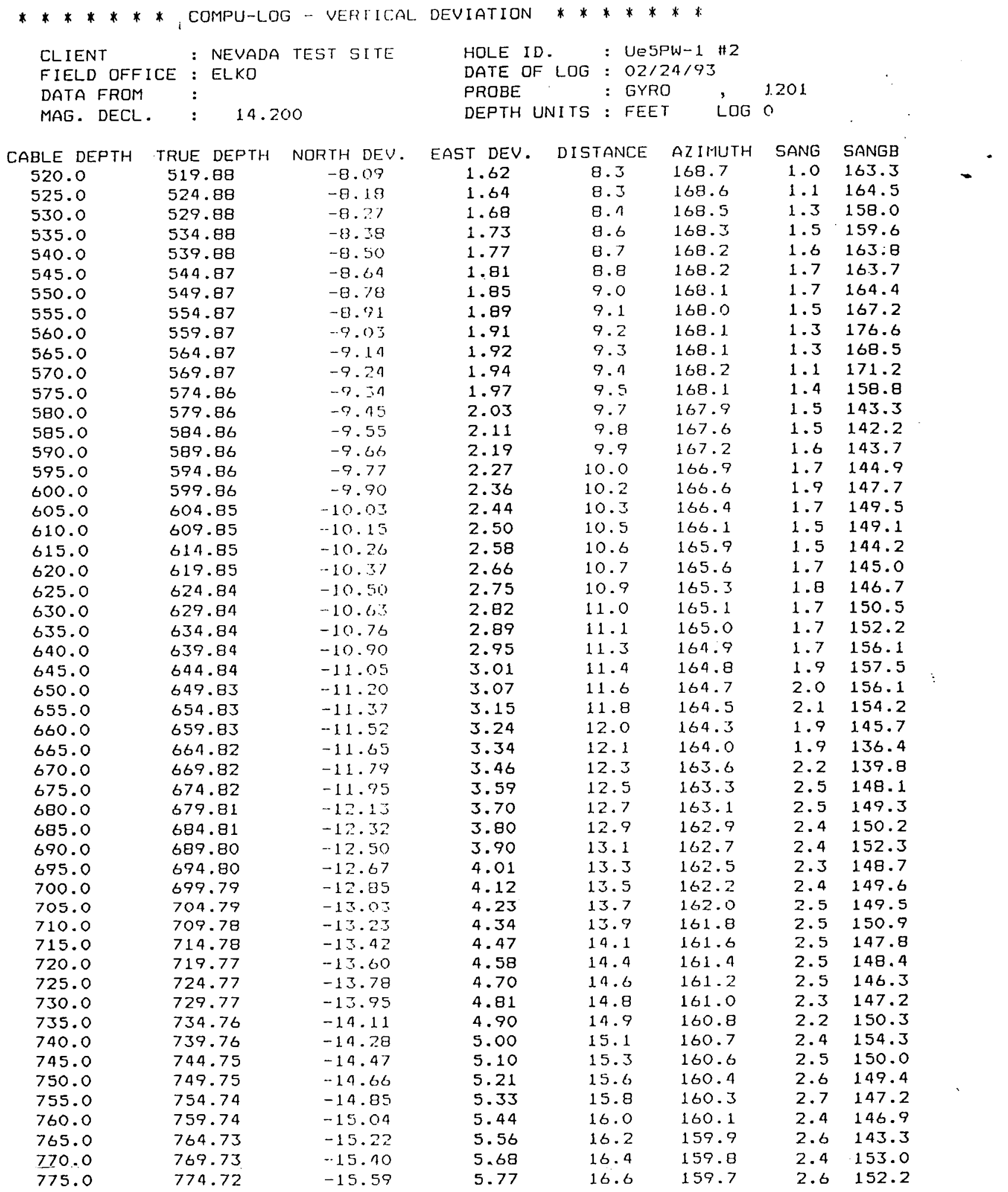


Appendix F.3.4 Borehole deviation logs run in Ue5PW-1 on 2/24/93 (Continued)

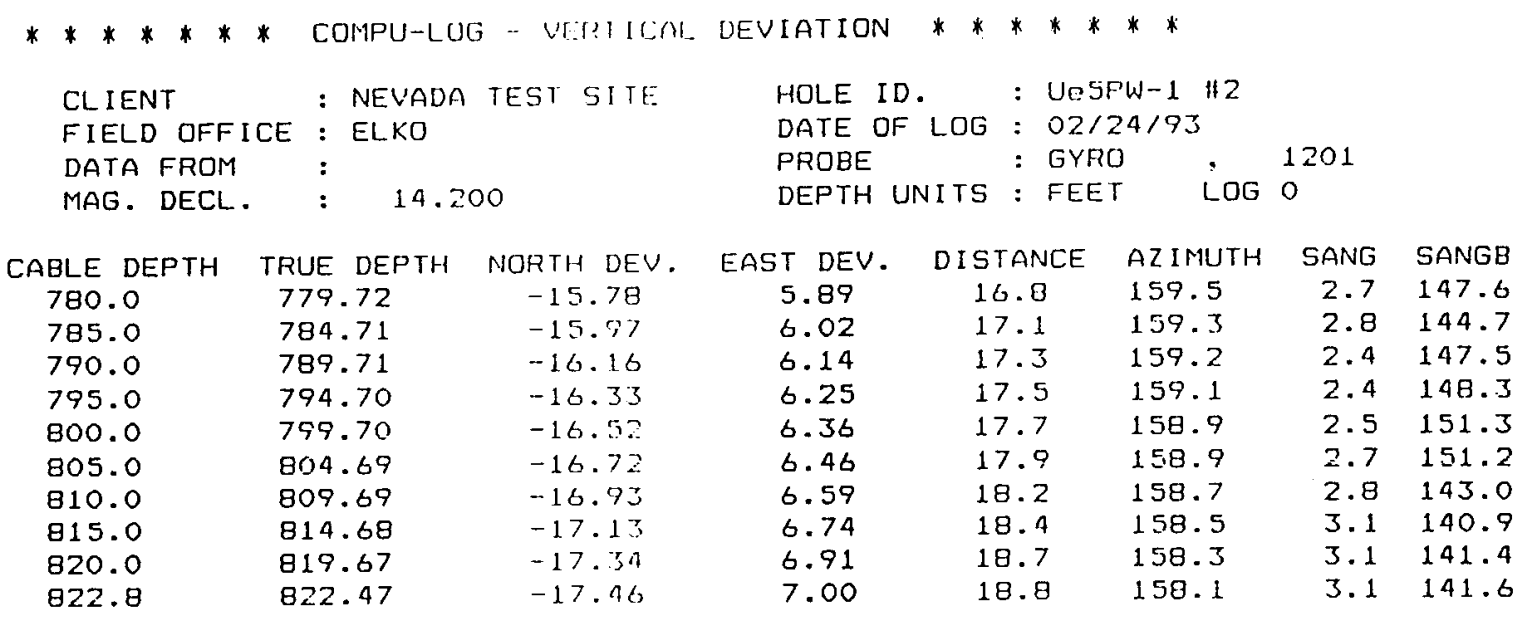


Appendix F.3.5 Borehole geophysical logs run in Ue5PW-2 on 7/20/92

\begin{tabular}{|c|c|c|c|}
\hline \multicolumn{4}{|c|}{ EQUIPMENT DATA SHEET } \\
\hline 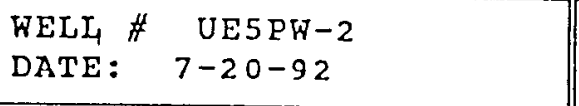 & GAMMA RAY & \multicolumn{2}{|c|}{ DENSITY/NEUTRON } \\
\hline $\begin{array}{l}\text { TOOL INFORMATION } \\
\text { RUN NO. } \\
\text { MODEL NO. } \\
\text { TOOI DIAMETER } \\
\text { DISTANCE TO SOURCE } \\
\text { DETECTOR TYPE } \\
\text { DETECTOR OFFSET (FROM O) } \\
\text { LENGTH \& DIAMETER (NEAY) } \\
\text { LENGTH \& DIAMETER (FAY) } \\
\text { LOGGING SPEED } \\
\text { CENTRALIZER } \\
\text { GAMMA RAY API CONVERSION } \\
\text { MANUFACTURER }\end{array}$ & $\begin{array}{l}\text { Three } \\
9035 \\
2.8 " \\
\text { na } \\
\text { Scintln. } \\
6.6 " \\
4.0 \times .875 " \\
30 \text { fpm } \\
\text { sidewall } \\
.658 \\
\text { Century }\end{array}$ & \begin{tabular}{||c} 
Three \\
9035 \\
2.811 \\
114.71 \\
$2-$ Sctin \\
$101 / 10711$ \\
$4.0 x .875$ \\
$1.2 \times .875$ \\
30 fpm \\
sidewal1 \\
Century
\end{tabular} & \begin{tabular}{|c} 
Two \\
9071 \\
$2.9^{\prime \prime}$ \\
99.01 \\
$2-\mathrm{He}$ \\
$75 / 88.2^{\prime \prime}$ \\
$4.0 \times 1.125$ \\
$10.0 \times 2.0$ \\
30 fpm \\
free hang \\
Century
\end{tabular} \\
\hline $\begin{array}{l}\text { RADIOACTIVE SOURCES } \\
\text { SOURCE TYPE } \\
\text { SOURCE SPACING } \\
\text { SOURCE STRENGTH } \\
\text { SOURCE SERIAL NO. } \\
\end{array}$ & & $\left|\begin{array}{ccc}C s & 137 \\
6 & \& & 12^{\prime \prime} \\
125 & \mathrm{mCi} \\
\mathrm{VL}-1 & -278\end{array}\right|$ & $\begin{array}{l}\text { AmBe } \\
10.8 \& 24^{\prime \prime} \\
5.0 \mathrm{Ci} \\
71-1-399 \mathrm{~B}\end{array}$ \\
\hline $\begin{array}{l}\text { TOOL INFORMATION } \\
\text { RUN NO. } \\
\text { MODEL NO. } \\
\text { TOOL DIAMETER } \\
\text { DETECTOR OFFSET (FROM } \\
\text { LOGGING SPEED } \\
\text { TYPE }\end{array}$ & RESISTIVITY & $\begin{array}{l}\text { CaLIp } \\
\text { Three } \\
9035 \\
2.811 \\
92^{\prime \prime} \\
30 \mathrm{FP} \\
\text { Singl }\end{array}$ & $\begin{array}{l}\text { ER } \\
\text { M Arm }\end{array}$ \\
\hline $\begin{array}{l}\text { OTHER TOOL INFORMATION } \\
\text { Detector TYpe and Size } \\
\text { Tool Type } \\
\text { Offset } \\
\text { Run Number }\end{array}$ & $\begin{array}{l}\text { Spectral Gamma } \\
\text { NaI } 1.5 \times 12^{\prime \prime} \\
9080 \\
68 " \\
\text { One }\end{array}$ & & \\
\hline \multicolumn{4}{|c|}{ 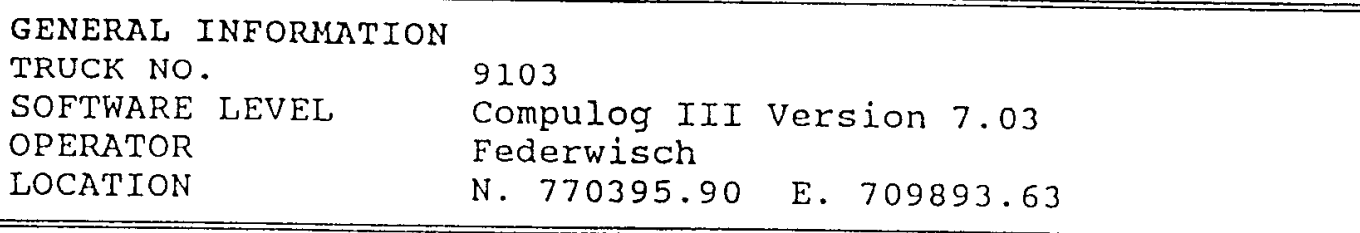 } \\
\hline 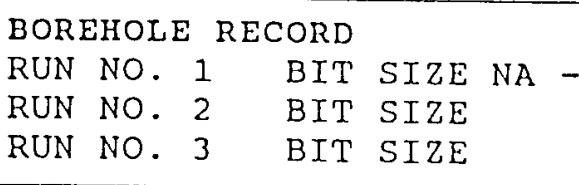 & CASING IS DRIVE & & \\
\hline \begin{tabular}{lll}
\multicolumn{3}{l}{ CASING RECORD } \\
RUN NO. 1 & SIZE $10^{\prime \prime}$ \\
RUN NO. 2 & SIZE \\
RUN NO. 3 & SIZE
\end{tabular} & $\begin{array}{lll}\text { FROM } & 0 & \text { TO } \\
\text { FROM } & & \text { TO } \\
\text { FROM } & & \text { TO }\end{array}$ & 551.0 & \\
\hline REMARRS: Run 1 of this & 11. & & \\
\hline
\end{tabular}


Appendix F.3.5 Borehole geophysical logs run in Ue5PW-2 on 7/20/92 (Continued)

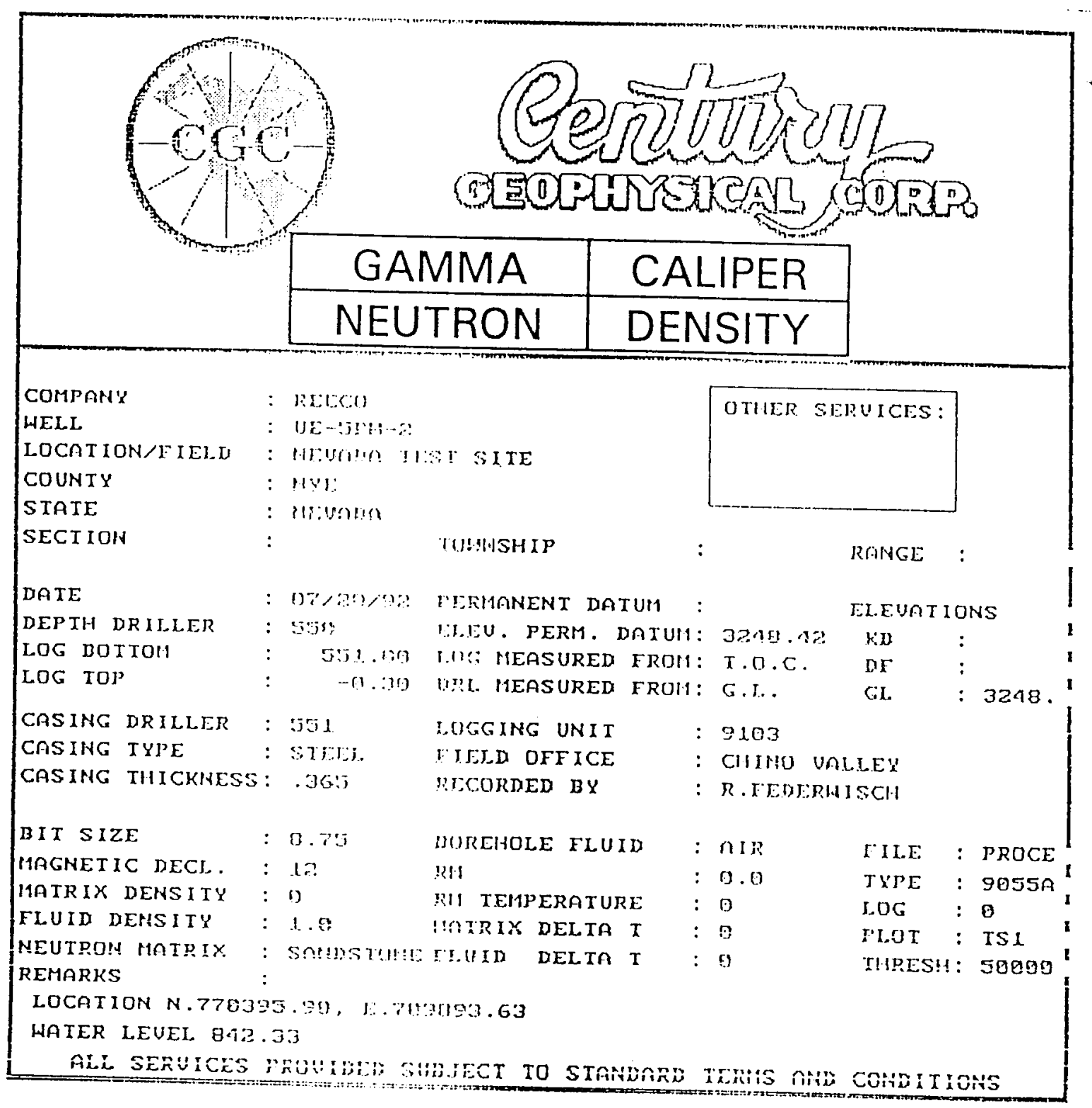


Appendix F.3.5 Borehole geophysical logs run in Ue5PW-2 on 7/20/92 (Continued)
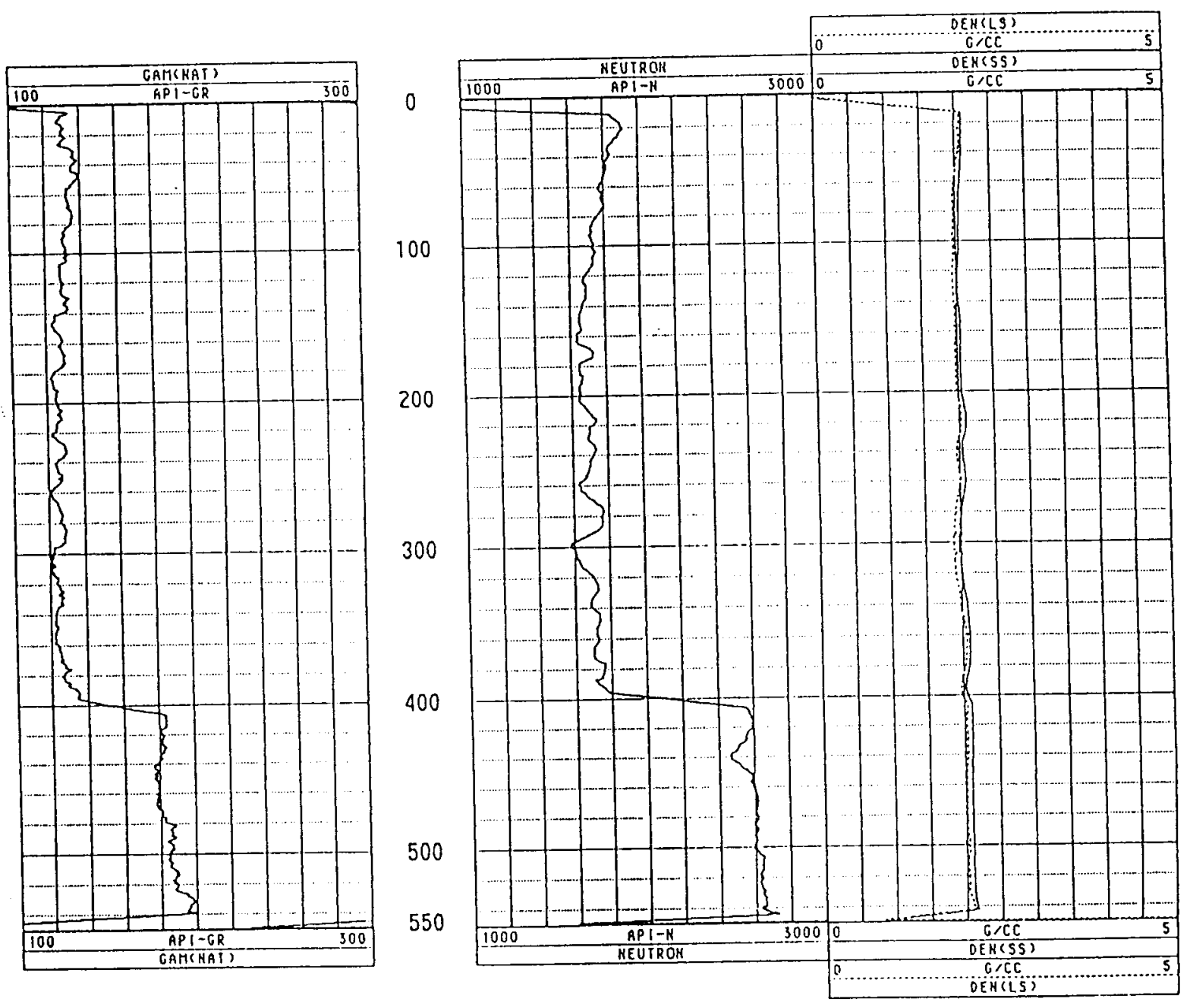

UE-5PW-2 07/20/92 245 
Appendix F.3.5 Borehole geophysical logs run in Ue5PW-2 on 7/20/92 (Continued)

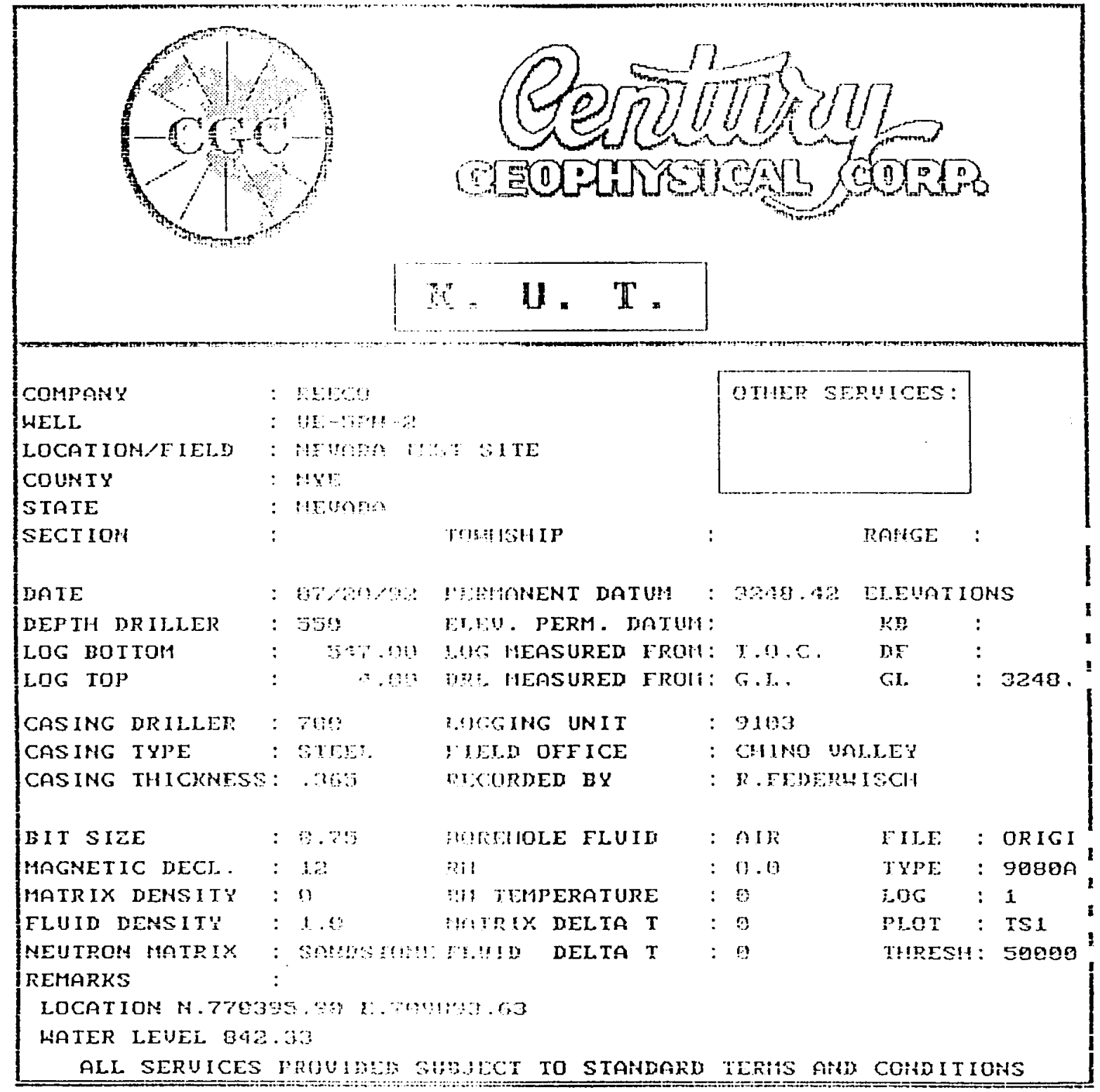


Appendix F.3.5 Borehole geophysical logs run in Ue5PW-2 on 7/20/92 (Continued)
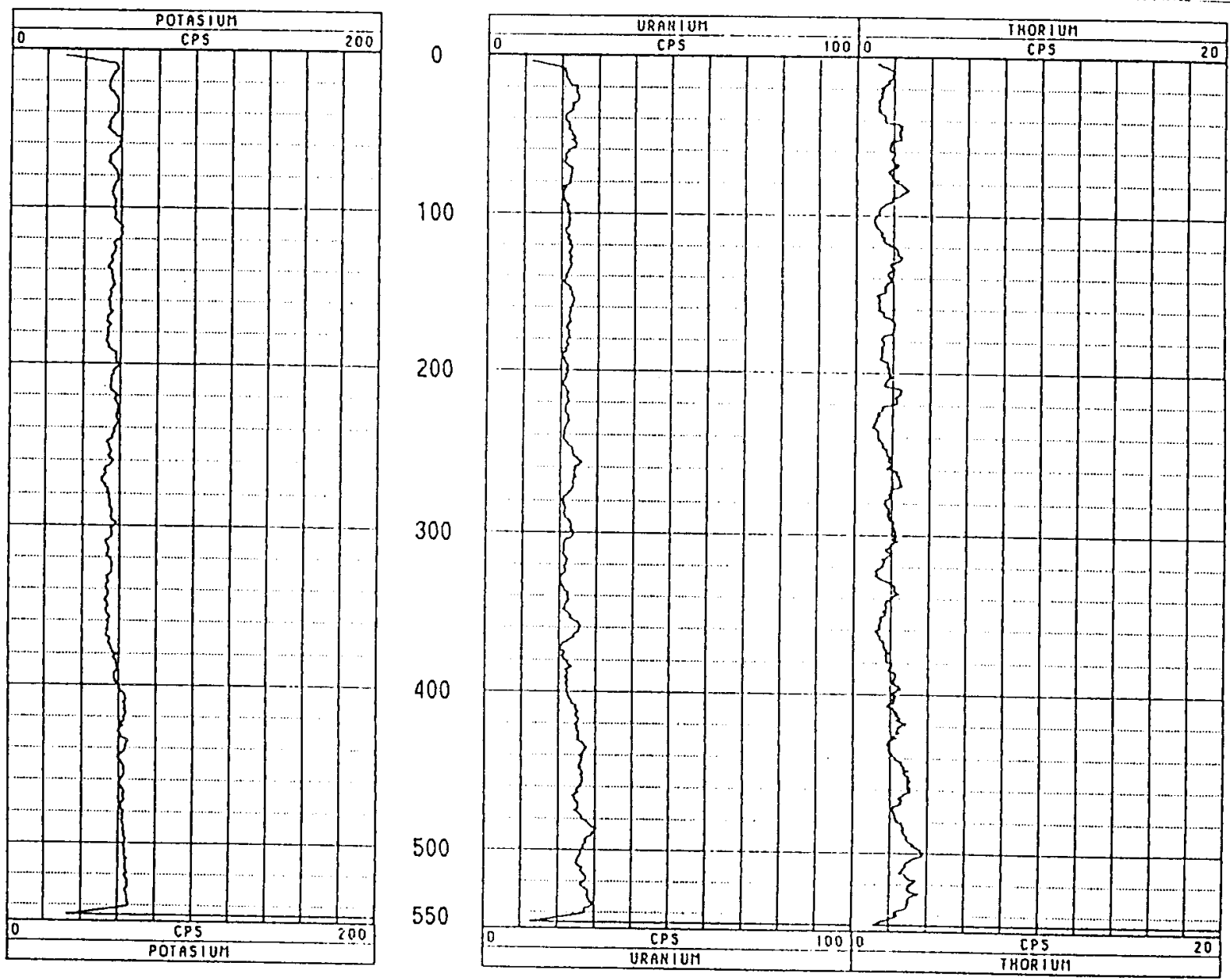

UE-5PW-2 $\quad 07 / 20 / 92 \quad 270$ 
Appendix F.3.6 Borehole geophysical logs run in Ue5PW-2 on 9/28/92

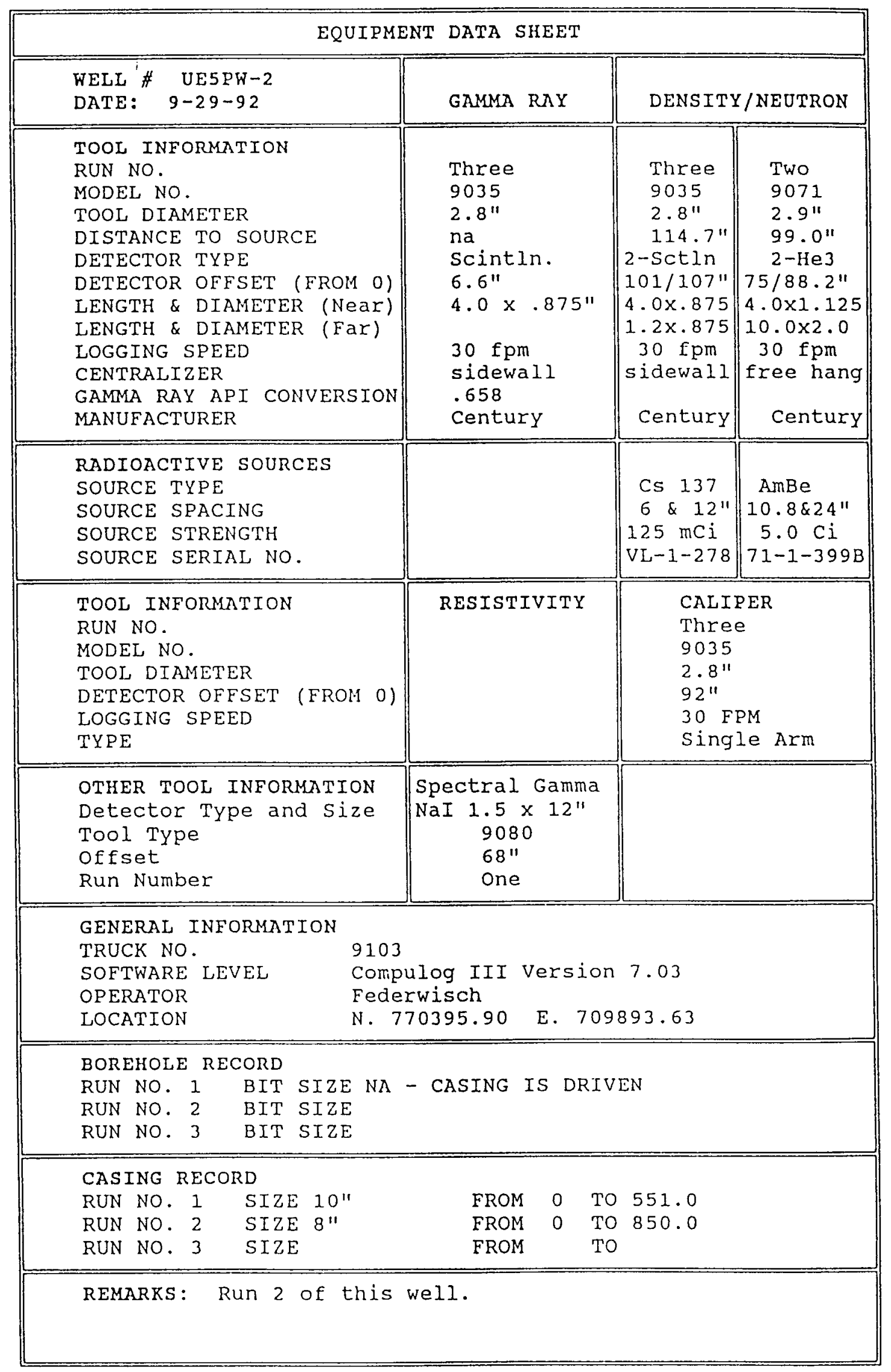


Appendix F.3.6 Borehole geophysical logs run in Ue5PW-2 on 9/28/92 (Continued)

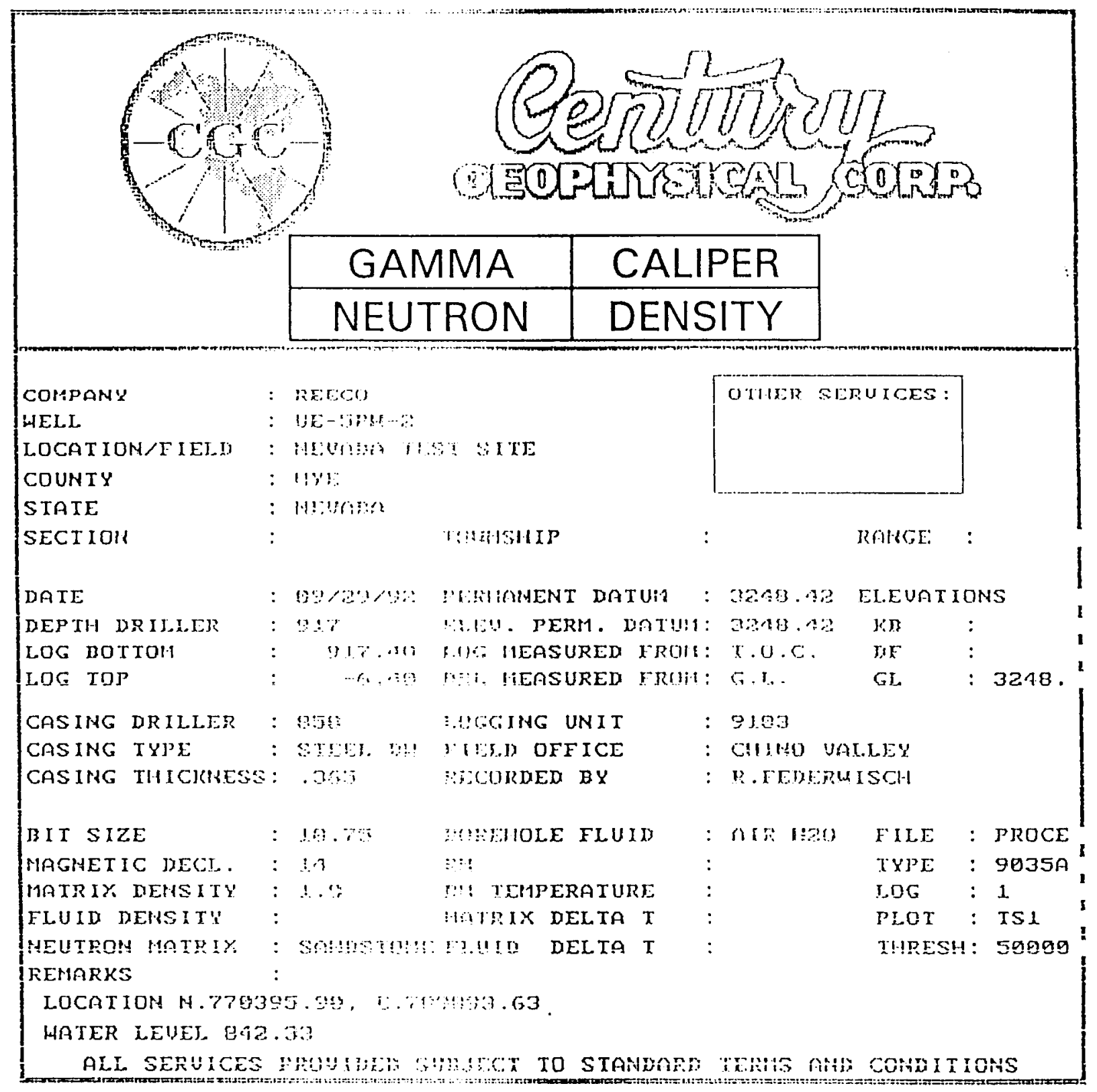


Appendix F.3.6 Borehole geophysical logs run in Ue5PW-2 on 9/28/92 (Continued)
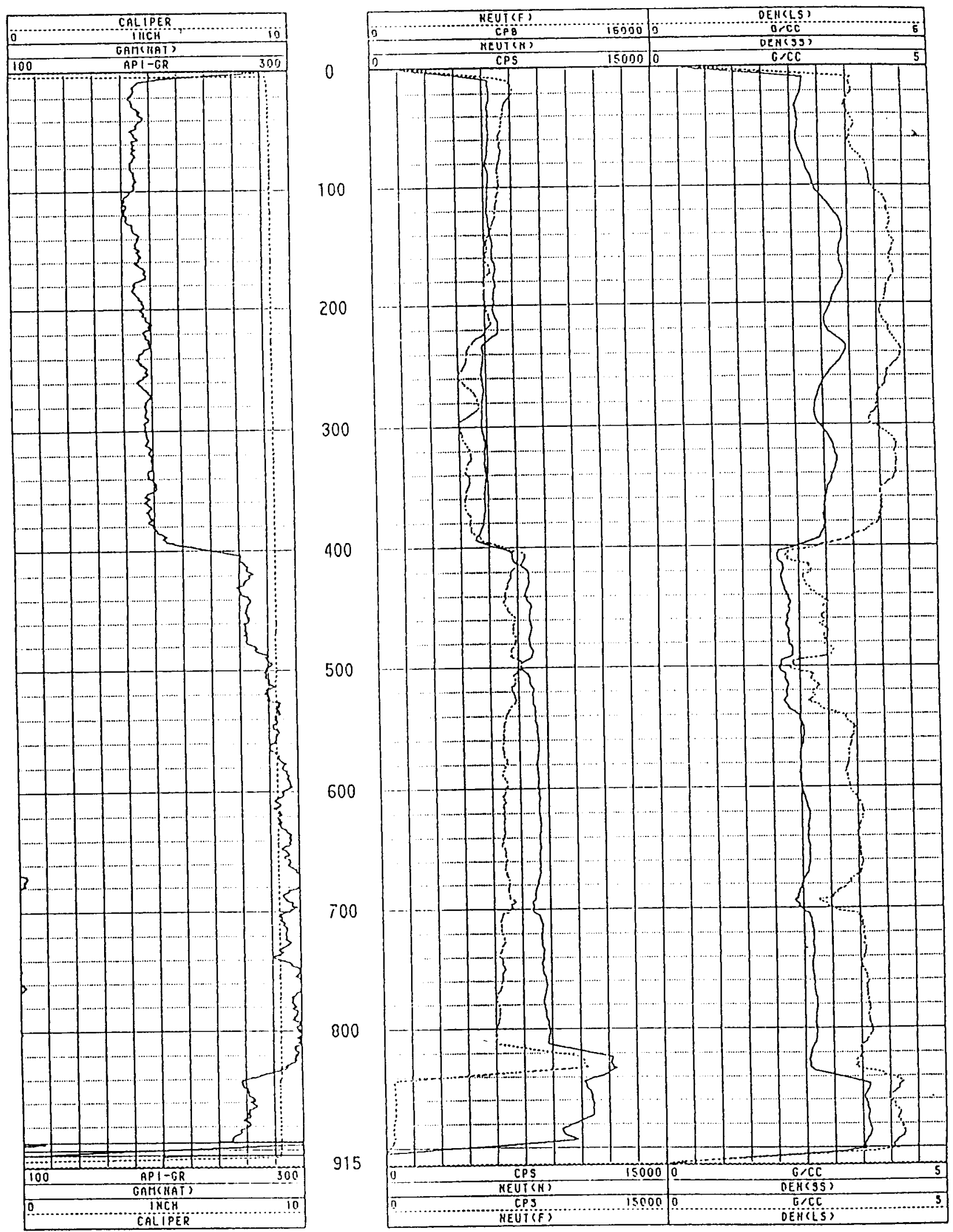

UE-5PW-2 $\quad 09 / 29 / 92 \quad 820$ 
Appendix F.3.6 Borehole geophysical logs run in Ue5PW-2 on 9/28/92 (Continued)

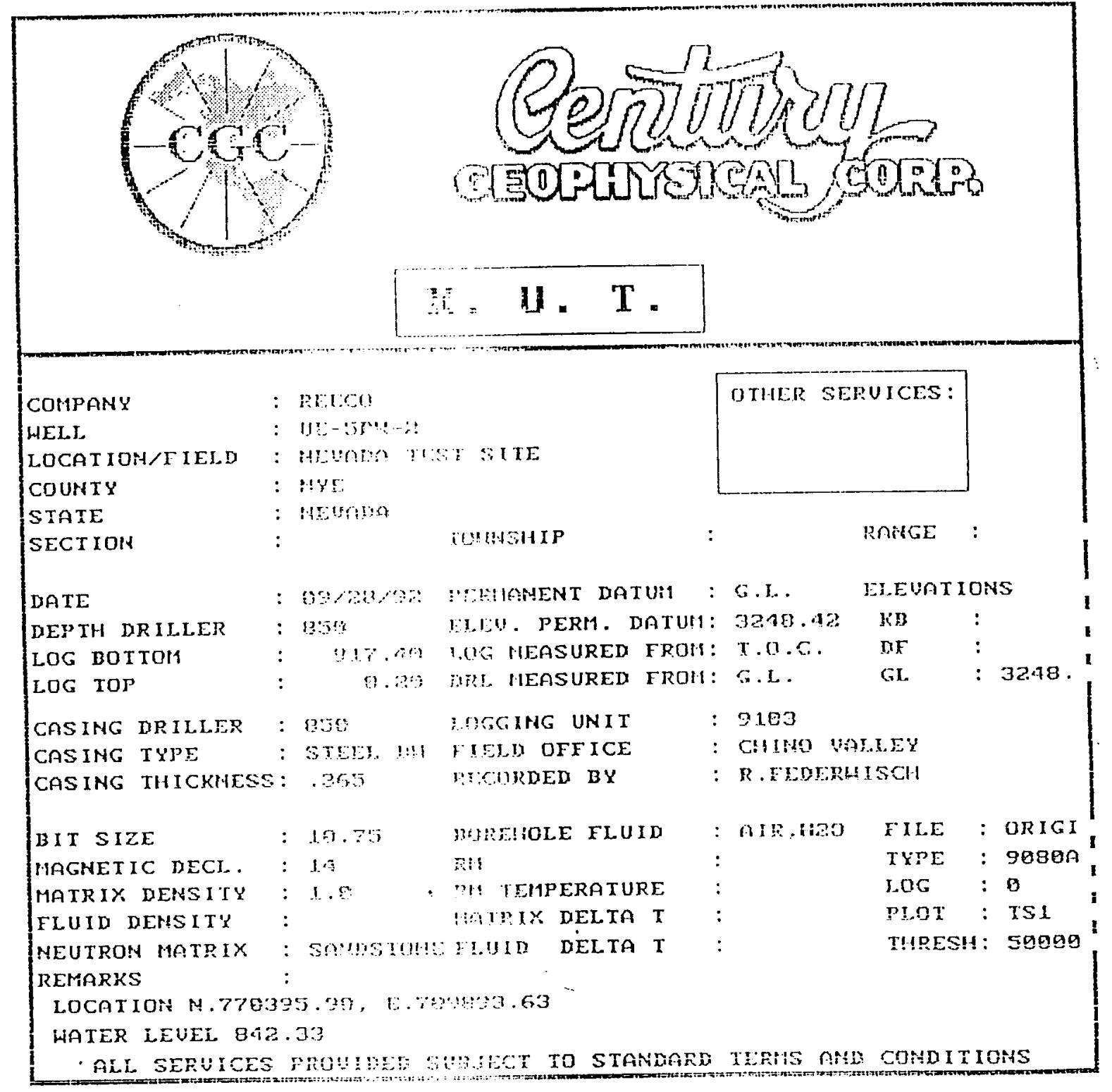


Appendix F.3.6 Borehole geophysical logs run in Ue5PW-2 on 9/28/92 (Continued)
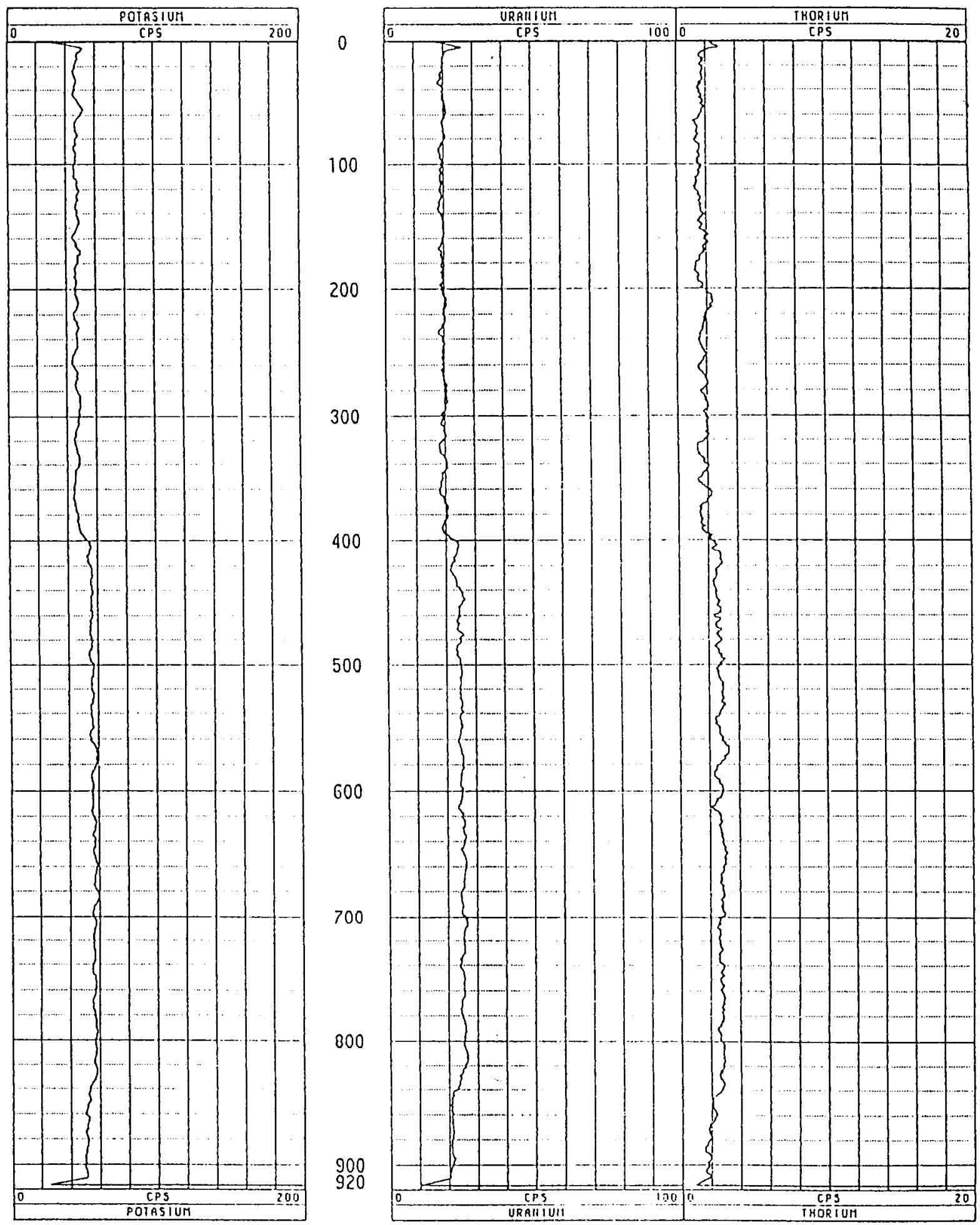

UE-5PW-2 $09 / 28 / 92 \quad 270$ 
Appendix F.3.7 Borehole deviation los run in UE5PW-2 on 2/24/93 (replaces previous Equipment Data Sheet).

\begin{tabular}{|c|c|c|}
\hline \multicolumn{3}{|c|}{ EQUIPMENT DATA SHEET } \\
\hline $\begin{array}{l}\text { WELL \# UE5PW-2 } \\
\text { DATE: } 2-25-93\end{array}$ & GAMMA RAY & DENB ITY / NEUTRON \\
\hline $\begin{array}{l}\text { TOOL INFORMATION } \\
\text { RUN NO. } \\
\text { MODEL NO. } \\
\text { TOOL DIAMETER } \\
\text { DISTANCE TO SOURCE } \\
\text { DETECTOR TYPE } \\
\text { DETECTOR OFFSET (FROM 0) } \\
\text { LENGTH \& DIAMETER (Near) } \\
\text { LENGTH \& DIAMETER (Far) } \\
\text { LOGGING SPEED } \\
\text { CENTRALIZER } \\
\text { GAMMA RAY API CONVERSION } \\
\text { MANUFACTURER }\end{array}$ & & \\
\hline $\begin{array}{l}\text { RADIOACTIVE SOURCES } \\
\text { SOURCE TYPE } \\
\text { SOURCE SPACING } \\
\text { SOURCE STRENGTH } \\
\text { SOURCE SERIAL NO. }\end{array}$ & & \\
\hline $\begin{array}{l}\text { TOOL INFORMATION } \\
\text { RUN NO. } \\
\text { MODEL NO. } \\
\text { TOOL DIAMETER } \\
\text { DETECTOR OFFST (FROM } \\
\text { LOGGING SPEED } \\
\text { TYPE }\end{array}$ & REBIBTIVITY & CALIPER \\
\hline $\begin{array}{l}\text { OTHER TOOL INFORMATION } \\
\text { Detector Type and Size } \\
\text { Tool Type } \\
\text { Offset } \\
\text { Run Number }\end{array}$ & $\begin{array}{l}\text { DEVIATION } \\
\text { InCl/GYro } \\
9095 \\
70.9 / 80.6 \\
\text { One }\end{array}$ & $\begin{array}{l}\text { Manufacturer } \\
\text { CGC/Humphrey }\end{array}$ \\
\hline $\begin{array}{ll}\text { GENERAL INFORMATION } \\
\text { TRUCK NO. } & 9101 \\
\text { SOFTWARE LEVEL } & \text { COMp } \\
\text { OPERATOR } & \text { T. K } \\
\text { LOCATION } & \text { N. } 7\end{array}$ & 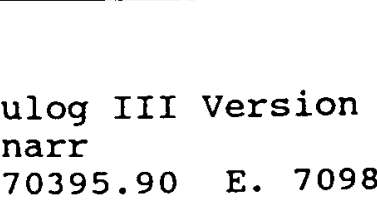 & $\begin{array}{l}7.03 \\
393.63\end{array}$ \\
\hline 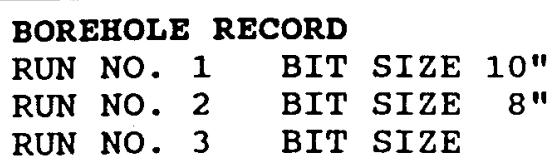 & $\begin{array}{l}0-551 \\
551-919.5\end{array}$ & \\
\hline 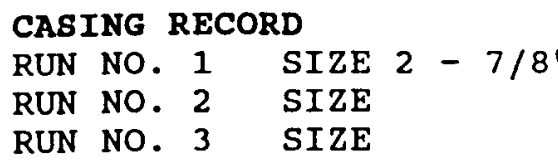 & $\begin{array}{llll}\text { FROM } & 0 & \text { TO } \\
\text { FROM } & & \\
\text { FROM } & & \end{array}$ & 919.5 \\
\hline $\begin{array}{l}\text { REMARKS: } \\
\text { Bottom lom log de }\end{array}$ & $\begin{array}{l}\text { d sighting stake } \\
\text { th } 894 \text { run } 1 \text {, and }\end{array}$ & $\begin{array}{l}\text { direction. } \\
878 \text { run } 2\end{array}$ \\
\hline
\end{tabular}


Appendix F.3.7 Borehole deviation logs run in Ue5PW-2 on 2/25/93 (Continued)

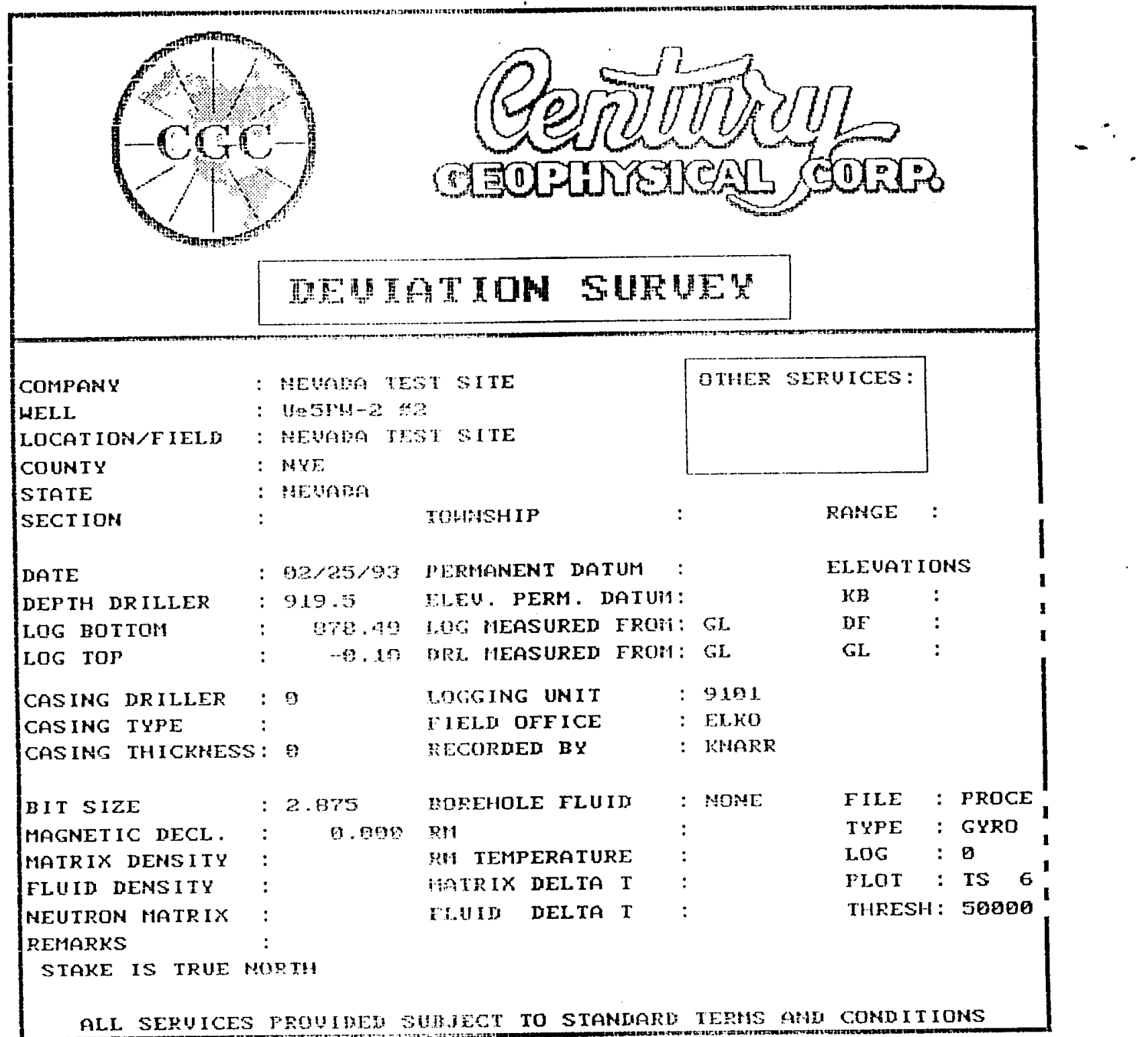


Appendix F.3.7 Borehole deviation logs run in Ue5PW-2 on 2/25/93 (Continued)

\section{PLRAN VIEH \\ COHPUI-LOG DEUIATION}

CLIENT: NEUADA TEST SITE

LOCATION: NEVADA TEST SITE

HOLE ID: Ve5PH-2 2

DATE OF LOG: $92 / 25 / 93$

PROBE: GYRO 1201

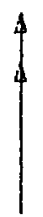

MAG DECL: 0.0
SCALE: $25 \mathrm{FI} / \mathrm{IN}$

IRUE DEPIH: 877.65 FI

AZIMUTH: 104.1

DISIANCE: $32.3 \mathrm{FT}$

$t=150 \mathrm{FI}$ INCR

$Q=$ BOTIOM OF HOLE

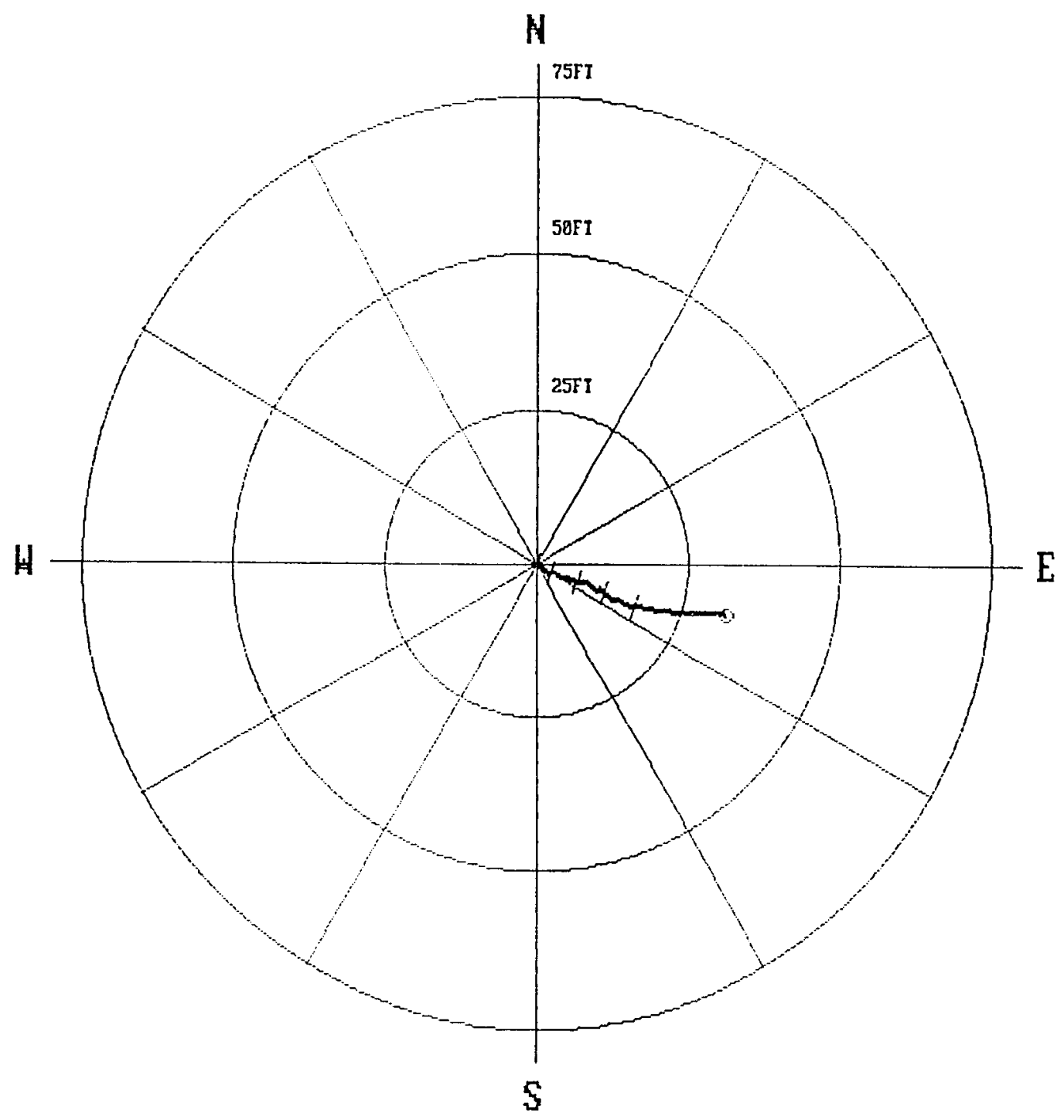




\section{Appendix F.3.7 Borehole deviation logs run in Ue5PW-2 on 2/25/93 (Continued)}

\begin{tabular}{|c|c|c|c|c|c|c|c|}
\hline CLIENT & : NEVADA & TEST SITE & HOLE ID. & : UesP & $w-2 \neq 2$ & & \\
\hline FIELD OFFIC & CE : ELKO & & DATE OF LOG & $: 02 / 2$ & $25 / 93$ & & \\
\hline DATA FROM & : & & PROBE & : GYRO & , & 1201 & \\
\hline MAG. DECL. & 0.00 & & DEPTH UNITS & : FEET & LOG & 0 & \\
\hline ABLE DEPTH & TRUE DEPTH & NORTH DEV. & EAST DEV. & STANCE & AZIMUTH & SANG & SANGB \\
\hline 0.2 & 0.20 & -0.00 & 0.00 & 0.0 & 138.7 & 0.6 & 139.7 \\
\hline 5.0 & 5.00 & $-0.0=$ & 0.04 & 0.1 & 131.1 & 0.6 & 134.6 \\
\hline 10.0 & 10.00 & -0.07 & 0.08 & 0.1 & 131.0 & 0.6 & 132.4 \\
\hline 15.0 & 15.00 & -0.11 & 0.13 & 0.2 & 129.7 & 0.6 & 123.6 \\
\hline 20.0 & 20.00 & -0.13 & 0.16 & 0.2 & 129.0 & 0.4 & 126.4 \\
\hline 25.0 & 25.00 & -0.14 & 0.18 & 0.2 & 129.0 & 0.3 & 59.3 \\
\hline 30.0 & 30.00 & -0.16 & 0.20 & 0.3 & 129.6 & 0.3 & 132.3 \\
\hline 35.0 & 35.00 & -0.19 & 0.22 & 0.3 & 129.5 & 0.4 & 126.9 \\
\hline 40.0 & 40.00 & -0.2 .1 & 0.26 & 0.3 & 129.6 & 0.7 & 131.0 \\
\hline 45.0 & 45.00 & -0.26 & 0.31 & 0.4 & 129.7 & 0.9 & 127.7 \\
\hline 50.0 & 50.00 & -0.50 & 0.36 & 0.5 & 127.6 & 0.8 & 128.9 \\
\hline 55.0 & 55.00 & -0.34 & 0.42 & 0.5 & 129.4 & 1.0 & 128.2 \\
\hline 60.0 & 60.00 & -0.89 & 0.48 & 0.6 & 129.1 & 0.9 & 125.2 \\
\hline 65.0 & 64.99 & -19.43 & 0.54 & 0.7 & 128.5 & 1.0 & 118.9 \\
\hline 70.0 & 69.99 & -0.48 & 0.62 & 0.8 & 127.7 & 0.9 & 107.5 \\
\hline 75.0 & 74.89 & -0.52 & 0.71 & 0.9 & 126.3 & 1.2 & 113.2 \\
\hline 80.0 & 79.99 & -0.56 & 0.80 & 1.0 & 125.0 & 1.1 & 112.4 \\
\hline 85.0 & 84.99 & -0.61 & 0.90 & 1.1 & 124.1 & 1.3 & 117.5 \\
\hline 90.0 & 89.99 & -0.66 & 0.99 & 1.2 & 123.6 & 1.3 & 121.1 \\
\hline 95.0 & 94.99 & -0.72 & 1.09 & 1.3 & 123.4 & 1.4 & 122.2 \\
\hline 100.0 & 99.99 & -0.77 & 1.19 & 1.4 & 123.1 & 1.4 & 121.1 \\
\hline 105.0 & 104.99 & -0.94 & 1.29 & 1.5 & 123.1 & 1.4 & 128.1 \\
\hline 110.0 & 109.98 & -0.92 & 1.38 & 1.7 & 123.7 & 1.7 & 132.5 \\
\hline 115.0 & 114.98 & -1.01 & 1.49 & 1.8 & 124.3 & 1.8 & 130.3 \\
\hline 120.0 & $11 \% .98$ & -1.12 & 1.61 & 2.0 & 124.7 & 1.9 & 128.2 \\
\hline 125.0 & 124.98 & -1.22 & 1.74 & 2.1 & 125.0 & 2.0 & 127.1 \\
\hline 130.0 & 129.97 & -1.30 & 1.87 & 2.3 & 124.8 & 1.8 & 117.8 \\
\hline 135.0 & 134.97 & $-1 . J b$ & 2.00 & 2.4 & 124.2 & 1.4 & 105.5 \\
\hline 140.0 & 139.97 & -1.40 & 2.13 & 2.5 & 123.3 & 1.4 & 100.3 \\
\hline 145.0 & 144.97 & -1.41 & 2.24 & 2.6 & 122.2 & 1.3 & 90.1 \\
\hline 150.0 & 149.97 & -1.41 & 2.34 & 2.7 & 121.0 & 1.2 & 86.1 \\
\hline 155.0 & 154.97 & -1.10 & 2.45 & 2.8 & 119.7 & 1.3 & 86.3 \\
\hline 160.0 & 159.97 & -1.40 & 2.56 & 2.9 & 118.6 & 1.3 & 89.8 \\
\hline 165.0 & 164.96 & -1.40 & 2.68 & 3.0 & 117.6 & 1.3 & 97.0 \\
\hline 170.0 & 169.96 & -1.4 & 2.74 & 3.1 & 116.9 & 1.4 & 99.7 \\
\hline 175.0 & 174.96 & -1.45 & 2.92 & 3.3 & 116.5 & 1.6 & 107.2 \\
\hline 180.0 & 179.96 & -1.50 & 3.05 & 3.4 & 116.2 & 1.8 & 112.9 \\
\hline 185.0 & 184.96 & -1.57 & 3.21 & 3.6 & 116.1 & 1.9 & 116.3 \\
\hline 190.0 & 189.95 & -1.65 & 3.37 & 5.7 & 116.1 & 2.1 & 118.8 \\
\hline 195.0 & 194.95 & -1.71 & 3.52 & $\therefore .9$ & 116.2 & 1.7 & 126.6 \\
\hline 200.0 & 199.95 & $-1.8 j$ & 3.69 & 4.1 & 116.3 & 1.8 & 114.7 \\
\hline 205.0 & 204.94 & -1.71 & 3.85 & 4.3 & 116.4 & 2.0 & 117.8 \\
\hline 210.0 & 209.94 & -1.79 & 4.00 & 4.5 & 116.4 & 1.8 & 115.2 \\
\hline 215.0 & 214.94 & -2.04 & 4.13 & 4.6 & 116.3 & 1.5 & 112.7 \\
\hline 220.0 & 219.94 & -2.08 & 4.24 & 4.7 & 116.1 & 1.5 & 103.6 \\
\hline 225.0 & 224.94 & -7.10 & 4.37 & 4.8 & 115.7 & 1.5 & 94.9 \\
\hline 230.0 & 229.93 & -2.12 & 4.50 & 5.0 & 115.2 & 1.6 & 96.0 \\
\hline 235.0 & 234.93 & -2.13 & 4.65 & 5.1 & 114.6 & 1.8 & 93.6 \\
\hline 240.0 & 239.93 & -2.15 & 4.82 & 5.3 & 114.0 & 2.1 & 96.3 \\
\hline 245.0 & 244.72 & $-2 \cdot 18$ & 5.01 & 5.5 & 113.5 & 2.3 & 101.7 \\
\hline 250.0 & 249.92 & -2.22 & 5.22 & 5.7 & 113.0 & 2.4 & 100.7 \\
\hline 255.0 & 254.92 & -3.26 & 5.43 & 5.9 & 112.6 & 2.4 & 102.4 \\
\hline
\end{tabular}




\section{Appendix F.3.7 Borehole deviation logs run in Ue5PW-2 on 2/25/93 (Continued)}

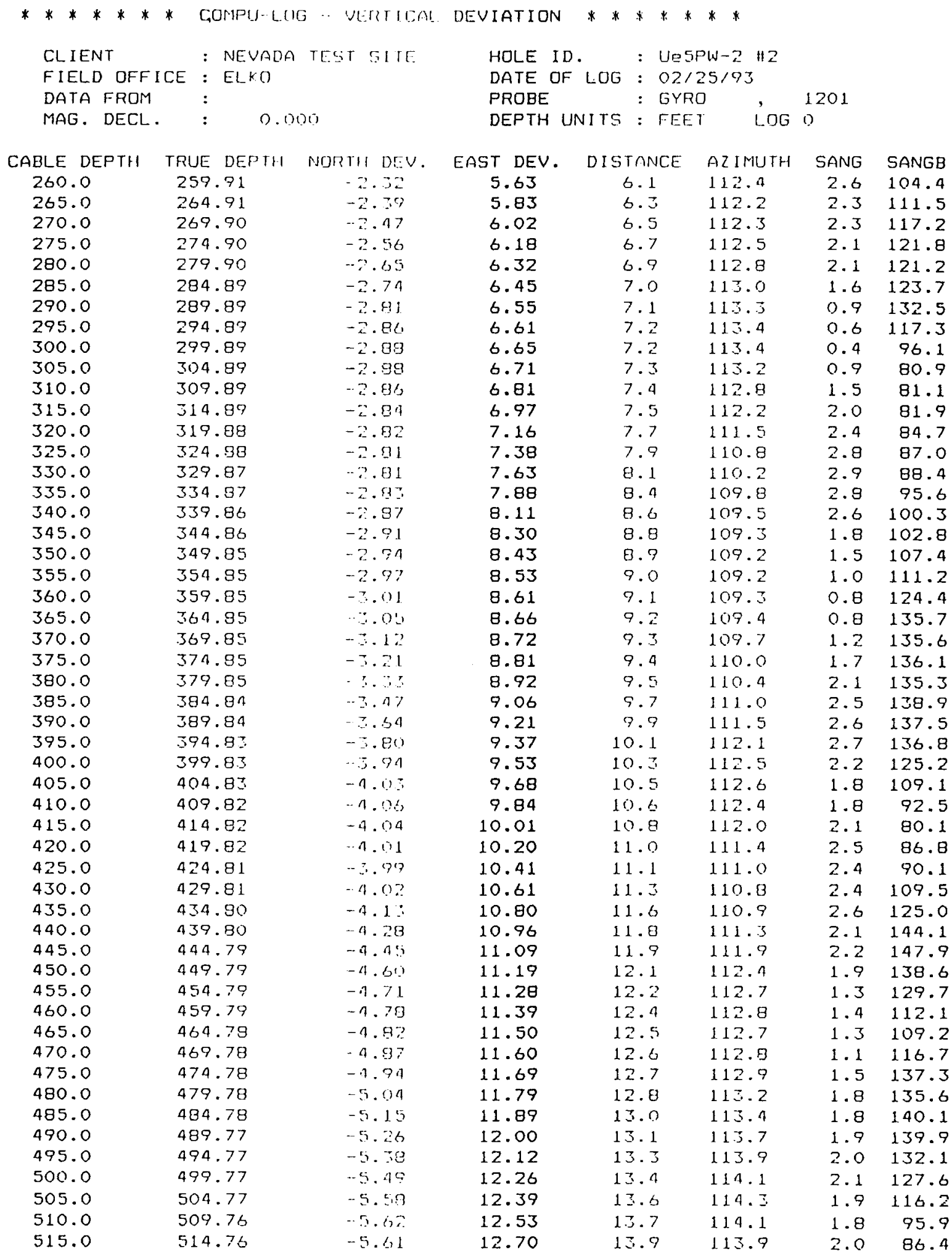


Appendix F.3.7 Borehole deviation logs run in Ue5PW-2 on 2/25/93 (Continued)

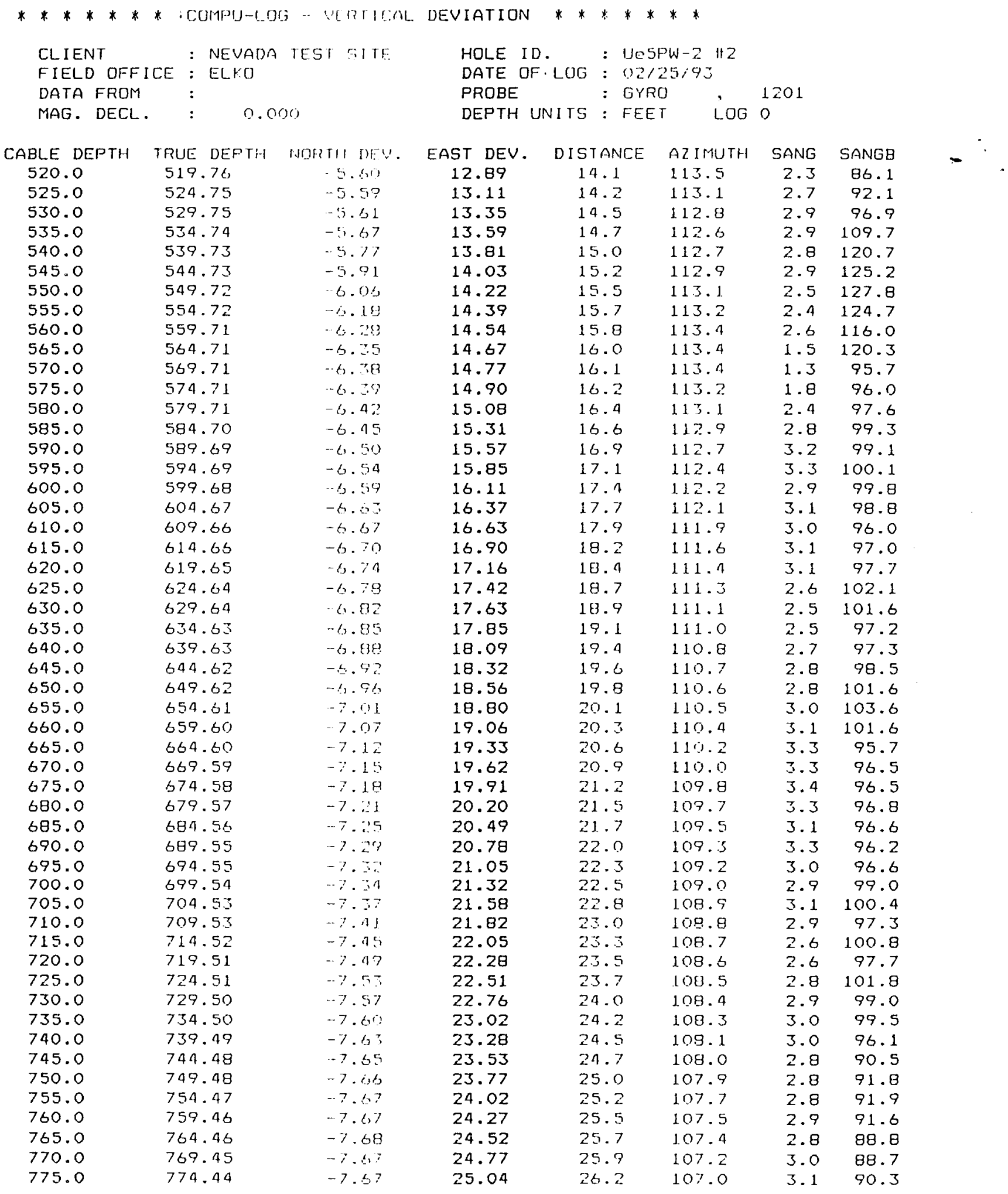




\section{Appendix F.3.7 Borehole deviation logs run in Ue5PW-2 on 2/25/93 (Continued)}

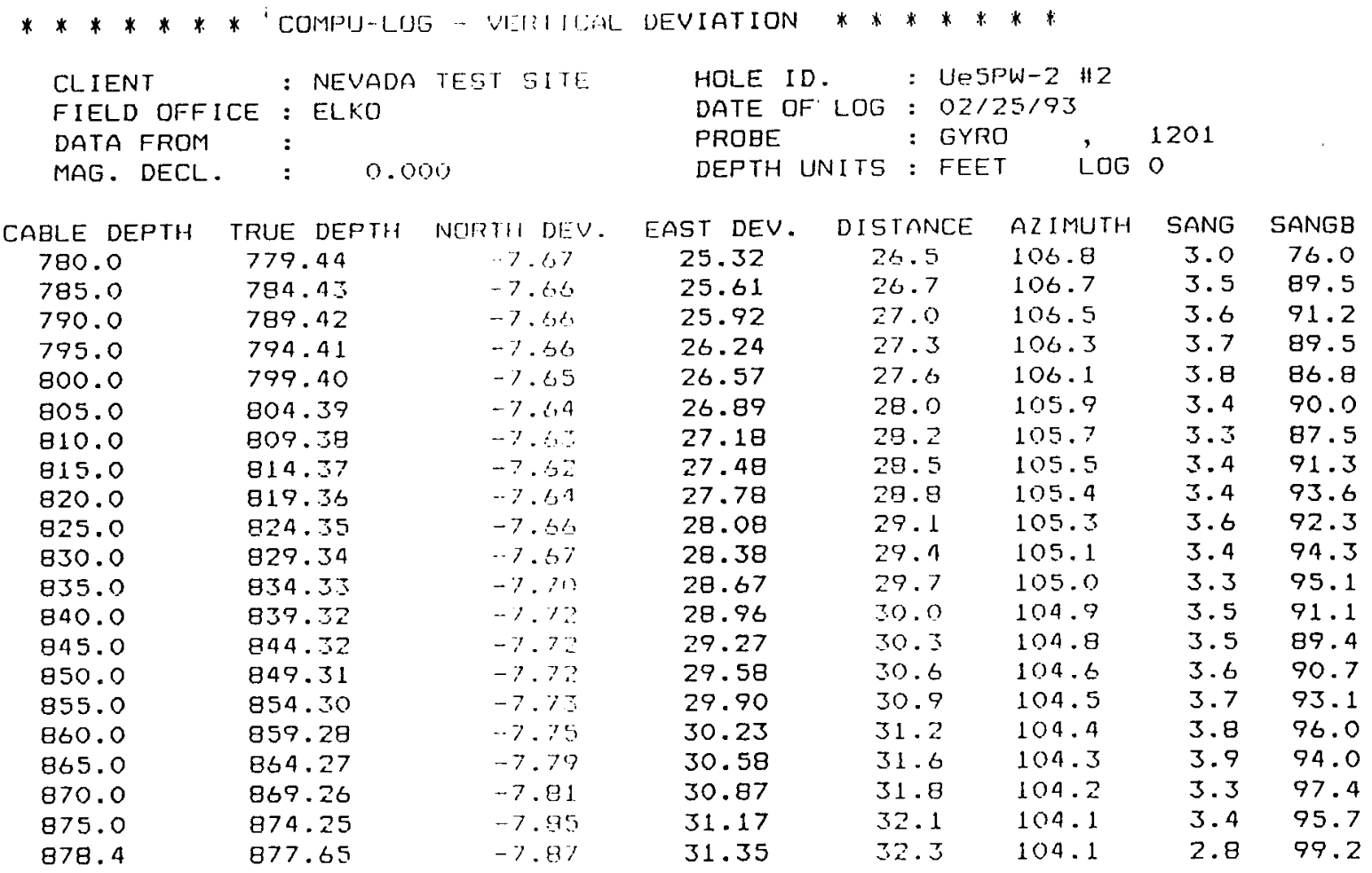


Appendix F.3.8 Borehole geophysical logs run in Ue5PW-3 on 9/28/92

\begin{tabular}{|c|c|c|c|}
\hline \multicolumn{4}{|c|}{ EQUIPMENT DATA SHEET } \\
\hline $\begin{array}{l}\text { WELL \# UE5PW-3 } \\
\text { DATE: } \quad 9-28-92\end{array}$ & GAMMA RAY & \multicolumn{2}{|c|}{ DENSITY/NEUTRON } \\
\hline $\begin{array}{l}\text { TOOL INFORMATION } \\
\text { RUN NO. } \\
\text { MODEL NO. } \\
\text { TOOL DIAMETER } \\
\text { DISTANCE TO SOURCE } \\
\text { DETECTOR TYPE } \\
\text { DETECTOR OFFSET (FROM O) } \\
\text { LENGTH \& DIAMETER (NEAY) } \\
\text { LENGTH \& DIAMETER (FAI) } \\
\text { LOGGING SPEED } \\
\text { CENTRALIZER } \\
\text { GAMMA RAY API CONVERSION } \\
\text { MANUFACTURER }\end{array}$ & $\begin{array}{l}\text { Three } \\
9035 \\
2.8 " \\
\text { na } \\
\text { Scintln. } \\
6.6^{\prime \prime} \\
4.0 \times .875^{\prime \prime} \\
30 \text { fpm } \\
\text { sidewall } \\
.658 \\
\text { Century }\end{array}$ & \begin{tabular}{|c} 
Three \\
9035 \\
$2.8 "$ \\
$114.7 "$ \\
$2-5 c t$ in \\
$101 / 107 "$ \\
$4.0 \times .875$ \\
$1.2 \times .875$ \\
30 fpm \\
sidewall \\
Century
\end{tabular} & \begin{tabular}{|c} 
Two \\
9071 \\
$2.9 " 1$ \\
$99.0 "$ \\
$2-\mathrm{He} 3$ \\
$75 / 88.2^{\prime \prime}$ \\
$4.0 \times 1.125$ \\
$10.0 \times 2.0$ \\
30 fpm \\
free hang \\
Century
\end{tabular} \\
\hline $\begin{array}{l}\text { RADIOACTIVE SOURCES } \\
\text { SOURCE TYPE } \\
\text { SOURCE SPACING } \\
\text { SOURCE STRENGTH } \\
\text { SOURCE SERIAL NO. }\end{array}$ & & $\left|\begin{array}{cc}\text { Cs } 137 \\
6 \& 12^{\prime \prime} \\
125 \mathrm{mCi} \\
V L-1-278\end{array}\right|$ & $\begin{array}{l}\text { AmBe } \\
10.8 \& 24^{\prime \prime} \\
5.0 \mathrm{Ci} \\
71-1-399 \mathrm{~B}\end{array}$ \\
\hline $\begin{array}{l}\text { TOOL INFORMATION } \\
\text { RUN NO. } \\
\text { MODEL NO. } \\
\text { TOOL DIAMETER } \\
\text { DETECTOR OFFSET (FROM } \\
\text { LOGGING SPEED } \\
\text { TYPE }\end{array}$ & RESISTIVITY & $\begin{array}{l}\text { CALII } \\
\text { Three } \\
9035 \\
2.8^{\prime \prime} \\
92^{\prime \prime} \\
30 \mathrm{FI} \\
\text { Sing }\end{array}$ & $\begin{array}{l}\text { PER } \\
\text { PM Arm } \\
\text { le Arm }\end{array}$ \\
\hline $\begin{array}{l}\text { OTHER TOOL INFORMATION } \\
\text { Detector Type and Size } \\
\text { Tool Type } \\
\text { Offset } \\
\text { Run Number }\end{array}$ & \begin{tabular}{|} 
Spectral Gamma \\
NaI $1.5 \times 12^{\prime \prime}$ \\
$9080^{\prime \prime}$ \\
$68^{\prime \prime}$ \\
one
\end{tabular} & & \\
\hline $\begin{array}{ll}\text { GENERAL INFORMATION } & \\
\text { TRUCK NO. } & 9103 \\
\text { SOFTWARE LEVEL } & \text { COMP } \\
\text { OPERATOR } & \text { Fede } \\
\text { LOCATION } & \text { N. } 7\end{array}$ & 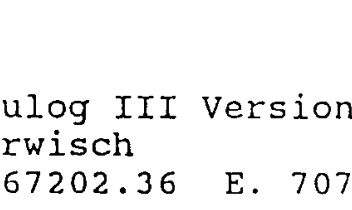 & $\begin{array}{c}7.03 \\
006.31\end{array}$ & \\
\hline 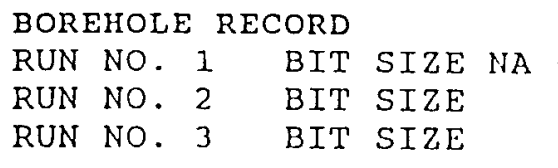 & - CASING IS DRIV & & \\
\hline 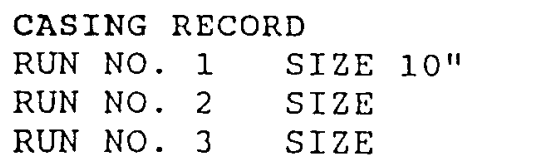 & $\begin{array}{lll}\text { FROM } & 0 & \text { TO } \\
\text { FROM } & & \text { TO } \\
\text { FROM } & & \text { TO }\end{array}$ & 450.0 & \\
\hline REMARKS: Run 1 of this & well. & & \\
\hline
\end{tabular}


Appendix F.3.8 Borehole geophysical logs run in Ue5PW-3 on 9/28/92 (Continued)

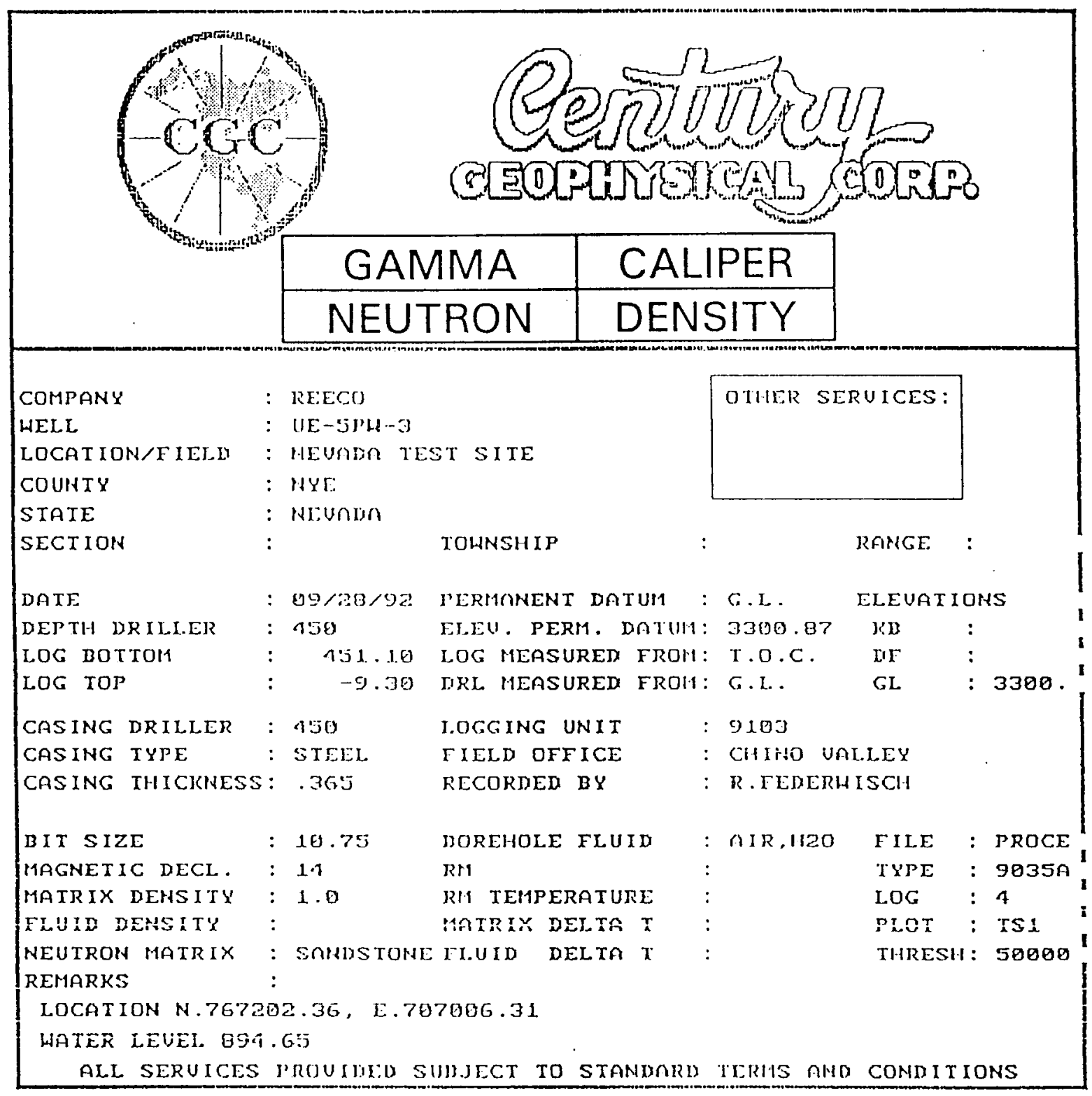


Appendix F.3.8 Borehole geophysical logs run in Ue5PW-3 on 9/28/92 (Continued)
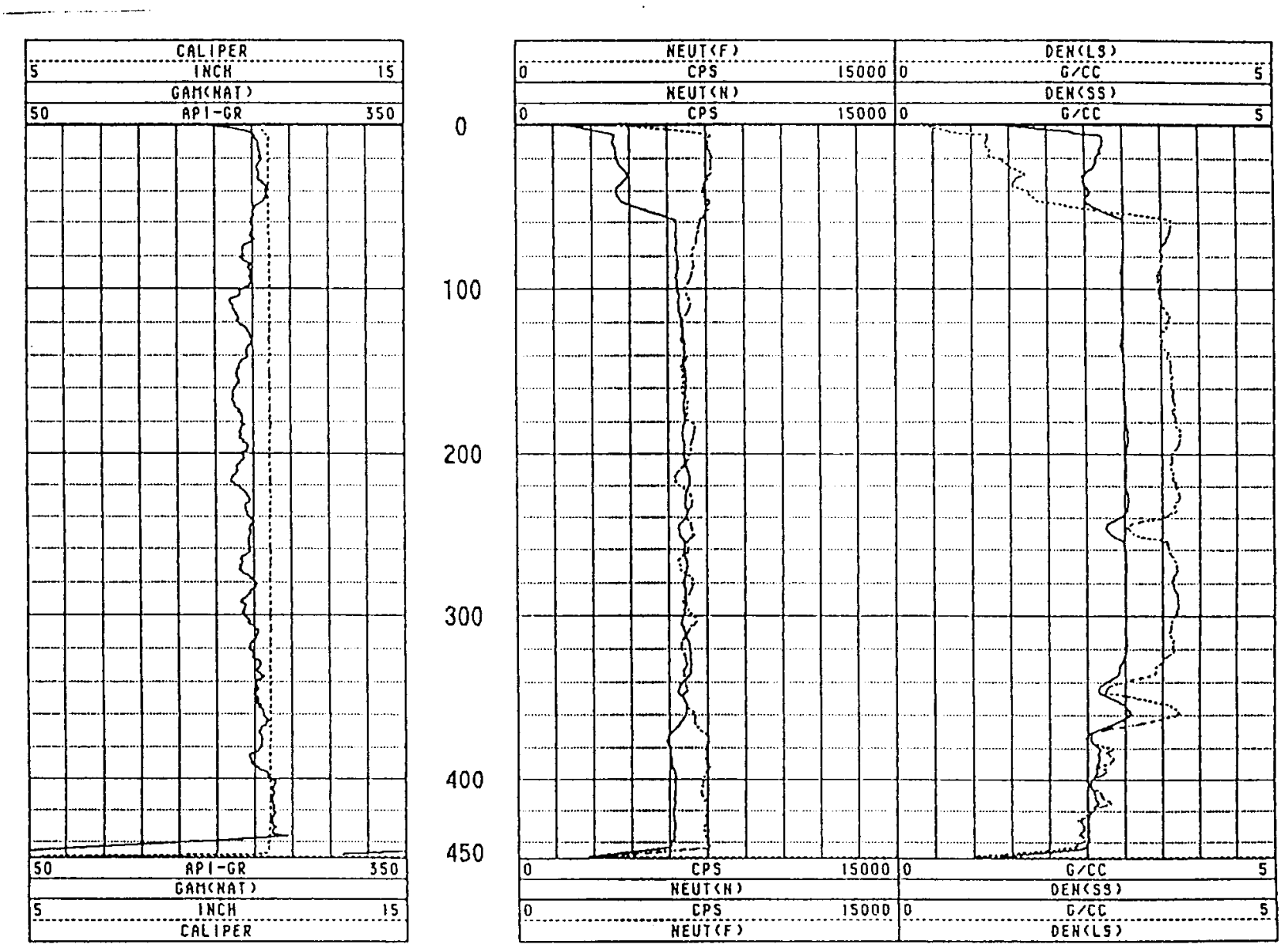

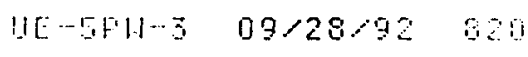


Appendix F.3.8 Borehole geophysical logs run in Ue5PW-3 on 9/28/92 (Continued)

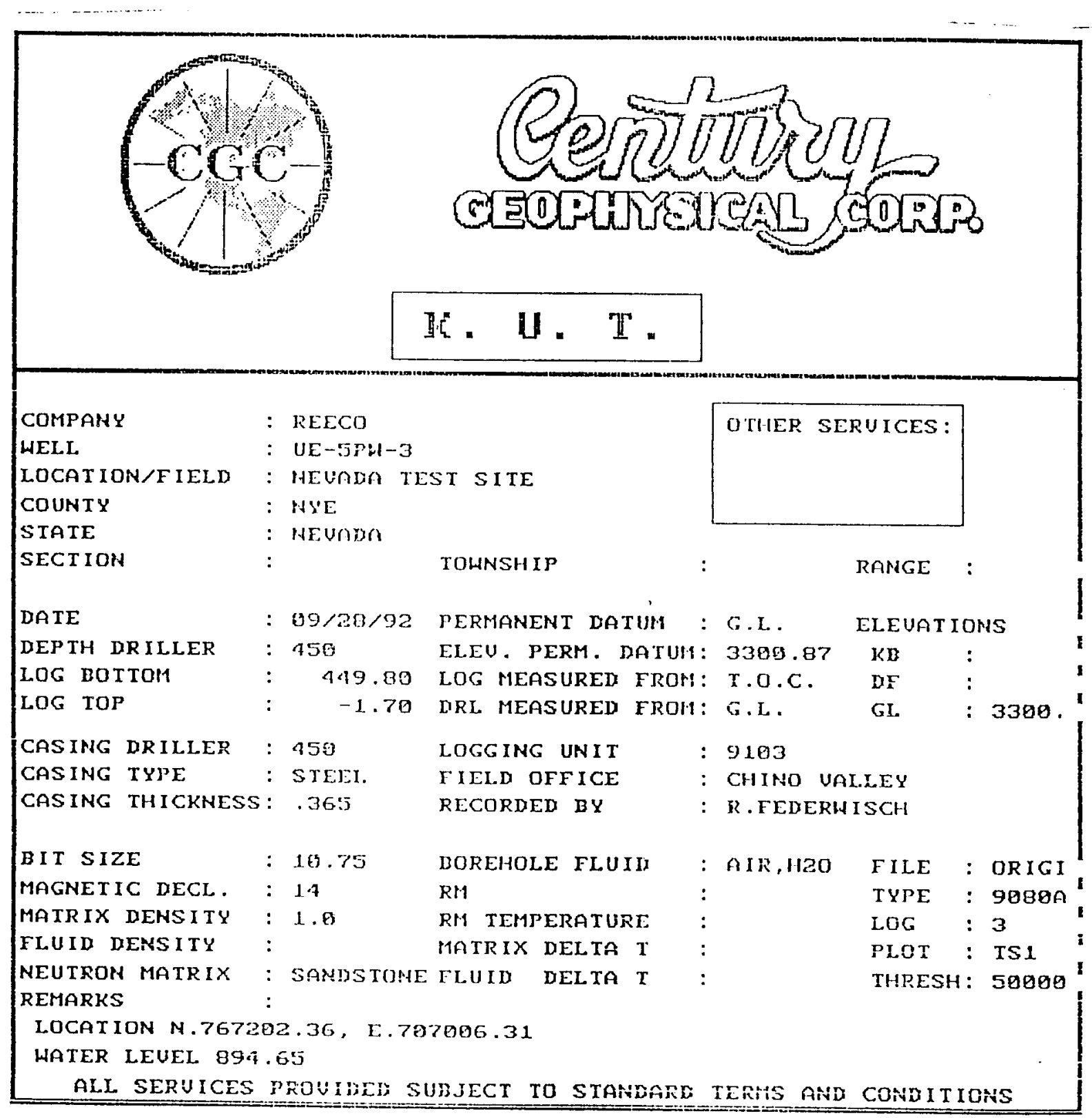


Appendix F.3.8 Borehole geophysical logs run in Ue5PW-3 on 9/28/92 (Continued)

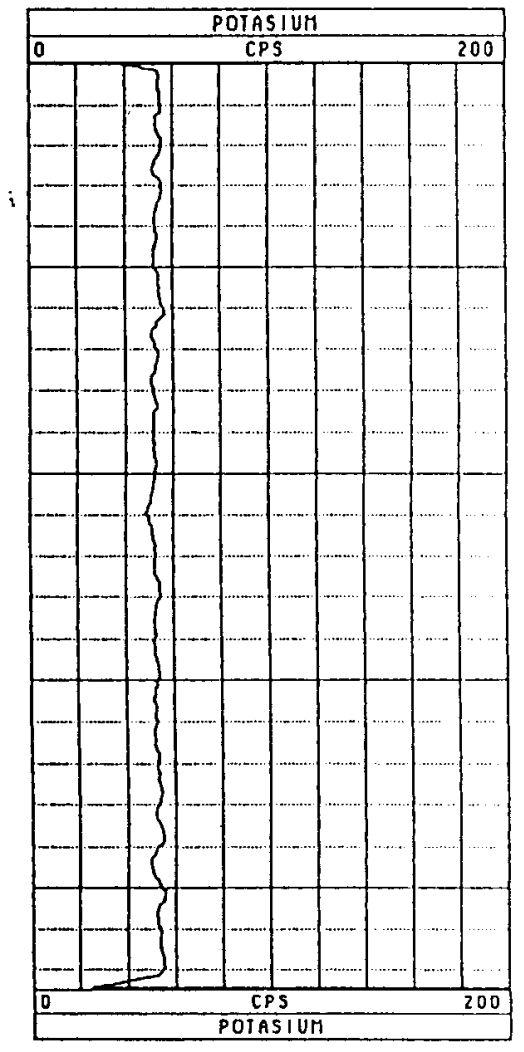

0

100

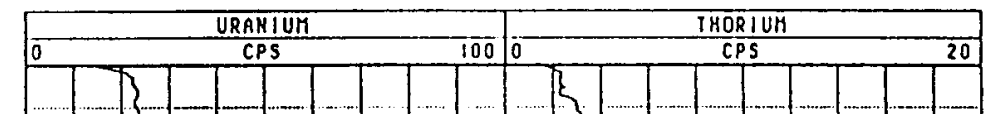

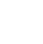

300

200

400

450

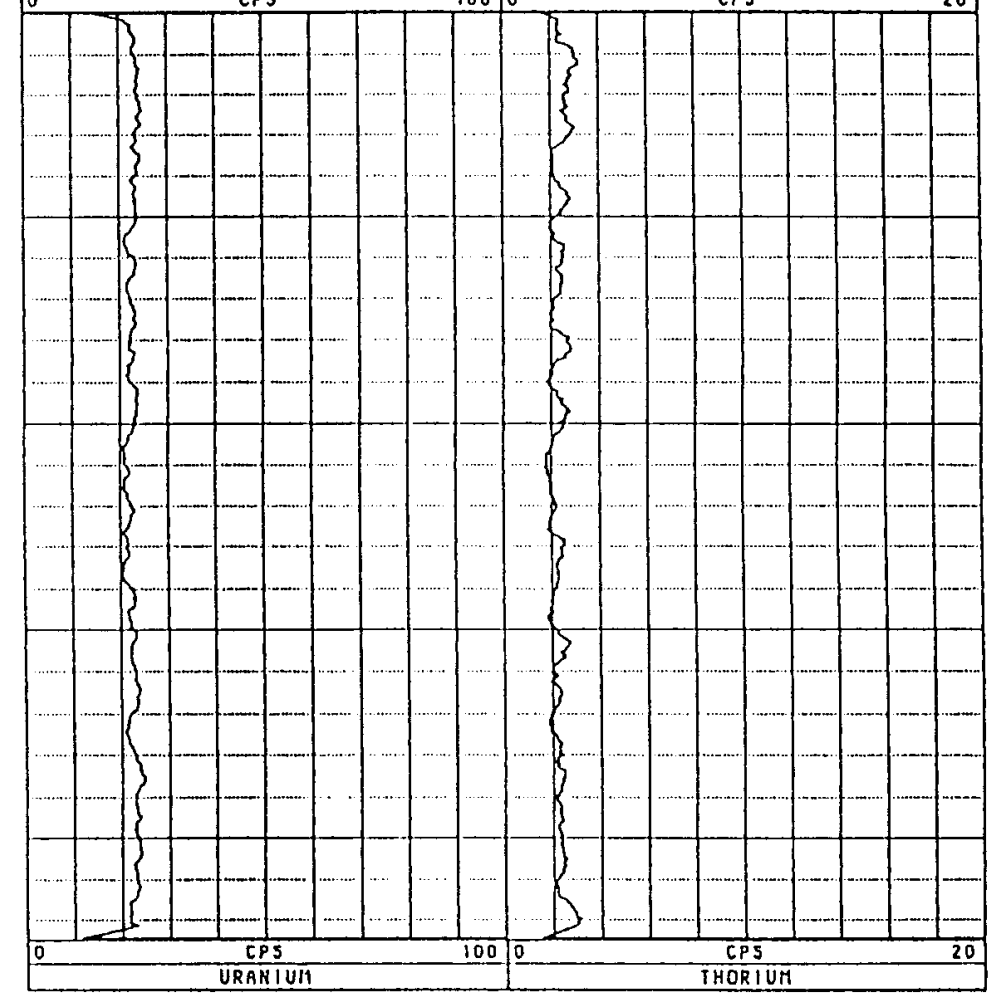

THORIUM 
Appendix F.3.9 Borehole geophysical logs run in Ue5PW-3 on 11/18/92

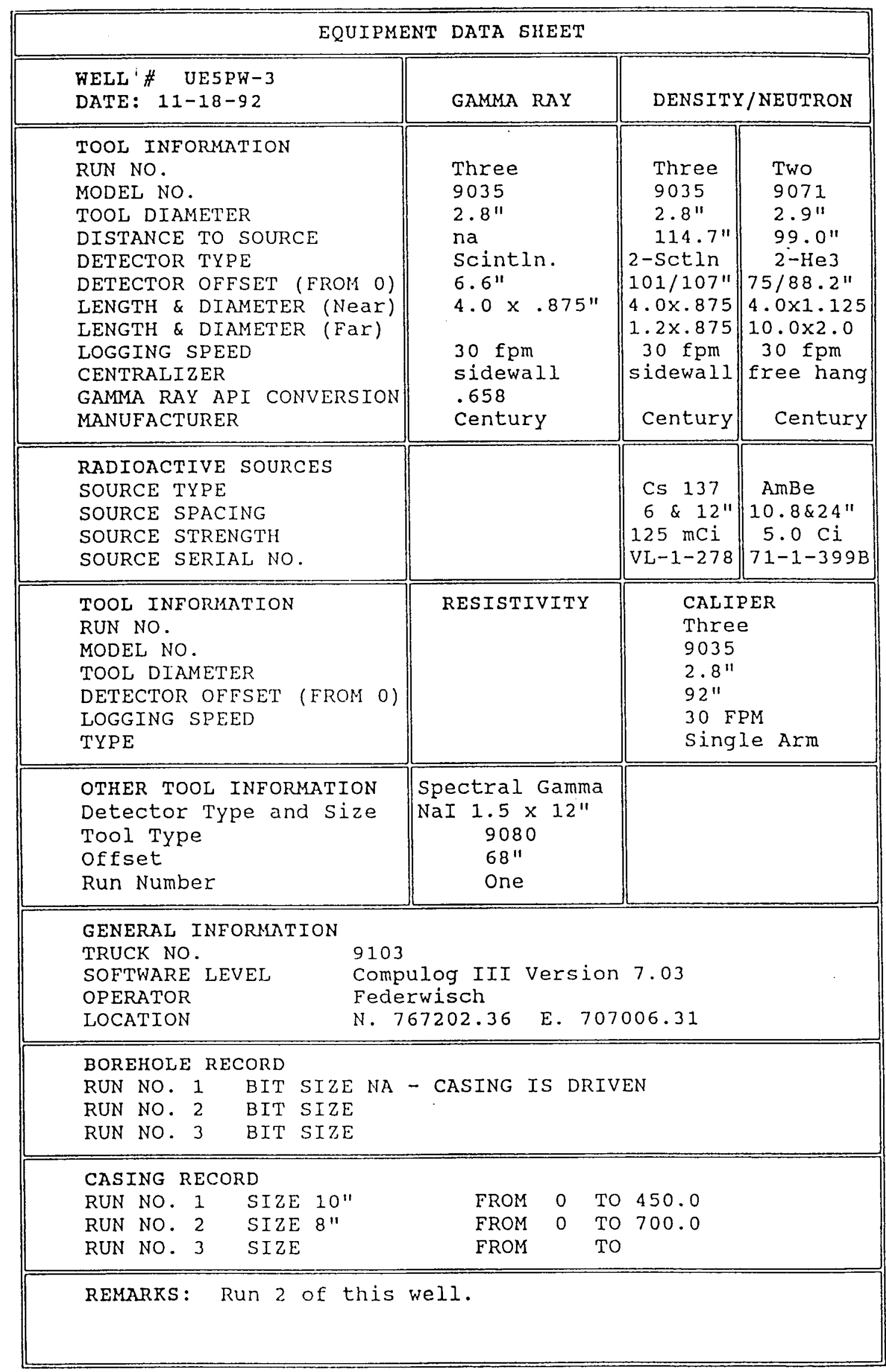


Appendix F.3.9 Borehole geophysical logs run in Ue5PW-3 on 11/18/92 (Continued)

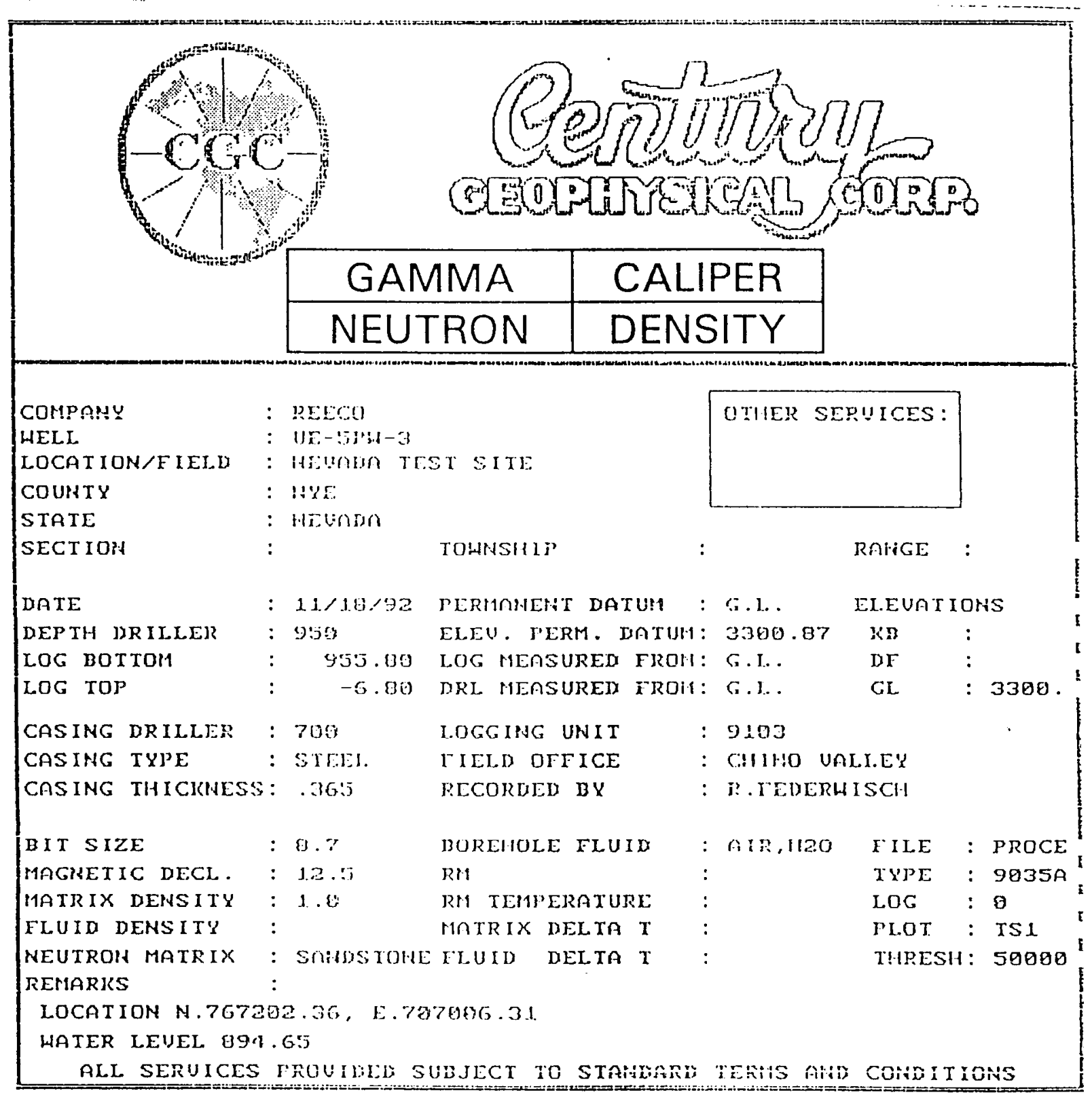


Appendix F.3.9 Borehole geophysical logs run in Ue5PW-3 on 11/18/92 (Continued)
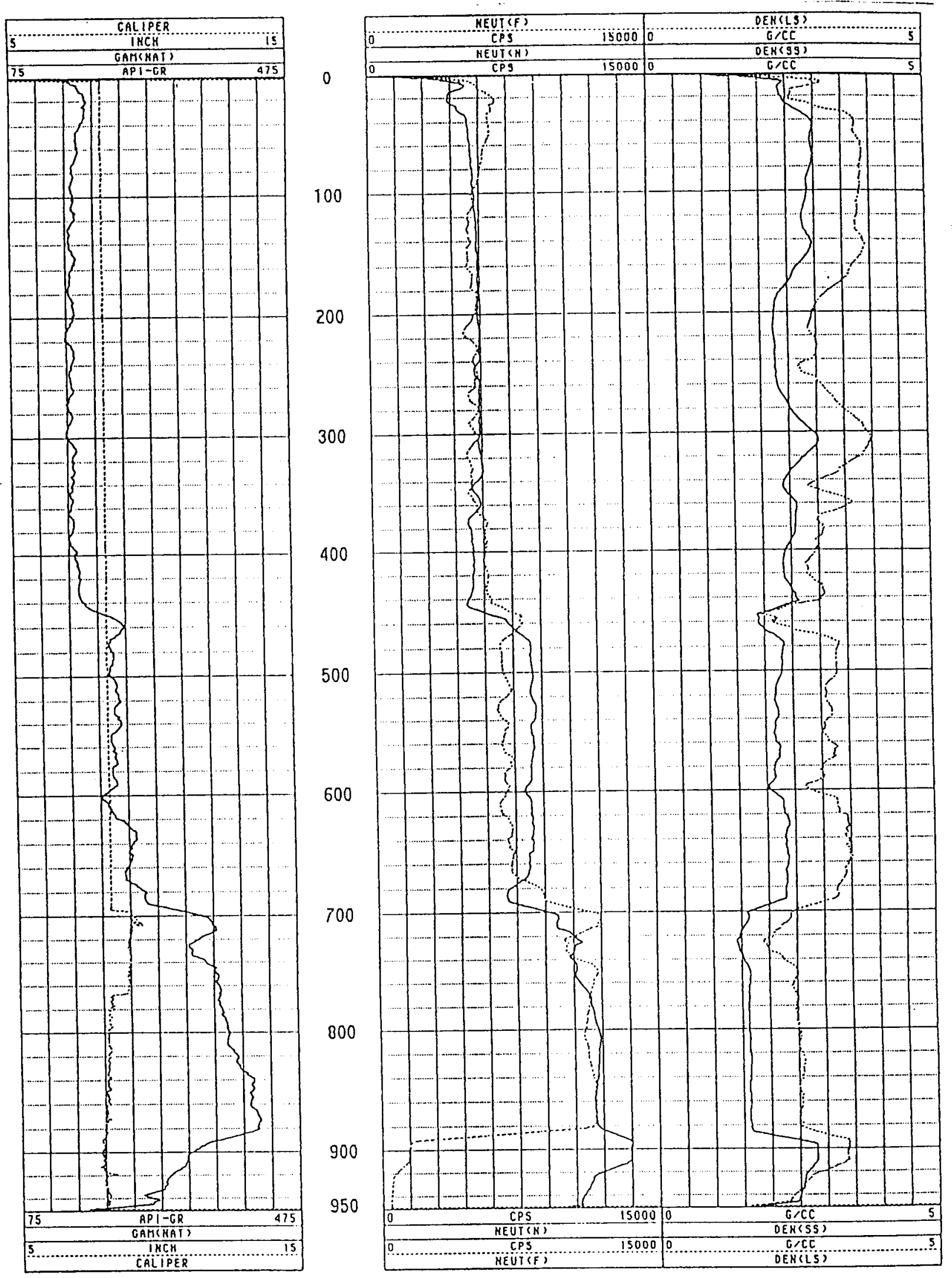

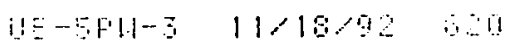


Appendix F.3.9 Borehole geophysical logs run in Ue5PW-3 on 11/18/92 (Continued)

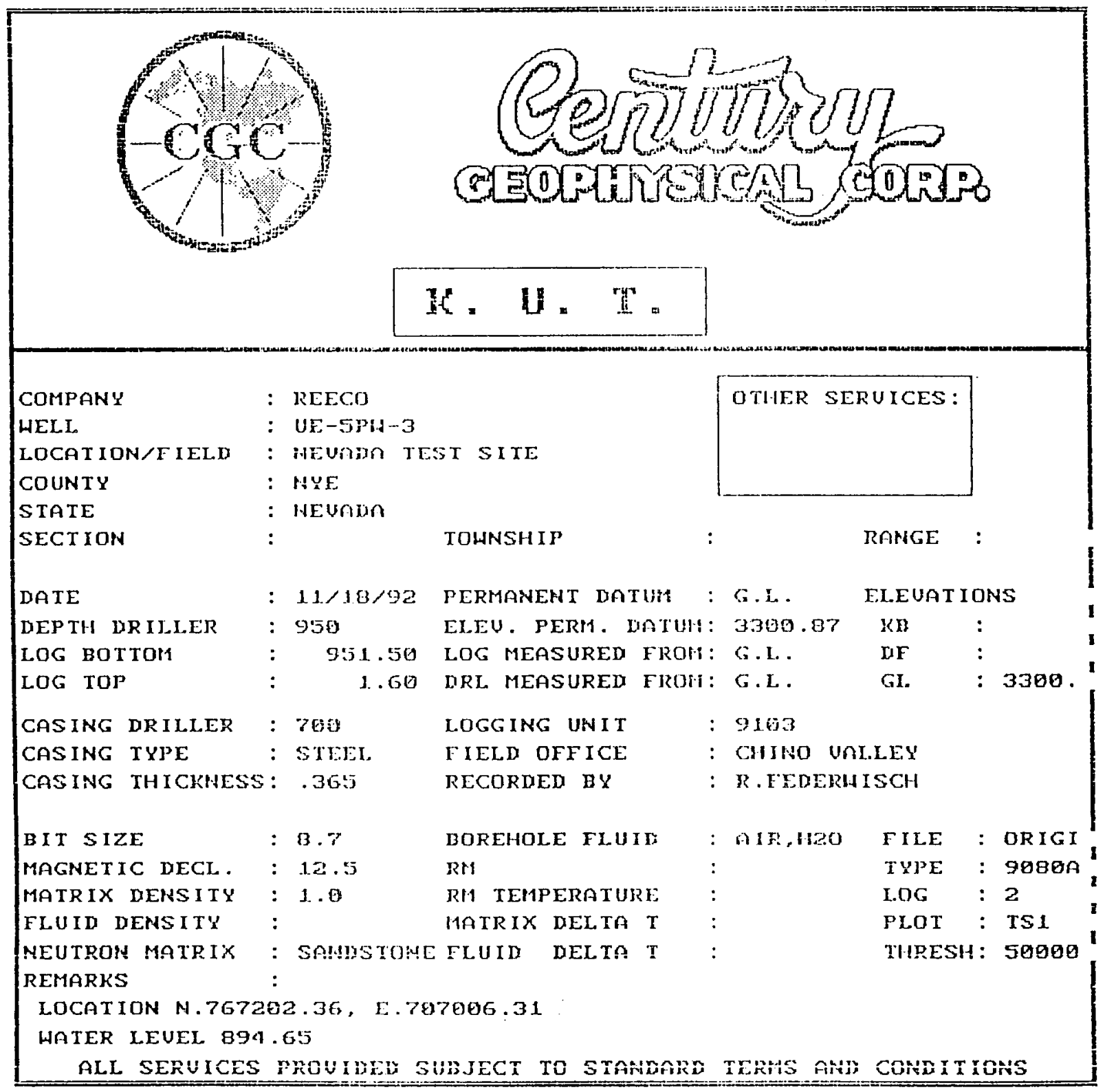


Appendix F.3.9 Borehole geophysical logs run in Ue5PW-3 on 11/18/92 (Continued)
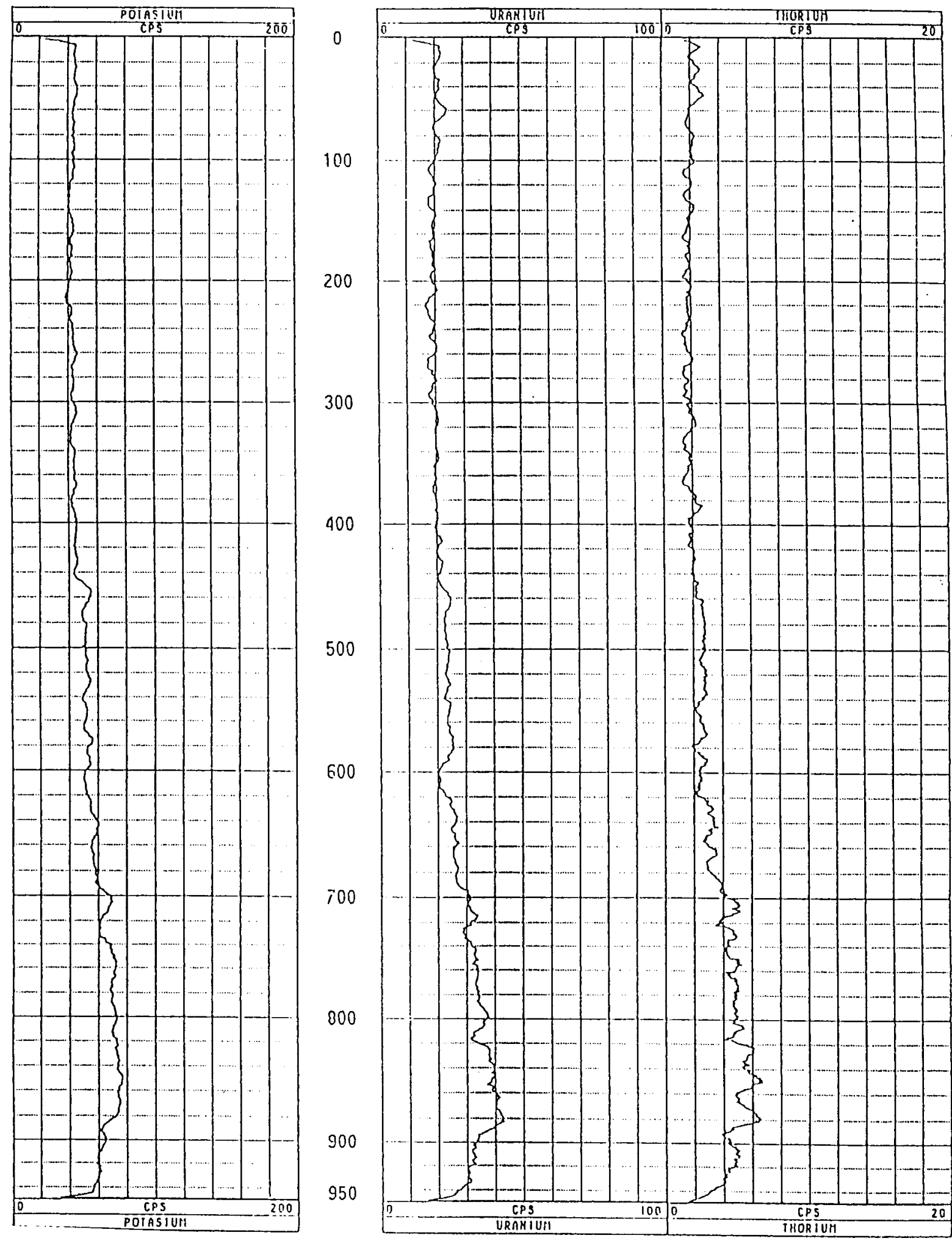

UE-5PW-3 $\quad 11 / 18 / 92 \quad 270$ 
Appendix F.3.10 Borehole deviation los run in UE5PW-3 on 2/24/93 (replaces previous Equipment Data Sheet).

\begin{tabular}{|c|c|c|}
\hline \multicolumn{3}{|c|}{ EQUIPMENT DATA BHEET } \\
\hline $\begin{array}{l}\text { WELL \# UE5PW-3 } \\
\text { DATE: } 2-25-93\end{array}$ & GAMQYA RAY & DENB ITY / NEUTRON \\
\hline $\begin{array}{l}\text { TOOL INFORMATION } \\
\text { RUN NO. } \\
\text { MODEL NO. } \\
\text { TOOL DIAMETER } \\
\text { DISTANCE TO SOURCE } \\
\text { DETECTOR TYPE } \\
\text { DETECTOR OFFSET (FROM 0) } \\
\text { LENGTH \& DIAMETER (Near) } \\
\text { LENGTH \& DIAMETER (Far) } \\
\text { LOGGING SPEED } \\
\text { CENTRALIZER } \\
\text { GAMMA RAY API CONVERSION } \\
\text { MANUFACTURER }\end{array}$ & & \\
\hline $\begin{array}{l}\text { RADIOACTIVE SOURCE8 } \\
\text { SOURCE TYPE } \\
\text { SOURCE SPACING } \\
\text { SOURCE STRENGTH } \\
\text { SOURCE SERIAL NO. }\end{array}$ & & \\
\hline $\begin{array}{l}\text { TOOL INFORMATION } \\
\text { RUN NO. } \\
\text { MODEL NO. } \\
\text { TOOL DIAMETER } \\
\text { DETECTOR OFFSET (FROM } \\
\text { LOGGING SPEED } \\
\text { TYPE }\end{array}$ & RESIBTIVITY & CALIPER \\
\hline $\begin{array}{l}\text { OTHER TOOL INFORMATION } \\
\text { Detector Type and Size } \\
\text { Tool Type } \\
\text { Offset } \\
\text { Run Number }\end{array}$ & $\begin{array}{l}\text { DEVIATION } \\
\text { InCl/GyYo } \\
9095 \\
70.9 / 80.6 \\
\text { one }\end{array}$ & $\begin{array}{l}\text { Manufacturer } \\
\text { CGC/Humphrey }\end{array}$ \\
\hline $\begin{array}{ll}\text { GENERAI INFORMATION } \\
\text { TRUCK NO. } \\
\text { SOFTWARE LEVEL } & 9101 \\
\text { OPERATOR } & \text { COMp } \\
\text { LOCATION } & \text { T. K } \\
& \text { N. 7 }\end{array}$ & 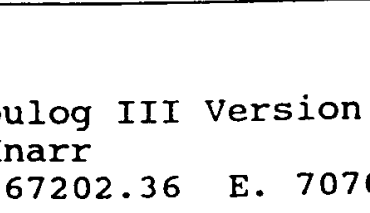 & $\begin{array}{l}7.03 \\
006.31\end{array}$ \\
\hline \begin{tabular}{llll}
\multicolumn{3}{l}{ BOREHOLE RECORD } \\
RUN NO. 1 & BIT SIZE & 10 \\
RUN NO. 2 & BIT SIZE & 8 \\
RUN NO. 3 & BIT SIZE &
\end{tabular} & $\begin{array}{l}\text { " } 0 \text { to } 450 \\
450 \text { to } 955\end{array}$ & \\
\hline \begin{tabular}{llll}
\multicolumn{4}{l}{ CASING RECORD } \\
RUN NO. 1 & SIZE & $2-7 / 8 "$ \\
RUN NO. 2 & SIZE & \\
RUN NO. 3 & SIZE &
\end{tabular} & $\begin{array}{lll}\text { FROM } & 0 & \text { TO } \\
\text { FROM } & & \\
\text { FROM } & & \end{array}$ & 955.0 \\
\hline $\begin{array}{ll}\text { REMARKs: } & \text { Client supplie } \\
& \text { Bottom log dep }\end{array}$ & $\begin{array}{l}\text { d sighting stake } \\
\text { th } 923 \text { run } 1 \text { and }\end{array}$ & $\begin{array}{l}\text { direction. } \\
924 \text { run } 2 \text {. }\end{array}$ \\
\hline
\end{tabular}


Appendix F.3.10 Borehole deviation logs run in Ue5PW-3 on 2/25/93 (Continued)

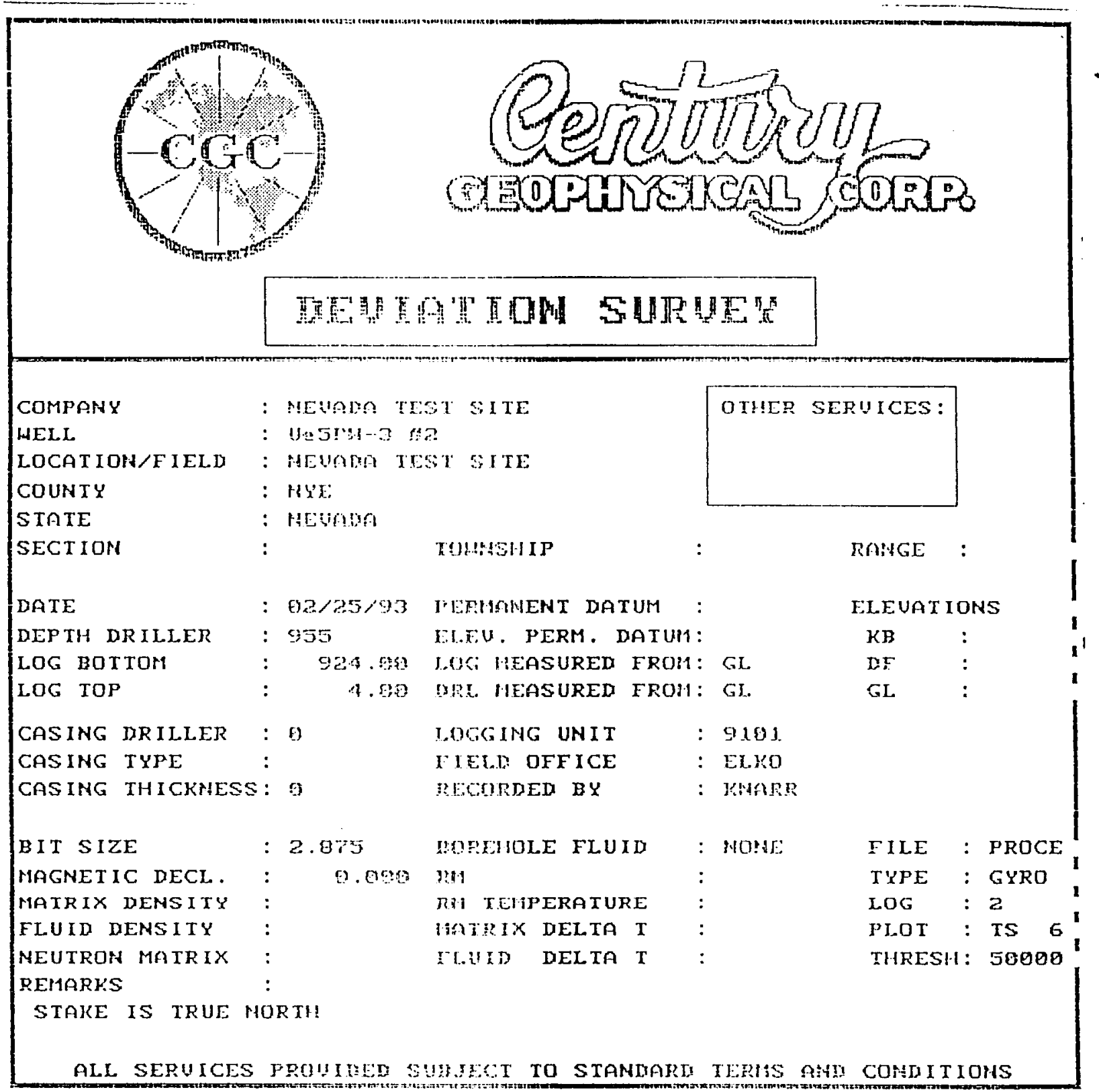


Appendix F.3.10 Borehole deviation logs run in Ue5PW-3 on 2/25/93 (Continued)

\section{PLAnM VICH \\ COHDU-LOG DEUIATIOH}

CLIENT: NEUADA IESI SITE

LOCATION: NEUADA IEST SITE

HOLE ID: UESPH-3 H2

DATE OF LOG: $02 / 25 / 93$

PRODE: GYRO 1201

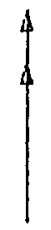

$\operatorname{Min}$ DECI: 8.0
SCALE: 2 FI/IN

IRUE DEPIH: $923.84 \mathrm{FI}^{\circ}$

AZIMUIH: 243.3

DISTANCE: $4 . \theta \mathrm{FI}$

$+=108 \mathrm{FT}$ INCR

$O=$ BOIIOK OF HOLE

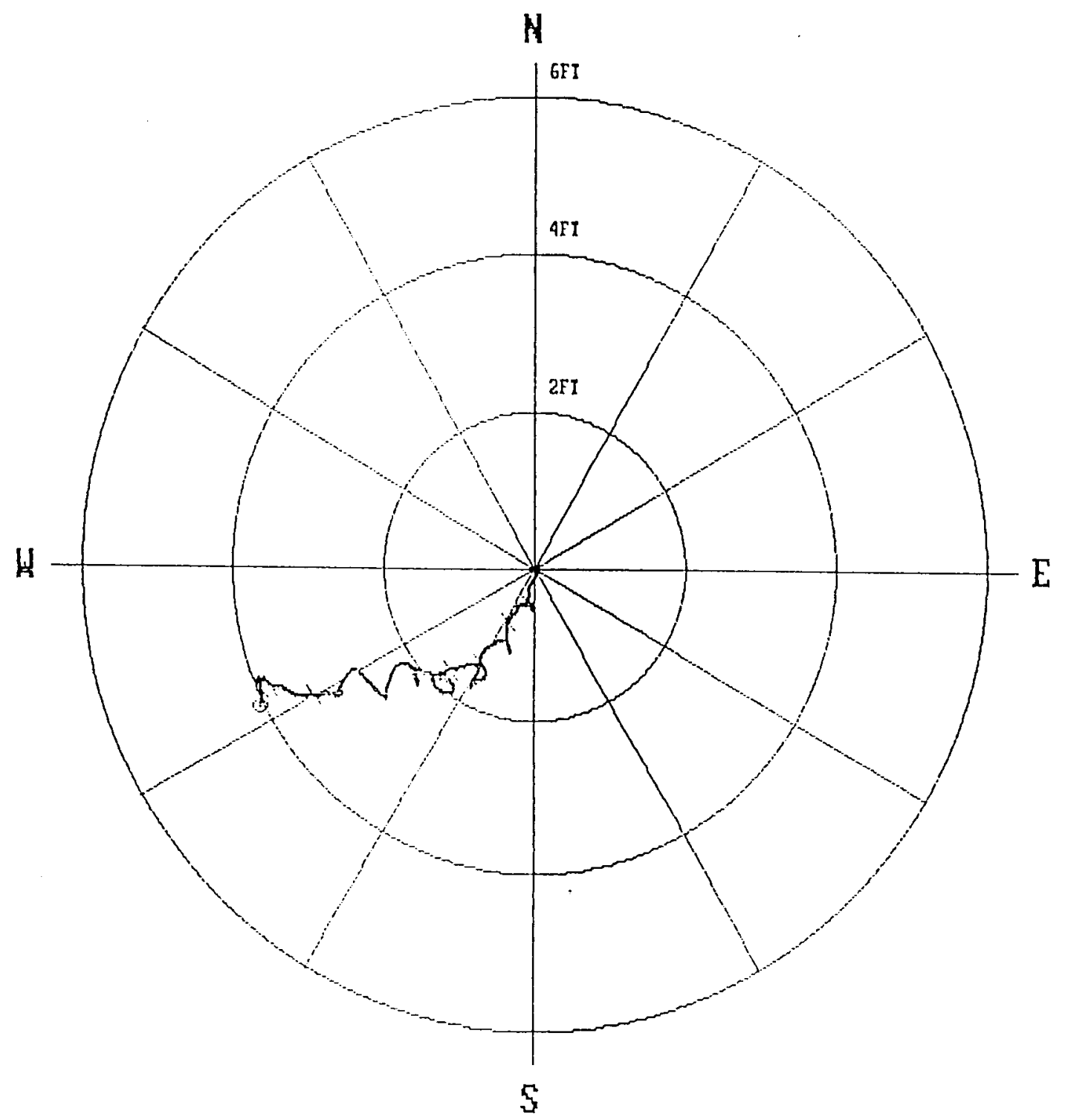


Appendix F.3.10 Borehole deviation logs run in Ue5PW-3 on 2/25/93 (Continued)

\begin{tabular}{|c|c|c|c|c|c|c|c|}
\hline CABLE DEPTH & TRUE DEPTII & MOLIH lYE"?. & EAST DEV. & DISTANCE & AZIHUTH & SANG & SANGB \\
\hline 5.0 & 5.00 & 0.00 & 0.00 & 0.0 & 0.0 & 0.0 & 0.0 \\
\hline 10.0 & 10.00 & 0.01 & 0.03 & 0.0 & 75.0 & 0.4 & 68.1 \\
\hline 15.0 & 15.00 & 0.02 & 0.06 & 0.1 & 72.3 & 0.3 & 62.9 \\
\hline 20.0 & 20.00 & 0.02 & 0.07 & 0.1 & 70.4 & 0.1 & 36.7 \\
\hline 25.0 & 25.00 & 0.02 & 0.07 & 0.1 & 70.2 & 0.0 & 31.0 \\
\hline 30.0 & 30.00 & $0.0 \%$ & 0.07 & 0.1 & 71.2 & 1.5 & 186.3 \\
\hline 35.0 & 35.00 & 0.01 & 0.06 & 0.1 & 82.9 & 0.2 & 156.2 \\
\hline 40.0 & 40.00 & -0.02 & 0.06 & 0.1 & 105.0 & 0.5 & 188.7 \\
\hline 45.0 & 45.00 & $\cdots 0.06$ & 0.05 & 0.1 & 139.7 & 0.6 & 208.8 \\
\hline 50.0 & 50.00 & -0.10 & 0.02 & 0.1 & 166.4 & 0.5 & 218.8 \\
\hline 55.0 & 55.00 & -0.1 .1 & -0.00 & 0.1 & 180.3 & 0.6 & 218.2 \\
\hline 60.0 & 60.00 & -0.18 & -0.03 & 0.2 & 189.8 & 0.6 & 216.7 \\
\hline 65.0 & 65.00 & -0.22 & -0.05 & 0.2 & 194.1 & 0.4 & 207.5 \\
\hline 70.0 & 70.00 & -0.25 & -0.07 & 0.5 & 195.7 & 0.3 & 50.1 \\
\hline 75.0 & 75.00 & -0.27 & -0.08 & 0.3 & 195.6 & 0.3 & 186.4 \\
\hline 80.0 & 80.00 & -0.30 & -0.07 & 0.3 & 193.7 & 0.3 & 159.4 \\
\hline 85.0 & 85.00 & -0.23 & -0.06 & 0.3 & 191.0 & 0.4 & 185.4 \\
\hline 90.0 & 90.00 & -0.56 & -0.07 & 0.4 & 190.6 & 0.4 & 195.8 \\
\hline 95.0 & 95.00 & -0.10 & -0.08 & 0.9 & 1.91 .0 & 0.5 & 189.3 \\
\hline 100.0 & 100.00 & $-0.4 \vdots$ & $-0.0 B$ & 0.5 & 190.0 & 0.6 & 179.1 \\
\hline 105.0 & 105.00 & -0.79 & -0.06 & 0.5 & 187.0 & 0.6 & 149.5 \\
\hline 110.0 & 110.00 & -0.55 & -0.03 & 0.5 & 183.4 & 0.5 & 139.2 \\
\hline 115.0 & 115.00 & -0.54 & -0.00 & 0.5 & 180.3 & 0.2 & 76.0 \\
\hline 120.0 & 120.00 & -0.53 & 0.01 & 0.5 & 178.8 & 0.1 & 27.8 \\
\hline 125.0 & 125.00 & -0.52 & 0.01 & 0.5 & 178.6 & 0.2 & 343.5 \\
\hline 130.0 & 130.00 & -0.50 & 0.00 & 0.5 & 179.5 & 0.3 & 321.6 \\
\hline 135.0 & 135.00 & -0.103 & -0.02 & 0.5 & 182.0 & 0.3 & 295.6 \\
\hline 140.0 & 140.00 & -0.47 & -0.05 & 0.5 & 185.6 & 0.4 & 282.2 \\
\hline 145.0 & 145.00 & -0.17 & -0.08 & 0.5 & 190.0 & 0.5 & 267.8 \\
\hline 150.0 & 150.00 & -0.17 & -0.13 & 0.5 & 195.1 & 0.6 & $273.4:$ \\
\hline 155.0 & 155.00 & $\cdots 0.18$ & -0.17 & 0.5 & 199.5 & 0.3 & 259.0 \\
\hline 160.0 & 160.00 & .0 .13 & -0.20 & 0.5 & 201.6 & 0.4 & 236.8 \\
\hline 165.0 & 165.00 & -0.51 & -0.22 & 0.6 & 203.0 & 0.3 & 219.5 \\
\hline $\begin{array}{l}170.0 \\
175.0 \\
180.0\end{array}$ & $\begin{array}{l}170.00 \\
175.00 \\
180.00\end{array}$ & $\begin{array}{r}-0.5 n \\
0.50 \\
-0.5 \theta\end{array}$ & $\begin{array}{l}-0.23 \\
-0.24 \\
-0.25\end{array}$ & $\begin{array}{l}0.6 \\
0.5 \\
0.6\end{array}$ & $\begin{array}{l}203.0 \\
202.8 \\
203.3\end{array}$ & $\begin{array}{l}0.3 \\
0.3 \\
0.3\end{array}$ & $\begin{array}{l}196.5 \\
196.2 \\
222.6\end{array}$ \\
\hline 185.0 & 185.00 & -0.010 & -0.27 & 0.7 & 204.2 & 0.4 & 224.3 \\
\hline 190.0 & 190.00 & $-0.6 I$ & -0.29 & 0.7 & 205.1 & 0.3 & 227.7 \\
\hline 195.0 & 195.00 & -0.65 & -0.32 & 0.7 & 205.8 & 0.4 & 220.9 \\
\hline 200.0 & 200.00 & -0.09 & -0.34 & 0.8 & 208.2 & 0.5 & 205.6 \\
\hline 205.0 & 204.99 & -0.71 & -0.36 & 0.0 & 205.7 & 0.8 & 193.8 \\
\hline 210.0 & 209.99 & -0.62 & -0.37 & 0.9 & 204.0 & 1.0 & 182.5 \\
\hline 215.0 & 214.99 & -0.90 & -0.36 & 1.0 & 202.0 & 0.8 & 177.5 \\
\hline 220.0 & 219.99 & -0.97 & -0.36 & 1.0 & 200.2 & 0.7 & 165.7 \\
\hline 225.0 & 224.99 & -1.05 & -0.34 & 1.1 & 198.4 & 0.6 & 170.6 \\
\hline 230.0 & 229.99 & -1.06 & -0.33 & 1.1 & 197.1 & 0.5 & 134.3 \\
\hline 235.0 & 234.97 & -1.06 & -0.32 & 1.1 & 196.3 & 0.1 & 121.5 \\
\hline 290.0 & 239.99 & -1.00 & -0.31 & 1.1 & 175.9 & 0.2 & 182.0 \\
\hline 245.0 & 244.99 & -1.07 & -0.31 & 1.1 & 195.9 & 0.2 & 3.2 \\
\hline 250.0 & 249.99 & -1.05 & -0.32 & 1.1 & 196.9 & 0.5 & 344.6 \\
\hline 255.0 & 254.99 & -1 . (i) & -0.33 & 1.1 & 199.4 & 0.5 & 344.1 \\
\hline 260.0 & 259.99 & -0.97 & -0.36 & 1.0 & 200.2 & 0.5 & 318.8 \\
\hline 265.0 & 264.97 & -0.71 & -0.39 & 1.0 & 202.5 & 0.6 & 285.6 \\
\hline 270.0 & 269.99 & -19.9 & -0.44 & 1.0 & 205.1 & 0.6 & 262.4 \\
\hline 275.0 & 274.99 & $-i) .97$ & -0.51 & 1.1 & 207.6 & 0.9 & 241.5 \\
\hline 280.0 & 279.99 & -1.01 & -0.58 & 1.2 & 209.8 & 1.1 & 236.2 \\
\hline 285.0 & 284.97 & -1.67 & -0.65 & 1.2 & 211.3 & 0.9 & 224.2 \\
\hline 290.0 & 289.59 & -1.12 & -0.69 & 1.3 & 211.7 & 0.7 & 212.2 \\
\hline 295.0 & 294.79 & -1.17 & -0.71 & 1.4 & 211.2 & 0.6 & 178.1 \\
\hline
\end{tabular}




\section{Appendix F.3.10 Borehole deviation logs run in Ue5PW-3 on 2/25/93 (Continued)}

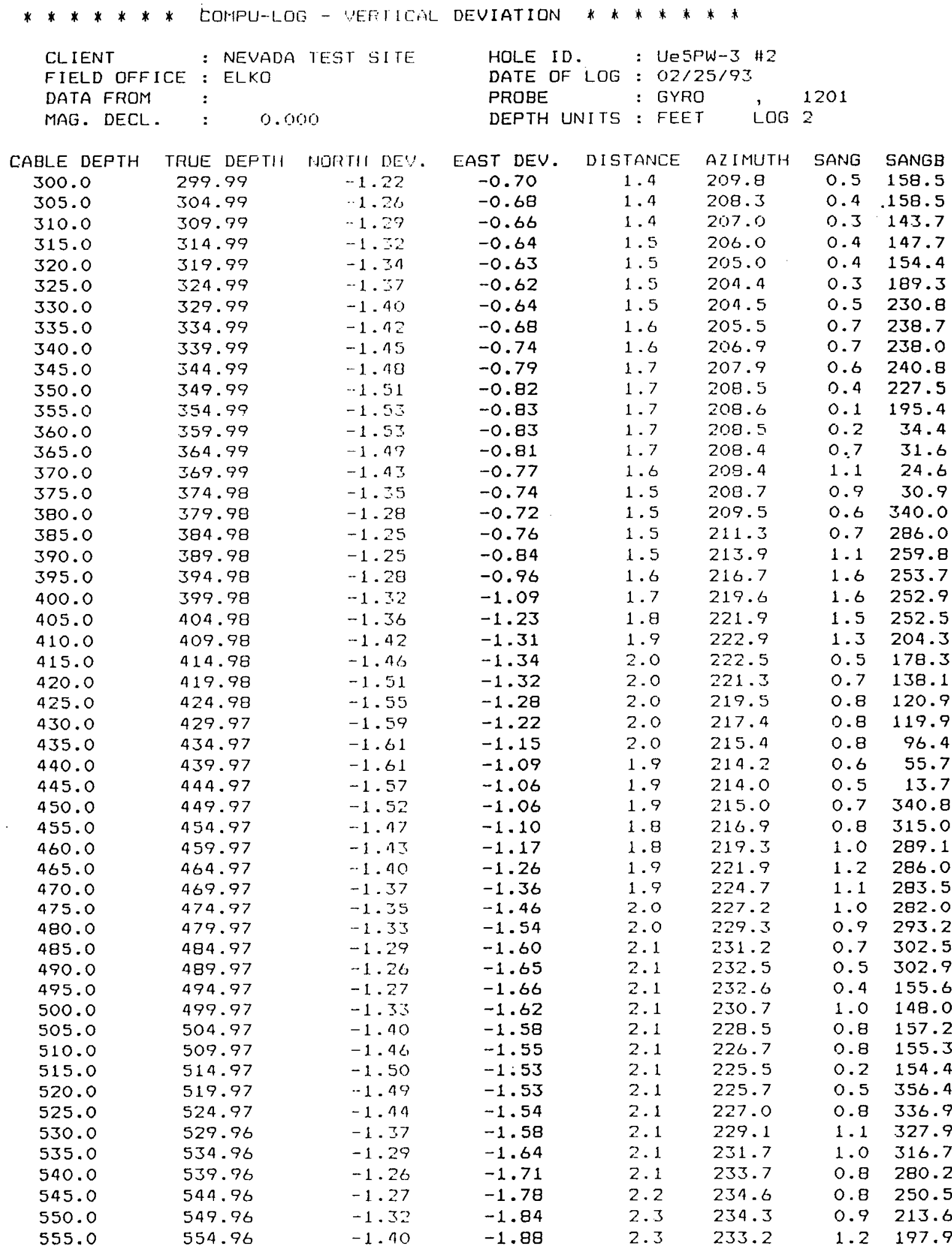




\section{Appendix F.3.10 Borehole deviation logs run in Ue5PW-3 on 2/25/93 (Continued)}

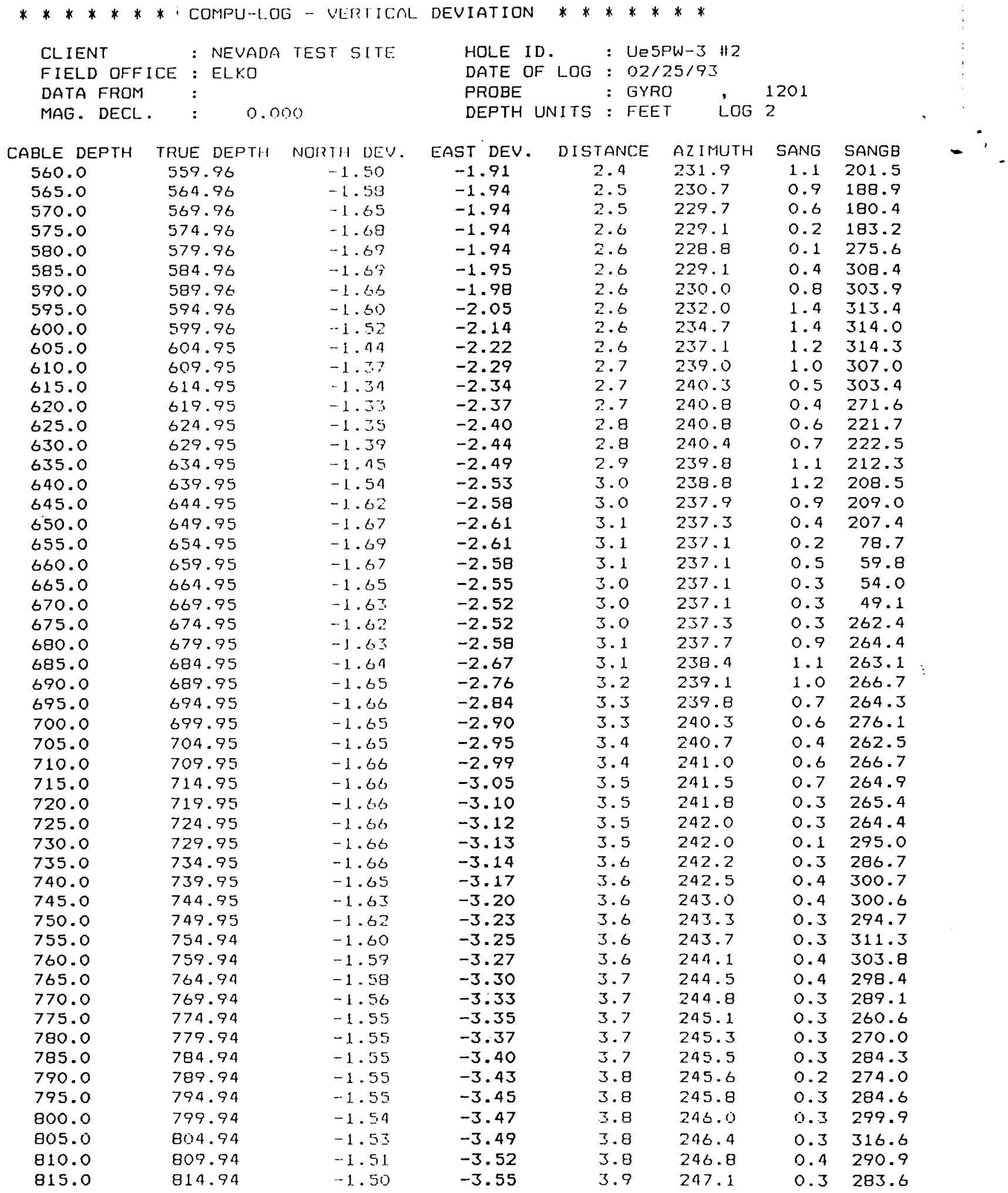


Appendix F.3.10 Borehole deviation logs run in Ue5PW-3 on 2/25/93 (Continued)

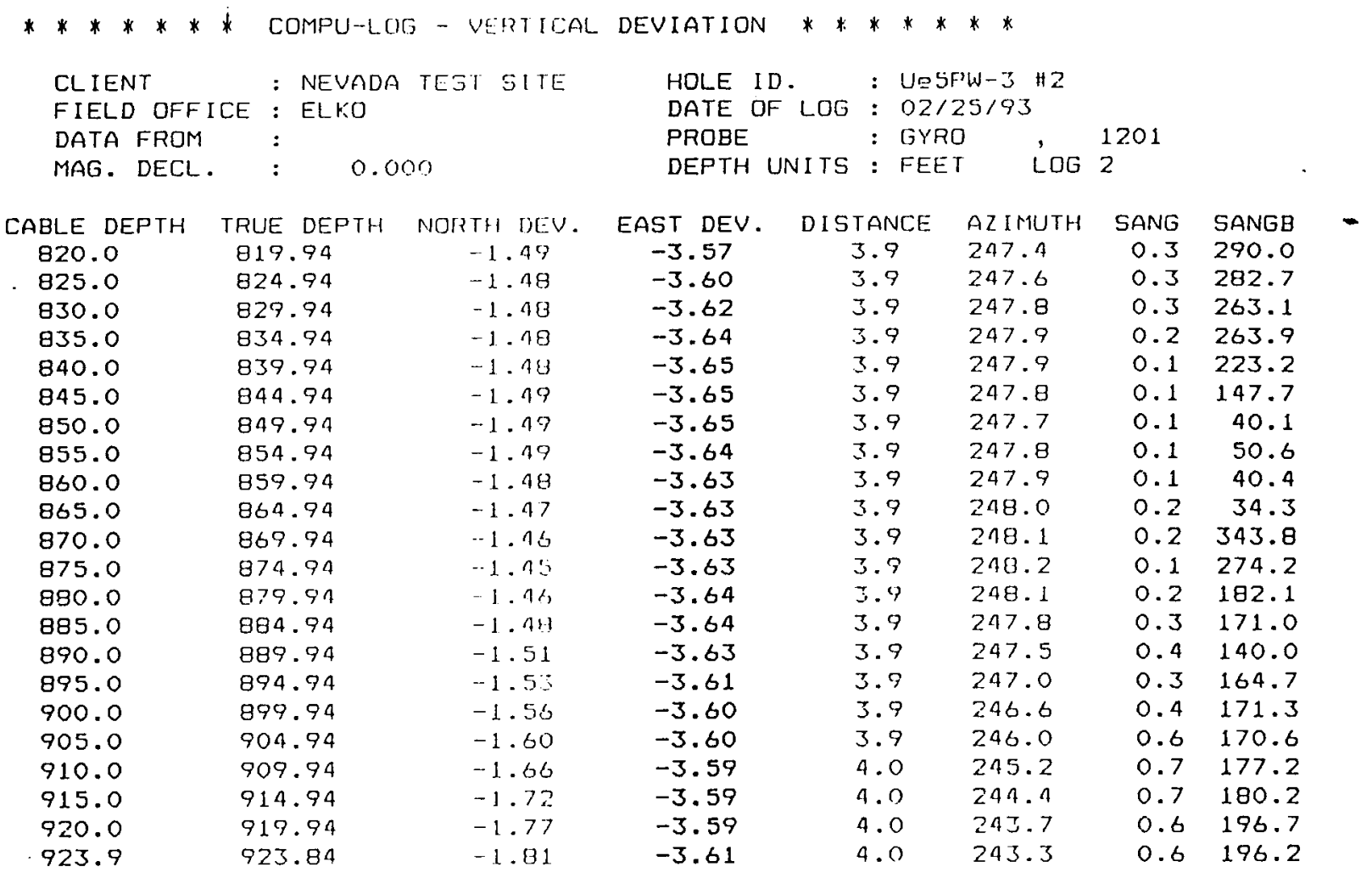


Appendix F.4.1 Depths and Dimensions of Air Permeability Testing Intervals for the Pilot Wells.

\begin{tabular}{||c|c|c|c||}
\hline Borehole & $\begin{array}{c}\text { Station Depth } \\
(\mathrm{m})\end{array}$ & $\begin{array}{c}\text { Interval Length } \\
(\mathrm{m})\end{array}$ & $\begin{array}{c}\text { Interval Radius } \\
(\mathrm{m})\end{array}$ \\
\hline \hline UE5PW-1 & 45.7 & 0.95 & 0.13 \\
\hline & 73.2 & 1.01 & 0.14 \\
\hline & 107 & 1.07 & 0.14 \\
\hline & 183 & 0.91 & 0.13 \\
\hline UE5PW-2 & 45.7 & 1.04 & 0.12 \\
\hline & 76.2 & 0.95 & 0.11 \\
\hline & 122 & 0.85 & 0.12 \\
\hline & 183 & 0.76 & 0.12 \\
\hline UE5PW-3 & 76.2 & 1.01 & 0.13 \\
\hline & 107 & 1.31 & 0.15 \\
\hline & 168 & 0.88 & 0.12 \\
\hline & 210 & 1.46 & 0.10 \\
\hline
\end{tabular}


Appendix F.4.2 In situ air permeability testing data for UE5PW-1, UE5PW-2, and UE5PW-3.

\section{UE5PW-1}

\begin{tabular}{|c|c|c|c|c|}
\hline $\begin{array}{l}\text { Station Depth } \\
\text { (m) }\end{array}$ & $\begin{array}{l}\text { Flow Rate } \\
\left(\times 10^{-2} \mathrm{~m}^{3} \mathrm{~s}^{-1}\right)\end{array}$ & $\begin{array}{c}\text { Barometric } \\
\text { Pressure } \\
(\mathrm{kPa}) \\
\end{array}$ & $\begin{array}{c}\text { Interval } \\
\text { Presssure } \\
(\mathrm{kPa}) \\
\end{array}$ & $\begin{array}{c}\text { Temperature } \\
(\mathrm{K})\end{array}$ \\
\hline 45.7 & 0.906 & 91.6 & 98.8 & 292 \\
\hline 45.7 & 1.18 & 91.5 & 101 & 294 \\
\hline 45.7 & 1.42 & 91.6 & 103 & 300 \\
\hline 45.7 & 1.68 & 91.5 & 105 & 302 \\
\hline 45.7 & 1.91 & 91.5 & 107 & 305 \\
\hline 45.7 & 2.16 & 91.5 & 109 & 308 \\
\hline 45.7 & 2.55 & 91.4 & 112 & 314 \\
\hline 73.2 & 0.916 & 92.1 & 95.5 & 299 \\
\hline 73.2 & 1.45 & 92.1 & 98.2 & 300 \\
\hline 73.2 & 1.89 & 92.1 & 101 & 305 \\
\hline 73.2 & 2.45 & 92.1 & 104 & 311 \\
\hline 107 & 0.911 & 92.4 & 93.4 & 297 \\
\hline 107 & 1.41 & 92.3 & 95.0 & 299 \\
\hline 107 & 1.94 & 92.3 & 97.5 & 303 \\
\hline 107 & 2.43 & 92.4 & 100 & 306 \\
\hline 107 & 3.04 & 92.4 & 104 & 308 \\
\hline
\end{tabular}


Appendix F.4.2 Continued

UE5PW-2

\begin{tabular}{|c|c|c|c|c|}
\hline $\begin{array}{l}\text { Station Depth } \\
\text { (m) }\end{array}$ & $\begin{array}{l}\text { Flow Rate } \\
\left(\times 10^{-2} \mathrm{~m}^{3} \mathrm{~s}^{-1}\right)\end{array}$ & $\begin{array}{c}\text { Barometric } \\
\text { Pressure } \\
(\mathrm{kPa}) \\
\end{array}$ & $\begin{array}{c}\text { Interval } \\
\text { Presssure } \\
(\mathrm{kPa}) \\
\end{array}$ & $\begin{array}{l}\text { Temperature } \\
\text { (K) }\end{array}$ \\
\hline 45.7 & 0.392 & 89.9 & 94.6 & 307 \\
\hline 45.7 & 0.935 & 89.9 & 100.3 & 309 \\
\hline 45.7 & 1.49 & 89.9 & 105.2 & 310 \\
\hline 45.7 & 2.08 & 89.9 & 111.7 & 312 \\
\hline 45.7 & 2.71 & 89.9 & 119.8 & 315 \\
\hline 45.7 & 3.39 & 89.9 & 128.7 & 317 \\
\hline 76.2 & 0.518 & 90.2 & 92.7 & 305 \\
\hline 76.2 & 0.932 & 90.2 & 94.7 & 307 \\
\hline 76.2 & 1.37 & 90.2 & 96.5 & 309 \\
\hline 76.2 & 1.86 & 90.2 & 98.8 & 313 \\
\hline 76.2 & 2.34 & 90.2 & 101.5 & 315 \\
\hline 76.2 & 3.02 & 90.1 & 105.6 & 316 \\
\hline 122 & 0.944 & 90.1 & 97.3 & 310 \\
\hline 122 & 1.33 & 90.1 & 99.6 & 312 \\
\hline 122 & 1.97 & 90.1 & 104.7 & 310 \\
\hline 122 & 2.38 & 90.1 & 108.0 & 316 \\
\hline 122 & 2.85 & 90.1 & 112.1 & 317 \\
\hline 122 & 3.56 & 90.1 & 120.1 & 317 \\
\hline 183 & 0.395 & 90.0 & 102.7 & 307 \\
\hline 183 & 0.510 & 90.0 & 106.9 & 309 \\
\hline 183 & 0.717 & 90.0 & 112.5 & 310 \\
\hline 183 & 0.920 & 90.0 & 118.7 & 312 \\
\hline 183 & 1.04 & 89.9 & 121.5 & 312 \\
\hline 183 & 1.26 & 90.0 & 127.1 & 311 \\
\hline
\end{tabular}


Appendix F.4.2 Continued

UE5PW-3

\begin{tabular}{|c|c|c|c|c|}
\hline $\begin{array}{l}\text { Station Depth } \\
\text { (m) }\end{array}$ & $\begin{array}{l}\text { Flow Rate } \\
\left(\times 10^{-2} \mathrm{~m}^{3} \mathrm{~s}^{-1}\right)\end{array}$ & $\begin{array}{c}\text { Barometric } \\
\text { Pressure } \\
(\mathrm{kPa})\end{array}$ & $\begin{array}{c}\text { Interval } \\
\text { Presssure } \\
(\mathrm{kPa})\end{array}$ & $\begin{array}{c}\text { Temperature } \\
(\mathrm{K})\end{array}$ \\
\hline 76.2 & 0.396 & 89.8 & 92.7 & 307 \\
\hline 76.2 & 0.508 & 89.7 & 93.1 & 308 \\
\hline 76.2 & 0.622 & 89.7 & 94.5 & 311 \\
\hline 76.2 & 0.741 & 89.7 & 95.2 & 312 \\
\hline 76.2 & 0.845 & 89.7 & 96.1 & 311 \\
\hline 76.2 & 0.949 & 89.7 & 96.6 & 312 \\
\hline 76.2 & 1.04 & 89.7 & 97.2 & 313 \\
\hline 76.2 & 1.18 & 89.6 & 98.2 & 314 \\
\hline 76.2 & 1.28 & 89.6 & 98.9 & 314 \\
\hline 76.2 & 1.38 & 89.6 & 99.7 & 314 \\
\hline 76.2 & 1.50 & 89.6 & 100.5 & 315 \\
\hline 76.2 & 1.60 & 89.6 & 100.4 & 316 \\
\hline 107 & 0.399 & 89.5 & 95.0 & 313 \\
\hline 107 & 0.539 & 89.4 & 98.4 & 314 \\
\hline 107 & 0.740 & 89.4 & 101.3 & 315 \\
\hline 107 & 0.847 & 89.4 & 102.8 & 315 \\
\hline 107 & 0.959 & 89.4 & 105.1 & 315 \\
\hline 107 & 1.09 & 89.4 & 107.3 & 315 \\
\hline 107 & 1.17 & 89.4 & 108.4 & 315 \\
\hline 107 & 1.37 & 89.4 & 111.6 & 315 \\
\hline 168 & 0.076 & 89.6 & 96.2 & 302 \\
\hline 168 & 0.113 & 89.6 & 99.1 & 302 \\
\hline 168 & 0.165 & 89.6 & 102.4 & 303 \\
\hline 168 & 0.217 & 89.6 & 105.3 & 304 \\
\hline
\end{tabular}


Appendix F.4.2 Continued

UE5PW-3 (Continued)

\begin{tabular}{||c|c|c|c|c|}
\hline $\begin{array}{c}\text { Station Depth } \\
(\mathrm{m})\end{array}$ & $\begin{array}{c}\text { Flow Rate } \\
\left(\times 10^{-2} \mathrm{~m}^{3} \mathrm{~s}^{-1}\right)\end{array}$ & $\begin{array}{c}\text { Barometric } \\
\text { Pressure } \\
(\mathrm{kPa})\end{array}$ & $\begin{array}{c}\text { Interval } \\
\text { Presssure } \\
(\mathrm{kPa})\end{array}$ & $\begin{array}{c}\text { Temperature } \\
(\mathrm{K})\end{array}$ \\
\hline \hline 210 & 0.480 & 89.6 & 91.8 & 307 \\
\hline 210 & 0.569 & 89.6 & 92.3 & 308 \\
\hline 210 & 0.658 & 89.6 & 92.8 & 309 \\
\hline 210 & 0.755 & 89.6 & 93.5 & 310 \\
\hline 210 & 0.847 & 89.6 & 94.3 & 312 \\
\hline 210 & 0.942 & 89.6 & 94.9 & 313 \\
\hline 210 & 1.02 & 89.6 & 95.5 & 313 \\
\hline 210 & 1.13 & 89.6 & 96.3 & 314 \\
\hline
\end{tabular}


Appendix F.4.3 Effective air permeabilities and inertial coefficients for field testing in UE5PW-1, UE5PW-2, and UE5PW-3.

\begin{tabular}{||l|l|l|l||}
\hline Pilot Well & \multicolumn{1}{|c|}{$\begin{array}{c}\text { Depth } \\
(\mathrm{m})\end{array}$} & \multicolumn{1}{|c|}{$\begin{array}{c}\text { Permeability } \\
\left(\times 10^{-12} \mathrm{~m}^{2}\right)\end{array}$} & \multicolumn{1}{|c|}{$\begin{array}{c}\text { Inertial } \\
\text { Coefficient } \\
\left(\times 10^{+7} \mathrm{~m}^{-1}\right)\end{array}$} \\
\hline UE5PW-1 & 45.7 & 8.1 & $\dagger$ \\
\hline & 73.2 & 13 & $\dagger$ \\
\hline & 107 & 47 & 5.4 \\
\hline & 183 & $*$ & $\dagger$ \\
\hline UE5PW-2 & 45.7 & 8.0 & 5.9 \\
\hline & 76.2 & 16 & $\dagger$ \\
\hline & 122 & 12 & 2.7 \\
\hline & 183 & 2.3 & $\dagger$ \\
\hline UE5PW-3 & 76.2 & 9.2 & $\dagger$ \\
\hline & 107 & 3.4 & $\dagger$ \\
\hline & 168 & 0.9 & 14 \\
\hline & 210 & 18 & $\dagger$ \\
\hline
\end{tabular}

$\dagger$ Inertial effects not significant

* No pressure response observed for this station 
Appendix F.5.1 Estimating the water table slope under the Area 5 RWMS

\subsection{Introduction}

After an extensive literature search, a rather sophisticated mathematical model, based upon the Dupuit-Forcheimer approximation, was proposed by Lindstrom, et al. (1992) as a means

of estimating the character (inclination, warping, torsion, etc.) of the water table under the Radioactive waste management site (RWMS) in Area 5 of NTS. This model requires knowledge of the elevation of the water table at eight distinct geographical locations ringing the RWMS. The required data, which has any credibility, is currently lacking. Lindstrom et al. (1992) demonstrated the feasibility of the model by using uncertain USGS data from eight Frenchman basin widely spaced drill holes and water wells. Their conclusion was that the water table was statistically "flat" (zero gradient) with essentially no horizontal motion. Some of the calibration wells were over 25,000 feet apart. One foot uncertainties in some of the water table elevation readings easily translated into 10 foot mounds of water under RWMS, a clearly infeasible situation.

Lacking the five additional wells circumscribing RWMS and required to use the DupuitForcheimer model of Lindstrom et al. (1992), a simple three-point interpolating plane approximation to the water table under RWMS was constructed. By knowing the elevations of the water table at each of the pilot well locations allows estimates of this plane (three dimensional) to be made. The model does not satisfy the simple Dupuit-Forcheimer approximation run under isotropic conductivity conditions. However, it can serve as a first order approximation with a more accurate analysis to be done if and when more characterization well data becomes available in the vicinity of RWMS.

\subsection{Three-Dimensional Plane Approximation}

Figure 1 shows a sketch of the simple three-dimensional plane approximation to the water table under RWMS. Equation 1 defines the plane

$$
H(x, y)=\alpha+\beta\left(x-x_{1}\right)+\gamma\left(y-y_{1}\right)
$$

where $\mathrm{H}$ is the water table elevation head in feet above mean sea level, $\mathrm{x}$ is the easting coordinate in feet (Nevada Coordinate System), $y$ is the northing coordinate in feet, and $\alpha, \beta$, and $\gamma$ are parameters to be determined from the three calibration water table estimates (pilot wells 1,2 , and 3 ). The ordered pair $\left(x_{1}, y_{1}\right)$ represents the (easting, northing) coordinates, chosen for pilot well 1 , as a convenient reference point. The three pilot wells are used as calibration wells. The water table at PW-1 is characterized by the ordered triple (3-tuple), $\left(\mathrm{x}_{1}, \mathrm{y}_{1}, \mathrm{H}_{1}\right)$. In like fashion we have $\left(\mathrm{x}_{2}, \mathrm{y}_{2}, \mathrm{H}_{2}\right)$ and $\left(\mathrm{x}_{3}, \mathrm{y}_{3}, \mathrm{H}_{3}\right)$ for PW-2 and $\mathrm{PW}-3$, respectively. Hence, the three equations in three unknowns 
Appendix F.5.1 Estimation of water table slope under the Area 5 RWMS (Continued)

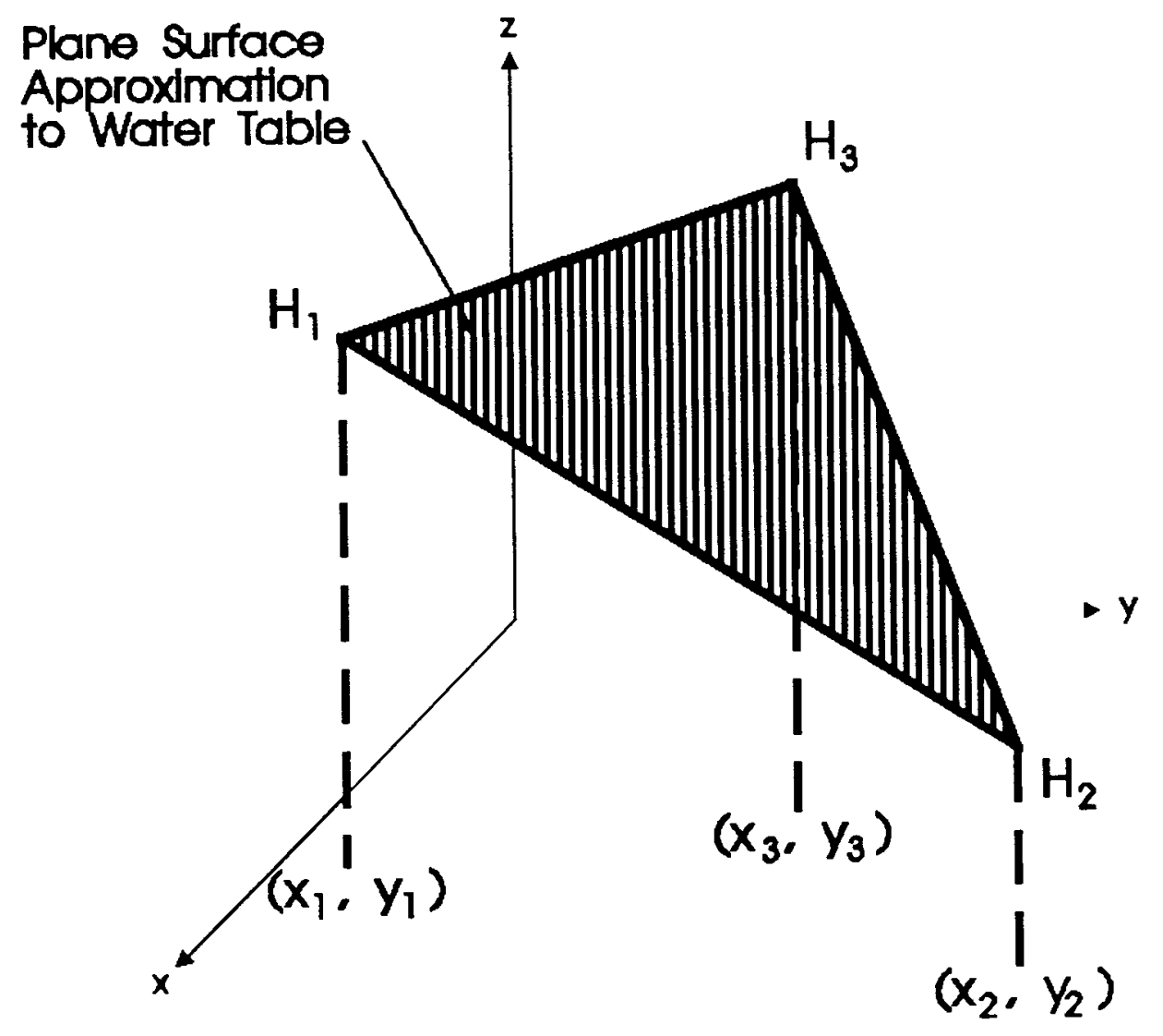

Figure 1 PLANE SURFACE APPROXIMATION TO WATER TABLE

$$
\begin{aligned}
& H_{1}=\alpha \\
& H_{2}=\alpha+\beta\left(x_{2}-x_{1}\right)+\gamma\left(y_{2}-y_{1}\right) \\
& H_{3}=\alpha+\beta\left(x_{3}-x\right)+\gamma\left(y_{3}-y_{1}\right)
\end{aligned}
$$

yield the unique solution

$$
\begin{aligned}
& \alpha=H_{1} \\
& \beta=\frac{\left(H_{2}-H_{1}\right)\left(y_{3}-y_{1}\right)-\left(H_{3}-H_{1}\right)\left(y_{2}-y_{1}\right)}{\left(x_{2}-x_{1}\right)\left(y_{3}-y_{1}\right)-\left(x_{3}-x_{1}\right)\left(y_{2}-y_{1}\right)}
\end{aligned}
$$


Appendix F.5.1 Estimation of water table slope under the Area 5 RWMS (Continued)

$$
\gamma=\frac{\left(H_{3}-H_{1}\right)\left(x_{2}-x_{1}\right)-\left(H_{2}-H_{1}\right)\left(x_{3}-x_{1}\right)}{\left(x_{2}-x_{1}\right)\left(y_{3}-y_{1}\right)-\left(x_{3}-x_{1}\right)\left(y_{2}-y_{1}\right)}
$$

whenever the three points are not collinear in space.

The Darcy components (horizontal only here!) are defined as

$$
q_{x}=-K_{x x} \frac{\partial H}{\partial x}-K_{x y} \frac{\partial H}{\partial y}=\epsilon u_{x}
$$

and

$$
q_{y}=-K_{x y} \frac{\partial H}{\partial x}-K_{y y} \frac{\partial H}{\partial y}=\epsilon u_{y}
$$

where

$q_{x}=$ easting component of Darcy velocity (ft/day),

$q_{y}=$ northing component of Darcy velocity (ft/day),

$K_{\mathfrak{x x}}=$ easting-easting component of saturated hydraulic conductivity (ft/day),

$K_{x y}=$ easting-northing component of saturated hydraulic conductivity (ft/day),

$K_{y y}=$ northing-northing component at saturated hydraulic conductivity (ft/day),

$\epsilon=$ porosity of alluvium $\left(\mathrm{ft}^{3} / \mathrm{ft}^{3}\right)$,

$u_{x}=$ easting component at seepage velocity (ft/day),

$u_{y}=$ northing component of seepage velocity (ft/day).

For horizontally isotropic alluvial conditions, $K_{x y}=0$. Also, $K_{x x}=K_{y y}=K_{\text {sath }}$, where $K_{\text {sath }}$ is the saturated horizontal component of the conductivity tensor.

The positive orientation of movement towards increasing easting numbers and movement towards increasing northing numbers has been chosen for this model. 
Appendix F.5.1 Estimation of water table slope under the Area 5 RWMS (Continued)

Recall from equations 4 and 5 that we need estimates of $K_{\text {sath }}$ and $\epsilon$. From the latest characterization of the Area 5 alluvium we find that reasonable estimates of the mean values of $K_{\text {sath }}$ and $\epsilon$ from all three pilot wells are $K_{\text {sath }}=2.8313 \mathrm{ft} /$ day and $\epsilon=0.375 \mathrm{ft}^{3} / \mathrm{ft}^{3}$; respectively. Thus, using equations 1,4 , and 5 , we find that

$$
q_{x}=-K_{\operatorname{sath}} \frac{\partial H}{\partial x}=-K_{\text {sath }} \beta=\epsilon u_{x}
$$

and

$$
q_{y}=-K_{\text {sath }} \frac{\partial H}{\partial y}=-K_{\text {sath }} \gamma=\epsilon u_{y} .
$$

Table 1 summarizes the location and elevation of the water table in each of the pilot wells. All measurements were conducted by the U.S. Geological Survey (USGS).

\begin{tabular}{|c|c|c|c|c|c|c|}
\hline $\begin{array}{l}\text { Pilot Well } \\
\text { Number }\end{array}$ & $\begin{array}{c}\text { Date of } \\
\text { measurement }\end{array}$ & $\begin{array}{l}\mathbf{N} \\
\mathbf{0} \\
\mathbf{r} \\
\mathrm{t} \\
\mathbf{h} \\
\mathrm{i} \\
\mathrm{n} \\
\mathrm{g}\end{array}$ & $\begin{array}{l}\mathrm{E} \\
\mathrm{a} \\
\mathrm{s} \\
\mathrm{t} \\
\mathrm{i} \\
\mathrm{n} \\
\mathrm{g}\end{array}$ & $\begin{array}{l}\text { Water level } \\
\text { measurement } \\
\text { (feet) }\end{array}$ & $\begin{array}{c}\text { Elevation } \\
\text { of surface } \\
\text { casing } \\
\text { (feet) }\end{array}$ & $\begin{array}{c}\text { Uncorrected } \\
\text { Water table } \\
\text { elevation (feet) }\end{array}$ \\
\hline Ue5PW-1 & $3-2-93$ & $765,702.19$ & $709,831.57$ & 773.39 & 3180.35 & 2406.96 \\
\hline Ue5PW-2 & $3-2-93$ & $770,395.90$ & $709,893.63$ & 842.33 & 3248.42 & 2406.09 \\
\hline Ue5PW-3 & $3-2-93$ & $771,290.92$ & $703,460.07$ & 894.65 & 3300.87 & 2406.22 \\
\hline
\end{tabular}

Table 1. Pilot Well Data.

The results of running the program WT3DPAI (Attachment A) with the above characterization data is given in Table 2. The program is a computer code of the above equations. 
Appendix F.5.1 Estimation of water table slope under the Area 5 RWMS (Continued)

Table 2 Three-dimensional plane approximation results.

$$
\begin{aligned}
& \alpha=2406.96 \text { feet, } \beta=-4.59 \times 10^{-5}, \gamma=-1.85 \times 10^{-4} \\
& \frac{\partial H}{\partial x}=-4.59 \times 10^{-5}(f t / f t), \frac{\partial H}{\partial y}=-1.85 \times 10^{-4}(f t / f t) \\
& q_{x}=1.30 \times 10^{-4}(f t / d a y), q_{y}=5.23 \times 10^{-4}(f t / d a y) \\
& u_{x}=3.47 \times 10^{-4}(f t / d a y), u_{y}=1.39 \times 10^{-3}(f t / d a y)
\end{aligned}
$$

Magnitude of seepage velocity is $1.44 \times 10^{-3}$ (ft/day) in the direction $14^{\circ}$ East of North.

\subsection{Uncertainty Analysis}

An uncertainty analysis for the water table is now given. Rather than go through the usual Monte Carlo simulation process, we seize on the simplicity of the water table formula, together with a few assumptions on the water table elevation random variable associated with each pilot well, to obtain a simple closed form expression for the mean water table formula and the associated variance envelope. The assumptions are:

$$
\underset{\sim}{H}=\underset{\sim}{\alpha}+\underline{\beta}\left(x-x_{1}\right)+\alpha\left(y-y_{1}\right)
$$

where

$$
\begin{aligned}
& \underset{\sim}{\alpha}=\underset{\sim 1}{H_{1}} \\
& \underset{\sim}{\beta}=\left(\underset{\sim 2}{H_{2}}-\underset{\sim 1}{H_{1}}\right) \phi_{1 \beta}+\left(\underset{\sim 3}{H_{3}}-\underset{\sim}{H_{1}}\right) \phi_{2 \beta} \\
& \underset{\sim}{\gamma}=\left(\underset{\sim 3}{H_{3}}-\underset{\sim 1}{H_{1}}\right) \phi_{1 \gamma}+\left(\underset{\sim 2}{H_{2}}-\underset{\sim 1}{H_{1}}\right) \phi_{2 \gamma}
\end{aligned}
$$


Appendix F.5.1 Estimation of water table slope under the Area 5 RWMS (Continued)

The geometric factors $\phi_{1 \beta}, \phi_{2 \beta}, \phi_{1 \gamma}$, and $\phi_{2 \gamma}$ are obtained from equations (3) and (4). These factors are rational functions of the products of differences of the coordinates (hence well pattern) locating the pilot wells.

Suppose that

$$
\begin{aligned}
& \stackrel{H}{1}_{1} \sim \operatorname{NIID}\left(\mu_{1}, \sigma_{1}^{2}\right) \\
& \underset{\sim 2}{H_{2}} \sim \operatorname{NIID}\left(\mu_{2}, \sigma_{2}^{2}\right) \\
& \underset{\sim 3}{H_{3}} \sim \operatorname{NIID}\left(\mu_{3}, \sigma_{3}^{2}\right) \\
& \operatorname{Cov}\left(\underset{\sim}{H_{1}}, \underset{\sim}{H_{2}}\right)=\operatorname{Cov}\left(\underset{\sim}{H_{1}}, \underset{\sim}{H_{3}}\right)=\operatorname{Cov}\left(\underset{\sim}{H_{2}}, \underset{\sim}{H_{3}}\right)=0
\end{aligned}
$$

Assumption (15) should make sense physically since the pilot wells are located at least 4,000 feet apart.

Then, since the moment generating function for $\underset{\sim}{H}(x, y)$ is defined in Moody et al., (1974) as

$$
\begin{aligned}
& M_{\mathscr{B f}}(t)=\mathscr{B}\left(e^{t \stackrel{H}{\sim})}=\mathscr{E}\left(e^{t\left(\underline{\alpha}+\mathcal{\beta}\left(x-x_{1}\right)+\gamma\left(y-y_{1}\right)\right)}\right)\right.
\end{aligned}
$$

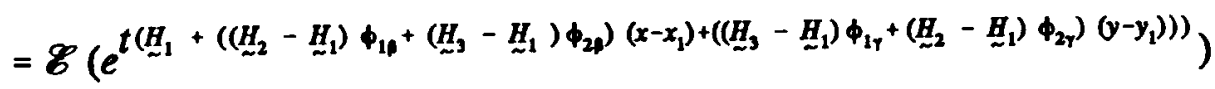

$$
\begin{aligned}
& =\mathscr{E}\left(e^{t H_{1}\left(1-\left(\phi_{1 \beta}+\phi_{2 \beta}\right)\left(x-x_{1}\right)-\left(\phi_{1 \gamma}+\phi_{2 \gamma}\right)\left(y-y_{1}\right)\right)}\right. \\
& \text { - } \mathscr{E}\left(e^{t H_{2}}\left(\phi_{1 \gamma}\left(x-x_{1}\right)+\phi_{2 \gamma}\left(y-y_{1}\right)\right)\right) \\
& \text { - } \mathscr{E}\left(e^{\star x H_{3}\left(\phi_{2 \beta}\left(x-x_{1}\right)+\phi_{1 \gamma}\left(y-y_{1}\right)\right)}\right)
\end{aligned}
$$


Appendix F.5.1 Estimation of water table slope under the Area 5 RWMS (Continued)

Carrying out the indicated integrations in the expectation operator yields

$$
\begin{gathered}
M_{g f}(t)=e^{\left.t\left(\mu_{1}+\left(\mu_{2}-\mu_{1}\right) \phi_{1 \beta}+\left(\mu_{3}-\mu_{1}\right) \phi_{2 \beta}\right)\left(x-x_{1}\right)+\left(\left(\mu_{3}-\mu_{1}\right) \phi_{1 \gamma}+\left(\mu_{2}-\mu_{1}\right) \phi_{2 \gamma}\right)\left(y-y_{1}\right)\right)} \\
\qquad e^{\frac{t^{2}}{2}\left(\sigma_{1}^{2}\left(1-\left(\phi_{1 \beta}+\phi_{2 \beta}\right)\left(x-x_{1}\right)-\left(\phi_{1 \gamma}+\phi_{2 \gamma}\right)\left(y-y_{1}\right)\right)^{2}+\sigma_{2}^{2}\left(\phi_{1 \beta}\left(x-x_{1}\right)+\phi_{2 \gamma}\left(y-y_{1}\right)\right)^{2}+\sigma_{3}^{2}\left(\phi_{2 \beta}\left(x-x_{1}\right)\right.\right.} \\
\left.\left.+\phi_{1 \gamma}\left(y-y_{1}\right)\right)^{2}\right)
\end{gathered}
$$

This formula indicates that $\underset{\sim}{H}(x, y)$ is also normally distributed; however, its mean and variance are non trivial functions of $x$ and $y$, a result to be expected. The "mean plane" is obtained from

$\mu_{H}^{(1)}=\left.\frac{\partial M_{g f}}{\partial t}\right|_{t=0}=\mathscr{E}(\underset{\sim}{H})$

So that

$$
\begin{aligned}
& \mathscr{Z} \underset{\sim}{(H)})=\mu_{H}^{(1)}(x, y)=\mu_{1}+\left(\left(\mu_{2}-\mu_{1}\right) \phi_{1 \beta}+\left(\mu_{3}-\mu_{1}\right) \phi_{2 \beta}\right)\left(x-x_{1}\right) \\
& +\left(\left(\mu_{3}-\mu_{1}\right) \phi_{1 \gamma}+\left(\mu_{2}-\mu_{1}\right) \phi_{2 \gamma}\right)\left(y-y_{1}\right)
\end{aligned}
$$

The second moment of $\underset{\sim}{H}$, defined as

$$
\mu_{H}^{(2)}=\left.\frac{\partial^{2} M_{g f}}{\partial t^{2}}\right|_{t=0}=\mathscr{C}\left(\stackrel{\sim}{\sim}^{2}\right)
$$

is needed in computing the variance of $\underset{\sim}{H}$. The variance of $\underset{\sim}{H}$ is defined as

$$
\operatorname{Var}(\underset{\sim}{H})=\mathscr{E}\left((\underset{\sim}{H})-\mathscr{E} \underset{\sim}{(\underset{\sim}{H}))^{2}}=\mathscr{E}\left({\underset{\sim}{2}}^{2}\right)-\left(\mu_{H}^{(1)}\right)^{2}\right.
$$


Appendix F.5.1 Estimation of water table slope under the Area 5 RWMS (Continued)

Computing the second partial derivative of $M_{\& f}(t)$ and evaluation at $t=0$ together with substitution into (20) obtains the formula

$$
\begin{aligned}
& \sigma_{\underline{H}}^{2}=\operatorname{Var}(\underset{\sim}{H})=\sigma_{1}^{2}+\left(\left(\sigma_{2}^{2}+\sigma_{1}^{2}\right) \phi_{1 \beta}^{2}+2 \sigma_{1}^{2} \phi_{1 \beta} \phi_{2 \beta}+\left(\sigma_{3}^{2}+\sigma_{1}^{2}\right) \phi_{2 \beta}^{2}\right)\left(x-x_{1}\right)^{2} \\
& +\left(\left(\sigma_{3}^{2}+\sigma_{1}^{2}\right) \phi_{1 \gamma}^{2}+2 \sigma_{1}^{2} \phi_{1 \gamma} \phi_{2 \gamma}+\left(\sigma_{2}^{2}+\sigma_{1}^{2}\right) \phi_{2 \gamma}^{2}\right)\left(y-y_{1}\right)^{2} \\
& -2 \sigma_{1}^{2}\left(\phi_{1 \beta}+\phi_{2 \beta}\right)\left(x-x_{1}\right)-2 \sigma_{1}^{2}\left(\phi_{1 \gamma}+\phi_{2 \gamma}\right)\left(y-y_{1}\right) \\
& +2\left(\sigma_{1}^{2} \phi_{1 \beta} \phi_{1 \gamma}+\left(\sigma_{3}^{2}+\sigma_{1}^{2}\right) \phi_{2 \beta} \phi_{1 \gamma}+\left(\sigma_{2}^{2}+\sigma_{1}^{2}\right) \phi_{1 \beta} \phi_{2 \gamma}+\sigma_{1}^{2} \phi_{2 \beta} \phi_{2 \gamma}\right)\left(y-y_{1}\right)\left(x-x_{1}\right)
\end{aligned}
$$

for the variance of $\underset{\sim}{H}$. A $95 \%$ uncertainty envelope is generated by defining the hyper planes

$\mathcal{Y}(x, y)=\underset{\sim}{\mu}(1)(x, y)+1.96 \sigma_{\mathscr{H}}$

and

$\mathcal{H}(x, y)=\mu_{\underset{\sim}{H}}^{(1)}(x, y)-1.96 \sigma_{\underset{H}{H}}$. 
Appendix F.5.1 Estimation of water table slope under the Area 5 RWMS (Continued)

Table 3 summarizes the mean and uncertainty values currently used for the three pilot wells in generating the lower and upper hyper planes.

\begin{tabular}{||l|l|l|l|l|l||}
\hline $\begin{array}{c}\text { Index } \\
\text { i }\end{array}$ & $\begin{array}{c}\text { Well } \\
\text { Name }\end{array}$ & $\begin{array}{c}\text { Easting } \\
(\mathrm{ft})\end{array}$ & $\begin{array}{c}\text { Northing } \\
(\mathrm{ft})\end{array}$ & $\begin{array}{c}\text { Mean } \\
\text { Elevation } \\
\mu_{i}(\mathrm{ft})\end{array}$ & $\begin{array}{c}\text { Uncertainty } \\
\sigma_{i}(\mathrm{ft})\end{array}$ \\
\hline 1 & UESPW1 & $709,831.57$ & $765,702.19$ & $2,406.96$ & 0.5 \\
\hline 2 & UE5PW2 & $709,893.63$ & $770,395.90$ & $2,406.09$ & 0.5 \\
\hline 3 & UE5PW3 & $703,460.07$ & $771,290.92$ & $2,406.22$ & 0.5 \\
\hline & & & & & \\
\hline & & & & & \\
\hline
\end{tabular}

Figure 2 shows a three-dimensional plot of the theoretical or "mean plane" elevated at the three water table calibration valves. The $97.5 \%$ and $2.5 \%$ and $2.5 \%$ uncertainty hyper planes, obtained by choosing $\sigma_{1}=\sigma_{2}=\sigma_{3}=0.5 f$, are also shown as bounding the theoretical plane. The $\pm 0.5 \mathrm{ft}$ uncertainties in the water table readings are simply "currently best available guesses." As time progresses and many more water table "taggings" by the USGS and REECo SPS personnel become available these individual uncertainty values will be refined and the $97.5 \%$ and $2.5 \%$ uncertainty envelopes will be recalculated.

Figures 3 and 4 show vertical slices of the uncertainty envelopes projected onto the verticalnorthing plane and vertical-easting plane, respectively. The region covered by the RWMS lies just inside the overall ranges in Easting and Northing used to make the uncertainty envelopes.

Observe that a great many other three-dimensional plane approximations to the water table under RWMS will nicely fit inside the bounding uncertainty envelope. Thus, it is possible to have the "real, but unknown" water table plane approximation tilting slightly in almost any direction. However, with more observational data available the uncertainty envelopes are exchanged for confidence envelopes which move toward each other and force the totality of admissible approximating planes toward a smaller population. The ideal limit of course is that as the number of repeated observations on each well goes to infinity that the uncertainty envelope converges to zero in probability (measure), thereby "pinning down" the approximating plane.

Clearly from Table 2 the horizontal seepage velocity components are small, giving an average NNE flow of about $0.53 \mathrm{ft} / \mathrm{yr}$. This estimate means that water at the water table currently under Ue5PW-1 will be in the vicinity of Ue5PW-2 in about 8,500 years. 
Appendix F.5.1 Estimation of water table slope under the Area 5 RWMS (Continued)

\section{References}

Lindstrom, F. T., L. E. Barker, D. E. Cawlfield, D. D. Daffern, B. L. Dozier, D. F. Emer, and W. R. Strong (1992) "Estimating the Water Table Under the Radioactive Waste Management Site in Area 5 of the Nevada Test Site: The DupuitForcheimer Approximation" in Interdisciplinary Approaches in Hydrology and Hydrogeology, M. E. Jones and A. Laenen eds., American Institute of Hydrology, pp. 146-171.

Mood, A. M., F. A. Graybill, and D. C. Boes (1974). Introduction to the Theory of Statistics. MacGraw-Hill, New York, 564pp. 
Appendix F.5.1 Estimation of water table slope under the Area 5 RWMS (Continued)

\section{ATTACHMENT A}

Model name: WT3DPAI

Version number: 1.0

Date last worked on: APR. 19, 1993

Key discriptors: 3-dimensional plane approximation for the wateer table under RWMS in Area 5 of the Nevada Test

site - three points required.

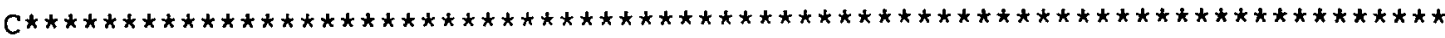

C

C

This model is the joint effort of: F. T. Lindstrom and David E. Cawlfield.

Special Projects Group.

Environmental Restoration \& Technology Development Department. M/S 738 .

Reynolds Electrical and Engineering Co., Inc.

$\mathrm{P} O$ Box $98521 \mathrm{M} / \mathrm{S} 738$ Las Vegas, NV 89193-8521

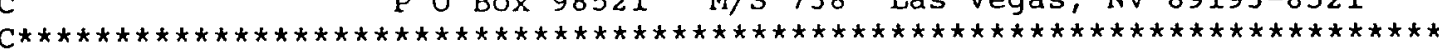

$\mathrm{C}$

C

PROGRAM WT3DPA1

DOUBLE PRECISION $X, Y, H, H E S T$

DOUBLE PRECISION KXX, KXY, KYY, PI, PHI, MAGN

DOUBLE PRECISION QX, QY, EPS , VX, VY, GRADX, GRADY

DOUBLE PRECISION XNUM1, XNUM2, DENOM, DENOMT

DOUBLE PRECISION ALPHA, BETA, GAMMA

DOUBLE PRECISION XIN, YIN, XINO, YINO, DXIN, DYIN

C

INTEGER I, J , NXEVAL, NYEVAL

C

COMMON/DATAI/X (3), Y (3), H(3), HEST

COMMON/DATA2/KXX, KXY, KYY, PI, PHI, MAGN

COMMON/DATA3/QX, QY , EPS , VX, VY, GRADX, GRADY

COMMON/DATA4 / XNUM1, XNUM2, DENOM, DENOMT

COMMON/DATA5/ALPHA, BETA, GAMMA

COMMON/DATA6/XIN , YIN, XINO, YINO, DXIN , DYIN

C

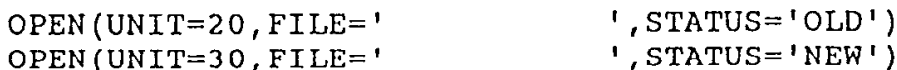

C READ IN ALL SYSTEM AND RUN CONTROL DATA

C

WRITE $(30, *)$

20 FORMAT $(5 X, '$ READ INPUT DATA IN FREE FORM 1,1$)$

WRITE $(*, *)$

WRITE $(30, *)$ ' INPUT KXX, KXY, KYY, AND EPS VALUES '

$\operatorname{READ}(20, *) \mathrm{KXX}, \mathrm{KXY}, \mathrm{KYY}, \mathrm{EPS}$

WRITE $(30, *) \quad K X X, K X Y, K Y Y, E P S$

WRITE $(30, *)$

$\operatorname{WRITE}(*, *)$

WRITE $(30, *) '$ INPUT $X, x$, AND H VALUES '

$\operatorname{WRITE}(30, *)$

DO $100 \quad I=1,3$

$\operatorname{READ}(20, *) \quad X(I), Y(I), H(I)$

WRITE $(30, *) \quad X(I), Y(I), H(I)$

WRITE $(30, *)$

100 CONTINUE

WRITE $(30, *)$

C

3 FORMAT $(1 X, A, \backslash)$

C CALCULATE CONSTANTS AND SXSTEM GROUP PARAMETERS 
Appendix F.5.1 Estimation of water table slope under the Area 5 RWMS (Continued)

\section{ATTACHMENT A (Continued)}

$c$

C

C

WRITE $(*, 21)$

21 FORMAT( $5 X$, 'CALCULATING CONSTANTS AND SYSTEM GROUP PARAMETERS')

$\mathrm{PI}=3.1415926 \mathrm{DO}$

ALPHA $=\mathrm{H}(1)$

XNUM1 $=(H(2)-H(1)) *(Y(3)-Y(1))-(H(3)-H(1)) *(X(2)-Y(1))$

XNUM $2=(H(3)-H(1)) *(X(2)-X(1))-(H(2)-H(1)) *(X(3)-X(1))$

DENOM $=(X(2)-X(1)) *(Y(3)-X(1))-(X(3)-X(1)) *(Y(2)-Y(1))$

DENOMT $=$ DABS (DENOM)

IF (DENOMT.LT. . .OD-50) GO TO 500

$B E T A=X N U M I / D E N O M$

GAMMA $=$ XNUM2 $/$ DENOM

GRADX $=$ BETA

GRADY $=$ GAMMA

$Q X=-G R A D X * K X X$

$Q Y=-G R A D Y * K Y Y$

$\mathrm{VX}=\mathrm{QX} / \mathrm{EPS}$

$\mathrm{VY}=\mathrm{QY} / \mathrm{EPS}$

MAGN $=D S Q R T(V X * V X+V Y * V Y)$

PHI $=$ DATAN $2(V Y, V X)$

$\mathrm{PHI}=\mathrm{PHI} \star 180.0 \mathrm{DO} / \mathrm{PI}$

WRITE $(30,22)$ ' ALPHA is ', ALPHA

WRITE $(30,22)$, XNUM1 is ', XNUM1

WRITE $(30,22)$ ' XNUM2 is ', XNUM2

WRITE $(30,22)$ ' DENOM is ', DENOM

WRITE $(30,22)$, BETA is ', BETA

WRITE $(30,22)$, GAMMA is ', GAMMA

WRITE $(30,22)$, GRADX is ', BETA

WRITE $(30,22)$ ' GRADY is ', GAMMA

WRITE $(30,22), \mathrm{KXX}$ is ', KXX

WRITE $(30,22)$ ' KXY is ', KXY

WRITE $(30,22)$ ' KYY is ', KYY

WRITE $(30,22)$ ' QX is ', QX

WRITE $(30,22)$ ' $Q Y$ is ', $Q Y$

WRITE $(30,22)$ ' VX is ', VX

WRITE $(30,22)$ ' VY is ', VY

WRITE $(30,22)$ ' MAGN is', MNGN

WRITE $(30,22)$ ' PHI is ', PHI

22 FORMAT ( $5 \mathrm{X}, \mathrm{A}, \mathrm{E} 12.6)$

$\operatorname{WRITE}(30, *)$

$\operatorname{WRITE}\left(30,{ }^{*}\right)$

C

$\mathrm{C}$

BEGIN EVALUATION LOOP

$\operatorname{WRITE}(*, *)$

C

$\operatorname{WRITE}(*, *)$

WRITE $(*, *)$ ' You next need to evaluate the elevation head $\operatorname{WRITE}(*, *)$, over a user defined rectangular sub region. First WRITE $(*, *)$, read in the number (integer) NXEVAL of $x$-coordinate WRITE $(*, *)$, evaluations desired and then read in the number WRITE $(*, *)$ ' NYEVAL of $y$-coordinate evaluations desired. This, $\operatorname{WRITE}(*, *)$ ' is done as an ordered pair of integers.

C

WRITE $(*, 3)$ ' Input the ordered pair: NXEVAL, NYEVAL

C $\operatorname{READ}(*, *)$ NXEVAL, NYEVAL

WRITE $(*, *)$ ' secondly, read in the base point ordered pair 
Appendix F.5.1 Estimation of water table slope under the Area 5 RWMS (Continued)

\section{ATTACHMENT A (Continued)}

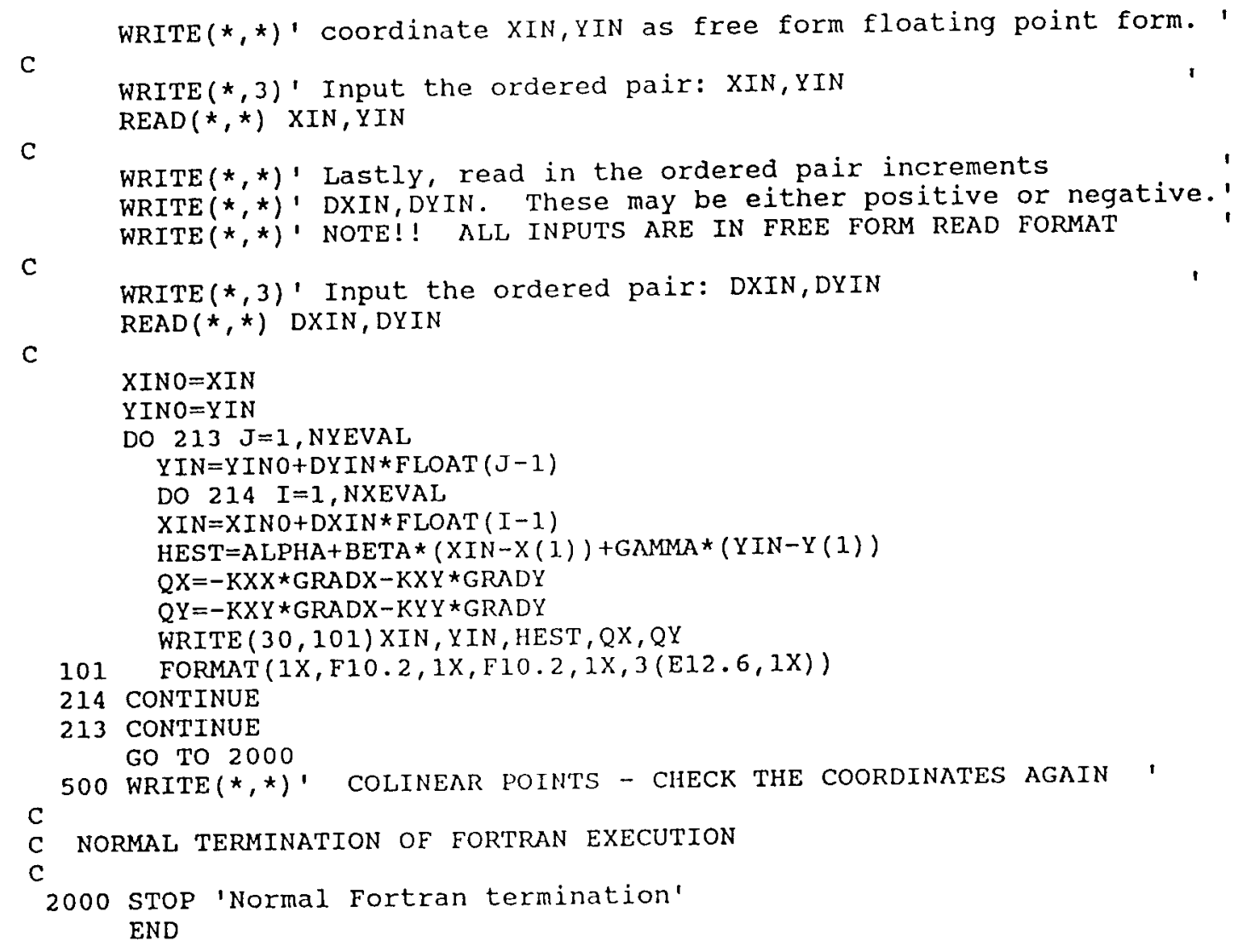




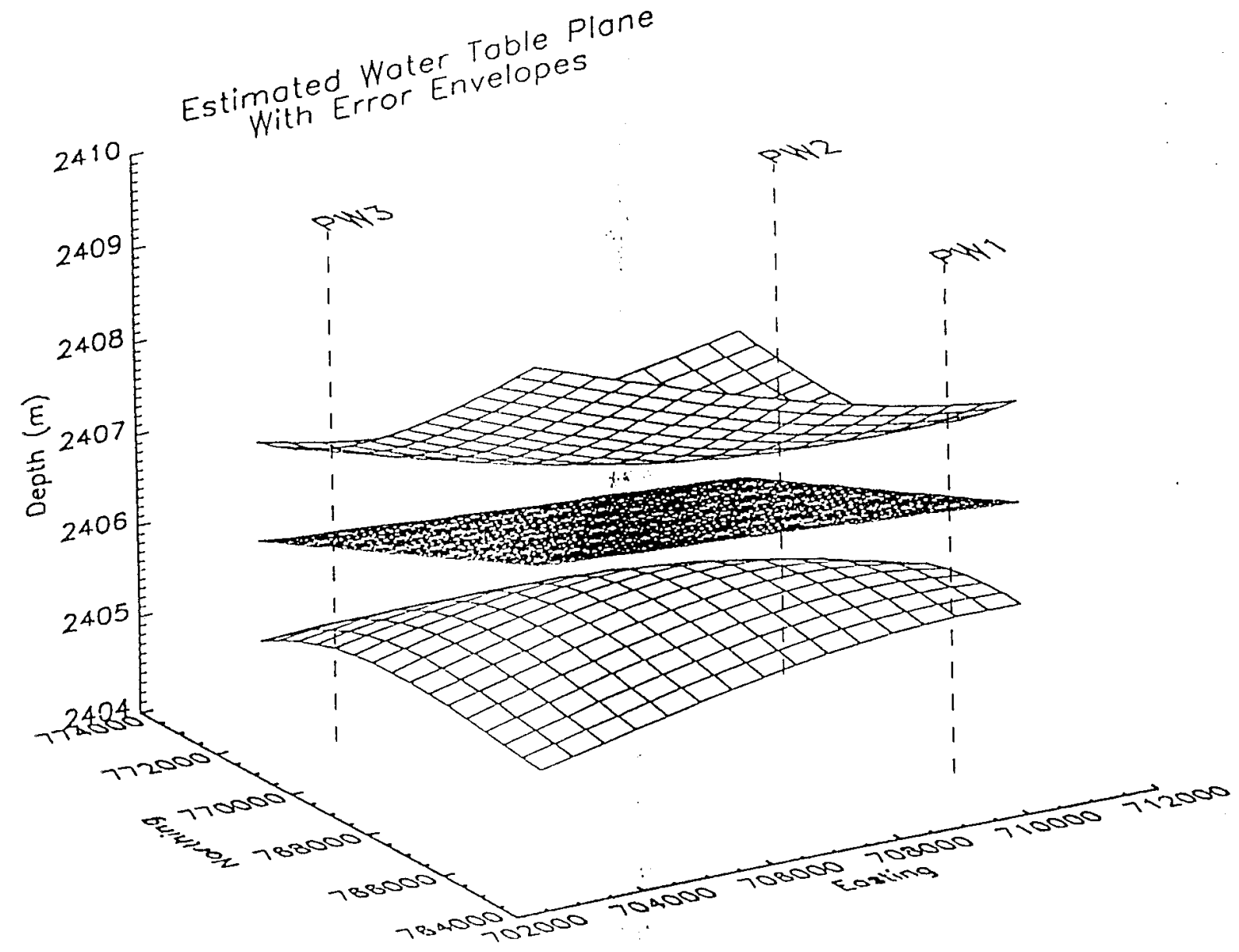

Figure 2 Theoretical plane water table elevated at the elevations shown in Table 3 together with the 0.975 and 0.025 uncertainty envelopes. 


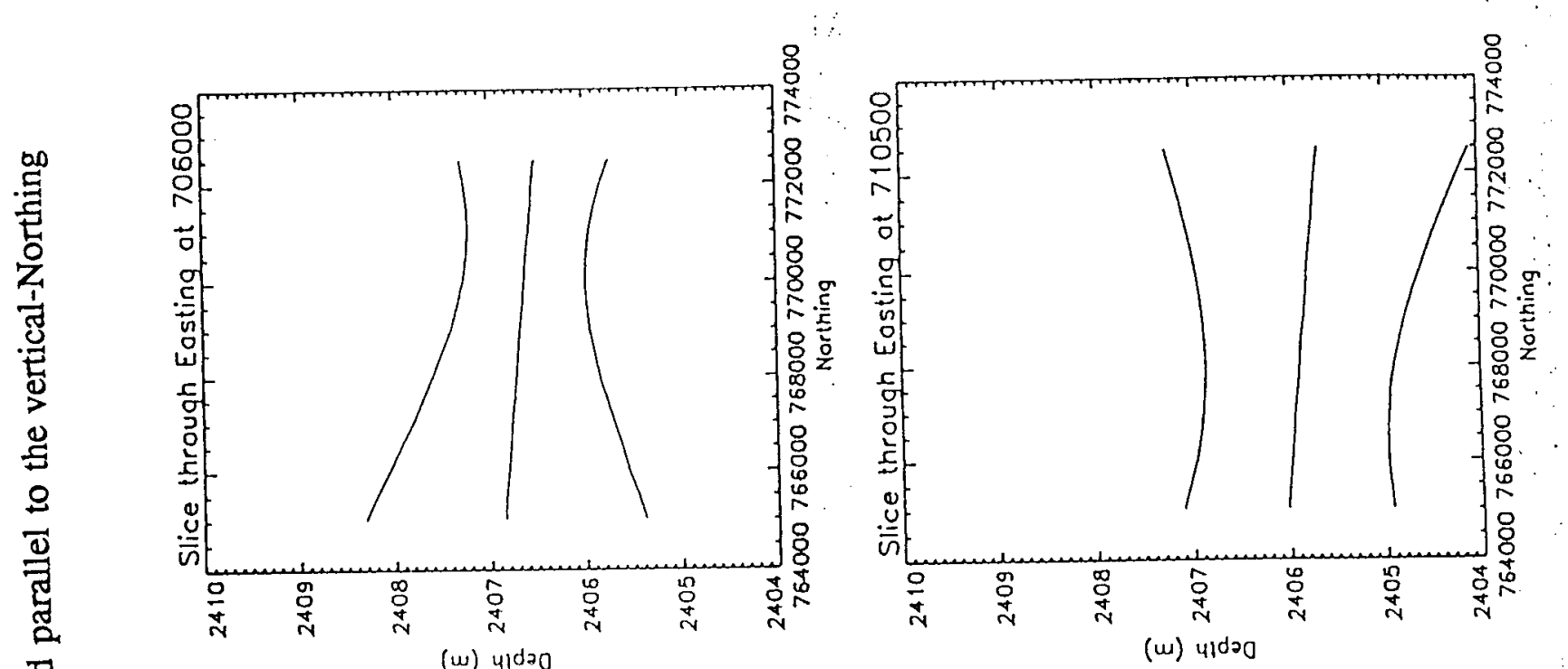

.

.

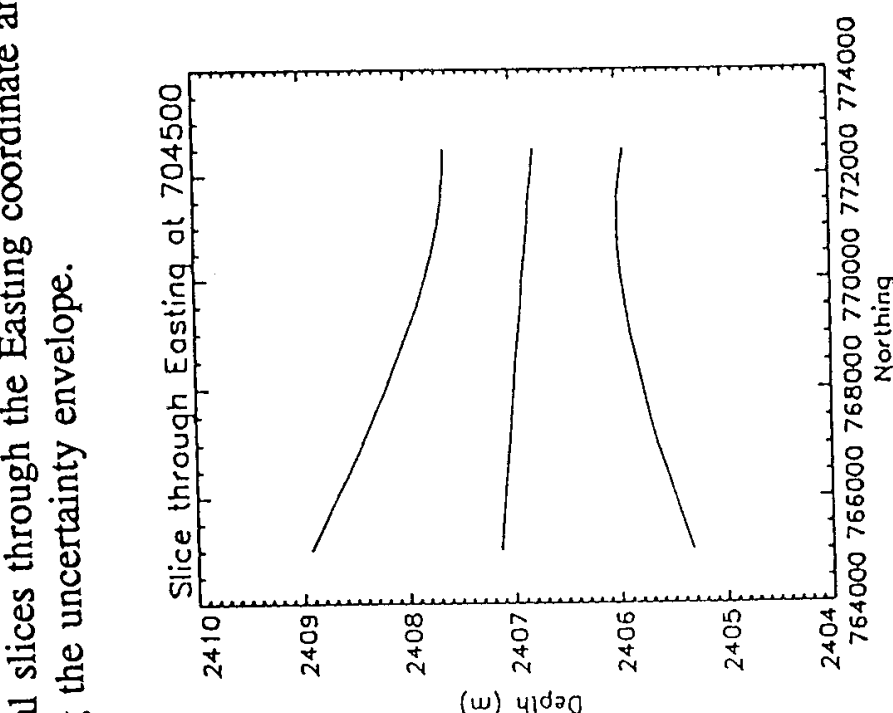

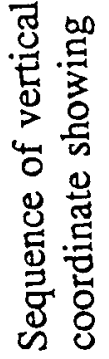

(w) 41020

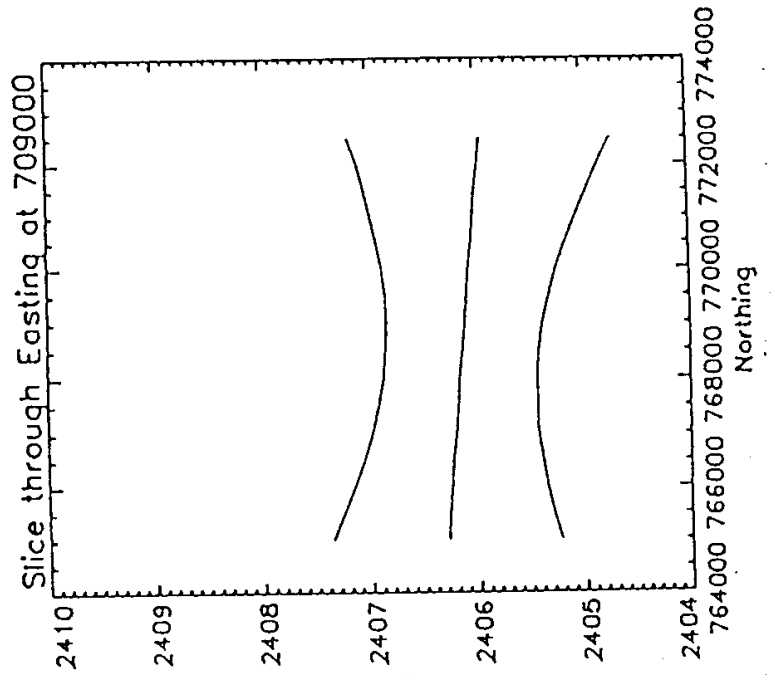

(w) $41 d 20$

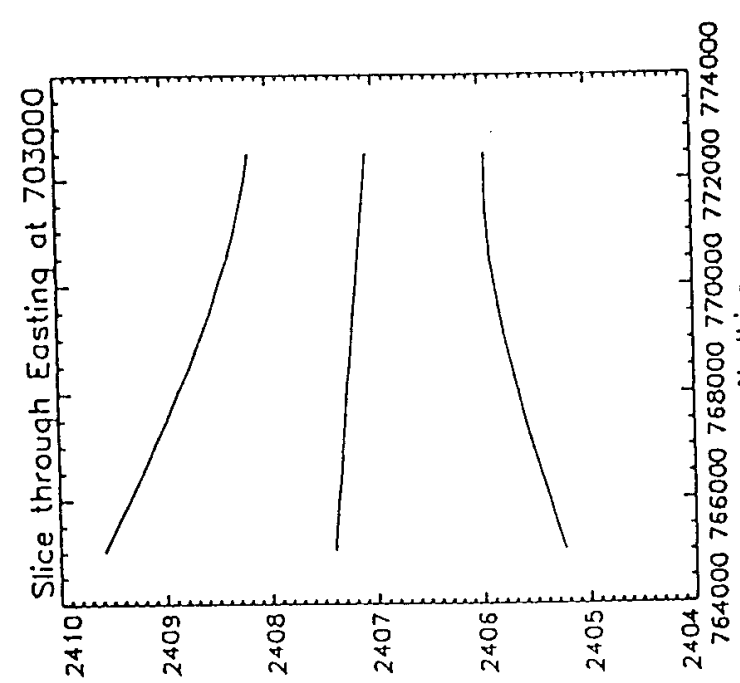

(w) 41020

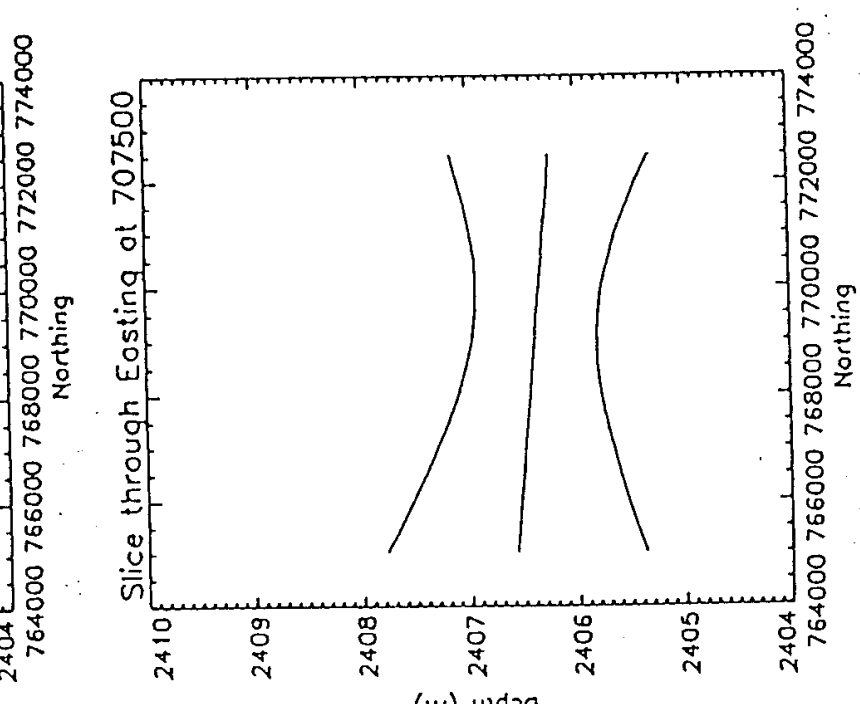



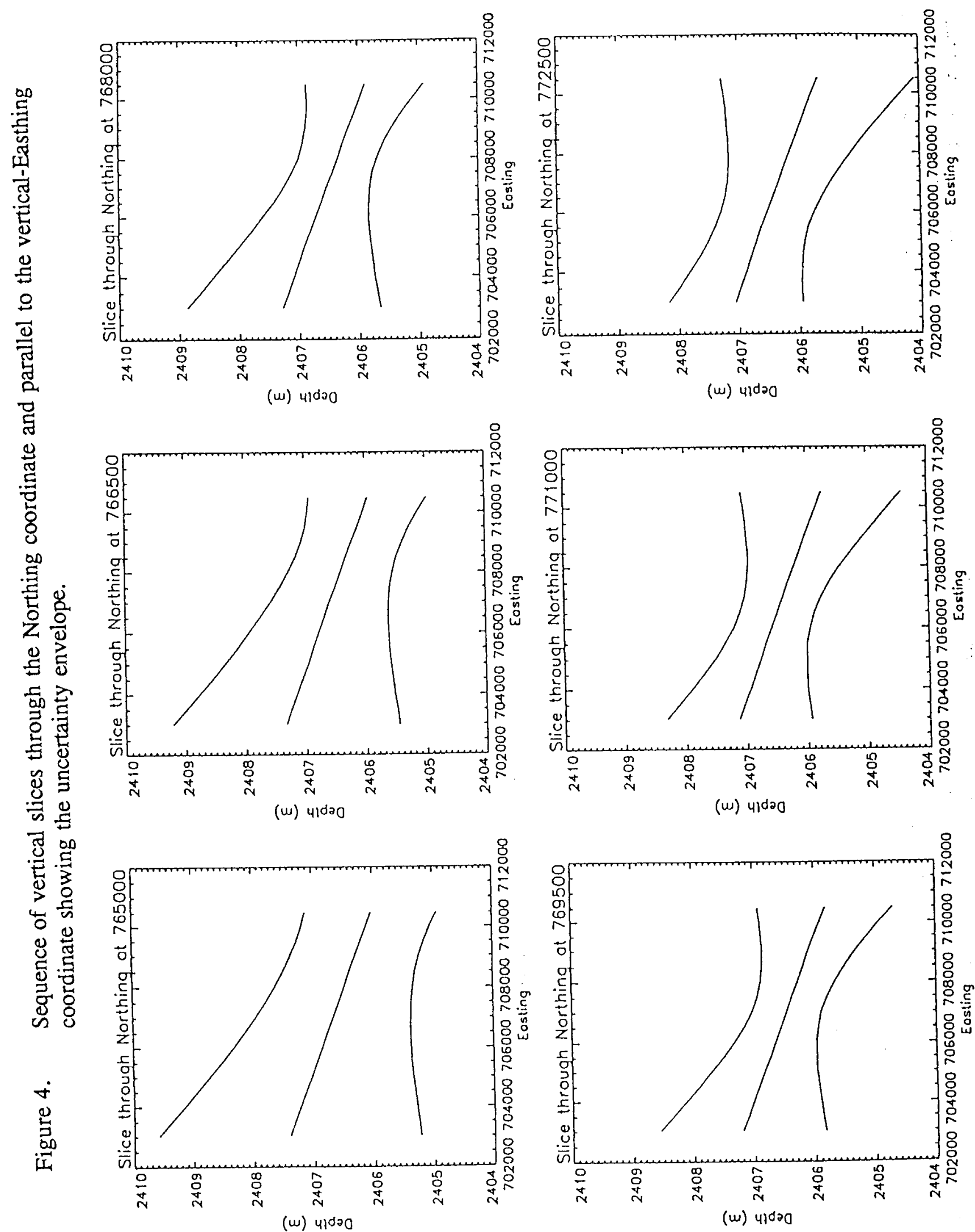

(w) $41 d 00$

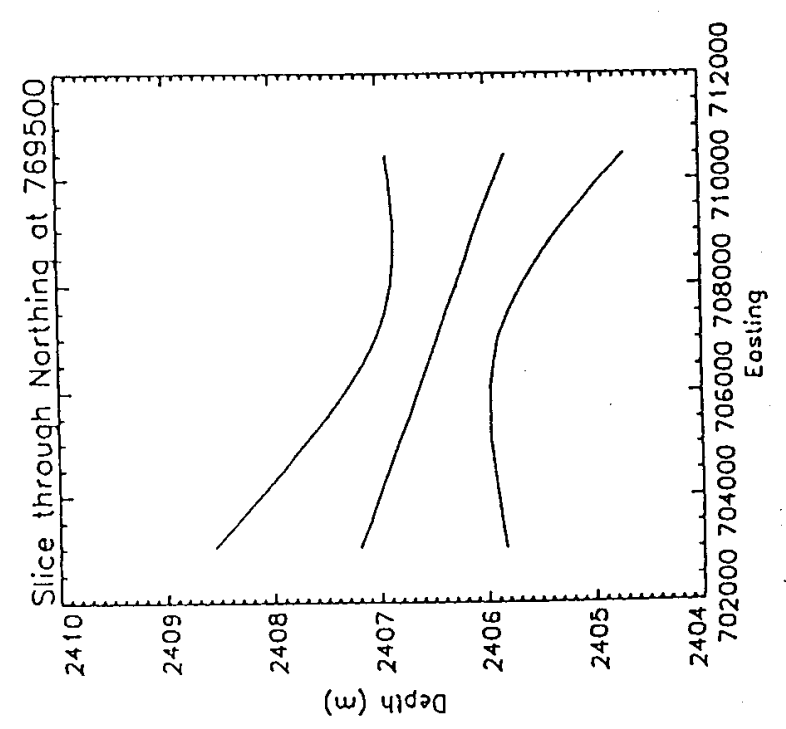


Appendix F.5.2 Results of hydraulic conductivity recovery tests

\begin{tabular}{|c|c|c|c|}
\hline Borehole & $\begin{array}{c}\text { Slug Test } \\
\text { Number }\end{array}$ & $\begin{array}{c}\text { Time Lag } \\
(\mathrm{s})\end{array}$ & $\begin{array}{l}\text { Hydraulic Conductivity } \\
(\mathrm{cm} / \mathrm{s})\end{array}$ \\
\hline \multirow{6}{*}{ UE5PW-1 } & 1 & 38 & $1.2 \times 10^{-3}$ \\
\hline & 2 & 31 & $1.4 \times 10^{-3}$ \\
\hline & 3 & 48 & $9.1 \times 10^{-4}$ \\
\hline & 4 & 46 & $9.5 \times 10^{-4}$ \\
\hline & 5 & 23 & $1.9 \times 10^{-3}$ \\
\hline & Average & 24 & $1.3 \times 10^{-3}$ \\
\hline \multirow{6}{*}{ UE5PW-2 } & 1 & 166 & $2.4 \times 10^{-4}$ \\
\hline & 2 & 101 & $3.9 \times 10^{-4}$ \\
\hline & 3 & 112 & $3.5 \times 10^{-4}$ \\
\hline & 4 & 119 & $3.3 \times 10^{-4}$ \\
\hline & 5 & 108 & $3.7 \times 10^{-4}$ \\
\hline & Average & 121 & $3.4 \times 10^{-4}$ \\
\hline \multirow{5}{*}{ UE5PW-3 } & 1 & 29 & $1.2 \times 10^{-3}$ \\
\hline & 2 & 23 & $1.5 \times 10^{-3}$ \\
\hline & 3 & 25 & $1.4 \times 10^{-3}$ \\
\hline & 4 & 22 & $1.6 \times 10^{-3}$ \\
\hline & Average & 25 & $1.4 \times 10^{-3}$ \\
\hline
\end{tabular}




\section{Area 5 Pilot Wells}

\section{APPENDIX G \\ Data from Neutron Logging Calibration Boreholes}

G.1 Drilling Information

G.1.1 Chronological Drilling Summary for UE5PW-2A, 2B, and 2C

G.1.2 Core Record for UE5PW-2A, 2B, and 2C

G.1.3 Nevada State Central Zone Coordinates for Neutron Logging Calibration Boreholes

G.2 Core and Drill Cuttings Sample Description Data

G.2.1 Borehole Log Sheets for UE5PW-2A

G.2.2 Borehole Log Sheets for UE5PW-2B

G.2.3 Borehole Log Sheets for UE5PW-2C

G.2.4 Drill Cuttings Log Data for UE5PWW-2A

G.2.5 Drill Cuttings Log Data for UE5PWW-2B

G.2.6 Drill Cuttings Log Data for UE5PWW-2C

G.3 Laboratory Testing Data of Geologic Samples

G.3.1 Stratigraphy and Mineralogy Data

G.3.1.1 Summary of USCS Group Names for Core and Drill Cuttings Samples from Calibration Boreholes

G.3.1.2 Results from XRF and INAA for Core Samples from UE5PW-2A

G.3.1.3 Results from XRF and INAA for Core Samples from UE5PW-2B

G.3.1.4 Results from XRF and INAA for Core Samples from UE5PW-2C

G.3.2 Material, Hydrologic, and Geochemical Parameter Data

G.3.2.1 Results of Laboratory Tests for Core Samples from UE5PW-2A

G.3.2.2 Results of Laboratory Tests for Core Samples from UE5PW-2B

G.3.2.3 Results of Laboratory Tests for Core Samples from UE5PW-2C

G.3.2.4 Results of Laboratory Tests for Drill Cuttings Samples from UE5PW-2A

G.3.2.5 Results of Laboratory Tests for Drill Cuttings Samples from UE5PW-2B

G.3.2.6 Results of Laboratory Tests for Drill Cuttings Samples from UE5PW-2C

G.3.2.7 Summary of Descriptive Statistics of Alluvial Samples from UE5PW-2A, UE5PW-2B, and UE5PW-2C

G.4 Field Test Data

G.4.1 Site Preparation Information

G.4.2 Neutron-Moisture Meter Data

G.4.2.1 Neutron-Moisture Meter Data for UE5PW-2A

G.4.2.2 Neutron-Moisture Meter Data for UE5PW-2B

G.4.2.3 Neutron-Moisture Meter Data for UE5PW-2C

G.4.3 Calibration of the Neutron-Moisture Meter in the Calibration Boreholes 
Appendix G.1.1 Chronological Drilling Summary for Ue5PW-2A, 2B, and 2C

\begin{tabular}{|c|c|c|c|l||}
\hline $\begin{array}{c}\text { DATE } \\
1992\end{array}$ & $\begin{array}{c}\text { CASING } \\
\text { DEPTH (ft.) }\end{array}$ & $\begin{array}{c}\text { CASING } \\
\text { SIZE } \\
\text { (in.) }\end{array}$ & $\begin{array}{c}\text { CORE } \\
\text { RUN } \\
\text { NO. }\end{array}$ & ACTIVITIES \& PROBLEMS \\
\hline $7-17$ & 37.5 & 8.625 & $1,2,3$ & $\begin{array}{l}\text { Moved onto PW-2A calibration hole } \\
\text { \& spuded. Welded hammer closed. }\end{array}$ \\
\hline $7-20$ & & 4 & $\begin{array}{l}\text { Took core sample in PW-2A @ } \\
\text { T.D. and moved off hole. }\end{array}$ \\
\hline $7-20$ & 22.5 & 7.625 & 1 & $\begin{array}{l}\text { Moved to PW-2B. Can't get Odex } \\
\text { back through casing due to “mill } \\
\text { reject" tolerance. Cut sampler sub. } \\
\text { Casing pulled and reset at 13.5 ft. }\end{array}$ \\
\hline $7-20$ & & 1 & Moved to PW-2C. \\
\hline $7-21$ & 37.5 & 10.75 & 2,3 & $\begin{array}{l}\text { Completed PW-2C. Moved off } \\
\text { hole. }\end{array}$ \\
\hline
\end{tabular}


Appendix G.1.2 Core record for the Ue5PW-2A, $2 \mathrm{~B}$, and $2 \mathrm{C}$.

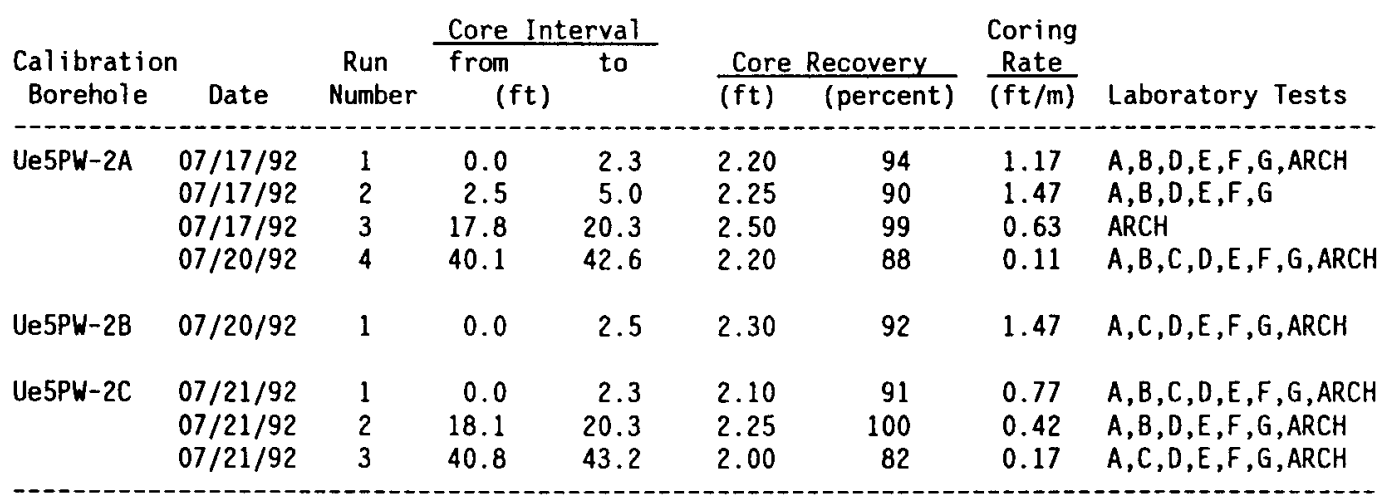

A: PHYSICAL AND HYDRAULIC PROPERTIES E: XRF, MINERALOGY AND GEOCHEMISTRY

B: PARTICLE SIZE ANALYSIS F: STABLE ISOTPES AND TRITIUM

C: CHLORIDE EXTRATION

D: WATER POTENTIAL

$G$ : CHLORIDE, BROMIDE AND CARBON ARCH: ARCHIVAL 
Table G.1.3 Nevada state central zone coordinates for neutron logging calibration boreholes

\begin{tabular}{||c|c|c|c||}
\hline \multirow{2}{*}{ Well No. } & $\begin{array}{c}\text { Elevation Above Sea } \\
\text { Level } \\
(\mathrm{ft})\end{array}$ & \multicolumn{2}{|c|}{ Nevada State Central Zone Coordinates } \\
\cline { 2 - 4 } & $3,245.60$ & North (ft) & East (ft) \\
\hline Ue5PW-2A & $3,244.66$ & $770,291.49$ & $709,974.51$ \\
\hline Ue5PW-2B & $3,245.59$ & $770,273.57$ & $709,965.90$ \\
\hline Ue5PW-2C & $770,308.96$ & $709,981.24$ \\
\hline
\end{tabular}




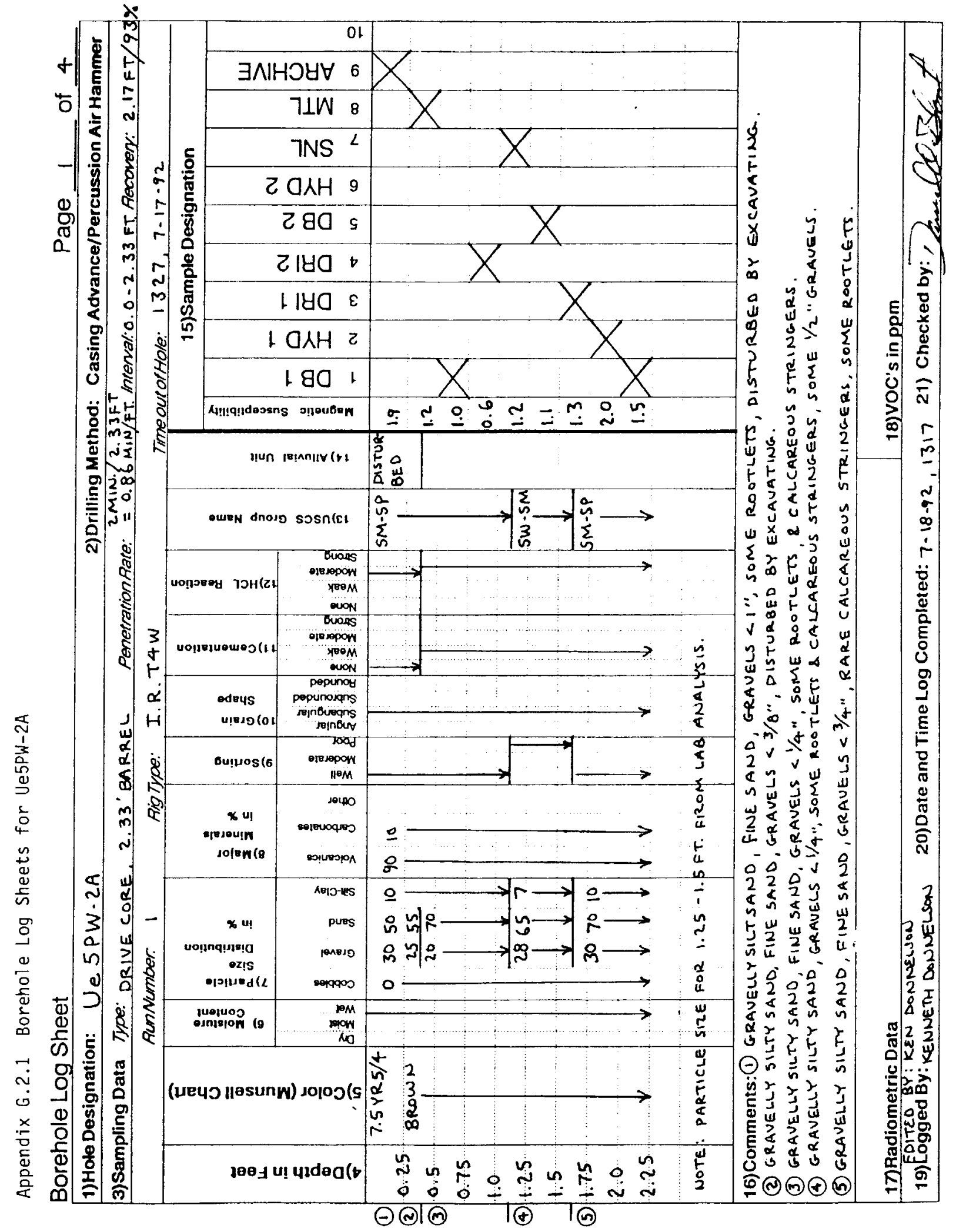




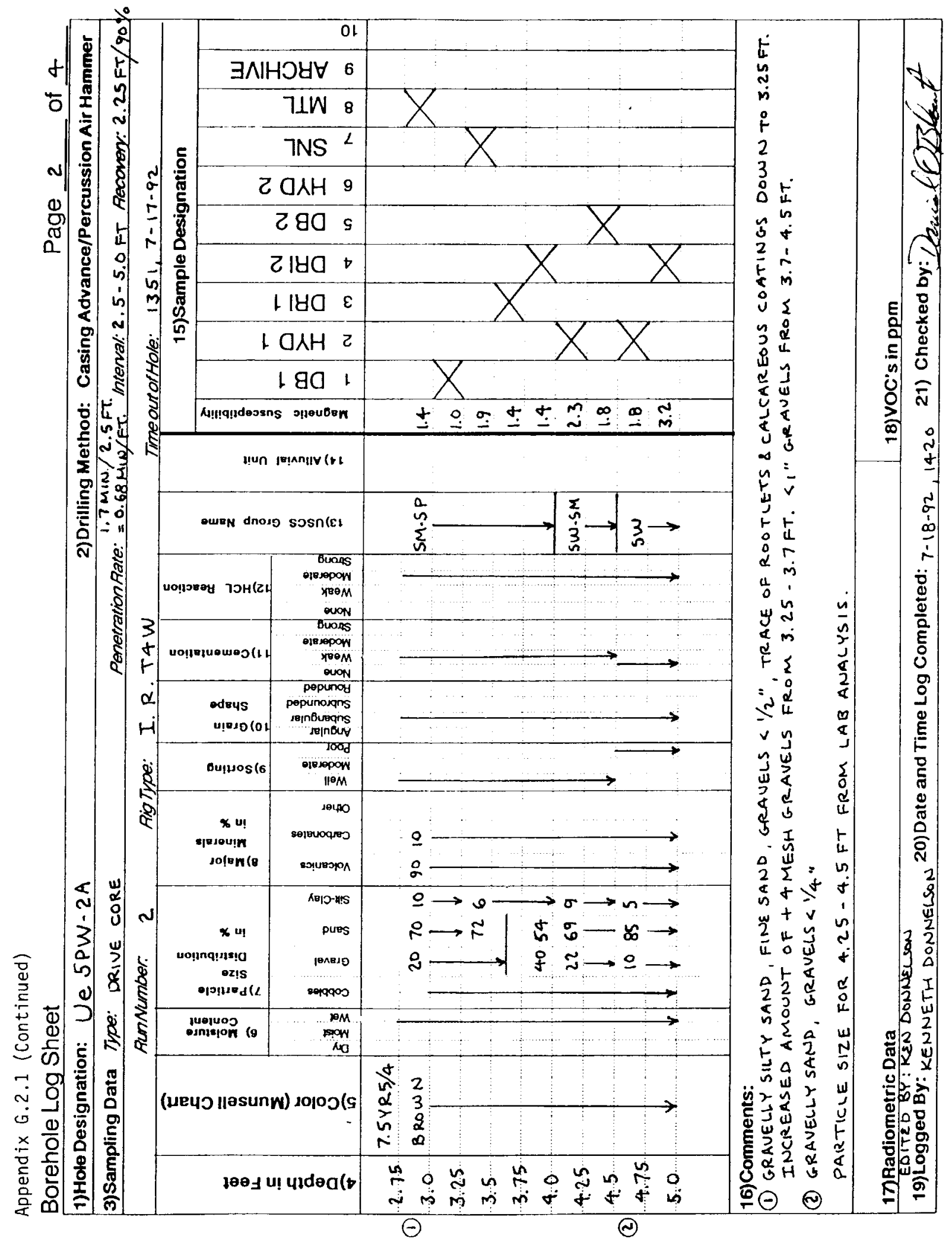




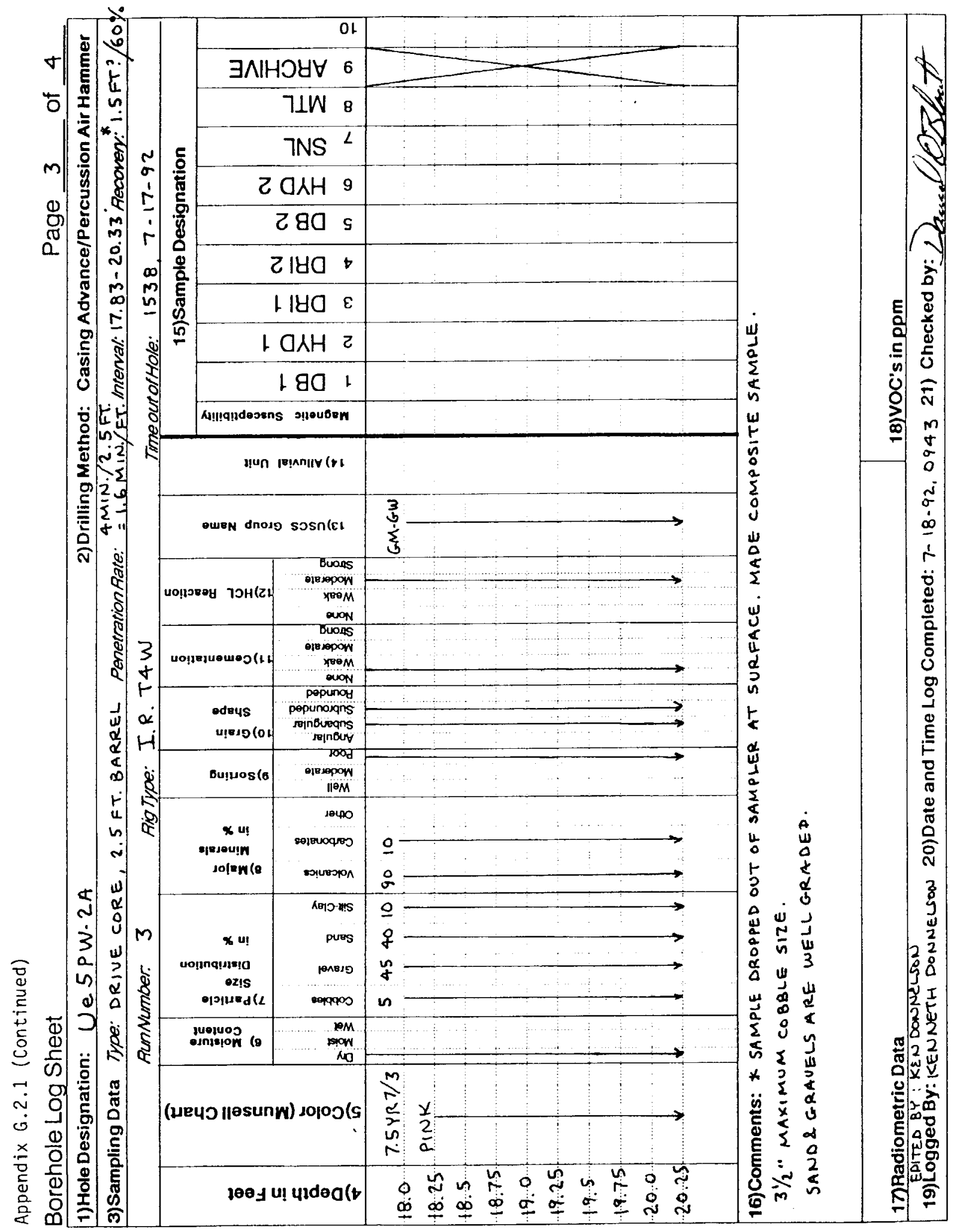




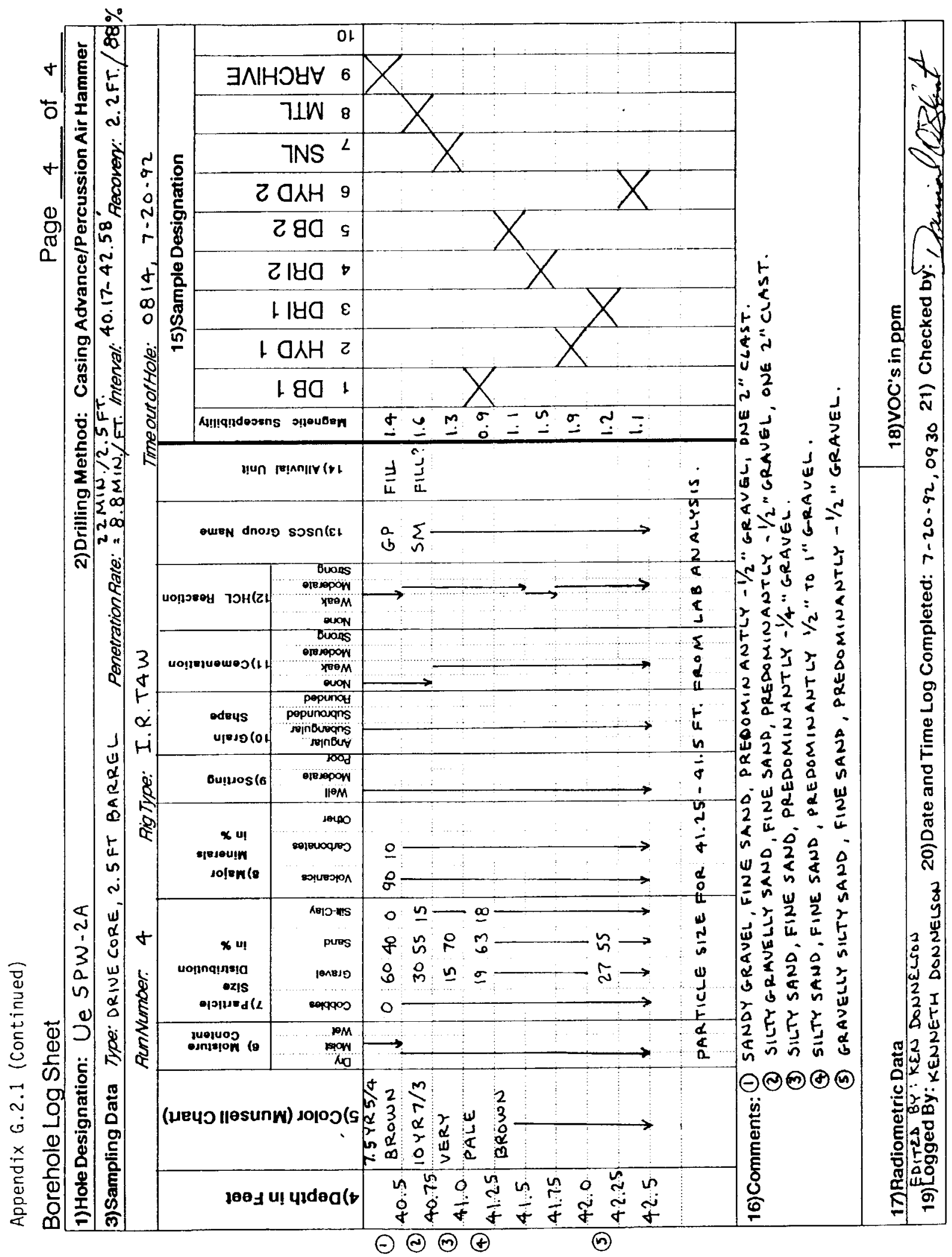




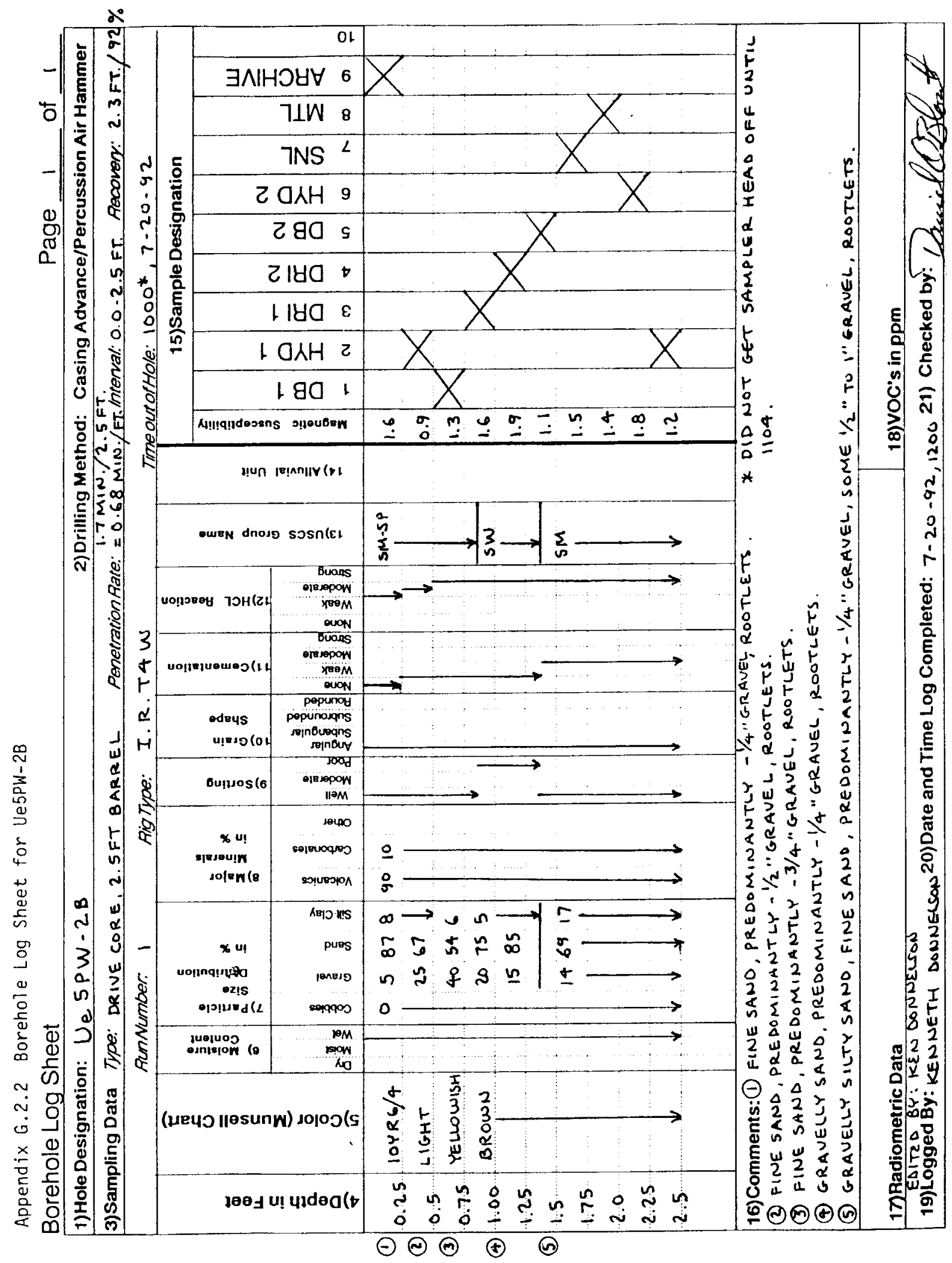




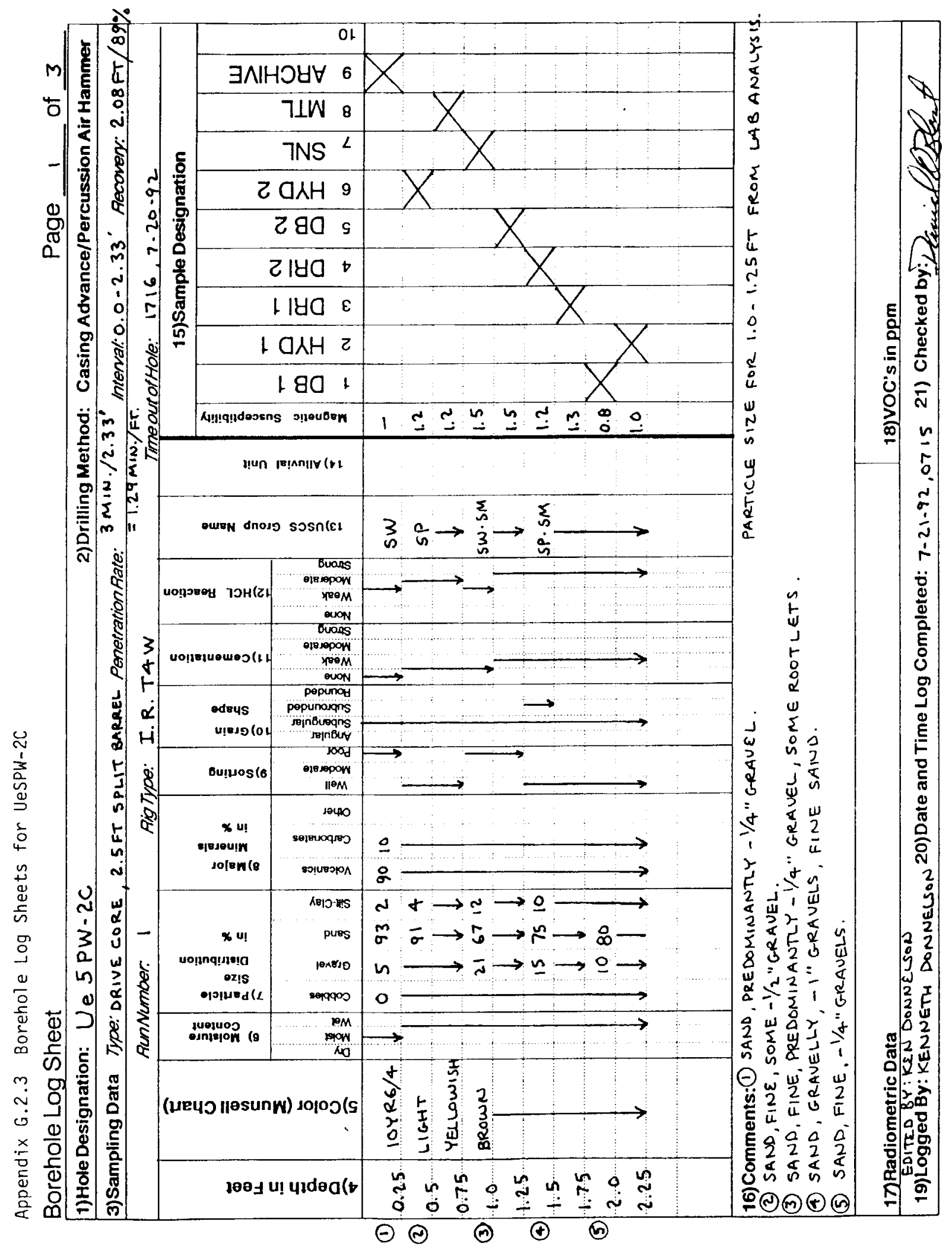




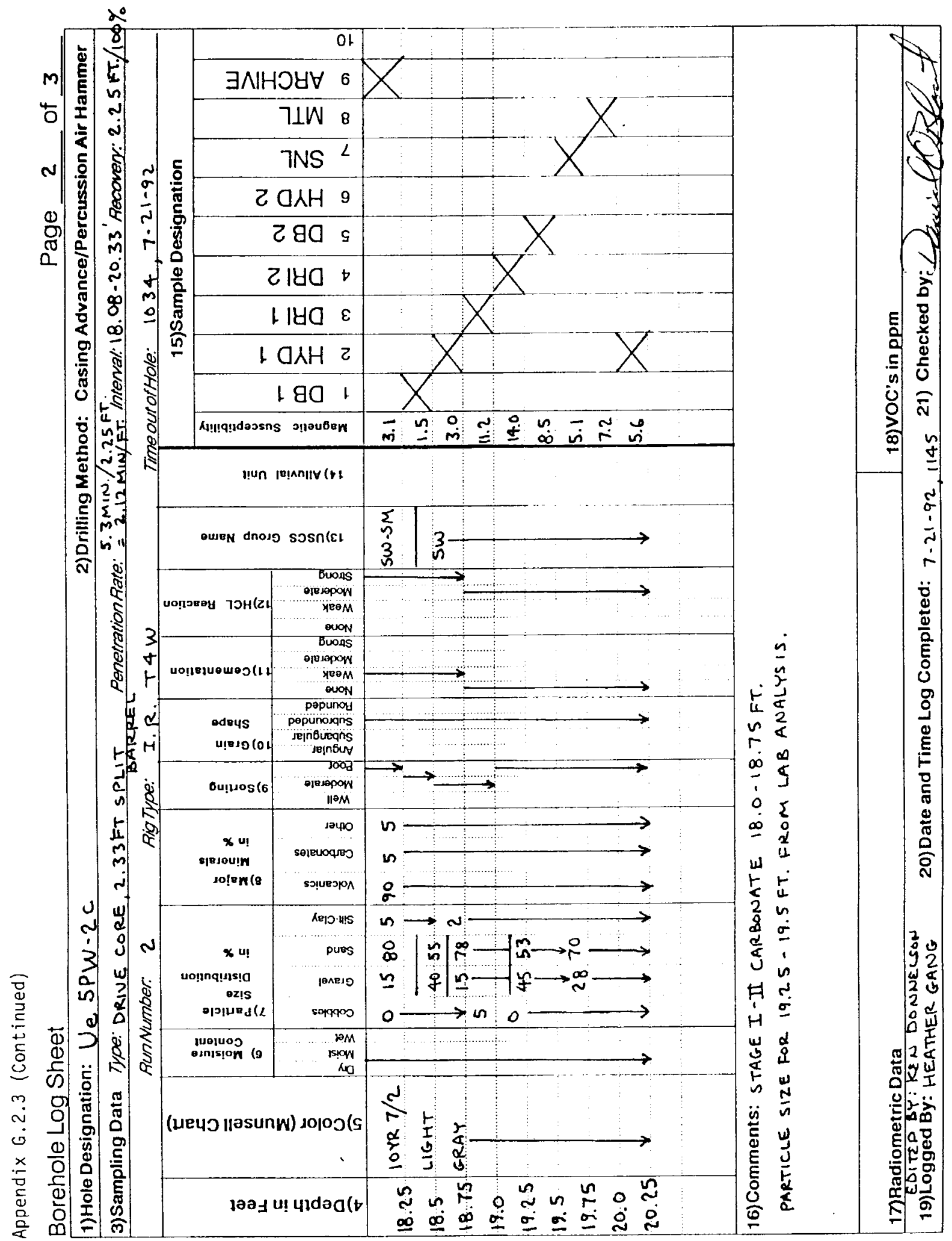




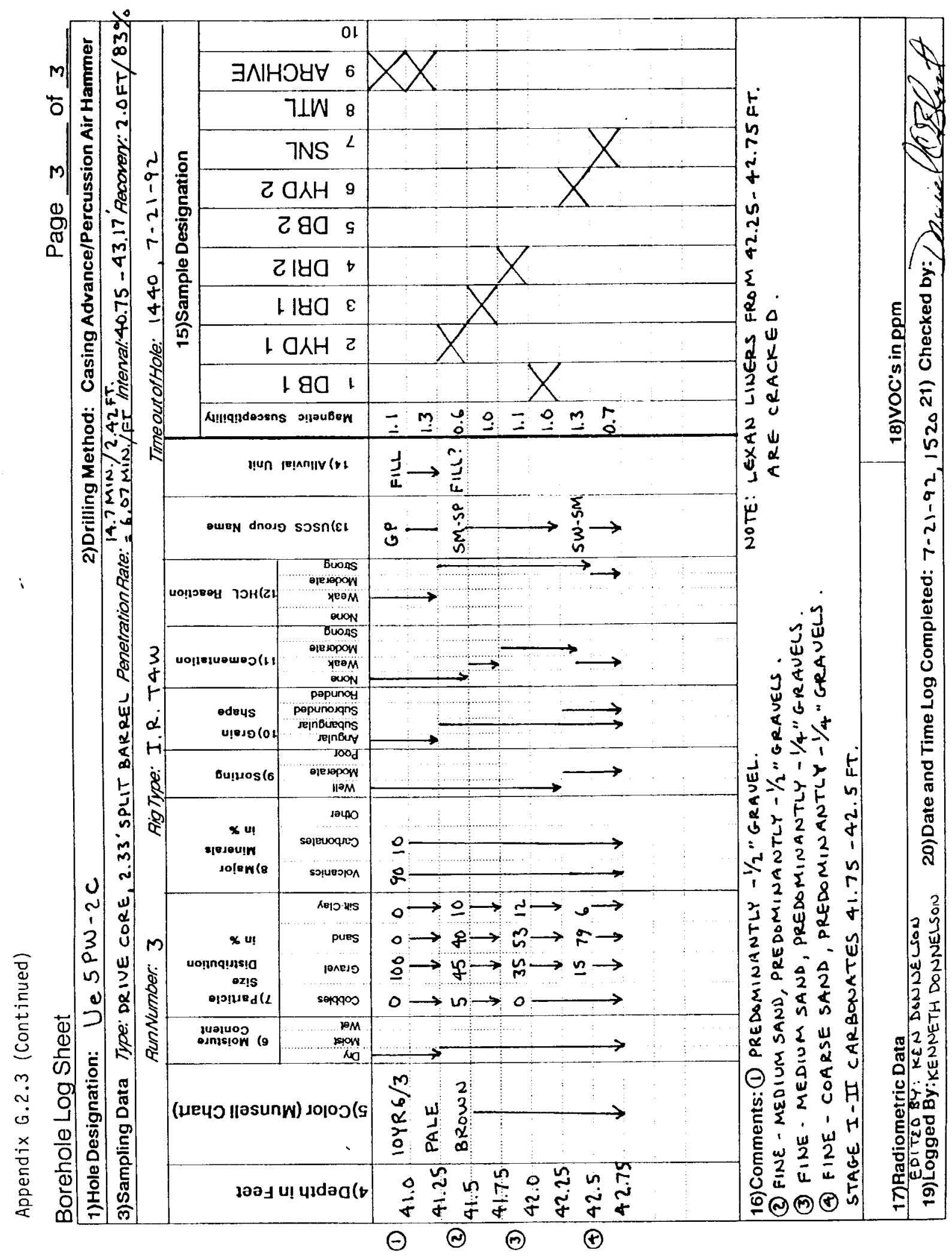




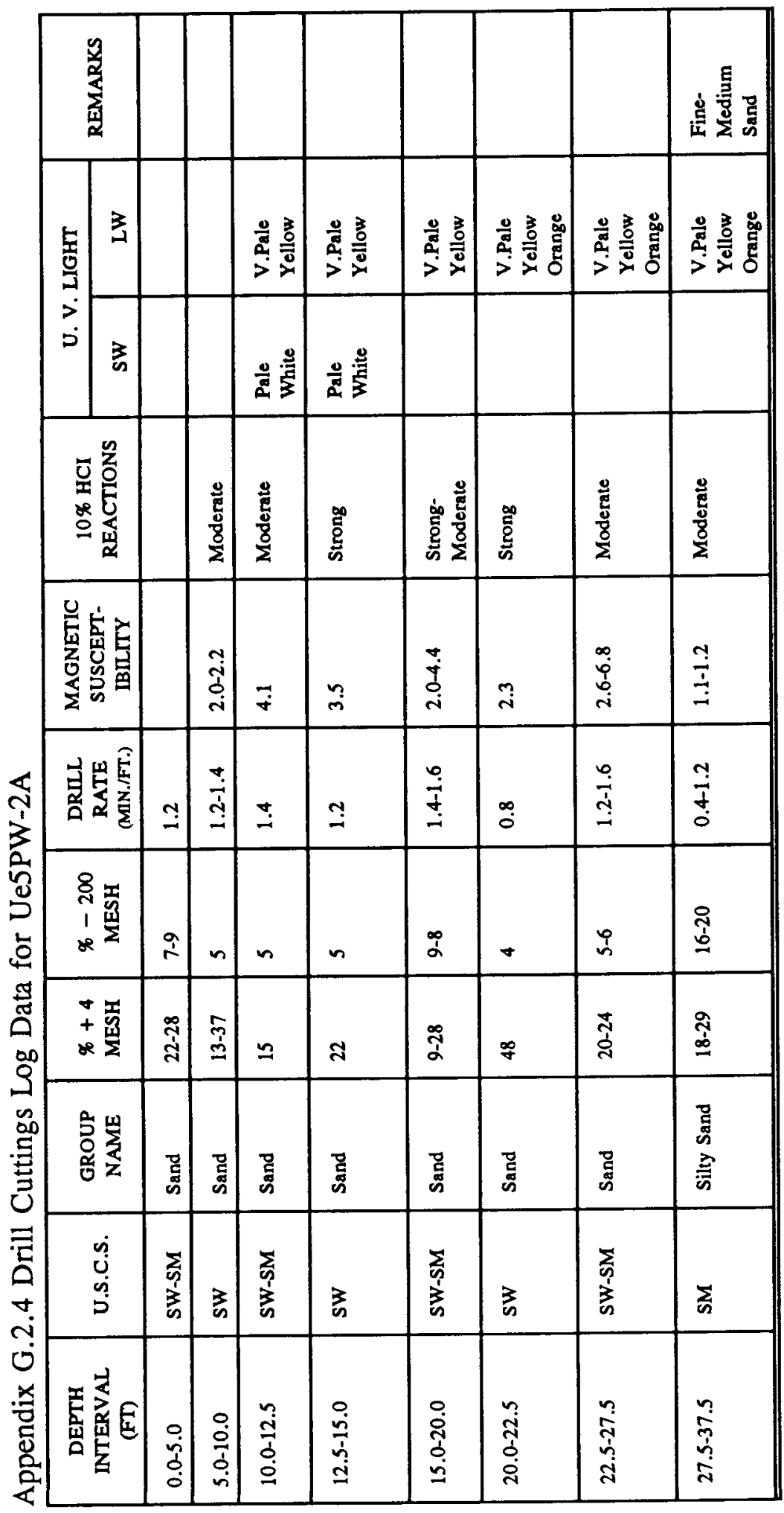




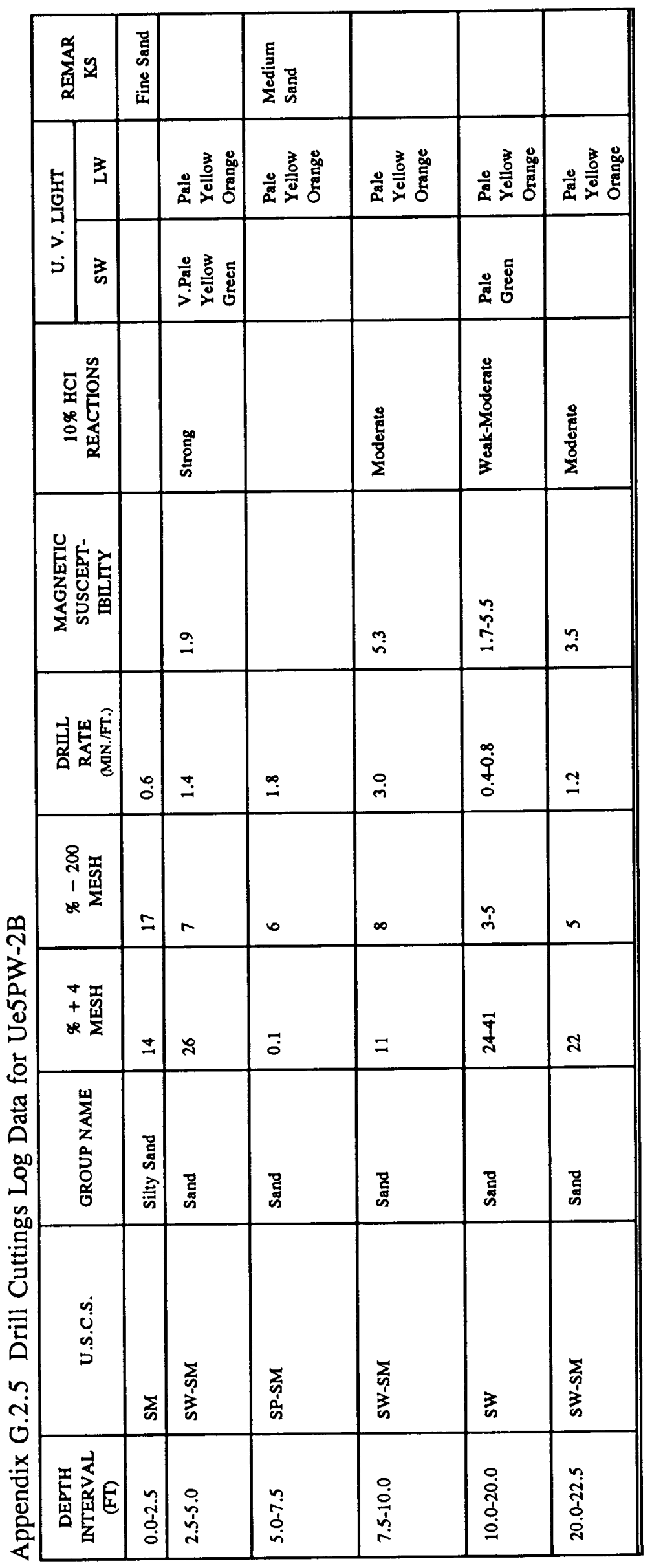




\begin{tabular}{|c|c|c|c|c|c|c|}
\hline & 紊 & & 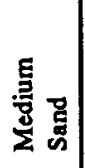 & & & \\
\hline & 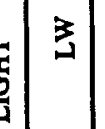 & 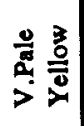 & 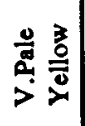 & 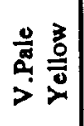 & 迹言 & 递 \\
\hline & $\dot{0}$ & 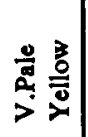 & 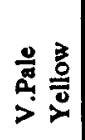 & 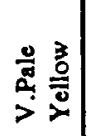 & 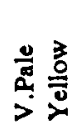 & 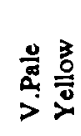 \\
\hline & 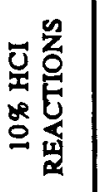 & 离 & 苟 & 离 & $\frac{\vec{E}}{\stackrel{\vec{E}}{\omega}}$ & 莺 \\
\hline & 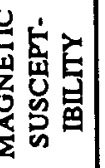 & $\stackrel{9}{\vec{A}}$ & $\stackrel{m}{m}$ & $\stackrel{\dddot{y}}{\stackrel{9}{9}}$ & $\stackrel{a}{0}$ & 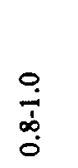 \\
\hline & 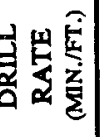 & $\begin{array}{l}0 \\
\stackrel{+}{0} \\
\stackrel{0}{0}\end{array}$ & $\stackrel{\infty}{\infty}_{\infty}$ & $\stackrel{\infty}{\dot{p}}$ & $\stackrel{t}{i}$ & $\stackrel{\dddot{n}}{\stackrel{3}{\leftrightarrows}}$ \\
\hline & $\begin{array}{l}8 \\
8 \\
1 \\
x \\
x\end{array}$ & ì & $\Xi$ & $\frac{0}{b}$ & $r$ & $\stackrel{a}{i}$ \\
\hline & $\begin{array}{l}+\frac{1}{3} \\
+ \text { 惫 } \\
\text { of }\end{array}$ & $\stackrel{\text { I }}{\Xi}$ & $a$ & $\underset{\hat{S}}{\underline{\underline{S}}}$ & f & $\frac{9}{m}$ \\
\hline & 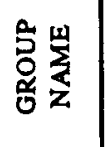 & 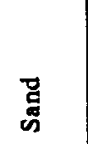 & 㺃总 & ถี & 总 & 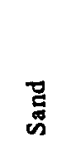 \\
\hline & 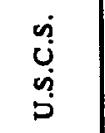 & 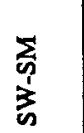 & $\sum$ & 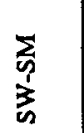 & $\begin{array}{l}\Sigma \\
\vdots \\
\vdots \\
\vdots \\
\vdots\end{array}$ & 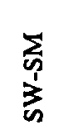 \\
\hline & 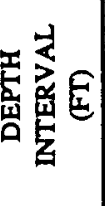 & $\begin{array}{l}n \\
\vdots \\
0 \\
0\end{array}$ & 㫄 & $\begin{array}{l}\stackrel{0}{0} \\
\text { ơ } \\
0\end{array}$ & $\begin{array}{l}\text { ñ. } \\
\hat{\delta} \\
\dot{0}\end{array}$ & $\begin{array}{c}n \\
\substack{n \\
n \\
n \\
n}\end{array}$ \\
\hline
\end{tabular}




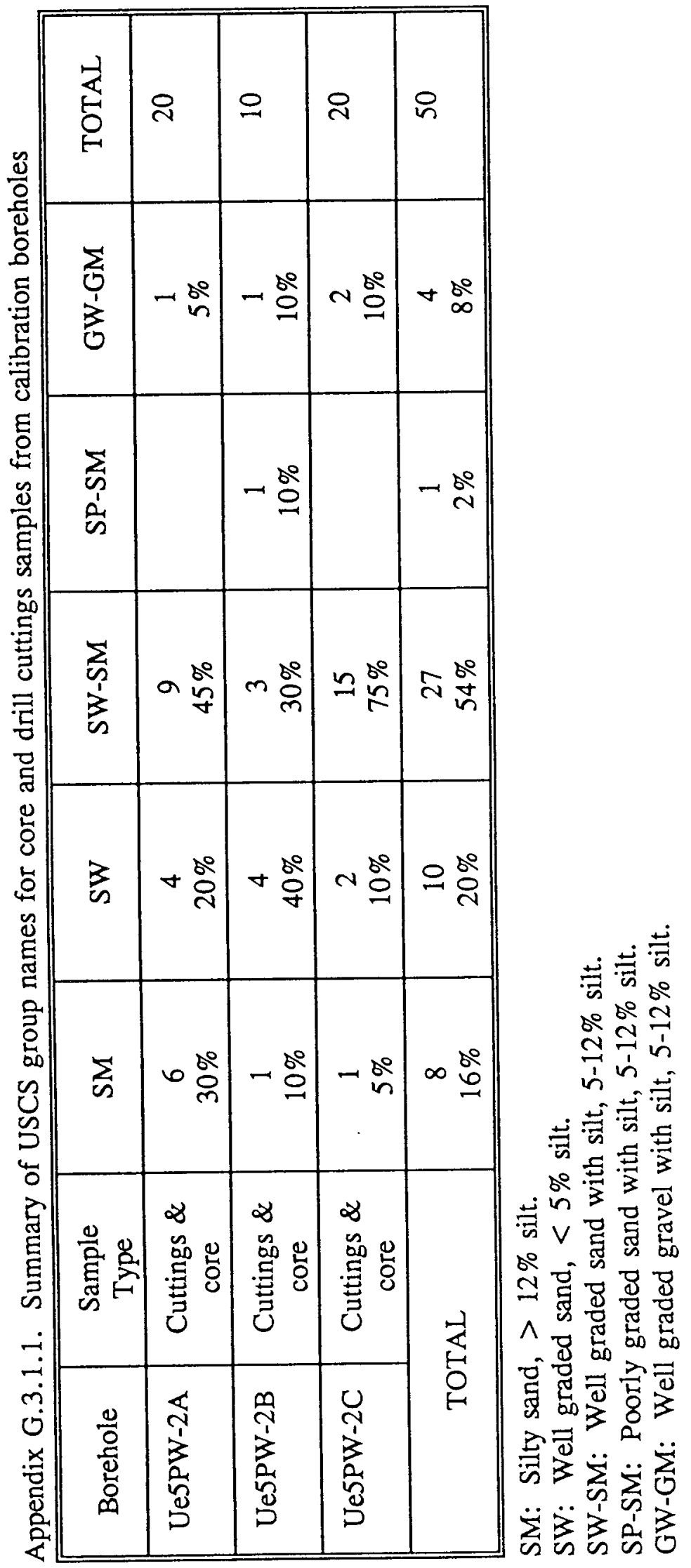


Appendix G.3.1.1 Profiles of USCS Textural Classes (Continued).

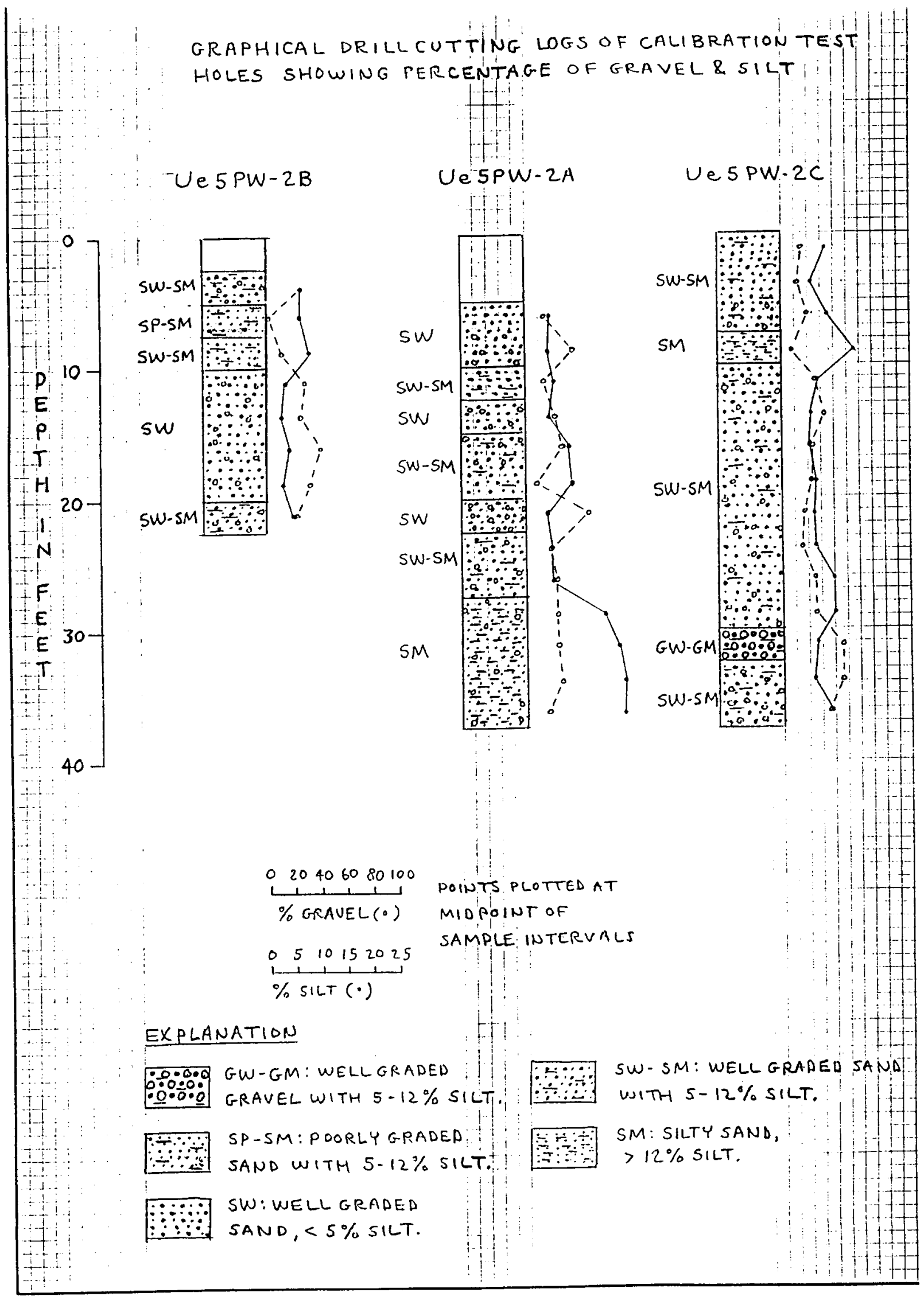




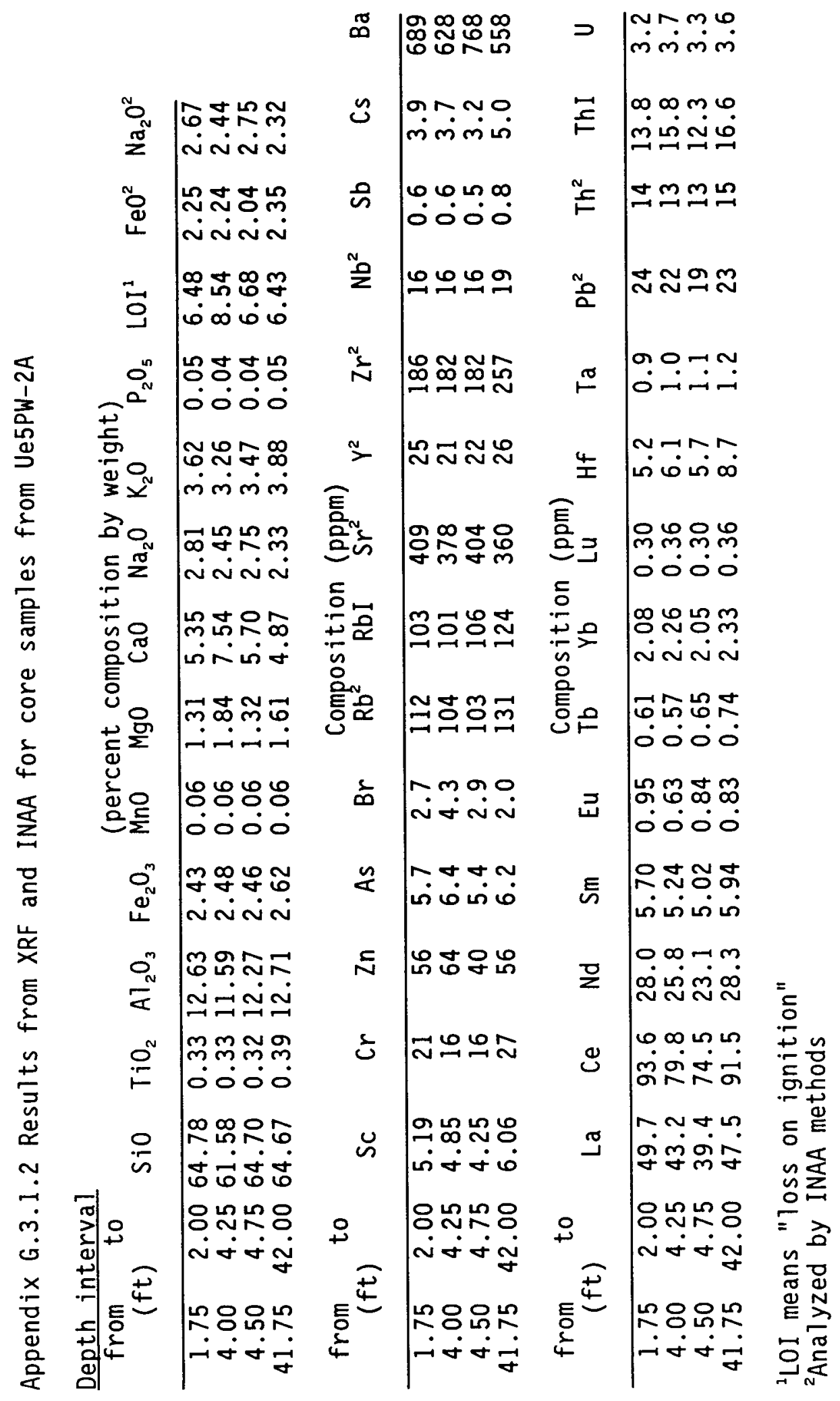




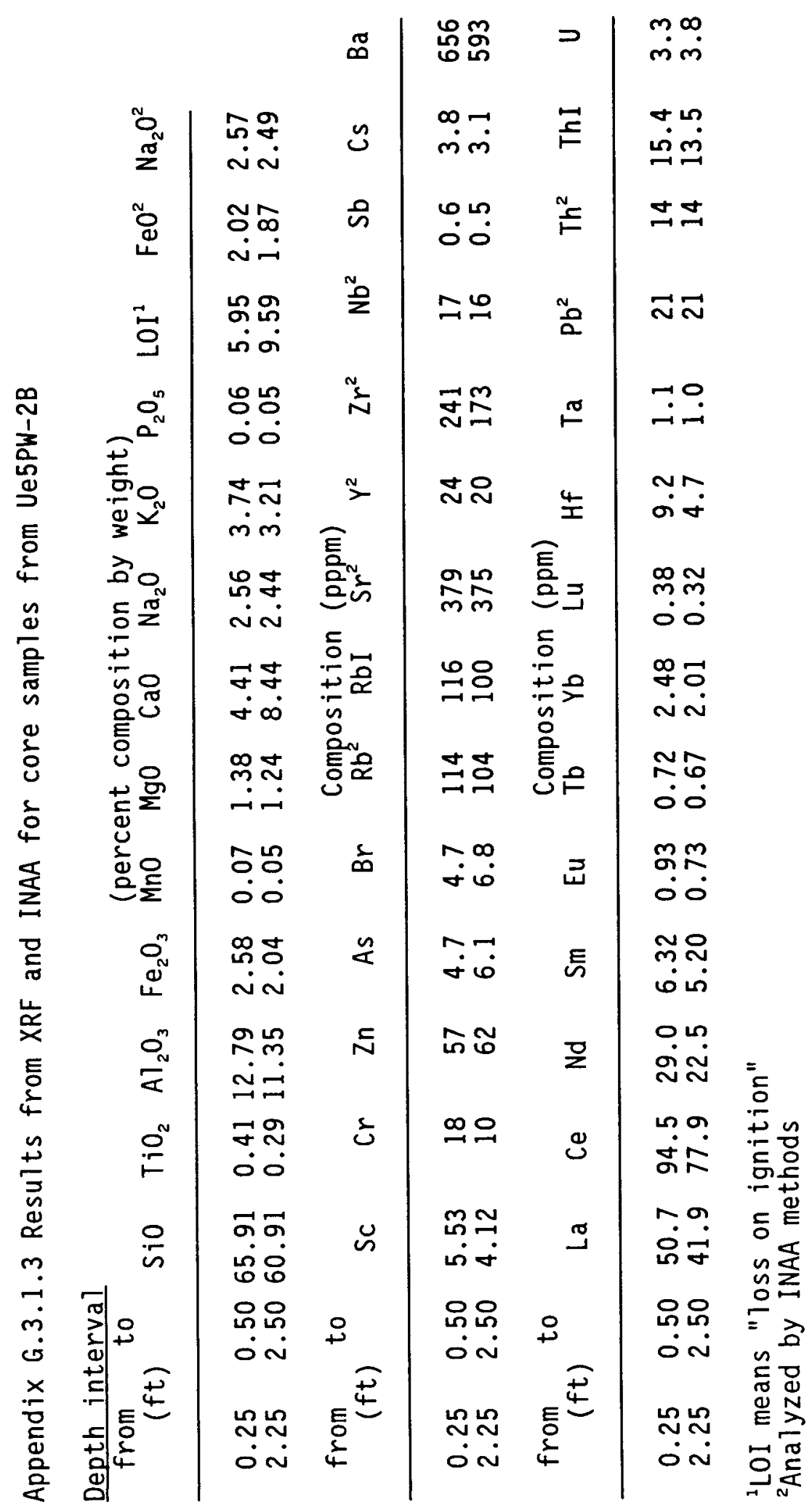




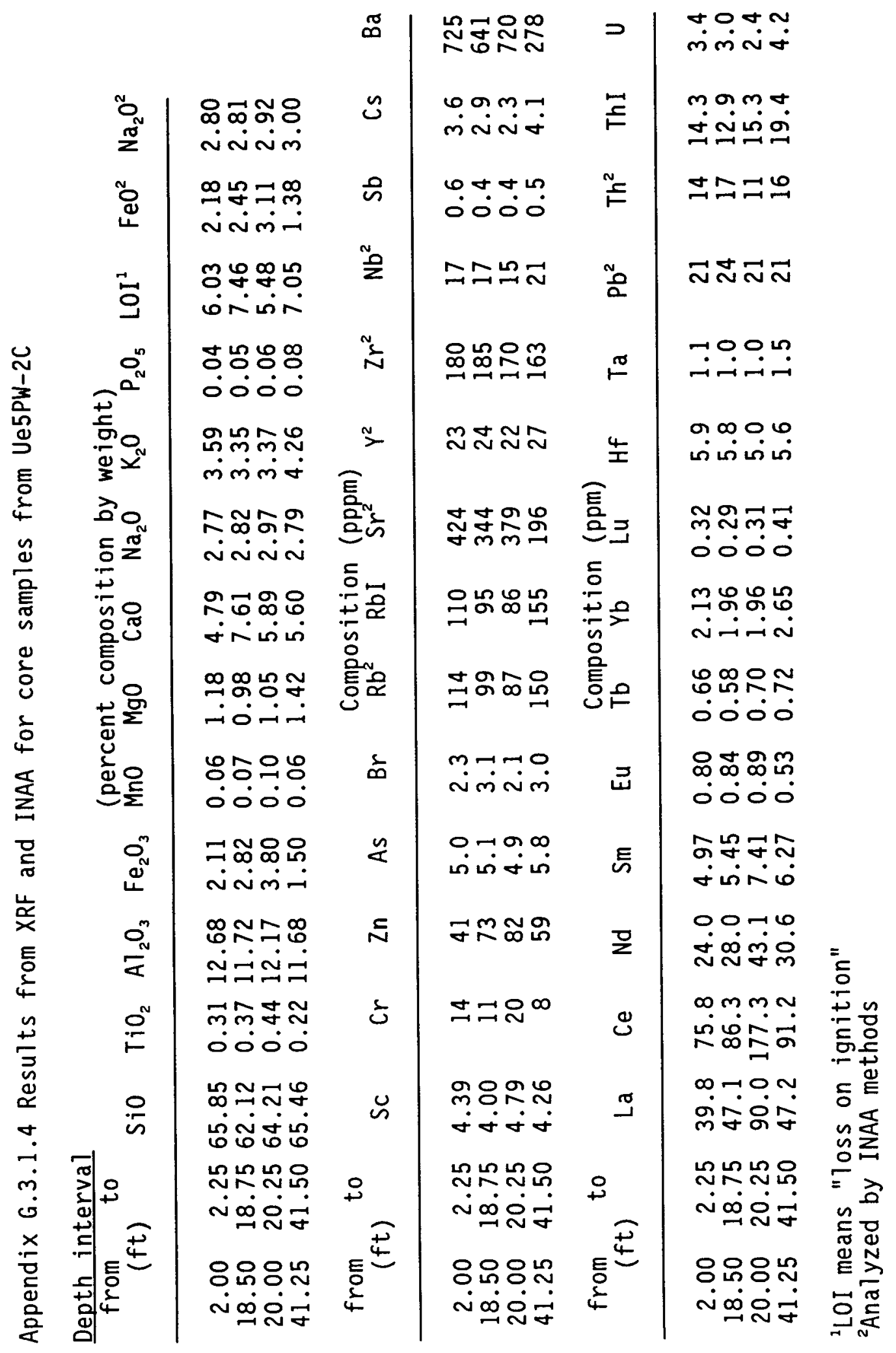




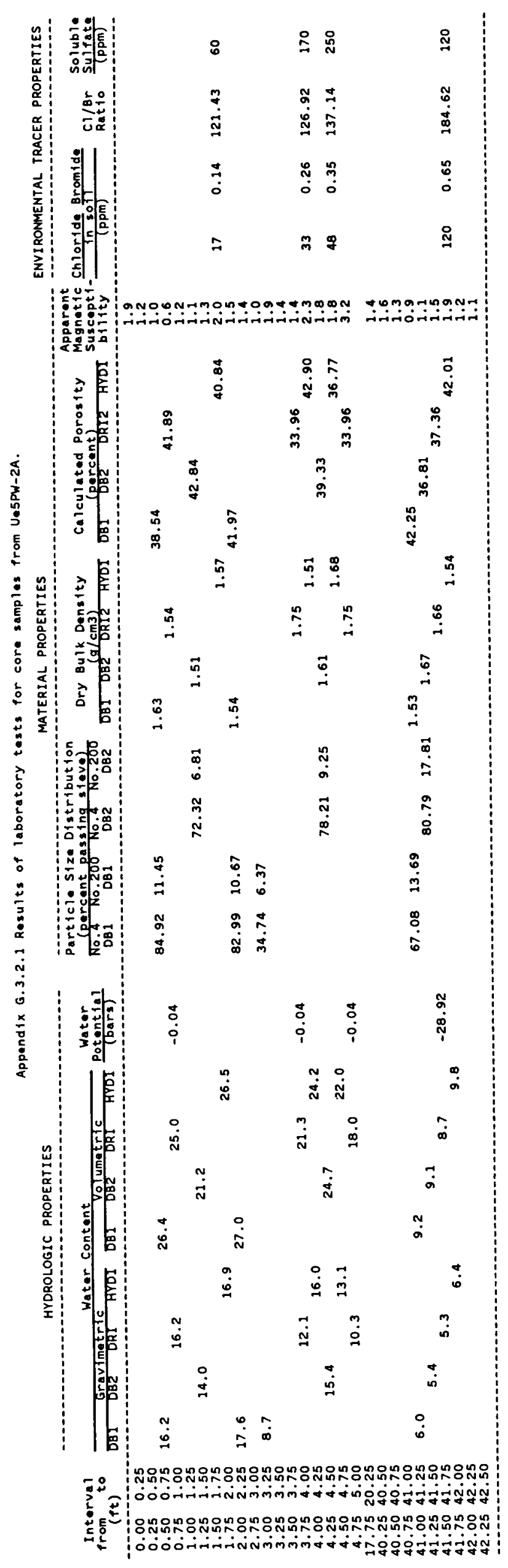




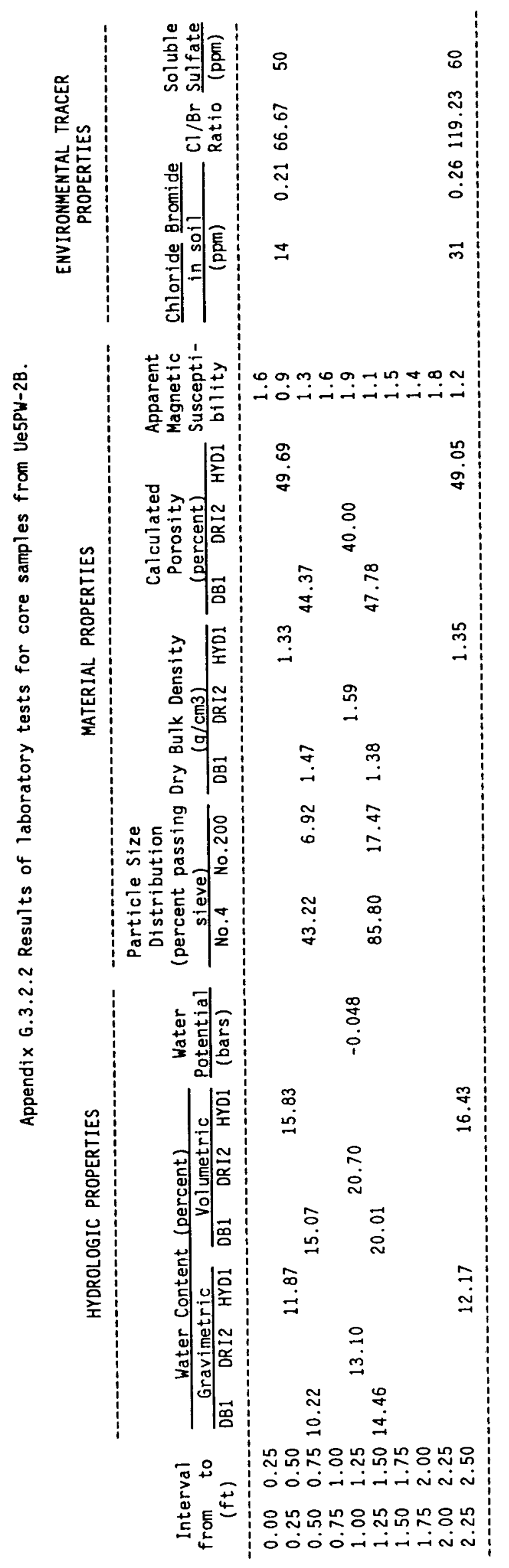




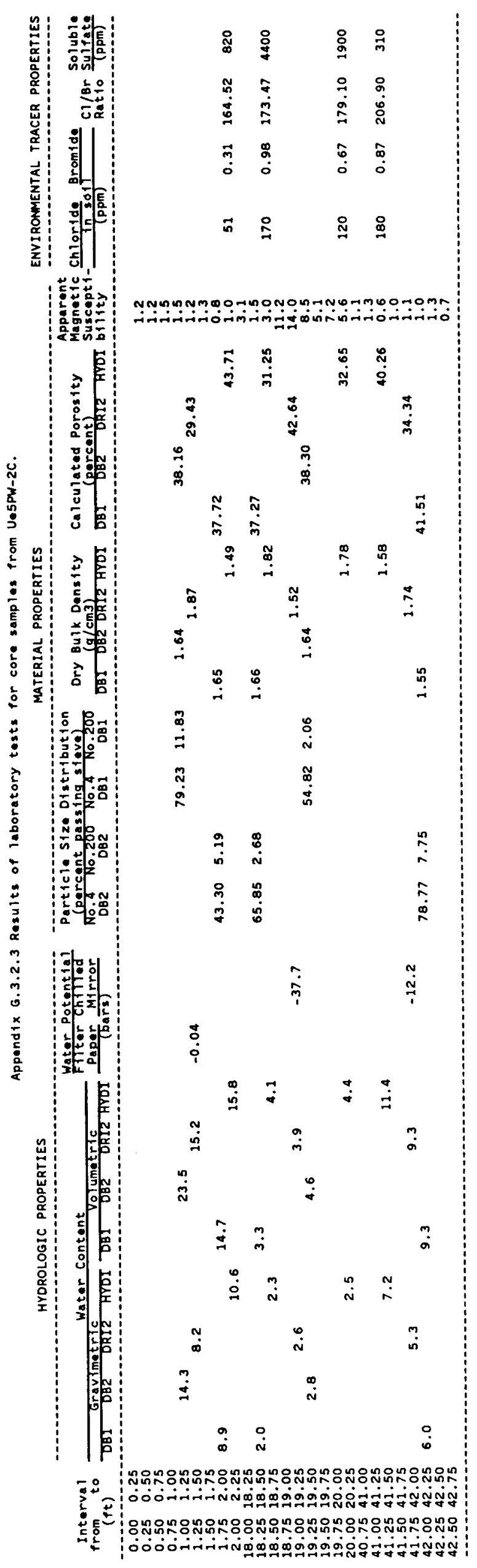


Appendix G.3.2.4 Results of laboratory tests for cuttings samples from Ue5PW-2A.

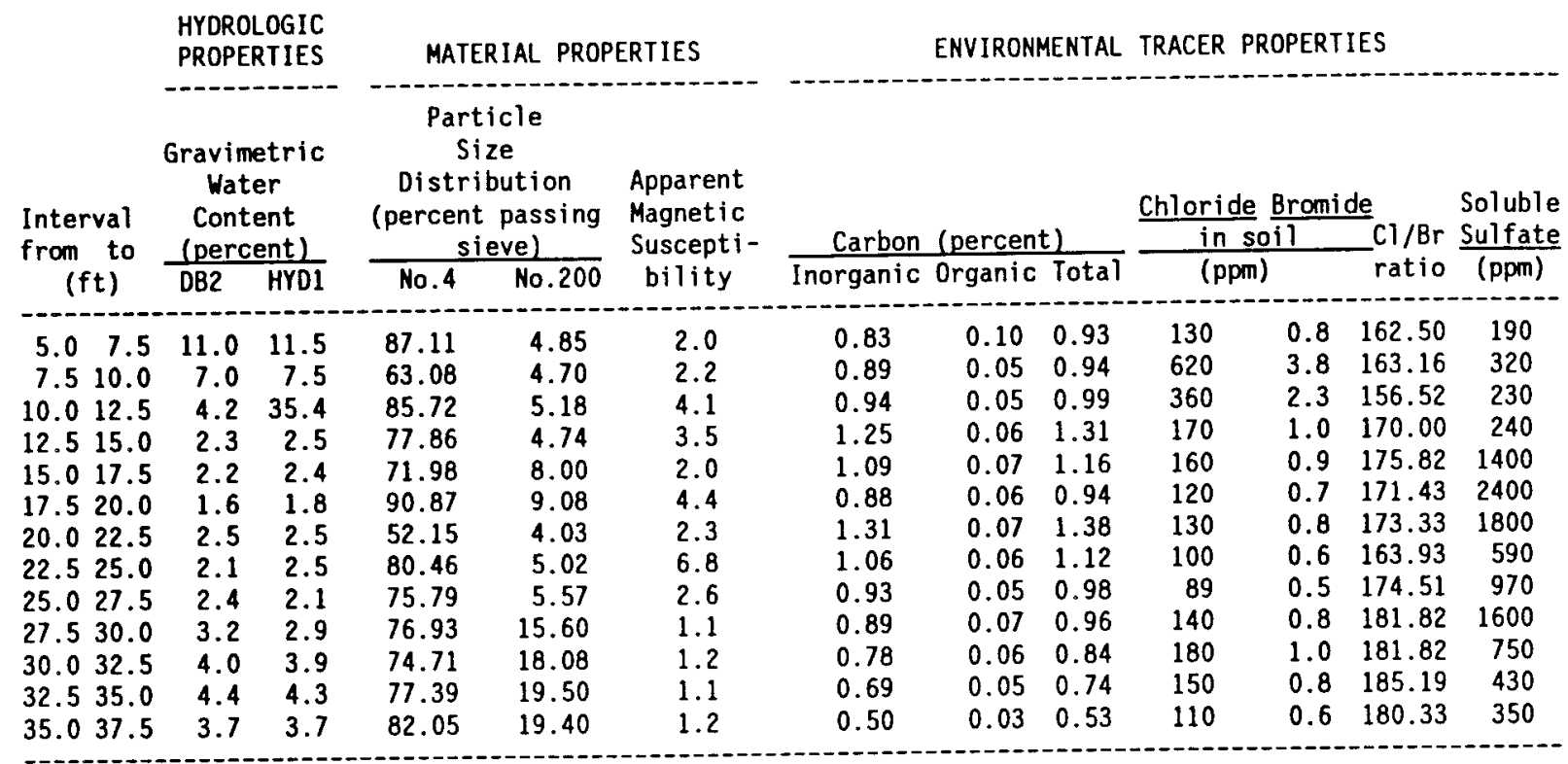


Appendix G.3.2.5 Results of laboratory tests for cuttings samples from Ue5PW-2B.

\begin{tabular}{|c|c|c|c|c|c|c|c|c|c|c|c|c|}
\hline & $\begin{array}{l}\text { HYDR } \\
\text { PROPE }\end{array}$ & $\begin{array}{l}\text { DGIC } \\
\text { TIES }\end{array}$ & MAT & IL PROF & IES & & EVIRO & NT & $2 A C$ & $\mathrm{PE}$ & $s$ & \\
\hline $\begin{array}{l}\text { Interval } \\
\text { from to }\end{array}$ & $\begin{array}{r}\text { Gravin } \\
\text { Wa } \\
\text { Con } \\
\text { lper }\end{array}$ & $\begin{array}{l}\text { ric } \\
\text { t) } \\
\text { t) }\end{array}$ & $\begin{array}{r}\text { Par } \\
\mathrm{S} \\
\text { Distr } \\
\text { (percen } \\
\mathrm{s}\end{array}$ & $\begin{array}{l}\text { e } \\
\text { ion } \\
\text { issing } \\
\end{array}$ & $\begin{array}{l}\text { Apparent } \\
\text { Magnetic } \\
\text { Suscepti- }\end{array}$ & Carbo & (percen & & $\frac{\text { Chlori }}{\text { in }}$ & & ${ }_{-}^{\mathrm{e}} \mathrm{Cl} / \mathrm{Br}$ & $\begin{array}{l}\text { Soluble } \\
\text { Sulfate }\end{array}$ \\
\hline$(f t)$ & $\mathrm{DB2}$ & HYDI & No. 4 & No. 200 & bility & Inorga & oro & Total & & & ratio & $(p p m)$ \\
\hline $\begin{array}{rr}2.5 & 5.0 \\
5.0 & 7.5 \\
7.5 & 10.0 \\
10.0 & 12.5 \\
12.5 & 15.0 \\
15.0 & 17.5 \\
17.5 & 20.0 \\
20.0 & 22.5\end{array}$ & $\begin{array}{r}11.6 \\
8.8 \\
5.5 \\
7.4 \\
6.5 \\
7.9 \\
7.8 \\
4.4\end{array}$ & $\begin{array}{l}5.8 \\
7.6 \\
6.3 \\
7.7 \\
7.4 \\
3.8\end{array}$ & $\begin{array}{l}89.20 \\
71.02 \\
76.47 \\
59.21 \\
68.02 \\
78.26\end{array}$ & $\begin{array}{l}6.56 \\
6.23 \\
7.77 \\
3.40 \\
2.62 \\
4.58 \\
3.01 \\
5.15\end{array}$ & $\begin{array}{l}5.3 \\
7.3 \\
5.5 \\
2.4 \\
1.7 \\
3.5\end{array}$ & $\begin{array}{l}1.03 \\
0.88 \\
0.77 \\
0.89 \\
0.86 \\
0.92 \\
0.86\end{array}$ & $\begin{array}{l}0.05 \\
0.04 \\
0.04 \\
0.05 \\
0.05 \\
0.03\end{array}$ & $\begin{array}{l}1.13 \\
0.93 \\
0.81 \\
0.93 \\
0.91 \\
0.97 \\
0.89\end{array}$ & $\begin{array}{r}74 \\
\\
50 \\
110 \\
120 \\
230 \\
490 \\
170\end{array}$ & $\begin{array}{l}0.3 \\
0.6 \\
0.7 \\
1.4 \\
3.0 \\
1.1\end{array}$ & $\begin{array}{l}160.87 \\
156.25 \\
171.88 \\
169.01 \\
164.29 \\
163.33 \\
154.55\end{array}$ & $\begin{array}{r}910 \\
150 \\
330 \\
830 \\
1400 \\
3600 \\
2600\end{array}$ \\
\hline
\end{tabular}


Appendix G.3.2.6 Results of laboratory tests for cuttings samples from Ue5PW-2C.

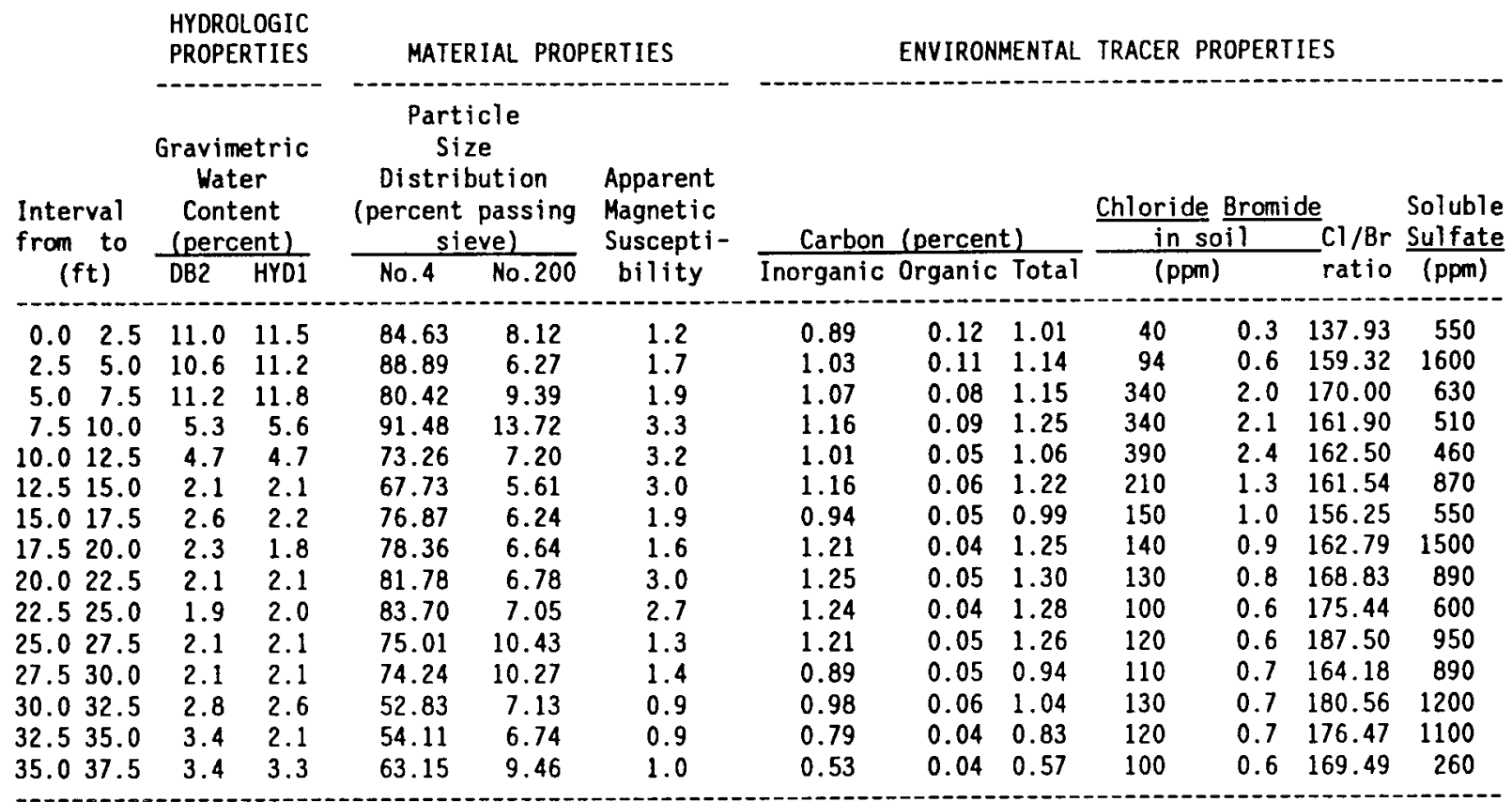




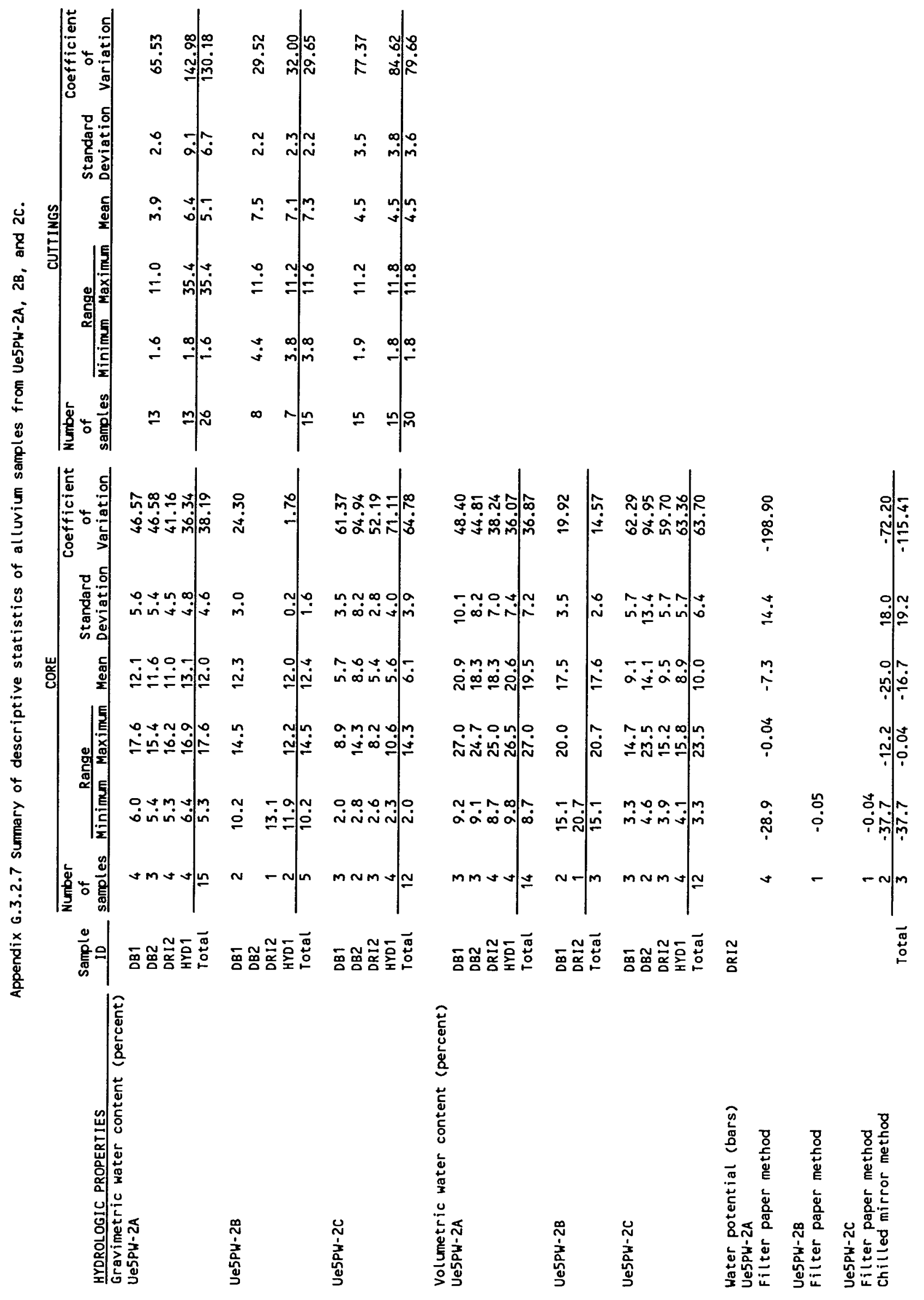




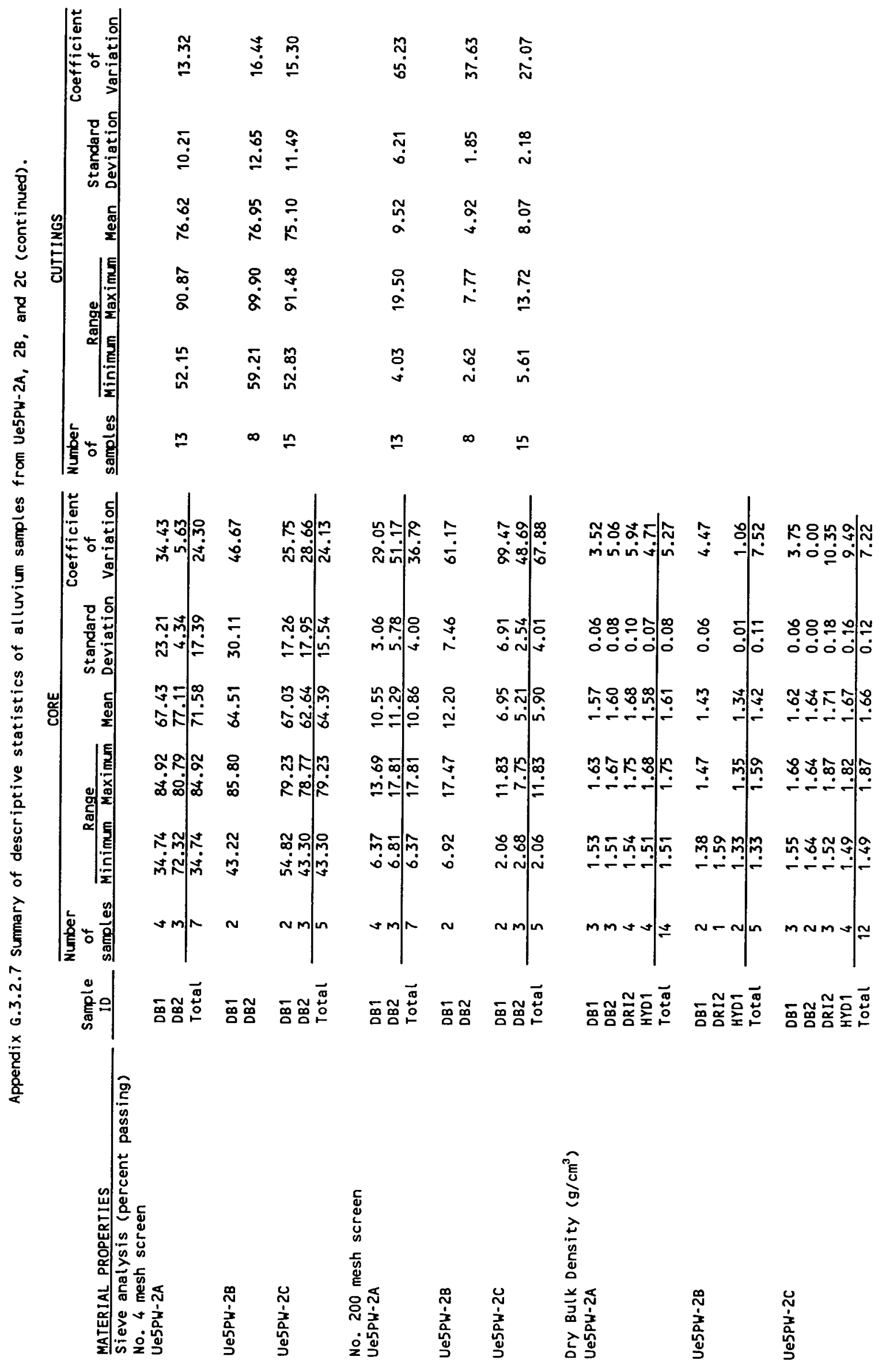




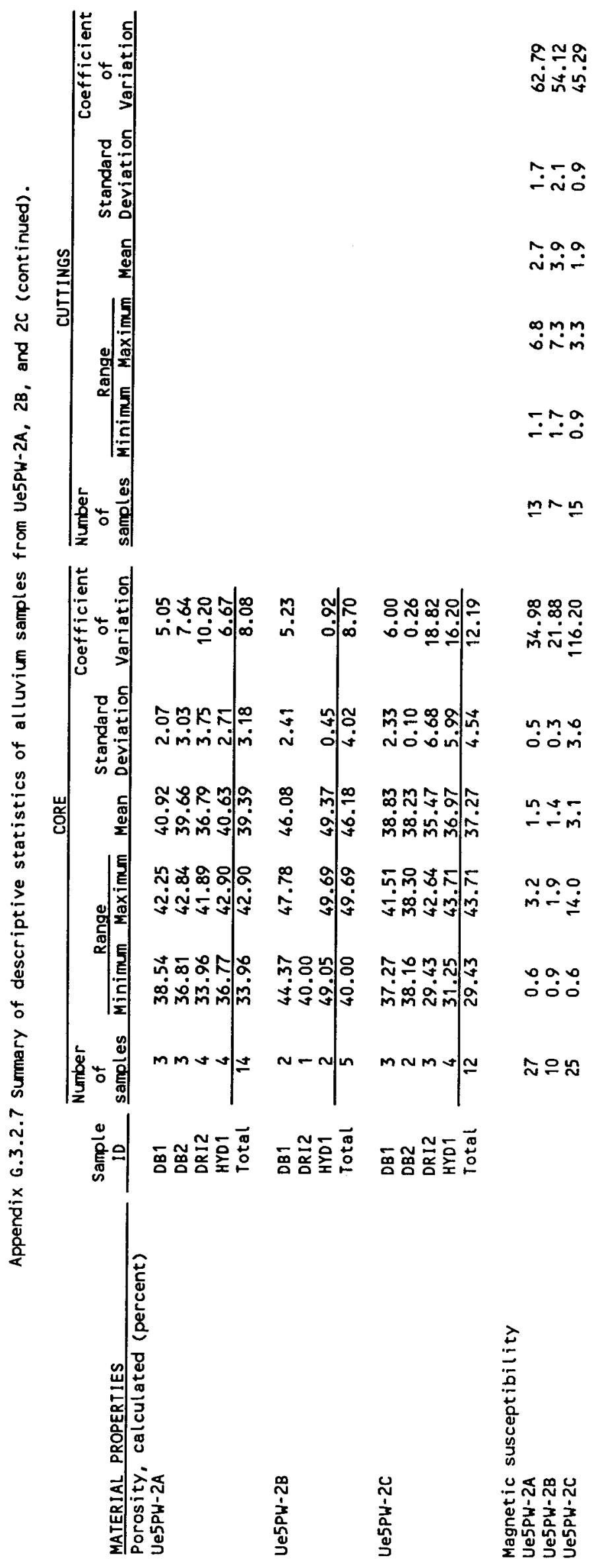




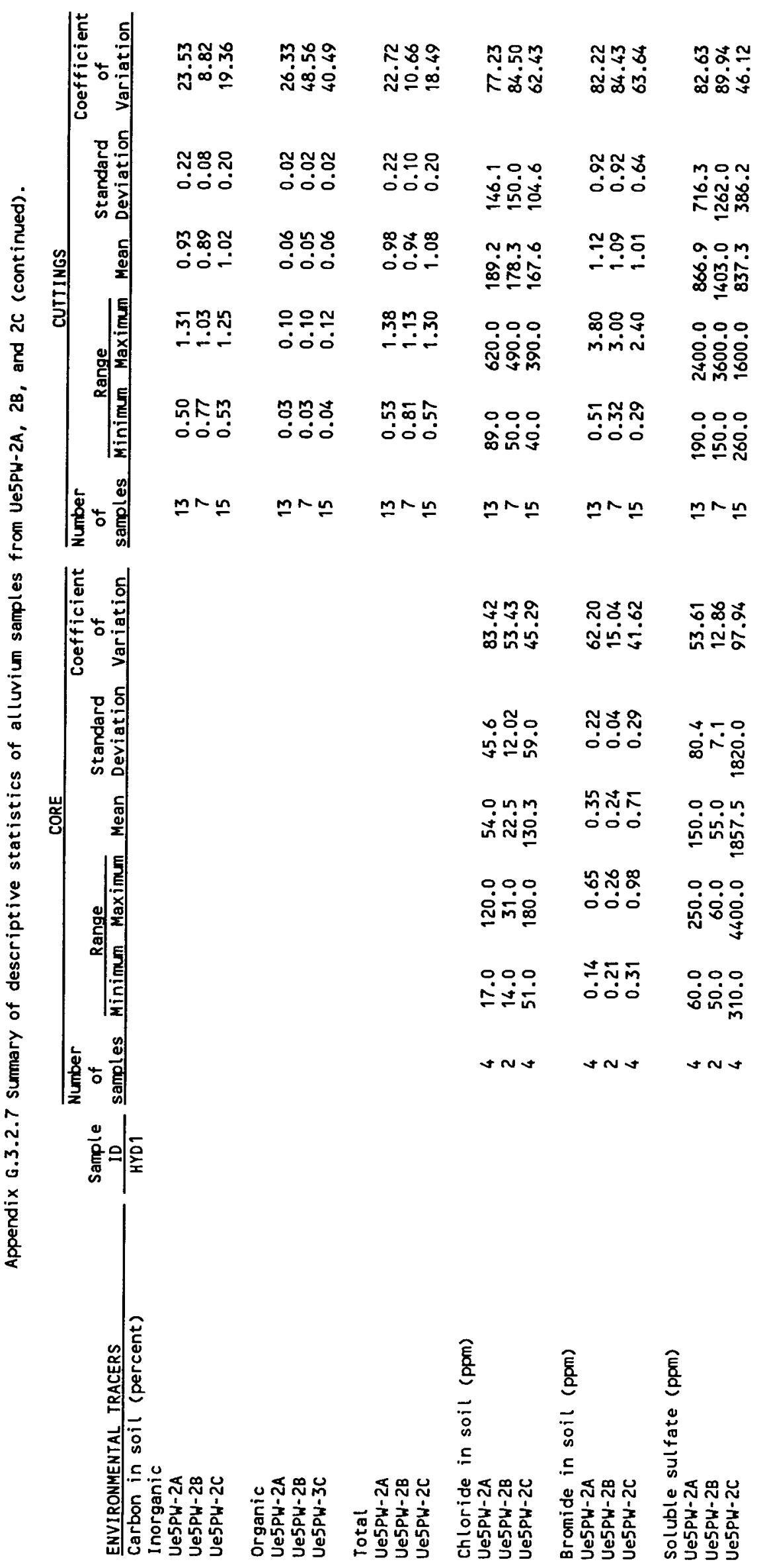


Appendix G.4.1 Site Preparation Information

\begin{tabular}{|c|l|}
\hline $\begin{array}{c}\text { DATE } \\
1992\end{array}$ & ACTIVITIES \\
\hline $7-13$ & $\begin{array}{l}\text { Calibration trench excavated } 8-12^{\prime \prime} \text { deep } \times 10^{\prime} \text { wide } \times 66^{\prime} \text { long. Filled } \\
\mathbf{w} / \sim 4500 \text { gal. water. }\end{array}$ \\
\hline $7-14$ & $\begin{array}{l}\text { Calibration trench excavated } \mathrm{B}^{\prime} 12^{\prime \prime} \text { deep } \times 16^{\prime} \text { wide } \times 66^{\prime} \text { long. Filled } \\
\mathrm{w} / \sim 4500 \text { gal. water. }\end{array}$ \\
\hline $7-15$ & Trench filled $w / \approx 3000$ gal. water. \\
\hline $7-16$ & Trench filled $w / \sim 3000$ gal. water. Trench covered w/plastic. \\
\hline
\end{tabular}


Appendix G.4.2.1 Neutron moisture-meter data for Ue5PW-2A.

Depth

(ft) $07 / 20 / 92 \quad 07 / 22 / 92 \quad 07 / 23 / 92 \quad 07 / 30 / 92 \quad 08 / 04 / 92 \quad 08 / 12 / 92 \quad 08 / 27 / 92 \quad 10 / 21 / 92 \quad 12 / 01 / 92$

\begin{tabular}{|c|c|c|c|c|c|c|c|c|c|}
\hline $\begin{array}{r}0.5 \\
1.5 \\
2.5 \\
3.5 \\
4.5 \\
5.5 \\
6.5 \\
7.5 \\
8.5 \\
9.5 \\
10.5 \\
11.5 \\
12.5 \\
13.5 \\
14.5 \\
15.5 \\
16.5 \\
17.5 \\
18.5 \\
19.5 \\
20.5 \\
21.5 \\
22.5 \\
23.5 \\
24.5 \\
25.5 \\
26.5 \\
27.5 \\
28.5 \\
29.5 \\
30.5 \\
31.5 \\
32.5 \\
33.5 \\
34.5 \\
35.5 \\
36.5 \\
37.5 \\
38.5 \\
39.5\end{array}$ & $\begin{array}{l}2148 \\
2010 \\
2000 \\
2091 \\
2195 \\
2085 \\
2155 \\
2110 \\
1892 \\
1847 \\
1613 \\
1435 \\
1351 \\
1274 \\
1251 \\
1239 \\
1198 \\
1231 \\
1403 \\
1380 \\
1367 \\
1375 \\
1283 \\
1304 \\
1277 \\
1326 \\
1539 \\
1539 \\
1542 \\
1547 \\
1544 \\
1561 \\
1639 \\
1539 \\
1408 \\
1422 \\
1322 \\
1365 \\
1431\end{array}$ & $\begin{array}{l}1489 \\
1981 \\
1849 \\
2075 \\
2044 \\
1993 \\
2125 \\
1907 \\
1768 \\
1742 \\
1635 \\
1471 \\
1506 \\
1512 \\
1238 \\
1264 \\
1204 \\
1273 \\
1270 \\
1347 \\
1333 \\
1386 \\
1331 \\
1276 \\
1220 \\
1247 \\
1429 \\
1497 \\
1527 \\
1516 \\
1558 \\
1641 \\
1659 \\
1497 \\
1446 \\
1383 \\
1302 \\
1327 \\
1374 \\
2165\end{array}$ & $\begin{array}{l}2213 \\
2033 \\
2070 \\
2197 \\
2239 \\
2064 \\
2107 \\
2000 \\
1797 \\
1784 \\
1562 \\
1489 \\
1590 \\
1636 \\
1276 \\
1262 \\
1243 \\
1310 \\
1271 \\
1336 \\
1453 \\
1420 \\
1299 \\
1285 \\
1252 \\
1390 \\
1485 \\
1454 \\
1542 \\
1597 \\
1609 \\
1651 \\
1566 \\
1506 \\
1465 \\
1476 \\
1309 \\
1353 \\
1410 \\
2220\end{array}$ & $\begin{array}{l}1411 \\
2001 \\
1942 \\
2113 \\
2182 \\
2139 \\
2195 \\
1987 \\
1960 \\
1798 \\
1592 \\
1528 \\
1552 \\
1793 \\
1733 \\
1324 \\
1274 \\
1281 \\
1340 \\
1360 \\
1355 \\
1411 \\
1363 \\
1303 \\
1268 \\
1275 \\
1409 \\
1469 \\
1410 \\
1627 \\
1558 \\
1637 \\
1646 \\
1517 \\
1491 \\
1462 \\
1320 \\
1333 \\
1445 \\
2099\end{array}$ & $\begin{array}{l}1509 \\
1948 \\
1983 \\
1991 \\
1968 \\
2047 \\
2130 \\
2135 \\
1871 \\
1861 \\
1589 \\
1461 \\
1559 \\
1915 \\
1891 \\
1406 \\
1278 \\
1280 \\
1291 \\
1303 \\
1377 \\
1448 \\
1357 \\
1291 \\
1267 \\
1277 \\
1398 \\
1544 \\
1438 \\
1517 \\
1500 \\
1629 \\
1598 \\
1585 \\
1448 \\
1479 \\
1342 \\
1318 \\
1383 \\
1996\end{array}$ & $\begin{array}{l}1337 \\
1983 \\
1913 \\
2008 \\
2046 \\
2106 \\
2200 \\
2005 \\
1898 \\
1816 \\
1600 \\
1433 \\
1598 \\
1929 \\
1957 \\
1627 \\
1299 \\
1243 \\
1372 \\
1296 \\
1340 \\
1467 \\
1367 \\
1325 \\
1272 \\
1240 \\
1363 \\
1481 \\
1522 \\
1582 \\
1590 \\
1739 \\
1704 \\
1539 \\
1456 \\
1433 \\
1415 \\
1341 \\
1402 \\
2112\end{array}$ & $\begin{array}{l}1731 \\
1895 \\
1937 \\
1938 \\
2042 \\
2039 \\
2119 \\
2030 \\
1773 \\
1781 \\
1503 \\
1395 \\
1607 \\
1960 \\
1938 \\
1687 \\
1262 \\
1357 \\
1289 \\
1337 \\
1397 \\
1416 \\
1268 \\
1337 \\
1251 \\
1356 \\
1493 \\
1489 \\
1515 \\
1585 \\
1577 \\
1670 \\
1635 \\
1543 \\
1474 \\
1519 \\
1235 \\
1318 \\
1449 \\
2170\end{array}$ & $\begin{array}{l}1534 \\
1708 \\
1692 \\
1869 \\
1982 \\
2056 \\
2017 \\
1967 \\
1725 \\
1715 \\
1439 \\
1429 \\
1500 \\
1802 \\
1785 \\
1724 \\
1519 \\
1373 \\
1353 \\
1387 \\
1397 \\
1442 \\
1317 \\
1283 \\
1317 \\
1269 \\
1518 \\
1543 \\
1488 \\
1581 \\
1595 \\
1557 \\
1620 \\
1565 \\
1534 \\
1443 \\
1301 \\
1323 \\
1436\end{array}$ & $\begin{array}{l}1393 \\
1657 \\
1732 \\
1866 \\
1923 \\
1962 \\
2041 \\
1806 \\
1721 \\
1705 \\
1409 \\
1319 \\
1478 \\
1800 \\
1717 \\
1727 \\
1601 \\
1427 \\
1418 \\
1349 \\
1401 \\
1496 \\
1358 \\
1304 \\
1290 \\
1292 \\
1427 \\
1491 \\
1567 \\
1558 \\
1589 \\
1666 \\
1585 \\
1560 \\
1436 \\
1359 \\
1306 \\
1366\end{array}$ \\
\hline
\end{tabular}


Appendix G.4.2.2 Neutron moisture-meter data for Ue5PW-2B.

\begin{tabular}{|c|c|c|c|c|c|c|c|}
\hline $\begin{array}{l}\text { Depth } \\
\text { (ft) }\end{array}$ & $07 / 22 / 92$ & $07 / 30 / 92$ & $08 / 04 / 92$ & $08 / 12 / 92$ & $08 / 27 / 92$ & $10 / 21 / 92$ & $12 / 01 / 92$ \\
\hline $\begin{array}{r}0.5 \\
1.5 \\
2.5 \\
3.5 \\
4.5 \\
5.5 \\
6.5 \\
7.5 \\
8.5 \\
9.5 \\
10.5 \\
11.5 \\
12.5\end{array}$ & $\begin{array}{l}2167 \\
2428 \\
2283 \\
2248 \\
2319 \\
2274 \\
2299 \\
2063 \\
2147 \\
2440 \\
2344 \\
2342\end{array}$ & $\begin{array}{r}399 \\
1994 \\
2362 \\
2225 \\
2355 \\
2334 \\
2311 \\
2321 \\
2194 \\
2228 \\
2388 \\
2194 \\
2225\end{array}$ & $\begin{array}{r}440 \\
2122 \\
2249 \\
2215 \\
2165 \\
2382 \\
2353 \\
2326 \\
2186 \\
2213 \\
2364 \\
2232 \\
2233\end{array}$ & $\begin{array}{r}300 \\
1986 \\
2309 \\
2195 \\
2320 \\
2363 \\
2390 \\
2317 \\
2233 \\
2195 \\
2445 \\
2187 \\
2228\end{array}$ & $\begin{array}{r}803 \\
2197 \\
2307 \\
2236 \\
2268 \\
2354 \\
2266 \\
2164 \\
2083 \\
2229 \\
2310 \\
2295 \\
2335\end{array}$ & $\begin{array}{r}653 \\
2060 \\
2165 \\
2172 \\
2192 \\
2251 \\
2254 \\
2159 \\
1872 \\
2138 \\
2333 \\
2123 \\
2202\end{array}$ & $\begin{array}{r}638 \\
2101 \\
2193 \\
2128 \\
2133 \\
2266 \\
2295 \\
2201 \\
2039 \\
2098 \\
2258 \\
2122 \\
2211\end{array}$ \\
\hline
\end{tabular}


Appendix G.4.2.3 Neutron moisture-meter data for Ue5PW-2C.

Depth

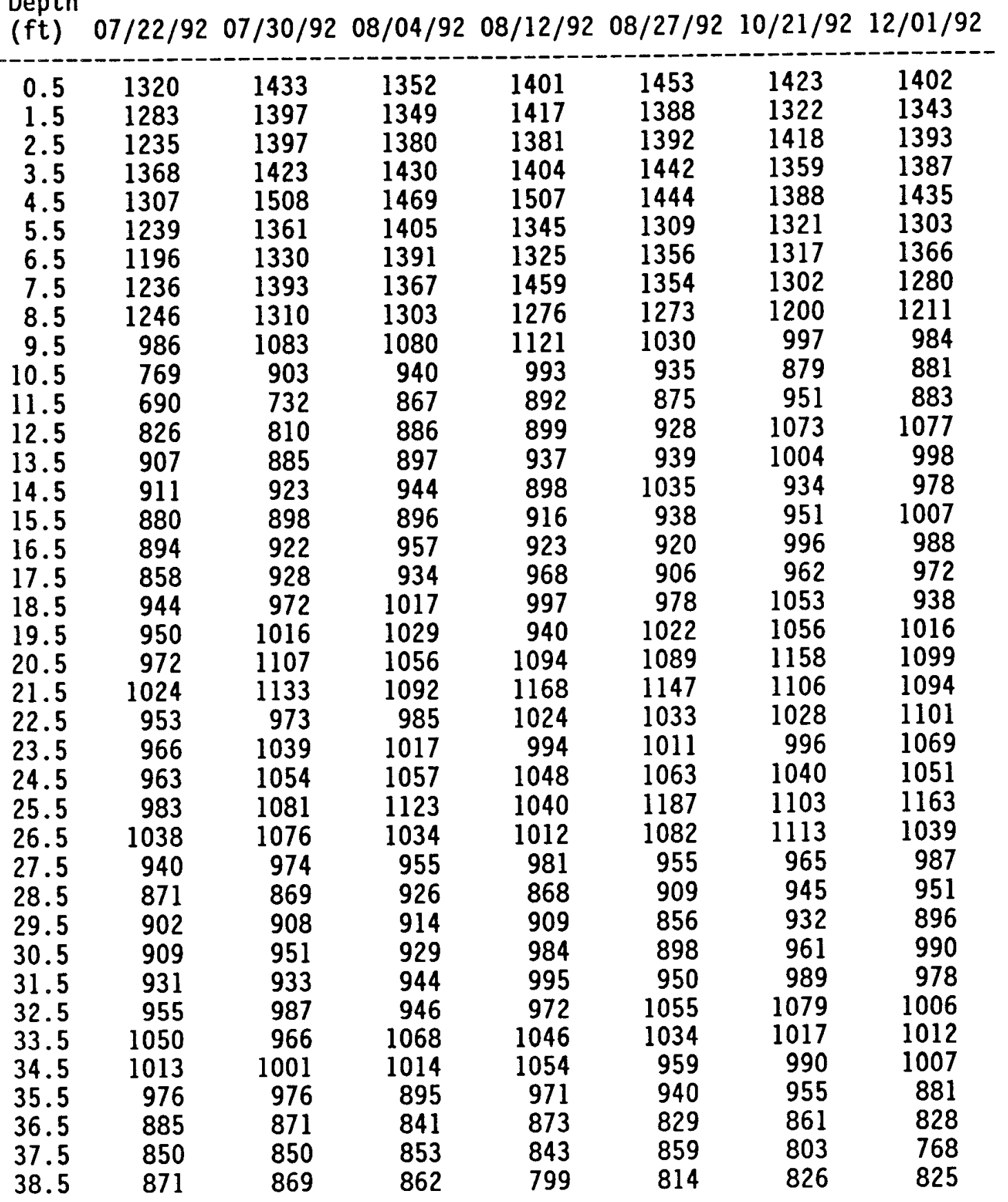


Appendix G.4.3 Calibration of the neutron-moisture meter in the calibration boreholes.

UE5PW-2A ODEX 8-5/8 in O.D. A calibration cannot be made due to the following: Core was taken at the top of the borehole (wet); core from the middle (dry) was significantly disturbed providing no samples; although core was taken at the bottom of the borehole, the casing was not advanced through the cored interval and thus can not be logged.

UE5PW-2B ODEX 7-5/8 in O.D. A calibration cannot be made due to the following: Core was take at the top of the borehole (wet); due to drilling problems the hole was abandoned at $22.5 \mathrm{ft}$ and no other core samples were taken.

UE5PW-2C ODEX 10-3/4 in O.D. A calibration can be made for this borehole. Data were used from core samples from the top (wet) and middle (dry) of the borehole. Although core was taken at the bottom of the borehole, the casing was not advanced through the cored interval and thus can not be logged.

The calibration equation is:

Volumetric water content $=$ Counts $\times 4.4 \times 10^{-2}+37.9$

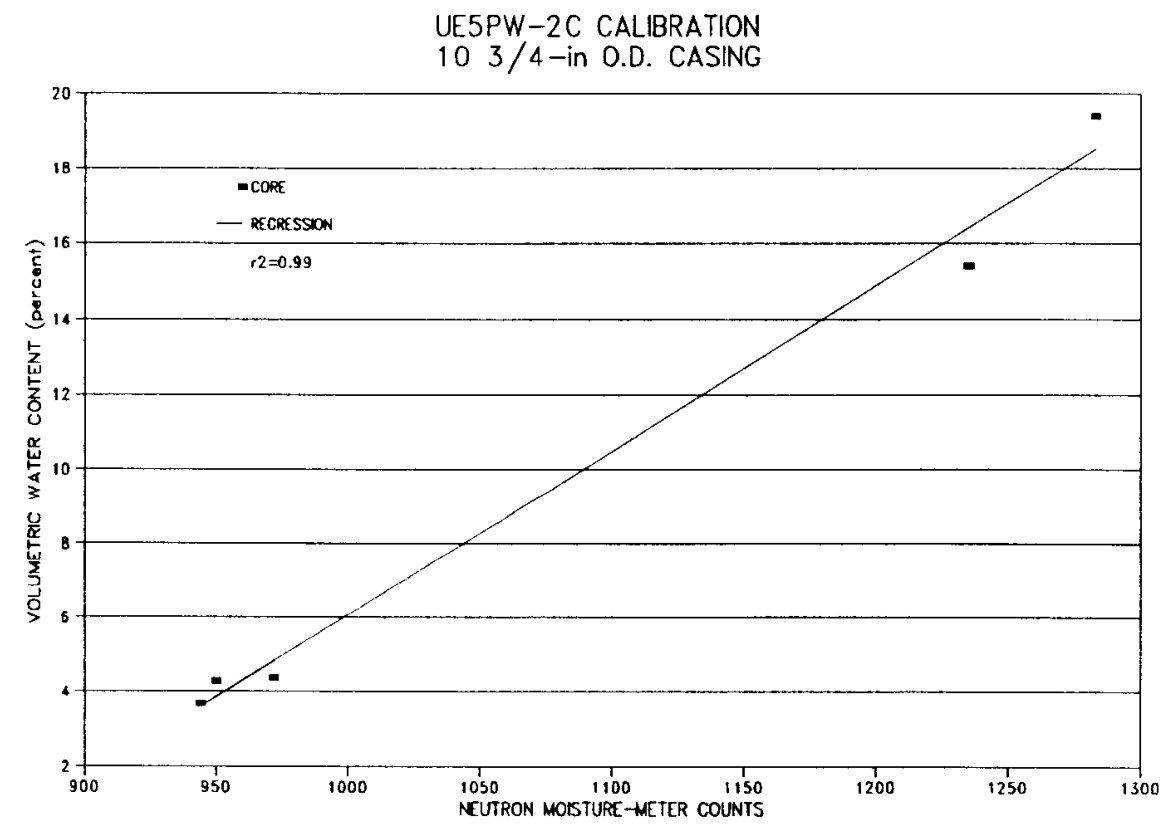




\title{
Area 5 Pilot Wells
}

\author{
APPENDIX H \\ Upper Aquifer Water Quality Data
}

H.1 RCRA Groundwater Sampling and Analysis Methods and Results H.2 Preliminary General Water Chemistry 
Appendix H.1 RCRA Groundwater Sampling and Analysis Methods and Results

\section{Sample Collection and Preservation Methods}

Groundwater samples were preserved in the field and containerized as described Table 1. The samples were collected in the same order as they appear in this table. Sample containers were precleaned and rinsed with sample before use. Samples designated for dissolved metal analyses were filter with a $0.45 \mu \mathrm{m}$ in-line teflon filter.

Each sample was collected in duplicate except for the contamination indicating parameters. These parameters were sampled in quadruplicate. A field blank was prepared for each sample by filling a precleaned container in the field and preserving it as a sample. An equipment or rinsate blank was prepared by passing distilled water through a precleaned sampling pump and preserving.

At the time of sample collection a chain of custody form was completed and custody seals were attached to each sample container. Chain of custody was maintained throughout sample transport, processing and analysis. The samples were promptly transported in coolers to REECo laboratories.

\section{Groundwater Analytical Results}

The results from the initial sampling of Ue5PW-1 are presented in Appendix H.1. Total organic carbon, TOX, specific conductance and $\mathrm{pH}$ were measured in quadruplicate as indicators of contamination. The mean $\mathrm{pH}$ was found to be 8.13 and the mean specific conductance was $0.389 \mathrm{mmhos} / \mathrm{cm}$. TOC was less than the detection limit of $1 \mathrm{mg} / 1$. TOX was detected in a single sample at the detection limit of $10 \mu \mathrm{g} / 1$.

Total and dissolved $\mathrm{As}, \mathrm{Ba}, \mathrm{Cd}, \mathrm{Cr}, \mathrm{Pb}, \mathrm{Se}, \mathrm{Ag}$ and $\mathrm{Hg}$ were measured to assess the suitability of groundwater as drinking water. Arsenic, $\mathrm{Cd}, \mathrm{Se}, \mathrm{Hg}$ and $\mathrm{Ag}$ were not detected in the dissolved or total fraction. In each case the detection limit was less than the State of Nevada primary standard for drinking water (Nevada Administrative Code, Chapter 445, 1980). Chromium was not detected but the detection limit was slightly greater than the primary standard. Total and dissolved $\mathrm{Ba}$ was found to be present at mean concentrations of $0.026 \mathrm{mg} / \mathrm{l}$ and $0.023 \mathrm{mg} / \mathrm{l}$, which are significantly less than the drinking water primary standard of $1 \mathrm{mg} / \mathrm{l}$. Dissolved $\mathrm{Pb}$ was detected in a single sample. The concentration of $0.009 \mathrm{mg} / \mathrm{l}$ was less than the primary standard of $0.05 \mathrm{mg} / 1$ and was less than the $0.002 \mathrm{mg} / 1$ found in the duplicate sample. Total $\mathrm{Pb}$ was also less than the detection limit in all cases. Since total $\mathrm{Pb}$ and the duplicate for dissolved $\mathrm{Pb}$ were all less than the detection limit, the $0.009 \mathrm{mg} / 1$ concentration is believed to be anomalous.

Total and dissolved $\mathrm{Fe}, \mathrm{Mn}$ and $\mathrm{Na}$ were measured to establish groundwater quality. As expected for an oxygenated groundwater, iron was found to be detectable in the total fraction 
Appendix H.1 RCRA groundwater sampling and analysis methods and results (Continued)

only. Manganese was present in the total and dissolved fractions at mean concentrations of $0.19 \mathrm{mg} / 1$ and $0.18 \mathrm{mg} / 1$, respectively. The manganese concentrations exceed the State of Nevada secondary standard for drinking water of $0.05 \mathrm{mg} / \mathrm{l}$.

Pesticides, herbicides, fluoride, and nitrate were measured to determine the suitability of groundwater as drinking water. Fluoride and nitrate were both found to be present at concentrations less than the drinking water primary standard. The pesticides endrin, methoxychlor and toxaphene were not detected. In each case the detection limit was less than the primary standard. Lindane was detected in both the sample and the field duplicate at approximately $5 \%$ of the drinking water primary standard concentration. Lindane was not detected in the field blank and the equipment blank. The herbicides 2,4-D and 2,4,5-TP Silvex were not detected. The detection limits were less than the primary standard limit.

Chloride and sulfate were measured to establish groundwater quality.

Chloride and sulfate were both found to be present at concentrations significantly less than the drinking water secondary standard.

Total dissolved solids, cyanide, and oil and grease were measured to characterize background for these parameters. The mean value for total dissolved solids was $272 \mathrm{mg} / 1$. Cyanide and oil and grease were not detected.

Radiological parameters were measured to determine the suitability of groundwater as drinking water and to comply with the requirements of DOE Order 5820.2A. The mean total and dissolved gross alpha activity concentration was $7.3 \mathrm{pCi} / 1$ and $5.4 \mathrm{pCi} / 1$, respectively. The EPA (1985) has reported a mean gross alpha activity concentration for Nevada drinking water of $3.6 \mathrm{pCi} / 1$. The Ue5PW-1 values do not exceed the $15 \mathrm{pCi} / 1$ gross alpha drinking water limit, but does exceed the $5 \mathrm{pCi} / 1$ limit that requires ${ }^{226} \mathrm{Ra}$ and ${ }^{228} \mathrm{Ra}$ analysis. ${ }^{226} \mathrm{Radium}$ and ${ }^{228} \mathrm{Ra}$ were both found to be less than the respective detection limits of $0.8 \mathrm{pCi} / 1$ and $0.6 \mathrm{pCi} / 1$.

Total uranium was found at a mean concentration of $5 \mu \mathrm{g} / 1$. Assuming a natural isotopic abundance of uranium, the uranium concentration expressed as an activity concentration would be $3.4 \mathrm{pCi} / 1$ as total uranium. Although gross alpha activity concentrations can not be equated to the activity concentration of specific radionuclides, it appears that most of the gross alpha activity can be attributed to uranium.

The mean total and dissolved gross beta activity concentrations were $6.2 \mathrm{pCi} / 1$ and $4.6 \mathrm{pCi} / 1$, respectively. The EPA (1985) has reported a mean gross beta value for Nevada drinking water of $4.9 \mathrm{pCi} / 1$.

Tritium samples were enriched by alkaline electrolysis and found to be less than the detection limit of $15 \mathrm{pCi} / 1$. Tritium is the most mobile radionuclide in Area 5 and occurs in significant quantities in the RWMS and in underground test debris. The observation that tritium is not present strongly suggests that no other contaminating radionuclides are present 
Appendix H.1 RCRA groundwater sampling and analysis methods and results (Continued)

in the groundwater. ${ }^{90}$ Strontium, ${ }^{99} \mathrm{Tc},{ }^{131} \mathrm{I},{ }^{238} \mathrm{Pu}$ and ${ }^{239,240} \mathrm{Pu}$ were all found to be either less than the detection limit or to have uncertainties greater than $100 \%$. The only photon emitting radionuclides detected were ${ }^{214} \mathrm{~Pb}$ and ${ }^{214} \mathrm{Bi}$. These radionuclides are progeny of the naturally occurring radionuclide ${ }^{222} \mathrm{Rn}$. The EPA (1985) found that the average ${ }^{222} \mathrm{Rn}$ activity concentration in Nevada drinking water was $448 \mathrm{pCi} / 1$. The concentrations of ${ }^{214} \mathrm{~Pb}$ and ${ }^{214} \mathrm{Bi}$ are close to this value.

Volatile and semi-volatile organic compounds were measured to obtain a background characterization for these parameters. No volatile or semi-volatile target compounds were detected. 
Appendix H.1 RCRA groundwater sampling and analysis methods and results (Continued)

Table 1 Groundwater Sample Containers and Preservation.

\begin{tabular}{|c|c|c|c|c|}
\hline Parameter & $\begin{array}{c}\text { Number } \\
\text { per } \\
\text { Sample } \\
\end{array}$ & Volume & Container & Preservation \\
\hline $\begin{array}{l}\text { Volatile Organics } \\
(8240)\end{array}$ & 2 & $40 \mathrm{ml}$ & $\begin{array}{l}\text { Amber glass vial } \\
\text { with teflon lined } \\
\text { silicone septum } \\
\end{array}$ & $\begin{array}{l}\text { Add } 4 \text { drops conc. } \\
\mathrm{HCl} \text {, Cool to } 4^{\circ} \mathrm{C}\end{array}$ \\
\hline $\begin{array}{l}\text { Total Organic } \\
\text { Halogen }(9020)\end{array}$ & 4 & $500 \mathrm{ml}$ & $\begin{array}{l}\text { Amber glass bottle } \\
\text { with teflon lined } \\
\text { cap }\end{array}$ & $\begin{array}{l}\text { Acidify to } \mathrm{pH}<2 \\
\text { with conc. } \mathrm{H}_{2} \mathrm{SO}_{4} \text {, } \\
\text { Cool to } 4^{\circ} \mathrm{C}\end{array}$ \\
\hline $\begin{array}{l}\text { Total Organic } \\
\text { Carbon }(9060)\end{array}$ & 4 & $250 \mathrm{ml}$ & $\begin{array}{l}\text { Amber glass bottle } \\
\text { with teflon lined } \\
\text { cap }\end{array}$ & $\begin{array}{l}\text { Acidify to } \mathrm{pH}<2 \\
\text { with conc. } \mathrm{HCl}, \mathrm{Cool} \\
\text { to } 4^{\circ} \mathrm{C}\end{array}$ \\
\hline $\begin{array}{l}\text { Oil and Grease } \\
(413.2)\end{array}$ & 2 & 1 liter & Glass Bottle & $\begin{array}{l}\text { Acidify to } \mathrm{pH}<2 \\
\text { with } 10 \mathrm{ml} \text { of conc. } \\
\mathrm{HCl}, \mathrm{Cool} \text { to } 4^{\circ} \mathrm{C}\end{array}$ \\
\hline Pesticides (8080) & 1 & 1 gal. & $\begin{array}{l}\text { Amber glass bottle } \\
\text { with teflon lined } \\
\text { cap }\end{array}$ & $\begin{array}{l}\text { Cool to } 4{ }^{\circ} \mathrm{C} \text {, Adjust } \\
\text { pH between } 6 \text { and } 8 \\
\text { with } \mathrm{NaOH} \text { or } \mathrm{H}_{2} \mathrm{SO}_{4}\end{array}$ \\
\hline Herbicides (8150) & 1 & 1 gal. & $\begin{array}{l}\text { Amber glass bottle } \\
\text { with teflon lined } \\
\text { cap }\end{array}$ & $\begin{array}{l}\text { Cool to } 4^{\circ} \mathrm{C} \text {, Adjust } \\
\text { pH between } 6 \text { and } 8 \\
\text { with } \mathrm{NaOH} \text { or } \mathrm{H}_{2} \mathrm{SO}_{4}\end{array}$ \\
\hline $\begin{array}{l}\text { Semivolatile } \\
\text { Organics (8270) }\end{array}$ & 1 & 1 gal. & $\begin{array}{l}\text { Amber glass bottle } \\
\text { with teflon lined } \\
\text { cap }\end{array}$ & Cool to $4^{\circ} \mathrm{C}$ \\
\hline $\begin{array}{l}\text { Total Metals } \\
(6010) \mathrm{As}, \mathrm{Ba}, \\
\mathrm{Cd}, \mathrm{Cr}, \mathrm{Fe}, \mathrm{Hg} \text {, } \\
\mathrm{Mn}, \mathrm{Na}, \mathrm{Pb}, \mathrm{Se}\end{array}$ & 1 & 1 liter & $\begin{array}{l}\text { Polyethylene } \\
\text { bottle }\end{array}$ & $\begin{array}{l}\text { Acidify } \mathrm{pH}<2 \text { with } \\
\text { conc. } \mathrm{HNO}_{3}\end{array}$ \\
\hline Total silver $(6010)$ & 1 & $500 \mathrm{ml}$ & $\begin{array}{l}\text { Amber glass bottle } \\
\text { with teflon cap }\end{array}$ & $\begin{array}{l}\text { Acidify } \mathrm{pH}<2 \text { with } \\
\text { conc. } \mathrm{HNO}_{3}\end{array}$ \\
\hline Cyanide (335.2) & 1 & 1 liter & Polyethylene & $\begin{array}{l}\text { Add } 10 \mathrm{M} \mathrm{NaOH} \text { to } \\
\mathrm{pH}>12, \mathrm{Cool} \text { to } \\
4^{\circ} \mathrm{C}\end{array}$ \\
\hline $\begin{array}{l}\text { Chloride, Sulfate, } \\
\text { Fluoride, Nitrate } \\
(300)\end{array}$ & 1 & $500 \mathrm{ml}$ & Polyethylene & Cool to $4^{\circ} \mathrm{C}$ \\
\hline
\end{tabular}


Appendix H.1 RCRA groundwater sampling and analysis methods and results (Continued)

\begin{tabular}{|c|c|c|c|c|}
\hline Parameter & $\begin{array}{l}\text { Number } \\
\text { per } \\
\text { Sample }\end{array}$ & Volume & Container & Preservation \\
\hline $\begin{array}{l}\text { Gross Alpha/Beta } \\
\text { Gamma } \\
\text { Spectroscopy }\end{array}$ & 1 & 1 gal. & Polyethylene & $\begin{array}{l}\text { Acidify to } \mathrm{pH}<2 \\
\text { with } \mathrm{HNO}_{3}, \mathrm{Cool} \text { to } \\
4^{\circ} \mathrm{C}\end{array}$ \\
\hline${ }^{90}$ Strontium & 1 & 1 liter & Polyethylene & $\begin{array}{l}\text { Acidify to } \mathrm{pH}<2 \\
\text { with } \mathrm{HNO}_{3}, \text { Cool to } \\
4^{\circ} \mathrm{C}\end{array}$ \\
\hline${ }^{99}$ Technetium & 1 & 1 liter & Polyethylene & $\begin{array}{l}\text { Acidify to } \mathrm{pH}<2 \\
\text { with } \mathrm{HNO}_{3}, \mathrm{Cool} \text { to } \\
4^{\circ} \mathrm{C}\end{array}$ \\
\hline Total Uranium & 1 & 1 liter & Polyethylene & $\begin{array}{l}\text { Acidify to } \mathrm{pH}<2 \\
\text { with } \mathrm{HNO}_{3} \text {, Cool to } \\
4^{\circ} \mathrm{C}\end{array}$ \\
\hline${ }^{131}$ Iodine & 1 & 1 liter & Polyethylene & None \\
\hline Plutonium & 1 & 1 gal. & Polyethylene & $\begin{array}{l}\text { Acidify to } \mathrm{pH}<2 \\
\text { with } \mathrm{HNO}_{3}\end{array}$ \\
\hline Radium & 1 & 1 gal. & Polyethylene & $\begin{array}{l}\text { Acidify to } \mathrm{pH}<2 \\
\text { with } \mathrm{HNO}_{3}\end{array}$ \\
\hline $\begin{array}{l}\text { Dissolved Metals } \\
(6010) \mathrm{As}, \mathrm{Ba}, \\
\mathrm{Cd}, \mathrm{Cr}, \mathrm{Fe}, \mathrm{Hg}, \\
\mathrm{Mn}, \mathrm{Na}, \mathrm{Pb}, \mathrm{Se} \\
\end{array}$ & 1 & 1 liter & Polyethylene & $\begin{array}{l}\text { Acidify } \mathrm{pH}<2 \text { with } \\
\text { conc. } \mathrm{HNO}_{3}\end{array}$ \\
\hline $\begin{array}{l}\text { Dissolved Silver } \\
(6010)\end{array}$ & 1 & $500 \mathrm{mlo}$ & $\begin{array}{l}\text { Amber glass bottle } \\
\text { with teflon cap }\end{array}$ & $\begin{array}{l}\text { Acidify pH }<2 \text { with } \\
\text { conc. } \mathrm{HNO}_{3}\end{array}$ \\
\hline $\begin{array}{l}\text { Dissolved Gross } \\
\text { Alpha/Beta } \\
\text { Gamma } \\
\text { Spectroscopy } \\
\end{array}$ & 1 & $1 \mathrm{gal}$. & Polyethylene & $\begin{array}{l}\text { Acidify to } \mathrm{pH}<2 \\
\text { with } \mathrm{HNO}_{3}, \text { Cool to } \\
4^{\circ} \mathrm{C}\end{array}$ \\
\hline $\begin{array}{l}\text { Total Dissolved } \\
\text { Solids (160.1) } \\
\end{array}$ & 1 & $500 \mathrm{ml}$ & Polyethylene & Cool to $4^{\circ} \mathrm{C}$ \\
\hline Tritium & 1 & 1 liter & Glass Bottle & None \\
\hline
\end{tabular}


Appendix H.1 RCRA groundwater sampling and analysis methods and results (Continued)

\section{References}

DOE, 1988. Radioactive Waste Management, DOE Order 5820.2A.

EPA, 1982. Methods for Chemical Analysis of Water and Waste, EPA-600/4-82-005.

EPA, 1985. Nationwide Occurrence of Radon and Other Natural Radioactivity in Public Water Supplies, EPA 520/5-85-008.

EPA, 1986. Test Methods for Evaluating Solid Waste, Physical /Chemical Methods, SW-846.

McArther, R.D., F.L. Miller, 1989. Off-Site Radiation Review Project Phase II, Soils Program, Desert Research Institute, Univ. of Nevada.

State of Nevada, 1980. Public Water Systems, Nevada Administrative Code, Chapter 445. 


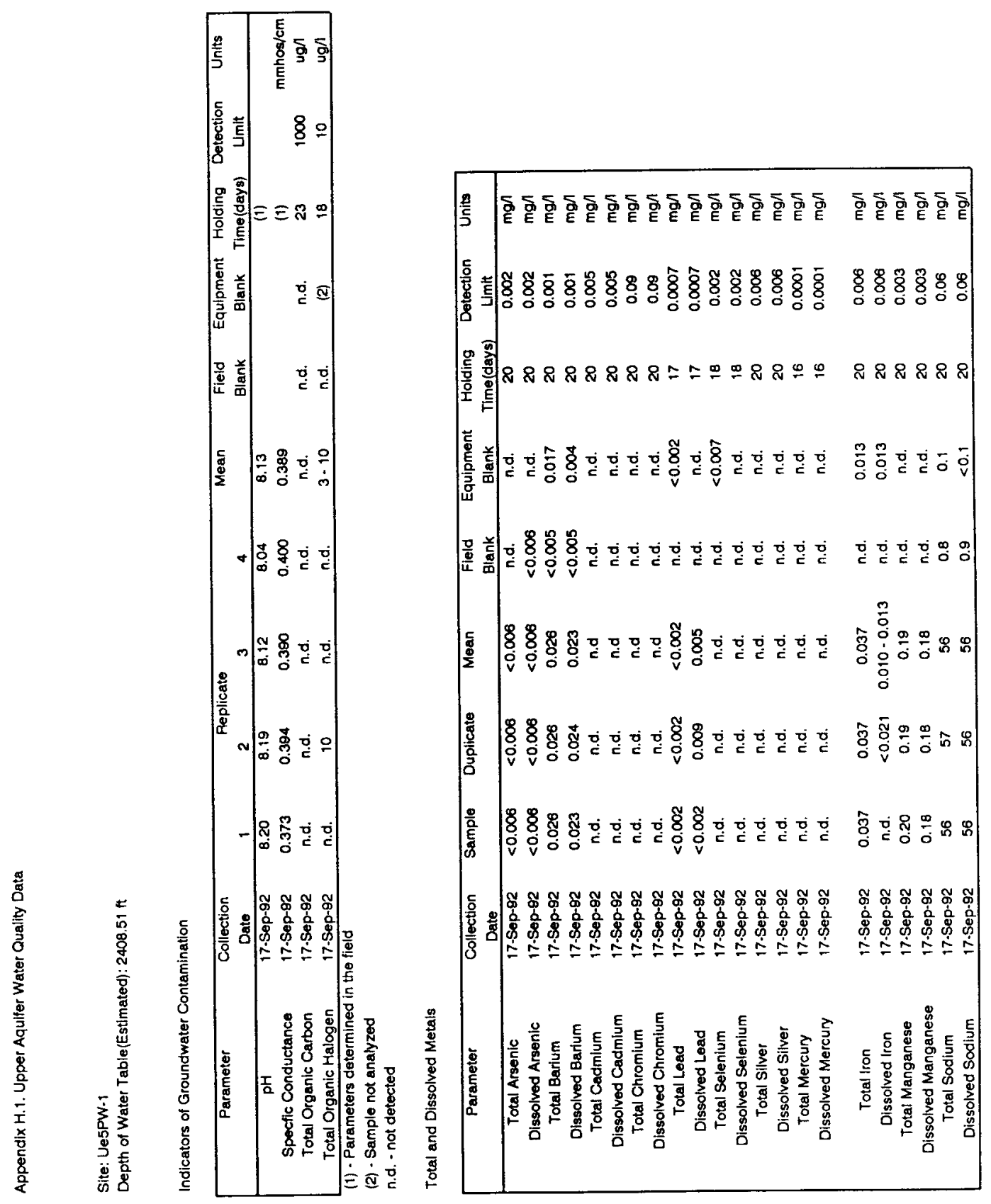




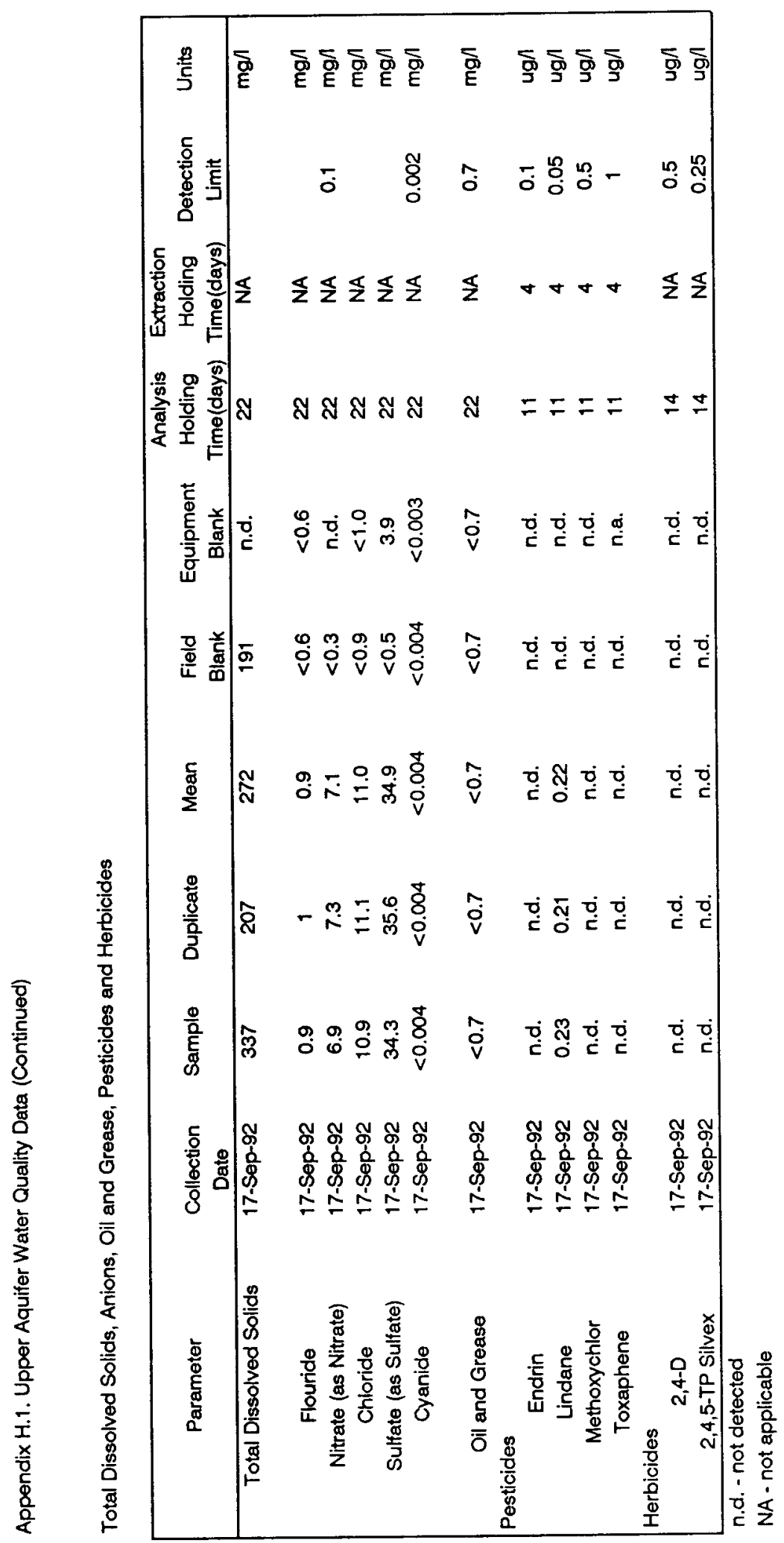




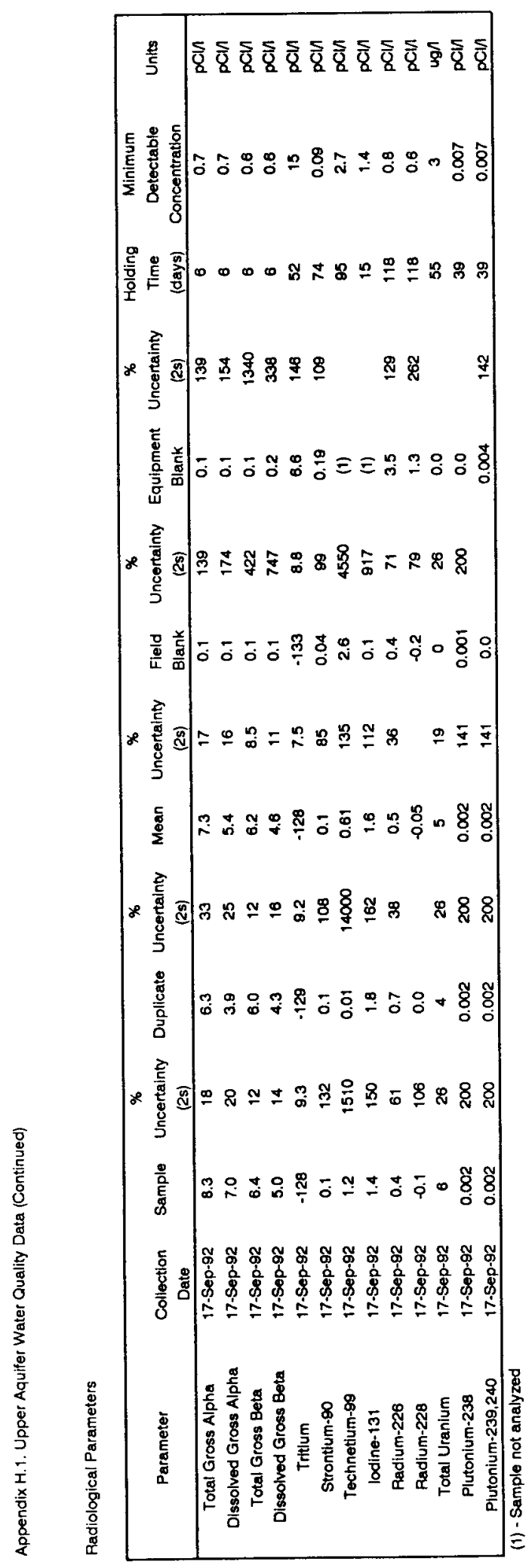




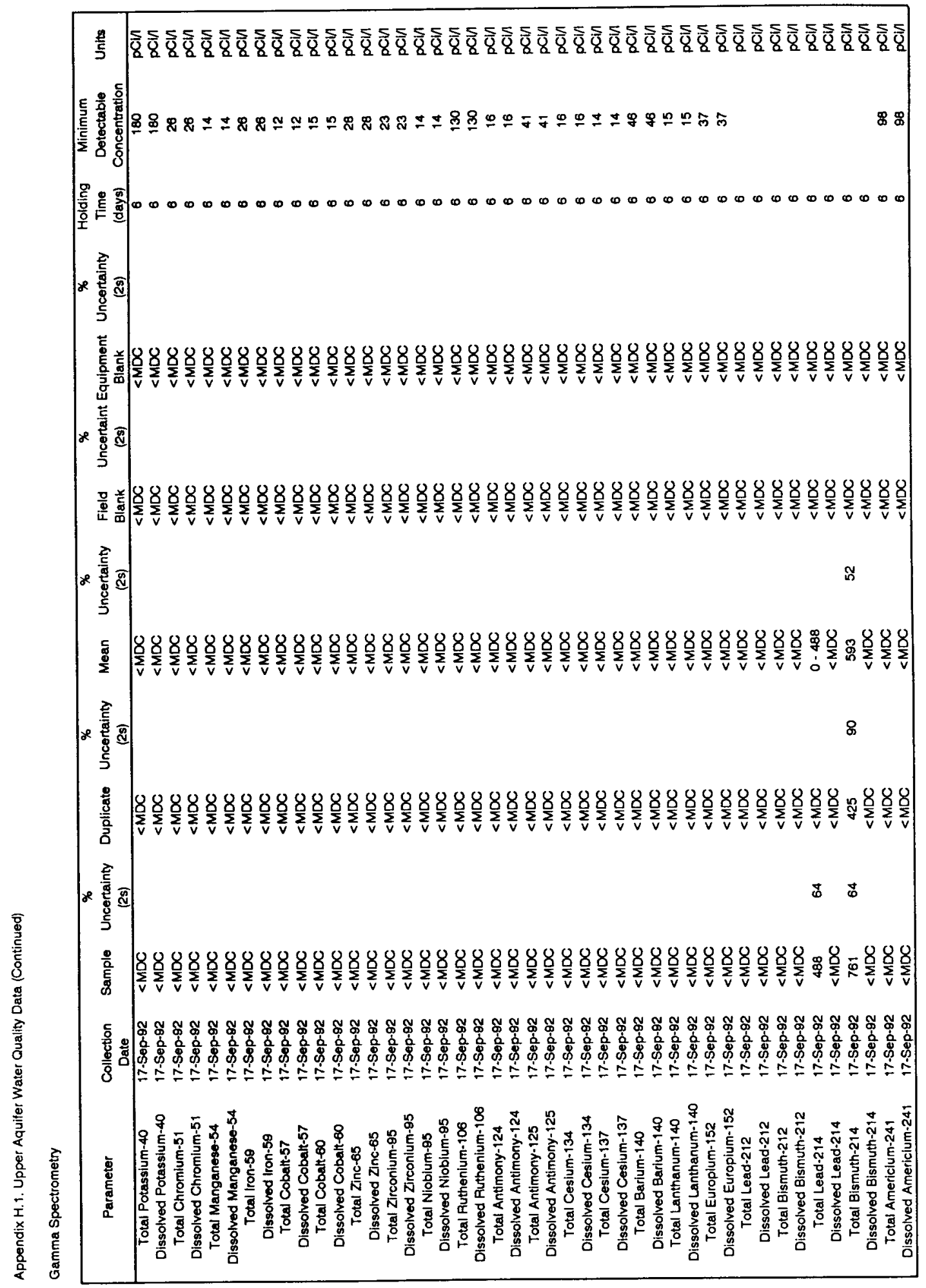


Appendix H. 1. Upper Aquifer Water Quality Data (Continued)

Site: Pilot Well 1/Ue5PW1

Analysis: Volatile Organics

EPA Method: 8240

Collection Date: 17-Sep-92

Analysis Date: 25-Sep-92

Water Table Elevation(Estimated): $2408.51 \mathrm{ft}$

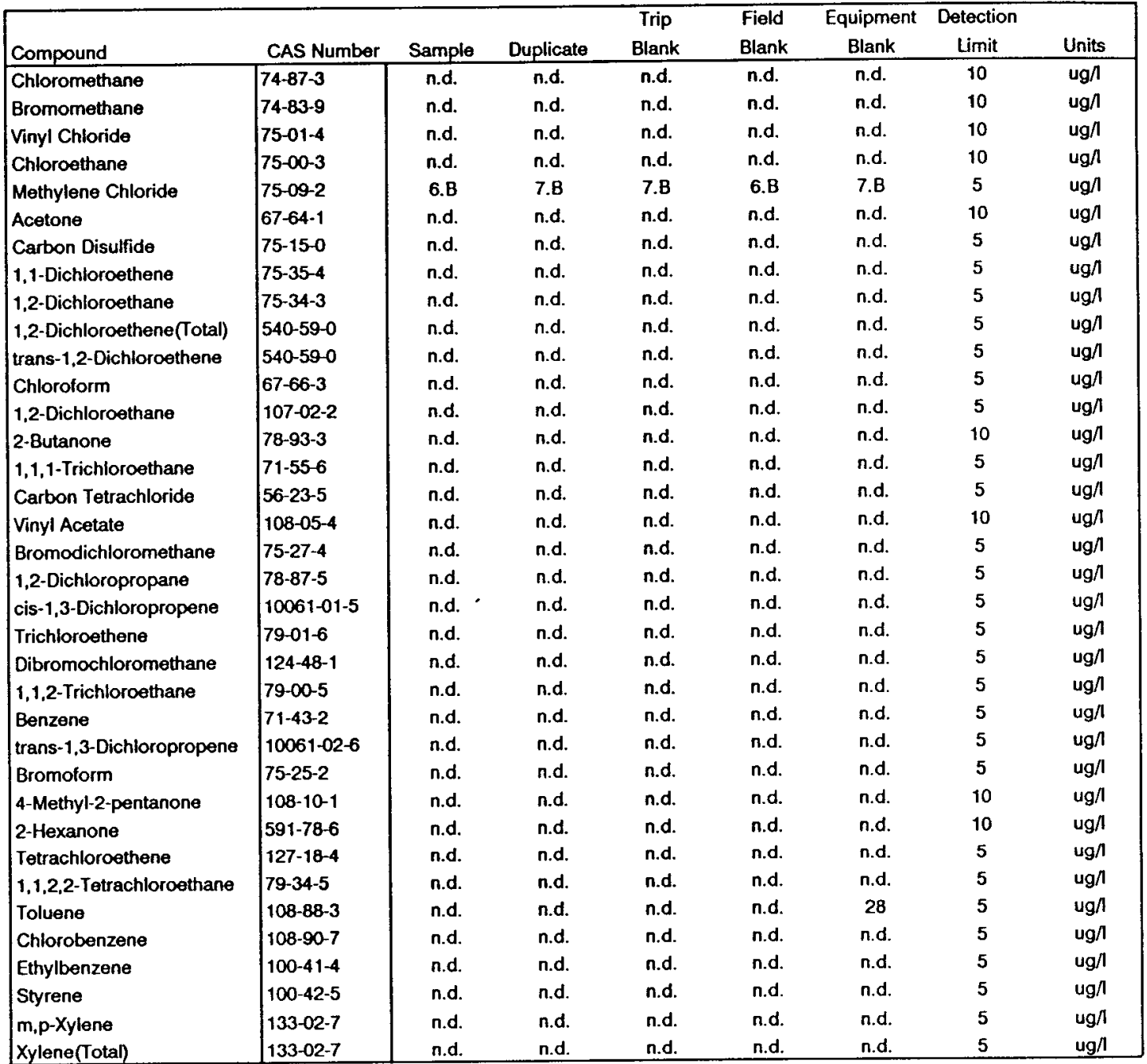

n.d. - Not detected

$\mathrm{J}$ - Estimated value, less than sample quantitation limit

B - Analyte detected in blank 
Appendix H.1. Upper Aquifer Water Quality Data (Continued)

Site: Area 5 Pilot Well 1/Ue5PW1

Analysis: Semi-Volatile Organics

Method: 8270

Collection Date: 17-Sep-92

Extraction Date: $22-$ Sep-92

Analysis Date: 12-Oct-92

Depth to the Water Table(Estimated): $777 \mathrm{ft} .0 .34 \mathrm{in}$.

\begin{tabular}{|c|c|c|c|c|c|c|c|}
\hline Compound & CAS Number & Sample & Duplicate & $\begin{array}{l}\text { Field } \\
\text { Blank } \\
\end{array}$ & $\begin{array}{c}\text { Equipment } \\
\text { Blank }\end{array}$ & $\begin{array}{c}\text { Detection } \\
\text { Limit }\end{array}$ & Units \\
\hline Phenol & $108-95-2$ & n.d. & n.d. & n.d. & n.d. & 10 & $\mathrm{ug} / \mathrm{f}$ \\
\hline bis(2-Chloroethyl)ether & $111-44-4$ & n.d. & n.d. & n.d. & n.d. & 10 & $u g / 1$ \\
\hline 2-Chlorophenol & $95-57-8$ & n.d. & n.d. & n.d. & n.d. & 10 & $u g / 1$ \\
\hline 1,3-Dichlorobenzene & $541-73-1$ & n.d. & n.d. & n.d. & n.d. & 10 & ug/l \\
\hline 1,4-Dichlorobenzene & $106-46-7$ & n.d. & n.d. & n.d. & n.d. & 10 & $\mathrm{ug} / 1$ \\
\hline Benzyl alcohol & $100-51-6$ & n.d. & n.d. & n.d. & n.d. & 10 & $\mathrm{ug} / 1$ \\
\hline 1,2-Dichlorobenzene & $95-50-1$ & n.d. & n.d. & n.d. & n.d. & 10 & ug/l \\
\hline 2-Methylphenol & $95-48-7$ & n.d. & n.d. & n.d. & n.d. & 10 & $u g / 1$ \\
\hline $2,2^{\prime}$-oxybis (1-Chloropropane) & $108-60-1$ & n.d. & n.d. & n.d. & n.d. & 10 & ug/1 \\
\hline bis(2-Chloroisopropyl)ether & $39638-32-9$ & n.d. & n.d. & n.d. & n.d. & 10 & ug/ \\
\hline 4-Methylphenol & $106-44-5$ & n.d. & n.d. & n.d. & n.d. & 10 & ug/l \\
\hline N-Nitroso-di-n-propylamine & $621-64-7$ & n.d. & n.d. & n.d. & n.d. & 10 & $u g /$ \\
\hline Hexachloroethane & $67-72-1$ & n.d. & n.d. & n.d. & n.d. & 10 & $u g / l$ \\
\hline Nitrobenzene & $98-95-3$ & n.d. & n.d. & n.d. & n.d. & 10 & $u g /$ \\
\hline Isophorone & $78-59-1$ & n.d. & n.d. & n.d. & n.d. & 10 & $u g / 1$ \\
\hline 2-Nitrophenol & $88-75-5$ & n.d. & n.d. & n.d. & n.d. & 10 & $u g / 1$ \\
\hline 2,4-Dimethylphenol & $105-67-9$ & n.d. & n.d. & n.d. & n.d. & 10 & ug/l \\
\hline Benzoic acid & $65-85-0$ & n.d. & n.d. & n.d. & n.d. & 50 & ug/l \\
\hline bis(2-Chloroethoxy) methane & $111-91-1$ & n.d. & n.d. & n.d. & n.d. & 10 & ug $/$ \\
\hline 2,4-Dichlorophenol & $120-83-2$ & n.d. & n.d. & n.d. & n.d. & 10 & $u g /$ \\
\hline 1,2,4-Trichlorobenzene & $120-82-1$ & n.d. & n.d. & n.d. & n.d. & 10 & ug/ \\
\hline Naphthalene & $91-20-3$ & n.d. & n.d. & n.d. & n.d. & 10 & ug $/$ \\
\hline 4-Chloroaniline & $106-47-8$ & n.d. & n.d. & n.d. & n.d. & 10 & ug $/ 1$ \\
\hline Hexachlorobutadiene & $87-68-3$ & n.d. & n.d. & n.d. & n.d. & 10 & $u g / 1$ \\
\hline 4-Chloro-3-methylphenol & $59-50-7$ & n.d. & n.d. & n.d. & n.d. & 10 & $\mathrm{ug} / \mathrm{l}$ \\
\hline 2-Methylnaphthalene & $91-57-6$ & n.d. & n.d. & n.d. & n.d. & 10 & $u g / 1$ \\
\hline Hexachlorocyclopentadiene & $77-47-4$ & n.d. & n.d. & n.d. & n.d. & 10 & $u g / 1$ \\
\hline 2,4,6-Trichlorophenol & $88-06-2$ & n.d. & n.d. & n.d. & n.d. & 10 & $u g /$ \\
\hline 2,4,5-Trichlorophenol & $95-95-4$ & n.d. & n.d. & n.d. & n.d. & 50 & ug/l \\
\hline 2-Chloronaphthalene & $91-58-7$ & n.d. & n.d. & n.d. & n.d. & 10 & $u g / 1$ \\
\hline 2-Nitroaniline & $88-74-4$ & n.d. & n.d. & n.d. & n.d. & 50 & ug/ \\
\hline Dimethylphthalate & $131-11-3$ & n.d. & n.d. & n.d. & n.d. & 10 & ug/l \\
\hline
\end{tabular}

n.d. - Not detected

$\mathrm{J}$ - Estimated value, less than sample quantitation limit

B - Analyte detected in blank 
Appendix H.1. Upper Aquifer Water Quality Data (Continued)

Site: Area 5 Pilot Well 1/Ue5PW1

Analysis: Semi-Volatile Organics

Method: $\mathbf{8 2 7 0}$

Collection Date: 17-Sep-92

Extraction Date: 22-Sep-92

Analysis Date: 12-Oct-92

Depth to the Water Table(Estimated): 777 ft. 0.34 in.

\begin{tabular}{|c|c|c|c|c|c|c|c|}
\hline Compound & CAS Number & Sample & Duplicate & $\begin{array}{l}\text { Field } \\
\text { Blank }\end{array}$ & $\begin{array}{l}\text { Equipment } \\
\text { Blank }\end{array}$ & $\begin{array}{c}\text { Detection } \\
\text { Limit }\end{array}$ & Units \\
\hline Acenaphthylene & $208-96-8$ & n.d. & n.d. & n.d. & n.d. & 10 & $\mathrm{ug} / \mathrm{kg}$ \\
\hline 2,6-Dinitrotoluene & $606-20-2$ & n.d. & n.d. & n.d. & n.d. & 10 & $\mathrm{ug} / \mathrm{kg}$ \\
\hline 3-Nitroaniline & $99-09-2$ & n.d. & n.d. & n.d. & n.d. & 50 & $\mathrm{ug} / \mathrm{kg}$ \\
\hline Acenaphthene & $83-32-9$ & n.d. & n.d. & n.d. & n.d. & 10 & $\mathrm{ug} / \mathrm{kg}$ \\
\hline 2,4-Dinitrophenol & $51-28-5$ & n.d. & n.d. & n.d. & n.d. & 50 & $\mathrm{ug} / \mathrm{kg}$ \\
\hline 4-Nitrophenol & $100-02-7$ & n.d. & n.d. & n.d. & n.d. & 50 & ug/kg \\
\hline Dibenzoturan & $132-64-9$ & n.d. & n.d. & n.d. & n.d. & 10 & $u g / k g$ \\
\hline 2,4-Dinitrotoluene & $121-14-2$ & n.d. & n.d. & n.d. & n.d. & 10 & $\mathrm{ug} / \mathrm{kg}$ \\
\hline Diethylphthalate & $84-66-2$ & n.d. & n.d. & n.d. & n.d. & 10 & $u g / k g$ \\
\hline 4-Chlorophenyl-phenylether & $7005-72-3$ & n.d. & n.d. & n.d. & n.d. & 10 & $\mathrm{ug} / \mathrm{kg}$ \\
\hline Fluorene & $86-73-7$ & n.d. & n.d. & n.d. & n.d. & 10 & $\mathrm{ug} / \mathrm{kg}$ \\
\hline 4-Nitroaniline & $100-01-6$ & n.d. & n.d. & n.d. & n.d. & 50 & $\mathrm{ug} / \mathrm{kg}$ \\
\hline 4,6-Dinitro-2-methylphenol & $534-52-1$ & n.d. & n.d. & n.d. & n.d. & 50 & $\mathrm{ug} / \mathrm{kg}$ \\
\hline N-Nitrosodiphenylamine & $86-30-6$ & n.d. & n.d. & n.d. & n.d. & 10 & $u g / k g$ \\
\hline 4-Bromophenyl-phenylether & $101-55-3$ & n.d. & n.d. & n.d. & n.d. & 10 & $\mathrm{ug} / \mathrm{kg}$ \\
\hline Hexachlorobenzene & $118-74-1$ & n.d. & n.d. & n.d. & n.d. & 10 & $u g / k g$ \\
\hline Pentachlorophenol & $87-86-5$ & n.d. & n.d. & n.d. & n.d. & 50 & $\mathrm{ug} / \mathrm{kg}$ \\
\hline Phenanthrene & $85-01-8$ & n.d. & n.d. & n.d. & n.d. & 10 & $\mathrm{ug} / \mathrm{kg}$ \\
\hline Anthracene & $120-12-7$ & n.d. & n.d. & n.d. & n.d. & 10 & $\mathrm{ug} / \mathrm{kg}$ \\
\hline Carbazole & $86-74-8$ & n.d. & n.d. & n.d. & n.d. & 10 & $\mathrm{ug} / \mathrm{kg}$ \\
\hline Di-n-butylphthalate & $84-74-2$ & n.d. & n.d. & n.d. & n.d. & 10 & $\mathrm{ug} / \mathrm{kg}$ \\
\hline Fluoranthene & $206-44-0$ & n.d. & n.d. & n.d. & n.d. & 10 & $\mathrm{ug} / \mathrm{kg}$ \\
\hline Pyrene & $129-00-0$ & n.d. & n.d. & n.d. & n.d. & 10 & $u g / k g$ \\
\hline Butylbenzy!phthalate & $85-68-7$ & n.d. & n.d. & n.d. & n.d. & 10 & $\mathrm{ug} / \mathrm{kg}$ \\
\hline 3,3'-Dichlorobenzidine & $91-94-1$ & n.d. & n.d. & n.d. & n.d. & 20 & $\mathrm{ug} / \mathrm{kg}$ \\
\hline Benzo(a)anthracene & $56-55-3$ & n.d. & n.d. & n.d. & n.d. & 10 & $\mathrm{ug} / \mathrm{kg}$ \\
\hline Chrysene & $218-01-9$ & n.d. & n.d. & n.d. & n.d. & 10 & $u g / k g$ \\
\hline bis (2-Ethylhexyl)phthalate & $117-81-7$ & n.d. & n.d. & n.d. & n.d. & 10 & $\mathrm{ug} / \mathrm{kg}$ \\
\hline Di-n-octylphthalate & $117-84-0$ & n.d. & n.d. & n.d. & n.d. & 10 & $u g / \mathrm{kg}$ \\
\hline Benzo(b)fiuoranthene & $205-99-2$ & n.d. & n.d. & n.d. & n.d. & 10 & $u g / k g$ \\
\hline Benzo(k)fluoranthene & $207-08-9$ & n.d. & n.d. & n.d. & n.d. & 10 & $\mathrm{ug} / \mathrm{kg}$ \\
\hline Benzo(a)pyrene & $50-32-8$ & n.d. & n.d. & n.d. & n.d. & 10 & $\mathrm{ug} / \mathrm{kg}$ \\
\hline Indeno $(1,2,3-c d)$ pyrene & $193-39-5$ & n.d. & n.d. & n.d. & n.d. & 10 & $u g / k g$ \\
\hline Dibenzo $(a, h)$ anthracene & $53-70-3$ & n.d. & n.d. & n.d. & n.d. & 10 & $\mathrm{ug} / \mathrm{kg}$ \\
\hline Benzo(g,h,i)perylene & 191-24-2 & n.d. & n.d. & n.d. & n.d. & 10 & $\mathrm{ug} / \mathrm{kg}$ \\
\hline
\end{tabular}

n.d. - Not detected

$J$ - Estimated value, less than sample quantitation limit

B - Analyte detected in blank 


\title{
Appendix H.2 Preliminary General Water Chemistry
}

\section{Groundwater Investigation Near the RWMS}

\author{
Jenny B. Chapman \\ Desert Rescarch Institute \\ March 16, 1993
}

The shallow groundwater zone beneath the Radioactive Waste Management Site (RWMS) was studied by collecting groundwater samples from two wells and logging the screened interval of one well. Samples were collecied from UIE-5e PW-1 and UE-5e PW-3 on January 20, 1993 and PW-1 was logged for temperature and ciccricill conductivity on the same day. A water sample was also collected from UE-5n, located south of the RWMS, near the Canibric test site, on Fcbruary 10, 1993 , to investigate infiltration from the Cambric ditch to the water table. All watcr samples were submitted for a gross chemical analysis, stable isotopic analysis, and enriched tritium counting. The gross analyses and stable isotopic anily'ses from the Pilot Wells and gross analysis from UE-5n are presented in this report, the other analyses have not been completed.

Logging and Sample Coliccion

Logging was performed in PW-1 10 dcicmine if there were any variations in temperature and electrical conductivity (EC) with depth that would dictate an optimum sample collection depth or need for multiple samples. The location of the water table is clearly defined by the sharp jump in both temperature and EC on the logs (Figure 1:1). Small increases in EC are present both at the top of the water column and bottom of the wcll (Figure 1b), but otherwise the profile is constant. The increase at the top could be rclated to minor evaporation at the water surface in the well bore, while the presence of loose fill in the bottom of the well may be contributing dissolved ions to the water at the bottom. The tcmperature profilc is constant throughout the water column (Figure lb), with the exception of minor cooling at the top, presumably due to heat losses to the cooler atmosphere above the water table. The logging results indicated that one sample from the middle of the water column would be sufficient to characlerize water in the wellbore.

Samples were collected from the midule of the saturated screened intervals in PW-1 and PW-3 using a discrete two-liter bailcr. This bailer is sealed on the surface and sent downhole closed, only to be opened at the desired simpling horizon. At PW-1, the screcn was reported to intercept the saturated zone between 771.6 and $822 \mathrm{fl}$ bclow land surface (bls). The sample was therefore collected at $800 \mathrm{ft}$ bls, mensured from the wcll stick-up. At PW-3, the screcn between 888 and 938 $\mathrm{ft}$ bls is in the saturated zone, and the simple was collected $918 \mathrm{ft}$ bls, measured from well stick-up. Field parameters measured on the samples are given in Table 1.

The primary purpose of the sample from UE-5n was to collect water from the top of the saturated zone to determine if tritium from the Cambric Ditch had infiltrated to the water table. The sample from UE- $5 n$ was collected at $720 \mathrm{ft}$ bls. The water level in this well was measured by DRI as 703.9 


\section{Appendix H.2 Preliminary General Water Chemistry (Continued)}

$\mathrm{ft}$ bls, but records show the perforalcd casing to be between 720 and $730 \mathrm{ft}$ bls, thus the sample was collected at the top of the perforated interval. Samples from all three wells were collected as follows: one liter in a glass bottle with a poly-seal cap for enriched tritium analysis, $125 \mathrm{ml}$ in a glass bottle with a poly-seal cap for carbon-13 analy'sis, $30 \mathrm{ml}$ in a glass bottle with a poly-seal cap for stable isotopic analysis of hydrogen and oxy'gen, $500 \mathrm{ml}$ in a plastic bottle for anion analysis, and $250 \mathrm{ml}$ filtered through a $0.45 \mu$ filter and preserved with nitric acid to a pH Iess than 2.0 for cation analysis.

Table 1. Ficlel l'arameters Measured at RWMS Wells

\begin{tabular}{|l|l|l|}
\hline well name & UE--Se l'W-1 & UE-5c PW-3 \\
\hline sample depth, feet & $8(0)$ & 918 \\
\hline collection date, MM-DD-Y'Y & $1-20 \ldots 93$ & $1-20-93$ \\
\hline collection time & $15: 00$ & $18: 00$ \\
\hline water temperature, ${ }^{\circ} \mathrm{C}$ & 18 & 17 \\
\hline $\begin{array}{l}\text { electrical conductivity, } \\
\mu \text { mhos/cm @ } 25^{\circ} \mathrm{C}\end{array}$ & 394 & 378 \\
\hline $\mathrm{pH}$, standard units & 8.3 & 8.4 \\
\hline $\mathrm{HCO}_{3}, \mathrm{mg} / \mathrm{L}$ & 128 & 140 \\
\hline
\end{tabular}

Discussion of Amalytical Results

The chemical analyses for PW-1 and PW-3 are shown on Tables 2 and 3 and the results from UE- $5 n$ are on Table 4. The PW-1 and PW-3 samples are virtually identical in terms of their gross chemistry and can be characterized as sodium bicambonate waters with a total dissolved solids content of approximately $360 \mathrm{mg} / \mathrm{L}$. All of the simples are saturated with respect to calcite, and several forms of silica and calcium-magnesiun silicates. The Pilot Well samples are also saturated with respect to dolomite.

The water chemistry of these samples can be compared to that of nearby ground water using trilinear plots and Stiff diagrams. The trilincar plot (Figure 2) represents the relative percentages of cations (left triangle) and anions (right mianglc) and a combined representation in the middle diamond. The Pilot Well samples clearly have a different ion distribution than the other samples from Area 5. The major difference is a higher proportion of cilcium and magnesium, relative to sodium, than most of the other samples. The only' wells with greater proportions of calcium and magnesium than the Pilot wells are HTH-3 (completed in carbonates on the east side of Frenchman Flat) and Water Well 4. The Stiff diagrams (Figures 3 and 4), which incorporate the absolute ion concentrations in graphical form, also show the greatcst similarity between the chemistry of PW-1, PW-3, and Water Well 4. The other wells, including UE-5n, have a more exclusively sodium bicarbonate composition that evolves from contact with volcinic-derived material. 


\section{Appendix H.2 Preliminary General Water Chemistry (Continued)}

PW-1, PW-3 and Water Well 4 are located in the northern part of Frenchman Flat (Figure 5), but a sharp change in potentiometric levels between the subbasin containing Water Well 4 and the rest of Frenchman Flat suggests that the Cane Spring Fault hydraulically separates the regions. The chemical similarity between the Walcr Well 4 and Pilot Well areas may therefore be primarily related to a similarity in alluvial matcrial. Specifically, the chemistry indicates that the water intersected by Water Well 4 and the Pilot Wells has had more contact with carbonate material than water sampled elsewhere in Frenchman Flat. This is most likely to have occurred by percolation through alluvium derived from carbonate rocks: fiom the CP Hills area north of Watcr Well 4 and from Nye Canyon east of the RWMS. Though calcium poor, the water in wells from UE-5C south is also at, or close to, saturation with respect to calcite. These waters apparcnty developed elevated $\mathrm{pH}$ values and bicarbonate levels prior to contacling caubonate material, allowing for little calcite dissolution before reaching saturation. Either carbonale material is poorly represented in alluvial material in the west-central part of Frenchman Flat, or the water sampled in this area originated in volcanic terrain to the west rather than by downward percolation.

The stable hydrogen and oxygen isotopic composition of the Pilot Wells (Table 5) is consistent with the deep soil water sampled during the drilling of PW-1. However, it is slightly more enriched than water analyzed previously from Watcr Well $5 B(\delta D=-110 \% \circ, \delta 180=-14.1 \%$ ), further supporting a difference between the history of water in the saturated zonc in the RWMS area and groundwater to the south. 


\section{Appendix H.2 Preliminary General Water Chemistry (Continued)}

Table 2. Chemical analyses for PW-1 and PW-3

WRC Waterlab

Requesicd by: Tyler. Scoll

Project: DOE Arca 5 Soils
Datc subnilucd: 26-Jan-93

Filc nanc: 27879 ST dat

\begin{tabular}{|c|c|c|c|c|c|c|c|c|}
\hline Sample \#: & \multicolumn{2}{|c|}{27879} & \multicolumn{2}{|c|}{27880} & & & & \\
\hline Samplc Date: & \multicolumn{2}{|c|}{ 20.Jan-93 } & \multicolumn{2}{|c|}{$20 \cdot \operatorname{Jan}-93$} & & & & \\
\hline Sample Name: & \multicolumn{2}{|c|}{ PW-1 RWMS 800) } & \multicolumn{2}{|c|}{ ['W.3 RWMS 918' } & & & & \\
\hline $\mathrm{EC}$ & \multicolumn{2}{|c|}{387} & \multicolumn{2}{|c|}{384} & & & & \\
\hline $\mathrm{SiO} 2$ & \multicolumn{2}{|c|}{49.1} & \multicolumn{2}{|c|}{39.1} & & & & \\
\hline $\mathrm{pH}$ & \multicolumn{2}{|c|}{8.34} & \multicolumn{2}{|c|}{8.25} & & & & \\
\hline & $m g / 1$ & cpm & $m g /$ & $\mathrm{cpm}$ & $\mathrm{mg} / \mathrm{l}$ & $\mathrm{cpm}$ & $\mathrm{mg} / \mathrm{l}$ & $\mathrm{cpm}$ \\
\hline $\mathrm{HCO} 3$ & 169 & 2.770 & 171 & 2.803 & & & & \\
\hline $\mathrm{CO} 3$ & 1.3 & 0.043 & & & & & & \\
\hline $\mathrm{Cl}$ & 10.0 & 0.282 & 9.2 & 0.259 & & & & \\
\hline $\mathrm{SO} 4$ & 38.5 & 0.802 & 35.3 & 0.735 & & & & \\
\hline $\mathrm{NO} 3$ & 11.0 & 0.178 & 14.7 & 0.237 & & & & \\
\hline Tolal Anions & & 4.075 & & 4.034 & & & & \\
\hline $\mathrm{Na}$ & 56.9 & 2.475 & 56.7 & 2.466 & & & & \\
\hline $\mathrm{K}$ & 6.62 & 0.169 & 6.15 & 0.157 & & & & \\
\hline $\mathrm{Ca}$ & 17.6 & 0.878 & 18.3 & 0.913 & & & & \\
\hline $\mathrm{Mg}$ & 5.83 & 0.479 & 5.58 & 0.459 & & & & \\
\hline Total Cations & & 4.002 & & 3.996 & & & & \\
\hline Anions/Cations & & 1.018 & & 1.010 & & & & \\
\hline
\end{tabular}




\section{Appendix H.2 Preliminary General Water Chemistry (Continued)}

Table 3. Additional analyses for PW-1 and PW-3

WRC Waterlab

Requesial by: Tyler, Scoll

Projecl: DOE Area S Souls

Date submilled: 26-Jan-93

Filc name: $278795 \mathrm{~S}$.dat

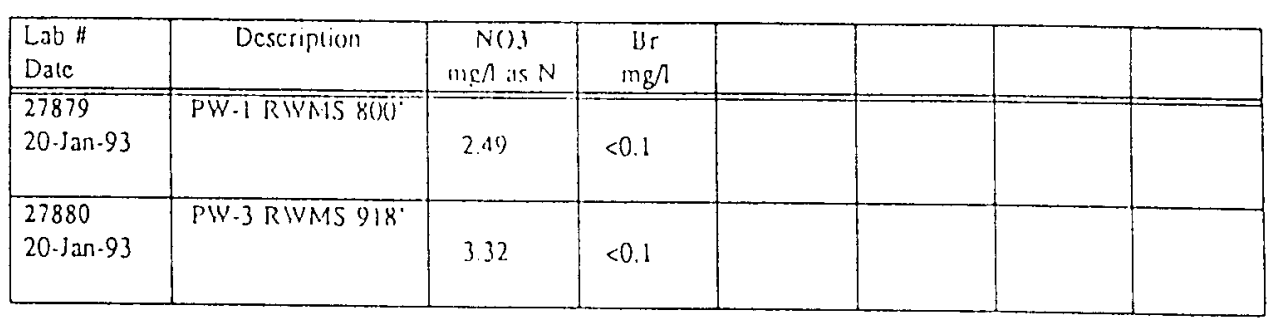




\section{Appendix H.2 Preliminary General Water Chemistry (Continued)}

Table 4. Chemical analysis for UE-5n

\section{WRC Waterlab}

Requesied by: Ty'ler. 5 coun

Projecl: DOE Area 5 Suils

Dale submitled: $12 \cdot[\mathrm{cb} \cdot 93$

File name: $280,55 T$.dat

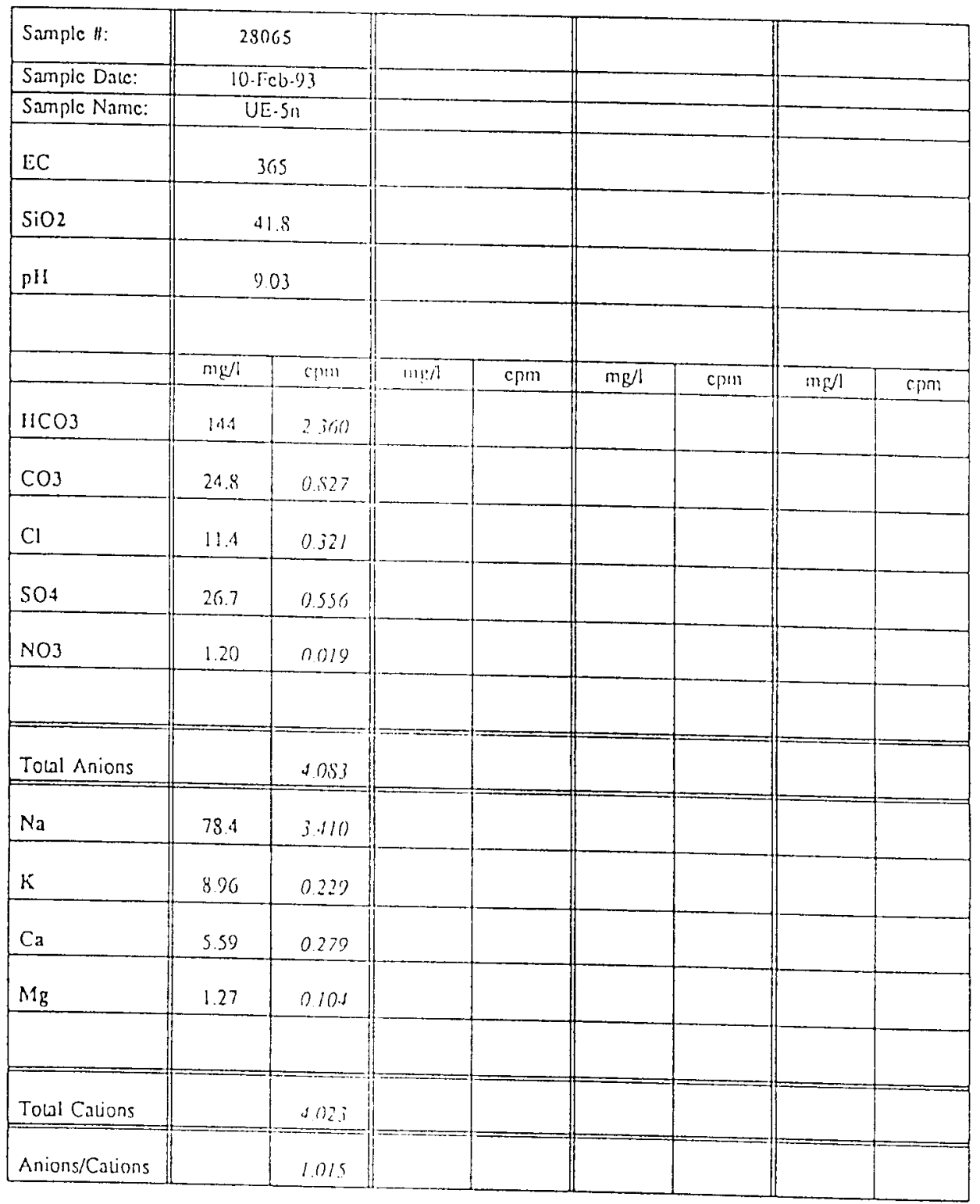


Appendix H.2 Preliminary General Water Chemistry (Continued)
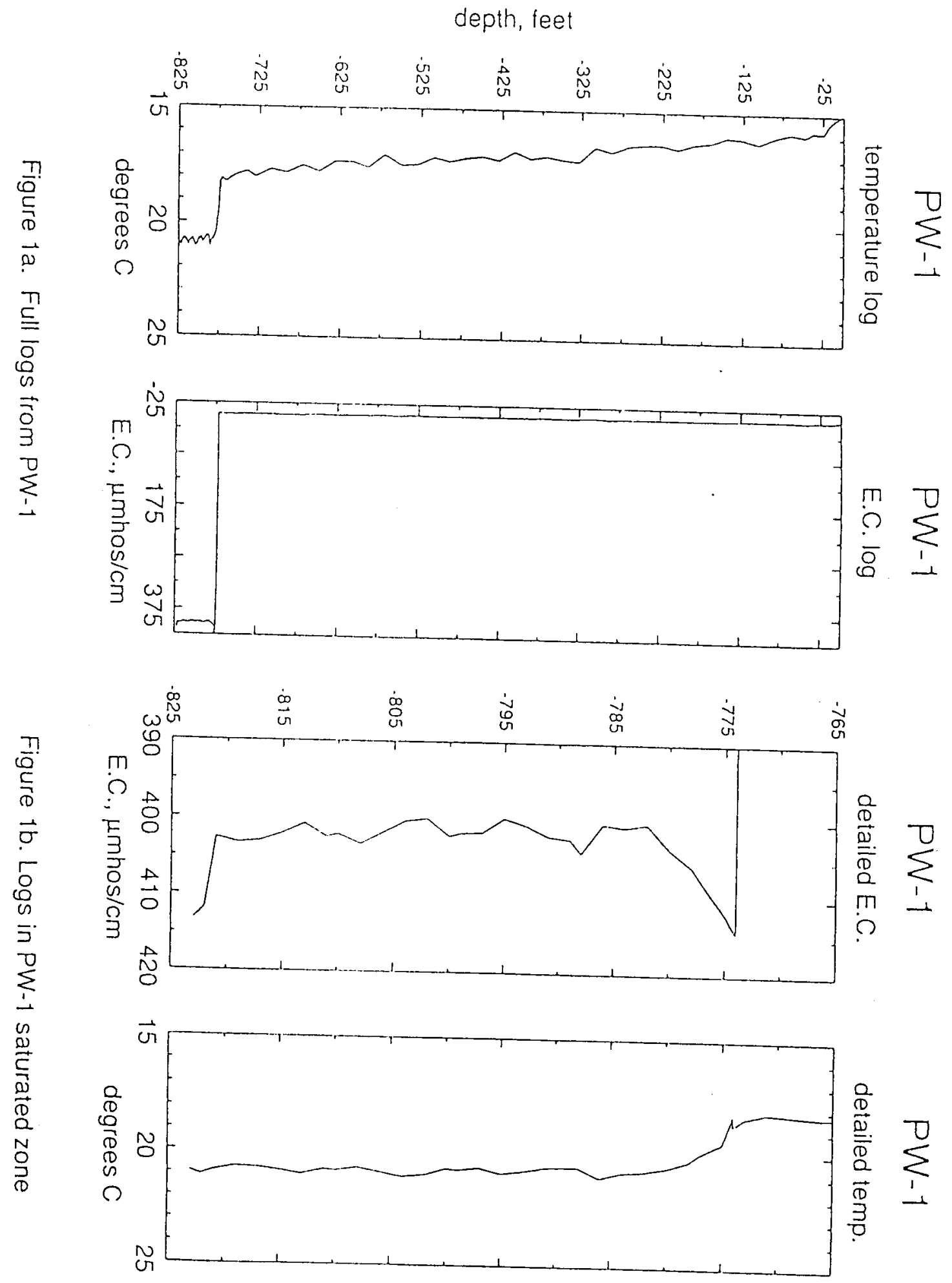


\section{Appendix H.2 Preliminary General Water Chemistry (Continued)}

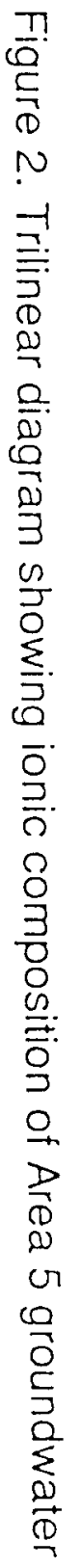

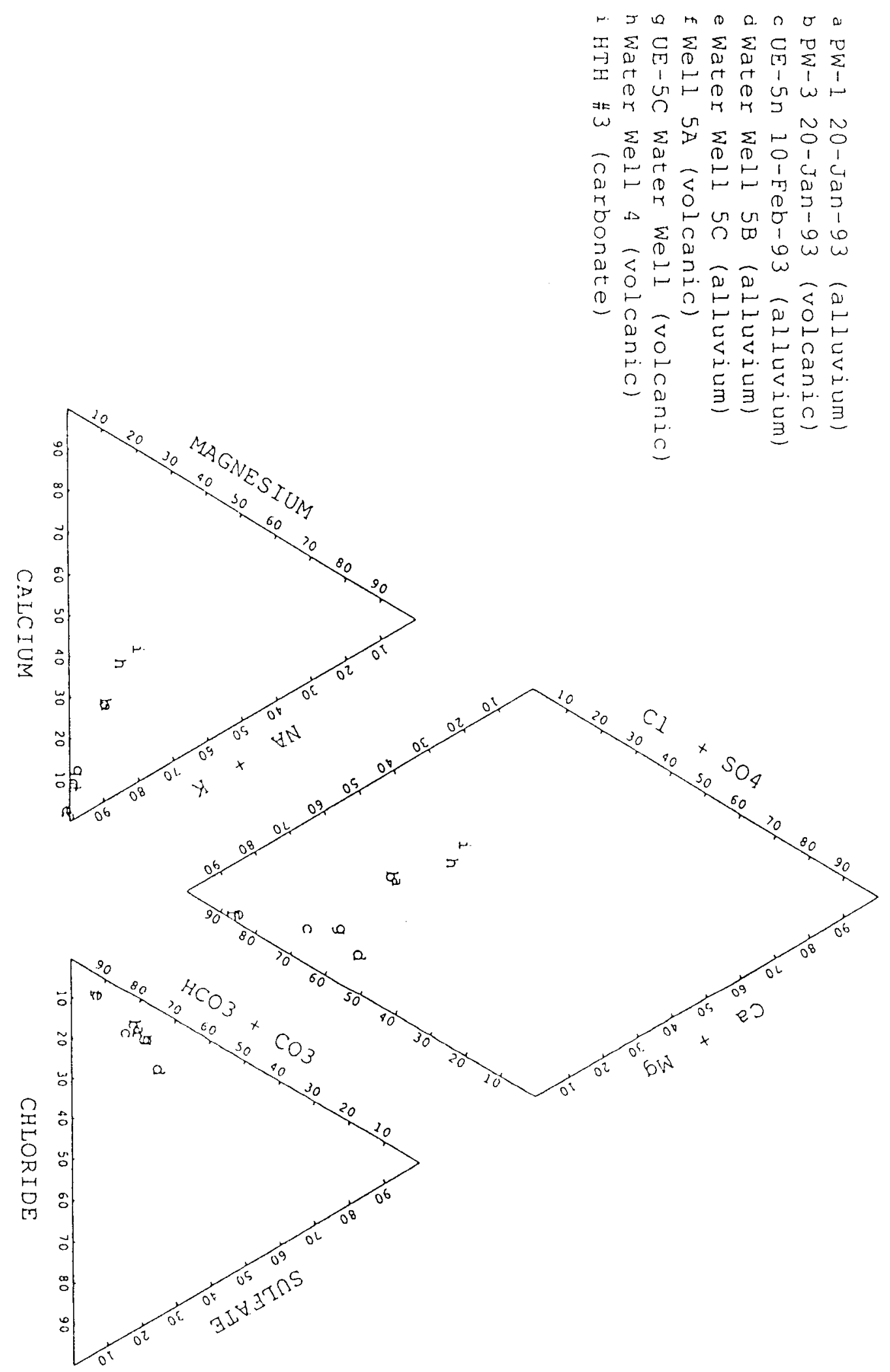


Appendix H.2 Preliminary General Water Chemistry (Continued)

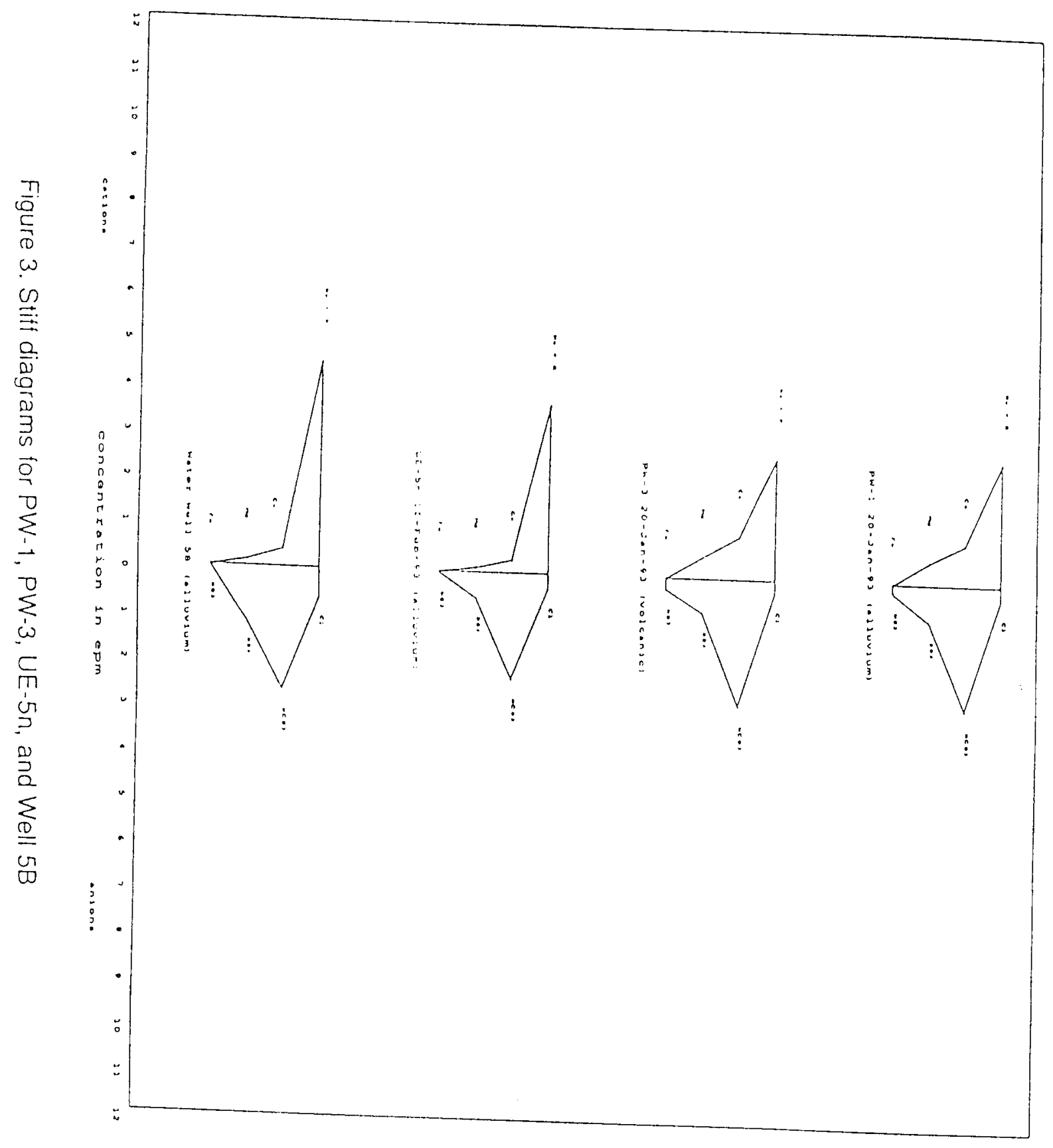


Appendix H.2 Preliminary General Water Chemistry (Continued)

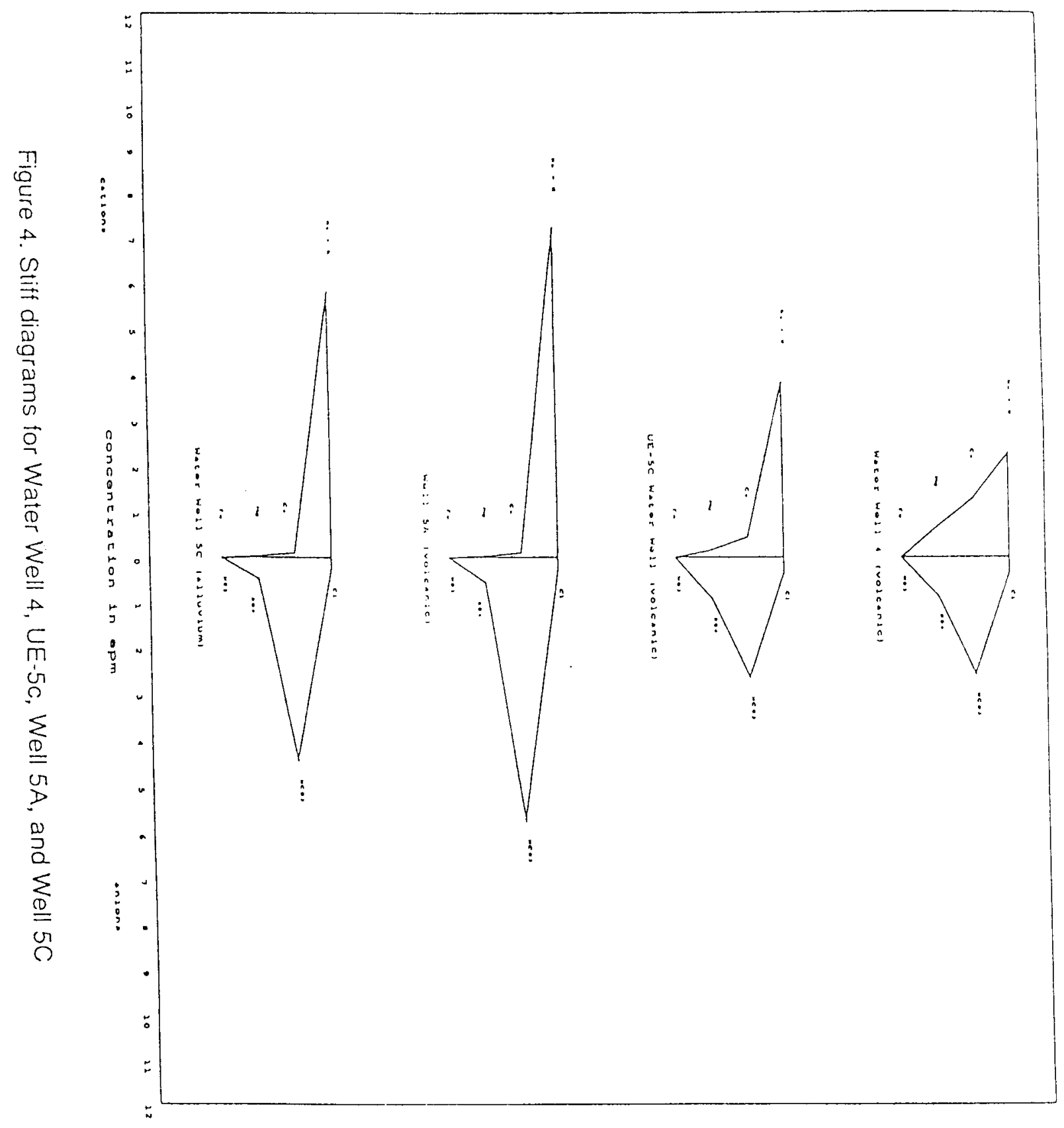


Appendix H.2 Preliminary General Water Chemistry (Continued)

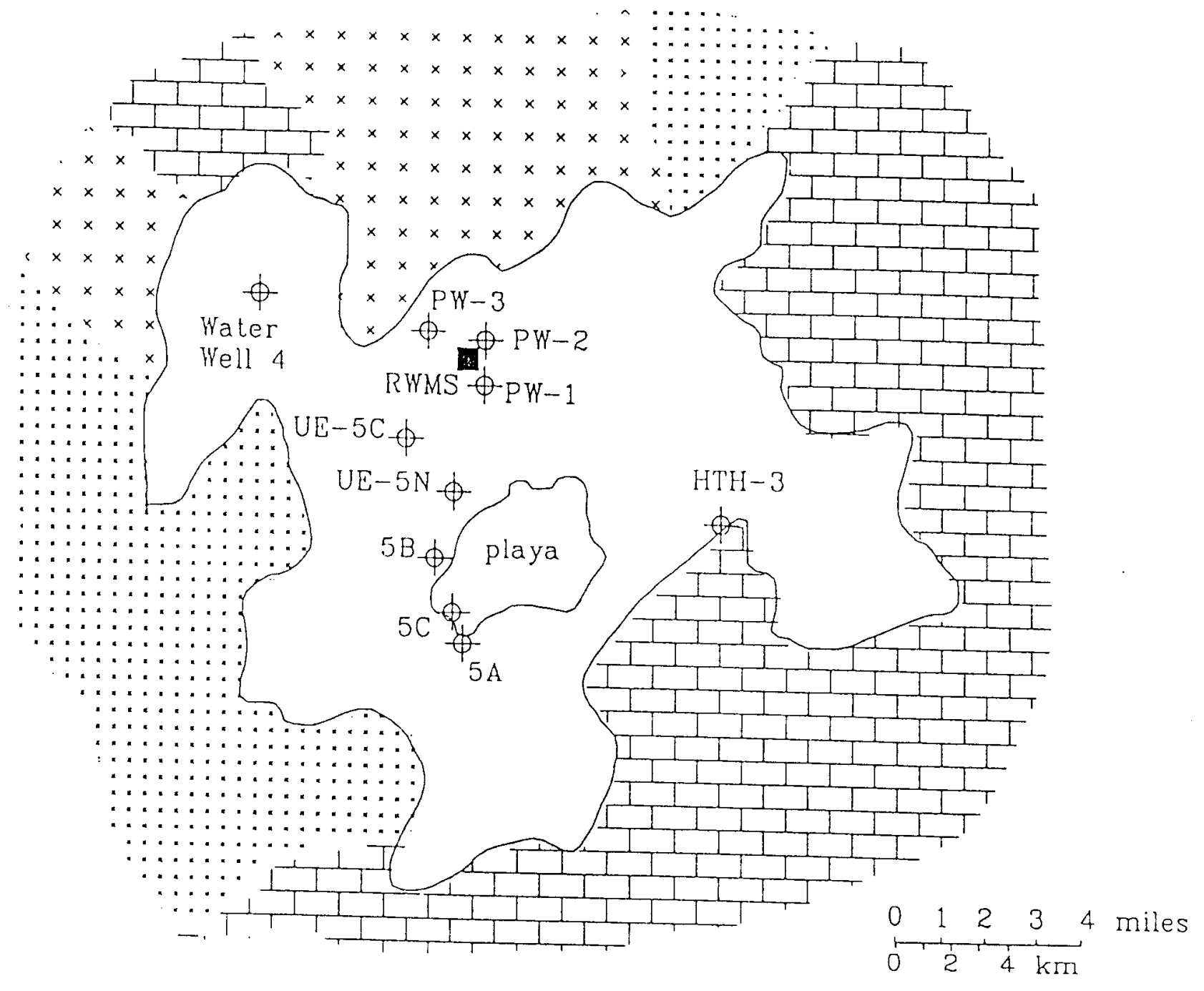

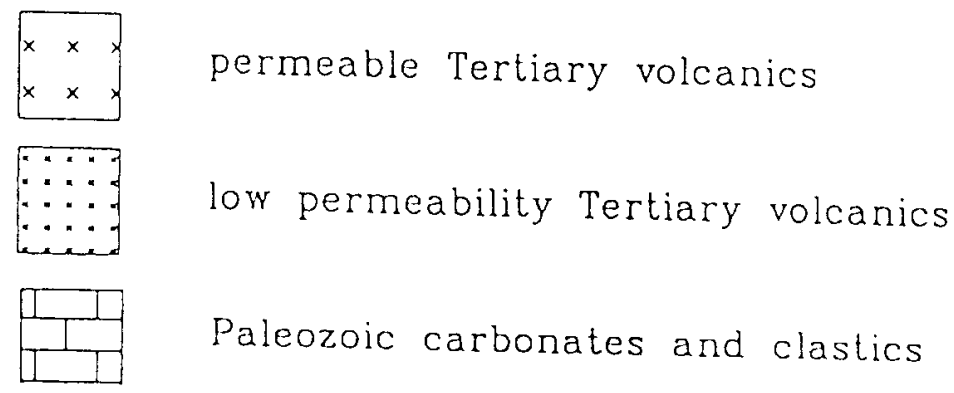

Figure 5. Location map for Area 5 wells mentioned in text, and nearby outcrops differentiated by lithology 


\section{Appendix H.2 Preliminary General Water Chemistry (Continued)}

Table 5. Stable isotopic analysis for PW-1 and PW-3

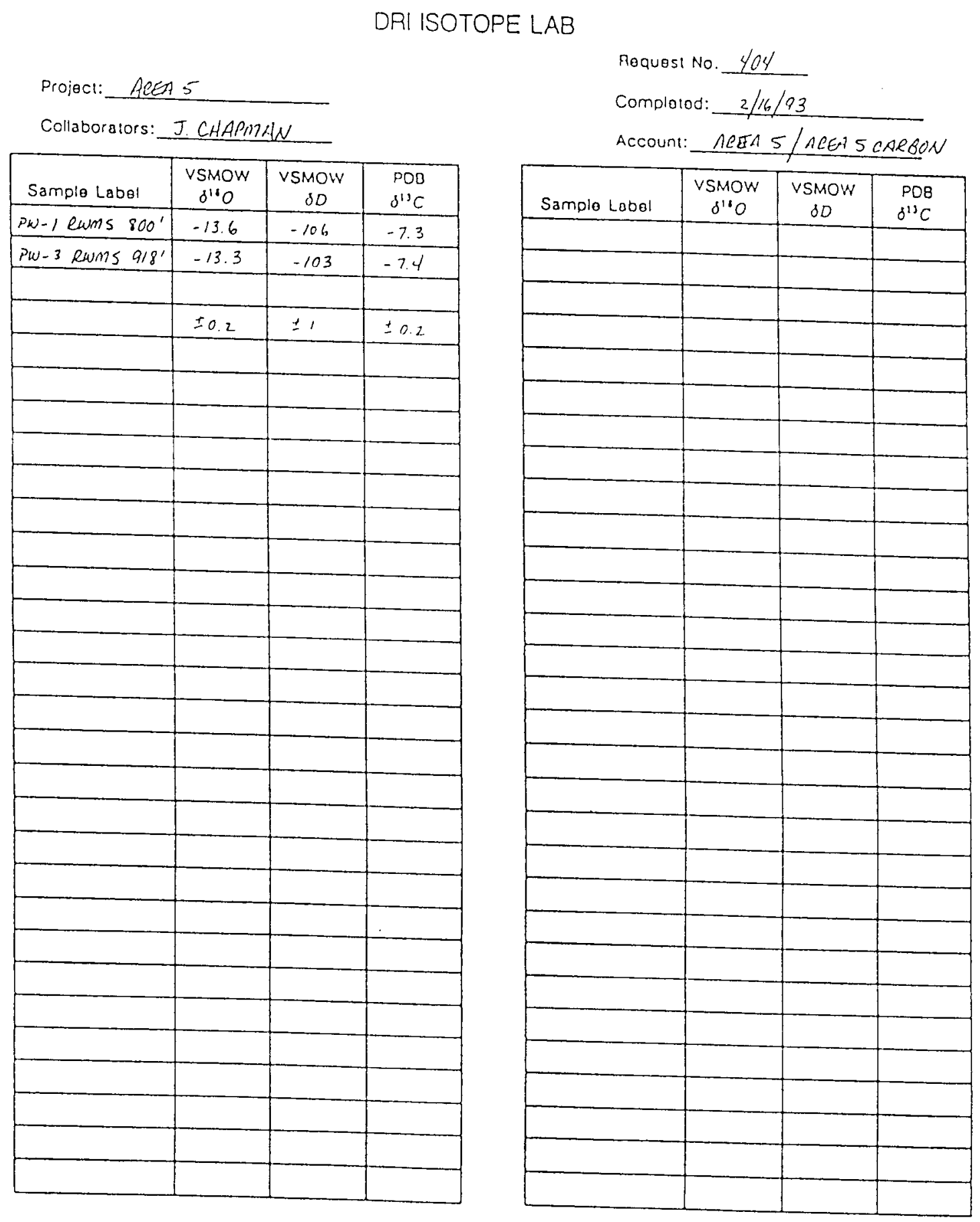




\section{Area 5 Pilot Wells}

\section{APPENDIX I \\ Vadose Zone Calibration and Monitoring Data}

I.1 Thermistor Calibration Data

I.2 Preliminary Temperature Monitoring Data

I.3 Pressure Transducer Calibration Data

1.4 Preliminary Pressure Monitoring Data

I.5 Thermocouple Psychrometer Calibration Data

I.6 In Situ Thermocouple Psychrometer Monitoring Data 
Appendix I.1 Thermistor Calibration Data

The down-hole temperature measurement system and methods used in the Pilot Wells were developed by the U.S. Geological Survey (USGS) for the Department of Energy Yucca Mountain Project (YMP). The USGS approach requires that the thermistors be previously calibrated in a calibration station designed specifically to provide stable temperatures and accurate voltage inputs and outputs. During this calibration, the thermistors are exposed to a known range of temperatures. A multiple regression analysis is then performed on the raw data taken during this calibration process. During the regression analysis, three variables are generated that are specific to each thermistor. After the thermistor is installed in the field and raw data is acquired from them these variables are then applied to the Steinhart and Hart equation:

$$
\frac{1}{T}=A+B(\ln R)+C(\ln R)^{3}
$$

where $\mathrm{T}$ is the temperature in ${ }^{\circ} \mathrm{K}, \mathrm{R}$ the resistance of the thermistor in ohms, and $\mathrm{A}, \mathrm{B}$ and $C$ are the thermistor-specific coefficients derived from calibration measurements. These coefficients are contained in the following tables. Coefficients of determination $\left(r^{2}\right)$ for each equation/thermistor are summarized in the last column of these tables.

Ue5PW-1 Thermistor Coefficients

\begin{tabular}{|l|l|l|l|l||}
\hline \multicolumn{1}{|c|}{ Thermistor } & $\mathrm{A}$ & \multicolumn{1}{c|}{$\mathrm{B}$} & $\mathrm{C}$ & $\mathrm{r}^{2}$ \\
\hline $\mathrm{R} 0011$ & 0.0014718608 & 0.0002378195 & 0.0000001043 & .99999996 \\
\hline $\mathrm{R} 0012$ & 0.0014713196 & 0.0002379707 & 0.0000001034 & .99999998 \\
\hline $\mathrm{R} 0013$ & 0.0014700013 & 0.0002379992 & 0.0000001025 & .99999999 \\
\hline $\mathrm{R} 0014$ & 0.0014694040 & 0.0002383432 & 0.0000001010 & .99999998 \\
\hline $\mathrm{R} 0015$ & 0.0014705912 & 0.0002380617 & 0.0000001028 & .99999998 \\
\hline $\mathrm{R} 0016$ & 0.0014722276 & 0.0002377905 & 0.0000001023 & .99999991 \\
\hline $\mathrm{R} 0017$ & 0.0013037612 & 0.0002704978 & -0.0000000756 & .99930399 \\
\hline $\mathrm{R} 0019$ & 0.0014718374 & 0.0002378550 & 0.0000001035 & .99999984 \\
\hline $\mathrm{R} 0021$ & 0.0014615199 & 0.0002396920 & 0.0000000941 & .999999997 \\
\hline $\mathrm{R} 0022$ & 0.0014654298 & 0.0002389685 & 0.0000000971 & .99999993 \\
\hline
\end{tabular}


Appendix I.1 Vadose Zone Monitoring Calibration Data (Continued)

Ue5PW-2 Thermistor Coefficients

\begin{tabular}{||l|l|l|l|l||}
\hline \multicolumn{1}{|c|}{ Thermistor } & \multicolumn{1}{c|}{ A } & \multicolumn{1}{c|}{ B } & \multicolumn{1}{c|}{ C } & $\mathrm{r}^{2}$ \\
\hline $\mathrm{R} 0033$ & 0.0014193909 & 0.0002392307 & 0.0000000925 & .99999680 \\
\hline $\mathrm{R} 0034$ & 0.0014598625 & 0.0002397175 & 0.0000000956 & .99999877 \\
\hline $\mathrm{R} 0035$ & 0.0014651988 & 0.0002388323 & 0.0000000997 & .99999995 \\
\hline $\mathrm{R} 0036$ & 0.0014634672 & 0.0002388244 & 0.0000001008 & .99999995 \\
\hline $\mathrm{R} 0037$ & 0.0014645647 & 0.0002387517 & 0.0000001006 & .99999985 \\
\hline $\mathrm{R} 0038$ & 0.0014641670 & 0.0002386864 & 0.0000001006 & .99999992 \\
\hline $\mathrm{R} 0039$ & 0.0014660518 & 0.0002385872 & 0.0000001009 & .99999983 \\
\hline $\mathrm{R} 0040$ & 0.0014636269 & 0.0002390765 & 0.0000000965 & .99999955 \\
\hline $\mathrm{R} 0041$ & 0.0014651500 & 0.0002388875 & 0.0000000990 & .99999875 \\
\hline $\mathrm{R} 0042$ & 0.0014562796 & 0.0002405315 & 0.0000000890 & .99999691 \\
\hline
\end{tabular}

Ue5PW-3 Thermistor Coefficients

\begin{tabular}{||l|l|l|l|l||}
\hline \multicolumn{1}{|c|}{ Thermistor } & \multicolumn{1}{c|}{$\mathrm{A}$} & \multicolumn{1}{c|}{$\mathrm{B}$} & \multicolumn{1}{c|}{$\mathrm{C}$} & \multicolumn{1}{c|}{$\mathrm{r}^{2}$} \\
\hline $\mathrm{R} 0023$ & 0.0018368436 & 0.0001654200 & 0.0000005210 & .99729803 \\
\hline $\mathrm{R} 0024$ & 0.0038278002 & -0.0000561224 & 0.0000000797 & .02616878 \\
\hline $\mathrm{R} 0025$ & 0.0017654394 & 0.0001787222 & 0.0000004542 & .99628745 \\
\hline $\mathrm{R} 0026$ & 0.0019819824 & 0.0001364998 & 0.9999996899 & .99618157 \\
\hline $\mathrm{R} 0027$ & 0.0017847121 & 0.0001750307 & 0.0000004733 & .99589254 \\
\hline $\mathrm{R} 0028$ & 0.0018371921 & 0.0001647015 & 0.0000005322 & .99576966 \\
\hline $\mathrm{R} 0029$ & 0.0018284713 & 0.0001665486 & 0.0000005199 & .99608363 \\
\hline $\mathrm{R} 0030$ & 0.0017566154 & 0.0001810695 & 0.0000004342 & .99706751 \\
\hline$R 0031$ & 0.0018352190 & 0.0001655690 & 0.0000005227 & .99698065 \\
\hline$R 0032$ & 0.0017657583 & 0.0001790292 & 0.0000004475 & .99662401 \\
\hline
\end{tabular}


Appendix I.2 Preliminary Temperature Monitoring Data.

\begin{tabular}{|c|c|c|c|c|}
\hline Borehole & Thermistor & Depth (ft) & Ohms & Temperature $\left({ }^{\circ} \mathrm{C}\right)$ \\
\hline \multirow{10}{*}{ UE5PW-1 } & $\mathrm{R} 022$ & 100 & 3018 & 18.43 \\
\hline & R021 & 100 & 3013 & 18.46 \\
\hline & R019 & 200 & 2987 & 18.65 \\
\hline & R017 & 200 & 2981 & 18.70 \\
\hline & R016 & 300 & * & * \\
\hline & R015 & 300 & 2941 & 19.00 \\
\hline & $\mathrm{R} 014$ & 500 & 2826 & 19.88 \\
\hline & $\mathrm{R} 013$ & 500 & 2842 & 19.75 \\
\hline & $\mathrm{R} 012$ & 700 & * & * \\
\hline & R011 & 700 & 2719 & 20.74 \\
\hline \multirow{10}{*}{ UESPW-2 } & R033 & 100 & - & - \\
\hline & R034 & 100 & - & - \\
\hline & R035 & 200 & 3067 & 18.15 \\
\hline & R036 & 200 & 3234 & 16.92 \\
\hline & $\mathrm{R} 037$ & 300 & 3017 & 18.43 \\
\hline & R038 & 300 & 3035 & 18.30 \\
\hline & R039 & 500 & 2907 & 19.25 \\
\hline & R040 & 500 & 2916 & 19.18 \\
\hline & R041 & 700 & 2874 & 19.51 \\
\hline & $\mathrm{R} 042$ & 700 & 2833 & 19.83 \\
\hline \multirow{10}{*}{ UE5PW-3 } & R023 & 100 & 2811 & 20.00 \\
\hline & R024 & 100 & 2813 & 19.98 \\
\hline & $\mathrm{R} 025$ & 200 & 2844 & 19.74 \\
\hline & R026 & 200 & 2845 & 19.73 \\
\hline & R027 & 300 & 2825 & 19.89 \\
\hline & R028 & 300 & 2825 & 19.89 \\
\hline & R029 & 500 & 2761 & 20.40 \\
\hline & R030 & 500 & 2753 & 20.47 \\
\hline & R031 & 689 & 2716 & 20.77 \\
\hline & R032 & 689 & 2717 & 20.76 \\
\hline
\end{tabular}

* Thermistor damaged during stemming operations and not operational. 


\section{Appendix I.3 Pressure Transducer Calibration Data}

Each of the Area 5 RWMS Site Characterization Pilot Wells is instrumented in the vadose zone with five Druck PTX 620 pressure transmitters with ranges of 0-15 psia. One Druck PTX 164 pressure transmitter with a range of 0-100 feet of water is submerged in the water table.

All of the pressure transmitters emplaced in the three Area 5 Pilot Wells were submitted to the REECo Physical Standards and Calibration Facility for calibration. However, the calibration information was not released in what was considered a timely manner. In fact, in some cases calibration sheets were not received until months after the calibration date. As a result, the instruments were irretrievably emplaced in the wells on the calibration technician's word that they were calibrated.

There were numerous discrepancies and errors in the calibration reports from the REECo Physical Standards and Calibration Facility. One calibration sheet was missing, and after contacting the Calibration Lab, they were unable to supply a duplicate. One Calibration Report stated the transmitter model number as "unknown". Another Calibration Report either had the wrong model number, or was calibrated over the wrong pressure range.

As a result, it was decided to rely on the factory certification of the instruments instead of the REECo Physical Standards and Calibration Facility calibration data. The following is a description of the method used to obtain pressure data from the Area 5 RWMS Pilot Well down hole pressure transmitters.

The Druck pressure transmitters use an industry-standard method to transmit pressure data, known as a 4 to 20 milliamp current loop, with a linear output. Basically, the device is provided with a power supply voltage. The device then varies its internal resistance until the current passing through the device is proportional to the pressure the transmitter is exposed to. For example, a 0 to 10 psi transmitter will pass 4 milliamps of current when exposed to $0 \mathrm{psi}$; and will pass 20 milliamps when exposed to 10 psi. By placing a low resistance resistor in series with the circuit, a voltage drop can be measured across the resistor. Using Ohm's Law, where $I$ is current, $E$ is voltage, and $R$ is resistance, the current passed by the transmitter is calculated.

The transmitter manufacturer, Druck Incorporated, certifies that the instrument leaves their facility with a maximum error of $\pm 0.1 \%$ "best strait line" over the full range of the instrument's rated span. The net span of the instruments is 16 milliamps (from 4 to 20 ). After the current in the loop is determined, a simple proportional calculation will be used to determine the pressure the device is seeing. 
Appendix I.4 Preliminary Pressure Monitoring Data

\begin{tabular}{||l|l|l|l|l||}
\hline \multicolumn{1}{|c|}{ Transmitter } & \multicolumn{1}{c|}{ Depth } & \multicolumn{2}{c||}{ Volts } & \multicolumn{2}{c||}{ psi } & \multicolumn{1}{c|}{$\mathrm{kPa}$} \\
\hline Ue5PW-1 & & & 13.36 & 92.12 \\
\hline 382357DJ & 100 & 9.1237 & 13.26 & 91.43 \\
\hline 308674DJ & 200 & 9.0720 & 13.26 & 91.43 \\
\hline 397287DK & 300 & 9.0706 & 13.36 & 92.12 \\
\hline 382368DJ & 500 & 9.1251 & $*$ & $*$ \\
\hline $396624 \mathrm{DK}$ & 700 & $*$ & 40.6 feet of water \\
\hline 393449 & submersed & 5.2530 & & \\
\hline Ue5PW-3 & & & $*$ & $*$ \\
\hline 382375DJ & 100 & $*$ & 13.20 & 91.04 \\
\hline 409496DJ & 200 & 9.0374 & 13.38 & 92.26 \\
\hline 382358DJ & 300 & 9.1382 & 13.36 & 92.12 \\
\hline 396623DK & 500 & 9.1232 & 13.40 & 92.39 \\
\hline 397298DK & 689 & 9.1634 & 38.9 feet of water \\
\hline 393447 & submersed & 5.1095 & & \\
\hline
\end{tabular}

* transmitter damaged during stemming operations and not operational. 
The thermocouple psychrometry measurement system and methods used in the Pilot Wells were developed by the U.S. Geological Survey (USGS) for the Department of Energy Yucca Mountain Project (YMP). The USGS approach requires that psychrometers be previously calibrated in a calibration station designed specifically to provide stable temperatures and humidities with accurate voltage inputs and outputs. During this calibration, the psychrometers are exposed to a known range of temperatures and humidities. A multiple regression analysis is then performed on the raw data taken during this calibration process. During the regression analysis, six variables are generated that are specific to each psychrometer. After the psychrometer is installed in the field and raw data is acquired from them, these variables are then applied to the following equation to calculate soil water potential:

$$
\Psi=A+B V+C V+D V T+E T^{2}+F V T^{2}
$$

where $\Psi$ is the soil water potential in bars, $V$ is the delta intercept voltage in microvolts, $T$ is the temperature in ${ }^{\circ} \mathrm{C}$, and $\mathrm{A}, \mathrm{B}, \mathrm{C}, \mathrm{D}, \mathrm{E}$ and $\mathrm{F}$ are the psychrometer-specific coefficients. These coefficients are contained in the following tables. Coefficients of determination $\left(r^{2}\right)$ for each equation/psychrometer are summarized in the last columns of these tables. 


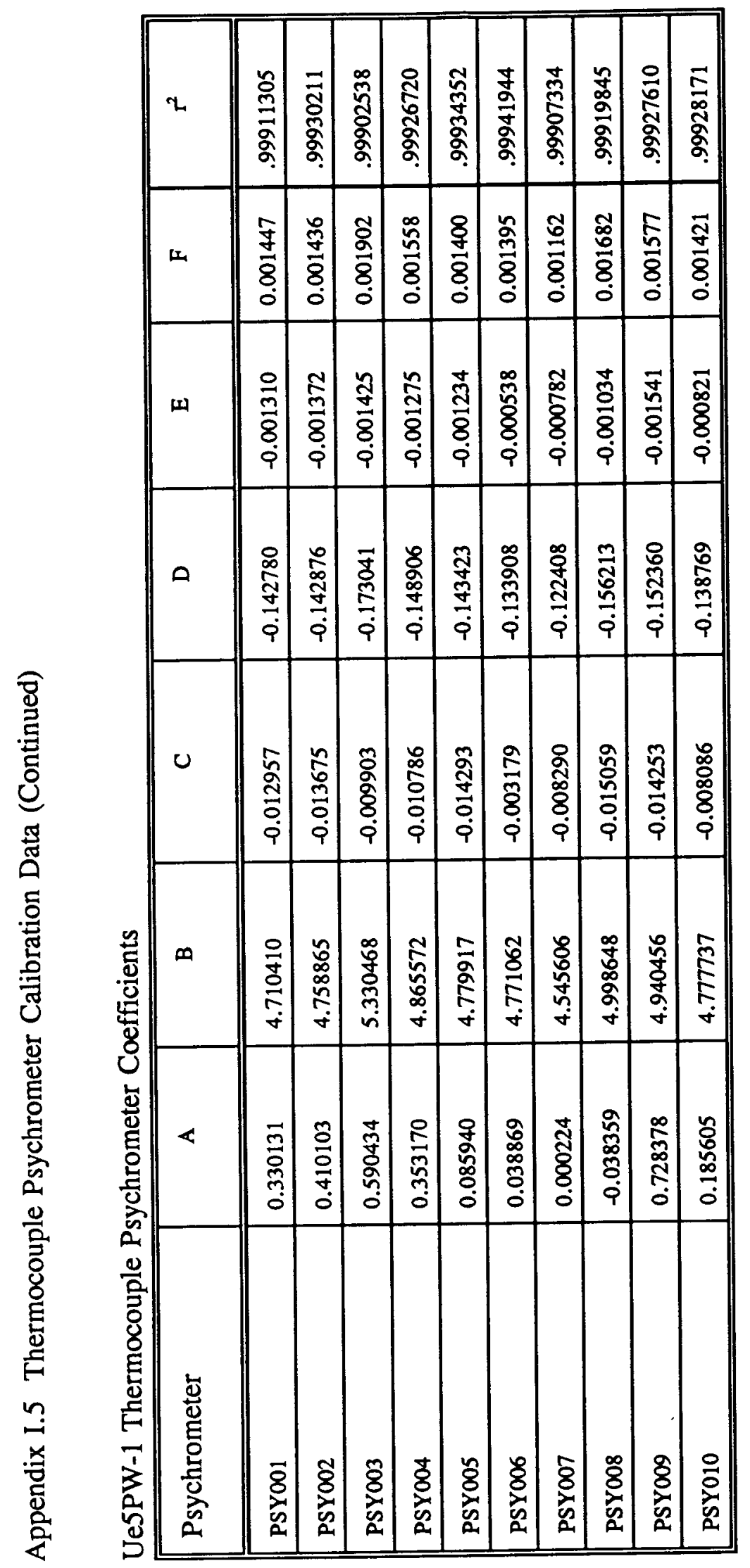




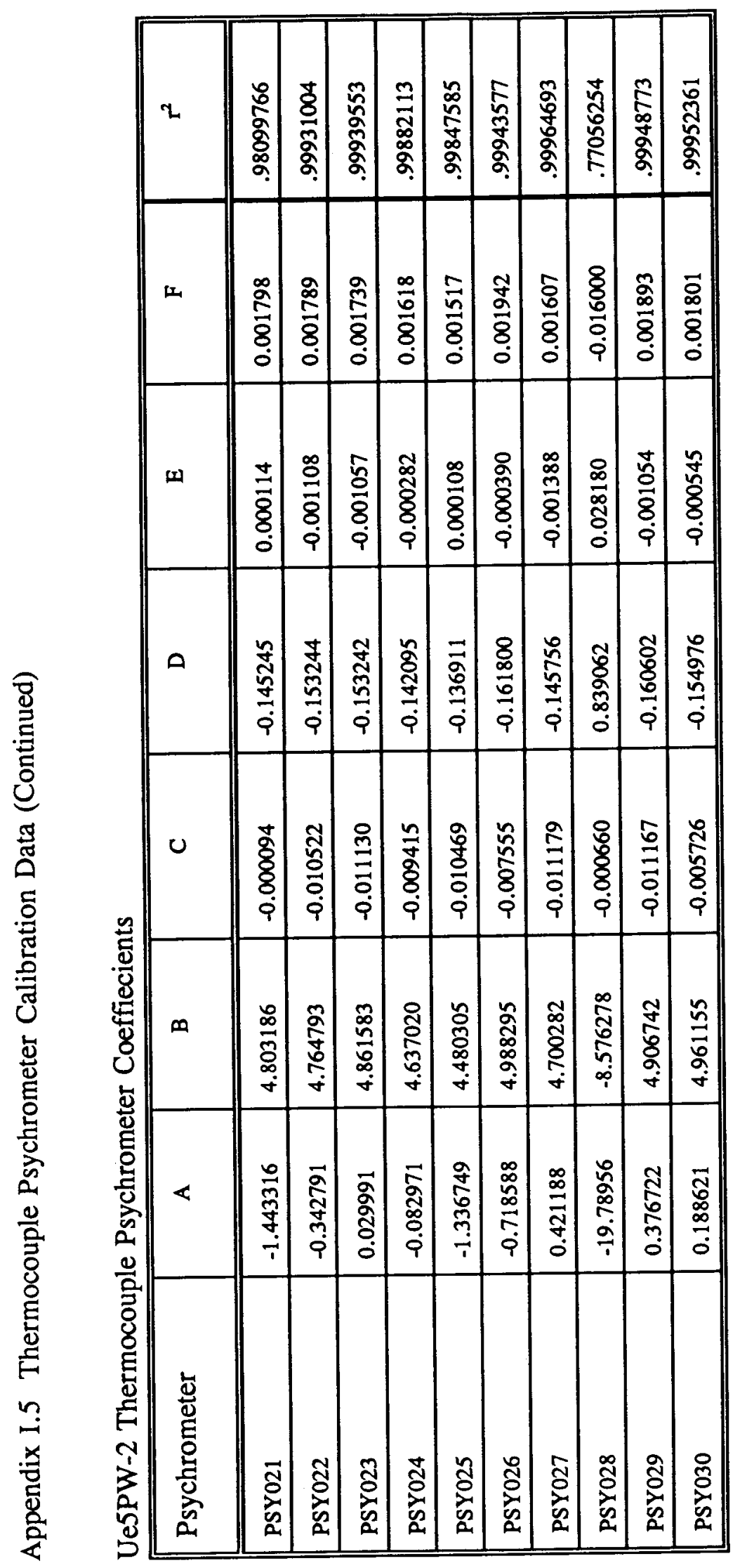




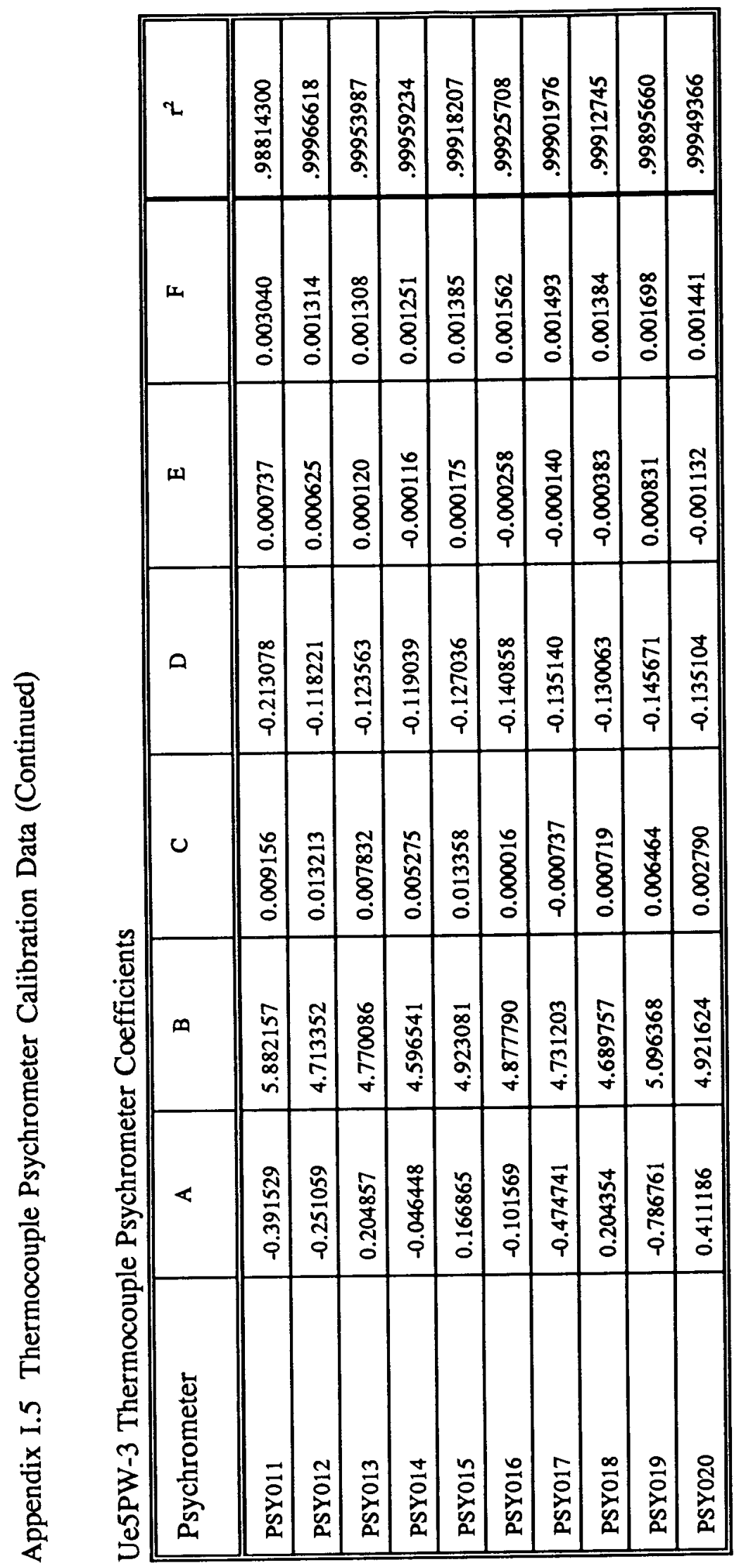


Appendix I.6 In situ thermocouple psychrometer monitoring data.

\begin{tabular}{|c|c|c|c|}
\hline \multirow{2}{*}{$\begin{array}{c}\text { Depth } \\
(\mathrm{ft})\end{array}$} & \multicolumn{3}{|c|}{ Water Potential (bars) } \\
\cline { 2 - 4 } & UE5PW-1 & UE5PW-2 & UE5PW-3 \\
\hline \hline 100 & -17.98 & -14.19 & -21.80 \\
\hline 200 & -8.39 & -6.75 & -10.75 \\
\hline 300 & -5.18 & -4.68 & -6.42 \\
\hline 500 & -3.91 & -4.66 & -6.27 \\
\hline 700 & -2.38 & - & - \\
\hline
\end{tabular}

